94.

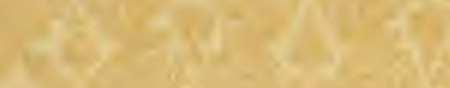

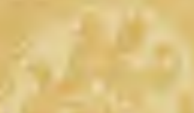

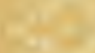

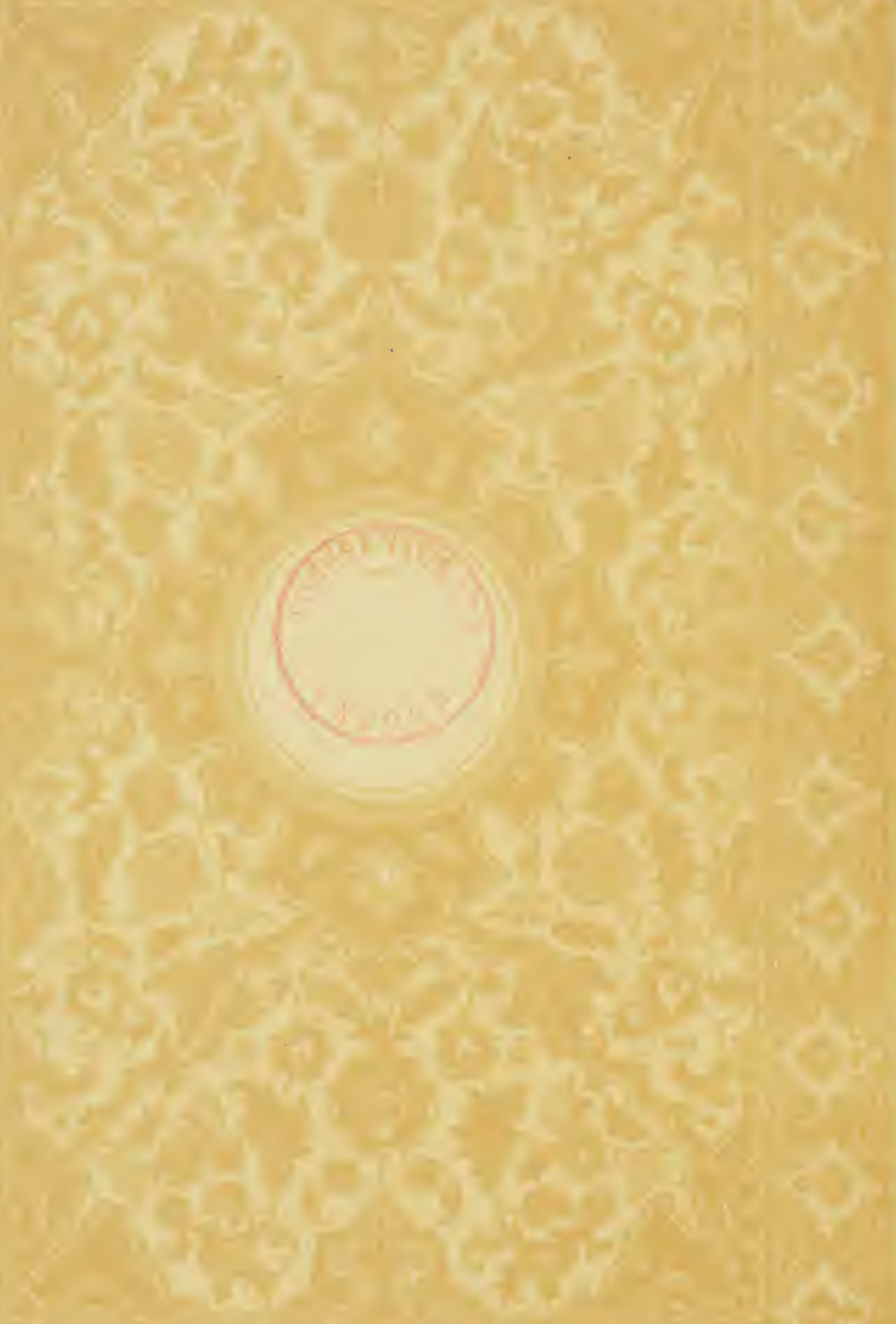

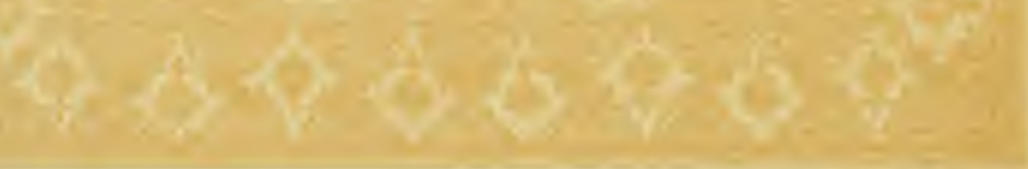


THIS BOOK BELONGED TO WILFRID E. HILEY 
Digitized by the Internet Archive in 2009 with funding from NCSU Libraries 


\section{Waldbau}

\section{auf naturgesetzlicher Grundlage.}

\section{Ein Lehr- und Handbuch,}

bearbeitet von

\section{Heinrich Mayr,}

Dr. philos. et oec. publ.,

o. ö. Professor der forstlichen Produktionslehre an der Universität München.

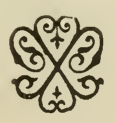

Mit 27 Textabbildungen und 3 Tafeln.

BERLIN.

Verlagsbuchhandlung Paul Parey.

Verlag for Landwirtachan, Gartenban and Foratwesen.

SW., Hedemannstrasse 10.

1909. 
Alle Rechte - auch das der Übersetzung - vorbehalten. 


\section{Vorwort.}

Für vorliegendes Werk wurde der Titel "Waldbau" beibehalten, obwohl das Wort nur einen Teil der begründenden, erziehenden und pflegenden Tätigkeit des Forstmannes im Walde wiedergibt; allein das Wort: Waldbau, Silvicultura, ist international verständlich geworden und begegnet nur noch bei Laien der engen Deutung, daß Waldbau mit dem Ansäen und Anpflanzen von Nutzbäumen sich erschöpfe. Man könnte fragen, ob denn die naturgesetzlichen Grundlagen heute schon genügend erforscht seien, um darauf einen für Theorie und Praxis zugleich bestimmten Waldbau aufbauen zu können? Man darf dies bejaen in der Erkenntnis, dafis der Waldbau selbst viel älter und weiter vorgeschritten ist, als es den naturwissenschaftlichen Grundlagen möglich war, ja, daß der ganze praktische Waldbau der vorausgehenden Jahrhunderte als eine Sammlung großartiger, ununterbrochener und naturwissenschaftlicher Versuche aufgefaßt werden mul, deren Ergebnisse noch der systematisch-wissenschaftlichen Deutung und Zusammenfassung harren. So manche Entdeckung der heuticen Naturwissenschaften bringt deshalb nur eine wissenschaftliche Begründung waldbaulich längst bekannter Erscheinungen, wie z. B. die Forschungen über das Lichtbedürfnis der Pflanzen. Durch dieses Toraneilen hat die Praxis an Ansehen nicht gewomnen; es schien, als ob Waldbau auch ohne wissenschaftliche Vorbildung erlernt und getrieben werden könnte, und vielfach gilt heute noch mechanisch-praktischer Drill als die wichtigste Grundlage für forstliche Ausbildung. Anderseits hat die Praxis selbst sich überschätzt, indem sie den Satz prägte: „Probieren geht über Studieren" und mit Verachtung auf die Theorie, die naturgesetzlichen Grundlagen des Waldbaues, herabblickte.

Es fallen aus diesem Grunde heute noch viele Praktiker in den Fehler, daß sie, in einen neuen Wirkungskreis mit nenen Holzarten und neuen Standorten versetzt, wieder ob ovo der Waldbaupraxis, das heißt mit Probieren beginnen, weil sie entweder die Theorie des Waldbaues nicht kennen oder Mißtrauen und Torurteile hegen gegen die Tätigkeit des Vorgängers oder des Nachbarn, gegen Theorie und Praxis in den Nachbarstaaten, gegen andere Holzarten, seien sie einheimische oder gar fremdländische.

Nur im theoretischen Waldbau auf naturgesetzlicher Grundlage vereinigen sich alle Erscheinungen und Ergebnisse der naturwissenschaftlichen Forschung und Waldbaupraxis zu einem harmonischen, logischen Ganzen; mit seiner Fortbildung hebt sich der Wert des Waldes, mindern sich die Kosten seiner Begründung und Pflege, mehrt sich die Rente, erhöht sich das Wissen und die soziale Stellung der Forstwirte; ohne ihn wird der Forstmann zum ITaldhandworker. 
Ruht Waldbau auf naturwissenschaftlicher Grundlage, so kann es nur eine Theorie des Waldbanes geben, da die großen Naturgesetze für alle Holzarten der Erde die gleichen sind: naturgesetzlicher Wraldhau ist international: verschieden ist nur das materielle Interesse. das der Mensch an den Produkten des Waldes nimmt, verschieden das Endziel der Wirtschaft: verschieden die Praxis, die Kunst. durch Waldbegründung, Walderziehung und Waldpflege dem rerschieclen crestalteten, ölionomischen Prinzipe im Walde gerecht zu werden.

Wer hierbei die naturgesetzlichen Grundlagen verläßt und nur allein auf' höchsten Gewinn bedacht ist, wie der heutige Kahlschlagbetrieh mit Pflanzung, fehlt gegen das natürliche Prinzip der Nachhaltigkeit der Bodengüte und der Holzarten: wer einseitig das natürliche Prinzip zu wahren sucht, wie es $\mathrm{K}$ arl Gayer in seiner gruppenweisen, natürlichen Begründung gemischter Bestände gelehrt hat, schädigt die Rente. C. T Tagner in Tübingen erstrebt in der saumweisen. schirmständigen Naturverjüngung (Blendersaum) eine Verkniiptung der widerstreitenden Prinzipien im Walde: sein System rerdient ernsthafte Beachtıung und Prüfung.

Seit vielen. Jahren suche ich auf einer anderen Fährte den goldenen Mittcher in einer Wirtschaft, welche das Recht der Lebenden, die höchste Rentabilität, wahrt, aber auch den Kommenden gibt, worauf sie berechtigt sind, Nachhaltigkeit in Bodengüte, in Holzarten, in Niutzung. (O) meine Vorschläge. welche am Schlusse dieser Schrift im zwanzigsten Abschnitte als "Kleinbestandswald" kurz zusammengefaßt sind, waldbaulich und betriebstechnisch richtig sind, mögen jene probieren, welche die Macht haben, Wirtschaftsregeln zu geben. sowie jene, welchen die Freiheit zugestanden ist, nach eigenem Wissen wirtschaften zu dürfen. Möchten jene, welche mit mir übereinstimmen, daß der theoretische Waldbau nur dann eine Wissenschaft ist. wemn er auf Naturgesetzen fufit, der praktische Waldbau nur dann eine richtige, Wald und Wirtschafter zugleich hebende Tätigkeit sein kann. Wenn dem Probieren das Wissen vorausgeht, den vorliegenden Waldbau nicht im ganzen rerurteilen, wenn sie in manchen Punkten mit demselben nicht einverstanden sind.

Hhr aber, welche ich mit Stolz und Frende meine jungen Freunde, meine sichüler nenne. ros estis spes nostra. Ihr habt seit zwei Dezennien gewünscht, daf die flüchtigen Worte über naturgesetzlichen Waldhau und seine Inrchführung im Walde in die feste Form eines Lehrbuches gegossen würden, hier habt Ihr es: in "Euren Händen liegt schon hente oder in Bälde das sichicksal des Waldes von den Tropen bis an seine Kältegrenzen: prüfet diese Schrift überall auf der Erde auf ihre Wahrheit und Branchbarkeit:

Grafirath, im september $1 ! 18$. 


\section{Inhalt.}

Seite

Einleitung. Die Anfgaben des Wallbaues............ 1

Erster Teil.

Die naturgesetzlichen Grundlagen des Waldbaues.

Erster Abschnitt.

Naturgesetzliche Grundlageu der Verteilung der Wälder auf

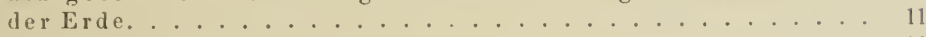

1. Klima. . . . . . . . . . . . . . . . 11

2. Boden. . . . . . . . . . . . . . . . . 34

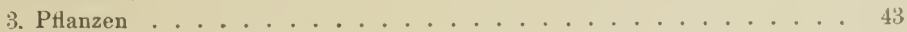

4. Tiere. ......................... 44

5. Der Mensch . . . . . . . . . . . . . . . 44

Zweiter Abschnitt.

Naturgesetzliche Grundlagen der Waldregionen der nördlichen Erdhälfte außerhalb der Tropen, innere Verwandtsehaft...

Dritter Abschnitt.

Naturgesetzliche Grundlagen der einzelnen Baumarten, Ansprïche derselben an Klima und Boden, waldbaulich-physiologisehe Eigenschaften der Holzarten .......... 53

A. Ansprüche der Holzarten an das Ḱlima . . . . . . . . . . . 53

B. Ansprüche der Holzarten an den Boden . . . . . . . . 105

Vierter Abschnitt.

Waldbaulich-biologische Eigensehaften der Holzarten ..... 11s

1. Art, Varietät, Individnum, Wuchsfehler und Wuchsvorzüge, Vererbung, Provenienz usw. . . . . . . . . . . . . 118

2. Schnellwüchsigkei t . . . . . . . . . . . . . . 132

3. Die natürliche Vermehrung der Holzarten durch Sämereien. . . . . 135

Fünfter Abschnitt.

Naturwissenschaftlich-waldbauliche Charakteristik der forstlich wichtigeren Baumgattungen, Baumarten und Sträueher. . . 146

A. Die Nadelbäume . . . . . . . . . . . . . . . . 149

B. Laubbäume . . . . . . . . . . . . . . . . . . . . 181

C. Halbbäume und Sträucher . . . . . . . . . . . . 213

Sechster Absehnitt.

Waldbaulich-biologische Eigensehaften der Baumvereinigungen (Bestandesbiologie). . . . . . . . . . . . 217

a. Soziologische Verhältnisse ............... 217

b. Klimatische Verhältnisse der Baumvereinigungen (Bestandesklimatologie) 224

c. Lichtverhältnisse der Baumvereinigungen, der Kronensehluß . . . . . . 2:30 
Siebenter Abschnitt.

Allgemeine Teränderungen im Waldzustande und in seinen natur- Seite gesetzlichen Grundlagen durch Eingriffe des Menschen....

Zweiter Teil.

\section{Die Waldbegrindung.}

Achter Absehnitt.

Die Wirtschafts-und Verjüngungsformen . . . . . . . . 249

A. Hochwaldungen. . . . . . . . . . . . . . . . . . . . . . 249

B. Ausschlagwaldungen . . . . . . . . . . . . . . . . 272

C. Mittelwaldungen . . . . . . . . . . . . . . 275

D. Astwaldungen . . . . . . . . . . . . . . 276

E. Rhizomwaldungen. . . . . . . . . . . . . . . 277

F. Übergangswaldungen . . . . . . . . . . . . . . . 277

Neunter Abschnitt.

Wahl der Wirtschafts - und Verjüngungsformen . . . . . . . 280

1. Klima . . . . . . . . . . . . . . 281

2. Der Boden . . . . . . . . . . . . . . . . . . . 281

3. Die Holzarten . . . . . . . . . . . . . . . . . . 283

4. Wie Zwecke des Waldbesitzers. . . . . . . . . . . . . 283

Zehnter Absehnitt.

Die natürliche Wiederverjüngung . . . . . . . . . . . 286

a) Ǩlima. . . . . . . . . . . . . . . . . . . . 291

b) Boden . . . . . . . . . . . . . . . . . . . . . . 292

c) Holzarten und Alter. . . . . . . . . . . . . . . . . . . . . 293

d) Wirtschaftsmethoden ................. 293

Beispiele für die natürliche Verjüngung in reinen und gemischten Beständen 331

A. Schattenholzarten. . . . . . . . . . . . . . 331

13. Halbschattenholzarten . . . . . . . . . . . . 342

C. Lichtholzarten . . . . . . . . . . . . . . . . . . 345

D. Gemischte Bestände. . . . . . . . . . . . 352

Elfter Abschnitt.

Die künstliche Wiederverjüngung. . . . . . . . . . . . . . 361

1. Die Saat . . . . . . . . . . . . . . . 364

A. Feststellung der Samengüte . . . . . . . . . . . 364

13. Verkaufsmaße der Sämereien . . . . . . . . . . 376

C. Iie Vorbereitung des Saatgutes für die Aussaat . . . . . . . . 377

D. Die Aussaat . . . . . . . . . . . . . . . . . 37s

2. Die Pflanzung. . . . . . . . . . . . . . . . . 388

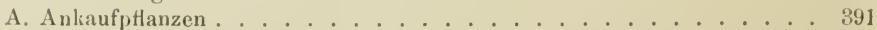

B. Vorwuchspflanzen . . . . . . . . . . . . . . 393

C. Schlagpflanzen . . . . . . . . . . . . . . . 893

1). Garteupflanzen, Kamppflanzen . . . . . . . . . . . . 395

E. Freilandptlanzung. . . . . . . . . . . . . 415

F. Die Stecklingspflanzung. . . . . . . . . . . . . 427

G. Absenkerpflanzung . . . . . . . . . . . . . . . . . . . 429

H. Aussehlagpflanzung . . . . . . . . . . . . . . . . 429

I. Rhizompflanzung ................. . . . . 430

K. Wurzelpflanzung . . . . . . . . . . . . . . . . . 430

L. Wurzelbrntptlanzung ................. . . 430

M. Stunumelpflanzung. ...................... 430 
3. Beispiele für die künstliche Begrïndnng von reinen und gemischten Beständen . . . . . . . . . . . . . . . . 431

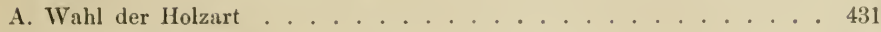

B. Schattenholzarten . . . . . . . . . . . . . . . . 433

C. Halbschattenholzarten. . . . . . . . . . . . . . . . . 434

D. Lichtholzarten . . . . . . . . . . . . . . . . . . . 436

E. Gemischte Anlagen . . . . . . . . . . . . . . 438

Zwölfter Abschnitt.

Die Ausschlagverjüngung . . . . . . . . . . 451

A. Der Niederwald. . . . . . . . . . . . . . . . 451

B. Der Mittelwald . . . . . . . . . . . . . . . . . 454

Dreizehnter Abschnitt.

Anbau fremdländischer Holzarten . . . . . . . . . 457

Vierzehnter Abschnitt.

ödland a ufforstung. . . . . . . . . . . . . . . . . 479

Das ödland im Mittelgebirge. . . . . . . . . . . . 481

Das Ödland im Hochgebirge . . . . . . . . . . . . . . . . 482

Karste. . . . . . . . . . . . . . . . . . 482

Heideflächen. . . . . . . . . . . . . . . . 483

Steppen . . . . . . . . . . . . . . . . . 485

Hoore. . . . . . . . . . . . . . . . . . . . . . 487

Dïnen. . . . . . . . . . . . . . . . . . . . . . 487

Sehutthalden . . . . . . . . . . . . . . . 488

Rauchschadenödland . . . . . . . . . . . . . . . 488

Eisenbahnlichtungen . . . . . . . . . . . . 489

Dritter Teil.

\section{WaIderziehung und WaIdpflege.}

Fïnfzehnter Abschnitt.

Pflege und Erziehung der Hochwaldungen . . . . . . . . 492

1. Jungwuchspflege . . . . . . . . . . . . . . . 492

2. Stangenwuchsptlege . . . . . . . . . . . . . . . . . 499

3. Baumwuchspflege und -Erziehung . . . . . . . . . . . 502

Sechzehnter Abschnitt.

Pflege und Erziehung der Ausschlagwaldungen . . . . . . 520

Siebzehnter Abschnitt.

Bodenpflege und Bodenverbesserung . . . . . . . . . 522

Achtzehnter Absehnitt.

schutzwaldpflege . . . . . . . . . . . . . 534

Neunzehnter Absehnitt.

Waldpflege aus ästhetisehen Gründen . . . . . . . $5: 9$

Zwanzigster Abschnitt.

Der Kleinbestandswald, Vorschläge für eine natur-und rentengerechtere Waldwirtsehaft . . . . . . . . . 546

Register. . . . . . . . . . . . . . . . 558 


\section{Einleitung. \\ Die Aufgaben des Waldbaues.}

Nach dem Urteil der größten Mehrheit jener, welche ihre Blicke Gedanken und Schritte dem Walde zulenken, erwächst der Wald wild, d. h. ohne Zutun des Menschen; ihnen ist Wald gleich Urwald, von dem sie keine greifbare Torstellung haben: ihnen ist der Urwald Ausgangspunkt und Schlußfolgerung ihrer Betrachtungen; für sie ist Waldban etwas Überflüssiges; die ganze forstliche Tätigkeit beschränkt sich auf die Ernte, auf die Nutzung des Waldes; für sie gleicht der Forstmann in seiner Tätigkeit dem Jäger, der nur schießt, was im WValde wild erwächst. Für die Mehrzahl jener, welche tiefer mit dem Probleme Wald, mit seiner wirtschaftlichen und klimatischen Bedeutung sich befassen, erschöpft sich die Aufgabe des Waldbaues in der Begründung des Waldes durch Saat oder Pflanzung. Für sie ist der Forstmann gleich dem Landwirte, der nur sät und erntet, gleich dem Gärtner, der zwar seine Pfleglinge nicht durch Verkauf in alle Himmelsrichtungen zerstreut, sie aber an einer Stelle eng zusammenhäuft als Wald, dem nach dem Urteil vieler gerade das Beste im Walde, die Schönheit fehlt. Es sind daher auch jene durchaus nicht in geringer Zahl, welche glauben, die naturwissenschaftliche Vorbildung sei dem Forstmanne eher ein Hindernis als ein Fördernis für den späteren, praktischen Beruf. Daß auch unter den Forstwirten selbst diese Ansicht tief wurzelt, zeigt die Mißachtung des naturwissenschaftlichen, des sogenannten theoretischen Waldbaues in der Schule und in der Praxis. Wer den Gedanken hegt, Waldbau könnte in seinen zahlreichen Aufgaben ohne Theorie, d. h. ohne Kenntnis der Naturgesetze des Waldes und seiner Holzarten, erlernt werden, der kennt die Autgaben des Waldbaues nicht und handelt nur folgerichtig, wenn er seinen Wald einem Halb- oder Ungebildeten anvertraut; wer vom Forstmann nichts verlangt, als daß er säen und pflanzen und verwalten kann, der braucht keinen naturwissenschaftlich gebildeten Mann; denn Säen und Pflanzen sind so 
einfache Geschäfte, daß jeder sie erlemen oder durch Herumprobieren im Walde, auch Praxis des Waldbaues genannt, sich erwerben kann: ist dann der Wald reif für die Ernte, so kann diese von jedem naturwissenschaftlich Ungebildeten betätigt werden, da ja nach der Ansicht selbst der Bestgebildeten unter den Laien diese nu darin besteht, die Bäume abzuhacken.

Das ist die landläufige Auffassung von der waldbaulichen Tätigkeit des Forstmannes im Walde, aber auch die Tendenz der Erziehung destorstlichen $\mathrm{Nachw}$ chses: in möglichst kurzer Zeit möglichst viele Verwaltungskenntnisse, möglichst viele einfache, praktische Handgriffe in der Betätigung des Waldbanes und möglichst wenige der naturgesetzlichen Grundlagen des Waldbaues dem jungen Manne beizubringen; so wird aus ihm ein Beamter, der den bis ins kleinste ausgearbeiteten Wirtschaftsregehn sich fügt.

Lie Einfachheit im forstlichen Betriebe feiert ihre höchsten Triumphe im Kahlschlage, wie ihn die Forsteinrichtung für ihre reinen, mangelhaft erzogenen, großen Bestände voraussetzt.

Am ersten hat die Natur mit heftigen und schweren Kalamitäten gegen die Unnatürlichkeit protestiert, welche an Stelle der ursprünglichen, natürlichsten Form des Waldes, an Stelle des Urwaldes getreten ist. Was liegt näher, als daß man anf der Rückfährte zum Urwalde heute die Heilung des Kulturwaldes erblickt. Zweifellos ist dieser Gedanke richtig, aber seine Ausführung ist schwierig. Die Annäherung an das Unerreichbare hängt ab von der heutigen, wirtschaftlichen Bedeutung des Waldes und ron der Wertschätzung des Urwaldes. Es kann den Vorschlägen, welche sich mit einer Verbindung zwischen Urwald und wirtschaftlichem Walde befassen, der Vorwurf nicht erspart werden, daß sie die heutige Bedeutung des wirtschaftlichen Waldes unterschätzen, die waldbanliche Bedeutung des Urwaldes aber überschätzen.

Nur letzteres kann hier kurz gestreift werden. Wer glaubt, der Urwald mit seinen Riesen erzeuge die hochwertigsten Stämme nach Art und Schaftform, wer glaubt in der Urwaldform, d. h. sich selbst überlassen, verjünge sich der Wald am vollkommensten und schnellsten, der steht unter dem Banne einer nebelhaften Vorstellung von dem Werdegange des Urwaldes, er ist gefangen von seiner Schönheit, seiner Ursprïnglichkeit, von seinem Artenreichtum, seinen mächtigen Gestalten, aber er vergißt, daß die Baumriesen gerade wegen ihrer Riesenhaftigkeit ungefügige Kolosse sind, deren Nutzungswert sich nur lohnt, wenn der Ankaufspreis äußerst niedrig ist. Nicht die Erziehung von Baumriesen ist das Ziel der forstlichen Waldbautätigkeit; jeder Baum soll nur so lange leben und nur so groß werden, bis er die höchste Wertstufe in seinem Körper erreicht hat; dem Waldbau speziell 
fällt dabei die Aufgabe zu, durch entsprechende Erziehung in möglichst kurzer Zeit dieses Ziel zu erreichen. Wer mit dem Urwalde imniger sich vertraut macht. findet bald, daß an den Banmriesen weniger die Grölỉe als deren Alter bewundernswert ist; auch der moderne Kulturwald wäre imstande. solche Riesen zu erzeugen, wenn das mit den Prinzipien einer gesunden und geregelten Wirtschaft rereinbar wäre; es fehlt hierzu nur die entsprechende Höhe der Umtriebszeit.

Die Begründung der Waldesjugend in Urwalde erfordert einen überaus langen Zeitraum; jahrzehntelang erhalten sich in dem Halbdunkel die rerschiedenen Altersstufen der jungen Pflanzen, bis endlich der überschirmende, alte Stamm abstirbt oder vom Winde gebrochen wird; mühsam kämpft sich die junge Pflanze durch das Gewirr der Äste empor, bis sie endlich zum vollen Lichtgenuf gelangt, nachdem 5i), $10($ ) Jahre, ja Jahrhunderte vergangen sind, seit das Korn vom Mutterbaume fiel. Unmöglich kann der heutige Waldbau diesem Verjüngungsgang folgen; sein Ziel ist darauf gerichtet, daß auf die Nutzung des erwachsenen Baumes so schnell als möglich die Wiederbegrüindung der neuen Generation folge. Ja, der Waldbau sucht, wenn irgend möglich, der jungen Generation das Dasein zu geben und zu sichern, ehe noch die alte Generation völlig von der Fläche verschwunden ist.

Im Urwalde fehlen Sturm-, Wasser- und Insektenkatastrophen durchaus nicht; sie sind aber dort seltener und abgeschwächt gegenüber dem Kulturwalde. Entsteht im Urwalde eine kahle Fläche, so verjüngt sich dieselbe ebenso wie eine künstlich geschaffene Kahlfläche, die wir der Natur zur Wiederbesamung überlassen; Tausende von Beispielen in Europa, Amerika und Asien lehren den gleichen, natürlichen Werdegang des Waldes auf Grund gleicher Naturgesetze. Überall strebt die Natur, die Kahlfächen möglichst rasch zu überkleiden mit einer Vegetation der leichtsamigsten Gewächse, der flugfähigsten Sämereien. Teils sind es annuelle und bienne Pflanzen, Kräuter, Gräser, Sträucher; vielfach sind sie denselben Familien wie z. B. den Kompositen, entnommen; bald sind es Bäume, insbesondere die leichtsamigen Gattungen Salix, Populus, Betula, leichtsamige Nadelbäume. wie vor allem Föhren, Fichten, Cupressineen mit geflügelten Sämereien, welche auf der Kahlfläche sich einfinden; wer zuerst erscheint, behauptet das Feld für die erste Waldgeneration, und zuerst kommt, wer zur Zeit der Kahlfächenbildung gerade Samen trägt. Die Unkräuter überwiegen, denn sie sind die alljährlichen Samenträger; ihre Sämereien sind all- und immergegenwärtig: die Bäume halten im Samenerträgnis einen Turnus ein, und ihre Keimlinge sind so zart, daß nur jene Art siegen kann, welche den klimaextremen Verhältnissen der Kahlfläche am besten gewachsen ist, welcher der Zustand des Bodens für Antlug und Keimung am besten entspricht. So ist die nene Genera- 
tion überall ein Find der Umgebung und des Zufalles. Zufällig kann anch der neve Wald den Absichten der Mensehen entsprechen: das sind Ausnahmen. Läßt man diese erste Generation der leichtsamigen Gewächse ungestört, das heißt, vernichtet man sie nicht durch Feuer oder Axt, so schliefot sie sich zum Walde zusammen, in dem auch die Tiere des Waldes, vor allem Vögel sich niederlassen können, um für die Einbürgerung schwersamiger Holzarten, besonders der Eichen, Buchen, Nufarten und dergleichen, zu sorgen. Nach langem Kampfe gelingt es schließlich auch den schwersamigen und zumeist forstlich wertvolleren Holzarten, die leichtsamigen wieder auf ihr ursprüngliches Gebiet zurüickzudrängen. Nun erst, vielleicht nach Jahrhunderten, ist wieder jenes Gleichgewicht im Walde hergestellt, das durch Sturmgewalt oder menschliche Eingriffe gestört worden war. Dieser langsame, umständliche Weg, den die Natur im Ur- und Kulturwalde zu gehen gezwungen ist, kann unmöglich vom Waldbau beschritten werden. Nur dann, wenn ein Meer einer Holzart die Kahlfläche umschlieft, ergreift diese sofort von der Scholle wieder Besitz.

Es ist allgemein die Ansicht verbreitet, die Natur wähle im Urwalde auf einem gegebenen Boden die für diesen passendste Holzart selbst ans. Abgesehen davon, daß es fraglich ist, ob diese Holzart auch für den Menschen die entsprechendste ist, trifft die Voraussetzung in den meisten Fällen gar nicht zu. Die Natur sät die Holzarten aus ohne Rücksicht auf die Bodengüte; sie bringt Föhren auf Boden, der nach waldbaulicher Auffassung für die Föhre viel zu mastig, zu gut ist; sie stuft Eichen, Nüsse, Kastanien mit Hilfe der Tiere auf Böden, die viel zu mager sind, um solche anspruchsvolle Holzarten zu ernähren; nach langem Kampfe um eine ärmliche Existenz siegt freilich allmählich die für den betreffenden Boden passendste Holzart. Die Anfgabe des Waldbaues ist von Anfang an, ohne Zeit- und Geldverlust jene Holzarten herauszufinden und anzubauen, welche für den Boden und die menschlichen Zwecke am passendsten sind.

Was für den Boden gilt, hat anch Geltung für das Klima. Seit Jahrtausenden macht die Natur Anbauversuche mit den Holzarten über deren beste Wuchsgebiete, ja, über deren natürliche Verbreitungsgrenze hinaus; seit Jahrtausenden ist das Endergebnis das gleiche: die Holzarten kümmern rnd verschwinden wieder, erdrüclit durch den Mitbewerb der im neven Gebiete heimischen, kampfesstärkeren Baumart. Die Verbreitung über die natürliche Grenze hinaus scheitert an der Unmöglichkeit der Bäume, sich an ein vom Heimatgebiet fremdes Klima anzupassen. Nur ein Studium der unwandelbaren, klimatischen Bedürfnisse der Baumarten und der Gesetze der Verbreitungsgebiete kann den Waldbau vor Mifgriffen bewahren, zu denen die Natur gezwungen wird, da sie blindlings nach allen Richtungen hin die Sämereien ausstreut. 
In ihrem Bestreben, jede wunde Stelle des Bodens möglichst schnell mit Vegetation zu überkleiden, wählt die Natur oft Pflanzen, weiche für später kommende Sämereien den Boden verschließen. Wo Gräser, vor allem der alles erdrückende Bambus sich angesiedelt hat, sind Holzgewächse für die erste Generation oder selbst für immer ausgeschlossen; was die Natur schafft, ist ïberall ein lückiger, von verunkrauteten, vergrasten Stellen durchbrochener Wald, ist eine unvollkommene Bestockung, eine mangelhafte Ausnutzung des Bodens, ist ein Wald, in dem die Individuen zu viele Äste und zu wenig wertvolle Schäfte ausbilden müssen. Daß es Aufgabe des Waldbaues ist, eine rollkommene Ausnutzung des Bodens und mit dieser auch Vollkommenheit in der Ausbildung der Schäfte zu erzielen, bedarf keiner weiteren Worte.

Der Waldbau hat längst heransgefunden, welche Vorzüge reine oder auch gemischte Bestände bieten, welche Baumarten und in welchen Verhältnissen die einzelnen Baumarten in Mischung treten können, um verschiedene Wirtschaftsziele zu erreichen. Nichts von all dem vermag die sich selbst ïberlassene Natur; bei ihr ist die erste Waldgeneration ein Zufallskind: sie schafft reine Bestände von Lichtholzarten, die ohne Beimischung anderer den Boden nicht zu schützen vermögen; sie schafft Mischbestände, welche an der betreffenden Stelle in kurzer Zeit im Kampfe der Arten um Licht und Boden in reine Bestände übergehen müssen oder ihr Leben lang an geringer Masse und Ästigkeit kranken.

$\mathrm{Zu}$ den Aufgaben des Waldbaues zählt der wirksame Schutz der neuen Waldgeneration gegen Naturereignisse, vorzugsweise Wind, Feuer, Insekten, Pilze, durch vorbeugende Maßnahmen, als da sind Anbau entsprechender Holzarten, passende Form und Methode des Anbaues und geeignete Erziehung der begründeten Waldbestände. Wenn hierin die vom Menschen unberührte Natur das Vorbild liefert, indem sie ihre Bestände in aufgelöstem Schlusse des Urwaldes erzieht, so ist es die Aufgabe des Waldbaues, in der Begründungs- und Erziehungsform eine Annäherung an den Urwald zu suchen und die Nachteile des von Jugend an aufgelösten Kronenschlusses des Urwaldes zu meiden.

Torbildlich ist die Natur für den Waldbau in der Kostenlosigkeit, mit der sie verjüngt. Die Natur arbeitet langsam aber billig: wer billig im Walde verjüngen will, muß langsam arbeiten und die Natur zur Hilfeleistung heranziehen; wer aber ohne Verlust an Zeit und Zuwachs wirtschaften will, muß schnell arbeiten; das schnelle Arbeiten aber ist kostspielig. Es muß Aufgabe des Waldbanes sein, eine Methode zu finden, für welche im Urwalde kein Analogon sein kamn, eine Methode, die natïrlich und schnell zugleich verjüngt; wer einer solchen nicht traut, aber dennoch schnell verjüngen will, muß eine künst- 
liche Verjüngung wählen und sie ausführen, ehe der Standort umnatürlich durch Kahlschlag verändert ist.

Dieser Gedanke führt naturgemäß zur Forderung, daß Waldbau und Waldbenutzung zusammenwirken müssen; jede Nutzung soll auch waldbauliche Zwecke, jede waldbauliche Handlung das Endziel, die spätere Nutzung, zur Richtschnur haben. Wie die Nutzung geregelt sein muß, so daß ihre Nachhaltigkeit gewährleistet ist, so muf auch jede waldbauliche Maßnahme so getroffen werden, daß durch sie die Nachhaltigkeit der Bodenkräfte als die Quelle aller Nachhaltigkeit der Nutzung gesichert bleibt; hierin ist voll und uneingeschränkt der Urwald das Ideal und sichert sich dieses durch den Nangel an Nutzung und durch Anreicherung des Bodens; diese wieder erfolgt in der besten Form durch stetige Überschirmung mit Kronen, welche Luft, Licht und Wärme zum Boden gelangen lassen, welche wegen des Mischwuchses leicht zersetzbare Abfallstoffe dem Boden zuführen. Naturverjüngung zur Erzielung der Stetigkeit der Bodenbedeckung, Durchforstung und Durchlichtung für die normale Streuauflösung und gemischte Bestände sind aus diesem Grunde Forderungen des heutigen Waldbaues; ob sie erfüllbar sind, soll in vorliegender Schrift geprïft werden.

Als Führerin versagt die Natur ganz auf jenen ungeheuren Strecken der Erdoberfläche, welchen sie selbst seit Urzeiten eine Walddecke verweigert hat, weil sie nicht imstande ist, die der Waldansiedlung entgegenstehenden Hindernisse $\mathrm{zu}$ beseitigen, als da sind Überschuß an Wasser, an Wind, Mangel an Niederschlägen, an Temperatur, waldfeindliche Vegetation und andere. Die Bewaldung solcher natürlicher ödländereien gehört zu den volkswirtschaftlich wichtigsten, wenn auch schwierigsten und kostspieligsten Aufgaben des Waldbaues. Das gleiche mufo gesagt werden von jenen ungeheuren Flächen, welche der Mensch des Waldes beraubt hat, auf denen der Mensch die natürliche Rückkehr des Waldes unmöglich gemacht hat. Asien hat zuerst begonnen mit der Entwaldung ungeheurer, jetzt bis zur Wertlosigkeit herabgesunkener Flächen; es fehlen die schützenden und Samen spendenden Mutterbäume für eine neue Generation, Bodendecke und Bodenklima sind durch die Entwaldung so verändert worden, daß die Waldansiedlung, auch wenn das Samenkorn vorhanden ist, zur Unmöglichkeit wird. Europa ist mit der Entwaldung und Schaffiung von Ödländereien gefolgt. Freilich sind die Gebiete viel kleiner, klimatisch vielfach günstiger, und vielfach braucht es in der Tat nichts anderes, als den Menschen von der Scholle zu vertreiben, um dem Walde sein ehemaliges Besitztum zurückzugeben. Amerika ist wiederum den Europäern in der Waldverwüstung und -vernichtung gefolgt; die Arbeit war aber viel schneller und gründlicher getan. Die waldvernichtende Tätigkeit 
des Menschen hat der waldbegründenden Tätigkeit die flächengrößten und schwierigsten Aufgaben gestellt.

Man wird dem Waldbau die Anerkennung nicht versagen kömnen, daß seine Aufgaben sehr mannigfaltige und schwierige sind, daß dio Lösung derselben ïber Forterhaltung, Bewirtschaftung und Rentabilität des Waldes als eines volkswirtschaftlich und finanziell hochwertigen Gutes in erster Linie entscheidet, und an die Lösung dieser Aufgaben sollen wir treten mit der Devise: "Probieren geht über Studieren?" Auch hente noch gibt es Forstwirte, welche diesem Grundsatze huldigen und verächtlich auf den "theoretischen" Waldbau herabblicken, der zur Devise hat: „Erst studieren, dann probieren." An die lernendell Jugend und an jene Minderheit unter den Praktikern, welche der wissenschaftlichen Entwicklung des Waldbanes olgen und selbst durch Versuche und Beobachtungen an dem Fortschritt des Waldbaues weiterbauen, wendet sich der nachfolgende Waldbau auf naturgesetzlicher Grundlage; er will dem Aufänger das Rüstzeug für seinen Eintritt in die Praxis, dem Praktiker Anregung und Führung zur Beobachtung und Prüfung bieten. Sollte er sein Ziel nicht erreichen, so kann die Schuld an der Unzulänglichkeit des Antors, aber auch daran liegen, daß die Naturgesetze des Waldes noch ungenügend erforscht sind. All unser Wissen ist nur Stückwerk; gerade die für den Waldbau wichtigste Wissenschaft, die kaum 30 jährige Pflanzenphysiologie, steckt noch ganz in den Kinderschuhen, und ihre wichtigsten und zuverlässigsten Grundlagen für den Waldbau hat nicht die wissenschaftliche Forschung, sondern die viel ältere Praxis im Walde, der praktische Waldbau gezeitigt. Es sind noch nicht zwei Dezennien verflossen, als im Hörsaal einer Universität das Wort fiel, Waldbau sei keine Wissenschaft, Waldbau an einer Hochschule vorzutragen, sei eine Schande für dieselbe. Wer unter Waldbaı nur das mechanische Säen und Pflanzen versteht, nicht aber die naturgemäße Begründung, Pflege und Erziehung des Waldes, wer den Waldbau von der bequemen Ecke des "Probieren geht über Studieren" beurteilt, der kennt nicht jenes Wissensgebiet, dem er den Charakter einer Wissenschaft abspricht.

Torliegende Schrift ist der Versuch, den Waldbau als Wissenschaft einzuführen durch den Versuch seines A ufbaues auf naturwissenschaftlicher Grundlage, wodurch seine Gültigkeit und Notwendigkeit eine universelle wird, und durch den Nachweis, daß er zur Lösung der mannigfaltigen, vielgestalteten Probleme in erster Linie theoretisches Wissen und logisches Denken beansprucht.

Wissen und Denken führen naturgemäß zur Freiheit im Denken, zur freien Beurteilung der Bedürfnisse des Waldes und seiner Glieder. Aus der Freiheit des Geistes erwächst das Streben nach Freiheit des Handelns. Für den Wirtschafter, der Waldbau treibt nach dem Grund- 
satze: „Probieren geht über Studieren“, sind Vorschriften und Wirtschaftsregeln notwendig, um das kostspielige, zeitraubende und insbesondere das aussichtslose Probieren einzuschränken; der Wirtschafter nach dem Grundsatze: „Erst studieren, damn probieren“, verdient die Freiheit des Handelns, aber die Freiheit ist nur ein wohltuender Schein, denı an Stelle der Vorschriften der vorgesetzten Behörden treten die Torschriften der obersten Instanz, die Naturgesetze, in deren Befolgung und Terknüpfung mit den Wirtschaftszielen des Menschen der wahre Meister des freien Waldbanes sich zeigt. 


\section{Erster Teil.}

\section{Die naturgesetzlichen Grundlagen des Waldbaues.}

Seit Menschengedenken hat sich keiner der Faktoren im Klima wie im Boden auf natürlichem Wege so verschlechtert, daß als Folge hiervon Wald verschwunden wäre, wo er früher bestanden hat; aber auch kein Faktor hat sich so verbessert, daß neuer Wald entstanden wäre, wo er ursprünglich fehlte; die walderzengenden und waldvernichtenden Faktoren sind noch heute nach Tausenden von Jahren in gleichem Sinne wirksam. Die Natur, sich selbst überlassen, vernichtet den Wald, wenn er a u $\beta$ erhalb der von ihr gezogenen Waldgrenzen angelegt wird; die Natur, sich selbst überlassen, baut den Wald wiederum auf, wenn er innerhalb der von ihr gezogenen Waldgrenzen vernichtet wurde. Könnte man den Menschen wieder vertreiben, Wald würde in kurzer Zeit zurückkehren auf jenen drei Vierteln des Deutschen Reiches, auf denen er durch den Menschen beseitigt wurde; Wald würde von Frankreich wiederum jene $83{ }^{\circ}{ }_{0}$ der Oberfläche zurïckerobern, welche heute als vom Walde entblößt sich darstellen; volle vier Fünftel der Oberfläche des Ostens der Vereinigten Staaten würden zu Wald zurückkehren; noch rascher würde Wald von ganz Großbritannien, ganz Japan Besitz ergreifen. Alle Versuche, welche in den Alpen angestellt wurden, um mit Pflanzungen aus Sämereien aus dem höchsten Norden noch über der Waldgrenze in den Alpen einen Wald zu begründen, hat die Natur gleich im Keime erstickt; wo immer es dem Menschen gelingt, an Stelle ron Ödland, Steppe, Prärie ohne künstliche Veränderung des Bodenzustandes Wald zu begründen, da war er früher bereits vorhanden.

So erscheinen die natürlichen Faktoren der Waldexistenz als etwas Unabänderliches, und sie zu ergründen und zu erkennen, ist das Alpha und Omega jeglicher Tätigkeit, welche die Waldbegründung zum Ziele 
hat. Der fortschreitenden Forschung entgeht es nicht, daß diese Naturgewalten nicht bloß ewig und unveränderlich sind, soweit die Zeit des menschlichen Daseins auf der Erde in Frage kommt; sie erkennt anch, daß ïberall auf der Erde die Faktoren die gleiehen, daß die mächtigsten unter ihnen klimatischer $\mathrm{Nat} \mathrm{ur}$ sind. Es ist daher logisch, zuerst die Einwirkung des Klimas auf das Dasein der Waldungen und ihre Verteilung anf der Erde anf Grund dieser Einwirkung festzulegen. 


\section{Erster Abschnitt.}

\section{Naturgesetzliche Grundlagen und Verteilung der Wälder auf der Erde.}

\section{Das Klima.}

Klima ist ein Sammelname für alle jene Einflüsse, die auf die Erde, ihre Pflanzendecke und ihre Bewohner von oben her einwirken, die das Dasein aller Lebewesen bedingen, ihr Gedeihen fördern oder schädigen und sie wiederum vernichten; die Faktoren des Klimas wirken auch auf die feste Erdkruste ein, indem sie an der Verwitterung derselben sich beteiligen, dieselbe mit Naß durchtränken und genügend erwärmen, wodurch die Erde erst für Pflanzen und Tiere bewohnbar geworden ist. Je nach dem Wechsel der einzelnen Faktoren im Klima wird die Einwirkung auf Boden und Pflanzendecke sich in verschiedenen Zuständen, in verschiedenen Pflanzenformen äußern müssen. Auf große Flächen hin herrschen, wie insbesondere Hilgard und Ramann gezeigt haben, unter den gleichbleibenden Faktoren gleiche Verwitterungsformen und Zustände im Boden und nur allmählich geht ein Bodentypus in einen anderen über. Es ist auch ein Charakteristikum des Klimas, daß es, nur allmählich in seinen Faktoren sich ändernd, allmählich in einen anderen Typus ïbergeht; es ist eine naturgemäße Folgerung, daß unter dem Einflusse dieser Erscheinung auch die Vegetation der Erde allmählich von einem Typus in einen anderen sich umwandelt. Unsere Aufgabe muß es sein, die Wechselbeziehungen zwischen Klima-, Boden- und Waldtypen aufzusuchen und in ihrem Zusammenhange kennen zu lernen. $\mathrm{Zu}$ diesem Ende muß zuerst das Klima in seinen einzelnen Faktoren geschildert werden, soweit diese den Vegetationsformen, deren wichtigste und vornehmste der Wald ist, ihren Charakter aufprägen, soweit sie vor allem das Dasein des Waldes überhaupt ermöglichen, sein Gedeihen fördern oder es ganz verhindern. 


\section{a) Die 'Temperatur.}

Nur jene Wräme, die von der strahlenden sonne der Erde gespendet wird, rechnet man zu den Faktoren des Klimas; Eigenwärme dry Vegetation, Eigenwärme des Bodens können die Wirkung der klimatischen Wärme erhöhen oder mindern. Sie sind jedoch nur ganz ausnahmsweise so mächtig. daß sie das Ergebnis der klimatischen Erwärmung in bemerkbarer Weise abändern.

Wiircle man die Frage an die Pflanzenzüchter stellen, ob es Flächen aut der Erde gibt, auf welchen es für das Dasein von Pflanzen, von Wald zu kalt ist, so würden wohl fast alle mit ja antworten; würde man an sie die Frage richten, ob es Flächen gibt, auf denen wegen allzu hoher Temperatur Pflanzenwuehs fehlt, so würde die Mehrzahl abermals mit ja antworten. In beiden Fällen aber mul. es nein heißen. wenn man die absolute Temperatur, das absolute Maximum der Somnenstrahlung und das absolute Minimum der Wärmeausstrahlung in Betracht zicht. Bezüglich der höchsten Temperatur haben die noch nicht veröffentlichten Untersuchungen des Verfassers ergeben, daß alle vege tabilischen Gewebe, ob sie Bäumen oder Stränchern, perennierenden oder annuellen hräutern, ob sie fertigen Geweben oder solchen angehören, welche eben im zartesten Entstehen begriffen sind, getötet werden, sobald ihre Erwärmung $5 t^{\circ} \mathrm{C}$ ïberschreitet.

Gegen Überhitzung, welche in einem plötzlichen Ausstofen großer Wassermengen in fiüssiger Form sich äußert, schützt jeder Pflanzenteil sich durch IVärmeableitung, beziehungsweise durch Empfang von Kälte von benachbarten Medien, wie er gegen das Übermaß der Wärmeansstrahlung von benachbarten Nedien Wärme empfängt. Nadeln und Blätter werden, obwohl sie nicht blok in den Tropen und Subtropen, sondern weit hinauf in den Norden der heißesten Mittagssonne ausgesetzt sind. von den Strahlen der Sonne nicht versengt, vorausgesetzt, daß sie im vollen Lichte erwachsen sind, weil ihre Wärme durch Leitung der umgebenden Lnft auf ein unschädliches Maß herabgedrïicht wird: an den Ästen und s'chäften der Bäume tritt, sofern ihro OberHächen stets im Lichte gewesen sind, keine Überhitzung ein, weil die hohe Temperatur sofort in die tieferen Gewebe verteilt wird; es bedarf einer besonderen Anordnung des Experiments oder besonderer, ungünstiger Verhälnisse, wie plötzlicher Freistellung im Schatten gebildeter Blatt- oder Rindenoberflächen, um die als Blattbleiche und Rindenbrand bekannten Erscheinungen hervorzurufen. Eine Erhitzung des Bodens durch Wärmeeinstrahlung kann die Ansiedelung einer Pflanze hindern, wenn fü̈ Wärmeleitung besonders ungünstige Verhältnisse vorliegen, wenn z. B. Wasser fehlt, das die Wärmeleitung in die tiefen Bodenschichten begïnstigt, wenn der Boden durch Humusbeimengungen eine dunkle Farbe besitzt, wie ror allem Humms und 
Torf' selbst. Ebermayer fand eine Erhitzung bis zu (ii) ${ }^{0}$; aut' nadelbedecktem Humus, lehmigem Sand, sowie auf Moorboden fand Verfasser nicht weniger als $68^{\circ} \mathrm{C}$ Maximalwärme; die dunkle Fläche der Saatbeete zeigt noch unter dem $49^{\circ}$ nördlicher Breite bei $570 \mathrm{~m}$ Erhebung $58^{\circ} \mathrm{C}$, obwohl die Sonnenstrahlen wie in ganz Mittel- und Nordeuropa nicht senkrecht auf solche Beetflächen auftreffen können. Bei solcher Temperatur stirbt natürlich jeder Keimling ab; durch Selbstsaat sowie durch künstliche Saat kömnen solche Flächen sich zwar wieder mit Pflanzen besiedeln, aber die Besiedelung geht äußerst langsam, schwierig und lückenhaft vor sich. Eine Durchforschung der Prärien und Wüsteneien der nördlichen Halbkugel findet zwar Fläch nn genug, von denen heute das Temperaturmaximum den Wald abläit: es läßt sich aber nachweisen, daß sie nicht von Uranfang an durch die Sonnenhitze, vielmehr durch Wassermangel waldlos waren. In diese Rubrik fallen auch alle kahlen Flächen im forstlichen Betriebe, wobei jene auf trockenen, schlecht leitenden Sand- oder Moorböden die schlimmsten sind. Das absolute Maximum der Lufttemperatur, das ist zum allergrößten Teile reflektierte Sonnenwärme, liegt stets un ter der Wärme, welche feste Gegenstände der Wärme absorbierenden Erdfläche durch direkte Strahlung annehmen: Maximaltemperaturen von $500^{\circ} \mathrm{C}$ in der Luft sind nur im Zentrum der großen Kontinente, in den luftrockensten Gebieten nachweisbar; die Lufttemperatur bleibt stets unter der Tödlichkeitsgrenze für regetabilische Gebilde: es wäre anch irrig. allzu hoher Temperatur oder dem durch die Hitze in seiner Oberfläche physikalisch veränderten Boden das Fehlen von Wald zuzuschreiben. Man brancht derartige Flächen nur zu bewässern, und ohne weitere Änderung des Bodens entspringt demselben eine Vegetation, ein erfrischender, kïhler, schattiger Wald.

Wie man die höchsten Temperaturen nicht in der Nähe des Äquators, sonderr nördlicher von diesem, selbst in gemäßigter Region, ja hart an der Baumgrenze findet (Ostsibirien), so liegen auch die tiefsten Temperaturen nicht, wie man wohl vermutet, möglichst nahe am Nord- oder Südpol, sondern im Festlande, vom erwärmenden Meer entfernt; auf der nördlichen Erdhälfte treften wir sie mit $-5.5^{\circ} \mathrm{C}$ tast an derselben Stelle, an der im Sommer auch die höchsten Temperaturen sich einstellen. So tiefe Temperaturen sind natiurlich absolut tödlich für die gesamte Pflanzenwelt, welchevom Äquator bis zum 40. ${ }^{\circ}$ nördlicher Breite bei geringer Eleration wächst; sie sind tödlich für die gesamte Baum-, Strauchund Krautflora der südlichen Halbkugel; eine einzige Nacht mit $-30{ }^{\circ} \mathrm{C}$ würde bereits genügen, sie alle zu vernichten. Aber es gibt Bäume und zahlreiche andere Pflanzen, es gibt Wälder, welche der tiefsten Temperatur von $-500^{\circ} \mathrm{C}$ und darunter trotzten. Es sind 
Fichten. Birken. Weiden, Lärchen. Zirben und andere, welche in dem ostsibirischen Kältebecken ohne șchaden gedeihen. So muß die Ansicht vieler, daf die höchsten Regionen der Gebirge, die nördlichsten und südlichsten Punkte unserer Erde waldlos seien, weil die Temperatur zu tief sinke, d. h. das absolute Ninimum zu tief liege, als den tatsächlichen Verhältnissen nicht entsprechend bezeichnet werden; die tiefste Temperaturkann das A ufwachsen von Wald nicht hindern; daf sie aber oine äuberst wichtige Rolle spielt in der Frage nach der Zusammensetzung des Waldes in IIolzarten, ist selbstrerständlich.

Da die Eigenwärme der Pflanzen und damit auch der Bäume infolge chemischer Vorgänge in ihrem Innern nur eine ganz geringfügige, für das Leben der Pflanzen belanglose ist, da die Eigenwärme der Ercle nur an wenigen Punkten bis zur Oberfläche empordringt, so ist für das Dasein der Bäume, für das Dasein des Waldes in erster Linie die Luftemperatur entscheidend, insofern als während einer bestimmten Zeit eine bestimmte Wärmemenge auf die Pflanze einwirken muß, damit sie leben kann; WT̈̈megrade und Zeit sind die beicten Faktoren, welche entscheiden, ob Wald hesteht oder nicht, ob ein Baum gedeiht oder nicht. Die günstigsten Wärmegrade können keinen Wald schaffen, wenn die Einwirkung nicht eine genügend lange Zeit dauert, wie die waldlosen Gebiete des hohen Nordens, der höchsten Regionen mit ihren für kurze Zeit nư hohen Temperaturen beweisen. Auf der südlichen Halbkugel fehlt jeglicher Wald, wo immer die durchschnittliche Jahrestemperatur nur $+8^{0} \mathrm{C}$ zeigt, welche Jahreswärme gleich ist jener der bestbewaldeten Gebiete Europas und Amerikas; aber auf der südlichen Halbkugel steigt bei $\gamma^{0}$.Jahrestemperatur die Wärme der vier Sommermonate nicht über den Durchschnittsbetrag von $10^{\circ}$; es fehlt somit bei der Jahresisotherme von $+8^{\circ}$ der Wald, weil die Temperatur zu niedrig ist, obwohl sie während der Sommermonate nicht bis auf $+5^{\circ}$ herabgeht. So überraschend eine derartige Aufstellung klingen mag, sie läht sich als ein allgemeines Naturgesetz beweisen. Beobachtungen an den Waldgrenzgebieten haben ergeben, daß ein Baum seine Vegetation innerhalb 45 Tagen beenden kann; es fehlt aber an Beobachtungen und Zahlen, wie groß die Wärmemenge während dieser Minimalzeit sein muf, und vollständig mangelt uns die Kenntnis, wie weit die Luftwärme hierbei durch die direkte Insolation ersetzt werden kann.

Indem eingehende Erörterungen für die Ansprüche der Holzgewächse an die Lufttemperatur einer späteren Betrachtung überlassen werden müssen, sei hier nur auf jene Fälle hingewiesen, in denen die Existenz des Waldes unmöglich ist, weil die Temperatur ungenügend hoch ist oder, wenn hoch genug, nur allzu kurze Zeit zur Verfügung steht. 
Aus Gründen, die später anzugeben sind, betrachtet der Verfasser als den besten Mafstab zur Beurteilung der Wärmeansprüche der Holzarten jene Temperatur, die sich ans dem Mittel von vier Monaten ergibt, welche die Hauptregetationszeit ganz oder teilweise umfassen. Auf der nördlichen Halbkugel wurden die Monate Mai, Juni, Juli und August, auf der südlichen November, Dezember, Januar und Februar gewählt. Unter dem 50. ${ }^{0}$ nördl. Br. und $40 .{ }^{0}$ südll. Br. fällt die Vegetationsdauer annähernd mit den vier Monaten zusammen; nördlich rom 50. ${ }^{0}$ bzw. südlich vom $410^{0}$ ist die Vegetationszeit kürzer, südlich rom 50. ${ }^{0}$ nördl. Br. bzw. nördlich vom $40 .{ }^{0}$ südl. Br. wird die Tegetationsdaner länger als die gewählten vier Monate; man könnte die Viermonatstemperatur als Tetra(meno)therme bezeichnen; sie ist der Naßstab der Wärmeansprüche der Holzarten und wird im Verlaufe der Darstellung der Naturgesetze des Waldbaues noch näher zergliedert werden.

Tergleichende Untersuchungen haben den Verfasser belehrt, daf, auf der ganzen Erde eine Viermonatstemperatur oder Tetratherme von $+10^{\circ}$ das Minimum ist, das ein Wald zu seiner Existenz verlangt.

Als Wald ist dabei eine Ansiedlung von Bäumen von mindestens $8 \mathrm{~m}$ Höhe verstanden. Nan kann diese natürliche Waldgrenztherme kurz als Horotherme, als Grenztherme bezeichnen und die Waldgrenze selbst als Folge der Horotherme, Thermohore des Waldes nennen. Sinkt die Horotherme unter den Betrag von $10^{\circ}$, so sinkt aneh der Wald zum Stranchwerk herab, steigt die Horotherme uiber diesen Betrag, so bleibt natürlich Wald als Bodendecke, es ändert sich aber sein Charakter, seine Zusammensetzung nach verschiedenen Holzarten.

Die polare Waldgrenze oder polare Thermohore.

Da auf der nördlichen Halbkugel die Landmassen gegenüber den Wassermassen beträchtlich überwiegen, nämlich in Verhältniss von $1: 0,4$, somit zehnmal mehr Land auf der nördlichen als auf der südlichen Halbkugel sich findet, erhält die nördliche Erdhälfte in ihren klimatischen Verhältnissen, von Küstenstrichen abgesehen, mehr oder weniger den Charakter des Kontinentalklimas mit Steigerung der Extreme während der heißen und während der kalten Zeit. Diese Verschiedenheiten kommen schon in den, der Waldgrenzwärme, der Horotherme von $10^{\circ}$ entsprechenden Winter- und Jahrestemperaturen zum Ausdruck. So entsprechen auf der nördlichen Erdhälfte der Horotherme von $10^{0}$ eine mittlere Temperatur der vier Wintermonate von $-5^{\circ}$ und eine durehschnittliche Jahrestemperatur von +3 ; auf der südlichen Hälfte entsprechen der Horotherme von $10^{\circ}$ eine durchschnittliche Temperatur von $5^{0}$ der vier kühlsten Monate und von $+8^{0}$ während des Jahres. Auf der südlichen Hälfte findet sich bei einer Jahrestemperatur von $8^{0}$ die Waldgrenze, obwohl in dieser Region während der kühlsten 
Mnnate Minusgrade noch ganz f'ehlen oder doch nur sehr mild auftreten, während auf der nördlichen Hälfte der Erde bei $8^{\circ}$. Jahrestemperatur und schwerem, lang andauerndem Winter die schönsten, ertragreichsten, ja man kann sagen die wertvollsten Waldungen der Welt stocken. Die Erklärung für diese Erscheinung ist einfach genug. Nördlich vom Äquator setzt sich die Jahrestemperatur zusammen ans sehr warmer Sommer- und kalter Wintertemperatur, während südlich vom Äquator die Jahrestemperatur das Mittel aus kühler Sommer- und warmer Wintertemperatur darstellt. Die kühle Sommertemperatur aber reicht nicht hin für das Dasein von Wald, wemn ihr durchschnittlicher Wert unter 110 ${ }^{0}$ liegt. Vorgreifend sei hier schon erwähnt, daß mit dem schroffen Wechsel der Jahreszeiten auf der südlichen Hälfte der Ercle auch der winterkahle Wald fehlt, daß der immergrüne Lanbbaumwald an der Thermohore zum immergrünen Laubbuschwald herabsinkt.

Durch die kontinentale Entwicklung der nördlichen Erdhälfte erleidet das Klima eine Erhöhung in seinen Wärmeverhältnissen während des Sommers, eine Vertiefung während des Winters: nachdem aber nicht die Winter-, sondern die Sommerresp. Vegetationszeittemperatur über die Existenz des Waldes entscheidend ist, so reichen die Bedingungen für Waldesdasein auf der nördlichen Erdhälfte viel weiter nach Norden und an Bergen viel höher nach oben als auf der südlichen Hälfte; dazu kommen noch warme und kalte Meeresströmungen, welche mit ihren gewaltigen Wassermassen die darüber liegenden Luftschichten erwärmen hzw. abkühlen. Werden nun diese Luftmassen in das Festland gesogen, so beeinflussen sie ebenfalls im positiven oder negativen Sinne die Wärmeverhältnisse des Kontinents. Auf der nördlichen Halbkugel werden die Westküisten der Alten wie der Nenen Welt von warmen, aus südlicher Breite kommenden Strömen, dem Golfstrom und dem Kuro Schino, getroffen und so günstig erwärmt, daß die Waldgrenzlinie oder Thermohore bis zum $65 .{ }^{0}$, ja stellenweise bis zum $70 .{ }^{\circ}$ nördlicher Breite rorgeschoben wird; es verstärkt sich somit sowohl in Europa wie in Westamerika die durch kontinentale Entwicklung bereits bestehende, positive Anomalie des Sommerklimas noch um einen weiteren Betrag, der waldfördernd, vorwiegend durch V erlängerung der Tegetationszeit wirkt. An den 0stlïisten der Alten Welt (Ostasien) und der Nenen Welt (Ostamerika) wälzen sich Ströme ron kühlen Wasser- und Luftmassen südwärts, so daß durch die Verkïrzung der Vegetationszeit, die sie bedingen, die Thermohore bis zum $55 .^{\circ}$, ja stellenweise bis zum 50. ${ }^{0}$ nördlicher Breite herabgedrückt wird.

Es liegt an den Ostküsten der Kontinente die Waldgrenze unter einem Breitengrarle, unter welchem an den Westküsten (Westamerika und -europa) noch mächtige Eichen, Douglasien, Fichten, Tannen, Föhren, ja das Gros der wichtiersten Waldungen der nördlichen Halbkugel wächst. 


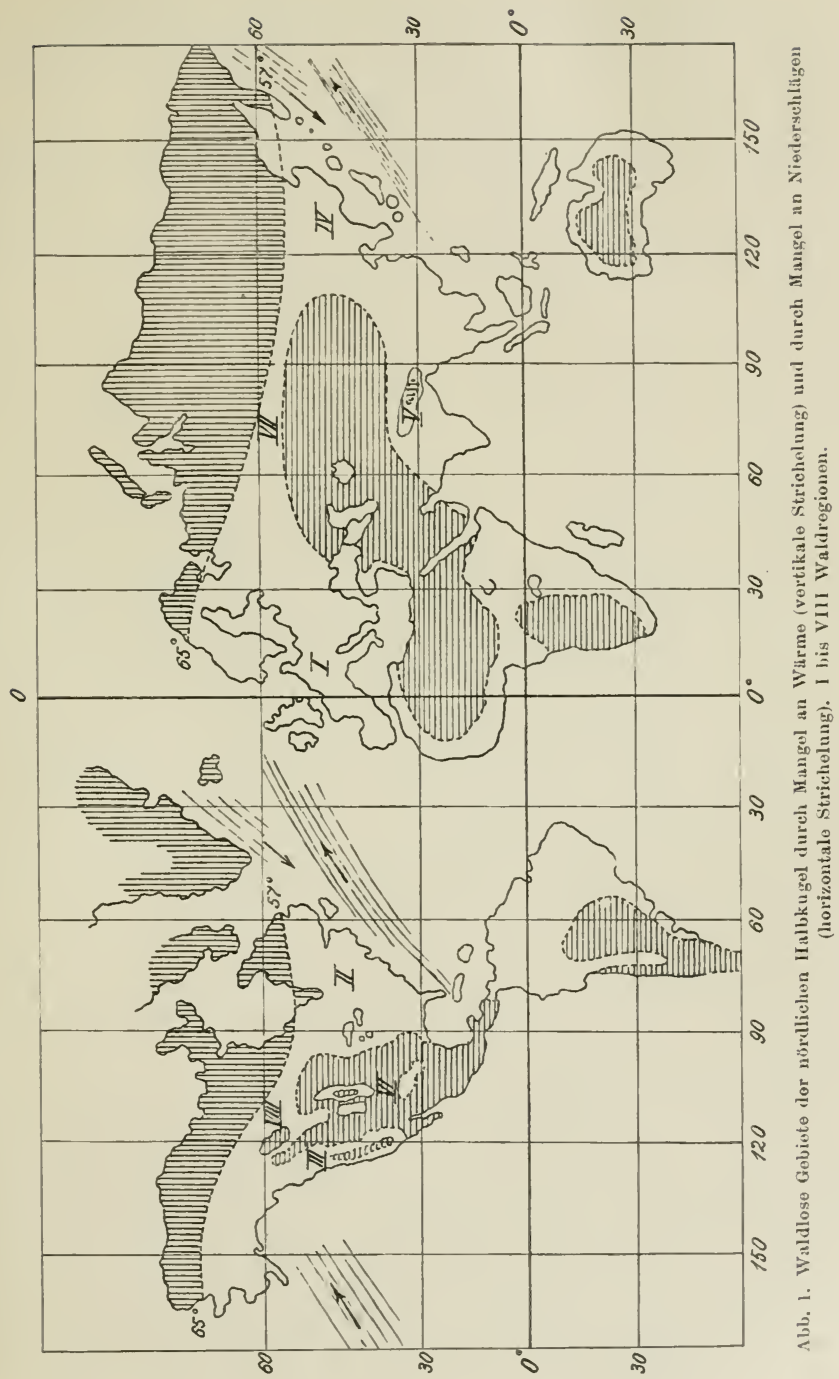


18 Erster Abschnitt. Naturgesetzliche Grundlagen u. Verteilung der Wälder usw.

Beiliegende Kartenskizze stellt den Verlaut der Thermohore des Waldes aut der nürdlichen Halbkugel dar; alle fiehiete nordwärts von dieser Grenzlinie sind waldlos aus Mangel an genïgender Vegetationswärme, und alle Versuche. Wald zu benründen, müssen an diesen natürlichen und umahänderliche'n Hindernissen scheitern.

Auf der südlichen Halbkugrel sind es ebenfalls Meeresströmungen, wie der Perustrom und der antarktische; ein weiterer, liühler Strom fließt norlwärts uregen Tasmanien und Neuseeland hin: aber auf der südlichen Halbkugel sind die I andmassen nicht weit genug nach süden vorgeschoben, um die Thermohore zu erreichen.

Nit der polaren 'Thermohore erreicht die Waldgrenze hoch im Norden der groben Kontinente das Meer; alle Ebenen, alles hügelige Grelände von 1$)-200 \mathrm{~m}$ Erhebung südlich ron dieser Grenzlinie tragen Wald, wemn die äbrigen Faktoren für Waldesdasein günstig sind.

1)ie alpine Waldgrenze oder alpine Thermolore.

Wären die nördliche und die südliche Halbkugel der Erde oround hydrographisch ganz gleichförmig entwickelt, Land- und Wassermassen gleichmäßig verteilt, wären die Meeresströmungen in parallelem Sinne ausgebildet, so mübite die polare Thermohore oder Waldgrenzlinie nach dem Äquator hin gleichmäßig als alpine Thermohore ansteigren, um südlich rom Äquator in einem, dem nördlichen Aufstiege symmetrischen Abstiege unter dem $65^{\circ}$ südlicher Breite die Meeresfläche zu erreichen. Eigene Beobachtungen an den alpinen Waldgrenzen nördlich und südlich rom Äquator haben den Verfasser überzeugt, daß auch bein Verlanfe der vertikalen oder alpinen Thermohore der EinfluB der großen laandentwicklung der nördlichen Halbkugel in die Erscheinung tritt dadurch, daß die alpine Thermohore von Norden gegen den Äquator hin rascher ansteigt, als dem Breitengrade nach entsprechen sollte, somit eine positive Anomalie in ihrer vertikalen Richtung ebenso wie in der horizontalen zeigt; die Waldgrenze erreicht bereits unter dem 10. ${ }^{0}$ nördlicher Breite ihre höchste Erhebung über dem Meeresniveau mit $3500 \mathrm{~m}$.

Trägt man die Breitengrade als Abszisse, die Elevation als Ordinate auf, so ergibt sich eine steilere oder flachere Parabel, je nachdem die Polargrenze des Waldes an der Ost-oder der Westkïiste der Kontinente dio Meeresfläche trifft. Alle Erhebungen nun, welche unterhalb der. Parabel verbleiben, tragen Wald bis in die höchsten Sipitzen, wenn die übrigen Verhältnisse für IVald gïnstig sind; alle Berge, welche ïber die Parabel hinausgreifen, sind waldlos an dem ganzen, überragenden Stück; ist das Verhältnis zwischen Ordinate und Abszisse richtig gewählt, so kann f’ür joden Punkt, für jeden Berg der Erifläche sofort dem Diagramm entnommen werden, in welcher Hïhe die natürliche Waldgrenze zu suchen ist. In der 
beigegebenen Tafel I ist das aus Wärmemangel waldlose Gebiet, die Strauchregetation, als Polaretum und Alpinetum bezeichnet.

An der Verschiebung der alpinen Waldgrenzlinie auf den Gebirgen der Erde sind folgende Falitoren beteiligt:

Die weitgehendste Verschiebung bringt die Exposition und die Steilheit der Bergwände hervor. An der kühleren Nordseite liegt die Thermohore stets tiefer als an der Südseite, an der sie auch höher steigt als anf den Ost- und Westseiten. Man kann im Durchschnitt die Verschiebung durch die Exposition auf $2100 \mathrm{~m}$ anfwärts an der Südseite und $200 \mathrm{~m}$ abwärts auf der Nordseite berechnen: an steilen Hängen von ïber $45^{0}$ und darüber verschiebt sich die Waldgrenze um volle $500 \mathrm{~m}$ auf- oder abwärts, je nachdem Süd-oder Nordseite vorliegt. Der Grund liegt in der intensiveren Besonnung auf der Süd- und in der Abnahme der Bestrahlung auf der Nordseite. Man kann berechnen, daß unter dem 45. ${ }^{\circ}$ nördlicher Breite die Nordseite eines Berges bei einer Steilheit des Hanges von $60^{\circ}$ von Sonnenstrahlen überhaupt nicht mehr getroffen werden kann. In solchen extremen Fällen, die in den Alpen wie in den Pyrenäen, im Himalaya wie im Hochgebirge der Sierra Nevada sehr häufig beobachtet werden, steigt die Waldgrenzregetation bis ins Tal herab. Wo sie mit den schönsten Hochwaldungen der Südseiten zusammenstößt, die unter dem Einflusse des Sonnenlichtes und damit anch der größeren Wärme erwachsen sind.

Es ist durch rerschiedene Messungen in den Alpen nachgewiesen worden, daß die Waldgrenze sich an großen Gebirgsstöcken höher erhebt als an isolierten Bergen; Vulkane unvermittelt aus der Ebene auftauchend und bis zur Schneegrenze sich erhebend, wie z. B. der Fuji in Japan, beweisen auf das vollkommenste die Anordnung der Waldvegetation nach Zonen und das Herabrücken der Waldgrenze.

Eine weitere Verschiebung erleidet sodann die Waldgrenze a uf feuchtem Boden, besonders bei stagnierender Feuchtigkeit; Feuchtigkeit übt während der Vegetationszeit eine abkühlende Wirkung auf die ïber ihr liegenden Luftschichten und damit auch auf die Pflanzenwelt aus. Dieser Umstand erklärt, daß auf feuchtem Moorboden bereits eine alpine Vegetation stockt, d. h. die Waldgrenze überschritten ist, während in dem rundherum anstoßenden, trockenen, wenn a uch höher gelegenen Gelände Baumwald herrscht. Wird die überschießende Feuchtigkeit beseitigt, so hebt sich die Wärme und mit ihr der Höhenwuchs der Baumflora. In Frostlöchern aus natürlichem oder wirtschaftlichem Grunde (Kahlschlag) ist durch die Entwaldung gleichsam eine Verschiebung des Terrains in ein ungünstigeres, kühleres Ge bi et eingetreten; Frostlöchern in der oberen Buchen-, in der Fichtenund Birkenzone kommt ein Klima zu, so extremereich und rauh, wie es den Strauchwald der Alpenwaldgrenze kennzeichnet; solche Frost- 
löeher wieder klimawärmer zu gestalten durch Ansiedelung einer Waldvegetation zählt naturgemäf, zu den schwierigsten, langwierigsten und kostspieligsten Aufgaben des Waldbaues.

Nachgewiesen ist sodann, daß die Waldgrenze nach abwärts gedrängt wird, wenn der Grenzwald durch Menschen oder Weidetiere vernichtet wird. Die Erklärung hiefür liegt in der Erseheinung, daß der Wald sein eigenes Klima besitzt, das milder ist als jenes der Umgebung. Mit diesom Klima ist er an den Bergen so hoch als möglich emporgelilettert; wird er durehlöchert oder vernichtet, so wird sein Klima zerstört und die Waldgrenze sinkt bis zu jenem Niveau herab, das ihr nach Breitengrad, Elevation und Exposition ureigentlich zukommt.

Eine zwar geringfügige, aber doch bemerkenswerte Verschiebung des Klimas verursachen die Flüsse; ihr Einfluß ist um so größer, je größer die Wassermasse und je direkter sie aus dem kühlen in ein wärmeres Gebiet oder umgekehrt strömen. In den Bergen z. B., den Alpenflüssen und alpinen Bächen trägt das kühlere Wasser von oben her das Klima und die Keime der kïhleren Waldregion an dem schmalen Ufersaume abwärts; dadurch wird die Krummholzföhre (Pumilio) ins Bereich der Fichten, selbst Buchen getragen; die Alpenflüsse der schwäbisch-bayerischen Hochebene begrenzen vorzugsweise Fichten, welche sie mit einem Stück des Klimas an ihren Ufern in das Grebiet des Fagetums herabgebracht haben. Noch viel großartiger aber ist die Wirkung der von Süden nach Norden fließenden Riesenströme des Jenissei, der Lena, welche mit dem Klima Keime des Picetums (Larix und Picea) bis an ihre Mündung tragen, somit das Picetum ihren Ufern entlang volle zehn Breitengrade weiter nach Norden verschieben.

\section{b) Feuchtigkeit.}

Auf großen Flächen, auf denen die Wärmeverhältnisse zum Autsprossen eines Waldes genügen würden, kann Wald fehlen aus Mangel an genügender Feuchtigkeit; Fenchtigkeit kommt in zwei Formen in Betracht, als Niederschlag, also in flüssiger oder fester Form, und Fenchtigkeit als Wassergas, also dampfförmig in der Luft verteilt. Die Niederschläge werden in Millimetern gemessen, ob sie als Regen, Schnee, Hagel oder 'Tau erscheinen; das Wassergas in der Luft wird bestimmt durch das Verhältnis der gegebenen zu jener Menge von Wassergas, welche die herrschende Temperatur zu fassen vermag, bis clas Wassergas flüssig wird; man nennt dieses Verhältnis die relative Feuchtigkeit und den Temperaturgrad, bei dem das Wassergas Hïssig wird, den Taupunkt. Wird der Taupunkt der Luft nicht an festen Gegenständen dmrch deren Abkühlung, sondern in höherer Luftschicht durch zuströmonde, kältere Luftmasson erreicht, so tritt die Ausscheidung von flüssigem Wassergas in Form von winzigen Tröpfchen, zunächst in der Form von Nebel und Wolken auf, aus denen dam die 
Niederschläge sich loslösen. Sowohl die Fenchtigkeit der Luft wie die Niederschläge kömnen bestimmend sein für das Dasein des Waldes: dał beide, Niederschläge wie Luftfenchtigkeit, von größster Bedeutung für das Gedeihen der einzelnen Bammarten, für die Ausführung dę waldbaulichen Operationen sind, soll an späterer Stelle ausführlicher gezeigt werden.

Die Niederschläge und Luftéeuchtigkeit. Für die Fest. stellung der für das Waldesdasein absolut notwendigen Menge an Luftfeuchtigkeit und Niederschlägen ist es mumgänglich, Ursprungsweise und Ursprungsstelle aller Feuchtigkeit des Festlandes zu kemnen, denn das Fehlen des Waldes aus hydrometeorologischen Gründen hängt eng zilsammen mit der Entfernung emes Gebietes von der Feuchtigkeitsquelle.

Verdunstung von seiten der Pflanzendecke und der festen Erdkruste. Man hat berechnet, daß ein voll entwickeltes Roggenfeld an einem windstillen Tag $1 \mathrm{~m}$ über den Ähren die Luftfeuchtigkeit gegenüber jerer über dem nackten Boden nur um joverhöht hat; von Hönel hat gefunden, daß eine 110)jährige Buche während eines Sonmmers rund $9000 \mathrm{~kg}$ Wasser abdunstet; ein Helitar eines solchen Buchenbestandes würde 3,6 Mill. kg Wasser in die Luft abgeben, was auf dem Hektar $360 \mathrm{~mm}$ Niederschläge bedeuten würde; es fehlen jedoch Beobachtungen über die Erhöhung der Luftfeuchtigkeit und die Fernwirkung dieser Erhöhung. Man hat der Vermutung lange /eit nachgehangen, daß die erhöhte Lutffeuchtigkeit auch eine erhöhte Niederschlagsmenge bedingen müsse, da ja bei erhöhter Luftfeuchtigkeit eine geringe Temperaturerniedrigung genüge, um den Taupmnkt zu erreichen. Allein man hat ïbersehen, dal. auf nicht bewaldeter Fläche die Temperaturerniedrigung viel früher und viel tiefer eintritt als im Walde, also die Wahrscheinlichkeit für Nebel- und Wolkenbildung auf einer Kahlfäche viel größer ist als über einer bewaldeten, was die abendliche Erfahrung bei Windstille auf Kahlflächen, besonders in Frostlöchern, bestätigt. So imponierend die Zahl $3611 \mathrm{~mm}$ pro Helitar als Wasserverlust erscheint, so geringfügig ist seine Bedentung für den Wald, denn von dieser Verdunstungsmenge kommt weder dem Walde noch der Umgebung etwas zugute: dem Walde nicht, weil die Wassermenge auf der Außenseite des Waldes, der Baumkrone gegen den freien Himmelsraum, abdunstet, der Umgebung nicht, weil der Wasserdampf infolge der Insolation und der Aufwärtsbewegung der Luft über dem Walde mit in die Höhe gerissen wird, wo er der trockneren Luft sich einmischt. Die bei fenchtkalter Witterung aufsteigenden Nebelschwaden entstehen nicht durch hëhere Luftfeuchtirkeit, sondern durch wärmere, lebhaft aufsteigende Luftströmungen. sin wichtig jene Feuchtigkeit ist, welche der Wald in seinem eigrenen Hause, das heiBt unterdem Dache seiner hronen, anlüuft und zurückhält durch Abdunstung von seiten der Blätter, '/weige und der 
Bodendecke, von seiten des Bodens selbst und durch Mäßigung, ja völlige Sistierung der Luftbewegung und Verhinderung der Entführung der Feuchtigkeit, so umbedeutend muf die Wirkung der vom Walde entströmenden Wassergase in den Außenräumen bezeichnet werden. Gäbe es eine Fernwirkung der Waldfenchtigkeit, belangvoll für Erhöhung der Luftfeuchtigkeit und Niederschläge auferhalb des Waldes - nur anf Waldblöfon und Waldrändern ist sie durch gering erhöhte Taubildung nachgewiesen -, so müßte jeder Wald in seinen Grenzen gegen waldlose Gebiete hin stetig wachsen oder, da hierzu seit Jahrtausenden Zeit war, es gäbe überhaupt keine, aus Fenchtigkeitsmangel waldlosen Gebiete.

Auch die Wasserverdunstung von seiten des nackten Erdbodens kann, da sie nicht eigenes, sondern nur von den Meeren mitgeteiltes $\mathrm{Naß}$ ist, zur Ausbreitung des Waldes nichts beitragen: unter dem Walddache dagegen wird diese Verdunstung von grofer Wichtigkeit.

Verdunstung von seitender Wasserflächen. Das Meer. Das an der Mreeresobertläche abdampfende Wasser ist es, welches das große Festland mit Wasser versieht, seine Wasserläufe und seine Luft speist, der Pflanzendecke, dem Walde, ja allen Lebewesen das T)asein gibt; es bedarf aber ständiger Zufuhr dieses Wassers, um der Erde Pflanzen und Tierwelt zu erhalten. Die Erde selbst besitzt das Mittel, um die feuchte Meerluft zum Eintritt in das Festland zu zwingen. Dieses Mittel heißt Erwärmung. Die stärkste Saugwirkung übt die ungleiche Erwärmung der großen Kontinente den Wassermassen, den Meeren gegenüber während des Wechsels der Jahreszeiten, das heißt, während der halbjährigen Wärme- und der halbjährigen Kältezeit. Während der Wärmezeit entstehen über den großen Kontinenten durch Erhitzung, Auflockerung und Aufwärtsbewegung der Luftteilchen in den höheren Luftschichten, Anstauungen der Luftteilchen, welche ein Abfließen der Luft nach allen Seiten hin zur Folge haben.

Der Altmeister der Neteorologie, J. Hann ${ }^{1}$ ), sagt in seinem vortrefflichen Buche: „Infolgedessen haben die Luftschichten in der Höhe ein Gefälle vom Kontinent gegen das kühlere Meer hinaus, und die Luft fließt dahin ab. Dadurch wird der Luftdruck über dem Innern des Landes sinken, weil die drückende Luftmasse sich dort vermindert, über dem Meere steigen, weil hier ein Luftzuschuß in der Höhe eintritt. Im Mecresniveau entsteht dadurch ein dem oberen entgegengesetztes Gefälle der Luft vom Meere gegen das Land hin, von der Stelle höheren Druckes gegen die Stelle niedrigeren Luftdruckes. und die untere Luft muß deshalb von allen Seiten gegen den erwärmten Kontinent zufließen." Der Einfluß der Luft aus der Antizyklone (loher Luftdruck) über dem Meere nach der Zyklone (niederer Luftdruck)

1).J. Hann, Handbuch der Klimatologie. I. Bd. 1×97. 
über dem Festlande vollzieht sich nach din Gexetzen der I unt hewegung bei Luftdruckdifferenzen. Die Rotation der Erde lenkt diese Windrichtung auf der nördlichen Halbkugel nach rechts, auf der süıl. lichen nach links ab. Während des Winters ïbernimmt das Meer die Rolle des Festlandes, da es wärmer ist als lieses; es lient dann iiber dem Meere die Zyklone und über dem Festlande der hohe Druck, die Antizyklone; die Luft bewegt sich vom Festlande zum Meere hin. Durch diesen Wechsel in der Erwärmung während eines Jalires ent-

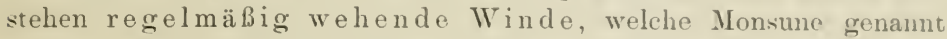
werden. Auf dem großen Kontinent Asien, dem die Halbinsel Europa als Westküste angehängt ist, wie auch in Nordamerika wehen daher nach Hann während des Sommers folgende Winde: an der W estküste aus $N \mathbb{W}$, an der Nordseite aus NO, an der Ostküste aus SO und an der Süidlïste aus SW ; auf der stidlichen Halbkugel, in Südamerika und Afrika sind die herrschenden Sommerwinde: an der Westküste aus SW, an der Nordseite aus NW, an der Ostküsto aus NO und an der Südliüste aus SO. Während des IVinters herrschen auf der nördlichen Halbkugel, in Asien und Nordamerika, folgende Winde vor: an der Westküste 0 , an der Nordküste $S \mathbb{W}$, an der Ostküste NW und an der Südkïste $\mathrm{N}$ und NO. Europa, mit Ausnahme des Südens, steht unter dem Einflusse einer großen, zyklonalen Luftbewegung ïber dem nordatlantischen ()zean, die es mit $\mathbb{W}^{\top}$ - und $\mathrm{SW}$ - IV ind en versieht.

Alle aus niederen Breiten kommenden Winde sind wärmer und, soweit sie über das Meer hinwegstreichen, bei hoher Temperatur mit Feuchtigkeit gesättigt; treffen sie auf das Festland, wo sie sich erheben und abkühlen, so teilen sie diesem große Mengen ron Lufteuchtigkeit und Niederschlägen mit; alle von hohen Breiten kommenden Winde sind kühler, und wo sie in das Land eintreten, bedingen sie trockenes Klima, da sie im Festlande sich erwärmen und trockener werden; erstere schaffen für Waldesdasein und -gedeihen günstige, letztere ungünstige Bedingungen; aus diesem Spiel der Winde zwischen Festland und Meer ergeben sich auch die großen Unterschicde im Klima zwischen den West- und Ostküsten der großen Kontinente in den höheren Breiten, worauf schon bei der Betrachtung der Wärmeverhältnisse hingewiesen wurde, und worüber bei den einzelnen Waldgrebieten noch Näheres mitgeteilt werden muß.

Den konstanten Luftströmen gehen die Meeresstrüme parallıl; Hann (1. c. S. 181) sagt: „Es kann jetzt kaum mehr ein Zweifel claribur bestehen, daß die großen Meeresströmungen ihre Entstehung den vorherrschenden Winden verdanken, weshalb auch in allgemeinen dio Richtung der Meeresströme mit der Richtung der über den betrettenden Teilen der Ozeane vorherrschenden Luftstrüme ïbereinstimmt." Dio durch IV-Winde von den Kontinenten unter dem :37." nürdl. Br. ab- 
gelenkten warmen Ströme, Golfstrom und Kuro Shiuo, wenden sich von da an nordostwärts und lassen nördlich von diesen Breitengraden Raum für den von Norden kommenden kalten Polarstrom. An der Westküste von Südafrika und Südamerika streichen zwar ebenfalls kalte Ströme - entsprechend den kalten Strömen an den Ostküsten der Kontinente der nördlichen Halbkugel -, doch ist das kalte Küstenwasser dort nach den neueren Forschurgen nicht allein diesen Strömen, snndern den direkt von der Tiefe aufsteigenden, kalten Strömen zuzuschreiben; diese aufsteigenden Ströme aber werden hervorgerufen durch den rom Land in das Meer wehenden Wind, der die oberflächlich erwärmte Schicht von der Küste hinwegtreibt; als Ersatz strömt von unten kaltes Wasser nach; dreht sich der Wind und weht er landeinwärts, so kommt er als kühle Brise, welche im Lande sich erwärmt, relativ trockener wird und so wenig Niederschläge bringt wie die von Osten kommende Landluft. Diese Erscheinung erklärt, daß, da die Niedersehläge unzureichend sind, an den Westküsten von $\mathbf{S}$ ü da merika und Südafrika Wald fehlen muf; erst bei hoher Elevation wird der Taupunkt des Meerwindes erreicht; im Gebirge erscheint der Wald. Gleiche Terlältnisse obwalten an der kalifornischen $\mathbf{K}$ ü ste von Nordamerika.

Aus obiger Darstellung ergibt sich, daf während der warmen Zeit, der Vegetationszeit, in Europa Winde aus SW, W und NT rorherrschend sind; sie kommen vom Atlantischen Ozean mit Feuchtigkeit gesättigt an die Kúste; es ergibt sich ferner, daß in ganz Ostasien die Winde aus SW, S und SO überwiegen, welche vom großen Stilleu Ozean befeuchtet werden; in Westamerika, nördlich vom $40 .{ }^{0}$ nördl. Br.. strömen die SW- und W-Winde ein; in Ostamerika sind es S- und SO-, also ebenfalls vom großen Wasserbecken kommende, feuchte, warme Winde; auf der südlichen Halbkugel korrespondieren mit den westlichen Küsten der nördlichen Halbkugel die östlichen; die Ostküste von Südamerika wird durch den feuchten, warmen SO-Wind mit Wasser versehen, gleiches gilt von der Ostküste Afrikas, während die Westküste sowohl von Südafrika wie von Südamerika vom Westwind, der über kalte Wasserflächen streicht, nur Fenchtigkeit bei niederer Temperatur erhält, aus welchem das Festland, da es die kühleren Winde erwärmt, keine Niederschläge ziehen kann; erst bei höheren Elevationen, seien sie Küsten- oder Binnenlandsgebirge, kühlen sich die kühlen Winde bis zum Taupunkt und zu Niederschlägen ab; die Gebirge sind die Regenmacher und Regenmehrer, nicht der Wald.

Soweit nun diese wasserdampfreichen Luftströme in das F'estland eintreten und dieses mit Luftfenchtigkeit, Nebel, Wolken und Niederschlägen versehen, herrscht Wald, vorausgesetzt, daß die Niedersehläge in genügender Menge, daß Temperatur und andere Verhältnisse. die 
im nachfolgenden betrachtet werden müssen, das Waldesdasein überhaupt ermöglichen. Die ganze Anorduung der Waldung in unserer Erde nach Waldregionen liänt auf das engste zusammen mit den meteorologischen Erscheinungendur Luftbewegung über den Kontinenten und den Ozeanen. Aut' dem Wege landeinwärts verlieren die feuchten, warmen Luftströme durch das fortgesetzte Ansteigen immer mehr von ihrer befruchtenden Feuchtigkeit, und endlich erreichen Lufteuchtigkeit oder Niederschläge oder beide zusammen einen so niederen Betrag, daß, trotz sonstiger günstiger Existenzbedingungen, Wald nicht mehr dem Boden entsprossen kann.

Zur Feststellung des für das Dasein des Waldes absolut notwendigren Minimums an Feuchtigkeit und Niederschlägen ist es nötig, über die Beziehungen beider, insbesondere im Leben der Bäume selbst, einiges vorauszuschicken. Jeder Wald beginnt, wenn ihn die Natur aufbaut, oder wenn er durch Saat begrïndet werden soll, mit äußerst zarten Keimlingen; für das Gedeihen dieser sind die Niederschläge während der ersten Vegetationszeit wie während der ersten Vegetationsruhe außerordentlich wichtig; mit dem Alter nimmt die Gefahr der Vertrocknung stetig ab; für das ganze Leben gilt der Satz, daß die Verdunstung von seiten der Pflanzen um so größer ist, die Gefahr der Überverdunstung um so näher liegt, je lufttrockener das Gebiet; je feuchter der Boden, um so leichter erträgt eine Pflanze Lufttrocknis : umgrekehrt kann die Regenmenge (Bodenfeuchtigkeit) um so geringer sein, je feuchter die Luft. Diese Momente spielen in der Wechselbeziehung bei der Frage der natürlichen Bewaldung unserer Erde, der ursprünglichen Ansdehnung der Waldungen wie auch bei allen Waldneuanlagen von seiten des Menschen eine einschneidende Rolle.

Die Beziehungen zwischen Lufteuchtigkeit und Niederschlägen sind keine direkt proportionalen; so empfängt z. B. die Ostseeküiste bei Durchschnitt $74 \%$ r. F. jährlich $224 \mathrm{~mm}$ Niederschläge, das Riesengebirge bei $600 \mathrm{~m}$ Erhöhung und $72 \%$ r. F. $307 \mathrm{~mm}$. Viel größer sind natürlich die Kontraste in größeren Kontinenten. Die Prärie zwischen dem Felsengebirge und dem Missourifluß erhält während der vier Monate Mai bis August $45^{\circ} 0$ r. F. noch $10(1) \mathrm{mm}$ Regen; die Prärie an der südkalifornischen Küste empfängt bei vollen $72 \%$ nur $40 \mathrm{~mm}$ während derselben Vegetationszeit. In diesen Gebieten fehlt $W^{\top}$ ald aus natürlichen Gründen, beide Male aus Mangel an genügenden Niederschlägen; auf der Prärie östlich vom Felsengebirge genügen nicht einmal $100 \mathrm{~mm}$, in Kalifornien nicht $7 .{ }^{\circ}{ }^{\circ}$ r. F., um einen Wald hervorzurufen. Aber in beiden Gebieten kann kïustlich Wald legründet werden; denn der Wald schafft sich unter seinem Dach sein eigenes Klima, wie es später besprochen werden muß.

Mehrmalige Studien an den Waldgrenzen, an den Prärierändern 
26) Erster Abschnitt. Naturgesetzliche Grundlagen u. Verteilung der Wälder usw.

von Nordamerika und Ostasien während der Jahre 18sj-18\& 7 haben den Verfasser veranlaßt, folgende Zahlen als minimale Beträge in Luftund Bodenfeuchtigkeit (Niederschlägen) für die Existenz des Waldes zu betrachten.

Fallen in cinem Gebiete weniger als in mm Regen, auf rler nördlichen Halbkugel während der Monate Mai, Juni, Juli und August, auf rler südlichen Halbkugel während der Nonate November, I) zember, Januar, Februar, so ist dort Waldansiedelung auf natürlichem Wege unmöglich, mag die Feuchtigkeit der Luft noeh so hoch sein, weil eben das dureh Wind oder Tiere vom Saum der Waldregion aus dorthin getragene Samenkorn als zarter Keimling während der I)ïrrperiode stets vernichtet wird. Man kann dieses Niederschlags- oder Regenminimum für den Wald die $\mathrm{Ombrohore} \mathrm{oder} \mathrm{Waldgrenze} \mathrm{durch}$ Regenmangel nennen. Ein solcher waldloser Küstensaum, auf dem die Niederschläge ungenügend, die Luftfeuchtigkeit aber genügend, ja stellenweise sogar hoch ist, erstreckt sich in Nordamerika rom 40. ${ }^{0}$ nördlicher Breite an südwärts durch Mittel- und Südamerika bis nach Patagonien; ein solcher Küstensaum liegt auch an der Westseite von Afrika südlich vom Äquator; es fehlt Wald, weil das notwendige Wasser im Boden fehlt; wird dieses aber künstlich zugeführt. so kann diese Prärie in ïppige Getreidefelder, Obstgärten und Waldungen ungewandelt werclen. Länderstriche, welche während der vier Monate mehr als j0 $\mathrm{mm}$ und weniger als $100 \mathrm{~mm}$ Regen erhalten, tragen ebenfalls noch keinen Wald, wenn die Luftfeuchtigkeit während derselben Zeit unter $50 \%$ herabsinkt; denn die erhöhte Verdunstung verbraucht den Überschuß an Niederschlägen, der über die Ombrohore von $50 \mathrm{~mm}$ hinaus gefallen ist. Steigt aber die Niederschlagsmenge über $1110 \mathrm{~mm}$, so kann die Luftfeuchtigkeit resp. Trocknis allein den Wald nicht mehr verhindern, so daß man von einer Psyehrohore, einer Grenze für den Wald durch Lufteuchtigkeitsmangel, wohl nicht sprechen kann. Wird der Boden kïnstlich bewässert oder anderweitig auf natürlichem Wege mit Wasser versehen (Grundwasser, oberflächliche Bewässerung), so entspringt diesem ein Wald, mag die Luft noch so trocken wälnend der Vegetationszeit sein. Unter $100 \mathrm{~mm}$ Niederschlägen bei weniger als durchschnittlich $5 \%$ Luftfeuchtigkeit empfängt die große Prärie zwischen dem Felsgebirge und dem großen Waldbande am atlantischen Ozean in Nordamerika: es zählen hierher die ausgedehnten Steppengehiete von Südrußland und Westasien, die Steppe der inneren Mongolei von Ostasien: die Steppe ron Uruguay, Paraguay, Sï dwestafrika und Australien. Jederzeit liann solches Gelände. in welches der Wald mit seinen natürlichen Hilfsmitteln nicht eindringen kamn, auf kïnstlichem Wege in Wald umgewandelt werden.

In einer Landschaft, in welcher während der genannten vier Monate sowohl die Niederschläge unter $3 \prime \prime \mathrm{mm}$ als auch die Luftfenchtigkeit 
unter if \% herabsinken, somit die Ombroliore und Psychrohore übrerschritten ist, löst sich auch die zusammenhängende, präriale Bodendecko auf, nackte, vegetationslose Erde erscheint dazwischen; trärt sie Vigotation, so können nur noch eigenartige, für tie ansuchmendo Troekenheit ausgerïstete Pflanzen (Agaven und Kakteen) ilı Dasein fristen. Der nackte Boden wird beweglich und vom Winde entfïhrt: solches Gelände nimmt die Zentren der großen Kontinente ein; es wirl in Nordamerika und Nordmexilio Desert, in Asien Gobi von den Mongrolen oder Shamo (Sand) von den Chinesen, in Afrika Sahara genannt: claß auch noch solche Wüsteneien durch Bewässerung in Gartenland und Wald umgewandelt werden können, beweisen die Bäume an den Fluß. läufen, die Oasen bei Untergrundbefeuchtung durch aufsteigende Qquellen.

Wie breit das Waldband von der Küste aus landeinwärts, d. h. wie weit die Ombrohore des Waldes von der Küste entfernt liegt, hängt von der Mächtigkeit der wasserreichen, einströmenden Luftmassen und von der Konfiguration des Landes selbst ab. Es gelang dom Verfasser bereits $1890^{\mathbf{1}}$ ), nach Auffindung der Waldgrenzwerte auch die Eigenart der Verteilung der Waldungen im Innern der Kontinente selbst auf naturwissenschaftlichem WVege zu erklären; da diese Theorie alle Fragen über die Ursache der Wald- und Steppenverteilung beantwortet, dürfte sie richtig sein.

Steigt von der Küste hinweg das Gelände nur ganz allmählich, abcr stetig an, tritt somit der feuchte Luftstrom vom Meere aus ungehindert in das Festland ein, so kennzeichnet seine Bahn einen Wald, der erst hundert, selbst Tausende von Kilometern von der Küste entfernt seine natïrliche Grenze, seine Ombrohore findet; derartig gelagert und entstanden sind der europäische Wald, der atlantische Wald von Nordamerika, der pazifische Wald von Ostasien, der brasilianisehe Wald von Sïdamerika, die Waldgebiete von Ostafrika: selbst große Inseln wie die Sundainseln, Madagaskar, Neuseeland, Neuguinea müssen aus obigen Gründen durchaus bewaldet sein.

Ragen Gebirge auf, so hemmen sie den Eintritt des felichten Luftstromes nicht, wenn sie dem Strome parallel grerichtet sind; kleinere Gebirge unter 100() in Erhöhung werden ï berschritten, das Dasein des Waldes aber wird nicht bedroht bzw. nieht verhindert. So liegen in Europa die Alpen, die Pyrenäen im Luftstrom des Atlantischen Ozeans, die Alleghanies in Nordamerika im Luftstrom, der vom Golf von Mexiko nordwärts streicht: ganz Jạan stellt einen großen von Süden nach Norden, also parallel mit dim feuchten, warmen Luftstrom verlaufenden Gebirgszug dar. Tie geringeren Erhebungen in Europa, wie S'chwarzwald, bayerischer Wald, Vorresen und andere werden vom Strom überschritten unter Abgabe crroßer Wasier-

1) H. Mayr, Die Waldungen von Nordamerika. 1-96. 
mengen, die Westseite der Gebirge ist die Regenseite; im Regen schatten, an der Ostseite der Gebirge, sind zwar für den WVald, seine Zusammensetzung und seine Behandlung wichtige Unterschiede gegenüber der Regenseite vorhanden, allein die Ombrohore erreicht der Luftstrom nicht, überall ist WVald.

Streicht aber ein hoher Gebirgszug entlang der Küste, also mehr oder weniger senkrecht auf die Bewegmussrichtung des Meeresluftstromes, so wird letzterer in seinem Anfstieg zur Paßhöhe des Gebirges zur Abgabe von großen Mengen ron Feuchtigkeit gezwungen, so daß er nach Überschreitung der Paßhöhe bei seiner Senkung durch Terdichtung und Erwärmung relativ so trocken wird, dals Nebel- und Wolkenbildung sich auflösen und die Niederschläge unter die Ombro hore für den Wald herabsinken. Ein ganz besonders schönes und deutliches Beispiel des Ganges des mächtigen, feuchten Luftstromes ïber den Kontinent hinweg und seimes Einflusses auf das Dasein bzw. Fehlen von Wald zeigt ein Profil durch Nordamerika, daß unter dem $40 .{ }^{\circ}$ an der Westküste beginnt. Hier trifft der Luftstrom anf drei einander parallel laufende und in ihren Höhenverhältnissen ansteigende, größere Gebirgszüge. Ein eingehendes Studium von TValdgrenzen, Elevationen und Feuchtigkeitsverhältnissen, letztere nach den übersichtlichen Angaben der meteorologischen Stationen der Union, ergaben nun nebenstehende Abbildung:

Der über dem großen Stillen Ozean gesättigte, westliche Luftstrom stößt an den ersten Gebirgszug, das Küstengebirge (Coast Range), kühlt sich bei dem Aufstieg ab, verliert ganz gewaltige Wassermengen und gibt einem Walde, überaus mächtig in Höhe und Raschwüchsigkeit, das Dasein. Die Paßhöhe wird bei $900 \mathrm{~m}$ überschritten. Der absteigende Luftstrom erwärmt sich, wird relativ trockener, die Niederschläge sinken unter den Betrag der Ombrohore, Grasprärie tritt auf und erfüllt das ganze Tal und reicht noch im zweiten Gebirge (dem Kaskadengebirge) bis zu einer Höhe empor, welche der Pabhöhe des vorliegenden, ersten Gebirgszuges entspricht, nämlich $900 \mathrm{~m}$; von da an aufwärts beginnen wiederum Wolken und Niederschläge und Wald, der mit dem Luftstrom bis zur Paß3höhe des zweiten Gebirg:zuges emporschreitet; aber auf der Windschattenseite des Gebirges lösen sich Wolken und Regen wieder auf, die Luft wird abermals erwärmt und getrocknet, die Ombrohore verhindert den Wald auf der ganzen Fläche zwischen den Kaskaden und dem dritten Gebirgszuge, dem Felsengebirge (Rocky Mountains); an der Westseite dieses Gebirges erscheint der Wald erst bei einer Höhe von $1200 \mathrm{~m}$, einer Höhe, welche der Paßhöhe des vorliegenden zweiten Gebirgszuges entspricht, und so weit steigt der Wald im Felsengebirge aufwärts, als die Temperatur es gestattet; auf der Ostseite des Gebirges aber fehlt jeder Wald, weil diesem Gebiete von Westen her nur trockene Luft zuströmt. Von 
1. Eas Klima.
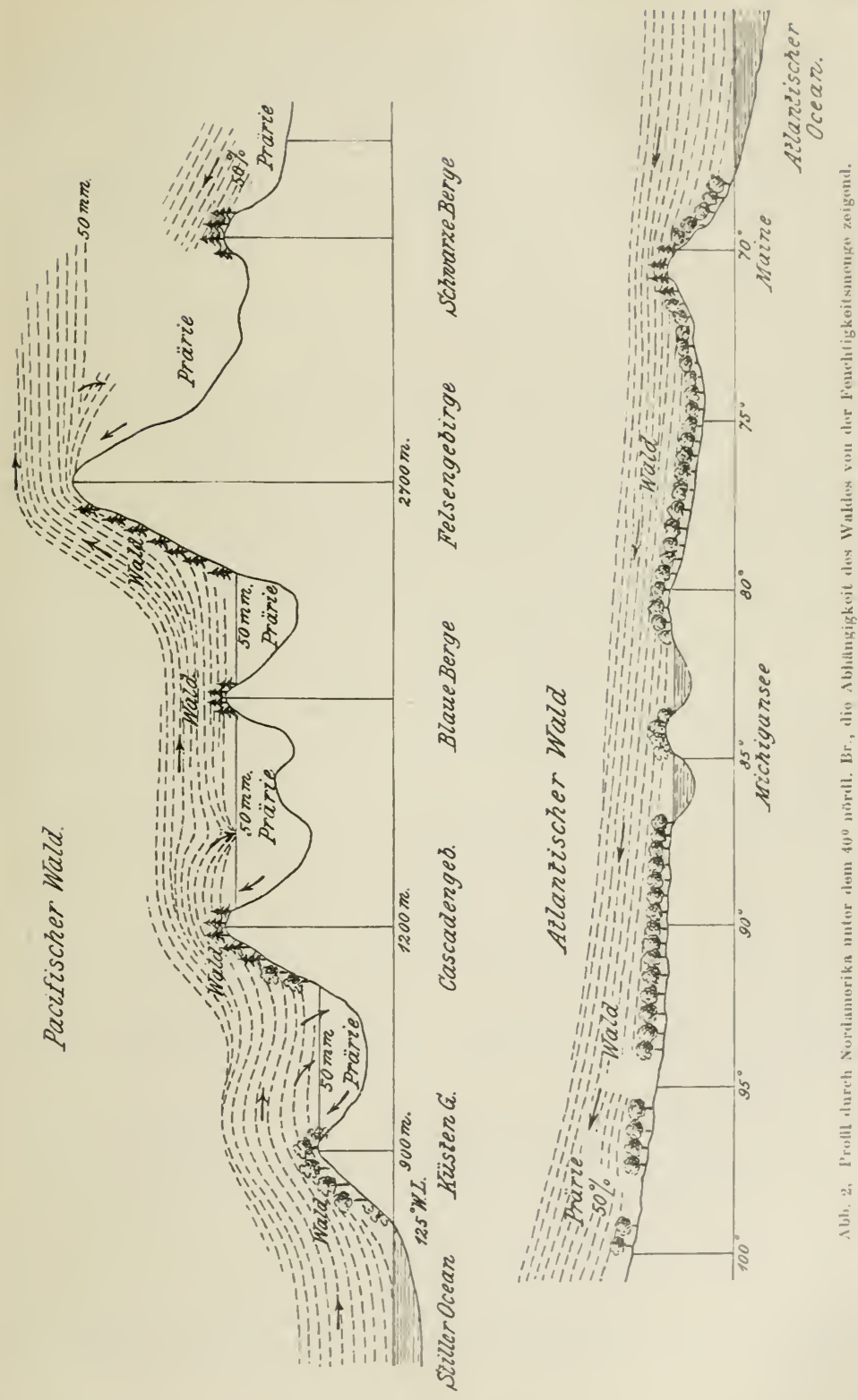
Osten her, vom atlantischen Ozean, reichen zwar Niederschläge bis an den Rand des Felsengebirges, allein sie sind zu spärlich, sie werden während der trockenen, heißen Zeit durch Überverdunstung beseitigt, so daß ein Einwandern von Wald in dieses Gebiet ron Osten her unmöglich ist. Zwischen den Kaskaden- und dem Felsengebirge liegt ein stattlicher Gebirgsstock, die Blauen Berge oder Blue Mountains: soweit ihre Plateaus und ihre Gipfel in den feuchten Luftstrom hineinragen, das heißt über $1200 \mathrm{~m}$ sich erheben, tragen sie Wald: unter dieser Grenze besteht Prärie.

So erklärt sich auf natürliche Weise die parallele Gliederung von Wald und Prärie an der Westküste von Nordamerika. Ehe ein weiteres Jahrhundert vergangen sein wird, wird die Prärie durch die menschliche Tätigkeit in eine Feld-, Garten- und Waldlandschaft umgewandelt sein, und wenn nicht bald ein Gemeinwesen ron ewigem Bestand, sei es Staat oder Union, die gerade hier so eminenten Schutzwaldungen der Gebirge an sich bringt, wird der Wald verödet und vergrast sein. Das Landschaftsbild, wie es ursprünglich bis zum Ende des rorigen Jahrhunderts als ein Ergebnis der natürlich aufeinander einwirkenden Faktoren des Klimas sich darstellte, wird dureh menschliche Dazwischenkunft röllig in das Gegenteil verkehrt sein.

Die langsame Erschöpfung der Meereswinde an Feuchtigkeit infolge des weiten Weges und langsamen Aufstieges landeinwärts, wie sie Europa und Ostamerika zeigen, wo erst unter dem 90. ${ }^{0}$ westl. Br. Luftfeuchtigkeit und Niederschläge zu Beträgen sinken, die dem natürlichen Fortschreiten des Waldes nach Westen hin eine Grenze setzen, wiederholt sich auch an der Ostküste von Südamerika, an der Ostküste von Afrika und Asien. Ihr Parallelismus in Waldesbreiten und Waldesgrenzen im Innern der Kontinente an der Ombrohore ist offenkundig. Die rasche Erschöpfung des feuchten Meereswindes infolge steilen Anstieges am Küstengebirge, die Ombrohore auf der Regenschattenseite des Gebirges, wie sie Nordamerika an seiner Westküste zeigt, wiederholt sich in Südamerika ostwärts der Anden, wiederholt sich hinter den Küstengebirgen von Afrika, Australien und Südasien (Himalaja). Hinter den Gebirgen fehlt Wald, wenn andere Feuchtigkeitsquellen ausgeschlossen sind.

Man kann daraus entnehmen, wie es um Europa stünde, wenn es in seinen Befeuchtungsverhältnissen allein auf das Hittelmeer und den Südwind angewiesen wäre; nördlich der Alpen würde sich eine Steppenlandschaft ausdehnen müssen, die bis hart an die Küste der Nord- und Ostsee heranreicht; es ist an einer anderen Stelle dieser Schrift der Nachweis versucht, daß Mitteleuropa nach der Eiszeit nie e ine O m brohorensteppe, wohl aber eine Thermohorensteppe besa 3 .

Ähnlich wie Außenmeere können auch Binnenmeere wirken; das Schwarze Meer, das Kaspische MLeer, die Gruppe der großen Seen der 
Vereinigten Staaten erzeugen ihre eigenen Monsune durch den Kontrast der Erwärmung ron Festland und Wasser: sie ermöglichen auch das Dasein eines Waldes in einer Region, welche, wäre sie nur aut den Atlantischen Ozean mit ihrer Fenchtigkeit angewiesen, wahrscheinlich Steppe sein müß3te.

Dem großen Gegensatze zwischen Winter- und Sommerhalbjahr und deren Wechsel während eines Jahres vergleichbar ist der Wechsel in der Erwärmung von Festland und Wasser während 24 Stunden. Tag und Nacht erzeugen ähnliche Schwankungen in der Erwärmung von Festland und Wasser wie Sommer und Winter. Gegenüber der. stärkeren Erwärmung des Festlandes während des Tages, der stärkeren Ablïhlung desselben während der Nacht erscheint das Meer, das Wasser als ein mit mittlerem Grad versehenes Medium. Die Erwärmung des Festlandes bedingt ein Einströmen der Meeres- oder Seeluft, während nachts die Luft vom kühleren Festlande zu den wärmeren Wasserflächen hinstreicht. Die etwa vier Stunden nach Sonnenaufgang einsetzende Seebrise, wasserdampfreich, kühl, erfrischend, schwach salzig, streicht bis zu $30 \mathrm{~km}$ landeinwärts, der nachts zum ILeere fliefende Luftstrom ist beträchtlich schwächer. In den Tropen ruft diese Tagund Nachtperiode rielfach gegen den Nachmittag hin Gewitter mit reichlichen Niederschlägen hervor. Auch die auf diesem Wege gespendete Luftfeuchtigkeit und Regenmenge kann Wald hervorrufen, während er weiter ab von der Küste fehlt. Kleinere Seen, selbst Flüsse äußern ihre Fernewirkung durch eine auffallende Milderung des Klimas, eine Verzögerung des Frühlings, Milderung des Sommers, Verlängerung des Herbstes und Mäßigung des Winters so lange, bis die Wasserfläche zu Eis erstarrt. Ein besonders auffallendes Beispiel der Verlängerung des Spätsommers erwähnte Verfasser in seiner bereits zitierten Schrift (1890): Der Einfluß des himmelblanen Sees Pend d'Oreille im Felsengebirge, von dicht bewaldeten Bergen eingefaßt auf die Terzögerung: des Spätsommers Ende Oktober (1885) ist unverkennbar; die Lärehen (L. occidentalis) an den Uferhängen waren noch grün, unmittelbar nach Verlassen des Seebeckens wieder wie vor der Annäherung goldgelb. Den Einfluß der Süßwasserseen auf die Reife der Frïchte von einem wärmeren Klima angehörigen Holzarten (wie Castanea vesca in Herrenchiemsee) ist ebenso für die Schweizer Seen von A. Engler 1!r00 nachgewiesen worden.

Tau und Reif. Die Kondensation des Wassersdampfes aus der Luft an allen sich abkühlenden Gegenständen - bei Abkühlung bis zu $0^{0}$ als Tau, unter $0^{0}$ als Reif - kommt zwar auch der Bodenoberfläche zustatten als Verstärkung der Niederschläge und der darïber liegenden Luft durch die relative Vermehrung ihres Wasserdamptgehaltes, also Erhöhung der relativen Feuchtigkeit; allein der Betrag an Flüssigkeit, den Tau liefert, ist so gering, daß höchstens ine Gras- 
vegetation damit sich begnügt, vielfach fehlt selbst diese. Nie aber kann durch Tau allein Wald erseheinen wegen der starken Verdunstung untertags; Tauniederschläge sind z. B. auf der Sahara fast täglich und in sehr starkem Maße zu beobachten, dennoch fehlt Wald. Künstlich Wald begründet, würde er in solchen Örtlichkeiten olne künstliche Wasserzufuhr sich nicht halten können, obwohl alle Bäume aus den Tauniederschlägen durch Blätter und Rinde einen sehr beträchtlichen Teil Wasser aufzunehmen und in sich aufzuspeichern vermögen. Künstlich begründeter Wald kann nur da sich halten, wo noch so reichlich Niederschläge fallen, daß der Wald durch seine Fenchtigkeit erhaltende Kraft einem durch Überverdunstung entstehenden Defizit in der Pflanze und im Boden die Wagschale halten kann; Wald kann sodann entstehen und bestehen, wenn von untenluer den Wurzeln stets neue Feuchtigkeit zugeführt wird.

Für den Wald ergibt sich als weitere Wasserquelle bodenfeuchtender Nebel bei Plusgrad oder Rauhreif bei Minusgrad. Ersterer entsteht, wenn die Luft bis zum Taupunkt sich abkühlt, letzterer, wenn die Abkühlung bis unter $0^{0}$ sich fortsetzt. Werden die winzigen Wassertröpfchen des Nebels oder die feinen Eisnadeln des Rauhreifes gegen irgendeinen Gegenstand vom Wind geworfen, so sammeln sie sich an diesem an; bei Nebel tropft der Überschuß ab und gelangt in den Boden, bei Reif können die in der Luft verteilten, in der Sonne glitzernden Eisnadehn bis zu solchem Massen sich ansammeln, daß Telegraphendrähte, im Walde Äste, ja ganze Bäume zusammenbrechen (Duftbruch). Rauhreif kann so stark im Walde auftreten, dafs sein Herabfallen durch beginnendes Tauwetter oder durch Wind den Boden wie mit einer Schneedecke überzieht. Folgt aber auf den Rauhreif trockene Witterung, so verdampft er, ohne dem Boden einen Tropfen Wasser gespendet zu haben. Die Wassermengen, welche durch diese beiden Naturerscheinungen geliefert werden, sind oft beträchtlich; der Tau ist für die aufkeimende Generation während der Vegetation durch die Befenchtung des Bodens oft von größtem Werte. Daß aber Nebel die durch Regen gebrachte so notwendige Feuchtigkeitsmenge ersetzen kïnnte, davon kann keine Rede sein. In den nebelreichsten Gebieten, z. B. in der Nähe des kühlen Labradorstromes, des kühlen Stromes von der Behringstraße des äußersten Ostasiens, der den Aleuten und Kurilen entlang streicht, ist der Wald nicht etwa begünstigt, sondern vielmehr durch den Wärmemangel infolge allzu geringer Besonnung geschädigt, ja stellenweise sogar ganz ver trieben.

Eisregen kann man eigentlich nicht hierher zählen. Es ist wie das Wort sagt, eigentlich Regen; daß er überkältet, an allen Gegenständen als Eiskruste sich anheftet, kann für die Vegetation verhängnisvoll werden; auch für die Bodenbefeuchtung ist Eisregen ungünstig, 
weil die Eisform das Wasser längero Zeit der Verdunstung aussetzt und damit die Menge, welche in den Boden eintritt, schmälert.

Ein Übermaß von wolkenbruchartig herabstürzenden Regen wassern scheint, von gelegentlich störenden Kalamitaten hier abgesehen, nur auf einer Stelle der Erde als Regel sich einzustellen; das ist im südlichen Assam, wo aus dem rasch emporstürmenden, feuchtwarmen Luftstrom aus dem Meerbusen von Bengalen so ungeheuere Regenmassen sich auslösen (10000 mm jährlich), daß nicht bloß für Wald, sondern für jegliche geschlossene Pflanzendecke der Boden vom Felsenplateau abgewaschen wird.

Schnee. Mag Schnee in noch so gewaltigen Massen während des Winters sich auf die Vegetation der Erde herabsenken, Schneo kann das Aufwachsen des Waldes nicht hindern; er kann sehr störend sein, kann insbesonders empfindliche Holzarten ganz aus. schließen, aber den Wald als solchen, und vor allem den natürlich erwachsenen Wald bedroht or nicht; waldlose Gebiete infolge allzu großer Schneemengen gibtes nicht. Ja, nicht einmal die kriechende Form einzelner Holzgewächse der obersten Vegetationszone, wie das so einfach und natürlich scheint und deshalb von allen Laien vermutet wird, kann dem Schnee zugeschrieben werden; die Alpen haben als oberste Strauchvegetation die kriechende Pinus Pumilio, in den Pyrenäen endet der Wald mit pfeilgerader Pinus uncinnata. Keine einzige Bergföhre kriecht dort, sie wäre denn von den Bewohnern gestümmelt. Im Westen der Vereinigten Staaten ist die Grenzregetation aufrecht stehend; in Ostasien bildet die Waldgrenze eine kriechende Zürbel. Wo Fichtenbäume, Lärchen oder Föhren bis zur Thermohore emporsteigen, besitzen sie - in diesem Gebiete der Maximalschneeanhäufung - eine wohl vom Schnee zerzauste, nicht aber eine kriechende Form; sie bleiben aufrecht, aber nieder, in folge Mangels an nötiger Wärme. Einen klassischen Beweis, daß suchnee den Wald nicht vernichten kann, durch ihn keine kriechenden Formen entstehen, nicht die Prärie an Stelle des Waldes treten kann, liefert die Nordwestküste von Japan. Der kalte, über das Meer geführte Nordwind oder sibirische Wind häuft dort ungeheuere Schneemassen an. Schneehöhen von $4 \mathrm{~m}$ sind dort Durchschnitte, welche jeder Winter bringt, und dennoch ist das ganze Gebiet eines der best bewaldeten von Japan und trägt den schönst und höchst entwickelten Wald; wo Wald fehlt, hat nicht Schnee ihn verhindert, sonderu der Mensch ihn zerstört.

\section{c) Wind.}

Die wohltätige Seite des Windes als Walderzenger wurd" in den vorhergehenden Zeilen betrachtet; Wind ist aber auch ein Waldzerstörer, wenn er gelegentlich zum Urkan anschwillt; er ist sodann 
ein Waldverhinderer, wenn er stetig mit großer Kraft über gewisse Gebiete hinwegstreicht. Trotzdem, daß alle Faktoren für das Aufwachsen von Wald günstig sind, kann Wald fehlen durch den Wind. Tor allem sind es flache Meeresküisten, über welche die ungebrochene Gewalt des Windes hinwegstreicht und die Ansiedelung von Bäumen verhindern kann. Felsige, bergige Küsten sind nur an der Windseite der Berge baumlos. An flachen Küsten ist erst weiter landeinwärts die Gewalt des Windes soweit gebrochen, daß Bäume, daß. Wald aufwachsen kann; der Wald kämpft gegen den Wind, indem er keilförmig gegen denselben vordringt; mögen es Buchen sein wie in Ostfriesland, oder Föhren wie in den Landes von Südwestfrankreich, Zypressen wie in Westamerika oder Eichen wie in Nordjapan, überall schieben sie sich keilartig gegen den Wind vor und besetzen soweit als möglich das zwischen dem Meere und dem Walde liegende Marschland, die Grassteppe. Waldlos sind sodann Küsten und flache Inseln im Gebiete der stürmischen Monsune, während alle Inseln in der Region der Kalmen Wald tragen.

Ähnlich wie die Küsten verhalten sich unvermittelt aus der Ebene emporragende Bergesgipfel, nicht allzuweit von der Küste entfernt. Kahle Bergesgipfel im Binnenlande, mitten im Waldgebiete können zweierlei Ursprungs sein: entweder besaßen sie ursprünglich Wald, dann kann ihn nur menschliche Tätigkeit vernichtet haben, oder sie waren schon von Anfang an waldlos, durch Mangel an genügender Wärme oder an genügenden Niederschlägen oder auch durch ungeeignete Bodenausformung, worïber in den folgenden Zeilen das bis jetzt bekannt Gewordene mitgeteilt werden soll.

Licht, ein Faktor des Klimas und mit den übrigen Faktoren des Ḱlimas im engsten Zusammenhange, kann nirgends das Aufwachsen des Waldes hindern; die nördlichste Waldvegetation, welcher der Lichtgenuß am meisten beeinträchtigt wird, bedarf während dieser Zeit des Lichtes nicht, da sie ruht; ihr nützt auch der Überschuß während der Vegetationszeit nichts, da sie Mangel an Wärme leidet. Die Bedeutung des Lichtes während der Vegetationszeit soll einer späteren Betrachtung vorbehalten sein.

\section{Der Boden.}

Allgemein, auch unter Pflanzenzüchtern, ist die Anschauung verbreitet, jede Holzart verlange zu ihrem Gedeihen ihren eigenen, spezifischen Boden mit spezifischen Nährsalzen, mit einer spezifischen Verteilung, spezifischen Menge; die Annahme der Wissenschaft, daß die in einem Baume gefundene Menge an Mineralsalzen auch den notwendigen Bedarf hieran darstelle, verführt hierzu; will eine Waldanlage nicht entsprechendes Gedeihen zeigen, wird in erster Linie auf den unpassenden Boden als die Ursache hingewiesen. Was liegt 
näher als der weitere Gedanke, daß es auf unserer Erde große Tandstriche gäbe, auf denen Wald fehlt, weil der Boden hierfür un. geeignet sei? Bei genauerer Prüfung wird sich ergeben, lak all dem Mißlingen einer Waldkultur weniger Boden als Klima, Behandlung und andere Momente schuld sind, und eine Prüfung der waldlosen Gebiete der Erde zeigt, daß überall, wo für WVald ungeeigneter Boden auftritt, dieser erst unter dem Einflusse des Klimas oder bestimmter Pflanzenformen odes des Menschen die ungünstige Verfassung angenommen hat. $\mathrm{Ramann}{ }^{1}$ ) sagt: Erst in neuerer Zeit hat man er. kamnt, daf die Böden in ihren wichtigsten Eigenschaften rom Klima abhängig sind; die Böden sind Produlite der Verwitterung und des PHlanzenlebens, die beide zunächst vom Klima bedingt werden; es ist daher ohne weiteres verständlich, daß auch je nach dem herrschenden Klima die Böden verschiedenen Charakter tragen. Den /susammenhang zwischen Klima und Boden haben russische und amerikanische Forscher zuerst betont. Verfasser ${ }^{2}$ ) hat vor 18 Jahren in seinen „Waldungen von Nordamerika" bereits gezeigt, daß nirgends, wo Wald endet oder fehlt, der Boden, sondern das Klima schuld ist, nicht weil es den Boden in eine für den Wald ungïnstige Form umwandelte, sondern weil den Bäumen zum Aufwachsen Wärme oder Niederschlag mangelte. Die primäre Ursache für das Fehlen von Wald ist, von wenigen Fällen abgesehen, immer klimatischer Natur. Der Sahara fehlt Wald, weil Wasser mangelt; die Flachmoore des kïhlsten Klimas sind waldlos, nicht weil es zu feucht, sondern weil es zu kalt ist. Die Flachmoore des wärmeren Klimas sind entweder noch nicht WVald geworden, oder sie sind, rom Menschen des Waldes beraubt, wieder in das Moorstadium zurückgekehrt. Erst in den Hochmooren lernen wir ein Gebilde der Natur kennen, welches keinen Wald duldet, aber wieder nicht wegen des Bodens, sondern durch das Klima und die Tätigkeit gewisser Pflanzen.

W ärme. Wie bei einer Erörterung über die Wärme in der Luft muß auch beim Boden die Frage berührt werden, ob es Böden gibt, die so kalt oder so heiß sind, daß aus diesem Grunde Wald fehlt. Diese Frage liegt bei der allgemeinen Überzeugung von der Wichtigkeit der Bodentemperatur für das Pflanzenleben sehr nahe. Milit man die Temperatur während der vier Monate Mai, Juni, Juli und August auf der nördlichen Halbkugel im Wurzelbereiche eines Waldes, z. B. eines erwachsenen Fichtenbestandes von Mitteleuropa, so ergibt sich. sofort, daß diese Temperatur weit unter der Lufthorotherme für das Dasein des Waldes, nämlich unter $10^{\circ} \mathrm{C}$ verbleibt: wäre in den Böden die Horotherme ebenfalls bei $10^{\circ} \mathrm{C}$ gelegen, so müBte in Europa die Waldgrenze bereits in Dänemark, im südlichen Norwegen und

1) Dr. E. R am a nn, Bodenkunde, 1905, 2. Aufl.

2 Dr. H. Mayr, Die Waldungen von Fordamerika. 1s9u. 
Schweden, somit um 5-10 ${ }^{0}$ südlicher liegen als in Wirklichkeit; an der Waldgrenze dürfte die Bodenwärme im Wurzelbereiche während der vier Monate den Betrag von $1^{\circ}$ kaum erreichen. Man kömnte nun sagen, die dort herrschende, niedere Bodentemperatur von $6^{0}$ entspräche der Lufthorotherme von $10^{\circ}$ und sei schuld, claß dort der Wald zu Ende geht. Dieser Schluß wäre nicht richtig; demn nach den Untersuchungen des Verfassers geht in einem Boden, der bis auf $+1^{0} \mathrm{C}$ künstlich abgekühlt erhalten wird, der Vegetationsbeginn zwanzigjähriger Bäume genau mit derselben Schnelligkeit vor sich, als in einem Boden, der künstlich auf eine höhere Temperatur, als die Umgebung zeigt, erwärmt wird; die Erwärmung hat die Vegetation nicht beschleunigt, die Abkühlung hat sie nicht verzögert. Diese Tatsache, daß die Bodentemperatur für die Vegetationsphasen der Bäume gleichgültig ist, daß über das Dasein des Waldes die oberirdische, nicht die unterirdische Wärme entscheidet, ïberrascht für den ersten Augenblick, steht aber völlig im Einklang mit weiteren Beobachtungen anderer Forscher, welche berichten, daß in nördlichen Regionen auf starkem Humusboden die Wurzeln ïber Schichten gefrorenen Bodens hinwegstreichen; die diesen Bäumen zur Verfügung stehende Bodentemperatur kann somit nur ein paar Grade über 0 betragen. $Z u$ hei $\beta$ für die Wurzelverbreitung kann der Boden nur unmittelbar an und in der Oberfläche sein, worüber bereits auf Seite 13 gesprochen wurde; in tieferen Schichten kann es nur zu heiß sein, wenn Wärme von unten, durch vulkanische Kräfte heißes Wasser oder heiße Luft zugeführt wird; diese Fälle sind nur ganz vereinzelt auf der Erde. Dagegen muß sofort zugegeben werden, daß die Bodentemperatur von größtem Belang ist für chemische und physikalische Prozesse der Streuzersetzung, Bodenaufschließung, Bodendurehlïftung, von größtem Werte ist für die Keimung und ersten Jahre der Baumjugend, sowie für alle jene niederen Gewächse, welche mit der umgebenden Luft dem Einflusse des Bodens in Temperatur unterworfen sind.

Feuchtigkeit. Die Niederschläge ans Regen, Tau, Nebel, Hagel, Graupeln usw. haben dann eine Bedeutung für die Baumvegetation, wenn sie vom Boden aufgesogen und dureh die Wurzeln den Bäumen zugeführt werden; so wichtig für alle Bäume und übrigen Pflanzen die oberirdische durch Blätter und Triebe aufgenommene Feuchtigkeit in Zeiten der Not sein kann, ist doch für das Waldesdasein nur die Menge an Wasser entscheidend, welche in den Boden eindringt und in die Tiefe sickert. Die ausgedehnten aus $\mathrm{M}$ angel an Feuchtigkeit waldlosen Gebiete unserer Erde kann man, wie schon früher gezeigt wurde, in drei Gruppen einteilen: 1. Die erste Gruppe umfaßt alle Flächen, welche während der vier Monate (Mai, Juni, Juli und August auf der nördlichen, November, Dezember, Januar und Februar auf der südlichen Halbkugel) weniger als $50 \mathrm{~mm}$ Niederschläge erhalten, während 
die Lufteuchtigkeit eine zuweilen hohe ist; trotz dieser ist die Verdunstung größer als die Wasseraufnalme; es dringt kein Sickerwassir. in die Tiefe, das Lebenselement für alle Bäume, welche ihre Wurzeln in die Tiefe zu richten gezwungen sind; nur die seicht wurzelnden Gräser und Standen finden sich mit geringer Oberflächentenchtigheit im Boden ab. Thnen kommen überdies die Niederschläge aus dem Tau zugute. Solche Flächen können jederzeit mit Baumwuchs bestellt werden, seien es Obstbäume oder forstliche Naturpflanzen; es bedart nur einer Bewässerung. Einmal begründet, erhält sich der Wald durch Herabsetzung der Verdunstung an der Bodenobertläche. 2. Flächen, welchen während der vier Monate nur $50 \mathrm{~mm}$ Niederschläge oder weniger zugeführt werden, welchen überdies wegen der trockenen, heißen Temperatur ein sehr großes Sättigungsdefizit in der Luf't zukommt, sind zum größten Teile vegetationslos; Wald erhält sich nur bei kïnstlicher Bewässerung: wird dieselbe unterbrochen, stirbt auch der Wald wiederum ab. 3. Gebiete, welchen während der vier Monate $50-100 \mathrm{~mm}$ Niederschläge zugeführt werden, kömmen durch künstliche Kultur in Wald umgewandelt werden, trotz hoher Trockenheit der Luft. Es genügt der Kampf gegen die Präriegräser bei der erstmaligen Begrïindung des Waldes und seiner naturgemäßen Behandlung, um die weitere Existenz des Waldes zu sichern. 4. Prärie- oder Steppenflächen, welchen während der vier Monate mehr als $100 \mathrm{~mm}$ Niederschläge zukommen, waren bereits ursprünglich mit Wald bedeckt; die menschliche Tätigkeit hat sich dort bisher auf Waldvernichtung und Unterstützung der Steppenpflanzen durch Feuer beschränkt; solche Gebiete in Wald umzuwandeln, würde zu erreichen sein, wenn der Mensch seine zerstörende Tätigkeit in eine aufbauende verwandeln wollte.

Wie Feuchtigkeitsmangel kann auch Feuchtigkeits ẗb erseh u $B$ die Teranlassung zu Strauch- und Grasflächen, zum Fehlen von Wald sein. Man kann diese Flächen in zwei Gruppen trennen je nach ihrem Ursprunge und nach ihrem Endziele; gemeinsam ist beiden die Anhäufung unvollständig zersetzter Pflanzenstoffe (Torf, Schlamm) bei Überschuß von Wasser.

1. Flachmoore, Grünlands - oder. Wiesenmoore, Moose, Brücher usw.; Wasseransammlung durch ïberreiche Zufuhr oder ungenügende Abfuhr nährstoffreicher Wasser: Beginn der Torfansammlung am tiefsten Punkte. Der Entwicklungsgang ist folgender: Wasserflächen. welche allmählich durch Pflanzenwuchs sich ausfüllen, werden in Wiese und dann Wald umgewandelt; man kann diese drei Phasen der Ent wicklung bei allen Flachmooren festhalten: Wasser, trasfläh Wrald; das Endziel dor ungestörten Entwicklung ist Tralit: greift der Mensch in den natürlichen Entwicklungsgang ein, sn kann er irgendeine Entwicklungsstufe oder auch cin Überganisitadium won einem zum anderen Trpus längere Zeit festhalten, er kann den Über- 
gang zur nächsthöheren Entwicklung beschleunigen oder auch ver zögern und die Rückkehr zu einem vorausgehenden Stadium herbeiführen. Ton den Tropen bis zur küllsten Waldregion ist der Entwicklungsgang: Wasser, Grasfläche, Wrald der gleiche; es wechselt mit der Wärme nur die Schnelligkeit der Entwicklung und die Pflanzenart.

2. Hochmoore, Buckelmoore. Ansammlung von nährstotfarmen Wassern in und auf der (1)berfläche des Bodens, Ansammlung durch die liapillare Wirkung von Moosen, besonders Sphagneen; Ausgangspunkt der Bildung sind Wiese oder Wald; die Wiesen- und Waldpflanzen ersticken und verhungern in dem nahrungsarmen Wasser: Endziel der Entwicklung ist das Flechtonmoor: auch diese Bildung zeigt drei Typen oder Phasen, nämlich: Wieso bzw. Wald (Wiese ist nur die Vorstufe des Waldes), Hochmoor, Flechtemmoor. Durch menschliche Eingriffe kann auch bei diesen Gruppen Wiese und Wald gegen den Übergang zum Hochmoor und Flechtenmoor geschützt, das Flechten- bzw. Hochmoor wiederum in die Ausgangsphase Wald zurïckgeführt werlen. Die Hochmoorbildung ist auf das kühlere Klima, das Picetum und Polaretum bzw. Alpinetum der später zu gebenden Klima- und Waldzonenbildung beschränkt. Hochmoore sind daher eine charakteristische Erscheinung des Nordens und der höheren Elevation. Bei einer Darstellung des Einflusses der Temperatur auf das Waldesdasein wurde bereits erwähnt (S. 19), daf alle Böden, welche einen Überschuß an Wasser führen, die über ihnen liegende Luft abkühlen. So heiß es mntertags ist, so kühl ist es während der Nacht, so daß das Plus an Wärme während des Tages durch das Minus an Wärme während der Nacht für die Pflanzenwelt wiederum verloren geht; Verzögerung des Frühlings, tiefe Temperatur während klarer Sommernächte - von 5 (1) $\mathrm{m}$ aufwärts können in Mitteleuropa in jedem Sommermonat Nachtfröste auftreten —, verlängerter Herbst und außerordentlich tiefe Wintertemperatur sind die bekannten, klimatischen Erscheinungen des nassen Bodens. Es wurde bereits erwähnt, da13 nasse Bodenflächen auf die Luft abkühlend wirken, dab an der betreffenden stelle nicht das Klima der Umgebung, sondern jenes der kühleren Rogion herrscht. Sumpfige Gebiete im Fichten- und kühleren Buchenwalde (kühleres Fagetum und Picetum nach einer später gegebenen Darstellung) besitzen das Klima des Alpinetum bzw. Polaretum; in dieser Klimazone ist somit der Übergang der Wiesenmoore in Wald a $\mathrm{W}$ Borordentlich erschwert, an der oberen und nördlichen Waldgrenze wohl auch ganz ausgesehlossen. Seichtes Wasser im alpinen oder polaren Klima liamn aus Mangel an Temperatur nur bis zur Wiese oder Sumpfsteppe, nicht bis zum Wald sich entwickeln; es fällt den Sphagneen anheim, wird Hochmoor und schließlich Flechtenmoor; stört der Mensch die Entwicklung des Wiesenmoores zu 
Wald im kühleren Fagetum und Picetun, so kann anch ans einem Wiesenmoor direkt ein Bnckel oder Hochmoor hervorgehen. Bei dar Gruppe der Hochmoore ist das Auftreten derselben im wärmeren Klima, d. h. wärmer als Fagetum, ummöglich, weil die wald. vernichtenden Pflanzen (Sphagneen) dem Alpinctum Lzw. Poluretum hauptsächlich angehören, welche nur noch im benachbartsn Pir.tum bzw. Fagetum zur Herrsehaft gelangen können; in wärmeren Klimalagen ist ihnen das Klima zu warm und zu trocken. Das Hochmoor geht nur dann in ein Flechtenmoor über, wenn es in der $1 /$ one des Polaretums oder Alpinetums gelegen ist, weil die Flochtenptlanz'n de's kühleren Klimas (Lichenetum) nicht mehr im Picetum oder in noch wärmeren Klimalagen herrschend werden können.

Mit dem Nachweis, daß alle seichten Wasserflächen der Frde im ungestörten Walten der Natur sich zu Wald entwickehn mïssen, soweit das Klima diesen gestattet, daßs alle auf der Erde vorhandenen, so mannigfaltig bevölkerten Sümpfe nur verschiedene Plasen in diesem Entricklnngsprozesse darstellen, erklärt sich in einfacher, naturgerechter Weise die ganze Mamigfaltigkeit der Sumpfbildungen unserer Erde. Wir erzielen damit eine naturgesetzliche (irundlage für die Behandlung und Umwandlung der sumpfigen Gebiete in Wald. Wir erhalten damit aber anch neue Anhaltspunkte zur Lüsung der Frage über die Entstehung der Bram- und Steinkohle. Wie der Nensch während der letzten Jahrtausende haben vor ihm in noch großartigerer Weise in den Entwicklungsgang der Sümpfe Katastrophen der früheren Erdgeschichte eingegriffen, Übersandung, Überflutung dureh Neere mit Gesteinsabsätzen. Unter dem Drucke und dem ungenügenden Sauerstoffzutritt ging eine außerordentlich langsame Zersetzung der Pflanzenreste vor sich, welche zu Torf, zu Brann- und Steinkohle führen mußte.

Nährgehalt. So außerordentlich wichtig der Nährwert des Bodens für das Auftreten gewisser Baumarten im Walde und das Gedeihen des gesamten Waldes ist, so einflußlos muß die Bodengüte und die geologische Abstammung des Bodens bezeichnet werden, wenn es sich um die Frage des Daseins von Wald überhaupt handelt. Der ungebundenen Natur ist kein Boden zu arm, um auf demselben einen Wald hervorzurufen; sind Wärme, Feuchtigkeit und Ruhe gegeben, trägt im [rwall] auch der von Natur aus ärmste Boden einen Wald: im Urwalt verriit erst die Zusammensetzung des Waldes und seine Wechsehnde Höhnentwicklung, dafs Unterschiede in der Bodengïte bestehen. Fihlt die Feuchtigkeit, so können gewisse Nährsalze, wie Karbonate und Sulfate der Alkalien bei starker Verdunstung aus dem Boden ausblühen, sn dals nach längerer Trockenheit die ganze Landschaft' wie mit leichtem schnco bedeckt erscheint (Salzböden der Steppe, Alkaliböden). Wo die mittlere Regenmenge gröfer als die Verdunstung, sickem die Nährsalze in 
tiefere Bodenschichten zur Ernährung des Waldes. Unter denselben Verhältnissen finden sich auch Kochsalzausscheidungen am Boden, die wie die Alkalisalze nur von bestimmten Pflanzen ertragen werden.

Nitten im Waldgebiete aber kann es waldlose Flächen geben durch Anhäufung von schwefliger Säure im Boden. Es kommt hier noch nicht die Einwirkung des Menschen auf Bodenvergiftung in Frage; Bodenvergiftungen mit schwefliger Säure sind auch ohne Zutun des Nenschen in der Natur keine seltenen Erscheinungen, aber stets an vulkanische Gebiete gebunden. Der Verfasser dieser Schrift lernte an der pazifischen Küste Asiens mehrere Vulkane kennen, die bei ihrem Ausbruche Wasserdämpfe und Schwefelsäuregase emporgestoßen hatten; in höheren Luftschichten erkalteten sie und kamen als schwefligsaure Regen zur Erde, wo sie auf weiten Umkreis hin den Wald völlig vernichteten. Das Überraschendste war, daß 15 Jahre nach dem Ausbruche am Rande des am Leben gebliebenen Laubwaldes immer noch einzelne Bäume abstarben. Mit der Zeit wird jedoch das Gift in die Tiefe gewaschen und der Wald kehrt von selbst auf die Stellen zurück, welche er vor der Katastrophe innehatte.

Bodenkonsistenz. Wenn hinreichende Niederschläge fallen, ist der Verwitterungsboden nirgends zu fest, nirgends zu locker für das Dasein des Waldes; wo der Boden beweglich ist, fehlt Wasser, oder er kann nicht zur Ruhe kommen, weil die Kräfte, welche an seiner Bewegung arbeiten, nicht zur Ruhe kommen, z. B. Wind und Wasser an den Meeresküsten (Dünenbildung). Bewegter Boden kann Wald zerstören (Wanderdünen) und neue Flächen für Wald aúfbauen; im gleichen Sinne wirken Wasser und vulkanische Kräfte; in früheren Erdepochen haben zerstörende und aufbauende Kräfte den Boden für die wichtigsten Waldungen der Erde geschaffen; ihre Tätigkeit in der Gegenwart ist eine abgeschwächte und lokale, weniger aufbanend als zerstörend durch die Beihilfe des Menschen.

Bodenneubildung. Nur im Bereiche genügender Regenmenge kann der Wind neues Land durch Aufschütten von Sand schaffen; die Sandwehen auf Tausende von Quadratmeilen in Nordafrika und über das Rote Neer hinweg nach Arabien können keinem Walde den Nährboden geben; denn es vergehen zuweilen Jahre, bis dort wiederum ergiebiger Regen fällt; jene unermeßliche Licht- und Wärmemenge, welche - auf diese Gebiete niederstrahlt, ist vergeudet, da sie nicht auf Pflanzen und Bäume auftrifft, welche sie durch ihr Blattgrün in ihren und damit in den Dienst der Menschheit stellen könnten.

Stürme aus einer Lößw üste der Mongolei waren es, welche dem nördlichen China den besten Grund für Acker und Wald, den Löß, brachten. Die Lößwüiste war bewaldet, als das sibirische Tertiärmeer noch gegen die Landmassen der nördlichen Mongolei schlug; durch das Zurückweichen des Meeres nach Norden hin, durch Freigabe des 
Landes nahm die Feuchtigkeitsmenge im Zentrum der Mongoloi stetir ab; der Wald ging allmällich in Steppe und die Steppe in vegetations. lose Wüste über. Nun erst konnten trockene Nordwestmonsune, die ebenfalls erst in dieser Zeit der großen Landbildung entstanden, oinsetzen und den lockeren Lehmboden aufgreifen. Die angewehten Lößmassen begruben in Nordchina den Wald; auf dem Löß entsprof ein neuer Wald, der heute wiederum vernichtet ist durch den Nenschen. Noch heutigen Tages bringt der Nordwestwind Löß aus der Mongrolei, in geringer Menge unschädlich, ja sogar nützlich für Feld und Walıl als mineralischen Dünger. Auch Japan, ebenfalls unter dem Einfluf, des Nordmonsuns während des Winters stehend, hat wie China seine Staubstürme, aber in Japan ist es humoser Boden der Felder, der vermischt mit Straßenstaub alles mit einer dunkelbraunen, sandigen Kruste iiberzieht. Kein Wald wird vernichtet, aber auch kein Boden für Wald neu geschaffen; was den Feldern entrissen wird, kommt dem Walde zugute.

Heutzntage ist das $\mathrm{W}$ asser als Neubodenbildner der wirksamste Faktor. Nenes Land entsteht durch Korrektion der Gebirgsflüsse, denen die zerfressene, waldlose Geröllfläche abgenommen wird. Hierbei muß Wasser, das durch seine Überflutungen und Geländeverschiebungen den Wald vernichtet und seine Rückkehr unmöglich gemacht hat, wieder Kies und feinen Schlamm zum Aufbau herbeitragen. Neues, noch unbewaldetes Gebiet entsteht an den Flußmündungen, Deltabildungen, dadurch, daß die feinsten Schlickstoffe, welche der Fluß mit sich führt, bei Abnahme der Fortbewegung des Wassers zu Boden sinken. Flüsse, deren Hinterland eine Vegetationsdecke, vor allem Wald trägt, führen nur geringe Mengen dieser besten, fruchtbarsten Bodenbestandteile hinaus in das unersättliche Meer; Flüsse, welche aus einem Gebiete kommen, in dem die Entwaldung und Bodenentblößung im vollen Gange ist, wie der Mississippi, schwellen mit ihrem Hochwasser zu immer unheimlicherer Höhe an; im Oberlaufe des Riesenstromes sind es Fener und Axt, welche den Wald vernichten, im Unterlaufe ist es der Strom selbst, der den seit Jahrtausenden unberührten Urwald mit Sand und Kies überschüttet. Nan hat berechnet, daß der Hwangho jährlich 500 Mill. cbm schlammige Sedimente mit sich führt; mit dem Jangtze fallen in jeder Sekunde $6 \mathrm{cbm}$ fester Stoffe ins Meer. Das flache Becken des Gelben Meeres füllt sich stündlich mehr und mehr und Hunderttausende von Hektaren an der Mündung sind bereits Land geworden: sie sind landschaftliche Gelände bester Art und wären heute längst Wald, wenn der Mensch es gestatten würde. Überall wiederholt sich der gleiche Vorgang; tiefe Wasser werden ausgefüllt zu seichten Wasserflächen; eine Vegetation ron Wasser- und Sumpfpflanzen bewohnt sie und hebt durch ihre Sinkstoffe den Boden immer mehr empor, bis er auch für die Pioniere des Waldes, für Weiden, Pappeln, Erlen, tür Gräser und Sträucher bewohnbar wird. 
Vulkanische Kräfte sehütten neues Land an, meist nur auf solchen Flächen, auf welchen sie zuerst den Wald vernichteten. Gräbt man auf der großen, vulkanischen Insel Eso in Nordjapan in den Boden, so wechseln Bimsstein und vulkanischer Sand mit schwarzen, kohligen Humuslagern ab; jede solche schwarze Schicht entspricht einer Vegetationsdecke, einem Walde, welcher von der Asche des Vulkans vernichtet wurde und immer wieder auf der verwitternden Asche zurückkehrte. Flüssiges Gestein, an der Luft abgekühlt und erhärtet, bleibt sehr lange Zeit ohne Pflanzendecke; so ist der schwarze Steinstrom, der 187.2 dem Krater des Vesuvs entquoll und Weinberge und Felder zerstörte, noch heute ohne alle Vegetation, weil die Verwittermng des Gesteins sehr langsam vor sich geht.

Bodenmangel. Man liest zuweilen in der forstlichen, häufiger aber noch in der gärtnerischen Literatur, daß dieser oder jener Baum auf völlig nacktem Felsen noch aufwächst; darnach könnte man vermuten, daß Wald nicht fehlen kann, wenn dem Felsboden die Verwitterungskrume fehlt; allein derlei Äußerungen entsprechen mangelhafter Beobachtung oder unvorsichtiger Reklame für den betreffenden Baum. Auf nacktem Felsboden wächst kein Baum. Finden wir Bäume, so haften sie mit ihren Wurzeln in den Klüften und Spalten des Felsgesteins, in welchen die abgewaschene Verwitterungskrume des Gesteins sich ansammelt; die scheinbar auf nacktem Felsen lebenden Bäume müssen durchaus nicht bescheiden, sie können sogar sehr anspruchsvoll an die Bodengüte sein, denn in den Felsspalten sitzt der beste Boden. Ganz ähnlich ist es mit dem "steinigen Boden", der ein sehr nahrungsreicher und sehr armer sein kann. Wird der Verwitterungsboden von der Oberfläche des Gesteins oder der Gesteinstrümmer in solche Tiefen gewaschen, daß er für die Wurzeln der Bäume nicht mehr erreichbar ist, dann fehlt auch der Wald. Solche waldlose Stellen sind teils ursprünglich - man nennt sie „Steinerne Meere", deren fast jedes Gebirge ein solches besitzt - , teils künstlich durch die waldvernichtende, menschliche Tätigkeit und durch Abschwemmung geschaffen; man nennt solche Flächen "Karste"; ihre Wiederbewaldung ist eine der schwierigsten Aufgaben des Waldbaues.

Waldlosigkeit durch Bodenmangel liegt sodann vor für die Felsenplateaux von Südassam, welche von den niederstürzenden Regenmassen kahl gewaschen sind. Es muß auch die Gürtelprärie an den Vulkanen von Zentral- und Südjapan hierher gerechnet werden. Diese natürliche Prärie liegt zwischen zwei bewaldeten Zonen an der ausladenden Basis der Vulkane; dort ist bei der Aufschüttung des Vulkans das gröbere Gestein zur Ruhe gekommen; die reichlich fallenden Niederschläge waschen die Verwitterungskrume immer noch in die tiefen Hohlräume; dio Sickerwasser aus den höheren, bewaldeten Regionen bewegen sich hier zwischen den tieferen Hohlräumen des Bodens abwärts, um an 
der Basis der Vulkane als eiskalte (Vuellen zntage zu treten. In der (iürtel prärie wird die Verdunstung durch die sonkiecht anffallenden Sonnenstrahlen besehleunigt. Alle diese Faktoron wirken zusammen, se) (laf nur Graswuchs aufkommen kann. Es hängt von der gengraphiselien Lagr ab, ob der Vulkan nur auf seiner Südseite (nordische Lagre) oder auf allen Seiten, auf der Südseite weiter als auf der Nordseite, diese (iïrtrlsteppe trägt. Dafs aneh hier, von der Steppe aukgehend, Feurx nach oben und nach unten den Wald angefallen und die Steppe verbreitert liaben, bedarf für den, der die Menschen kennt, keiner Erwälınung.

\section{Pflanzen.}

Es gibt eine Menge sogenannter forstlicher Unkränter, die wir als Sehädlinge unserer Waldkulturen kennen, weil sie diese durch ihr rasches Wachstum verdämmen, d. h. ihnen Licht, Luft und Bodenraum entziehen; schädlich werden sie sodann genannt, weil sie die natïrliche Rückkehr des Waldes, den Anflug von Sämereien und das Keimen derselben auf längere Zeit ausschließen können. Aber unter allen diesen höher entwickelten Gewächsen ist kein einziges, welehes imstande gewesen wäre, ursprünglich den Wald von einem bestimmten (rebieto fern zu halten; sie finden sich nur in Gebieten, welche keinen Wald tragen können - aus den früher erwähnten Gründen. In solchen Örtlichkeiten kämpfen gewisse Unkräuter erfolgreich gegen angeflngene oder eingetragene Waldkeime. Alle forstlichen Unkräuter im Walrlgebiete sind ursprünglich ohnmächtige, harmlose Zierden des mäßig gesehlossenen Urwaldes gewesen oder auf Stellen beschränkt geblieben, welche aus lokalen Gründen keinen Wald tragen konnten. Auch die Heide mit der Rohhumus-Bleichsand- und Ortsteinbildung kann hiervon nicht ausgenommen werden, denn die Heide wurde erst mächtig durch den Eingriff des Mensehen; die Stufenleiter abwärts bis zur Heideprärie war Wald, mißhandelter Wald. Überhandnahme der Heide, Umwandlung des Bodens und Ersehwerung der Rückkehr für den Wald, der sicher auch die Heideflächen zurückerobern würde, wenn man ihm einen unbegrenzten Zeitraum zur Verfügung stellen könnte. Im Urwald siegt immer der Wald; im Kulturwald, der seine Laufbahn als mißhandelter Wald beginnt, werden den Unkräutern die Waffen zum Kampfe gegen den Wald geschliffen. Erst unter den niederen Pflanzen sind Waldverderber und Waldverhinderer; das sind vor allem Moose und zwar die erwähnten Sphagneen, welche durch ihre Wasseransammlung innerhalb der Bodendecke die Bäıme des Waldes ertränken und diesen in Hochmoore umzuwandeln vermögen.

Die Kleinarbeit der Pilze geht in ihren schädlichen Wirkungen ins große. Aber trotz stellenweiser Massenvermehrung der Pilze, z. B. des Wurzelkrebses, gibt es keine größeren Stellen im Waldgubiete, 
44 Erster Abschnitt. Naturgesetzliche Grundlagen u. Verteilung der Wälder usw.

welche durch Pilze waldlos gemacht worden wären und als solche aufrecht erhalten werden würden.

\section{Tiere.}

Nur bei Massenvermehrung der Tiere, welche gewisse Bäume des Waldes benützen oder doch wenigstens sie bevorzugen, werden Waldungen selbst auf größeren Flächen hin in Frage gestellt; aber es ist kein Beispiel bekannt geworden, daß es waldlose Stellen gäbə infolge der Tätigkeit del pflanzenfressenden oder den Boden umgestaltenden Tiere; mit den Pflanzen hätten auch die Tiere absterben müssen. Gegen eine Massenvermehrung schützt sich die Natur, indem sie den Tieren nur spärlich Futter im Walde gibt, durch die Vielartigkeit des Urwaldes und dadurch, daß sie den Massenvermehrungen Massenkrankheiten, Epidemien folgen läßt.

\section{Der Mensch.}

Die Eingriffe und Veränderungen in den naturgesetzlichen Grundlagen des Waldes, seine dauernde Vertreibung und seine Ansiedlung, wo er von Natur aus fehlte, die zerstörenden, erhaltenden und aufbauenden Tätigkeiten des Menschen sind im VII. Abschnitte kurz besprochen. 


\section{Zweiter Abschnitt.}

\section{Naturgesetzliche Grundlagen der Waldregionen der nörd- lichen Erdhälfte außerhalb der Tropen, innere Verwandtschaft.}

Aus der Darstellung des vorigen Abschnittes, daß alle Waldmassen ihr Dasein den großen Feuchtigkeitsspendern, den Ozeanen, verdanken, ergibt sich für die Verteilung der Waldregionen und ihre Benenmung eine natürliche Grundlage. Der Atlantische Ozean erzeugt zwei große Waldregionen, eine in der Alten Welt und eine zweite in der Nenen Welt; der Stille Ozean gibt ebenfalls zwei Waldregionen das Dasein, die eine liegt in der Nenen, die zweite in der Alten Welt; der Indische Ozean erzengt eine Waldregion im Süden von Asien; das Nordische Eismeer befruchtet die anliegenden Länder der Alten und der Nenen Welt und gibt einem Wald den Ursprung, wo immer es die Temperatur gestattet. Daraus ergeben sich folgende Waldregionen (Abb. 1):

I. die atlantische Waldregion der Alten Welt, umfassend die Waldungen von Europa und Nordafrika;

II. die atlantische Waldregion der Neuen Welt, um fassend die Waldungen von Ostamerika;

III. die pazifische Waldregion der Neuen Welt, umfassend die Waldungen von Westamerika;

IV. die pazifische. Waldregion der Alten Welt, umfassend die Waldungen von Ostasien;

V. die sibirische Waldregion, welche die beiden Waldregionen von Europa und Ostasien miteinanderverknüptt:

VI. die kanadische Waldregion, welche die beiden Waldregionen von Ost- und Westamerika mitoinander verbindet;

VII. die indische Waldregion, ein zentralasiatisches Waldgebiet mit Berührung nach dem europäischen und dem ostasiatischen Walde hin; 
VIII. die nordmexikanische Waldregion, ebenfalls ein zentrales Waldgebiet mit Berührung zum ost-und westamerikanischen Walde.

Ein Blick auf Abb. 1 zeigt den Parallelismus der beiden großen Kontinente in der Verteilung der Waldregionen; beide Welten tragen in ihrem Zentrum eine waldlose Landschaft; waldlose und waldbedeckte Gebiete der neuen wie der alten Welt verhalten sich in ihren Größen zueinander wie die Größen der beiden Welten; Nordamerika trägt im Sïden wegen seiner außerordentlichen Verschmälerung des Kontinentes nur die kleine nordmexikanische, artenarme Waldregion, deren Parallele in Asien, entsprechend der gewaltigen Verbreiterung Asiens an dieser Stelle zur weitausgedehnten und artenreichen, indischen - chinesischjapanischen - Waldregion ausgebildet wurde; ein schmales und kurzes Band ist die kanadische, ein schmales, aber sehr langes Band ist die sibirische Waldregion.

Dem Parallelismus der Lagerung der Waldregionen entspricht ein Parallelismus im Klima, in der Anordnung der Waldregionen nach klimatischen oder Waldzonen, in der Abstammung der Böden aus gleicher, geologischer Formation und aus gleichem Gestein, in der Verwandtschaft der Waldtypen und der Bäume, welche diese Waldregionen bevölkern. Sämtliche acht Waldregionen erstrecken sich, mit der Zone der Subtropen angefangen, bis zu jenen kühlsten Lagen, in welchen die Horotherme dem Walde eine Grenze setzt; sechs Waldregionen erreichen diese Grenze durch ihre Erstreckung nach Norden und nach höheren Elevationen hin, die beiden Regionen im Süden erreichen diese Grenze nur im Hochgebirge bei entsprechender Erhebung über dem Meere.

Verfasser war wohl der erste, der vor 18 Jahren den Nachweis erbrachte, daß bei Gleichheit der Temperatur während der vier Monate Mai, Juni, Juli und August auf der nördlichen Halbkugel überall anch eine Gleichheit der Wälder auftreten muß, das heift den $\mathrm{gleichen}$ Temperaturen entsprechen gleiche Baumgattungen (Gonera). Wenn aber keine Gleichheit zwischen den drei Regionen in den Arten (Spezies) besteht oder diese nur auf einige wenige Arten sich beschränkt, so erklärt sich dies aus den unberechenbar langen Zeiträumen, seitdem diese acht Waldregionen voneinander getremnt sind; wenn das eine Waldgebiet Gattungen zeigt, die dem anderen fehlen, so erklärt sich dies aus den Ursachen, welche die Trennung veranlaßten und ans den geologischen Katastrophen, welche über die Weltteile nach ihrer Trennung hereinbrachen. D i e in ne re Verwandtschaft der Waldregionen, welche in der Gleichheit der Gattungen und in der Gleichheit der Biologie der Waldungen zum Ausdruck kommt, erklärt sich ans dem früheren, territorialen Zusamenhang der. Waldgebiete, der all- 
mählichen Abtrennung der boidon Kontinente und der Abstammung der Bäume von den gleiclion Voreltorn.

In den Gesteinsschichten der Tortiärformation Europas beobachtert man zahlreiche Baumgattungen, wie Magnolia, Liriodendron, Juglans, Magnolia Catalpa, zahlreiche schmetterlingsbliitige Gewächse, ja selbst fremdartige Nadelhölzer wio 'Thuja, Sequoia, Gingkyo, Gattungen, die heute in Europa gar nicht mehr vorlianden sind. Da diese Baumgattungen dem wärmeren Gebiete des winterkahlen Laubwaldes (dem Castanetum der späteren Ausführungen) angohören, muß diese jetzt nur noch in Südeuropa vertretene Waldzone mit zahlreichen Eichen, Esehen, Ahorn und sonstigen Laubbäumen zur 'Tertiärzeit in Europa bis zum $60 .{ }^{0}$ nördl. Br. vorgedungen sein; nördlich vom Castanetum muß dann jener kühle Laubwald, den wir nach der Buche Fagetum nennen, sich angeschlossen haben, nördlich davon der Nadelwald der Fichten, Tannen und Lärchen, den man Picetum nennt, gefolgt sein, und für die kälteste Stranchregion, das Polaretum, bleibt nur die unmittelbare Umgebung des Nordpols übrig. Es fehlt an den nötigen Forschungen, wie weit diese Voraussetzung zutreffend ist; daß aber zur Tertiärzeit das zusammenhängende Festland um den Pol herum mit einer Baumflora von gleichen Gattungen und vielen gleichen Arten bevölkert war, ergibt sich vor allem auch aus der Verwandtschaft des amerikanischen, europäischen und asiatischen IValdes. Alle drei Weltteile hatten gleichzeitig ihre letzte Eiszeit, wie mehrere solche Katastrophen selbst in der geologischen .Jugend unserer Erde nachgewiesen sind, womit die Theorie von der allmählichen Wärmeabnahme auf der Erde als Folge der inneren Erkaltung als unhaltbar über Bord geworfen ist. Die Abkühlung der nördlichen Halbkugel während der Eiszeit kam verhältnismäßig rasch; im äußersten Norden und auf den höchsten Gipfeln der Alpen und der Pyrenäen begannen die Eismassen talwärts zu rücken; langsam, aber fortgesetzt verschoben sich dic Waldzonen nach $\mathrm{S}$ und an den Bergen nach unten. Zur Zeit der schlimmsten Vereisung war von Mitteleuropa nur das Gebiet zwischen den oberbayerischen Seen $\left(48^{\circ}\right)$ und dem 54. nördlicher Breite eisfrei; in diesem, ebenfalls entsprechend abgekïhlten, schmalen Bande wurde die ganze Vegetation zusammengedrängt; das Castanetum mit seinen Holzarten wurde vollständig vertrieben, soweit es nach $\mathrm{SO}$ ausweichen konnte; jene Holzarten, die nicht rasch genug zu wandern vermochten, wurden erdrückt; vom Fagetum konnten sich Reste in den wärmsten Tälern erhalten, vorherrschend aber waren in dem eisfreien Gebiete das Picetum und an dieses sich anschließend das Polaretum oder Alpinetum. Nach der Eiszeit erfolgte zwar wieder Erwärmung, aber nicht mehr his zu jenen Graden, die vor der Eiszeit geherrscht hatten.

Das Castanetum blieb ausgeschlossen, das Fagetum rerbreiterte sich wieder, aus SO wanderten Laubhölzer hinzu, das Picetum und 
das Polaretum wurden auf ihnen klimatisch entsprechende Gebiete zurückgedrängt. Dieser Werdegang des europäischen Waldes erklärt seine gegenwärtige Zusammensetzung an Baumarten und s e in e a u B er ordentliche Armut an solehen; der Tertiärflora war das Ausweichen nach $\mathrm{S}$ durch die Pyrenäen und Alpen verlegt.

Amerika und Asien hatten ebenfalls gleichzeitig mit Europa ihre Vergletscherungen, aber die der Bahn der Kältebewegung parallelen Gebirgszüge ermöglichten das Ausweichen der Baumflora nach $\mathrm{S}$ und insbesondere die Rückkehr in die alten Gebiete nach der Eiszeit. Aber auch dort hat die Wärme nicht mehr den Höhepunkt wie vor der Eiszeit erreicht; in Ostamerika und in Ostasien haben sich zwar die meisten Baumarten erhalten, sie sind aber auf südlicherem Standorte stehen geblieben; Nordamerika und Ostasien sind, wie Asa Gray zuerst nachgewiesen hat, die glücklichen Erben des vorglazialen Baumreichtums der nördlichen Halbkugel; in Westamerika konnten die warmen, dem Laubwalde zusagenden Gebiete von den Laubhölzern nicht wieder besiedelt werden, wegen eingetretenen Mangels an Niederschlägen.

Abstammung von gleichen Eltern ist die erste Ursache für die nahe Verwandtschaft der Waldgebiete; sehr wenig scheint die Verbreitungsfähigkeit der einzelnen Holzarten zum verwandtschaftlichen Verhältnisse der großen Waldregionen beigetragen zu haben. Man überschätzt gewöhnlich die Entfernung, bis zu welcher leichter, flugfähiger Samen vom Wind getragen werden kann. Die Vermutung Griesebachs, der, wenn auch geflügelte, doch immer noch schwere Same der Himalayastrobe (Pinus excelsa) sei vom Wind bis nach Mazedonien, sohin rund $4000 \mathrm{~km}$ weit getragen worden, widerspricht den einfachsten Gesetzen der Schwere und der Luftbewegung. Es gelang nicht einmal den leichtsamigsten Pappeln und Weiden die $500 \mathrm{~km}$ breite Prärie zwischen Ost- und Westamerika zu überbrücken; nur solche Baumarten sind beiden Waldregionen gemeinsam, welche die Prärie mittels des kanadischen Waldstreifens zu umgehen vermochten. Auch die Verbreitung durch Wasser bei schwimmfähigen Sämereien kann auf große Entfernung hin nicht wirken. Samen, die im Wasser liegen, gehen nach wenigen Tagen unter. Große Strecken können somit auf diesem Wege nicht zurückgelegt werden; ein Transport von lebenden Sämereien aus Amerika nach Europa mittels des Golfstroms ist somit ganz ausgeschlossen; wohl aber werden Sämereien von Holzarten der kühleren Waldzonen, z. B. Krummholzföhren, in die Zone der Lärchen und Fichten, diese in die Zonen der Buchen durch fließende Gewässer abwärts getragen. Daß Tiere, zumal Vögel, auf ziemliche Entfernung hin Sämereien verschleppen, muß zugestanden werden; da aber das verzehrte Samenkorn nach wenigen Stunden den Darmkanal passieren muß, kann es sich nur um Entfernungen von höchstens $400-500 \mathrm{~km}$ handeln, abgesehen davon, daß die Vögel solche 
gewaltige Flïge nicht ost- oder westwärts. somblern süblwärts unternehmen, "o die nordischen sämoreien nicht gedeihen kïnnen, oder nordwärts, wo die südlichen sämereicn verkimmern müssen. firiose. bach hat die kühne Behauptung anfgestellt, es künnten Drosiselarten, also mäßige Flieger, den schweren samen einer Juniperus-Art von spanien nach Kleinasien rersehleppt haben. Da die Entfirnung rumel

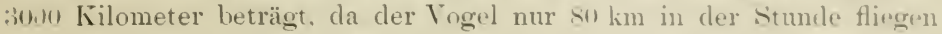
kann und absolut keine Veranlasiung hat in grüßter Eile zwei Tagre und eine Nacht hindurch ostwärts zu fliegen, wobei es nütig wärw, während der langen Zeit die Facees zurïclizuhalten. so ist diese Erklärung der scheinbaren Identität der beiden Wachholder von spanien und Kleinasien ebenso wenig naturwissenschaftlich müglich und lialtbar wie die Erklärung der sogenannten Indentität zwischen der griechischen und der indischen Strobe. Erst der Menseh hat sich als der wirksamste Mischer der Flora aller Waldregionen in den letzten Jahrzehnten herausgebildet.

Von diesen Verschiebungen durch den Menschen natürlich abgesehen, bestand die ursprüngliche Baumflora der vier wichtigsten Waldregionen aus folgenden Gattungen und Arten: die Zahlen sind nicht feststehend: es sind auch nur jene Holzarten gezählt, welche regelmäBig über \& m Höhe erreichen. Dazu kommt, daf es noch viele Botaniker gibt, welche Bäume mit konstanten und erblichen, äußeren und biologischen Merkmalen, mit einem Verbreitungsgebiete, in welchem andere, mah verwandte oder die sogenannten typischen Arten ausgeschlossen sind, als Varictäten des willkürlich gewählten Typus auffassen oder den bisherigen Typus als Tarietät ausehen, demn der Typus hat vor solchen Varietäten uur den Vorzug, früher entdeckt worden zu sein. Hier sind solche lionstante Varietäten mit erblichen Eigenschatten als das gezählt, was sio sind, als Arten. Unsicherheit bringt sodann in die unten angeführte $/ u$ sammenstellung der erfreuliche Umstand, daß es immer noch Regionen der nördlichen Halbkugel gibt, insbesondere in Zentralasien, in welchen noch neme Baumarten von Forschern und Reisenden aufgefundin werden. Die Zusammenstellung kam somit ahsolute Richtigkeit nicht beanspruchen, gibt aber doch für die Beurteilung der Zusammensetzung der Waldregionen einen, für den vorliegenden $/ /$ weck verwertbaren Eimblick: sie gilt für alle Baumarten nördlich hzw. oberhall, der Subtropenzone, somit für Castanetmon, Fagetm uml Picetura der späteren Austührıngen.

Waldregion I. Der emropäische Walk umfaft

$$
\text { an Laubhölzern } 30 \text { trattungen mit iil Arten. }
$$


50) Zweiter Abschnitt. Naturgesetzl. Grundl.d. Waldregionen d. nördl. Erdhälfte usw.

Waldregion II. Der ostamerikanische Wald umfaßt

an Laubhölzerı 110 Gattungen mit 2:0 Arten.

"Nadelhölzern $13 \quad$ " $\quad 30 \quad$ "

Waldregion III. Der westamerikanische Wald umfaßt

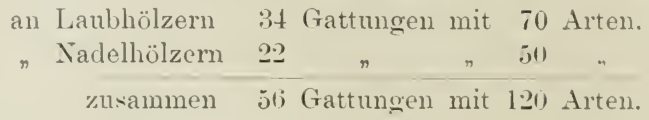

IV aldregion IT. Der ostasiatische (chino-japanische) Wald umfaßt

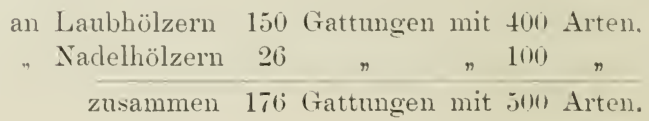

Aus diesen Zahlen geht zunächst deutlich hervor, daß die Osthälfte der großen Kontinente, Ostamerika und Ostasien, am meisten Bammarten ron der vorglazialen Baumflora gerettet hat, daf dagegen Europa infolge seiner mächtigen Gebirgszüge im Süden durch die glaziale Katastrophe den größten Teil seiner ursprünglichen Baumflora verloren hat. Daraus ergibt sich für alle Pflanzenzüchter der zwingende Schluß, diese vertriebenen Gattungen mit solchen, welche dem europäischen Walde überhaupt fehlten und welche heutzutage nicht mehr imstande sind. das trennende Meer auf natürliche Weise zu ïberbrüicken, als neue Glieder dem europäischen Tralde einzufügen und sie hinsichtlich inrer Anbanfähigkeit und Branchbarkeit zu prïfen.

Vergleicht man die Verwandtschaftsverhältnisse der einzelnen Waldgebiete, durch Feststellung der identischen Gattungen und Arten, so muk vorausgeschickt werden, daß die Zahl der identischen Bam. arten nur gering ist und nur gering sein liann. Es liegt nahe, dafs es im europäischen und ostasiatischen Waldgebiete identische Bamarten gibt, da beide ja territorial verbunden sind. Es hat sich aber gezeigt. daß nur solche Arten identisch sein können, aber nicht müssen, welche im Waldesbande von Sibirien ohne Unterbrechung ron Europa nach Asien oder umgekehrt auch heute noch zu wandern rermögen: nachdem dieses Band aber der kïhlsten Waldzone, dem Picetum, angehört, künnen nur Holzarten dieser Klimazone zwischen Europa und ()stasien identisch sein: daf somit irgend eine asiatische Buche oder Eiche oder Kastanie mit der europäischen gleicher Art sei, ist eine gengraphische, biologische und pflanzengeschichtliche Unmöglichkeit; aher unter den Fichten, Birken, Erlen. Pappeln, Wacholdern, Weiden undander en kann es identische Arten geben, und 
daß besonders Weiden von Europa bis zu dren Kurileninseln im tirustru Usten in ein und derselben Art sich erstrechen, lionnte Vertasser ant seinen Reisen selbst nachweisen.

Auch in der nordamerikanischen Baumflora kann nur dann rine Art mit einer europäischen oder asiatischen ilentisch sein, wenn diese Ant imstande ist, die schmale Meeresstrabe zwischen den heiden linntinenten (ca. $70 \mathrm{~km}$ ) zu überbrticken: das ist in der Tat möglich für alle Bammarten, welche in der kïhlsten Region des Waldes zu leben imstancle sind. Es sind dies wieder Birken, Weiden, Erlen. Wacholder, welche diese Wanderungen ausführen können. Alle wärmeras Klima verlangenden Holzarten mïssen eigene Arten sein.

Die territoriale Trennung zu Ende der Tertiärzeit, die sürwärtswanderung infolge der Vereisung, die Nordwärtswanderung nach der Wiedererwänmung und vor allem die Abänderungen in den Arten durch sprungweise Änderung während der Geburt haben so unendlich lange aut die jetzige Baumflora eingewirkt, daß die ehemalige Gleichheit ler Arten als Nachkommen einer rings um den Pol wohnenden Elternflora verloren gegangen ist. An stelle der ehemaligen, imnigen Verwanitschaft in Arten ist eine lockerere Verwandtschaft in Gattungen getreten. Berechnet man die $\mathrm{Zahl}$ der Gattungen, welche in den rerschiedenen Waldregionen identisch sind, so sind die

La ubholzgattungen des ostamerikanischen Waldes (II) im emropäischen Wald vertreten mit $45^{\circ} 0$, im ostasiatischen Wald vertreten mit $6.5 \%$ :

Nadelholzgattungen des ostamerikanischen Waldes (II) im eurn päischen Wald vertreten mit 5.\% \%, im ostasiatischen Wald rertreten mit $90 \%$;

La ubholzgattungen des westamerikanischen Waldes (III) im emropäischen Wald vertreten mit ... \% , im ostamerikanischen Wald vertreten mit $55^{0} 0$ :

europäischen La ublolzgattungen (I) im ostamerikanischen

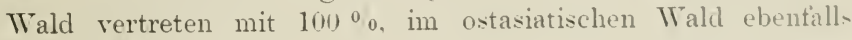
mit 100$)^{0} 0$ :

europäischen Iadelholzgattungen (I) im o-tamerilianischen Wald vertreten mit $100^{\circ} 0$, im ostasiatischen Wald gleichiallmit $100 \%$.

Alle Bamgattungen (Genera), welche in Europa den hontinim Wald zusammensetzen, sind auch in Amerika und in Asien zu fimlun: aber viele Baumgattungen. Welche in Amerika und A-icn zusamusn mit den europäischen Baumgattungen den Trald bilden. tihlen in Eimopra. Es liegt damit naturgesetzlich nalse. dab jene tremilen fiattlungm. welche in Amerika mit den etropäischen znsammenlehus. a $11 \mathrm{ch}$ in Europa mit den europäischen zusammenlelen liönres wher mit 
andern Worten, daB sie im europäischen Wald im korrespondierenden hlima und Boden werden anbaufähigs sein mïssen.

Es erhellt aus der Vergleichung der verwandtschaftlichen Beziehungen der Waldregionen aber noch ein weiteres Naturgesetz, das crundlegrend ist für den Waldbau. Nachdem die Kinder ein und derselben Eltern so auferordentlich naho stehende, äufere Merkmale besitzen, so nah, daß für viele Baumarten von einigen Forschern die Identität amerikanischer, europäischer und asiatischer Arten behauptet wird, ist es eine naturgesetzliche Folgerung, daß auch die inneren Eigenschaften, die biologischen und anatomischen, auf welche die ganze, wirtschaftliche Beliandlung und Benutzung sich gründen muf, zwischen den Angehörigen derselben Gattung enge verwandt sein müssen; es ist naturgesetzlich begründet, wenn man schließt, daß die Fichten in Amerika und Asien wirtschaftlich, d. h. waldbaulich ebenso behandelt werden kömnen wie die europäischen Fichten; das gleiche gilt für die Buchen, für die winterkahlen Eichen, für zweinadelige und fünfnadelige Föhren, fürr Eschen usw., mit einem Wort für alle emropäischen Gattungen, bzw. Föhrensektionen, da bei den Föhren die Sektionen sich wie Gattungen verhalten. Es ist ein a u Berhalb aller Naturgesetze liegendes Moment, ob die erzielten Produkte den mens $\bullet h l i c h e n$ Bedürfnissen entsprechen oder nicht; mmgekehrt ist es naturgesetzlich begründet, da $\beta$ alle Erfahrungen und Gesetze, gefunden an den Bamgattungen in Amerika und in Asien, sofort auch auf die emropäischen Vertreter dieser Gattungen übertragen werden können; was der amerikanische oder asiatische Waldbau an seinen Fichten oder Buchen oder winterkahlen Eichen autfindet, hat auch für den europäischen Wald Gültigkeit und muß von der Wissenschatt und Praxis angenommen werden, wenn anders die dabei erzielten Produkte den europäischen, menschlichen Bedürtnissen gerecht werden.

Die Internationalität des naturgesetzlichen W aldbaues berulht anf dieser engen Verwandtschaft der Holzarten der klimagleichen Waldgebiete, beruht aut der allgemeinen fïltigkeit aller Naturgesetze: die Internationalität der europäischen Baumgattungen verleiht dem europäischen Waldbau internationalen C'haraker. 


\section{Dritter Abschnitt.}

\section{Naturgesetzliche Grundlagen der einzelnen Baumarten, Ansprüche derselben an Klima und Boden, waldbaulich- physiologische Eigenschaften der Holzarten.}

\section{A. Klima.}

Die Anordnung der Bamarten imnerhalb der Waldregionen ist durchaus keine zufällige und willkürliche: sie unterliegt ganz bestimmten Gesetzen, als deren wichtigste jene des Klimas erscheinen. Im allgemeinen Klimacharakter der Waldregionen nördlich der Tropen treten, da sie rom Deere das Dasein erhalten und diesem anliegren. bei gleicher Elevation wie bei gleichem Breitegrad zwei verschiedene Trpen in die Erscheinung. welche für die Pflanzenwelt, ihre Verteilung. ihre Aufzucht und Erziehung grundlegende Differenzen und Folgerungen nach sich ziehen müssen: der eine Trpus ist das Küsten-oder insulare Klima mit zahlreichen Niederschlägen, hänfigem Winde und Abstumpfung aller Extreme in Temperatur und Luft. fenchtigkeit. Der zweite Trpus ist das Inlandklima mit seinen Extremen in Wärme und Feuclitigkeit. Im Inland ist der Winter, wie Ham in seiner Kilimatologie ansführt und dem hier teilweise gefolgt ist, ansgezeichnet durch die Gleichmäßigleit im Witterungscharakter: längere Andaner schöner Witterung, längren Regenperiode, andauernde Nebeldecke und trübe Tage olne Sonnen. schein und Niederschläge. Trocken ist die Witterung im ostasiati-chun Monsungebiet, feucht im europäischen, west- unl ostamerikanischen Waldgebiet. Störungen dureh wandernde Luftiruckminima in Eurogra ron SIT nach $\mathrm{NO}$, in Ostamerika ron $s$ mach $N$ sind licht angeschlossen. Der Frühling zeigt in allen Waldgehieton eines gemischten Typus. Die rasche Zunalme der Erwärmung d r Eril. oberfläche bedingt aufsteigende Luftströme: shöne Tage nim Rugren in bunter Abwechslung: Hitzperioden mit Regren und hilteriekischligren. Je kühler und fenchter das Klima, wio z. B. im Bereis ber le Piretums. 
desto rascher der Übergang vom Winter zum Sommer, desto kïrzer der Frühling. Der sommer ist die Zeit der größten Erwärmung; rasch emporsteigende Luftströme, Gewitter, Platzregen und Hagel sind rlie Folge. Stellt sich im Sommer bereits der stetige Charaliter des Herbstes ein oder verspätet sich der andauernde Frühlingsregen, so arten heide zu Katastrophen aus, ersterer wegen Vertrockmungsgefahr für die Pflanzen, letzterer wegen Überschwemmungsgefahr für Wald und Boden. Im Herbst ist die Wärmeverteilung überall gleichmäfiger, der Witterungscharakter ist der ruhigste während des ganzen Jahres: Platzregen und Gewitter werden seltener. Hoher Luftdruck breitet sich über das Inland und bringt klare Tage mit kühlen Nächten. Während die Erwärmung der Erde im Frühjahr bis zur höchsten Sommertemperatur mit jähem Ansteigen und jähem Abfallen der Temperatur allmählich erreicht wird, wird das Gefälle von der höchsten Sommerwärme zur tiefsten Wintertemperatur durch den Herbst hindurch mit schwachem Gegengefäll (Wärmerückschlägen) allmählich erreicht.

Gegenüber diesem wechselvollen Klima der gemäßigten Region ist der Charakter des Tropenklimas jener der größten Gleichmäßigkeit in Temperatur und Fenchtigkeit; den Einfluß des wechselvollen Klimas auf den Menschen, das weniger den Pflanzen als den Tieren und dem Menschen zusagt, gegenüber dem erschlaffenden, aber die Pflanzen begünstigenden Klima der Tropen hat Ratzel besonders zutreffend in seiner Anthropo-Geographie 1882 geschildert.

$\mathrm{D}$ as K üsten - oder insulare Klima mit seinen Abstumpfungen der Extreme in Wärme und Trockenheit findet ein Analogon im Gebirge, besonders wem dieses mit Wald bedeckt ist; die erhöhten Niederschläge, die konstante, hohe Luftfeuchtigkeit fördern den Pflanzenwuchs wie im insularen Klima; beiden fehlt vom tropischen Kklima nur die Wärme.

Wer nur das mittlere Europa oder nur Deutschland oder einen noch kleineren Teil der Erdobertäche kennen gelernt hat, dem kann man verzeihen, wenn er in der Literatur behauptet, es gebe lieine Vegetations-, keine Waldzonen. Durch .Jahrhunderte menschlicher Tätigkeit sind die einen Holzarten an Zahl so vermindert worden, dał ihre Heimatsgrenze scheimbar nicht auffindbar ist: andere Holzarten wurden so begïnstigt, daß ihre Heimat nunmehr fast ganz Europa zu umfassen scheint. Wollte man nach der gegenwärtigen Verteilung der Baumarten in Europa rersuchen, Zonen zu bilden, so wäre dies allerdings ein Ding der Unmöglichkeit. Wegen dieser Verschiebungen der Holzarten, wegen des möglichen Anbanes derselben außerhalb ihrer heimatlichen Zone haben Schriftsteller behauptet, die Zonenbildung habe keine wissenschaftliche und praktische Bedentung. Diese übersehen, da es a B Berhalb der Heimat zahlreiche Punlite gibt, welche mit der Heimat 
klimagleich sind, somit derselben Klimazone angehören, daß aluer die Holzarten mit ihren natürlichen Hilfsmitteln die zwischenliegrenden Gebiete nicht zu ïbersehreiten rermochten. Was dio pralitische Bedeutung anlangt, so sei nur kurz angedeutet, daß mit der Eintfermung einer Holzart von ihrem heimatlichen Klima hinweg eine Ifengr. von Schwierigkeiten in der Begründung, in der Erziehmug, in der Erreichung des gewünschten Holzproduktes entstehen, deren Beseitigrung Zeit und Aufwand an Mitteln verlangt; man wird nicht lengnen, daß die Kenntnis dieser Verhältnisse, welche über die ganze Rentabilität der Wallanlagen entscheiden, für den Forstmann wichtig ist. I)as Stndium der Gesetze der Zonenbildung gibt hierüber einen Anhalt vor der Waldbegründung. der ja wohl durch den praktischen Versuch, durch langwieriges und kostspieliges Probieren, 10, s0 oder 100 .Jahre später anch gewonnen und wieder verloren werden kann.

Klima und Oberflächenbildung erschweren in Mitteleuropa die Erkennung der Klima- und Waldzonen : ist doch die Wärme in sïddeutschland vielfach geringer als in Norddeutschland: die höhere Elevation durch die Alpen und ihre Abdachungen nach Norden hin erklären dieses; ist doch der Osten von Mitteleuropa in seiner durchschnittlichen Wärme bei ganz gleicher. geographischer Breite viel kälter als der Tresten; die Einwirkung des Golfstromes erklärt die Erscheinung, daf Klima und Waldzonen nicht den Breitegraden parallel, sondern von SW nach NO, ja stellenweise ron $S$ nach $N$ verlaufen. Dadurch erhalten die Zonen eine Drehung: Elevation und Exposition erzeugen Ausbuchtungen und Einbeugungen an den Grenzen der Zonen, und wie der Wechsel in der Temperatur geht auch jener in den Gewächsen nur allmählich vor sich. lauter Erscheinungen, welche die, in der erdrückenden Mehrheit ganz ungenügend in der Klimalehre gebildeten Baumzïchter. Forstwirte wie Gärtner, verwirren und ihre Erkenntnis der Bedeutung dieser Wissenschaft für praktische PHlanzenzucht trüben. Gründlicheres Studium der Meteorologie und Klimatologie, tieferes Eingehen in die Biologie der Gewächse würden lehren, da $\beta$ das ganze Entstehen und Gedeihen der Pflanze. insbesondere Anbau, Erziehung und Ernte, in erster Linie von der Wärme des Klimas de: Standortes abhängig sind; sieht man von den durch die menselaliche Gewinnsucht abgemagerten und erschöpften Büden ab, so kommt der Boden erst als der in zweiter Linie entscheidende Faktor in Betracht: bei Klimagleichheitentscheidet der Boden.

Es bedarf tür den raturwissenschaftlich gebildeten Leser wohl kaum des Hinweises, daß ron den Tropen im sïden his zn den Polaren im Norden oder von den Kastanienhainen am Fuße eines Borges lis. zu den alpinen Büschen in höheren Elevationen Gew üclıs-oder Waldzonen bestehen, die schon äußerlich in ihrem Gesmuthilde als 
Einheiten sich darstellen, da sie von Bäumen mit annähernd gleichen Ansprüchen an das Klima gebildet werden: dem der Einheit im Klima entspricht die Einheit in der Tegetation und umgekehrt: in seiner Einheit erscheint der subtropische Wald als ein immergrüner, dunkler Laubwald, der winterkahle Laubwald als ein in sommer hellgrüner Laubwald, der Fichten- und Tannenwald wiederum als dunkles, immergrünes Band, mit dem die Waldregetation abschliefit.

Änderungen in der ursprünglichen, äußeren Erscheinung und in der inneren Zusammensetzung haben erst die Eingriffe des MLenschen hervorgerufen durch Verdrängung von Baumarten, Änderungen des früheren, natürlichen Waldzustandes, Ersetzung des früheren Halbdunkels des Urwaldes durch das Tolldunkel oder Vollicht des Kulturwaldes, Einführung neuer Baumarten, Teränderung des Bodens, womit auch eine Änderung in der Zusammensetzung der Waldflora rerknüpft ist. Will man aber die Lebensgeschichte der Holzarten auf naturgesetzlicher Grundlage erforschen, will man auf Grund der Erkenntnis der Anforderungen der Holzarten an Klima und Boden einen Wald begrïnden, so muß man die ursprïnglichen, natürlichen Grenzen einer jeden Holzart aufsuchen, d. h. jene Standorte studieren, an welchen eine Holzart trotz tausendjähriger Anbauversuche der Natur durch rerwehte oder verschleppte Sämereien zu versagen beginnt, da die Bedingungen für ihr Gedeihen, in erster Linie die Temperatur, ungünstig geworden sind.

Das Studium der Ansprïche einer Holzart in ihrem natürlichen Verbreitungsgebiet führt zunächst zur Feststellung ihrer wahren, klimatischen Bedürfnisse, wie ausführlicher im Verlanfe dieses Abschnittes dargelegt werden soll; aus dem Klima des Heimatgebietes ergibt sich der naturgesetzlich richtige Schluf a uf die Klimazone der Holzart, welche nicht bloß die Heimat, sondern auch das künstliche Aubaugebiet mit heimatgleichem Klima umfaßt. Es scheint nach Äuferungen in der Literatur für manche ein Unding zu sein: Anbau einer Itolzart außerhalb ihrer Heimat in heimatlichem Klima.

Es ist eine in allen Mittelschulen bereits gelehrte Tatsache, daßdieselben Klima- und Vegetationszonen, denen man auf unserer Erde von irgendeinem Punkte bis zum nördlichen oder südlichen Polarkireis hin begegnet, sich wiederholen, wenn man einen hohen Berg in diesem Punkte besteigt. Wer in den Tropen bis zur alpinen Region emporsteigt, hat einen Weg durch die gleichen Klima- und Vegetationszonen zurückgelegt wie jener, der von den Tropen bis zu den Polarzonen gereist ist. So wichtig und richtig diese Vorstellung der Zonenbildung für die gemäßigten Ḱlimate ron Europa ist, für die Tropen trifft sie nicht zu; die südliche Halbkugel vollends besitzt andere Klima- und Tegetationszonen als die nürdliche. Yom 20. ${ }^{0}$ nördl. Br. sïdwärts zum Äquator und nach süden bis zum $200^{\circ}$ hin ist der Unterschied zwischen Winter- und Sommertemperatur ein geringer: die Zunahme der Yeeres- 
fläche und der Luftenchtigkeit, der hohe Stand der Sonne herlingrun eine Abstumpfung der Extreme zwischen Winter und Sommer. Deutlich beweist dies die nachfolgende, dem grolien, klassischen Werke wn J. Hann, "Die Meteorologie", entnommene Tabelle. Unter dem :-3." nördl. Br. beträgt der Unterschied zwischen lältestem und heifustem ILonat nur mehr $6^{0}$ und hebt sich ron da an sïdwärts durch die ganze sïdliche Halbkugel nicht ïber den Betrag ron $7^{\circ}$.

Mittlere Temperatur der Breitengrade.

\begin{tabular}{c|cc|c}
\hline & Januar & Juli & Differenz \\
Breiten & \multicolumn{2}{|c|}{ Mittel } & \\
& \multicolumn{2}{|c|}{} & \\
\hline Nördl. Br. & & 14 & 30 \\
60 & -16 & 18 & 25 \\
50 & -7 & 24 & 19 \\
40 & 5 & 27 & 12 \\
30 & 15 & 28 & 6 \\
20 & 22 & 27 & 1 \\
10 & 26 & 26 & 11 \\
Äquator & 26 & & \\
Südl. Br. & & 24 & 2 \\
10 & 26 & 21 & 4 \\
20 & 25 & 15 & 7 \\
30 & 22 & 9 & 7 \\
40 & 16 & 3 & 5 \\
50 & 5 &
\end{tabular}

Wo es heiß oder warm ist, ist es heiß oder warm das ganze Jahr hin. durch, wo es kühl oder kalt ist, ist es kühl oder kalt das ganze Jahr hindurch; es fehlt somit rom $200^{0} \mathrm{nördl}$. Br. süd wärts und über die ganze, südliche Hälfte der Erde hinweg der winterkahle La ubwald. Nur der im kühlen Klima auf der nördlichen Halbliugel sn reich rertretene Nadelwald ist angedentet durch Aranearia. Podocarpus und andere Gattungen, welche jedoch den Subtropen oder Tropen angehürrn. Wenn dem entgegengehalten wird, daß es auch auf der südlichen Halbkugrel Buchen gibt, so wird rergessen, daß diese immorgrün sind, den Gattungsnamen Nothofagus führen und den suhtropen angehuren.

Das Gesetz der Klima- und Vegetationszonentilhtung aut der Erite gibt am dentlichsten die umstehende Tatel I wieder.

Es fehlt in den Tropen und auf der ganzen, südlichen Hailfte wegen mangelnder Sommerwärme und mangelnder Winterkälte das ('as aı trum. Fagetum und Picetum der nördlichen Halbkugel. Bänme der sul roun'n- 
zone reichen bis zur Thermohore empor und bilden schließlich niedere Sträncher, das Alpinetum. Nachdem aber für alle folgenden Betrachtungen die Tropen und die sülliche Halbkugel ansgeschlossen sein sollen, hat der allbekamnte Satz vom Parallelismus der Zonen nach der horizontalen (nach Norden) und nach der vertikalen Richtung (nach oben hins seine Geltung. Ein Blick auf Tafel I lehrt aber auch, daß es für jede Holzart, welche im Süden in höheren Elevationen lebt, noch weitere Kilimagebiete im Norden zunächst bei geringeren Elevationen und schließlich in der Ebene nur ein paar hundert Meter über dem Neere geben muß, welche der gleichen Zone angehören. Manche Holzart ist dort im Norden ebenfalls wie im Süden bei höherer Elevation beheimatet, z. B. die Fichte in Mittel- und Nordeuropa; andere sind nur auf höhere Elevationen oder nur auf den höchsten Norden beschränlit; die emropäische Lärche hat ihre Heimat in den Alpen, aber Norwegen und das mittlere und nördliche Schweden gehören zur Klimazone der Lärche. Dieses sind somit die Länder, in welchen für die Lärche naturgesetzlich die günstigste Aussicht besteht, wemn man die Lärche in der Ebene unmittelbar über dem Meere anbanen will: die Lärche käme durch solchen Anbau weit hinweg von der Heimat - in heimatliches Klima!

Um Zahlen zu besitzen, mit welchen die Klimate der einzelnen Vegetationszonen beschrieben und verglichen werden können, hat Verfasser für die sogenamnten Hauptregetationsmonate Mai bis August inklusive die durchschnittliche, relative Fenchtigkeit, Regenmenge und Temperatur für mindestens fünf Jahre für zahlreiche Punkte jeglicher Elevation für alle drei Weltteile berechnet. Die Vegetation der Buchenregion des winterkahlen Laubwaldes spielt sich zum größten Teil innerhalb dieses Zeitraumes ab; in der kühlsten Waldregion der Fichten sind nur die Monate Juni und Juli Vegetationsmonate, ja der alpinen oder polaren Region der Krummhölzer stehen nur sechs Wochen für die vegetative Tätigkeit zur Verfügung, während in der Zone der immergrünen Laubhölzer die Vegetationszeit natürlich länger danert als vier Monate. Eigentlich sollte es nicht nötig sein, über derartige Anfangsgründe der Pflanzenphysiologie und Klimatologie zu schreiben: allein es steht irgendwo gedruckt, daß Verfasser mit seinen Klimazonen behauptet hätte, die Vegetationszeit an der oberen Waldgrenze danere vier Monate!

Wäre es möglich, die einer jeden Vegetationszone dargebotene Wärmesumme genau zu berechnen, so wäre damit allerdings ein guter Maßstab zur Beurteilung der Ansprüche der Holzart an die Wärme gegeben; allein die Feststellung seheitert an der Unvollkommenheit der Beobachtung, der Messung und Berechnme. Nach Kalenderfrühjahr und -sommer zu rechnen, paßt auf der nördlichen Hemisphäre nur für jene Region, in weleher der Kalender entstanden ist, das ist 
die Edelkastanienzone; die durehschnittlielle Jahrestemperatur allem ist ebenso ungenügend wie die höchste T'mpreratur des Sommers oder die tiefste des Winters für den Vergleich ron Landyelneten mit großen Unterschieden in der Luftenchtiglseit. Nimmt man für Mitteleuropa dis tiefsten Wintertemperaturen als Klimamafstab, so sind die "wirmeren" Ebenen die kältesten Punkte; im beriichtigten Winter 187!/81) limmte der Verfasser bei $400 \mathrm{~m}$ auf der bayerischen Hochebene eine tiefste. Temperatur von $-35^{\circ} \mathrm{C}$ beobachten, während gleichzeitig in den Alpen bei $800 \mathrm{~m}$ Erhebung nur $-4^{\circ} \mathrm{C}$ herrsehten. Das treset\% der Temperaturumkehr erklärt es vollständig, weshalb vicle, fremic Holzarten, z. B. Donglasien, Sequoien u. a., in der "wärmeren "Ebene während des Winters erfrieren, in den kühleren Höhenregionen aber von Winterfrösten umberührt bleiben.

Es wäre wohl der beste Maßstab zur Abgrenzung der Klima- und Vegetationszonen, zur Beurteilung der Bedürnnisse einer Holzart an Wärme, wenn es möglich wäre, für alle Holzarten die Vegetationstherme ermitteln zu können. Es fehlt an phänologischen Beobachtungen zur genauen Feststellung des Vegetationsbeginnes und -Abschlusses und zugleich an meteorologischen Beobachtungen in den Heimatgebieten der Holzarten. Unter Vegetationstherme versteht Verfasser die durchschnittliche Temperaturkonstante, welche eine,jede Holzartzu ihrem Gedeihen bedarf, gleichgültig, wie lange der Zeitraum ist, der über das Zeitminimm von $1 \frac{1}{2}$ II onaten hinaus ihr dabei zur Verfügung gestellt wird. E: gelang dem Verfasser, für die Alpenlärche eine Vegetationstherme von $14^{\circ} \mathrm{C}$ zu finden, indem die durchschnittliche Temperatur vom Vegetationsbeginn bis zum Vegetationsabschluf an verschiedenen Standorten des: natürlichen und künstlichen Anbangebietes berechnet wurde. In der höchsten Region der Alpen steht der Lärche nur das Zeitminimum von $1^{1 / 2}$ Monaten - Mitte Juni bis anfangs Angust - zur Vertïgung: die mittlere Temperatur dieses Zeitraumes beträgt dort in der obersten Lärchenregion $14^{\circ}$; in das kühlere Fagetum der bayerischen Hochebene verpflanzt, beginnt die Vegetation der Lärche Mitte April und endet Iitte August mit dem Abschlufo des Jahresringes; die ihr dort grebotene Durchschnittswärme während dieser Zeit beträgt 14". In wärmeren Fagetum der Rheinebene umfaßt die Vegetationszeit der Lärche sechs Monate, Mitte März ergrünt sie, gegen Mitte Septemher schlielit sie den Jahresring ab: Nadelverfärbung und Narlelabfall liegen natürlich später; allein diese Torgänge sind von Wärme insofern mahhängrg. als sie anch in der Nähe von $0^{0}$ sich abspielm liönnen. Die Inurchschnittstemperatur während dieser "Zeit ist wiederum 14". In Caslanetum von Südfrankreich beginnt anfangs März die Ergrïnung. Endle Novinher ist der Jahresring geschlossen; auch während dieser " Teit ist dir. I unchschnittstemperatur $14^{\circ}$. Daßs mit dem wärmeren Fagretum infolde $A t$ 
nahme des Höhenwuches der Lärche, frühzeitiger Rottäule, die forstliche Branchbarkeit erliwcht. sei hier nur nebenbei bemerkt. I ie Anbaufähigkeit wird wegen Wärmeüberschusses zur Unmöglichkeit werden mïsen in jenemGebiete, dessen durchschnittliche Jahrestemperatur über der Vegetationstherme ron $14^{0}$ liegt, ebenso wie in einem Gebiete, dessen Temperatur während der Minimalzeit von $1^{1 / 2}$ Monaten den Betrag ron $14^{0} \mathrm{C}$ nicht erreicht.

Wie kläglich z. B. im kïhlsten Lauretum die europäische Lärche sich verhält, beweisen die Anbauversuche mit dieser Holzart an der Grenze der Subtropen. Da die Lärche bis zur Waldesgrenze emporsteigt, so folgt daraus die Tatsache, daß es Bäume mit einer Vegetationstherme von weniger als $14^{\circ} \mathrm{C}$ überhaupt nicht gibt und die Waldgrenzeda liegen mu, wo während $l^{1} 2$ Monaten nicht mehr 14" C Durchichnittstemperatur geboten sind. Die Beobachtungen reichen noch nicht hin, um als Tatsache festzustellen. daß die Tegetationstherme für die europäische Fichte ebenfalls $14^{\circ}$, für die europäische Buche $16^{\circ}$, für die stieleiche $17^{\circ}$ beträgt. Es bedarf wohl kam der Erwähnung, daß die Kenntnis der Vegetationstherme die Festlegung der Vegetationszonen einerseits und die Auffindung der Anbangebiete für jede Holzart anderseits außerordentlich erleichtern und sichem würde. Das Optimum ilıres Gedeihens brauchte dam nicht mehr in. den meisten Ptlanzenzüchtern ungeläufigen und langwierig zu ermittelnden Wärmegraden, sondern in einer Zeitangabe fixiert zu werden. So ist das Optimum der Lärche und Fichte gegeben, wenn die Tegetationstherme von $14^{0}$ als Durchschnittstemperatur aus $3^{1 / 2}$ Monaten sich ergibt: $14^{\prime \prime}$ während der beiden, wärmsten Monate kennzeichnet ein Klima kühler, als für das Optimum nötig ist: $14^{\circ}$ aus fünf Monaten ist ein Kilima wärmer, als für das beste Gedeihen der Fichte und Lärche zuträglich ist: bei der Tegetationstherme von $14^{\circ}$ aus sieben Monaten hört die forstliche Branchbarkeit ron beiden Holzarten auf.

Mangels phänologischer und klimatologischer Beobachtungen im Walde in den rerschiedensten, natürlichen und kïnstlichen Verbreitung:gebieten für jede Holzart ist die Vegetationstherme einstweilen meln theoretisch als praktisch verwertbar.

Auf die einschneidende Bedeutung der Feuchtigleit der Luft für das Verhalten der Holzarten, für die Wahl der Anbaumethode und andere waldbauliche Maßnahmen hat Verfasser zuerst $18 \% 0$ hingewiesen: es ist nötig. hierüher während der entscheidenden Jahreszeit Auskmft zu erhalten.

Alle Angaben ron Temperaturen (in Celwins), relativer Fenchtigkeit (in Prozenten), Regenmenge (in Millimetern), welche ror der fe ttge druck te $n$ Zahl der durchschnittlichen. Jahrestemperatur stehen, beziehen sich auf den Zeitram Mai bis Angust inlilusive; die Monats- 
namen wie, Mai, september, bedeuten lotzter hzw. erster Frost: div lutzte Zahl gibt die tiefste bis jetzt beobachtete 'T'(-mpleratmr.

Die Höhenangaben für die Znnen in Mntern -inrl nm Inuchschnittswerte, wie sie gegeben werden müsien, mm nicht ilureh die Zahlenfüllo mehr zu verbergen als zu enthüllen: schon der. Unstand, daßs die Vegetation:zonen ebenso wie die Klimate allmählich ineinander ïhergehen, daß an solchen Grenzpunten lokale Eintlüsse, wie Exposition, Boden, waldbauliche Behandlung, eine Verschiebung der Holzarten nach Süden oder Norden, nach unten oder oben bewirken kïmnen, macht grofe Zahlen, d. h. Durchschnittsrechnungen nötig.

Die Einreihung der Bammarten in Vegetationszonen macht jerrliche Angaben über Breitengrad und Elevation des heimatlichen Standortes der Holzart entbehrlich; aus solchen Angaben kann olnedies nitmand das Klima beurteilen. Jeder Laie kann verstehen, was es bedeutet, wenn von einer Holzart durch ihre Eimreihung in ihre Vegretationszone gesagt ist, daf sie in einem Klima wächst, in dem immergrüne Eichen oder Edelkastanie oder Buche oder Fichte ihre natiurliche Heimat finden.

In die Holzartenparallele wurden nur forstlich beachtenswert erscheinende Baumarten von mehr als s m Höhe aufgenommen.

\section{A. Tropische Waldzone, das Palmetum,}

bleibt aufer Betracht, da in Europa keine Parallele besteht.

\section{B. Subtropische Waldzone der immergrünen Eichen und Lorbeerbäume, das Lauretum.}

\section{Europa.}

Suldküste, insulare Westküste ron Mitteleuropa, $20-24^{\circ}, 50-60^{\circ} 0,50-100 \mathrm{~mm}$, 16-19 ${ }^{\circ}$, Dezember, Februar, $-5^{0}$.

Quercus suber usw., Q. Ilex, Laurus nobilis, Arbutus Lnello, Buxus, Ceratonia Oiea, Cupressus fastigiata, Pinus canariensis, Pinea, maritima, aleppensis, Chamaerops-Palme.

Atlantische Region:

Florida, Küstengebiete der Stidstaaten, $25-28^{\circ}, 75^{\circ} 0$, $600 \mathrm{~mm}, \mathbf{1 5 - 2} \mathbf{1}^{\circ}$, Januar, Februar, $-7^{\circ}$.

Quercus virens, Persea, Sabalpalmen, Pinus cubensis, palustris, Taxodium distichum, Juniperus virginiana, Chamaecyp. sphaeroidea, Magnolia grandiflora

\section{Nordamerika.}

Zentrale Region:

Tiefste Lagen von Arizona, Neumexiko, Nordmexiko, $24^{\circ}, 40^{\circ} 0,13-2.0 \mathrm{~mm}$, $17^{\circ},-5$ bis $10^{\circ}$.

Q. grisea. Arbutus chalapensis, Prosopis juliflora, Cereus giganteus, Cupressus arizonica Agave, Yuccal.
Pazifische Region:

Kalifornien bis $500 \mathrm{~m} \mathrm{Er}$ hebung, $16^{\circ}, 7500,30 \mathrm{~mm}$. $14^{0},-20$.

Q. agrifolia, ('astanopsis Cubellularia calif . Arbutus Menziesii, W: incrtonia (Palme), Cupressus macrocarpa. si yu sempervireus, P'inos insignis, muricata, ntetallata, Subiniata, I'ne dotstunit marelirpa, Torrevit kallitors the 


\begin{tabular}{|c|c|c|}
\hline Himalaya: & $\begin{array}{l}\text { A-ien. } \\
\text { Japan: }\end{array}$ & China: \\
\hline $\begin{array}{l}\text { zwischen } 1300 \text { und } 2200 \mathrm{~m} \\
\text { Erhebung. Klima der } \\
\text { kuhleren Lage: 15-19", } \\
72-93^{\circ 0} \text {, } 550-1200 \mathrm{~mm} \text {, } \\
11-13^{\circ},-4^{\circ} \text {. } \\
\text { Quercus incana, fenestrata } \\
\text { usw., Cupressus torulosa, } \\
\text { Buxus, Cedrus Deodar, } \\
\text { Pinus excelsa, Rhododen- } \\
\text { dron, Immergr. Magnolia. }\end{array}$ & 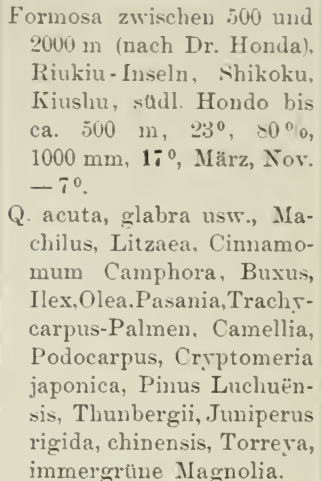 & $\begin{array}{l}\text { Sudchina bis zum Kuen- } \\
\text { lun. Erhebung? Klima? } \\
\text { Q glauca, semecarpifolia, } \\
\text { usw. Machilus, Litzaea, } \\
\text { Cinnamonum Camphora, } \\
\text { Buxus, Ilex, Olea, Pasa- } \\
\text { nia. Zsergpalmen, Ca- } \\
\text { mellia,I'odorarpus, Cryp- } \\
\text { tomeria japonica, Pinus } \\
\text { sinensis, Cunninghamia } \\
\text { sinensis, Keteleeria, } \\
\text { Glyptostrobus hetero- } \\
\text { phrlla, Juniperus rigida, } \\
\text { chinensis, recurva. Biota } \\
\text { orientalis, immergrune } \\
\text { Magnolienart. }\end{array}$ \\
\hline
\end{tabular}

Landwirtschaftliche Kulturpflanzen der Zone: Citrus-Arten. Baumwolle, Zuckerrohr, Reis.

\section{Ca. Gemäßigt warme Zone des winterkahlen Laubwaldes, wärmere Hälfte, das Castanetum. \\ Europa.}

Südliches:

Mittleres:

Italien von 500-1000 m, von 0-400 m Süulengland, Sudirland, Nordwestfrankim Norden. Griechenland, Sudfrauk- reich $155^{\circ}, 80^{\circ} 0,200 \mathrm{~mm}, 10^{\circ}$, April bis reich, Spanien, Portugal bis $600 \mathrm{~m}$, November, $-16^{\circ}$.

Sudtirol bis $300 \mathrm{~m}, 20-23^{\circ}, 50-60^{\circ} 0$, Castanea resca, kultiv.. Quercus pedunc., $100-200 \mathrm{~mm}$. 13-17 ${ }^{\circ}$, März bis No- sessilif., Carpinus usw rember, $-11^{\circ}$.

Castanea resca, Quercus pedunc., sessil., pubescens, Cerris, hungarica, Ostrya, Celtis, Platanus, Aesculus, Fraxinus, ['lmus, Carpinus. Cupressus fastigiata, Pinus maritima, aleppensis, Pinea, austriaca, corsic., silvestris u. a.

$$
\text { Nordafrika: }
$$

Atlas von $1000-2000 \mathrm{~m}$.

Cedrus atlantica, Juglans regia, Quercus pubescens.

\section{Ii aukasus:}

von $200-1000 \mathrm{~m}$.

Mehrzahl der europäischen Holzarten, Pterocarta, Zelkowa.

\section{Nordatuerika.}

Atlantische Region:

Sudliche Unionsstaaten bis $1000 \mathrm{~m}$, mittlere lis $400 \mathrm{~m}$, nördl. bis $200 \mathrm{~m}$ Erhebung. $2: 3-24^{\prime \prime}, 70^{\circ} 0,400 \mathrm{~mm}$, 1.2-15. ${ }^{\circ}$, April bis Oktober; $-14^{\circ}$ bis $-20^{\prime \prime}$.
Zentrale Region:

Neumexiko und Arizona von s $40-1200 \mathrm{~m}$, mittlere Staaten bis $800 \mathrm{~m}$. Kilima? Quercus?

Platanus Wightii, Juglans. Fraxinus, Populus, Pinus
Pazifische Region:

Kalifornien v. 500-1500 m, Oregon, Washington, Kolumbia bis $300 \mathrm{~m}, 15^{\circ}$, 8.50 , $90 \mathrm{~mm}, 10^{\circ}$, Febr., Norbr.. $-60^{\circ}$.

QuereusGarryana, Kellog- 
Castanea dentata, Quercus lyrata, imbricaria, alba, macrocarpa, falcata usw.. Carra alba,porcina,amara, sulcata, olivaeformis, Nrssa silvatica, Fraxinus quadrangulata, Ulmusalata, Robinia Pseud., (ileditschia, Acer, Carpinus, Celtis, Aesculus, Ostrya, Juglans, Liriodendron, Grmnocladus, Sassafras. Prumus serotina, Catalpa, winterkahle Magnolia, Platanus occid.. Liquidambar. Pinus glabra, Taeda, palustris, clausa, inops, pungens, mitis, rigida, Tsuga carol.. Taxodium dist., Junip. virgin., Thuja occident., Cham. sphaeroidea.

\section{Himalaya:}

Ton $2200 \mathrm{~m}$ bis? Klima?

Cedrus Deodar, winterkahle Magnolia, Prunus, Pinus excelsa

\section{Kleinasien:}

Libanon ron $1000-2600 \mathrm{~m}$. Cedrus Libani, Juglans regia. chihuahuana, arizonica, Mayriana, ponderosit, scopulorum. gii, densiflora. Platunus racenosa. Arbutus Menziensii, Aesculus, Cireis. Acer, Lilocerlrus decurr. Pinus ponderosil, Sahiniana, Jeffreri. ('oul. teri, attenuata, iunignis, Chamaecrparis nutk., Lawsoniana. Pseulo. tsuga Mouglasii, nacrocarpa.

\section{A-ien.}

J a pan:

Südjapan von 500-1500 m, Erhebungen? Kilima? mittl. Hondo bis $800 \mathrm{~m}$, Castaneacreuata, Zelkowa Nordhondo bis $200 \mathrm{~m}: \mathrm{ST}$ Ecke ron Eso, $20^{\circ}, \rightarrow 0^{\circ} 0$, $500 \mathrm{~mm}, 1.2-15^{\prime \prime},-20^{\circ}$.

Castanea crenata. Zelkowa Keaki. Magnolia hypoleuca, Kobushi, Juglans, Quercus serrata, variabilis. glandulifera usw.,Paulownia, Aesculus. Rhus, Horenia, Albizzia, Phellodendron, Celtis, Gleditschia, Cercidiphrllum, Fraxinus, Carpinus, Sophora. Acanthopanax. Acer, Ulmus, Prunus. Pinus Thunhergii, densiflora, Cryptomeria japonica. Chamaecrparis. Thuja, Thujopsis, Nciadopitys, Torrera, thies firma, Tsuga Sieboldii. Juniperus rigida, chinensis, Cephalo. taxus.
Keaki, Quercus serrata, Paulownia, Phellodendron, Cataipa, Liriodendron, Rhus, Gleditschia, Grmuocladus. Hovenia, Aesculus. Sterculia, Albizzia, Juglans. Celtis Fraxinus. Carpinus.tcer. Elmus, Ailanthus, Pru. nus, Cercidiphrllum, siophora, Liyuidambar.Cunninghamia, Libocedrus macrolepis, Biota orin.1talis, Juniperus chinmsis. rigida. recurva. $L_{1}$ pressus funebris. Cephalotaxus. Torrềa, Püunsinensis. Henrit. T-U an

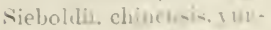
nanensis, ['sovintolux Formoei. IryphormBungeana, glandulifera.

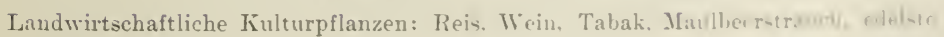
Obstiorten. 


\section{C b. Gemäßigt warme Zone des winterkahlen Laubwaldes, kühlere Hälfte, das Fagetum.}

\section{Europa.}

Sudliches:
Nördliches:

Apennin $900-1400 \mathrm{~m}$, Bal- stlulich bis $900 \mathrm{~m}$, nördlich stldlichste Gebiete von kan $800-1200 \mathrm{~m}$, Prre- bis $600 \mathrm{~m}$. näen $800-1300 \mathrm{~m}$.
Schottland, Dänemark, Schweden, hurland.Livland und Estland.

16-150. $70^{\circ} \%, 250 \mathrm{~mm}$, ;-12", Mai bis September, $-25^{\circ}$ bis $-30^{\circ}$.

Facrus silvatica, Quercus pelunculata, sessiliflora, pubescens, hungarica, Acer, Ulmus, Betula, Carpiuus, Prunus, Alnus, Populus, Fraxinus, Salix, Tilia, Pinus Peuke, silvestris, austriaca, leukodermis, Picea excelsa, Abies pectinata, Pinsapo, cephalonica, Larix europaea.

$$
\text { Ural: }
$$

$1000-1400 \mathrm{~m}$.

Pinus sibirica, Abies sibirica, Picea obovata, Larix sibirica (erstes Auftreten).

\section{Nordamerika.}

Atlantische Region:

Sudliche Unionsstaaten von $1000-1800 \mathrm{~m}$, mittl. von 400-900 m, nördl. u. SüdCanada von $200-800 \mathrm{~m}$, $19^{\circ}, 65^{\circ}$ 0, $200 \mathrm{~mm}$, 7-1: ${ }^{0}$, Nai bis September, $-25^{\circ}$ bis - $35^{\circ}$.

Fagus fermginea, Quercus alba, macrocarpa,coccinea, palustris, tinctoria, Carya alba, porcina, amara, tomentosa, Acer rubrum, saccharum, Fraxinus, Salix, Betula, Juglans, Liriodendron, Prunus, Clmus, Poprulus, Tilia, Sorbus, Pinus Strobus, resinosa, rigidi, Banksiana, Thuja occilentalis, Cham. sphaeroidea, Abies balsamea, Picea alba, nigra, Larix americana.

\section{Himal a ya:}

östl. 2500-:900 m, westl. $2000-2500 \mathrm{~m}$. Kilina? Tiefste Temperatur nicht unter $-155^{\circ}$.

\section{Zentrale Region:}

Arizona, Neu-Mexiko von $1200-2000 \mathrm{~m}$, Felsengebirge bis $1000 \mathrm{~m}$. Klima?

Fraxinus, Populus, Prosopis julif., Salix, Pinus chihua., ponderosa, scopulorum, Nurrayana, arizonica, Mayriana, strobiformis, Abies arizonica, concolor, Psendotsuga glauca, Picea Engelmanni, pungens.

\section{A-ien.}

$J$ a pan:

Mittleres Japan von 800 bis $1500 \mathrm{~m}$, nördliches Japan von $400-1000 \mathrm{~m}$, Eso 200 bis $500 \mathrm{~m}, 17^{\circ}, 80^{\circ} 0$,
Kaukasus:

Abies Nordorientalis.

Pazifische Region:

Sierra Nevada von 1500 bis $2000 \mathrm{~m}$, Kaskadengebirge, Küstengebirge, $15^{\circ}, 80^{\circ} 0,140 \mathrm{~mm}$, $;$ bis $10^{\circ}$, März bis November, $-16^{\circ}$.

Quercus Garryana, Kelloggii, Acer macroph., Fraximus oregona, Populus tricho., Alnus, salix, Pseudotsuga Douglasii, Abies grandis, bracteata, concolor, Thuja gigantea, Tsuga heterophylla, Chamaecyparis Lawson., nutkaënsis, Libocedrus decurrens, seyuoia gigantea, Pinus monticola, Lambertiana, ponderosa, Jeffrevi, contorta, Picen sitkaënsis, Larix occidentalis.

\section{China:}

Fagussinensis, Engleriana, Quercus dentata,mongol. u. andere.Tilia,Acer,Prunus, Fraxinus, I'lmus, 
Acer, Pyrus, Tsuga dumosa, Abies Pindrau, Webbiana, Pinus excelsa, Khasiana, Gerardiana, Picea Morinda, Larix Griffithii.
$400 \mathrm{~mm}$, i-!). Mai, 1)ktober, $-25^{\circ}$.

Fagus japonica, Sicboldii, Quercus dentata crispula, Fraxiuus mandshur., longicuspis, Phellodendron. Magnolia hypolenca, Cladr. amur., Acer, Cercidiphyllum, Acanthopanax, Ostrya, Betula, Salix, Carpinus, Prunus, Populus, Tilia, I'lmus, Chamaecyparis, Thuja, Cryptomeria, Thujopsis, Sciadopitys, Pinus-Arten, Pseudotsuga japonica, Tsuga diversifl., Taxus, Abies homolepis, sachalinensis, Picea polita, bicolor, ajanensis, Larix leptolepis.
Betula, Carpinus, Populus, salix, Biotu orientalis, Taxus haccutu ("), Pinus sinensis, Armandi, Bungeana, H'nryi,mantshurica, Pinus koreensis. Abies, Tsuga, I'seuilo. larix Fortunei, Larix. Picea.

Landwirtschaftlich: Hopfen, Weizen, Gerste, Winterroggen; in den wärmsten Lagen noch Wein, Tabak, Mais, feineres Kern- und Steinobst.

\section{Gemäßigt kühle Region der Fichten, Tannen und Lärchen, das Picetum oder das Abietum oder das Laricetum.}

\section{Europa.}

Südlich es:

von über $1300-2300 \mathrm{~m}$.
Mittleres:

Nördliches:

er $900-2100 \mathrm{~m}$ im Süden uber $500 \mathrm{~m}$

$600-1000 \mathrm{~m}$ im Norden.

Sorbus, Alnus, Betula, Salix, Populus, Abies pectinata, Pinsapo, cephalonica, Picea excelsa, Omorica, Pinus silvestris, (im Norden P. lapponica) uncinnata, Cembra Peuke, Larix europaea.

$$
\text { Ural: }
$$

Ka ukasus:

Abies sibirica, Pinus sibirica, Picea obo- Abies Nordmanniana, Picea orientalis. vata, Larix sibirica.

\section{Nordamerika.}

Atlantische Region: mittlere Lnionsstaaten von $1800 \mathrm{~m}$ aufwärts, nördl. ron $1000 \mathrm{~m}$ an, Kanada $500 \mathrm{~m}$ nordwärts bis zum Meeresniveau, $15^{\circ}$, $75-80^{\circ} 0, \quad 400-600 \mathrm{~mm}$, (i $^{0}$, Mai, Septbr., $-15^{\circ}$ im Súden, $-40^{\circ} \mathrm{im}$ Norden. May r, Walubau.
Zentrale Region:

Felsengebirge uber $1000 \mathrm{~m}$ im suden, uber 500 im Norlen. Klima?

Sorbus, Betula, Picea pungens, Engelmamni, Pinus Murravana, aristata, scopulorum, Pseudotsuga

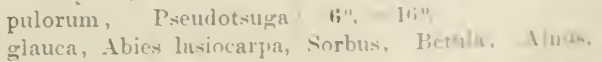

Pazifisclie $R e g$ ion

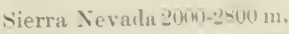
Kaskadengrobirge $1,(k)$ bis $2700 \mathrm{~mm}$, Aluska un te. dem $5.5 .00-501$ m. I niter dem 6u." 0 -lin m Fr-

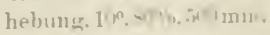
"i", 1ti"
Sorbus, Bettilis. I/nom. 
Sorbus, Betula. Populus, Salix, Abies balsamea, Fraseri, Tsuga canadensis, Picea alba, nigra, rubra, Thuja occidentalis, Pinus strobus, resinosa, Banksiana, Larix americana

\section{Himalay a:}

östl. 2900-4300 m, westl. $2500-4000 \mathrm{~m}$. Klima?

Sorbus, Betula, Alnus, Salix,

Abies Webbiana, Pindrau, Tsuga dumosa, Picea Morinda, Larix Griffithii.

Kleinasien:

Abies cilicica. concolor, Juniperus pachyph., Larix Lyallii, occidentalis.

\section{Asien.}

J a p an :

sudl. von $1500-2700 \mathrm{~m}$, Sorbus, Alnus. Betula, nördl. von $1000-1500 \mathrm{~m}$, Eso ron $500-1000 \mathrm{~m}$, Kurileninsel Iturupp ther $100 \mathrm{~m}$. Lrupp uber $0 \mathrm{~m}$, $12-15^{\circ} .80-90 \%, 300$ bis $1000 \mathrm{~mm}, 4-\mathbf{0}^{\circ},-30^{\circ}$.

Sorbus, Betula, Aluus, Salix, Abies Veitchii, Mariesii, sachalinensis, Pinus koreensis. parviflora, densiflora, Picea bicolor, hondoënsis, ajanensis, Glehnii, Larix leptolepis, kurilensis.
Abies grandis, concolor, nobilis, amabilis, magnifica, Pinus contortix, monticola, Balfouriana, flexilis, albicaulis, ponderosa, Picea sitkaënsis, Breweriana, Pseudotsuga Iouglasii, Tsuga heterophylla, Pattoniana, Larix occidentalis. Schrenkiana, Wilsoni, Neoreitchii, Mastersii, brachityla, likiangensis, bicolor, ajanensis. Abies Delavayi, Fargesii, Veitchii, Pinus Bungeana, Henryi, sinensis, Larix Principis Rupprechtii $॥$. dahurica, sibirica (?, thibetica, Griffithii, chinensis.
Salix, Populus, Picea

Landwirtschaftlich: Sommerroggen, gepflegte Alpenwiesen.

\section{E. Kühle Region der Krummhölzer und Halbbäume, Waldgrenzen, das Alpinetum, das Polaretum.}

\section{Europa.}

Südliches:

IIttleres:

Apennin bei $2.500 \mathrm{~m}$, Balkan Nordalpen $2000 \mathrm{~m}$. $2000 \mathrm{~m}$.
Nördliches:

uber $600 \mathrm{~m}$.

$8-10^{\circ}, 80^{\%} 0,400 \mathrm{~mm}, \mathbf{1}-\mathbf{3}^{0}, \mathrm{Juni}$, August, $-35^{\circ}$ bis $-45^{\circ}$, Hochalpen - $25^{\circ}$.

Im Norden Strauchbirken, Erlen, Weiden, Picea excelsa, Pinus lapponica, im mittleren Europa Pinus pumilis, Picea excelsa, Pinus Cembra, Larix europaea.

\section{Nordamerika.}

Atlantische Region: Zentrale Region:

nördl. Kanada $7-9^{\circ}, 80^{\circ}$, Felsengebirge bei $3500 \mathrm{~m}$, $0^{0},-45^{\circ}$.

Betula, Alnus, Salix, Juniperus, Abies hurlsonica, Pinus Bankiana, Larix americana. tiefste Temperatur ?

Pinus flexilis, Pinus albicaulis, Pinus aristata, Picea pungens u. Engelmanni, Lurix Lỵallii.
Pazifische Region: , Sierra Nevada $3000 \mathrm{~m}$, Alaska 500-1200 m (sudhänge d. Eliasalpen, $8^{\circ}$, $90 \%, 150 \mathrm{~mm},-\underline{2}^{0},-20 \%$. Salix, Populus, Alnus, Pinus Balfouriana, Picea Albertiana, Larix Lyallii, Tsuga Pattoniana. 
Himalaya:

Asion.

$4000 \mathrm{~m}$, tiefste Temperatur mitt'. bei $2500 \mathrm{~m}$, nörill - 4i:". $-10^{\circ}$.

Sorbus, Abies Pindran, Larix Griffithii.

uber 100 m, Kurilen uber strauchförmige Remte der $310 \mathrm{~m}$, vou [rupl norilostwärts, von der Jeeres-

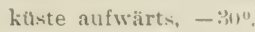

Sorbus, Alnus, Salix, Populus, Betula, Pinus pumila, Picea Hondoënsis, Picea rorigen Zoue, inshusnu. dere Birken (Taign). I'icea obovata, Larix sibirica, L. dahurica. Cajauderi.

ajanensis, Larix kurilensis, Larix leptolepis.

Landwirtschaftlich: ungepflegte Alpenweiden.

Das Auffinden der Vegetationszone kann mit Hilte ent. sprechender, klimatischer Beobachtungen oder mit Hilte der sogenannten klimatypischen Ba umgattung en geschehen. In Ländern. in denen die gleichen, typischen Genera wis in anderen Ländern nicht vorhanden sind - z. B. fehlen Buchen (Fagus) in Westamerika - treten andere Baumgattungen mit gleichem Klima oder mit der Fagus zusammenwachsende Gattungen an die Stelle: das: dürfte aber kein genügender Grund sein, für das betreffends Walelgebiet eine andere Benennung der Zone zu wählen, nachdem die klima. typische Fagus in den übrigen großen Waldgebieten vertreten ist.

Für Landgebiete, in deren Waldungen die Holzarten noch in der ursprünglichen Verteilung angeordnet sind, ist das Auffinden einer Zone sehr einfach, trotzdem eine Zone stets allmählich wie das Kima in eine andere übergeht. Wo z. B. die Edelkastanie (Castanea) ror. wiegt, fehlt die Buche (Castanetum), wo die Edelkastanie eine seltenere Erscheinung wird oder erst durch kümstlichen Anbau hingebracht ist. Buchen aber reichlicher werden, dort liegt die Grenze zwischen Edelkastanienzone (Castanetum) und Buchenzone (Fagetum): das Tor. herrschen der Buche, ihre beste Entwicklung kemzeichnet die mittlere Zone ihrer Verbreitung (das Optimum); wo bereits Fichten oder Tannen in reichlichem Maße sich beimengen, liegt das kühlere Fagetum und die Grenze zwischen dem Fagetum und der Fichtenzone (Picetum oder Abietum); wo Fichte vorherrscht, eine vollkommene Entwicklung zeigt. Buche dagegen in reinen Beständen seltener wird, da liegt das Optimum der Fichte usw.; nach diesem Beispiel sind die übrigen '/onen zu beurteilen und zu konstruieren.

Schwieriger liegt der Fall in den alten Kulturländern, in dewa'n die ursprüngliche Tegetationsgrenze dureh die menschliche Tritigherit verwischt ist. In solchen Fällen mub das gegenwärtige (iedeihen dir. Holzarten - für alle gute Büden voransgesetzt —. das Torhandensein ron alten Bämen und Waldungen, die ans dem Fenclbetroh herror. 
gegangen sind. müssen etwa vorhandene, klimatische Beobachtumgen, Elevation, Exposition, Bodenbefeuchtung usw. in Betracht gezogen werden.

Die vorherige, richtige Konstrulition der Vegetationszonen der Erde vorausgesetzt, kann aus der auf Tafel I gegebenen, graphisehen Darstellung sofort für $\mathrm{jeden} s \mathrm{tand}$ ort der nördlichen Halbkugel ermittelt werden, welcher Klima- oder Waldzone er angehört, nachdem zuvor die Erhebung des Ortes über dem Ifeere und dessen geographische Breite und dessen allg e me ine La gerung - Europa, Ostamerika, Westamerika, Ostasien festgestellt wurde.

Daß eine derartige Terteilung des Klimas und der dem Klima entsprechenden Holzart für die Aufforstungen von Ödländereien, von einschneidender Bedeutung sein muß, bedarf nicht vieler Worte.

Nachdem Verfasser in der Klima- und Zonenbildung der bewaldeten Gebiete der Erde und in der Einreihung einer jeden Holzart in die ihr zukommende Zone die wichtigsten Grundlagen für Anbau und Erziehung aller Holzarten erblickt, wurde die Tafel der horizontalen und vertikalen Wald- uud Klimazonen gefertigt; sie macht keinen Anspruch auf absolute Genauigkeit in allen ihren Teilen; hierzu fehlen noch vielfach meteorologische Beobachtungen in den verschiedenen Zonen und im höheren Luftraum; es mangelt auch an genauerem, pflanzengeographischem Wissen.

Anch in dieser Wissenschaft spiegelt sich ein wichtiges Stïck der Biologie der Holzgewächse $\mathrm{ab}$, nämlich der Anspruch der Holzarten an Klima und Boden und der Wettkampf unter den Holzarten um Wärme, Licht, Wasser und Boden; das Endergebnis dieses Wettkampfes ist die ursprüngliche; geographische Verteilung der Holzarten, die Pflanzengeographie.

Daß dieses Wissensgebiet in den höheren und höchsten Schulen den Pflanzenzüchtem gar nicht orler nur ganz nebenbei und nebensächlich geboten wird, wurde bereits früher betont.

Teils ans den Darstellungen der Tafel, teils aus anderweitigen Beobachtungen des Verfassers und anderer lassen sich folgende, allgemeine Schlüsse gewinnen.

Bezüglieh des Klimas:

a) Die Temperaturen der vier I onate nehmen vom Äquator zum Pol auf der nördlichen Halbkugel langsamer ab, als dies nach der theoretischen Abnahme pro Breitengrad der Fall sein sollte; die einzelnen Horizontalzonen streichen weiter nach Norden, die vertikalen Zonen steigen höher hinan, wie die Verbreiterung und Emporwölbung in der Darstellung erkennen lassen; auf der südliehen Halbkugel dagegen nimmt die Temperatur rom Breitengrad bis zum Pol mit jedem 
Breitengrad rascher ab, als die thermische Normale für den betreftinden Breitengrad beträgt: die horizontalen und rertikalen Zonen verschmail.rn sich, wie der steile Absturz der Zonen in der Tatel andrutet.

b) Die Temperaturen der vier Monate nehmen aut' der nördlichen Halbkugel rom 37. Grad nördl. Br. an auf den Wstseiten der Kinntinente (ostamerikanische und ostasiatische Waldregion) sowohl in der horizontalen als in der vertikalen Richtung rascher ab als aut den Westseiten der Kontinente (europäische und westamerikanische Waldgehiete).

c) Die tiefste Temperatur des. Winters sinkt zimlich gleichmäßig. In Milde des Winters kam mit dem westamerikanischen Walde nur der westlichste Wald ron Europa und der südjapanisthe Wald rerglichen werden; die Waldungen des Binnenlandes in Ostasien (chinesischer Wald) und in Europa, sowie der Wald der Zentralgebirge ron Nordamerilia (Felsengebirge) müssen wohl dieselbe tiefe Wintertemperatur haben, wenn auch die meteorologischen Notizen wegen des Yangels an Stationen, vor allem in China, dieses noch nicht erkemen lassen.

d) Die Horotherme ron durchschnittlich $10^{0}$ während der vier Monate bildet auf der nördlichen wie auf der südlichen Erdhälfte sowohl in der horizontalen Richtung (polare Thermohore) wie in der vertikalen (alpine Thermohore) die Waldesgrenze.

e) Mit der Erhebung über dem Meere nimmt die sommerwärme rascher $a b$, als hierbei die Winterkälte steigt; in windstillen, klaren Nächten liegt die tiefste Temperatur im Tale, in den Ebenen und im Plateau des Vorlandes, nach oben hin wird es wärmer: bei intensirster Besonnung liegt die größte Erwärmung der Luft unmittelbar über dem Boden, nach oben hin wird es kïhler: bei be wegter L uft ist die Temperatur der Berge niederer als die der Ebene und des Vorlandes. Das Gesetz der Temperaturumkehr bewirkt in allen klaren, windstillen Nächten ein Anhäufen der kälteren Luft an den tiefsten Punkten, somit im Tale und in der Ebene. Da Täler und Ebenen es sind, welche untertags am meisten sich erwärmen und bei Wind die größte Wärme genießen, so wird dort frühzeitiger die Vegetation erweckt und länger der Abschluß derselben verzögert als in den Bergen; da aber bei klaren Nächten im Frühjahır und Herbst gerade die Ebenen und Täler infolge der Temperaturumkehr die tief́te Temperatur, z. B. solche unter ", zeigen, ist die S Pät- und Frïhfrostgefahr gerade in den wärmeren Ebenen am grüBten: daß dabei jene Holzarten, welche zuerst erwachen. in grübter (ivfahr schweben, liegt auf der Hand. Nanche im Verhalten der llnlzarten auffallende Erscheinung wird dadureh geklärt.

f) In den Tropen fehlt der Wechsel der Jahreszeiten, welche wath Norden hin immer deutlicher sich au-prägen: im Castanetum sind die vier Jahreszeiten am deurlichsten. Frühling und Herb-t ven langer 
Daner; nach dem Fagetum hin schwächen sich Frühling und Herbst inmer deutlicher ab. Im Picetum erfolgt der Übergang vom Winter zum Sommer und umgekehrt sprungweise. Dieses letztere Verhältnis ist für die Ptlanzenwelt günstig. Während das lange Frühjahr und der lange Herbst mit ihren Kälte- bzw. Wärmerückfällen von verderblichem Einfluß anf die Pflanzenwelt sich erweisen. Im Castanetum und Fagetum sind verspätete und verfrühte Fröste am schlimmsten; im kühlen Picetum, wo der Laie das Maximum an Frostgefahr vermutet, fehlen Fröste nach Erwachen der Vegetation und ror Abschluf derselben fast gänzlich.

g) Aus der Zonenbildung lemen wir eine Charakteristik der zweinadeligen Föhren, welche keine klimatypischen Nadelhölzer sind, sondern als Stellvertreter anderer Holzarten in mehreren Klimazonen auf Böden erscheinen können, welehe den typischen, anspruchsvolleren Holzarten nicht mehr genügen.

h) Südwest-, Südsüdwest- und Westseiten sind stets wärmer und trockener als die entgegengesetzten Expositionen; je steiler die Gebirgsflanken, um so extremer die Temperatur; südliche Expositionen bedeuten gleichsam eine Verschiebung der Fläche in ein wärmeres Gebiet, so daß sogar klimatisch eine Verschiebung in die wärmere $\mathrm{Nach}$ barzone eintreten kann, wenn der Berg ohnedies schon dieser Zone genähert ist; im wärmeren Fagetum gehören Südhänge bereits dem Castanetum an; im wärmeren Picetum tragen die Südhänge Fagetumklima; die Folge ist, daß alle Holzarten auf den südlichen Expositionen weiter nach oben steigen, als die Durchschnittserhebung für alle Expositionen beträgt. In gleicher Weise ergeben alle nördlichen Expositionen eine Abkühlnng, die wiederum um so stärker ist, je steiler das Grefälle. Nördliche Expositionen bedenten daher im Pflanzenleben eine Verschiebung des Standortes in die kühlere Zone; Nordseiten des kühleren Fagetums zählen klimatisch zum Picetum; Nordseiten des Picetums tragen bereits Krummholzvegetation oder Grenzwald; auf der Nordseite des kühleren Castanetums erscheint bereits die Buche, somit das Fagetum. Diese allgemeinen Naturgesetze haben natürlich anch zur Folge, daß eine Holzart dem beobachtenden Bergbesteiger zuerst auf der Nordseite entgegentritt, zuletzt auf der Südseite, zuerst auf der Nordseite entschwindet, zuletzt auf der Südseite. Die Verschiebungen in den Bergen kömmen 200-500 m betragen; d. h. eine Holzart, die auf der Nordseite bereits bei $1000 \mathrm{~m}$ verschwindet, ist auf' der Südseite noch bis zu 1200, 1300, 1400, selbst $1500 \mathrm{~m}$ Elevation anzutreffen. Es gibt Äuferungen in der Literatur, welche abfällig über die Zonenbildung lanten, weil es dem betreffenden Beobachter geglückt ist, in einer Höhe noch Vertreter des Fagetums zu finden, bei weleher auf demselben Berge auf' der Nordseite bereits einzelne Büsche der Krummhölzer auftraten. Verfasser hat bereits erwähnt, dafo ihm noch schönere Bei- 
spiele - der Zonenbildung: - aus den Pyrenäen hekannt sind, wohei anf' der Südseite eines Berghanges Buchen wuchs(n), während ant' der steilen Nordseite, welche während des ganzen .Jahres kinen sionnenstrahl empfingen, bloß die typische Holzart des inrtigen Alpinetmms, die P. uncinnata, autrat. Das sind keine Ansnahinen vom groben Naturgesetze der Klima- und Waldzonen, das sind nur Probleme im Rahmen des Gesetzes, deren Lösung nicht jedermann glüelit.

i) Fouchter bis nasser Boden, inbesonclors in Mulden und Einsenkungen, wirkt erkältend auf' die Luft- und Bodentemperatur ${ }^{1}$ ), so daf derartige Standorte das Klima der nä chsten, kïhleren Zone besitzen. So erklären sich Fichten mitten im Geliete des Fagetums, polare oder alpine Vegetation mitten im Gebiete des Picetums. In allen vier Waldgebieten sind diese Verschiebungen nachweisbar und auf die gleiche Ursache zurïckzuführen.

k) Die relative Feuchtigkeit der horizontalen /one (Ham erklärt ausdrücklich die relative Fenchtigkeit als einen genüigenden und bequemen Maßstab zur Beurteilung der Lufteuchtigkeit für klimatologische Zwecke) nimmt auf der nördlichen Halbkugel von den Tropen bis zum Castanetum stetig ab; von da an nimmt sie wieder nach Norden hin zu; das wärmste Gebiet des winterkahlen Laubwaldes ist somit das trockenste; in der vertikalen Richtung nimmt mit der Erhebung ïber dem Meere die Luftfeuchtigkeit bis in das Picetum zu. Mit der Auflösung der Waldungen in dieser Zone und dem Übergang zum Alpinetum nimmt die Lufteuchtigkeit wieder ab.

1) Je mächtiger und massiver das Gebirge und je größer die dasselbe bedeckende Waldmasse, desto höher und gleichmäßiger die Feuchtigkeit der Luft im Walde und in engen Tälern und Schluchten, weil durch diesen Faktor die Luftbewegung gehemmt wird; das Klima nähert sich dem insularen.

m) Die Niederschlags menge während der vier Monate nimmt sowohl im ostamerikanischen wie im ostasiatisch-japanischen Walde vom Lauretum bis in das Fagetum hinein stetig ab, bis auf ein Dritte! der Menge im Lauretum, im europäischen und westamerikanischen Walde dagegen bis auf das Vierfache des Lauretums zu; im Picetum steigt in allen vier Waldregionen die Niederschlagsmenge durchsehnittlich auf das Dreifache des Fagetums, d. h. die Fichten- und Tamnenwaldungen sind in allen Waldregionen die lufteuchtesten und regenreichsten frebiete. Nur das Palmetum zu beiden Seiten des Äquators ist regenreicher. Von allen vier $\mathrm{W}$ aldregionen iberhaupt ist das regrenreichste das ostasiatische, das unter dem Einflusse des mit Fenchtigheit gonsättigten Südmonsuns steht.

1) Prof. Buhler fand im Boden 1-60 Uninterschied. Mitt. d. wart. forstl. Vers. 1906. 
n) Die dem feuchten Luftstrom entgegengelagerten Abdachungen der Gebirge sind regenreicher als die im Regenschatten gelegenen; z. B. West- und Ostseite des Schwarzwaldes, des bayerischen Waldes in Deutschland, des Urals in Rußland, der Anden in Südamerika, Südwest- und Nordostseite des Himalara und andere.

o) Gebirgsketten, langgestreckte Täler erzengen Windstraßen, auf denen die Winde entweder in der einen oder in der entgegengesetzten Richtung, parallel der Richtung der Gebirgskette oder der Täler, wandern, wenn nicht der Luftstrom senkrecht auf die Streichrichtung stößt; Ebenen und schwaches Hügelland haben Wind aus allen Windrosen, wenn auch die gefährlichen Stürme meist nur einer bestimmten Richtung angehören, nämlich in ganz Europa Südwest und West, in Ostasien Süd und Nord, in Ostamerika Süd, West und (1st, in Westamerika West.

Bezüglich der Holzarten ist den Waldzonen folgendes zu entnehmen:

a) Die Zahl der Baumgattungen und Arten nimmt von Süden nach Norden, von unten nach oben hin stetig ab.

b) Die Verwandtschaft der Bäume in den von Süden nach Norden folgenden Zonen nimmt nach Gattungen und Arten stetig zu; im Picetum und Polaretum gibt es sogar identische Arten.

c) Nach dem kühleren Klima hin nimmt die Zahl der Individuen einer Art zu; es überwiegen daher in den Subtropen die Mischbestände mit Einzelmischung der Holzarten; im Castanetum beginnen bereits reine Bestände einer Art, die im Picetum aus natürlichen Gründen überwiegen.

d) $\mathrm{Da}$ in jeder Klimazone zonentypische Baumgattungen auftreten und der gleichen Klimazone die gleichen, typischen Gattungen entsprechen, kann die Klimazone bei dem Fehlen von Klimadaten auch aus dem Auftreten der klimatypischen Baumgattungen abgegrenzt und in ihrem klimatischen Charakter mit ziemlicher Sicherheit ergänzt werden. Dieser letztere Fall wird zur Auffindung der Zonen und Bestimmung des Klimas einstweilen noch der häufigere sein müssen. Um das Klima eines gegebenen Standortes zu bestimmen, wird die Praxis zunächst noch auf das nat ïrliche, ursprüngliche Auftreten gewisser Holzarten an dem betreffenden Ort oder in seiner Nachbarschatt angewiesen sein.

Bezüglich des Bodens sei folgendes bemerkt:

In den Tropen entstehen unter Einwirkung des feuchten, heißen, regenreichen Klimas vorzugsweise ausgewaschene Böden, Laterite: in den Subtropen mit oft langandauernder, sommerlicher Dürre sind Böden mit rötlichen Verwitterungsprodukten (terra rossa) typisch; den gemäßigten Klimaten gehören nach Wohltmann Böden mit hohem 
Humusgehalt, wie der L $\mathrm{u} B$, an. Ramann teilt die Bölen mit holem. Humusgehalt wieder in braune und graue Erden. Mangelt II awer (wie insbesondere im Bimenland der ('astanetum- md Farretumzon('). so bildet sich unter Einwirkung von Klima und PHanzr der steplenboden, ist Wasser im T̈berschub rorhanden (wis im Picetmm mul Polaretum), so entstehen Moorböden.

Es mag der Hinweis gestattet sein, daß anch div Tie re des Waldes, schädliche wie nützliche, ein bestimmtes Klima beanspruchen; freilich sind deren Klimazonen weniger scharf abgegrenzt; anch die Fähigheit, waldlose Gebiete zu überfliegen, ist größer. Verfasser tand, daß zahlreiche, europäische Borkenkäfer sich auch im japanischen VIalde wieder. finden. Teiland Prof. Döbner ron Aschaffenburg schrieb 18sii dem Verfasser bezüglich der in Nordjapan gesammelten Käfer" "Ich bin über. rascht, wie viele der japanischen Borkenkäfer mit europäischen Arten identisch sind." Man muß darans schließen, daß sie anch dem breitrn Bande des sibirischen Nadelwaldes, das den europäischen Wald mit dem japanischen verknüpft, nicht fehlen werden.

\section{Das klimatische Optimum.}

Der mittlere Teil des ursprünglichen, natürlichen Verbreitungsgebietes einer Holzart, der mittlere Teil der Klimazone einer Holzart muß naturgemäß jenes Gebiet sein, in dem die Holzart am besten gedeiht, das klimatische Optimum; nach der Wärme- wie nach der Kältegrenze hin muß naturgemäß eine $A b$. nahme der ganzen Lebensenergie der Holzart eintreten, welche endlich an der Terbreitungsgrenze, an den Rändern der Klimazonen zum Unterliegen der Holzart im Kampfe mit jenen Holzarten führt, welche an der betreffenden Stelle ihr klimatisches Optimum finden, somit biologisch kräftiger sind als erstere. Dies scheint eine so einfache. selbstverständliche Wahrheit zu sein, daß man sich nur wunderm mut. warum sie bis heute nicht beobachtet und in ihrer fundamentalen Bedeutung für die Forstwirtschaft, ja für die ganze Pflanzenzucht nicht beachtet wurde. Für jene Holzarten, denen nur eine horizontale Terbreitung zukommt, kann es nördlich ron dieser kein Uptimum geben; im Verbreitungsgebiete kanm das Optimum je nach der flacheren Ausformung des Geländes größere oder kleinere Teile der Landschaft umfassen; man kann dieses in der horizontalen Klimazone der Holzart 0-200 m über dem Meere gelegene Uptimum das Horizontaloptimum nemnen, südlich ron diesem Uptimum muß es ein zweit... Optimum bei entsprechender Elevation geben, das Tertika lopt $1 \mathrm{mum}$. Jene Holzarten, welche nu bei höherer Elevation. somit nu in ener vertikalen Klimazone auftreten, müssen neben clem Tertikalof t im in m noch ein zweites in der Ebene, ein Horizontaloptimm im Norden besitzen: im gebirgigen Gelände gibt es natiurlich zalilrenchr. 
Optima; je sanfter der Anstieg, um so breiter die Optimumzone, je steiler derselbe, desto sehmäler wird sie sein müssen. Manche Holzart, wie z. B. die europäische Fichte, streicht aus dem vertikalen Optimum im Süden nach Norden hin sich senkend in das horizontale hinein; bei anderen, wie z. B. der Alpenzürbel, kann das horizontale Optimum nur durch kïustlichen Anbau getrotfen werden; eine natürliche Verbindung fehlt. Nachstehende Abb. 3 gibt die Lage des klimatischen, vertikalen und horizontalen Optimums für die Alpenzürbel wieder.

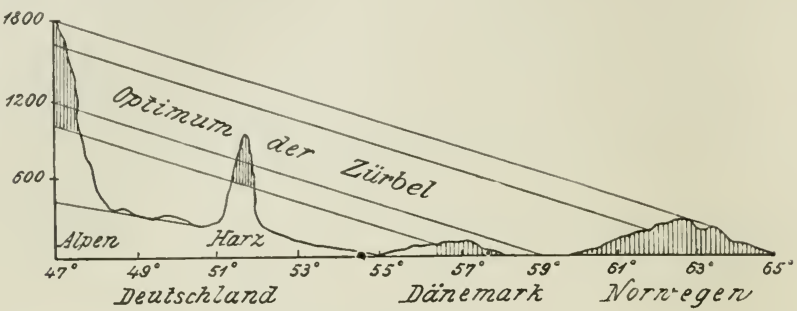

Abb. 3. Die Lage der Klimazone und des klimatischen Optimums der Zürbel unter dem 10.0 östlicher Länge von Greenwich.

Man kamn für jede Holzart fünf Klimazonen der Verbreitung unterscheiden; nämlich drei Zonen für das ursprüngliche, natürliche Vorkommen, zwei für das künstliche.

Künstliches Anbaugebiet kühler als das natürliche Verbreitungsgebiet.

Natürliches
Verbreitungs-
gebiet $\left\{\begin{array}{l}\text { kühler als das Optimum. } \\ \text { Optimum. } \\ \text { wärmer als das Optimum. }\end{array}\right.$

Künstliches Anbaugebiet wärmer als das Optimum.

Der Wert obiger Darstellung kommt in einer Reihe von naturgesetzlichen Erscheinungen im biologischen Verhalten aller Holzarten zum Ausdruck; für die Bedürfnisse der Forstwirtschaft betrachtet und geordnet sind es folgende:

1. Die Bedeutung des Optimums für Holzmassenproduktion und Umtriebszeit, für die Zwecke der Forsteinrichtnng.

a) Unter Voraussetzung gleich guten Bodens und gleichen Alters nimmt der Höhenzuwachs rom Optimum hinweg nach dem kühleren Klima hin gleichmäßig ab, nach dem wärmeren Klima hin anfänglich stark zu, später rasch ab.

b) Unter Voraussetzung gleich guten Bodens und gleichen Alters zeigt der laufende Stärkezurachs denselben Verlanf wie der Höhenzuwachs, d. h. vom Optimum hinweg nach dem kühleren Klima hin 
durchwegs Alnahme: nach dem wärmeren Kilima hin anfänglich stark Zunahme, später rasche Almahme.

c) Unter Voraussetzmng gleich gruten Bodens und gleichen Altris zeigt auch die Holzmasse des einzelnen Baumes von Gytimum hinweg eine gleichmäßige Abnahme nach dem kühleren Kilima hin: in wärmeren Klima anfangs große Massenprodultion: später sinkt die Produlition unter den Betrag, der im Optimum erzielt wird.

d) Unter Voranssetzung gleicher Bodengüte und niedrigen Alters (niederer Umtriebszeit) von etwa $20-40$ Jahren erzengt cin Baum den maximalen Holzertrag in einem Ḱlima, das wärmer ist als sein natïrliches Verbreitungsgebiet: daran reiht sich jenes wärmer als das Optimum, dann das Optimum, endlich ein Klima kühler als sein Uptimum: noch geringer wird der Ertrag im kïnstlichen Anbangebiete sinken müssen, soweit dieses kühler ist als das natürliche Verbreitungsgebiet der Holzart.

e) Unter Voraussetzung gleicher Bodengite und eines hohen Alters (Umtriebszeit von $80-120$ Jahren) ist die $\mathbb{T}$ achstumsleistung des Baumes am gröfiten im Optimum; sie nimmt nach dem wärmeren Klima hin ab und ebenso nach dem Klima hin, welches kühler ist als das Optimum. Abb. 4 (S. Ti) erläutert dieses Terhalten des Baumes. Es wäre gewiß eine dankenswerte Anfgabe, anch das Verhalten der Massen eines Bestandes ron diesem Gesichtswinkel aus zu betrachten.

f) Wird eine Holzart außerhalb ihres Optimums, aber noch innerhalb ihres natürlichen Verbreitungsgebietes kultiviert, muß ihre Umtriebszeit dem Optimum gegenüber sowohl bei Nieder-als Hochwald in wärmeren Gebieten verkürzt, in kühleren verlängert werden.

g) Wird eine Holzart über ihr ursprüngliches Verbreitungsgebiet hinaus künstlich angebaut, so muß ihre Umtriebszeit, mag sie als Nieder- oder als Hochwald behandelt werden, in wärmeren Gebieten abermals verkürzt, in kühleren abermals verlängert werden.

h) In letzterem Falle (g) wird die Entscheidung, ob eine Holzart noch den Anbau lohnt, neben der Massenerzeugung und Umtriebszeit auch den Umstand berücksichtigen müssen, daß die Kosten des Anbaues rom Optimum hinweg ständig steigen.

i) Die Umtriebszeit des Eichen schälwaldes muß wegen gesteigerten Wachstums und rascher Zunahme der Borkigkeit der Rinde nath dem wärmeren Klima hin verkïrzt, nach dem kühleren hin verlängert werden.

2. Die Bedeutung des Optimums für die liute der Holzproduktion, somit für Zwecke der Waldbenutzung. Die Bodengiite wird als gleich voransgesetzt.

a) Vollholzigkeit, Geradschaftigkeit und sichaftládue nehmen vom Optimum hinweg nach beiden seiten lin ah. 
b) Die Astreinheit nimmt rom Optimmm hinweg nach beiden Seiten hin hei allen Holzarten stetig ab, weil dabei der reine Bestand des Optimums allmählich anfgelöst wird; führt bei den Lichtholzarten die Auflöstmg des reinen Bestandes zur Mischung mit Schattenhölzern, damn verbessert sich die Astreinheit: es nimmt in diesem Falle die Astreinheit rom Optimum hinweg zu.

c) Wie die Astreinheit, verhält sich auch die Spaltbarkeit, Elastizität. Tragkraft.

d) Wesentlich unterstützt wird die Spaltbarkeit und Elastizität durch die Gleichmäßigkeit des Jahresringbaues. Dieselbe nimmt rom Optimum hinweg gegen das wärmere Klima hin ab, gegen das kïhlere zu, so daf auch der Satz gilt: Je kühler das Klima, um so gleichmäßiger das Gefüge der Jahresringe. (Fichtenholz der warmen Ebene einerseits und Resonanzholz des kühleren Picetums andererseits.)

e) Zähigkeit und Biegsamkeit nehmen rom Optimum hinweg zum wärmeren Klima zn, zum kälteren ab, d. h. je wärmer das Klima, um so zäher und biegsamer das Holz.

f) Druckfestigkeit nimmt rom Optimum hinweg nach beiden Seiten ab.

g) Schwere des Holzes erwachsener Stämme und damit auch seine Härte und Brennkraft nehmen rom Optimum hinweg nach beiden Seiten ab.

h) Jahresring breite (siehe Stärkenzuwachs 1 b). Über das Terhältuis von .Jahresringbreite und Gewicht bei Laub- und Nadelhölzern wollen die Ausführungen des Verfassers ${ }^{1}$ ) in der „Forstbenutzung eingesehen werden.

i) Die Dauer des Holzes nimmt, soweit Substanzgehalt des Holzes entscheidet, mit dem Gewichte rom Optimum hinweg ab; soweit Farbstoff des Kermes entscheidet, steigert sich die Daner mit dem wärmeren Klima; bei den Nadelhölzern hat der Harzgehalt keinen ausschlaggebenden Einfluß auf die Daner; es entscheidet das spezifische Gewicht und der Farbstoff des Kerns. Bei den farblosen Hölzern der Nadel bäume, Fichten, Tamnen u. a. ist ausschließlich das spezifische Gewicht für die Daner maßgebend, und es gelten daher die Gesetze zwischen Klima und spezifischem Gewichte.

k) Die Borkigkeit der Rinde (das Rindenprozent) nimmt rom Optimum nach dem kühleren Klima ab, nach dem wärmeren zu; in gleichem Simne rerändert sich somit anch der Brennwert und der Gerbwert gleichalter Rinden.

1) Da die Blattgröße und Blattmenge mit dem wärmeren Klima zunimmt, so ist der streuabfall in einem Klima, wärmer als das Optimum, größer, in einem Klima, lïhler als das Optimum, kleiner

1) K. Gayer und H. M a yr. Die Forstbenutzung. 9. Aufl. 190:3. 
als im Optimum; da aber die Streu (ceteris paribus) sich mu so schneller zersetzt, je wärmer das Klima, so ist die Streuansammlung im kühllsten Klima am größten.

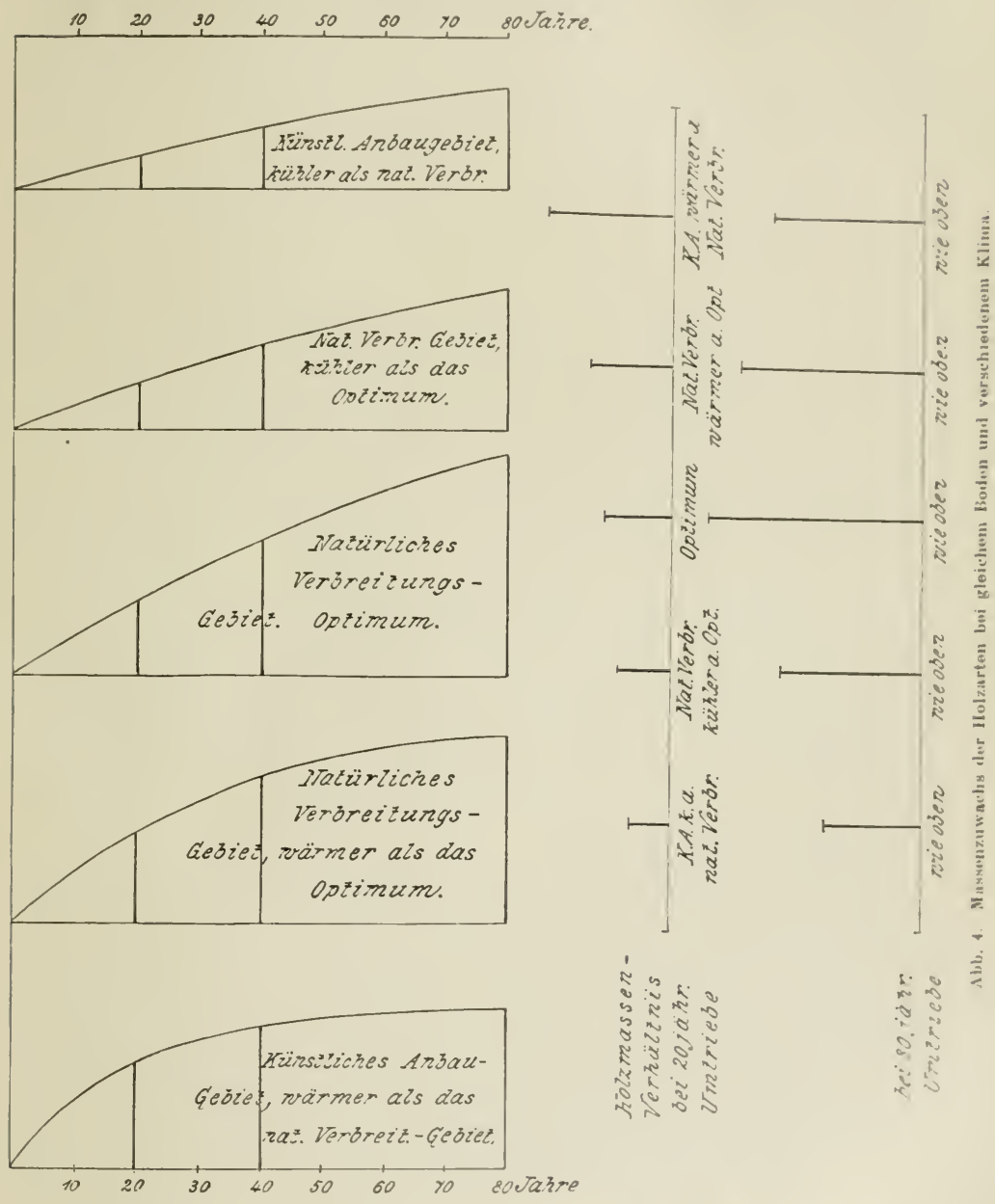

3. Die Bedeutung des klimatischen (1)timus tio den Wald bau.

a) Schnellwüchsigkeit = Höhenzuwachs. Es wurdu luereitsub 1 a betont, daß die Schnellwüchsigkcit im ersten Le hensiritel eines 
Baumes steigt gegenüber dem Optimum in einem Gebiete, das wärmer ist als das Optimum, und abermals steigt, wemn wärmer als das natürliche Verbreitungsgebiet, daß mit der Anuäherung an die zweite Lebens. hälfte eines Baumes die Schnellwüchsigkeit am gröbten im Optimum, daß sie in einem Klima, wärmer als das Optimum, ebenso abnimmt wie in einem Klima, das liühler ist als dasselbe. Dieser Satz hat grundliegende Bedentung für die Mischung mehrerer Holzarten auf' ein und demselben Boden und in ein und demselben Klima.

b) Werden zwei oder mehrere in der Raschw üchsigkeit nicht allzusehr verschiedene Holzarten auf ein und denselben Standort gebracht, so wächst in der ersten Zeit jene voran, welche an dem betreffenden standorte in einem Gebiete ist, das wärmer ist als das Optimum; mit Amnäherung an die zweite Lebenshälfte bleibt sie zurück, und jene wird roraneilen, welche an dem betreffenden Standorte im Optimum ist; ist erstere in ein Gebiet kühler als das (1ptimum geraten, wird sie stets von der anderen unterdrückt werden müssen. Es genügt hier, einstweilen auf die Bedentung, z. B. für das Wuchsrerhältnis von Eiche und Buche, Fichte und Lärche, Fichte und Buche, Föhre und Lärche usw. hinzuweisen.

c) Das Lichtbedürfn is einer Holzart wird bei gleichem Boden durch das Klima mächtig beeinflußt. Je wärmer das Ḱlima, um so geringer das Lichtbedürfnis; umgekehrt: je külller, desto größer. Eine Holzart, welche im klimatischen Optimum eine Lichtholzart ist. wie Eiche, Föhre, Lärche, kann in einem Klima, wärmer als das Optimum, zur Halbsehattenholzart werden; eine Holzart, welche im Optimum eine Schattenholzart ist, wie Tame, Buche, wird in einem Ḱlima, kühler als das Optimum, zur Halbschattenholzart; eine Holzart, welche in ihrem Optimum Halbschattenholzart ist, wie Hainbuche, Ahorn, Strobe, wird im wärmeren Klima zur sichattenholzart, im kïhleren zur Lichtholzart.

d) Da die Blattgröße und Blattmenge mit dem wärmeren Kilima zunimmt, so beschattet eine Holzart den Boden am meisten im wärmeren, am wenigsten im kïhleren Gebiete.

e) Der BestandsschluB, das Aneinanderrïcken der Kronen nimmt vom Optimum hinweg nach dem kühleren Klima ab, nach dem wärmeren zu. Führt die Auflösung des Bestandsschlusses zur Auflösung des reinen Bestandes, dam nimmt der Bestandsschluß bei den Schattenholzarten nach beiden Richtungen rom Optimum hinweg ab, bei den Lichtholzarten nach beiclen Richtungen hin zu.

f) Mit dem Bestandsschluf geht Hand in Hand die Verunkrautung des Bodens in dem Sinne, daß mit dem Schlusse die Verunkrautung: abnimmt.

g) Die Ansprüche einer Holzart an die Bodengüte werden bei größerem Wärmegenuß etwas ermäßigt. 
h) Die Ansprüche an bestimmte chemischestofte in Boden steigern sich bei jeder Holzart rom Uptimm hinwers: allo Holzarten verlangen an ihren Verbreitungrogenzen ein Ülrewiegen br. stimmter Stoffe; im (1)timum sind sie bodenvag, an don Verloreitungsgrenzen werden sie bodensteter.

i) Die Ansprüche an die Lufteuchtiugeit nehnen nach dem wärmeren Klima hin stetig zu wegen der stärkeren Verlunstumer überhaupt und der vergrößelten Blätter inshesondere.

k) Je wärmer das Klima, um so lutttrockener dasselhe, um sn

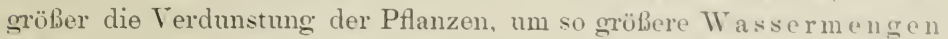
müssen ihnen in $\mathrm{Boden}$ zugeführt werden. Eine Holzart, die im Optimum im frischen Boden lebt, verlangt in wärmeren Klima feuchteren, im kühleren Klima trockeneren Boden.

1) Die A usschlagsfähigkeit, soweit die Ienge der Ausschlïge in Betracht kommt, steigert sich konstant nach dem wärmeren Klima hin; dagegen nimmt die Dauer der Ausschlagsfähigkeit ab.

m) Das Samenerträgnis beginnt um so frïher, je wärmer das Klima; Tiederholung und Samenmenge sind im wärmeren Klima gïnstiger als im Optimum, im Optimum gïnstiger als im kühleren Klima; die Dauel des Samenerträgnisses ist jedoch am längsten im Optimum.

n) Natürliche und künstliche Verjüngung sind am leichtesten und sichersten im Optimum der Holzart: von diesem hinweg nehmen die Gefahren und S̈chwierigkeiten zu: im Optimum ist daher die Verjüngung überhaupt am billigsten durchzuführen, je weiter ab ron diesem, um so teurer wird die $\mathrm{h}$ ultur, da sie eine lïnstliche werden muß, um schnell und rollkommen zu sein.

o) Wird eine Holzart aus der Fremde eingeführt, so erfüllen sich an ihr die gleichen Naturgesetze wie an den einheimischen Bammarten: die Feststellung ihres limatischen Optimums in der nenen Heimat kamn auch ohne vorherige Tersuche durch die Angleichung an die Tegetationszonen in der alten Heimat geschehen, wie dies rom Verfasser ror 18 Jahren bereits tür die wichtigsten, westamerikanischen Holzarten in Europa geschehen ist. Die Anbauversuche hahen 20) Jahre später die Richtigkeit dieser Aufstellungen hewieven.

p) Der Anbau irgend einer einheimischen oder fremden Holzart in einem Gobiete, das kïhler ist als deren natürliches Verbreitmurgebiet, ist ummöglich, wenn letzteres bis zur Waldgenze selbs (Tlumm hore) vorrüiclit.

Akklimatisation nemnt man die Ampassum (Akkomumbtion) an das Klima: die Frage der Akklimatisation oder Amparsumg an ila Klima ist nur dann gegeben. wemn eine Holzart auberhalb ihres kilina- 
tischen Heimatgebietes, außerhalb ihrer Klimazone auf einen nenen Standort verbracht wird, dessen Klima von allen Standorten, auf welchen die Holzart in der. Heimat wächst, versehieden ist. Wächst z. B. eine Fichte in ihrer Heimat in wärmerem Tiefland und in den kïhlsten Alpenwaldregionen, so bedart es für diese Fichte keiner Akklimatisation an das Klima, wemn sie vom wärmsten zum kältesten oder umgekehrt versetzt wird; wird aber diese Fichte außerhalb ihres Heimatgebietes aut Standorte gebracht, die wärmer oder kälter sind als die wärmsten oder kältesten Standorte des Heimatbezirkes, so müßte sie sich dort an das fremde Klima anpassen, um normal wie in der Heimat gedeihen zu könmen; gedeiht sie aber nicht der Heimat gleich, damn ist sie eben nicht imstancle gewesen, sich anzupassen. Die erste Frage, die gelöst werden muf, lautet somit: Welches Klima hat der neue Standort? Ist dieses verschieden von allen Klimaten der Standorte der Heimat? Ergibt sich Klimagleichheit mit irgendeinem Punkte in der Heimat, so liegt keine Akklimatisation, sondern einfach Reaktion von seiten der Pflanze vor, welche in der Pflanze die gleiche Erscheinungsform (Standortsform) hervorrufen muß, wie sie der klimagleiche Standort der Heimat aufweist. Reaktion a f das Klima ist keine Akkom modation oder Akklimatisation; eine Akkommodation und damit anch Akklimatisation liegt nur dann vor, wenn eine Holzart den ihr typischen Anspruch an Wärme und damit auch die Wiederstandskraft gegen Kälte zugunsten des neuen Standortes abändert, d. h., wem sie am neuen Orte die typische Vegetationstherme erhöht bzw. ermä $\beta \mathrm{igt}$.

Die europäische Lärche hätte sich akklimatisiert, wenn sie irgendwo in ihrem künstlichen, wärmeren Verbreitungsgebiete imstande gewesen wäre, ihre Vegetationstherme auf $15^{\circ}$ oder $16^{\circ}$ zu erhöhen; weil sie aber das nicht vermochte, hat sie in diesen Standorten einfach die Vegetationsdauer verlängert, um ihre Vegetationstherme von $14^{0} \mathrm{zu}$ erfüllen; die europäische Lärche hätte längst im Hochgebirge höher aufwärts wandern müssen, wemn sie imstande wäre, ihre Vegetationstherme zu erniedrigen. Wie die Lärche, verhalten sich alle Holzarten. Verfasser muß auf seine Schriften ${ }^{1}$ ) hinweisen, in welchen der Nachweis gefïhrt ist, daß ein selbst tausendjähriger Anbau mit verschiedenen Holzarten nicht imstande gewesen ist, die Holzarten zu aklikimatisieren. Forstwirte und vor allem Gärtner stellen sich die Aklilimatisation als etwas ganz Einfaches dar; die Systematiker raten stets anf Klimavarietät, wenn sie zwei nahestehende Arten vor sich haben. Bei den meisten gärtnerischen und waldbaulichen Versuchen ist die naturnotwendige Voraussetzung für Akklimatisation, nämlich die

1) H. Mayr, Fremdländische Wald- und Parkbäume für Europa. 1906. 
Klimadifferenz, gar nicht gegebon. Ptlanzenzïehter urtcilon hicrin allzu rasch. Will eino Holzart nicht wachsen, so ist, wemn nicht del. Boden, doch sicher das Kílima, nie aber die Behandlung oder Mißhandlung schuld. Gedeiht eine Holzart anf nenem Standort, so hoißt sio sofort akklimatisiert. Von der ostamerikanischen, forstlich so wichtigen Weymouthsföhre z. B. wird mit Bestimmtheit behauptet, daß sie sich in Mitteleuropa vollständig akklimatisiert habe. Erforscht man grenaner das Klima der neuen und alten Heimat, so findet man keine Kilimadifferenz, eine Aklklimatisation war daher umütig. Liegt wirlkliche Klimadifferenz vor, so verwechselt man Realition mit Alklimatisation, weil man nicht abwartet, wie viele und wie grofe Nachteile an einem Baume auftreten, der wirklich auf klimadifferentem Standorte steht. Die verschiedenen Reaktionen einer Pflanze in verschiedenen Klimalagen können nicht erblich sein. Gäbe es Akliommodation und Akklimatisation, was nur mit einer Wesensänderung der inneren, seit Jahrtausenden gefestigten und vererbten Anlagen (Änderung der typischen Vegetationstherme) möglich wäre, so dürfen wir vermuten, dafs eine solche Änderung auch erblich wäre.

Terhalten gegen Frost. Ein Beweis gegen die Akklimatisation, vor allem gegen die vermutete rasche Anpassung, ist die Empfindlichkeit der Holzgewächse gegen Temperaturextreme und die zahlreichen Beschädigungen, die sie durch dieselben erleiden.

Auf den ursprünglichen Standorten unter den natürlichen Bedingungen der Heimat sind die Toraussetzungen zur Widerstandsliraft der Holzarten gegen Frost erfüllt. Diese erschöpfen sich in dem Vorgange des Ausreifens der Gewebe, d. h. des Abschlusses der Triebe und in der Jahresringbildung, der Auswanderung der wiehtigsten Nährsalze aus den vergänglichen in die bleibenden Teile, der Auswanderung des Plasmas aus den spindelförmigen, eigentlichen Holzzellen des eben gebildeten Jahresringes, womit in diesen Organen jegliches Leben erlischt. In dem heimatlichen Klima erreicht jede Holzart den normalen Vegetationsschluß und damit auch die Vorbereitung für den normalen Winter, der diesen Standorten eigentümlich ist. Wird nun eine Holzart außerhalb ihrer Heimat (Tegetationszone) auf einen wirklich klimadifferenten Standort gebracht, z. B. in ein wärmeres Ǩlima, so glaubt jeder Pflanzenzüchter, daß sie damit in günstigere Wuchsverhältnisse geraten, besonders gedeihen und dem forstlichen Zwecke ganz herrorragend entsprechen müsse. Die PHanze reagiert aber in folgendem Sinne: Sie verlängert ihre Vegetationsz it durch früheren Vegetationsbeginn und späteren Tegretationsab-chlulis (siehe die Ausführungen über die Vegetationstherme S. ili); es bestelit große Gefahr durch verspätete Fröste im Frühjalır (man sicho die Ausführungen über Temperaturumkehr während der Näichtr), während der im wärmeren Klima verlängerte sommer und die weniger trüben Mayr, Waldbau. 
und tiefen Herbst- und Wintertemperaturen dem Vegetationsabschluß günstig sind. Alle Holzarten, welche aus dem Picetum in das Fagetum, aus dem Fagetum ins Castanetum oder gar aus dem Picetum ins Castanetum übergesiedelt werden, reagieren im obigen Sinne.

Wird dagegen eine Holzart aus einer wärmeren 'Zone in eine kühlere verpflanzt, so ist sie nach Ansicht der Pflanzer, wenn sie gedeiht, akklimatisiert; sie reagiert jedoch folgendermaßen: Sie beginnt ihre vegetative Tätigkeit später als in der Heimat; sie bedarf gleichsam einer größeren Wärmesumme, d. h. längerer Zeit, bis sie zu neuer Tätigkeit erwacht. Diese Verschiebung bringt die Holzart glücklich hinweg über die Gefahr durch verspätete Fröste, sie ist spätfrosthart. Die geringere Sommerwärme aber verzögert den Vegetationsabschluß, und die ersten Fröste im Herbst treffen die Pflanzen noch in voller Tätigkeit und Vorbereitung für den Winter; sie werden durch diese Frühfröste beschädigt. Selbst dann, wenn sie äußerlich ihre Tätigkeit normal abgeschlossen zu haben scheinen, kamn das innerliche, unfertige Gewebe durch tiefere Temperaturen des kommenden Winters getötet werden. Hierher ist auch der forstlich sehr lästige, bei Holzarten aus wärmerem Klima zu beobachtende Gipfelknospentod während des Winters zu rechnen; die Gipfelknospe ist die letzte, welche fertig wird. Alle Holzarten, die aus dem heimatlichen Castanetum in das Fagetum oder Picetum transferiert werden, zeigen dieses Verhalten, je weiter sie in die kühleren Zonen vordringen. (Man vergleiche die Skala der Frostempfindlichkeit auf Seite 88.) Um diese Erscheinung auszulösen, ist es nicht notwendig, eine Holzart ganz aus ihrer Heimatzone herauszubringen; bei ungeeigneter waldbaulicher Behandlung kann sie auch auf heimatlichem Boden durch Spät-, Früh- oder Winterfröste geschädigt werden (Kahlflächen).

Allewaldba ulichen Operationen, durch welche der normale Wuchsbeginn im Frühjahr oder der normale Abschluf im Herbste beeinträchtigt wird, wie Spätsaat oder -pflanzung im Frühjahr, spätes Beschneiden, später Stockabhieb, Beschädigung während der Vegetationszeit durch Fröste, Hagel, Tiere, Menschen, kräftige Düngung, allzu dichte Überschirmung, allzu frühe Saat oder Pflanzung im Herbste und dergleichen, bringen die betreffenden Holzarten in Gefahr durch verfrühte oder durch Winterfröste geschädigt zu werden. Im folgenden Frühjahr ist sie gezwungen, zuerst neue Organe zur Begrünung zu schaffen, wodurch ihre ganze Tegetation abermals verschoben und verzögert wird und die Gefahr im kommenden Winter neuerdings besteht. Erst ein besonders milder Winter bringt solche Individuen wieder in ihr normales Geleise.

Alle Holzarten sind weniger empfindlich gegen Frost während der Wuchsperiode, wenn diese ihrem Ende sich nähert, als in jener Zeit, in der die Wuchsperiode beginnt; im Moment der Knospenentfaltung 
sind alle Holzarten am empfindlichsten; jene Nadelbäume (Lürchnn), welche ihre Vegetation mit einer Kurztriebbegrünung einleiten, sind am empfindlichsten, wenn der Längstriob einsctzt. Es genügt sehnı ein halber Grad unter Null, um an den Gattungen Abies, Picea, Psendn. tsuga, Tsuga u. a. die zarten Enden der neuen Triebe zı tüten und damit für diese Holzarten (z. B. am Höhentriebe) einen ganzen Jahreszuwachs zu vernichten. Stellt sich der letzte Frost im Frühjahr erst so spät ein, daf der neue Trieb schon eine Strecking erfahren hat, so beschränkt sich die Frostwirkung vielfach nur auf Krümmungen des neurn Triebes: je weiter im Herbst die Vorbereitung für die Winterruhe vorgeschritten ist, um so weniger leiden die Pflanzen durch Herbstfröste, um so tieferer Temperaturen bedarf es während des Winters, un noch eine Beschädigung herbeizuführen. In feuchten, kahlen Mulden innerhalb des Fagetums und Picetums treten selbst mitten im Hochsommer Morgenfröste auf, durch welche Erlen, Eschen, Birken imnerhalb der Grasspitzenhöhe im entstehenden Holzringe beschädigt werden (Sommerfrost).

Wird eine Holzart als lebende Pflanze aus dem wärmeren Standort in kühleres Klima oder auf eine Kahlfläche verbracht (Pflanzenbezug aus wärmerem Klima, Anlage des Pflanzgartens in wärmerem Klima und Auspflanzen des Materials in einem kühleren Standorte), so besteht Gefahr, daß die Pflanzen leiden, wenn die Transferierung der Pflanzen im Herbst stattgefunden hat. Die Pflanzen haben sich an ihrem früheren Standorte während des Sommers für den kommenden Winter, wie er dem wärmeren Standorte entspricht, vorbereitet; finden sie auf dem neuen Standort früheren Wintereintritt, einen strengeren Winter, so werden sie leiden müssen, da sie darauf nicht vorbereitet sind. Werden aber die Ptlanzen im Frühjahre, also nach überstandenem Winter ausgehoben und auf den neuen Standort verbracht, so reagieren sie auf die kommende Vegetationswärme des neuen Standortes so, daß sie anch für die kommende Wintertemperatur des neuen Standortes vorbereitet sind: sie bleiben infolgedessen unbeschädigt. Einstweilen sei diese für die Praxis beachtenswerte Beobachtung hier nur angedentet.

Es herrscht allgemein unter den Pflanzenzüchtem der Glaube, daß eine Pflanze vor dem Erfrieren (Tod durch Gefrieren) bewahrt werden kann, wenn sie langsam a ufgetaut wird. Nenere Forschungen von Molisch haben jedoch ergeben, daß dies nur für wenige, krantartige Pflanzen zutrifft. Wenn es gelingt, eine Holzptlanze durch langsames Auftauen am Leben zu erhalten, dann war sie überhaupt noch nicht erfroren, und auch das schnelle Auftauen hätte ihr nichts gesehadet.

Die klimatischen Verhältnisse des eimzelnen Baumos und deren Beziehungen zur Biologie des Baumes können hier nur so weit berührt werden, als daraus Änderungen in der waldbanlichen Behandlung entstehen kömnen. 
Es ist eine allgemein verbreitete Anschauung, daß die Wärme im Innern des Baumes eine Mischung von Luft- und Bodenwärme darstelle, derart, daß die mit dem Bodenwasser aufsteigende Temperatur sich in den feinen Zerteilungen des Baumes allmählich mit der Außentemperatur ausgleicht. Diese Vorstellung ist zwar verführerisch naheliegend, sie ist aber doch irrig. Jahrelange, noch nicht veröffentlichte Beobachtungen haben den Verfasser zu folgenden Ergebnissen geführt. Der erwachsene Baum hat ein eigenes Klima; nur seine Wurzeln hängen in der Wärme vom Boden, nur seine feinsten Verzweigungen in der Wärme von der Luft ab, der Schaft und die stärkeren Äste sind auf die Wärme der Luft und Insolationswärme angewiesen.

Es liegt der Satz nahe: Die Wurzeln haben die Temperatur der umgebenden Bodensehichten. Der Satz ist nicht richtig. Zur Zeit der Hauptverdunstung des Baumes zeigen die Wurzeln, besonders die kräftigen, über fingerdicken, nicht die Temperatur der unmittelbar anliegenden Erdmassen, sondern die kühlere Temperatur der etwa $5-10 \mathrm{~cm}$ tiefer liegenden Erdschicht, da der Wasserstrom aus den tiefen Bodenschichten die kühlere Temperatur nach oben trägt. Zur Zeit der geringsten Verdunstung, bei Eintritt von Taubildung, sistiert die Wasserbewegung; dann ist die Wurzel wärmer als die umliegende Erdschicht, da vom erwärmten Schaft aus die Wärme durch Leitung, sowie höchstwahrscheinlich anch durch den abwärts erfolgenden Stoß des Vegetationswassers im Baume Wärme nach unten in die Wurzeln hineingetragen wird. Während des Winters, zur Zeit der geringsten, ja oft wochenlang ganz unterbrochenen Verdunstung sind die stärkeren Wurzeln je nach Witterungsperioden bald kälter, bald wärmer als die Umgebung durch direkte Wärmeleitung im Stamme nach der Tiefe.

Würde der Bodenwärme die Bedeutung für die Waldbäume zukommen, die ihr allgemein zugesprochen wird, so wären die tiefwurzelnden Holzarten sehr zweckwidrig gebant, da sie gerade zur Zeit des größten Wachstums aus den tiefsten Bodenschichten das kälteste Wasser durch die Wurzelspitzen aufnehmen und durch Leitung nach oben der Erwärmung des Bodens und der Wurzeln entgegenarbeiten würden.

Wählt man nun den extremsten Fall von Verdunstung ans (Hochsommer, Mittagszeit, volle Besonnung), so muß man voranssetzen, daß der Wasserstrom von den Wurzeln zu den verdunstenden Blättern am lebhaftesten sich bewegt. Die Beobachtungen des Verfassers haben ergeben, daß selbst in diesem Fall die von den Wurzeln gebrachte Abkühlung nur $0,5 \mathrm{~m}$ vom Boden im Schafte nachweisbar ist; zwischen 1,5 und $1 \mathrm{~m}$ erlischt der Einfluf völlig; das Wasser im Baume hat die 'T'emperatur angenommen, die ihm zukommt, wenn es stille gestanden hätte; es läßt sich dies leicht nachweisen durch Be- 
obachtung an zwei nebeneinander stehenden Bäunen, von denen inr eine vollständig entästet steht, der andere vollständig belauht dasteht : an der vou der Somme getroffenen, tiefsten sichaftstelle ist sogar das Wasser des Splintes wärmer als irgendwo am Baume: dem diese Schaftstelle wird von der Sonne am intensirsten erwärmt. Zeigte clie Splinttemperatur auf der Nordseite unmittelbar ïber dem Bolen zur Mittagszeit $16^{\circ} \mathrm{C}$, so war sie auf der Südseite bereits auf $44^{\circ}$ erwärmt; $0, \overline{\mathrm{m}}$ über dem Boden betıug die Temperatur anf' der Nordscite 1! ${ }^{0}$, auf der Südseite $35^{\circ}$; von da an aufwärts nahm die Temperatur auf der Südseite ständig ab, auf der Nordseite ständig zu, durch Wärmeleitung von der Südseite her und den Einfluß der warmen Luft $\left(34^{\circ}\right)$; in der Baumkrone war der Splint der Süd- und Nordseite gleich warm. Wemn man bedenkt, daß bei den Nadelbäumen der Kern kein Wasser leiten kann, das $\mathbb{T}$ asser somit auf die enge Bahn des Splintes zusammengedrängt ist, so ist demnoch die Bewegung des Wassers aufwärts so langsam, daß dieser Vorgang geradezu als einflußlos für die Temperatur des Schaftes und der Krone der Bäume bezeichnet werden muß. An den von der Sonne getroffenen, isolierten oder randständigen Bäumen ist die Temperatur des Schaftes eine Mischung aus Insolationswärme und Luftwärme, erstere durch Strahlung, letztere durch Leitung mitgeteilt; die Erwärmung ist extrem. Über die Wärmeverhältnisse in den Schäften der Bäume eines Bestandes ist die Lufttemperatur entscheidend. Je dünner der Schaft und die Zweige, um so genauer und rascher folgt die Baumwärme den Schwankungen der Luftwärme; je dicker und stärker, um so unabhängiger wird der Baum von den Extremen der Luft; er bewegt sich in seiner Innenwärme auf unbesomnter seite mehr oder weniger parallel der Durchschnittstemperatur; die besomte Seite eimes Schaftes liegt in der Durchschnittstemperatur höher als jene der Luft. Die dünnsten Zweige, die Nadeln sind von der Lufttemperatur in erster Linie abhängig.

Folgt auf Nachtfrost warmer Sonnenschein, so ta uen zuerst Schaft und Äste, von der. Sonne getroffen, auf, während die feinsten $\mathrm{Z}$ weige und $\mathrm{Nadeln}$ noch gefroren sind, wem die Temperatur der Luft unter $0^{0}$ beträgt. Jene Hypothese, welche das Braunwerden der Nadeln an immergrïnen Laub- und Nadelholz. arten während des Winters durch Überverdunstung von seiten der a ufgetauten $\mathrm{Nadeln}$ bei beschränkter Wasseraufinahme aus den gefrorenen Äste- und Stammteilen zuschreibt, operiert mit Erscheinungen, die im Leben des Bames, in der Natur nicht wintreten, ja geradezu umgekehrt sich abspielen. Das Braunwerden ist ein Erfrieren des Chlorophylls, das im gefrorenen Zustand gegon dirckite Insolation empfindlich wird, weil die Chlorophyllk̈̈ruer nieht in die Schutzstellung zu wandern vermögen. Für alle immernimen Holz- 
arten, immergrünen Nadelbäume der kühleren, immergrünen Laubbäume der wärmeren Gewächszone besteht, wenn sie in kühleres Klima oder auf Kahlfächen verbracht werden, oder wenn sie aus dem Bestandschlusse durch Beseitigung der über schirmenden Bäume während des Winters in Freistand geraten, die Gefahr dieses Chlorophylltodes. Sonnige, frostreiche Winter werden allen immergrünen Holzarten durch Rötung gefährlich. Ebenso ist das Absterben der über die Schneedecke hervorragenden Pflanzenteile bei gewissen Holzarten nicht eine Vertrocknung, sondern ein Erfrieren, da unmittelbar über dem Schnee die tiefsten Temperaturen liegen.

Eine Sonnenwirkung ist die gesunde Rötung, selbst Bräunung der Nadeln einjähriger Föhren und Lärchen vor Eintritt des Winters, die Winterfärbung der Thujen und Chamaecyparis und anderer immergrüner Baumarten; im Schatten bleiben trotz tiefer Temperatur die betreffenden Pflanzen grünlich; im Frühjahr tritt wiederum die normale Grïnfärbung der Nadeln und Zweige ein: hiervon ist grundversehieden die Nadelröte (Schütte) der Föhre, welche als Pilzinfektion Millionen von Föhren während der Vegetationszeit befällt, so daßs sie während der Vegetationsruhe, besonders im März, mit roter Farbe vertrocknen. Alle diese Vorgänge, so wichtig als naturgesetzliche Grundlagen und Erscheinungen im Leben der Pflanzen und damit anch des Waldbaues, an dieser Stelle zu besprechen, um zu zeigen, daf die Forschungen des Verfassers Ergebnisse gezeigt haben, die mit den herrschenden Theorien vielfach in Widerspruch stehen, liegt außerhalb des Rahmens dieser Schrift.

Je größer die Körpermasse eines Baumes, um so unabhängiger wird er in seiner Temperatur von seiner Umgebung: das Samenkorn keimt oder kümmert, je nach Temperatur und Feuchtigkeit der obersten Bodenschicht; der Keimling steht unter den extremsten Verhältnissen der Bodenoberfläche; die aufwachsende Pflanze hängt ab ron der Temperatur und Fenchtigkeit der unteren Luftschicht; da mit der Höhe die Extreme abnehmen, wird der höhere Baum nicht härter gegen Spät- und Frühfröste, weil er sich aklklimatisiert, sondern weil or in wärmere, weniger extreme Luftschichten hineinwächst.

Im Winter gefriert, wenn die Lufttemperatur tief genug sinkt, anch der Baum vollständig. Verfasser hat mehrfach in völlig erwachsenen Fichten von $80 \mathrm{~cm}$ Durchmesser nahe am Marke Temperaturen von $-17^{\circ}$ gemessen. Daß durch besonders ticfe Temperatur Bäume aufreißen können, ist bekannt. Die Theorie, daß das gefrierende und sich ausdehnende Wasser die Bäume sprengt, ist längst über Bord geworfen; nach ihr könnte es in ganz Mittel- und Nordeuropa keine ungeplatzten Bäume geben. Es verdient aber auch dic andere Theorie das gleiche Schicksal, nach welcher durch das Gefrieren das Wasser 
der toten Zellen aus der Wandung heraustritt, so dab diese sthlieflich so trocken wird, daß ein Schwinderib in Bamm entstehen muß. Alle Versuche des Vertassers ergaben, daß das Wasser in toten /allon la gefriert, wo es gerade von dem Minusurad überrascht wird. 1)wr Splintkörper des Baumes ist so wasserreich, lak man iln einen Wasserkörper nemmen liam, der somit bei genügend ticfer Temperatur cin Eiszylinder wird. Wie nun clas Eis äberhaupt bei besmulers tiefer Temperatur durch Kontraktion zersprengt wird, so platzt auch der Baum auf, wenn der bereits gefrorene schaft inmer tiefer sich abhïhl. Diese Eisklüfte schädigen den Baumwert und sind tür Laublıolzarten, welche beim Anbau an ihre Kältegrenze gelangt sind, geradezu rine typische Erscheinung: es leiden gerade die schönsten, geradtaserigen. spaltbarsten Schäfte der Eichen, Ulmen, Eschen und anderer Lanbbäume; auch bei Nadelhölzern sind ähnliche Erscheinungen bchannt; ob sie aber gleichen Ursprungs sind, ist moch zweifelhaft.

Winter- wie Sommertemperaturen sind für die Bäume nötig; f'ür die Bäume des gemäßigten Klimas sind die Extreme in der Temperatur, wie sie durch Tag und Nacht während der Vegetationszeit hervorgerufen werden, unentbehrlich für die Durchlüftung, durch Erwärmung oder Expansion und Abkühlung oder Kontraktion. Je grüßer die Differenz in der Temperatur zwischen Baumluft und Außenluft, um so rascher der Austausch durch die Stomata der Blätter, den Ausmündungen der Gefäße des Laubholzkörpers. Die Grefäßu des Holzes selbst führen nie $\mathbb{W}$ asser; sie sind die Luftwege des Holzes: sie können sich daher auch nicht an der Wasserbewegung beteiligen: Wasser würde auch die Gefaße verstopfen und so deren Daseinszweck, die Durchlüftung der Bäums, vereiteln. Extreme in der Temperatur sind nötig für die Auflüsung, für die Wanderung der Stoffe, für die Zwecke der Assimilation, mit einem Wort für das ganze Leben der Bäume; nicht nötig aber sind die Extreme im Frühjahr und Herbst; würden sie ganz ausfallen, wäre die Vegetation am gïnstigsten bestellt. Es wurde schon angedeutet, claB, je länger Frühjahr und Herbst sich hinziehen, bis einerseits Sommer. andererseits Winter zum Durchbruch kommen, um so grüßer die Gefahren für die Pflanzen, um so notwendiger waldbauliche Maßnalımen diesen vorzubeugen.

Will man eine Skala, nach welcher sich die Holzarten bei Ver bringung in wärmeres Klima oder auf eine Kahltiäche hinsichtlich ihrer Spätfrostempfindlichkeit aneinander reihen, so II är dies, mit den empfindlichsten angefangen, folgende:

Abies, Pseudotsuga, Tsuga.

Picea, Fagus.

Thuja, Chamaecyparis, Juglans, Rohinia, Castanea, Magnolia.

Betula, Larix, Pinus. 
Zwischen diesen beiden extremen Reihen liegen alle übrigen Baumgattungen. Daß bei Auswahl besonders ungünstiger Verhältnisse (Frostlöcher) oder bei besonders spätem Auftreten von Frösten (Mai bis Juli) gelegentlich auch alle Holzarten in Mitleidenschaft gezogen werden können, sei hier nur angedeutet; bei so sehweren Kalamitäten gehen in der Regel nur Birken und Föhren noch ziemlich unverletzt hervor. Will man eine Skala der in kühlerem Winterklima oder auf Kahlfläehen durch Früh- und Winterfröste besonders gefährdeten Holzarten, so stehen an der Spitze der empfindlichsten Baumgattungen :

Robinia, Juglans, Castanea, Magnolia.

Chamaecyparis, Thuja.

Pseudotsuga, Tsuga, Quereus, Fagus.

Abies, Pinus (Angehörige des kühleren Klimas), Picea, Larix.

Überhitzung. Bei der Betrachtung der klimatischen Verhältnisse des Bodens wurde berührt, daf freiliegende Böden (Saatbeete, Kahlflächen), besonders bei dunkler Farbe, somit humusreiche Böden, sich außerordentlich erhitzen können. Verfasser selbst maß Temperaturen von $68^{\circ}$ unter einer dümnen Nadeldecke. Es liegt auf der Hand, daß die Mangelhaftigkeit der natürlichen oder künstlichen Ansaat bei der Zartheit aller Keimlinge nicht immer auf Vertrocknung, somit Wassermangel im Boden, sondem ebenso häufig, wenn nicht sogar regelmäßig der Überhitzung, der Verbrennung durch Überhitzung zugeschrieben werden muß.

Blätter, Nadeln und dünne Zweige der Bäume, obwohl der vollen Bestrahlung durch die Sonne ausgesetzt, erhitzen sich nicht bis zur Maximalgrenze der Erwärmung $\left(54^{\circ} \mathrm{C}\right)$, da ihre Temperatur durch das umgebende Nedium, durch die Luft auf einen unschädlichen Betrag herabgedrückt wird. Es bedarf einer besonderen Anordnung des Versuches oder, auf die Praxis übertragen, einer unvorsichtigen, allzu raschen Lichtung über vorhandenem Vorwuchs, um auch eine Beschädigung durch die kombinierte Wirkung Hitze und Licht an den Pflanzen herbeizutühren, welche Beschädigung, analog der Nadelbräune, Blätter-oder $\mathrm{Nadelbleiche} \mathrm{genannt} \mathrm{werden} \mathrm{kamn.} \mathrm{Die} \mathrm{bei} \mathrm{ge-}$ mäßigtem, ja vielfach bloß diffusem Licht gebildeten Organe der Vorwuchspflanzen sind gegen die Erhitzung und Bleichung der rollen Sonne ebenso empfindlich, ihr Chlorophyll wird ebenso zerstört und gebleicht wie bei den Blattpflanzen, die, im Zimmer erzogen, plötzlich der vollen somne ausgesetzt werden.

An Baumschäften und Ästen tritt eine Überhitzung, ein Absterben der Rinde, Rindenbrand, unter folgenden Umständen auf.

1. Bei glattrindigen Bäumen, welche überhaupt keine oder nur spät Borkenrinde bilden, ist das einzige Schutzmittel Beschattung 
durch die eigene oder eine fremde hrone: werden daher im Bestands schluß erzogene und damit astreine Schäfte durch Beseitigung der. Um. gebung der Sonme preisgegeben, stirbt die Rinde an der Stelle ab. an weleher die stärkste Insolation und Erhitzung erfolgnt; hierher zählen z. B. Buchen, Hainbuchen, Weibtamen, Zelkowa, Macnolien.

2. Auch bei Borke bildenden Bäumen tritt Rindenbrand auf, wenn diese plötzlich aus dem Bestandsschluß in den Freistand geraten. Bui ihnen ist die bei mangelhafter Licht- und Wärmemenge, aber erhöhter. Luftfeuchtigkeit gebildete Borke dümn oder fehlt überhaupt noch ganz.

Es war wohl Verfasser der erste, der 1st. bereits nachwies, daf freistehende Bätme früher die Borkenbildung beginnen zum Sichutze gegen Extreme in Temperatur und Verdunstung. Werden erwachsene Bäume freigestellt, ist Rinderbrand an den dickborkigsten wie Eichen. Lärchen, Föhren unbekannt. Die dickborkigen Holzarten sind zugleich Lichtpflanzen, welche schon von Jugend auf einer stärkeren Erwärmung ihrer Rinde durch Besonnung ausgesetzt sind.

3. Je mehr der Auffallswinkel der Sonnenstrahlen einem rechten sich nähert, um so größer ist die Gefahr: die Übergangsstellen rom Schaft zur Wurzel, die Oberseite der stärkeren Äste, die uber dem Boden herausragenden Wurzeln sind am meisten durch Rindenbrand gefährdet.

4. Die Beschädigung ist auf die Zeit der höchsten Lufttemperatur beschränkt, welche 1-2 Stunden nach dem höchsten Stand der Sonne sich einstellt; damit ist auch ausgesprochen, daß ein nach SSW orientierter Längsstreifen im bestehenden Schaft als die Anfangsstelle für die rindenbrandige Fläche zu betrachten ist.

5. Nur nördlich rom $30 .{ }^{0}$ nördl. Br. kanm an glattrindigen S'chäften Rindenbrand auftreten; an südlicher stehenden Bäumen wird der Schaft durch die Krone gegen die Sonne zur heißesten Tageszeit geschützt; der Schaft selbst kann nur unter spitzem Winkel getrofien werden. Zur Zeit des rechtwinkligen Auffallens der Strahlen hat die Somme entweder ihre höchste Kraft noch nicht erlangt oder bereits wieder rerloren.

Luftfeuchtigkeit und Regenmenge. Schon ans der trüheren Zonenbildung kann entnommen werden, daß während der in erster Linie entscheidenden Tegetationszeit Lufteuchtigkeit und Vietlerschlagsmenge innerhalb der Waldgebiete sehr vershieden sind: dennoch ist der Charakter der Waldungen ein gleichnäBiger, diesellw. Holzart tritt waldbildend auf, mögen $\delta 10 \%$ oder $\$ 1)^{\circ}$ o relative Feuchtiz. keit, 100 oder $1001 \mathrm{~mm}$ Niederschlag während der vier Nonate Mai bis August zur Verfügung stehen. Es gibt eben wio ein Minimum flu die Waldexistenz so auch ein Maximum der Luftenchtigkeit und der Niederschlagsmenge, über das hinaus den Holzarten kem Vurteil erWächst; bei $70 \%$ relativer Fenchtigkeit und hei Inu mu Romenmente 
während der Yegetationszeit kann jede Holzart gedeihen; ïber diesen Betrag hinans wird nur noch die Verjüngung der Holzart, sei es die durch Menschenhand herbeigeführte, künstliche, oder die natürliche erleichtert und gesichert.

An die Waldgrenze jedoch, wo das Minimum an Luftfeuchtigkeit und Niederschlägen nach einer früheren Darstellung auftritt, rücken nur wenige Holzarten heran. Diese sind es, welche die durchschnittlich trockenste Luft, somit den größten Wechsel in Luftfenchtigkeit bzw. das Minimum an Bodenfeuchtigkeit ertragen. So treten bis an den Rand der Präric oder Steppe vor die Föhrensektionen Pinaster, Iurraya, Jeffreya, alle winterkahlen Eichen, Cupressus und andere; auf das Zentrum großer Waldmassen, in enge, windgeschützte, feuchte Schluchten, in höhere Regionen, unmittelbar an das Meer, an Flüsse und Seen und ihre Inseln ziehen sich zurïck die Gattungen Thuja, Taxodium, Chamaecyparis, die Föhrensektionen Strobus und Cembra, die Gattungen Picea, Abies, Taxus, Larix und andere. Baumgattungen wie Juniperus, Betula, Alnus, Populus (Zitterpappel) gedeihen in trockenen und in feuchten Klimaten. Daß mit dem wärmeren Standort einer Holzart größere Bodenfrische, mit dem kühleren geringere Bodenfenchtigkeit geboten werden muß, wurde bereits angedeutet.

Bei gleichbleibender Temperatur, aber erhöhter Luftfeuchtigkeit und Bodenfrische ist eine Steigerung der Zuwachsgeschwindigkeit bei allen Pflanzen nachweisbar. Steigerung der Luft- und Bodenfeuchtigkeit bei gleichbleibender Temperatur ist nur möglich bei gleichzeitiger Bewegung in ein wärmeres Klima; denn erhöhte Luft- oder Bodenfenchtigkeit setzt die Temperatur herab. Damit sie dem trockneren Standorte gleich wird, muß man die Pflanzen in wärmere Gebiete verbringen. Es ist gewiß kein Zufall, daß die warmen, luftfenchten Küisten des größten Feuchtigkeitsspenders, des Stillen Ozeans, die schnellwüchsigsten Holzarten, die größten Baumriesen der nördlichen Halbkugel, aber auch unter den zonengleichen Baumgattungen die winterweichsten Arten tragen.

Erhöhte Feuchtigkeit in Luft und Boden erleichtert das Gelingen aller waldbaulichen Maßnahmen, welche die natürliche und künstliche Begründung sowie auch die Erziehung des Waldes zum Ziele haben. In den luftfeuchtesten und regenreichsten Waldgebieten ist es kaum möglich, eine Verjüngungsmethode zu erfinden, die nicht zum Ziele führen würde; in den Gebieten mit schnell wechselnder Luft- und Bodenfenchtigkeit aber, z. B. in der warmen Ebene, auf den trockenen Kahlflächen, hat die Praxis anmähernd so viele Methoden der Waldbegründung ersomen, als es Wirtschatter gegeben hat.

Erhöhte Luftfeuchtigkeit mindert stets die Frostgefahr; trockene Luft kühlt sich durch Ansstrahlung rascher ab als feuchte. Längere Trockenperioden sind der Schrecken aller Wirtschafter im Walde. Für 
Saat- und Neuptlanzungen wäre es erwünscht. wenn jeden zweiten Tay während der Vegetationszeit Regen fiele; fïr Ptlanzen, welche bureits mehrere. Jahre im Boden fußen, wïrle es genüren, wenn sich alls acht Tage Regen einstellen würde; an erwachsenen Bämen grhen 'Trockenperioden längerer Daucr während der Vegetationszeit spurlos voribur. Untersuchungen des Verfassers ergaben, dafintolere abmormer 'Trockinis, z. B. 1905, die Bäume je nach Individuen balıl stärkeren, halı schwächeren Zuwachs zeigten als in .Jahren mit normaler Lutt- und Bodenfeuchtigkeit, woraus der schluß berechtigt ist, daß Trockenperioden auf den Zuwachs erwachsener Bäume keine sofortige Tirkung ausüben; nach Cieslar und Hesselmann tritt dio Wirkung crst im nächsten .Jahre (1906) ein.

Über das Minimum an Luft- und Bodenfeuchtigkeit, das bei alljährlichem Auftreten von Trocknis währond der Tegetationszeit zur Existenz von Wald überhaupt notwendig ist, wurde bereits im ersten Abschnitte das Nötige mitgeteilt. Es wurde früher betont, daß die Pflanze durch ihre ober- und unterirdischen organe Feuchtigkeit aufnehmen kann, wenn beiderlei Organe mit Wasser in Berührung kommen; für die oberirdischen Organe genügt auch, daß diese bis zum Taupunlit der umgebenden Luft sich abkühlen, um mit Wasser sich versehen zu können; ja, ehe noch tropfbares Wasser als Tau erscheint, nehmen oberirdische Baumteile hygroskopisch Wasser auf.

Es mag hier erwähnt werden, duß dem Baume noch eine Feuchtigkeitsquelle zur Verfügung steht, welche bis jetzt unbeachtet geblieben zu sein scheint. Während der Vegetationszeit, zumal nach warmen, luftfeuchten Nächten oder bei raschem Witterungsumschlag von kïhl zu warm, kann beobachtet werden, daß der unterste halbe Meter des Schattes, besonders von glattrindigen Bäumen, trophnaß ist, ja, daß das Wasser am sichafte abfließt und den Wurzeln entlang in den Boden gelangt ${ }^{1}$ ). Was ist Taumiederschlag aus der feuchteu Luft, nicht infolge Abkühlung der Luft, sondern infolge der Abkühlung des Baumschattes, kühl durch direkte Leitung der Temperatur von unten nach oben, kühl curch die Wasserbewegtung aus den kïhleren Bodenschichten; am lebhattesten ist deshalb dieser Vorgang nach Sonnenautgang, wemn mit der Terdunstung der aufsteigende Wasserstrom lebhatter im Banme wird: der Einfluß erstreckt sich aber nur auf die oberen Wurzeln und pinen halben Meter hoch im s'chafte, da eben hüher hinauf der EinfluB der Abkühlung des Schaftes durch den Wasserstrom erlischt. Der Vurgang dauert an freistehenden Bämmen nur kurze \%eit, weil mit der zumehmenden Erwämung der sichaft sich erwärme und die umprobente Luft trockener wird. Im Bestandsinnern rölt sich dieser Virzang,

2) Weise erwähnt in seinem Leitfaden zum Waldbau diese Betaung. dutet aber ihre Entstehung anders und erwähnt ron der Bedrutung dieser Wassmpurlle nichts. 
den man die Selbstbegiefung der Bäume nemnen lam, mehreve Stunden. Auch an borkigen Bäumen geht derselbe Prozeß vor sich, wenm anch tropfbares Wasser nicht sichtbar wird. Der Moos ansatz, den wir am Fuße der Bäume finden, verdankt dieser Wasserquelle sein Dasein.

Die Menschen beurteilen die Härte des Winters nach seiner Schneemenge und nach seiner Dauer: der Winter 19196/ war auf der bayerischen Hochebene auferordentlich schneereich und dauerte bis zum Mai; er war durch seine Trübung des Himmels, durch den Schnee, durch seine Abkürzung des Frühjahrs der mildeste Winter für die Pflanzen; der Winter 1907/08 war sonnig, kalt, schneearm; er war der ärgste Pflanzenverderber seit Jahren.

Schnee ist das Federbett der zarten, jungen Pflanzen während des Winters: unter dem Schnee erfriert nichts: auf dem Schneo liegt die tiefste und gefährlichste Wintertemperatur. Schree in außerordentlichen Mengen kann alle Pflanzen schädigen; aber gegen normal eintretende, große Schneemassen schützen sich die Bäume selbst, nicht durch eine liriechende Form, sondern durch Ausbildung einer eigenen Schneekrone mit fast vertikal von oben nach unten hängenden Ästen an den aufrecht bleibenden Bäumen.

Wind. Wind scheint für das Leben der Bäume notwendig zu sein; kräftige Windbewegung wirkt saugend und drückend auf die Luft im Boden wie auf die Spaltöffinung der Blätter und die Lentizellen der Rinde; bei dem Aufprallen des Windes drückt er die Binnenluft zusammen, bei dem seitlichen Berühren saugt und verdünnt er dieselbe. Das langsame Wachstum der Bäume, der erhöhte Flechtenansatz in völlig ruhigen, mit höchster Luftfeuchtigkeit gesättigten Schluchten dürfte neben dem Nangel an größeren Temperaturdifferenzen auch dem Mangel an Luftbewegung zuzuschreiben sein; wie weit dieser Faktor auch die Entwicklung der allzu dicht geschlossenen .Jungwüchse und Bestände beeinträchtigt, verdient weitere Untersuchungen. Daß das Übermafo von Windhäufigkeit und Windstärke schädigt, bedarf keiner Erwähnung. Wind, der regelmäßig nur von einer Seite weht, verhindert die Ausbildung der Äste nach dieser Seite hin: an Küstenbäumen entwickeln sich Kronen vorzugsweise nach der Landseite zu, auf den höheren Bergen Mitteleuropas zeigen alle Nadelbäume der Westhänge, wo jahraus, jahrein nur. Westwind weht (demn auch der Ostwind weht auf der Westseite des Berges als Überfallswind von unten nach oben, also wieder westlich), das Fehlen der Äste auf der Westseite, ihre stärkere Entwicklung nach Osten hin.

Die Beschädigungen, welche Schnee und Wind dem Walde zufügen kömnen, teilen sich in drei Gruppen. Schneebruch und Windbruch bestehen im Brechen der Äste und Schäfte durch Schnee und Wind; Windwurf und Schneedruck nemnt man das Umstürzen 
der Bäume durch diese Einflïsse; Windschub und Schneeschub ist Schiefdrücken unter Zerrung der Wurzeh. Über din Widerstandskraft gegen Bruch entscheidet neben den hronenverhältnissen das IIol\% der Holzarten; an exponierten Örtlichkeiten bildet sich, jo nach Holzart, eine Krone geringster Widerstandstläche in spindelartiger oder horizontalflacher oder etagenartiger Ausformung; eine typisehe Schurekrone besitzt vertikal abwärts hängende Äste; jo sprörler ein Holz, lesto brïchiger; es steht hierin unter den gefährdetsten Holzartnn, obenan die Föhrensektion Jeffreya ; daran reiht sich die Sektion Pinaster, daran Murraya; unter den Laubbäumen sind die Robinia, der eschenblättrique Ahorn besonders empfindlich. Es entscheidet sodann die Bewurzelung der Holzart; tief wurzelnde Holzarten, wie Lärchen, Föhren, Eichen, sind fester als die seicht wurzehnden Fichten. Gegen Schneedruck sind besonders empfindlich die am dichtesten geschlossenen Stangenhölzer, insbesondere der Nadelbäume und der mit verdorrten Blättern ïberwinternden Laubbäume. Unter den Nadelbäumen sind wierlerum am meisten gefährdet Picea, Pseudotsuga, Chamaecyparis, Tsuga, Abies, Pinus; gegen Windwurf sind die erwachsenen Stämme genannter Narlelbäume, voran die seicht wurzelnde Gattung Picea, gefährdet. Soweit hierbei die Bewurzelung mit entscheidet, kann natürlich auch der Boden, in welchem je nach seinen Eigenschaften die Bewurzelung der Bäumo sich ändert, die Gefahr erhöhen oder abschwächen. Es wird später gezeigt werden müssen, daß in der Erziehung der Bestände, in der dadurch bedingten Abänderung der Kronenverhältnisse und des. Standraumes die wichtigsten, waldbaulichen Mittel zur Bekämpfung aller Gefahren durch Schnee und Wind gelegen sind.

Gegen Hagel, der zur Zeit der Streckung der Triebe im .Juni und Juli niederstürzt, sind alle Holzarten empfindlich; ob die Beschädigung von dem weichen, eben sich bildenden Trieb noch weiter abwärts auf die älteren Teile der Pflanzen sich erstreckt, hängt natïrlich auch von der Glattrindigkeit dieser Organe und von der Größse der Haggelkörn!r $\mathrm{ab}$; es sind Fälle bekannt, daf von den Hagelliörnem die Rinde der Fichten und Föhren bis zur starken Borke herab weggeschlagen wurde, so daß die Stämme gefällt werden mußten. Jedenfalls ist so viel erwiesen, daß der Wald ebenso verhagelt wird wic die landwirtschaftlichen Gelände, und daß es keine Mittel gibt, die ('iefahr alizuwenten oder den Schaden zu mäfigen: die erste Jugrend mag nuter dun Schirme der Althölzer Deckung finden.

Das Licht. Das Licht ist für jeclen Punkt der Errolerertich he ein in seiner Quantität wechselnder Faktor; es verhält sich wi mulere Faktoren des Klimas, vor allem wio Würme, und wird dahere oflist zlum Klima gerechnet. Die Kenntnis des Lichtyuantums unter rerechiedenen Breitengraden, bei verschiedenen Expositionen und Elevationun int die Grundlage für die Feststellung des Lichthlimas einos stamblerte. 
Wie die Quantität des Lichtes nirgends die gleiche, wenn anch auf großen Flächen hin anmähernd gleich, ist auch die (qualität, die Spektralzusammensetzung des Lichtes wie es scheint nicht die gleiche. Licht ist für das Pflanzenleben absolut notwendig. Ilie Bedeutung des Lichtes im Walde ist den ältesten Schriftstellem des Waldbaues nicht entgangen: solange es eine Naturverjüngung für die Buche gibt - und diese ist bereits mehr als hundert Jahre alt —, hat man der Lichtmenge, welche in den einzehnen Stadien der Verjüngung der Jugend zu geben ist, ein besonderes Augenmerk zugewendet: die alte Bezeichnung "Lichthieb" ist ein Beweis hierfür. Mehr als hundert Jahre alt ist die Feststellung durch die forstliche Praxis, daß es Holzarten gibt, welche bei Lichtentzug schneller kümmem als andere, worauf sich die Unterscheidung ron Licht- und Schattenholzarten gründet. An diesem Ergebnis der Praxis hat anch die erst in den beiden letzten Dezennien einsetzende, wissenschaftliche Erforschung des Einflusses des Lichtes nichts zu ändern, nur zu bestätigen und zu begründen vermocht.

Es muß zugestanden werden, daß mancher Praktiker etwas zu weit ging, wenn er alles Kümmern der Pflanzen unter Schirm allein dem Lichtentzug, statt einer sich gegenseitig verstärkenden Wirkung von Lichtund Wassermangel zuschrieb; es war aber sicher ein Fehlgriff, wemn Borggreve und Fricke die Behauptung aufstellten, das ganze Dogma vom Lichtbedürfnis und Schattenerträgnis der Holzarten sei falsch; wäre in der bisherigen Auffassung von der Abhängigkeit der Holzarten vom Lichte ein Fehler, so hätte die vielküpfige, langjährige Praxis ilın längst herausgefunden.

Es war Theodor Hartig der zuerst eine Methode zur Messung der Lichtintensität im Walde mittels lichtempfindlichen Papieres behufs Feststellung des Durchforstungsgrades angab. Unabhängig ron $\mathrm{H}$ artig. hat Professor Wiesner ${ }^{1}$ ) in Wien bereits seit mehreren Dezennien sich der Erforschung der Bedentung des Lichtes für das Pflanzenleben gewidmet, und die Forstwirte schulden dem Gelehrten den wärmsten Dank, denn er ist es, welcher die erste Grundlage für eine wissenschaftliche Erklärung und Bekräftigung der bisher von der Praxis gewonnenen Erfahrungssätze beigebracht hat: Wiesner war der erste. der eine Methode zur Messung der Lichtintensität erfand, welche es ermöglicht, ausgedehnte Untersuchungen unter den schwierigsten Verhältnissen z. B. im Bereich der Baumkronen verschiedener Holzarten, rerschiedenen Alters auszuführen.

Um Lichtquelle und Lichtquantum auch in Worten, schärfer, als dies bisher geschehen ist, ausdrücken zu können, ist es notwendig, daß in den waldbaulichen Sprachschatz eine Reihe von neuen Begriffen eingeführt wird; ein Teil dieser stammt ron Untersuehungen auf land-

1) Professor Dr. Wiesner, Der Lichtgenuß der Pflanzen. 1907. 
wirtschaftlichem Gebiete, der größte Teil ist von Wiosner sellut: für forstliche Bedürfnisse hat Verfasser einige livizu gefügt.

Das Tageslicht ist eine Wirkung der von der somne ausgrehendun Lichtwellen, welche auf die in der lufthülle vorhandenen, kileinsten Teilchen, Stäubchen, Wassertröpfchen auftreflen und ron diesen nach allen Richtungen hin zerstreut werden. Dieses Licht, das bei hedecktem Himmel allein scheint, heiß3t diffuses Licht. Verfasser ${ }^{1}$ ) hat schon vor Jahren auf Grund ron Beobachtungen ïber das Lichtbedürfnis verschiedener Holzarten in Versuchswalke zu Grafrath den Satz aufgestellt, daß für das Wachstum aller Holzarten das diflinse. bzw. das ron den Wolken reflektierte Licht dem Pflanzenleben, das ist der Assimilation der grïnen Organe, am zuträglichsten sei. Wiesner hat durch seine Untersuchungen diese 'Tatsache vollauf' bestätigt. Das direkt gestrahlte Sonnenlicht ist so intensiv, daß die Pflanzen sich gegen die „Übersonnnng", wie man diese schädliche I.ichtwirkung nennen kann, durch Veränderung der Blattstellung oder Änderung in der Chlorophyllkornstellung (nach Stahl) zu schützen suchen. An klaren Tagen herrscht das "gemischte" Licht nach Wiesner, d. h. diffuses und Somnenlicht. Das diffuse Licht nimmt nach Norden wie auch an den Bergen nach oben hin ab, das sonnenlicht nimmt nach Norden hin ab, nach oben hin zu. Arktische oder Polarregionen und alpine Regionen können in Wärme und Luftfenchtigkeit gleich sein; in ihrem Lichtklima bestehen große Unterschiede. Das Höhenklima zeigt während der Vegetation der Pflanzen große Schwankungen in der Lichtintensität, in nordischen Regionen wird das Lichtlkima wegen der geringen Mittagssonnenhöhe gleichmäßig: dazu kommt, daß in geringen geographischen Breiten die Nordseite der Bäume am wenigsten belichtet, im Norden dagegen am stärksten belichtet wird. In den Polar- oder arktischen Gebieten nehmen die somenlosen Tage zu, das diffuse oder zerstreute Licht kommt zur größten Geltung.

Nur ausnahmsweise steht ein Baum unter Einwirkung des vollen Lichtes, das ron dem gesamten Himmelsgewölbe und dem Himmelskörper ihm zugestrahlt wird: andere Bäume. Unebenheiten des Geländes schneiden ihm einen Teil des zugestrahlten Lichtes ab, so daß der Lichtgenuß eines Baumes kleiner als das gesamte Licht ist; denkt man sich an der Außenseite der Krone eines Baumes eine lichtabfangende Hülle gelegt, so ist anch die auf diese Hülle strahlende Lichtmenge immer unch bedeutend größer als jene Lichtmenge, welche der Baum mittels seiner Blattflächen auffangen und nutzbar machen kann. Jene Lichtmenge die dem Banme zuströmt und ron diesem rerarbeitet. 1. h. ahsirbicrt

1) H. Mayr, Naturgesetze des Waldbaues. Allgemeine Forst- wal Jaglzeitung 1901 . 
91; Dritter Abschnitt. Naturgesetzliche Grundlagen der einzelnen Baumarten usw.

wird, heißt der relative LichtgenuB: er ist wahrscheinlich auch der Maßstab für das relative Lichtbedürfnis des Baumes.

Das dem Baume zuströmende Licht zerlegt Wiesner in:

1. Oberlicht $(a)$, das ist das vom Himmelsgewölbe auf die Außenseite der Kronen strahlende Gesamtlicht;

2. Unterlicht (d), Licht, das von unten her von hellem Boden, Wasserflächen, von den Blättern der Unkräuter und Unhölzer ${ }^{1}$ ) in das Innere der Baumkronen einströmt;

3. Lichtintensitätsminimum (b), im absterbenden Teil der Kronen gemessen, ist somit jene Kronenlichtmenge, bei der die Blätter sich noch am Leben zu erhalten, d.h. zu assimilieren vermögen; für wald-

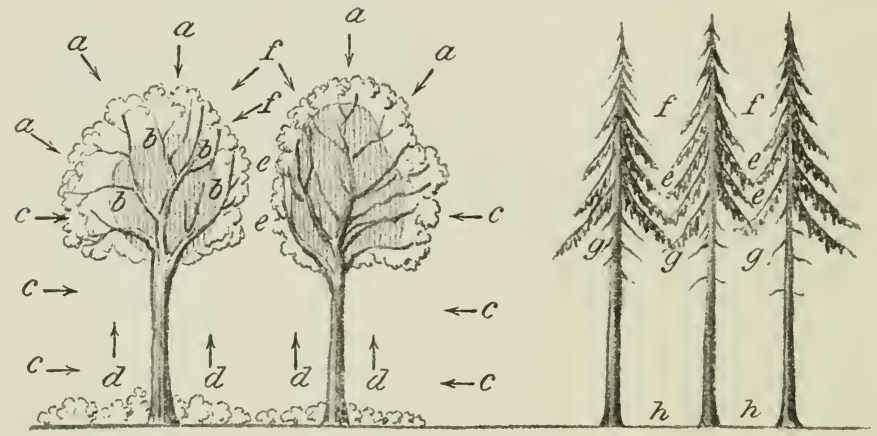

Abb. 5. Einwirkung des Lichtes. "“ Oberlicht, bb Lichtgenu(Bminimum (Baumkronenlicht), $c c$ Vorderlicht, dd Unterlicht, $\epsilon \epsilon$ Hinterlicht, ff verschleiertes Licht, gg Bestandesschlußlicht, lh Bestandesschattenlieht.

bauliche Zwecke ist dieses Licht von hoher Bedeutung; es wäre daher vielleicht als "Baumkroneninnenlicht" statt des "Licht intensitätsminimums" zu bezeichnen:

4. Baumschattenlicht, das gedämpfte Licht des Baumschattens, dem noch

5. Vorderlicht $(c)$ zufließt;

1). Hinterlicht (e); es ist gegeben, wenn eine Beeinträchtigung cles Lichtzuflusses von der Seite her durch Berge, Mauern, Schlagwände und Bäume stattfindet. Für waldbauliche Bedürfnisse ist aber obige Einteilung IV iosners noch nicht erschöpfend.

7. Das Licht, das den Kronen eines aufwachsenden Bestandes von oben zuströmt, ist nicht das volle Außen- oder Oberlicht des einzenenl und freistehenden Baumes, es ist ein durch Nachbargipfel gedämpftes Licht, das Wiesner "verschleiertes Licht" $(f)$ nemnt.

') Nach Wagner, Pflanzenphrsiologische Studien im Walde. 1907. 
8. Bestandskroneninnenlicht oder BestandssehluB. li cht $(\mathrm{g})$ ist von dem hroneninnenlicht des einzehnstehendinn Bammes inso. fern verschieden, als ilım das Unterlicht fehlt, wele hes dem fireistehenclen Baum zugute kommt. Zur Zeit des somnenuntrganges lringen lichtstrahlen in die Krone des freistehenden Baumes; im Bustandsschlub werden diese Strahlen von den Stämmen mud Ästen ahgetangren. Dieses Innenlicht der Bestandskronon wechselt je nach der BestandsishluBdichte.

9. die Bodendecke und ihre Vegetation unterhall, der Baumkronen steht unter der Herrschaft eines Lichtes, welches man Bestandsschattenlicht (h) nemnen kamn; dieses ist das schwächste Licht und rom Baumschattenlicht durch den Mangel an Vorderlicht ausgezeichnet. Dazu kommt, daß von dem Licht, das die Baumbrone durchdrungen hat, nur jener Teil zum Boden gelangt, der von den dürren Ästen und Schäften nicht abgefangen wurde. Wi es ner berechnet das Lichtgrenuß minimum (3) für jede Pflanze in einem Bruch, zum Beispiel 1 20, welcher besagt, daß die Pflanze im Licht 1 einer durch intensivste Schwärzung des lichtempfindlichen Papieres festgelegten Einheitszahl bis z u $1 / 20$ dieser Lichtintensität sich entwickeln kann sinkt das Licht auf ${ }^{1}{ }_{21}$, so würde dies bedeuten, daß das Blatt zwar ergrünen aber nicht mehr assimilieren kann. Das Blatt muß bei einer Lichtintensität 1/20, wie Wiesner sagt, vertrocknen, wie Verfasser glaubt verhungern, das heißt durch Stoffwanderung in die Herbstfärbung und Ablösung iibergehen. Für die betreffende Pflanze ist somit ${ }^{1} \geq 0$ das I icht intensitätsminimum.

Jede Pflanze besitzt ein Optimum der Lichtintensität, bei der sie am vollkommensten gedeiht; dieses Optimum liegt bei den meisten Holzarten dem Maximallicht (1) näher als dem Minimum (3). Die forstlicheu Kulturpflanzen wechseln ihr Lichtbodïrinis während ihrer Entwicklung: soll eine Holzart Nutzbaum werden, muß ihr während eines bestimmten Zeitabschnittes. Hanptlängenwachstumszeit genannt, eine größere Lichtmenge geboten werden, als anfänglich zum schutze und später in hauharen Alter notwendig ist. Das Lichtquantum muß größer sein als das Minimum des Lichtgennsises. In der Jugend geht die waldbauliche Behandlung vicler Holzarten bis hart an die Grenze des Maximums der Überschirmung, somit des Minimums der Belichtung der überschirmten Pflanze, wolwi nicht der Entzug des Lichtes Zweck, sondern Mittel zum Z/werk. des Sichutzos der Verjüngung gegren Übersonnnng, Vertrocknung. Frost ist. Wie Kunst der Begrïindung des Waldes und seiner Erziehmer wahreml the Stangen- und Baumalters besteht in der Regrelume les I icbigenumes.

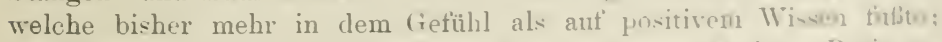
durch Wiesners Lichtmeßmethode hat sie wine zuverlia-iurere Basis or halten. Doch bedarf es noch eines mähtigren Fortscluritos der meluen Mayr, Waldbau. 
Wissenschaft rom Licht, speziell in ihrer Anwendung für forstliche Kulturpflanzen und ihr Leben, um auch noch die Beziehungen feststellen und messen zu können, welche zwischen Licht und Wärme, Licht und Bodengüte im Pflanzenleben bestehen; der Aufhellung bedarf noch das qualitativ verschiedene Licht und die qualitative Selektion (Zederbauer) ron Seite der Bäume. Eine andere Beziehung besteht darin, dab im Walde jede Maßnahme, welche die Lichtgebung erhöht, auch zugleich eine Erhöhung des Wärmeund des Wassergenusses mit sich bringt.

Über den Einflußder verschiedenen Lichtarten im Walde läßt sich einstweilen folgendes feststellen:

1. Das Oberlicht, welches das Maximum an zerstreutem oder diffusem Licht enthält, bedingt die Anordnung der Blätter an den Sprossen, ihre Lage zum Licht, die Stellung der Zweige, um den rom Licht durchfluteten Innenraum der Krone möglichst auszunützen (Blattund Zweigmosaik); der Längs- oder Gipfeltrieb strebt dem stärksten, zerstreuten, nicht dem Sonnenlichte zu; dieses Streben wird unterstützt durch die Schwerkraft, welche eine symmetrische Ausbildung aller Anhangsorgane des Haupttriebes, der zum Gipfel, zum Schaft des Banmes wird, behufs Herstellung des Gleichgewichtes hervorruft; geht der Gipfeltrieb verloren, überträgt sich diese Wirkung des Oberlichtes und der Gleichgewichtslage vielfach auf einen Seitentrieb.

2. Das Unterlicht ist in der Regel so schwach, daß sein Einfluß nicht nachweisbar; Wagner (l. c.) hält es in seinen pflanzenphysiologischen Studien für wichtig als Lichtquelle für die Baumkronen; nur wenn das Unterlicht von Wasserflächen reflektiert wird, wird es als Lichtquelle zum Ziel, dem die Unteräste der Bäume zustreben.

3. Das Baumkroneninnenlicht oder das Lichtintensitätsminimum ist jener Bruchteil des Außenlichtes, bei dem die Assimilation der Blätter noch nicht ganz unterdrückt ist. Diese Zone im Kronenraum liegt bei Schattenholzarten näher der Außenseite der Kronen als bei den Lichtholzarten, weil bei ersteren die Blätter sich an ihren Kronenhüllen anhäufen, bei letzteren die Belaubung spärlich, die Krone offener und für Licht tiefer durchdringbar ist. Blätter, welche durch die Blattzunahme der Krone während der Vegetationszeit in einen Lichtgenuß geraten, welcher geringer ist als das Minimum, müssen absterben; mit ihnen sterben auch die sie tragenden Zweige und Äste ab. Wiesner glaubt, daß dem Absterben eine Vertrocknung zugrunde liege. Verfasser glaubt, wie erwähnt, daß es um ein Verhungern sich handelt. Alle diese Vorgänge sind bei dem einzelnen Baum verlangsamt und in ilhrer Wirkung beeinträchtigt. In vollkommener Weise vollzieht sich dieser Prozeß der Astreinigung bei dem Bestandskroneninnenlicht (8). 
Das Lichtintensitätsminimum reduziert die Zahl der Zweigrordnungen durch ungenügende Belenchtung der lichtberlürttigen Knospen. Nimmt man z. B. einen Birkenzweig mit zwei S'eitenknospen, so müßten ans diesen, wenn im nenen Jahre jedesmal zwei hinspen zu Trieben sich entwickeln, im zehnten Lebensjahre 19683 \%weige hervorgehen, welchen $10-1$, d. h. nem Jahresbildungen oder /wreigordnungren entsprechen müßten. Wiesner fand nun an einem von der sonne getroffenen, zehnjährigen Birkenzweig nux 238, an einem in Schatten stehenden Zweig nur 182 Seitenzweige und statt der neun Zweigordnungen nur deren fünf. Offenbar sind jene Holzarten, welche die geringste Zahl der $/$ weigordnung aufweisen, die lichtbedürftigen, jene mit der größten $/$ ahl die am besten Schatten ertragenden Holzarten. Wiesner stellt folgende Reihen auf:

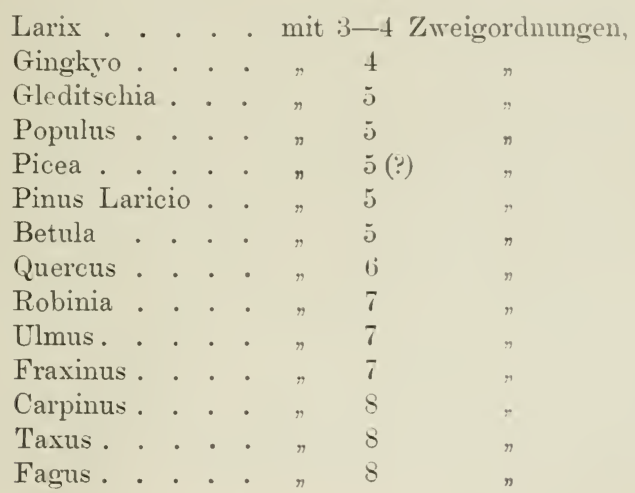

Ton obigen Gruppen wäre die erste mit den Lichtholzarten, die letzte mit den Schattenholzarten, forstlich gesprochen, identisch. Es fällt die Fichte auf, welche nach der gefundenen $Z$ weigordnung zu den Lichtholzarten geraten würde. Es ist aber zu bedenken, daß die $Z$ Wweigreduktion nicht ausschließlich eine Wirkung des minimalen Lichtgenusses ist; gerade bei den alten Fichten ist Beseitigung ron Zweigen durch Tiere, besonders durch Eichhörnchen, durch Wind sehr häıfig: vielleicht hat ein solches abnormes Exemplar vorgelegen.

4. Das Schattenlicht wirkt in seiner Kombination als Kronenschirmlicht und Vorderlicht; letzteres ist das stärkere; es bewirkt daß die Äste im Schattenlicht stehender Pflanzen dem Vorderlicht sich zuwenden, die Pflanzen sich somit einseitig entwiskeln.

5. Das Vorderlicht regt die Knospen der Seitenzweige zur Entwicklung an; die Seitenzweige wachsen dem Vorderlichte zu. I) ie Ausbildung der Bestandsränder, die Umsäumungen der Bestandslücher sind Wirkungen des Vorderlichtes, das in der Astentwicklung forstlich 
ungünstige Verhalten gruppenweiser und stammweiser Holzartenmischung ist Folge des in den Bestand durch die Mischung hineingetragenen Vorderlichtes.

6. Das Hinterlicht zwingt wegen seiner Schwäche die meisten Äste zum Absterben; nur jene entgehen, welchen die Fähigkeit innewohnt, sich aufwärts, dem Oberlichto zuzuwenden; dadurch entsteht die in Figur 5 abgebildete Astbildung.

7. Das verschleierte Licht ist jenes Licht, welches den über das Kronendach des Bestands hinausragenden Gipfeln zukommt, es ist somit in seiner Wirkung gleich einem abgeschwächten Oberlicht.

8. Das Bestands sehlußlicht, das Kroneninnenlicht der Baumvereinigungen, wirkt wie abgeschwächtes Ober-, Vorder- und Hinterlicht, es zwingt somit die Ïste zur Aufwärtsbewegung nach dem Oberlicht, wie dies unter 6 erwähnt wurde: darans folgt, daß im lebenden Teil der Baumkrone die Äste nach oben, im absterbenden Teil horizontal und im toten Teil nach abwärts gerichtet sind, wie dies auch Dr. Metzge r in seinen Studien über den Aufbau der Schäfte bereits gezeigt hat. Diesem Typus folgen im Bestandsschlusse Laub- und Nadelbäume. Um die Erhöhung oder Herabsetzung dieses Bestandsschlußlichtes drehen sich die verschiedenen Meinungen bezüglich der Stärke der Durchforstungen, der Durchlichtungen, der ganzen Erziehung eines Baumes im reinen und gemischten Bestand von seiner Begründung bis zur Haubarkeit. Es erscheint dem Verfasser jedoch zweifelhaft, ob durch die Lichtmessung ein Maßstab für jeden speziellen Fall gewomnen werden kann; die reinen Bestände werden am ehesten nach einem roraus bestimmten Lichtgrad sich durchforsten lassen; bei den gemischten Beständen tritt die individuelle Behandlung der einzelnen Stämme allzusehr in den Vordergrund.

9. Das Bestandsschattonlicht, wegen der Schäfte und Äste noch schwächer als das Bestandsschlußlicht, entscheidet mit dem Falitor Wasser über das Gelingen aller Verjüngungen unter Schirm, seien sie natürlich oder kïnstlich; Pflanzen, die an Licht Mangel leiden, können nicht durch Wasser gerettet werden; Pflanzen, die an Wasser Mangel leiden, können durch mehr Licht gerettet werden, denn die Durchlichtung der Baumkronen schafft Licht und Wasser zugleich. Das Bestandsschattenlicht ist jener Rest von Licht, der durch die Baumkronen, die diurren Äste hindurch bis zum Boden gelangt. Es ist die Kunst des Waldbanes, dieses Licht in seiner Menge so zu regeln, daß die Sämereien keimen und aufwachsen unter den verschiedenen Ernährungsbedingungen, welche ihnen die Verschiedenheiten des Bodens bieten. In der Regelung des Lichtgenusses, in der möglichsten Vermeidung des für das Aufwachsen der Pflanzen notwendigen Minimums, in der Darreichung des den Zweeken des Schutzes noch zuträglichen Maximums an Licht bzw. Minimums der Beschattung beruhen die 
wichtigsten Aufgaben der natürlichen Wierlerverjüngung. Sinkt das Bestandsschattenlicht unter das Minimum, so kamn div PHanze zwa ergrünen, aber nicht assimilieren, sie muls allmählieh zugrunde guhen; wird ihr mehr Licht geboten, so bedingt eine schwache Assimilation ein langsames Aufwachsen und eine Verbreiterung der Kronc, eine Verflachung, wie sie bei don meisten Laul)- und Nadelhölzorn auftritt, oder auch eine dünne, schlanke Säule, wie sie z. B. Juniperus zeigt. Das Bestandsschattenlicht entscheidet über die Verfassung ler Bodendecke, ob Laub- oder Nadeldecke, ob Begrünmng, ob beschlemnirte oder gehemmte Zersetzung der Abfallstofte, ob Rohhumusibilung u. dgl. auftritt.

Die Lichtintensitäten obiger Lichtarten im Walde und ihre fördernde oder schädigende Wirkung auf forstliche Kulturgewächse steht in Abhängigkeit von folgenden Umständen:

1. Ton der Zeit, in welcher einer Pflanze durch eine andere Licht entzogen wird. Lichtschmälerung außerhalb der Vegetationszeit, ist für winterkahle Holzarten sicher gleiehgültig. Auf den ersten Blick möchte es scheinen, daß die immergrünen Holzarten von der Belichtung während ảer Vegetationsruhe Gewinn ziehen müßten. WV i esner wenigstens erwähnt Bildung und Auflösung von Stärke an warmen Wintertagen bei den immergrünen Nadelbäumen; in die äußere Erscheinung tritt ein solcher Vorteil nieht. Die winterkahle Lärche wächst auf ein und demselben Boden anfänglich sogar viel sclineller als die immergrüne Fichte, welche sechs Monate länger, wemn auch vielfach unter ungünstiger Temperatur belichtet wird. Auch immergrüne Eichen haben den unmittelbar neben ihnen stehenden, winterkahlen Eichen gegenüber keinen Vorsprung in W uchsgeschwindigkeit oder Früchteerträgnis.

Zur Zeit der Knospenentfaltung ist nach Wiesnor ein erhöhter Lichtgenuß für alle Holzarten notwendig; so ist das Anfangsminimum der Belaubung bei der Lärche $1 / 2$ des vollen Lichtes, später sinkt dasselbe auf den Wert von 1/5 herab; bei der Buche ist das Anfangsminimum 1/4, später sinkt es auf $1 / 60$. Auch dies ist der forstlichen Praxis wohlbekannt; zur Erweckung der sehlafenden Knospe der Stöcke im Niederwaldbetriebe ist die Beseitigung des beschattenden Unkrautwuchses in der Umgebung der Stöcke ein altes, die $7 / a h l$ der Ausschläge förderndes Mittel. Zum Blühen und Fruchtansatz ist wieder etwas mehr Licht notwendig als zum bloßen Wachsen. Im gemäßinten, z. B. im verschleierten Kronenlichte des Bestandsschlusses, hegimnen sämtliche Holzarten später zu blühen als im vollen Freistand. Die Forstwirte berechnen die Terspätung auf durchschnittlich :-1) Jahru. Auch der uralte Vorbereitungshieb im geschlossenen Bustande fiur Verjüngungszwecke wird geführt, um den bleibenden stämmen mah licht zu bieten und sie zur Samenbildung anzuregen. 
102 Dritter Abschnitt. Naturgesetzliche Grundlagen der einzelnen Baumarten usw.

2. Ganz allgemein zeigt sich im Walde, daß es füx das Aufwachsen der.Jugend am günstigsten ist, wenn ihr Seitenbeschattung, somit verschleiertes Licht und auf der Südseite gedämpftes Vorderlicht geboten werden kann; wem aber wegen des Schutzes gegen Frost, Unkrautwuchs usw. statt der Seitembesehattung Schirmbesehattung gewählt werden muß, dann ist dieses notwendige Übel stets mit einem Verlust an Zuwachs in der Jugend wegen ungenügender Assimilation verknüpft.

3. Bei Übersehirmung, weniger anch bei seitlicher Besehattung, hängt die Intensität des Bestandsschattenlichtes von dem Lichtbedürfnis der ïberschirmenden Holzart ab; liegt das Lichtminimum dieser sehr tief, d. h. ist sie selbst sehattenertragend und deshalb ihre eigene Krone verdichtend, so gibt sie auch intensiven Schatten. Am stärksten ist die Beschattung unter geschlossenen Buchen, wo weder Buche noch irgendeine Holzart genügend Licht findet; daran reihen sich Abies, Picea und andere; am wenigsten beschatten die Lichtholzarten wie Eiche, Föhre, Birkie, Lärche und andere. Unter den Schattenholzarten könuten nur solche Arten noch wachsen, welche ein geringeres Lichtgenußminimum als die Schattenhölzer besitzen; unter den Buchen müßte eine Holzart ein geringeres Lichtminimum als ${ }^{1 / 80}$ des vollen Lichtes besitzen.

Wiesner gibt an, daß das Minimum des Buxus unter 1/100 herabgehe; aber niemand wird wohl an die Kultur des Buchses unter Buchen denken. Schattenhölzer unter voll geschlossenen Schattenhölzern sterben in der Regel schon nach 10-20. Jahren ab; Lichthölzer unter Schattenhölzern exliegen schon nach fünf Jahren. Schattenhölzer unter Lichtholzarten haben eine wegen genügenden Lichtgenusses unbeschränkte Lebensdauer; Lichtholzarten unter Lichtholzarten erhalten sich in der Regel 10-20 Jahre, also ebensolange wie Schattenholzarten unter Schattenholzarten.

4. Da der Lichtentzug durch die überschirmende Holzart sich nicht gleich bleibt, sondern zur Zeit des dichtesten Schlusses im Stangenholzalter sein Maximum erreicht, so können mur Schattenholzarten unter Lichtholzarten diese Periode des minimalsten Lichtgenusses überdanern.

5. Es besteht kein Zweifel, daß das wärmere Klima die Beschattungsdichte der überschirmenden Bäume erhölıt, dafür aber auch die Beschattungsfähigkeit der darunter stehenden Holzarten steigert.

6. Es dürfte auch kaum zweifelhaft sein, daß in gleichem Sinne ein guter gegenüber einem weniger guten Boden sich geltend machen muß.

7. Die Holzarten hat die forstliche Praxis anf Grund ihrer bisherigen Messungen des Lichtes, wobei als Maßstab wohl das empfindlichste Reagens, das biologische Verhalten der Pflanzen selbst, benutzt 
wurde, in zwei Gruppen geteilt, in Lichtholzarten, welcho längerı Beschattmong nicht ertragen, und sichatton holzart"n, welche Lichtentzug ertragen, ohne zugrunde zu gehen, ja unter mäßigem Lichtentzug sogar zu forstlich nutzbaren Bäumen aufwachsen kïnmen.

Soweit es sich um extrem lichtbedürftige und extrem schattrinertragende Bäume handelt, besteht in der Praxis kein '/sweifel: aber für eine Reihe von Holzarten, welche in der Mitte stehen, ist der ab. ändernde Einfluß von Klima und Boden renügrencl, um sie bald den Licht-, bald den Schattenholzarten näher zu bringen. Je nach rlem Beobachtungsort hat ein Waldbausehriftsteller eine Holzart zu den Lichtholzarten gerechnet, welche ein anderer Autor in rinem anderen Beobachtungsgebiete den Schattenholzarten angliederte. Schoidet man diese mittleren und strittigen Holzarten als eine mittlere Gruppe der Halbschattenholzarten aus, so erhält man biologisch zusammengrehörige Holzarten, welche in schlechterem Boden und in kïhlerem Klima den Lichtholzarten, in wärmerem Klima und besserem Boden den Schattenholzarten in ihrem Verhalten sich nähern; es ist selhstverständlich, daß auch jede Licht- und Schattenholzart ihr Verhalten dem Licht gegenüber entsprechend den günstigen oder ungünstigen, klimatischen und pedologischen Verhältnissen, wie früher angegeben, abändert. So werden z. B. Buchen und Tannen auf schlechtem Boden, im kühlsten Klima zu Halbschattemholzarten, Föhren und Lärchen im günstigsten Boden und günstigsten Klima zu Halbschattenholzarten.

Zur Gruppe der Schattenholzarten zählen folgende B a umgattungen: Taxus, Fagus, Abies, Picea, Tsuga, Pseudlotsuga, Thujopsis, Thuja, Sciadopitys, Aeseulus, immergrüne Laubbäume, darunter auch die immergrüne Sektion der Gattung Quereus u. a.

Zur Gruppe der Halbschattenholzarten sind zu rechnen: Carpinus, Tilia, Acer, Fraxinus, Ulmus, Alnus, Föhrensektion Strobus, Föhrensektion Cembra, Chamaeeyparis, Liboeedrus, Cryptomeria, Sequoia, Robinia, von Quereus die Sektion der Schwarzeichen u. a.

Als Lichtholzarten werden betrachtet: von (Quercus die Sektion der Weißeichen, von den Föhren die S'ektionen Pinaster, Murraya, Jeffreya u. a.; Larix, Salix, Populus, Betula, Taxodium, Magnolia, Liriodendron u. a.

Halbbäume und Sträucher: Schattenholzarten, immergrüne Laubholzsträucher wie Buxus; Halbschattenholzarten: Corylus, Cornus, Ligustrum, Evonymus, Lonicera u. a.: Licht. holzarten: Prunus, Spartium, Evonymus, C'alluna, Crataecrus. Viburnum u, a.

Forstliche Unkräuter: Schattenptlanzen: Polythrichum, Hypnum, Aspidium, Taccinium, Hedera n. a.; Halbsclu at tenpflanzen: Anemone, Pteris u. a.; Lichtptlanzen: Cirsim, silene, Fragaria, die meisten Gräser- und Kleearten us:w. 
104 Dritter Abschnitt. Naturgesetzliche Grundlagen der einzelnen Baumarten usw.

Nach den Untersuchungen ron Wiesner sinkt das Minimum des Lichtgenusses bis zu folgenden Beträgen des Tollichtes:

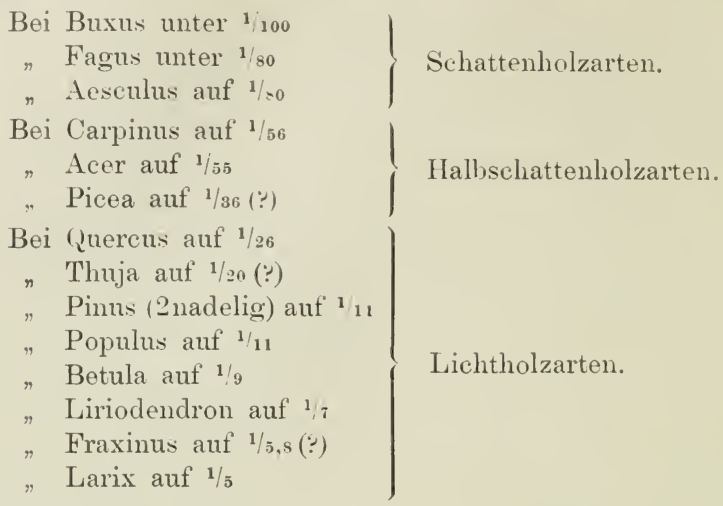

Obige Holzarten lassen sich mit ihrem Lichtbedarfsminimum ungezwungen in die nebenstehenden, forstlichen Gruppen einreihen, wodurch sich eine Bestätigung der Richtigkeit der forstlichen Auffassung ergibt; nur bei der Gattung Picea erscheint für die Ermittelnng des Lichtminimums eine abnorm situierte oder behandelte Pflanze rorgelegen zu haben; denn die Fichte ist nach allen Erfahrungen nur auf schlechtem Boden eine Halbschatten-, sonst stets eine Schattenholzart; ebenso dürfte die Esche nur auf schlechtem, ihr unpassendem, trockenem Boden oder im kühlsten Fichtenklima eine Licht-, sonst stets nur eine Halbschattenart sein; sie ist sicher weniger lichtbedürftig als die Birke. Die schöne Übereinstimmung, welche die Wiesnersche Forschung über das Lichtbedïrfnis der Holzarten mit den Erfahrungen der forstlichen Praxis zeigt, läßt der Hoffnung Ranm, daß es der jungen Wissenschaft von der Qnantitätsmessung und der physiologischen Bedentung des Lichtes im Walde in kurzer Zeit gelingen wird, aus ihrer Rolle der Bestätigung zı jener der Führung für die forstliche Praxis fortzuschreiten.

Wenn man an eine Anpassung an Klima und Boden von seiten der Pflanze, an eine Festigung der so erworbenen Eigenschaften und schließslich an eine Erblichkeit derselben glaubt, wofür aber bis jetzt noch kein nach jeder Richtung hin zwingender Beweis vorliegt, so liegt es nahe, ja, es ist wolıl notwendig, daß man dam anch eine Anpassung an das Licht erwartet. Es muß hier ebenfalls zwischen Realition von seiten der PHanze auf veränderten Lichtgenuß einerseits und Anpassung (Alkommodation) anderseits, welehe wohl passend als Allumination zu bezeichnen wäre, unterschieden werden. 
Wie die Pflanze abgeänderter Lichtquantität gegentïber in der. mannigfachsten Weise reagiert, ist auf den vorhergehenden sieiten ge. zeigt worden: eine Buche kam asimilioren beim rollen Lichtgenul 1 bis zum achtzigsten Teil desselben. Innerhalb dieses weiten spiel. raumes muß die Buche zunächst in der Wuchsgeschwindigkeit, in der Ausbildung ihrer Krone, in dem Ausbau ihrer Blätter innerlich (Anatomie) wie äußerlich (Größe) Abänderungen erleiden. Ijes ist jerloch einfache Reaktion, keine Anpassung: letztere wäre erfitllt, wenn die Buche bei 1/so des vollen Lichtes ebenso schnell oder mit der gleichen Äste- und Blätterentfaltung, mit gleichem Ausban der Blatt organe emporwachsen würde wie beim Lichtgenuß 1. Eine Rraktion auf das Licht ohne Fixierung des reränderten Zustandes der Ptlanze bis zur Erblichkeit kann keine Allumination sein. Die flache Krnn der unterdrückten Bäume kann nur eine Reaktion, keine Anpassung sein, denn sie geht sofort bei steigendem Lichtgenuß wieder verloren und führt bei plötzlicher Einwirkung des Vollichtes zum Wachstumsstillstand. Eine Anpassung an fremdes Lichtklima bedingt eine vollständige Wesensänderung der Pflanze, welche eingetreten wäre, wemn die Buche unter allen Lichtverhältnissen und in allen Nachkommen eine flache oder eine normale Krone zeigen würde; dann läge aber keine Reaktion, keine Variation, sondern eine neue Art vor. In Europa wie in Amerika ist aber aus der einen Art weder durch Wärme (Akklimatisation) noch durch Licht (Allmmination) eine zweite Art entstanden: wo mehrere Arten sich finden, können weder Wärme noch Licht und, wie hier hinzugefügt werden mag. unch Boden die artbildenden Faktoren gewesen sein. Die Erhlichlieit einer neuen Lichtgescalt bei den Holzarten ist schon dadurch unmöglich, daß eine durch Lichtmangel in ihrer Gestalt veränderte Ptlanze keine Früchte trägt. So vermag der Faktor "Licht" im Klima so wenig wie der Faktor Wärme oder wie der Boden Variationen oder Individualitäten in der Natur nicht hervorzurufen.

\section{B. Ansprüche der Holzarten an den Boden.}

Die natürliche Verteilung der Holzarten imerhalb der ihren Trärmebedürfnissen entsprechenden Klimazonen übernehmen auf gn te $\mathrm{m}$ Boden die Faktoren Wärme, Licht. Raschwüchsigkeit, Verbreitungstähigh.i: und andere; je mehr aber der Boden eine einseitige $\mathrm{K}$ onstitution zeigt, um so mächtiger wird die Rolle, welche der Boden hei drs. Verteilung und im Gedeihen der Holzarten spielt. Auf gntem Boden gedeihen alle Holzarten, welche der Wärmeanspruch dem betretlidulen Standorte zuweist; ist aber im Boden irgendein für das Wachistum der Holzart nötiger, zumeist physikalischer Faktor im Mininaus vi rharulen. so können nur jene Holzarten wachsen, die mit diram Felitor am 
besten sich abzufinden vermögen; ist in einem Boden irgendein Faktor in einem für das Pflanzenleben schädlichen Maximum vorhanden, so können nur jene Holzarten gedeihen, welche mit dem schädlichen Faktor noch am besten anszuliommen vermögen. Alle Holzarten verlangen einen guten Boden, um das Ziel ihres Daseins, das freilich von den Zielen der Menschen meist verschieden ist, zu erreichen.

Die Bezeichnung "guter Boden" ist eigentlich ein Sammelname; denn die Bodengüte kann bestehen:

1. in der Bodenmenge, welche horizontal wie vertikal dem Verbreitungsbedürfnisse der Wirzeh genügen muß;

2. im Reichtum an mineralischen Salzen, welche in einer für Wurzeln aufnehmbaren Form vorhanden sein müssen;

3. im physikalisch günstigen Zustande des Bodens, der genügend locker, durchlüftet, durchfeuchtet, durchwärmt sein muß.

ad 1. Bodenmenge. Horizontal wird die Bodenmenge im Walde eingeengt, wenn die Wurzeln der Bäume an größere Steine und Felsen anstofen, wenn sie auf größeren, isolierten Steinplatten sich verbreiten, wenn sie auf Gräben, Straßen, Flußufer u. dgl. in ihrem Längenwachstum anftreffen oder endlich, wenn sio in der Verbreitung und Ausnützung des Bodens durch die Wurzeln der benachbarten Bäume oder anch tiefwurzelnder Nachbarsträucher, -gräser und -kräuter verhindert wercen, was man mit dem Worte "Wurzelkonkurrenz" in neuester Zeit bezeichnet. Der mechanische Einfluf ist hier weniger entscheidend als der physiologische, der Entzug von Wasser und Nährstoffen.

Die Bodenmenge in der vertikalen Richtung heift Bodentiefe. Die keimende und heranwachsende Pflanzê strebt so rasch als möglich den frischeren und tieferen Bodenschichten zu, um der größten Gefahr, welche ihr droht, der Vertrocknung, zu entgehen. Es genügen einige Jahre, um die Pflanzen gegen die schlimmsten Trockenperioden $\mathrm{zu}$ sichern, wenn der Boden mächtig genug ist, um den Pflanzen das Vordringen zu größeren Tiefen zu ermöglichen. Findet ein Vertrocknen während einer Dürreperiode statt, so war die Pflanze entweder noch nicht mit ihren Wurzeln in tiefere Schichten vorgedrungen (Jugend, Verpflanzung), oder sie komnte infolge eines mechanischen Hindernisses nicht in die Tiefe vordringen, aus Mangel an Tiefe des Bodens. Ist mit dem Stangenholzalter der Bäume das Haupttiefenwachstum der Wurzeln abgeschlosien, so zeigt sich, daßs auf gleich tiefom Boden nicht alle Holzarten gleich tief vorgedrungen sind.

Boden, der das Eindringen der Wurzeln auf mehr als $1 \mathrm{~m}$ Tiefe gestattet, nennt man sehr tiefgründig; Holzarten, welche ilhre Wurzeln mehr als $1 \mathrm{~m}$ tief in den Boden versenken, nennt man Pfahlwurzler; sie dringen mit einer Wurzel, welche die genaue Fortsetzung des oberirdischen Schaftes ist, senkrecht in den Boden; hierher zählen 
die Gattungen Quereus, Pinus, ('astanea mul andere, denen eine er. höhte Stmmfestigkeit zukommt. 'Tiof'gr ïndigror Borlen ermüglicht eine Durchwurzelung bis zu $1 \mathrm{~m}$ Tiefe: zwischen $1,5 \mathrm{~m}$ und $1 \mathrm{~m}$ liegt das Wurzelwerk der Hauptzahl der Bamartun: sie beuriunen ihr 'Tiofwachstum mit einer Pfahlwurel, welehe aber nicht weiter vordringt und in der Folge ron stark wachsenden, ans de'm Wurzellialse entspringenden, schief uach unten vordringenden Wurzeln (Herzwurzeln) abgelöst wird. Man nennt diese Bammarten, Herzwurzle r" ihro Verankerung im Boden ist eine genügende, ihre Sturmfestigkeit rino große.

Boden, der nur bis zu 0 ,e m ron Wurzeln bewohnbar ist, lncilit fla chgründig: Holzarten. welche trotz vorhandener, größerer Borlentiefe nur bis zu $0, \bar{m}$ mit ihren WTurzeln vordringen, sohin in flachem, aber sonst gutem Boden ihre vollkommene Entwicklung erreichen kïmnen, heißen „Flachwurler"; die Gattungen Carpinus, Betula, Robinia und vor allem Picea, die Fichten, zählen hierher. Boden, der ein Eindringen der Wurzeln nur bis $0.3 \mathrm{~m}$ Tiefe erlaubt, wird s e ic htgr ï n lig genannt. (Unterlage Ton- oder Lettenlager, Kies, Gierölle, Felsen, Grundwasser usw.) Ist der Boden in allen übrigen Eigenschaften gut, so vermag jede Holzart auf seichtem Boden zu wachsen und wenigstens ihren Lebenszweck, die Vermehrung, zu erreichen; es wird aber iler vegetative Teil der Pflanzen, der Schaft, um so mehr zurücktreten, je größere Bodentiefe sie für die normale, forstlich notwendige Bammdimension beansprucht. Auf seichtem Boden werden nicht sofort Eichen, Föhren und andere Pfahlwuzler sogleich verschwinden, sondern sie werden wachsen mit verkïrztem, verkrïmmtem sichafte, weit ausladender Krone, mit einer für forstliche Zwecke wertlosen Wuchsform. Auf seichtem, aber sonst gutem Boden dagegen werden jene Holzarten vollkommen nach forstlicher Forderung sich entwickeln können, welche auch auf tieferem Boden Flachwurzler bleiben. Ilas sind die oben genannten Gattungen, vor allem die Fichtenarten: aher auch das Heer der Sträucher und Halbbäume im Walde ist hierher zu zählen.

Diese letzteren Baum- und Strauchgattungen sind somit als bescheidene Holzarten, bescheiden in ihren Ansprïchen an Bodentief. aufzufassen; mit Rücksicht auf die ïbrigen Eigenschatten des Bodins jedoch sind sie anspruchsvolle Holzarten. Steiniger Borlen gilt in der Praxis immer als schlechter Boden, weil er dem Saat- mul Ptlan\%geschäfte; zuviel Schwierigkeit bereitet: für Ptlanzen kamn oin stulchr Boden sehr gut oder sehr schlecht sein. je nach der toimm 13 whinmenge, welche zwischen den stemen eingelagert ist. Was win der Redensart zu halten ist, daß eine Holzart noch aut nackitem Fidsen wächst, wurde schon früher betrachtet und clabei betont, IaB solcho Holzarten ihre Wurzeln in Felsspalten versenkt haben. Wi der heste 
Verwitterungsboden angehäuft ist: solche Holzarten als bescheiden hinzustellen, ist daher falsch und führt zu irriger Verwendung.

ad 2. Der Reichtum an mineralischen und organischen Nähr salzen kann nur dann durch eine Holzart ausgebeutet werden, wemn diese in aufnehmbarer Form den Wurzeln geboten werden, $d . h$. wenn sie im Bodenwasser gelöst sind. Die Erwartungen, welche J. ron Liebigs Entdeckungen erweckten, daß die chemische Bodenanalyse alle Rätsel des Gedeihens und Versagens der Holzarten auf' dem gegebenen Standorte lösen und damit zur wichtigsten aller Forschungen im Walde werden mübte, haben sich nicht erfüllt; bei den geringen Ansprïchen der Holzarten an die chemisch wichtigsten Nährsalze hat sich vielmehr gezeigt, daß diese fast stets in größerer Menge vorhanden sind, als sie für die Existenz und das Gedeihen einer Holzart nötig sind, dafs sie stets bei Erhaltung der normalen Verwitterungsdecke des Bodens durch Aufschließung von gebundenen in aufnahmsfähiger Form angehäutt werden. Wichtiger haben sich die mechanischen und die physikalischen Bodenanalysen, welche die Untersuchung der Zusammensetzung und der Eigenschaften der Böden zur Aufgabe haben, erwiesen. Die Schwierigkeit der Feststellung quantitatir und qualitativ der füir die Pflanzen als notwendig erkannten Nährsalze hat es wohl mit sich gebracht, daß unsere Kenntnisse darüber noch äußerst mangelhaft sind und im wesentlichen die Untersuchungen von R. Weber, E. Ebermayer und E. Ramann heute noch als die grundlegenden betrachtet werden müssen; wir kennen die notwendigen Nährstoffe, aber immer noch nicht das ïber alles entscheidende Minimum, dessen die verschiedenen Holzpflanzen für ihr Gedeihen bedürfen. Es ist zweifelhaft, ob jener Betrag an Nährsalzen, der nach dem Verglühen der Hölzer in der Asche gefunden wird, als das absolut notwendige Minimum betrachtet werden darf, ob nicht vielmehr die Holzarten mehr von einem Salze aufnehmen, wemn dieses reichlicher geboten ist, als es für das normale Wachstum nötig wäre. Dazu kommt der störende Faktor der Individualität, wonach jede Pflanze wiederum ein spezifisches, qualitatives und quantitatives Bedürfnis an Nährsalzen besitzt. Kali wurde in der europäischen Tamne (Abies pectinata), in Juglans nigra und Fagus silvatica im Betrage von $38-45^{\circ}$ o der reinen Asche gefunden: an Natron erwiesen sich Ulmen und Legföhren (P. Pumilio) besonders reich; Kalk macht in der Regel drei Viertel des Gesamtgewichtes der Holzasche aus. Tamnen haben davon nur $10 \%$, dafür aber etwas melur Kieselsäure. Fichte (Picea excelsa) ist stets reich an Kieselsäure, nämlich bis $36 \%$. Kieselsäure und Kali spielen zusammen mit Magnesia eine Rolle beim Aufbau des Zellengerüstes; Eisen ist für die Ergrïnung, Phosphorsäure für die Kernsubstanz nötig. Die Bedeutung des so wichtigen Kalis ist noch unbeliannt. 
Alle diese Angaben, welche dem großen Werko von ( $z$ apork $k^{2}$ ) entnommen sind, deuten jedoch erst an, wio viel im Chemismus der Vorgänge im Leben der Pflanzen noch zn lïsen ist. Waldbauliche Folgerungen darauf aufzubanen, ist hente noch mumöglieh; was dor Waldbau tum kann, ist, jenen Boden zu verbessorn, wolcher durch das Wachstum der Holzarten selbst, der bestru Reagentien auf dis fresant güte des Bodens, als nährstoffarm, als mincler gut orler schlecht bezeichnet wird. Die Verbesserung kamn durch passive Malsnahmen, durch Vermeidung aller, die Bodengüte schädlichen Operationen orler durch aktive, durch direkte Zufulır von Nährstoffen (Düngung) guschehen, worüber in einem späteren Abschnitte gesprochen werden muß.

Organische Bestandteile, wie in Verwitterung be griffene, humose Stoffe der Pflanzen, die stichitoffreichen Reste der verwesenden Tiere sind als Bodenverbesserer, als Düngemittel aufzufassen, wenn ihre Zersetzung unter Mitwirkung von Bakterien fortschreitet, und wenn sio dabei den mineralischen (anorganischen) Bestandteilen des Bodens eingelagert werden. Diess Einlagerung wird durch das Eindringen, Absterben und Terwitterm der Wurzeln, durch Tiere (Regenwürmer und andere unterirdisch wohnende Tiere) vermittelt. Die beste Verfassung zeigt ein Boden, in dem die Auflösung der organischen Stoffe und ihre Zufuhr sich die Wagschale halten, so daß keine oder eine unbedeutende Anhäufung ungenügend zersetzter, organischer, besonders humus- resp. ptlanzensäurereicher, pflanzlicher Abfallstoffe erfolgt. Anhäufung von unzersetzten Pflanzenstoffen, die wegen des Gehalts an Humussäure [nach $\mathrm{Baumann}{ }^{2}$ ) an unzersetzter Pflanzensäure der Mnose] eine saure Reaktion besitzen, heißen Rohhumus, Waldtorf, Moorboden, je nachdem Wasserübersehuß oder Wassermangel an der Verzögerung der Auflösung Schuld tragen. Diese schichtenartig auf dem mineralischen Boden aufliegenden Rohhumusmassen bedingen stets eine Verschlechterung des Bodens, obwohl der Rohhumus alles enthält. was zur Ernährung einer Pflanze ausreichen würdr.

Es ist Aufgabe des Waldbaues, speziell der Walderziehumg. das Verhältnis zwischen Abfall und Terwitterung der organischen stofte so zu regeln, daß eine Anhäufung, eine Bildung von Rohhumus, von Bleichsand, von Ortstein unterbleibt. Um dieses zu erreichen. wird dir Erziehungsmethode nach Holzart, Boden und Klima eine versidiedent sein müssen, von welchen drei Faktoren die Geschwindigkeit der $/ 2 \cdot 1$. setzung der Streumassen abhängt.

Um die Holzarten in ihren Ansprïchen an den Boden eimwerten zu können, muß man die Böden nach ihrer (qualitität gruppieres.

2) Dr. Fr. Czapek, Biochemie der Pflanzen. G. Fisther, Jewa. 22 B le, 190.5.

2) Dr. B a umann, Naturw. Zeitschrift fur Land- und Forntwirt duft 1907 
Setzt man die notwendige, physikalische Bodenbeschaffenleit als gegeben voraus. so gelten nach dem Nährwerte

als die besten Böden: sandiger Lehm. Mergel (Kalk, Ton, Sand), Löß (poröser, verwitterter Staubsand), vulkanischer Verwitterungsboden, harte Erde, alle genamnten Büden mit dem Wassergehalt frisch;

als gute Böden: lehmiger Sand, humoser Sand, kalkreicher Sand, alle genamnten Böden mit dem Wassergehalt frisch (siehe Bodenfeuchtigkeit);

als geringe Böden: sandige, kieselsäurereich und arm an Lehm und Ton, trockener Sandboden, Kalksand, Ton, Letten, Moorboden, alle trockenen Böden, seichte Fichtenböden (siehe Bodenfeuchtigkeit);

als schlechte Böden: Flugsand, Dünensand, Schutthalden, Geröllboden und alle unverwitterten, felsigen Böden, alle nassen und alle dürren Böden (siehe Bodenfeuchtigkeit).

Was die Ansprüche der Holzarten an die Bodengüte anlangt, so gilt als Leitsatz: Jede Holzart liebt guten bis besten Boden; nur in der Fähigkeit, auch mit weniger gutem Boden noch vorlieb zu nehmen, sind die Holzarten verschieden, und jene, welche auf weniger gutem Boden noch forstliche Brauchbarkeit erreichen, werden bescheiden genannt. Hinsichtlich der Ansprüche an dell Bodennährgehalt gelten, günstige übrige Eigenschaften im Boden rorausgesetzt, folgende allgemeine Gesichtspunkte:

1. Alle Holzarten sind im ersten, ja selbst noch im zweiten Lebensjahrzehnt anspruchsloser als später; ihre Entwicklung auf geringem Boden während der beiden ersten. Jahrzehnte ist daher eine trïgerische (Lärche!), und der wahre Anspruch äußert sich erst bei der Amuäherung und während des Stangenholzalters. Eine anspruchsvolle Holzart auf geringen Boden verbracht, wird sonach anfänglich nach den Leidensjahren der Verpflanzung gut gedeihen; sie wird infolge des ungenügenden Bodens mit einem Male nur dam absterben, wenn während dieser Zeit äufere Störungen (Insekten, Pilze) hinzugetreten sind; nur auf schlechtem Boden verkümmert die Pflanze und stirbt meist schon im ersten Dezennium ab.

2. Laubbäume, welche befähigt sind, zu mächtigen Bäumen heranzuwachsen, können nur damn bescheiden sein, wemn ihnen die Fähigkeit innewohnt, den Bodemnährwert durch Aufnalıme von Stickstoff aus der Luft zu erhöhen; alle schmetterlingsblütigen Bäume, wie Robinia, Cladrastis, Gymnocladus usw., alle Erlen (Alnus glutinosa, incana, rubra, maritima) und andere zählen hierher.

3. Laubhölzer mit schwerem Holze sind anspruchsvoller als solche mit leichtem Holze, ausgenommen sind nur Stickstoffsammler. 
4. Von den Nadelhölzern sind nur jene hescheiden, welehe sehon in der freien Natur des Urwaleles aut gutem unl greringem Boden zugleich oder nur auf geringem Boden sich finten, wie die zwei- unt dreinadeligen Föhren, Juniperus usw; , je geringer der Boden, um so geringer die Höhenentwieklung und der forstliehe Wert.

5. Bescheiden sind alle Holzarten, welche anch auf bestem Boden nur zu Halbbäumen oder Bäumen III. Gröbe oder nur zu Sträuchern sich zu entwickeln vermögen.

b. Mit geringerem Borlemnährgehalt nehmen dic Holzarten vorlicb, bei größerer Bodenfrische, bei größerem Wärme- und cbenso bei erhöhtem Lichtgenusse.

7. Den Boden verbessert im Nährgehalt jede Holzart, wenn auf ihre und der Bodendecke Nützung rerzichtet wird. Wird nur Holz genützt, so ist es wahrscheinlich, aber noch nicht erwiesen, dafs der Nährgehalt des Bodens wenigstens keine Schmälerung erfahren wird; wird Holz und Bodendecke zugleich genützt, so ist es bereits erwiesen, daß der Boden eine fortschreitende, langsame Verschlechterung erfahren muß; diese tritt auch ein, wenn die Stetigkeit der Bodenaufschließung plötzlich unterbrochen wird (Kahlschlag).

8. Die geologische Abstammung des Bodens ist gleichgültig; ist derselbe gut, kann auf ihm jede Holzart gedeihen.

Gruppiert man die Holzarten nach ihren Ansprïchen an den Nährwert der Böden, so stehen an der Spitze der anspruchsvollen die Gattungen Quercus, Carya, Magnolia, Juglans, Fraxinus, Ulmus, Larix, Fagus, Castanea und andere. Ziemlich anspruchsvoll sind die Angehörigen der Sektion Strobus. Cembra, Picea, Abies, Pseudotsuga, Tsuga, Chamaecyparis und andere. Ziemlich bescheiden sind die Gattungen Robinia und andere schmetterlingsblütige Gattungen, die Birken (Gelbbirken), Erlen (Alnus), Pappeln. Weiden. Bescheiden sind die zwei- und dreinadeligen Föhrensektionen und die Birken (Weißbirken).

Bodenfeuchtigkeit. Wasser ist ein wichtiger Faktor im Boden, der keinem Boden fehlen darf, aber anch geradezu als ein Nährwert im Boden erscheint. Nicht jedes Wasser vermag außer einer physikalischen auch eine nahrungsstoftliche Wrirkung in Boden zu äußern; meteorologisches Wasser ist nahezu chemisch rein, somit als Nälnfaktor am wenigsten geeignet; jedoch haben die neuesten Forschungen ergeben. daß gerade die wichtigen Stickstoffsalze mit dem Regen hei elektrischen Entladungen dem Boden aus der Luft zugetührt werden. T'ntergrzundwasser, Oberflächenwasser ist reich an Mineralien und erhöht damit den Bodennährgehalt.

Werden dem Boden größere Mengen von Feuchtigkeit in kurzer Zeit zugeführt, wie insbesondere in regenreichen Gehieten, hei guter Bewässerung, so wird damit anch eine Auswaschung der lïslichen 
Stoffe veranlaßt. wobei diese in die tieferen Bodenschichten getragen werden: in regenarmen Gebieten findet eine umgekehrte Bewregung der Nährsalze statt; sie häufen sich in den oheren Bodenschichten an; ja, sie kömnen selbst aus dem Boden ausblühen (Alkaliböden), wie bereits bei den Daseinsbedingungen der Waldungen erwähnt wurde. Wasser lockert den festen und bindet den allzu lockeren Boden; wasserüberreicher Boden ist im Frühjahr und Sommer kühler, im Herbst und Winter wämmer als benachbarter, wasseramer Boden. In der Praxis unterscheidet man hauptsächlich folgende Stufen des Feuchtigkeits gehaltes des Bodens:

Na B: Alle Zwischenräume des Bodens mit Wasser erfüllt, so daf. dieses beim Ausheben des Bodens abtropft.

Feucht: Wasser erst beim Zusammendrücken des Bodens abtropfend.

Frisch: Die den Boden zusammendrückende Hand wird feucht.

Trocken: Nur die Pflanzenwurzeln vermögen noch etwas Wasser dem Boden zu entnehmen.

D ürr: Der Borlen zerfällt, wenn er locker, und erhärtet, wenn er bindig ist.

Alle Bamarten auberhalb der Tropen lieben den frischen Boden; keine Holzart liebt den fenchten, keine den trockenen Boden; es gibt aber Holzarten, welche besser als andere geeigenschaftet sind, sich mit den Extremen in Fenchtigkeit, wenn auch auf Kosten ihrer Entwicklung, abzufinden.

Bei Überschuß von Wasser in Boden muß unterschieden werden: sauer reagierende und nährstotfarme, versumpfte Böden; eine mnvollständige und verlangsamte Zersetzung der Pflanzenstoffe führt Ansammlung derselben und Anreicherung des Wassers mit Humussäure (Pflanzensäure) herbei. Solche samre Böden tragen ihre eigene Kleinflora von Carex, Drosera n. a.: unter den Holzarten gedeihen noch am besten die Gattungen Alnus. Betula, Thuja, die Föhren der Sektionen Strobus. Murraya und Pinaster. Picea, Taxodium u. a.

Nentral ist der nasse Boden, in dem durch strömendes Grundwasser oder oberirdisch fließendes Wasser eine fortgesetzte Ernenerung und Zufulur von gelösten, mineralischen Nährsalzen stattfindet.

Den milden, neutralen, nas sen Boden ertragen am besten die (iattungen Fraxinus, Ulmus, Alnus, Betula, Platamus, Salix, Populus u. a.

Der frische Borlen ist das Optimum für alle Holzarten: trockenen Boden ertragen noch am besten die Gattungen Betula, Robinia, von Pinus die zweinadeligen Scktionen Pinaster, Murraya und die dreinadelige Jeffreva.

Anspruch an Bindigleit (Durehlüftung des Bodens). Mit der Durchlüftumg des Bodens, der Lockerheit, steigt und fällt 
auch die Durchdringbarkeit desselben für die Pflanzenwurzeln. Jede Holzart ist imstande, im Laufe ihres Lebens sollsst durch ihre Wurzel. tätigkeit und durch Anlockung der den Boden bewohnenden Tiero (besonders Regenwürmer, als Folge der unter dom Kronendache erhöhten, gleichmäBigen Bodendurchfeuchtung) den Boden zu lockern, somit denselben sich ihrem Bedürfnis hierin anzupasimen. Seichtwurzler lockern und beanspruchen die Lockerung nur auf geringe Bodentiefe, Pfahlwurzler lockern allmählich bis in die tiefsten, ihnen nötigen Schichten. Wird das Kronendach plötzlich durchbrochen oder ganz beseitigt (Kahlschlag), wird die normale Zersetzung der Borlenstren unterbrochen oder letztere gar beseitigt, so ändert sich auch der Bindigkeitsgrad des Bodens; die Böden werden fester, trockener, die den Boden lockernden Tiere fliehen, oder die Böden ermüden, wie die Praxis z. B. den durch Streurechen erhärteten Buchenboden nennt.

Die Praxis unterscheidet in allgemeinen nur drei Härtegrade für die Bindigkeit des Bodens:

Schwer, fest, schwer zu bearbeiten: Ton, Lehm, Letten, alle sandarmen Böden, welche beim Austrocknen erhärten und zerspringen.

L ocker, mürbe, leicht zu bearbeiten: sandiger Lehm, lehmiger Sand, humusreicher Boden, frischer Sandboden, Gartenerde.

Lose, flüchtig, sehr leicht zu bearbeiten, aber der Zusammenhang fehlt: Flugsand, Dünensand, Schutthalden usw.

Alle Holzarten verlangen als optimalen Grad der Bindigkeit einen lockeren Boden; den festen ertragen noch am besten die Eichen, Zitterpappeln; den losen, flüchtigen Boden zu festigen, golingt am besten mit zwei- und dreinadeligen Föhren oder grasartigen Gewächsen. Der schwere, feste Boden ist zumeist auch feucht und damit auch kalt, so daß das Nichtgedeihen einer Holzart, z. B. der Nadelbäume, das durch den kümmerlichen Wuchs, durch gelbliche Färbung der Nadeln, durch Frostbeschädigungen usw. sich verrät, in der Regel einer Anhäufung von ungünstigen Faktoren zuzuschreiben ist.

Auf die Ansprü che der Holzarten an Bodenpilze zum Zwecke einer Wurzelsymbiose (Mrkorhiza) zur Unterstützung der Aufnahme der gelösten Nährstoffe im Boden sei hier nur hingeriesen mit der Entdeckung Stahls, daß mit dem Schattenerträgnis der Holzarten die Wurzelverpilzung zunimmt, die Ernährung somit immer mohr von der Mykorhiza abhängig wird. Die Schattenholzarten sind schwach transpirierende Pflanzen, welchen die im Boden wucheruden Pilze die Nährsalze vorwegnehmen würden, wenn sie mit ihnen nicht ein (ienossenschaftsverhältnis eingehen würden, die Wurzelsymbiose. Ilicses Streben nach Sicherung genügender Bodemnahrung ilurch Vermitteling der Pilze bildet nach Stahl den Sinn der Mykorhizenbildung (Wiesnor 1. c. S. 219 ).

Mayr, Waldbau. 
Es ergibt sich die Frage, ob es eine wirkliche Anpassung, Akkomodation, einer Holzart an ihr ungünstigen Boden gibt. Man vermutet die Möglichkeit einer solchen Anpassung, ähnlich wie bei der Akklimatisation durch allmähliche Terbringung der Holzart in verändertes Klima bzw. hier durch Verbringung in allmählich veränderte Böden. Graf v. Schwerin ${ }^{2}$ ) hat diese Anpassung an rerschiedene Böden Atterenisation genannt. Es wäre eine verlockende Aussicht für den Waldbau, wenn es gelänge, eine Eiche zu züchten oder allmählich durch Anpassung so in der Biologie umzugestalten, daß sie mit schlechtem Sandboden vorlieb nimmt oder ihre Pfahlwurzel einzieht zugunsten eines seichten Bodens; wemn umgekehrt die Fichte ihre Seitenbewurzelung durch Züchtung auf tiefgründigem Boden allmählich zugunsten einer sturmsicheren Pfahlwurzel aufgeben, unsere versauerten Sümpfe sich mit Eichen allmählich durch Steigerung des den Eichen gereichten Wassers bevölkern würden. Wemn es eine Atterenisation gibt, so muß sie auch möglich sein bis in das äußerste Extrem. Wer aber dieses Endergebnis von vornherein als unmöglich bezeichnet, der gesteht damit die Unmöglichkeit der Atterenisation zu. Die forstliche Praxis hat bisher der Atterenisation direkt entgegengearbeitet, indem sie die jungen Pflanzen stets auf bestem Boden aufzuziehen strebte zur Erzielung starker, engbewurzelter Pflanzen; eine Aufzucht auf geringem Boden rerbreitert das Wurzelsystem in einer für die Pflanzung ungünstigen Weise. Die Praxis fürchtet nicht, daß die Föhre dadurch an ihrer Bescheidenheit einbüßt, und hoffit nicht, daß die Fichte dadurch tiefwurzelnder wird. Das aber müßte eintreten, wenn es eine Atterenisation gäbe. Auch die freie Natur, die bereits Jahrtausende hindurch Experimente wiederholt, hat nur Mißerfolge aufzuweisen. Die zahllosen Eichen, welche der Eichelhäher auf magere Böden gebracht hat, haben sich alle auch mager entwickelt, sie haben ihre Normalität aufgeben müssen, um auf dem schlechteren Boden wachsen zu können, sie haben stets mit Wuchsverlusten auf den schlechteren Böden reagiert; hätten sie dort nichts verloren oder das Verlorene trotz des schlechten Bodens wieder zurüickerobert, dann wäre eine Atterenisation im wahren, durch das Wort beabsichtigten Sinne eingetreten. Noch viele Fichten stehen auf dem ihnen seit Jahrtansenden ureigenen, tiefgründigen Boden, die Jugend stammt ron den Eltern desselben Standortes. Trotzdem ist dort die Fichte so seichtwurzelnd, als wäre das Eindringen der Wurzeln in die Tiefe seit Jahrtansenden von einer Felsenplatte gehemmt worden. Reaktion auf abgeänderte Bodenverfassung vermag die Ptlanze, eime Anpassung ohne Wesensänderung vermag die Pflanze nicht; der Boden ist ein äußerer

1) Fritz Graf von Schwerin, Mitteilungen der dendrologischen Gesellschaft, Jahrgang 1907. 
Faktor, und äußere Faktoren vermögen keine VTesensïnderungen horvor. zubringen. Wäre dies der Fall, müBte Atterenisation, wie Aklilinatisation und Allumination zur Entstehung nener Arten fülnen, ja, es lïge darin die Erklärung für die Entstehung neuer und vorhandoner Arten: die Anban- und Züchtungsergebnisse in der freien Natur abre weisen bis jetzt den Gedanken ab, daß durch äuBere Falitoren: Boden, Klima, Licht, neme Arten gebildet worden lönnen; für ncue Arten lusteht die gleiche Voraussetzung der Genesis wie für nene Individuen, das ist die Befruchtung und sprungweise Abänderung im Augenlickio dor Bofruchtung.

Bodenwärme. Obwohl nach dem Innern der Erde die Temperatur zunimmt, dringt doch nichts von dieser $\mathrm{W}$ ärme bis zur Obertläche: die mit heißen Quellen in vulkanischen Gebieten emporgebrachte oder an heiße Dämpfe gebundene Wärme kamn an einigen Örtlichkeiten für Kulturzwecke verwendet werden; die mit flüssigem Gestein emporgedrückte Wärme wirkt nur schädlich; Wärme von unten liefern brenmende Kohlenflöze; Wärme, welche frei wird bei Verwitterung des Bodens, bei Auflösung der organischen Bestandteile ist für das Pflanzenleben ohne allen Wert; es bedarf einer besonderen Anordnung (Mistbeete), um diese Wärme meßbar und nutzbar zu machen. Es muß zugestanden werden, daß man der Wärme im Boden eine Bedeutung zugeschrieben hat, die ihr nicht zukommt. Professor Eberma yer $^{1}$ ) sagt, daf das Erwachen der Vegetation im Frühjahr erst eintreten könne, wenn die Bodentemperatur 7 - ${ }^{\circ}$ erreicht hat: die Produktion erreiche ihren Höhepunkt, wenn die 'Temperatur im Bereiche der Wurzeln auf 20-2.20 $\mathrm{C}$ gestiegen sei: im Herbst und Winter erlischt schon bei 7 - 0 C alle Tätigkeit der Wurzeln. Wäre diese Auffassung richtig, damn kömnte es in den /onen des Fagetums und des Picetums überhaupt keinen Wald, keine Bäume geben; der Wald würde sich die Existenz selbst nehmen, dadurch, daß er den Boden beschattet, so daß die für notwendig erachteten Tem. peraturbeträge bei weitem nicht mehr erreicht werder kïnnen; jede Art von Deckung des Bodens in den Saatbeeten mit Moos, Lauh, Tort: mull u. dgl. müßte die Pflanzen schädigen, demn eine nur 111 'm starke Bodendecke hält nach den Untersuchungen des Verfassers rund $30^{\circ} 0$ der zugestrahlten Wärme vom Boden zurück. Das Kronendach eines erwachsenen Fichtenbestandes von gutem schlı h hält $4.2 \%$ der Wärme. das Laubdach der Buche sogar $5 \% \%$ der zugestrahlten Wärme rom Boden ab. Die abkühlende Wirkung ist bis in grüßere Tieten tühlbar: bei $60 \mathrm{~cm}$ Bodentiefe beträgt der Wärmeausfall im Buchenhestand no: $\mathrm{h}$ $30 \%$ gegenüber der Blöße; so kommt es, daß auf der hayrrischen

1) Dr. Eberma cer, Die Bedeutung der Bodenwäme far das Pfinzenleben in E. Wollngs Forschungen auf dem Gebiete der Agrikulturphysik. 1-11. XIV. 193. 
116 Dritter Abschnitt. Naturgesetzliche Grundlagen der einzelnen Baumarten usw.

Hochebene mnter dem $48 .^{\circ}$ nördlicher Breite bei $500 \mathrm{~m}$ Erhebung die Bodentemperatur im Wurzelbereich auch während des Hochsommers eine sehr niedrige bleibt. Während des Sommers 1896 stieg die Bodenwärme im Wurzelbereich bei $40 \mathrm{~cm}$ Bodentiefe nicht über $12,9^{\circ}:$ in (i0) $\mathrm{cm}$ Tiefe war die höchste Temperatur $12.5^{\circ}$. Da das untersuchte Gebiet klimatisch noch dem Fagetum angehört, so muß die Bodentemperatur im kühleren Gebiete des Picetums während der heißesten Zeit noch geringer sein. Aus Tafeln II und III, welche auf Grund von Hanns' Angaben und von Untersuchungen des Verfassers bei $570 \mathrm{~m}$ über dem Meere angefertigt wurden, mögen folgende, allgemeine Gesetze entnommen werden. Im Hoch sommer ist während einer klaren Nacht und eines klaren Tages die Bodentemperatur bei Sonnenaufgang höher als die Lufttemperatur über nacktem und über begrastem Boden, höher als anf dem Kronendach der Bäume, zur Mittagszeit aber niederer als die Luftwärme bis zu $500 \mathrm{~m}$ aufwärts; die nackte Bodenoberfläche ist wärmer als die Luft; nackter Boden ist wärmer als begraster and vollends als bewaldeter. Die Bodentemperatur wandert durch Leitung - jo nach Bodenwert verschieden rasch - in die Tiefe. Das Maximum der Erwärmung untertags erseheint nach 12 Stunden in $50 \mathrm{~cm}$ Bodentiefe, selbstverständlich mit stark abgemindertem Betrag; schon in $1 \mathrm{~m}$ Tiefe verschwinden die täglichen Schwankungen in der Temperatur, schon bei $5 \mathrm{~m}$ erlöschen auch die jährlichen Schwankungen, der Unterschied zwischen Sommer und Winter fast vollständig; dort herrscht jahraus, jahrein nahezu dieselbe Temperatur, welche der Durchschnittslufttemperatur des Beobachtungsortes während des Jahres gleich ist. Die extremsten Temperaturen weist der nackte Boden, und zwar in seinen obersten Schichten auf, die gleichmäßigsten der bewaldete Boden; in der Mitte steht der begraste. Je wärmer das Klima, um so geringer wird der Unterschied; uutertags sind Luft und Boden annähernd gleich warm; wie die durchschnittliche Wärme der Luft vom Äquator zum Pol hin und an den Bergen von unten nach oben abnimmt, so folgt auch die Durchschnittsbodentemperatur diesem Gesetz; aber den Zonen der Bodenwärme kommt nicht die Bedeutung zu wie jenen der Luftwärme, und es scheint, daß es ein Temperaturoptimum im Boden für Holzarten überhaupt nicht gibt.

Im Winter ist die Temperatur des Bodens bei klaren, windstillen Tagen höher als alle Temperaturen oberhalb der Erdschicht. Der Waldboden ist der wärmste; daran reiht sich der schneebedeckite Boden; der schneefreie ist der kälteste, da die Minusgrade am tiefsten eindringen. Das Frühjahr findet im Boden den Vorrat an Winterkälte; der ausgehende Herbst zehrt bereits vom Wärmevorrat des Sommers.

Aus der Abbildung Taf. III kann entnommen werden, welche Veränderungen in Luft- und Bodentemperatur vor sich gehen, wenn ein Waldteil kahl abgeschlagen wird (nackter Boden) und allmählich eine 
Verunkrautung (begraster Boden) sich oinstellt. Werden dio Kahlffächen besät, so ist das Samenkorn der intensivsten Erwärmung auf dem nackten Boden ausgesetzt. Dunkel gefärbtu Büden künnen, wiø bereits erwähnt, sich so sehr erhitzen, daß die Keimlinge gretötet werden; solche Böden verlangen Schutzmittel zur Abhaltung der stärksten Bestrahlung. Alle Keimlinge suchen zunächst durch cine zum oberirdischen Trieb unverhältnismäßig starke und tiefgehende Wurzelbildung dem Bodenniveau, in dem es am heißesten und leshalb auch am trockensten ist, möglichst rasch zu enteilen und von don Schwankungen dieses Faktors unabhängig zu werden, auch wenn dabei der Faktor Wärme, scheinbar wenigstens, ungünstiger wird. Nur das keimendos Korm ist in seiner ganzen Biologie von der 'Temperatur des Bodens unabhängig; die ein- und zweijährigen Pflanzen stehen bereits unter dem Einfluß der Luftemperatur, die unmittelbar über dem Boden in den schlimmsten Extremen schwankt, zumal wenn der Boden verunkrautet ist. Je älter die Baumpflanze, um so mehr entwächst sie dem Einfluß des Bodens, soweit seine Temperatur in Frage kommt. Daß aber trotz der geringen Temperatur im Boden alle Prozesse der chemischen Auflösungen und Verbindungen, alle Funktionen der Wurzeln, vor allem auch deren Wachstum normal vor sich gehen kann, lehren die Waldungen der kühlsten Regionen. 


\section{Vierter Abschnitt.}

\section{Waldbaulich-biologische Eigenschaften der Holzarten.}

\section{Art, Varietät, Rasse, Individuum, Wuchsfehler und Wuchs- vorzüge, Vererbung, Provenienz usw.}

$\mathrm{Da}$ es ganz aussichtslos erscheint, eine Verständigung über die Begriffe: Art, Varietät, Formen, Rassen zu erzielen, muß jeder, der wissenschaftlich und selbständig arbeitet, definieren, was er unter Varietäten oder Rassen oder Arten versteht. Der Begriff Arten oder Varietäten, wie er gegenwärtig besteht, ist durehaus nichts Feststehendes, Dogmenhaftes, so wenig wie die herrschende Benennung der Pflanzen; Einheit in den Begriffen ist so unmöglich wie Einheit in den Benenmungen. Denn die Einheit setzt als erstes voraus die Dauer der Begriffe und der Namen. Da aber beide nur das Resultat wissenschaftlicher Forsehung sein können, können Einheit und Begriffe nur so lange danern, bis die wissenschaftliche Forsehung einen Fortschritt zu verzeichnen hat.

Ein solcher mächtiger Fortschritt war es, als man erkannte, zum Wesen einer Pflanze gehöre nicht bloß ihre äußere Erscheinung, sondern vielmehr auch ihr innerer Bau, ihre Lebensgeschichte, die in der freien Natur zur Abgrenzung von Verbreitungsgebieten führt, Die frühere Definition der Art (Spezies), die ausschließlich auf äußere (morphologische) Merkmale fußte, mußte daher fallen gelassen und zum Artenbegriff neben Norphologie auch Anatomie, Physiologie und Geographie der Pflanze als gleichwertige Faktoren hinzu genommen werden.

1. Zu einer Art (Śpzies) sind wach Ansicht des Verf. Bäume zu rechnen, wolche in einem Komplex von äußeren, d. h. morphologischen und zugleich erblichen Eigenschaften (Blite, Fruchtbildung, Belaubung, Berindung, Bewurzelung, Tracht) in ihren immeren, d. h. anatomischelementaren und zugleich erblichen Eigensehaften (anatomische Elemente der Rinde, des Holzes, der Blätter), in einem Komplex von physiologischen und biologischen Eigenschatten (Verhalten gegen Licht, Wärme, Boden, in Schnellwüchsigkeit usw.) übereinstimmen, welcho 
sodamn ein geographisch in sich insoweit alugeschlosicnes Verbreitumgsgebiet besitzen, daß sie in dem bestimmten (rohiet hei entsprechendon Wärme-, Licht- und Bodenverhältnissen herrschend auftroten, d. h. dio anderen nah verwandten Arten (Spezies) vou diesem Gebiete ausschließen.

Als Arten in diosem erwähnten, naturwissonschaftlichen sinn nicht aber im Sinne des alten Speziesdogmas oder der Kinnreßbeschlüsse haben daher folgende Holzgewächse zu gelten, die trïher als Varietätun mit konstanten und erblichen Eigenschaften hetrachtet wurlen.

Picea oborata, die sibirische Fichte, ist nicht eine Varietät, vor allem keine Klimavarietät der Picea excelsa oder europäischen Fichte, sondern eine Art, in einem Klima erwachsen, das dem der ursprïnglichen Heimat der europäischen Fichte, soweit die Beobachtungen reichen, in Temperatur und Lufteuchtigkeit gleich ist: daß an den Grenzgebieten beider Fichten die Arten sich geographisch und physiologisch mischen (Bastarcle bilden) ist eine bei den meisten Holzarten zu beobachtende Erscheinung. Falsch aber ist es, solche Bastarde als Übergangsformen von einer Art in die andere aufzufassen. Larix sibirica, die sibirische Lärche, kann keine Varität, sondern muß cine Art sein, denn ihre Individuen entsprechen vollständig obigen Anforderungen an eine Art. Pinus sibirica, die sibirische Zürbel, muß aus dem gleichen Grunde als eine Art, nicht als eine Varietät der Alpenzürbel betrachtet werden. Pinus lapponica ist aus diesem (irunde eine Art, welche in Finnland, Schweden und Norwegen wächst, wnzu aber die Föhre von Riga, wie Verfasser stets ausdrücklich betonte, nicht gehört, weil letztere nur die Fortsetzung der mitteleuropäischen Fölıre von Westpreußen über Ostpreußen, Kurland nach livland und Estland darstellt; Pseudotsuga glauca, die Colorado-Douglasie, ist morphologisch, anatomisch, biologisch und geographisch eine eigene Art, ebenso wie Pseudotsuga Douglasii oder Pseudotsuga japonica ihre nächsten Verwandten in Westamerika bzw. Japan; Pinus uncinuata, Mughus, Pumilio, austriaca, corsicana, Jeffreyi, scopulorum usw. sind Arten.

Daß die Feststellung der Art botanisch, waldbaulich und gärtnerisch von größter Wichtigkeit ist, bedarf keines Hinweises; ebenso wichtin ist natürlich auch die Herkunft (Provenienz) des Saatgutes von der richtigen, gewünschten Art.

Als Varietät (Varietas) faßt die hentige Systematik jone Pflanzenformen auf, welche abweichende Merkmale von der Art (Spezies) aufweisen; diese abweichenden Merkmale müssen dur h Generationen hindurch erblich, somit konstant sein. Mit dirser Lefinition ist der Willkür und Deutung freier Sipielram grelasien lenu damit ist der Unterschied von der Art ganz allein anf di. änßere Fr scheinung gelegt und es jeden einzelnen ïherlasien, olu abweichente Merkmale für groß genug hält, um die betreffenden Pflanzen als larietüt 
einer Art oder als eigene Art aufzufassen. Erblichkeit und Konstanz der Eigenschaften sind Jerkmale der Art.

Ein Varietätmerkmal soll konstant und erblich sein; ist das nicht ein Widerspruch? Entweder ist alles variabel, das schließt dann die Erblichkeit aus, odler es ist alles erblich, d. h. konstant, wenigstens für so langen Zeitraum hindureh, als der Mensch für seine Erkenntnis und Beobachtung zu erfassen vermag, dam ist die Variabilität ausgeschlossen. Das scheinbar geringfügigste Merkmal wird dadurch groß genug, daß es konstant, d. h. erblich ist. Zwei Ahornbäume, die morphologisch und biologisch absolute Gleichheit aufweisen würden, müßten als zwei getrennte Arten gelten, wenn der eine Milchsäfte führt, der andere nicht; schmetterlingsblütige Ptlanzen, die in Blïten, Früchten und Blättern absolut gleich sind, müßten als eigene Art gelten, wenn die eine eine Schlingpflanze, die andere ein Baum wäre, eine dritte selbst unter den günstigsten Bedingungen nur ein Strauch wird. So wie heute der Begriff "Varietät" gefaßt wird, gibt es lieine Varietät mehr; solche Tarietäten unterscheiden sich von den Arten nur durch ein Plus oder Minus in der menschlichen Erkenntnis.

2. Als Lusus oder Mutationes, Spielarten, Spielformen wären solche Bäume zu bezeichnen, welche nur in der morphologischen, nicht aber in der elementar-anatomischen Eigenschaft von der Art abweichen, wenn dieser variierte Charakter für das ganze Leben des betreffenden Banmes konstant, aber nicht oder nur zum kleinsten Prozente auf die Nachkommenschaft vererbt wird; für sie ist charakteristisch, daß sie mitten unter den typischen Exemplaren. zumeist vereinzelt, selten in größerer Zahl entstehen. Gerade diese Entstehungsweise aber beweist, daß weder Boden noch Klima, noch Erziehung die Ursache dieser Spielarten sein können: hierüber brauchen wir kein Experiment, dem es wiederholt die Natur dasiselbe seit Jahrhunderten stetig vor unseren Angen. Wer Pflanzen einer Art nach tausenden ziichtet, gewahrt mitten unter den typischen Pflanzen plötzlich eine hängende oder eine astlose, eine rot-oder gelbgefärbte Form. Auf ganz gleichem, von der umgebenden Natur völlig unabhängigem Wege entstehen alle die gärtnerisch interessanten Traner-, Kriech-, Zwerg-, Busch-, Schlangenformen, juvenile, panaschierte, zerschlitzt-blätterige, Gold- und Silber- oder monophylle Formen. Für die meisten dieser Formen ist charahteristisch, daß ilır Alter - von den vielen Mißhandlungen außerhalb des Waldes natürlich ganz abgesehen - verkürzt, ihre Stammentwicklung geschmälert, somit ihr Wert für forstliche Zwecke Null ist, während der gärtnerische Wert zumeist erhöht ist. Was Mifgeburten und hretins im Tierreiche, sind diese Spielarten (Lusus) in Pflanzenreiche; der Zeitpunkt der Entstehung der Lusus, ja höchstwahrscheinlich auch die Ursachen der Entstehung sind dieselben wie bei den Tieren: von äußeren Einflüssen 
1. Art, Varietät, Rasse, Individuum, Wuchsfehler und Wuchsvorzlge usw, 1:21

unabhängige, immere Ursachen, welche bei der Vereinigung der s'exualzellen zu einer neuen Art oder zu cinem Lusus oder zu wiuem neuen Individum den Anstoß geben. Spielarten (Iusus) simul durchaus nicht häufig in der Natur: unter den Fichten triflt anf haum eine Million normaler PHanzen eine cinzige sillangenspielart; manch. Holzarten neigen hierzu häufiger, wie die Rothucho zur IBlutbuchenbildung, Buchenstockausschlag zur Silberform der Blätter: für die japanischen Föhrenarten gelang es Verfasser 4:3 Spielarten. ofor Lusus festzustellen. Sämereien von den śpielarten gesammelt geben zuweiln in einigen Prozenten die Charaktere der Spielarten wioder; in den weitaus häufigsten Fällen ist man zur ungeschlechtlichen Vermehrungr (Steckling, Pfropfung) gezwungen aus Mangel an Erblichkeit der vom Typus abweichenden Formen.

3. Individualitäten (individualitas) vielfach auch Rassen genannt, gibt es unendlich viele. Nicht zwei Individuen dersolben Art sind in allen Punkten ihrer äußeren Erscheinumg und inneren Entwick: lung einander röllig gleich; selbst wenn äuBerliche Gleichheit zu bestehen scheint, sind im Innern der Pflanzen Differenzen im Verhältnis der Verteilung der anatomischen Elemente (Beteiligung der einzelnen Zellenformen am Aufbau des Holzes nach (Qualität, Jahrringsbau usw.). kaum zwei Individuen zeigen den ganz gleichen Vegretationsbeginn, Blütebeginn, Fruchtansatz, Tegetationsabschluf. Auf allen Böden uncl in allen Klimalagen gibt es Bäume einer Art, welche Differenzen im Wachstumsbeginn ron einigen Tagen bis zu mehreren Wochen zeigen. welche in Wuchsgeschwindigkeit ganz beträchtlich divergieren, und diese divergenten Individuen stehen unmittelbarneben. einander und stammen seit Urzeiten ron Bäumen ab. welche an demselben Boden und in demselben Klima seit Urzeiten erwachsen sind. Diese Tatsache, auf die Verfasser zuerst in seinen Schriften hingewiesen hat, schließt die Erklärung aus, daß die Schnell- oder Langsamwüchsigkeit der Individuen, der frühe oder späte Tegetationsbeginn und die übrigen Abweichungen auf Einflüsse des Bodens oder des Klimas zurüchgeführt werden kümmen: da auf ein und demselben Boden nebeneinander aus gleicher saat hervorgegangene gerad- und krummschäftige Laubhölzer. solche mit und solche ohne Klebeäste, gabelgipfelige und normale sich finden, so müssen auch diese Eigenschaften zu den individuellen rerechnet werden, die in der Pflanze schlummern und unabhängig von Klima und Boden in die Erseheinung treten. I)aB in dir individuellen Anlage nicht die einzige Ursache für Krmmwüchsirticit, Klebästebildung, Langsamwüchsigkeit usw. liegt, davon werlen die folgenden Auseinandersetzungen Zeugnis geben.

Die nächste Frage ist: Sind die Inclivilualitätcharalitere ertlich? Seit zehn .Jahren führt Terfasser über diesen Punkt Vurmehe im forst- 
lichen Versuchsgarten zu Grafrath aus: alle hatten bisher ein negatives Ergebnis. Ans Früchten, die von einer sehr früh treibenden Roßkastanie genommen wurden, erwuchsen die am spätesten austreibenden Pflanzen des Versuches, aus Samen des spät treibenden Baumes erwuchsen die am frühesten austreibenden Pflanzen des Versuches: nicht einmal die Majorität der Pflanzen richtet sich nach dem Mutterbaum.

Soweit heute schon geurteilt werden kann, muß das Urteil lauten: Der Individualitätscharakter bleibt für das betreffende Individunm das ganze Leben hindurch unverändert, es vererbt sich nur die Neigung $\mathrm{zu}$ einer neuen Individnalität, für welche somit der Individualitätscharakter des Mutterbaumes nicht alleinbestimmend sein kann. Damit fällt aber die Forderung für Kulturzwecke, die Sämereien von bestimmten Individuen zu sammeln, um den uns erwünschten Charakter des Nutterbaumes in den Nachkommen vorherrschend oder alleinherrschend wieder zu finden oder sogar durch Selektion bestimmte Eigenschaften zu züchten, in sich zusammen; die Provenienz des Saatgutes hat für Individualitätseigenschaften der Nachkommen keine Bedeutung. Da individuelle Langsam- oder Raschwüchsigkeit, Frühzeitigkeit im Vegetationsbeginn dieselbe Tendenz während des ganzen Lebens der betreffenden Pflanze beibehalten, ist unter den jungen Individuen die Auswahl je nach dem beabsichtigten Zweck von größter, waldbaulicher Bedeutung:

4. Standortformen (Klimarassen, Bodenrassen), Erziehungsformen. Licht-, Sehatten- und Freistands-, Schirmstands-, Beschädigungs- usw. Formen (Formae). Das K'lima des Standortes beeinflußt natürlich die äußere Erscheinung und imnere Entwicklung auf daș mächtigste; Verfasser hat, um diesen Einfluf zu präzisieren, für jede Holzart ein mittleres Klima (entsprechend dem mittleren Teile des Verbreitungsgebietes) als das beste Klima angenommen (Optimum), von dem hinweg nach der Kältegrenze die Wuchsgeschwindigkeit stetig abnimmt, während nach der Wärmegrenze hin die Wuchsgeschwindigkeit anfänglich zunimmt, d. h. größer ist als im Optimnm, um dann früher zu erlöschen als im Optimum. Durch veränderte Klimalage werden daher die schnellwüchsig reranlagten Individuen im gleichen Sinne beeinflußt wie die langsam veranlagten. So kann eine schnellwüchsig veranlagte Pflanze, in kühleres Klima versetzt, so langsamwïchsig werden als eine langsam veranlagte Pflanze im heimatlichen, wärmeren oder eine schnell veranlagte Pflanze im kühleren Klima; umgekehrt werden im kühleren Klima wachsende und langsamwüchsig veranlagte Pflanzen, im wärmeren Klima zwar schneller wachsen, immerhin aber noch langsamer sich entwickeln als die schnell oder normal, vielleicht sogar als die langsam veranlagten Pflanzen des wärmeren Klimas. Dieser Satz gilt als sicher, wenn die Pflanze selbst. 
1. Art, Varietät, Rasse, Individuum, Wuchsfehler und Wuchsvorzlnge usw. 1:3

transferiert werden kann. Was im saatkorn liegt, nb ein sclinell- oder langsamwüchsig veranlagter Keim, kann a priori nicht bestimmt werden. da die Individualität des Mutterbaumes nicht wrblich ist.

Cieslar ${ }^{1}$ ) und nach ihm Engle $r^{2}$ ) haben nun gefundeu, dats die Nachkommen der in kühlsten und wärmsten Klima (rwachscnen Fichten ihre dort durch das Klima hervorgebrachte Langsamwüchsigkeit hzw: Schnellwïchsigkeit beibchalten: Cieslar und nach ihn Engler nemnen dies die Erblichkeit des Zuwachsvermögens; das Klina hahe so lange auf die betreffenden Individuen eingewirkt, daß eime nklimatische Varietät" entstanden sei. Das wäre der erste Nachweis, daß eino von außen wirksame Ursache bei Bäumen erbliche Veränderungen hervorrution kann; nun bleiben noch die praktisch wichtigen Fragen zu lösen; wie viel Jahre diese Erblichkeit nachhält, wo in der Natur die Grenze zwischen Hochgebirgs- und Tieflandsfichte liegt. Ist Klima rlie $\mathrm{Ur}^{\mathrm{r}}$ sache, muß es mit dem Klima alle Übergänge von Tief- zu Hochlandsfichten, somit ungezählte, sogenannte, Klimavarietäten ${ }^{\text {geben. }}$

Die vor 20 Jahren in den bayerischen Stautswaldungen an mehreren Orten eingeleiteten Tersuche mit der Fichte aus Norwegen und schweden (var. septentrionalis damals genannt) haben schon nach acht Jahren die völlige Gleichwüchsigkeit mit den umgebenden Fichten gezeigt: Cieslar fand das Gleiche (S. 141): auch die äußere Gestalt, Bemadelung, Zweigbildung, Farbe war derart, daß in der Umgebung sich die gleichen Formen auffinden ließen: so oft ein Spätfrost die einheimische Umgebung schädigte, wurden gleichzeitig auch die Nordlandsfichten in Mitleidenschaft gezogen: die notorische, anfängliche Langsamwüchsigkeit, welche ein Ergebnis tausendjähriger Festigung soin soll, hat nicht einmal acht Jahre hergehalten.

Freilich kann bei allen diesen Versuchen mit nordischem samen die Prämisse falsch sein, d. h. der Samen kann trotz seiner nordischen Provenienz aus einem Gebiete stammen, das wärmer ist als das nene Anbaugebiet. Zeigen die Pflanzen solchen Saatgutes dennoch langsames Anfangswachstum, dann kann keine Kältevarietät oder -rasse vorliegen.

Beim Bestreben, Sämereien aus nordischen Regionen zu beziehen, ist in erster Linie der Wunsch, frostharte, d. h. spätfrostharte Pflanzen zu erhalten, entscheidend. seit 10 Jahren betont Verfasser die Naturwidrigkeit einer solchen Forderung und kämpftggegen die șatgutverteuerung durch die Versicherung des siamen-

1) Dr. Cieslar. Über die Erblichkeit des Zuwachsvermögens. Zritwir f. d. ges. Forstwesen 1875 .

2) A. Engler. Einfluß der Provenienz des samens auf die Eigen-chaften der forstlichen Holzgewächse. Mitteil. d. schweiz. Zentralanstalt f. d. for tl Vernuchswesen 190.5. 
händlers, dafs er von besonders nordischer oder hochgelegener Provenienz sei. Alle Beobachtungen zeigten deutlich, daß die Natur, das Klima nicht imstande ist, spätfrostharte Individuen zu zïchten, und in der Tat erfrieren die Nachkommen der nördlichsten Provenienz ebenso wie die aus der höchsten Waldregion in die wärmere Zone verbrachten Ptlanzen, ebenso häufig und ebenso stark wie die im neuen Standorte sie umgebenden, heimischen Pflanzen. Professor Engler in Zürich kommt zu dem gleichen Ergebnisse, wenn er sagt, daß es frostharte Rassen nicht gibt, d. h., daß die Provenienz des Saatgutes nach dieser Richtung keinen Wert besitzt.

Der Erforschung der Ursachen der $\mathrm{Krummwitchsigkeit} \mathrm{des}$ Schaftes ist noch am meisten Zeit ron seiten der Forscher, der Praktiker und der Samenhändler gewidmet worden. Es ist tief zu beklagen, daß hierbei so viel Mangel an Feingefühl und Takt in der Kritik gegenteiliger Überzeugung, eine solche Fülle persönlicher Gereiztheit und Interessiertheit zutage getreten ist. Nachdem Verfasser auf Grund seiner Studien der Verbreitungsbezirke der Holzarten und ihrer Wuchsverhältnisse in Europa, Amerika und Asien zur Überzeugung gekommen ist, daß es eine Tererbung der im Laufe des Lebens einer Pflanze durch äußere Umstände er worbenen Eigenschaften anscheinend nicht gibt, kann es nicht auffallen, wenn er auch die Erblichkeit der Krummwïchsigkeit, derDrehwüchsigkeit, desniederen, krüppelhaften IVuchses ebenso wie der Geradschaftigheit, der Vollholzigkeit, der Baumhöhe für bestimmte Arten in Abrede stellt und den Wert der Auswahl (Provenienz) des Saatgutes nach dieser Richtung hin bestreitet. Eine exale Prüfung der Provenienzversuche Ph. Vilmorins in Les Barres hat des Verfassers Überzengung nicht zu erschüttern, n ur z u befestigen vermocht. Auf Anregung des Verfassers hat der internationale Verband der forstlichen Versuchsanstalten die einschlägige Frage in sein Arbeitsprogramm aufgenommen. Sind Gerade- oder Krummwïchsigkeit er bliche Erscheinungen, so müssen sie bereits in der Baumjugend sich zeigen; die Nachkommen der Krummholzföhren (Pinus Pumilio) sind bereits in der. Jugend krumm; jene der nordischen Föhre (lapponica) bereits in der. Jugend gerade; jene der mitteleuropäischen Föhre (silvestris) bald krumm, bald gerade, je nach Klima, Boden und Behandlung; alle drei Föhren repräsentieren bereits in der Jugend die erblichen Eigenschaften ihrer Eltern. Tritt Krummwüchsigkeit erst in späterem Alter, etwa nach dem 20. Lebensjahre auf, so liann sie wohl nicht auf Erblichkeit zurïckgeführt werden.

Man kann lier drei Gruppen unterscheiden: die erste umfaßt die Gattung Picea, die Fichtenarten Abies, die Tamnenarten, Pseudotsuga, die Douglasien, Taxodium, Sciadopitỹs, die Föhrenselition 
1. Art, Varietät, Rasse, Individuum, Wuchsfehler und Wuchsvorzllge usw. I:",

Strobus, die Stroben und andere: bei ilnen erwachsen anch unter den ungünstigsten Verhältnissen des Bodens, des Klimas und der Behandlung tadellos gerade Schäfte; auf 1014) Stämme trifft noch nicht ein Stamm mit gebogenem Schafte: nur an schroffen Hängrnn beginnt auch bei diesen Baumarten der Schaft mit einer Biegung. Zur zweiten Gruppe, welche durch innere und äußere Einflüsso krummschaftig werden kann, gehören dio Gattumen Larix, die Lärchenarten, die Sektion der zwei- und dreinadligen Führen, die Gattungen Tsuga, Cupressus, Chamaecyparis, Sequoia. Cryptomeria und andere. Am stärksten zeigen als dritte Gruppo, die Laubhölzer, diø Abweichung von der Geradwüchsigkeit als Folge uröberer Empfindlichkeit gegenüber den äußeren Störungen und als Folgre verstärkter, innerer Anlage, intensiveren Individulitätsdranges.

Die äußeren Ursachen, welche die Geradschaftigkeit beeinträchtigen können, sind vor allem im Klima gelegen. Es wurde bereits hervorgehoben, daf jede Holzart vom Optimum ihres Verbreitungs. bezirkes hinweg eine Abnahme der Hoch- und Geradschaftigkeit erkennen läßt; die Extreme in Schlechtschaftigkeit an den Grenzen der Verbreitungszone sind dem Wärmeü berschuf an der Wärme- und dem Wärmemangel an der Kältegrenze zuzuschreiben. Höherer Feuchtigkeitsgehalt der Luft fördert die Geradschaftigkeit. Durch geraden Schaft auffallend und berühmt ist die Föhre oder Kiefer (P. silvestris) in ihrem klimatischen Optintum, das ist West- und Ostpreußen, die baltischen Provinzen (Riga), sind die Eichen in ihrem Optimum in Nordamerika, Japan wie in Südosteuropa, ist die europäische Buche in ihrem Optimum (Nordfrankreich, Deutschland, Böhmen, Ober- und Niederösterreich) und alle anderen Holzarten, deren Optimum aus der Zentralzone ihres Verbreitungsgebietes sich ergibt; von ihrem Optimum hinweg nimmt die Schönheit der Schäfte ab; die Föhre von Riga, die in ihrem Optimum unter 100 Stämmen noch nicht einen aufweist, der eine Schaftkrümmung besäße, ist im lufttrockenen und warmen Zentralfrankreich (in Les Barres) unter den gleichen Verhältnissen mit der süddeutschen Föhre ebenso krummschaftig wio diese. Siebzigjährige Bestände der Rigaföhre wiesen an krummwüchsigen Stämmen $37 \%, 32 \%$ und $26{ }^{\circ} 0$ der Gesamtzahl auf'; dio mmittellbar daneben stehende, süddeutsche Föhre hatte $31^{0}$ o lirummwüchsige Individuen; die Entfernung der Rigaföhre von ihrem Uptimum hatte sic ebenso nachteilig beeinflußt wie die süddeutsche Fölure, d. h. sio war unter dem gleichen Klima der süddeutschen sclıon in der ersten Generation gleich geworden; die Anlage dir Schönschaftigkeit des Optimums der mitteleuropäischen Föhre (Ostpreußen und baltische Provinzen Rußlands) ist daher nicht gefestigt und nicht erblich. Dem Winde fillt chenfalls etliche Schuld an der Krummschattigkeit der Bätune, insbesondure 
an den Nordwest-, West- und Südwesträndern der Waldungen und Bestände zu. Terfasser fand bei Untersuchungen der Bestandsränder und des Bestandsinnern von Rigaföhren in Les Barres, daß unter 100 Randbäumen $\vec{i}$ i stark bis sehr stark gekrümmt waren, während im Innern des Bestandes die Zahl dieser auf 24 herabsank. Schon einer frischgesetzten Pflanze kam der Wind gefährlich werden: wird durch Wind die Wurzcl gezerrt, die Pflanze oder der Baum ngeschoben", so ist keine Pflanze imstande, sich wiederum ohne Krümmung und Gegenkrümmung zur Herstellung der Gleichgewichtslage gerade zu richten. Im gleichen Sinne wie Wind wirkt besonders im jugendlichen Alter der Schnee.

Auch der Boden kann die äußere, mechanische Ursache zur Krummschaftigkeit sein. Holzarten der zweiten und dritten Gruppe, welche Pfahlwurzler sind, werden auf sehr steinigem oder auf seichtem Boden zur Krümmung und Abbiegung ihrer Wurzeln und ihres Schaftes infolge eines korrelativen Verhältnisses zwischen Schaft und Wurzehn gezwungen.

Weitere Ursachen dieser Schaftlirümmung sind Beschädigung und Verlust des Gipfeltriebes, durch absichtliches Einkürzen. durch Schnee, Hagelschlag, Erfrieren, Verletzung durch Insekten, abäsende Tiere u. dgl. Es erhebt sich dann oft ein Seitenzweig als Gipfeltrieb, und eine Krümmung des Stämmchens bleibt zurtick. Häufen sich solche unglückliche Zufälle auf ein und demselben Standorte, so wird ein besonders schafthäßlicher Bestand erwachsen müssen.

Neben den äußeren gibt es offenbar auch innere Ursachen, welche auf gleichem Boden und bei gleichem Klima gerad- und krummschaftige Individuen nebeneinander stellen; unmöglich kann man annehmen, die krummwüchsigen Schäfte stammen alle von ebenso mißgestalteten Eltern ab. Die innere Neigung ist bei der dritten Gruppe mächtiger als bei der zweiten und bei beiden gröfer als bei der ersten. Auf Auslösung der inneren Anlage zur Krummschaftigkeit wirkt offenbar eine iippige Emährung durch besten, besonders gedüngten Boden, ein besonders schlechter Boden, ein wärmeres oder kühleres Klima. Ist die innere Veranlagung zur $\operatorname{Krummw} u ̈ c h s i g k e i t$ gefestigt und voll erblich. wie bei den Kriechföhren P. Pumilio, Mughus, pumila, Juniperus prostrata und vielen anderen, so ist sie Artcharakter; ist die Geradwüchsigkeit voll erblich, wie bercits für Pinus lapponica mihi, die nordische Föhre, nachweisbar, dann ist sie Artcharakter; zeigt eine Holzart je nach Ḱlima, Boden, Behandlung bald geraden, bald krummen Schaft, so ist diese Variabilität und Abhängigkeit Artcharakter (Pinus silvestris); Bastarde haben nicht einen gemischten, sondern einen eigenen Clarakter; in dieser Abgrenzung liegt die Provenienz des Saatgutes.

Allgemein bekannt sind die Auseinandersetzungen, welche der 
1. Art, Varietät, Rasse, Individuun, Wuchsfehler und Wu-hsvor\%(lgu usW. 1:7

Präsident des baltisehen Forstvereins, II ax v. Sivers, veranlafte. indem er die Behauptung aufstellte, dals die Kieftern. oder Fïhren. bestände Dentschlands deshalb so mangelhaft in Schaftform sien. weil die Samen aus inländischem, deutschem Siagtgute oder, wie er sagte, ans I larmstädter Saatgit crwachsen seien: aus solcher Saat erwüchsen zumeist nur krüppeligo Stämme, us sei dies die Folge der Erblichkeit der in Süddentschland ïherhaupt krummwüchsig erwaehsenden Föhren; als schlagendster Beweis milisere das Verhalten der Jugend des Darmstädter Saatgutes in den baltischen Provinzen gelten. Es erfolgten Gegenäufermugen ans den Krreisen ron Forstwirten, daß es sehr wohl aueh in Deutschland schönschaftige Föhren gebe. Verfasser mußte anerkennen, daß dic Saatpflanzen aus Darmstädter Saatgut in Livland zum Teil sehr schlechtschaftig, zum Teil aber auch doch tadellos standen, dafs baltische Jugend bald tadellos gerade, bald doch aueh unter den vom Menschen geänderten Bidingungen recht krumm erwuehs, daß die baltischen Föhrenaltbestände dagegen tadellosen, vollendet geraden Wuehs aufwiesen: die I)ifferenzen bezogen sich auf die Erblichkeit der Anlage zur Geradschaftigkeit in der baltisehen, der Anlage zur Krummschaftigkeit in der mitteldentschen Föhre. Verfasser glaubte, die Krummschaftigkeit der jungen Föhre in Livland, sowohl Darmstädter als baltischer Herkunft, auf die Erziehungsmethode, Steigerung der Feinde und Auswahl des sehlechtesten Bodens. die Krümmung der deutschen Tieflandsföhren auf größere Wärme. geringere Luftfeuchtigkeit (Lage außerhalb des Optimums) zurückführen zu müssen. Dabei mußte Verfasser auch auf die Tatsache hinweisen. daß auch in Deutsehland über $5110 \mathrm{~m}$ Elevation, d. h. bei gleichem Klima wie in Livland, ebenso schönschaftige Föhren erwüchsen wie jene Evon Riga (Schwäbisch-baverisehe Hochebene, Fichtelgebirge. Schweiz und Schwarzwald ${ }^{1}$ ).

Die oben angeführten Zahlen über die Krummschaftigkeit der Rigaföhre in Les Barres beweisen nicht die Erblichkeit der Schönsehaftigkeit der Rigaföhre; sie bestätigen vielmehr das allgemeine Naturgesetz, daß über Gerad- und Krummschaftigkeit der Silvestristöhre nicht die Abstammung des Saatgutes (Provenienz), sondern Kilima. Boden, Behandlung und MiBhandlung auf dem uemen Standorte entseheidend sind. Es ist hier nicht der Ort, mm den Nachweis zu erbringen, daß auch die Versuche über Erblichlieit und über Züehtung der Geradschaftigkeit bei der Lärche, welche in Oldenburg ${ }^{2}$ ) angestellt wurden, nach der Auffassung und Brobachtung des Verfassers als mißlungen bezeichnet werden mïssen. V'n der Drehwüchsigkeit der Holzfaser des Schaftes wirl tets

1) C. Wa g ner, Die räumliche Ordnung im Walde. 1907.

$\left.{ }^{2}\right)$ H. M a yr, Supplement der Allgem. Forst.- u. Jagdz. 1\$ $5 \%$ 
behauptet, daß dieser Formfehler erblich sei: nirgends ist ein beweisender Versuch mit einer Baumart, die neben drehwüchsigem anch geradfaseriges Holz besitzt, darüber ausgeführt worden. Soviel ist sicher, daß alle Holzarten auf seichtem Boden, auf Südhängen und steinigem Boden zur Drehwüchsigkeit und $\mathrm{zu}$ daraus resultierender Schwerspaltigkeit hinneigen.

Zwiesel- oder Doppelgipfelbildung, eine äußerst lästige Erscheinung, welche bei ungenügender. Jungwuchspflege im höheren Alter zu einer Quelle von Verlegenheiten für den Wirtschafter wird,

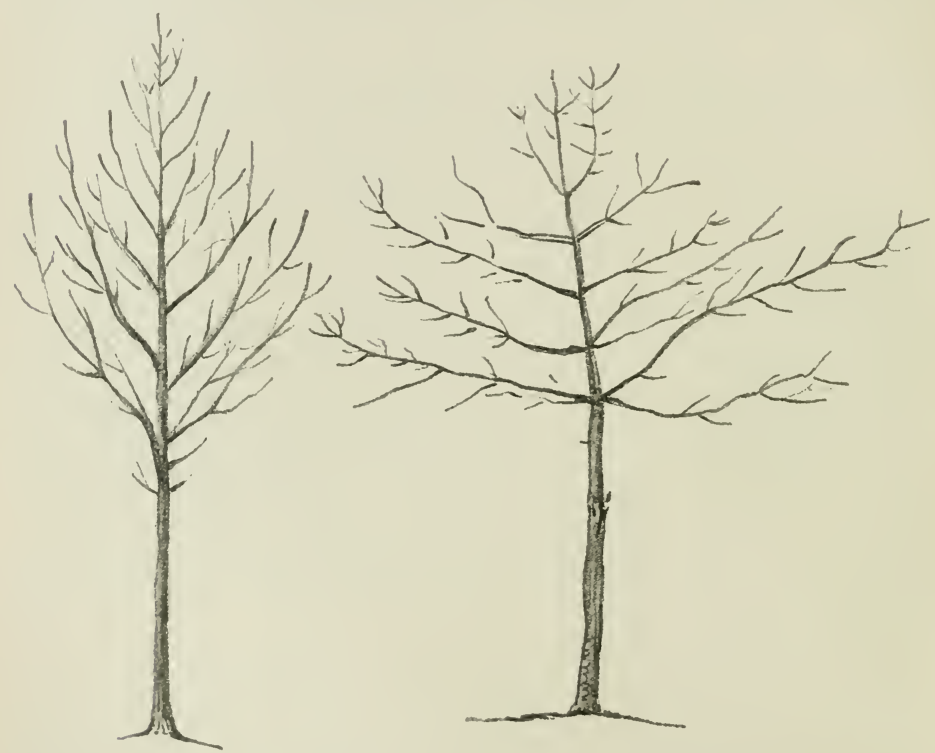

Abb. 6. IreiBigjahrige kichen (Quercus pedunculata) mit normaler und mit quirlästiger Krone, von Jugend auf fehlerlos und fehlerhaft.

ist bei den (rattungen Picea, Abies, den fünfnadeligen Pinusselitionen, bei Pseudotsuga, Larix und anderen Folge einer Verwachsung zweier eng beisammen stehender Pflanzen (Büschelpflanzung) oder Folge eines Gipfelverlustes, wobei zwei Seitentriebe zu neuen Gipfeln sich erheben. Dureh innere Steigung doppelgipfelig werden am meisten die Gattungen Tsuga, Chamaecyparis, einige Laubhölzer, wie Cereidiphyllum, Fraxinus, Acer; die innere Steigung (individuelle Anlage) wird besonders häufig ausgelöst in nicht zusagendem Klima und auf unpassendem Boden; im Streben, zuerst den Boden zu decken, treiben genannte Holzarten Seitenäste, welche zu aufrechten Trieben werden. 
1. Art, Varietät, Rasse, Individuum, Wuchsfehler und Wuchsvorzage usw. 1:??

Vergabelung des Schaftes kommt vorwiegend boi den Iauhhölzern vor und wird dadureh hervorgernfen, daß ein Sieitenzweig ohne erkembare, äußere Ursachen stärker wächst als die folgenden und die vorausgehenden, ja, daß er dem (iipteltriel, hierin wleich wird, so daß beide gleich stark und gleich hoeh neheneinander anfwürts streben, bis der eine zurückbleibt und bald daraut ein zweiter, mit dem zurückgebliebenen korrespondierender seitenast den Rhythmus seines Vorgängers wiederholt.
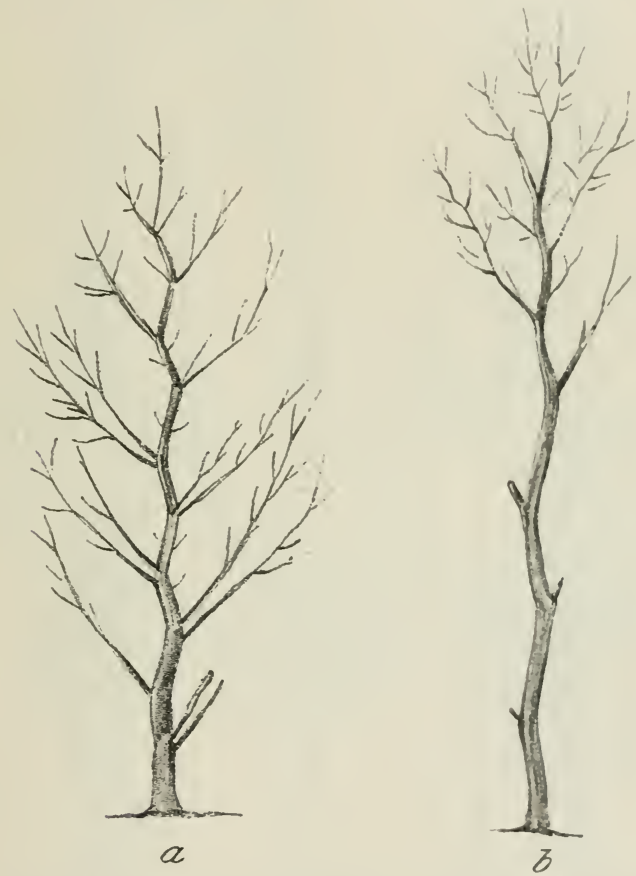

Abb. 7. Fünfunddreißigjulırige Eichen mit quirlästiger Krone ije zwei $̈$-te bilılen einen sichein. quirl), $a$ in lockerem, $b$ in vollem Schlusse, beide von Jugend auf fehlerhaft.

Da unter den gleichen Boden- und Klimaverhältnissen vergabelte und geradschaftige Stämme nebeneinander stehen, kann man nicht Boden und nicht Ḱlima für diese forstlich ungünstigen Austormungen des Schaftes verantwortlich machen; es liegen wiedcrum individulle, innere Veranlagungen vor, die allerdings auf' unpassendem Boden oder ebensolcher Klimalage bei jeder Holzart häufiger in die Erscheinung treten als auf guten Böden und in zusagenden Klimaten. Daß pine ïberlegende Erziehung der Bestände auf diese individuelle Veranlagnung I a y $\mathrm{r}$, Waldbau. 
cin besonderes Augenmerk richten muß, kam hier nur angedeutet werden, um der Praxis die Wichtigkeit solcher Kronenstudien zu zeigen.

Klebeäste und Wasserreiser werden in der Regel zusammengenommen als den Nutzwert schädigende Ausschläge des Schaftes. Beide sind jedoch verschiedenen Ursprungs, physiologisch verschieden.
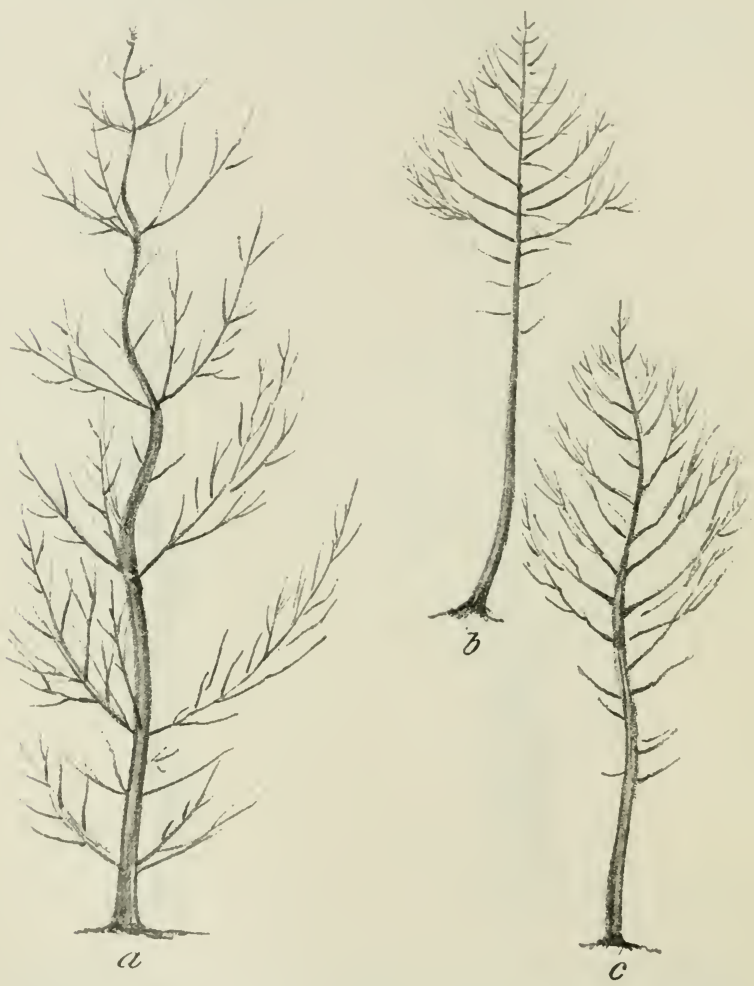

Abb. 8. a neunjahrige japanische Lürche (L. leptolepis), krumm aus naturlicher Anlage. b dreißigjahrige europaische Larche, krumm durch Wind. $c$ dreißigjahrige europăische Lärche, krumm durch innere Anlage von Jugend auf.

Klebeäste sind kurze Triebe, die den Schaft, z. B. an Buchen oder Eichen, im tiefsten Bestandesschatten und im vollen Lichte umkleiden, ohne daß in ihrer Krone, in ihrer Ernährung eine erklärende Ursache zu erkennen wäre. Wasserreiser sind rasch emporwachsende Triebe, die durch das volle Vorderlicht ans schlafenden Knospen erweckt werden; 
1. Art, Varietät, Rasse, Individuum, Wuchsfehler und Wuchsvorzuge usw. 1:31 sie nehmen der Krone das Vegetationswaster vorweg, so daß diese absterben muß (Gipfeldürre, Zopftrocknis). Plützliclie Freistellung.

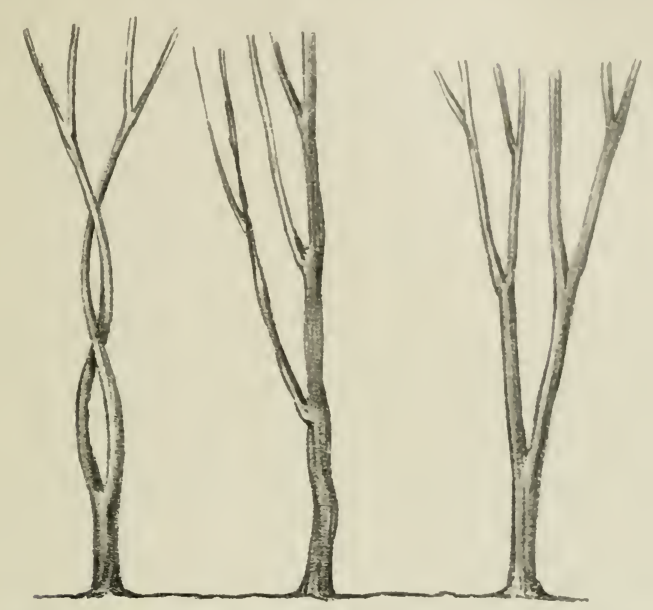

Abb. 9. Schăfte von drei fünfzigjährigen, herrschenden Buchen aus rollem Bestandesschlusse, ihre Fehler wiederholen sich von der Jugend bis zur Haubarkeit.

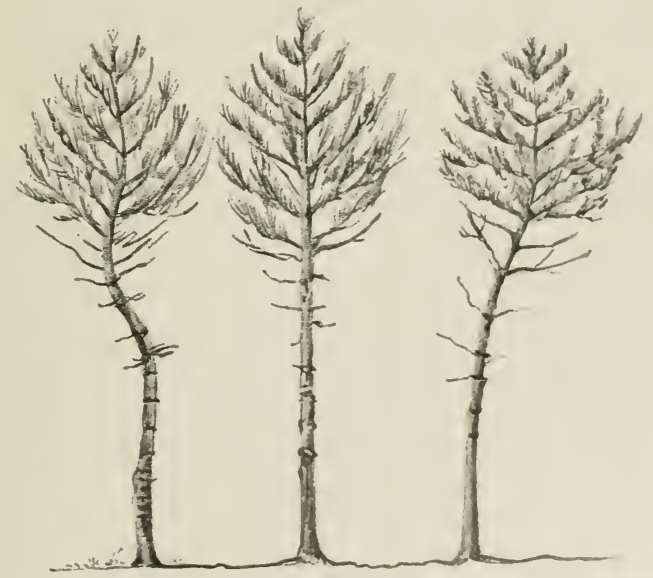

Abb. 10. Drei nebeneinanderstehende, siebzigjăhrige Nachkonmen der Riga-Fỏro in Les Barres (Frankreich).

Senkung des Grundwasserspiegels, sowie allzu weitgchendle Ent wässerung sind die Torbedingungen für Wasserreisertildung bei allen Lanh- 
holzarten, insbesondere Lichthölzern, die aus einer Umgebung von Schattenholzarten losgelöst werden. Klebeästeanlage und Wasserreiseranlage sind individuell; denn es gibt Bäume, die trotz obiger Angriffe ohne Wasserreiver bleiben und solche, welche von Jugend an mit Klebeästen behaftet sind. Zur Ḱlebeästebildung veranlagte Individuen kömmen als Freiständer nicht verwendet werden, denn ihre Klebeäste gehen bei Freistellung in Wasserreiser über. Klebeästefreie Stämme zeigen bei Freistellung gar keine oder nur mäßige Wasserreiserbildung. Die Erziehung der Bestände, ebenso wie der Mittelwald- und Überhaltbetrieb werden hierauf Rüicksicht nehmen müssen. Zư K'lebeästebildung neigen besonders die Gattungen Quercus, Fagus; von Nadelhölzern wären zu nennen: Pinus mitis, rigida, Nurrayana, Taxusarten, die japanische Lärche, Cryptomeria und andere; dabei sind Klebeäste auf das Stangen- und jüngere Baumalter, Wasserreiser an kein Alter gebunden. Bäume mit krummwüchsig veranlagten Schäften wiederholen diese Anlage auch in den Ästen, welehe die Krone bilden, in weit ausgreifenden, hin und her gebogenen, mehr horizontal abstehenden Ästen. Sie beanspruchen unverhältnismäßig große Luft- und Lichträume, sind unduldsam gegen die Nachbarn und gegen von unten aufwachsende Pflanzen (Unterbau); Bäume, denen die Anlage einer engen Krone, welche aus aufwärts strebenden Ästen sich aufbaut, eigen ist, sind nicht nur geradschaftig, sondern können auch in größerer Zahl auf der gleichen Fläche wohnen und ermöglichen dem Unterbau, sich hart bis zum Schafte zum Zweeke seiner Astreinigung heranzuschieben.

\section{Schnellwüchsigkeit.}

Zur Aufstellung einer Reihenfolge der Wuchsgesehwindigkeit der Holzarten kann ein einzelner Versuch, welcher die Holzarten alle auf demselben Boden und in demselben Klima anbant, nicht dienen; denn der Boden sowohl wie das Klima mögen für eine Holzart optimal sein, für eine andere Holzart sind sie es nicht; beide stehen somit hinsichtlich ihrer Vergleichbarkeit nicht auf gleich günstiger oder gleich ungünstiger Grundlage. Die Prüfung muß berücksichtigen, daß die Schnellwüchsigkeit von folgenden Faktoren abhängig ist:

1. vom $\mathrm{Boden}$; für jede Holzart ist ein Boden von bestimmter Nährstoffmenge und physikalischer Beschaffenheit der beste, wie frühere Auseinandersetzungen bezeugen;

2. vom Klima; es wurde der Satz nachgewiesen, daß in der Jugend der Bäume die Raschwüchsigkeit mit dem wärmeren Klima steigt, vom mittleren Alter an aber das Klima des Optimums den Pflanzen die höchste Wuchskraft verleiht, daß im kühleren K'lima jede Pflanze trägwüchsig werden muß. 
3. Nicht die rolle Belichtung durch die Sonne, sondern cine Einschränkung des Sommenlichtes bei rollem Oherlicht, das ist Soiten. schutz gegen Süden hin, gewährleistet dio höchste Wuchwgeschwindirrkeit.

4. Die einer jeden IIolzart zukommende Wuchskratt ändert sich naturgemäß mit dem Alter; zu Begimn des Stangenholzalters und während desselben, das ist zwischen 15. und 3\%. Lebensjahr, liegrt das Höhenwuchsmaximum.

5. Sehr verschieden ist die einem jeden Individuum imerhall, der Art zukommende Wuchsgeschwindigheit; es ist unzulässig, die langsamer wüchsigen Individuen als weniger günstig im Boden untergebracht zu betrachten; es ist ebenso unzulässig, die langsamwüchsigen Individuen als von langsamwüchsigen Eltern abstammend aufzutasisen.

6. Jeder Eingriff in die normale Weiterentwicklung, wis Ver. pflanzung, äußert sich sofort in einer autfallenden Verkürzung des Längenwuchses; bei jungen Pflanzen von 4-111 Jahren vergehen 2-3 Jahre, ehe die Pflanze zur Normalität zurückgekehrt ist. Je älter die Pflanze, um so länger verzögert sich diese Rückkehr.

7. Das Beschneiden der Seitenäste hat eine größere Streckung des Längstriebes zur Folge; in demselben sime muß auch das Unterdrücken der Seitenäste durch den Baumkronenschluß wirken, wemn auch durch den Wurzelschluß eine Abschwächung der Wirkung erfolgt.

8. Es wird die Erblichkeıt des Zuwachsvermögens, der Schnell- und Langsamwüchsigkeit, soweit diese durch wärmeres oder kühleres Klima hervorgerufen wird, von Cieslar und Engler behauptet.

Die Praxis hat noch am ehesten alle obigen Gesichtspunkte bei der Aufstellung einer Skala der Wuchsgeschwindigkeit berückicichtigt. Fügt man zu ihren Listen noch die außereuropäischen Holzarten. soweit möglich, ein, so ergibt sich hinsichtlich der Wuchsgeschwindigkeit in Mitteleuropa

für das fünfte Lebensjahr folgende, absteigende Reihe:

La ubhölzer: Pappel, Ulme, Zelkowa, Birke, Eiche (('. pedunculata und sessiliflora), Esche, Ahorn, Juglans, Buche, Carya;

Nadelhölzer: Larix leptolepis. Küstendouglasie. Sitkafichte, Pinus Banksiana, europäische Lärche, Strobe, Föhre (Pinus silvestris), europäische Fichte, Kolorado-Donglasie, Picea pungens, Tanne, Larix sibirica, Zirbe, Eibe.

$$
\text { Zehntes Lebensjahr. }
$$

L a ubhölzer: Pappel, Birke, Ulme, Esche, Erle. Ahorn, Eiche, Buche, Carya.

Nadelhölzer: Japanische Lärche (Larix leptolepir), Küstendouglasie, Sitkafichte: Larix europaea, Pinus Bankiana, Weymonths- 
föhre, Föhre (Pinus silvestris), Fichte, Koloradodouglasie, Tanne, Zirbe, Eibe.

Mit dem Übergange vom 20. zum 30. Lebennjahre beginnt der typische Anspruch einer jeden Holzart an Boden und Klima und ein für das spätere Verhalten als Baum entscheidender Wechsel in der bisherigen Wuchskraft; vor diesem Zeitpunkt kann für keine fremdländische Holzart ein sicheres Urteil über ihre Wuchskraft abgegeben werden.

Dreißigstes Lebensjahr.

L a u bhölzer: Pappel, Birke, Robinia, Ulme, Ahorn, Linde, Erle, Hainbuche, Esche, Eiche, Buche, Edelkastanie.

Nadelhölzer: Sitkafichte, europäische Lärche, Weymouthsföhre, Fichte, Tsuga canadensis, japanische Lärche, Koloradodouglasie, Tanne, Zirbe, Eibe, Pinus uncinnata (Hackenföhre), Pinus Pumilio.

Höhenentwicklung der mitteleuropäischen Holzarten im 70. Lebensjahr.

Nadelhölzer: Lärche, Föhre, Fichte, Tanne, Hackenföhre, Eibe, Kriechföhre (P. Pumilio).

Laubhölzer: Buche, Eiche, Esche, Ulme, Ahorn, Linde, Erle, Birke, Pappel.

Im 100. Lebensjahr.

Nadelhölzer: Fichte, Tanne, Lärche, Weymonthsföhre, Föhre, Hackenföhre, Eibe, Kriechföhre. Birke.

Laubhölzer: Buche, Eiche, Ulme, Esche, Ahorn, Linde, Erle, Im 120. Lebensjahr.

Nadelhölzer: Tanne, Fichte, Lärche, Weymouthsföhre, Föhre, Hackenföhre, Eibe, Kriechföhre.

L a ubhölzer: Buche, Eiche, Ulme, Esche, Ahorn, Linde, Erle.

Es eilen somit die Lichtholzarten während der ersten Dezennien den Schattenhölzern vorans; im Stangenholzalter werden sie von den Schattenholzarten eingeholt und übergipfelt, so daß im Baumalter die Schattenholzarten, welche in der Jugend zu den letzten zählten, nummehr die ersten geworden sind.

Es läßt sich daraus schon ermessen, daß die Aufzucht einer Mischung von schnell- und langsamwïchsigen, von Licht- und Schattenbaumarten ganz besondere, waldbauliche Vorsichtsmaßregeln erheischen müsse, um eine solche Mischung durch das gefährliche Stangenholzalter in das Baumalter hindurch zu retten.

Es hat nur ein naturwissenschaftliches, aber kein forstlich praktisches Interesse mehr, jene Höhen zu kennen, bis zu welchen die höchsten Riesen einer Baumart emporgewachsen sind, unberührt rom Menschen oder in nenerer Zeit geschïtzt vom Menschen. 
Eine solche Höhenskala müßte mit den S'equoien von Westamerika mit $120 \mathrm{~m}$ beginnen, hätte $100 \mathrm{~m}$ hohe Küistendouglasien, sil m hohe Znckerföhren, Gelbföhren, $70 \mathrm{~m}$ hohe westamerikanische Fichten (Sitkafichte) und Tamnen, die japanische Cryptomeria, die indische Deodarzeder und andere zu erwähnen; mit 50 - i0 $\mathrm{m}$ wïrde dio Melrrahl aller Fichten, Tannen, Föhren und Lärchen, die Taxodien, die Clıamaecyparisarten und zahlreiche andere Baumarten anzuschließen sein. Das Bewunderungswürdigste an solchen Riesen ist eigentlich deren Alter, das mit den 3000 und 4000 jährigen Sequoien in der Altersskala der Riesen anhebt; den Naturforscher beschäftigt zunächst die Ausdauer der Lebenskraft, ja die rein physikalische Dauer des zuerst vor vielen Hunderten, selbst ror Tausenden ron Jahren gebildeten Holzes im Herzen der Bäume; andere hält die Größe gefangen; Durchmesser und Höhe sind aber nur Funktionen der Zeit, da jedes Jahr Durchmesser wie Höhe, wenn auch um einen minimalen Betrag, wachsen müssen. soll der Baum am Leben bleiben; die Dicke kommt also bei den Bäumen im Alter mit den Jahren, in der Jugend mit der besseren Ernährung.

Legt man aber ein Alter zugrunde, wie es im forstlichen Betrieb immer noch als ein durchschnittlich Erreichbares Geltung hat, z. B. 120 Jahre, so können auf günstigem Boden, im optimalen Klima folgende Höhen erzielt werden:

Bäume der I. Größenklasse:

Tanne und Fichte $40 \mathrm{~m}$, Lärche und Weymouthsföhre, Föhre (silvestris) 35-40 m, Buche, Eiche, Ulme, Esche, Linde, Ahorn, Erle $30-35 \mathrm{~m}$.

Bäume der II. Größenklasse:

Birke, Zitterpappel, Hainbuche, Prunus 25-30 m.

Bäume der III. Größenklasse:

Zürbel, Eibe, Hackenföhre, Sorbus und Pyrus 20_25 m.

Großsträucher und Halbbäume:

Eronymus, Sambucus, Viburnum, Corylus $8-110 \mathrm{~m}$.

Sträucher:

Juniperus, Crataegus, Corylus, Lonicera und viele andere unter $` \mathrm{~m}$.

\section{Die natürliche Vermehrung der Holzarten durch Sämereien.}

Unter Voraussetzung der Kenntnisse über Entstehung unll Morj Lologie der Sämereien, welche Lehrgegenstände der Botanik sein mïssin, kann hier nur auf jene Erscheinungen Bedacht genommer worden, welche mit waldbaulichen Fragen, hier zunächst mit drer ratïlichen oder künstlichen Verjüngung der Büume, mit der natürlichen Ver. 
breitungsfähigkeit der Holzarten in kausalem Zusammenhange stehen.

a) In erster Linie entscheidet hier das Gewicht des Samen. kornes und seine Ausrüstung mit Fallschirmen oder mit flügelartigen Anhängseln, welche das Samenkorn zur Rotation und dadurch zur verzögerten Fallgeschwindigkeit zwingen, wodurch das Korn längere Zeit vom Winde schwebend erhalten und auf gröfiere Entfernungen getragen werden kann. Auf den ersten Blick fällt es auf, daß die größten und schwersten Samenkörner durchaus nicht, wie es allgemein erwartet wird, den Riesen der Pflanzenwelt angehören, daß gerade die kleinsten Samenkörner mit dem geringsten Eigengewicht mit dem ergiebigsten Flugapparat ausgerüstet sind. So stehen an erster Linio unter den leichtesten und flugfähigsten Sämereien jene der Gattungen Salix, Populus und andere; es wurde aber bereits im ersten Abschnitt darauf hingewiesen, daß die Flugweite dieser Sämereien viel geringer ist, als man vermutet, indem eine Entfernung von $700 \mathrm{~km}$ von ihnen nicht überbrückt werden kann. Immerhin genügen einige Exemplare dieser Holzart und ebenso von forstlichen Unkräutern, um auf jeder Kahlfläche die Allgegenwart dieser bestbeschwingten Sämereien sicherzustellen. Sehr viel mehr schränkt sich der Verbreitungskreis ein für die Sämereien der Gattungen Betula, Ulmus, Paulownia, Catalpa, Picea, Larix, Pseudotsuga, Tsuga, Thuja, Chamaecyparis, den meisten zweiund dreinadeligen Föhren und vielen anderen. Immerhin können aber noch Nethoden der Verjüngung auf die größere Flugweite dieser Sämereien aufgebaut werden. $\mathrm{Zu}$ den schwereren Sämereien, die zwar mit Fallschirmvorrichtung versehen, aber doch nur bei starkem Wind auf eine Entfernung von $1-2 \mathrm{~km}$ verschleppt werden können, zählen die Gattungen Abies, die Föhren der Sektion Strobus, die Gattungen Tilia, Carpinus, Fraxinus, Liriodendron, Acer und viele andere. Den schweren Sämereien olne Fallschirmvorrichtung kommt eine kugelige oder walzenförmige Gestalt zu, um sie zum Rollen auf einer geneigten Ebene zu befähigen; überdies sind die meisten derselben entweder im Kern oder in der Umhüllung anch ron der Natur genießbar gemacht, damit sie von Tieren verspeist und verschleppt werden; die Natur opfert gleichsam Tausende von Keimen, um einzelnen wenigstens eine Verbreitung und Keimung zu sichern. Es ist allbekamnt, daf einige alte Eichen in der Nähe des Waldes genügen, um dort auf einer baum. freieni Stelle massenhaft Eichenjugend aufsprossen zu sehen, welche der Habgier und Fürsorge des Eichelhähers ihr Dasein verdankt; die Zürbelnuß im Hochgebirge wird massenhaft von Tamenhäheru vertilgt, aber anch massenhaft an anderen Orten wiederum angebaut. Weniger günstig ergeht es len für einige Tage schwimmfähigen Sämereien, da die guten Körner meist im Wasser am frühzeitigsten zu Boden sinken und selten ein geeignetes Keimbett finden. Auf Tiere zumeist sind die 
Sämereien der Gattungen Prrus, Sorbus. Prums, der Sektion Cembra. der Gattung Quereus, Fagus, Juglaus, ('arya, Castanea, Arseulus, Magnolia, Juniperus, Taxus, Robinia, Gleditsehia und viele andere angewiesen.

b) Die Entleerungsart der Sämereim ist ron Eintlub auf die Verbreitungsfähigkeit. Die in Fruchthïllen und Zajfen eingreschlosienen Sämereien bedürfen zumeist trockener Witterung, damit die Frucht. hüllen oder Zapfen platzen, aufklaffen oder zertallen und die Sümreien dadurch frei werden. Auf trockene Witterung sind ancrewiesen die Gattungen Picea, Pinus, Larix, Tsuga, Pseudutsuga, Thuja, ('hamancyparis, Abies und viele andere Nadelbaumgattungen; ferner Juglaus, Carya, Robinia, Castanea, Fagus, Aesculus, Magnolia, Catalpa. Liriodendron, Alnus. Betula und viele andere Laubbaumarten. Trockene Witterung aber stellt sich in ganz Mittel- und Nordeuropa nur bei Föhnlage oder bei Ostwind ein. Soweit die Sämereien der genamnten Gattungen flugfähig sind und in Europa angebant werden, haben sie daher die Tendenz zur Verbreitung $n \mathrm{ch}$ Westen hin. Unabhängig in der Ablösung von der Witterung sind die Gattungen Quercus. Prrus, Sorbus, Prunus und andere.

Andere Sämereien bedürfen weniger trockener Witterung als vielmehr heftiger Windströmungen, damit sie gewaltsam rom Baume ah. gerissen werden, wie die Sämereien der Gattungen Fraxinns, Acer, Tilia, Carpinus und andere. Häufige Winde aber sind in Mittel-unt Nordeuropa zumeist aus Westen zu erwarten: die Sämereien obiger Bäume haben somit die Tendenz, rorwiegend nach $\mathrm{Osten}$ hin ihre Sämereien zu verbreiten.

c) Der Eintritt des Samenertrages, die Häufigkeit der Wiederkehr der Samenjahre, die Menge der gebildeten Sämereien sind für die Terbreitungsfähigkeit einer Holzart von größtem Belang, wie die folgenden Auseinandersetzungen zeigen werden.

d) Ton den Tausenden ron Keimen, welche ein Baum bildet und welche Wind und Tiere rom Intterbaume hinwegtragen, wirl die Mehrzahl wieder zugrunde gehen, weil sie auf umpassenden Standort geraten sind. Sind aber die Sämereien einer Holzart zugehörig, welche gegenüber den rerschiedenartigsten Bodenverhältniscen sowie gegrenüber heterogenem Klima unempfindlich sind, wie die Gattungen PopmluBetula, Alnus. Juniperus, die zwei- und dreinadeligen Fühm inu anderen, so besteht die Wahrscheinlichkeit, dafs ron den ansirestrenten Sämereien dieser Bäume die größte Zahl sich behanpten kamı.

.Tene Holzart, welche am frühesten mit der Erzeugung linimfihigur Sämereien beginnt, hat die meiste Ausicht für groibere Vertreitung. der Eintritt der S a menerträgnistäligkeit alor häng von einer Reihe von äußeren und imneren Einwirkungren aut di. Pflanze ab. 
138 Vierter Abschnitt. Waldbaulich-biologische Eigenschaften der Holzarten.

Je wärmer das Klima eines Standortes, um so frither beginnt jede Holzart ihr Samenerträgnis; jede Holzart beginnt zuerst im wärmsten Anbaugebiet, wärmer als das natürliche, sodamn im Gebiete wärmer als das Optimum früher als im Optimum. dort früher als im Gebiete der natürlichen Verbreitung kïhler als das Optimum und am spätesten in einem lïnstlichen Verbreitungsgebiete kïhler als das natïrliche.

Je freier Licht und TÏ̈rme auf die Kronen der einzelnen Pflanzen einwirken können, um so früher setzt das Samenerträgnis ein. Kronenschluß verzögert um Dezennien den Eintritt gegenüber dem freien Stande, die Vorbereitungshiebe der waldbaulichen Praxis bezwecken erhöhten Licht- und Wärmezufluß für die zur Samenbildung bestimmten Bäume.

Schlechter, umpassender Borlen nötigt alle Bäume zu frïherem Eintritt der Samenbildung. So vorteilhaft guter Boden nach anderer Riclıtung, für die reproduktive Tätigkeit der Pflanze ist, den Eintritt der Mannbarkeit verzögert er.

Schwere Eingriffe in das Leben der Pflanze, wie Verpflanzung, Wurzelstïmmelung, Erkrankungen aller Art, welche ein Kümmern der Pflanze nach sich ziehen, nötigen dieselbe zur frühzeitigen Samenbildung.

Zu den individuellen und variablen Eigenschaften muß auch der Eintritt des Samenerträgnisses gezählt werden.

Obstsorten sind Individualitäten und Lusus oder Spielarten; wie verschieden im Beginne des Samens bzw. Fruchterträgnisses sie sein kömnen, ist allbekannt. Ähnliche Unterschiede zeigen die Individuen ein und derselben Holzart.

Jede Holzart beginnt mit einem gewissen Alter von selbst das Samenerträgnis; bei allen Holzarten erlischt aber die reproduktive Kraft erst mit dem Tode des Baumes. Zu den Holzarten, welche am frïhesten beginnen, zählen die Lichtholzarten mit leichten Sämereien, somit die Gattungen Betula, Populus, Salix, Larix, zwei- bis dreinadelige Föhren und andere; unter den schwersamigen Lichtholzarten sind die Gattungen Quercus, Juglans, Carya als Beispiele zu nemnen; leichtsamige Schattenholzarten, wie Picea, Pseudotsuga, auch Thuja, Thujopsis und andere beginnen frïher als schwersamige Schattenholzarten, als deren bestes Beispiel die Gattungen Abies und Fagus gelten können.

f) Wichtig für die natürliche Verbreitungs- und Verjüngungsfähigkeit einer Holzart ist sodam die Wiederkehr der Samenjahre und die Ergiebigkeit der einzelnen Holzarten in ihrer Samenproduktion ( $\mathrm{S}$ a menmenge). Es läßt sich erwarten, daß die kleinsten Sämereien von den Bäumen in größter Zahl gebildet werden müssen, da zu ihrer Fertigstellung die geringste Stoffmenge nötig ist. In Preußen sind scit vielen. Jahren hierüber Notizen gesammelt worrlen, 
aus denen Professor sichwappach tolgende Zusammenstellumg grofertigt hat:

Zur Samenmenge, welche als eine Vollemte hezeichnet wird, liefert die

\begin{tabular}{|c|c|c|c|c|c|}
\hline \multirow{5}{*}{$\begin{array}{r}\text { mitteleuropäische } \\
\text { europäische }\end{array}$} & Birke & pro & Jahr & durchschnittlich & $41,8 \%$ \\
\hline & Hainbuche & " & , & , & $4.2,11 \%$ \\
\hline & Roterle & , & $\pi$ & 7 & $: 3 !, 1,1^{\circ} 0$ \\
\hline & Föhre & , & " & 7 & $37,1^{\circ} 0$ \\
\hline & Eichte & , & $n$ & , & $3 \pi, 1 \%$ \\
\hline , & Tamne & , & , & ת & 34.500 \\
\hline , & Esche & , & " & , & $3: 3,3^{\circ} 0$ \\
\hline , & Stieleiche & $"$ & $"$ & , & $17,1^{\circ} \mathrm{o}$ \\
\hline 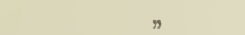 & Buche & , & $\eta$ & , & $11 ;, 2{ }^{0} 0$ \\
\hline
\end{tabular}

Es sind somit bei der Birke zwei Jahre nötig, um das Quantum einer Vollernte zu ergeben; bringt ein Jahr eine Vollernte, so wird nicht das nächste, sondern erst das übernächste Jahr wieder eine Ernte bringen; die Eiche verlangt das Samenerzeugnis ron sechs Jahren, um das Quantum einer Tollernte, Vollmast, zu erfüllen. Man kann daraus entnehmen, daß bei Eintritt einer Tollmast in einen Jahr sechs Jahre vergehen können, ehe wiederum reichliche Samenbildung sich einstellt. Bei der Buche beträgt die Ruhepause der Fruktifitation sechs bis acht Jahre und darïber. Tollmasten sind stets selten, Halbmasten häufig, sogenannte Sprengmasten am häufigsten zu erwarten. Die Eigentümlichkeit, daß manche Bäume bei allen Holzarten fast alljährlich etwas Samen bilden, andere nur nach langen Ruhejahren wieder Samen liefern, mus zu den individuellen Anlageu gerechnet werden, wie dies am besten bei den Obstbäumen bekamnt ist.

Besonders auffällig ist, daß bei einer sogenannten $\mathrm{Vollmast}$ fast sämtliche Individuen einer bestimmten Baumart in Fruktifikation treten, daß in einem solchen Ausnahmejahr sogar der Fruktifitationsbeginn bei den jüngeren Individuen beschleunigt wird, so daß die Altersdifferenz der Holzarten fast völlig ausgeglichen erscheint. .Ja, in einem solchen .Jahre fruktifiziert alles, als wenn Boden und Klima aut dieso innere Leistung der Bäume keine Einwirkung hätten. Alle Holzarten zeigen diese Erscheinung, aber jede Holzart hat wiederum ilren eigenen Zyklus, indem sie diese Massensaat wiederholt. Sicher wirl eine natur. gesetzliche Ursache hierfür sich noch auffinden lassen; der Fichten-

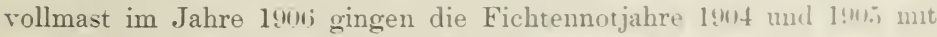
ihren außerordentlich trockenen siommern voraus.

Abnorme Witterungsverhältnisse künnen den normalen Zykins der Wiederkehr der Samenjahre rurchkreuzen: deshalh kohren Blütenjalure regelmäßiger wieder als Fruchtjahre, weil aus der Blüte nicht immer eine Frucht sich entwickeln muß. Fällt in die Blïtezeit ein schwererer, 
verspäteter Frost oder naßkalte Witterung oder fehlt Wind, so wird die Blüte zerstört oder die Eizelle nicht befruchtet.

Im wärmeren Klima ist die Ruheperiode in der Samenbildung bei allen Holzarten kürzer als im kühleren; die Buchen und Eichen tragen in der kühlsten Lage erst alle 10, selbst alle 12 Jahre Sämereien in größeren Mengen. Robert Hartig hat den Satz aufgestellt, daß bei Eintritt eines Samenjahres eine bis in die tiefsten Holzschichten eingreifende Auflösung und Erschöpfung an Stärliemehl einträte, weshalb der Baum mehrerer Jahre bedürfe, um diesen Vorrat wiederum zu ersetzen und zu neuer Samenbildung anzuhäufen. Gewiß ist diese Theorie richtig, aber entscheidend ist der weitere Punlit, daß die günstige Witterung e in es Jahres genügen kamn, um wieder vollen Ersatz an Reservestoffen zu bringen. Die warmen Sommer 1892, 189:3 und 1894 haben nach Beobachtung des Verfassers dieselben Eichen zu alljährlicher, Samenbildung gezwungen. Die Schnelligkeit des Ersatzes, die Länge der Ruhepause hängt somit in erster Linie wieder von den Witterungsverhältnissen der Jahre ab, welche auf ein volles Samenjahr folgen: auch die Obstbäume zeigen das gleiche Verhalten.

g) Ton einschneidender Wichtigkeit für den hier zu behandelnden Gegenstand ist der Umstand, ob der gebildete Samen auch gut, d. h. keimfähig ist; die Feststellung dieser Eigenschaft einer späteren Betrachtung zuweisend, sei über die Keimfähigkeit bemerkt, daß sie abhängt rom Alter des Mutterbaumes: im jugendlichen Alter sind die Sämereien, die von kümmernden Pflanzen gebildet werden, zumeist taub. Erst ron einem bestimmten Jahre an, dem Eintritt des normalen Samenerträgnisses, beginnt auch die Erzeugung keimfähig૯r Sämereien; daß aber im höchsten Alter der Bäume der Same wiederum schlecht, d. h. taub ansfalle, ist nur unbewiesene Vermutung; die Beobachtung an ganz alten Bäumen und an der von ihnen zweifellos stammenden .Jugend rechtfertigt den Satz, daß die Erzeugung keimfähiger Sämereien bis zum Tode des Baumes sich erhält; die Beobachtung lehrt sodam, daß die alten Bäume immer noch den gleichen Tumus einhalten, in welchem sie auch in jüngeren. Jahren fruktifizierten. Schlecht ge. nährte Bänme tragen zwar hänfiger, aber minder keimkräftigen Samen gegenüber gut emährten, vor allem im vollen Lichte fruktifizierenden Bäumen. Waren die Witterungserhältnisse während der Bestäubung ungünstige, d. h. naß und kalt, so unterbleibt vielfach die Befruchtung, während Frucht- und Samenliülle sich entwickeln. Auch der weitere Verlauf der Witterung des Fruchtjahres, besonders ein warmer, trockener, lichtreicher Sommer fördert die Ausbildung der Keimanlage und die Reife der Samen und Frïchte.

Es ist gewiß allgemein richtig, daß liurz vor der $R$ oife gesammelte Sämereien nachreifen, wenn sie in einer dicken, wasserreichen Fruchthülle cingeschlnssen hleiben: daraus losgelöste Sämereien oder 
solche, welche von Anfang an nur dümne Hüllen besitzen, dürfen erst während oder nach der Reife gesammelt werden. wemn nicht ein Teil der Sämereien seine Keimkraft cinbüßen soll. I)ie Art und W eiso der Ernte, das Herabschlagen der Sämereien, das Klengen der Sümereien unter Anwendung höherer Temperaturgrade, muß aut die Leimkraft, cl. h. Keimzahl der Samenkömer von Einfluß sein, wie dies ja dio Lehre der Gewinnung der Sämereien näher bespricht. Ess gibt Sämereien, die nur ganz kurze Zeit ihre Keimfähigkeit beibehalten: solche, die unter bestimmten Vorsichtsmaßregeln, welche später zu lohandc.ln sind, längere Zeit aufbewahrt werden können, so daf je nach Holzart resp. Baumgattung und je nach Behandlungsweise die (irenzen sehr weit auseinander liegen können. Pappel- und Weidensamen beginnt sehon nach wenigen Tagen zu verderben; die steinharten Sämereien der Robinie können jahrelang trocken aufbewahrt werden, olne ihre Keimkraft zu verlieren.

Die Korngröße ist insofern von Belang, als allgemein die Ansicht gilt, je größer das Samenkorn, um so kräftiger die daraus hervorgehencle Pflanze. Die Samengröße ist abhängig: rom Ernährungszustand des Mutterbaumes und damit von der Bodengüte; je kräftiger die Mutterpflanze, um so größer die Früchte und Sämereien; Sämereien, die im Lebensabschnitte des größten Zuwachses gebildet werden, sind die größten und schwersten; vom Klima: je kühler der Standort, um so geringer die gesamte Entwicklung der Pflanze, um so kleinere Blätter, Früchte und Sämereien. Professor Dr. Ciesla $r^{1}$ ) in Wien hat hierüber die eingehendsten Untersuchungen angestellt.

Er fand, daß Fichtensamen, aus Finnland und Nordschweden

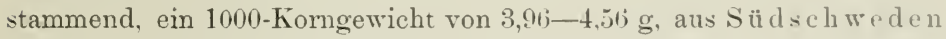
ein solches von $5-5,5 \mathrm{~g}$ und aus $\mathrm{D}$ änemark, das jerloch klimati.ch Südschweden gleich ist, $7,5-8,6 \mathrm{~g}$ Gewicht hatte.

Das Korngewicht zeigt, daß die sibirisehe Lärche keine Varietait der europäischen sein kann; denn das 1000-Korngewicht der sibirischen ist $11,25 \mathrm{~g}$, das der europäischen $5,50 \mathrm{~g}$; wäre die sibirische Lärche nur „eine Klimavarietät", so müßte das Korngewicht umgekehrt sich verhalten.

Cieslar fand, daß ans Fichtensämereien mit dem 1"un-Korngewicht von $11,00 \mathrm{~g}$ im ersten. Jahr eine Pflanze von 2,74 $\mathrm{ccm}$, aus Samen von $5,4 \mathrm{~g}$ im ersten Jahr eine Pflanze ron $1,4: 3 \mathrm{ccm}$ Inhalt hervorgeht.

Die durchschnittliche Höhe der rierjährigen Pflanzen des schinem Samens betrug $50,15 \mathrm{~cm}$, jene des leichten samens $37,5 \mathrm{~cm}$; achtiahrigo

1) Dr. Cieslar, Über die Erblichkeit des Zuwachsvermögens. Zelinchr. f. d. ges. Forstwesen 189.5 . 
Pflanzen waren bezüglich ihrer Herkunft roneinander nicht mehr zu unterscheiden. Die bayerischen Untersuchungen der Praxis vor 21) Jahren stimmen mit diesen Resultaten überein: die Tersuche des Verfassers ergaben, daß aus großen und schweren Roßkastanien zahlreiche kleinere, dreijährige Pflanzen erwuchsen als aus kleinen und leichten Samen: von allen die schnellwüchsigste war eine Pflanze aus den kleinsten und leichtesten Sämereien des gleichen Klimas (Nachbarbaumes. Cieslars berühmt gewordene Untersuchung über die Erblichkeit des Zuwachsvermögens gründet sich auf das Ergebnis, daß bei gleichem 1000-Korngewicht von $10 \mathrm{~g}$ zweijährige Pflanzen aus Sämerereien, welche 500 m unterhalb der Kältegrenze gesammelt wurden, eine durchschnittliche Länge von $43 \mathrm{~mm}$ erreichten, während aus Sämereien, welche $5100 \mathrm{~m}$ tiefer gesammelt wurden, eine Höhe von $70 \mathrm{~mm}$ sich ergab. Professor Engler ${ }^{1}$ (Zürich), bestätigt im wesentlichen die Ergebnisse Cieslars durch eigene Forschungen. Es sind dies jedoch seit P. Vilmorins berühmter Anpflanzung in Les Barres nicht die ersten exakten Versuche, welche darauf hinzielen, den Nachweis zu erbringen, ob eine Eigenschaft, welche durch änfere Verhältnisse einer Pflanze anerzogen wurde, erblich werden könne.

Damit wäre die Betrachtung der Fortpfianzungsverhältnisse der Baumarten beim letzten Punkt, bei den inneren Eigenschaften, welche im Samenkorn ruhen, angelangt. Über dieses Thema, im Zusammenhang mit Vererbung, enthalten die vorausgehenden Abschnitte bereits alles, was der Verfasser aus eigenen und fremden Versuchen und aus jenen in der freien Natur gelernt und geschlossen hat.

h) Ausschlagsfähigkeit. Allen dikotyledonen Laubbäumen und wohl anch den meisten Nadelhölzern kommt bei entsprechender Behandlung die Fähigkeit zu, an oberirdischen Pflanzenteilen, somit Zweigteilen, an Wurzeln (Stecklinge, Absenker), sowie an unterirdischen Pflanzenteilen, somit an Wurzeln beblätterte Triebe (Wurzelbrut) entwickeln zu können: damit aber Zweige oder der Pflanzenschaft selbst oder Wurzeln beblätterte Triebe, welche man gewöhnlich Aus schläge nennt, hervorsprossen lassen, bedarf es einer Verletzung, einer Stümmelung oder einer Erkrankung des betreffenden Pflanzenteiles. Ausschläge, welche an den Aststummeln eines Baumes entstehen, heifen Stammtriebe, Stammausschläge; Ausschläge, welche nach Abtremnung des Schaftes an dem am Boden verbleibenden Baumteile (Stock, Strunk) hervorbrechen, werden Stockausschläge genannt; Triebe, welche einer Verletzung der Wurzeln ilu Dasein verdanken, heifen Wurzelauschläge, Wurzelbrut.

1) Prof. A. Engler, Einflub der Provenienz des Samens auf die forstlichen Holzgewächse. Mitteil. d. schweiz. Zentralanst. f. d. forstl. Versuchswesen 190.5. 
Die naturwissenschaftliche Erklärung für Auscchlagsbildung ist wohl bei allen diesen Vorgängen die gleiehe: Herberführung einer Staung von Wasser und Bildungsstoffen (Reservestotio), welcher Vorgang unter erhöhtem Licht- und Wärmegenuß etwa vorhandene, schlafende Augen zur Entfaltung bringt und rlie Öberwallung der Wunde einleitet, wobei nene Kunospen entstehon, die zn Ansschlägen werden. Auf demselben Vorgange der staumg beruht auch die gärtnerische Maßnahme, an Obstbäumen durch einen Einschnitt oberhalb einer schlafenden Knospe diesclbe zum Anstreilen zu zwingell.

Wurzeln entstehen an oberirdischen Organen (Zweigen, Ästen) entweder freiwillig (Luftwurzehn) oder erst nach einer Verletzung der Zweige bzw. Abtrennung derselben (Zweigstecklinge), oder durch fortgesetzte Feuchterhaltung (Unterwassersetzung, Übererdung) von mit dem Baume noch verbundenen Pflanzenteilen (Absenkern); neue Wurzeln (Ausschlagswurzeln) an miterirdischen Organen (an Wurzeln) bilden sich bei Verletzung der Wurzeln (Wurzelschnitt) oder auch bei Zerteilung der Wurzeln und Einlage der Stücke in Wasser oder Erde (Wurzelstecklinge).

Wo immer Neubildungen von Wurzeln entstehen sollen, ist somit ein hohes und konstantes Maß von Feuchtigkeit in Luft, Erde oder direkt Wasser die Voraussetzung; tritt unter solcher Voraussetzung noch Verletzung des Pflanzenteiles hinzu, so wird die Wurzelbildung außerordentlich beschleunigt. Stockausschläge entstehen bei allen Laubbäumen, bei den Nadelbäumen aber nur an vereinzelten Baumgattungen und -arten; die Zahl der Ausschläge hängt ron der Holzart, ihrem Alter, von Licht, Wärme und Boden ab. Die größte $/$ ahl von A us schlägen liefern in absteigender Reihe: Carpinus, Salix, Corylus, Castanea, Alnus, Carya, Cercidiphyllum, Quercus, Robinia, Ulmus, Zelkowa, Tilia, Magnolia, Populus, Fraxinus, Acer, Betula, Fagus. Unter den Nadelhölzern sind zu nennen: Cumnighamia, Gingkyo. Cryptomeria, Sequoia, Sciadopitys, Chamaecyparis, Thuja, Pinu: rigida, Murrayana, mitis, Taxus und andere; den Gattungen Psendotsuga, Tsuga, Abies, Picea, Larix und den meisten übrigren Führen fehlt die Ausschlagsfähigkeit.

Hinsichtlich des Alters sei hervorgehoben, daß die größte Zahl sich in dem Alter ansetzt, in welchem der größte Zuwachs an Längr. und Dicke erfolgt. das ist das Stangenholzalter, und zwar die \%eit kurz vor dem Auftreten der Schuppenborke, welche eine grobe '/ahl der schlafenden Augen am Stamme zum Absterben hringt.

Von einem bestimmten Alter an erlischt die Aussehlagstäbigkeit: lis in das hohe Baumalter erhält sich die Ausschlagsfähigkeit, besotrders biri Alnus, Tilia, auch bei Quercus, Castanea, Ulmus; bei Acer, Carpinu- Fraxinus, Juglans, Carya und besonders bei Fagus ertischt sie am fruhesten. 
Da nach einer früheren Darstellung erhöhter Lichtgenuß zur Erweckung der Kuospen nötig ist, so erklärt sich hieraus auch die allremein beobachtete Erhöhung der stockausschlagstähigkeit, wenn in der Umgebung des Stockes aller beschattende Gras- und Unkrautwuchs bescitigt wird: es erklärt sich dadurch anch die Erscheinung, weshalb an sonnigen Standorten dio Ansischläge reichlicher als in entgegengesetzten Lagen erfolgen, und daß unter Lichtabsehluß eines Bestandes Ausschläge ganz unterbleiben, ein Mittel, um z. B. das Ausschlagen unbeliebter. Holzarten zu verhindern: sie werden vor ihrer Umgebung zur Fällung gebrar:ht (Populus, Alnus incana und andere).

Ähnlich wie Licht wirkt Wärme. Das wärmere Klima oegünstigt die Zahl der Ausschläge: die Ausschlagsfähiglieit setzt früher ein, freilich erlischt sie anch früher als im kühleren Gebiete infolge starken Wachstums und frühzeitiger Korkbildung des Mutterstammes. Ähnlich wirkt auch der bessere Boden fördernd auf die Zahl der Ausschläge, aber auch die Dauer der Ausschlagsfähigkeit verkürzend. Nur die Wurzelansschläge, die Wurzelbrut, werden durch weniger guten, ja schlechten Boden besonders angeregt, da die ungenügende Ernährung einen schwächlichen, kränkelnden Zustand schafft, der die bereits vorhandene Wurzelbrutfähigkeit einer Art frühzeitig und in auffallender Zahl auslöst.

i) Wurzelbrut erscheint am zahlreichsten bei bestimmten Holzarten, wenn der Stamm abgeschnitten oder ron einer langsam um sich greifenden Infelitionskrankheit, besonders durch Polyporusarten, ergriffen wird. Wurzelbrut bilden vor allem Populus, Robinia, Prunus, Ulmus, Alnus, (Weißerle) Gingkyo.

k) Durch Stecklinge lassen sich alle Holzarten vermehren, wie die gärtnerische Geschicklichkeit bei Anzucht von Kiergehölzen beweist; für die Mehrzahl der Holzarten bedarf es jedoch einer besonderen Anordnung im Glashause, um Luft- und Bodenfenchtigkeit und Wärme möglichst gleichmäßig zti erhalten, so daß Wurzelbildung auftritt, ehe ein Vertrocknen oder Verfanlen des Zweigstïckes (Stecklings) eintritt. Nur bei jenen Holzarten, die auch in der freien Natur sich rasch genug bewurzeln, ist die Stecklingspflanzung eine forstlich branchbare Kulturmaßnahme. Am leichtesten lassen sich die Gattungen Salix, Populns und Buxus vermehren, wobei die Wurzeln aus den Leticzellen der Rinde hervorbrechen; eine forstmäßige StecklingspHanzung ist dann möglich bei den Nadelholzgattmngen Chamaecyparis, Cryptomeria, Thuja, Thujopsis, Sciadopitys, Sequoia, Taxus und anderen, bei welchen die neuen Wurzehn aus dem Wundenkallus der Abschnittsfläche entstehen. Zu Wurzelstecklingen, d. h. zu Wurzelstücken, welche bei einer Verbringmo in den Boden beblätterte Triebe an der freigelegten, von der Sonne gutroffenen Sclmittfläche entwickeln, dürften wohl die jüngeren Wurzeln aller Laubbäume geeigenschaftet sein; 
wenigstens sieht man bei allen Laubbämmen, an wolchen dir Wurz.ln beim Ausheben von (iräben algestochen worden, Ans:chligge auftreten. Bei Robinia ist diese Art der Vermehrung sngar in dis Praxis übergegangen; anch in jedem Nioder- und Mittelwaln ist diese Mothode zur Verdichtung des PHanzenstandes anwendbar. Nur bei der Gattung Panlownia sind Wurzelstücke als stecklinge allegemeiner bekunt nud forstlich verwertet.

1) Absenker. Alle Lanb- und Nadelhölzer sind hefähingt, Wurzeln zu schlagen, sobald Zweige herabgebogen mol längere $/$ s:it mit fencliter Erde bedeckt werden. 1st die Bewurzelung erfolgt, kann die neue Pflanze von der Mutterpflanze abgetrennt werlen. Eine kleine Wunde an der Übererdungsstelle ruft einen Überwallungswulst hervor, ans d'nu besonders leieht Wurzeln hervorbrechen. Absenker entstehen aue h in der freien Natur, wenn auf dem Boden aufliegende Seitenzwaige verschiedener Baumarten von Unkrautwuchs und dessen Yersetzunersproduliten eingeschlossen werden. Die fortgesetzte Befenchtung regt zur Wurzelbildung an; selbst an Fichten, den oft beschriebenen $\mathrm{Ab}$. senkern der obersten Waldregion, ist diese Erseheinung nicht selten. Bei jenen Banmarten, welche leicht durch Stecklinge sich vermehren lassen, sind die Absenker sehon im ersten Jahre genügent für die Selbständigkeit bewurzelt; bei anderen, wie z. B. bei Abies, Picea, Psendotsuga, Pinus, Larix und anderen vergehen viele Jahre, the die Zweige Wurzeln in die Tiefe senden.

m) Monokotylen Gewächsen, vor allem Gräsern, zn denen anch die Bambusarten gehören, ist noch eine weitere Art dh ungeschlechtlichen Vermehrung, jene dureh unterirdisch kriechende Ausläufer (Stengelteile, Rhizome), eigen; an den Knoten senden sie beblätterte Triebe nach oben und Wurzehn nach unten ans. Werden solche Rhizomstücke abgetrennt, können sie als selbständige Pflanz'n Verwendung finden (Rhizompflanzen).

Bei allen diesen ungesehlechtlichen Vermehrungen erhalten sich die individuellen Eigenschaften der Intterpflanze orler anch siner Spielart auf das genaueste, was, wie früher dargestellt, forstlich vorteilhaft oder auch nachteilig sein kann; es kommt aher hierzu, daß nach allgemeiner Ansicht ungeschlechtlich vermehrte Pflanzen nicht das holu" Alter der geschlechtlich erzengten PHanzen erreichen mol ïhertien ein Holzprodukt besitzen, das dureh frülizeitiges Auftreten von Rot fäule minderwertig ist. Das allgemein beobachtete, frülızitigr $\Lambda_{1}$. sterben der nur durch Stecklinge vermehrten Pyramidenpapun lu, die Tatsache, daß Stockansschlägr hei höherem Alter rottahle stamrine geben, die früher genützt werden müssen, legen allerdings don (it danken an eine Qualität.verschlechterung der. Bänme, wilche anf wh. geschlechtlichem Wege selbständlig treworden sind, nahe. 


\section{Fünfter Abschnitt.}

\section{Naturwissenschaftlich-waldbauliche Charakteristik der forstlich wichtigen Baumgattungen, Baumarten und Sträucher.}

Die Zahl der Baumarten, welche die Waldungen der nördlichen Halbkugel mit Auschluf., der Tropen und Subtropen bevölkern, ist eine ganz gewaltige; nach den Ausführungen des zweiten Abschnittes sind es mindestens ! 138 Arten, von welchen wiederum 750 Arten den Laubäumen und 1s8 Arten den Nadelbäumen angehören. Unter bestimmten Klima-, Boden- und waldbaulichen Verhältnissen, für bestimmte, menschliche Bedürfinisse kann jeder Holzart eine forstliche Brauchbarkeit und Bedeutung zukommen. Es würde aber den Umfang dieser Schrift ins Ungeheure vergrößern, wenn jede Baumart, ja, nur jede Baumgattung, welche irgendwo oder irgend einmal nützlich sein kann, hier besprochen werden wollte. Es ist die Einschränkung auf forstlich wichtigere Baumarten schon aus rein mechanischen Gründen notwendig. Eine weitere und wesentliche Vereinfachung in der Behandlung dieses Abschnittes tritt dadurch ein, daß es sich als ein großes Naturgesetz herausstellt, daß die wichtigsten, waldbanlichen Eigenschaften der einzehen Arten zugleich der betreffenden, ganzen Gattung zukommen, daß somit die Biologie der Gattung sich in sämtlichen Arten wiederspiegelt; es gen ügt somit, waldbaulich die Charaktere der Gattungen zu schildern, um damit jene der sämtlichen Arten dieser Gattung kemnen zu lernen; umgekelırt ist die ganze Gattung durch das Erkennen der Biologie einer einzigen Art dieser Gattung erfaßt; es genügt zum Beispiel eine einzige Fichte, um an ilı die Lebensgeschichte aller ïbrigen Fichten zu schildern; was an den Fichten in Amerika oder Asien gefunden wurde, gilt auch für die europäisehe Fichte und umgekehrt. Die wirtschaftliche Behandlung der Begründung und Erziehung, welche für eine Art passend befunden wurde, muß auch für die übrigen Arten der Gattung zutreffend sein. Versehieden innerhalb der 
Gattung kann nur eines sein, was auberhall, der Natureresetzo liengt. das sind die Bedürfnisse dor Mensehen; sir allein bredingron rime $\mathbf{A b}$ änderung in der Beliandlungsweiso der oinzelnen Arten. Allen Arten gemeinsam sind folgende Kennzeichen:

a) die systematischen Merkmale in der Blite mul Frurht. bildung; nach ihnen werden die Arten in die zugehörige Gattume eingereiht;

b) die allgemeinen morphologischen Merkmale der Blättr. bzw. Nadeln, der Rinde, des Sehaftbaues, des Kionenlanes, drr Br. ästung, der Bewurzelung, der gesamten Tracht. Es bedart immer ge. naueren Studiums, um die einzelnen Arten, z. B. Fichtenartern der Gattung Picea, voneinander zu unterscheiden; der Laie ist nicht imstande einen Unterschied in den Buchen-oder Fichtenwaldungen von Europa, Ostamerika oder Ostasien zu entdecken:

c) die anatomischen Eigensehaften des Holzes, dor Rinde, der Blätter und damit anch die allgemeinen technischen und physikalischen Eigensehaften dos Holzes und der Rinds. Niemand ist imstande Fichten- oder Buchen- orler Eschenholz aus Amerika, Europa oder Ostasien zu unterscheiden; nur wenn das Holz mit seinen schmalen .Jahresringen dem Urwaldschlusse entstammt, kann man vermuten, daf es aus Waldregionen kommt, in der es noch Urwaldungen gibt.

Auch in Amerika und Asien ist die Zeit nicht mehr fern, da der Urwald der Geschichte angehören wird. Das Produkt, das als zweitrs Wachstum (second growth) im Holze erwächst, wird von dem des Kulturwaldes in Europa und Asien nicht mehr verschieden sein kömen, da die gleichen Naturgesetze und die gleiche Behandlungsweise des Menschen auf alle Baumarten einer Gattung im gleichen sime wirkin. Naturwidrige Ansicht ist es, zu erwarten, daß es Fichten gehen kann, welche ein eichenholzähnliches Produkt liefern könnten. Alle Fichten geben ein Holz, das in seiner Anatomie und in seiner Güte im Rahmen der Anatomie und Gütequalität der Gattung bleiben muß.

d) Anspruch an das Licht. Alle Arten einer Gattung rleichen sich hierin, muß das Naturgesetz lauten, und naturwidrig ist daher die Vermutung, daß es z. B. Eichen geben künnte, weluhe schatten ertragende Bäume sind, daß es Fichten und Tamnen geben kömnte, welch. Lichtholzarten sind.

e) Nicht weniger den Naturgesetzen widersprechend ist der (rlatzlu, daß z. B. unter den Eichen bescheidene Holzarten, soweit dic Ansprïche an die Bodengüte in Frage kommen, sein künnteu; denn arrh hezüglich der Ansprüche an den Boden oleichen sich the Arten einer Gattung.

f) Es ist naheliegend, daß auch die Schmellwïch-igheit. die Ausschlagsfähigkeit, die Tief- oder Seichtwurzelung; mit vinem Wort anch 
alle übrigen waldbaulichen Eigenschaften, die an einer Art gefunden wurden, auch allen übrigen Arten derselben Gattung zukommen müssen. Es kamn somit keine schnellwüchsige Eibe, keine von Natur aus langsamwüchsige Lärche geben. Man kamn durch besondere Anordnung des Versuches eine langsamwïchsige Art zu rascherem Treiben, eine raschwïchsige zu langsamerem Wuchs zwingen, dadurch ist das Gesetz nicht aufgehoben, sondern nur verdeclit.

g) Umgekehrt kam man gerade das gleiche physiologische oder biologische Verhalten der Baumarten (z. B. bei den Föhren) benützen als Maßstab der Verwandtschaft und zur Abgrenzung der frattungen selbst. Es scheint diese Bemerkung vielleicht überflüssig, denn es obwalten doch nach allgemeiner Auffassung bezüglich der Abgrenzung: der Gattungen kine Zweifel mehr, aber sie bestehen doch. Z. B. rechnet man zur Gattung (uereus winterkahle und immergrïne Eichen, Eichen mit ein- und zweijähriger Samenreife, Eichen mit ringporigem Holz und solche, denen der Frühjahrsporenkreis fehlt, Eichen, welche ausgesprochenes Lichtbedürfnis besitzen, und solche, welche kräftigen Lichtentzug ertragen; so kommt man zur Überzengung, daß bei der Gattung Quercus die Natur nicht ihre Gesetze anfgehoben hat zur Vereinfachung der Systematik, sondern daf vielmehr die ron der Wissenschaft getroffene Einschachtelung der Eichen in eine einzige Gattung Quercus naturwidrig ist. Gegen alle Naturgesetze, gegen alle systematischen, anatomischen und kiologischen Merkmale ist die Gattung Pinus gebildet. Pinus war schon unter Linné das große Schiebfach, in dem alles untergebracht wurde, was Nadeln besitzt. Nur äußerst langsam brach sich die nenere Abtrennung und Benennung Bahn, welche die übrigen Abietineengattungen wie Abies, Picea, Larix usw. als selbständige Gattungen anerkennt; immer noch aber bleibt die Gattung Pinus zurück als ein Schiebfach, in das alles eingezwängt wird, was man an Nadelbäumen anderweitig nicht unterbringen kann; die heterogensten Arten mit zwei, drei oder fünf Nadeln, mit den größten Verschiedenheiten im Zapfenban, in den Sämereien, mit biologischen und gengraphischen Unterschieden und grundverschiedenem Bau des Holzes, alles ist unter Pinus vereinigt. Längst hat man die Widersprüche gefühlt und hat die Gattungen wiederum in Sektionen zerlegt, um eine systematische Urdnung hineinzubringen. Nach der Ansicht des Verfassers kommt diesen Sektionen systematisch und biologisch der Wert der Gattungen zu.

Nachstehende Gattungen sind nicht nach botanischer Verwandtschaft, nicht nach forstlicher. Wichtigkeit, sondern der Bequemlichkeit wegen nach alphabetischer Anordnung, getrennt nach Nadel- und Laubhölzern, autgeführt. Es ist nicht beabsichtigt, durch nachfolgende Beschreibung die forstbotanische ('harakteristik entbehrlich zu machen; die botanischen Merkmale zur Erkiennung der Bammarten beschränken 
sich auf jugendliche Exemplare; was die für dic Pllanzenzüchter wi.h. tige Frage der Sicherheit der Artenbestimmung anlangt, darf Vertasser wohl auf sein jüngst erschienenes Buch ${ }^{1}$ ) verweisen, das die Erkemmug der fremdländischen Bammarten an jungen PHanzen zur speziellen dutgabe sich machte.

\section{A. Die Nadelbäume.}

Die gegenwärtig am meisten knltivierten Nutzbiume sind Nadel. bäume: ihnen gehört auch die kommende Zeit, welche leichters. trag. kräftiges Holz rerlangt. Den Nadelbämmen kann auch in späteren Jahrhunderten der Boden von der Landwirtschaft nicht ganz entzogren werden: denn für diese ist der Boden entweder zu kalt (Fichte) orler zu schlecht und umpassend, (Föhre, Sumpfzyuresse). Auch dio wich. tigsten Zierbäume sind Nadelhölzer. Alle Nadelbäume fülıren wasierarmes Kernholz, so daß der Baum nach Durchtrennung der splintlage in wenigen Tagen absterben mus.

\section{1. (Gattung: Abies, die Tannenarten ${ }^{2}$ ), firs, sapins.}

Immergrüne Baumarten; Nadeln zumeist flach gedrïckt, meistens: nur an der Unterseite zwei helle Linien. welche die Spaltüffnungen tragen: die Nadeln verschmälern sich gegen die Basis hin und enclen in ein Organ, das einer Froschzehe gleicht, mit welchem die Narleln direkt am Trieb aufsitzen; beim Ablösen der Nadeln bleibt nur ein heller, kreisrunder Fleck zurück: der Trieb ist deshalb glatt. Am Gipfeltrieb sind die Nadeln einspitzig, seltener auch an Seitentrieben; je mehr eine Pflanze oder ein Zweig am Lichtgenuß behindert wird (durch Überschirmung), um so deutlicher wird die Gabelung oder Kerbung der Nadelspitze; bei normalem Lichtgenuß ent.steht im zweiten Lebensjahr der jungen Tamnenpflanze neben der Gipfelknospe eine Seitenknospe, aus der im dritten Lebensjahr ein senkrecht abstehender Trieb, „der Sporn“, entspringt. Das Unterbleiben dieser Bildung ist ein gutes Kennzeichen ungenügender Entwicklung durch Mangel an Iicht. Die Zapfen stehen bei allen Tannen aufrecht, zerfallen hei der Reife. so daß nur die Spindel zurückbleibt; der hierbei frei werdendo samm ist verhältnismäßig groß, sehwerfällig (gering flugfähigr): der Flügel ist mit einer Seite des Samenkornes (der glänzenden) fest verwachsen; dio

1) H. Ma y r. Fremdländische Wald-und Parkbäume fur Furopa. II t fil: Ab)bildungen und 20 Tafeln. Berlin. Paul Parey 1:Mb. Bezliglich der enropits-hen Nadelbäume sei auch auf G. Hempel und Dr. K. Wilhelm, Die Bänne und Sträucher des Waldes in botanischer und forstwirtschaftlicher Bezichung. virwiusn.

2) Das Wort WeiLtanne ist absichtlich vermieden. Nachdm wan Tanuen und Fichten botanisch scharf trenut, sollten Pflanzenzachter whilgst"ns vermeiden, noch weiter Weißtaune fur Tanue und Rottanne far Fichte zu gebrauchen. 
andere, weiche Sieite trägt nur eine dümne Samenhülle, an welcher leicht Verletzung und überdies Austrocknung und Verderbnis des Samenkomes eintritt.

Lie Ansprïche der Tannenarten an Wärme, Luftfeuchtigkeit, Regenmenge ergeben sich aus der /ugehörigkeit zum Picetum (Klimaparallele $\therefore$. (il ff): ihr Optimum liegt in der wärmeren Hälfte des Picetums: im lïhleren Fagetum erscheinen sie bereits zahlreich; im kïhleren Picetum verschwinden sie. In manchen Örtlichkeiten vertreten sie die Fichten (Apennin, Pyrenäen, Alleghanies, Zentraljapan). Besitzt eine Landschaft, inshesondere Gebirgslandschaft, mehrere Arten, so sind sie geographisch und klimatisch nach Höhenzonen getrennt; es gibt dann Tannen im Castanetum und kühleren Picetum. Hohe Luftfeuchtigkeit sagt allen Tammen zu. Auferhalb des Schirmes vom Mutterbaum. auf liahlen, ebenen Flächen sind sie empfindlich gegen verspätete Fröste. Jene Tannen, welche am frïhesten in Vegetation treten (sibirische Taune, Himalajatanne), leiden am häufigsten und schlimmsten. Frost Ende Mai oder gar im Juni schädigt alle Tannen. Gegen Fröste im Herbst sind die Tannen gesichert: ticfe Winterkälte schadet bei einigen Arten nur den Nadel- und Triebspitzen, wemn dabei intensivo Besonnung herrscht (Chlorophỵlltod, Nadelbräune); unvermittelte Freistellung junger Pflanzen während des Winters bedingt ebenfalls Rötung und Absterben der Nadeln.

Alle Tannen sind während der ersten fünf .Jahre langsamwüchsig; unter Schirm von älteren Bäumen zum Schutz gegen verspätete Fröste erhält sich die Langsamwüchsigkeit lange /eit, ohne daß die Pflanzen infolge Lichtentzug zugrunde gehen oder kümmern: aus diesem Grunde werden alle Tamnen Sehattenholzarten genannt. Reine Tannenbestände halten sich im Stangenholzalter besonders dicht geschlossen und sind deshalb der Schncedruckgefahr ausgesetzt; auch im Alter erhält sich der Kronenschluß mit allen Torteilen desselben auf Astreinheit und Formenzahl und allen Nachteilen desselben in bezug anf Langsamkeit des Zuwachses. Streuanhäufung auf dem Boden und Erschwerung der natürlichen Wiederverjüngung. Alle Tannen lieben den Boden, der insbesonders der Rotbuche zusagt, frisch, tiefgründig, nahrungsreich; an Stelle der Pfahlwurzel bilden sich frühzeitig kräftige, in die Tiefe gehende Herzwurzeln aus, so daß die Tannen ziemliche Sturmfestigkeit hesitzen. Alle Tannen leiden von allen Nadelholzarten am empfindlichsten durch Verbiß der Gipfeltriebe: auf die Gipfelknospe mit ihren 3-7 Seitenknospen haben es vor allem Hirsche, Rehe, Eichhömchen abgesehen; ob auch der Nußhäher sich beteiligt, ist nicht ganz sicher. Die Gipfelknospe mit der Quirlknospe ist die kiräftigste Knospe an der Pflanze, in der überdies im Winter eine Anhäufung an Nährstoffen stattfindet; der Bissen ist somit für die Verbeißenden schmackhaft und nahrhaft. Da aber zwischen Gipfellinospe und dem 
tiefer stehenden Astquirle bei schwächlichen, \%. B. trisch versetzten Pflanzen keinerlei Seitenknospen sich fintru, so ist der ganzo Jahreszuwachs verloren; das Vegetationsjaln narh dem Winterverbil erzengt nur neue Knospen an der Basis des rntgiptelten 'Triehes: erst im zweiten Vegetationsjahr nach dem Verbif gehen ans rom meistons in Virlhoit angelegten Ḱnospen mehrere Längstriebo hervor, rlie, weil sie in Viul. heit auftreten, wiederum schwach bleiben, lis endlich rincr dersolleen die Führung übernimmt. In der Regel sind dnreh den Giftel. knospenverbiß 2-3. Jahre Längszumalss verloren. [)er Tammenkrebs, eine Pilzkrankheit, befällt alle Tamenarton; ist der Hauptstamm oder Gipfeltrieb ergriffen, so wird die ganze I'flanzo so frïhzeitig als möglich, längstens im Stangenholzalter entfornt: alta Krebsstämme zu beseitigen, kann nu den /wweck haben, der weiteren Verschlechterung des Schaftes und der Gefahr des Windbruchos an der Krebsstelle vorzubeugen, nicht aber die Krankheit zu bekämpf'n. Das Holz aller Tamnenarten ist weich, leicht, ohme Harzgänge, daher harzarm, leicht spaltbar, ohne gefärbten Kern, d. h. splint und Kern in Farbe gleich, ohne Dauer; im Werte steht Tannenlolz allgemein dem Fichtenholze etwas nach.

Abies balsamea (Mill.), Balsamtanne, balsam fir. Ustamerika.

Nadeh schmal und mittellang; Knospe rötlich, besonders beim Austreiben, mit Harz überzogen. Für Europa forstlich untergeordnet, da dort nur ein Baum zweiter Größe.

Abies cephalonica $(L k$.), griechische Tanne. Friechenland.

Alle Nadeln mit einfachen Spitzen, stechend. Wird Baum erster Größe.

Abies concolor (Limull. et Gorl.), westamerikanische Silbertanne, silver fir. Felsengebirge.

Nadeln an Seitentrieben nach oben gekrïmmt; im Lichte boiderseits weißlich; sie übertrifft in ihren Höhenmaßen die mitteleuropäische Tanne; Schw appach sagt, claß sie in Preußen schneller wächst als die mitteleuropäische Tamno; Verfasser kam dies nicht bestätigren.

Abies firma (Sieb. et Zucc.), Momitanne, Momi. Japan.

Nadeln an Seitentrieben mit zwei dentichen șpitzen: unterseits nur wenig heller als oberseits; in Deutschland etwas emptimllich gegren sehr tiefe Wintertemperaturen.

Abies grandis (Limoll.). große Kïstentanne. White fir. IV estamerika.

Knospe violett, mit Harz äherzogen; Nadeln der Uherseite des 
152 Funfter Abschnitt. Naturwissenschaftlich-waldbauliche Charakteristik usw.

Seitentriebes kïrzer als auf der Unterseite: alle gleich gerichtet und gekämmt. Erreicht bis 70 m Höhe.

Abies homolepis ((Sieb. rt Zuce.), Nikkotanne, Urashiromomi. J a p a 11 .

Nadeln ebenfalls zweispitzig wie Momi, aber zarter, an kräftigen Trieben einspitzig, von verschiedener Länge, unterseits hellwoiß.

Abies Nordmanniana (Link.), Nordmannstanne. Kaukasus.

Nadeln größer, glänzender und dichter stehend als bei der mittelenropäischen Tanne. Seitentrieb oft in vier hnospen endend; ergrünt später als die europäische Tamme und entgeht den mittelspäten Frösten im Frïljahr.

Abies pectinata (I). C.), enropäische Edeltanne. Gebirge von Mittel- und Südeuropa.

Das natürliche Verbreitungsgebiet ist nach Norden hin im mittleren Deutschland; im Süden ist sie die Tanne der Pyrenäen, des Apennin, des Balkan.

Abies Pindrau (Spach.), Pindrautanne, Pindrow fir. Westlicher Himalaja.

Diese prächtige Tanne mit sehr langen, unterseits kaum helleren Nadeln, spindelförmiger Krone erreicht $40 \mathrm{~m}$ Höhe. Außerhalb ihrer Heimat überall früh- und winterfrostempfindlich.

Abies Pinsapo (Boiss.), spanische Tanne, Pinsapo. Spanien.

Eine Tanne mit fichtenähnlichen Nadeln, vom Trieb rechtwinklig und allseits abstehend, auch in ganz Mitteleuropa frostharte Tanne.

Abies sibirica (Ledel,), sibirische Tanne, Pichta. Nordosteuropa, Sibirien.

Die sibirische Tamne erimmert lebhaft im Bau der Nadeln, Knospen und in der Tracht des Bammes an die amerikanische Balsamtanne. Nadeln sehr schmal, lang, weich; Knospe mit Harz verklebt, griin. Ergrünt selnr frühzeitig und ist daher in warmen Klimalagen mit langem Frïhjahr und häufigem Erost dazwischen die empfindlichste aller Tannen.

Abies Veitchii (Limell.), Veitchstanne, Shirabe. Japan und China.

Nadeln lang, gleich breit, unterseits kreideweiß. Diese Tamne geht durch das ganze Picetum bis zur Waldgrenze empor: erreicht kaum melır als 30 m Höhe. 
Abies Webbiana (Lindl.). Webbstanne. Indian silver tir. i)stlicher Himalaja.

Große, glänzendgrüne, mnterseits kreilewcibe Nalıln. D)iese 'Tanno wird im östlichen Himalaja immer mehr verdrangr durch den unter der Herrschaft der Weidetiere begünstigten Bambus; die 'l'anm wirl ham höher als $30 \mathrm{~m}$ mit Hach anxgebreiteter, dem Winde an wenigstern Widerstand leistender Krone.

\section{Gattung und Art: Biota orientalis (Emall.), chinesische oder orientalische 'Thuja. ('hina, Mongolei.}

Schuppenförmige Blätter, anf der Olserscite mit einer Rinne versehen; Samen ohne Flügel. In Ansprïchen an Boden und Kilimatrocknis bescheiden; dem Castanetum und wärmeren Fagretum angehörig: für Aufforstungen in trockenen Gebieten verwendbar. Holz mit rötlichem Kern sehr dauerhatt.

\section{Gattunx: Cedrus, die Zederu, Cedars, Cedres.}

Obwohl es in ganz Amerika keine eigentliche Zeder gibt. wirt diese Bezeichnung doch für eine Reihe ron Holzarten olne eigentliche Nadeln, wie Thujen, Scheinzypressen und andere, gebrancht. Dadur.h ist in der alten Welt Verwirrung entstanden. dem nur diese besitzt wirklich Zedern, welche eine immergrüne Benadelung mit Kinrztriel,und Längstriebbildung wie bei den Lärchen kemzeichnet. Der Kapfen reift im zweiten .Jahre, steht aufrecht und zerfällt bei der Reite wie jener der Tanne, wodurch die schweren, großen, getlügeltrn Sämereien frei werden. Nadeln vierkantig, lang, dümn, auf einem Vorsprung der Rinde wie bei den Fichten sitzend. Nur im Gebiete des Castanetums gedeihen sie zur Vollkommenheit; sie erscheinen schon im Lauretum und betreten noch die wärmeren Zonen des Fagetums: dort erlischt ihre forstliche Brauchbarkeit. Tiefe Wintertemperatur wird bei ungenügendem Abschluß des Längstriebes gefährlich.

Insulares- oder auch montanes Klima mit abgeschwächten Wintertemperaturen sind den Zedern besonders gïnstig: sie verlangen einen guten Boden und vollen Lichtgenuß: dabei sind sie raschwiichsig von höchstem forstlichen Gebrauchswert. Hhr Holz ist weich, leicht zurerarbeiten, mit bräunlichem Kern, der dem Holz eine schr hohn Ilauer verleiht; es wird bei allen Erdbauten, z. B. Eisenhahnschwellen. Brückenbau, ganz besonders gesmeht. Das indische '/edermholy ist so berïhmt wie das des Libanon, dessen das alte Trostament liei dir. Bundeslade gedenkt: ebenso wird die atlandische $/ /$ orler. die ïber ganz Nordafrika verbreitet ist, schon von Plinins als mverwiistlich gratilumt. Kräftig wachsende Exemplare zeigen einen nickenden (iiptiltriob: num vier Arten sind noch rorhanden, nachelem sie in friihn'm Fropuchen auch ganz Europa bewohnten; eine Zecler. die cyprische. ist unch aut 
europäischem Boden. Alle Zedern verdienen nicht bloß in ihrer Heimat, sondern übcrall. wo sie anbaufähig sind, die größte, forstliche Beachtung; sie zählen zu den wertvollsten Bäumen des Castanetums.

Cedrus atlantica (Man.), atlantische Zeder. Nordafrika.

Äste von ungefähr :20jährigen Bäumen aufwärts gerichtet. Diese Zeder steht Europa am nächsten auf dem Berge Tabor in Algerien; schon bei $1500 \mathrm{~m}$ Erhebung über dem Meere (Castanetum) erscheint die erste Zeder: mit der Erhebung in das Gebiet der Eicho, Ahorn, Eibe wächst ihre Höhe bis zu 3.) m. Wo Abies numidica, die numidische Tanne, erscheint (Fagetum), versehwindet die Zeder. Die ausgedehntesten Bestände dieser Zeder mit Yorrat an diesem Holz von unberechenbarem Wert - Schäfte bis zu $40 \mathrm{~m}$ Höhe und darüber werden gemeldet - bedecken die inneren Berge Marokkos.

Cedrus Deodar (Lond.), Deodar-oder Himalajazeder, Deodar. Westlicher Himalaja.

Hellere Benadelung und abwärts gerichtete Aststellung unterscheiden diese Art von der vorigen; sie ist der wichtigste Nadelbaum der indischen Bergvegetation vom Lauretum aufwärts bis zur Tanne; Bäume mit $60-70 \mathrm{~m}$ Höhe sind gefunden worden.

Cedrus Libani (Barr.), Libanonzeder. Kleinasien, Syrien.

Äste mehr horizontal abstehend; wird ebenfalls bis $40 \mathrm{~m}$ hoch und betritt noch das Gebiet der cilicischen Tanne.

\section{Gattung: ('hamaecyparis, Scheinzypressen.}

Die waldbauliche Tätigkeit ihrer Heimat beginnt erst ganz allmählich diesen hochwertigen Holzarten gerecht zu werden, nachdem bisher nur Holzhandel und Technik die Seheinzypressen ob ihres vorzüglichen Holzes bis zur Erschöpfung verfolgt haben. Von den eigentlichen $/ 2 y$ pressen wie ron den Thujen unschwer unterscheidbar; von den Zypressen durch den flachen Qucrschnitt der Seitentriebe, von den Thujen durch den bei normal wachsenden Pflanzen überhängenden Seitentrieb. Der Samen ohne Flïgel, gering flugfähig; aber wegen sehr häufiger und reichlicher Bildung ist die natürliche Verjüngung leicht. Auch durch Stecklinge kann Waldanlage betätigt werden. Die Scheinzypressen finden ihr klimatisches Optimum im Castanetum. wo in luftfeuchten Tälern, auf frischem Boden alle Scheinzypressen bis zu 40 $\mathrm{m}$ Höhe und darüber erreichen. Mit dem Auftreten der Fichte oder Tanne im kühleren Fagetum verschwinden sie allmählich. Ganz hart gegen verspätete Fröste, können sehr tiefe Wintertemperaturen (Chlorophylltod) ihnen gefährlich werden. Der Boden muß gut sein; Sandboden dritter Bonität ist die äußerte Grenze. Ohne Frische, 
ist anch der beste Boden ungenügend. Ant' fenchterem Bulun in Gesellschaft mit Erlen oder Weynoutsföhen weileihen sie vorziglich. Ohne diese Gesellschaft sind den cicheinzyuressen lerartige (̈rtlich. keiten im Fagetum zu kalt. Thr (untimum erroichen sir in reinrn Beständen, weniger im lockeren schlub von Lanhlichtholzarten. Man muß die Scheinzypressen zu den Halbschattenholzarten rechnen, weil sie den Lichtentzug lange Zeit urtragren. Im vollen Licht sind sie alle schnellwüchsig. Als tiefahren sind hesonders nennenswert Agarieus melleus, der Wurzellirebs und ein die Zweige tiotender Pilz, der wahrscheinlich mit Frost und anderen Störuneron, z. B. Agariens, zusammenwirkt und vorläufig ron $B o ̈ h m ~(l s ! 14)$ als Pesta. lozzia funerea bestimmt wurde. Doch vermögen liräftig wachsundo Pflanzen den Pilz abzustoßen. Das Holz ist weich, leicht, zähe: das gefärbte Kermholz ist sehr damerhaft, für Hochbau und Wasserbau sehr hoch geschätzt. Jede Art hat einen speziellen, überaus aromatischen Geruch im Kernholz; sie empfehlen sich alle als Ersatz des Bleistiftholzes. Im europäischen Wald fehlen Scheinzypressen vollständig. Amerika und Asien sind die glücklichen Besitzer dieser ausgezeichneten Holzarten. Es ist zu belilagen, daß in Emropa mehr das Vinurteil der Forstwirte als das Klima den Anbau dieser Bammart verhindert.

Camaecyparis Lawsoniana (Parl.), Lawsonie, Lawsonsscheinzypresse, White Cedar, Port Orfordcedar.

W estamerika.

Triebe zart, langoestrecht, zwischen den schuppenblättern helle Streifen, unterseits heller als oberseits. sie werden bis il) m hoch: mit so Jahren erwachsen in luttfeuchten Grobieten des Castanetums Bäume mit $35 \mathrm{~m}$ Höhe und $7 \mathrm{~cm}$ Iurchmesser in Brusthöhe. Ihr Vorkommen in der Heimat unmittelbar an der Kïste des stillen (Izeans und an den Küstenbergen aufwärts bis in frostreiches Höhenklima ist ron enger, rämmlicher Begrenzung.

Chamaecyparis nutkaënsis (Spuch.), Nutkascheinzypresse, Yellow Cypress. Westamerika.

Schuppenblätter kräftig mit scharfen spitzen. Wo sie beheimatet ist. an der Küste Westamerikas bis ins Picetum aufirärts und nori. wärts, gilt sie als der wertrollste Nutzbaum mit einem dauerhaften Holze.

Chamaecyparis obtusa (Sich. et Zuce.). Feuersecheinzypresce, Hinoki. Japan.

Leittriebe nicht in schönen Bögen wie die amerikanische Irt. sondern in geradlinigen Stücken ïherhängend. Schmpenhlïtter stmut. Unterseits der Zweige weiße Linien an den Gremzen der ciotuppen. In Japan teils in reinen Beständen, teils einzeln im Laubmall: setur viel künstlich durch Pflanzung und durch stecklinge ang baut: e- grilt 
das Holz dieser Art als das weitaus wertrollste unter sämt. lichen Nadelbäumen. Der Kern rosa gefärbt, sehr fein gefügt, von sehr großer Dauer.

Chamaecyparis pisifera (Sicb. et Zuce.), Weichholzscheinzypresse, Sawara. Japan.

Schuppenblätter mit scharfen Spitzen, unterseits einen weißen Fleck tragend. Diese Scheinzypresse ist die minderwertigere Schwester der rorigen, soweit ihr Holz in Frage kommt. Der Kern ist gelb gefärbt, das Holz ist weicher und weniger schön.

Chamaecyparis sphaeroidea (Spach.), Kugelscheinzypresse. White Cedar. Ostamerika.

Diese Scheinzypresse hat die zierlichsten Triebe von allen. Im Castanetum und Lauretum von Ustamerika a uf sumpfigen Böden bildet diese Art sehr dichtgeschlossene Waldungen mit hohem Holzwerte. Solche Standorte in Fagetum sind dem Baume viel zu kalt.

\section{Gattung und Art: Cryptomeria japonica (Jou.), liryptomerie, Sugi. China und Japan.}

Ton dieser Gattung ist nur eine einzige Art in Ostasien bekannt; Nadeln pfriemenförmig, dreikantig. Dieser Baum ist raschwïchsig, lichtbedürftig, verlangt guten, nahrungsreichen Boden, noch auf Sandboden dritter Bonität zu brauchbarer Dimension erwachsend. Maximalhöhe im Optimalklima des Castanetums sind $70 \mathrm{~m}$; nur das wärmere Fagetum kann nördlich vom oder ïber dem Castanetum für diesen Baum zu forstlichen Zwecken in Frage kommen. Das Holz ist leicht, weich, mit seinem braunen Kern danerhaft; bei kurzem Umtrieb im vollen Licht anf mäßigem Boden erzogen, liefert der Baum ein auferordentlich leicht zu bearbeitendes, billiges Baumaterial für die Holzbehausungen der Japaner. I)ie Kryptomerie ist für Ostchina und ganz Japan der forstlich wiehtigste Nadelholzbaum.

\section{Gattung: Cupressus, Zypressenarten, Cypress, Cyprès.}

'/weige vierkantig: alle Angehörigen dieser Gattung gehören dem Lauretum und wärmeren Castanetum an: einige erhalten sich noch mühsam im warmen Fagetum: forstlichen Wert besitzen sie in dieser Klimazone nicht mehr: nur in den milden Lagen des Insularklimas gedeihen sie dort auch für forstliche /wecke gentigend. Da die Bäume sclinellwachsend sind und ein gutes und dauerhaftes Holz bilden, verdienen sie forstliche Beachtung und forstlichen Anbau. Sie sind Lichhölzer, welche guten Boden verlangen. Daf keine Holzart, anch diese 'Lypresse nicht, wie es geschrieben steht, auf nacktem Boden gedeiht, wurde schon bei den allgemeinen Grundlagen besprochen: die Zypressen 
verlangen sogar guten Boden, den sio zwischen den Felsinspalten finden. Die Mehrzahl der Angehörignen sind, weil Halhbämmo, ohno forstliche Bedeutung.

$$
\text { Cupressus semperrirons (I.), }
$$

die orientalische Zypresse, ist in sizdeuropa heimisch.

$$
\text { Cupressus matrocarpa (Hurtu.), }
$$

die Montereyzypresso von Kalifornien, verdient Erwähnung worgen ihres auberordentlich raschen Wachstums und ilures Anbaues auf gefostigtrn Dïnen.

$$
\text { Cupressus torulosa (Dom.), }
$$

die Nepalzypresse, wird im Himalaja bis ju $\mathrm{m}$ hoch.

\section{Gattung: Juniperus, Wacholderarten, Junipers, Genèvriers.}

Nur soweit die Wacholderarten Bäume werden, welche forstlicher Benutzung dienen, verdienen sie auch forstliche Pflege: die bald pfriemenförmige, bald schuppenförmige Benadelung, die Beerenfrucht, die auf besonderem Exemplare (weiblichen) allein zur Ausbildung kommt, der aufrechte Längstrieb sind die wichtigsten Merkmale. Die Wacholder sind ziemlich langsam wachsende Lichtholzarten, welche auf den verschiedensten Böden: geringen, sandigen, kiesigen, trockencn, guten und frischen Böden, selbst in sumpfigen Örtlichkeiten, sich finden; einzelne Arten sind schon im Lauretum zu finden und streichen bis in das kühle Picetum, aber es ist zu beachten, daß alle Wacholderartru sowohl auf geringem Boden als auf gutem Boden im Klima kïhlor als das Castanetum nur Halbbäume werden, welche somit keine für Nutzzwecke brauchbare Größe erreichen. I)er brauchbare Teil der Wacholderarten ist nur das schön gefärbte Kernholz. Tiefe Wintertemperaturen werden allen Wacholderarten gefährlich.

Juniperus chinensis (L.), chinesischer Wacholder, Ibuki. China und Japan.

Reine Bestände dieses Baumes sind nirgends vorhanden; er ist in China besonders häufig bei Tempeln angebant: das Holz steht dem virginischen Wacholder an Schönheit der Farbe, nicht aber an IVolhl. geruch nach.

Juniperus virginiana (L.), der virginische Wacholder. Bleistiftholz, Red Cedar. (Istamerika.

Diese Art ist die bekannteste ron allen, und um das wertwolle. zu Bleistiften wegen seiner Farbe und seines Gernches verwendete IIol\% auch in Europa zu gewimnen, hat man dem Bamme forstliche Antmerksamkeit erwiesen, die er otfenbar in ganz Mittele unpa, wn del 
warmen Küiste abgesehen, nicht verdient. Auch in Nordamerika liegt die Zone der technischen Terwendbarkeit in den südstaaten (Castanetum und Lauretum).

\section{s. Gattung: Larix, Lärehenarten, Larches, 'Tamaracks, Mélèzes.}

Die Lärchen sind winterkahle Nadelbäume; ihre erste Benadehung im Frïhjahr besteht durchaus aus kurzen Trieben, in welchen die Nadeln bis zu $j u$ angehäuft sind. Später bricht aus den kurzen Trieben der Längstrieb hervor mit zerstreut stehenden Nadeln. Die Nadeln sitzen auf einem längswulstigen Vorsprung der Rinde. Der Samen wird schwierig ans aufrechten Zapfen frei; trockene Winde sind nötig. Samen dreikantig, lilein: Keimlinge an den Kotyledonen und Erstlingsnadeln ohne Zähnchen am Rande. Allen Lärchen ist gemeinsam, daß sie bis zur Kältegrenze des Waldes. sei es im Norden (Polaretum), sei es in höheren Regionen (Alpinetum), vordringen. Ton da an süd- beziehungsweise abwärts streichen sie bis ins Picetum und Fagetum; keine aber betritt in iluem natürlichen Torkommen das Castanetum. Das Optimum liegt im Picetum und kïhleren Fagetum. Im Castanetum erschöpfen sich die Lärchen in Zapfenerträgnis und Kurzschaftigkeit. Alle Lärchen sind frosthart. Selbst nach dem ersten Erorïnen kömmen sie noch $-5^{\circ} \mathrm{C}$ ohne Schaden ertragen; nur in besonders schweren Frostlagen erfriert im Juni der Längstrieb; im wärmeren Klima verlängert sich die Wuchsperiode, dort sind auch Schäden durch Frühfröste nicht selten. Alle Lärchen sind anfänglich sehr raschwïchsige, volle Lichtholzarten; infolge ihrer tiefgehenden Herzwurzeln zeigen die Lärchen große Sturmfestigkeit; in der Jugend ist Schneedruck und Krümmung des Schaftes als Folge hiervon nicht selten; die gleiche Erscheinung ruft noch häufiger Wind hervor. Sie vertragen keine Überschirmung, höchstens seitliche Einengung der Kronen durch ihresgleichen: 15-20jährige Gipfelfreiheit sichert allein ihr Gedeihen in Mischung mit anderen Holzarten. Alle Lärchen verlangen einen guten, tiefgründigen, nicht allzu schweren und feuchten, kalkreichen Boden; aut nahrungsarmem Boden, Kiesgerölle. Sandboden dritter Bonität und geringer, entwickeln sich die Lärchen nur die beiden ersten .Jahrzehnte rasch, wodurch eine unheilvolle Täuschumg erwecht wurde; vorzeitig läßt das Wachstum nach, und von unten nach oben fortschreitend, stirbt allmählich die Krone unter Flechtenansatz und Krebswülsten ab. Im Holze sind alle Lärchen gleich; in einem warmen Standorte wird jede ein weitringiges, leichtes, weiches, in einem kühlen jede ein engringiges, hartes, schweres Holz bilden müssen. Der schmale Splint deckt einen rotbraumen Kerm von großer Dauer und Härte. Härte und Kernfarbe hängen ganz vom Standort und von der Erziehungsweise ab. In der Schaftschönheit sind die Lärchen verschieden; je wärmer das Klima, um so grölier die Tendenz zur Terschlechterung 
der Schaftform. Aber auch von cliesum Fahtor aheresohen. Lestehen Unterschiede in den Arten; die japanische Lärehe seheint von all'n die ungünstigste, die sibirische Lärehe und die westamerikanische scheineil die günstigste Schaftform zu besitzen. Aus dem Holzu wirl Harz gu. womnen. Den Lärchen werden Motten und Läus länfig. Agaricus mellens zuweilen schädlich; der sehlimmste Feind abex ist ter lärchenkrehs, Peziza Willkommii, dem gern in die Schuhe geschoben wirl, was an Fehlern in der waldbaulichen Behandlung der lä̈rchen virbrochen wird: an keiner anderen Holzart fegt der Rohbock mit gröberer Vurliebe als an den Lärchen.

Larix americana (Mich.r.), die ostamerikanisehe Lärche, Tamarack. Ostamerika.

Fertige Triebe gelbrot, kahl. An der Wärmegrenze in sumpfigen Standorten selbst in reinen Beständen von geringer Höhe; im 1 ptimm. das auf kanadischem Boden liegt, auf normalen Böden mit normaler Frisehe anch mit normaler Höhe.

Larix europaea (CD.), die europäische Lärche. Alpen, Karpaten und Sudeten.

Die fertigen Triebe hell, strohgelb, glänzend. Knospe hellbram mit gleicher Basis. Der Anban dieser Lärche weitab von der Heimat in dem wärmeren Gebiet (Castanetum und wärmerem Fagetum), unter naturwidriger Anbauart und unpassender Erziehung, hat viele Erwartungen getäuscht; besonders sind in Schottland, in Norddeutschland große Kulturen zugrunde gegangen. Man kann sagen, mit heiner Holzart ist so viel von der Praxis experimentiert und so wenig Erfolg erzielt worden, als mit der Alpenlärche nördlich von den Alpen. Millionen von Lärchen sind bereits zugrunde gegangen, und Millionen von Lärchen, in den letzten Jahrzehnten begründet, droht das gleiche Sulnickisal. Über die Krummwüchsigkeit der Lärche und der allgemein vermuteten Erblichkeit dieser Eigenschaft ist bereits in Abschnitt IV berichtet worden. Tor hundert Jahren ausgeführte Versuche haben stämme mit $40 \mathrm{~m}$ Höhe ergeben. Daß das Holz in der. Jugend infolgre les freien Standes und des wärmeren Klimas nördlich der Alpen zumleich breitringiger und minderwertiger ist gegenüber dem im hohen Alter oder im kühleren Klima gebildeten Holze, ist ein a llgemeines $\mathrm{N}$ a t u $\mathrm{r}$. gesetz für alle Holzarten, verdient aber hier besonders erwithnt zu werden, weil allen Ernstes die Behauptung anfgestellt wurde. dafi. mit einem Samenkorn aus der obersten Alpenregion sic hanch Engringigkeit und śchwere des Holzes vererben müsis!

Larix leptolepis (frorl.), die Hondolärche, japanisehe Lärche, Karamatzu, Fujimatzu. Ta pan.

Fertige Triebe hell bis dunkelrot, Knospe rot. Nadcln mit deut- 
licher, heller Unterseite. Wegen ihres rasthen Wachstums im ersten Lebensjahrzehnte und ihrer Schönheit ist diese Holzart vielfach zum Liebling der For'stwirte in Europa geworden; je älter aber die Kulturen werden, um so mehr schwindet die Liebe dahin. Verfasser mußte bereits $\left.1 \times ! \mathbf{B}^{1}\right)$ lionstatieren, daß die japanische lärche rom zweiten Lebensjahrzehnt an in Wuchskraft hinter der emropäischen Lärche zurückbleibt. Die Schaftform ist noch schlechter als jene der europäischen; gegen Pilz und Insekten etwas härter, gegen Wurzelkrebs bedeutend empfindlicher als die europäische Lärche. Dagegen ist die Leichtigkeit der natürlichen Wiederverjüngung sowie die hohe Keimkraft des Saatgutes ${ }^{2}$ ) ïberraschend.

Larix occidentalis (Nutt.), westamerikanische Lärche, Tamarack. Westamerika.

Junge Triebe gelbbraun, glänzend. Knospe braun. Im Felsengebirg*e bildet die Lärche mit der blanen Donglasie einen lockeren Bestand von durchschnittlich fo $\mathrm{m}$ Höhe.

Larix sibirica (Led.), sibirische Lärche. Nördlicher Ural und sibirien.

Junge Pflanze dieser Lärehe schon in S'aat- und Pflanzbeeten von allen übrigen Lärchen durch auffallend geraden Wuchs, kurze, fast rechtwinklig abstehende Äste und derbe Entwicklung unterscheidbar. Tielfach in wärmerem Klima langsam, in kühlerem sehr raschwïchsig. Fertige Triebe der emropäischen Lärche in Farbe gleich, Kunspe mit tast schwarzer Basis. Die sibirische Lärche färbt sich im Herbste bereits goldgelb, während alle übrigen Lärchen noch grün sind. Die anffallende Geradschaftigkeit verleiht dieser Lärche einen besonders hohen II ert.

\section{9. (Gattumg: Picea, die Fichtenarten, Spruces, Epicéas.}

Für alle Länder, welche dem Fagetum und Picetum angehören, wie Mittel- mnd Nordeuropa, Kanada, Sibirien, für alle Berglandschaften, welche in diese Znnen hineimragen, liefert die Gattung Picea das wertvollste Bau- und Stammholz, eine hoch geschätzte, nur von der Föhre (Kiefer) ïbertroffene Brettware. In allen Ländern, welcho einer wärmeren Klimazone als Fagetmm zufallen, wie südemropa, Vereinigte Staaten von Nordamerika, (Ntasien (C'hina und Japan), liegen die Fichten vom Verbramchsorte weitab in höheren Elevationen oder im Norden. In solehen Fällen sind die Angehörigen der Grattung Picea, die selbstverständlich in Amerika und Asien dasselbe Holz wic in Europa bilden,

1) H. M a $y \mathrm{r}$, Anbauversuche mit japanischen Holzarten usw. Forstwissenschaftliches Zentralblatt 1s! $\times$ S. 4:3.

2) Joh. Rafn, Kopenhagen, hat bis $70 \%$ festgestellt. 
einstweilen moeh ziemlich wertlos weren der Entferumer vom Ver brauchsorte und wegen des Auftretens von Narlollänmen, welche dio Fichten in ihren Verwendungszwecken vollaut' ersetzrn, ja noch übertreffen, wie Pitchpine, Strobe, Donglasie, (relbführe in den Vereinirntun Staaten, Cryptomerie in Japan und China, dio Keder im Ilimalaja. Die: europäische Fichte verdankt teilweise dor Güte des Holzes, alur auch ihrer massenhaften, natürlichen Anwesenheit, ihrem schnellen Wuchs, ilner Schaftform, ihrer Bescheidenheit und leichten Autzurht ihro Berühmtheit, welche sie aber mit sämtlichen übrigen Angrörörigen der Grattung Picea, nach dem Grundgesetz, daß derlei Eigenschaften Gattungscharaktere sind, teilt.

Die Fichten sind immergrüue Bamarten mit einspitzigren Nadeln; diese am Grunde verschmälert und auf einem aus der Rinde des Triebes rorspringenden Nadelkissen aufsitzend. Nach dem Nadelabtall bleibt das vorstehende Kissen am Triebe noch Jahre lang erhalten. Nadeln vierkantig: in diesem Falle sind alle vier Flächen mit weißen Spaltöffnungslimien versehen, oder flach zweikantig: in diesem Falle trägt die Oberseite der Nadel zwei breite, weißo streifen. An Seitenzweigen drehen sich die Nadeln nach unten, so daß bei solchen Fichten eine weißliche Zweigunterseite erscheint. Der Zapfen reift in e in e $\mathrm{m}$ Jahr, hängt bei der Reife nach abwärts. öffnet sich bei trockener Witterung, so daß die Sämereien durch ihre Schwere horausfallen. Der Samen liegt in einer löffelartigen Vertiefung des Flügels, aus der er sich loslöst. Am Keimling sind Kotyledonen und Primärnadeln, somit alle Nadeln des ersten Jahres fein gezähnt. Die Ansprüche an das Klima ergeben sich für alle Fichten aus der Zonenbildung. Sire erscheinen bereits im Fagetum, erreichen kurz nach dem Ïbergang in das Picetum ihr Optimum und erstrecken sich aufwärts und nordwärts bis zur Waldgrenze. Thr Heimatgebiet ist der luftfenchteste und kühlste Waldgürtel in allen Weltteilen. An den Meereskïsten streichen sie deshalb weiter nach Süden als im Bimnenland, wenn dieses nicht dureh Gebirge ebenfalls Picetumklima aufweist. Trotz ihres nördlichen Vorkommens, ihres Auftretens in Gebieten mit tiefen Wintertemperaturon sind alle Fichten durch verspätete Fröste im Frühjahrr getährdet, und zwar auf freien Lagen, Kahlflächen, in Frostlöchern. I)ie eben neu ergriinende Fichte ist wie die Tanne in diesem Augenblick so zart wie eine tropis ho Pflanze. Bezüglich der Methode der Aufzucht zur Vermeidung dur Gefahren muß auf' später verwiesen werden: Ungleichheiten in Fru-t. härte erklären sich durch mngleichen Vegetationsbeginn; für einige lessteht auch Grefahr durch somnige Winter I Nadelliäune, Chlowphylltod, Erfrieren der Gipfellinospe und selbst des (iipfeltricbes).

Die Fichten sind im Freistand ziemlich raschwüchs s. nachlem das jugendliche Alter von etwa j-10. Jahren zuriekgelegt ist; bis dahin 
und noch darüber hinaus ertragen sie den Entzug des Lichtes ohne zugrunde zu gehen. Alle Fichten sind deshall Schattenholzarten. Alle Fichten verlangen guten und frischen Boden, begnügen sich aber wegen ihrer seichten Bewurzelung mit geringer Bodenticfe.

Durch ihre auch auf tiefgründigem Boden seichte Bewurzelung sind sie gefährdet durch Sturm, insbesonders wenn sie in größeren Massen zusammen aufwachsen. Von Jugend auf isoliert stehend sind sie ganz sturmfest; länger anhaltende Dürre wird besonders im jugendlichen Alter auf seichten Böden gefährlich; im Bestande aufgewachsen wird durch plötzliche Freistellung des Stammes außer Sturm auch noch Rindenbrand verderblich; in der Jugend bedroht die eng geschlossenen Fichten Schneedruck, im Alter, besonders in Zapfenjahren, Schneebruch. Als Schattenholzarten erhalten sich die Fichten bis in hohes Alter mit geschlossenen Kronen, woraus vollendet astreine, vollholzige Schäfte hervorgehen.

Unter den Feinden der Insektenwelt sind solche, welche Massenvermehrung erfahren und Massentod der Fichten verursachen, wie Nonne, Borkenkäfer, Rüsselkäfer, Blattwespen; von Hirschen, Rehen und Eichhörnchen werden die Triebspitzen abgebissen; da der Trieb mehrere Knospen zwischen zwei Quirlen trägt, ist der Verlust geringer als bei den Tannen; die Rinde wird von den Hirschen geschält, und außer zahlreichen, holzbewolnenden Pilzen (Rotfäule z. T.) sind es vor allem die beiden Wurzelkrebse Agaricus melleus und Polyporus annosus, welche von der Jngend bis in das höchste Alter die Stämme im Bestande dezimieren. Häufig ist Rotfäule im höheren Alter, frülızeitig auf Ackerböden, Viehweiden, feuchten Böden, im wärmeren Klima, in mit Zugtieren befahrenen Waldungen. Das Holz der Fichten entspricht den modernen Ansprüchen am besten: zweischnürige Stämme, leicht, weich, elastisch, astrein; Dauer fehlt; Splint und Kern in Farbe völlig gleich, d. h. Kern ohne Farbe und daher auch ohne Dauer; die Zweige geben Einstreumaterial, die Rinde ist an Gerbstoff reich; aus dem Holze wird Harz gewonnen.

Picea alba (Lk.), Weiffichte, White spruce. Ostamerika.

Nadeln kurz, stumpf, kaum stechend, mit weißlichem Schimmer. Fertige Triebe rosafärbig, von oben her bereift. Beim Zerreiben der Nadehn nnd dïnnen Triebe wird neben dem Harzgeruch ein Beigeruch frei, der den Tieren widerlich ist und die Pflanze vor dem Verbisse durch Hirsche und Rehe schützt. Sie erreicht in der Heimat bis jll $\mathrm{m}$ Höhe, bleibt aber auf ihrer Wärmegrenze (Vereinigte Staaten) in sumpfigen Örtlichkeiten ein Baum II. Klasse. In allzu warmen Örtlichkeiten wurde sie auch bisher in Europa angebaut und bleibt daher ebenfalls ein kleiner, forstlich wertloser Baum. 
Picea ajanensis (Fisch.), a janisehe Fichto, Kurnesomatzu. Ostsibirien und Hokkailo.

Sadeln flach, ant einer Seite weiBliche streifon: fertigr. Triebo struh. gelb. Schon auf Eso (so wird das in den Atlanten und Geomraphinn bis zur Unkenntlichkeit entstellto Wort Yezze gesprochen und sonit auch geschrieben) erscheint diese Fichte in reinen Boständen mit bis 60) m Höhe; nach den Kurileninseln hin nimmt sio zu, anf Sachalin und in Ostsibirien wird sie einstens der wertrollste furstliche Nut\%. baum sein, der ganz nach dem Muster der europäischen Fichno hehandelt werden kann.

Picea bicolor (Mayr), Buntfichte, Iramomi. Yentraljapan.

Diese der europäischen Fichte am nächsten stehende japanischn Art besitzt rierkantige, oberseits weißliche Nadeln, kräftigere Liingsund kräftigere Seitentriebe, dicht rosafarbig bis rostfarbig behaart. Sie wird fortgesetzt mit der Hondo-Fichte verwechselt. Im Fagetum und Picetum des hohen, gebirgigen Zentraljapans ist diese Fichte die höchste (bis $40 \mathrm{~m}$ ) und forstlich die wichtigste. Ihre auffallend späte Ergrünung sichert sie gegen Spätfröste besser als die europäische Fichte.

Picea Engelmannii (Engelm.), Engelmannsfichte, White spruce. Felsengebirge.

Vierkantige Nadeln, ziemlich scharf stechend, am Triebe nach vorn gerichtet, junge Triebe schwach rosa bereift, behaart: mit einem Beigeruch der alba, daher ebenfalls vom Wilde nicht verbissen. Schuppen an den Knospen anliegend. Sehr hoher Gerbstoffgehalt der Rinde mit $11^{\circ}{ }^{\circ}$.

Picea excelsa (Lk.), europäische Fichte. Europa.

In der äußeren Erscheinung sehr rariabel, nur braune Farhe der Triebe und Knospen ist konstant. In Europa fehlt sie ursprünglich auf allen Standorten, welche dem wärmeren Fagetum und dem Castanetum im Klima angehören. Im Süden, natürlich bei entsprechender Elevation, erscheint sie in den östlichen Pyrenäen, in den Alpen und von da nordwärts über Erz- und Riesengebirge, Gstpreußen, Westrußland bis nach Schweden, Norwegen und Lappland; die Linie BaselKönigsberg bildet die europäische Westgrenze, die Linie Kasan-Kón die Ostgrenze. Ton da an ostwärts herrscht die sibirische Fichte. Sie fehlt in ganz Großbritannien. Durch künstlichen Anhan ist die Ficlut weit über ihren Heimatbezirk hinausgeraten, soweit das Klima der Heimat gleich oder milder war, mit gutem, soweit schr warm (wärmstes Fagretuu und (astanetum) mit schlochtem Erfolge.

Picea Morinda (Lli.), Morindafichte. Westl. Mimalaja.

Eine prächtige. sehr langnadelige Fichte, welche ebentall- bis sil w Höhe erreicht; gegen Wintertrost empfindlich. 
Picea nigra $(L k$.$) , Schwarzichte, Black spruce. Ost-$ amerika.

Nadeln kurz, vierkantig, Triebe rotbraun, behaart. Von der alba durch die dunkle Farbe der Nadeln und das Fehlen des Beigeruches unterschieden. Der forstliche Wert ist geringer als jener der alba, nur für Papierstoff scheint sie besser zu sein.

Picea obovata (Ant.), die sibirische Fichte. Ural, Sibirien.

Durch längere, schmälere Nadeln, dünnere Triebe mit rosafarbigem Reif von der europäischen Fichte - von Blüten und Zapfen abgesehen verschieden. Sie erreicht dieselbe Dimension und verlangt natürlich anch die gleiche Behandlung wie die westliche Schwester.

Picea Omorika (I'(mč.), Omorikafichte. Balkan.

Nadeln flach gedrückt mit weifen Streifen auf einer Seite. Nadeln dem Längstriebe hart angedrückt; eine mächtige Fichte im Gebiete des Balkans.

Picea orientalis (Lli. et Cur.), Kaukasus-oder Sapindus fichte. Kaukasus und Kleinasien.

Nadeln auffallend kurz, stumpf, glänzend, Triebe sehr dünn, behaart. Anfangs langsam-, später raschwüchsig, vertritt sie die europäische Fichte im kleinasiatischen Orient; in der Heimat bis $50 \mathrm{~m}$, kultiviert in wärmeren Klimaten nur bis $20 \mathrm{~m}$ hoch.

Picea pungens (Engelm.), Strichfichte, Blue or white spruce. Sïdliches Felsengebirge.

Nadeln sehr stark stechend, fast rechtwinklig vom Triebe abstehend, Knospenschuppen an der Basis der Knospen abstehend. Nadeln und Triebe mit demselben unangenehmen Beigeruche wie Picea alba; aus diesem Grunde wird die Fichte von Rehen und Hirschen nicht verbissen. Das späte Austreiben sichert gegen die Spätfrostgefahr, selbst auf sumpfigen, kalten Örtlichlieiten. Sie wird in der Heimat bis 50) $\mathrm{m}$ hoch.

Picea sitkä̈nsis (Carr.), Sitkafichte, Tideland spruce. West a merika.

Junge Pflanzen mit scharfstechenden, etwas abgeplatteten, zwei weife Streifen tragenden Nadeln. In wärmerem Klima (Eichen) auf anmoorigem, feuchtem Boden, in kühlerem Klima in normalem Boden wächst diese Fichte sehr rasch, doch ist sio empfindlicher gegen Spätfröste und vor allem gegen Winterfröste und Gipfelknospentod als die europäische Fichte: von der kühlen Küste Kaliforniens bis nach Alaska zusammen mit der Douglasie bildet sio nur in ihrem Optimum reine 
Bestände, wobei eine Höhe von till m und darïher. normale Errscheinungen sind. Entgegen marktschreierischer Anpreisung sei betont, daßB anch diese Fichte nur ein Fichtenholz produzieren kann. Die stechenden Nadeln schützen nicht genügend gegen das Verbriben durch das Wild, da ihnen der lästige Beigeruch der Alba- nnd Pungrensfichten fehlt.

\section{Gattung oder besser Sammelgattung Pinus, die Föhren, die lifefern, Pines, Pins.}

Schon 1890 versuchte der Verfasser eine Tremnung der sammelgattung Pinus in natürliche Sektionen unter Benützung der äußeren Merkmale der, damals fast noch ganz unbekannten Anatomio des Holzess und der ebenfalls unbekannten, biologischen Eigenschaften dor Führen, wobei er hinwies, daß die natürlichon Sektionen sich genau wie die Gattungen verhielten. Behufs Charakterisierung der Föhren zwecks forstlicher Behandlung ist die Aufteilung der Gattung Pinus in Sektionen naturwissenschaftlich und praktisch ein Ding der Notwendigkeit.

Alle Föhren haben gemeinsam, daß die Kotyledonen des Keimlings olne Zähne, die Erstlingsnadeln, welche einfach sind, mit Zähnen versehen sind, daß ferner der Zapfen nicht im Jahre der Blüte, sondern in dem diesem folgenden Jahre reift und daß alle Führen ein schwach rötlich gefärbtes, dauerhaftes, harzreiches Kernholz:besitzen. Sie zählen durch ihre Produkte und durch ihre waldbaulichen Eigenschaften, Standorte zu berölkern, welche ron anderen Holzarten nicht mehr bewohnt werden (Sandböden), zu den forstlich wertvollsten Nutzbätmen. All dringen mit kräftiger Pfahlwurzel in die Tiefe.

\section{Sektion, besser Gattung Pinaster: Pinasterföhren oder Pinaster- kief'er'u.}

Zweinadelig: nene Zapfen an der Spitze des Triebes an Stelle ron Quirlknospen, reife Zapfen somit an der Stelle eines Quirltriebes. Der Same wird vom Flügel wie von einer 'Zange gefaßt. Die Führen dieser Sektion gehören teils dem Castanetum, teils dem Fagetum und teils dem Picetum an: auf gutem Boden stehen sie einzeln zwischen anderen Holzarten: bei Abnahme der Bodengüte scheiden allmählich die anspruchsvollen Holzarten aus, und die Föhren bleiben als alleinherrsch nd zurück. Die Pinasterföhren vermögen mit den geringsten sandigen, kiesigen, trockenen, heißen wie auch versumpften und samren Bülen noch fürlieb zu nehmen; darin liegt ihre große, waldbanliche Bedentung. $\mathrm{Daß}$ ilıre Höhenentwicklung parallel der Bodengrite mi lew Kilima geht, ist selbstverständlich. Je lehm- und humnsreicher der Buden, um so breiter wird der splint und kernärmer das. IInlz. Iie l'tahlwurzel ist kräftig und dringt bis $2 \mathrm{~m}$ Tiefe in ton Boilen pin: auf seichtem Boden seichtwurzelnd mit geringer Wilerstulskiaft gren 
Wind und mit ungünstiger Schaftform; wegen des spröden Astholzes dem Schneebruche ausgesetzt. Alle Pinasterföhren sind Lichtholzarten, welche von Jugend an schnellwüchsig sind: im heimatlichen Kilima sind sie frosthart. Eine Castanetumföhre in das Fagetum oder gar Picetum verbracht, ist ein unnatiurlicher Versuch, der zu negativem Ergebnis führen muß. Insekten leben viele auf den Pinasterföhren. Einige, wie Föhrenspanner, Föhrenspinner, Eulen usw. können sehr schädlich auftreten; anch von Pilzen werden die Föhren häufig angefallen, z. B. das Kernholz der Föhren von Trametes Pini, junge Pflanzen und alte Bäume von Agarieus melleus, Polyporus annosus. Keimlinge und wenigjährige Pflanzen sterben nach Nillionen durch den Schïttepilz dahin; doch sind hierin die Arten verschieden. Das Holz der Pinasterföhren steht in Härte dem Fichtenholz nach, übertrifft aber dieses in Daner und Harzgehalt. Unter sich bastardieren die Pinasterföhren ziemlich leicht.

Pinus (Pinaster) aleppensis (Mill.), A leppoföhre. Mediterrangebiet ostwärts von der Adria.

Diese langnadelige Föhre wird ein mächtiger Baum, der neben Holz auch Harz und in der Innenrinde Gerbmaterial liefert.

Pinus (Pinaster) a ustriaca (Höss.), österreichische Schwarzföhre. Ost-und Südostalpen, Balkan.

Nadeln lang, dunkelgrün, starr, stechend. Rinde am Baume bis in die Spitzen von gleichmäßigen Schuppen und grauer Farbe. Dieselbe wird nur ausnahmsweise $30 \mathrm{~m}$ hoch; ihre forstliche Bedeutung liegt in der Besiedelung von trocken-heißen, kalkreichen Hängen, bei mäßig raschem Wuchs, im reichlichen Nadelabfall, in der Frosthärte, im Harzreichtum und in der Holzgüte; ihre Empfindlichkeit gegen Schneedruck ist groß.

Pinus (Pinaster) densiflora (Sicb. ct Zucc.), japanische Rotföhre, Akamatza, Mematza. Japan, Kcrea.

Nadeln länger und weicher als bei der mitteleuropäischen Art, Triebe schwach bereift, junge Stämme und damit auch der obere Teil der alten Stämme mit rötlicher, dünner Schuppenborke versehen. Knospen rot mit zuriickgerollten Schuppen. Dem Castanetum und Fagetum angehörend, ein Baum bis $40 \mathrm{~m}$ Höhe. Sehr raschwüchsig, frosthart und selır empfindlich gegen Schneedruck.

Pinus (Pinaster) lapponica (Muyr), hochnordische Föhre. Europa.

Auf keinem Punkte Mitteleuropas tritt diese Föhre auf. Die Föhren von Norwegen, Nordschweden und Finnland gehören in ihren Formenkreis; Schaft geradwüchsig, bis jetzt (20) Jahre) auch in wärmerem 
Klima; Wnehs träger als bei der mitteleuropaiischen Art; weniger empfindlich gegen Schïtte.

Pinus (Pinaster) Laricio (Poir), knrsikanische Schwarzföhre. Korsika.

Nadeln lang, kräftig, hellgrün; bilden unter den verwandten Sehwarz. föhren die höchsten und schönsten Schäfte: sie ist forstlich wichtigrer als andere Sehwarzföhren. Frost- und sehneehart werden sie aurh von Kaninchen und Rehen nicht befressen; sie ist von allen Schwarzfïhren für Deutschland die wichtigste; leider wurde zumeist die ïsterreichische angebant. L. Pardé ${ }^{1}$ nennt P. calabrica die beachtenswerteste Schwarzföhre.

Pinus (Pinaster) leueodermis (Ant.), weißrindige Föhre. Bosnion.

Der österreichischen Föhre nahestehend, mit weißlich bereiftem, einjährigem Triebe.

Pinus (Pinaster) Mughus (Scop.), Sumpfföhre. Mittleres und nördliches Alpenvorland.

Sie bewohnt als niederliegender Strauch die sumpfigen Standorte. Pinus (Pinaster) Pallasiana (Lamb.), taurische Schwarzföhre. Krimm und Kleinasien.

Wegen der schlechten, ästigen und geteilten Schaftbildung auf allen Standorten ein forstlich minderwertiger Baum.

Pinus (Pinaster) Pinaster (Sob.) oder maritima (I'oir.), Strand-

föhre, Sternföhre. Westliches Mediterrangebiet.

Nadeln sehr lang und kräftig. Im Castanetum zur Anfforstung von dürftigem Sandboden; zur Holz- und Harzproduktion von größtem Werte.

Pinus (Pinaster) Pumilio (Henk.), Krummholyföhre, Kriechföhre, Latsche. Nittleres Europa und höchste Lagen von Südeuropa mit A usnahme der Pyronäen.

Ein alpiner Strauch, der auch im wärmeren Klima ein strauch bleibt; im Alpinetum als Schutzpflanze wichtig.

Pinus (Pinaster) resinosa (Ait.), amerikanische Rotföhre, Red fir. Nordstaaten von Ostamerika.

Nadeln länger und dünner als bei der europäischen Führe, frischeres Grün. Fertige Triebe rotbrann. Geradschaftigkeit und Astreinheit machen diese Föhre in Kanada und den Nordstaaten dur. ITnim zum wichtigsten Nutzbaum, nachdem die Vorräte an Wermotusführenholz so ziemlich erschöpft sind.

1) L. Pardé, Emploi des Essences forestieres. 1905. 
Pinus (Pinaster) silvestris (I.), mitteleuropäische Rotföhre, Kiefer. Mittleres Europa und westlicher Teil von Asien.

Nadeln ziemlich kurz, Kunospen hellockerfarbig, mit orler ohne Harzüberzug. Da nach Auffassung des Verfassers die nordische Föhre (Norwegen, Nordschweden, Finnland, Nordrußland) eine von der mitteleuropäischen Föhre äuferlich und biologisch und sicherlich auch forstlich wohl unterscheidbare und nach den Mitteilungen Dr. Denglers ${ }^{1}$ ) auch eine in ihren Eigenschaften konstante Art ist, muß als Verbreitung'sgebiet Mitteleuropa bezeichnet werden. Auch dort ist die Fölure für die meisten Standorte nicht ursprünglich, sondern eingeführt, z. B. in ganz Nordfrankreich, Belgien, Holland und Westdeutschland. Jüngere Bäume und das obere Stück alter Bäume sind mit dünner, roter Schuppenborke versehen. Forstlich kann diese als die wichtigste Föhre Mitteleuropas bezeichnet werden. Ihr klimatisches Uptimum liegt augenscheinlich im Fagetum; Ostpreußen, Polen, Kurland, Livland bilden das Zentrum des Optimums; dort erwächst die Föhre in bester Schaftform und Höhe: Holz der Urwaldstämme außerordentlich gleichmäßig und feinringig. Holz der Kulturwaldstämme dagegen grobfaserig mit rasch wechselnder Ringbreite. Stämme mit $35 \mathrm{~m}$ Höhe und darüber sind keine Seltenheit. Die russischen Forscher berichten, daß die Fölre auch Sibirien und Kaukasien und die Berglandschaft bis nach Persien hin betritt; in England fehlt sie, in Schottland erscheint sie wiederum.

Pinus (Pinaster) sinensis (Lamb.), chinesische Rotföhre. China.

Nadeln weich, dünn, lang. Tom Castanetum bis zum Picetum in China verbreitet. China besitzt nur mehr lockere Haine, da das Beste, das von dieser Föhre in Küstenwaldungen vorhanden war, längst ansgerottet wurde. Yur Aufforstung in Kiautschau neverdings neben der japanischen Schwarzföhre verwendet.

Pinus (Pinaster) Thunbergii (Parl.), japanische Schwarzfölre, Kuromatra, Omatza. Japan.

Nadeln sehr starr, stechend, Kunospen weiblich: eine Schwarzföhre mit dunklerer Riude bis in die Kronenregion; vorzugsweise Küstenbewohnerin, auch zur Dünenaufforstung benützt. In geschützter Lage geradschaftig bis $411 \mathrm{~m}$ Höhe.

Pinus (Pinaster) uncinnata (Rumd.). Hakenföhre, Spirke. Mitteleuropa und Südeuropa.

Diese Föhre mit kưzen Nadehı und grauer, kleinschuppiger Borke

1) Dr. Dengler, Das Wachstum von Kiefern aus einheimischeni und nordischem Saatgut. Zeitschr. f. Forst- u. Jagdwesen 190s. 
wächst stets aufrecht: anfänglich deckt sio den trockenen wir nassen. moorigen Boden mit mangelhaftem riptel- und lebhafteren Seiten wachstum; je mehr aber der Boden dureh Zweigschutz sich verbessirt. desto mehr erhebt sich der Gipfel; auf' Hartland und in den Prrenäen als alpine Grenzregetation überall mit talellos geradem Schafte wachsend; auf Hartland im klimatischen ()ptimum, im Picetum ein Baum bis $25 \mathrm{~m}$ Höhe. In seiner forstlichen Bedeutung noch ungenügend erkannter Baum : sein außerordentlich hoher Wert für Düncnaufforstung jedoch ist an der Ostsee und in Dänemark festurestellt.

Das Saatgut dieser Föhre kommt als rsüdtranzösische "Führe orler. Kiefer vielfach in den Handel.

Pinus (Pinaster) uncinnato $x$ silvestris mihi. Die Bastaruföhre der Auvergne, südfranzösische Föhre.

Terfasser hat an anderen Orten bereits betont, daß Pinus uncinnata und Pinus silrestris an ihren zahlreichen Berïhrungspunkten entlang den Alpen von Oberösterreich bis nach Frankreich sehr leicht Bastarde bilden, welehe bald mehr der einen. bald der anderen Art in Erscheinung und Biologie sich nähern. Untersuchungen in der Auvergne haben den Terfasser überzeugt, daß in dieser .südfranzüsischen" Föhre obiger Bastard durch Kunst und Natur eine herrschende Verbreitung auf größeren Flächen hin gefunden hat. Das anfänglich niedere und langsame Wachstum slammt ron uncinnata, die sichütteempfindlichkeit von silvestris. Zapten und Benadelung stehen in der Mitte zwischen beiden; der Sehaft ist silvestris mit allen Fehlern und Torzügen.

\section{Sektion (Gattung): Murraya, Murayaföheu.}

Teils nur zweinadelig, teils nur dreinadelig, teils zwei- und dreinadelig gleichzeitig bilden die Föhren dieser Sektion; sie bilden alljährlich am Längstriebe zwischen dem Quirltrieb und der abschließenden Knospe, je nach Üppigkeit des Wuchses, ein oder zwei, selbst trei Scheinquirle, an welchen auch in der Regel die Zapfou erscheinen. Fast alle Pflanzenziichter fallen in den Irrtum. die Scheinquirle für echte, das Iängenwachstum begrenzende Quirle zu halten und berichten deshalb, die Pinus Banksiana mache in oinem Jahre zwei, selbst drei Triobe. Wächst eine solche Führe sehwach. fallen die Scheinquirle aus; wäehst sie kräftig. so bildet sie die Anlagv zu den Scheinquirlen bereits in der abselulietienden huospe aus; wird somit eine solche Föhre rerptlanzt, $m$ uf sie in dies'm ärgsten Leidensjahre Scheinquirle bilden, die sicher nich mf lig. von Üppigkeit sich erst bilden, sondern schon vorhanden sin l als \%orchen der vorausgehenden Ernährung; eime weitere Folge ist. lats schon sehr jugendliche Individuen Zapfen tragen: es wird dies al wir schlechtes 
Zeichen für Nadelbäume betrachtet, und es bekundet diese Erscheinung in ihrer Art zumeist einen leidenden Zustand, sei er durch trockene Witterung, sei er durch die Verpflanzung herbeigeführt; bei den Murrayaföhren ist das Z a p fenerträgnis das Z Zichen des besten Wohlbefindens, des besten Wachstnms. I)ie Pflanzezeigt ihr Leiden dadurch an, daß sio keine Scheinquirle und deshalb aneh keine Zapfen bildet. Das Samenkom liegt in einer löffelartigen Verbreiterung des Flügels, welche mit einem Spalt versehen jist.

Die Mrurrayaföhren sind ausgesprochene Lichtpflanzen, die raschwüchsigsten unter allen Föhrenarten; sie gedeihen noch auf trockenstem, magerstem, verhärtetem und vergrastem Sand- und Geröllboden, wie auch auf feuchten, sumpfigen Standorten; sie eignen sich für verkarstete Grebiete und sind die besten Pioniere für Ödlandsaufforstungen. Sie neigen bei isoliertem Stand anfänglich zur buschigen Verbreiterung und haben so die Legende hervorgerufen, daß sie überhaupt keine nutzbaren Bäume würden. Auf lockerem, trockenem Boden zwingt sie Wassermangel zn anfänglicher Verbreiterung der Krone, wie anch andere Holzarten in gleicher Lage $\mathrm{zu}$ tun gezwungen sind. Im engen Schluf sind sie normale Schäftebilder.

Sie sind, soweit auf südliche Standorte angewiesen, frostempfindlich, so weit dem Fagetum oder Picetum zugehörig, gegen tiefe Temperaturen imempfindlich. Da sie auch rom Schüttepilz nicht befallen werden, ist ihr forstlicher und waldbaulicher Wert hoch anzuschlagen. Daß ihr Holz geringwertiger sei als das der Pinasterföhre, ist nicht bewiesen.

Pinus (Murraya) Banksiana (Lamb.), Banksföhre, Jack Pine. Nördliches Ostamerika.

Nadeln der jumgen Pflanze lang, der älteren kurz; sie ist daher schneedruckfester als sämtliche Pinasterföhren; stets zweinadelig; Knospen hell, mit Harz übergossen, bucklig bei Anlage der Scheinquirle. Selbst noch auf Unionsgebiet erreicht die Föhre nach Messungen des Verfassers $22 \mathrm{~m}$; in ihrem Optimum, im kïhleren Fagetum und Picetum von Kanada ist sie mit $35 \mathrm{~m}$ gefunden worden. Wegen ihres Vorkommens in Amerika auf trockenen, sandigen Höhen mit änßerst geringer Bodenlirume schien sie dem Verfasser 1885 eine auch für Europa wünschenswerte Einfülırung zu sein. Die Urteile, welche von seiten der Praxis nunmehr reichlich einlaufen, stimmen alle in ihrem Lobe überein. Daß Krankheiten und Insekten nóch an ihr auftreten werden, ist mit Sicherheit zu erwarten, sind doch dio einheimischen Föhren ein wahrer Leckerbissen für Insekten und andere Tiere. 
Pinus (Muraya) inops (- tit.), Jersoytuhru, Jersegpine.

IIt lerestaaten von Ostamerika.

Was man in Dänemark und Ostpreuben zur I) inenautiorstme verwendet und Pinus inops nennt, ist keine imops, keim Amerikanerm, sondem eine gute Europäerin die Pinasterfüh\% Pinn uncinnata. Die Jerseytöhre hat zwei und drei Nadeln in einem Kurztriob; die cinjährigen Triebe sind dümn und weibblau hereitt. Anch sie wird ant gutem Boden ein hoher Baum. Ihr Wert liegt in ihrer Ausnitzung des geringwertigsten Bodens des C'astanetums.

Pinus (Murraya) insignis (Ilougl.), Montereyföhre,

Montereypine. Kalifornische Kïste.

Drei lange Nadeln in einem Kurztrieb, mit großen Zapfen. Diese Art wird zur Aufforstung der Dünen Kaliforniens henützt; ihr Optimum ist im kühleren Lauretum und wärmeren Castanetum.

Pinus (Murraya) mitis (Michx.) (echinata), kurznadelige Föhre, Karolinaföhre, shortleafpine. Südliche und mittlere Staten von Ostamerika.

Fertige Triebe ebenfalls bereift. Der Baum tritt in Ustamerika allmählich an die Stelle der wegen ihres Holzes und Harzes verfolgten und mißhandelten Pitchpineföhre (Pinus palustris). Sie schlägt gut am Stamme und an den Aststummeln aus, ist aber so wenig wie andere Föhren mit gleichen Eigentïmlichkeiten zu Niederwald geeignet. Beläßt man einige Äste bei der Stümmelung, so eignen sith sämtliche Föhren zu einem derartigen Krüppelwaldbetrieb; dem Castanetum angehörig.

Pinus (Murraya) Murrayana (Bay.), Murraysöhre, Lodgepolepine. Sierra und Felsengebirge von Nordamerika.

Nadeln zu zweien, anfangs lang, später kurz: der Banksführe biologisch nahestehend; Verfasser hat sie wegen ihres Torkommens auf den kalten, sumpfigen Standorten 1^@) zur Aufforstung ron Monrboden sowie in Schneedrucklagen empfohlen: sinkt in solchen Standorten die Winterkälte bis $25^{\circ} \mathrm{C}$ und tiefer herab, leiclet sie durch Blattgrüntod und färbt sich leuchtend rot. Ihr (1),timum ist das Picetum; sie wird bis $30 \mathrm{~m}$ hoch.

Pinus (Murrara) pyrenaica (Lapeyr.), Brutia oder Pyrenäon. föhre, Paroliniföhre. Pyrenäen.

Die einzige europäische Föhre dieser sicktion. sie hat sich im Karst auf den trockenen, heißen. windigen Felsenköptin und Hohen als Pionier der Neu- und Wiederbewaldung hewährt, 1. h. sie ist lem allgemeinen Charakter der Murrayafüren treu. 
Pinus (Muraya) rigida (Mill.), Pechiöhre, Pitchpine der Amerikaner, nieht der Enropäer. Küstenstaten von Ustamerilia.

Dreinadelig, mit hellbraunen, slänzenden Trieben. In den ersten Jahren sehr raschwïchsig: später erlahmt ihre Wuchskraft; Nadeln lang, starr, dem Schneedruck von allen Yurrayaföhren am meisten ausgesetzt. Hhre Ausschlagfähigkeit am Stamme und an den Aststummeln hat so wenig praktischen Wert wie dieselbe Erscheinung bei der mitis; von den Ansschlägen gehen in den folgenden .Jahren um so mehr zngruude, je kïhler das Ḱlima.

Pinus (Mrraya) Taeda ( $L$.), Taedaföhre, Loblollypine. sïdstaaten von Ostamerika.

Dreinadelig; Nadeln lang und dünn. Dem Castanetum angehörig. Ilit mitis nimmt sie allmählich den Platz der Pinus palustris ein.

\section{Sektion (Gattung): Jeffreya, Jeffreyaföhren.}

Zu dieser Sektion oder Gattung gehören dreinadelige Föhren, welche die Zapfen an Stelle von (Quirlknospen, somit nach ähnlichen Vorgängen wie die Pinasterföhren zur Ausbildung bringen. Der Same wird vom Flügel zangenförmig gehalten. Einige sind raseh, einige sehr langsamwüchsig, wenigstens in ihrer Jugend: einige liefern ein sehr hartes, hoch wertvolles (südl. Arten), einige ein weiches Holz, wie die Pinasterföhren; einige sind ganz frosthart, andere auferordentlich empfindlich. Sie verlangen einen besseren (lehmigen Sand) Boden als die Pinasterfölnren; sie leiden sehr unter dem Schüttepilz. Einige worden zu wahren Riesen des Waldes. Infolge ihrer langen Benadelung schadet ihnen schmeedruck im Stangenholzalter. Sie sind Lichtholzarten, welche in ihrer Melırzahl den wärmeren Klimalagen, dem ('astanetum angehören; diese kömnen zux Harznutzung herangezogen werden: das Ergebnis ist bei der südlichsten aller Arten das beste.

Pinus (Jeffreya) Jeffreyi (Murr.), Jeffreys Föhre, Jeffreypine. Pazifische Küste Nordamerikas.

Sehr lange Nadeln, rechtwinklig rom Trieb abstehend; fertiger Trich kräftig rosa bis weißblan bereift. In einem Klima, das dem Fagetum zugerechnet werden muß, erreicht der Baum eine Höhe von (it) m. Das Holz mit schön rosafarbigem Kern ist besonder's wertvoll.

Pinus (Jeffreya) palustris (Mill. Parkett-oder Pitchpine der Europäer, Longleavedpine der Amerikaner.

Südstaaten ron listamerilia.

Mit sehr langen Nadehn ansgestattet; Wuehs dieser Föhre in den ersten fünf Jahren sehr langsam, so daßs sie kaum über dem Boden 
sich erhebt; während dieser Zeit ist sie ïberans emplindlich gregen tiefe Wintertemperaturen. Ia sio das wigentlicle Pitchpinchulz liefiert, geht sie in den Sïdstaaten der Erschëpfung ("ntereug'n; duzn tragen noch die Harznutzung bei, die sehr ergiobig ist, sowie die emplindlichen Beschädigungen durch Bodenfeuer.

Pinus (Jeffreya) ponderosa (Jougl.), Gelbfïhre, Jollowpine. W estamerika.

Lange Nadeln, sehr grobe, dicke, brame kinospen, Triebe rlänzent braungrün, ohne Reif. Junge Pflanzen vom fünften Jahre an zirmlich raschwïchsig, mit sehr dicker stammbasis beginnend. Als wiuhtigsto Föhre Westamerikas erreicht sie bis sı m Höhe bei sehr hohem Altur. Dem Schneedruck und dem Verbif durch Eichhörnchen ausgesetzt.

Pinus (.Jeffreya) scopulorum (Lem.), Felsenföhre, Rock Pine. Felsengebirge bis Dakota.

Nadeln kürzer: in den schwarzen Bergen von Ilakota; für Europa vielleicht wertroller als die Gelbföhre.

\section{Sektion (Gattung): Strohus, Weymouthsföhren, Strohen.}

Fünf weiche Nadeln in einem Kurztriebe. Same mit dem Fliigrel innig verwachsen und flugfähig. Alle Stroben sind Halbsehattenhölzer, die durch die Ungunst des Bodens oder des Klimas zu Lichthölzern werden. Die Angehörigen dieser Sektion sind alle rasch bis sehr rasch wachsende Baumarten, verlangen guten Boden bis herab zu Föhrenboden dritter Bonität: frischer bis etwas feuchter Boden sagt ihnen am besten zu, aber auch im erlenfenchten Boden worden sio noch forstlich nutzbar. Die Stroben erreichen alle bedeutende Dimensionin: j) $\mathrm{m}$ Höhe sind keine Ausnahmen. Ihr Holzkörper hat Eigenschatien, welche den besonders hohen Gebrauchswert als Grobnutzholz rechtfertigen, das ist Dauerhaftigkeit, Leichtigkeit, Tragfestigkeit und selur leichte Bearbeitungsfähigkieit. Alle Weymouthsföhrenhölzer sind sproder als andere Föhrenhölzer; sie gleichen dem Holze der C'embraarten. Zahlreich sind die Feinde der Stroben, vor allem der Wurzellirelis Agaricus melleus, verursacht starke Abgänge; in der Jugend int Bla-enrost lästig: der Wildbeschädigung sehr ausgesetzt. Schmecbruch tritt nur selten auf. Ihre Frosthärte ist besonders bemerlienswert.

Pinus (Strobus) excelsa (Wall.), Himalajastrol,e. Himalajo. weymouthsföhre. Mittlorer und nordwestli, lier

$$
\text { Himala ja. }
$$

Von allen Stroben mit den längsten Nadeln versolum min walb

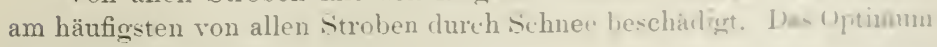
liegt im Castanctum. 
Pinus (Strobus) Lambertiana (I)ougl.). Znckerföhre.

Westameriku.

Div langsamwüichsigste ron allen Stroben; Nadeln kurz, etwas steif, stechend. Ein hochwertiger Baum der Sierra, wo er 9 !n m Höhe und dariiber erreicht. Das Optimum gehört dem Fagetum an.

Pinus (strobus) Peuke (Gries.). griechische Strobe. Sïdosteuropa.

Besonders an der bulgariseh-rumelischen Grenze, im Rilo- und Dospod-Dagh verbreitet; ist fast so schnellwüchsig und ebenso frosthart wie die ostamerikanische Strobe, der sie auch an Holzgüte gleich ist. Anch sie erreicht $40 \mathrm{~m}$ Höhe und darïber.

Pinus (Strobus) Strobus (I.), ostamerikanische Strobe, Weymouthsföhre, White Pine. Ostamerika.

Wohl die einzige fremdländische Holzart, die in Mitteleuropa das Bürgerrecht erlangt hat ob ihrer Raschwüchsigkeit, ihrer Frosthärte, nicht aber wegen ihrer Ansprüche an den Boden, die bereits bei der Selition erwähnt wurden. Es genügt zur Anbauwürdigkeit einer fremden Art, claf ihr Holz andere Eigenschaften als das der einheimischen Arten besitzt, und diese Forderung ist erfüllt, nachdem in ganz Mitteleuropa keine Föhre der Sektion (Gattung) Strobus vorhanden ist. Auch diese Strobe erreicht bedeutende Dimensionen bis zu $50 \mathrm{~m}$ Höhe. Im Fagetum liegt ihr Optimum.

\section{Sektion (Gattung): Cembra, Zirben, Zürbeln.}

Fünf, meist steife Nadeln zusammenstehend: Same nur mit Flügelstummeln oder ohne Flügel. Die Verbreitung der Holzarten ist auf Tiere angewiesen; Samen efbar; einjähriger Trieb kräftig braun behaart. Alle Zürbeln sind ziemlich langsamwïchsige Holzarten, welche guten, frischen Boden beanspruchen. Am besten und höchsten gedeihen sie in den Ebenen auf' Eschenböden. Auf nacktem Fels wächst kein Banm, anch die Zürbel nicht, obwohl solches in den Büchern steht. Im Picetum, sowohl der Hochgebirge als der Ebene (Norden). heimisch. Halbsehattenholzarten von auffallender Frosthärte. Das Holz ist dem der Stroben völlig gleich; natürlich darf man nieht junges, weitringiges Strobenholz mit ganz altem und deshalb sehr engringigem Zirbenholz vergleichen. Ganz alte Stroben haben dasselbe weiche, etwas spröde, eng gefügte und dauerhafte Holz wie die Zürbehn.

Pinus (Cembra) Cembra ( $\left.L_{\text {. }}\right)$, Alpenzürbel oder Zirbe, Arve. Alpon, Enropa.

Eine langsamwüchsige Zirbe, welehe gelegentlich in wind- und wettergeschützten Lagen bis zu $30 \mathrm{~m}$ emporwächst. $\mathrm{Ihr}$ Optimum ist 
das Picetum. Ihr wegeu des Freistandes sthr astig orwachones Holy ist wegen seiner Sichönheit bei lintäfolungen. Si hränken losonrlers hoehgesehätzt. Thre waldbauliehe Bedentung limert darin, lals sie tïr Wiederbewaldung der höehsten Regionen wio in Sümpten der kinene sich sehr vorteilhaf't bewährt hat.

Pinus (Cembra) koreensis (Sirb. Ct Zure.). Koreaziurbel. O)stasion.

Lange Nadeln von dunkelgrüner Anßen- und hellbliulicher lmen. seite; anfangs langsam-, später aber selm raschwïchsig. Das Optimum liegt im Fagetum. Sie erreicht $32 \mathrm{~m}$ Höhe, und ihro Nïsse sind in Korea Vollisspeise.

Pinus (Cembra) sibirica (Mayr), sibirisehe $/$ ür lol. Sibirien.

Vor der Alpenzïrbel dureh rascheres Wachstum, dunklere Farbe usw. ausgezeichnet, ist sie für fenchtere Standorte der Ebene eine will. kommene Bereicherung der forstlichen Kulturgewächse. Sie wird bis 41) $\mathrm{m}$ hoch; ihr Optimum ist das Picetum.

\section{Gattung: P'seulotsuga, Douglasien.}

Die Angehörigen dieser Gattung sind weder 'Tamnen noch Fichten noch Tsugen. Die Terquiekung des Namens Douglas mit Fichte odir Tanne führt daher zu irrigen Vorstellungen und ist besser zu vermeiden. Nadeln flach bei mehr rhombischem Querschnitt; Kuospen groß; Same mit dem Flügel auf einer Seite rerwachsen wie bei Tannen. flugfähig. Von den Forstwirten, Gärtnexn und Samenhandlungen wirl nur eine einzige Art genaunt; die Folge ist, daf. diese Art als etwas ganz Wunderbares in ihrer Verbreitung und in ihrer Biologie erscheint. Aber all das Wunderbare und das Widerspruchssolle iluer Biologie versehwindet, sobald man auf Grund der äuferlichen Erscheinung. der. Biologie und der geographisehen Verbreitung zwei Arten bildet. Auch die Praxis hat das Bedürfnis hierzu längst herausgefïhlt, nur den Mut und die Erfahrung nicht gehabt. Die Douglasien sind schwache Brsehattung ertragende Holzarten: einige wachsen sehr rasch, andere anfänglich langsam. Gegen verspätete Fröste sind sie alle gleich emptindlich; tiefer Winterfrost schadet nu einigen Arten durch Nadelhrämme und Nadelverlust im darauffolgenden Frïhjahr: bei länger tamerndem. klarem Winterfrostwetter gehen mit den Nadeln auch dir Knospen und ein Teil des letzten Triebes verloren. Verfiühter oder Herlistfrost sehadet den rasehwïchsigen Arten, wemn diese ihre Endknospen m Juli oder August noch eimmal zu einem kleinen Siprob austreibus. dir bis zu den ersten Frösten in seiner Vegetation imerlich nicht ab sehließt. Daß die Douglasien frosthart oder war absolut frusthart seien. ist ein Irrtum. Große Lufteuchtigkeit ist wichtig: alle I)urglasion passen sich leicht dem gegebeneu Boden an: aut seichtem Buden werden 
sie Hachstreichend, auf lockerem Boden entwickeln sie eine kräftige Pfahlwurzel, welche später ron liräftigen Herzwurzeln ersetzt wird. Eine Anzahl von Wurzehn verlänft flach. Nassen, tonigen Boden meiden sie: Sandböden geringerer als dritter Bonität sind ungenügend. Sie sind keine Inlzarten zur Aufforstung mageren Bodens. Unter den Feinden sind bis jetzt die äsenden Tiere des Waldes sehr lästig geworden, weniger durch Verbeilsen als vorzüglich dureh Verfegen seitens rles Rehbockes; Mänse fressen an der glatten Rinde besonders in dichten .Jungwüchsen, Rüsselkäfer nehmen alle Nadelhölzer an; der Wurzellirebs ist nicht häufiger als an einheimischen Baumarten. Torz ü gl ich muß ihr Holz mit hell- und dunkelrotem Kern genannt werden. Das ziemlich schwere Holz besitzt eine hohe Dauer und wird in Westamerika neben den zahlreichen Föhren, Lärchen und Fichten als das wertrollste Bau- mnd Sägeholz geschätzt. Das Holz dürfte im Werte nach den Untersuchungen des Verfassers ${ }^{1}$ ) (1884) zwischen Lärchen- nnd Föhrenholz stehen. Dazu kommt ein hoher Gehalt der Rinde an Gerbstoff.

Psendotsuga Douglasii (Carr.). Küstendouglasie, grüne Douglasie, Douglas fir, red fir. Pazifische Küstenregion von Nordamerika.

Nadeln lang, weich, an unterdrückten Ptlanzen und Zweigen gekämmt wie bei den Tannen, an kräftigen Trieben allseits abstehend wie bei den Fichten. Farbe der Nadeln saft- bis dunkelgrün. Knospen grofi, glänzendbraun, glatt, ohne Harz. Das Optimum gehört klimatisch zum Castanetum (kühlere Hälfte) und Fagetum. Das Picetum betritt sie in der Sierra ebenfalls. Große Luftfeuchtigkeit erklärt das häufige Gedeihen in höheren und kühleren, IIangel an Luftfeuchtigkeit das Nichtgedeihen aufierhalb des Waldes in tieferen, wärmeren Lagen. Der nordwestliche Teil ron Mitteleuropa kommt dem Op t i m u m am nächsten. Die Rasehw ̈̈chsigkeit ist ganz auffallend; von allen Seiten laufen jetzt Berichte über die Wuchsleistungen ein, welche die europäischen Holzarten ïbertreffen; die Sorge, daß infolgedessen ein frühzeitiger Wuchsrückgang eintreten werde, ist bis jetzt (nach 30 Jahren) unbegründet geblieben: ganz beseitigt ist sie jedoch noch nicht. In ihrer Heimat erwächst sie im Optimum mit 80 . Jahren bis zu $40 \mathrm{~m}$ Höhe. Eine sehr

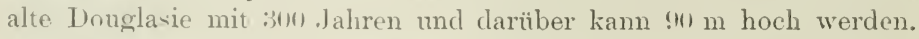

Pseudotsuga glauca (Muyr), Kolorado-Douglasie, blaue louglasie, Colorado Douglas fir. Felsengebirge vou Nordamerilia.

Inurch die Abtremung dieser "blanen Douglasie“ als einer eigenen Art sind alle Wirlersprïiche in der Biologie der Douglasien gelöst.

1) Siehe ausfuhrlichere Angaben bei H. II a vr, Fremdlandische Wald- u Parkbäume für Europa. Berlin, P. Parey, 1916. S. 393. 
Diese Art hat kïrzere Nadeln, steif, am Triol, nach vorne grerichtert. Farbe vorwiegend hell- bis dumkelbläulich. Knospen mit Har\% ühwrzogrn. Anffallend durch ihre Langsamwëchsigkeit währencl des ersten I cebensjahrzehntes, ist sie von da an raschwüchsig. Völlig frosthart erecrun

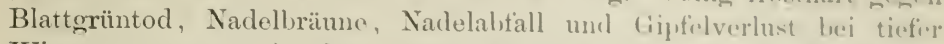
Wintertemperatur; frosthart gegen verfriihtes Fröste, da die Nachtrisbu im Spätsommer nnterbleiben. Sie ist als Bam des kontinentalen Klimas zu bezeichnen. Ihro Holzcrite, Ansprïche an lun Boden sind der grünen Art gleich. Sie erreicht nicht die Höho der hüistendonglasie, doch dürfte die rom Verfasser in Frlsengrobirge gremessemes Maximalhöhe von $45 \mathrm{~m}$ füir forstliche $/$ weeke genügrus.

$$
\begin{aligned}
& \text { Pseudotsuga japonica (Shiras.), japanische Louglasiu. } \\
& \text {.Japan. }
\end{aligned}
$$

Erreicht nicht dic gewaltigen Höhen der vorigen Arten.

Pseudotsuga macrocarpa (Mayr.), grobtrichtige Douglasio. $\mathrm{K}$ alifornien.

Längere und breitere Nadeln als die vorigen Arten: doppelt so grofus Sämereien. Nur im Castanetum leimisch, im Fagetum nicht mehr kultivierbar.

\section{Gattung und Art: Sciatopitys verticillata (Sieb. et Zur.e.), japanische Schirmtanne, Koyamaki. Japan.}

Grasgrüne, dicke, lange, quirlständige, ans der Verwachsung von zwei Nadeln hervorgegangene Nadeln, unterseits mit einem weililichen Streifen. Jeder Nadelquirl entspricht einem. Jahrestriebe. Forstlich ein hochwertiger Bamm durch sein vorzügliches, weißes, fein gebautes Holz, durch seine waldbaulichen Vorzüge, das sind Frosthärte und starkes Schattenerträgnis. Nachteilig ist der sehr langrsame Wuchs: während der ersten 15. Jahre; das Optimum liegt im Castanetum, sie betritt aber auch das Fagetum; sie ist kein Halbbaum, sondern vom Terfasser mit $32 \mathrm{~m}$ Höho und 1,37 m Durchmesser gemessen.

\section{Gattung: Sequoia, Sequoien, Wellingtonien, Bigtrees.}

Immergrüne Bäume mit teils flachen, scharf zugrespitzten, teils pfriemenförmigen Nadeln; Same klein. flach, dümrandigr: junge PHanze nach einigen. Jahren sehr raschwïchsig und mit dicker viammlasis emporsteigend. Lichtholzarten, hohe Luttfuchtigkeit mul fri-chen. guten Boden verlangend; auch aus stecklingen vermohrbar. cirnbe Stockausschlagfahigkeit des Stammes. Im insularen Klina uder im feuchten Waldklima der Berge, soweit dieso Standorte noch dum Fane tum angehören, ziemlich frosthart. Besonters tiefo Wintertemperatur (unter $25^{\circ} \mathrm{C}$ ) bleibt stets gefährlich und schädlich dnrch $/ 2$ weig oder If a y r, Waldbau. 
Gipfeltod (Nadel- und Triebbräme). Das rote Kernholz ist hochwertig durch seine Feinheit, Leichtigkeit, leichte Bearbeitungsfähigkeit, Tragkraft und Daner.

Sequoia gigantea (Decs.), Riesensequoie, Bigtree. Sierra Nevada ron Kalifornien.

Nadehn durchwegs pfriemenförmig; anfangs langsamwüchsig, später, besonders auf gutem Boden, andanernd selir rasch; erreicht bei außerordentlichem Alter auch außerordentliche Höhen, nach des Verfassers eigenen Messungen über $100 \mathrm{~m}$ Höhe und $7 \mathrm{~m}$ Durchmesser in $2 \mathrm{~m}$ Höhe über dem Boden. Das Holz ist in mehrtausendjährigen Stämmen anßerordentlich gleichmäßig, aber von geringem Wert wegen der ungefügigen Größe der Bäume.

Sequoia sempervirens (Endl.), Küstensequoie, Red wood. Kalifornien.

Junge Pflanze mit flachen Nadeln und zwei weißlichen Streifen mnterseits, an blühenden Zweigen pfriemenförmig. Dem Lauretum und Castanetum mit hoher Luftfeuchtigkeit zugehörig; im Fagetum nicht mehr emporzubringen. Wird nach des Verfassers eigenen Messungen ebenfalls $100 \mathrm{~m}$ hoch mit entsprechendem Durchmesser und Alter.

\section{8. (kattung und Art: Taxodium (Rich.), Sumpftaxodie, Bald Cypress. Südstaaten ron Ostamerika.}

Die Seitentriebe mit gekämmt stehenden Nadeln färben sich im Herbst braunrot und fallen ab, daher winterkahl; Längstriebe mit zerstreut stehenden Nadeln, welche ebenfalls abfallen; das Optimum liegt im wärmeren Castanetum; sie verlangen feuchten, nassen Boden, aber nicht versäuerte Fenchtigkeit. Der nasse Boden im Fagetum ist ihnen zu kalt und frostreich, der wärmere, bessere Boden ist ihnen $\mathrm{zu}$ trocken. Raschwüchsige Holzart; Höhen von $j($ ) $\mathrm{m}$ sind bekannt; ihr Holz mit bräunlichem Kern ist weich, leicht und sehr danerhaft; sie ist durch die Erschöpfung an P. palustris-Holz wertvoll geworden.

\section{Gattung: 'Taxus, Eibenarten, Yews, Ifs.}

Immergrüne Bäume mit flachen, zugespitzten, unterseits hellen Nadeln. Alle Eiben haben ein auferordentlich wertrolles, hartes, schön rot gefärbtes Kernholz mit schmalem Splint. I) Bie Bildung nutzbarer Stämme aber verlangt lange \%eiträume; demn alle Eiben sind langsamwïchsig. Das allein ist der Grund, warum sie im forstlichen Betrieb so wenig berücksichtigt werden; freilich hat auch der Kahlsehlagbetrieb lie Eiben verdrängt; denn auf Kahlthächen erfrieren die Eiben während eines strengen Winters dureh Blattgrüntod der Nadeln und Triebe. Die Eiben verlangen guten Boden und den Schutz des licht wich stellenden Laubholzes; sie ertragen starke Beschattung, neigen aber zu Vielgipfelig- 
keit und Verteilung des Schaftes, sn daß̉ nutzhar stänme nieht häutig sind. Sie besitzen Stockausschlagsfähigkeit mul kwmen durch streklingre vermehrt werden. Sie gehören alle dem Faretum an: in l'icetum seltener. Luftfeuchtes Klima und zwar die Kïisten von Westemona, das Innere großer Waldungen, sagt ihnen am hesten zu. Die Fiben Crob. britanniens sind aus diesem Grunde hochberühnt. "Wher 르 m schemt keine emporzuwachsen.

Taxus baceata (I.), europäische Eibe. Enropla.

Nach den Studien von Professor Compentz ist die Fibe in ganz Europa verbreitet gewesen, in ganz Europa nahezu ans serottet: sie verdient Beachtung und Anbau von seiten der Forstwirte.

Taxus cuspidata (Sieb. et Zucc.), die japanische Eibe. Araragi. Japan.

Scheint rascher wüchsig als die europäische zu sein, mit der sir alle übrigen Eigenschaften teilt. Verfasser maß Bäume mit 오 m Höhe.

\section{Gattuny: Thuja, Thujen, Lebensbäume, Arbores vitae.}

Zweigquerschnitt durch die flachgedrückten Schuppenblitter elsen. falls flach, Ober- und Unterseite vorhanden: Leittrieb auch beim raschesten Wuchse der Pflanze aufrechtstehend: mäBig- bis schnellwüchsige Arten, Schatten ertragend. Sie verlangen guten, trischen. selbst feuchten Boden. Hohe Luftfenchtigkeit ist ihnen besonder: günstig. Im Picetum erlischt ihr forstlicher Wert, der im Fagretum am größten ist. Das weiche. leichte Holz mit bräunlichem hern ist sehr dauerhaft. Außer Mäusen und Rehen ist unter den Feinden eim Pilzkrankheit an Zweigen (Pestalozzia funerea) ${ }^{1}$ ) in Verbindung mit Zweigtod durch Frost zu nennen.

Thuja gigantea (Nutt.), Riesenthuje, Red Ceder. Pazifische Region von Nordamerika.

Ohne sichtbare Harzdrüsen an der (Oberseite der Zweige, unterseit hell: hervorragender Wohlgeruch der Rinde dürrer Zweige. I)ine Art ist die schnellwüchsigste der Gattmng, voransgesetzt, daß sie ron ler Pestalozzia verschont bleibt: sie erreicht auch die stirksten Dimen sionen; Verfasser maß jt $\mathrm{m}$ Höhe. Der Sichaft ist abfällig. auttallew neiloidartig. Das Holz wird als sehr dauerhates Banholz verwenh er zu Brückenbauten, Eisenbahns:hwellen. Zamptnsten, Fü-sern u-w.

Thuja japonica (Max.), japanisehe Thuje. Netzuko. Japen.

Die japanische Art wächst langsamer als dip vorizre, zoigt aler in ihrem Schaft nicht die ungünstige Neiloidform.

1) Böhm, Zeitschr. f. Forst- u. Jagdw. 1-14. 
Thuja occiclentalis (L.), ostamerikanische Thuje, Lebensbaum. Arborvitae. White Ceder. Ostamerika.

Harzdrïsen im Rücken der Schuppen deutlich; oberseits mattgrün, unterseits etwas hellgrün. Langsamwüchsiger als die vorige Art. Theren auberordentlicher Frosthärte selbst in Sümpfen des Fagetums noch verwendbar, auf Hartboden auch noch im Picetum, am besten aut frischem, etwas fenchtem (nicht verwäuerte Feuchtigkeit) Boden des Castanctums: in solehen (O)thchkeiten maß Verfasser stämme mit (3) 1 Höhe. Überall in Europa bekannt, verdient der Baum forstlich Beaclitung.

\section{1. (iattung und Art: Thuyopsis dolabrata (Sieb. et Zucc.), Hiba, Asunaro. Japau.}

Die großen Schuppenblätter an der Unterseite mit einem großen, weiben Fleck; Leittrieb sehr liräftig, aufrecht, der erste Seitentrieb im rechten Winkel abstechend. Die Hiba ist eine sehr langsamwüchsige Holzart, auch in ihren besten Standorten, im lufteuchtesten Gebiet des C'astanetums. Sie ist auch im Fagetum noch ganz frosthart, erträgt starke Beschattung, bildet sehr leicht Absenker und wird leicht durch Stecklinge vermehrt, verlangt aber guten Boden bis zu Föhrenboden dritter Bonität. Sie wird ein hoher Baum: Teriasser maß 30 m Höhe. Sie würde auch für Amerika und Europa eine wertrolle Bereicherung der Waldflora darstellen; denn ihr eigenartig riechendes Holz ist sehr fein und sehr dauerhaft; sie bildet in ihrer Heimat selur dichtgeschlossene Bestände, welche sich sehr leicht auf natürlichem Wege wieder verjüngen.

\section{Gattung: Tsusa, Tsugen, Hemlocks.}

Nadeln flach, tamnenartig; unterseits zwei helle Streifen. Die Nadel endet in ein Stielchen, das auf einer schwachen Erhöhung der Rinde aufsitzt. Der kleine, mit dem Flügel verwachsene Same ist dem Lärchensamen am ähnlichsten. Die Tsugen sind raschwïchsige Holzarten, welche in ihrem schattenerträgnis sich den Fichten nähern. Sie vorlangen aber guten, frischen, tiefgründigen Boden etwa wie die Tanne; ihre /ugehörigkeit zum Castanetum bzw. Fagetum kennzeichnet ihr Wärmebedürfnis. Ihr normales Gedeihen äußert sich in einem überhängenden oder schief gestellten Leittrieb, der im folgenden Jahre sich gerade richtet. Sie neigen frïhzeitig zu Entwicklung mehrerer Gipfel, welche beseitigt werden müssen, um den Haupttrieb zu fördern. Das Holz ist nicht dem der Tanne gleich, wie es meistens behauptet wird, snndern übertrifft dieses Holz, da es große Dauer in seinem grauhraunen Kern besitzt. Die Rinde aller 'Tsugen ist reich an Gerbstoff'. Lnter den Feinden sind Tiere und Pilze beobachtet worden, doch nirgends in auffällig scliädigenderweise. 
Tsuga canadensis (Carr), kanadische 'T'-uga, Homlurk. Ustamerika.

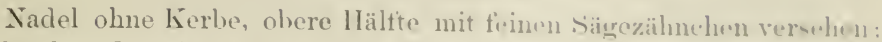
Triebe kmrzflamig behart. Die kanarlische Tsugra neigt an meinen zur I ielgipfeligkeit, wird aber im engen sichlul.j cine selir s-hlanki. astreine Stange. Sie wird bis $30 \mathrm{~m}$ loneh: das Optimm liong im Fagetum; sie betritt aber auch rlas Picetum.

Tsuga diversifolia (Muxim.), japanisthe Tsuga. Kometsuga. J a p a 1 .

Nadeln sehr kurz, unterseits weißer als bei Sicholds 'Tsuga: 'Triol, rotbraun; langsamwüchsig; im Fagetum heimisch.

Tsuga heterophylla (Sarg.) ( M'ertensiana) (Curr.), west. amerikanische Tsuga. Thestern. Hemlock. Pazif'ische Region.

Ganze Nadel gezähnt. Trieb mit langer. lockiger Behaarung versehen, welche bald verschwindet: diese Tsuga ist rle schnellwüchsigrste vou allen und bildet die schönsten schäfte mit geringster Neigung zur Tielgipfeligkeit. Die Douglasien, die Strobe und diese Tsuga sind die wichtigsten Nadelholzarten, um welche Europa Amerika beneilen kann. Das Optimum liegt im Castanetum und Fagetum: sie betritt auch das Picetum, ist dort aber anfänglich etwas durch Frïhfroste geführdet.

Tsuga Sieboldii (Car.). Siebolds Tsuga, Tsuga. .J a pan und China.

Nadeln ohne Sägezähnchen, Trieb ohne Haare. Eine raschwïchsige Art, die ihr Optimum im Castanetum besitzt, aber auch das Fagrium noch betritt.

\section{B. Laubbäume $\%$.}

Trotz des Überwiegens der Laubbaumgattungen und -arten aut der nördlichen Halbkugel sind es doch nur wenige Arten, welch. ilen modernen Ansprüchen an eine forstliche Kulturpflanze entsprechen. Nur solche, welche ein sehr hochwertiges Holz, oder solche. welche Holz in großer Menge in kuzer Zeit bilden, haben Ansicht zur Mawn. aufzucht im forstlichen Betriebe. Es töhrt dieser satz, wiv w. E. fahrung lehrt, zu einer allmählichen Verdrängrung der Lanhhänu. an

1) Wegen der botanischen und forstlichen Wurdigung der lin na hentaf nuter besprochenen, forstlich wichtigeren Laubbäume mul Virfasser auf selor Irluis. Fremdländische Wald- und Parkbäume for Europa (Berlin, I'aul I'arry, Itoul wh wi

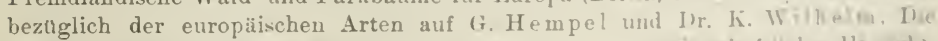
Bäume und Sträucher des Waldes in hotanischer und forstwirt-haftll her Hrustut. hinweisen. 
dem Walıle, wie clas in den Ländern mit der ältesten Forstkultur, in Ientschland und Frankreich, am anffälligsten in die Erscheinung tritt.

Bei der hente schon bemerkbaren Zunahme der Wertschätzung aller Holzarten, auch jener, die bisher im Wald als unwillkommen oder war als schädlich bezcichnet wurden, wird eine weitschanende Forstwirtschaft nicht umhin können, viel mehr als bisher auch die sogenannten Sebenholzarten zu beachten und einen gewissen Vorrat hierin für konmende Geschlechter heranzuziehen. Vor i) Jahren ahnten nur wenige, daß die vielgeschmähte Fichte, welche aus den Beständen, in welchen sie natïrlich erschien, absichtlich hinausgeworfen wurde, sehon nach wenigen Dezennien zu einer der wichtigsten Holzarten Europas wrrden konnte. Freilich ein Mangel wird den Laubholzarten immer ankleben: sie sind ansprnchsvoller an den Boden, langsamer wüchsig, und ihre Anzucht und Aufzucht auf kahler Fläche ist weniger leicht und sicher als bei den Nadelbäumen.

\section{Gattung: Acer, Ahorn, Maples, Erables.}

Same geflügelt, doch immerhin ziemlich schwer und nur bei hettigem Winde auf große Entfernmng getragen. Wird der Same bald nach der Reife in den Boden gebracht, keimt er im nächsten Jahre; trocknet er über. Winter aus und wird er im Frühjahr zur Aussaat gebracht, so keimt er erst im daranffolgenden Frühjahr. In den unberührten Waldungen der nördlichen, gemäßigten Halbkugel sind die Ahornarten reichlich verbreitet; wo sich die ursprüngliche Verteilung der Holzarten noch erhalten hat, verleihen sie dem Laubwald, insbesondere zur Zeit der Herbstfärbung, sein besonderes Gepräge. In Europa weist nur im südlichen Rußland der Laubwald noch Bestände von Ahornen anf, so wie hente noch der Zuelierahorn in Nordamerika, der Spitzahorn (Acer pietum) in (1stasien. Die wichtigsten Baumahorne zoichnen sich dadurch aus, daß ihre Blätter fünf- oder handnerrig sind; der als eigene frattung ausgeschiedene Negundo hat fiedernervige 13lätter. Iie rigentlichen Ahorne sind fast alle raschwüchsig. Ialbschattenhölzer, die bri Ungunst von Boden oder Klima zu Lichtholzarten werden. Der ihnen am besten zusagende Boden ist frisch und humuskräftig, dem Borlen der Rotbuche am meisten genälıert. Sie finden ihr Optimum im warmen Teil des Fagetums; sie betreten auch das Picetum. Ihre Ansschlagstähigliest rom stock ist nicht sehr grob und von kurzer Damer. Ihr Holz ist hoch geschätzt durch scine GleichmäBigkeit mnd seine weiße Farbe hei entsprerhender Härte, aber ohne Dauer. Ier höchste Preis, der für Holzrohware üherhaupt erzielt wird, wird für Maseranschwellungen, sngenannte Vogelangenmaser, welehe man an allen Ahornen findet, geboten. Am höchsten im Preis steht gegenwärtig die Vogelaugenmaser des Zuckerahorns. Alle thorne führen sodann im s'aft des Holzkörpers Zueker, der im Spätwinter den Bäumen 
abgezapft, einen vorzüglichen syrup und \%ucker grilst: anch hiorin steht der Zuckerahorn an erster Stelle. Die Blätter dienen zn Futterlaub. Alle unten aufgefuhrten Ahorne erreichen für forstliche Zweclie genügende Dimensionen; am seltensten wirl rin Banm zwojter GrößBo

Acer campestre (L.), Feldahorn, Mabholder. Europa.

Blätter 3-5lappig, Triebe mit Korkleisten; zwei Früchte mit den Flïgeln horizontal; liefert auch Wurzelhrut; Holz für l)rechsterwaren gesucht.

Acer Negundo (L.), Eschenblättriger Ahorn, Box Edler. Ostamerilia.

Dieser, vielfach unter dem Namen Negundo aceroides als eigene Gattung aufgefaßte Ahorn ist einer der wertlosesten, auf den aber hingewiesen werden muß, weil er in Europa am häufigsten kultiviert wirl und zwar in der Varietät; Acer Negundo pruinosum oder violaceum, eine Form mit bereiftem Trieb, welche sehr rasch wächst, wenigr Widerstandskraft gegen Wind besitzt und sehr schlechtes Holz liefert und von den Gärtnern fälschlich als Acer californicum in den Handel gebracht wird.

Acer nigrum (Mich.), schwarzer Ahorn, Black maple. Ost. a merika.

Vom Zuckerahorn, der weiter unten beschrieben, nur durch die hehaarte Unterseite des Blattes unterschieden; besitzt ähnlichen forstlichen Wert wie der Zuckerahorn.

Acer pictum (Thumb.), Itaya-Ahorn, Itaya-Kaede. Japan und China.

Dieser Spitzahorn ist in Ostasien am weitesten verbreitet und von den vielen Ahornen Ostasiens forstlich der wichtigste.

Acer platanoides (L.), Spitzalıorn. Europa.

Blätter fünfnervig. in feine Spitzen ausgezogen, beiderseits gleich grün, Blattstiel mit Milchsaft, Knospen rot: Früchte platt credrï̀lkt, Rinde eine fest anliegende Borke, vorzïghch der nördlichen Mälfte Europas angehörig. Der Spitzahorn wird ein stattlicher Bamm, doch gilt sein Holz im allgemeinen etwas wenjger gut (weili) als das des Bergahorns. Das Optimum liegt im wärmeren Fagetum.

Acer Pseudoplatanus (I.), Bergahorn. Enropa.

Blätter fünfrippig, nicht zugespitzt, nhne Milehsaft. Knospum grtï, Same dick, Blätter unterseits weißlich, Rinde in dïnnen silmplen cir h lösend. Das Fagetum der Bergwaldregion sagt dirsum Ahorn, der in Europa von allen der wertvollste ist, ganz besonders zu. lli. Juelionzone der Ebene meidet er; ar follt in Eurnpa rom ITar\% an nordwirta. 
Acerrubrum (L.), Rotahorn, Red maple. Ostamerika.

Blätter vorwiegend dreirippig, mehr durch seine Herbstfärbung als durch Wuchs und Holz bemerkenswert.

Acersacuharm (March.), Zuckerahorn, sugar maple. Ostamerika.

Von allen thornen wohl der wertvollste; dem europäischen Spitzahom im Blatt ähnlich, von diesem aber leicht durch den Mangel an Milchsaft in Blättern und Trieben unterscheidbar; Knospen lang zugespitzt. Er liefert das meiste Maserholz und in Amerika fast die Hälfte der konsumierten Süßstoffe.

\section{Gattung: Aluns, die Erlenarten, Alders, Aunes.}

I)ie Erlen sind wohlbekannte Halbbäume und Bäume mit gestielten Knospen, kleinen, zapfenförmigen Fruchtständen, welche bei trockener Witterung sich öffnen und den etwas flugfähigen Samen entlassen. Sie haben sich dadurch einen Platz in der Forstwirtschaft gerettet, daß sie aut Standorten noch gedeihen, auf welchen andere Holzarten rersagen; dieser Standort ist der nasse, moorige, sogar versäuerte und mit Carexarten bewohnte Bruchboden; ihre beste Entfaltung erlangen sie aber in sehr frischem, neutral reagierendem, lockerem, humusreichem Boden (Flußauen); von diesem Optimalboden hinweg gehen sie auch auf trocknere Standorte über, ja siedeln sich auf diesen als die ersten Holzarten mit den Birken an (Weißerlen); dafür muß größere Luftfeuchtigkeit geboten werden. Die Erlen sind zu den Halbschattenholzarten zu rechnen, welche als \%wischenpflanzen zwischen anderen Holzarten, besonders Nadelhölzern auf diese einen zuwachsfördernden Einfluß ausüben; infolge der Eigenschaft der Wurzelknöllchen, Stickstoff aus der Luft direkt aufnehmen zu können, raschwüchsig, von sehr großer Stockansschlagfähigkeit, leiden sio in den ihnen überlassenen kahlen, nassen Standorten zuweilen durch Sommerfröste. Das Holz ist weich, leicht und wird bei Berührung mit der Luft meist rot; das Holz der Weilerlen ist minderwertig. Dafür sind diese für ödlandsaufforstungen wiederum zumal wegen ihrer größeren Bescheidenheit und Wurzelbrutbildung wertvoller.

Alnus grlutinosa (Garrn.), Rot-oder Sehwarzerle. Europa.

Knospen gestielt, junge Triehe kahl, klebrig, Stämme mit schwarzbrauner Borke. A uf günstigen Standorten wird die Schwarzerle bis $33 \mathrm{~m}$ hoch; je nasser und je trockener der Standort, um so früher erlischt die Lebensdauer. Sie gehört dem Fagetum an und reicht bis ins Picetum, je nach der Bodenausformung in reinem Bestande oder in reinen Gruppen; mit anderen Holzarten in Flufanen. 
Alnus incana (Willd.). Weißerle. Wurupa.

Blätter mnterseits heller als oherseits, wit niner spitzo verselen. Stämme mit glatter, graugrünor Rincle, vorwiogrend in nirellieluen

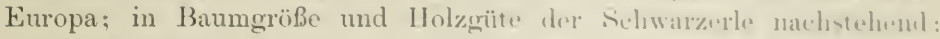
bildet Wurzelbrut.

Alnus rubra (Bomg.), amerilianischo Rotorla, Adler. Pazi fische hïste.

Ein mächtiger Baum von der Wichtigkeit uml Brelentung der Schwarzerle in Europa.

Die zahlreichen, japanischen Frlen sind von Biologie der our päischen Bamarten nicht verschieden.

\section{Gattung: Betula, die Birkenarten, Birehes, Bmuleaux.}

Den Birkenarten kommt eine große forstliche Bedeutung zu: töir jene Landschaften, welche dem Picetum angehören, sohin inslussondere im Norden der Alten und Nenen Welt müssen die Hölzer der Birk'n das harte und weiche Holz der in wärmerem Klima wachsenden Laubbäume ersetzen; das Holz hat jedoch keine Dauer, ist mittelhart, abur gut spaltbar. Die Birken sind ausgesprochene Lichtholzarten, welche mit den Erlen die heterogenen Standorte teilen: man findet sis aut nassem, selbst versäuertem Boden oft alleinherrschend, wie dies auch bei den Erlen der Fall ist, ron da an gehen sie auch auf trocknerm Gebiete über und schließlich, als letzte der Laubbäume auf d'm alogemagerten Föhrenboden wachsen noch die Birken, besonders in der Nähe des Meeres wegen der großen Luftfenchtigkeit. Ihre Frosthürte ist so hervorragend. daß sie als Schutzholzarten in kalten, sumpfigen Frostlöchern gelten. Sie streichen rom Castanetum bis zur Walderenze nach oben und nach Norden. Auf waldentblöftem Boden urscleinen zuerst Birken, da deren Sämereien außerozdentlich leicht sind und weit vom Winde getragen werden können; nackten, vom Regen er. härteten Boden besiedeln sie am liebsten: anf bearbeitetem. obertlär. lich aufgelockertem Boden geht das keimende Korn an Trascermangel zugrunde. Der Zapfen, in welchem der Samen gebilelet wird, ïflnet sich durch Zerfall des Zapfens, so daß die Zapfenspindel autrocht (ficlboder Hainbirke) oder abwärts gerichtet (Weißhirke) ïbrig hleihn. All. Birken mit weichen, dünnen, hängonden Ästen künnen wicht vin Winde hin und her bewegt werden; dadurch sind diese Birken umiuls sam gegen Nachbarn oder darmerstehende Ptlanzen. Ihre B.:- urж. lung ist seicht, weit ausgreifend. In warmen Klimatrn hurzlelugh. Bäume, welehe selten über s(1) Jahre alt werden: im kïlilen Klinu z h

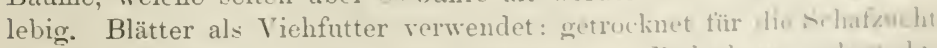
im Norden wichtig. Rinde zu Gefäßen, zur Buedaclung webraluht. Teer des Holzes zur Lederbereitung (Juchtenled.r\%) 
181 Funfter Abschnitt. Naturwisensschaftich-waldbauliche Charakteristik usw.

Betula lutea (Mich.). II a inbirke, Redbirch. Ostamerika.

Ein rrob-doppelgezähntes Blatt, eine grelbliche, lockere Papierlorke und ein braunes Kernholz charakterisieren diese hainbuchenblätricre Birke. Sie erreicht eine Höhe ron $311 \mathrm{~m}$. Sie ist nicht ein Baum der sumpfigen oder truclienen standorte, liebt vielmehr frischen, guten Borlen wie die Rotbuche.

Betula nceidentalis (Honk.), westamerikanische Birke,

Black birch. Pazifische Region von Nordamerika.

Vertritt die Weißbirke in Westamerika: die biologisehen und allgemeinen äußeren Erscheinungen sind von der Weißbirke nicht verschieden.

Betula papyrifera (Marsh.), Papierbirke, Canoe birch, Paper birch. Ostamerika.

Vertritt in Ostamerika die europäische Birke, mit der sie die gleiche Bedeutung und forstliche Behandlung teilt.

Betula pubeseens (Ech.), fla umharige Birke. Europa, Asien.

Junge Triebe flaumhaarig, Blätter etwas größer, Zweige weniger abwärtshängend; von den Alpen an nordwärts und ostwärts bis zum Stillen ()zean an der ostasiatischen Küiste.

Betula verucosa (E\%.), Warzenbirke. Europa, Asien.

Junge Triebe kahl, warzig, klebrig; Zweige im hohen Alter hängend; auf gutem Boden, besonders im Norden, im Picetum wird sie ein Baum bis zu $30 \mathrm{~m}$ mit vollendetem Schafte.

\section{Gattung: Buxus, Buxarten, Boxes, Buis.}

Immergrïne Holzarten, welehe in Lauretum zu nutzbaren Halbbäumen bis zu 2.; $m$ Höhe erwachsen: alle sind anspruchsvoll, langramwïchsig, gregen tiefe Wintertemperatur unter gleichzeitiger Besommug (Chlorophylltod, Blattbräune) empfindliche Iolzarten; im Castauetun erlischt ihre forstliche Brauchbarkeit, im Fagetum werden sio zu Ziersträuchern. Jo nrößer die Luftfeuchtigkeit, desto besser; nur anf grutem Boden wachsend: sie verjüngen sich leicht durch Stecklinge: sehattenholzarten. Las Holz ist sehr schwer, hart, gleichmäßig, gelb, das beste Matcrial für Holzschnitte; es wird nach dem fiewichte rerkauft.

Buxus microply ylla (Sieb. ct Zuce), japanischer Buehs, $\mathrm{T}$ s uge. J a pan.

Ant den sïdlichen Inseln an den dem feuchten Sïdmonsun voll ausgesetzten Gebirgshängen des Lauretums. 
Buxus sempervirens (I.), Buchs. Europaischer ()rinut Kleinasien.

Kommt in likeineren, reinen Bustänclen vor.

\section{7. (Gattung: Carpiums, Hainbuchen, Hornbeams, ( harmes.}

Nur im wärmeren Fagetum, auf frischen und gutem Buclen wordon die Hainbuchen Nutzbäume erster Giröße. Anf greingen, besonflors steinigem, kiesigem Boden der Kalktormationen bleiben die Hainbuchen vielfach unter Baungröße oder erheben sich nur zu Halhbäumen: durt aber sind sie wertvoll, weil andere Holzarten ham imstande sind, dergleichen Standorte zu bewalden. Es bedarf tür rlie Technik anch nicht starker Bäume, schon schwächere sind wegin ihres auBerordentlich harten und festen, brennkräftigen Holzes selir gresucht. Iie Hainbuchen sind sehr raschwïchsige Halbschattenholzarten, welehe in den Jahresringen des Holzkörpers und im ganzen Baume statt des annähernd kreisförmigen einen welligen Verlauf zeigen (spamnrückiges $\mathrm{Holz}$ ); dem Holze fehlt der gefärbte Kern und damit auch die Jauer. Allen Hainbuchen kommt eine außerordentlich große Stockausschlarfähigkeit und eine auffallend große Frosthärte zu. Die Blätter sind wertvolles Viehfutter. Das Blatt buchenähnlich, aber mehr gezähnt, die Blattfläche wellig, Knospen am Triebe anliegend. Die Frucht eine harte, gerippte, flachgedrückte Nußs in einer dreitciligen Fruchthülse; Samen dadurch in beschränktem Grade flugfähig: wemn frisch im Herbste ausggesät, keimt er im nächsten Frühjahr: wenn er austrocknet, liegt er ein ganzes Jahr im Boden, ehe er keimt.

Carpinus americana, amerikanische Hainbuche. Hornbeam. Ostamerika.

Wie es scheint, in allen Eigenschaften, mit Ansmahme der systo. matischen, der europäischen Art gleich.

Carpinus Betulus (I.), Hainbuche, Hornbaum. Weibbuche. Europa.

Über ganz Europa, soweit Castanetum und Fagetum: cin kir\%lebiger Baum, der zumeist in den modernen, geschlossenen In hwaldungen mit langem Antrieb nicht geduldet wird, weil er dureh wn allzufrühes Absterben den Bestand durchlöchert: dafs clie Bärme wh nicht nach der Wirtschaftsform, sondern umgekehrt dis se sich nach ten Bäumen zu richten hat, soll später gezeigt werden: der Honulaum ver tritt stellenweise die Buche.

Carpinus laxiflora, edö̈nsis, tordata sind japanische Hainbuchen mit der wleichen Biologr der wanzon Gattung. 
1s8 Funfter Abschnitt. Naturwissenschaftlich-waldbauliche Charakteristik usw.

\section{2จ. (Gattunュ: ('arya (Hicoria), Hickoryarten, Hickories.}

Fiederblättrige Bämme, zur Familie der Walnußarten (Juglans) gehörig und deshall, in Katalogen noch vielfach unter dem Namen Juglans zum Verkaufe angeboten; von den Walnußarten durch eine solide, nicht gefïcherte Markröhre sofort unterscheidbar. Die Nüsse liegren über, wemn sie erst im Frühjahr in die Erde gebracht werden. Die wertrollsten Hickorys sind alle bis zum zehnten Jahre langsamwüchsig, ertragen mäßige Beschattung, verlangen sie aber nicht, soweit geneigtes Gelände im Castanetum in Frage kommt. Auf ebenen Flächen und vor allem im Fagetum ist ein lockerer Schutz von Lichtholzarten gegen Früh- und Winterfröste erwünscht. Vom Fagetum können nur die wärmeren Standorte den Hickories entsprechen. Nur auf dem besten Boden, der dem Walde zur Verfügung steht, ist rasches Aufwachsen zu Baumdimensionen zn erwarten; ihre starke Stockansschlagfähigkeit ermöglicht einen Ausschlagbetrieb, in dem das Material zu Reifen, Griffen usw. gewomnen werden kann. Das Holz ist das beste aller Laubh ̈̈lzer der gemäßigten Zone, wenn von der Dauer abgesehen wird. An Elastizität wird es von keiner winterkahlen Baumgattung übertroffen.

Carya alba (Nutt.), (Hicoria orata [Britt.]), Weife Hickory, Shellbark Hickory. Ostamerika.

Die weike Hickory ist woitaus die wichtigste von allen Arten: F ïnf Fiederblättchen bilden das Blatt; die drei obersten Blättchen sind die größten; beiderseits kahl; Blattzähne behaart. Sie wird über $30 \mathrm{~m}$ hoch, bei der Verwendung zu Wagnerholz bleibt der spät anftretende, braune Kern außer Beachtung. Nuß mit 4-6 Kanten, Frucht in der grünen Schale aptelförmig.

Carya porcina (Nutt.), (Hicoria glabra [Britt.]), Pignuthickory. Ostamerika.

;-i Fiederblättchen. Frucht mit vier Rippen: wemn von der grünen Hülle umgeben, birnenförmig. Diese Art ist minderwertiger als die vorige, wird auch auf etwas weniger gutem, doch immerhin noch gutem Boden getunden; wie die vorige auch noch im wärmeren Fagetum kultivierbar.

Caryasulcata (Nut.), Großhickory, Big shell-bark Hickory. Ostamerika.

Mit $\mathbf{\imath}$ !) Fiederblittchen; eine sehr raschwüchsige Art, welche nur für das Castanetum als Nutzbaum in Frage kommt.

\section{Gattung: ('astanea, Edllkastanie, Chesnuts, Châtaigniers.}

Grofe, grobgezälnte Blätter, die Frïchte in einer stacheligen Hülle eingeschlossen. Die Edelkastanien stehen sich systematisch sehr nahe, 
so daß lange der Streit bestand, ob die anerikanischen, europiaisehen und asiatischen Edelkastanion nicht identische Irten seien. Jie Eilel kastanien sind durch ihr Vorkommen in oiner gan\% lustinuten hilima lage die besten Wegweiscr für das botroflindo Klima sellst: sie reichen bis an das Lauretum, und wo die Buche aufzutreten leginnt, verschwinden sie wiederum, weil es ihnen zu lialt ist. His zwischen diesen heiden Irenzen liegende Gebiet umfaßt die ganze wärmere Hältte des I anuh. waldes der nördlichen Halbkugel, das deshall, auch na.h der Fin]. kastanie das Castanetum genannt wrole: nach ler kïhleren suite hin schlicft sich das Fagetum an. Das klimatische O'ptimum dor Fill.1kastanie ist selbstredend im Castanctum selbst. Allo Erlelliastini-n lieben frischen, tiefgründigen, lockeren Boden; kieselsäurureher Budın wird dem kalkreichen vorgezogen. Sie ertragen anch trockencn Budin, wie sie auch neben Gebieten mit hoher Iuftfeuchtigkeit solche mit raschwechselnder Luftfeuchtigkeit bewohnen; sie sind ziemlich raschwïchsige Holzarten, in ihren besten Wuchsgebieten Halbschattenholzarten, die im kïhleren Teile ihres Verbreitungsgebictes und vor allem auferhalb desselben, im wärmeren Fagetum angeptlanzt, zı aısgesprochenen Lichtpflanzen werden. Mit tiefen Herzwurzeln in den Boden dringend, sind sie sturmfest; eine sehr hohe Stockausschlagfähigkeit befähigt die Kastanie zu einem Niederwaldhetriebe. Anßrrhalb ihrer Heimat bleibt die Kastanie eine vom verfrühten Froste und ron tiefer Wintertemperatur gefährdete Holzart. Ihre Kultur gilt wicht blof den elßbaren Früchten, sondern anch dem Holze, das in suiner bramnen Farbe und seinen sonstigen Eigentümlichkeiten, in I)aner, Hïrte und Verwendung dem Eichenholz sehr nahe kommt. Anch das Laubwrk wird verwendet als Futter. Die nicht veredelten, wildwachsenden, typischen Edelkastanien haben wenig Feinde: nur der M[ensch verstümmelt sie der Frïchte halber anf die grausamste Weise.

Castanea crenata (Sieb. ct Zucc.), japanische Eclelliastanie. Kuri. Japan, China.

Blattstiel anfangs starkfilzig behaart, Blatt unterseits etwas haller als oberseits. In Japan und China vielfach sogar dem Eichemhol\%: vorgezogen.

Castanea dentata (Borlih.), amerikanisclue Erlelkastaric. Chesnut. Ostamerika.

Blätter mit starken Zähnen. Blattstiel stets kahl. In allen Bucziehungen mit den übrigen Edelkastanien anf das niich-to verwands.

Castanea vesca (Gaertn.), enropäischo Euclkastanic. sind o $u$ ropa.

In der Schweiz hat Engler nachgewiesen, dafo dims Art mu wimign stellen die Hauptkette der Alpen nach Norden hin ant watiolichem 
Wege ïberschritten hat: Gleiches ist in Frankreich der Fall; im Walde selbst ist die Erlelkastanie ein seltener Baum greworden; auf künstlichem Wege ist die Edelkastanie in die wärmsten Gebiete nördlich der Alpen eingeführt worden: dies ist der Fall in Mittel- und Westfrankreich, in England, in der Rhein- und Mainebene und an anderen Orten.

\section{Ciattung: ('atalpa. 'Trompertenbaum.}

Alle dieser Gattung Angehörigen sind etwas schattenertragende, frischen, guten bis mittelguten Boden beanspruchende, sehr raschwachsende Holzarten, welche ganz dem Castanetum angehören. Werden sie außerhalb desselben liultiviert, sehen wir sie wegen späten Vegetationsabschlusses durch verfrühte Fröste oder durch Winterfröste zurückgesetzt: die Trompetenbäume haben ein dunkelgrau gefärbtes, ziemlich leichtes Kernholz, das eine außerordentliche Dauer besitzt und eine vielfache Verwendung im Boden findet; dabei ist mit Ausnahme des letzten Jahresringes der ganze Holzkörper Kernholz; die wichtigste Art scheint

('atalpa speciosa (Ward.), westlicher Trompetenbaum. Western Catalpa. Ostamerika

zul sein. Das große Blatt läuft in drei Spitzen aus. Auf dem frischen Boden der Flußauen bis $45 \mathrm{~m}$ hoch. Vielfach wird der Baum wegen seines hohen Wertes in Amerika angebaut, aber wegen der starken Neigung zur Astbildung in engen Schluß gebracht.

\section{Gattumg und Art: Cercidiphyllum japonicum (Sieb. et Zucc.). Kíchenbaum, líalsura. China, Japan.}

Blätter des einjährigen Triebes länglich, des zwei- und mehrjährigen mehr kreisrund, gekerbt mit rotem Stiele; Kurztriebe der zweiund mehrjährigen Zweige ebenfalls nur e in Blatt tragend; der Kuchenbaum ist eine raschwïchsige, lichtbedürftige Holzart, welche guten und frischen, besonders Flußauenboden verlangt. Er wird bis $30 \mathrm{~m}$ lıch und liefert ein zu schachteln, Kuchenblättern sehr gut verwendbares, leicht zu bearbeitendes, dabei anch dauerhaftes Holz; der Baum besitzt große Stochausichlagfähigkeit, gehört aber dem Castanetum an, so daß er in wärmsten Tale des Fagetums bereits mehrfach durch verfirihte oder Winterfriste zuriteligesetzt wird: mit 2 m Höhe ist die schlimmste Getalır vorüber.

\section{Gattung und Irt: Cimmamommu Camphora (Vees.), Kampfer-

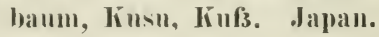

Dieser Baum grohort ganz dem I, auretum an. Eine raschwüchsige, sehattenertragende Holzart ant gutem Boden: ihr höchster 
Wert besteht in einem kampfereichen und dahei suln danerluates. Holze.

\section{Gattung und Art: ('ladrastis ammensis (III).). Malchir.

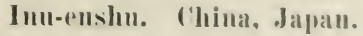

Die umparig gefiederten Blätter unterseits schwach hohart. junge Blätter silberweiß behaart. Ein Baum dos C'astanetmus mul facretum. Das Optimum liegt auf dem Übergangsgobiete ler boiden Zonen. Der. Baum ist anch auf geringem Boden heimisch. doch verlangt pr Frische: das sehr wertvolle, brame Kermholz ist von grober Daner und silurin. heit; der Splint sehr schmal.

\section{Gattung: Fagus, die Buchenarten, Berehes, Hetres.}

Die Gattung enthält nur wenige Arten; die einzelnen Artun aher verdrängen durch ihr intensives Schattenerträgnis und dement:_prochnd auch Beschattungsvermögen alle anderen Holzarten und bilden deslıall, weitausgedehnte, reine Bestände in Amerika, Asiən und Europa: in allen drei Weltteilen herrschen sie in der kühleren Hältte des blatt. abwerfenden Laubwaldes; sie erscheinen mit dem Terschwindis der. Edelkastanien und verschwinden mit dem Erseheinen der Fichten hzw. Tammen; dadurch werden sie zur typischen Holzart einer bestimmten Klima- oder Waldzone, welche nach den Buchen „Fagetum" genamt wurde. Alle Buchen verlangen guten, frischen, tiefiründigen, kalkreichen Boden zur vollendeten Entfaltung: sie ertragen noch humosen Sandboden mit Grundwasserbefeuchtung sowie seichten Kalliboden (Kalkplatten); da die Buchen allen Unkrautwuchs erclrücken, sn zeigt der Boden in Buchenwalde die günstigste Verfassung: frisch. krimelin. humos, selten unreife Humusmassen. Hierin liegt der hohe wallhanliche Wert aller Buchen. Auf kahlen Flächen. insbesondere in Mulden. sind sie von verspäteten Frösten belästigt: unter Schirm fällt Front im Frühjahre weg, dafür sind aber die Buchen dann langsamwür/hig: freigestellt hebt sich ihr Wruchs sehr rasch, so daß sic allen heigemischten Bammarten gefährlich werden kömnen. Den waldbanlichen Torzügen bezüglich des Bodens stehen forstlich-technische Niahteil. gegenüber: das harte, schwere $\mathrm{Holz}$ mit seinen feinen (infiifen (Poren) ist zwar vorzüglich als Bremnolz, ist aber als Nutzholz nur in grermurer Ienge und nur in den besten Qualitäten wut verwertbar. Ex firhll der Rotbuehe die normale Kernfarhe, daher tehlt anch die Tiner: mit tem Auftreten des roten oder falschen herns rom rund humlen-ten Jabre an wird der Gebranchswert des Holzes heeintrïhtigt. Jiw Buten besitzen geringe Stoekausschlagfähigkeit: ihr Laul, ist al- Walletreu

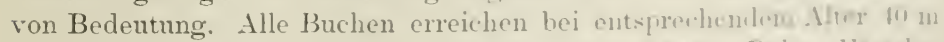

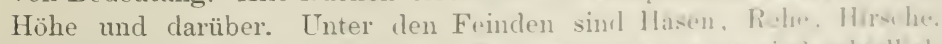

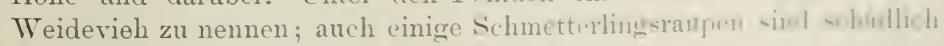


geworden: scln empfindlich sind die glattrindigen Buchen gegen die Besonnung (Rindenbrand), insbesondere wenn bisher in Schlusse stehencle siämme plötzlich der vollen Śonne preisgegeben werden; ant s'ichtgrïndigem Boden mit kiesiger Unterlage, auf Felsplatten. ant einer (irundwasserschicht rermögen die in die Tiefe suchenden Herzwurzeln die Buchen nicht gegen Sturm zu sichern; Schnee kamn verderblich worden, da viele der jüngeren Buchen während des Winters inre dürren Blätter behalten.

Fagus ferruginea (Ait.), amerikanische Buche, Beech. Ostamerika.

Blätter in eine längere Spitze ansgezogen als wie bei der europäischen Art, kräftig gezähnt; Rinde frühzeitig eine schuppige Borke.

Fagus japonica (Max.), japanische Buche, Inubuna. Japan.

Nur in der oberen Hälfte ist das Blatt schwach gezähnt, Früchte langrrestielt.

Fagus Sieboldii (Endl.), Siebolds Buche, Buna. Japan.

Das Blatt an Rancle weit gekerbt, lange Zeit die kräftige, seidenglänzende Behaarung festhaltend. Auffallend ist, daß in Japan jener Teil des Holzes als wertvoll gilt, der in Europa als der wertloseste angesehen wird, das ist der rote, falsche Kern. Ihm wird grofe Dauer und Beständigkeit gegenüber den Einflïssen wechselnder Luftfenchtigkeit und Temperatur zugeschrieben, so daf er absichtlich, kïinstlich, durch jahrelanges Einlegen in Wasser hervorgerufen wird.

Fagus silvatica (1.), europäische Buche. Europa.

Blätter ganzrandig, zuweilen in der oberen Hälfte gezähnt. Über yanz Europa, im Süden bei entsprechender Erhebung, verbreitet, soweit das Fagetum selbst im Klima vorliegt. Demnach fehlt die Buche im mittleren Sichweden, Norwegen, Fimnland sowie bei holer Elevation, wo Fichten auftreten.

\section{Gattung: Fraxinus, Eschenarten, Ashes, Frênes.}

Blätter gefiedert; Same plattgedrïckt mit Flïgolrand, nu bei stärkerem Wincle auf größere Entfernungen wie die Ahorn- und I.indensamen flugfähig. Wenn sofort nach der Reife ausgesät, keimt der same im nächsten Frühjahre; in andern Fall liegt er über. Die Eschenarten gchören sowohl dem Castanetum als dem Fagetum an: rerade die wichtigsten, dio Weißeschen, besitzen ihr Optimum auf dem İbergangsgebiet rom Castanetum zum Fagetum, sio dringen sogar bis in das wärmere Picetum vor. Bei tiefen Winterfrösten platzen ihre ștämme auf; bei sehr verspäteten Frösten, besonders auf den nassen 
Böden, leiclen sie im Frühjahr wie im Herbst und Winter: selhst Sommerfröste sehaden im Jahresringe. Inshesondere ist hierin das Verpflanzjahr, wie bei allen Holzarten, gefährlich. Ine lischen lieben sehr guten, frischen his fenchten Boden mit rascher brusuermer des Wassers, sei es durch oberirdisehe Zufuhr, sei es unterirlisch durh Infiltration von benachbarten Flußläuten (Aneboden); bei stagnierender Nässe noch gut, wenn keine Versänerung des Bodens rintritt, wenn Torfbildung unterbleibt (Erlenbruchboden); dio Eschen sind schnell.

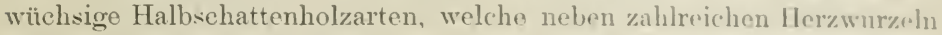
in die Tiefe eine Unmenge von feinen Wurzehn flach uncl weitansgreifend in der ganzen Umgegend umhersenden; sio erschiopton anliegende Gelände ähnlich wie die Pappelarten; hohe stockansschlangfähigkeit; Bäume bis $40 \mathrm{~m}$ Höhe und darüber, vom Wilde und von Jäusen stark verbissen. Das Eschenholz ist dureh seine hervorragrende Elastizität nur mit dem Hickoryholze vergleichbar, mit dem es anch den Nachteil, nämlich den Nangel an Daner, teilt. Splint breit, Kern bräunlich: bei der Verwendung zu Wagnerholz ist der Splint durch seine helle Farbe wertvoller als der Kern; kleine Mengen von Eschonhölzern sind sehr hoch im Preis; aber die Nachfrage nach Eschenhölzern wird schon mit geringer \lenge befriedigt; große Mengen sinı nur ein wertvolles Brennholz: die Blätter sind als Futter verwertbar.

Fraxinus americana (L.), Weibesche, White Ash. Ostamerika.

T Fiederblättchen, das Endblatt ist das größte von allen, Blättcr unterseits hell; Knospen rost-, Rinde frühzeitig ockerfarbig. In spätfrostlagen wird diese Esche, weil sie später in Vegetation tritt, mit Vorteil angebaut.

Fraxinus cinerea (Bose.), Grauesehe ist entweder alba oder pubescens.

Fraxinus excelsior (I..), europäische Esche. Eurnpa.

Knospen schwarz, Triebe grangrün, Fiederblättchen ober- und unterseits gleichmäßig grün; über den größten Teil Europas und den Kankasus: verbreitet.

Fraxinus mandshurica (liup.), mandschurische Escche, Yachidamo, Shioji. China, Japan.

Blättchen unsymmetrisch, Knospen mattviolett bis schwarygrün. Ein mächtiger Nutzbaum mit sehr raschem Wuchse.

Fraxinus Oregona (Nutt.). ()regonesche, Oregon $A ;$ h. Westamerika.

Diese westamerikanische Vertreterin dieser Gattung glcicht mit mehr ovalen Fiederblättern etwas der Blumenesche Europas; FiederMayr, Waldbau. 
blättchen schwach gekerbt oder ganzrandig. Knospen gelbrot, sehr raschwiichsig.

Fraxinus pubescens (Lamb), Rotesche, Red Ash. Ostamerika.

Junge Triebe, fertige Blattstiele und Blätter unterseits weich behaart; Knospen hellbraun; ein mittelhoher Baum, der auch auf geringerem Boden in Amerika noch aufwächst.

\section{Gattung: Gleditschia, Gleditschien, Christusdorn.}

Die Christusdornen zählen zu den Papilionaceen; sie sind in Europa gar nicht, in Amerika in einigen, in Ostasien (besonders China) in großer /ahl ron Arten vertreten; der Nutzwert des Holzes dieser Bäume, obwohl hart und schwer und wegen des rötlichen Kerns von ziemlicher Daner, ist nirgends hervorragend. Nenerdings nimmt ihre Wertschätzung zu, da die wertvolleren Hölzer seltener werden. Sie gehören ausschlieflich dem Castanetum an; je weiter man beim Anbau in das Fagetnu vordringt, desto größer wird die Gefahr durch verfrühte oder durch Winterfröste, welche einen Teil des unfertigen Triebes alljährlich töten. Wo diese Gefahr gering ist oder ganz wegfällt, wachsen die Gleditschien sehr rasch; sie verlangen volles Licht, können aber als schmetterlingsblütige Gewächse noch auf geringerem Boden kultiviert werden; das Blatt zierlich, doppelt gefiedert, starke Äste und der Stamm selbst mit großen Dornen bewehrt.

Gleditschia japonica (Miqu.), japanischer Christusdorn, Saikachi. Japan.

Junge Blätter werden gegessen.

Gleditsehia Triacanthus (L.), amerikanischer Christusdorn, Honey-Loeust. Ostamerika.

Erreicht in Flufanen bis $40 \mathrm{~m}$ Höhe.

\section{3i. Gattung und Art: Gymmocladus dioica, amerikanischer Schusser- baum, Kentucky Coffee-tree.}

Doppelt gefiederte Blätter, einjährige Triebe weißbereift mit zahlreichen, korkigen Lentizellen versehen; raschwüchsige Lichtholzart, welche auch auf geringerem Boden vorkommt, aber wohl nur in Castanetum forstlichen Wert erreicht. Da sie frosthärter als die Gleditschien sind, wäre der Anbau auf geringeren Böden im Fagetum vielleicht noch lohnend, demn das Holz hat einen bramen, harten, daverhaften Kern.

\section{Gattung und Irt: Horenia dulcis (Thumb.), Quaffbirne, Horenie, líenponashi. (hina, Japan.}

Das breitlanzettliche Blatt ist fein gesägt; im Blattgrunde bilden Seitenrippen die Begrenzung desselben; der Baum wächst im Casta- 
netum auf gutem Boden, verlangt Licht unı gil,t ein vorzügrliches schönes, rotes Kernholz.

\section{Gattung: Juglans, Waluufarten, Walunts, Noyers.}

Fiederblättrige Bänme mit aromatischem (ïle in dun Blättern und Schalen der Früchte; Narkröhre der Zweige gefïchert. Alle Ninßarten geben ein hochwertiges Nutzholz, das durch leichte Brarbeitungsfahig. keit, gleichmäßigen Aufbau und schöne Farbe des licrnes anvermeichnet ist. Maserbildungen stehen sehr hoch im Preisc. Das (1)timum aller Nußarten liegt im Castanetum auf gutem Boden, wo dic Nubarten anch reine Bestände bilden; im Boden muß Kalk sein. Sie wachsen rasch, mit einer Pfahlwurzel in die Tiefe dringend. Am besten redeihen sie im vollen Lichte, wenn nicht zum Schutz gegen Früh-unıl Winterfröste in der .Jugend etwas Schirm gegeben werden muß. Auch im Eichenklima des Fagetums wächst die Walnuß noch zum wertwollen Nutzbaume heran.

$$
\begin{gathered}
\text { Juglans cinerea (L.), graue Walnuß, Butternut. } \\
\text { Ostamerika. }
\end{gathered}
$$

Blättchen oberseits wollig, unterseits auch drüsig behaart. Yan rühmt der Graunuß eine größere Bescheidenheit und Frosthärte nach: allein ihr Holz ist wegen geringer Farbgüte dem Holze der ührigren Walnußarten unterlegen.

Juglans mandshurica (Max.), Mandschureiwaluuß. Japan und China.

Mit sehr großen Blättern und rotgranem Kernholze.

Juglans nigra (L.), schwarze WalnuB, Black Walnut. Ostamerika.

Fiederblätter nur unterseits schwach behaart. Früchte mehr kugelig. Rinde frühzeitig eine fast schwarze, kleinschuppige Borke. Kern braun bis violett.

Juglans regia (L.), europäische Waluuß. Süidosteuropa b is China.

Jede Behaarung fehlt, das Endblättchen des Fiederblattes am größten. Kernholz unregelmäßig geflammt, hellbraun bis violett: im Kaukasus in reinen Beständen von größter Ausdehnung vorhanden.

Juglans Sieboldiana (Mux.), Siebolds WalnuB, () ni-gurumi. J a p a 11 .

Diese Art besitzt die längsten Blätter und grölten 13littchen von allen bekannten Walnußarten; sie übertriftt deshalb im Zierwerte alle anderen; Blättchen beiderseits weich, wollig behaart: Knospen groß, 
hellockerfarhig. Ïbertrifft an Raschwïchsigkeit und Frosthärte die amerikanirchen Walnüsse.

\section{0. (iaftung und Irt: Liquidambar styraciflua (L.), Sweet gum. Ostamerika.}

Blätter dem Ahorn ähnlich. fünflappig mit scharfer Spitze und Sägezähnchen: junge Triebe mit Korkwarzen und Korkleisten. Der raschwïchsige, lichtliebende Baum erreicht sein Optimum auf den nassen, nicht rersänerten Böden des Castanetums und Lauretums: nur im wärmsten Teile des Fagetums kann der Baum anf frischen, nicht nassen Böden noch Fuf fassen: das Holz ist sehr wertroll und kommt in großen Mengen unter dem Namen Satinholz nach Europa: wenn die prächtige Herbstfärbung nicht rechtzeitig eintritt, droht die Gefahr einer Beschädigung durch Herbst- oder WTinterfröste.

\section{Gattune und Art: Liriodendron tulipifermm (L.), Tulpenbaum, Tulip-tree, Yellow Poplar. Ostamerika.}

Das rome fast gerade abgeschnittene Blatt ist so auffallend, daß eine Verwechselung mit anderen Baumgattungen fast ausgeschlossen ist: Endknospen von zwei großen Nebenblättern bedeckt. Der lichtverlangende Baum wächst nur auf gutem und frischem Boden. vor allem in Flußauen, engen Tälern und frischen Talsohlen, wo ja sämtliche Laubhölzer die günstigsten Wuchsbedingungen genießen; auf sonnigen, warmen Hängen versagt er oft, weil der Boden, mag er mineralisch noch so liäftig sein, ungenügend frisch erhalten wird. Verpflanzt man den Baum in nasse Standorte, verlangt er ein wärmeres Klima, d. h. Annäherung an sein Optimum, das im Castanetum liegt; clort wird rer Baum bis $60 \mathrm{~m}$ hoch mit pfeilgerarlem schafte; er hält aber im Eichengebiete des Fagetums noch sehr wohl aus, wemn auch sehr ïppige Pflanzen hier und da ihre Spitzen in Winter verlieren. Der schönschaftige und schönlaubige Baum ist forstlich ziemlich wertvoll durch sein fein gefügtes, ziemlich leichtes und weiches Holz, das dem der Magnolien am nächsten kommt und mit diesem die Ständigkeit, das geringe Werfen und sehwinden teilt. Es kommt als „amerikanisches Pappelholz" in Blöcken und Brettern nach Europa.

\section{4:. (iattung: Magnolia. Magnolien.}

Selbstverständlich ist diese Gattung nicht aufgeführt wegen des allbekannten Zierwertes, den sie für Garten- und Parkanlagen besitzt - denn die allgemein kultivierten Ziermagnolien sind forstlich wertlos -, sondern wegen ihrer forstlichen Wichtigkeit und zwar in der natürlichen, wildwachsenden Form; sie erzeugen ein Holz von schwachnlivenfarbigem Kern, mittelhart, leicht, unter dem Einflnsse wechselnder Luftfeuchtigkeit sehr stetig und deshalb zu Möbelunterlagen, Lack- 
waren, Zeichenbrettern, Schwerticheilen gl,ich vorzüglich greeignet. Ein solches Holz fehlt dem europäischen Wvald. vollständig. I) Magnolien beanspruchen guten Boden, volles licht und gröbere Boden. frische (Buchenboden, Eschenboden): anf geringerem onlor trockenrm Boden, z. B. Südhängen, ist ilı Wuchs träge, auf zusagrnden Boden und passendem Klima wachsen sie rasch; ihr (1) timum ist das ('astanetum, einige, gerade die forstlich wichtigsten, betreten anch noch das wärmere Fagetum, wo sie, auf eine absolut kalıle Flächo ausgeptlanzt. durch Zurückfrieren leiden. Ihre Stockausichlagfähigkeit ermöglielst einen Niederwaldbetrieb und die lIeranzucht von nenen PHanzen. wo. von bei der künstlichen Verjüngung die Rede sein wird.

\section{II agnolia hypoleuca (Sieb et Zuec.), Homagnolio, Ho. China, Japan.}

Diese Art ist die forstlich wertrollste von allen Magnolien, kommt somit für den Waldbau allein in Frage; die mit rotem Fruchtfleische bedeckten Samen in zapfenartigen Fruchtständen. Um die Keimfähigkeit zu erhalten, empfiehlt es sich, die samen in den Kapten, und dieso in Kohlempulver verpacht, zu versenden. Das Blatt ist das größte (bis 1),ri m lang). welches ein Baum der gemäBigten, blattwechselnden (rewächs. zone bildet: ganzrandig, oben mattgrün, unterseits weißlich. Knospen langgestreckt, violett. Nur im Verpflanzjahr ist ein Zurückfriermu zu fürchten; es empfiehlt sich, in diesem. Jahre einen besonderen, in den übrigen Jahren nur einen mäßigen Schutz zu geben, den man anderen Holzarten, wie den Eichen, auch zuteil werden läßt. Iie Homagnolie wird ein Baum von $30 \mathrm{~m}$ und darüber mit heller, glatter Rinde, buchenähnlichem Schafte und bei geeignetem Schlusse mit vollkommener Ast reinheit.

\section{Gattung: Ostrya. Hopfenbuchen.}

Blätter hainbuchenartig: Fruchthülle das Samenkorn blasenfürmig umgebend; dem Castanetum und Fagetum angehöriger Baum ron geringer forstlicher Bedeutung. Nur Ustrya japonica (Sary.), die japanisch h. Hopfenbuche, Nanakamado, wird nach den Untersuchungen dos Ver fassers im Fagetum noch ein hoher Baum mit einem Holze, das dem der Pyrusarten in allen Eigenschaften gleicht; die Art verlangrt muten. und frischen Boden; die europäische Hoptenbuche Ustrya carpinitolia (Scop.) ist nur ein Halbbaum.

\section{H. Gattung: Pasania. Immergrüne Kastanieneichen. Pasanien.}

Früher wurden diese Bäume immer Qnereus genannt. chw dil dw. Anatomie des Holzes und der Frucht sie von dieser Gattung trennen muß. Immergrüne Bäume des Lauretums mit hartem, schwerem, elastischem, dauerlosem Holze; Früthte meist guneßhar: Mhatteh. ertragende Bäume, auf gutem Boden ziemlich raschwïchrig, für welche 
in Europa nur die Heimat der Quercus Ilex und die warmen Gebiete am Atlanticchen Ozean in Frage kommen kömen.

Pasania cuspidata (Oerst.). Pilzpasanie, Shii. Japan.

Als Niederwaldbaum in Japan zur Gewinnung von Prügelholz für dic Pilzkultur (Agaricus Shitake) behandelt.

Pasania densiflora (Oerst.), Gerber-Pasanie, Tanbarkoak. Kalifornien.

Ebenfalls nur dem Lauretum zugehörig, immergrüner Baum mit borstigen Fruchtbechern und hohem Gerbstoffgehalt der Rinde (17\%).

\section{5. (xattung und Art: Paulownia imperialis (sieb. et Zuce.), Paulownie, Kiri. Japan und China.}

Wegen großer, herzförmiger Blätter mit ungleich großen Zähnen und weicher Behaarmng. wegen der violett gefärbten, glockenförmigen Blüten ist der Baum als Ziercle längst nach Europa gebracht; er ist anch forstlich von Bedentung wegen seiner außerordentlichen Schnellwïchsigkeit und seines außerordentlich leichten Holzes; der Gedanke, daß bloß schweres und hartes Holz wertvoll ist, ist ja nicht richtig. Gerade durch seine Leichtigkeit, die es für eine Reihe von Gebranchszwecken passend erscheinen läßt, ist es so wertvoll. Im Stockansschlagbetriebe ist der Baum mit zehn Jahren ein Nutzbaum, der Brettware gibt. Seine Heimat ist das Castanetum, der gute, frische Boden; nur in den wärmsten Lagen des Fagetums noch von forstlicher Bedeutung.

\section{Gattung und Art: Phellodendron japonicum (_/a.x.), japanischer Korkhaum, líwada. Japan.}

Das Blatt gefiedert, am Rande mit (̈ldrüsen, die auch am Blattstiele und jungen Triehe sitzen und einen unangenehmen Geruch beim Zerdrücken von sich geben. Den Baum kennzeichnet eine überaus weiche, dicke, hellgrane Korkbildung; aus diesem Grunde empfiehlt der Verfasser den Baum seit 15 Jahren für Europa zum forstlichen Anban. Wieweit der Kork benutzt werden kann, und ob er nach der an den Korkeichen üblichen Methode gewonnen werden kann, müssen natürlich Versuche feststellen. Aber selbst wenn die Korkgewimumg versagen sollte, wäre der Baum als forstlicher Nutzbaum zu bezeichnen durch sein Holz, das dem der Edelkastanien (Castanea) in Anatomic, Kernbildung, in Wert und Verwendung gleicht. Der Baum gehört dem Castanetum an und betritt noch das Fagetum, ist lichtbedürftig und raschwïchsig. In der Heimat wird der Baum bis $30 \mathrm{~m}$ hoch.

\section{ti. (iattung: Pirms und th. fiattung: Sorbus. Birn-, Aptel- mnd Vogelherebiume.}

Bei der geringen forstlichen Bedentung dieser Bäume und ihrer großen Ähnlichkeit in Holz und waldhaulichem Verhalten können beide 
Gattungen zusammen besprochen wrolen. Alle Angohirigen der heidin Gattungen sind Bäume mit den gleichen Antordormugenn an Klina und Boden wie die Buche. Sio funden norh im waineren Furetum ihr Optimum. Alle sind Halbschattenholzarten: ihr Wert in wallhanlicher Hinsicht, z. B.' der s'orbusarten im Picetum, ist erribler als fencr, den die Bäume durch ihr Holz goben, das mur den Vorzug geringen WTerfens und Schwindens besitzt.

Pirus eommunis, diewilde Birne. Enropa.

Nebenzweige in scharfe Dornen endigent; Blittror meist kahl, ebenso Triebe und Knnospen; Iolz mit rötlichrm Kurn.

Pirus Malus (L.), der wilde Apfel. Europia.

Nebenzweige in dünne, eine $K$ nospe tragendus sitzen endigend. Triebe, Blätter and Knospen behaart. Ilolz mit vinlettrotem Kern.

Pirns ussuriensis (Maxim.), (sinensis), chinesische Birnu. Ostasien.

Ein sehr stark wachsender Birnbaum mit großen, sehr spitzigr zu. laufenden Blättern; als Waldbaum anscheinend besser als der curopäische.

Sorbus aucuparia (L.), Vogelbeere. Europa.

Blätter gefiedert, Früchte in Dolden, scharlachrot; forstlich wertvoll als Schutzpflanze des kühleren Picetums; die amerikanisc. lo Vogrel. beere ist Sorbus sambucifolia.

Sorbus domestica (L.), Sperberbaum, Speierling. Sï dë europa.

Blätter der vorigen Art ähnlich, Früchte grïßer, grenießhar: dem Castanetum und wärmsten Fagetum angehörigr: als Oberholz im Mittelwalde brauchbar.

$$
\text { Sorbus Mrabei (Mayr) }
$$

tritt im Fagetum Nordjapans besonders anf Eson in recrelrentell, reinen, den Buchen sehr ähnlichen Beständen aut.

\section{9. (Gattung: Platanus, Platanen, Plane-trees.}

Die Platanen sind nicht blok allhekamnte Kierbämme, sie verdienen auch durch ihr waldbauliches Verhalten und iln Holz eine tor-tiche Beachtung. Das Holz, von zahleeichen, kirätigren Markistrahlen dureli-

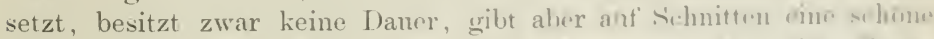
Textur; das Holz wirtt sich stark. Die. Platanen gehoren dem Canta netum an: in liesigen Flubauen stellen sie sich als woto Holzart mach Überschwemmungen orler auf Nenlandbildungen ein, Lichthotzarten, die sehr rasch wachsen mul keine Feinde unter den Tienen zu hesitz'n ar-heinen. 
Platanus occidentalis (I.), amerikanische Platane, Plane-tree, freomore. () st tamerika.

Plat anus orientalis (L.), orientalische Platane im europäischen Orient.

\section{Gattung: Populus, Pappelarten, Poplars, Peuples.}

Als frostharte Lichtholzarten von schuellstem Wuelise finden und verdienen die Pappeh auch forstliche Beachtung. Der Markt für die Aufuahme des sehr leichten, weichen, zähen Holzes ist in Zunahme begriffen. Der Boden jedoch muß gut und ganz besonders frisch sein; er darf auch feucht sein, wem die Feuchtigkeit sich rasch erneuert (Flußauen); die Pappeln sind in ihrem Schatte von einem schlimmen Feinde, dex Raupe von ('ossus ligniperda, bedroht, welche die Stämme so durchlöchert, daß sie absterben: allen ist eine außerordentliche Stockausschlagtähigkeit und Wurzelbrutbildung eigen; durch letztere ist anch die Vermehrung leichter als durch Sämereien; auch Stecklingsvermehrung ist möglich. Sie gehören dem Castanetum und Fagetum an. Bastarde zwischen rerschiedenen Arten sind häufig.

Populus alba (L.), Silberpappel. Europa.

Blätter vorwiegend dreiteilig, fast schneeweiß-wollig unterseits. Gehört mehr dem südlichen und mittleren Europa, besonders dem östlichen Teile an; ein mächtiger Baum bis $40 \mathrm{~m}$ Höhe.

Populus deltoidea (Marsh.), kanadische Pappel, und Populus monilifera (Ait.),

ebenfalls amerikanische Pappeln, gehören zu den Balsampappelı oder jenen, deren junge Blätter und Triebe mit gelbem, klebrigem. wohlriechendem Harze versehen sind. Sie wachsen ganz außerordentlich rasch, wie verschiedene Beobachtungen in Doutschland ergeben; es sind Messungen ${ }^{1}$ ) vorhanden, nach denen Balsampappeln mit 31 Jahren 2,9 Festmeter Holz bildeten.

Populus nigra (I.), Schwarzpappel. Europa.

Dreieckiges Blatt; besonder's in den Flußauen ron Süd- und Mitteleuropa: dic italienische Pappel ist eine Varietät (lusus) dieser Art; sie hat keine forstliche Bedeutung.

Populus suavoolens (Loud.), japanische Balsampappel. Ostsibirien und Japan.

Eine Balsampappel, welche der amerikanischen in Wuehskraft nicht nachsteht und prïfenswert erscheint.

3) Dr. Hausrath, Über Wachstumsleistungen der kanadischen Pappel. Forstwissenschaftliches Zentralblatt 1896. 
Populus tremula (L.), Zitterpappel. Europa.

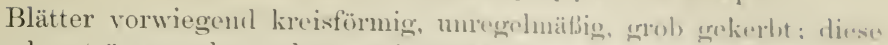
Pappel erträgt anch noch stagnierende Näisse mul knmme un h ant trockenem, solbst schwerom Tonboden ver, sie ist winer dor arstent Bäume auf kahlen Flächen und bileket dort wohltatigen sidnt\%: ihre forstliche Wichtigkeit ist in Zumahme begritien: ihr Uptimun lient im

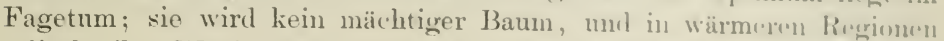
erlischt ihre Wuchskraft sehr bald; ihre auberordentlich reiche. Wumel. brut nach Fällung des Stammes ist cher schärllich als nützlich.

Populus trichocarpa (Torr. rt (rm!l), Pazifische Balsam . pappel, Black Colton wood. Wostamerika.

Anßerordentlich raschwachsend, erreicht eine llöhe his sil $\mathrm{m}$, mit 40 $\mathrm{m}$ langem, astreinem s'chafte.

\section{Gattumg und Art: Prosopis juliflora (J). ('.), Mesunit, Honey Locust. Trockenstes Gebiet von Nordamerika.}

Diese zu den schmetterlingsblütigen Bäumen gehörige Art rreicht zwar nur $15 \mathrm{~m}$ Höhe, allein sie hat sich a uerordentlich wert voll zur Beholzung von Steppen, ja fast vegetationslosem, alkalischem Buden erwiesen, so daß ihre Verbreitung in warmen bis heilsen. trockenen, kahlen Gebieten die volle, forstliche Aufmerksankit verdient; der Durchmesser geht bis zu $1 \mathrm{~m}$, und das Kiernholz ist dabei dunkelrot, schwer, hart, sehr dauerhaft; vorzïgliches Brenn- und Nutzholz.

\section{Gattung: Prumus, Kirschen- und Pflaumenarten. (herry-tree, Plum-tree, ('erisiers, Pruniers.}

So wertvoll das Holz aller Prunusarten für die Möbelindustrie ist, so sind sie doch in Europa nicht Gegenstand forstlicher Kultur, da der Bedarf durch die Obstbäıme dieser Gattung gedeckt wirl. Trotzdon verdienen einige Arten auch forstliche Beachtung. Alle Prunusarten lieben frischen, guten Boden. wie er der Rothuche am hesten zusagt: sie sind raschwüchsig, Lichtholzarten mit grober Stockanssehlaghähigkeit und Wurzelbrutbildung. Dem rotbramen oder gelbhramen hernhol\%. komm七 große Daner und Schönheit zu; mur solche Bämme sind hicr aufgeführt, welche mindestens $25 \mathrm{~m}$ Höhe erreichen.

$$
\text { Prunus arium (I..), Togelkirsche. Europa. }
$$

Besonders an Waldrändern, Bachufern im Gebiete dre ('antanetums und noch des Fagetums hä̈fig, aher selten mit schönn', walzenformigor Schaftbildung.

Prunus pseudocerasus, japanische Kirsche, saknra. Japan.

Vertritt die Vogellirsche Europas in Japran. 
Prunusserotina (Ehrh.), Traubenkirsehe, Wild blackeherry. Ostamerika.

Blätter langgestreckt. lanzettlich, hart, fast lorbeerartig; im Fagetum wohl nur auf gutem Boden und in wärmsten Lagen bis zum Nutzbaum heranwachsend. Anf geringerem Boden bleibt diese Kirsche cin Halbbaum; sie verdient aber wegen ihres wertvollen Holzes den guten Boden.

Prunushiuri (Fr. Schmidt); Schiurikirsche, Shiuri. Japan, If andschurei.

Von allen Tranbenkirschen durch das grobe Blatt, das am Rande abwechselnd einen langen, pfriemenartigen und einen ebensolehen kurzen Zahn trägt, unterschieden; der vollendet gerade, tadellos astreine Schaft, das Vorkommen bis in das Picetum, machen diesen Baum forstlich beachtenswert.

\section{3. (Aattung: P’terocarya, Flïgelniisse.}

Die fiederblättrige Pflanze erinnert an eine Walnuß, ist aber von dieser dadureh unterschieden, daß über jedem Blatt zwei Knospen sitzen, von denen die obere gestielt ist; Markröhre ebenfalls gefächert. Die Flügelnüsse lieben guten, sehr frischen Boden; sie stehen im Flußschotter und Flußsand, wenn dieser nicht mehr von den Wassern hin und her bewegt wird; sio ertragen längere Überschwemmungen, im Castanetum liegt das Optimum. Nur in den wärmsten Lagen des Fagetums werden sie zu Bäumen, die sich forstlich durch ihre Biologie und ihr weiches, leichtes Holz empfehlen.

Pterocarya fraxinifolia (Spach.), kaukasische FlügelnuB. $\mathrm{K}$ a uk asus.

Knospen offen, seheint nur im engen Schluß zur Einschaftigkeit grezwumgen werden zu können.

Pterocarya rhoifolia (Sieb. ct Zucc.), japanische Flügelnuß, Kawagurumi. Japan und China.

Nit schönem, geradem Schafte emporwachsend; ein hoher Bann. Fünf weitere Flügchufarten sind bis jetzt in China gefunden worden.

Śammelgattung ( uercus. Eichenarten, Oaks, Chênes.

Die Eichen zählen forstlich und floristisch in Enropa, Amerika und Asien zu den wichtigsten Glierlem des Laubwaldes; reine Bestände größerer Ansdehnung hilden nur solche Arten, welche anch mit minder gutem Boden vorlieb nehmen, wie die Roteiche in Nordamerika, die Kaisereiche in Japan und die immergrünen Eiehen, welehe wegen ihrer intensiven Beschattung andere Baumarten som Mitbewerbe ansschließen. Ïberblickt man die grofe Schar von Eichen, so firdet man, daß so 
verschiedene Arten damuter sich befinden, dals dus Buhiurnis zur Sektionsbildmog, um nicht zu sagen zur Anftellung der fiatumg Quercus in mehrere Gattungen, sich von selbut anfilrëingt. Nach dur Auftassung des Vertassers haben nur jene Siektmonen Barechtipmug. welche neben ämberen Erscheinungen, Fruchthildung, anatumischen Merkmalen auch hiologe Eigentümlichkeitrn hröcksichtigrn: tür di. vorliegende Schrift, welche waldbauliche '/weck hefolert. geniigen drei

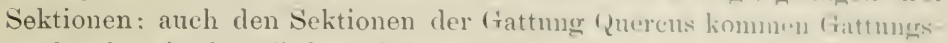
merkmale wie den Kiefernsektionen in systematicrhor, hiolocriseher mul anatomischer Hinsicht zu, so daß die Sammelgattung Luerens wir di Sammelgattung Pinus nicht in Untergattungen, sonclern in wirklieh. Gattungen aufgelöst werden sollte.

\section{Gattung resp. Sektion: (quereus, Weifzeichen (albae).}

Diese Sektion umfaßt die forstlich wichtigsten Bameichen: Blätter nur gelappt oder gekerbt, winterkahle Bäume; die Frïchte reifon im Blïtenjahr. Das klimatische Optimum liegt im kïhleren C'astanesum und wärmsten Fagetum; mit Annäherung an das Picotum einerseits und das Lauretum andererseits nimmt ihr wirtschaftlicher Wurt al: anf feuchten, umnatürlichen Standorten, auf kahlen Flächen leiden sie clurch verspätete Fröste; eine Behandlungsweise, welche die Vegetatinn hinaus zögert, vermag auch Beschädigungen durch verfrülite Frïste lurbeizuführen; in einem sehr strengen Winter können in den tietsten Lagen die Stämme durch Klüfte (Frostrisse) geschädigt werden. I)i: Eichen sind ziemlich schnellwüchsige Holzarten, wenn ihnen die nütigren Balinguneren in Klima, Boden und Erziehungsweise dargebot'n werlen: wrolen sir genügend alt, erreichen sie auch Höhen bis $40 \mathrm{~m}$ und im freien sitandorte eine Dicke, die stets bowundert wird. Alle Weifuichen verlangrn guten bis besten Boden; tiefgründig wegen der starken Ptahlwurzelbildung: auf Sandböden nur bei erster und zweiter Bunität: sic rurlangen Licht und lichten sich in ihren Kronen schom firilizeitig. Ille Eichen zeigen hohe Stockausschlagtähigkeit und eirmen si, h zn Niecler. waldbetrieb. Plötzliche Veränderungen im Borlen, sei cs lurels irmul. wassersenkungen oder -staumngen oder durch plützlichr Einnritti in das Verhältnis des Kronenschlusses, welehe eim Indermur ilur Burdonverfassung bedingen, gefährden die Eichen, inden sie $\mathbb{W}$ isscroisur mul Zopftrocknis hervorrufen (Gipf(aldiurre). Alle Eichen smel tem lins: beißen durch Wild stark ansgesetzt: zahlreiche In-kiten Lelwn an den Blättern und selbst im Holze; autiallend viele. Holz zr-turmuly. Pilze

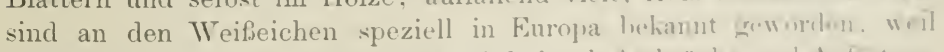
auch kein Baum mehr verwundet wird dureh A-thriblhe mol dufa-tume als die Eiche. Das Holz der Weibeicloe gilt als da- he-te Nitzhol\%.

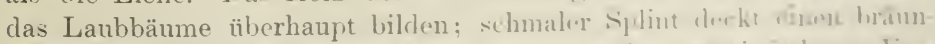

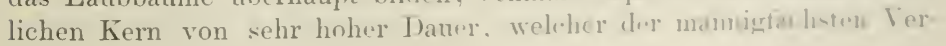


wemlung nuterlient. Woder anatomisch noch in der Farbe ist ein Untrrsehieal in den Holzern aller Wrißeichen zu finden. Das harte, schwere und spaltbare Holz wird rom Markte in solehen Mengen gesm ht, daB Europa längst nicht melne den Bedarf decken kam, Amerika Arre Erschöjufung am hesten Material sich nähert und nur die mberïhrten Waldumeren von Nordjapan noch als gewaltige Reserven an Wenbeichen sich darstellen: in Wentschland ist die Aufzucht der Eichen in fortwährender /sumahme begrittin: in Frankreich wird der rorhandene Bestand nicht weiter veringrert: England, das vorzüglich für Eichenzucht sich engnet, hegrinnt erst systematischen Anbau: in Amerika ist tas luerrliche Irwalilurolukt aufirebrancht. somit bereits minderwertiges second arrowth an dor hoilse, ofler den Weibeichen verlangenden Eurofü̈rn wirel an stelle rles Weibeichenholzes minderwertiges Roteichenholz

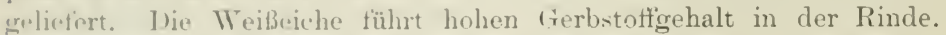
Allex hewrist, dats unter den Eichen die Weißeichen die meiste waldhauliche Försorere verdienen.

Quercu- alha (I.), amerikanisehe Weibeiche, White oak. Ust a merika.

Dies. wichtigste allor amerikanischen Eichen in Ostamerika hat pin tiefigelapptes Blatt, das der ungarischen Zerreiche nicht unähnlich ist: Frïcht' und Rinde der Traubeneiche ähnlich; das Uptimum liegt tief' in C'astanetum.

(?urens bicolor (Willd.), weiBe Sumpfeiche, swamp White oak. Ust amerika.

Ihas Blatt wie hei der amerikanischen Traubeneiche, jedoch unters.its wililich. in den bodenfrisehen Niederungen die vorgenamnte Weibriche ersetzend: das ()ptimum liegt näher dem Fagetum.

(2uerus conferta (K̈it.). ungarische Eiche. Südoste uropa.

Tiefirelapptr, lwhaarte Blätter. Das klimatische Optimm liegt im ('astanutum.

Yuercuserisula (B/.), Krausoiche, Onara. Japan.

Blätter groh, wärert, heiderseits kahl: im hohen Alter eine weißliche, in dïnmen sichichten sich ablösende Borke. Das Optimum liegt Jom Fayrtum näher. Sie ist die wertrollste Weißeiche Japans, soweit Nintzholzprodulition im auropäis hen simne in Frage kommt.

Quereus deutata (Thunle). Kaisereiche, Kashiwa. Japan. ('llina.

Diese Gic he hilket weitaus die größten Blätter unter den Eichen : Blïtter und 'Triehe dicht behart: sie ist besonders aut' vulkanischem 
Sande, selbst geringer Güte, als niederer Baum verbreitet, selbst als Dünenpflanze an den Küsten von Nordjapan und Eso zu finden: sie ist die wertrollste Gerbstofteiche Ostasiens. Ihr Uptimum liegt im Übergangsgebiete rom Castanetum zum Fagetum.

Quereus Garryana (Hook.), Garryseiche. Whiteoak. ()sta merika.

Diese Weißeiche vertritt die Selition in Westamerika; ihr Blatt ist ausigezeichnet durch zwei tiefe Buchten im oberen I)rittel ter Blattes und eine Borke, welche der Krauseiche älnlich ist.

Quercus glandulifera (Bl.), japanischestieleicho. Konara. J a p an.

Blatt nur grob gesïgt, lanzettlich, unterseits heller als oberseits. Thr Optimum ist das Castanetum: selbst noch im Lauretum als Niederwald behandelt zur Gewinnung ron Kohlenholz.

Quercus macrocarpa (Fisch. (t Meyer.). Großfuchteiche. Bur oak. Ostamerika.

Blatt breit, die beiden tiefsten Buchten in der Mitte des Blattes. Blätter unterseits wollig behaart: als Weißeiche ebentalls mit wertrollem Holze.

Quercus pedunculata (Ehrh.), Stieleiche. Europa.

Blätter mit ungleich großen Lappen: Blattbasis zurtickgeschlagen, kurz gestielt. Früchte an langem stiele. Thre Heimat ist der größte Teil ron Europa, ron Kleinasien und dem Kaukasus, mit Ausnahme jener Gebiete, die dem kühleren Fagetum und dem Picetum zufallen, und jener Gebiete. welche dem Lauretum angehören; das Optimum liegt im Castanetum und wärmeren Fagetum: in das Optimum fallen somit England, Irland, ganz Frankreich, Belgien, Holland, von Dentschland nur die wärmsten und tiefsten Lagen. Norditalien, die Tiefenländer von Österreich-Ungarn: Kroatien, Kärnten, Slaroien usw. Die rertikale Erhebung ergibt sich ron selbst aus der Zonenbildung: sehr dieke und, wie Laien stets vermuten, deshalb sehr alto Bäume dieser Art sind bekannt. Die eigentliche Heimat sind Fluftäler, während die Traubeneiche mehr dem Hügellande angehört. Die weiteren biologischen Unterschiede zwischen Stiel- und Traubeneiche sollen bei letzterer angegeben werden.

Quercus Prinos (L.), Gerbereiche, Chesuut nak. Osta merika.

Blatt breit, aber nur grob gesägt, nicht gelappt: gilt als rie beste Gerbstoffeiche ron Ostamerika. 
( uercus pubescens (Willd.), f'laumlatige Eiche. Europa, Nordafrika.

Lnospen, jungro Triebe und Blätter unterseits mit Flaumhaaren ledecht: lie Eiche grehört dem ('astanctum an, fehlt daher in Dentsch. land fist ganz: mur im westlichen Teile (Elsaß-Lothringen) ist sie heimisch: im sürlen von Europla int sie hochwertig: das Holz war schun zur Römerzeit für schifti unt wegen der Dauer gesucht.

(Quercus sessilitlora (Sm.), Traubeneiche. Europa.

Lapren dles Blattes gleich groß; Blätter länger gestielt als bei der Sticloiche, Früchte traubentörmig sitzend angehäuft. Terbreitungswrobiet und optimum decken sich mit der Stieleiche. doch nimmt sie mehr das Hügelland ein. wo sie ursprünglich reine Bestände in größerer Ausdehmung bildete. Wer sitieleiche gegenüber zeigt sie etwas geringere Ansprüche an lie Bodengüte und an die Wäme les Klimas; ebenso ist ilue Suhaftform, Geradschaftigkeit, Tollholzigkeit günstiger, die cichätte sind astreiner als jene der Stieleiche; auch erträgt sie etwas hesser den Lichtentzug: ebenso muß das Ausformungs- und Auslarkungsormögen der Stangenhölzer der Traubeneiche als günstiger brzeichnet werden.

\section{5.). (iattung baw. Selition: Quercus, Nchwarzeichen, Roteichen, Nigrae, Rubrae.}

Diese Sektion enthält winterkahle Eichen, deren Blattlappen in feine sipitzon ansgezogen oder deren Blätter gezähnt sind; der Same (Eichw) reift im zweiten Jahre: ilure schäfte sind im allgemeinen in Rincle und Borke dunkler als die der Weißeichen; ihre Rinde ist sehr arm an Gerhstoften; sie erheben geringere Ansprüche an den Boden als die Wrißeichen: sind etwas schnellwüchsiger, etwas mehr Schatten ertragend, stehen aber in der Hauptsache in ilrem Holze den Weißcichen bedentend nath. Wo Weiß- und Schwarz-oder Roteichen zusammen wathon, geben die W'eißeichen das Nutzholz, die Schwarzeichen das Brembolz; wo Weißeichen fehlen oder durch Raubbau hereits erschöptt sind, liefern die Schwarzeichen Nutz- und Bremnholz. Es ist rine allgemoine Klage in Europa, daß nach der Erschöpfung Nordamerikas an wertrollem Weißeichenholze gegenwärtig minderwertiges vichwarz- oder Roteichenlolz nach Europa verfrachtet wird; hei frisch gräallten Bämmen ist die Unterscheidumg von Weip- und Roteichenholz nieht schwierig, dem das Holz der Roteichen hat einen ausgresprochenen rütlichön Kern grgenüber dem dunklen, graubramen Kurn drr Wrißeichenhölzer; der rote Farbstoff kam anch noch im getrockneten Hulze als Anhaltspunkt, aber nicht als allein entscheidender henutzt werdin. Mit dem geringeren Farbstotf kommt dem Sehwarzeichenholze auch eine geringere Ilauer $\mathrm{zu}$; außerdem ist es durch 
breitere Porenkreise im Frühjahr anffallend. Nach den Untersuchungen des Verfassers beträgt der Porenhrois des Frïhholzes hei den ITeißeichen 12-1:\% \%, bei den śchwarzeichen 30 - $110^{\circ}$ o der Jahresringloreite: als Faßhölzer mit alkoholischem Inhalte sind die Roteichen fast wertlos.

Quercus Aogilops (I.), Valoneaeiche. Südostenropa und Kileinasien.

Durch den holien Gerbstottigehalt der Fruchtbecher (3500) eine für Sïdeuropa forstlich wichtige Art.

Quercus californica (Coop.), (Kelloggii), halifornische Roteiche. Westamerika.

Vertritt die Roteiche des Ostens (ruhra) an der pazifischen Küste. Quercus Cerris (L.), Ziereiche. Südosteuropa und Orient.

Blätter regelmäßig tief gelappt, Knospen mit langen, schmalen, rertrockneten Pfriemenblättern. Diese Art gehört allein dem Castanetum an. Bezïglich ihres Holzwertes golten obige Ausfïhrungen.

Quercus palustris (Münch.). Spießeiche, Pin oak.

Ostamerika.

Die tief eingeschnittenen Blätter sind die kleinsten der Roteichengruppe: Lappen vielfach anf ungleicher Höhe. Von allen Rot- und Schwarzeichen durch einen vollendet geraden schaft ausgezeichnet, der wie bei den Nadelbäumen bis in die spitze verfolgbar ist: Krome durchsichtig, Seitenäste sehr dümn; nur in sehr frischem, warmem, nicht sumpfigem und kaltem Boden, wie der Name palustris nahe legt, erreicht diese Eiche ihre beste Entwicklung.

Quercus rubra (I.), Roteiche, Red oak. Ostamerika.

In dem großen Blatte reichen die Buchten bis zur Hälfte der Blattbreite. Diese Eiche ist die wichtigste der großen Rubraguppe in Ustamerika. Sie ist sehr raschwüchsig und noch im ganzen Fagetum ein voller Baum, der in der Heimat ausgedehnte, reine Bestände bildet. Bezüglich seines Holzes sei auf die allgemeinen Anstührungen ausdrülcklich hingewiesen.

Quercus tardissima (mihi), Späteiche. Europa.

Die Späteiche ist cine Holzart, deren Eigenschaften konstant in allen Klima- und Bodenlagen erblich sind; aus diesem Grunde ist sic eine Art: durch ihre späte Begrünung verdient sie forstliche Beachtung.

Qorcus serrata (Thunb.), japanische Kohleiche. Kunugi. Japan. China.

Das langgestreckte Blatt gezähnt, lem der Edelkastanie sur ähnlich; der Baum wird seines harten und seliweren Holzes wegen als 
Niederwald zur Kohlholzgewinnung bewirtsehaftet. Er gehört ausschließlich lem Castanetum an, als Niederwald auch noch im Lauretum.

Q nercus rariahilis (137.), asiatische horkeiche, Natakunugi, Alemaki. Japan, Korea, China.

Blätter der vorigen Art sehr ähnlich, aber unterseits weißlich behaart. Sie bildet wie die immergrüns Korkeiche Korklagen und hat weren dieser Figenschaft in Jajuan bereits forstliche Beachtung gefunden. Sie kann nur im ('astanetum kultiviert werden; das wärmerc Faretum ist bereits dio Kältegrenze. I) Korkbildung scheint jedoch langsamer als bei der Korkeiche nach Entfermung der ersten groben lorkschicht sich wieller zu ersetzen.

\section{ji. (iattung bzw. Sektion: Quercus, immergrine Eichen, Lebens- eichen, Nemperirentes.}

I) ir immergrïnen Eichen sind sämtlich Schatten ertragende Holzarten, welche wegen dieser Eigensehatt zur Bildung von reinen Beständen neigen; sie gehören dem Lauretum an, wo sie guten, frischen Bolen rerlangen: nur der warme, insulare Westen von Europa ermöglicht ihr Giedeihen in Gebieten, die nach der Durchschnittstemperatur des sommers dem Castanetum zugezählt werden müssen. Ihre gröfite fiefahr sind tiete Wintertemperaturen. Im Holze ïberragen sie alle Eichen an Härte und schwere und damit auch an Brennwert, sind aber allen Weißeichen an Nutzwert unterlegen; da dem Kern der kräftige Farbstoff fellt, ist er auch zumeist von geringer Dauer: die Rinde luat kinen brauchloaren Gerbstoff.

'quercus acuta (Thunh.), rote Lcbenseiche, Aligashi. J a p a $n$.

Wo milfle Winter herrschen, kamn dieser Bam ebenfalls noch in ('astanetum erwachsen.

Quereus anrifolia (Nie), kalifornisehe Lebensoiche, ('alifornia live oak. Kalifornien.

I) he häufigste, immergrüne Eiche der Westküste von Nordamerika.

Quercus Ilexil.l, europäische Lebonsoiche. Südeuropa. (quercus oceidentalis, westliche Korkeiche.

siid westemropa.

Dirse Eiche wirl rorzursweise an lor atlantischen Kïste von siidfrankroich, spanien und Portugal ant Kork genntzt.

そuercus śuber (I.), südlicho Korkeiche. Südouropa.

Jieso Eicho griht in Nordafrika (Algier, Marolkko) Kork, und zwar der besten Qualität. 
Quereus rirens (Ait.), Floricla Lebenseivhe, Live oak. Ost a merika.

Dieser Baum ist die immergrüne Eiche des Laurotums von Florida mol den anderen Südstaaten von Ostamerika.

\section{5\%. Gattung und Art: Rhus vernicifera (ID.C.), Lackbaum, Urushi. Japan.}

Ein fiederblättriger, winterkahler Waldhaum des Castanetums. der guten Boden und freies Licht verlangt: sein Wert besteht nicht im gelbgefärbten, dauerhaften Holze, sondern im Milchsafte der Rinde, aus dem Lack gewonnen wird.

\section{Gattung und Art: Robinia Pseudoacacia (L.), Robinie, Locust. Ostamerika.}

Die Robinie ist eines der glänzendsten Beispiele, daß Anbauversuche mit nichtheimischen Holzarten eine volle Berechtignng besitzen: ja, der erfolgreiche Anbau der Robinie beweist sogar, daß im eigenen Heimatlande. im Urwald, seltene und unscheinbare Holzarten für die Kulturzwecke des Menschen von hervorragendem Worte sein können. Aus der Heimat in den südlichen Alleghanies wurdo die Robinie, empfohlen als einfacher Blütenbaum, über Ostamerika, ganz Mittel- und Südeuropa, Westamerika, Japan und Australien verbracht; es ist keinem Zweifel unterlegen, daß eine ähnliche Laufbahn noch mancher anderen Holzart, besonders schmetterlingsblütigen zuteil werden kann. Die Robinie besitzt ein gefiedertes Blatt, Domen als Nebenblatter: zwischen denselben liegt die Knospe in der Rinde des Triebes eingebettet. Der Baum erreicht seine Vollkommenheit im Castanetum; im wärmeren Fagetum wird er noch ein Nutzbaum; jo kühler das Klima, desto größer die Trieblänge, die alljährlich von den Früh- und Winterfrösten abgefroren wird. Sie gedeiht noch auf geringem, sandigem, kiesigem Boden, hat sich zur Aufforstung der Steppen besonders geeignet erwiesen (Ungarn), verlangt aber auf solchen Standorten volles Licht; die Robinien wachsen sehr rasch, haben eine sehr starke Reprodulitionskraft aus dem Stocke und entsenden auch Wurzelbrut nach oben. Der Anbau lohnt sich durch das vortreffliche Holz, das grüngelben Kern besitzt und techniseh der Eiche am nächsten kommt; Blätter als Futter, Blüten für die Bienenzucht. Die Robinie ist überaus gefährdet durch die Nagetiere, besonders Hasen und Kaninchen.

\section{9. (Aattung: Salix, Weidenarten, Willows, Saules.}

Die sehr leichtsamigen Holzgewächse sind als Bäume von greringer. als Sträucher von großer forstlielıer Bedentumg; alle sind anferordentlich rasehwüchsige Lichtholzarten, welche frischen, ja nassen Buden lieben, vorausgesetzt, daß er nicht versänert ist; sie erscheinon anf den 
Kahlschlägen znerst, wo sie zumeist als wohltätige Schutzpflanzen zu betrachten sind, bis sie in schärlliche Bedränger übergehen. Die W'eiden grehören teils dem Castanetum, teils dem Fagetum und als strauchund krantartige Pflanzen selbst der alpinen oder polaren WValdgrenzvegetation an. Sie sind zumeist frosthart. Thre außerordentliche Stockausschlagfähigkeit ermöglicht einen Niederwaldbetrieb zur Gewinnung von zähem Flechtmaterial, worin der Hauptwert der Weiden beruht. Das Holz ist weich, leicht, zäh, ohne besonderen Vorzug; wertroller ist oft das Strauchwerk zu Faschinenbauten.

\section{Salix alba (L.), weiße Weide. Europa.}

Junge Blätter beiderseits, ältere nur unterseits weiß, seidenglänzend behaart. Die Weißweide ist die vollkommenste Tertreterin der Baumweiden, die sich fast an allen Flüssen Europas findet.

$$
\text { Salix purpurea (I.) }
$$

mit einem Blatte, dessen größte Breite im oberen Drittel, dessen oberer Rand gezähnt ist.

$$
\text { Salix viminalis (L.) }
$$

mit mattgrüner, runzeliger Blattoberfläche und silberglänzender Blattunterfläche.

$$
\text { Salix amygdalina (I.), }
$$

die Mandelweide mit Nebenblättern zu beiden Seiten des Blattstieles.

Salix daphoides (L.)

mit weifer Bereiftheit der in das zweite Jahr gehenden Triebe; auch zahlreiche Bastarde zwischen den genannten Arten bilden die wichtigsten Kulturweiden für Niederwaldbetrieb in Weidenhegern.

\section{0. (Gattung und Art: Sassafras officinale (Tres.), Sassafias. Ostamerika.}

Dieser zu den Lorbeergewächsen gehörige, winterkahle Baum fällt auf durch sein veränderliches Blatt, das bald ganzrandig, bald zwei-, bald dreilappig ist; Holz in seinem Charakter und seiner Güte dem der Edelkastanien nahestehend. Der raschwüchsige, liehtliebende Baum gehört dem Castanctum an, wo er auf gutem, sehr frischem Boden ein mäehtiger Baum wird.

\section{Gattung: Nophora, Sophoren.}

Schmetterlingsblütige Bämme, welehe auf geringerem Boden des C'astanetums gedeihen und aut' Standorten geprüft werden sollten, wo die Robinie sich boreits bewährt hat. Im wärmeren Fagetum werden sie von Früh- und Winterfiösten bedroht; raschwüchsige Iichtbäume mit vorzüglichem Iolze nach dem Typus der Robinien. Kernfarbe braun. 
Sophorajaponica (L.), Sophore, Enshu. China, Japan.

Diese in wärmeren Europa bereitr allbohannte, japanische Holzart mit grüner Rinde an den einjälnrigen 'Trieben tormt braunes Kernholz bei einem $6-7 \mathrm{~mm}$ breiten splinte.

Sophora platycarpa (Mux.), Fujisophore, Fujiki. Japan.

Die Art scheint forstlich härter zu sein als die vorige.

Gattung Sorbus (4i) siele Pirus (4i).

\section{6:. (Aattung: 'Tilia, Lindenarten, Linden, 'Tilleul.}

Dadurch, daß das Nüßchen an einem häutigen Deckblatte mit dem langen Stiele angewachsen ist, wird der Same auf' geringe Entfermungen hin flugfähig. Der Same liegt über, wenn er nicht von der Reife an im Boden liegt oder in feuchtem Zustande überwintert wird. Dic Linden gehören dem Fagetum an; raschwüchsige Halbschattenholzarten, welche den Boden der Rotbuche berorzugen; in manchen Waldgebieten, z. B. südöstlichen Rußland, vertreten sie die Buchen. Thre große Stockausschlagfähigkeit macht sie zu Niederwaldungen geeignet. Das Holz findet trotz seiner Leichtigkeit und $W^{T}$ eichheit cine vielseitige Terwendung und steht, in kleineren Mengen angeboten, im Werte ziemlich hoch. Der Hartbast der Rinde liefert cin vorzügliches Bindematerial.

Tilia americana (Du Roi), a merikanische Linde, Bass wood. Ostamerika.

Blätter groß und gröber gesägt als bei den europäischen Arten.

Tilia grandifolia (Ehr.), sommerlinde. Europa.

Blätter ober- und unterseits gleich grün gefärbt, glänzend; im südlichen und westlichen Europa am meisten rerbreitet; die Nordlinie geht durch das mittlere Deutschland.

Tilia japonica (Mayr.), japanische Linde, Shinanoki. J a p an.

Blätter mit längeren Spitzen. Tertritt diese Gattung in .Japan.

Tilia parrifolia (Eh/.), Winterlinde. Europa.

Blätter durchschnittlich etwas kleiner als bei der siommerlinde, von dieser aber dadurch unterschieden, daß die Unterseite des Blattes stets heller ist als die Oberseite; erreicht bei genügend hohem Alter sehr starke Dimensionen.

\section{Gattung: Clmus, die Ruister- oder Ulmenarten, Elms, (Ormes.}

Blätter grob gesägt, rauhaarig, zweizeilig, letzter Trieb schiet abstehend; der Same mit dünnem Flügelrande, auf ziemlich weite Ent- 
fernungen rom Wintle getragen. Sichnellwïchsige Halbschattenholzarten. welche ïberall gedeihen kïnmen, wo Ahorne oder Eschen ihr Fortlinmmen finden: ilıre Heimat sind Castanetum und Fagetum. Auffallend ist ihre Frosthärto im Frülijahre: nur im Winter leiden ilnre Schäfte hei selnr tiefer Wintertemperatur durch Aufplatzen; hohe Stockans.chlagtähigkeit und Wrurzellurut sind den Ulmen eigen; das Holz der meisten, schönschaftigen Ulmen hat einen braunen Kern, der dem Holze Daner verleiht und seinen Wert als Möbelholz nsw. bedingt; es ist gering spaltbar und hart: immerhin verdienen die Ulmen rine urofiere, forstliche Aufmerksamkeit, als ihnen während der letzten Dezemien zuteil wurde. Die Ulmen erreichen 30 m Höhe und darüber und ein sehr hohes Alter: ihre Rinde enthält einen nutzbaren Bast.

Ulmus americana ( $L$.). amerikanische Ulme, White Elm. Ostamerika.

Blattepitzen länger als bei der europäischen Art.

Ulmus effusa (Willd.), die Flatterulme. Europa.

Rinde des Bammes in flachen, dünnen Stücken sich ablösend.

Ulmus laciniata (Mayr), Gewebenlme. Whio. Japan.

Eine sehr großblättrige Ulme; Blätter in drei anch vier Spitzen anslaufend, doppelt und grob gesägt. Der Bast zu Fäden, Stricken und Kleidern verarbeitet.

Ulmus montana (Smith), Bergulme. Europa.

Rinde eine längsrissige Borke: die hänfigste und stärkste aller Ulmen Europas. Das Holz gilt als das wertvollste aller Ulmen.

Ulmus parvifolia (Jacq.), chinesische Ulme, Akinire. Japan, Korea, China.

Die Blätter kleiner als bei allen andern Ulmen; junge Zweige mit Korkleisten. Früchte reifen im Herbste.

Ulmus suberosa (compestris L.), Korkulme. Enropa.

Junge Zwrige zuweilen mit Korkleisten. Rinde des Baumes eine tiefrissigr Borke.

\section{(it. Giattme und Art: Umbellularia raliforniea (Nutt.), Kalifornischer Lorherer, Myrtle-tree. Kalifornien.}

Dicser immergrüne Lorbererhanm gehört aussehließlich dem Lauretum an: ein Baum his :31 m llöhe mit rorzüglichem Holze, das an der pazitischen Küste das Wahnuls- und das Eichenlnolz zngleich ersetzt.

\section{6.i. (iattung: Zelkowa, lipakihäume.}

Zur Familie der Uhmיn grehürige Bäıme mit grobgesägten, ranhhaarigen Blättern, schiefer Stellung der Endtriebe. Sie teilen voll- 
kommen die Naturgeschichto der Ulmen, verlangen abor vorzngsweise ein Castanetumklima; nur im wärmsten Fagetun noch kultivierbar. Sie übertreffen die Ulmen an Raschwüchsigkeit und in der Güte des Holzes, das sie bilden. Das Holz nähert sich im anatomischen Charakter dem Ulmenholze, hat rotbramen Kern und hohe Daner.

Zelkowa crenata (Spach.), kaukasische Keaki. Kaukasus. Blattspitzen stumpf endend. Diese Art scheint gegen verfrühte und Winterfröste empfindlicher zu sein als die folgende.

\section{Zelkowa Keaki (Sieb.). Keaki. Japan, Korea.}

Blatt in eine lange Spitze ausgezogen; sehr raschwüchsig auf sehr gutem und frischem Boden: sie bildet in Schlusse sehr hohe, walzenförmige Schäfte von $30 \mathrm{~m}$ Länge und darüber. Ihr Holz gilt als das schönste, das eim Laubbaum bildet. Ihr Renoméo ist aber japanisch. Das geringe Schwinden und Werfen des Holzes macht es zu den verschiedensten Gebrauchsgegenständen geeignet.

\section{Halbbäume und Sträucher.}

Raumersparnis erfordert eine Beschränkung auf Halbbäume und Sträucher des e uropä ischen Waldes; zu den Halbbäumen werden solche Arten gezählt, welche regelmäßig $1 \mathrm{~m}$ Höhe überschreiten und nur bis $8 \mathrm{~m}$ Höhe erreichen; daß gelegentlich auch größere Dimensionen rorkommen, ist zwar beachtenswert, aber forstwirtschaftlich nicht ausnützbar: ausführlichere Angaben enthalten: G. Hempel und K. Wilhelm, Die Bäume und sträucher des Waldes.

Alnus viridis (D.C.). Grünerle, Bergerle.

Sitzende Knospe; kleine, rundliche Blätter, dem Picetum und Alpinetum bzw. Polaretum angehörig; ihr forstlicher Wert liegt in der Festigung des Bodens gegen Schnee und Geröllabrutschung.

Berberis rulgaris (L.). Sauerdorn, Berberize.

Auf sonnigen Hängen, besonders auf Kalliboden beruht sein forstlicher Wert in der Besiedelung ron Kahlfächen: Holz als Drechslerware geschätzt.

Betula humilis (Scler.) und naua (L.), Strauch-oder Zwergbirken.

Zwei niedere Sträucher, welche den Torfmooren Europlas typisch sind.

$$
\text { Clematis Vitalba (L.), Waldrohe. }
$$

Die Triebe dieser kletternden Pflanze sind zwar als Bindematerial nützlich, ihr Schaden aber durch Überlagem und Ühernuchern ron 
Nutzholzstämmchen, besonders im Nieder- und Mittelwald und in Verjüngungen der Auwaldungen von Nittel- und Nordeuropa ist größer als ihr Nutzen.

Cornus mas (L.), Kornelkirsche, und Cornus sanguinea $(L$.$) ,$ Hartriegel.

Eistere Art vorzugsweise in Mittel-und Südeuropa, letztere in ganz. Europa heimisch, können als wohltätige Besiedler der Kahlflächen bezeichnet werden, welehe die Aufforstungsarbeit zwar etwas beeinträchtigen mögen, dafür aber durch Schutz der Kultur deren Aufwachsen fördern; auch ihr Holz gibt vorzügliche Drechslerarbeiten, besonders Spazierstöcke, Schirmgriffe.

Corylus Avellana ( $L$.), die Haselnuß, und Corylus Colurna (L.). Baumhasel, türkische Hasel.

Erstere Art zeigt immer guten Boden an, wirkt, da Halbschattenholzart. als Unterholz unter Lichtholzarten wie Unterbau auf den Boden gïnstig ein: vermehrt sich stark durch freiwillige Stockausschläge und Wurzelbrut. Das Holz, besonders aus schlanken Ausschlägen, vielfach benutzt. Die Baumhasel dem südöstlichen Europa angehörig, wird ein Baum bis zu 12 $\mathrm{m}$ und darüber. Das Holz als feines Schnitz- rnd Möbelholz gesucht.

\section{Crataegus Oxyaeantha (I.) und Cr.monogyna (Jacq.), We if dorn.}

Die forstliche Bedeutung liegt in der Verwendnng zu lebenden Züunen und Hecken: das Holz sehr hart, zur Herstellung kleinerer Fegenstände verwendet; ihre Anzucht empfiehlt sich zum Schutz der nützlichen Vögel gegen ihre Feinde.

Evonymus europaea (L.), Spindelbanm.

l)as Holz von weißer Farbe von großem Wert für Drechsler; der iisthetische Wert der Pflanze, besonders im Herbst, läßt es erwünscht arscheinen, daß sie bei der Verjüngmng nicht deshalb beseitigt wird, weil sio im Wege steht: sie schïtzt anf der Kahlfläche und ist im Mittelwalıle und an Waldrändern ein harmloser Stranch- oder Halbhaum.

Fraxinus Ornus (L.), Blumen-oder Mannaesehe.

Ein Hall,banm der trockenen, kalkigen Böden von Südeuropa; dort durch das 110lz und den bei Einschnitt in die Rinde ansfliefienden Saft (Manna) forstlich beachtenswert.

Hippophä rhamnoides (L.), Sanddorn.

Der grane Ton der Blätter und die dicht angehäuften Scheinbeeren verleihen dem Stranch grofen Vicrwert. Er dient zur Bindung von 
Flugsand, wächst noch auf Schotterboden mit reichlicher Durchfenchtung. Seine Vermehrung kann neben der ans Sanen auch durch Stecklinge erfolgen.

Ilex Aquifolium (L.), Hülsen, stechpalma.

Dieser immergrüne Strauch oder Halbbaum bewohnt vorzugsweiso die Küsten von West-, Nordwest- und Südenropa; in den klimaverwandten, waldreichen Mittelgebirgen der Vogesen, des Schwarzwaldes und der Alpen ist er ebenfalls zu finden, dann am Niederrhein und in Westfalen. Er sucht im Innern der Kontinente Schut\% anderer Holzarten, sogar der Tanne; in hohem Maße Schatten ertragend ist der Hülsen langsamwüchsig; es wäre zu prüfen, ob er nicht als Bodenschutzholz in den genannten Gebieten verwendet werden könnte.

Laurus nobilis (L.), der Lorbeorbaum.

Ein immergrüner und deshalb stark schattenertragender Halbbaum, der im südlichsten Europa bis zur Baumgröße emporwächst. Sein Auftreten als Halbbaum kennzeichnet die nach diesem aromatischen Baume und seinen Terwandten benannte Klimazone, das Lauretum. Er vermehrt sich leicht durch Wurzelausschläge und hat im Süden einige forstliche Bedeutung.

Ligustrum vulgare (L.), Rainweide.

Allbekannter, nahezu immergrüner Strauch, der freiwillig Absenker in größter Menge gibt: Schatten ertragend. Sein Auftreten kennzeichnet einen guten Boden, sein Holz ist sehr hart.

Lonicera Xylosteum (L.), Beinweide.

Dieser Strauch liebt wie seine Verwandten kalkreiche Böden, ist äuferst genügsam, gibt ein sehr hartes, zu manchen Zwecken, wie Peitschenstielen, gesuchtes Holz.

Lonicera Caprifolium (L..), Geißblatt.

Ist ein in den warmen Laubwaldungen zuweilen als schädlicher Würger auftretender Schlingstrauch.

Prunus Mahaleb (I.), Felsenkirsche, türkische Weichsel.

Besonders im südlichen und östlichen Europa auf kalkigem, felsigem Boden heimisch, sehr lichtbedürftig. Die schlanken, glattrindigen Ausschläge als Pfeifenrohre mit starkem Cumaringeruch schr gesucht.

Prunus Padus (L.), Traubenkirsche.

Am häufigsten findet man diesen Halbbaum im Nieder- und Mittel- 
waldbetriche vorzursweise wegen seines hohen Ausschlagsvermögens; oin Hallschattenbaum, der auch zum Unterbau unter Lichtholzarten sich rimet.

$$
\text { Prunus spinosa (L.), Schlehdorn. }
$$

Wäre auf geröllreichen Hängen zur Bindung zu verwenden, da er Weitausgreifende Wurzeln und Wurzelbrut gibt; ebenso wie Weißdorn ist er zum Schutze der nützlichen Vögel zu schonen.

Rhamnus cathartica (I..), Kreuzdorn, Elsbeer.

Wegen seines schön geflammten, roten Drechslerholzes an Waldrändern zu dulden.

Rhamnus Frangula (L.), Faulbaum.

Als Schutzholz wie alle Sträucher umsomehr willkommen als eingepflanzte Edelhölzer, insbesondere Nadelbäume, ohne sonderliche Beihilfe ihrem Schutze entwachsen, ihn erdrücken und als Dünger dem Boden einverleiben; Holz früher für Pulverkohle gesucht.

Salix caprea (L.), Salweide, Solweide.

Allbckamnter Großstrauch, der als Wohltäter auf den Kahlflächen erscheint und, wemn er lästig wird, wieder beseitigt wird.

Viburnum Lantana (I.), Hundszunge. junge Triebe zu Bindwieden.

Viburnum Opulus (I.), Schneeball, mit hartem Holze; dekorativ auch seine roten Beeren. 


\section{Sechster Abschnitt. \\ Waldbaulich-biologische Eigenschaften der Baum- vereinigungen (Bestandesbiologie).}

\section{a. Soziologische Verhältnisse.}

In der Vereinigung mehrerer Pflanzen zu einem größeren Verbande, zu einer Genossenschaft, müssen wir ein Mittel erblicken, durch welches die einzelne Pflanze besser ausgerüstet ist zum Kampfe gegen ungünstige Verhältnisse in Boden und Klima, gegen die in Mitbewerb tretenden, fremden Pflanzen, gegen Insekten und größere Feinde; Vereinigungen der Bäume schaffen günstige Bedingungen zum Keimen und Aufwachsen, zur Erhaltung der Art; die Holzarten vereinigen sich zu Genossenschaften zum Schutze des Ganzen auf Kosten des einzelnen Baumes; denn das einzelne Individuum verliert an Licht, Luft, Raum, Wärme, Wasser, Boden und Fortpflanzungsmöglichkeit, wio die folgenden Zeilen zeigen werden.

Je nach der Gröbe der Vereinigungen unterscheidet man: Trupp, wenn nur eine kleine Zahl von Baumindiriduen, bis zu etwa zehm Stück, zusammensteht; Gruppe oder Horst wird eine gröfere, amähernd runde Vereinigung von Holzarten ${ }^{1}$ ) bis zu einer Flächenausdehnung von 0,3 ha genannt; $\mathrm{B}$ and ist eine streifen- oder kulissenartige Anordnung einer Holzart; Kleinbestand muf die Vereinigung genannt werden, wenn sie mehr als 0,3 ha bis etwa 3 ha aufweist: Bost an nd ist eine Wirtschaftsfigur der Forsteinrichtung von beliebiger (iröße. einheitlich in Holzart, Alter und Behandlungsweise. Ein gr üBerer Wald kann aus Beständon oder anch ans Kleinbeständen, ans Bändern, aus Gruppen und Trupps sowie aus isoliert stehenden Individuen zusammengesetzt sein.

Besteht eine Baumvereinigung aus einer einzigen Itolzart, sw heißt sie rein; rein kann somit sein ein Trupp, ein Bancl, rine (iruppe, ein Kleinbestand, ein Bestand und schliefblich auch ein Waldkomplex.

1) Dr. K. Gayer, Der Waldbau (4. Aufl. 1895), nenut Horst die grüßere, (iruppe die kleinere Vereinigung ohne Größenabgrenzung. 
Sind aber zwei oder molnere Holzarten beigemischt, so unterscheidet man einen gemischten Trupp. eine gemischte Giruppe, ein gemischtes Band, einon gemischten Kleinhestand, einen gemischten Bestand und einen gemischten Wald: st a m m w ise (femelartig), truppwrise, bandweise, grupuenweise, kleinbestandsweise, bestandsweise uremischten $\mathbb{W}^{r}$ ald, wenn jede der genannten Voreinimugen aus einer von der Nachbarschaft versehiedenen Holzart besteht oder in sich gemischt erscheint. Beträgt die Beimischung einer anderen Holzart weniger als ; \% so heißt die Vereinigung rein mit einzelnen anderen Holzarten.

Nur bei Kronenmischung spricht man von gemischter Vereinigung; sind die Kronen einer Holzart unter den Kronen einer anderen Holzart, so ist dies ein reiner Bestand, Kleinbestand usw., mit \%wischen - oder Unterstande.

lie vorherrschende Holzart wird bei der Bezeichnung einer Mischung vorangestellt, z. B.: ein Fichtenbestand mit Tannen stammweise, gruppenweise, bandweise gemischt bedeutet die Vorherrschaft (ler Fichte: Tamne mit Fichte bedeutet die Vorherrschaft der Tanne.

Die $/$ wecke und Vorteile der Mischung sind in erster Linie waldbaulicher Natur, wie sie in den folgenden Zeilen näher beschrieben werden müssen. Die gegenseitige Einwirkung der Bäume anfeinander ist die intensivste, und der /wock der Mischung wird am vollkommensten erfüllt in der stammweisen oder Einzelmischung, bei der jeder Baum mit dem Nachbarbaum einer anderen Art in Kronenberïhrung tritt oder doch treten kann; im Trupp ist dio Berïhrung der Bäume mit solchen der eigenen Art häufiger und vollends in der Gruppe, im Bande: im Kleinbestande beschränkt sich die Berïhrung mit anderen Arten auf die Peripherie; das Innere trägt bereits mehr oder weniger den Charakter des reinen Bestandes; es steht. aber das '/entrum der Gruppe, des Bandes und des größten Teiles des Klinhluestandes noch unter dem Einflub der Vorder- und Hinterbeliehtung der Nachbarn, es besteht noch Streumischung, Sturmsicherung usw. chrch die mmgebende Bammart. Aber zweifellos hört jegliche Einwirkung auf das Innere einer Bammereinigung von seiten der Umgroung ant. Wenn erstere 1,3 ha in der Größe ïberschreitet. Es widerstruht sthon den allgemein ïblichen Begriffe, eine Baumvereinigung, die mouber ist als ein Tagewerk, noch als Gruppe oder Horst zu bezeichnen; solche Flitchen tragen bereits den Charaliter der reinen Bestinde und werden auch als solehe waldbaulich behandelt. \%um Unterschicel gegenüber den groben Beständen der Forsteinriehtung dürfte dirse waldbaulicho Finheit, etwa bis :3 ha sich erstreckend, zweckentsprechend, "Kleinbestan d" genannt werden.

Über das A nftretender reinen und gemischten Bestände und über die $/$ ahl der in Mischung tretenden Holzarten entseheiden folgende Naturgesetze: 
1. In den wärmeren Vegetationszonen (Tropen und Subtropen) überwiegen die Holzartenmischungen, die Mischbestände : an ler Mischung des Waldes beteiligt sich die größte Kahl der Bammarten: die Mischung selbst ist die innigste, vorwiegend stammweise: je kühler rlas hlima der Vegetationszonen, sei es nach Norden nder nach oben hin, desto mehr nimmt die Zahl der Holzarten und der Mischbestände selbst ab: an der obersten Waldgrenze herrschen Reinbestände anf crüberen Flächen hin vor (Fichte, Föhre, Birke, Lärche n. а.).

2. Alle Holzarten neigen im Optimum ihres natïrlichen Verbreitungsbezirkes zu reinen Beständen, weil sie dort anderen Holzarten gegenüber mit besseren Waften für den Kampf un das Hasein ausgerïstet sind; vom Optimum hinweg nach der Kälte und Wärmegrenze ihrer Tegetationszone hin löst sich der reine Bestand in isoliert zwischen anderen Holzarten stehende Individuen auf.

3. Wird eine Holzart künstlich a uerhalb ihres natürliehen Verbreitungsbezirkes gebracht, muf sie in größeren reinen Gruppenoderin reinen Kleinbeständenoder reinen Beständen angebaut werden, um sie gegen die anderen Mitbewerber zu sichern und den Aufwand an Kosten und Fürsorge für ihre Erhal. tung möglichst zu verringern.

4. Alle Holzarten können Reimbestände bilden: zu gemischten Beständen können aber nur jene Holzarten wich vereinigen. welche amähernd gleiche Ansprüche an Klima und Boden erheben. Die /ahl der Variationen solcher Mischbestände ist eine sehr grolie.

j. Je besser, mineralreicher und physikalisch vollknmmener ein Boden ist, desto mehr treten die Reinbestände natürlichen Ursprungs zurück und Mischbestände an ihre Stelle: je vorzüglicher der Boden, um so mehr Holzarten beteiligen sich in dem Mischbestande. Im besseren Boden findet nicht bloß eine größere Zahl von Holzarten mit verschiedenen Ansprüchen an Bodengüte ihre Bofrierligung: es kommt noch hinzu, daß der bessere Boden die Unterschiede und Ansprüche an das Licht und an die Wärme auszugleichen vermag, wodurch eine größere Zahl von Holzarten für den gleichen Standort mitbewerbend auftreten kann.

i. Je mehr ein chemischer oder physikalischer Faktor im Buden ïberwiegt, z. B. Feuchtigkeit. Lockerheit, Sand usw. um so melu nehmen die beigemischten Holzarten an Zahl ab und reine Baunveremigungen treten an die Stelle. Aut Boden, der durch mifbräuchliche Benutzung, z. B. kahlschlagweisen Betrieb mit maßjlosem sitrenentzug, rasch verarmt und schließlich zu fast reinem Sand heruhsinkt, kann oft nur noch die bescheidenste aller Holzarten, die Fiilire, in reiner Form ihr Gedeihen finden.

7. Alle Schattenholzarten neigen mehr zur reinen Bustandshildung als die Lichtholzarten; weren ihres Lichtbedürfnisses entziehen sio mit 
ihrer clicht gehauten Kirne das Licht anderen lichtbedürftigeren Holzarten.

s. Sichattenholzarten mit schwerem Samen (wie Buchen. Tannen) neigren mehr zn reinem Bestand als solche mit leichten Sämereien.

(1. Iichtholzarten mit schwerem Samen (z. B. Eichen) neigen zu reinen Baumvereinigungen in höherem Maße als Lichtholzarten mit lvichten Simereien: wem man trotzdem viele leichtsamige Lichtholzarten (Birken, Weiden. Pappeln) auf ausgedehnten Flächen alleinherrschend findet. so ist es entweder ein einziger Falitor des Klimas (Kältegrenze des Waldes) oder ein solcher im Boden (Sumpf, Moorboden, liesgeröllhoden usw.). welcher nach Punkt if dem reinen Bestande Vorsihub leistet.

11. Besitzt eine Baumgattung zwei oder mehr Arten, so bilden diese nahen Verwandten keine Mischbestände, sie sind vielmehr wegen ihrer Unverträgliehkeit, ihrer divergenten Biologie, räumlich in der Hauptmasse roneinander getrennt, so daf nur der Rand ihrer Verbreitungsbezirke Misehbestände und Bastarde aufweisen kann; so sind z. B. für die Stieleiche die Flußniederungen, für die Traubeneiche das anschliefiende Hügelland die ursprüngliche Heimat; erst durch die Tätigkeit des Menschen ist die weniger wertvolle Stieleiche vielfach an die stelle und in die Gesellschaft der Traubeneiche gekommen.

11. Zwei oder mehrere Baumarten mischen sich um so leichter, je näher ihre Verwandtschaft in waldbaulichen Eigenschaften, je weiter ihre systematische, morphologisch-anatomische Verwandtschaft; z. B. die Schattenhölzer Fagus und Abies; (Quercus mit Föhren, Pinaster und Murrayaföhren oder einer anderen Lichtholzart, die Halbschattenholzgattungen Tilia mit Acer oder Ulmus, die immergrünen Eichen mit immergrïnen Laurusarten u. drgl.

12. Die im Waldbau gebräuchliche Methode der Verjüngung übt insofern einen Einfluf aut das Auttreten bestimmter Bestandsarten ans, als z. B. der Kahlschlag mit darauttolgender künstlicher Verjüngung fast stets rinen Bestand ergibt, während der langsame, natürliehe Verjüngungsgang an besten die Frhaltung vorhandener Baumartmischungen gewährleistet.

Folgende biologisch-waldbauliche Gesetzmäßigkeitrn und wirtschaftliche Vor- und Nachteile sind in den reinen Baumvereinigungen am stärksten ausgeprägt, sind im reinen Bestand mit oinzehen anderen Holzarten bereits etwas abgeschwächt und verlieren sich allmählich, jo mehr andere Holzarten einzeln oder gruppenweise oder bandweise beigemengt sind, d. h. je mehr der reine Bestand in einen Mischbestand ïbergeht.

1. Bestände einer Lich tholzart sind nur während des jüngeren Stangenholzalters geschlossen, später lockert sich das Kronendach, die Ästereinigung wird von diesem \%eitpunkte an unterbrochen; die 
Schäfte bleiben kurz; es erscheinen (rräser bei wroniger gutem, etwas trockenem Boden, Kräuter und holzige Standen bei frischem und besserem Bocken: Sträucher anf geringem, troekenem Brolen lilken Rohlimmus.

2. 1)iese Bodenverwilderung zehrt an Nälirkapital des Burlens, verringert den Nähr- und Wurzelraum, nimmt Niederschläge vorweg. verschlieft die Luftzirkulation, bis schlieblich die Hulzarten selbst gerschädigt werden; für die Wiederverjüngung hestehen die ungünstigsten Verhältnisse.

3. Bestände einer Halbschat tenholzart halten sich iiber clas Stangenholzalter hinans gesehlossen. die Schätte der stämme werden vollkommener und höher hinanf von den Ästen gesänbert, und lis zu diesem Zeitpunkt bleibt auch der Boden unkrautfrei; rlic ahfallenden sitoffe zersetzen sich bis dahin normal. Ton da an stellt sich rie Verunkrautung ein wie bei den Lichtholzarten, zn denen die Halbschattenholzarten während der zweiten Hälfte ihres Lebens zu rechnen sind. während sie in der ersten Hälfte den Schattenholzarten sich nähern.

4. Bestände einer Schattenholzart bleiben bis in das hohe Baun alter geschlossen; die Folge ist vollkommene Ästereinigung. Vollholzigkeit, Schafthöhe; bei Nadelholzarten zeigt sich jedoch im Boden eine Anhäufung ungenügend zersetzter Streu (Rohhmmus), welcher dem Boden Feuchtigkeit, Wärme und Luft vorenthält: für die Naturbesammng liegt die Aussicht ungünstig; bei Laubhölzern. welche im Winter kahl sind und deshalb Licht und Fenchtigkeit mgehindert zum Boden gelangen lassen, unterbleibt die Anhäufung von Rohhumus fast ganz: es entsteht Mull- oder Normalboden : die immergrünen Lanbholzarten nähern sich in ihrem Verhalten den immergrünen Nadel-Schattenholzarten: Rohhumus fehlt aber wegen gröferer Wärme und Fenchtigkeit.

j. Reinen Beständen kommt eine geringere Widerstandskraft gegen Ereignisse der unbelebten Natur zu. wie gegen Sturm. Schneemassen. Hochwasser, Lawinen, Abrutschungen.

i. Reine Bestände erliegen am häufgsten und grïndlichsten den Massenvermehrungen ihrer Feinde ans der belebten Welt, das sind vor allem Insekten; reine Bestände hegünstigen die Massenvermehrungen dieser schädlichen Tiere.

7. Alle Nachteile verringern sich, aber auch alle Vorzüge vermindern sich, je größer innerhalb eines reinen Bestandes die Altersunterschiede der einzelnen Individuen sind.

s. So wenig waldbauliche Vorzüge die reinon Bustänlo bieten. $\rightarrow$ zahlreich sind dieselben in hetriebstechnisch-turstlicher Hinsicht, als da sind Leichtigkeit der Regelung des ganzen Betriebes. der Kontrolle, Vorbilligmng des Holztransportes, Tereinfachuner des Verkanfes, Leichtigheit der Verjüngung. Leishtigkeit der Erziehung. gröpere Nutzholzmassen, höhere Rentabilität. creringere Anforderungan an kïrperliche und geistige T,eistungstahigheit des Per- 
somals. Vertasser ist geneigt, liesen letzten Punlit als einen Sachteil der reinen Bestände zu betrachtru. Da der Kahlschlag durchaus kein notwendiges Attribut der reinen Banmvereinigungen ist, so ist der Vorwurf ,ler allmählichen Bodenverschlechterung nicht gegen den reinen Bestand an sich, vielmehr gegen die vorherrschende, wirt $\therefore$ chaftliche Behandlung des reinen Bestandes zu erhehen. Der den reinen Beständen zugeschriehene Vorteil der größten Holzmassenund Wertserträge dart diesen auch wohl nicht bestritten werden: zweifelhat aher bleiht es einstweilen noch, ob dieses Ziel am vollkommensten in der Kahlschlagswirtschaft erreicht wird.

Man kïnnte geradezu den Satz aufstellen, alles, was die reinen Bestände a $\mathrm{Nachteilen} \mathrm{zeigen,} \mathrm{ist} \mathrm{ein} \mathrm{Vorzugdergemis} \mathrm{chten}$ Bestände: alle Vorteile der reinen Bestände verkehren sich bei den gemischtrn Beständen in deren Nachteil. Gleichfalls behuts stärkerer Betonung der Vor- und Nachteile der gemischten Bestände seien die waldbaulich-biologischen Eigenschatten der gemischten Bestände hier den reinen Beständen gegenüber gestellt: es liegt anf der Hand, daß Vor-und Nachteile am meisten denstammweise, weniger den gruppenweise und bandweise, am wenigsten den kleinflächenweise gemischten Beständen zukommen.

1. Die nachteilige, waldbauliche Wirkung, welche reinen Lichtholzbeständen vorherrschend in bezug auf Schaftform und Bodenrerfassung zugeschrieben werden mußte, wird abgeschwächt, wenn dieser eine Halbschattenholzart, und wird ganz aufogehoben, wemn ihr eine schattenholzart beigemengt wird; was jedoch hierbei die Lichtholzart an forstlicher Brauchbarkeit gewinnt, verliert die Halbsehat ten - und ganz besonders die Schat tenholzart (Schaftverkürzmng. Astigkeit).

2. Der nachteiligen Wirkung der Verlichtung der reinen Halbschattenholzarten während ihrer zweiten Lebenshälfte liamn rorgebeugt werlen durch Beimengung einer Schattenholzart: es bleibt aber die nachteilige Nutzholzausbildung der Schattenholzart.

3. Wie nachteilige Wirliung der reinen Schattenholzarten in bezug auf' den Bolen wirl autgehoben durch Eingriffe in das Kronenschlußverhältnis ofler dare heimischung einer anderen Schattenholzart, besser einer Halbschatten- und besonders durch Beimischung einer Lichtholzart: dabei wirl jerloeh stets an Masse und Nutzholzgüte bei den Schattenholzarten verloren: der Verlust an Masse kann williommen sein (Bnche), um an ihre stelle die geringere, aber wortrollere Masse einer Lichtholzart (Eiche, Führe, Lärche) zu setzen.

4. Siellst bei Schattenholzarten, z. B. Fichte und Buche, ist Kronemmischung ungünstig durch Verlust an Masse, an Nutzholzgïte, so daf der reine s.hattruholzbestand mit Lnterbau einer anderen Holzart als das Ideal einer konservierenden und rentierenden Wirt- 
schaft erscheint. Treten zwei oder mehrero Holzarten mit verschioden tiefgrehender Bewurzelumg in einem Bestand in Voreinirmmg, so gewinnt dadurch die Sturm- und Schmerestigkeit des Bestandes: doch gibt es Wege, um dies auch tür den roinen Bestand zu procichen.

5. Treten zwei oder melnere Holzarten mit verschiedenen Ansprïichen an den Nährgehalt im Boden in Mischung, so wird dersell,. besser ausgenützt; die Art der Mischung: gruppen- ocler klointlächenweise. soll ein naturgetreues Abbild der gruppen-oder kleinflächenweisen Verschiedenheiten im Boden selbst sein.

6. Gemischte Bestände leiden weniger durch Insckten, durch Pilz', durch Fener, als der reine Bestand der Licht- wie auch der sehattenholzarten.

7. Zu den waldbaulichen Vorzïgen kommen noch forsttechnische, wie Vielseitigkeit der Produkte, geringere schwankungen in der Rentabilität, billigere, weil vorwiegend natürliche Wiederverjüngung. welche jedoch auch im reinen Bestande erzielbar: die Verjüngung der gemischten Bestände ist jedoch sehr viel schwieriger. sehr viel langsamer und erfordert ein höheres Maßs körperlicher und geistiger Arbeit von seiten des Wirtschafters.

¿. Alle obigen Vorzüge der gemischten Bestände vermindern sich, je größer, und alle ihre Nachteile erhöhen sich, je geringer die Altersbzw. Höhenuntersehiede der einzehen Individuen eines Mischbestandes sind.

9. Mischungen von Lichtholzarten unter sich müssen größsere Vor züge in bezug auf den Boden, aber größere Nachteile in bezug auf' den Bestand (Masse, Ästereinheit, sichaftform) zugesprochen werden, als den reinen Beständen einer Lichtholzart.

11. Mischungen von Halbschattenholzarten unter sich verhalten sich in bezug auf den Boden günstiger, in bezug auf Nutzholzmasse des Bestandes ungünstiger als ein reiner Bestand einer Ilalbschattenholzart.

11. Mischungen ron Schattenholzarten (z. B. Picea und Abies, Picea und Fagus usw.) üben wohltätigen Einfluf aut den Bodenzustand, dagegen ist sicher, daB reine Bestände höhere Erträge in Masse und Güte ergeben als gemischte.

Stellt man aus der Ertragstafel, wie sie der $N$ oum eister. Retzlaffsche Forst- und Jagdkalender ${ }^{1}$ ) bringt, die Leistungen ron reinen Beständen auf $z$ weiter Bodenbonität in 110 . Jahren hei der ïblichen Behandlung und Erziehung im Kahlschlagbetrieb nach Licht und Schattenholzarten zusammen, so ergibt sich als Hauptbestanchiolzmasice an Derbholz pro Hektar in Festmeter: La ubholz: Lichtholzart. Eiche 310, Schattenholzart: Buche,$\cdot 20$ : Nadellülzer: Licht -

1) Fur das Jahr 190s; nach den Untersuchungen ron tichwaplpach, Lore Grundner und anderen. 


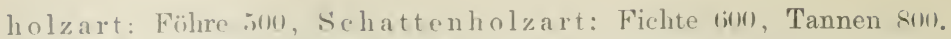
Man dart aus diesen $/$ ahlen den Schluß ziehen, d a $\$$ a lle La ubholz arten. Wenn wie nach derin Jeutsehland übliehen Hoch wallwirtschaftsmethode und in einem dem deutsehen iilnlichen Klima helandelt werden, aut gutem Boden zweiter Bonität nit 10u, Jahren Derhholzerträge abwerfon werden, welehe zwischen :un tim und iul fm pro Hektar liegen missen, la Balle Nadelhölzer unter den gleichen Voraussetzungen zwischen jul mul sill fim ergeben werden. Was his jetzt im In- und Auslande an Wuchsleistungen fremder, forstlicher Baumarten bekaunt grworden ist, ihbertrifft obige Leistungen nur bezüglich der Holzarten, deren rattungen im europäischen WValde nicht vertreten und in Westamerika beheimatet sind.

Konservatire Vorsicht ist es, welche nach möglichster Erhaltung der ungeschwächten Bodenkraft strebt und dieses durch den Mischwald zu erreichen hotit; die einschmeichelnde Berechnung höchster (rewinne ist es, welche auf die reinen Bestände hinweist.

Damit einer Wirtschaft die Zukunft gehöre, muß sie sichere Gewähr bieten, daß bei ihr die Bodenkraft nicht abninmt, und darf sio die Erwartung ('iner möglichst hohen Rente nicht schmälern; im Verlaute dieser Schrift werden Wirtschaftsformen zu nemnen sein, welche darauf abzielen.

\section{b. Klimatische Verhältnisse der Baumvereinigungen (Bestandesklimatologie).}

Dem einzelnen Waldesteile (Gruppe oder Bestand) kommt natürlich jones allgemeine Klima $z u$, das der Elevation und dem Breitensrarle. somit d'r cresamten Klima- oder Waldzone entspricht; seine I age zur Meeresnäho bestimmt den insularen oder kontinentalen ('harakter des hetreflenden Waldortes; aher jeder Bestand hat, wemn auch im verkleincrten Maße, wieder sein eigenes Klima je nach Holzart (Licht-odre Sichattenholzarten), je nach der Mischung beider; dazu kommt noch der Einftub, den Bod'n und Behandlung anf das K'lima ausühen. Jir. Klimatologric der cinzelnen Bestandsarten ist noch sehr ungenügend ertorscht, sulhst die fregensätze zwischen Wald und Waldblöße oder Feld sind durch die Beobachtungen und ihro Berechmungen mehr verliillt als aufigederelit. Forschung und Berechnung haben ergeben, daß zwischen Wald mud Fold ouler Blïße nur ein wanz geringfügiger Untershlied besteht. l)ieser zahlommäBig uringtünge Untersehied ist aber ein kïnstlicher, durch Borechnumg von I)urchschnitswerten erzielt; er brancht somit in der Natur gar nicht zu existieren, jedenfalls trifft er in den entseheidenden, extremen $7 /$ aniten des Hothsommers und Hoch- 
winters nicht zu; aber schon geringe Ḱlimaunterschicdo können zu Beginn der Vegetation für die Entwiclilungsegeschichto dos Waliles von einschneidender Bedeutung sein, wie folgender, selır hänfigre Vorgang im Walde beweist. Unter dem lockeren Śchirme des alten Holzes wurde eine Verjüngung, z. B. von Fichten oder Tamen orler Buchen, begründet; in einer klaren Nacht Mitte Mai lagert sich üher der bereits in Vegetation getretenen . Jugend eine Luftschicht von (1). Eino unmittelbar anschließende, kahle Fläche, mit der .Jugend der gleichen IIolzarten bestellt, weist - 1, 50 auf. Die beschirmte Jugend geht völlig intakt ans der Frostgefahr hervor, die unbeschirmto büft ihre sïmtlichen Triebspitzen ein; bei den Nadelhölzern ist der volle Höhenzuwachs eines ganzen Jahres, bei den Laubhölzem ein Teil desselben vırloren durch die Geringfügigkeit von nur einem halben Grad Wärmounterschied: Das Beispiel wurde einer Beobachtungsroihe des Verfassers entuommen; es treten aber Differenzen bis zu $5{ }^{0}$, bei der tiefsten Wintertemperatur bis zu 10 ${ }^{\circ}$, ja im vollen Sonnenlichte in der Bodennähe Differenzen bis zu 20 ${ }^{\circ}$ Wärme an der nicht bewalcleten und an der bewaldeten Fläche auf. Alle diese für das Pflanzenleben so einschneidenden Extreme aber werden mit der Durchschnittsberechmung des Klimas der kahlen Fläche und des Walcles wegnivelliert.

Die durchschnittliche 'Temperatul' gibt die Wärme an, welche eine Pflanze überhaupt zum Leben brauclst; die Extreme bestimmen die Wechselfälle in ihrem Leben.

Welche extreme Temperaturen in Walde und auf dem waldlosen Boden herrschen, zeigt folgende Darstellung, welche Verfasser nach eigenen, sechsjährigen Beobachtungen und, soweit höhere Luft- und tiefere Bodenschichten in Frage kommen, nach den Angaben der Literatur für $570 \mathrm{~m}$ über dem Meere gefertigt hat. Es wurden die beiden Extreme Mittsommer und Mittwinter gewählt, da an Extremen die Gesetzmäßigkoiten am ausgeprägtesten sind; rote Kreise bedeuten eine Temperatur ïber $0^{*}$, blane eine solche unter $0^{*}$, de gxößeren roten Kreisen entspricht die höhere, den größeren blaum die niedere Temperatur. (Tafel I und II.)

Im Hochsommer zur Mittagszeit, somit zur Zeit der größten Erwärmung, wird vom Kronendache des Waldes wie von einer grünen Fläche der größte Teil der zugestrahlten Wärme zurïckgeworfen, cin kleinerer Teil erwärmt das Dach, das durch Leitung und sitrahlung wiederum den größten Teil der Wärme an die Luft abgibt; ¿̀ m über dem Kronendache ist diese Wärmezutiuhr nicht mehr nachweishar, d. h. die Luft ist $5 \mathrm{~m}$ über dem Walde mit den benachbarten I,uftichichten der kahlen Flächen von gleicher Temperatur. Innerhalb der Kronen ist nur ganz geringe Wärmeanläufung durch die Besonnung der Äste der Kronen nachweisbar, da die Blätter oder Nadeln nie vollkommen 
die Brlichtung abschließen: die Luftsänle zwischen Krone und Boden z-irt nur gringe Differenzen: eine schwache Zunahme an Wärme besteht in der Bodennähe, da der Boden, wenn auch in kleinen, wandernden Fleckichen, von der Sonne gretroffen wird. Die Temperatur des Bodens s.llbst ist bereits auf Seite 11:5 besprochen worden. Gegen Somnenuntergang hin nimmt die Temperatur rasch ab, die Abkühlung setzt sich während der Nacht hindurch fort, $n$ etwa $1 / 4$ Stunde vor Somnenautigang ihren tiefsten stand zu erreichen: der Beginn der Dämmerung, das Auftreten von diftusom Licht bedingt bereits eine, wenn auch schwache Erwärmung der Erdoberfäche und damit auch der Lutt.

Auf den waldlosen, den verunkrauteten Kahlschlägen, den kahlen Löchern der Verjüngungshiebe liegt zur Mittagszeit die größte Hitze unmittelhar über dem Unkrautwuchs; ron da nimmt die Temperatur aut- und abwärts ab. Schon bei Sonnenuntergang ist dort die Temperatur nierlerer als in geringer Höhe ïber dem Boden; Taubildung begimnt. Eine Stunde ror Somnenaufgang liegt auf der Unkrautdecke die tiefste Temperatur; der Unterschied zwischen höchster und tiefster Temperatur innerhalb zwölf Stunden kann bis auf $35^{\circ}$ steigen: Verfasser konnte $\mathrm{im}$ Juli und in August in seinem Versuchswalde, $570 \mathrm{~m}$ über dem Meere, auf einer begrasten Stelle mehrmals in der Mittagszeit $35^{\circ}$ und am frühen Morgen (im Hochsommer!) $w^{0}$ beobachten. Durch Aufstellen eines mit Wasser gefüllten Tellers gelang es, eine Eisschicht von $1-2 \mathrm{~mm}$ zu erzielen, die freilich bei Sonnenaufgang morgens 4 Uhr raseh dahinschmolz.

In den Erlenbrüchern sind Frostbeschädigungen mitten im Jahresringe, ja Absterben von Erlen, Eschen durch Frost während des Hochsommers durchaus keine seltenen Erseheinungen. Daß begraste MIulden und Ebenen im Frühjahre und lerbst ron Frost ganz besonders heimgesuchte Örtlichkeiten sind, ist längst bekannt. Der röllig nackte Boden, wie er im Walde auf kahlen Flächen, in kahlen Löcherhieben zum Zwecke der natürlichen oder kïnstlichen Ansaat zubereitet wird, woist die stärkste Erhitzung in seiner obersten Schichte auf; es wurde bereits crwähnt, daf Temperaturen bis zu fis ${ }^{\circ}$ beobachtet werden: diese Schichte ist das Keimbett der Sämereien. Yon da an nimmt die Temperatur nach oben and nach unten ab; kurze '/eit vor Somnenaufgang liegt die kälteste Luffichicht bei etwa 1 m Höhe über dem Boden, da aus dem Boden Wärme auf'steigt, welche bei begrastem und bewaldetem Boden alogeschlosien ist; diese aufsteigende Wärme vermindert auf völlig nacktem Borlen die Frostgefahr im Frühjahr und Herbst.

Eine klare Nacht und ein darauffolgender klarer Tag im Mittwinter schafft folgende Tersehiebungen in der Temperatur einer bewaldeten und beschneiten, einer kahlen, aber beschneiten und einer 
anderen schneefreien Fläche. Vor sonnenaufgame liegt das Minimum an Temperatur von allen drei Flächen ummittelbar auf der s'chneedeke der waldfreien Fläche. Verfasser fand auf seinen Versuchsflächen in einer Mulde zu Grafrath bei München als Minimum während der let»ten 15. Jahre $-3 \mathrm{~s}^{0} \mathrm{C}$ : $50 \mathrm{em}$ höher betrug die Luftumperatur nur melır -250! Es besteht kein Zweifel. daß noch viel tiofere Temperaturen in Mitteleuropa sich einstellen kümnen. Diese Beoharhtung genn̈gt rollständig zur Erklärung des Absterbens oder der Nallelröte, besonders fremdländischer Pflanzen: unmittelbar üher der Suhncedectie sind sie einfach erfroren, während der Teil, der in dem wärmeren s'chnee eingehettet war. lebend und grün blieb. Aus diesem Grunde ist dir mittel- und südleuropäische Tame in Rußland anf freier Lage nicht empor zu bringen. Es bedarf zur Erklärung der Rötung der Nadeln und des Abfrierens der über den Schnee hervorstehenden Pflanzen nicht eigener Tertrocknungstheorien mit Windbeteiligung, die vielleicht für die zentralasiatischen oder polaren, somit für die Walsgrenzgebiete zutreften mögen, für das Innere der großen Waldregionen aber sicher talsch sind. Die Schneedecke hält zur Zeit des Sonnenaufganges pro $1 \mathrm{~cm}$ Schichtendicke $1^{\circ} \mathrm{C}$ zurïck, so daß eine Schneedecke von $20 \mathrm{~cm}$ genügt um - $20^{\circ}$ vorübergehend von der Erdoberfläche vollständig abzuhalten, d. h. an der Bodenoberfläche beträgt die Temperatur $0^{0}$.

Im Walcle liegt die tiefste Temperatur auf der Schneedecke der Baumkronen. Von dieser an aufwärts ist es wärmer; ein Teil dieser kalten Luft an der Aufenfläche der hrone sinkt auch in den Innenraum der Krone ein und fällt zu Boden: die zwischenliegende Luft ist insbesondere durch Leitung von den Baumschäften her wärmer.

Ian kann den Wald in seinem Einfuß aut sein eigenes Kilima mit einem Haus rergleichen, dessen Binnenwärme und Binnenluft verschieden sind ron jenen der äußeren Umgebung; ihr besonderes Klima haben auch die Außenwände des Hauses, die Bestandsränder des Waldes. Gleich den West- und Südwänden eines Hauses sind auch die West- und Südränder eines Bestandes warm und trocken: die entgegengesetzten Ränder Nord und Ost sind kühler und feuchter. Der Südrand bedentet in der Temperatur und Luftfenchtigkeit eine Verschiebung in ein wärmeres Klima, der Nordrand eine Verschiebung in ein kälteres: am Südrande werden die wärmebedürftigen Baumarten trotz geringerer Boden- und Luftfeuchtigkeit gedeihen, während sie im Klima des Nordrandes versagen, wo wieder die Holzarten des kïhleren Klimas ihr Optimum finden werden.

Wird daher im erwachsenen Walde zum '/wecke der Verjüngung ein saumförmiger Angriff geführt. so rückt der bisherige Waldrand mit einem Male tiefer in den Bestand ror. Erfolgt der erste Sambieb am Nord-oder Ostrand des Bestandes, so kommen erhöhte Bodenfirische 
und Inftfenchtigkeit der aut'kommenden orler nachrückenden Verjüngmug zugute. Anf' diese Erscheinung fußt C. W agners Forderung der Verjüngung im "Blendersammschlage", der am Nordrande anhebt und nach süden vorrückt. Wird der saumweise llieb mitten durch den Bestand gelegt als sogenamter Durchgriff, oder durchsetzen mehrere solcher llicbe einen größeren Bestand (Kulissenhieb) von W. nach O. vler $X^{*}$. mach S., so entstehen neue West- bzw. Südwände im Imnern les Bestandes. welche ob ihrer größeren Wärme, Lufttrocknis und Austrockmmg des Bodens natürliche wie künstliche Waldbegrïndung, insbesnndere saat erschweren und meistens zur Pflanzung zwingen. Am ungünstigsten liegt der Fall bei kahlen Löchern oder auch bei gruppenweiser Bestandsverjüngmng, sobald eine solehe Durchbrechung im Durchmesser die Baumhöhe überschreitet: es entsteht eine Vielheit von Wänden mit einer Vielheit von wohltuenden bzw. schädigenden, klimatischen Einflüssen auf die Verjüngung.

Feuchtigkeit. Die Regenmenge, die dem Boden zuteil wird, ist im $W^{\top}$ alde stets geringer als auf einer kahlen Fläche und auch auf einer Waldblöße; immerbegrünte Holzarten, wie Fichten, Tannen, Führen, immergrüne Laubbäume fangen jederzeit einen beträchtlichen Teil der fallenden Niederschläge ab: winterkahle Bäume lassen während der Tegetationsruhe fast den ganzen Betrag an Niederschlägen in den Boden gelangen: während des ganzen Jahres dringen in den Boden ein: nach Prot. Ebermayer $78 \%$ bei Buche, bei $73 \%$ Fichte, $60 \%$ hei Föhre, nach den schweizerischen Untersuchungen $90 \%$ für die Buche und $77 \%$ für die Fichte: Prof. Bühler fand, dal3 20jährige Buchen nur $2{ }^{\circ} \mathrm{v}$, 5ljährige $27 \%$, (6)jährige $23 \%$ und 90jährige $17 \%$ der pro Jahr gefallenen Niederschläge abfangen. Nux bei lang andanerndem Regen wird alles durehtränkt, und gelangt von den Bäumen herabtroptend und am schafte herabfliefend der größte Teil der fallenden Regemmenge anch in das Bereich der Wurzeln, wobei die dureh das Dickenwachstum der älteren Wurzeln immer enger werdenden Kapillaren zwischen Wurzel und Bodenumgebung für das rasche und tiefe Eintreten des Wasscrs in das Wurzelbereich Sorge tragen. In Sommer fanıren auch div Laulhölzer größere Mengen des fallenden Regens ab; hei der Buche ist sogar ein höherer Betrag nachgewiesen als bei den Fichten und Tamen. Unter den Buchen bleibt sehr oft, wenn nicht ranz außerorlentlich starke Gewitterregen niederstürzen, der Boden währond des ganzer śommers ohne Niederschläge. Aber auch die in den Kronen hängrnbleibende Feuchtigkeit ist für die Bäume nicht verloren: ler Baum nimmt mit seinen Blättern und Ästen Wasser auf und ergänzt dannit den Wasservorrat seines sichaftes; so daß ex mit der geringeren Wasseraufuahme durch den Boden sich begnügen kamn. Das in den Kronen verdunstete Wasser erzeugt sodann in und mnter den Kronen eine größere Luftenchtigkeit, welche wiederum die 
Verdunstung des Wassers aus dem Waldbotlen sellost und soiner lebenden und toten Decke beschränkt. Das Kronendach an und für sich schafft schon einen lufteuchten Znstand der Waldhuft durch Verdunstung aus den Blättern, so daß die Waldlutt bei Windstille unter dem Dache der Kronen eine um 10-1.5\% größere, relative Fenchtigkeit aufweist gegenüber den Kahlfächen im Walde, gegenüher dem Felde: die Differenz wird um so geringer sein müssen, je mehr lufthewegung herrscht. Daß diese erhöhte Luftfeuchtigkeit im Waldesinnern ebensis wie größere Luftfenchtigkeit im Gesamtklima für das Gedeihen der Baumjugend und den Erfolg aller Saaten und Pflanzungen ron ein. schneidender Bedeutung sind, wurde rom Verfasser vor ?() Jahren zuerst und auch in dieser Schrift bereits mehrmals betont. Auch an der Verhinderung der verspäteten oder verfrühten Fröste im Walde fällt nicht der durch das Kronendach der Althölzer ermäßigten Ausstrahlung von seiten der kleinen Pflanzen das alleinige Verdienst zu: es trägt hierzu auch die erhöhte Luftfenchtigkeit bei, welche zur Zeit der Frostgefahr (Windstille) gerade im Walde am größten ist.

Schnee wird von den begrünten Bäumen in noch größerer Menge rom Boden zurückgehalten als Regen; in geschlossener Fichtenjugend kommt kaum $1 / 10$ der bei Windstille fallenden Schneemenge zu Boden: erst wemn die Schneomassen so schwer werden, daß sie teilweise zwischen den Kronen hindurchbrechen, erhält der Boden größere Mengen: ein erwachsener Fichtenbestand, gut geschlossen, läßt nur 2.5\% des fallenden Schnees hindureh; es verändert sich natïrlich diese Zahl, wenn der Schnee bei einigen Graden unter 1), somit in feinen Kristallen fällt, in welchem Falle größere Mengen durch die Kronen der Bäume hindurchrieseln; der bei Plusgraden in grofen Flncken fallende Schnee wird am meisten von den Bäumen abgefangen. Das Übermaß von Schnee führt dam zu Kalamitäten (Gipfel und Ästebruch). oder zum flächenweisen Niedersinken der Bestockung, besonders im mittleren Alter. Wird Schnee durch kräftigen Wind herangetrieben, so ist die Gefahr der Beschädigung durch Überlastung ausgeschlossen; es gelangen dann auch gxößere Schneemengen an den Boden der Bestandes: in Bestandeslöehern, an Osträndern fällt aber der Schnee bei geringem Winde, selbst bei Windstille in größerer Menge und schadet.

Hagel fällt auch im Bestand ganz zu Boden; ob er auch am Bestand selbst Schaden verursacht, hängt von der Korngröße des Hagels und dem Alter und der Art der Bämme und der Jahreszeit ab; mur wenn Wind mit Hagel auftritt. wird die Rinde der vertikalen sichäfte und Gipfeltriebe, welche für die forstlichen Gewächse dir wichtigsten Teile der Pflanzen sind, getroffen. Bei vertikal fallendem Hagel leiden nur Seitentriebe; der Wind aber ist fast aufgehoben im Windschatten der Schlagwand beim Saumschlag. in Löcherhieben oder auch im Be- 
stande sellst. Tort ist somit die Hagelheschädigung geringer als ant Kahlfliche'n, in welchen der Wind die Hagelkörner schief gegen die Baumvergetation wirft.

Wrind "rhöht somit dic Hagelbeschädigung, mäßigt oder hindert die s'lnneebeschädigung, mäbigt oder hindert die Frostbeschädigung. Erreichen die Löcher im Bestande eine bestimmte Größe, die nach Höhe des Bestandes und Lage der Örtlichkeit verschieden sein mu, so tritt gerade bei diesen windgeschützten, kahlen Bestandslöchern der Spät- oder Frühfrost besonders häufig und schädlich anf. Wächst ein Bestand mit isoliert stehenden Individuen in den letzten Jahrzehnten seines Lebens seiner Haubarkeit entgegen, so ist er am besten gegen Wind gesichert: seine Abnutzung kann sich mehr dem Zwecke der V'erjüngung als der Furcht ror dem Winde anpassen. Wird aber der Bestand bis dahin absichtlich gegen die Absichten der Natur geschlossen gehalten, und beginnt num mit einem Malo die natürliche Verjüngung mit Lockerung des Bestandsschlusses, dann ist es zumeist der Sturm, der die so schön ausgedachten V'erjüngungspläne des Wirtschafter's über den Hanfen wirft. Wind begïnstigt die Besamung einer Fläche, indem er die flugfähigsten Sämereien darïber strent. Bei allen Holzarten mit Hiegenden Sämereien sind es nur die trockenen, meist schwachen Windle, welche sämereien bringen; denn nur bei trockener Witterung öffnen sich die /apfen und Früchte oder lösen sich die Sämereien.

In Mitteleuropa sind die Ost-, seltener die Südwinde trocken; die starken Winde kommen aus dem Westen und Nordwesten und sind feucht; es ergeben sich darans Folgerungen für die Naturverjüngung der Bestände, welche an der zugehörigen Stelle Erwähnung finden müssen.

\section{c. Die Lichtverhältnisse der Baumvereinigungen, der Kronen- schluis.}

Der Laie, welcher eine Waldnenanlage betritt, rügt stets den rngen Verbanci, in dem Saat oder Pflanzung ausgeführt wurden; er ist grmeigt, sis als mnfreiwilliges oder verschwenderisches Prodult. der forstlichen Tätigkeit zu betrachten. Es ist jedoch damit beabsichtigt, daß keine Pflanzo den ästhetisch-schönen, tief herab und stark beästeten Freistandshabitus anmehmen soll, daß viehmehr die Äste sich berühren. incinander wachsen, sich gregrenseitig Licht entziehen und töten sollen, dab möglichst bald dic sehneller wüchsigen Pflanzen jene mit langsamer II uchsliratt ïhereriuteln und zum Untertauchen unter das gemeinsame hronemdach der Voraneilenden zwingen sollen. Sichlieflich sollen auf einer Flärhe, die bei der Begründung vicle Tausende von Pflanzen trugr, nur noch ringe Hunclerte erwachsene Bämme bei der Ernte übrig sein. Die naturgesetzliche Erklärung für dieses Streben 
nach Übergiptelung wird in einem reinen Bostand in dor versehiedenen, individuellen Veranlagung zur Schnellwüchsigkeit zu suchen sein, worüber in einem früheren Abschnitte ausfüihrlich berichtet wurde; dazu werden auch noch äußere Zufälligkeiten, wie ober-oder unterirdische Verletzungen, unpassende Behandlung, Beeinträchtigung in der Ausbreitung und Vertiefung der Wurzeln, beitragen. Es mag auch soin, daß ein individuelles, stärkeres Wasserbedürnis, ein stärkeres Lichtbedürfnis, ein etwas höherer Anspruch an Bodengüte einzelne Pflanzen zum Zurückbleiben gegenüber iluren für den betreffienden Standort etwas günstiger individuell veranlagten Nachbarn der gleichen Baumart zwingt. Es muß aber abgelehnt werden jene bequemere, aber deshalb nicht wahrscheinlichere Erklärung, daß die langsam wïchsigen Individuen von langsam wüchsigen Eltern abstammten. Damit müßte zugleich behauptet werden, daf diese Langsamwïchsigen von schlechterem Boden oder kühlerem Klima kämen; denn im günstigen Klima und Boden kommen Langsamw ïchsige nur im Ur - und Femelwald zur Fruktifikation und Vererbung eines Teiles ihrer Individualität; es ist wohl ebensowenig zulässig, die Ausscheidung dem eintretenden Wassermangel im Wurzelbereich durch den Wasserentzug der Voranwachsenden zuzuschreiben; denn die Ausscheidung und das Absterben der Ausgeschiedenen findet auch statt in Böden, welche jederzeit Wasserüberschuß in die Tiefe sickern lassen. Die Vorwüchsigkeit liegt in individueller Anlage, das Kümmern und Absterben der Zurüickbleibenden ist die natürliche Folge des Lichtentzuges; es ist ein Verhungern wegen mangelnder Assimilation, selbst dann, wenn im Boden Wasser und Nährstoffe in Fülle vorhanden sind.

In einer stammweise gemischten Baumvereinigung entscheidet natürlich die Wuchsgeschwindigkeit der in Mischung getretenen Arten sowie deren Lichtbedürfnis bzw. Schattenerträgnis, welche Ilolzart ohne Eingriff des Menschen schließlich zur siegerin wird.

Zweck und Bedeutung des Kronenschlusses findet in der forstlichen Literatur eine sehr verschiedene Beurteilung. Früher erschöpfte sich die Kunst des Forstmannes in der ängstlichen Erhaltung des Kronenschlusses bis zur Haubarkeit. Davon ist die nenere \%eit abgekommen, und täglich mehren sich auch unter den Praktikern die Anhänger für freiere Erziehung in der zweiten Lebenshältte in der Erkenntnis, daß von einem bestimmten Alter an der volle Kronenschluß nicht bloß überflüssig, ja für Boden und Zuwachs sogar schädlich sei. In nenester Zeit sind sogar Stimmen lant geworden, welche auch den Kronenschluf in der Jugend als etwas Üherflüssiges. ja sogar Schädliches bezeichnen. Sie wünschen möglichst lange den Eintritt des Kronenschlusses hinauszuzögern, während die Forstleute, insbesondere die Kahlschlägler, bisher mit sehnstichtigem Herzen auf' den Eintritt des Kronenschlusses ihrer Pflanzungen als das Ende allor 
Sarhhesicrungen, aller Gefahren, aller Sorwen für die nene. Jugend wartetun. Manche Saat wird deshall, sn dicht, manche Pflanzung deshall so eng ausgefïhrt, um den Eintritt des Kronenschlusses möglichst zu beschleunigen: es wurde hisher begrüßt, daß schnellwüchsige Holzarten so rasch sich schliefen, daß auf gutem Boden früher als au schlechtrm dieses erwünschte Ereignis eintritt.

Dir Dichtigkeit des Kronenschlusses wird beeinflubt:

1. Von der Begründungsweise des Bestandes: natürliche oder künstliche Ansaaten liefern die am dichtesten geschlossene Jugend: enge Pflanzungen schließen sich au, weitständige Pflanzungen geluen den lockersten Schluß.

2. Auf gutem Boden ist der Kronenschluß vollkommener und lïnger andauemd als auf minder gutem Boden, obwohl letzterer eine größere Zahl von Pflanzen trägt, da die Ausscheidung im Übergipfelungskampf auf minder gutem Boden langsamer geführt wird als auf kräftigerem.

3. Sind zwei Standorte in Luft- und Bodenfeuchtigkeit gleich, so trägt der wärmere einen dichter in seinen Baumkronen geschlosienen Wald: in der liühlsten Waldregion löst sich der Kronenschluß völlig auf. Sind zwei Standorte in Temperatur gleich, so ist der trockenere von Bäumen mit dichter anemander gerückten Kronen bewohnt, als der luft- oder bodenfenchtere.

4. Die Holzart selbst entscheidet ïber die Dichtigkeit des Kronenschlusses. Lichtholzarten stellen sich, wie bereits erwähnt, immer lieht, d. h. ihr Kronenschluß ist ein lockerer: Halbschattenholzarten erhalten eine Kronenspannung längere Zeit als Lichtholzarten, aher im höheren Alter löst sich diese ebenfalls auf: Schattenholzarten wohnt die Fähigheit inne, bis in das Alter eine Kronenberïlurung festzuhalten.

5. Im Il a uptlängenwachstum, im Stangenholz- oder Mittelalter ist die gegrenseitige Bedrängung stets die dichteste.

ti. Es ist selbstverständlich, daß jeglicher Lockerungsgrad dureh die Eingriffe hei der Erziehung eines Bestandes künstlich durch den Wirtschatter hergestellt werden kamn. und in dieser Kunst zeigt sich der Meister der Wirtsehaft. Vielfach hat man versucht, fürr den Schlußgrad eines Bestandos einen zahlemmäßigen Ausdruck und damit ein bequemes Mittel zur Erklärmng und Kontrolliermng des Sehlußgrades je nach Holzart, nach Standort, nach Wrunsch und Kiel und jeweiliger Anschaumg des Wirtschafters zu finden. Kein passender Maßstab konnte gefunden werlen, und keiner wird gefunden werden. Verfasser ist geneigt, sich über diese Miferfolge zu freuen; dem eine solche Schablone mülito zur Verflachung der waldbaulichen Beobachtung und zu den größten Mißgriften führen. da in einer Baumvereinigung, 
in einem reinen Bestande nicht eine, sondern viele, in cinen gemischten Bestande ungezählte Kronenschlubverhältnisse notwendig sein werden.

Zu den Angaben der Stammzahl pro Hektar hei gemebenem Alter, gegebener Holzart, gegebener Bodengüte und heabsiclitigtem $/$ weck, zur Ermittlung der Grundflächensumme der vorhandenen Stämme, zur Ermittlung des Durchschnittstandraumes eines Baumes in curarlratmeter, zur Abstandszahl ist in nenerer \%eit eine Methode gretreten, dic eher dem Ziele sich nähert: die photometrische mittels lichtrmpfindlichen Papieres, zu welcher bereits Th. Hartig die Anregung gegehen, welche Wiesner rervollkommt und Dr. Cieslar bereits für forstliche Zwecke in Anwendung gebracht hat. Bis heute hat keine ron diesen Methoden Eingang in die Praxis gefunden, dio sich bei der großen Menge ron Wirtschaftsobjekten und den großen Verschiedenheiten in einer Baumvereinigung mit der Einschätzung des Kronschlusses und der Anwendung technischer Bezeichnungen, wenn diese auch wenig zutreffend gewählt sind, begnügt. Zur Erklärung der bildlichen Darstellung auf der folgenden Seite sei erwähnt, daß die Kreise die auf den Boden projizierten Baumkronen bedeuten.

Dicht-oder gedrängt geschlossen heißt die Baumvereinigung, wenn ihre Kronen tief ineinander und übereinander greifen; von diesem Schluß geben Schattonholzarten im Hauptausscheidungsalter, im Dickungsschluß, wie er vor Einlegung der ersten Durchforstung zu bestehen pflegt, ein naturgetrenes Bild.

Vollkommen geschlossen heißt die Baumvereinigung, wenn ihre Kronen schwach ineinander greifen; das ist der dichteste Schluß für die Lichtholzarten, der Dickungsschluß, wie ihn ein gedrängtes Gestänge von Eichen, Lärchen, zwei- und dreinadeligen Föhren aufweist: Schattenholzarten nähern sich mit diesem Schluf hereits der Mannharkeit.

Geschlossen ist jenes Kronendach, bei dem die /weigspitzen sich berühren; Schattenholzarten zeigen diesen Grad des Schlusses im haubaren Alter; bei den Lichtholzarten ist dieser Zustand längere Zeit auf gutem Boden nur im Stangenholzalter als Übergang zur Verlichtungr vorhanden.

Locker oder licht heißt der Schluß, wenn sich die hronen roneinander entfernen, jedoch nicht so weit, daß noch ein Baumindiridum mit normaler Krone dazwischen Platz fände; in diese Verfassung treten alle Lichtholzarten im haubaren Alter, während bei den schattenhol\%arten dieser Zustand erst durch einen künstlichen Eingrift', weleher ihre Verjüngung beabsichtigt (Verbreitungshieb), geschatfen wirt.

Durchlöchert, räumig oder lückig heißt eine Bamvereinigung, wenn größere Löcher in ihr vorhanden sind, anf welchen ein und selbst mehrere Bäume mit normaler hromenbilinng Raum und 
Licht finclen würden: wenn Liehtholzarten auf' natürlichem Wege verjüngt werden sollen, ist ein derartiges Kronenverhältnis zur Besamung ansreichend: bei schattenholzarten muß Verjüngung bereits Fuß gefaßt laben, wo und wemn ihr hronensehlufs derartig durchlöchert ist.

Mittelwaldsehluß ist der isolierte Stand der Kronen der alten Bümme (Oberholz) in Einwirking auf den nach obigen Graden wechselnden Sichlup des Interholzes.

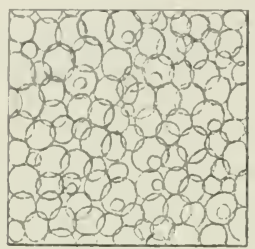

Iichi oder gecirärgt.

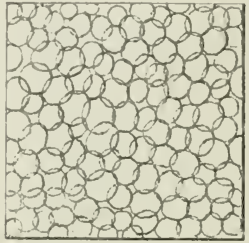

Votzk. geschlossen.

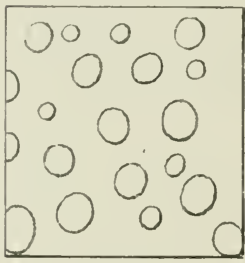

Rüumig.

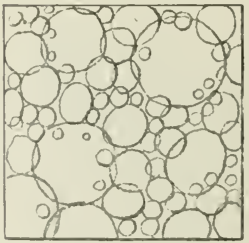

UTratd
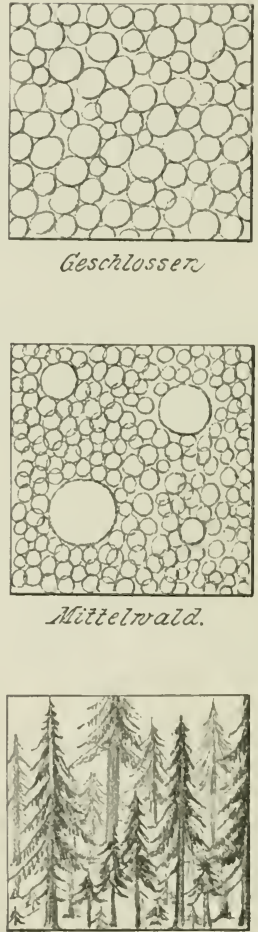

viruald.

Ahb. 11. Darsfellung der verschiedunen fichlußgrade (7) der laumvereinigungen.

Urwaldartiger oder FemelsehluB, eigentlich der normale, weil natürlicho sechluf für alle Holzarten, ist jene Lagerung der Baumkronen, bei der kein horizontales, gemeinsames Dach gebildet wird, bei der vielmehr die Kronen in allen Ebenen zwischen Boden und höchsten Baumkronen angeordnet liegen. 


\section{Die Bedentung des homenschlusses und seine Einwirkung anf die Biologie der Bammvereinigungen.}

1. Ausnützung des śtandraumes, größerustammzah! a uf gegebener Fläehe; über diesen Punkt bedarf' us hei Vorgleich einer dichtgeschlossenen und einer durchlöcherten Bammvereinigung keiner weiteren Erörterung. Es ist aber noch zweifelhatt, (1) Femelschluß nicht eine größere Zahl von Individuen anf einer Fläche beherbergt als ein Kronenverhältnis, das man für vollkommen geschlossen erklärt. Im Plenterschlusse fußen anf dem Boden sicher mehr Pflanzon als beim lichten oder durchlöcherten Schlusse gleichalteriger Banm. vereinigungen, obwohl im Femel- und Urwalde ein Sichlub nach üblicher Auffassung in den Kronen üherhaupt nicht eintritt.

2. Der enge Standraum engt den Durchmesser der Kronen ein und verpeitscht dieselben. Tancht ein Individnum unter das Kronendach, so rerflachen sich die Kronen; nimmt die Üherschirmung in Dichte zu, so kümmert die Krone und stirbt ab.

3. Verkürzung der Kronen beginnt mit der Reinigung des Schaftes von den Ästen; in dem Maße, in dem die Krone nach oben wächst, nimmt sie den tiefer stehenden Ästen das Licht: es stirbt somit die Krone an der nach unten gekehrten Seite ab.

Im vollen Freistand zeigen Licht- wie Schattenholzarten dieselbe Verbreiterung der Krone mit Erhaltung der Äste bis zur Basis herab; die unteren Äste weichen durch ihr Längenwachstum der Üherschirmung durch höher stehende Äste ans. Bei engem Verbande ist das Ausweichen unmöglich, die Äste begegnen sich und töten sich durch Lichtentzug. Diese Astreinigung ist am vollkommensten, wenn Schattenhölzer im reinen Bestand auftreten, ist am ungünstigsten in Lichtholzmischungen. In reinen, gleichalterigen Beständen ist der Kampf m Licht und Raum am intensivsten, weil alle Individuen einer Art mit annähernd gleichen Waffen ausgerüstet sind; als Verschiedenheiten bestehen nur individuelle und solche im Boden: der Kampf danert am längsten zugunsten der Astreinigung. Im gemischten, gleichalterigen Bestande (der ungleichalterige gibt stets mäfigen sichlub und mäbige Astreinheit) ist der Kampf ein solcher mit ungleichen Watfon: zu den Verschiedenheiten der Individuen und des Bodens kommt noch jene der Arten: das Schicksal ist schneller entschieden. dor whä̈here unterliegt früher und in die entstehende Läckt wächst der siegrer mit seinen Ästen hinein als minderwertiger, astreicher Stamm. Werden Licht- und Schattenhölzer stammweise gemischt, so wird lie Lichtholzart astrein, die Schattenholzart dagegen astiger als im reinem, weniger astig als im vollen Freistand. Mit dem Eintritt der natiirlichen (Lichtholzart) oder künstlichen Verlichtnuy (I)urchlichtmagshiebe) hört die Astercinigung des S'chaftes zwar nicht auf, wie ist aber 
eine Funktion sn langer Zeitrüume geworden, daß sie außerhalb der forstlichen Branchliarkeit liegt.

4. Formverbesserung der Schäfte. Tollholzigkeit. Bei jedem Binme "rfolgt an zwei Stammquerschnitten ein Stärkezuwachs, der grofor ist als an den übrigen Querschnitten. Die eine Zone kanm man dir mechanische $/$ uwachszone, die andere die physiologische $\%$ u wachsone nennen. Die mechanische Zuwachszone ist jen stelle, an welcher der Baum eine erhöhte Beanspruchung anf Beugung iführt durch Verschiebung der Gleichgewichtslage, sei es infolge ungleicher Ausbildung der Kronen oder infolge Druckes von stärkeren. vorwiegend ron einer Seite kommenden Winden. Bei allen Bämmen liegt diese mechanische Zone möglichst tief am Schafte, wo dieser ans der Erde hervorbricht. im Wurzelhalse, im Drehungspunkt des Hehels. Die Aushuchtung des Schaftes, die Bildung ron Druckholz in stark verdickten Zellwandungen, die Ausformung starker Stützwurzeln an dieser Stelle sind die Folgen dieser Zuwachssteigerung. Die physinlogische Zone erhöhten Zuwachses liegt an jener Stelle, an welcher die ron den Blättern oder Nadeln der Seitenäste erzeugten Bildungsstofte hei der Abwärtswanderung zusammenfließen, das ist die Zone. in der die untersten lebenden Äste in den Schaft einmünden. Im freistehenden Baum nun fällt die mechanische mit der physiologischen Zuwachszone zusammen, und beide bedingen eine abholzige, dem Neiloid sich nälernde. minderwertige Schaftform. Durch den Kronenschlnß wird zwar die Menge an Bildungsstoffen überhaupt rerringert, aber die Zone physiologisch erhöhten Stärkezuwachses rückt mit dom Alsterben der Kronen von unten nach oben allmählich nach ohen, so daf der Reihe nach alle (vuerschnitte des Schaftes für einige /eit erhöhten /uwachs geniefen. Daraus muf sich eine Schaftform ergeben. Welche sich mehr oder weniger dem Zylinder oder dem anscrebanchten Kegel nähert (Vollholzigkeit).

$\therefore$ Las Längenwachstum erfährt eine Steigerung durch eine mäßige Bereitigung der Seitenäste infolge des Kronenschlusses: daß im gleichen Sime das Finstutzen oder Abschneiden der Seitenäste wirkt, weiß jerler (iärtner. Es ist zn erwarten, daß die Einengung der Kronen durch den Kronenschluf im gleichen sinne wirken muf. Jener pathologische Fall, bei dem infolge allzu gedrängten Standes alle Pflanzen in Wachstum sich stören, ist kein Beweis gegen die Beschleunigung des Höhenwnchses durch Kronenschluß; in jeder Baumgruppe sind nicht die Randbanme, trotz tles größseren Nährbodens und Lichtraumes die höchsten Individuen, sondern jene des Zentrums der Gruppe; auf magerem Boden wird jecle Bedrängung znr Zuwachsschädigung.

i. Sitärke- und gesamter Holzmassenzuwachs desein$z$ lnen Bammes erfahren durch den Kronenschluß zweifelsohne eine Terminderung gegenüber den Leistungen des freistehenden Baumes; 
ist aber die ganze Baumvereinigung (ciruppe, Band, Kleimbestand. Bestand) in ihren Leistungen betrachtet, so stehen zwar un so mehr Bäume auf der Fläche, je dichter der Schluß, aber ihre Gesamtleistungr ist nicht größer als jene von einer geringeren '/ahl von Bäumen bei lichterem schlusse.

Ђ. Die Holzqualität erfährt eine Steigernng in Ästcreinheit, Verschmälerung der Jahrringbreite und in Gleichmäfiglieit des Aufbanes der Jahresringe, je dichter der Schluls. Diese (iloichmäßigkeit der Ringbreite nimmt mit dem Alter $z u$; sie ist in erster Linie rlem durch den Kronensehluf nivellierten Klima zuzuschreiben.

8. Tom Klima wird der Faktor Wärme infolge der beschränkten Einwirkung der Sonne herabgemindert, im Winter wird dic allzu starke Abkühlung und Temperaturerniedrigung verhindert; die Feuchtigkeit der Luft erfährt unter dem Kronendach eine Steigerung, die Niederschlagsmenge eine Abnahme; das Licht wird in seiner Einwirkung auf die einzelnen Baumkronen beeintrïchtigt; geringere Holzmassen entstehen. und Tausende von Stämmen sterben ab, nachdem sie längere Zeit gegen den Hungertod gekämpft haben.

9. Durch Kronenschluß und ungleiches Wachstum wird der Nebenbestand von den voranwachsenden Baumvereinigungen ausgeschieden. Diese Ausscheidung ist bei Lichtholzarten am schnellsten: bei den Schattenhölzern häufen sich die unterdrückten Stämme in größerer Zahl an: die Ausscheidung selbst geht am raschesten zur Zeit des Hauptlängenwachstums vor sich.

11. Es wurde bereits erwähnt, daf durch den Kronenschluß der Eintritt des Samenerträgnisses um 201)-31) Jahre gegenüher dem Freistande hinausgeschoben werden kamn; im geschlossenen Bestand rerlängern sich auch die Ruhepausen zwischen zwei Samenjahren.

11. Die Erhaltung der Bodenkraft sichert nicht der dichteste Kronenschluß der Schattenhölzer, denn unter ihm häuft sich Rohlnumıs an, der Boden wird gegen Luft, Wärme und Wasser abgeschlossen; auch der lückige Schluf der Bammereinigungen kamn nicht als jener Grad bezeichnet werden, bei dem wegen völliger Aufzehrung der Abfall- oder Streustoffe durch das Bodenunkrant der Boden in der günstigsten Verfassung sich befindet. Die vollkommenst. Zersetzung der Abfallstoffe der aufwachsenden Bammereinigungen findet bei lichteu Schluß statt. Zersetzung und Anhäuting der Zersetzungsurodulite in für die Pflanzen sofort neuerdings antnehmbarer Form geht aber nur im Urwalde vor sich; der Femelschlul, ahmt in seinen Lichtrerhältnissen dem Urwald nach, erreicht ihn aber sicher nicht in der Anhäufung des Nährkapitals im Boden: der Kronensehlulfi de's reinen Bestandes ist dem Boden stets woniger günstig als joner von gemischten Beständen. 
D)r WurzelschluB, auch Wurzelkonkurrenz genamnt. Trie die oberirdischen, hegegnen sich im Laufe des Wachstums einer

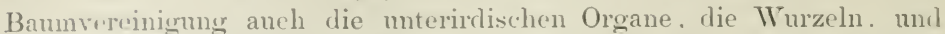
bilden rin sichludverhältnis ähnlich wie die Äste. Man nimmt an. daß auch lir. Wrurzeln sich hierbei behïmpfen und Nahrung und Wasser sich gorenseitig zu entreißen snchen, dal. somit der Wurzelsehluß eine mngünstige Erseheinmog ist. Um so heftiger wird dieser Kampf von den Wurchn qefochten werden müssen, je mehr sie in ein und demsollen Niveau des Bodens sich auszubreiten suchen. Die reinen, gleichalterigen Baumvereinigungen werden hierin am ungünstigsten, ungleichalterige oder mit melreren Holzarten gemischte Vereinigungen am günstigsten bestellt sein. Bei Böden, welche arm an Nährstoffen, mag durch Wurzellionliurrenz ein Mangel an Nährstoffen eintreten; bei Buden, die in regenarmen Gebieten liegen, mag dureh den Wrurzelschluls Mangel an Wasser sich einstellen; aber alle diese Probleme harren noch der genaueren Untersuchung und der Lösung. wozu Fricke und Il athes die Anregung gegeben haben. Einstweilen aber ist es rorfrüht, in jedem Wurzelschlußverhältnis $W^{\top}$ assermangel zu vermuten und im Wassermangel allein die Ursache des kümmerlichen Wachstums zu vermuten in allen Fällen, für welche die forstliche Wissenschaft und Praxis bisher den Lichtmangel verantwortlich machen Zu müssen glaubte.

Die Wiederverjüngung. Regeneration. Eine Bamvereinigung, sei es Gruppe oder Kleinbestand oder Bestand, verjüngt sich nur damn von selbst, d. h. anf natürliche Weise ohne Zutun des Menschen, wenn gleichzeitig drei Faktoren, nämlich Licht tïr lie öftere und regelmäloige Samenproduktion der alten Bämme. Bodenemp fäugliehlieit für die Aufnahme und Keimung der sämereien. Boden- und Lichtraum für das Aufwachsen der jungren PHanzen, gegeben sind. Diese Forderung ist nur im Urwalde erfüllt: er ist deshalb anclı stets verjüngungsbereit; in ihm stürzen alljährlich älıeralte Bammiesen zu Boden, und junges Leben ersteht an ihrer Stelle. Von den Kulturwaldformen, wie sie unter der Einwirkmng der verschiedenen Wrirtsehatsmethoden entstehen, kommt nur der Frmelwald dem Urwalde hierin nahe: bei den ẗbrigen WTaldformen fehlt meist das Licht und dic Erlaubnis zu lichten, wenn der Boden am empeänglichsten wäre: wenn das Licht günstig wird, fehlt die Borlenempfänlichkeit. und wenn hei einer Generalmast alles frulitifiziert und Tausende von Keimen im Boden entstehen, dann fehlt Boden- und lichtraum, um diesen Kieimen das Dasein zu erhalten: der zweite Teil dieser schritt wirl zeimen, wie die forstliche Praxis einerseits sich abmüht, mnter solchen unnatürlichen Verhältuissen eine natürliche Verjüngung zu erzielen, andererseits von vornherein auf jede Mitwirkung ron seiten der Natur an der Verjüngung verzichtet, ja, alles 
kahl niederschlïgt und die Wiederbestellung der Flüche selbst in die Hand nimmt.

\section{Das Ausladungs- mol Ausformungsvermögen der Bammrereinigungen.}

Wird eine Gruppe, ein Band, ein Klein- oder (rmpbestand nach seiner Begründung sich selbst überlassen, so drängt sich im Dickicht und Stangenholzalter eine nach IIolzart, Bodengiite und Klima verschieden große Zahl von Individuen zur Herrschaft, um später die hiebreife Gruppe oder das hiebreife Band, den reifen Kleinbestancl oder Großbestand zu bilden. Hauch ${ }^{1}$ ) und (1pperinann haben zuerst auf diese wichtige Erscheinung der Bestandshologie autmerksam gemacht und sie "Verbreitungsvermögen" genannt. Um die /weideutigkeit, die in dieser Bezeichnung liegt. zu beseitigen, hat $\mathrm{Augst}{ }^{2}$ ) vorgeschlagen, statt "Verbreitungsvermögen" „Ausladungsvermögen zu wählen. Diese Bezeichnung deckt sich mit der Zahl der vordringenden Individuen, läßt aber unentschieden, welcher Form, welcher Güteklasse die vordrängenden Stämme angehören. Da auch diese Eigenschaft nach Holzart, Klima und Boden verschieden ist und mit dem Ausladungsvermögen nicht parallel geht. so muß neben dem Ausladungs- noch ein "A us formingsvermögen " unterschieden werden. $\mathrm{H}$ a uch und Oppermann sagen, das Ansladungsvermögen sei größer bei der Buche, Eiche und Föhre, geringer bei Fichte und Esche; für Fichte genügt daher eine Pflanzenzahl ron s1000 Stück pro Hektar, für die Buche sind auf gleicher Fläche $2-3$ Millionen Pflänzchen nötig. Holzarten mit großem Ausladungsvermögen seien schwierig. solche mit geringem leicht zu verpflanzen. Dabei wird den schlechtgeformten Bäumen die Abstammung von schlechtgeformten Mutterbäumen vorgeworfen.

Petraci $\left.{ }^{3}{ }^{3}\right)$ hat 1908 eine Untersuchung über das Aus formung $\mathrm{g}$ vermögen vorgenommen; aus ihr kamn entnommen werden, daß im Durchschnitte seiner Versuchsflächen bei der sitieleiche die vorherrschenden Stämme mit $40 \%$ den hest- und besser geformten Stämmen, mit $61 \% \%$ den minder gut bis ganz schlecht geformten angehören; bei der Traubeneiche kehrt sich das Verhältnis um, indem $71 \%$ der herrschenden den best- und besser geformten, 311\% den minder gruten bis schlechten Stämmen angehören: bei der Buche ist das Verhältnis der vorherrschenden Stämme wie $411^{\circ} 0$ (gut- und bestgeformte) zn til \% (gut- und schlechtgeformte): bei der Föhre (silvestris) sind von den vorherrschenden (i) $\%$ gut und sehr gut, $411 \%$ gering und sihlecht

1) $\mathrm{Hauch}$, Das Verbreitungsvermögen unserer Holzarten. Allgem. Forst- u. Jagdzeitung 1905.

2) A ugst an demselben Orte 1905.

3) Petračić, Untersuchungeu aber die selbständige Bestandesansscheidung ron Eichen, Buchen und Föhren in stärke- und Nutzholzg(ateklassen. Diswert 190s. 
greformt. Die allerstärksten unter den vorherrschenden Stämmen sind bei allen ILolzarten minderer Gïte als die schwächeren muter den vorherrschenden Stïmmen; je kïhler das Klima oder je geringrer der Boden, $u m$ so langsamer die Ausscheidung des Bestandes, 1. h. $17 \mathrm{~m}$ so größer die Zahl der herrschenden Stämme, um so geringer ihre Stïrke und IIöhen- und Formunterschiede gegenüber den beherrschten stämmen.

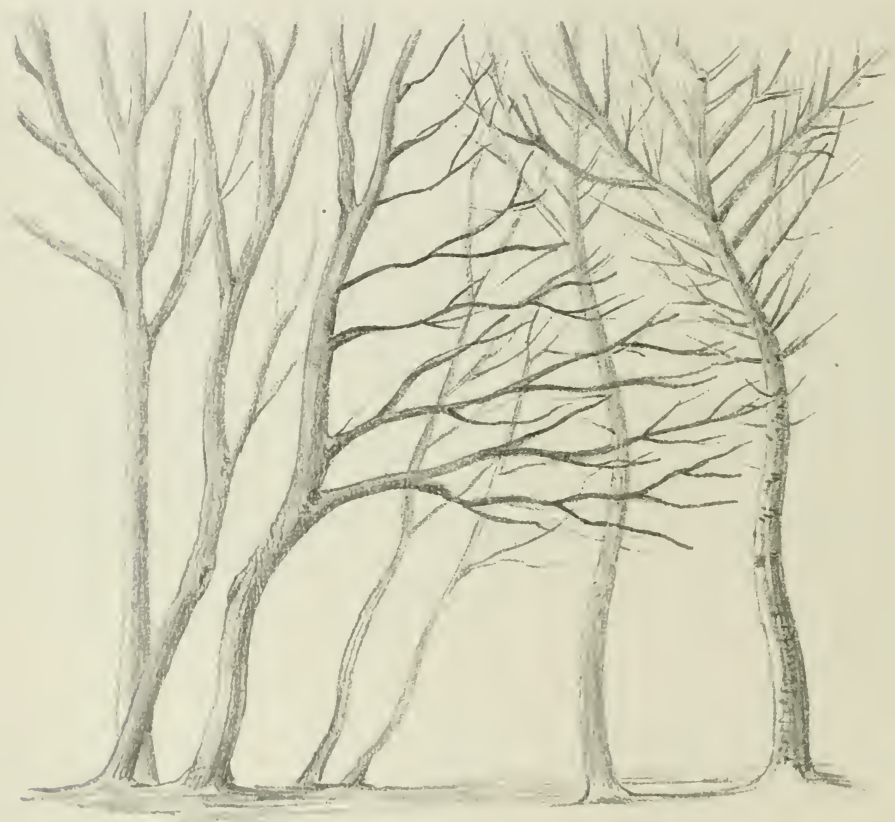

Abb. 12. Berahrumgsrand einer gruppenweisen Mischung von Buche links) und Före (rechts) (funfzigjuhris, aus den Versuchstlichen zu Grafrath).

Her Einfluß des Lilimas und des Bodens auf das Ausformungsvermögen kam daran erkamnt werden, daß bei den Laubhölzern in wärmerom Klima dio vorherrschenden Stämmo besser goformt sind, hei den Nadelhölzern dagegen schlechter als in kühlerem: in gleichem Sinno wirkt besserer Boden. Daß bei den S'chatten ertragenden Nadelhäumen das Ausladungsvermögen geringer ist, hat H a n ch bereits angenreben; das Vordrängen besonders starker, besonders hoher lndividuen ist viel seltener als bei allen Laubhölzern; 
bei den vordrängenden bleibt zwar immer der sehaft gerado, aber dio Ästigkeit nimmt zu. Die Halbschattenholzarten wio Woymonthsföhro, Tsuga, Chamaecyparis und andere verhalten sich bereits weniger günstig als die Schattenholzarten; die Liehtholzarten miter den Nadelbäumen nähern sich den Laubhölzern noch mehr. In den Fölrenbeständen, welche Petračic untersuchte, waren $60 \%$ der vorherschenden Stämme den bestgeformten, 40\% den schlechter geformten angehörig; besonders interessant ist das Ergebnis von einem seichtgrïndigen, kiesigen standorte in der Nähe von München. Das Verhältnis zwischen gut- und

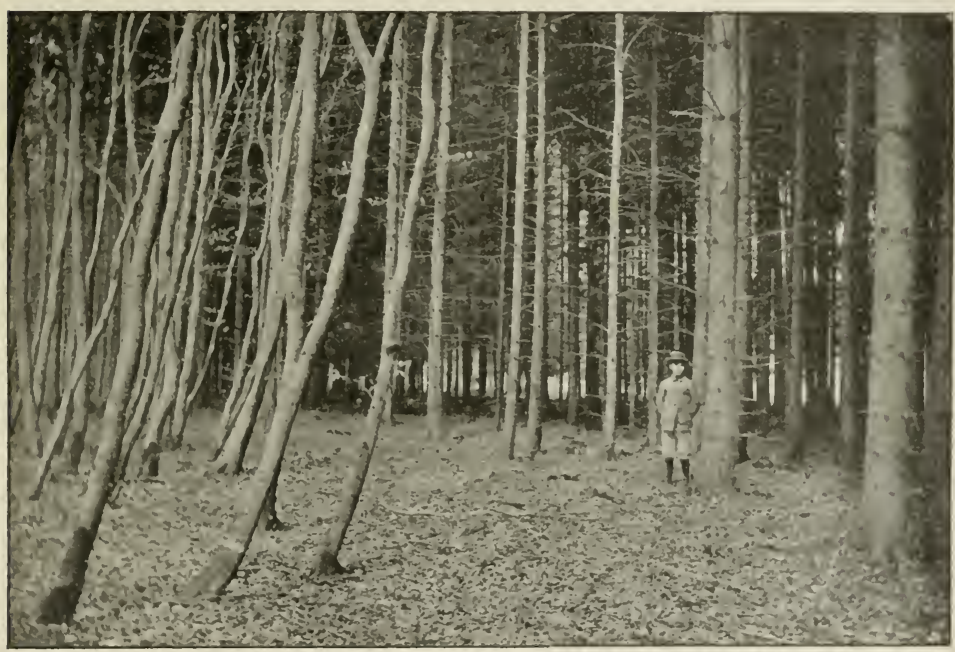

Abb. 12. Berührungsrand einer gruppenweisen Mischung von Buchen und Fichten (fünfzigjahrig).

schlechtgeformten Stämmen unter den Herrschenden kehrt" sich vollständig um. $60 \%$ waren schlecht- und nur $40 \%$ gutgeformt, und gerade zu den schlechtesten muften die allerstärksten Stämme gezählt werden. Eine solche Jugend sich selbst ïberlassen oder nur schwach durchforstet, wie dies bei den Schattenholzarten ïblich ist, würde cinen ganz minderwertigen Altbestand lietern müssen; daß bei Föhre und Lärche in einem wärmeren, trockeneren Klima die A $u$ formung sich verschlechtert, beweist die abnehmende Schafthildung der Lärche von der Höhe nach dem Tietlande, der Föhre von Norksten nach Südwesten. Soweit die Beobachtungen des Verfassers reichen, dürfte die europäische Lärche noch ein etwas bessereres Anstormungsvermögen besitzen wie die Föhre in wärmerem Klima; etwa 70 ${ }^{\circ}{ }^{\circ}$ gute 
zu $30 \%$ schlechtgeformten Stämmen. Noch schlechter ist die Ausformung der japanischon Lärche gegenüber der europäischen. Es wäre hoch erwünscht, wenn über diese Frage noch umfassendere Studien vorgenommen würden: die vom Verfasser im internationalen Verbande der forstlichen Versuchsanstalten angeregten Versuche über die Schaftformbildung der Föhre und Lärche bei verschiedener Provenienz und auf verschiedenem Standorte dürften in den ersten zwei Jahrzehnten bereits die Beweise für die Abhängigkeit der Schaftform von Individualität, vom Klima und Boden, sowie die Nichterblichkeit dieser Erscheinung bringen für den, dem die mehr als zwanzigjährigen Versuche noch nicht genügen. Was krumm werden will, krümmt sich bei Zeiten.

Die Folgerungen, welche die Begründung und Erziehung der Bestände aus dem Ausladungs- und Ausformungsvermögen der Holzart zu ziehen hat, sind dem dritten Teile dieser Schrift einverleibt. 


\section{Siebenter Abschnitt.}

\section{Allgemeine Veränderungen im Waldzustande und in seinen naturgesetzlichen Grundlagen durch Eingriffe des Menschen.}

Der atlantische Wald der Alten Welt, der europäische Walr. Wenn man behauptet, dieser Wald bedeckte ursprünglich ganz Europa von seiner Südspitze bis zum Polarkreis, vom atlantischen Meer bis zum Ural, so bedarf das Wort „ursprïnglich" einer bestimmten Umgrenzung. Es gilt die Behauptung zweifellos für das geschichtliche Europa; für das nachglaziale wird auf Grundlage von Boden- und selbst Vegetationsresten das Vorhandensein waldloser Gebiete, von Steppen in Landschaften angenommen, die heute Wald tragen oder doch tragen würden, wenn der Mensch ihn nicht beseitigt hätte. Verfasser hat auf Grund seiner vergleichenden Studien an Waldgrenzgebieten in Westamerika 18\%) den Satz aufgestellt, daß in Europa die Landschaft nördlich der Alpen bis zum Einfluß der Nordsee hin eine Prärie sein müßte, wenn Europa in seinen Feuchtigkeitsverhältnissen allein auf das Mittelländische Meer angewiesen wäre; erst das liäufige Einbrechen des Westwindes vom Ozean her sichert dem mittleren Europa hente seinen Wald. Wird daher angenommen, daß es eine Zeit gab, in der Mitteleuropa Steppe war, so kamn damals der warme Golfstrom, der Erreger der großen Temperaturdifferenzen in der Luft, der Urheber der barometrischen Minima und ihrer Wanderungen nach Europa, der Vater der Westwinde in Europa nicht bestanden haben. Daß or in der Tertiärzeit fehlte oder nur ganz abgeschwächt floß, liegt nahe, weil damals die warme subtropisehe Zone bis zu den Küisten der Nord- und Ostsee sich erstreckte. Damals konnte Mitteleuropa prärialen Charakter getragen haben. Aber nach der Eiszeit, welche für Europa eine beträchtliche Abkühlung zưückließ, war der Golfstrom sehr liräftig, ja, wahrscheinlich liäftiger wie heute; dann aber war auch alles in Europa Wald, und Prärie aus Mangel an Niedersehlägen ummöglich. Es liegt viel näher, solche Steppenrelikten nach der Eiszeit als Reste einer 
Vegetation zu betrachten, welche zwar auch steppenartigen Charakter, aber grundverschiedenen Ursprung besitzt. Damals schloß sich an den Saum der Gletseher, welche von Norden her nach Süden und von den Alpen her nach Norden vordrangen, so wie hento das Lichenetum mit seinem Flechtenwuchs auf den Felsen und seinen Grasmatten auf Ebenen und schwach geneigten Geländen an; an diese \%onen reihte sich beiderseits das Polaretum bzw. das Alpinetum, ebenfalls mit ausgedehnten Grasflächen, mit seinen Sträuchern und letzten Baumresten; zwischen diesen nördlichen und südlichen Steppenländern blieb in Mitteleuropa nur noch Raum für das Picetum und in den tieferen, westlichen Lagen für das kühlere Fagetum. Seit der Wiedererwärmung der nördlichen Halbkugel auf den heutigen Höhepunkt ist eine Steppe in Mitteleuropa naturgesetzlich unmöglich, und was trotz genügender Temperatur und genïgender Feuchtigkeit Steppe ist, ist Menschenwerk.

Die Entwaldung in der Ebene hat keine Abwaschung des fruchtbaren Bodens im Gefolge gehabt, wohl aber wurde er durch Winde aufgegriffen und flüchtig. War er durch lehmige, tonige Bestandteile gebunden, begraste er sich, die Humusmassen erhielten sich und häuften sich an, wie in Ungarn und im mittleren Rußland. Im bergigen Gelände erfolgte Abwaschung um so schneller, je steiler die Hänge, je wärmer das Klima. Es sammelte sich fruchtbarer Boden in Vertiefungen, auf Hacherem Gelände, wc Gras mit Stranchwerk sich mengte. Das sind jene zahllosen, öden Mittelgebirge, die Karste von Spanien, Südfrankreich, Italien, Tirol, Griechenland; hierher zählen jene ertragsarmen Weiden der Nittelgebirge, die Heideflächen von Deutschland und Dänemark. Die Entwaldung im Hochgebirge endlich entführte alles bis zum nackten Fels. In der Ebene braucht es zur Wiederbewaldung keine Sicherung gegen Abwaschung, es genügt die Aufforstung; im Hügelland erheischt die Bindung des Bodens wenig, die Aufforstung am meisten Opfer. Im Hochgebirge sind die Bindung des Bodens und die Aufforstung gleich schwierig und kostspielig.

Man darf die Zerstörung des Waldes und aller seiner Wohltaten für das Tiefland im südlichen Europa nicht ausschließlich den Eigenheiten der romanischen Völker, wie es geschehen ist, aufbürden. Ein Zung der Abneigung gegen Bäume und Tiere, eine Neigung zur Mißhandlung, Stümmelung und Zerstörung der pflanzlichen und tierischen Lebewesen liegt in den südlichen Nationen, aber doch nicht mehr, als in den nordischen Nationen Vorliebe, Schonung und Pflege für Pflanzen nnd Tiere gelegen sind. Zur Zeit des Waldüberflusses war die Waldbehandlung im Süden und Norden, Osten und Westen von Europa nur wenig versehieden; verschieden aber waren die Folgen der Entwaldungen wegen der Verschiedenheit der naturgesetzlichen Grundlagen in den verschiedenen Himmelsgegenden Europas. Im Süden von Europa stand und steht noch heute der Wald mit seiner erhöhten Verdunstung, ver- 
minderten Feuchtigkeit an der Grenze soiner Daseinsmöglichkeit; ein Eingriff von seiten des Menschen, eine Auflösung des Wraldes muß eine Verminderung der Feuchtichkeit in seinem Bareich erzeugen, uncl entraldete Flächen bleiben waldlos. bis sie die hultur wiedernm in Wald verwandelt. Den günstigen, klimatisehen Bedingungen, den häufigen, stets Feuchtigkeit bringenden Westwinden, dieser heilenden und wiederverjïngenden Kraft verdankt der Wald im mittleren Europa und ganz besonders im Norden seine Erhaltung und sein ungeschwächtes Streben, alles Land zurück zu erobern, das die Menschen ihm entzogen haben.

Das Fehlen der Fenchtigkeit im Süden Europas erklärt die rasche Abnahme der Bodengiite bei unpfleglicher Behandlung, erklärt es, weshalb in Mitteleuropa trotz schwerster Eingriffe in die Bodensubstanz die Bodengïte nicht rascher dahinschwand; die feuchten Westwinde, welche meist zur rechten Zeit über den kontinentalen Ostwind siegen, mäßigen die Unbilden der kahlen Flächen unserer, nach heutiger Auffassung geregelten Waldbetriebe und verhindern, daß unsere kïnstlichen Kulturen nicht noch schlimmer von Frost und Hitze und der Geißel der Steppe, von Fener, heimgesucht sind. Der heutige WVald ron Mitteleuropa, in erster Linie der deutsche WVald, ist ein hundertjähriges Experiment, bei dem er aus einem urwaldartigen, offenkronigen, artenreichen, gemischten, rentenarmen 'Lustande in einen artenarmen ${ }^{1}$ ), gleichaltrigen, von einem geschlossenen Kronendach bedeckten, von sturm, Feuer, Insekten und Pilzen gefährdeten, aber rentenreichen Wald übergeleitet wurde; nur der höchsten Kunst des Waldbaues, der Waldpflege und der Waldeinrichtung ist es bis hente gelumgen, mit den feindlichen Gewalten einen erträglichen Frieden zu schließen; allen Hoftnungen zum Trotze nimmt im Kulturwalde die Bodengüte stets ab, die Schwierigkeit der Waldbegründung stets zu. Es war zuerst $\mathrm{K}$ arl Gayer, der die Rückkehr zur Natur als das alleroberste Prinzip zur Erhaltung der Bodengüte, als die Grundiage der Nachhaltwirtschatt festlegte; er verlangt Stetigkeit der Bodenbedeckung durch Walr mittels Naturverjüngung und Nischung der Holzarten: er hoft't das Ziel zu erreichen durch seinen Femelschlag oder den grupponweisen Schirmschlag. C. W agner in Tübingen will Naturverjüngung in s a mweisem Schirmsehlag, er nennt sie Blender-Saumschlïge: er will gemischten Wald und erklärt den Nordrand des Bestandes als die beste Ürtlichkeit für eine langsame Verjüngung, welehe an zahl. reichen Punkten des Waldes gleichzeitig einsetzt. Der Verfisser vorliegender Schrift sucht auf einer dritten Eährte, den Rückwegr zur Natur; er teilt den ganzen Wald in kleine Flächen; eimer jroden Fläche wird die nach Klima, Boden und Wirtschaftsbedürtnis passende IInlz-

1) Man vergleiche: $\mathrm{H}$. $\mathrm{H}$ a us rath, Der deutsche Wald. 1907. 
art zngewiesen: eine geeignete Erzichungsweise sichert jede beliebige ökonomische Ordnung und Nutzung. Die Stetigkeit der Bodenboschirmmg wird erreicht durch eine für alle Holzarten, alle Bestandsformen und Bestandsgrößen, für alle Forsteinrichtungswünsche branchbare Naturerjüngung in der denkbar raschesten Verbindung von Schirmschlag und Kahlschlag. Ob dieser Vermittelungsvorschlag zwischen Naturkräften und Menschenziel den goldenen Mittelweg bezeichnet, auf rem das natürliche, naturgesetzliche Prinzip im Walde einerseits, das ïkonomische im Menschen gelegene, zerstörende und gewinnsuchende, anderseits zu einer rationellen und wahrhaft nachhaltigen Waldwirtschaft sich vereinigen können, ob damit die Hemmnisse und Nachteile beseitigt oder doch bis zur Unschädlicheit abgeschwächt werden, welche die Eingritte des Menschen in die naturgesetzlichen Grundlagen des Waldes herbeiführen müssen, mag der Zukunft überlassen sein.

Der nordamerikanische Wald. Verfasser hatte das Glück, vor 23 Jahren im Auftrage und mit Unterstätzung der königl. bayerischen Regierung, ein zweites Mal vor 20) Jahren und ein drittes Mal vor : Jahren die wichtigsten Waldungen ron Nordamerika zu bereisen. Als Frucht der beiden ersten Reisen erschien ein Buch: Die Wald ungen von Nordamerika 1890 . Weil diese Originalarbeit die erste Schrift war, welche über die waldbaulichen Eigenschaften und Bedürfnisse der amerikanischen Holzarten, die klimatischen und pedologischen Verhältnisse der amerikanischen Waldungen Aufschluß gab und somit die naturgesetzliche Grundlage für einen späteren Waldbau dort und den Anbau der amerikanischen Holzarten in Europa schuf, hat das Buch auf seinem Schicksalswege sehr viele, warme Freunde, aber auch Neider in Amerika wie in Europa gefunden. Inzwischen sind recht viele der ewigen und unwandelbaren Naturgesetze ron späteren Forschern in Amerika wie in Europa neu entdeckt worden: dio Anbanergebnisse in Enropa haben die damals gegebenen Vorschläge grlänzend gerechtfertigt, und was auf Grund von naturwissenschaftlichen Vergleichen vorhergesagt werden konnte, ist bis ins Kleinste eingetroftion. Ton der (1riginalquelle, aus der so viele und so ergiebig dies. und jenseits der Atlantik geschöpft haben, spricht und schreibt heute niemand melir. Das ist das Schicksal aller Bücher. Aber ein Faktum, eine geschichtliche Erinnerung, verdient festgehalten zu werden. Angresichts der begimnenden Verödung der Berge, der steigenden Hochwasser schrieb der Tertasser aut Seite 21:

"In allen Gebirgen und auf allen mageren Böden, die keine andauernde, landwirtichaftliche Benutzung ertragen, an allen Flußufern, snlange nicht eine liünstliche Regrelung derselben eingetreten ist, ist dic Erhaltung des Waldes ein Gebot der Natur zum Schutze des Tieflandes. Infolge des mugeheneren Reichtums des Landes und der Arbeitskraft des unternehmenden amerikanischen Volkes hat der Staat 
stets große Überschüsse in seinem Haushalt. So lächerlich es vielleicht in Amerika klingen mag, nach meiner Meinung gribt es lieine passendere Rückgabe eines Teiles des Geldes an die Nation, als die Waldungen in den Bergen und aut' absoluten Waldböden, mit einem Wort, die Schutzwaldungen, die in den Händen der Privaten mit dem abhängigen Tietlande dem Untergange geweiht sind, aufzukaufen, durch Maßregreln einfacher Art, etwa nach dem in Indien gebräuchlichen System, gecren Waldbrand zu schützen, durch Beamte zu verwalten und durch eine ordentliche Zahl von Sichutzleuten gegen Diebe, Jäger und gebildete Ausflügler zu sichern."

Damals; vor 23 Jahren. haben die maßgebenden Persönlichkeiten in Amerika über diese Vorschläge des "deutschen s'chwärmers" ihr Zwerchfell erschüttert und heute? Nicht weniger als 30 Millionen Hektar Gebirgswaldungen hat die Unionsregierung bereits aufgekauft, und hoffentlich gelingt es, die herrliche Waldregion der Appalachen, über deren Sein und Nichtsein gegenwärtig gekämptt wird, ebenfalls der Nation zı erhalten. In der Freude über diese Erfolge kann der Verfasser die damalige Behandlung vergessen, und auch in Amerika hat man vergessen, daß man vor 2:3 Jahren die Gebirgswaldungen um einen Bruchteil des heutigen Preises hätte kaufen können, wenn eben damals der Gedanke des Ankaufes nicht gar so lächerlich gewesen wäre.

Noch vieles andere, was als Folge der Entwaldungen für die nächsten Jahrzehnte vorausgesehen werden konnte, ist eingetroffen. Im Süden haben sich die Treibsandflächen, im Norden die Sümpfe vergrößert und die Überschwemmungen, die Dammbrïche der großen Stauwerke, durch welche man den Wald als Wasserregulator überflüssig machen wollte, haben an Zahl und Furchtbarkeit zugenommen; die Erschöptung an edlen Nutzholzarten, die rom Verfasser vor 25. Jahren in den ostamerikanischen Waldungen für die nächsten jo Jahre bereits angekündet wurde, wird gegenwärtig von den s'chriften amerikanischen und europäischen Ursprungs - auf die nächsten 2.) Jahre verlegt.

Im atlantischen Waldgebiet schreitet die Entwaldung zwar weiter; sie scheint aber bald der Wiederaufforstung, sowohl der absichtlichen durch den Menschen als der unabsichtlichen durch die Natur, die Wage zu halten; gewaltig aber vergrößern sich die Waldbegründungen in den sogenannten Präriestaaten. Das Endergebnis wird eine Ausgleichung der klimatischen und ökonomischen Verhältnisse zwischen Ost und West sein: die Präriestaaten werden sich den Waldstaaten abseits von der Küste und diese den Präriestaaten nähern; beide zusammon werden schließlich in Wald und Waldwirtschaft Europa so ähnlich sein, daß alles, was in Europa beobachtet und als waldbaulicher Fortschritt erwiesen wird, auch für Amerika und umgrekehrt Geltung hat.

Was in Ostamerika in der Beeinflussung der Bodendecke durch die menschliche Tätigkeit aut' großen Flächen nach der Horizontalen hin 
sich ahspielt, geschieht in Westamerika auf kleinen Flächen nach der vertikalen Richtung hin. Das Gebirge, soweit es noch nicht in Staatsbesitz übergegangen ist, wird entwaldet, die Ebenen, die ursprünglichen Prärien, werden bewaldet; nur in jenen gesegneten Gebieten, in welchen dio Ebenen in Felder, Gärten und Wald umgewandelt, der Wald der Gebirge als natïlicher, clurch kein Stauwerk zu ersetzender Wasserhehälter für das Tietland erhalten wurden, ist jene Harmonie zwischen Klima, Boden, Borlendecke und menschlicher Tätigkeit geschaffen, die wir mit dem Worte .Kalifornien" zusammenfassen und ersehnen.

Im ostasiatischen, chinesischen Walde ist die Umgestaltung der Bodendecke der Verlust des Waldes durch die Eingriffe des Menschen seit mehr als tausend Jahren bereits vor sich gegangen; der Gedanke, in diesen ungeheuren Ländereien im Norden Chinas durch Wiederbewaldung das natürliche Gleichgewicht zwischen Wald und Tiefland durch Regelung der Wasserversorgung herzustellen, ist dort ein Problem vielleicht der kommenden Jahrhunderte. Von selbst kann dort der Wald nicht zurückiehren, teils weil dort die Mntterbäume fehlen, teils weil die Schattenlosigkeit während regenloser Zeiten alle zarten Keime wieder vernichtet. Günstiger liegen die Waldlandschaften und Ebenen von Indien, Korea und Japan. Häufige Regengüsse auch in der trockenen Winterzeit haben die völlige Schutzlosigkeit der Berge durch Entwaldung und die Preisgabe des Tietlandes an die Wassermassen verhindert; demn wo der Mensch nicht alljälırlich alles absichelt, säet der Wald erfolgreich seine Keime. Aber unheilvoll für den Wald war und ist noch hente jedes Fener, das Löcher in den Wald frißt, ebenso wie die Axt, die unbedacht geführt, den Wald beseitigt, ehe eiue neue Waldgeneration bereits rom Boden Besitz genommen hat. Wo dieser oberste Grundsatz aller Waldwirtschaft im Bereiche des ostasiatischen Monsungebietes versäumt wurde. erscheint der alles verschließende Bambus, gegen welchen eine europäische oder nordamerikanische Begrasming der Kahlfläche als eine Wohltat bezeichnet werden muß. 


\section{Zweiter Teil. \\ Die Waldbegründung.}

\section{Achter Abschnitt. \\ Die Wirtschafts- und Verjüngungsformen.}

Nachdem die moderne Forstwirtsclaft soweit vorgeschritten ist, daß jede Nutzung im Walde zugleich einen waldhaulichen Zweck erfüllt, sind Nutzungs-, Wirtschafts- oder Betriebsformen des Waldes zugleich bestimmte Verjüngungsformen geworden. Der daraus hervorgehende, neue Wald trägt ein den speziellen Wirtschaftsformen zukommendes, spezielles Gepräge. Entsteht hierbei der neue Wald aus $\mathrm{Samen}$ und soll die neue Generation bis zur Samenertragsfähigkeit wieder heranwachsen, so heißt er Hochwali. Entsteht der Wald aus Ausschlägen und Trieben, welche ans schlafenden oder ans țherwallungsknospen nach vorheriger Stümmelung des Stammes hervorbrechen, so heißt der Wald Ausschlagswald. Wird der Baum durch Abkappen der Gipfel, bzw. ihrer Ersatzgipfel verkrïppelt, so entsteht der Krüppel- oder Astwald: erfolgt die Verjüngtug alljährlich freiwillig durch Triebe aus unterirdischen Trieben (Rhizomen). so kann man einen derartigen Wald Rhizomwald nemnen. Entsteht der neue Wald aus Samen und Stockausschlägen zugleich. wobei einzelne Stämme ein vielfaches Alter der auf den Stock gesctzten Stämme erreichen, so nennt man einen derartigen Wald Mittelwald. Im Rahmen dieser fünf Wirtschafts-oder Betrielssklassen werden nachstehende Betriebs- oder Verjüngmngsformen unterschinden

\section{A. Hochwald.}

Die Vorteile des Hochwaldes gegenuiber den AnsichlagsKrüppel- und Mittelwalde seien in folgende Punkte zusammengefabt: 1. Bei geeigneter hronenschlukregelung gehen Hochwaldungum die hest" 
Aussicht der Erhaltung der ursprüngliehen Bodenkraft, bzw. creht unter geeigneter Wirtschaftsführung bei ihnen die Erschöptung des Bodens am langsamsten vor sich; 2. Beseitigung aller Wuchsfchler durch geeignete Erziehungshiebe während des langen Lebens der Banmvereinigungen; für die Anhänger der unbewiesenen Vererbung von Wuchstugenden und Wuchstehlern liegt darin anch die Möglichleit der ständigen Baumformenverbessermng durch den Samen der durch dio geeignete Erziehung gesehaffenen Elitebestände: 3. Erziehung der stärksten und schwäehsten, wertvollsten Nutzholz- und Brennholzsortimente zugleich in größter Nenge, in bester Form und innerer Güte (Gleichmäßigkeit des (Gefüges, Astreinheit); 4. Möglichkeit der Gewinnung von Streu; 5. im Laubholzhochwald leichter Übergang zn den anderen Betriebsklassen, Niederwald und Mittelwald: 6 . die Hochwaldungen gewähren reichlichen Arbeitsverdienst; 7 . der Hochwald setzt naturwissenschaftliche Kenntnisse voraus, regt an und verlangt eine ständige Beobachtung im Walde; er arbeitet damit an der naturwissenschaftlichen Fortbildung seiner Wirtsehafter mehr als die übrigen Betriebslilassen. Zu den Nachteilen des Hochwaldes sind zu zählen: 1. Bei ungeeigneter Wirtschaftsform und -führung wird der Boden rascher der Erschöpfung nahe gebracht als bei den Nieder- und Mittelwaldbetriebsklassen; 2. da Hochwald aus Samen entsteht, so besteht Abhängigkeit vom Eintritt des Samenjalirs bzw. Abhängigkeit von den vorhandenen Vorräten an Sämereien im IJandel: Unsicherheit der Verjüngung und hohe Kosten gegenüber dem Ausschlagsbetriebe; 3. die Hochwaldungen erfordern lange Zeiträume und geben bei der herrschenden Erziehungsmethode nur geringe Erträge zwischen zwei, weit auseinanderliegenden Endernten: 4. Es ist kaum zweifelhaft, daß Ausschlags- und Mittelwald den Hochwald an Gesamtholzmasse innerhalb derselben Keitrïume übertreffen; 5. die Hochwaldungen sind am meisten greführdet durch Sturm, Schnee, Fener, Insekten ; (i. sie verlangen kostspielige und schwierige Betriebe, höhere Anforderungen an die naturwissenschaft liche Vorbildung des Personals; 7. Sehwierigkeit der Fällmngen mit Rücksicht auf den Nachwuchs und die persönliche Sicherheit der Arbeiter: $\diamond$. starke Besehädigmng durch Beschattung an anliegenden, landwirtschaftlich"n Grundstüeken: 4. es besteht die Gefahr, daf aus waldästhetischenRücksichten, ans allzu großer Ängstlichlieit bezüglieh der Nachhaltigkeit anf (irund ungenügender Ermittelung der Zuwachsverhältnisse die Untriebszeit zu hoch angesetzt wird, wodurch Verluste an Holz durch Fäuhnisprozesso herbeigeführt werden.

\section{Die Wirtschafts- oder Betriehsformen des Hochwaldes.}

Während des grölsten Teiles des vorigen Jahrhunderts bis zu den Achtzigerjahren war das Streben der führenden (ieister und Meister der Forstwirtschaft zumeist auf eine möglichst großzügige Regelung 
der Benützung des Waldes, auf eine möglichst kleinzügige, d. h. mögr. lichst einfache Schablone der Wiederverjüngung des Waldes zerichtert. Aus diesem streben ging die Einteilung des Walros in möglichst grofie Elächen - Bestände - hervor, welcho der walduaulichen Tätigkeit zur möglichst raschen und vollkommenen Verjünguner in .Jahre der Hanbarkeit zugewiesen wurde. Die Lösung dieser Aufigabe war der Prütstein für das forstliche Können im Walde. Dies, großen Wlächen, Abteilungen genannt, bildeten die Wirtschaftsficrur, die Wirtschaftseinheit, den Bestand, coup, stand; die Wirtschaft sellst kam man als eine Großbestandswirtschaft bezeichnen: G. L. Hartig stelle als höchstes, erreichbares Ziel der waldbaulichen Kunstfertigheit die Begründung eines möglichst gleichalterigen, möglichst einförmigren, d. h. reinen Bestandes hin; das Holzarten- und Baumaltersdetail, das der Wald bei der ersten Eimrichtung noch aus seiner Urzeit oder aus seinem Femeldasein besaß, das als Unterabteilung ausgeschieden wurcle, sollte im Laufe der Umtriebszeit zugunsten der Einheit Abteilung verschwinden. Die Durchführung dieses Programms ist freilich vielfach am Widerspruch der Natur gegen diese Gleichförmigkeit gescheitert, die Ungleichartig- und -altrigkeit imnerhaib des Bestandes wird jetzt als willkommene Wohltat empfunden, die Unterabteilungen sind bleibende Bestandesfiguren geworden, - Bestandeswirtschaft der neuzeitlichen Richtung, - sind aber immer noch von einer Größe. welche bestimmend ist für die Art und Geschwindigkeit der Verjüngung. Soll den Anforderungen der Forsteinrichtung entsprochen werden. führen diese beiden Bestandswirtschaften orler Großflächenwirtschaften zum Kahlschlag mit lïnstlicher Verjüngung. Jerler Bestand kann dabei aus einer Holzart bestehen, reiner Bestand oder ein aus mehreren gemischter Bestand seì, kann auf natülichem oder auf künstlichem oder auf heiden Wegen zugleich entstanden sein, kann aus Kahlschlags oder schirmschlagsstellung hervorgegangen sein: die Feststellung der zu wählenden Holzart, des zu wählenden Verjüngungszeitraumes und damit auch des zu wählenden Verfahrens beansprucht die Forsteinrichtung, welche auf diese Übergriffe in den Waldbau auch nicht verzichten kann, ohne ihre Groliflächeneinteilung des Waldes selbst, die Grundlage der ganzen heutigen Forsteinrichtung, zu erschüttern. Auf dieser Grundlage sind heute nicht bloß fast sïmtliche Waldungen Deutschlands, sondern, unter Führung Dentschlands, auch jene der Nachbarläuder, ja selbst jene der außereuropäischen Waldungen eingerichtet und bewirtschaftet.

Die Tatsache, daß erstens Abteilungen bzw. Unterahteilumen - Bestände - immer noch so große Flächen sind - stets müber als 3 ha daß sie bei Naturverjüngung nicht rasch genugr, bei künstlicher Verjüngung nur mit sehr groljen Kosten wieder bestockt werten kïnnen, daß zweitens dic Bestandswirtschaft zu reinen Bestänclen grolier Aus- 
rlehnung führt. welche die Natur zu Katastrophen herausfordern, gegen welche wieder im Walde Vorsichtsmaßregeln getroffen werden müssen, welche der Verjüngung hinderlich sind (Hiebsfolge); daß drittens nach allen bisherigen Erfahrungen der Großbestand rait der durch die Größe notwendigen, küinstlichen Verjüngung im Kahlschlagsbetriebe nicht imstande ist, die gegebene Bodengüte zu erhalten, vielmehr langsam, aber sicher dessen Verminderung herbeiführt: daß viertens eine in die weite Zukunft blickende Forstwirtschaft nicht ausschließlich den gegenwärtig rentabelsten Holzarten ihren Wald ausliefern, vielmehr in demselben nicht nur sämtliche einheimischen Holzarten in angemessenen Verhältnissen. sondem auch ron den fremdländischen die aussichtsvollsten neben einzelnen wichtigen Halbbäumen und Stränchern aufzunehmen und zu erhalten hat: dürfte eine andere Ordnung im Walde den naturgesetzlichen Grundlagen des Waldes und den gegenwärtigen und kommenden Bedürfnissen der Menschen besser entsprechen, das wäre die Aufteilung des Waldes in Kleinbestände, Kleinflächen. Unter Kleinbeständen rersteht Terfasser, wie bereits angedeutet, eine Fläche von $1,3-3,0 \mathrm{ha}$. Diese Flächengröbe bildet die Wirtschaftseinheit, den Kleinbestand. Jeder Kleinbestand ist ein Wirtschaftsobjekt für sich: dic Anordnung im Walde ist schachbrettartig; unter sich sind die Kleinbestände in Holzart oder doch in Alter verschieden.

Sinkt die Einheitsfläche für die wirtschaftliche Behandlung des Waldes unter den Betrag von 0,3 ha (etwa ein Tagwerk, Joch, Morgen). ist sie aber größer als etwa 1 a, den Standraum eines Trupps. so nennt man eine derartige Einheit Gruppe. Man denkt sich den ganzen Wald aus Gruppen von obiger Größe zusammengesetzt, die (rruppen unter sich in Alter und Holzart verschieden und jedefür sich ein eigenes Wirtschaftsobjekt. Die Anordnung ist eine schachbrettartige. Die bildliche, kartographische Darstellung, welche schon bei einer Kleinbestandwwirtschaft mechanischen, grolien Schwierigkeiten begegnen wird. was selbstredend keinen EinAuß auf ihre Einfühırung und Durchführung ansüben kann, ist bei der (iruppenwirtshaft nach bisheriger ITethode eine Unmöglichkeit. Der waldbaulichen Tätigkeit bleiht es ganz überlassen, wie, wo und wann eine Gruppe zur. Nutzung und zur Verjüngung, wie und wo somit der Etat zur Frfüllıng kommt. Die Auswahl der Holzart bei der Neuhegründung. welche eine natürliche oder kïnstliche sein kann, erfolgt ganz im Anhalt an Bodlen, Klima und Rentabilität.

Sinkt endlich die Einheit der Flächengrölse und -behandlung bis zum Trupp- und Einzelindividum, damn hat der Wald äußerlich den Charakter des Urwaldes angenommen; er wird Plenter-oder F emelwald genannt; die Forsteinrichtung haßt ihn, weil er den rechnerischen Kalkülen und der räunlich-ordnenden Gleichmäßigkeit die größten schwierigkeiten in den Weg legt. 
In jeder Wirtschaftsform sind die Bestandsränder oder die Berührungsstreifen zwischen den Wirtschaftsfiguren die walebaulich und forstlich ungünstigste Stelle im Walde; nur soweit der Berührungsstreifen zwischen einem höheren Lichtholz- und einem niederen Schattenholzbestande bzw. -gruppe verläuft, wirkt er gïnstig auf das Lichtholz ein. In der Großflüchen- oder Großbestandswirtschaft ist das Verhältnis der Summe der Berührungsstreifen zur Gesamtfläche am vorteilhaftesten; die Berührungen sind überdies zu Schneusen oder zu Wegen umgebaut. Bei der Bestands-und Kleinbestandswirtschaft wächst die gesamte Länge der Berührungsstreifen beträchtlich, doch nicht über jenes МГaß hinaus, das nicht mehr für Wege und Bringungszwecke ausgenützt werden könnte: bei der Gruppenwirtschaft verlängert sich die Summe der schädlichen Berührungsstreifen ins unmeßbare. Der ganze Wald endlich löst sich in Verhältnisse auf, wie sie auf den Berührungsstreifen bestehen, bei einem stammweisen Wirtschaftsbetriebeoder auch stammwaldwirtschaft oder Femelwaldwirtschaft oder Plenterwaldwirtschaft. Diese Wirtschaft ist die älteste von allen: sie nähert sich dem Urwalde am meisten, sie ist die intensivste. die waldbaulich f'einste, aber auch die schwierigste Wirtschaft. Weil sie jeden einzelnen Baum bzw. einen jeden Trupp ron Bäumen für sich nach den jeweiligen Anforderungen an Boden, Licht und Wert behandelt. Sie ist die Wirtschaft, welche den Naturgesetzen des Waldes am vollkommensten entspricht. Jegliche flächenweise Ausscheidung, jerle Kartierung, jede Hiebsfläche fällt hinweg: der jährliche Zuwachs ist die Formel für die Regelung der Nachhaltigkeit im Femelwaldbetriebe; er genießt und gewährt im vollen Maße die Vorzüge des Urwaldes, verzichtet aber auch ganz auf die Vorzüge in Masse und (rüte der Produkte der Bestands- oder Flächenwaldwirtschatten.

Obige fünf Waldwirtschafts- oder Waldeinrichtungsformen, Großbestands- oder Großfächenwirtschaft, Bestands- bzw. Kleinbestandsoder Kleinflächenwirtschaft, Gruppenwirtschaft, Stammwirtschaft finden ihre Unterscheidung in der Flächengröße, welche gleichzeitig oder doch in kurzem Zeitraume genützt werden soll; die Art und Weise der Nützung und Verjüngung, das heift die gleichzeitige Beseitigung aller Stämme oder eines Teiles derselben, die künstliche oder natürliche Neubegründung in Verbindung mit den Wirtschaftsformen gebracht, gibt Anlaß zu weiteren technischen Buzeichnungen, die folgender Art sind: Kahlschlagsverjüngung in der Grofbestandswirtschaft, Kahlschlagsverjüngtung in der Kleinlestandswirtschaft, Kahlschlagsverjüngung in der Gruppenwirtschatt : eine Kahlschlagsverjüngung in der Stammwirtschaft hann nur die Beseitigung eines einzigen Stammes oder eines ganzen Trup'ps von Bäumen bedeuten; sie kommt daher begrifflich und praktisch gleich einer Schirm- 
schlagsverjüngung: Schirmschlagsverjüngung in der Gruppenwirtschaft, in der Kleinbestands- und in der Grobbestandswirtschaft sind weitere Terjüngungsarten, welche zusammen ebenfalls eine Gruppe bilden.

\section{Die Hauptverjüngungsarten.}

a) $\mathrm{Kahlhiebs-oder} \mathrm{K}$ a hlich lagsverjüngung.

Werden auf der Wirtschaftseinheit - Großbestand, Bestand, Kleinbestand, Gruppe - alle Stämme mit e in em Nutzungshiebe beseitigt, so entsteht eine Kahlfäche von der Fröße des Bestandes (größer als :3 ha), des Kleinbestandes von 1),3-3 ha, einer Gruppe von 0,3 ha bis 1 a ; die Größe eines Großbestandes oder Kleinbestandes kann Veranlassung geben, daß nicht alle stämme auf der ganzen Fläche, sondern nur auf Teilen der Flächen geschlagen werden, deren Größe sich nach waldbaulichen Bedürfnissen oder auch nach Forsteinrichtungserwägungen (Verjüngungszeiträumen) richtet. So wird der Großbestand zum Zwecke der leichteren Verjüngung in Kleinbestände oder in Gruppen, Kleinbestände in Gruppen. Gruppen in Einzelnstämme aufgelöst. Beim Kahlschlage ist zu erwägen: Je größer die Kahlfläche,

1. desto unvollkommener die Verjüngung, wenn diese allein der Natur überlassen bleibt:

2. desto größer bei geregelten Wirtschaften der Aufwand an Kulturkosten ;

3. desto mehr treten wegen der künstlichen Begründung die Mischbestände und mit diesen die Vorteile, aber auch die Nachteile der Mischbestände zurück: es entstehen vorwiegend Reimbestände: die Tachteile der Reinbestände kleben vorzugsweise den Kahlschlagsmethoden an;

4. desto schwieriger wird die Ausnützung der Verschiedenheiten des Bodens mit der passendsten Holzart;

5. desto größer bei gleichen Bedingungen des Gedeihens und Erkrankens die Gefahr durch Fröste, Irsekten, Pilze:

1). desto rascher verschwindet die Empfänglichkeit des Bodens, er verwildert auf Kosten der Nutzbäume; es steigern sich die Gefahren, welche Unkränter und Gräser auf einer Kahlfläche im Gefolge haben, das sind Vild- und Mäuseverbiß, Verdämmung. Fröste, Feuer, Schnee:

7. desto mehr werden Humus und Feinerdebestandteile rom geneigten Boden durch Regen oder Schneewasser abgeschwemmt;

४. desto mehr kann der Wind mit seinen austrocknenden Eigenschaften einwirken: im extremen Falle werden Humus oder andere lockere Bodenbestandteile in Bewegung gesetzt;

9. desto mehr schwankt im Boden und über demselhen der Feuchtigkeitsgehalt: es nimmt die Feuchtigkeit der Luft und des Bodens während der Trockenheit gegenüber dem Walde ab; es steigert sich die Frostgefahr, so daß die śchwierigkeiten für die 
Kulturmethode und die Gefahren für die nenhegrïndete Jugend wachsen ;

10. desto ungehinderter kömnen Licht und Wärme auf die, im vollen oberen und reichlichen, vorderen Lichte strhenden Pflanzen einwirken und ein von den jeweiligen Witterungsverhältuissen ganz abhängiges, grobfaseriges, ungleichbreitringiges Holz erzengen;

11. desto gleichartiger und gleichmäßiger wirl hei der Haupternte das zu erwartende Nutzholz in seiner Ausformung gering order stark, je nach dem Alter der Bestände.

Die bisher aufgeführten Punkte sind Nachteile, welche den Kahl hiebsflächen je nach der Flächengrölie imewohnen: von den Vorteilen seien folgende hervorgehoben: Je größer die Kalıltäche,

1. desto leichter die ganze Technik und Mechanik der Wirtschaftsgebarung, Einrichtming und Kontrolle der Wirtschaft;

2. desto leichter das Fällungs- und Sortierungsgeschäft: Unabhängigkeit ron der Geschicklichkeit der Arbeiter: Entbehrlichkeit ständiger Holzarbeiterschaften, welche unter den gegenwärtigen /eitverhältnissen immer schwieriger zu beschaffen sind;

3. um so geringer die Auslagen für Transport des Materials;

4. um so leichter die Kulturmanipulation, welche zumeist aut' künstliche Verjüngung abzielt; Aufstellung von Kostenvoranschlägen, Austührung der Arbeiten, Anwendung von Maschinen;

5. um so einfacher Kontrolle und Ersatz der Pflanzenabgänge; Unabhängrigkeit der Verjüngung rom Eintritt ins Samenjalır;

i. um so aussichtsvoller die Bekämpfung der stockbewohnenden schädlichen Insekten und Pilze:

7. um so enger wegen der Gleichalterigkeit und Gleichartigkeit der aufwachsenden Bestände der Kronenschluß, un so massenreicher die Bestände, um so vollholziger dio schäfte, um so geradschaftiger und um so astreiner die Bestände, weil sie reine sind.

8. desto einfacher alle waldbaulichen Maßregeln, desto geringere Ansprüche an die leiblichen und geistigen Leistungen des Wirtschafters. desto größer kömnen die Verwaltungsbezirke genommen werden. desto geringer die Zahl der Wirtschatter im Walde.

1. Die kahle Fläche ist naturgemäß am größten bei $\operatorname{dem} G r o B$ flächen-oder Großbestandskahlschlag: sie wirl kleiner bei der Bestands -, noch kleiner bei dem Klein bestandskahlschlag (in maximo $3 \mathrm{ha}$ ), am kleinsten bei der (truppentrschaft oder dem Löcherhiebe (in maximo 0.3 ha) oder bei dem Fumelhiehe (in maximo 1 a). Die Verjüngung auf der Kahlfäche kam eine natürliche oder künstliche oder eine aus beiden Methorlen gemischte Verjüngung sein. Der aufwachsende Wald zeigt auf der Verjüngmngstläche die geringsten Altersunterschiede, tritt frühzeitiog in Kronenselıluß und 
hleibt entweder im haubaren Alter mit allen Vor- und Nachteilen dieser Lichtverhältnisse geschlossen (Schattenholzart) oder verlichtet mit allen Nachteilen dieses Zustandes (Lichtholzart).

Um den Nachteilen der Großflächenwirtschaft tunlichst entgegenzuarbeiten, ohne auf die Vorteile verzichten zu müssen, ist man schon trühzeitig auf eine Einschränkung der Kahlflächengröße bedacht gewesen.

2. Der kahle Saumschlag oder saumweise Kahlschlag. The Saumbreite beträgt ${ }^{1}{ }_{2}-4 \mathrm{~m}$ Baumhöhen. Bei langem Saume kaun derselbe in mehrere Teile zerlegt werden, welche voneinander unabhängig gegen die Hauptwindrichtung fortschreiten, d. h. eine verschiedene Hiebsfolge in der Zeit ihrer Ausführung aufweisen; stoßen die Saumstücke in Winkeln aneinander, so spricht man auch von gebrochenen Saumschlägen. Je schmäler der Saum, um so geringer die Nachteile der dadurch entstehenden Kahltlächen, um so größer die Altersdifferenzen der entstehenden Jugend. Der kahle Saumhieb mit natürlicher oder künstlicher Verjüngung ist heutzutage die Regel bei der Bewirtschaftung von Fichten und zweinadeligen Föhren.

3. Kulissenkahlschlag entsteht, wenn mehrere parallele Saumhiebe in einem Bestande angelegt werden, so daß zwischen zwei Kahlhiebsstreifen ein breiter Bestandsstreifen verbleibt. Die Kahlflächengefahr wird geringer, aber die Windgefahr für den bleibenden Bestand wächst; für Bestände von zweinadeligen Föhren in Anwendung; die entstehende Verjüngung wird ungleichaltriger, unregelmäfiger abgestuft als beim kahlen Saumschlage.

t. Der ringförmige Kahlschlag beginnt als Kahlhieb auf einer annähemd kreisförmigen Fläche (kahler Löcherhieb); durch peripherisch sich erweiternde, also ringförmige, kahle Saumschläge schreitet die Nutzung und Verjuingung bis zu den Bestandsrändern fort; die Verjüngung ist eine natürliche oder künstliche; die Gefahren für die anfwachsende. Jugend sind beträchtlich gemindert, jene für den bleibenden Bestand besonders von seiten des Windes durch die fortschreitende Verjüngung erhöht. Um dieser zu begegnen ist:

5. eine Verbindung des kahlen staumschlages mit dem kahlen Löcherhiebe zulässig. Hat der ringförmige Kahlschlag cine solche Bestandesdurchbrechung herbeigeführt, daß Windgefahr zu drohen beginnt, werden die peripherischen oder Ringhiebe ausgesetzt, bis die Samnliebe an das Verjüngungsergebnis auf den kahlen Löchern heranrïcken und dieses in ihre Verjüngung mit einschließen. Sowohl der saumweise als der ringförmige Kahlschlag als auch die Verbindung beider könen in der Großbestands- wie in der Kleinbestandswirtschaft zur Anwendung kommen. Die Verjüngung kann eine natürliche und eine künstliche sein. In der Gruppenwirtschaft ist wohl nur der Kahlschlag. kaum mehr der kahle Saumhieb anwendbar; es entstehen dadurch 
ebenfalls kahle Löcher, welche aher nicht periphorisch erwoitert werden können, weil die Nachbargruppen aus andiren Holzarten odor ans anderen Altersklassen bestehen.

b) Schirmhiebs - oder Schirmschlagsverjüngungen ${ }^{1}$ ).

Werden auf der Wirtsehaftseinheit, (iroßbestand, Bestand, Kleinbestand, Gruppe, Trupp nicht alle stämme auf oimmal, wirl mu ein Teil derselben beseitigt, so entsteht dureh die bleibenden siämmo ein lockerer Schirm, welcher bestimmt ist:

1. Anflug der Sämereien von allen Seiten zu ermöglichen und für Bedeckung des Samens zu sorgen;

2. die aufwachsende Jugend gegen jegliche schädlichen, äußereu Einflüsse der Natur, wie Frost, Hitze, Hagelschlag, Wind, zu schützen;

3. den Unkrautwuchs möglichst zurückzuhalten:

4. mit der natürlichen Verjüngung die Ersparnis an Kulturkosten und alle übrigen Vorzüge dieser Methoden der Naturverjüngıngen zu sichern :

5. die Gewinnung eines Lichtstandswuchses an den Schirmbäumen zu erzielen;

6. den neuen Bestand zu gleichmäBigerem Holzgefüıe durch Entzug ron Licht und Wärme zu zwingen;

7. die Schirmbäume allmählich in den Freistand, einige von ihnen in den Überhaltsbetrieb überzuführen:

8. einen ungleichaltrigen neuen Bestand zum Schutze gegen Insekten, Wind, Schnee hervorzuruten.

Diese Vorteile werden zwar erreicht, jedoch müssen dam auch folgende Nachteile des Schirmbestandes in den Kant crenommen werden:

a. die Langsamkeit des Verjüngungsganges, Verzögrerung der Wirtschaftsführung und damit Ersehwerung des von der Forsteinrichtung vorgeschriebenen Tempos der Bestandsverjüngung:

b. Zuwachsverlust an den jungen Pflanzen infolge der Überschirmung, des Entzuges von Wärme, Licht und Wasser;

c. Ersehwerung der Fällung, Bringung, Sortierung und Verwertung des anfallenden Materials:

d. Erhöhung der Gefahr für den gelichteten schirmstand durch Wind, bei glattrindigen Bäumen durch Rindenbrand:

e. Vergrößerung der Arbeitslast für den Wirtschafter sownhl in leiblicher wie in geistiger Hinsicht.

1) Leider werden die Schirmschlagwirtschaften bzw. -verjungungen auch Femeloder Plenterverjungungen genannt, wodurch Konfusionen wic zwischen Femelhieb und Femelschlag Heyers Femelschlag ist z. B. - [unkelschlag') ohue Ende entstehen.

I a y $\mathbf{r}$, Waldbau. 
Schirmstandsformen der Verjüngungen sind folgende:

6. In der herrschenden Großfläehen- oder Großbestandswirtschaft hat die Schimschlagverjüngung seit mehr als hundert Jahren eino besondere Ausbildung erfahren unter dem Namen Dunkelschlagverjüngung. Sie erstreckt sich in der Großbostandswirtsehaft entweder über den ganzen Bestand auf einmal orler über große Teile desselben, in gleicher Weise setzt sie im Bestands- und Kileinbestandswalde ein; im Gruppenwalde umfaßt sio die ganze Gruppe. Der Angriff des Bestandes erfolgt an einer oder an wenigen Stellen des Bestandes. Die Dunkelschlagterjüngung besteht aus folgenden, zeitlich voneinander getrennten Hieben, welche alle die natürliche Wiederverjüngung der Wirtschaftsfigur bezwecken.

Ausgehend vom geschlossenen Schattenholzbestande, in dem die ganze Erziehungskunst bisher dahin abzielt, daß das unterdrückte Stammaterial beseitigt, der Bestandsschluß aber ängstlich erhalten wird, sind die ersten Hiebe bestimmt, die Nachteile dieser Erziehungsmethode für die kommende Verjüngung wieder langsam zu beseitigen. Die letzte Durchforstung wird als starke Durchforstung ausgeführt, d. h. wird stärker gegriffen als alle vorherigen Durchforstungen; es wird nämlich nicht nur sämtliches unterdrückte, sondern auch das der Unterdrückung nahe Material hinweggenommen als für die Zwecke der Naturbesamung hinderlich; diese Hiebe hat man Vorhiebe genannt.

$\mathrm{Er}$ ist kein Angriff, kein Verjüngungshieb im eigentlichen Sinn, denn im Falle weitere Hiebe nicht folgen, tritt keine Verjüngung, vielmehr wieder Bestandesschluß ein.

Der erste Verjüngungshieb ist der Vorbereitungshieb. Seine Aufgabe ist, den Kronensehluß der Althölzer dureh Herausnehmen von sehr starken und schwachen Bäumen, etwa der Hälfte des ganzen Bestandes, so zu durchbrechen, daß eine möglichst gleichmäßige Verteilung der S'chirmständer zum Zwecke einer möglichst gleichmäßigen Besamung erzielt wird. Diese Gleichmäßigkeit herbeizuführen, ist bei der Mannigfaltigkeit der inneren Natur eines Bestandes und bei den Störungen des Kronenschlusses im Laufe des Bestandslebens in der Tat eine Kunst, aber doch nur eine brotlose; demn die gleichmäßige Schirmstellung über große Flächen hinweg ist eine naturwidrige, für die besten Aussichten einer Verjüngung ungünstige. Die Sehirmdichte hat vielmehr mit der Bodengüte, mit dem Zustand der Bodendeeke, in bergigen Geländen mit diesen und mit der Exposition, d. h. mit dem Ḱlima zu wechsehn. Der Hieb heißt Vorbereitungshieb, um durch den größeren Lichtzufluß die Schirmbäume zum Samenerträgnis und den infolge des Bestandesschlusses unempfänglichen Boden zur Aufnahme der Sämereien vorzubereiten. Kurz vor einem Samenjahr oder wälırend desselben oder ummittelbar nach demselben wird ein zweiter Hieb in 
den schirmenden Bestand eingelegt, der Basamungshieb; er chtnimmt so viel Stämme, daß geniigend I icht fïr dio Entwicklung der erwarteten Jugend während der ersten Jahre geloten wird. Es folgen nun weitere Hiebe, welche alle als lichtungs-oder Lichthiebo zusammengefaßt werden und alle dic gleiche Tendenz verfolgrn, den Wasser- und Lichtgenuß der jungen fieneration zn steigerm und die Gefahr des Freistandes (Frost, Unlirant usw.) abzuwenden; die letzten Bäume des völlig anfgelösten Schirmstandes fallen dem $\mathrm{N}$ ach hiebe bzw. Endhiebe zum Opfer, womit wenigstens in der Theorie, seltener in der Praxis die Verjüngung abschließt.

Der daraus hervorgehende. junge Bestand zeigt, da er im wesentlichen aus einer Besamung entspringt, nur geringe Altersdifterenzen und besteht, wenn der alte Bestand gemischt war, in der Regel eben. falls aus mehreren Holzarten, welche stamm-, trupp- oder gruppenweise gemischt stehen. Ob die stammweise Mischung hierbei sich in der Zuliunft erhalten liamn, hängt von den naturgesetzlichen Grundlagen aller Mischungen ab, welche im ersten Teile näher besprochen wurden.

Um den Verjüngungsgang zu beschleunigen und endlich der . Jugend Ruhe zu geben, wird vielfach rom Dunkelschlag zum Kahlschlag oder kahlen Saumschlag übergegangen, womit die künstliche Verjüngung einsetzt. In nenerer Zeit hat man den Dunkelschlag abgekürzt, indem man Torhieb und Vorbereitungshieb mit dem Besamnngshieb vereinigt, „ins Tolle" greift, den Boden künstlich verwundet und in wenigen Lichthieben die Terjüngung, welche im regulären Dunkelschlag bis zu 40 Jahren umfaßt (Schwarzwald), beschleunigt (Dänemark).

Um der schweren Gefahr des Windes bei diesen Verjüngungsformen zu begegnen, legt man $\%$ den sa mmeisen Dunkelschlag ein. Die Verjüngung in dieser Form umfaßt nur Streifen des Bestandes, meist von einer Breite von 2-4 Bestandshöhen; an der dem Wind entgegengesetzten Seite wird dieser saumweise Schirmschlag hegonnen; aut jedem Streifen erfolgen der Zeit nach obige vicr Hiebe, während gleichzeitig auch die Hiebe nach dem Bestande hin in Säumen fortschreiten; theoretisch sollte auf dem ersten Streifen der Besammushieb zur Ausführung kommen, wenn ein neuer Streifen mit dem Vorbereitungshieb bedacht wird; auf dem ersten Streifen sollte der Lichthieb folgen, wenn aut dem vorausliegenden streifen der Besamungshieb einsetzt und ein Vorbereitungshieb einen nemen Streiten in Angrift' nimmt, und so fort bis zur Vollendung der Verjüngung des Bestandes. Wie alle saumweisen Hiebe, ist auch dieser für die Terjüngrung selbst ein sehr günstiger, er verzögert aber die Vollendung der Verjüingung außerordentlich, ein Nachteil, der um so grüßer ist, je größero Bestände die Forsteinrichtung ausgeschieden hat. Durch Autteilung der Süume in kürzere Stücke. Brechung der Säume künnen zahlreiche Angritł́s- 
punkte geschaffen werden, wodurch etwas das Tempo der Verjüngung sich beschlemigt; je schmäler die Säume, um so liräftiger können die cinzelnen Hiebe geführt, um so mehr in ilırer Zahl reduziert werden. Professor Engle ${ }^{1}$ ) empfiehlt den saumweisen Dunkelschlag mit dem saumweisen (rmppenhieb tür Fichte, Föhre und Lärche im Hochgebirge. C. Wagners ${ }^{2}$ ) ${ }_{n}$ Blendersam " ist elenfalls cine schirmständige Saumrerjüngung mit Annäherung an Dunkelschlag und Gruppenhieb.

8. Auch in der Kleinbestands- oder Kleinflächenwirtschaft kann der Dunkelschlag auf der ganzen Fläche oder. 9. in Säumen zur Durchführung gelangen, wie eben für die Großbestandswirtschaft geschildert. Es liegt aber auf der Hand, dałs die größte Gefahr der Großflächenwirtschaft, welche von seiten des Windes droht, bei der Kleinbestandswirtschaft bereits auf

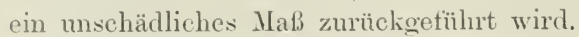

10. In der Gruppenwaldwirtschaft ist der Dunkelschlag auf einer Gruppe mit allen vier Hieben oder mit einer Abkürzung des Verfahrens sicher eine sehr zuverlässige, aber langsame Verjüngungsmethode, welche auch auf der Maximalgröße der Gruppe von 0,3 ha ohne Rücksichtnahme auf den Wind ausgeführt werden kann.

11. Als ringförmiger Dunkelschlag oder ringförmige Schirmschlagverjüngung muß jene Methode bezeichnet werden, bei der an zahlreichen $\mathrm{P} u n k t e n$ im Bestande, auf kleinen Flächen, annähernd Kreisen, der Vorbereitungshieb des Dunkelschlags cinsetzt; während auf diesen ersten Flächen der Besamungshieb durchgeführt wird, schlieft sich ringförmig ein neuer Saum mit dem Vorbereitungshiebe an; so schreiten die Hiebe sukzessive und peripherisch in ringförmigen Sämmen von der Breite 2-4 Baumhöhen nach außen fort. Wird hierbei weniger auf die genaue Einhaltung der vicr Hiebe, weniger auf die Stärke der Hiebe und Breite der Säume angesichts der Bestandsumgebung, seines erhöhten Sehutzes und seiner günstigen Samenstrenung Bedacht genommen, als der eigentliche Dunkelschlag auf den wrölioren Flächen beansprucht, so entsteht eine Verjüngungsform, welehe in Süddeutschland als 1\%. Gruppenweise oder anch als "horst-und gruppenweise" Verjüngme, viele Anhänger gefunden lat. (Geheimrat $\left(\right.$ i a yer ${ }^{3}$ ) wünscht letztere Bezeichnung, nicht das irreführende Wort Femelschlagverjüngung, das er früher anwandte. Das Verfahren kïmnte man auch schirmständige Löcherwirtschaft nemen. In ihr erbliclit er die vorteilhafteste Verjüngungsform für den Walc. Die aus dieser Verjüngung hervorgehende Jugend

1) Prof. A. Engler, Schweizer Forstverein 1900.

2) Prof. C. W agner, Die räumliche Ordnung im Walde. 1907.

${ }^{8}$ ) Geh. Lat Dr. K. Gayer, Der gemischte Wald. 1886. 
zeigt ein mit langgezogenen Höckern versehenes Niveau der Kron'nflächen, entsprechend den Anfangspunliten und dem Alter cler Verjüngung: die Altersunterschiede jedoch, die wegen der Anforderumgen der Großbestandsforsteinrichtungen an den Verjüngumgrseitraun nicht groß sein können, verwischen sich schon mit dem Fintritt ins Stangenholzalter. Der Bestand verhält sich von diesem /seitpunlite an wie ein aus dem Kahlschlagbetriebe hervorgegangener Bestand.

Auch in der Kleinbestandswirtschaft läßt sich der regelrechte, ringförmige Dunkelschlag mit breiten, schirmständigen säumen durchtühren: ebenso paßt für die Kleinbestandswirtschaft dio abgekürzte Gayersche Form mit verschmälerten Säumen und verstärkten, in /ahl verminderten Hieben.

Je größer die Fläche ist, über welche eine Schirmschlagrerjüngung sich erstreckt, je weiter die Verjüngung und Auslichtung des Schirmstandes fortschreitet, $u \mathrm{~m}$ so größer werdendie $\mathrm{Nach}$ teile dieser Terjüngungsmethoden, vor allem die Langsamkeit der Verjüngung, die Ungleichmäßigheit der erzielten Bestockung, die Sturmgefahr für den Schirmbestand. Um diesen Nachteilen vorzubeugen, wird die Verjüngung vielfach 13. zwar in der Dunkelschlagform begonnen, jedoch im Kahlschlag oder kahlen Saumschlag mit künstlicher Verjüngung zu Ende gebracht. Da die gleichmäßige Dunkelschlagstellung zum Zwecke der Besamung nur bei einer Vollmast aller Bäume anch eine gleichmäßige Verjüngung bringt, in allen übrigen Fällen aher nur ein lückenhafter, junger Wuchs entsteht, so werden die bestgelungenen Stellen als Verjüngungszentren (Gruppen im Sinne Gayers) ausgewählt und ihre Erweiterung und Abrundung mittels schmaler, ringförmiger Kahlschläge (Umsäumungen) oder ringförmiger Schirmschläge (Rändelhiebe) zu erzielen gesucht, worauf wieder kahle Absäumung folgt oder auch durch jahrzehntelanges Zuwarten auf Naturbesamung gehofft wird (14.); im ersteren Falle folgen drei Verjüngungsformen nacheinander auf einer Fläche. Man kann als 15., als bayerisches oder von Hubersches Verfahren jenes bezeichnen, das im Innern eines Groß- oder Kleinbestandes mit gruppenweiser Verjüngung im sinne von Gayers Femelschlag begimnt, während gleichzeitig an windentgegengesetzten Seiten ein kahler Saumschlag eingelegt wird. Dieser Kahlschlag beabsichtigt eine Beschleunigung der Verjüngung, ermöglicht die Erfüllung der jährlich gleichen Abtriebssätze, indem das Holzquantum aus den Fällungen über den Gruppenverjüngungen, dessen Höhe vom Gange der Verjüngung abhängig ist, durch die Fällungen auf dem Kahlsaumschlage bis zu seiner normalen Etathöhe ergänzt wird. Diese von $\mathrm{v}$. Huber „Kombiniertes Verfahren " genannte Verjüngungsart hat in Bayern weitgehende Terbreitung gefunden. Fast alle Natur. verjüngung vollzieht sich nach dieser G a yer-H ub ershen oder bayerischen Methode. 
Bei den bisher hetrachteten Verjüngungsformen trifft der erste, die Verjüngung einleitende Hieb die Baumvereinigung völlig unvorbereitet: wo der Boden für die Aufnahme der Sämereien empfänglich ist, hat es der /ufall, ganz gegen den Willen des Wirtschafters so gefügt. Dank der heute noch fast allgemein üblichen Erhaltung des Bestandsschlusses (Schattenholzarten) sind kostbare Jahre der Verjüngung nötig, um die Folgen dieses Mifstandes, welche in Unempfänglichkeit des Bodens gipfeln, zu beseitigen (Vorhereitungshieb!); andererseits ist bei Licht- und Halbschattenholzarten die beste Empfänglichkeit des Bodens längst vorüler (Verunkrantung); die Bestände müssen auf künstlichem Wege verjüngt werden. Soll eine Bammvereinigung im A ugen blicke cler Nutzung auch auf natürlichem Wege verjüngbar sein, so muß sie hierzu erzogen sein. Man kann eine solche Verjüngung oder Wirtschaft, welche eine Verbindung zwischen Verjüngung und Erziehung darstellt, 16. die Erziehungsverjüngung oder Erzieh ungswirtschaft nennen und auf Großbestands-. Bestands- und Kleinbestandseinteilung des Waldes anwenden. Ihr Hauptzweck ist, wie später ausgeführt werden muß, schnelle, sichere und leichte Naturverjüngung in reinem Bestande für alle Holzarten.

1\%. Die Schirmschlagsverjüngung auf der kleinsten Fläche, Maximalgröße = Trupp, Ninimalgröße ist Einzelstamm, die stammweise oder truppweise Terjüngung ist das Charakteristikum der Femel wal d wirtschaft, der Plenterwaldwirtsehaft, der Schleichwirtsehaft. Diese Verjüngungsform kann auf den gesamten Wirtschaftswald sich erstrecken, sie kann aber auch nur einzelne Großbestände, selbst Kleinbestände umfassen, wie zumeist in den höchsten Regionen des Waldes, in Auwaldungen oder in Schutzwaldgebieten; dabei ist gleichgültig, ob der ganze Wald aus einer Holzart oder aus einer großbestandsweisen oder kleinbestandsweisen oder gruppenweisen oder stammweisen Holzartenmischung besteht. Theoretisch sind auf einer Fläche ron etwa I0 a bereits alle Altersklassen vertreten: die Verjüngung stellt sich fortgesetzt ein, rla fortgesetzt alte, hiebreife Bäume geschlagen werden; Kronensehluf felilt ganz oder erstreckt sich nur auf Jaumansammlungen von der fröße eines Trupps (1 a). Da allen Individnen licht zufliefst, ist das Wachstum derart begünstigt, daß Biolley und Prof. Engler') den Femelwald als jene Waldform bezoichnen, in welcher im Hochgebirge die größte Holzmasse erzeugt werle.

Bewrgt sich diese Femelverjüngung der Reihe nach in bestimmten über- oder nebeneinander liegenden $/$ onen des Waldes, so nennt man ein derartiges Verhältnis auch wohl den (18.) zonenweisen Femelbetrieboder die zonenweise Femelverjüngung.

Theoretisch soll der Femelhieb über den ganzen Waldkomplex,

$\left.{ }^{1}\right)$ Schweiz. Forstrerein 1901. 
welcher dem Betrieb unterstellt ist, alljährlich hinweggehen. Allein vielfach wird für bestimmte Waldesteile eine Anzahl von Jahren festgelegt, nach welehen der Femelbetriel, in diese 'Toile zurückkehrt; sie sind somit 19. einem umlaufenden oder aus.

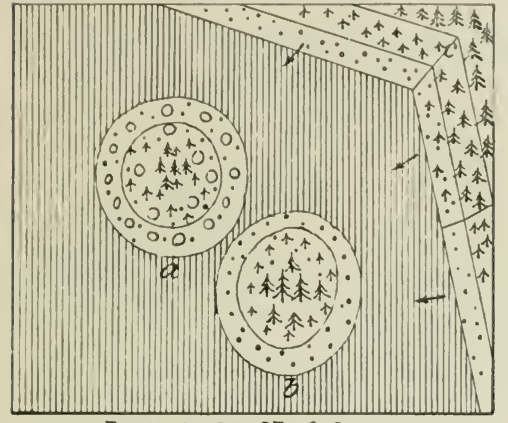

Bayerisches Verfahrer.
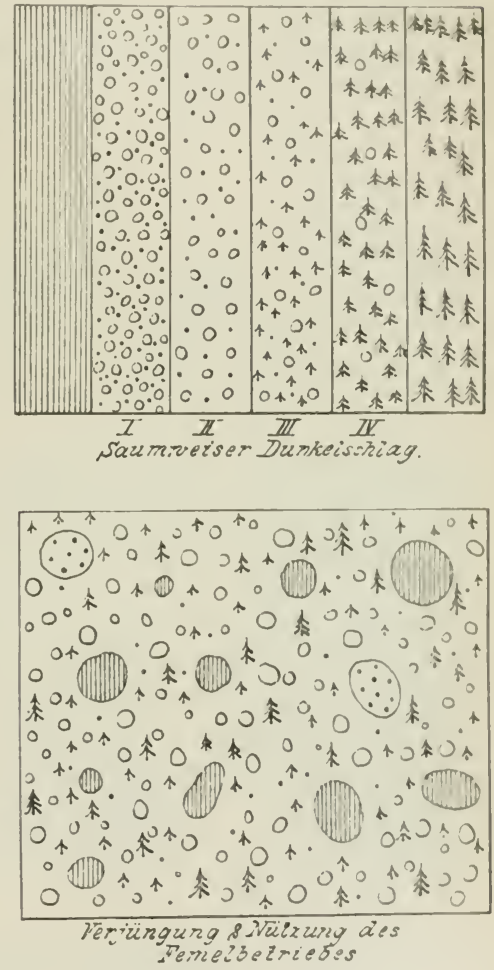

semerbezrezies

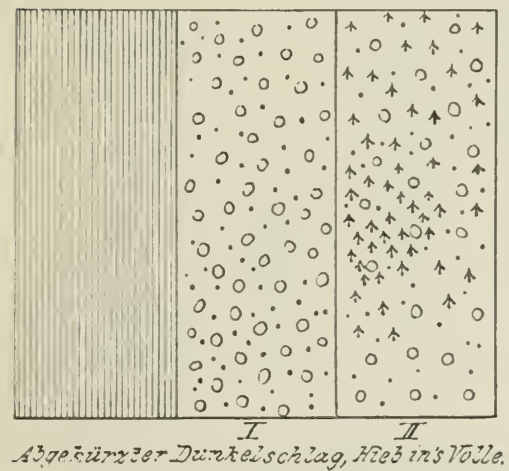

Abb. 14. Schematische Darstellung verschiedener Verjüngungs-bzw. lietricbsformen.

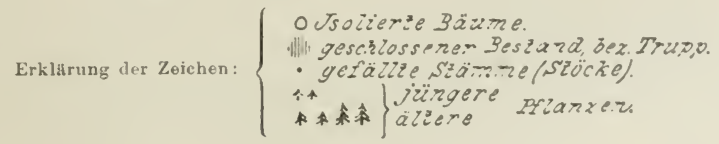

setzenden Femelbetriebe bzw. einer solchen Verjüngung unterworfen. Wächst die Periode zu mehreren Dezennien an, und nimmt der Femelhiel, alle erwachsenen Stämme bis zu ciner Minimalstärke im Durchmessser, z. B. bis $25 \mathrm{~cm}$ herab, hinweg, so kann man 
eine derartige Wirtschaft $\mathbf{2 0}$. den periodischen Femelbetrieb memnen, wie er in weit ausgedehnten Urwaldungen vielfach als die erste und beste Nutzung und Verjüngung erscheint.

Bei den vorgenanuten Femelverjüngungen stehen die Altersklassen stammweise oder truppweise regellos durcheinander. Neben einem ganz jungen Baum oder Trupp kann ein alter Baum oder Trupp zu stehen kommen. Diese unregelmäßige, schachbrettartige Anordnung der Altersklassen birgt Übelstände in sich, wie Beschädigung des jungen Wuchses durch die Fällung und Bringung des alten Holzes, mangelhafte und äherlangsame Entwicklung der Jugend durch allzu starke Seitenbeschirmung $u$. a. Um diese Mißstände zu vermeiden, hat Oberforstmeister Ney 21. den Sa umfemelbetrieb bzw. diese Verjüngung vorgeschlagen. Er denkt wich zunächst den Wald in große Bestände aufgeteilt, jede Verjüngung als eine kleinste Gruppe (Trupp nach obiger Abgrenzung) und diese Kleingruppen wiederum in einem Saum angeordnet. Wenn nun die natürliche Verjüngung im Osten am haubaren Saum mit schmalen, schirmständigen Saumhieben beginnt, so muß der Westrand des Bestandes ein Jahr alt sein. Ist die Verjüngung am Westrand angelangt, muß der Ostrand wiederum so alt sein, wie die festgestellte Umtriebszeit beträgt. In dieser Form kommt der ältere Neysche Femelsaumschlag dem „Blendersaum“ C. Wagners sehr nahe. Es erscheint jedoch nicht notwendig, den Begim der Yerjüngung auf den Bestandsrand zu verlegen: man kann nach Ney auch im Zentrum eines Bestandes beginnen mit ringförmigen Schirmhieben (alljährlich oder nach wenigen Jahren) und die Verjüngung gegen den Bestandsrand hin fortsetzen. Ist der Saumhieb im Bestandsrand angelangt, muß das Zentrum wiederum haubar sein. Ne y nennt diese Form des Femelhiebes 2:. den Ringfemelbetrieb. Um die nütige Zahl von Saumhieben einlegen zu kömnen, ist die Aufteilung des Waldes in große Bestände nötig. Die Anordnumg der jungen Wüchse nach Altersabstufungen ergibt sich direkt aus den neben gegebenen Bildern der Naturverjüngungen.

23. Der Urwald wähert sich in seiner Verjüngung dem Femel- oder Plenterwalde; es unterbleibt jedoch jegliche Nutzung von seiten des Menschen. In den Waldungen der Fürsten Schwarzenberg in Böhmen, deren Munifizenz die Erhaltung eines Stïckes unberührten Urwaldes in Mitteleuropa an cler höhmisch-bayerischen Grenze zu danken ist, gibt es anch einen Urwald, der in Wirtschaftsbetrieb genommen ist: 24. der bewirtschaftete odergeregelte Urwald, bei welchem nur jene Bäume beseitigt werden, welche absterben oder von Naturereignissen zu Boden geworfen werden.

Jene, welche glauben, ein Urwald entstehe wieder dadurch, daß man mit einem Male in einem Kulturwalde jegliche Fällung unterläßjt, täuschen sich. Gerade das urwüchsig Erscheinende, wie dicke, 
knorrige Eichen, ist niehts Urwaldartiges; es wird sofort zerstört, wenn man die angesiedelte Jugend von Schattenholzarten, z. B. Buchen oder Fichten oder Tannen, in die Kronen der niederen, dicken Bäume hineinwachsen läßt. Um das Kraftvolle, aber doch nicht Urwaldartige im Kulturwalde zu erhalten, müssen Fällungen stattfinden, um die nachdrängenden Zerstörer des Urwüchsigen zu beseitigen (Oldenburg).

25. Der Überhalt. Er ist keine selbständige Wirtschaftsform, kann aber mit sämtlichen vorhin genannten Wirtschaftsformen, mit

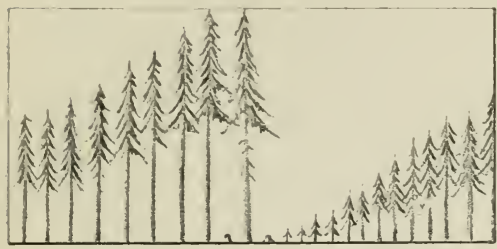

Neys u. Wagners s'aumfermel.

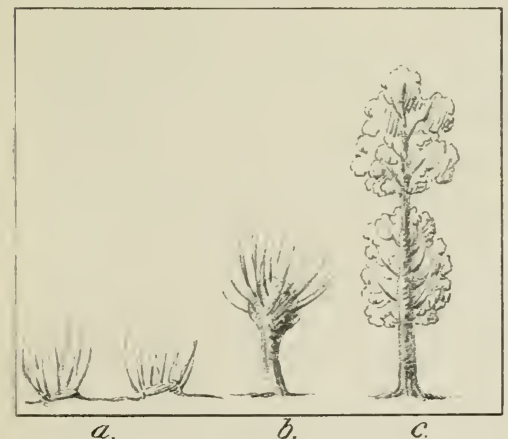

Ausschlagvenjüngungern

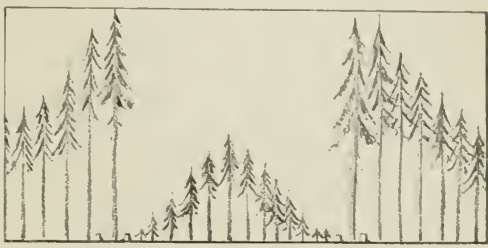

Neys Ringfemet

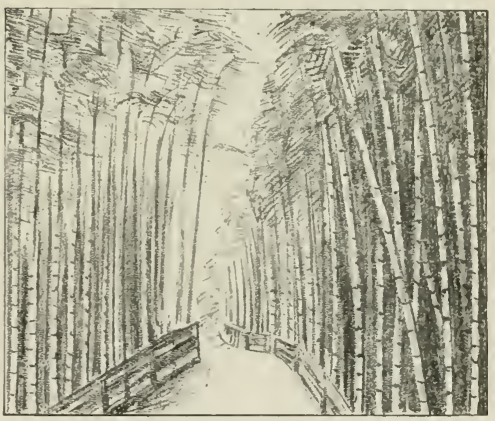

Rzizomirald, Bambiusfemelwald.

Abb. 15. Schematische Darstellung versehiedener Verjüngungs- bzw. Betriebsformen. a. Stockausschlag: b. Kopfausschlag: c. Kropfausschlag.

Ausnahme von 23 und 24, welche ohnedies keine Altersbeschränkung in ihren Individuen kennen, verknüpft werden. Der Überhalt besteht darin, daß bei der allgemeinen Nutzung im Haubarkeitsalter einzelne Bäume oder Baumvereinigungen gelassen werden, um das doppelte, selbst dreifache Alter der Umtriebszeit zu erreichen. Der Überhalt kann in drei Formen auftreten: a) Einzelnüberhalt; möglichst schönschaftige, normalkronige Bäume werden in geringer Zahl, etwa 25-30 pro Hektar, möglichst gleichmäßig auf der ganzen Fläche verteilt, zum Überhalt bestimmt; b) Baumvereinigungen, möglichst gut in Schaft und 
Krone, in der Größe von 1 a bis 0,3 ha, somit Gruppen werden behuf's Überhaltes rom Hiebe verschont, grupenweiser ÏTberhalt; auf größeren Flächen kann auch eine Verhindung beider, nämlich einzelnund gruppenweiser Überhalt, Platz finden: c) Kulissen oder streifen-oder bandweiser Überhalt. Die Überhaltstämme werden in Streifen oder Bändem parallel der Hauptwindrichtung übergehalten (russischer Überhalt): oder endlich, d) es werden Kleinbestände von 1),3-3 ha orler (iroßbestände $\ddot{3}$ ber 3 ha aus Forsteinrichtungsgründen nicht im .Jahre ihrer Haubarkeit genutzt (Überhaltbestand, Reservebestand. bost andsweiser Überhalt). Die Vorteile, weiche der Öberhalt bietet, sind: 1. Erziehung von sehr starkem Nutzholz, von bester technischer und physikalischer Qualität, da die Freistellung erst nach der Astreinigung und nach der Jugendperiode mit der schwankenden Jahresringbreite erfolgt: 2. Erleichterung der Besamung der zu verjüngenden Fläche; :3. Ausgleich für Jahre mit geringerer Nutzungrsquote als Holz- bzw. Kapitalreserve. Dagegen sind als sehwere Nachteile zu erwähnen: 1. Sturmgefahr der Ïberhälter, insbesondere bei plützlichen Ïbertührungen in den Freistand. Entstehung von peripherischen Rissen im Holzlörper des unteren Sehafteiles, erhöhte Blitzgefahr: „2. bei Laubhölzern Entstehung von Wasserreiserm, Gipfeldürre, Rindenbrand, insbesondere bei plötzlicher Freistellung; 3. Beschädigung des Jungwnehses durch eine frühzeitị notwendig gewordene Fällung, durch das Herausschaftén der schweren Stämme: t. Wertverlust, im Falle der Stamm zum Sehutze der Verjüngung zu weniger wertvollen Sortimenten aufgeschnitten werden muß, Beeinträchtigung des Unterstandes durch die Baumkronen der Ïberhälter; verminderter /uwachs des jungen Wuchses unter den Kronen. Die Nachteile sind am größten beim Einzelnüberhalt, der aber auch die Vorteile der Holzmassen. produktion des Lichtstandes am besten ausnützt; geringer müssen die Nachteile. aber auch die Vorteile beim gruppenweisen ITberhalt, am geringsten beim bestandsweisen Überhalt sein; Unterbau und Durchlichtumg rhöhen die Vorteile; Ïberhaltbetrieb ist nur an Eichen, Waln ïssen, Fïhren, Lärchen und, wie zu erwarten ist, auch an den Jonglasien ein rentabler Betrieb, da nur bei diesen Holzarten mit der Zmmahme der stärke der Wert steigrt.

26. I)er doppeltaltrige Hoehwald oder Kompositionsbetrieb. Elsässer zweilhiebiger Hochwald, Spessartwirtse haft. Das Wesen dieser Wirtschaftsformen, die nur in Holzart und Alter des Grundbestandes verschieden sind, ist folgendes: Eine größere '/ahl von Bäumen, etwa l(u) pro Hektar, wird übergehalten (Lichtholzart, besonders Eichen); (ler Frundbestand, aus einer Schattenholzart (Buchen) bestehend, wird in dem abgekürzten Umtrieh von 60-80. Jahren mit doppeltem Alter des Überhaltes (Elsässerform), von $\times(1$ - 100 .Jahren mit dreifachem Alter des Überhaltes (Spessartform) bewirtschaftet. Der 
Schwerpunkt liegt im Ïberhalte, der zu ganz besonders schönschaftigem, feinfaserigem, hochwertigem Nutzholz heranreift.

2i. Homburgs Nutzholzwirtschatt in geregeltem Hochwald überhaltbotrieb ist eigentlich nur eine Verbindung des Überlialthetriebes von Nutzholzgruppen mit Buchenhochwald. Es wird der Buchengrundbestand im Dunkelschlag verjüngt; vor dieser Verjüngung aber werden in Löchern des Grundbestandes einzeln und in Gruppen Eichen, Eschen, Ahorne, Ulmeu, Tamnen durch Stïckrillensaat vorgebaut. Vor der Fällung des Buchengrundbestandes werden die vorgebauten Nutzhölzer freigehauen, um sie zum Überhaltfreistande vorzubereiten. Der Ïberhalt umfaßt zwei, selbst drei Buchengenerationen. Der Zweck ist Gewinnung besonders starker Nutzhölzer verschiedener Baumarten, ohne auf die zu Homburgs Zeit wichtigste Wirtschaft, die Buchenbremnholzwirtschaft, verzichten zu müssen.

25. ron Seebachs Lichtwuchsbetrieb oder modifizierter Buchenh ochwald. Auch diese Form geht von dem damals wichtigsten Hochwalde, dem Buchenbrennholzwalde, aus: sie will ihn schon 30-4) Jahre vor Erreichung der Haubarkeit im Dunkelschlagverfahren verjüngen; jedoch sollen von den Schirmbäumen so viele belassen werden, daß in 30-40.Jahren diese wiederum einen Kronenschluß bilden. Die erste Verjüngung hat nur den Zweck des Bodenschutzes. Erst die num einsetzende zweite Verjüngung gibt den zukünftigen Bestand. Torzeitige Nutzung zur Befriedigung ron Berechtigungsansprïchen war die Teranlassung für von Seebach zu dieser Tirtschattsform.

$\mathrm{Zu}$ den Lichtwuchsbetrieben zählen sodann noch folgende Formen: 29. Der zweihiebige $\mathrm{Hochwald}$ ist eigentlich keine Terjüngung. sondern nur eine Bestandserziehungsform, mag aber der Tollständigkeit wegen hier Platz finden. Schattenhëlzer werden nach Ablauf der halben Umtriebszeit stark durchlichtet und unterbaut; Lichtholzarten werden zur Zeit der natürlichen Verlichtung mit Unterbau versehen; es besteht dabei die Hoffnung, daß dieser Unterbau, unterstützt durch Hiebe im älteren Bestande, zu brauchbarem Nutzholz bis zur Haubarkeit des älteren Bestandes heranwachsen wird.

30. Die Lichtungsbetriebe sind ebenfalls Erzichungsormen: sie unterscheiden sich vom zweihiebigen Hochwalde nur dadurch, daß der Unterbau erst nach Ablauf des größten Teiles der Umtriebszeit (etwa $\% / 4$ u) ausgeführt wird. Ausnutzung des Lichtungszuwachses olne Nachteile durch Freistellung für den Boden sind Zwecke dieser Wirtschaft.formen.

31. Wageners Lichtwuchsbetrieb beabsichtigt eine große Ernte von Vorerträgen und Ausmutzung des Lichtungszuwachses. Er denkt sich den Bestand weitständig begründet: zwischen 25 und 30 Lebensjahren erfolgt der erste Kronenfreihieb der wuchskräftigsten 
stangen in gegenseitigen Abstänten ron t-5 m. Ter Zwischenstand wird bei lichtholzarten unterbant, bei Schattenholzarten stark durchtorstret. Nach zehn .Jahren wird der Kronenfreihieb wiederholt: der Unterban wird ant der granzen Fläche mit Buchen und Hainbuchen betätigt. Nach Nutzung des Iauptbestandes soll der Unterbau zum Hauptbestand heranwachsen. Um seine Nutzholztüchtigkeit zu orhöhen, ist von Wagener die Finpflanzung ron Nutzhölzern, wie Fichten und Lärchen, auf Lücken in den Buchen bealsichtigt. Fehlen die Lücken, werden in dem ehemaligen Unterban liahle Gassen geschlagen, in welche die beiden Nutzholzarten eingeptlanzt werden. Diese Art der Begrïndung eines Mischwaldes ist der schwächste Punkt in Wageners Wirtschafts- und Verjüngungssystem. Geht das Bodenschutzholz verloren, so erfolgt Neubegründung des Bestandes wiederum durch weitständige Pflanzung: von welcher bei Beschreibung des Systems ausgegangen wurde.

3:. Borgmanns horstweiser Lichtwuchsbetrieb fïi die Fichte ist. wio der Name sagt, ein Lichtwuchsbetrieb, der auf zahlreichen Gruppen (bis zu 10 a Größe) im Fichtenbestand sich er. streckt; die Gesamtsumme aller Horste oder Gruppen soll zwei Drittel der ganzen Fläche einnehmen. Im Zentrum der ausgewählten Horste beginnt mit dem ju. Lebensjahr des Bestandes ein Kronenfreihieb der bestgeformten Stämme in etwa $3-6 \mathrm{~m}$ Abstand. Das Unterständige verbleibt im Lichtwuchshorste: alle fünf Jahre wird der Freihieb wiederholt, so daß mit 70 Lebensjahren des Bestandes die Freihiebe an den Ründern der Lichtwuchshorste angelangt sind. Im 75. Jahre heginnt die Verjüngung dieses Horstes rom Zentrum ausgehend in Kahlschlägen mit Pflanzung, im 85. Jahre kann die Verjüngung aller Horste beendet sein, worauf die Kahlschlagsverjüngung des zwischenliegenden Bestandes sich anschließt. Auch dieser zwischenliegende Bestand wird stärker als bisher, unter Kronenhilfe für bestgeformte Stïmme durchtorstet. Größere Vorerträge, Erzielung der Lichtwuchsvorteile für die sturmschwache Fichte, Sicherung des Aufwuchses durch die uruppenweise, lïustliche Verjüngung sind die Hauptzwecke der Wirtschaft.

1)as gleiche /iel erreicht im Fichtenwald anch 33. Urichs Licht wuchskulissenbetrieb. Es erfolgt der Freihieb der bestgeformten Stämme in breiten Streifen (Kulissen), wolche durch geschlossen bleibende Bestandsteile voneinander getreunt sind.

34. Borgereves Reformald. In dem bis zum (io. Jahre in der bisher ïblich'n, (d. h. mit ängstlicher Erhaltung des Bestandsschlusises), durchforsteten Bestande werden von da an alle zehn Jahre die rorherrshend stärlisten Stämme herausgenommen, bis $z u \quad 20 \%$ der Greamtmasse. Borggreve nimmt an, daß die vorherrschenden Stämme (Protzen) die fehlerhaftesten Glieder des Bestandes seien, was angesichts der mangelhaften .Jungwuchspflege und der mpassenden Durchforstungs- 
methoden in zahhreichen Fällen auch richtig ist. Die verbleibenden, bisher von den Protzen beherrschten Stämme sollen sich wieder erholen (Erholungswirtsehaft auch genamnt), wofür diesen ein verlängerter Umtrieb bis zu 140 Jahren geboten wird.

3.). Preblers Hochwaldideal, idealor Hochwald; die Stämme sind hiebreif, sobald ihr Weiserprozent unter den geforderten wirtschaftlichen Zinsfuß herabsinkt. Natürliche, auch künstliche Verjüngung begrüudet den Neubestand.

In Waldungen, in welchen nicht das erzengte Holz, sondern ein anderes Produkt des Baumes oder ein anderes Produkt des Bodens oder nur ideelle Genüsse das Endziel der wirtschaftlichen Tätigkeit bilden, richtet sich auch die Form der Wirtschaft und der Verjüngung nach diesem Ziele.

Hierher zählt 36. der Harzwaldbetrieb, wie er vorzüglich bei zweinadeligen Schwarzföhren, auch bei einigen drei- oder fünfnadeligen Föhren, selten bei Angehörigen der Gattungen Picea, Abies, Larix, Tsuga, Pseudotsuga angetroffen, wird bzw. eingerichtet werden kann.

37. Korkwaldwirtschaft. Torzugsweise sind es zwei immergrine Eichen Quercus Suber und Quereus oceidentalis, welehe in den Subtropen Nordafrikas und im benachbarten Castanetum des westlichen Europa zum Zwecke der Korkgewinnung in aufgelöstem Kronenschlusse erzogen werden. Im Castanetum Japans hat man in neuerer Zeit auch eine winterkahle Eiche, Quereus variabilis mit Erfolg für die Korkgewinnung herangezogen.

35. In der WValdweidewirtsch a f im Flachlande und hügeligen Gelände ist die Gewinnung der Gräsereien durch den Weidegang der Tiere aus rechtlichen Gründen zu dulden. Zur Befriedigung dieser Servituten ist Kahlschlagbetrieb nötig, um die verunkrauteten Flächen bis zu ihrer Verjüngung wie auch die haubaren Bestände der Tiehweide zu eröffnen.

39. A lpenweidewirtschaft scheidet bereits für einen Umtrieb ständige Weideflächen im Wirtschaftswalde aus; auch alle übrigen Bestände sind der Weide geöffnet mit Ausnahme jener, welche in Verjüngung stehen. Ist endlich die Weide der wichtigste und ständige Ertrag einer Fläche, ist der Wald aufgclöst in weiträumig gestellten. Nutzbäumen, welche in einem Femelhiebe genutzt und in einer Femelpflanzung wiederum verjüngt werden, so wird diese Wirtschaftsform 40. Hutweidewirtschaft genannt; hierher zählen die Weideflächen mit Eichen oder Föhren, im Hochgebirge mit Lärchen (Lärchenwiesen).

41. Wildparkwirtschaft. Je nach der Tiergattung, welche geliegt werden soll, sind Holzart und Wirtschaftsform zu wählen; fruchttragende Laubbäume und Sträucher, schützende Nadelhölzer, vergraste Flächen, Fruchtfelder sind nötig, so daß Kahlschlag, Femel. 
wald. Mittelwald und landwirtschaftlicher Betrieb im Wildpark sich veroinigen kïmnen.

4:. L ustparkwirtschatt: sie verfolgt ästhetische Ziele: Schönlreit des Anfbaues des Waldes in Baumhöhe, Kronenform, in Freistand und Veleinigungen, Erhaltung der Naturschönleit, des landschaftlichen Bililes, der Tiere, besonders der Vogelwelt, Umrahmung von Baulichleviten und anderes sind die Ziele, denen der Lustpark zur Freude seines Besitzer: und seiner Besucher dienen soll. Alle Bämme und Sträucher, pinheimische wie fremdländische, alle Wirtschaftsformen, insbesondere der Femelwaldbetrieb, der Mittelwald, am wenigsten der Kahlschlag im Hoch- und Niederwald, können diesen Zwecken dienen.

In allen Örtlichkeiten, in welchen die Erhaltung einer Baumvereinigung zum Schutze des Bodens gegen Abschwemmung, Überschwemmung. Lawinenbildung, Flugsandbildung, Bergabrutschung u. dgl. wichtiger erscheint als die Holzprodultion, ist 43. die Schutzwaldwirtsch aft am Platze. Großbestands- und Kleinbestandswirtschaft sind so weit zulässig, als sie in einer Form verjüngen, die nicht auf einmal größere, kahle Flächen schafft: das sind vor allem Sehirmbestandsverjüngungen, insbesondere der Femelbetrieb. Im Hochwalde, der nur aus Gruppen besteht, wäre anch der Kahlschlag zulässig. Sohr steiles, felsiges Gehänge, welches nur mit Schwierigkeit betreten werden kamn und nur einen minimalen Gewinn abwirft, sollte überhaupt unberührt als Urwald zum ästhetischen Genusse erhalten bleiben.

Als neuzeitliche Wirtschaft mag 4. die Schmuckbaumzucht, der Schmuckbaumbetrieb Frwähnung finden, der in der Nähe der größseren Städte immer melr notwendig und rentabel wird. Nadelhölzer werclen auf mittelguten Böden (nicht auf schlechten wegen Langsamwïlehsigkeit, nicht auf sehr guten wegen allzu raschen WVachstums) angepflanzt, um Weilınachtsbäume, Dekorationsbäume, Deckreisig usw. zu liefern. In Nadelholzgebieten werden auch Laubhölzer gewïnseht.

Nene Wirtschatts- und Verjüngungsformen entstehen sodann, wemn der Hochwald mit $L$ andwirtschaftsbetrieb verbunden wird, womit ein' doppelte Ausnützung der Fläche beabsichtigt, aber anch eine beschleunigte Erschöpfung des Bodens herbeigeführt wird. Die grïndliche Bodeniockerung der landwirtschaftlichen Benutzung erleichtert die Wieclerbegründung der nenen Waldgeneration, schädigt sie aber durch Erregung ler Wrurzelfäule.

45. Die Walifeldwirtschaft. Der Hochwald wird durch Kahlschlag beseitigt. Die künstliche Begründung der Pflanzung geschieht grleichzeitig mit dem Fruehtbau. Der Boden wird von Unkrantwuchs und Wurouln greinigt und in Reihen werden in einem Abstand von 1,2--2 m Liehtholzarten gepflanzt. Zwisehen den Reihen werden Kartoffeln eingelegt oder in wärmeren Lagen Mais gebaut: seltener 
werden zwei Ernten gewonnen; es kann aber anch die Fläche gleichzeitig mit landwirtschaftlichen und forstlichen Sämereien bestellt werden (z. B. Haferschutzsaaten).

46. Röderwaldbetrieb. Die künstliche Neubegründung des Bestandes erfolct nach der landwirtschaftlichen Ernte durch Saat oder Pflanzung; um etwas die Bodengüte zu heben, wird der Schlagabraum mit Graspolstern, Stauden und sonstigem Unkrautwuchs in eincm kleinen Meiler verbrannt, die gewonnene Asche über die ganze Fläche ausgebreitet, worauf die landwirtschaftliche Benutzung bis zur Erschöpfung des Bodens anhebt.

47. Die Reutberg-oder Birkbergwirtschaft gleicht ganz dem Röderwalde, ist aber auf sehr leichtsamige Holzarten beschränkt. Solche Bestände werden gerodet, der Boden landwirtschaftlich bis zur Ertragslosigkeit ausgenützt. Darauf wird die Verjüngung der Natur überlassen, die reichlich die leichtsamigen Holzarten, darunter auch Fichten, Föhren, selbst Tannen, wo davon ältere Bäume in der Umgegend sich finden, vor allem aber Birken, Weiden, Pappeln, Erlen, ansät; mit Nadelhölzern mischt sich der neue Bestand vorzugsweise im Bayerischen Wald: mit weichen Holzarten bestockt sich der Birkenberg in Baden: werden aber auf der kahlen Fläche einzelne Birken verschont, so dafs sie den doppelten Umtrieb erreichen und die Besamung der Fläche außerordentlich erleichtern, so entsteht 4S. der Birkbergüberhaltbetrieb, wie er in den Ardennen im Gebrauche ist und in Finland als Kaski Sred bekannt ist.

49. Die Alpenbrandwirtschaft ist eine auf Nadelhölzer, insbesondere Fichten, beschränkte Wirtschaftsform. Etwa im 30. Lebensjahr werden die Stangen bis oben geschneitelt (entästet) zum Z/recke der Streugewimnung; sodann werden die Stangen gefällt und zu Brennund Papierholz verwendet. Der Schlagabraum wird ansgebreitet und zu Asche rerbrannt; es folgt landwirtschaftliche Benutzung für drei bis vier Jahre, worauf die Fläche der Selbstbesamung und dem Weidegange der Haustiere überlassen wird.

50. Des historischen Interesses wegen sei noch Cottas Baumfeldwirtschaft erwähnt. Cotta teilt den Gesamtwald in 30 bis 81) Schläge; alljährlich soll ein Schlag gerodet und einige Jahre mit landwirtschaftlichen Gewächsen benützt werden; darauf folgt Pflanzung in einem Abstand von $4-17 \mathrm{~m}$ und die Fortsetzung des landwirtschaftlichen Betriebes bis zum Kronenschlub. Nun wird die Hälfte der Bäume herausgenommen, die andere llälfte soll die Haubarkeit erreichen. Cotta erwartete höhere Holzerträge wegen erhöhter Bodenfruchtbarkeit, wegen Abwechslung in der Aufzucht der Gewächse (Fruchtweclisel). 


\section{B. Ausschlagwald.}

Zu den A usschlagwaldungen werden alle jene Waldungen rrerechnet, deren Verjüngung a uf $\mathrm{A} u s s \mathrm{chlägen,}$ auf Trieben aus schlafenrl gebliebenen oder nengebildeten Überwallungsknospen beruht. Bei dieser Verjüngung wird jedoch der Baum selbst, der gestümmelt werden unf, um Ausschlag zu entwickehn, immer älter und erreicht sein physisches Ende um so früher, je öfter die Verstümmelung war. An Laub- und Nadelbäumen sind diese Stümmelungs- und Ausschlaghetriebe bekannt: vorwiegend aber werden Laubhölzer in den wärmeren Klimazonen auf diese Weise bewirtschaftet.

Die Ausschlagwaldungen und -betriebe weisen folgende Vorzüge auf: 1. Größere Holzmassen als beim Hochwaldbetrieb innerhalb gleicher Zeiträume. 2. Gewinnung der größten Menge von wertvollen Kleinnutzhölzern. 3. Einfachheit und Leichtigkeit der Wiederverjüngung. 4. Einfachheit des ganzen Betriebes, geringe Anforderung an die naturwissenschaftliche Vorbildung des forstlichen Verwaltungspersonals. 万. Öftere Wiederkehr grölierer Einnahmen. 6. Geringste Gefahr durch Sturm und Schnee. $\bar{i}$. Geringe Nachteile für anliegende, landwirtschaftliche Besitze. 8. Gefahrlosigkeit der Holzgewinnung, ausgenommen den Sehneitelbetrieb.

Den Vorteilen stehen folgende Nachteile gegenüber: 1. Einseitigkeit der Nutzung; meist nur ein wertvolleres Produkt ist das Ergebnis des Betriebes, daher 2. Abhängigkeit der Rentabilität der Wirt.chaft von dem jeweiligen Preise dieses Produltes. 3. Stärkere Ausnützung des Bodens und raschere Verarmung desselben. 't. Höhere Ansprüche an das Klima gegenüber dem Hochwalde. 5. Große Gefahr für den Lohnarbeiter beim Schneitelbetriebe.

Je nach dem Stammteile, der gestiummelt wird und an welchem Ausschläge erfolgen, je nach dem '/wecke der Wirtschaft unterscheidet man folgende Ausschlagformen und Wirtschaften:

1. J)ie stockaussehlag formen, Niederwaldwirtschaften. Bei allen Niederwaldwirtschaften werden die Stämme unmittelbar über lem Boden abgeschnitten; da eine gröliere Zahl von Stämmen gleichzoitig so liehandelt wird, wird ein Kahlhieb geführt. Für die Ausschläge des ersten Jahres besteht somit eine erhöhte Spät- und Frühfrostgefahr, die mit jedem . Jahre sich mindert; denn die neve Generation erwächst sehr rasch, liommt frühzeitig in Kronenschluf, und gibt astreines Stangenhol\%. Je nach dem Zweek der Wirtsehaft, der Umtriebszeit, der Holzart, werden teilweise nach $\mathrm{Hamms}$ Ansschlagwald ${ }^{1}$ ) folgende Wirtschaftsformen des Niederwaldes untersehieden :

1) Ha mm, Der Ausschlagwald. 1896 . 
51. Der Stangenwald, ein Niederwald mit 10-40 jährigem Umtriebe, vorwiegend mit Laubhölzern. Das erzielte Produkt ist entweder Bremnholz oder Kleinnutzholz, Drechslerware, Wagnerholz, Faßreifen oder Nadelholzstangen; letztere erzeugt in grolien Mengen der Niederwald der Cryptomeria japonica in Japan (Kitayama-maruta).

j:. Der Sehälwaldbetrieb; behufs Gewinnung der Gerbrindo werden vorzugsweise Eichen ans der Gruppe der Weileichen (albae) im Niederwaldbetriebe bewirtschaftet, wobei, wie später ausgefuihrt werden mul, die Güte des Produktes von der Holzart, von Klima; Boden und Behandlung abhängig ist; die Umtriebszeit bewegt sich zwischen 15 und 30 Jahren.

Strauch holzbetrieb besitzt eine Umtriebszoit von 1-4.Jahren; je nach dem Zwecke und der Holzart spricht man 53. von WVeidehegern. wenn die ganze Bestockung aus Weiden für die Korbindustrio besteht; von 54. Papierhegern, wenn die Ausschläge von Rindenbastpapier gebenden Holzarten, wie Broussonetia, Edgewörthia, Wickströmia и. a., alljährlich abgeschnitten werden;

55. Gründ ̈̈ngungsbetrieb, wenn das Material unmittelbar mach der Begrïnung abgesichelt und zur Düngung der Felder, besonders der Reis- und Simsenfelder, verwendet wird; auch 56. Futterla ubniederwald ist bekannt; die alle 2-3 Jahre nach voller Begrünung abgeschnittenen Zweige werden teils grün, teils getrocknet verfüttert.

Der Buschwald entsteht bei einem Umtriebe von 5-15 Jahren; Weiden, Pappeln, Erlen und andere Weichhölzer bilden 5\%. den Faschinenwald, dessen Material für Wasserbauten, Gradierwerke Terwendung findet.

Werden im Niederwaldbetrieb einzelne Bäume vom Hiebe verschont, so daf sie die doppelte Umtriebszeit alt werden, so ergibt sich 5S. der Ni e derw a ld ü berhalt be tri e b, der beabsichtigt, starkes Nutzholz auf der gleichen Fläche mit dem Niederwalde zu erzeugen.

Niederwaldungen können auch mit landwirtschaftlichen Betrieben vereinigt werden. So findet man in Schälwaldungen von Eichen unmittelbar nach der Fällung der Stämme eine Düngung der Fläche mit Rasen- und Schlagabraumasehe, ein Behacken des Bodens und eine Ansaat von Roggen, seltener Anbau von Kartoffeln; wegen der noch in demselben. Jahro aufkommenden Stockausschläge ist nur eine Fruchternte möglich; vielfach reiht sich aber noch Viehweide an, wodurch die Versehlechterung des Bodens und des Holzbestandes beschleunigt wird. Dieses Wirtschaftssystem ist im Bereiche des Schälwaldes vielfach verbreitet und heißt 59. Hauberg-oder Hackwaldwirtschaft, Rotheckenbetrieb, Lohheckenbetrieb. 
2. Kopfausschlagformen (Abb. 15b) entstehen dadurch, daß die Stämme nicht am Boden, sondern erst in 1-4 $\mathrm{m}$ Höhe über dem Boden geköpft werden, damit an der Stümmelungsstelle Ausschläge mit verstärktem Längenwachstum hervorbrechen. Die Stümmelung erfolgt alljährlich oder alle 2-4 Jahre, wodurch das Stammende immer mehr anschwillt. Je nach dem Zwecke und den Holzarten unterscheidet man 60. Kopfholzkorbweidenbetrieb. Die einzehnen Stämme stehen isoliert meist entlang den Entwässerungsgräben, Bach- und Flußlänfen in wechselnden Abständen. Dazwischen findet auf' dem frischen, guten Boden der Flufauen meistens landwirtschaftliche Grasmutzung statt; eine ähnliche Verbindung mit Landwirtschaft, so dal, forstliche und landwirtschaftliche Benutzung des Bodens gleichzeitig und dauernd nebeneinander ausgeführt werden, besteht beim 61. Kopfholzfutterlaubbetrieb, der im Castanetum von Südund Westeuropa gefunden wird und mit Erzeugung von Futterlaub für Haustiere sich befaßt. 62. Kopfholz für Brennholzzucht an Eichen, Ulmen, Baumweiden, Linden, Pappeln u. a. locker über Wiesflächen gestellt, ist in wärmeren Lagen, besonders Frankreich und Spanien, häufig. Werden im Niederwaldbetrieb einzelne Bäume statt über dem Boden in größerer Höhe abgeschnitten, so erfolgt der Ausschlag der neuen Generation in zwei Etagen, am Boden und in $2-4 \mathrm{~m}$ Höhe; Heyer hat diesen Betrieb 63. den doppelten Ausschlagwald genannt.

3. Kropfholzzucht, Schneitelbetriebe (Abb. 15c). Seitenäste der Bäume, selten auch die Gipfel werden gestümmelt; die neuen Ausschläge erfolgen an den Stümmelungsstellen und den Überwallungswülsten, wodurch diese kropfartig anschwellen; jeder Baum trägt somit für kurze Zeit eine doppelte Krone, die kugelförmige des Gipfels und die säulenförmige der Kröpfe. Ḱropfholzzucht ist in den wärmeren, besonders in den von romanischen Rassen bewohnten Ländern Südund Westeuropas sehr beliebt; zwischen den Kropfholzbäumen dient die Fläche landwirtschaftlichen Betrieben.

64. Der Schneitelbrennholzbetrieb an Pappelarten ist ïberaus häufig in Frankreich; ja, er gibt den Landschaften Frankreichs ein ganz eigenartiges Gepräge. Zwischen den weitständig gepflanzten Pappeln findet Grasnutzung statt. 65. Schneitelfutterla ub betrieb zur Fütterung der Haustiere, besonders der Ziege in Südeuropa mit dem Zürgelbaume als Ilauptholzart, zur Fütternng der Schafe im Norden Europas mit der Birke. An stehenden Nadelhölzern, besonders Fiehten und Tannen, ist endlich 66. der Schneitelstreubetrieb behnfs Gewinnung von immergrünem Streumaterial in an Feldfruclit armen (iebirgsgegenden zu finden. 


\section{Mittelwaldungen.}

Der Mittelwald ist eine Verbindung des Niederwaldes mit dem femelartig genützten, ohne Kronenschluf anfwachsenden Hochwalde und entsteht derart, daß im Niederwaldkahlsehlag die besten Ausschlagsstangen oder auch Kernwüchse von Nutzholzarten vom Hiebe verschont werden (L a ßreitel) in der Absicht, daßsie als Oberholz ein Alter erreichen, welches ein mehrfaches der Umtriebszeit des Niederwaldes (Unterholz) beträgt; die Oberhölzer unter sich sind daher stets um die Umtriebszeit des Unterholzes im Alter verschieden. Diese Waldform ist sehr alt, hat einige Zeit so ziemlich das ganze Laubwaldgebiet von Mitteleuropa inne gehabt und ist noch hente der vorherrschende Wirtschaftswald in Frankreich.

Die Vorzüge des Mittelwaldes lassen sich in folgende Punkte zusammenfassen: 1. Größere Gesamtholzmassen in den gleichen Zeiträumen als beim Hochwald- und beim Niederwaldbetriebe. 2. Aufzucht ron geringer Nenge sehr starken Nutzholzes neben großer Menge Brennholzes oder Kleinnutzholzes in kürzester Zeit: Nutzung eines jeden Oberholzstammes zur Zeit seiner größten Brauchbarkeit. 3. Oftere Wiederkehr der Einnahme aus dem Walde gegenüber dem Hochwalde. 4. Bodenpfleglichere Betriebsarten gegenüber dem Niederwalde; Ausnützung von Bodenverschiedenheiten durch verschiedene Zusammensetzung des Unterholzes und dichtere oder dünnere Stellung des Oberholzes. 5. Leichtigkeit und Billigkeit der Verjüngung; im Unterholz als Ausschlagwald, im Oberholz wegen der reichlichen Samenbildung infolge des Freistandes. 6. Geringere Nachteile der Kahlfläche beim Hiebe des Unterholzes wegen der Schutzstellung durch das Oberholz. 7. Für den Kleinbesitz besser geeignet als der Hochwald.

Als Nachteile des Mittelwaldes sind folgende Punkte aufzuführen: 1. Geringerer Holzzuwachs im Niederwalde infolge der Überschirmung durch das Oberholz. 2. Geringere Stockansschlagfähigkeit infolge des Lichtentzuges. 3. Ungünstige Form des Holzes, Schaftkürze, Neigung zu Wasserreisern, Abholzigkeit des Schaftes. Ungleichheit im Holzgefüge, Grobfaserigkeit. 4. Beschränkung in der Auswahl des Oberund des Unterholzes: nur wenn ersteres eine Lichtholzart ist, kann das Unterholz, eine Halbschatten- oder Schattenholzart, gedeihen. j. Erhöhte Sturm- und Blitzgefahr besteht für das Oberholz, das durch den Freistand zur Klebeästebildung neigt; für glattrindige (Jberholzbäume besteht die Gefahr des Rindbrandes. 6. Beschädigung des Unterholzes bei vorzeitig notwendig werdender Fällung des Holzes (Auszugshauung). 7. Bei Eichenschälwaldungen wird das Erzeugnis an Rinde in Masse und Gerbstoffgehalt durch den Lichtentzug des Oberholzes geschädigt. 8. Rasche Bodenerschöpfung wegen großer Reisigmengen. 
Ter Mittelwald wird in folgende Wirtschaftsformen eingeteilt:

6i. Niederwaldartiger Irittelwald. Oberholz in gleichmäßiger Verteilung und in geringer Zahl: das Schwergewicht der Wirtschaft liegt im Unterholze, welches in der Regel der Gerbstoffgewiunung oder der Bremnolzzucht dient.

68. Werden die Oberhölzer gleichzeitig geschneitelt, so entsteht eine Wirtschaft, welcher der Name Schneitelmittelwald gegeben werden kann; sie ist in Frankreich vielfach verbreitet. Der Kropfausschlag schädigt zwar den Nutzwert des geschneitelten Stammes, allein mit dieser horizontalen und vertikalen Holzzucht wird die größte Holzmasse erzeugt, welche dem Standorte ïberhaupt abgerungen werden kann.

69. Im trupp- und gruppenständigen Mittelwalde ist das Oberholz trupp- und gruppenweise angeordnet; in ihm ist die Gerbstoffproduktion teils eine gute, teils eine ganz schlechte (unter den Überhaltgruppen); die Nutzholzzucht ist begünstigt.

i). Hochwaldartiger Mittelwald. Diese Form entsteht, wem das Oberholz einzeln und gruppenständig vorhanden ist. Der Schwerpunkt liegt im Oberholze; diese Form bildet meist nur den Übergang zum Hochwalde.

\section{Astwaldungen.}

Astwaldungen müssen als eine eigene Betriebsklasse ansgeschieden werden, da sie weder durch Samen noch durch Ausschläge sich erneuern; sie sind vielmehr das Ergebnis eines Verkrüppelungs-

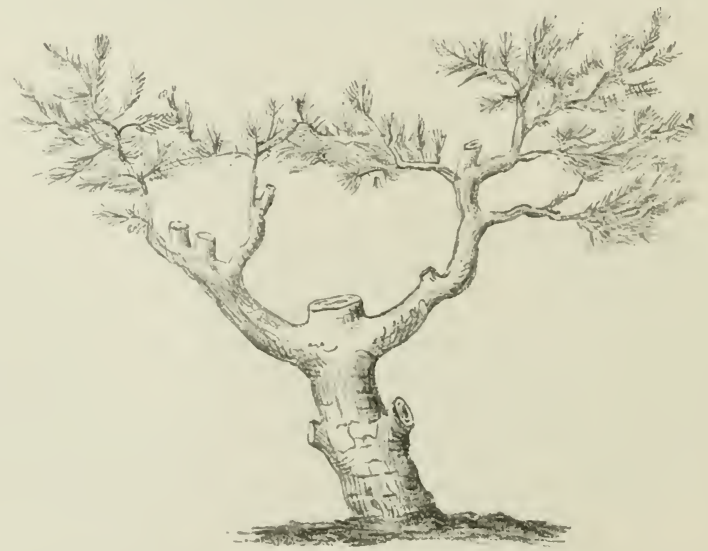

Abb. 16. Verkrüppelte Föhre aus den Astwaldungen der Auvergne (Frankreich). 
betriebes, bei dem fortgesetzt der Gipfeltrieb gestümmelt wird, worauf Seitenäste zu Gipfeln werden, welche wiederum der Stümmelung anheinfallen, worauf neue Seitenäste sich erheben. Der ganze aufgelüste, rerkriippelte Waldbestand besteht somit aus Astwerk, das teilweise zu Gipfeln emporzustreben sucht; daher mögen die Bezeichnungen: Ast wald oder. Verästelungsbetrieb oder Astwaldbetrieb passend sein. Sie sind bis heute nur bei den $N$ adelhölzern bekannt geworden, und zwar in zwei Formen:

i1. Flächenweiser Astwaldbetrieb; bei ihm erstreckt sich der Entgipfelungshieb über größere Flächenteile. $\mathrm{Er}^{\mathrm{r}}$ ist in Japan, Korea und China an zweinadeligen Föhren bekannt und ausgeübt.

i:. Astwaldfemelbetrieb ist eine Wirtschaftsform, welche Verfasser in der französisehen Auvergne an der Bastardföhre und ebenso in Ostasien kennen lernte und die wahrscheinlich in allen Ländern mit kleinparzelliertem Besitze in Ausübung ist.

\section{E. Rhizomwaldungen.}

Rhizomwaldungen entstehen aus alljährlich freiwillig sich erhebenden Trieben oder Schößlingen, welche ron unterirdisch wachsenden Stengelteilen (Rhizomen) abzweigen, und welche mit den Schößlingen der rorausgegangenen Jahre 8-25 m hohe Waldungen bilden. Alle Bambuswaldungen sind Rhizomwaldungen. Von den Vegetationszonen, die in dieser Schrift Berücksichtigung finden, tragen nur das wärmere Castanetum und das Lauretum Baumbambus in Rhizomwaldungen. Die Triebe oder Schösse schießen in einer Tegetationszeit zur normalen Dicke nnd Höhe empor: der Wald ist der dichteste Bestand, der bekannt ist (vgl. Abb. 15). Die einzige Wirtschaft, die in diesen Waldungen durchgeführt werden kann, ist $\mathbf{3 3 . ~ d e r ~ F e m e l r h i z o m - ~}$ betrieb, welcher einzelne Schößlinge, zumeist die ältesten aus dem dichten Bestande, zur Ausnützung heranzieht.

\section{F. Übergangswaldungen.}

Die Übergangsbetriebe können keine selbständigen Wirtschaftsoder Verjüngungsformen, vielmehr nur vergängliche Notbehelfe sein, um möglichst raseh und ohne allzu großen Verlust an Nutzung und Einkommen von einer Wirtschaftsform zu einer anderen zu gelangen. Mannigfach können die Gründe sein, die zum Verlassen der bisherigen Wirtschaftsform und zum Übergang zu einer neuen Veranlassung geben können. Ein Wechsel in der Wirtschaft wird angezeigt sein beim Wechsel in der Holzart. Günstigere, finanzielle Erwartungen können zwingen, die bisherige Holzart zu verlassen und eine andere Holzart, für welche auch eine andere Wirtschaftsform nötig sein kann, anzubauen, während a) die B odengï teselbstkeine Veränderung 
erfahren und deshalb auch keinen Anlaß zu einer Veränderung in der Bestockung gegeben hat, z. B. Übergang von Buche zu Fichte, von Eichenniederwald (Schälwald) zu Eichenhochwald. Dagegen wird ein Übergang zı einer anderen Holzart und Wirtschaftsform stets nötig sein, wenn b) die Bodenvermagerung zugenommen und von einer anspruchsvolleren Holzart, z. B. von Eiche auf Sandböden, welche mit Streurechten belastet sind, zu einer wenig anspruchsvollen, z. B. Föhre, übergegangen werden muß. Durch Senkung des Grundwasserspiegels ermattete Laubholzvereinigungen (Mittelwaldungen) werden Fichten und Föhren den Platz überlassen müssen und andere. Seltener dürfte der Fall sein, daß c) Bodenverbesserung eingetreten ist, so daß von einer weniger anspruchsvollen zu einer anspruchsvolleren Holzart übergegangen werden kann, z. B. von Föhren zu Eichen.

Ohne Wechsel in der Holzart können den Übergang von einer Wirtschaftsform zu einer anderen wünschenswert erscheinen lassen: Mißerfolge in der bisherigen Wirtschaft; Sturmschäden in Dunkelschlagwaldungen zwingen oft zum Kahlschlag; allzu häufige Frostschäden auf den Kahlflächen zwingen zum Schirmschlag u. dgl. Endlich können Naturereignisse, Feuer, Sturm, Insektenfraß, welche den Wald so sehr in seiner Substanz schädigen, daß für die Durchführung der bisherigen Wirtschaftsform das nötige Stammaterial fehlt, zu einer anderen Wirtsehaftsform nötigen.

Unmöglich kann für alle Wirtschaftsformen die Art des Übergangs von einer zur anderen hier beschrieben werden; für die meisten ergibt sich der Weg von selbst ans dem Wesen der alten und neuen Form. Nur in allgemeinen Andeutungen können diese Vorgänge hier berührt werden. Soll aus einer Kahlschlagform mit künstlicher Verjüngung zu einer Schirmschlagform mit Naturverjüngung übergegangen werden, so ist zu bedenken, daß die Naturverjüngung stets langsamer zum Ziele führt als die künstliche, daß somit eine größere Zahl von Verjüngungsobjekten, von Angriffspunkten für die Verjüngung zur Verfügung stehen muß; wird der umgekehrte Weg beliebt, kann eine Reduktion der Angriffspmukte eintreten. Geschieht der Übergang mit Holzartenwechsel, so vergeht eine volle Umtriebszeit, ehe der Übergang vollendet ist. Bis zur Vollendung sind in einem solchen Übergangswalde beide Wirtschaftsformen nebeneinander vorhanden, wie aus späteren Beispielen entnommen werden kamn.

Soll vom Niederwalde zum Hoehwald übergegangen werden, so genügt es nicht, daß man die Stockaussschläge einfach wachsen läßt, daß man also die Umtriebszeit des Niederwaldes erhöht bis zur beabsichtigten Umtriebszeit für den Hochwaldbetrieb; denn die Stockausschläge werden nicht dieses Alter erreichen, da sie mit faulenden, alten Stöcken im Zusammenhang stehen. Dr. Kahl'1) empfiehlt Fort-

1) Dr. Kahl, Elsaß-Lothring. Forstverein. 1896. 
führung des Niederwaldes unter Einbringung von Nadelholzgruppen als Vorbereitung für die Umwandlung. Adjunkt Flnry ${ }^{1}$ ) ist für verstärkte Durchforstungen und Durchlichtungen zur Deckung des Etats. Der erste Hochwaldumtrieb wird kürzer sein müssen als der folgende, dessen Bäume aus Sämereien hervorgehen werden. Um den immerhin noch lang andauernden und empfindlichen Verlust an Ernte einzuschränken, kann ein Teil des Niederwaldes als oberholzreicher Mittelwald ausgeformt werden, von dem ausgehend der Übergang zum Hochwald ieichter sich vollzieht als der direkte Übergang vom Niederwald zum Hochwald oder auch vom oberholzarmen Mittelwald zum Hochwald. Derartige Waldbilder haben in der Praxis die Bezeichnung „Übergangswald" erhalten. Mangler. ${ }^{2}$ ) will holzarme Mittelwaldungen durchlichten, unterbauen und die Schirmständer allmählich

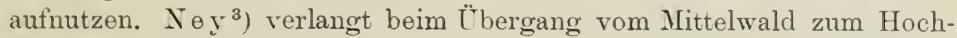
wald Pflege der gutgeformten, noch zuwachsenden Oberholzstämme sowie der Kernwüchse bzw. der Ausschläge aus jungen Stöcken; diese werden regelmäßig frei gehauen. Die Verjüngungen erfolgen unter Schirm; Nadelhölzer sollen in größeren Horsten (Kleinbestände nach dieser Schrift), Laubhölzer ungleichaltrig auf kleinsten Fläehen (Gruppen nach dieser Schrift) begründet werden. Verfasser ist der Ansicht, daß bei der Umwandlung von Mittel- in Hochwald, ebenso wie bei Umwandlung der Aueplenterwaldungen, der Kleinbestand mit Unterbau und Naturverjüngung in sich rein, aber jeder aus einer anderen Holzart den waldbaulichen und ökonomischen Forderungen am besten entspricht. Wäre der Übergang rom Niederwald zum Nadelholzhochwald beabsichtigt, so müßten auf jeder Fläche, auf der der Niederwaldkahlhieb geführt wurde, die Laubholzstöcke gerorlet werden, damit das Nadelholz begründet werden kann. Auch diese erste Nadelholzgeneration müßte mit Rücksicht auf den Ertragsentgang in kürzerer Zeit genützt werden. Soll vom Kahlschlag zum Femelbetrieb übergegangen werden, so werden der Reihe nach alle haubar gewordenen Bestände dem Femelhiebe unterstellt, so daß eine volle Umtriebszeit des Hochwaldes abläuft, bis der Übergang erreicht ist. Auch der Übergang ron einer Einteilungsform des Waldes in eine andere, wie der Forsteinrichtung als Aufgabe zukommt, kann keine unüberwindlichen, technischen Schwierigkeiten bieten, wemn es gelingt, geschichtliche Erinnerungen, Vorliebe und Vorurteile zu besiegen.

$\left.{ }^{1}\right)$ Flury, Mitteilungen der schweiz. forstl. Versuchsanst. 190:3.

2) M a ngler, Badischer Forstverein. 1899.

$\left.{ }^{3}\right)$ Oberforstm. Ney, Deutscher Forstrerein. 1907. Lehre vom Waldbau. 1 185. 


\section{Neunter Abschnitt. \\ Wahl der Wirtschafts- und Verjüngungsformen.}

Unter Voranstellung der naturgesetzlichen Gründe, welche zur Wahl einer bestimmten Waldeinteilung und deren Wirtschaft und Verjüngung: Teranlassung geben können, sei

besprochen.

\section{1. das Kilima}

Hochwald. Weder die größte noch die geringste Wärmemenge, welche dem Walde geboten ist, verlangt Einteilung des Hochwaldes in Wirtschaftseinheiten von einer bestimmten Größe als der Grundlage für die Wirtschaftsführung und für die Verjüngung; Wärmeverhältnisse hindern aber auch nicht, daß nicht jede Waldeinteilung durehgeführt werden könnte. Großbestandsw e is e, kleinbestandsweise, gruppenweise, band-, streifen- oder stammweise Einteilung des Waldes ist in allen Klimalagendes Waldes müglieh, vorausgesetzt, daß die übrigen Faktoren hierzu günstige sind. Der Großbestandswald mit dem am häufigsten in seinem Gefolge schreitenden Kahlschlag ist in der kühlsten Waldregion, z. B. in Nord europa, nicht mehr dureh Spät- und Winterfröste gefährdet als derselbe in den wärmsten Lagen von Mitteleuropa; die Spätfrostgefahr ist im hohen Norden sogar geringer, weil dort das schädliche, lange Frühjahr in Wegfall kommt. Wenn wir den Stammwald (Femelwald) vorwiegend im kühlsten Elevationsklima der Waldungen antreffen, so ist dafür nicht das Klima, sondern die Ausformung des Geländes verantwortlich; wenn in den kühlsten Krlimalagen Naturverjüngung bevorzugt wird, so ist die Ursache nicht in der Temperatur, sondern in technischen Schwierigkeiten zu suchen, welche den Wirtschafter zwingen, die sich überall aufdrängende Naturverjüngung auch zu benützen.

Sind Luftfeuchtigkeit und Niederschlagsmenge in dem Walde günstiger Menge gegeben, wie insbesondere in insularen Klimaten, so kann jede Waldeinteilung, jede Wirtschaft Platz greifen, im Falle die übrigen Bodingungen hierfür vorhanden sind. Je mehr 
aber durch Abuahme der Luftfenchtigkeit und der Niederschläge der Wald an die Grenze seiner Existenzfühigkeit gerückt wird, um so wichtiger wird die durch die Baumvereinigung bewirkte Erhöhung der Luftfeuchtigkeit und Minderung der Verdunstung für das Dasein des Waldes, seine Wirtschaft und seine Verjüngungsform. Je kontinentaler das Klina, um so mehr müssen Formen vorherrschen, welche eine Bodenentblößung auf größere Flächen tunlichst vermeiden. Wird dor Wald in Großbestände oder in Kleinbestände zerlegt, so sollten diese auf natürlichem Wege verjüngt werden, ist dieses unmöglich oder zu tener, so muß eine andere Waldeinteilung gewählt werden, z. B. die gruppenweise oder stroifenweise oder stammweise Aufteilung des Waldes; die einfache Nachahmung von Eimrichtungsund Wirtschaftssystemen, welche sich bewährt haben in Ländern mit klimatisch günstigerer Lage, kann zur Terwüstung eines klimatisch ungünstig gelegenen Waldes führen. Gegen Stürme sichert am besten der stammweise oder gruppenweise oder streifenweise eingeteilte Wald; soll aber Großbestands- oder Kleinbestandswald gewählt werden, so empfiehlt sich entweder die Holzartenmischung statt reiner Bestände oder besser eine andere Erziehung der letzteren als jene Methoden, die gegenwärtig in der Praxis vorherrschend sind. In Schneedrucklage sind es dieselben Formen und Erwägungen, die der Sturmgefahr zu begegnen suchen. Ausschlagwaldungen, zu welchen auch das Unterholz im Mittelwald zu rechnen ist, verlangen größere Wärme und zur Zeit der Verjüngung volles Licht; sie sind daher auf wärmere Klimate und Kahlschläge angewiesen.

Die Astwaldwirtschaft an Laub- und Nadelhölzern ist an kein Klima gebunden, wenn es auch selbstrerständlich ist, daß sie in wärmerem Klima rentabler sein wird als in kühlerem.

$\mathrm{R}$ hi z o m w a l ungen sind an jene Klimalagen gebunden, in welchen die baumartigen Bambus heimisch sind.

Ausführlich muß der Einfluß auf die Verjüngungsart selbst. ob natürliche oder künstliche, in den folgenden Abschnitten behandelt werden.

\section{Der Boden.}

Wenn die klimatischen Verhältnisse für die Durchführung verschiedener Waldwirtschaften günstig sind, so besteht die Einwirkung der Bodengüte auf die Wahl der Wirtschaftsform in folgendem:

a) Je besser der Boden, um so leichter jegliche Waldeinteilung: und innerhalb dieses Rahmens die Einführung und die Durchfülırung jeder Wirtschaftsform. Ist der Boden bis zu den geringsten Bonitäten herabgebracht, so sind meistens nur Kahlschlagformen mit künstlicher Verjüngung im Gebrauch, weil die Naturverjüngung auf der großen Fläche, an welcher auf solchen Standorten immor noch festgehalten 
wird, undurchführbar ist. Die wachsenden Schwierigkeiten der Naturverjüngung sind nicht bloß im wachsenden Mangel an Geduld und Zeit, sondern auch in der zunchmenden Bodenvermagerung zu suchen. A uf solchen geringen Böden kann die weitere Abminderung in Güte nur eine Wirtschaftsform authalten bzw. verzögern, welche zu keiner Bloßstellung des Bodens zwingt: Einteilung des Waldes in Kleinbestände, in Gruppen-oder Streifen-oder in stammweisen Wald (Femelwald) dürfte zum Ziele führen.

b) Je besser der Boden, um so eher können bodenerschöpfende Betriebe, wie Ausschlagwald. Mittelwald, Astwald, Hochwald mit Großbestands- und Kahlschlagswirtschaft, Fuß fassen, um so eher können auch landwirtschaftliche Betriebe mit den forstlichen verknüpft werden.

c) Auf flachgründigem Boden sollte Stammwald oder Gruppenwald stehen; wird Klein- oder Großbestandswald gewählt, so müßten sie zur natürlichen Verjuingung erzogen werden; bei der herrschenden Frziehung sind jedoch Kahlschlagsformen unentbehrlich.

d) Auf Böden, welche übermäßig feucht sind und hierin nicht verbessert werden können, sind bei Laubholzbestockung Ausschlagformen oder stammweiser Hochwald, bei Nadelholzbestockung nur letzterer (F'emelwald) empfehlenswert.

Bodenneigung. Auf ebenem oder sanft welligem Gelände sind alle Wirtschaften, wenn Klima und Bodengüte günstig sind, durchführbar; je steiler dagegen das Gelände, um so schwieriger sind Großbestands- und Kleinbestandswirtschaft, um so mehr müssen Kahlschlagsformen zurücktreten und die Aufteilung des Waldes in einen gruppen- oder stammweisen an die Stelle treten.

IIan kann dementsprechend folgende Abhängigkeitsrerhältnisse der Bodenneigung und der Betriebsklassen und Wirtschaften festlegen:

Felsabsturz. - Urwald.

Bodenneigung über $40^{\circ} 0$. Stammweise Waldeinteilung (Femelwald), Verjüngungsflächen möglichst klein, Schirmverjüngung.

Bodenneigung 25-40\%0. Stammwald, Gruppenwald. VerjüngungsHäche klein, Schirmverjüngung und Kahlschlag auf der Gruppe.

Bodemneigung 111 -2.5\%. Stammwald, Gruppenwald, Kleinbestandswald: Schirmverjüngungen oder Kahlschlag auf der Gruppe und Saumschlag der Ǩleinbestände.

Bodenneigung $11-11^{0} \mathrm{v}$. Alle Betriebsklassen, alle Wirtschaftsformen in den nach Bodengüte, Klima, Holzart und anderen Erwägungen zu wählenden Verjüngungstormen.

Exposition. Alle südlichen Expositionen sind als wärmere, lufttrocknere, alle nördlichen als kïhlere und feuchtere Lagen zu betrachten und in ihrem Einfluf auf Wald sowie Wirtschaftsform nach klimatischen Gesichtspunkten zu beurteilen. 
Die ausfïhrlicheren Angaben über Einwirkmng des Bodens auf natürliche oder künstliche Verjüngtung muß den folgenden Abschnitten ïberlassen werden.

\section{Die Holzarten.}

Alle $\mathrm{Nadelholzbäume} \mathrm{könmen} \mathrm{in} \mathrm{Hochwaldform} \mathrm{bewirtschaftet}$ werden; Stockausschlagwaldungen sind nur bei wenigen Nadelbaumarten zulässig; die Stammausschlag- oder Schneitelformen dagegen sowie der Astwald passen wiederum für alle Arten; die L a u b hol z a r te n können sämtlich in Hochwald bewirtschaftet werden; bei jenen, welche eine geringe Ausschlagfähigkeit besitzen (man vergleiche den zehnten Abschnitt), sind die Ausschlagsformen in der Regel ausgeschlossen. Astwaldwirtschaft ist bei allen Laubholzarten möglich, Rhizomwaldungen sind auf' Bambusarten beschränkt

\section{Zwecke des Waldbesitzers.}

a) Rentabilität. Größte Holzmasse, geringere Holzgüte, beschränkte Verwertbarkeit: Es dürfte obenan stehen der Schneitelmittelwald von weichen Holzarten unter den La ubbäumen, voran die Pappelarten; etwas geringere Mengen liefern Niederwaldungen oder Hochwaldungen mit kurzer Umtriebszeit der weichen Laubholzarten. voran die Pappelarten. Daran schließen sich die übrigen Ausschlag- und Mittelwaldungen, dann die Hochwaldungen. Steigt die Produktion bei den Ausschlag-, Mittel- und Hochwaldungen mit weichen Holzarten über eine bestimmte Menge im Angebote, so sinkt sofort der Wert des Produktes und damit die Rentabilität der Betriebe.

Größte Holzmasse, höchste Gütevon überproduktionsfreier Verwertbarkeit. Obenan steht: Hochwald von Nadelschattenholzarten (Picea, Abies, Pseudotsuga, Thuja, Tsuga und andere): Hochwald von Nadelhalbschattenholzarten, (Föhren Sektion Strobus, Cembra, Chamaecyparis, Cryptomeria und anderen): Hochwald von Laubschattenholzarten (Fagus, Aesculus: größte Masse aber von geringer Verwertbarkeit): Hochwald von Lichtholzarten der Nadelbäume, Larix, Taxodinm, zwei- und dreinadeligen Föhren; Hochwald ron Laublichtholzarten (Juglans, Quereus, Robinia, Carya ; geringere Masse aber größte Verwertbarkeit); von Laubholzhalbschattenarten (Fraxinus, Ulmus, Acer, Carpinus, Alnus; zwar größere Massen aber geringere Verwertbarkeit).

Was die Waldeinteilung, die Wirtschaftseinheiten des Hochwaldes anlangt, so dürften als die rentabelsten Formen die Großbestandsund die Kleinbestandseinteilung des Waldes gelten; weniger günstig stehen Gruppenwald und der Stammwald. Es gibt Stimmen, welche, vielleicht mit Recht, dem Stamm- oder Femelwald die hüchste Massenproduktion unter den Hochwaldformen zuerkennen; seine Nutzholz- 
güteproduktion innerhalb vernünftiger Umtriebszeiten steht wegen Mangels an Bestandesschluß den geschlossenen Hochwaldformen sicher nach.

Was die Art dor Zusammensetzung nach Holzarten der Wirtschaftseinheiten betrifft, so erweisen die reinen Baumvereinigungen in Grobbestand, Bestand, Kleinbestand, Gruppe, der reine Stammwald sich in Masse und Güte günstiger als die gremischten Bestände.

Was die Betriebs-oder Verjüngungsart anlangt, so dürfte die Erziehungsverjüngungsform (natürliche Verjüngung) die finanziell gïnstigsten Ergebnisse zeigen; sollen hierbei anch noch die waldbaulichen Vorzüge der Mischwaldungen möglichst ansgenützt. soll dem jetzigen und dem kommenden Bedürfnisse an Holz am vollkommensten Rechnung getragen werden, so wäre dies möglich durch einen Hochwald. der in Kleinbestände aufgeteilt ist; jeder Kleinbestand besteht aus einer einzigen Holzart: jede Holzart, nach ihrem gegenwärtigen und kommenden Wert beurteilt und nach Boden und Klima in einem Ḱleinbestandswalde verteilt, soll in allen von fünf $\mathrm{zu}$ fünf Jahren abgestuften Alterkliassen im Walde vertreten sein: wird der kleinbestandsweise gemischte Wald nicht gewählt, mag di e gegenwärtige Waldeinteilung in große Bestände, wenn diese aus verschiedenen Holzarten in verschiedenen Altersklassen bestehen (der bestandsweise gemischte Wald), sich anschließen, wemn dieser Wald in der Erziehungsverjüngung behandelt wird. Wird aber die gegenwärtige Erziehungs- und Verjüngungsmethode beibehalten, so stehen immer noch die reinen, geschlossenen Bestände im Kahlschlag und künstlichen Verjüngungsbetrieb, in Rentabilität wenigstens, den mit natürlicher Verjüngung arbeitenden Betrieben, insbesondere in Mischbeständen voran.

b) Die Staatsforstwirtschaft, der konservativ-volkswirtschaftliche Betrieb, sucht eine Tereinigung der finanziellen und volkswirtschaftlichen Interessen derart, daß sie Rentabilität, Nachhaltigkeit in Nutzumg. Erhaltung der Holzarten und der Bodengïte anstrebt. Der ökonomisch-finanzielle Z $\mathrm{Z}$ weck steht den naturgesetzlichen Grundlagen mit Nachhaltigkeit entgegen. Ein Interesse beeinträchtigt das andere. Die Rentabilität strebt nach Formen, wie sie oben beschrieben wurden; das Nachhaltigkeitsprinzip für die Bodengüte ist am besten im gruppenweisen oder stamm- und truppweise aufgeteilten Wald mit Erhaltung aller Holzarten (Bäume, Halbbäume, selbst Sträncher und Kräuter im Femelbetriebe) gewährleistet. Eine Vereinigung dieser Prinzipien ist im K'leinbestandswalde mit Erziehnngsverjüngung angestrebt.

c) Sollen Maximalerzougungen bestimmter Produkte angestrebt werden, so würden das Maximum an größerem Nutzholz und größerem Bremnholz die Hochwaldungen in der obigen Reihenfolge der Rentabilität mit hohen Umtriebszeiten ergeben. Kleinnutzholz, 
Kleinbremholz in größten Mengen ergeben Ausschlags- und Astwaldungen; sie erschöpfen den Boden rascher als Hochwaldungen.

Die N e be n prod ukt e der Bäume, wie Gerbstoff, Harz und andere, erzielt man in den nach diesen Produkten früher aufgeführten Betrieben.

Sollon die Nebenprodukte des Waldbodens, wio Weide, Beeren, Wild, das Hauptziel der Wirtschaft sein, so müssen die nach diesen Produliten genannten Betriebe gewählt werden.

Ist landwirtschaftliche Zwischemutzung beabsichtigt, sind ebenfalls die bereits genannten Betriebe zu wählen. Am vollkommensten wird den landwirtschaftlichen Ansprïchen Cottas Feldwaldwirtschaft entsprechen. Daran schließen sich jene Betriebe, welche eine landwirtschaftliche Benutzung bis zur Erschöpfung des Bodens kennen. Im Röderwalde und Hackwald ist das landwirtschaftliche Ergebnis am geringsten; Wiesenbau mit Ausschlagformen oder Hutweiden (Eichen, Lärchen, Birken).

Die größte Sicherheit des Waldbesitzes gegen Feuer, Sturm gewähren Ausschlagwaldungen oder Hochwaldungen mit gruppenweiser, band- oder stamm- und truppweiser Einteilung und Mischung der Holzart in femelartigen Betrieben; geeignete Erziehung festigt jeden Bestand.

Für kleineren Waldbesitz eignen sich am besten die Ausschlagwaldungen oder auch der Femelhochwald insbesonder der schattenertragenden Nadelhölzer, Hoch- und Niederwald mit landwirtschaftlicher Bei- oder Zwischennutzung.

Für größeren Waldbesitz mögen die Wirtschaftsformen des Hochwaldes in der höchsten Rentabilität entsprechen, voran jene Betriebsformen, welche den Wald in kleine Bestände verschiedener Holzarten teilen und diese zur höchsten Nutzholzmasse und zur natürlichen Verjüngung erziehen.

Berechtigungsverhältnisse können zu ganz bestimmten Betrieben zwingen, um die Berechtigten zu befriedigen.

Für Wirtschaftspersonal, ungen ügend in Zahl oder Ausbildung, eignet sich der einfachste Betrieb am besten, das ist Ausschlagwald, Hochwald mit periodischem Femelbetrieb, Hochwald in Kahlschlagformen.

Schutzwaldungen. Gruppenweiser oder streifenweiser oder stammweiser eingeteilter Wald, in letzterem reiner Femelletrieb.

Parkwaldungen, bei welchen der ästhetische Zweck voransteht, kleinbestands- oder gruppen- oder stammweise eingeteilter Wald; in allen Fällen mit Schirmstandsverjüngung zulässig; Mittelwald; geringe ästhetische Wirkungen wohnen im Kahlschlaghochwalde und die geringsten im Kahlschlagniederwalde. 


\section{Zehnter Abschnitt. Die natürliche Wiederverjüngung.}

Die natürliche Wiederverjüngung ist die Besamung einer Fläche durch den rom benachbarten Mutterbaume stammenden Sameu, der entweder durch seine Schwere oder durch Wind oder durch Wasser oder durch Tiere an eine empfängliche Bodenstelle gelangt und dort keimt und eine nene Waldgeneration bildet. Die natürliche Wiederverjüngung setzt dasiVorhandensein von Bäumen in samenertragsfähigem Alter, dio Empfänglichkeit des Bodens für Aufnahme und Keimung und die Möglichkeit des Emporwachsens der neuen Waldgeneration voraus. .Jede Holzart kann auf natürlichem Wegeverjüngtwerden. Wenn es heutzutage Örtlichkeiten und Bestandsverfassungen gibt, unter denen die natürliche Wiederverjüngung der heimischen Holzarten ganz versagt oder nicht mehr genügend reichlich erzielt werden kann, oder unrentabler, weil langwieriger erscheint als die küustliche, so kann dies ein Fehler der waldbaulichen oder der technischen Einrichtungstätigkeit des Wirtschafters sein oder in der Benützung des Waldes seine Begründung finden, wodurch entweder Boden oder Baumvereinigungen in eine naturwidrige Verfassung geraten sind. In der Forstwirtschaft hat sich während der letzten Dezennien immer mehr die Ansicht festgewurzelt, daf, mit einer rationellen Wirtschaft die natürliche Wiederverjüngung nieht vereinbar sei und damit die waldbauliche Tätigkeit des Forstmannes zu dem Zwecke der Wiederverjüngung des Waldes im weventlichen auf das einfache Pflanzengeschäft sich beschränken kïmne, wobei heutzutage auch noch die Arbeit der Pflanzenaufzucht dem Forstmanne durch die großen Massenzüchtungen der PHanzenhändler abgenommen werde. Angesichts des Zustandes der haubaren Bestände kamn man diesen Gedankengang, der den Forstmann dem Walde entfremden und den vereinfachten und nebensächlich gewordenen Waldbau den untergebenen Organen ausliefern muf, eine gewisse Berechtigung nicht absprechen. In erster Linie fällt hierfür die Verantwortung der Forsteinrichtung zur Last, welche den Wald 
ohne Rücksicht auf naturgesetzliche Grundlagen einteilt und bindende Vorschriften bezüglich der Wahl der Holzart, Nethode der Verjüngung, Zeit und Geschwindigkeit der Verjüngung geben zu können glaubt. Die Überhebung der Forsteinrichtung und ihre nachteiligen Folgen müssen sich noch steigern, sobald solche Arbeiten jüngeren, unreifen Beamten oder einer Behörde übertragen werden, welche ihr Leben lang sich nicht mit Waldbau, sondern nur mit Forsteinrichtung beschäftigte. Sie verbannt die ohnedies allzu großen Bestände und ihre Schiebfächer, bi sie den Zeitpunkt gekommen erachtet, um in Bestand dem Wirtschafter im Walde zur Verjüngung zu übergeben. Die einen Bestände sind bereits über den Zeitpunlit des verjüngungsfähigsten Alters, der Bodenempfänglichkeit, hinaus (Lichtholzarten), die anderen sind künstlich durch das Verbot des Eingriffes in den herrschenden Bestand (Bestimmung des Zwischennutzungsetats durch die Forsteinrichtung!) in einen Zustand geraten, der erst nach vielen Jahren wieder zur Empfänglichkeit einer Terjüngung übergeführt werden kann.

Wenn es eine Einteilung und Methode gibt, welche gestattet die Torteile des Mischwuchses zu genießen und den Wald nicht blo s für den Nutzungs-, sondern gleichzeitig auch für den Verjüngungszweck zu erziehen, so daß die natürliche Verjüngung des Waldes so schnell und so erfolgreich wie eine künstliche ror sich geht, dann müßte ein derartig eingerichteter und behandelter Wald das Ideal aller finanzpolitischen und waldbaulichen Wünsche im Walde sein. Denn unter solchen Umständen ist die natürliche Wiederverjüngung des Waldes voll von Nutzen und ohne Nachteile. Ob der Kleinbestandswald und seine Erziehungsverjüngung diesen Wünschen entsprechen, mögen jene beurteilen, welche den rorliegenden Waldbau lesen und den Mut haben, seine Lehren in die Praxis zu übertragen; wer aber an den großen Beständen der heutigen Waldeinteilung und der herrschenden Erziehung festhält, der wird immer den Vorzïgen der Naturverjüngung schwerwiegende Nachteile gegenüberstellen, und bei der Entscheidung wird in der Regel das Urteil zugunsten der schnelleren, leichteren und sichereren kïnstlichen Verjüngung ausfallen.

Als Vorzüge der natürlichen Wiederverjüngung wird folgendes geltend gemacht:

1. Lösung der Frage der Provenienz des Satgutes in dem nach der herrschenden Auffassung günstigsten Sinne der Abstammung des Saatgutes von den Mutterbäumen des betreffenden Waldliomplexes: aber nur die Erziehung zur Verjüngung gewährt dabei die Sicherheit, daß das Saatgut wirklich von Elitebäumen abstammt.

2. Verhinderung der Verhärtung des Bodens durch den fallenden Regen, der Verkohlung des Humus dureh Überhitzung und Austrocknung: wenn auch unter Baumschirm geringere Regen- und schneemengen zur Erde gelangen als auf freier Fläche, so verdunsten infolge 
Beschattung, mangelhafter Lufthewegung und erhöhter Luftfeuchtigkeit diese reringeren Nengen unter Schirm weniger rasch als auf freier Fläche: somit größere Bodenfeuchtiglieit in der Bodenobertläche, Erhaltung der munterbrochenen Bodenverwitterung und der 'Tätigkeit der Bodenorganismen.

3. Erhölite Luftfeuchtigkeit durch Verminderung der Bestrahlung und des Windes; dadurch aber ist die Keimung auch der weniger günstig in den Boden eingebetteten Sämeren begünstigt.

4. Verhinderung der Verunkrautung des Bodens durch Licht liebende Pflanzen und Verlängerung der Empfänglichkeit des Bodens für Sämereien von Schatten ertragenden Holzarten; diese Vorteile werden bei der Erziehung zur Verjüngung am vollkommensten ausgenüitzt.

5. Erleichterung des Anfluges der Saat bei leichtsamigen Holzarten, welcher von allen Seiten bei jedem Wind geschehen kamn; bei schwersamigen Holzarten bietet Schirmverjüngung die einzige Möglichkeit einer genügenden Naturbesamung.

6. Beste Art der Bedeckung und des Schutzes der Saat durch den natürlichen Laub- oder Nadelabfall.

7. Schutz der aufkeimenden und a ufkommenden Jugend gegen extreme Temperaturen, vor allem gegen Nachtfröste zu den gefährlichen Jahreszeiten, im Frühjahr nach Beginn der Vegetation (Spätfröste) und im Herbst vor Abschluß derselben (Frühfröste); Schutz gegen Winterfröste ist gleichfalls wichtig, insbesondere für die unter Schirm erwachsenden immergrünen, Pflanzen, welehe empfindlicher gegen tiefe Wintertemperatur sind als die auf Kahlfächen stockenden Pflanzen; gleichzeitig hindert die Beschirmung die allzu starke Belastung durch sichnee, mäßigt die Heftigkeit der Hagelsehläge, bricht den Wind, der auf Kahlflächen im ersten Jahr der Pflanzung lästig werden kann.

8. Die natürliche Wiederverjüngung gewälurt Schutz gegen jeno Insekten, welche größere Kahlflächen zum Hochzeitsflug benützen, wie derr Maikäfer, oder gegen die Grapholitha, welehe vorwiegend die durch Spätfröste (Kahlflächen) kïmmernden Pflanzen aufsucht: auch regen Pilze, welche aut ein Zusammenwirken mit Insekten angewiesen sind, wie z. B. Girapholitha und Neetria an Fichten, gewähren natürliche Wiederverjüngungsmethoden Schutz; die Ungleichalterigkeit der Jugend ist das beste Mittel gegen die epidemisch auftretenden Pilzlirankheiten wie Agaricus melleus, Polyp. annosus, Phytophora und andere.

9. Die aus natürlicher Verjüngung hervorgegangene, somit ungleichalterige Jugend ist auch in späteren. Jahren zum IV iderstand gegen Schnee und Wind wegen ungleich hoher Krone und ungleich tiefer Bewurzelung besser ausgerüstet als die auf Kahlflächen gleichzeitig entstandene, somit gleichalterige. Jugend; ie langsamer die Natur- 
verjüngung fortschreitet, $\mathrm{mm}$ so größere Unterschiede im Alter, um so bessere Widerstandskraft der Stämme im kritischen Stangenholz- und Bamalter.

10. Gewinn an $\mathrm{Z}$ e it und $\mathrm{Z} u \mathrm{w}$ a c hs bei der neuen Generation, wemn die natürliche Verjüngung nach vorheriger entsprechender Erziehung des alten Bestandes schon vor dem Hauptabtriebsalter durchgefülnrt wurde.

11. Es dürfte sich als eine allgemeine Erseheinung erweisen, daß die Erhaltung der im alten Bestande in Mischung vorhandenen Holzarten durch die natürliche Wiedervereinigung desselben besser gewährleistet ist als durch die künstliche. Die künstliche Begrïudung eines Mischbestandes auf kahler Fläche ist eines der sehwierigsten Probleme des Waldbanes, und die zahlreichen Mißerfolge solcher Versuche beweisen die Richtigkeit des Satzes. Dazu kommt, daß bei entsprechender Wahl der Schirmstellung im neuen Bestand ein beliebiges Mischungsverhältnis sich erzielen läßt, wenn überhaupt am gemischten Bestande festgehalten werden will.

12. Gewinnung des Lichtstandszuwachses an den Schirmbäumen, der sich bei geeigneter Auswahl der überschirmenden Althölzer, an den bestgeformten Stämmen der Nutzhölzer und an dem wertvollsten, ästefreien Teil des Schaftes anlegen wird. Daß dieser Vorzug ganz besonders den Beständen zugute kommen muß, welche zur Verjüngung erzogen sind, somit nur aus Elitebäumen bestehen, liegt nahe.

13. Allmähliche Überführung der zum Überhalt bestimmten Bäume in den freien Stand. Am günstigsten hierin muß sich die Erziehung zur natürlichen Verjüngung erweisen, weil bei ihr die Stämme schon rom frïhesten Alter an (nach der Ästereinigung) durch den Freistand gegen Wind, Rindenbrand, Wasserreiserbildung in noch bildungsfähigem Alter gefestigt werden.

14. Geringe $A u s g a b e n$ für $K u l t u r e n$, im günstigsten Falle völlige Ersparnis an Kulturkosten.

15. Die Vorteile der natürlichen Wiederverjüngung kommen im vollsten Maße den Schirmverjüngungen zugute; sie entgehen fast ganz den natürlichen Verjüngungen auf Kahlflächen (Seitenbeschirmung und -besamung).

16. Nötig erscheint die natürliche Wiederverjüngung auf s teil en, unzugänglichen Hängen; unter allen Umständen willkommen ist sie, auch wenn sie minder gute Bestände liefert, in sumpfigen, kalten Örtlichkeiten, in Hochmooren, in den höchsten oder nördlichsten Lagen des Waldes, somit an seiner Kältegrenze; in Śchutzwaldungen vollends, welche ständig Hochwald bleiben sollen, bildet die Naturverjüngung die Regel.

M a y $\mathbf{r}$, Waldbau. 
17. Der verfeinerte Fällungs- und Verjüngungsbetrieb, wie ihu schon die Erziehung zur natürlichen Verjüngung und diese selbst voraussetzt, verlangt ein erhölites Maß von liörperlicher und geistiger Tätiglieit. Wer diese Melnleistung, die erzieherisch auf den Forstmann einwirken mul, beklagt, wird nicht zustimmen, wenn dieses Moment als ein Vorteil gegenüber dem Kahlsehlag und der darauffolgenden künstlichen Verjüngung aufgezählt wird.

Dieser stattlichen Kahl von Vorzügen, welche die natürliche Verjüngung gegenüber der künstlichen aufweist, stehen jedoch z a h l re iche, schwerwiegendo Nachteile gegenüber. Was als Nachteil bei der natürlichen Verjüngung beklagt werden muß, vermeidet die küinstliche Terjüngung; es sind dies die Vorzüge derselben. Die Nachteile der natürlichen Verjüngung sind:

1. L angsamer Verjüngungsgang, da dieser rom Eintritt der Samenjahre abhängig ist. Dieser Vorwurf kommt bei der Naturverjüngung mit vorheriger Erziehung hierzu in Wegfall, denn bei diesem Terfahren können große und kleine Bamvereinigungen durch ein einziges Samenjahr verjüngt werden.

2. \%uwachsverlust an der Terjüngung infolge der Ï̈berschirmung. Durch den Freistand der schirmenden Bestandesglieder wird der Zuwachsverlust wieder teilweise ausgeglichen.

3. Gefahr der Erdrückung der lichtbedürftigen Holz arten durch die weniger empfindlichen Schattenholzarten.

4. Erhaltung der Brutstätten für sehädliche Tiere, besonders Mäuse, Begünstigung der wurzelbewohnenden Insekten, besonders Rüsselkäfer, der stockbewohnenden Pilzparasiten, besonders Agarieus melleus und Polyporus amosus.

5. Erschwerung und \%ersplitterung der Fällung, Terteuerung des Fällungs- und Transportbetriebes, Beeinträchtigung der Sortierung des Holzanfalles dureh Mangel an Vergleichsobjeliten.

6. Verlust der Übersiehtlichkeit der ganzen Wirt schaftsführung, Ersehwerung der Kontrolle und der Handhabung des Forstschutzes.

7. Beschädigung der Verjüngung und der Schirmständer durch die Fällung und Bringung, Abhängigkeit von der Geschichlichkeit der Arbeiter, ein Nachteil, der sich mit der ständigen Abnahme der eigentlichen Waldarheiter immer mehr vergrüßert.

s. Rindenbrandgefah $\mathrm{r}$ an den Schimbäumen bei dünnrindigen Holzarten, besondors Rotbuchen, Hainbuchen, Fichten, Tamnen.

!. Es liegt nahe, daß der Nachteil der Naturverjüngung am schwersten in die Erscheinung treten mub bei den Wirtsehaftsformen, welehe auf derkleinsten Fläche eine Verjüngung erstreben (Feme)betrieb). 
10. Undurchführbar ist die Naturrerjüngung bei Ödländereien, verlassenen, landwirtschaftlichen Geländen, bei gewünsehtem Holzartenwechsel, bei Betrieben, welche vor dem samenerträgnis der Bestände diese zu Fällung bringen (Alpenbrandwirtschaft, /ellulosebetrieb, Christbaumbetrieb); endlich wird man zur künstlichen Verjüngung greifen, wenn die natürliche von vornherein im hiebsfähigen Alter der Bestände als schwierig oder gar als unwahrscheinlich und aussichtslos erscheint, worüber in den folgenden Ausführumgen das Nötige enthalten ist.

Bei allen Beständen, welche hiebsreif geworden sind, ohne vorherzur Verjüngung erzogen wordenzu soin, ist die Entscheidung, ob eine natürliche Terjüngung überhaupt und in angemessener Zeit durchführbar oderdoch wahrscheinlich ist oder nicht, die allerwiehtigste. Aber auch für Bamvereinigungen, welche zur Verjüngung erzogen wurden, ist ein richtiges Urteil über Leichtigkeit und Gang der Verjüngung wesentlich. Dem Urteile und der Entscheidung kam nicht durch allgemeine Vorschriften zur natürlichen oder künstlichen Verjüngung präjudiziert werden. Sie müssen frei sein, um von Fall zu Fall an jedem einzelnen Objekte das Richtige zu treffen: aber folgende allgemeine Betrachtungen und Gesichtspunkte dürften das Urteil über die Wahrscheinlichkeit und den Gang der natürlichen Wiederverjüngung überhaupt erleichterm.

\section{a) Kilima.}

Es ist eine allgemeine, vom Verfasser seit 18 . Jahren bereits betonte Erscheinung, daß die Wiederverjüngung des Waldes um so leichter aus freien Stücken sich vollzieht wie auch unter der Hand des Menschen gelingt, je luftfeuehter und regenreicher das Klima; demgemäß ist die natürliche Verjüngung der Waldungen wie die künstliche in den Tropen und im Picetum leichter als in den subtropen und im Fagetum, während das zwischenliegende Castanetum der Verjüngung des Waldes nach den Absichten des Wirtschafters am meisten Schwierigkeiten bieten wird. Nur in den zentralen Gebieten Mitteleuropas mit geringster Luftfeuchtigkeit und Regenmenge (Castanetum und wärmeres Fagetum) konnte sich die Legende bilden, daß die Kiefer oder Föhre auf natürlichem Wege überhaupt nicht zu verjüngen sei. Schon in dem luftfeuchteren Ostpreußen, vor allem in den baltischen und angrenzenden Provinzen Rußlands, damn in dem luftfeuchten Schottland, in südschweden, Dänemark drängt sich die Naturverjüngung so massenliatt freiwillig auf, daß man oft fragen muß, wanum zuerst diese Naturgabe herausgerissen wird, um nach dem Muster des trockeneren Mitteleuropa dem Walde eine kïnstliche Föhrenverjüngung aufzunotigen; auch im wärmeren Mitteleuropa spendet die Föhre bei lufttenchteren, 
kïhleren Elevationen so willig Samen und geradschaftige Jugend wie in ihren nördlichen Standorten. Waldungen im Innern größerer Waldgebiete, welche einen erhöhten Gehalt an Luftfenchtigkeit gegenüber dem zerstïckelten, von Blößen und Feldem durehsetzten Walde aufweisen, Waldungen in Gebieten, welehe unter dem Einflusse feuchter Wincle stehen, wie an Meereskïsten, in der Nähe von Seen, selbst an Flußufern, sodann Wälder in engen Tälern und sehluchten mit gehindertem Luftzutritte, mit einem Worte, alle Waldungen mit erhöhter Luftfenchtigkeit sind leichter zu verjüngen als Wälder in Örtlichkeiten mit einem in Luftfenchtigkeit extremeren Ḱlima.

Jeder Holzart kommt in Temperatur ein Uptimalklima zu. In diesem Optimum ist jegliche Verjüngung, natürliche wie künstliche, leichter durchführbar als in den Gebieten, welche auferhalb dieses Optimums, also kühler oder wärmer als dieses, gelagert sind; wegen der gröferen Luftfeuchtigkeit ist im kïhleren Verbreitungsgebiet die Verjüngung wiederum leichter als im wärmeren Teile des Verbreitungsbezirkes.

Eine entscheidende Rolle bei der Erwägung über die Möglichkeit der Naturverjüngung fällt der Sturmgefahr zu; im Innern größerer Gebirgswaldgebiete, in denen sich die Kraft der Stürme bricht, ist eine Naturverjüngung mit überschirmenden Mutterbäumen leichter durchführbar als in Beständen, welche gegen Felder, Wiesen, Sümpfe, Wasser u. dgl. Ebenen angrenzen und dem vollen Anprall des Windes ausgesetzt sind; Hochplateaux, ausgedehnte Ebenen gestatten meist nur cine teilweise Durchfühnung einer Naturverjüngung; jene Methoden, welche den bislang aufrecht erhaltenen Bestandsschluß mit einem Male auf größere Flächen des Bestandes hin durchbrechen (Dunkelschlag), sind unter solchen Verhältnissen die unsichersten und gefährlichsten. Kommt dazu noch, daß. der Boden durch seine Seichtgründigkeit eine flache Ausbildung des Wurzelsystems der Mutterbäume bedingt, dann ist die Windgefahr so grof, daß man der Kunst den Hauptanteil an der Verjüngung zuweisen muß, so wünschenswert es für die kommenden Waldgenerationen wäre, auf solchen Böden eine möglichst ungleichalterige und ungleichlohe Bestnckung zu erzielen. Alle diese Gefahren kommen bei einer Erziehung der Baumvereinigungen zur Verjüngung in Wegfall.

\section{b) Boilen.}

Die beste Emptänglichkeit des Bodens für Aufnahme und Keimung der sämereien beginnt mit der Auflösung des Bestandsschlusses, sei es, daß dieser auf natürlichem Wege sich einstellt (Lichtholzarten) oder künstlich erzielt wird (Durehlichtungen), wie bei Sihattenholzarten. Diese Empfänglichkeit dauert jedoch nur eine kurze Zeit an; bei den Lichtholzarten verliert sich die Empfänglichkeit durch 
zunehmende Verunkrautung bzw. Bestockung mit Holıgewächsen: bei den Schattenholzarten verliert sich dieselbe durch zunehmende $\mathrm{Be}$ schattung, d. h. Wiedereintritt des Bestandsschlusses bei Aussetzung der Durchlichtung und Verunkrautung des Bodens bei Fortsetzung dieser. Je besser der Boden, um so günstiger die Aussicht für eine Naturverjüngung. Je mehr der Boden in seiner (1)ertäche diurch Streuentnahme verarmt ist, um so schwieriger die Naturverjüngung; auf' schwachem Boden vermagert der Boden durch den $\mathrm{Kahlschlag-}$ betrieb immer mehr; dieser selbst aber wird in diesem Circulus viciosus immer unentbehrlicher wegen der fortgesetzten Verschlechterung des Bodens.

\section{c) Holzarten und Alter.}

Schon früher wurde ausgeführt, in welch inniger Wechselbeziehung Bodenoberfäche und Holzart stehen; für alle Holzarten gilt der Satz, daß der Boden um so reiner an Pflanzen irgendwelcher Art ist, je dichter der Bestandsschluß; der Bestandsschluß ist aber nach Schatten-, Halbschatten- und Lichtholzarten verschieden; bei den Lichtholzarten wird mit dem Alter der Bodenzustand für die Naturverjüngung rom Stangenholzalter, diem Zeitpunkte des dichtesten Schlusses hinweg immer ungünstiger; bei den Halbschattenholzarten tritt die Terlichtung im mannbaren Alter, bei den Schattenholzarten im Hauptalter, zumeist durch Naturereignisse verursacht, am leichtesten ein. Man kann daher ganz allgemein den Satz aufstellen, daß ein Bestand um so leichter auf natürlichem Wege verjüngt werden kann, je näher er dem Ein tritte seiner vollen Mannbarkeit im Samenerträgnis steht, das ist stets die dem wirtschaftlichen Alter, dem Abtriebsalter vora usgehende Altersklasse. Halbschatten- und Schattenholzarten vermögen sich in der Regel bis zum Verjüngungszeitpunkte genügend geschlossen zu halten; für Lichtholzarten und für jene Baumvereinigungen, welche zur Terjüngung erzogen werden, ist zum Zweck der Erhaltung der Empfänglichkeit des Bodens bis zu Haubarkeit Unterbau mit einer Halbschatten- oder Schattenholzart unerläßlich.

\section{d) Wirtschaftsmethode.}

Bei der gegenwärtig allgemein üblichen Einte il ung des $\mathbb{W}^{\top}$ a l d e : in Wirtschaftseinheiten größeren Umfanges (Bestände) und bei dem Zwange, den die Forsteinrichtung auf den Waldbau mit dem Verjüngungszeitraum ausübt, ist die Naturverjüngung teils Glückisache, teils nur für kleine Teile eines solchen Bestandes ausführbar. Wo aber zu einem Walde mit kleineren Einheiten übergesrangen wird, z. B. Kleinbestand oder Gruppe, oder zum Femelwalde, da gilt allgemein das Gesetz: je kleiner die Fläche, um so zuverlässiger, aber auch um so langsamer die natïrliche Verjüngumg. 


\section{e) Die Verfassung der Baumbereinigungen,}

wie sie unter dem gegenwärtigen System der Großbestände und der geschlossenen Erziehung dem Wirtschafter zum Hiebe und zur Verjüngung übergeben werden, ist nur ausuahmsweise eine derartige, daß eine Naturverjüngung ..kmstgerecht“, d. h. genau im Sinne der Systeme oder Vorschriften, für Schirmschlagverjüngungen durchgeführt werden könnte: in der Regel sind die Bestände durch Naturereignisse im Schlusse gelockert worden, was als ein Nachteil aufgefaßt wird, in Wirklichleit aber als ein Vorteil, als Segen für Wald und Wirtschafter sich erweist; dem auf solchen sichlußdurchbrechungen hat die Natur in der Regel bereits für diesen Bestand die Entscheidung getroffen, ob er überhaupt auf natïrlichem Wege verjüngt werden kam oder nicht. Diese Fingerzeige der Natur zu verstehen und für die Entscheidung über die Verjüngungsart des Bestandes zu benutzen, wird die erste und wichtigste Tätigkeit des Forstwirtes sein, wenn er zur Verjüngung nicht erzogene Bestände ror sich hat. Für diese allein, welchen heute noch fast alle haubaren und haubar werdenden Bestände angehören, gelten die folgenden Ausführungen.

\section{Musterung der SchluBdurchbrechungen.}

Unter dem Einfluß der sichlußdurchbrechung zeigt der darunter liegende Boden entweder:

1. eine Verunkrautumg oder eine V'erunholzung;

2. eine Besiedelung mit den Holzarten des Mutterbestandes ( V o r w uchs, bei leichtsamigen Holzarten auch $\mathrm{A} u \mathrm{f} l \mathrm{ug}$, bei schwersamigen auch A f s chlag genannt);

3. eine Mischung der Bodenvegetation von 1 und 2;

4. einzelne Schlußdurchbrechungen sind mit Nutzholzarten, andere mit Unhölzern und Unkräutern bestellt;

5. die Bodendecke ist ohne Veränderung wie im benachbarten, reschlossenen Bestande geblieben.

'/u 1. Hat die Schlufidurehbrechung die für Klima, Boden und Holzart entsprechend exscheinende Maximalgröbe nicht überschritten, so muß unser Urteil lauten, daß füir den betreftienden Bestand die Naturverjüngung unwahrscheinlich ist; was aber unwahrscheinlich ist, wird besser unterlassen zugunsten des sicheren; ist dagegen die Schlußdurchbrechung zu grof, so müfte die Frage der natürlichen Verjüngungsmöglichkeit unentschicden bleiben.

Ku 2. Hat sich der Boden unter den Schlufolurchbrechungen mit Anflug oder Aufschlag der Holzart des Mutterbestandes bedeckt, so ist der Erweis erbracht, daß der Bestand in einem älmlichen Grade der sichlußdurchbrechung auf natürlichem Wege verjüngt werden hann. 
Zı 3. Haben Unhölzer und Unkräuter mit den Nutzholzarten auf ein und derselben schlußdurchbrechung sich angesiedelt, so ist darin ein Zeichen zu erblicken, daß Naturverjüngung möglich ist, daß aber die Schlußdurchbrechung kleiner, die Schirmstellung also eine dunklere sein muß, als der Zufall sie ausführte.

Zu 4. Einzehe Schlußdurchbrechungen verunkrautet, andere mit Anflug oder Aufschlag versehen; dann ist die Naturverjüngung möglich, und zwar in jener Schirmstellung oder Schlußdurehbrechung, bei der der Verwuchs sich einstellen konnte. Die Naturverjüngmng wird in diesem Falle der kïnstlichen Beihilfe nicht entbehren können, um die verwilderten Schlußdurchbrechungen mit Nutzholz zu bestocken.

$\mathrm{Zu}$ j. Sind weder Unhölzer und Unkräuter noch Baumjugend erschienen, dann ist die Möglichkeit der Naturverjüngung unentschieden; jedenfalls aber ist so viel zu lernen, daß die Schirmstellung eine lichtere sein muß, als sie von seiten der Natur geboten war.

Diese Musterung der Schlußdurchbrechungen als allererste Aufgabe, ehe noch an irgendeine, auch Kahlschlagsverjüngung, herangetreten werden sollte, erscheint so wichtig, daß es künftighin bei Beibehaltung des gegenwärtigen Großbestands- und Erziehungsystems sich empfehlen dürte, in sämtlichen Beständen schon 20-25. Jahre vor dem ersten Angriffshiebe zum Zwecke der Verjüngung einzelne, verschieden geformte Schlu $\beta \mathrm{d} u \mathrm{rch}$ brechungen - vielleicht als "Vorgriffshiebe" zu bezeichnen von verschiedenen Größen absichtlich einzulegen, so daß dann bei Beginn der Verjüngung nicht nur über die Möglichkeit der Naturverjüngung, sondern auch über den Grad der Lichtstellung Anhaltspunkte aus dem vorliegenden Experimente direkt abgelesen werden kömnen.

Ergab die Musterung der Schlußdurchbrechungen eine für die Naturverjüngung günstige Prognose, so schließt sich sofort, ehe noch Verjüngungshiebe, Kahl- oder Schirmhiebe erfolgen, als erste Tätigkeit an die

\section{Behandlung der SchluBdurchbrechungen.}

Diese erstreckt sich auf Erweiterung bzw. auf Lichtersteilung jener Öffinungen, welche, weil zu klein oder zu dunkel, keine Verjüngung erzielten, sowie auf Behandlung der bereits verwilderten Schlußadurchbrechungen. Im letzteren Falle ist Entfernen des Unkrautwuchses und Warten auf neue Naturbesamung ebenso unrichtig als etwa die künstliche Ansaat solcher Stellen. Die Natur hat bereits gezeigt, daß Saat nicht schnell genug gegenüber dem Unkraute emporkeimt: verunkrautete Stellen sollen richt von Unkraut gereinigt, sondern, wie sie sind, sofort a usgepflanzt werden. Als dritte Tätigkeit schlielst sich an die 


\section{Musterung der Vorwüchse.}

Die Vorwuchsmusterung hat sich auf das Alter, die Kronenbildung, die Bewurzelung, auf' Höhe und Ausdehnung des Vorwuchses und auf' das ïberschirmende Altholz zu erstrecken.

1. Was das Alter des Vorwuchses hetrifft, so ist die Feststellumg desselben durch die Zahl der Quirle und der Knospensehuppenringe bei Laub- und Nadelbäumen nur an jungem Torwuchs durchführbar: ist der Vorwuchs älter als zehm Jahre, so muf man an möglichst tief geführten Querschnitten der Stämmehen die Jahresringe (meist mit der Lupe oder selbst dem Mikroskop) zählen oder zur Abzählung der Jahresbildungen an dem am tiefsten sitzenden und am besten entwickelten Seitentriebe schreiten oder eine Abschätzung des Alters vornehmen, welche in der Regel auch für die waldbaulichen Bedürfnisse genügt, da die Brauchbarkeit des Vorwuchses mit der Feststellung der folgenden Punkte sich erledigen läßt. Im allgemeinen kamn als Regel gelten, daß Vorwuchs von Lichtholzarten, welcher über zehn Jahre alt ist, und Vorwuchs von Schattenholzarten übe! 211. Jahıre für Verjüngungszweclie zu alt, somit unbrauchbar ist; es wäelist mit dem Alter und dem Grade der Unterdrückung der Zeitraum, der zur Erholung und Umbildnng des Vorwuchses für die neugeschaffenen Licht-, Wärme- und Feuchtigkeitsverhältnisse beansprucht wird.

2. Die Kronenbildung ist bei allen Verwüchsen, seien sie aus Licht- oder aus Schattenholzarten bestehend, die gleiche; je stärker der Lichtentzug, um so flacher entwickelt sich die Krone zur Ausnutzung des Lichtes; die unter den Kronen geschlossener Föhren stehenden Eichen werden ebenso flachkronig wie Fichten- oder Tamenvorwüchse unter Fichte oder Tanne. Solche tellerförmige Kronen zeigen zugleich einen minimalen Höhenwuchs an, die untersten Äste der Stämmchen sind bereits abgestorben; solcher verbutteter Vorwuchs ist in der Regel sehr viel älter, als er geschätzt wird. Bei starker Beschattung kömen Sehatten ertragende Holzarten 50 Jahre und darüber alt sein und erst $1 \mathrm{~cm}$ Durchmesser und $1 \mathrm{~m}$ Höhe aufweisen. Solcher Vorwuchs ist unbrauchbar wegen allzu langer Dauer der Erholung und wegen erhöhter Gefahr des Absterbens bei plötzlicher Freistellung. Branchbarer Vorwuchs muß bis zum Borlen beästet sein und Gipfeltriebe aufweisen, an welchen das Alter noch gezählt werden kann. Die brauchbare Kronenform nähert sich der Prramide.

3. Die Bewurzelung des branchbaren Vorwuchses muß innerhalb des mineralischen Bodens sich verbreiten; vielfach aber sind unter Schattenhölzern oder unter verunkrauteten Lichthölzern solche Massen von Rohhumus angehäuft, daß die Wurzehn in diesem verlaufen oder noch seichter in den abgestorbenen Mnoslagem sich verzweigen. Wird soleher Vorwuchs freigestellt, so kränkelt or auf Jahre hinaus, bis die Wurzeln allmählich, durch die Abtrocknung von oben gezwungen, in 
tiefere Bodenschichten hineinwachsen. Solcher Vorwhchs kann aber durch die Beseitigung des schirmenden Altholzes und durch das Betreten von seiten der Lensehen und Tiere zum Zweck der Fällung und Bringung durch das Absprengen der flachen Wrurzeln nicht bloß leirlen, sondern selbst absterben. Es ist bei weit heraufdringendem Grundwasserstande auch der Fall zu beobachten, daf der Vorwuchs durch die Beseitigung des Altholzes ersäuft wird durch die reichlicheren Niederschläge (Wasserbewegung von oben nach unten) und das Ansteigen des Grundwassers (infolge Zunehmens der Wassermenge und Abnehmens. der Drainage durch die Althölzer).

4. In Krone, Wurzel und Alter brauchbarer Vorwuchs kamn unbrauchbar sein, wenn er allzusehr im Höhenwuchs vorangeeilt und noch reichlich von starken Althölzern überschirmt ist, welche bei ihrer Nutzung den Vorwuchs allzusehr beschädigen; der brauchbare Vorwuchs soll @2 m Höhe bei Beginn der Freistellung nicht überschreiten; je niederer, desto besser.

5. Allen bisher betrachteten Anforderungen genügender Vorwuchs kann demnoch unbranchbar sein. wenn die einzelnen Pflanzen so isoliert stehen, daß Gefahr besteht, daß sie nach der Freistellung zu breitkronigen Wölfen sich auswachsen würden; durch Einpflanzung kamn jedoch soleher Vorwuchs brauchbar gemacht werden.

b. Brauchbare Torwuchsgruppen sollen allmählich gegen die Ränder hin in ihrer Höhe sich abstufen, damit sie an spätere Verjüngungen in ihrem Umkreis sich harmonisch anschließen könnell. Ist das nicht der Fall, d. h. besitzen solche, etwas ältere Horste nach ihrer Freistellung und Abrundung steile Ränder, so können sie bei größeren Horsten durch Umpflanzung ansehlußfähig gemacht werden; Vorwuchsgruppen dagegen ron geringerer Ausdehnung als etwa ji) $\mathrm{qm}$ werden besser beseitigt, weil die Ränder solcher Horste trotz fortgesetzter Aufästungshiebe später demnoch zu ästigen Bäumen sich entwickeln: je älter der Torwuchs, desto größer muß die Fläche sein, die er bedeckt.

7. Brauchbarer Vorwuchs soll wenigstens il) qm Fläche schon bei seiner Entstehung bedecken; kleinere Flächen können nur dann berücksichtigt werden, wenn die Möglichkeit besteht, sie in kurzer Zeit durch anschließende Hauungen zu vergrößern.

8. Minder guter, weniger gut geschlossener, etwas zu alter Vorwuchs kamn auf guten Böden sich noch zu einem brauchbaren Vorwuchs entwickehn; auf geringeren Böden dagegen muß der Torwuchs müglichst rollkommen sein.

9. Auf steinigen, mit Trümmern überlagerten, steilen Hängen, in versumpften Örtlichkeiten, welche der künstlichen Wiederverjüngung große Schwierigkeiten entgegenstellen, dann in der höchsten oder nürdlichsten Waldregion ist jeder Vorwuchs brauchbar.

10. Vorwuchs aus Stockausschlägen ist unbrauchbar. 
Vorwuchs kam aus einer Holzart hestehen, roiner Vorwuchs sein, oder aus mehreren zusammengesetzt sein, gemischter Vorw u $\mathrm{chs}$. In letzterem Falle kommt zu den obigen Punkten noch hinzu:

11. Gemischter Vorwuchs, welcher nur S'chattenholzarten oder nur Lichtholzarten enthält, ist brauchbar, wemn alle Holzarten annähernd gleich hoch sind und auch im entscheidenden Stangenalter annäbernd gleich schnell emporwachsen. Ist dies nicht der Fall. so wird die schnellwïchsige Holzart entfernt, wenn sie weniger wertvoll ist als die bedrückte; im entgegengesetzten Fall ist keine Hilfe notwendig.

12. Sind Licht- und Schattenholzarten im Vorwuchs gemischt, und wächst die Lichtholzart mit Sicherheit anch während der Stangenperiode vcraus, so ist solcher Vorwuchs brauchbar.

13. Die Beurteilung der Brauchbarkeit des gemischten Vorwuchses kann der Kenntnis der Naturgesetze und ihres Einflusses auf die Wuchsgeschwindigkeit der Holzart, wie sie in dem ersten Teile des Waldbanes niedergelegt sind, nicht entbehren. Die Mischung ist branchbar, wemn die Holzarten im Wuchse bis zum Baumalter Schritt halten.

14. Finden sich in einer Jungwuchsgruppe (gleichviel, ob aut natïrlichem oder künstlichem Weg entstanden) zwei Schattenholzarten in Mischung, so verlänft die beiderseitige Wuchsgeschwindigkeit nach dem Typus der beiden Arten (Seite 132); die voranwachsende siegt über die zurückbleibende; jene Holzart, welche zuerst Kronenschluß erreicht, erdrückt die andere (Buche und Fichte, Fichte und Tanne).

15. Findet sich in einer solchen, annähernd gleichalterigen Mischung von Sichattenholzarten unter sich öder ron Licht- und Schattenholzarten eine Holzart in ihrem Optimum, während für die andere der betreffende Standort ein K'lima kühler oder wärmer als ihr Optimum aufweist, z. B. Fichte und Buche im Picetum, Eiche und Buche im Fagetum, Lärche mit Fichte oder Buche im Fagetum, so ist die Holzart, welche außerhalb ihres Optimums ist, stets bei uatürlicher, bei künstlicher und in Vorwuehsmischung zumeist verloren, wenu ihr nicht fortgesetzt im Kampfe gegen die Optimumsholzart geholfen wird.

16. Der Boden kann eine oder die andere Holzart in einer gleichalterigen Mischung hegünstigen oder schädigen; dadurch wird das naturgesetzliche Verhalten sich ändern müssen, bei Begünstigung der Optimumsholzart wird der Sieg letzterer beschleunigt: bei Begünstigung der schwächeren Art kann dieso sogar mit der Optimumsholzart Schritt halten Eiche und Buche auf kalkarmen Böden im Fagetum).

17. Eine raschwächsige und durch den Boden in ihrer Wuchsgeschwindigkeit der beigemischten Holzart gegenüber noch geförderte Holzart (z. B. Fichten, Tannen oder Buchen mit Föhre auf geringeren Sandböden) kann zu einem gleichen Wuchstempo mit den beigemischten gezwungen werden, wenn diese Mischung in einem Klima kühler als 
das Cptimum der schnellwüchsigen Art liogt; dort ist oin derartiger Torwuchs bzw. eine derartige Verjüngung zulässig. Auf besserem Boden besteht bereits die Gefahr, daß die anfangs schnellerwïchsigo von den Holzarten, welche im kühleren Klima ibr Uptimum finden, überwachsen wird.

\section{Behandlung der Vorwïchse.}

1. Soll älterer Vorwuchs von genügender Flächenausdelınung, aber mit steilem Rande beibehalten werden, so ist er durch Umpflanzen mit starken Pflanzen abzustufen; wemn möglich, sind schnellerwüchsige Holzarten, aber von ähnlichem Lichtbedürfnis wie die Vorwnehsholzart, zu wählen. Unter den fremdländischen Baumarten hat sich die Küsiendonglasie für diese Zwecke bereits bewährt.

2. Isoliert stehender, aber im übrigen brauch barer Vorw uehs soll durch Eimpflanzung kräftiger Pflanzen derselben Art verdichtet werden: Einptlanzung von Lichtholzart zwischen Schattenhölzern ist fast stets ein Mißgriff (Eiche in Buche, Lärche in Buche oder Fichte).

3. Allzu dicht stehender Vorwuchs, welcher deshalb im Wuchs auch nach der Freistellung kümmert, ist zu durchschneiden; hilft das nicht mehr, ist er zu beseitigen und die Stelle in weiterem Verbande mit einer anderen Holzart anszupflanzen.

4. Findet sich unter oder zwischen altem, verbuttetem Vorwuchse jüngerer, brauchbarer Anflug oder Aufschlag, so werclen zunächst alle Althölzer, welche noch darïberstehen, beseitigt, von dem verbutteten Torwuchs aber wird alles herausgeschnitten, was zur Beschïitzung des brauchbaren T'orwuchses nicht notwendig erscheint. Solche Vorwuchshorste werden behandelt wie haubare Bestände in Schirmverjüngung en miniature.

j. Findet sich unter verbuttetem Vorwuchse kein brauchbarer, so werden die Althölzer belassen, die unbranchbaren Torwüchse werden mit möglichster Bodenverwundung herausgerissen. Ist nene Besamung nicht zu erwarten, erfolgt Fällung der Althölzer und kïnstliche Ansaat oder Pflanzung der Stelle.

i. Über brauchbarem Vorwuchse werden die zu einer lichten bzw. einer freien Stellung nötigen Hiebe im Altholze vorgenommen; da der Übergang zum Freistande um so langsamer erfolgen muß, je stärker und langandatrernder die vorhergehende Überschirmung sich erries, so kann. besonders bei tiefbeästeten Bäumen, die erste Mafnahme sich nur auf Bezeichnung jener Stämme beschränken, welche zugunsten des Torwuchses aufgeästet werclen müssen; je nach Bedarf liönnen sodamn Lichthiebe oder Endhiebe einsetzen.

7. Sollen brauchbare Vorwuchsoruppen als Anfangspmnkte für eine peripherisch fortschreitende Terjüngung (ringfürmiger I) unkelschlag oder Gayers Femelschlag) gelten, so ist durch ringfürmigon sichirmschlag 
(Rändelhieb) orler auch durch ringförmigen Kahlschlag (Umsäumungshieb)) für Erhaltung von anschluffähigen Verlaufsrändern des Vorwruchses zu sorgen.

8. Besteht ein gemischter Vorwnchs nur aus Schattenholzarten oder nur aus Lichtholzarten, welche zwar anfänglich, im Jungwuchsalter, nicht aber im entscheidenden Stangenalter gleich rasch emporwachsen, so werden die schnellerwüchsigen Arten beseitigt, wenn die geführdete Art die wertvollere ist; ist dies nicht der Fall, bedarf es keines Eingriffes.

!. Ist in einem ans Licht- und Schattenholzart gemischten Vorwuchs die Vorwüchsigkeit der Lichtholzarten im Stangenalter zweifelhaft. so müssen die Schattenholzarten gestümmelt oder ganz beseitigt werden, wemn kine Anssicht besteht, daß die Schattenholzart durch Naturereignisse (Frost, Wildverbif. u. dgl.) künstlich niedergehalten wird. so daß die Lichtholzarten einen genïgenden Vorsprung erhalten, elie sie ins Stangenalter eintreten. Viele im Prinzip falsch angelegte, künstlich gemischte Horste von Fichte und Lärche. Buche und Lärche sind durch solche Ereignisse rom Ausscheiden der Lärche gerettet worden. Werden die Schattenholzarten ganz beseitigt, erfolgt in einem späteren Alter ein ernenter Unterbau der Lichtholzarten.

10. Ist in einem aus Licht- und Schattenholzarten gemischten Torwuchse die Vorwüichsigkeit der Lichtholzart zweifelhaft, die Schattenholzart aber ebenso wertvoll oder wertvoller als die Lichtholzart, wird am besten die Lichtholzart beseitigt, um einer Termehrung von Insekten und Pilzen, welche die kränkelnden Individnen bevorzugen, vorzubeugen.

11. Jede Vorwuchsgruppe muß als ein Terjüngungsobjekt für sich betrachtet und behandelt werden.

12. Bchufs Schonung der Torwüchse sind alle Fällungen im Altholze bei Schneelage und so auszuführen, daf die stürzenden Stämme aus der Vorwnchsuruppe wenigstens mit der Krone hinausfallen.

13. Ist dies nicht möglich, so können die alten Stämme vorher entästet oder zu Brennhölzern aufgeschnitten werden, um den Transport zn erleichtern. Iiese letztere Maßnahme dart' nu ein seltener Ausnahmefall sein: hranchbarer Torwuchs heilt leicht, Vorwuchs nach Punkt $f$ (S. 2! 29 ) wird besser erschlagen als benützt.

\section{Die Schnelligkeit der Verjüngung.}

Die Schnelligkeit, mit der eine Waldfläche auf natürlichem Wege verjüngt werden kann oder werden soll, hängt von einer ganzen Reihe von Faktoren ab und ist für das Gelingen des Werkes von größter Bedeutung. Im allgemeinen kann hehauptet werden, daß , langsam, aber sicher" die Devise der Naturverjüngung ist. Rücksichtnahme ant' Ruhe und Ptlege der .Iungwüchse, auf die Forderungen der Forst- 
einrichtung und der Rentabilitätsrechmung lassen es aber wünschenswert erscheinen, jede Verjüngung, die natürliche wie dic künstliche, tumlichst zu beschleunigen: mit dem schnelleren Tempo aber wächst für die natürliche Verjüngung das Risiko bezüglich des (ielingens; denn die Beschleunigung muß naturgemäß den Erfolg auf wenigre, vielleicht auf eine einzige gute Karte, auf ein einziges Samenjahr setzen und auf eine ergänzende Besamung der Flächen durch spätere Samenjahre verzichten.

Entscheidend für die Schnelligkeit der Verjüngung ist zunächst a) die Erziehungsweise dos Bestandes. Wird der Bestand irgendeiner Größe, irgendeiner Form, irgendeiner Holzart mittels Iurchforstungen und daran sich anschließende Durchlichtungen so erzogen, daß die einzelnen Bäume mit ihren Kronen im Haubarkeitsalter völlig isoliert stehen, und daß den Boden ein Schutzbestand einer Halbschattenoder Schattenholzart deckt, so besteht ständige Bereitheit für die Verjüngung, und es ist im höchsten Grade wahrscheinlich, daß in einem solchen Bestande mittels eines einzigen Samenjahres die Bammvereinigung auf natürlichem Wege unter Schirm (Erziehungsverjüngung genannt) in wenigen Jahren verjüngt werden kann.

Ist aber der Bestand für die Verjüngung nicht erzogen, d. h. ist er, soweit aus einer Schattenholzart bestehend, noch im Haubarkeitsalter geschlossen gehalten, soweit aus einer Lichtholzart bestehend, zurzeit der Verjüngung verunkrautet, dann ist eine schnelle Verjüngung in der Regel unmöglich; demn die Vorbereitung der Bäume zum Samenerträgnis und des Bodens zur Empfänglichkeit nehmen bereits Jahre in Anspruch.

Wird z. B. für einen solchen, zur Verjüngung nicht erzogenen Bestand; die Dunkelschlagverjüngung gewählt, so wird die Verjüngung auf großen Teilen oder dem ganzen Bestand auf einmal eingeleitet; sie wird nur dann in kurzer Zeit sich abspielen, wenn zur Geschicklichkeit der Ausführung auch noch das entsprechende Glück eines vollen Samenjahres zu günstigster Zeit sich gesellt. Bleibt aber letzteres aus, so ist die Fläche für natürliche Verjüngungen zumeist unbrauchbar geworden. Je kleiner die Flächenteile sind, welche man zur Naturverjüngung auswählt (bis herab zur Löcherschirmvereinigung), um so sicherer zwar das Ergebnis, da mehrere Samenjahre benutzt werden können, um so langsamer aber auch kommt die Verjüngung des Bestandes zum Abschluf; neben derartigen Erwägungen sind es aber auch natürliche Verhältnisse, welche das Tempo des Verjüngungs ganges beeinflussen.

b) Das Klima. Je kühler die Lage, sei es durch höhere Breitengrade oder Elevation oder Exposition, um so langsamer ist die Entwicklung der Jugend und dementsprechend langsam ist die Auflichtung der Schirmstellung über dieser. In Ländergebieten mit hoher 
Luftfeuchtigkeit und genügender Regenmenge während der Vegetationszeit, somit in Gebieten, in denen andauernde Sommerregen zu den Ausnahmen. Gewitterregen zur Regel gehören, wie z. B. Mittelund Nordeuropa, ist eine Lichterstellung und eine raschere Beseitigung der schirmenden Althölzer wünschenswert, um den aufkommenden Pflanzen die wohltätige Wirkung der Gewitterregen zukommen zu lassen: in den kontinentalen felicten aber, in denen der Ausfall aller Sommerregen die Regel, Gewitterregen seltene Ausnahmen sind, ist die stärker beschirmte Fläche in ihrer oberen Schicht immer noch feuchter, somit für die Jugend günstiger als die stärker aufgelichteten oder sogar kahlen Flächen. Im Bereiche der sommertichen Regen und der winterlichen Trockenheit (Monsungebiet von Ostasien) empfiehlt sich stärkere Beschirmung der Verjüngungsflächen, un die zarten, einjährigen Pflanzen über die gefährliche Zeit der Winteraustrocknung und den rordringlicheren Graswuchs hinwegzubringen.

Lagen. welche des Windsehutzes entbehren, verlangen eine raschere Lichtung and Beseitigung der Beschirmung, um die drohende Sturmgefahr möglichst abzukürzen; es wird zu erwägen ein, ob in solchen Örtlichkeiten überhaupt die Naturverjüngung in größeren Flächen durchgeführt werden soll: werden aber kleine Verjüngungsflächen gewählt, so ist der Gang der Verjüngung schon dadurch verzögert. Nur eine Erziehung zur Naturverjüngung braucht auf Wind keine Rücksicht zu nehmen.

Eingesenkte, muldenförmige Lagen, Hochplateaux können durch den Kahlschlag zu Frostlöehern schlimmster Art werden; schon im Castanetum beginnt diese Gefahr, die nach der Kältegrenze des Waldes hin sich steigert: für solche Lagen ist eine dichtere und länger aufrecht erhaltene Überschirnung und damit eine Verzögerung des Verjüngungsganges unerläßjlich.

c) Holzarten, welche in kurzen Zwischenräumen und reichlich Samen bilden, lassen sich rascher verjüngen als solehe, welche nur in längeren Zwisehenpausen frulitifizieren. Holzarten, welche in der ersten Jugend bereits liehtbedürftig sind, müssen in besehleunigter, abgekürzter Schirmhiebsführung verjüngt werden, wie z. B. Föhren gegenüber Fichten, Eichen gegenüber Buchen: je empfindlicher eine Holzart gegen verspätete Fröste, um so dichter die Schirmstellung, um so länger die Erhaltung derselben.

d) Der Boden übt seinen Einfluß nicht in der zunächst erwarteten Richtung, nämlich, daß auf gutem Boden die Verjüngung rascher sich abwickehn könne als auf minder gutem. Je besser der Boden, um so größer die Unkrantgefahr. Um dieser vorzubengen, ist eine stärkere Überschirmung wenigstens für die schattenertragenden Arten angezeigt: auf' geringerem Boden ist ein rascher Gang schon deshalb nötig, weil 
alle llolzarten auf solchen geringeren Böden empfindlicher gegen Überschirmung sind als aut besseren Böden. Frische bis nasse Böden sind zumeist ausgesprochene Frostlöcher, sie verlangen vorsichtige Lichtung, dazu kommt ihre außerordentliche Neigung zum Graswuchse: je stärker die $\mathrm{B}$ odenbearbeitung, desto lichter kann die Stellung, desto liürzer die Funktion der Schirmbäume sein.

e) Je größer das in einer Hand vereinigte Waldareal, um so langsamer kanu auf einer in Angriff genommenen Fläche die Verjüngung fortsehreiten; wo aber nur wenige Objekte zur Verjüngung bestimmt werden kömnen, da muß rascher geschlagen werden, um den Etat zu erfüllen.

f) Beschleunigend wirken wirtschaftliche Umstände, wie z. B. A bsatzverhältuisse. Zur Verbilligung des Transportes kann es wünschenswert erscheinen, auf einer. Stelle größere Holzmengen durch stärkere Schirmschläge zur Fällung zu bringen; wo reichliche Kulturmittel zur Verfügung stehen, kann ebenfalls rascher vorwärts gegangen werden, wobei allenfalsige Fehlstellen nachträglich durch Saat oder Ptlanzung ergänzt werden.

g) Je schneller die Lichthiebe geführt werden und der Endhieb folgt. desto rascher erwächst die nene Generation, desto mehr steigert sich aber auch die Gefahr durch Unkraut und Frost, durch Wildverbif, desto geringer aber sind die Beschädigungen der jungen Generation durch die Fällung und Bringung der Althölzer. Hierin das rechte Tempo zu treffen, kann nur auf Grund der Naturgesetze des Bodens, des Klimas und der Holzarten sowie lokal gesammelter Erfahrungen gelernt werden. Allgemein mag indes der Satz als recht gelten, so schnell als möglich mit den Schirmständern zu räumen, denn für die Jungwïchse im Walde gilt derselbe Grundsatz wie für ihre größten Feinde, das Wild: Ruh nimmt zu:

h) Bei keiner Verjüngungsweise prägt sich der Einfluß des Temperaments des Wirtschafters auf den Gang der Terjüngung so sehr aus, als bei der natürlichen Verjüngung. Der Vorsichtige, Überängstliche wird den Verjüngungsgang verzögern, der Wagende, Ungeduldige wird ihn in beschleunigtem Tempo zu Ende zu führen suchen. Karl Gayer ${ }^{1}$ ) sagt hierüber sehr zutreffend:

,Unter den vielen Tugenden, welche den Wirtschaftsbeamten zieren müssen, sind für das waldbauliche Vorgehen die Geduld und das Bewußtsein, daf Zweck und Ziel der Arbeit in der fernen Zukunft, nicht in der Gegenwart liegen, mit die wichtigsten.

In der natürlichen Anlage des Wirtschafters kamn ein günstiges oder ungünstiges Moment für den Erfolg einer Naturverjüngung lięren: aber die Qualität des Wirtschafters in erster Linie nach dem Gelingen

1) K. Gayer, Aus dem Walde (1ऽ91), Nr. 27. 
oder Mißlingen einer Naturverjüngung beurteilen zı wollen, wäre ebenso unrecht, wie das Gelingen einer künstliehen saat oder Pflanzung als Prüfstein für den Wirtschafter zu betrachten: bei allen Verjüngungen im Walcle sind viel mächtigere, außserhalb der Kraft des Wirtschafters liegende Faktoren im Spiele, welchen in erster Linie das Gelingen oder Mißlingen zugeschrieben werden muß, daß sind die L a un en der Wit terung.

\section{Der Verjüngungszeitraum.}

Der Zeitraum, während dessen die Verjüngung auf einer bestimmten Fläche sich abspielt, heift spezieller Verjüngungszeitraum; lierbei ist es gleichgültig. ob diese Fläche einen ganzen Bestand, einen Teil desselben, einen Kleinbestand, eine Baumgruppe oder einen Trupp umfalit ; es ist die Zeit, welche vom ersten bis zum letzten Verjüngungshiebe verstreicht. Die Bezeichnung allgemeiner Verjüngungszeitraum trifft nur bei (⿳亠丷厂巾ß- und Kleinbeständen zu, wenn diese in mehreren Teilen nacheinander verjüngt werden. Der allgemeine Verjüngungszeitraum ist somit die Summe der speziellen Zeiträume. Ler spezielle Zeitraum ist der nat ürliche, naturnotwendige: er ergibt sich aus der Eigenart der Holzart, des Bodens, des Standortes, mit einem Wrort, aus dem natürlichen Gang der Verjüngung; der allgemeine Verjüngungszeitraum wird von der Forsteinrichtung bestimmt, die nur dann eine zeit- und naturgemäße ist, wenn sie dem Wirtschafter in der Wahl des Beginnes der Verjüngung und der Daner derselben völlig freie Hand läßt. Wählt sie die Bestände zu groß, den allgemeinen Verjüngungszeitraum zu klein, dann wird die Verjüngung auf natürlichem Wege ebenfalls auf grofe Flächen sich erstrecken und schnell sein müssen, obwohl die Bestände hierfür nicht erzogen sind; für manche Holzart, für manche Bestände wird dadurch die Durchführung einer Naturverjüngung erschwert, ja, geradezu zur Unmöglichkeit. So liegt eine schwerwiegende Veranlassung zum Kahlschlage mit künstlicher Verjüngung in dem Systeme der herrschenden Großflächenforsteinrichtung und Bestandeserziehung.

\section{Die natürliche Wiederverjüngung bei den Kahlschlagwirtschaften, die natürliche Nachverjüngung.}

Re in bestände.

Wie aus dem achten Abschnitte entnommen werden kamn, gibt es Kahlsehlaghetriebe, wie Birkeubergwirtschaft, Alpenbrandwirtschaft, bei denen die Wiederverjüngung stets der Natur überlassen bleibt; bei kahlen Saumschlägen, hesonders im Gebirge und bei vielen Kahlschlägen im bäuerlichen Waldbesitze, ist es zumeist der Natur überlassen, wie und wann die Kahlfläche mit einer Holzart der Umgebung sich bestoclit. Diesen Betrieben stchen solche gegenüber, bei denen 
prinzipiell alles, was auf einer Fläche erwachsen ist, Altholz und Jungwuchs, ebenso Unbölzer beseitigt, tabula rasa gemacht wird; auf ihr entsteht ein nener Wald allein durch menschliche Kunst und nach menschlichen Gedanken. Die ersteren Methoden blicken allzı vertranend, die letzteren allzu mißachtend auf die Tätigkeit und Mithilfe der Natur; die einen wollen gar nichts zur Naturgabe hinzufügen, die anderen lassen jegliche, auch die beste Gabe der Natur zuerst herausreißen, um mit großem Aufwand an Fleiß, Zeit und Geld die neue Generation nach dem bewährten Rezepte anzupflanzen. Eine Wirtschaft, welche Anspruch auf die größjte Rentabilität im Walde erhebt und zugleich an Nachhaltigkeit des Bodens denkt, muß alles tun, um den Nachteilen der plötzlichen Kahlstellung des Bodens entgregenzuwirken, muß auf möglichste Einsparung an den Kosten, auf möglichste Sicherheit der aufwachsenden .Jugend (Ersparung der Nach. besserungen) bedacht sein. Sie kann dies nur, wenn sie den goldenen Nittelweg zwischen den hentigen Kahlschlagformen mit künstlichem Anban und den Schirmschlagformen mit Naturbesamung beschreitet und zum obersten Grundsatz erhebt: Auch im Kahlschlag muß jeder brauchbare Vorwuchs erhalten und zum Ausgangspunkt der anschließenden, künstlichen Verjüngung gemacht werden; auch im Kahlschlagbetriebe muß die Begründung von brauchbarem, natürlichem Vorwuchse als das Ziel der Verjüngungstätigkeit des Wirtschafters gelten; die Kunst soll nur ergänzen, was auf natürlichem Wege sich nicht erreichen lieB.

In wenige Worte zusammengefaßt sind die Vor-und $\mathrm{Nachteile}$ einer Naturverjüngung auf einer Kahlfläche folgende:

Als größter Vorzug der natürlichen Verjüngung auf der Kahlfäche muß die Ersparnis an Kulturkosten bezeichnet werden; die Erleichterung der kïnstlichen Verjüngung durch den Anschluß derselben an einen bereits vorhandenen Jungwuchs ist eine augenfällige und allbekannte; die Verhinderung der Verunkrautung und Verwilderung solcher Stellen ist eine Wohltat für den Boden; die übrigen Vorzüge kommen den Kahlschlagflächen als solchen zu. Als Nachteil muß man geltend machen: Unvollkommene Bestockung, im Falle die Verjüngung allein der Natur überlassen bleibt; Beimischung von forstlich gleichgültigen oder sogar schädlichen Holzarten; der Schaden tritt aber erst dann ein, wenn solche Unhölzer nicht rechtzeitig, d. h. vor Bedrückung der Edelhölzer beseitigt werden; bis dahin sind sie nützlich. Die übrigen Nachteile kommen den Kahlschlagflächen als, solchen zu. Man könnte noch hinzufügen: Die Erschworung der Fällung bei der Rücksichtnahme auf vorhandenen Jungwuchs. Dieser letztere Punkt wird schwer wiegen in den Augen vieler Praktiker. Vielleicht sind einige der weiter unten angegebenen Kahlschlagformen 
geeignet, diese Bedenken gegen eine Naturverjüngung beim Flächenkalilschlag zu beheben.

Alserste Tätigkeit beim Kahlschlag muß die Musterung der. Vorwüchse in dem zur Fällung bestimmten Bestande oder Bestandsteile bezeichnet werden; an das Ergebnis dieser Untersuchung, welche im Sinne von S. 2quitr. anszuführen ist, schliebit sich sofort der Kahlschlag an, da eine Erweiterung der Vorwüchse nicht im Programm des Kahlschlags gelegen ist; es kamn aber bei der Fällung über dem Vorwuchs selbst auf möglichste Schonung dieses nhne Verzögerung oder Erschwerung der Fällung Rückicht genommen werden. Die klimat ischen Bedingungen größerer Kahlflächen wurden bereits früher besproehen; die Ungunst im Klima (Spätfrostgefahr, Trocknis) wächst mit der Größo der kahlen Fläche; am ungünstigsten werden daher die kahlon Flächen sein müssen, welche im Grofbestandswalde entstehen; daran reihen sich Bestände (Unterabteilungen) und Kleinbestände. Im saumweisen Kahlhiebe, sowie ringförmigen Kahlhiebe oder kahlen Löcherhiebe bei allen bestandsweisen Walcleinteilungen sind kahle Flächen besser geschützt; am kleinsten wird die kahle Fläche sein beim Kahlhieb, der einer Waldeinteilung zugrunde liegenden Gruppe, oder des einzclnen Stammes und des Trupps im Femelwald; solche kahle Flächen kommen in ihrem Klima jenen unter dem Dach des Waldes am nächsten; ihre Verjüngung ist eigentlich unter Schirm.

Böden. Unter Schattenholzarten, welche soweit als möglich bis zur Haubarkeit geschlossen erhalten werden, trägt der Boden bei a) Laubhölzern nur eine dümne Laubdecke, seltener Rohhumus, darunter liegt vortrefflicher Verjüngungsboden; bei der plötzlichen Freistellung entfernt der Wind die Laubdecke, von Einsenkungen und Gruben abgesehen, und es liegt ein Boden von bester Empfänglichkeit zutage. Aber gerade deshalb erscheint auch, wemn nicht der Same der Nutzholzart hingebracht wird, in kürzester Zeit der Unkrautwuchs; da die schattenholzlaubbäume (Buchen, immergrüne Eichen, Lorbeerbaum, Kastanien und viele andere) schwere Samen tragen, müssen derartige kahle Flächen in kürzester Zeit mit Unhölzern und Unkräntern verwildern: meist ist ungenügend, was an solehen Sämereien durch Vögel auf die kiahle Fläche gebracht wird.

b) Unter Schatten ertragenden Nadelhölzern (wie die Gattung Picea, Abies, Preudotsuga, Tsuga, Thuja. Taxus, Thujopsis und andere) liegt im haubaren Alter meist eine Moos- oder Farnkrautdecke mit Rohhumusschichten, welche eine geringe Empfänglichkeit für Aufnahme und Keimung der sämereien besitzen; durch plötzliche Freistellung verschlechtert sich der Boden noch weiter; nur bei reichlicher Bodenverwundung und Durchwühlmng entstehen empfängliche Stellen, die sich mit den leichtsamigen Schattenholzarten auch leicht besiedeln. 
Unter Halbschattenholzarten, Laub- wie Narlolbüumon (s. S. 221), ist der Boden beim Kahlschlag selten noch emptänglich; er trägt bereits Unkraut- und Unholzwuchs oder bereits .Jugend von der gleichen Art wie der alte Bestand. Ist dieser Torwuhs unbrauchbar, wird er gleich Unhölzern boim Kahlhieb beseitigt, un neuem Anflug Platz zu machen. Wird gepflanzt, können Unhölzer und unbranchbare Torwüchso als vollkommener Schutz auf der sonst kahlen Fläche benutzt werden.

Unter den Lichtholzarten der Laub- und Nadelbämme ist dio Verwilderung des Bodens oder die Verjüngung zur Keit der Haubarkeit am weitesten vorgeschritten; auf natürlichen Anflug kann nur gerechnet worden, wem der Kảhlschlag alles beseitigt und den Boden nou verwundet.

Der Anf'lug der Sämereien auf der kahlen Fläche hängt von der Windrichtung und Hiebsrichtung der liahlen Fläehe sowie von den Witterungsverhältnissen ab. Nur bei trockencr Witterung oder bei Wind findet die Ablösung der Sämereien von den Bäumen statt. Es gilt dies insbesondere von solchen, welche in holzige Dauerfiüchte eingeschlossen sind wie die Sämereien der meisten Nadelbäume. Erst mehrtägige Trockenperiode oder intensive Besonnung zwingt die Früchte zum Aufplatzen und Klaffen ihrer Schuppen. Bei der Gattung Larix stehen die Zapfen aufrecht, so daß die Sämereien nicht durch ihr Gewicht, sondern nur bei heftigem Wind aus den Schuppen geschleudert werden. Bei den Gattungen Cedrus, Abies und einigen Föhren zerfällt der Zapfen, wodurch die Früchte auch bei Windstille frei werden. 'Trockene Witterung aber stellt sich in Europa zumeist bei Windstille oder Ostluft ein; bei westlichen Winden nur in Gegenden mit Föln. Die vorherrschenden, häufigen IVinde aus TWest sind fencht und bringen Regen; bei ihnen öffnen sich die Früchte nicht. Da nun in Europa der kahle Saumhieb gegen die gefährliche Windrichtung, nämlich Westen, geführt wird, folgt naturgemäß, daß die meisten Sämereien der Schlagwand nicht auf die kahle Fläche nach Osten, sondern in den haubaren Bestand hinein nach Westen getrieben werden, wo sie aus Mangel an Licht oder Wasser verkümmern müssen. Nur bei Kulissenschlägen, Löcherhi€ben und den unten angegebenen Kahlschlagformen bringt jeder Wind auch sämereien der Umgebung auf die kahle Fläche. Heftige Stürme entführen die Sämereien über die kahle Fläche hinweg, wie dies besonders bei der Lärche bekannt ist, welche am liebsten ihre Jugend nicht da begründet, wo es am nächsten und am günstigsten erscheint; man sagt, sio erzieht ihre Kinder bei den Nachbarn.

Über die Verbreitung der Holzartens ämereien über eine kahle Fläche hin bieten das Gewicht der sämereien und ihre Ausrüstung für Rotation und Schwebe dio nötigen Anhaltspunkto. Schwerer Same ohne Fallschirn und Flügel, wie z. B. die 
Sämereien der Gattung Quereus, Fagus, Castanea, Aesculus, aller Lauraceen, dann von Zelkowa, Magnolia, Cembra und vielen andern, welche der speziellen Beschreibung der Holzarten entnommen werden mögen, vermögen sich nur auf geneigtem Gelände von ihrem Mutterbaum weiter als $10 \mathrm{~m} \mathrm{zu}$ entfernen. Bis zu $30 \mathrm{~m}$ schweben vom Winde getragen vom Mutterbaum hinweg die Sämereien der Gattung Tilia, Carpinus, Fraxinus, Acer, Abies, Liriodendron, die schwersamigen Pinusarten der Sektion Strobus; bei $50 \mathrm{~m}$ Abstand dürfte die Grenze für die leichtsamigen Nadelbäume, nämlich Picea, Larix, die meisten zwei- und dreinadeligen Föhren, Alnus, Ulmus und andere Holzarten, liegen; von $50 \mathrm{~m}$ bis zu einer fast unbestimmbaren Grenze dürfte die Flugfähigkeit der Gattung Betula, Populus, Salix, Paulownia und andere sich erstrecken.

Die Dichtigkeit des Anfluges oder Aufschlages ist nicht, wie man erwartet, am Stamm der Nutterbäume anschließend am vollkommensten; es bleibt das Tropfenbereich der Mutterbäume bei den leichteren Sämereien von Jungwuchs frei, weil die Sämereien durch schwere Regentropfen herausgeschlagen werden oder vertrocknen; nur bei schweren Sämereien liegt die Zone der gröliten Aufschlagsdichte dem Stamme am nächsten. Bei den Sämereien, die bis zu $30 \mathrm{~m}$ sich verbreiten, ist die Zone zwischen 10 und $20 \mathrm{~m}$ am besten besamt, bei jenen, welche bis zu $50 \mathrm{~m}$ fliegen, liegt die Zone des besten Ergebnisses zwischen 10 und 4 t! $\mathrm{m}$.

Die Samenbedeckung und Keimung. Die Eindeckung der Saat durch den Blattabfall bleibt auf den kahlen Flächen stets spärlich oder fehlt ganz. Nur jene Holzarten sind bevorzugt, welche die schwächste Deckung, ja nur ein Festdrücken auf der Erde und Umerdung dureh den Regen verlangen; das sind wiederum die leichtsamigsten unter den Baumarten, Birken, Pappeln, Weiden, Erlen und andere. Bei größeren Sämereien und den größten mangelt jede Bedeckung und mit dieser jeglicher Schutz gegen Tiere. Im Herbste abfallende größere Sämereien keimen vielfach infolge der starken Besonnung und Erwärmung und erfrieren dann dureh die ersten Frühfröste aus Mangel an Bedeckung. Jegliche Betretung der kahlen Fläche durch Mensch und Tier, jegliche Bodenverwundung vor der Keimung der Sämereien muß der natürlichen Besamung sowolıl auf kahler Fläche wio unter Schirm zuträglich sein.

\section{Führung der Kahlschläge zur Förderung der natürlichen Verjüngung.}

Wohl überall ist an Stelle der großen Kahlflächen von unregelmäßiger Form und Lagerung eine Anordnung in Säumen getreten. Der Verlauf des Saumrandes, die Saumrichtung und die Breite der Säume wechseln; alle drei sind in ihrer Ausformung für den natürlichen Anflug von Sämereien von Wichtigkeit; je länger der Zeitraum, der 
zwischen zwei Saumhieben an derselben Stelle verstreicht, um so wertvoller und ergiebiger an Naturverjüngungen und Beiträgen für die kïnstliche werden die unten gegebenen Saumhiebsformen sein müssen.

Was zunächst den Verlauf der Grenzliniezwischen Saum und Bestand, den Saumrand anlangt, so ist dieser stets eine rerade Linie. Es unterliegt aber wohl keinem '/weifel, daß Ausbuchtungren in dieser Linie dem Erscheinen von jungem Wuchse mehr Aussicht bieten als die grade Linic mit ihrer exzessiven Erwärmung und WVärmereflexion, ihrem Wassermangel und Tropfenwirkung bei Bereguung. Man kann einen derartigen Saumhieb vielleicht zellenförmigen, kahlen Saumschlag (Abb. 17 a) nennen, wenn die Ausbuchtungen rechteckig oder quadratisch sind. In diesen Ausbuchtungen siedeln

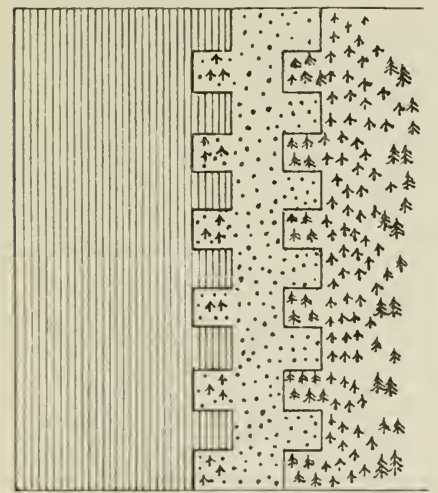

a.Zellersaumscizäge.

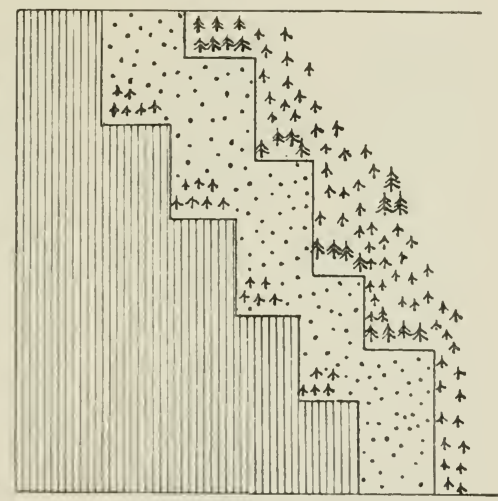

ס. Treppersaumscizäge.

Abb. $17 a, b, c, d, \epsilon, f$ (S. 309, 310, 311). Schematische Darstellung von Saumhiebsformen, Kahlschlagen von 0 nach W zur Erzielung natürlichen Anfluges.

sich innerhalb 2-5. Jahren sicher junge Pflanzen an, welche beim folgenden Kahlschlag willkommen sind, und weil sehr klein, am Leben bleiben werden, auch wenn die schwere Prïfung der Fällung, Sortierung, Bringung und Abfuhr des Holzes über sie hinweggegangen ist. Gegen die Rüsselkäfer schützt Entrindung der Stücke, der Maikäfer wird die Zellen meiden.

Eine andere Form könnte der Treppenkahlschlag gemannt werden (Abb. 17b). Auch er ist der Besamung förderlicher als eine geradlinige Wand; denn es entstehen Nordränder, welche der natürlichen Ansamung günstig sind. Buchtensäume entstehen, sobald der ungleich fortschreitenden, natürlichen Verjüngung durch Ausbuchtungen der Saumgrenze Rechnung getragen wird (Abb. $17 c$ ). Eine 
andere Form der Saumhiebe, welche vielleicht noch besseres Ergebnis bringt, wäre in Abb. 17 d gekennzeichnet. Es wird, wenn ein Streifen z. B. von (i) $m$ Breite beabsichtigt ist, derselbe in drei Längsteile à $20 \mathrm{~m}$ breit zerlegt; der mittlere (II) bleibt Altholz, I und III werden beseitigt. Beim nächsten Saumlieb fällt der Streifen II und neue kahle Streifen I and III werden angelegt. Man kann diese Form den kahlen Saumschlag mit Zwischensaum (II) nemnen: auf I wird sich Anfug cinstellen müssen, auf III wird or so mangelhaft wio bisher sein. Eine andere Form endlich bietet Abb. 17 $e$. I iese Form ist im Hochgebirge bereits bekannt; dort wird 10-15. Jahre vor dem Abhieb des Saumes dieser kräftig durchhauen, so daß bei der Lichtstellung der Bäume eine Naturverjüngung eintreten kann. Der kahle

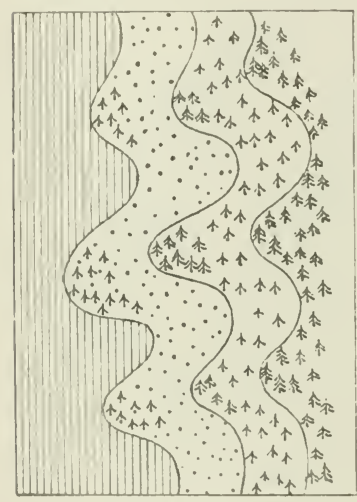

c. Buchzersuumschíge.

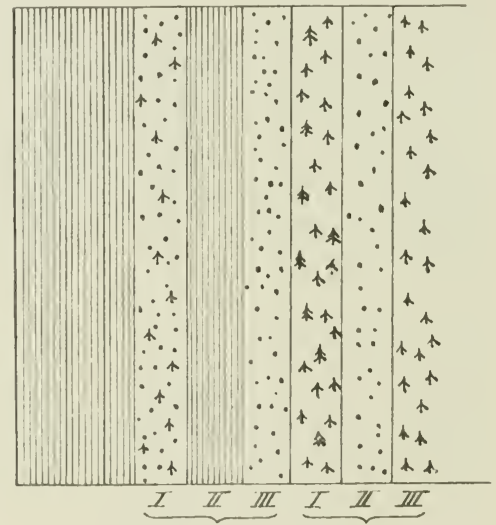

d. Znisc.zersuzinschläge.

Saumhieb beseitigt dann den Schirmsaum und legt einen neuen Schirmsaum an: kaliler Saumschlag mit Torlichtung.

Auch diese Verjüngung muß zu den Kahlschlägen gereehnet werden, da der Hich ausceführt wird, auch wenn keine Naturbesamung 'eingetreten ist. Alle obigen Formen werden keine genügende, aber doch eine willkommene Verjüngung liefern, welche die Kunst nur zu ergänzen brancht. Wird oin Samm der (knere nach anfgeteilt und jeder Teil als selbständiger llirbszug weiter geführt, so entsteht der geteilte saumsclilag (Abb. $17 / 7)$ : stofen die Teile (Abb. 18) in Winkeln aneinander, hat man von gebrochenen Saumhieben (Neuessinger Wirtschaft-regeln) gesprochen.

J) ie Zeit, in der solche Sammschlïge ausgeführt werden, ist nicht gleichgültig. Es empfiehlt sich, wegen der Borlenverwundung die Fällungen 
ummittelhar vor Samenabfall (Nadelhölzer) oder nach demselben (Laubhölzer und Tamnen) vorzunehmen und, wonn möglich, damit eine woitgehende Bodenverwundung zu verbinden.

Die Richtung der s'aumhiebe ist verschieden und hat in Gebirge mit der Exposition zu wechseln. In dor Ebene entscheidet allein die Hauptwindrichtung, gegen welche die Sïume vordringen.

Im Gebirge sind für die Richtung der Saumschläge folgende Gesichtspunkte zu beachten: 1. die Bringung des Materials, welche stets bergabwärts und nie durch eine Verjüngung hindurch ge. führt werden dart', somit immer entweder auf der Kahlfläche oder im geschlossenen Altbestande sich zu bewegen hat. Im letzteren Falle ist es besser, kahle Gassen zu hauen, um den Transport auf einer Bahn zu

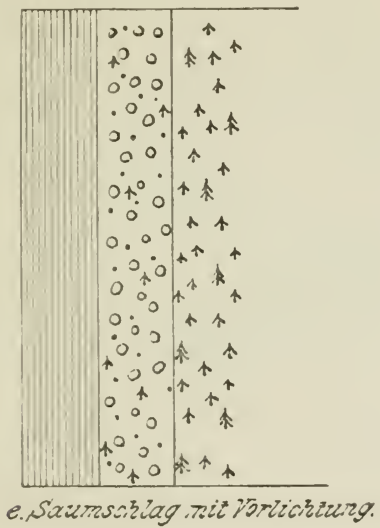

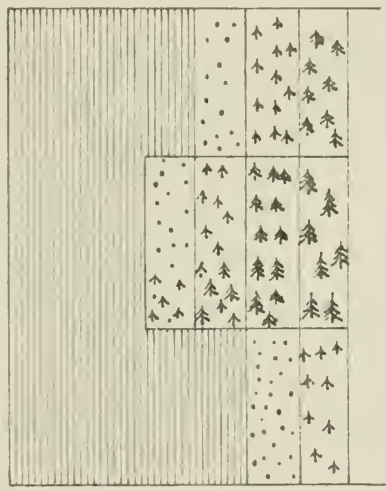

f. Gęezizze suumschiöge.

vereinigen. 2. Die Sturmgefahr besteht anch im Gebirge und zwar auf den dem Winde zugekehrten Bergseiten in verstärktem II $B_{\theta}$ : auf der abgewendeten Seite aber, wo Ïberfallswind von der entgegengesetzten Seite weht, ist diese die gefährliche Windrichtung: in Europa ist somit auf den Westhängen der Wostwind, auf den Osthängen der Ostwind der gefährlichste. Der Terlauf der Febirgszüge

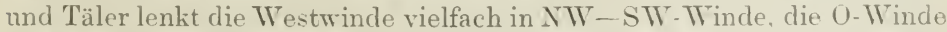
in Nu-SO-Winde ab. 3. Die Sonnenwirkung ist dam allzu stark in Licht und Wärme, wenn die Sonnenstrahlen von einer sichlagwand des stehenden Bestandes zurïckgeworfen werden. Dort herrschen dio heißesten und trockensten Verhältnisse, ähnlich wie bei einer Wand aus Holz oder Stein, welche beim Obstbau für Sjualierzwecke ausgenützt wird: Keimung und Emporkommen von. Jungwuchs ist dort wegen 
der herrschenden Trocknis am schwierigsten; man nennt dies Übersonnung, vielleicht besser $R u ̈ c k s o n n u n g$.

Die Richtung der Saumhiebe und deren Fortschreiten (Hiebszng) veranschaulicht nachstehende Abb. 18, welche einer ausführlichen Beschreibung nicht bedarf. Eine Linie, welche von NW nach SO verlänft, teilt den Berg in zwei Hälften, eine nordöstliche und eine südwestliche; auf der nordöstlichen Hälfto werden die Saumhiebe senkrecht gegen die Horizontalkurven, also im Gefälle abwärts von einer Nordlinie an nach Osten und nach Westen in mit den Horizontalkurven parallelen Hiebszügen weiter geführt; auf der südwestlichen Hälfte lanfen die Saumhiebe den horizontalen Kurven annähernd parallel schief über das Gehänge. Der Hiebszug ist annähernd senkrecht auf

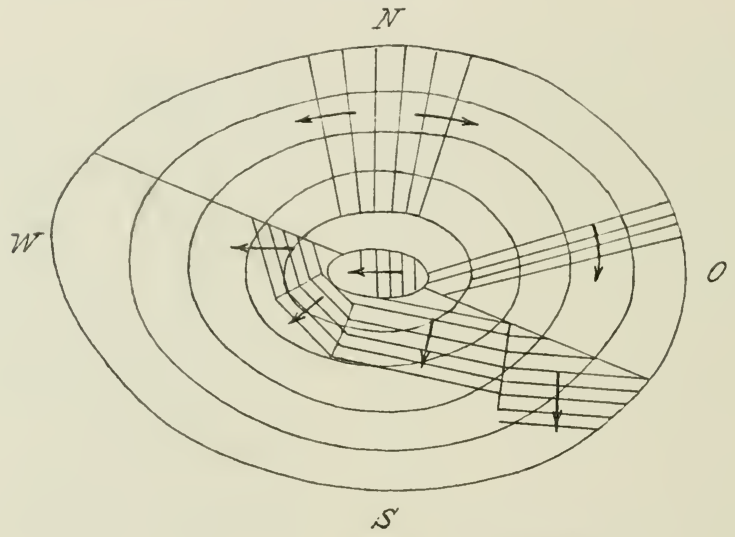

Abb. 18. Richtung der Siamhiebe im Gebirge.

die Horizontalkurven gerichtet. Die Verjüngung beginnt im Plateau, am höchsten Punkt des Berges, nicht an der Talsohle.

Die Breite der Saumhiebe. Ist die Frage der Breite der Saumhiebe von der Holzmenge abhängig, welche gesehlagen werden soll, um den Etat zu erfüllen, so hat die Entscheidung ein waldbauliches Interesse nur insofern, als mit der Entfernung von der Schlagwand die Naturverjüngung immer ungenügender, die künstliche immer sehwieriger werden muf. Soll aber die Saumbreite so eingerichtet werden, daß vom natürlichen Anflng möglicht viel gewonnen wird, so entseheidet über die Breite die bereits behandelte Verbreitungsfähigkeit der Holzart. Die Saumbreite soll die Zone des dichtesten Anfluges in sich sehließen. Wählt man für schwersamige Holzarten die Kahlsehlagsaumverjüngung, so dürfte die Saumbreite $10 \mathrm{~m}$ nicht übersehreiten; bei den Holzarten, welche bis $\mathrm{zu}: 30 \mathrm{~m}$ durchsehnittlich zu schweben imstande sind, wäre 
die Saumbreite mit etwa $25 \mathrm{~m}$ zu begrenzen. Für solche Bäume, welche bis zu $50 \mathrm{~m}$ ihre Sämereien aussenden - hierzu grehören die Mehrzahl der Fichten, die kleinsamigen Föhren, die Lärchen, die Douglasien, Tsugen und viele andere Nadel- und Laubbäume -, so dürfte mit der Saumbreite bis zu zwei Baumhöhen gegangen werden. Jene leichtsamigen Bäume endlich, wie Populus, Betula und andere würden auch noch auf Säumen vou einer Breite gleich drei Baumhöhen sich einfinden können. Es liegt nahe, daß innerhalb eines Waldgebietes, in dem eine bestimmte Holzart mit leichten Sämereien das Übergewicht besitzt, die Säume auch breiter gemacht werden dürfen, wegen der Allgegenwart der Sämereien dieser Holzart. Zur Bekämpfung von Insekten, zum Beispiel des Rüsselläfers, kann es wünschenswert erscheinen, eine unüberbrückbare, pflanzenlose Zone von größerer Breite zwischen Bestand und Verjüngung einzuschalten. Doch führt auch das Entrinden der Stöcke zum Ziele.

Bei einer geregelten Saumhiebswirtschaft sollte ein neuer Saumhieb erst geführt werden, wenn der vorhergehende bestockt ist; wo die natürliche Verjüngung ungenügend erscheint, hat die künstliche ergänzend einzugreifen.

\section{Der kahle Löcherhieb, ringförmiger, kahler Saumschlag.}

Nur bei einer Waldeinteilung in größere Bestandseinheiten kann dieser Hieb eingelegt werden; bei einem Wald, der in Gruppen, Bändern oder Trupps und Einzelstämme, Femelwald anfgeteilt ist, kann der Löcherhieb, welcher ringförmige Erweiterung verlangt, überhaupt nicht durchgeführt werden. Es können die Gruppen, Bänder oder Trupps zwar kahl geschlagen, aber nicht vergrößert werden. Der Löcherhieb schafft Bedingungen, unter welchen der Anflug von Sämereien von allen Seiten, somit am vollkommensten erfolgen muß; aus ihm geht eine Verjüngung des Bestandes in Gruppen von verschiedenem Alter und Höhenwuchs hervor, welche allmählich durch den ringförmigen Saumhieb zusammenfließen soll. Was die Anlage der Löcher und Ausführung der Saumhiebe anlangt, so wäre folgendes festzustellen. Die Anlage der Löcher erfolgt, nachdem die bei allen Hieben rorausgehenden Musterungen der Schlußdurchbrechungen und der Torwüchse sowie ihre Behandlung erledigt sind: 1. Unter Benutzung vorhandener Schlußdurchbrechungen; sind solche Stellen verunkrautet, so werden sie entweder überhaupt nicht benutzt oder entsprechend ausgeformt und sofort ausgepflanzt. 2. Wo natürliche Durchbrechungen fehlen, werden solche geschatfen durch herausfemeln von sehr starken oder anbrüchigen oder sehr breitkronigen Stämmen und entsprechende Abrundung und Erweiterung der Öff̈nungen. 3. Die Anlage der Löcher beschränkt sich auf das Innere der Bestände, vor allem sind die Sturmränder zu schonen. 4. Die Lücher sind so zu 
mrupuicren, daß sie besonders in ihren Erweiterungen den Holztransport. nicht beeinträchtigen. 5. Der I)urchmesser solcher kahler Löcher sowie die Breite der folgenden Säume wechselt mit der Holzart: für Schatten ertragende und Schutz verlangende Arten müssen die Durchmesser kleiner sein als für Licht verlangende und Schutz abweisende Holzarten, wic aus den später zu berührenden Beispielon ersehen werden möge. i. Beseitigung der lockeren Bodendecke, Streu, Moos und andere Arten von Bodenverwundungen fördern die Ansiedelung von Jungwuchs. 7. 1)ie kahlen Umsäumungshiebe werden erst geführt, wemn das Yentrum bzw. der vorhergehende Sammhieb mit Jugend bedeckt ist. \&. Nur bei einer sturmfesten IIolzart oder in einer sturmgesicherten Lage oder nach vorheriger Erziehung eines Bestandes zur Verjüngung und Sturmfestigheit ist es möglich, einen Großbestand oder auch einen Kleinbestand durch ringtörmige Kahlhiebe so weit zu verjüngen, daß die letzten Ringsammiebe die Bestandsränder treftien, welche kïinstlich in Bestand gebracht werden müssen. Wo diese Toraussetzungen nicht gegeben sind, wird vom Löcherhieb zum saumweisen Kahlschlag übergegangen wer den müssen. 9. Die am stärksten besonnten Binnewränder der Löcher, die Nord- und Nordostränder bleiben, da wasserärmer, in der Besamung und im Wachstum der Jungwïchse gegenüber den im Schatten liegenden, feuchteren und günstigeren südund Westrändern zurück. Dadurch nimmt die ursprïngliche Kreisform des kahlen Löcherhiebes allmählich bei den weiteren, kahlen Ringsaumhieben eine eiförmige, schließlich sackförmige Gestalt an: es ist wesentlich, das Streben der Natur nach Ausdehnung der Besamung in einer bestimmten Richtung möglichst durch Ausformung der Kahlsaumschläge zu unterstützen; wie die klimatischen Unterschiede der Binnemränder des Löcherhiebes können auch Bodenverhältnisse das ungleiche Fortschreiten der Naturverjüngung in Buchten nach verschiedener Richtung hin veranlassen.

Mischbestände.

Soll ein aus zwei oder mehreren Holzarten gemischter Bestand im Kahlschlag anf natürlichem Wege verjüngt werden, so ist zu beachten, daß jede Holzart verschieden ausgerïstet ist für die Zweclie der passendsten Ansiedelung auf einer Kahlfäche. Es wurde bereits früher lei den naturgesetzlichen (irundlagen errïhnt, daß für die Ausbreitung einer Holzart ihr Samenerträgnis in Menge und Häufigkeit, die Schwebetähigkeit der Sämereien, die Getahren bei der Keimung, ihr Schatten(rträgnis, šchntzbedürfnis, Ansprüche an Boden, Klima, W̛chsgeschwindi@keit morl andere während der ersten und der späteren .Jahre entscheidend sind, daß alle diese Dinge dem Wirtschafter bekannt sein müssen, wenn or im voraus entscheiden will, welehe Holzart in einer Mischung der anderen gegenüber im Vorteile ist; es wird sich ergeben, daß für den 
betreffenden Standort eine Holzart waldbauschwach, eine andere waldbanstark ist; daß aber mit dem standortwechsel ein Wechsel in diesem gegenseitigen Verhältris eintreten kann. Der oberste Grundsatz aller Verjüngungstätigkeit im Mischbestande mit der Absicht der Erhaltung der Mischung wird daher sein müssen: die möglichste Unterstützung der waldbauschwachen Holzarten durch die Wahl der Wirtschaftsmethode sowohl bei den Kahlschlägen als auch bei den Schimschlagformen. Als waldbauschwächere Holzart ist in einer Mischung von Schattenholzarten unter sich oder von Lichtholzarten unter sich jene Art anzusprechen, welche in der Iugend an empfindlichsten gegen verspätete Fröste, somit am sehutzberlürftigsten ist, jene, welche in der Jugend langsamer wächst, welche höheren Anspruch an die Bodengüte erhebt, welche zahlreicheren Feinden bei der Keimung und weiteren Entwicklung ausgesetzt ist. So haben sich z. B. alle Tannenarten (Gattung Abies) waldbanschwächer erwiesen als die Angehörigen der Gattung Picea, der Fichtenarten; bei einer Mischung von Psendotsuga und Picea wird im luftfenchten, wärmeren Tiefland (warmes Fagetum) Picea die schwächere, Pseudotsuga, weil im Optimum, die stärkere sein: bei einer Mischung derselben Arten im Picetum selbst wird die Pseudotsuga die schwächere, Picea, weil im Optimum, die stärkere sein: bei einer Mischung Taxus mit einer anderen Schattenholzart werden die Eiben stets die schwächeren sein; bei Lichtholzartenmischungen werden die schwersamigeren die schwachen sein, z. B. die winterkahlen Eichen gegenüber den zwei- oder dreinadeligen Föhren: die Gattung Lärche wird schwächer sein als die Föhre, die Fölıre schwächer als die Birke.

Werden nun gemischte Bestände im Großflächenkahlschlag angogriffen, so erscheinen auf der Kahlfläche von den Holzarten des angrenzenden Anßenrandes des Mischholzbestandes in der ersten Generation noch fast alle, jedoch in einem anderen Verhältnis, als sie im Mutterbestand rorhanden waren; in der zweiten Kahlschlagsgeneration ans Naturverjüngung hervorgegangen, ist in der Regel der reine Bestand der waldbaulich stärksten Holzart an die Stelle des Mischwuchses getreten; auch der Kleinbestand im Kahlschlag mit Naturbesamung nähert sich mit denselben ungünstigen Ergehnissen dor großen Kahlfläche. Nur auf der minimalen Fläche des Kleinhestandes von 0,3 ha liegen die Aussichten für eine Erhaltung der Misehumg günstiger.

Bei den kahlen Saumhieben mit natürlicher Seitenbesamung stehen dem Wirtschafter bereits Mittel zur Verfügung, das Verhältnis der Artmischung im Jungwuchse zu erhalten, indem die Breite der Saumschläge und ihre Fortsetzung sich nach der waldbanlich schwächeren Ifolzart richten; dazu kommt zur Unterstiitzung der schwächeren Holzart die Schädigung der stärkeren durch vorherige Fällungen im Bestande. Im kahlen Löcher- 
hieb, der ja überhaupt zur möglichsten Ausnützung der natürlichen Ansiedelung der Holzarten geführt wird, ist in dem Durchmesser der geführten Kahlhiebsfläche und in der Breite der darauffolgenden Kahlsäume ein Mittel gelegen, um der waldbaulich schwächeren Holzart die Erreichung des ihr zugebilligten standrames auf der Kahlfläche zu sichern.

\section{Die natürliche Verjüngung bei den Schirmschlagwirtschaften, Naturverjüngung unter Schirm, natürliche Verjüngung im engeren Sinne.}

Reinbestände.

Zu den wichtigsten Gründen für die künstliche Wiederverjüngung zählt die mleugbare Tatsache, daß sie für die weitaus größte Zahl der Kulturwaldungen und ihrer Bestände nicht nur schneller, sondern a ueh sicherer und leichter als die natürliche ist. Es muß oberster Leitsatz einer jeden Wirtschaft sein, jene Verjüngungsform zu wählen, welche am leichtesten, schnellsten und sichersten zum Ziele führt, wenn der Wirtschafter Beständen gegenübergestellt wird, welche ihre beste Verjüngungszeit überschritten, zu alt geworden, welche zu lange im Schluß gestanden und ihren mineralischen Boden mit einer Auflagerung von Rohhumus verdeckt haben, oder welche längst durch. löchert und in diesen Stellen durch Unkrautwuchs verwildert sind. Für solche Bestände kann der Forderung: schnell, sicher und leicht, nur auf dem Wege einer künstlichen Terjüngung Genüge geleistet werden. Wenn es aber dem Wirtschafter möglich ist, Bestände so zu erziehen, daß die natürliche Wiederverjüngung des betreffenden Objehtes ebenso leicht, ebenso sicher, ebenso schnell durchzuführen ist wie die künstliche, dann ist die natürliche Wiederverjüngung allein die berechtigte, wegen der zahlreichen Wohltaten, die diese Verjüngung dem Boden und der .Jugend gewährt, wegen der Kostenersparnis.

Daß die natürliche Verjüngung auf der $\mathrm{K}$ a h $\mathrm{l} \mathrm{fl}$ ä c he die schlimmsten Nachteile der kahlen Fläche der Freilage nicht zu umgehen vermag. wurde vorhin guzeigt. Ausschließlich der Naturverjüngung unter Schirm kommen alle Vorzüge, aber auch alle Nachteile der Naturverjüngung zu. Über die Ausnützung dieser Vorzüge aber entscheiden bei dieser eigentlichen Naturverjüngung drei Falitoren: 1. Die Verfassung des Bestandes und seines Bodenzustanles; 2. die Gunst des Klimas überhaupt und der Witterung während der Verjüngungsperiode, 3. die Geschicklichkeit des Wirtschafters.

Was den ersten Punkt, die Verfassung des Bestandes und den Boden. anlangt, so trägt diese in ihrer Ungunst in den Kulturwaldungen Mitteleuropas in erster Linie die Schuld, wemn eine Naturverjüngung mißlingt, ja wemn sie von Anfang an als unbrauchbar und mrentabel betrachtet werden muß weil es in der Tat unmöglich ist, 
solche Bestände, wic sie gegenwärtig erzogen werden, bis sie das Schiebfach des Forsteinrichters verlassen und in Verjüngung mit festgelegter $/ /$ it eintreten dürfen, entweder überhaupt natürlich zu verjüngen oder die Naturverjüngung so durchzuführen, daß sie nschnell, sicher, leicht" ist. Die gegenwärtig erwachsenen und erwachsenden Bestände sind in der crdrückenden Mehrheit nach dem Frundsatze der Erhaltung des Bestandsschlnsses crzogen; die Durchforstungen und Durchlichtungen, entsprechend der fortgeschrittenen Erkenntnis der Naturgesetze im Walde, stehen heute noch zumeist auf dem Papier oder werden als praktische Versuche eines theoretischen Gedankens vereinzelt geduldet. Man beklagt es seit einem Jahrhundert, daß die Natur der Lichtholzarten das Prinzip der Erhaltung des Bestandschlusses schon im Stangenalter durchkreuzt, und lobt die Schattenholzarten, die dieser Behandlung sich fügen, soweit nicht die Natur durch Ereignisse, Unglücksfälle genannt, zum Protest gegen die unnatürliche Behandlung auch hier dazwischen fährt und die Bestände auflockert. Nach diesem Grundsatz erhält der Wirtschafter Bestände zur Verjüngung überwiesen, welche entweder noch voll geschlossen mit hinderlichen Rohhumusmassen bedeckt, oder von der Natur nach ihrem Gutdünken durchlöchert, bald verwildert, bald mit unbrauchbarem Vorwuchs versehen und nur selten in einer Verfassung sind, welche die Durchführung einer Naturverjüngung und dann nur auf langem Wege gewährleistet. Soll daher hierin von Grund aus geholfen werden, dann muß das bisherige Prinzip der Erziehung der Bestände verlassen werden: die Erziehung muß den Zweck der Nutzholzzucht wie jenem der Verjüngung gleich dienstbar sein; nur auf solchem Wege gelangen die Bestände in eine Verfassung, welche ihre Naturverjüngung nach dem Grundsatze: nschnell, leicht und sicher ${ }^{*}$ gewährleistet und überdies gestattet, die Umtriebszeit, die vielfach noch zu hoch erscheint, ohne Schaden, ja zum Gewinn für die Bäume, für Boden und Rente herabzusetzen.

Der zweite Punkt, die Abhängigkeit der Naturverjüngung von der Gunst des Klimas und der Witterung während des Verjüngungszeitraumes, ist bereits so ausführlich früher behandelt worden, daß hier der Hinweis genügt, daß die Witterung während der Verjüngungsperiode durchaus nicht nach dem Durchschnitt des Klimas, wie er für die betreffende Landschaft nach den Beobachtungen berechnet ist, sich abspielt. Die Zusammenrechmung von Perioden mit trockenem, heifem Sommer und solchen mit feuchtem, kïhlem Sommer zu einem milden, mittleren Durchschnitt ergibt ein Klima, das sehr oft in der Natur gar nicht besteht. Fällt eine Verjüngung in eine feuchte Periode, ist alles erleichtert und gelingt alles überraschend; fällt sie in eine Trockenperiode, die oft zwei, ja dreimal sich wiederholen kann, verunglïckt dic Verjüngung trotz aller Geschicklichkeit und 
Bemühung des Wirtschafters. Dieser letztere Punlit, die Gieschicklichlieit des Wirtschafters, ist türs Gelingen oder Mißlingen einer Naturverjüngmug mit entscheidend, aber doch nur selten allein entscheidend. wenn sie gelingt, und allein entscheidend, wemn sie mif., lingt. Viel häufiger ist die Weigerung des Wirtschatters, überhaupt eine Naturverjüngung zu versuchen. Wie sehr diese Weigerung berechtigt ist und durch die unnatürliche Verfassung der zur Terjüngung kommenden Bestände gestützt wird, wurde oben und früher bereits ausgeführt. Fs sei anderen dio Entscheidung darüber ïberlassen, oh es Praktiker gibt, welche aus Bequemlichkeit oder aus Unkenntnis oder aus Vorurteil oder aus Angst, es liönnte das Mißlingen allein ihnen auf das Konto geschrieben werden, jede Naturverjüngung prinzipiell ablehnen. Wer auf Naturverjüngung nur deshalb verzichtet, weil sie umständlicher, schwieriger, für den Wirtschafter zeitraubender ist, der handelt nu folgerichtig, wenn er die leichtere und einfachere, künstliche Verjüngung seinen Untergebenen ïberläßt, welche in liürzester Zeit nach den Wïnschen des Wirtschafters vedrillt werden können. Wer aber so handelt, der gibt die schönste, seiner Torbildung würdigste Autgabe seines Berufes im Walde, die Beobachtung der ewigen Naturgesetze und ihre Vereinigung mit seiner Geistesarbeit zur Begründung und Erziehung des Waldes hinweg in die Hand der Untergebenen, wo die freie Handlung nach Naturgesetzen und eigenen Gedankien zur einfachen Maschine wird; so bleibt allerdings dem Forstmann viel Zeit zu anderen Dingen, die seine Eigenschaft als Beamter und als Jäger beanspruchen auf Kosten des Wirtschafters, entgegen dem Ideal des forstlichen Berut's, welcher in diesen drei Beschäftigungen den Wirtschafter an die Spitze stellt.

\section{Die Erziehungsverjüngung.}

Verfasser hat unter den Wirtschaftsmethoden diese Form aufgefïhrt, weil sie eine grundlegende Umgestaltumg des Waldes in seiner Verjüngung und seiner Erziehung bedentet; sie erscheint für jede Bestandesgröße, jede Bestandesart, in jedem Klima anwendbar und empfehlenswert. Die Erzichungsgrundzïge, uber welche im dritten Teile ausführlicher gesprochen werden mul., lanten: Intensivere schlagund Dickungspflege; Ruhe für den Bestand während des Kronenschlusises und der Abstoßung der Seitenäste; Durehforstung und allmähliche Durchlichtung der Licht- und Schattenholzbestände unter prinzipieller Beseitigung alles Unterdrückten; Unterbau mit einer Laubholzschattenart bzw. Halbschattenart Mit der Annäherung an das Baumalter und die Maubarkeit verstärken sich die 1)urchlichtungen, so daß schließlich nur die besten Nutzholzstämme zum vollen Genuß des Freistandes und der Samenbildung gelangen, während der Unterstand für Bodenschutz sorgt. Bei dex num folgenden Naturverjüngung 
unter Schirm, einem Dunkelschlag ins Volle mit nur zwei Hiohen, werden schatten- und Lichtholzarten gleich hehandelt. Es erfolgt im Jahre der Samenbildung der Schirmbäume mmittellar vor, hesser nach Abtall des Samens, je nach Art die volle oller teilweise Beseitigung des Unterbaues unter gleichzeitiger Beseitigung etwa der Hälfte der S'hirmbäume; eine intensive Bodenverwundung durch Unterbaurodung oder auch durch Instrumente bereitet den Boden für die Aufuahme der Sämereien vor, bzw. bringt die gefallenen Sämereien unter. Nach 3-4 Jahreı fällt, wenn möglich bei Schneelage, der Rest des Schirmbestandes in einem oder zwei Hieben, gleichgïltig, ob die Verjüngung ganz oder nur teilweise oder gar nicht gelungen ist. Das Fellende wird auf künstlichem Wege durch Pflanzung ergänzt und zwar mit starken Pflanzen nach den später gegebenen Andeutungen. Wenn der verschonte, schützende Teil des Unterbaues entbehrlich geworden ist, wird er beseitigt. Diese Naturverjüngungsform dürfte den Forderungen schnell, leicht and sicher voll entsprechen; sie ist schnell, denn sie vollzieht sich in wenigen Jahren; sie ist leicht, denn die Hauptarbeit der Verjüngung fällt hier der Erziehung zu, welehe zugleich den Nutzzwecken gerecht wird: sie ist sicher vor allem deshalb, weil eine halbe Umtriebszeit hindurch die Nutter- und Nutzbäume an den Freistand gewöhnt wurden. Eine besondere Rücksichtnahme auf die Windriehtung ist entbehrlieh.

Daß diese Verjüngung für alle jetzt haubaren oder innerhalb der näehsten 30 Jahre haubar werdenden Bestände unmöglich ist, liegt in der bisherigen Erziehung dieser Bestände begründet.

Für alle gegenwärtig haubaren Bestände und solche. welche in den nächsten .Jahrzehnten zum Hiebe kommen, bleibt die Naturverjüngung unter Schirm überhaupt ein Versuch, der rasch, sicher und leicht zum Ziele führen kann; es gibt viele Beispiele, welche die Richtigkeit dieser Behauptung bestätigen; noch mehr Beispiele aber bezeugen die Schwierigkeit und Langsamkeit der Naturverjüngung, und die meisten beweisen, daß sie besser unterblieben wäre. Es wäre aber irrig, auf Grund dieser Statistik auf eine Naturverjüngung unserer heutigen Bestände ïberhaupt verzichten zu wollen. Die folgenden Darstellungen beabsichtigen, die Zahl der Versuche der ersten Art zu vermehren, jene der zweiten Art durch Beschleunigung und Erleichterung der Verjüngung zu verbessern und jene der dritten Art ganz aus dem Walde zu schatfen.

\section{Der Dunkelschlag.}

Der Dunkelschlag ${ }^{1}$ ) hat schon ror mehr als lnundert Jahren auf größeren Flächen Anwendung gefunden und bei der damals herrschenden

1) Leider wird die Dunkelschlagverjungung auch Plenterverjungung genannt, obwohl sie vou der Verjungung des Plenterwaldes grundverschieden ist. 
Ansicht, daß die Buche als wichtigste Brennholzart den größten Anteil an der ' /usammensetzung des Waldes zugewiesen erhalten müsse, hat der Dunkelschlag an ihr eine Verfeinerung erfahren, wie sie heute noch vorbildlich ist. Im Laufe des vergangenen Jahrhunderts fand dann die I) unkelschlagwirtschaft auch auf andere Schatten-, selbst auf Lichtholzarten teils naturgemäße, teils naturwidrige Anwendung. Der Dunkelschlag kann entweder auf die ganze Bestandsfläche zugleich sich erstrecken, oder bei großen Beständen nur auf Teile desselben, oder er schreitet saumweise fort, oder er beginnt von zahlreichen Zentren aus und erweitert sich mit ringförmigen Schirmschlägen; danach unterscheidet man wiederum bestands-oder fläehenweisen Dunkelschlag, sodann saumweisen Dunkelschlag oder saum weisen Sehirmschlag, and endlich ringförmigen Dunkelschlag, auch Gruppenschirmschlag im Sinne Gayers, auch Femelschlag genannt.

\section{Dunkelschlag auf größeren Flächen.}

Zu der bereits auf Seite 258 gegebenen allgemeinen Charakteristik dieser Wirtschaftsform bedarf es hier nur weniger Ergänzungen.

Der Vorhieb. Die Bestände, welche bis zur Annäherung an die Nutzungen nach dem herrschenden Durchforstungsprinzip mit ängstlicher Erhaltung des Bestandsschlusses erzogen wurden, beherbergen noch eine Menge Material, das, obwohl hauptständig, in seiner verpeitschten Krone für die Verjüngung keinen Wert besitzt. Der Vor hi eb, der 10-15 Jahre vor dem ersten eigentlichen Angriffshiebe eingelegt werden soll, nimmt nur solehes Material hinweg, das eigentlich längst den Erziehungshieben hätte zum Opfer fallen sollen; er beseitigt unterdrückte, mit den Kronen eingeklemmte Stämme, setzt aber dann 10-15 Jahre aus, damit der Bestand sich wieder schließt.

Wie der Vorhieb, ist auch der Vorbereitungshieb bestimmt, die Folgen einer langen, fehlerhaften Erziehung in Stamm und Boden auf langem Wege wieder gut zu machen und den Bestand, wenn möglich, noch in eine Verfassung zu bringen, daß er auf natürlichem Wege verjüngt werden kann.

Der Vorbereitungshieb ist so gedacht, daß seine Wirkung 5-10) Jahre danert, ehe der eigentliche Verjüngungshieb für die $\mathrm{Be}$ samung einsetzt; er heift Vorbereitungshieb, da die Vorbereitung des Bestandes und des Bodens für die Naturbesamung beabsichtigt ist. Der Vorbereitungshieb durehbricht zu diesem Ende das Kronendach endgültig, in dem er ein Drittel bis zur. Hälfte der stehenden Stämme hinwegnimmt, in erster Linie schwach bekronte, oder sehr starke, sehr breitkronige, kranke Stämme. Lieser Freihieb der best bekronten Bäume regt sie zum Samenerträgnis an, und das einfallende Licht mit der durch Erwärmung und Abkühlung erzeugten Luftbewegung und 
Sauerstoff'erneuerung, mit erhölter Oberflächenbef'euchtung beschleunigt die Verwitterung der angehäuften Laub- und Nadelabfällo; der entsïterto und verwitternde Rohhumus zerstört den Moosüberzug, bis sich jene Bodengare einstellt, bei welcher die ersten Spuron einer Verunkrautung erscheinen. Dieser Zustand gilt in der Praxis als jener der besten Empfänglichkeit für Sämereien. Um dieses Ziel zu erreichen, stellt der Dunkelhieb die Aufgabe, den Vorbereitungshieb so zu führen, daß die bleibenden Stämme eine gleichmäßige Schirmstellung ïber die ganze Fläche hin bilden. Diese Forderung wird noch besonders erschwert durch den Zusatz, daß die Schirmstellung möglichst aus den bestbekronten Stämmen, welche voraussichtlich den reichlichsten Samen hervorbringen werden, gebildet sein müssen.

Dadurch wurde und wird noch hente der Vorbereitungshieb zu einer schwierigen Aufgabe des Dunkelschlags; denn wie früher fast alle, sind noch heute viele der haubaren Bestände aus der ungleichmäßigsten aller Wirtschaftsformen, dem Eemelhieb, und zwar in seiner willkürlichsten Ausführung, hervorgegangen; überdies strebt die Natur, die Gleichmäßigkeit bei der Entwicklung eines Bestandes möglichst zu durchkreuzen; rechnet man hierzu die zahlreichen Unfälle, welche den Bestand in seinem hohen Alter bereits durehlöchert haben, so ist die gleichmälige Schirmstellung des Vorbereitungshiebes zum Zweck der Erzielung einer gleichmäßigen Verjüngung eine kaum durchführbare, weil naturwidrige. Gerade bei Ausdehnung des Hiebes über größere Flächen hin ist durch die Forderung der Gleichmäßigkeit den überall vorhandenen Ungleichmäßigkeiten im Bestand und Boden keine Rech. nung getragen. Soll aber die Verjüngung eine gleichmäßige sein, so kann dies somit nur durch eine ungleic hmäßige Schirmstellung geschehen. Die Verjüngungsergebnisse der gleichmäßigen Schirmstellung sind daher auch meist eine ungleichmäßige Besamung; nur eine Vollmast gleicht alle Fehler aus.

Der Besamuingshieb. Der programmäßige Eintritt dieses Hiebes soll $5-10$.Jahre nach dem Vorbereitungshieb erfolgen; ist aber die Natur nicht folgsam gewesen, d. h. hat sie schon nach 5 Jahren oder erst nach 10 Jahren den Bestand mit einem ergiebigen Samenjahr bedacht, so ist die Zeit der besten Aussichten in dem einen Fall noch nicht gekommen, d. h. der Boden ist noch nicht genügend empfänglich; im zweiten Falle beginnt bereits die Verunkrautung. Kommt aber das Samenjahr zur gewünschten Zeit, so muß es überdies sehr reichlich Samen bringen, damit die ganze Fläche bestellt wird; mit Sprengsaat ist nur wenig gedient, denn aus ihr geht eo ipso eine ungleichmäßige, unvollkommene Bestockung der ganzen Fläche hervor. Fällt aber eine Vollsaat zur rechten Zeit ein, dann ist es nötig, den Besamungshieb zul führen.

I ay r, Waldbau. 
Dieser Hieb kann nun vor oder nach Eintritt des Samenjahres zum Tollzug kommen; die I)urehfülnumg vor der Besamung setzt die Sicherheit des Eintrittes der vollen Besamung voraus. Soll der Hieb noch vor der Blüte der Bäume zur Ausfülhrung gelangen, so muß der Wirtschatter es verstehen, die Kennzeichen für das liommende Samenjalır zu deuten. Er findet aber nur die Anzeichen tüur das kommende Blütenjahr in den dickeren Knospen; ob aber aus den Blüten auch Frïchte und Sämereien werden, das kann er nicht wissen, dem dies hängt von der kommenden Witterung ab; die Witterung aber füir mehrere Monate vorauszusagen, ist heutzutage noch ein Ding der Unmöglichkeit. Ist aber der Besamungshieb geführt, und fällt der Same mangelhaft oder ganz aus, so ist es um die natürliche Terjüngung des Bestandes meistens geschehen. Die beste Zeit der Führung des Besamungshiebes ist daher ummittelbar die Zeit nach der Reife des Samens, vor Abfall, am besten zur Zeit des Abtalles oder nach Abfall bis zur Keimung. Dieser Hieb beseitigt 50-75\% der ursprünglichen Stammzahl, wobei vorzugsweise auf die stärksten Stämme gegriften wird. Der Grad der hierbei geforderten, gleichmäßigen Überschirmung richtet sich nach dem Lichtbedürfnis der zu erwartenden Pflanzen während der ersten .Jahre ihres jungen Lebens.

Unter dem Namen Lichthiebe" wird eine Gruppe von Hieben zusammengefaßt, welche dem jeweiligen Lichtbedürfuis der aufwachsenden .Jugend dienen. Wie viele solcher Lichthiebe bis zum letzten Hieb, dem Endhieb, nötig sind, hängt von den verschiedensten Umständen ab. Das Wichtigste hierüber ist unter dem Teil ..Gang der natürlichen IViederverjüngung " bereits erörtert.

Die vor dem Endhieb liegende Gruppe von Hieben hat man noch einmal eigens zusammengefaßt als sogenannte "Nachhiebe". Waldbaulich haben diese Bezeichmugen kein Interesse. Die Hiebe sind alle nichts anderes als Lichthiebe bis zum Endhieb; die Bezeichnung ist von der Forsteinrichtung gegeben. Aber aus diesem Bedürfnis nach Bezeichnungen kamn geschlossen werden, wie überaus schleppend die Verjüngung gefühnt wurde und noch heute wird, bis endlich die fortgesetzte Belästigung der Jugend mit dem "Endliebe" endet.

Schon aus dem Wesen dieser Wirtschaftsform ergibt sich, daß der ganze Erfolg von dem rechtzeitigen Eintritt eines ergiebigen Samenjahres abhängt. 'Triflt dieses $z u$, so liann die Saat dennoch mißlingen, wenn die Sehirmstellung zu licht oder zu dunkel war, wem der Boden nicht gleichmäßig gut, wenn der alte Bestand künstlich in einer (Ortlichkeit angelegt wurde, welche klimatiseh allzu weit ron dem Klima der Heimat der Holzart sich entfernt. Dazu kommen die Jugend zerstörende oder schädigende klimatische, tierische und pflanzliche Einflüsse. Dieses alles erklärt, warum aus dem Dunkelhieb ganz vorzügliche, aber auch ganz mangelhatte Verjüngungen hervorgegangen 
sind und noch hervorgehen. Nur allzu hänfig war und ist noch heute in der Praxis in Übung, durch Korrekturen der Schirmstellung tür eine neve Besamung günstigere Verhältnisse zu schaffen; aber finst alle diese Versuche enden mit der Verwilderung der Bodenoberfläche; Windbrüche durchlöchern die Stellung. Frost- und Unkrautwuchs nehmen iiberhand. Man hilft wich schlieflich mit der Ausformung etwa vorhandener oder geschlossener Partien oder Gruppen: auf der ïbrigen Fläche aber gibt man nach vielen Jahren schwerer Verluste die Naturverjüngung für rerloren und geht üher zum kahlen Saumhiebe mit daraut folgender Ptlanzung. Es muß hinzugefügt werden, daß es vielfach beim Dunkelschlag, besonders bei Fichten, nicht bis zum Besamungshiebe gekommen ist, weil Sturm die gleichmäßige Vorbereitungsstellung gleichmäbig niederlegte. Eine solche Verjüngung kann somit nur für sturmfeste Holzarten oder für sturmschwache nur in sturmgesicherten Lagen, wie sie besonders Gebirge bieten, gewählt werden. Es darf auch nicht rerhehlt werden, daß gewisse Insekten, besonders Stöcke bewohnende Rüßler, durch diese zerstrenten Fällungen, bei denen die Stöcke nicht gerodet werden können, fortgesetzt Brutstätten finden: durch möglichst tiefgehendes Entrinden kann freilich diese Gefahr etwas gemindert werden.

\section{Der saumweise Dunkelschlag.}

Um der Sturmgefahr entgegenzuarbeiten, werden die Hiebe des Dunkelschlags in Säumen geführt, welche im 0 oder $N 0$ des Bestandes mit einer ron $\mathrm{NW}$ nach $\mathrm{SU}$ oder von $\mathrm{N}$ nach $\mathrm{S}$ verlanfenden Wand einsetzen. Dieses gilt für solche Örtlichkeiten (z. B. Mitteleuropa), in welchen Westwinde die herrschenden sind. Schematisch könnte man sich das Terfahren derart denken, daß ein neuer Torbereitungssaum (I) eingelegt wird, wenn der rorausgehende Saum aus dem Vorbereitungsstadium in das Besamungsstadium (II) eintritt; der nächste Vorbereitungssaumbieb würde sich anschliefen, wenn der vorhergehende zum Besamungshiebe, der diesem vorhergehende zum Lichthiebe wird usw. (Fig. 14). In der Natur wird sich der Terjüngungsgang mit einer solchen RegelmäBigkeit schon deshalb nicht abspielen können, weil die einzelnen Hiebe nicht durch gleiche Zeiträume voneinander getrennt sind, sondern vielmehr nach Bodenzustand, Samenerträgnis und Licht- und Schutzbedürfnis der Holzart fortschreiten müssen. Es wird wünschenswert sein, solche säume so viel als möglich aufzuteilen oder zu brechen und jerlen Teil für sich in Betrieb zu nehmen. Hierauf sowie bezüglich der Richtung der saumschläge in der Ebene, ihre Drehung im Grebirge, bezüglich der Ausgestaltung und Fortführung der Saumwände wird auf die Ausführungen beim kahlen Saumschlag verwiesen werden kïnnen (S. 30!!). 
Die Vorteile der saumweisen Dunkelschläge sind erkauft mit dem Nachteile des langsameren Verjüngmussganges. Bei großen Beständen wird sich emptehlen, mehrere solche saumschlïge kulissenartig einzulegen. Auch hier gilt die Weisung, die Lichtungshiebe möglichst schonend (bei Schneelage) zu führen und in ihrer Zahl einzunchränken, um der Verjüngung die so wohltätige Ruhe zu geben. Man kann auch über den ganzen Bestand den Vorhieb führen. unmittelbar darauf die Aufteilung des Bestandes in vier Säume von gleicher Bieite vornchmen und mit dem Vorbereitungshieb auf dem ersten Saum im Osten beginnen: alle fünf Jahre wenigstens wird ein neuer Saum vom Vorbereitungshieb getroffen; über dem Saume selbst spielt sich die Verjüngung nach dem Bedürfnis von Klima, Boden und Holzart ab; es würde somit nach 15 Jahren der Westsaum in Vorbereitungsstellung gebracht; man darf erwarten, daß inzwischen der erste Samm am Ostrand bereits verjüngt ist. Ist die Windgefahr groß, mag der Samm am Westrand ganz unberührt bleiben, bis die ganze nach Osten anliegende Fläche verjüngt ist.

\section{Schirmverjüngung mit Hieb ins Volle sowohl auf größeren Flächenteilen eines Be- standes als in Säumen; im letzteren Falle ist die saumweise Schirmverjüngung mit Hieb ins Volle auch als abgekürzter, saumweiser Dunkelschlag zu bezeichnen.}

Diese Formen dienen zur Beschlemnigung der Naturverjüngung unter Schirm derart, dal., statt Torbereitungs- und Besamungshieb nur letzterer geführt wird, dat. die Lichthiebe sich auf wenige beschränken, um möglichst bald den Endhieb folgen zu lassen; sie setzen Bestände voraus, welche bereits mit einer Lichtstellung der Kronen den Beginn der Verunkrautung, somit die beste Empfänglichkeit für die Sämereien verraten; sie setzen weiter voraus, daß durch vorliegende Berge oder den vorliegenden Bestand oder die Holzart selbst die Sturmgefahr abgeschwächt ist. In saumweiser Anordnung verzögert sich zwar die natürliche Ernenerung eines Bestandes, sie rückt aber mit größerer Stetigkeit und Sicherheit vor. Wird mit der Saumbreite unter einer Baumhöhe verblicben, so erleichtert sich die Verjüngung dadurch, dafs das seitlich in den noch nicht angegriffenen Bestand einströmende Licht vorbereitend für die Empfänglichleit des Bodens einwirkt, so daß dem Iliebe ins Volle eine sofortige Besiedelung mit natürlichem Anwuchse folgt. Trotzdem schreitet diese Verjüngung so langsam vor, daß sie nur als Ergänzung oder in Verbindung mit anderen Wirtsehaftsformen sich rechtfertigen läßt, wie beim bayerischen oder von Huber'schen Verfahren in Verbindung mit dem Gruppenhiebe. 


\section{Der ringförmige Dunkelschlag, Gayers Gruppenschlag, Femelschlag ${ }^{1}$.}

Auch für diese śchirmschlagform gilt der allgemeine (irundsatz, daß bei jeder Art von Verjüngung eines Bestandes, sei sie eine künstliche oder natürliche, als erste Tätigkeit des Wirtschafters die Musterung und Behandlung der Schlußdurchbrechungen, die Musterung und Behandlung der Torwïchse (S. $294 \mathrm{ff}$.) zu gelten hat. Ist dieso Aufgabe erfüllt, so liann, wenn die Zeichen für eine Naturverjüngung überlıaupt güustig gedeutet werden können, zur Anlage mehrerer, 1(1)_-,)(n) qm großer, aunähernd kreisförmiger Schirmflächen geschritten werden. Die günstige Lage sowohl dieser ersten Verjüngungsstellen als ihrer ringförmigen Erweiterungen mitten im geschlossenen Bestande wird es gestatten, daß die Zahl der Dunkelhiebe vermindert, die einzelnen Hiebe selbst durch Beseitigung der starken Stämme verstärkt werden. So wird auf der Anfangsstelle der Vorhieb mit dem Vorbereitungsund Besamungshieb vereinigt werden können. An diesen Hieb schließt sich ein Lichthieb an. dem der Endhieb folgt. Bei den ringförmigen Erweiterungen wird die Zahl der Hiebe weiter sich verringern lassen auf die beiden Hiebe: Besamungshieb, in diesem Falle ${ }_{\pi}$ Rändelhieb* genannt, und Endhieb: ja, es wird selbst der Fall eintreten können, daß statt eines ringförmigen Schirmhiebes ein ebensolcher Kahlhieb (in diesem Falle Umsäumungshieb genannt) sich anschließt.

Die erste Anlage der Verjüngungsgruppe und ihre Verbreiterung sind keine willkürlichen; sie werden bei allen Holzarten unter Beachtung nachfolgender Gesichtspunkte zu geschehen haben:

1. Zahl und Größe der anzulegenden Gruppen richten sich nach der Größe des Bestandes, nach dem allgemeinen Verjüngungszeitraum, in dem es wünschenswert erscheint, die Verjüngung des Bestandes zum Abschluß zu bringen, ferner nach Holzart und Bodenverfassung. Holzarten, welche eines langsameren Verjüngungsganges bedürfen wie die Schattenholzarten, verlangen eine grölere Zahl von Gruppen: für Halbschattenholzarten genügt eine geringere Zahl, für die Lichtholzarten kann eine kleine Zahl von Gruppen größerer Flächenausdehnung. welche rascher in der Verbreiterung fortschreiten, in Aussicht genommen werden.

2. Die Südwest-, West- und Nordwestränder eines Bestandes bleiben von der Anlage verschont, so verführerisch gerade an den westlichen Rändern der Bestände die Verjüngungsbedürftigkeit und -fähigkeit sich zeigen sollten.

3. Bei der Anlage ist Rücksicht auf die Holzabfuhr zu nehmen. so daß diese nicht erschwert wird und die erzielten. Jungwüchse nicht belästigt werden.

$\left.{ }^{1}\right)$ Es ist beklagenswert, $\mathrm{daB}$ auch diese Terjungungsform vielfach, wie alle Schirmverjügungen, einfach "Plenterverjungung" genannt wird. 
4. Als Anfangspunkte der Grippennaturverjüngung werden Bestandspartien mit bester Bodenverfassung (Bodengïte und Bodenoberfläche) oder schon durch Naturereignisse im Bestand vorhandene Löcher mit brauchbarer Naturverjüngung (Verwuchsmusterung und -behandlung nötig) benutzt. Sind mit Unkraut bedeckte Stellen vorhanden, so werden diese sofort ausgepflanzt und ebenfalls als Anfangspunkte der natürlichen Verjüngung mit anschließenden Besamungsringen verwertet.

5. Bezüglich der Größe der ersten Gruppenanlage und ihrer Schirmstellung gilt als Regel: Für Schatten- und Halbschattenholzarten soll bei kleineren Gruppenanlagen (Durchmesser unter Bestandshöhe) eine lichtere Stellung der Althölzer, bei größeren Anlagen (Durchmesser über Bestandshöhe) eine dich tere Stellung derselben, für Lichtholzarten stets eine größere Gruppe (zwei Bestandshöhen und darüber) mit lichterer Stellung der Schirmständer gegeben werden.

6. Bei Schatten- und Halbschattenholzarten soll der Unter- oder Zwischenstand so weit bei dem Besamungshieb verschont werden, daß dadurch eine gleichmäßige, lockere Überschirmung der Flächen erzielt wird; diese gestattet dam eine lockere Stellung der auf der Gruppe stehenden Stämme, und erlaubt, daf nach der Besamung die Althölzer völlig beseitigt werden können und nur noch geringes Gestänge, mag es noch so vom Wind und Schnee hin und her gebogen und häßlich sein, auf der Fläche schützend verbleibt. Dieses aber wird ohne Beschädigung für die jungen Pflanzen entfernt, sobald letztere des Schutzes entbehren können.

7. Jede Gruppe ist für sich nach ihrem speziellen Bedürfnis zu behandeln.

8. Bei allen Hieben sind, wenn irgend möglich, immer zuerst die stärksten Stämme aus der Gruppe hinauszufällen.

!. Es ist selbstrerständlich, daß anch bei der gruppenweisen Naturverjüngung alle Hiebe möglichst bei Schnee und milder Winterwitterung ausgeführt werden.

10. Ist die Verjüngung in dem zuerst begonnenen Kreis zum Abschluf gelangt, so wird sich zeigen, daß der der vollen Besamung ausgesetzte, wasserärmere Nord- und Nordostrand sich weniger vollständig verjüngt hat als der im S'chatten liegende Sürl- und TVestrand. Die Natur zeigt damit die Richtung, nach der die folgenden Ringliebe ansgebaucht werden sollen.

11. Allgemeine Regel ist, dafs ein Ringhieb erst geführt wird, wemn die roransgehende Fläche rerjüngt ist.

12. Je nach Sturmfestigkeit kommt die Erweiterung der Verjüngungsgruppen früher oder später zum Stillstand, worauf zumeist Saumschlag folgt. 
13. Begimnen (impponhiebe und śaumschlägo (kahle oder schirmständigo) gleichzeitig, und schreiten boide in raschem Tempo fort, so ist dieses das bayerische oder von $\Pi$ u berscho Verfaluren, das eine sichere und vielfach auch eine schnelle Verjüngmug erziclt.

Wenn auch der Gang der Gruppenverjüngung im allgemeinen ein langsamer ist und mit der Vergrößermug der Gruppe die Giefahr wächst, daß die zwischenliegenden Bestandsreste dem Winde erliegen, so fehlt es dennoch nicht an Beispielen, daß in dieser Form ganze Bestände völlig kostenlos verjüngt wurden. Dem Dunkelschlag gegenüber besitzt der Gruppenschirmschlag mehrfache Vorzüge; so die Auswahl der bestgeeigneten Örtlichkeit im Bestande für die Verjüngung, die bessere Schonung der Jungwuchsgruppen bei der Fällung der schirmenden Althölzer, größere Sicherheit für den unberührt bleibenden Zwisehenbestand. Nachteilig ist vor allem, daß in die dichten Gruppen schädliche Tiere, besonders Mäuse, sich flüchten, die Fällungen auf zahlreicho Punkte des Bestandes verteilt werden mit allen ungünstigen Begleiterscheinungen eines derartig verzettelten Betriebes.

Es sei noeh angefügt, daß dieser Gruppenschirmschlag auch aus dem Dunkelschlag auf großen Flächen hervorgehen kann, wenn aus den ungleichmäßigen Verjüngungen die bestgelungenen Partien herausgewählt, abgerundet und ringförmig erweitert werden.

\section{Schirmschlag auf der kleinsten Fläche, Femelhieb, Femelwald, Schleichwirtschaft (Plenterwirtschaft), Plenterverjüngung, Verjüngung des Plenterwaldes.}

Jener Plenter- oder Femelhieb, der als Kind der Not in Schutzwaldungen besteht, damit der Boden nicht entblößt, seine Erde nicht abgewaschen, Bergrutschungen, Lawinen ı. dgl. Unfällen vorgebeugt wird, jener Femelhieb, der zu den ältesten Zeiten als erste Art der Benutzung und Naturverjüngung der Wälder bestanden hat, gehört wie der periodische Femelhieb kaum noch zum Waldbau; seine Ausführung ist auch cine solche, daß waldbauliche Kenntnisse nicht beansprucht sind. Jene verfeinerte Form dagegen, welche nicht bloß jeden Stamm zur Zeit seiner höchsten Brauchbarkeit nützt, sondern auch für die Erhaltung des Waldzustandes, seiner Mischung, seiner Altersklassen- und Holzartenverteilung und den raschen, natürlichen Ersatz der Abgänge im Bestande sorgt, nur diese verfeinerte Wirtschaft soll hier mit einigen Worten kurz besprochen werden.

Ein Bestand im Femelbetriebe enthält theoretisch alle Altersklassen in annähernd gleichen Stammzahlen und gleichmäßiger Verteilung; in der Natur wird sich eine solche schachbrettartige Verteilung der verschieden alten stämme nur selten finden. Sio trachtet nach truppweiser Anordnung der Altersklassen als das Ergebnis einer truppweisen Ansaat (Kronenbereich der Samen tragenden Bäumo) und eines platzweisen Wechsels in der Bodenverfassung. Solcho Trupps werden 
auch im Femelwald als Einheit betrachtet, gleich dem einzelnen Stamm. Ein Trupp wird, wenn noch nicht haubar, bei der Erziehung $\mathrm{nicht}$ aufgelöst, und wenn haubar. in allen seinen Stämmen zur Fällung gebracht.

Die Fällungen im Femelwald ergreifen in erster Linie alle rïckgängigen, schadhaften Stämme, die schlecht geformten Stämme jüngeren Alters, wenn Aussicht besteht, daß benachbarte, bessere Stämme dadurch gewinnen. Weitere Fällungsobjekte sind sodann die nicht erwünschten Holzarten und von den Nutzholzarten die besten, stärksten, haubaren Glieder des Bestandes, endlich solche Stämme, gute oder schlechte, welche eine jüngore Baumgruppe oder Jungwuchstrupps allzusehr überschirmen und im Wachstum hemmen. Ub statt der Fällung eine Aufästung am Platze ist, wird ron Fall zu Fall zu entscheiden sein. Auf diese Weise wird der Femelhieb zu einer verfeinerten Arbeit voll von waldbaulichen Problemen, insbesondere, wenn der Betrieb sich in einem aus mehreren Holzarten gemischten Bestande und auf ebenem Gelände bewegt, wo der Ausführung keine Schwierigkeiten entgegenstehen. Daß aber diesem Femelbetrieb schwere Bedenken bezüglich der Nutzholzaustormung, bezüglich der Fällungs- und Transportschwierigkeiten, eine gewaltige Häufung der Arbeitsleistung und andere Nachteile gegenüberstehen, ist bereits in früheren Andeutungen enthalten, ebenso wie die Wahrscheinlichkeit, daf der Femelwald wegen der gründlichsten Ausnützung ron Licht, Wärme, Wasser und Boden die größte Holzmasse, aber nicht bester Güte, in gegebener Zeit innerhalb der Hochwaldungen erzeugt.

Denkt man sich für den ganzen Femelrald die gleich alten Bäume oder Trupps so aneinander gereiht, daß die älteste Reihe im Ostrand haubar ist, wenn am Westrand die jüngste Alterslilasse liegt, so könnte man einen derartigen Bestand auch saumweise nüitzen und verjüngen, wie es Noys Saumfemel und Ringfemel verlangen. Toraussichtlich ginge aber dabei die Naturverjüngung verloren; da die Säume von gleicher Breite wie die Trupps wären, müßte die natürliche Verjüngung gerade an der Stelle (Schlagwand der Reihe) erfolgen, welche nach den früheren Ausführungen die ungünstigste Aussicht für eire Naturverjüngung eröffnet. Denkt man sich die Säume breiter (eine lialbe Baumhöhe bis zu zwei Baumhöhen, auf dem Saume eine schirmständige Naturverjüngung), so entsteht W a gners Blendersaumhieb.

\section{Mischbestände in schirmständiger Naturverjüngung.}

Es muß zugegeben werden, daß die in einem Bestande rorhandene Holzartenmischung am ehesten bei der Terjüngung wieder gewonnen wird, wenn diese unter Schirm erfolgt; es darf aber bezweifelt werden, ob diese Verjüngung eine leichte ist; jedenfalls aber ist die künstliche Begrïndung von Mischbeständen noch schwieriger als die natürliche. 
Als allgemeine Gesetze für die Naturverjüngmug der Misehbestände unter Schirm mögen folgende Punkte Beachtung finden:

1. Bezüglich dor Beurteihnng und Behandlung etwa vorhandenen, gemisehten Verwuchses gelten die bereits früher anf seite 2918 gegobenen Ausfülırmugen.

2. Finden sich mehrere Holzarten stammweise gemischt, und soll dieselbe Mischung wiederum erzielt werden, so wird, wemn wir dir Bäunne fragen. wie sie begründet worden waren, die Antwort wohl lanten, in einer gleich alten, stammweisen Verjüngung. Eine solche Begründung würde aber voraussetzen, daß alle Holzarten gleichzeitig Samen tragen, und daß die in der Jugend stammweise gemischten Holzarten auch im kritischen Alter, in der Stangenperiode, zwischen dem 15. und 40. Lebensjahr gleiche Wuchsgeschwindigkeit beibehalten. Das gleichzeitige Samenerträgnis ist aber ein äuferst seltener Ausnahmefall, und die Gleichwüchsigkeit richtet sich nach den bereits früher erwähnten klimatischen und pedologischen (bodenkundlichen) Verhältnissen. Da die gleichzeitige Verjüngung unmöglich ist, wird eine Trennung der Verjüngung nach der Zeit eintreten müssen, indem eine Holzart zuerst, eine zweite hierauf und so weiter zur Verjüngung gebracht wird.

3. Eine stammweise Mischung im alten Bestand ist sodamn erzielbar, wenn die Verjüngung eine kleingruppen- oder truppweise Mischung darstellt; ans den Trupps in der Jugend werden später nur einzehne Stämme sich erhalten. Dieser Terjüngung liegt eine Trennung der Verjüngung nach der Fläche zugrunde, indem jede Holzart eine eigene Fläche zugewiesen erhält, wobei geringe Unterschiede im Alter (Differenz der Samenjahre der verschiedenen Holzarten) benachbarter Gruppen bestehen.

4. Am sichersten wird sich die Mischung erhalten lassen, wenm die Verjüngung der Holzarten nach Zeit und Ort roneinander getrennt vor sich geht; das ist eine Gruppenverjüngung: mit größeren Altersdifferenzen zwischen den Gruppen.

j. Bei der Trennung der Holzarten nach der Fläche wird die A us formung des Bodens zu beachten sein, derart, daß jede Holzart der Mischung auf den ihr am besten behagenden Boden gerït (Anlage der ersten Kleinflächen für den Gruppenschirmsehlag).

6. Bei der Trennung der Verjüngung der Holzarten nach der 'Zeit gilt als Regel, daß jene Holzart zuerst verjüngt, somit eimen Vorsprung an Zeit erhalten soll, welche als die waldbaulich sehwächste der Mischung bezeichnet werden muß.

7. Bei einer Holzartenmischung, welehe Licht- und s'chattenholzarten, Licht- und Halbschatten-, Halbschatten- und Schattenholz umfaßt, ist die waldbaulich schwächste jene, welehe am meisten schatten erträgt 
und am stärksten Schutz verlangt. Es ordnet sich somit die Reihenfolge der Terjüngung im śchirmshlag naeh der Reihe des Sehattenerträgnisses: es begrinnt somit die Verjüngung mit den Sehattenarten, wie Eibe oder Abies usw., wie die Biologic der Holzarten Seite $10: 3$ rorschreibt.

R. Bei amähernd gleichem S.hattenerträgnis oder Lichtbedürfnis wird jene Holzart als die waldbaulich schwächere zuerst verjüngt, welche den schwereren Samen trägt, seltener frulifiziert (Eichen und Föhren).

9. Wird eine Lichtholzart durch eine Schattenholzart im kritischen Alter des Hauptlängswuchses gefährdet, so ist die Lichtholzart die waldbaulich schwächere und muß zuerst begründet werden (Fichten und Lärchen). Die richtige Behandlung einer Mischung in der Schirmschlagverjüngung setzt somit auch die Kenntnis des gegenseitigen Wuchsverhältnisses und des Einflusses hierauf durch Boden- und Klimalage (Optimum) roraus (Seite 14 i).

10. Eine Holzart wird zuerst verjüngt, weun ihr eine Schirmstellung gegeben werden kann, bei der keine andere Holzart, wenigstens nicht in demselben Maße, sich ansamon kann. Dieses ist im Dunkelschlag nur möglich, wenn die am stärksten Schatten ertragende zugleich die waldbanlich schwächste ist; ist eine Lichtholzart waldbaulich schwächer als eine Schattenholzart, z. B. Fichten und Lärchen im Optimum der Fichten, Eichen im Optimum der Buchen, so kann eine aussichtsvolle Naturverjüngung durch den Dunkelschlag überhaupt nicht gewonnen werden.

11. Der Besamungshieb für die am meisten Schatten ertragende Holzart soll Verbreitungshieb für die weniger Schatten duldende Holzart soin; der Lichthieb für erstere soll Besamungshieb für die zweite Holzart sein; gesellt sich hierzu noch eine Lichtholzart, so soll diese im Lichthiebe über der ersten Holzart ihre Besamung erlangen.

12. Sicherer und leichter fülırt eine Mischungsverjüngung zum Ziele bei der flächenweisen Trennung der Holzarten, bei dem Gruppensuhirmsehlag oder Gayers Femelschlag. welche den Verjüngungsgang auf den einzelnen (viruppen ganz nach dem Bedürfnis der zu er\%ielenden Holzart regeln liann.

13. Eine Begïnstigung der waldbaulich schwächeren Holzart wird sodann dadurch geboten, daß alle Hiebe vorzugsweise Stämme der stärkeren Holzart treffen; bei dem Gruppenschirmschlag tritt noch dio Auswahl des der schwäclısten Holzart passendsten Bodens hinzu.

14. Inreh Beibehaltung der für die betreffende Holzart entsprechendsten Schirmstellung rermelnt sich die Zahl der jungen Pflanzen dieser Art; durch Erweiterung der Gruppe mit ringförmigen Hieben, welche einer Holzart besonders zusagen, vergrößert sich der Flächenanteil dieser Holzart, so daß es anch in der Naturverjüngung 
möglich wird, rin vorher festgesetztes Mischungsverhältnis annähernol zu erreichen.

1.. Mißlingt boi der ersten Hiebstührung die Verjüngung der walıbaulich schwächsten llolzart, so muß entweder anf Beimischung dieser verzichtet werden oder sie muß kïnstlich und zwar sotort durch Pflanzung, nicht durch Saat eingebracht werden.

\section{Beispiele für die natürliche Verjüngung in reinen und gemischten Beständen.}

Es ist unnötig und überdies unmöglich, an dieser stelle die Lebensgeschichte einer jeden Holzart in reinen oder gemischten Baumvereinigungen zu wisderholen: unnötig, weil in der Baumbiologie des fünften Abschnittes und in der Bestandesbiologie des sechsten Abschnittes alles niedergelegt ist, was zur Charakteristik der Holzarten allein oder in Verbindung mit anderen dient; unmöglich, weil es auf der nördlichen Halbkugel sehr viele Holzarten gibt, welche rein oder in Mischung zu Verbänden sich vereinigen. Der Waldbau auf naturgesetzlicher Grundlage kann nur in allgemeinen Zügen eine Beschreibung der Verjüngungsmethode geben; ihre Anwendung und Abänderung für die einzelnen Holzarten, für verschiedene standörtliche Verhältnisse und die verschiedenen Zwecke muß Sache des beobachtenden Wirtschafters sein. Im nachfolgenden sollen einige Beispiele erwähnt werden, an welchen gezeigt wird. wie natïrliche Verjüngung unter Anlehnung an die naturgesetzlichen Eigenschaften der einzelnen Holzarten durchgeführt werden kann.

\section{A. Schattenholzarten.}

A. Die Schirmverjüngung bei den Schattenholzarten.

In mehr oder weniger gleichalterig erwachsenen Beständen erhält sich der Bestandsschluf bis zur Haubarkeit. Die Bodendecke ist ron Moosen oder Farnen und anderen Schattenpflanzen, von Rohhumus oder Laubdecke gebildet; nu in Klimaten wärmer als das Castanetum könuen unter den immergrünen Schattenhölzern auch noch Schatten ertragende Sträucher vegetieren: alle diese Hemmnisse für die Natursaat müssen verschwinden. Dor Vorbereitungshieb zur allmählichen /ersetzung der Bodenoberfläche ist unentbehrlich; beschleunigt wird die notwendige Vorbereitung des Bodens durch Beseitigung des Unterstandes an Sträuchern und Kräutern, durch Streurechen, durch Befahren, Betreten, Eintreiben von weidenden und wïhlenden Tieren und vor allem llureh Unterhacken und Unterwïhlen des ungenügend zersetzten Humus und der Baumabtallstotfe mittels eigener Bodenbearbeitungsgeräte. Schattenhölzer ermöglichen am vollkommensten die Herstellungr einer regrelmäßignen Schirmstellung und eines gewünschten Belichtungsgrades rles 
Bodens; selbst die Korrektur einer zu stark gewählten Auslichtung ist möglich, da Schattenholzarten durch Frweiterung ihrer Kronen sich wiederum schließen und sogar entstandenes Unkraut wieder zum Terschwinden bringen. Unter Schattenluolzarten ist eine Naturbesamung am leichtesten herbeizuführen, aber am schwierigsten zu erziehen. Schattenhölzer bedrücken die aufkommende .Jugend am meisten wegen ihres dunkleren Schirmes; beseitigt man eine größere Zahl von Schirmstandsholz, so wird die Zahl allzu stark überschirmender Kronen zwar kleiner, dafür aber vergrößert sich die Fläche der zu wenig überschirmten Bodenfläche. Schattenhölzer entziehen der Jugend zu ihren Füßen am meisten Wärme und Licht und vor allem die für die seicht wurzelnden Keimpflanzen so nötigen Niederschläge. Unter Schattenhölzern wächst die Jugend langsamer, sie paßt sich der verminderten Terdunstung und Belichtung an, so daß Wuchsstörungen an den Pflanzen auftreten, sobald allzu schnell die Dichte der Beschattung aufgehoben wird; mit anderen Worten, die Überführung der Anwüchse und Vorwüchse in den Freistand ist viel schwieriger als bei Halbschatten- und bei Lichtholzarten.

\section{Die reinen Bestände der Gattung Picea, reine Fichtenbestünde.}

Die natürliche Verjüngung auf der kahlen Fläche kann bei den Fichten gute Frgebnisse zeigen, wenn die Kahlfläche gleichsam eine Insel im Fichtenmeere darstellt, wie dies in der eigentlichen Heimat der Fichten vielfach der Fall ist. Die Frostgefahr auf der Kahlfläche wird von den meisten Wirtschaftern überschätzt; jedenfalls kann jede geneigte Kahlfäche in Mittel- und Nordeuropa mit Fichten natürlich oder künstlich ohne Schutz bestockt werden; auch ebene Flächen werden noch am vorteilhaftesten ohne Schutzholz besamt oder bepflanzt; erst Einsenkungen bedürfen des Vorwaldes. Wegen der geringen Schwebefähigkeit des Fichtensamens kann bei dem kahlen Saumschlag die Saumbreite nur 1-2 Baumhöhen betragen; die Drehung: der Saumrichtung im Gebirge, Vorlichtung, Ausbuchtungen nsw. der Saumlinie werdeu sich stets vorteilhaft erweisen. Wird eine partielle Verjüngung im kahlen Löcherhiel gewünscht, so hat die erste Schlußdurchbrechung eine halhe Baumhöhe im Durchmesser zu betragen, wenn man das Tropfbereich der Bäume bei der Messung außer acht läßt; obenso dürften die anschließenden kahlen Ringe in Breite eine Baumhöhe wohl nicht übersehreiten. Mit 1-3 solchen ringförmigen Kahlschlägen dürfte jede Verjüngungsgruppe ihre Maximalgröße erreicht haben, da der Wind für den bleibenden Bestand immer drohender wird. Es muf sodann zum kahlen Saumsehlag übergegangen werden.

Es fehlen Beispiele, daß ein Fichtengroß- oder kleinbestand so erzogen worden wäre, daß er rasch und gegen Sturmgefahr gesichert auf natürlichem Wege unter Schirm von alten Hölzern verjüngt 
werden kann, wie es die Erziehungsverjüngung dieser Schrift verlangt. In einem solchen Walcle gibt es zwar nur Sichlufolurchbrechmnen aber keinen natürlichen Anflug, da alle Bestände Unterbau mit zumeist Buche tragen. Der Borgmannsche Lichtwuchsbetrieb sieht eine derartige Erziehung nur in Gruppen, aber nicht eine natürliche Verjüngung voraus. Urichs Kulissenlichtwuchsbetrieb nähert sich ebenfalls der Erziehmugsverjüngungsform dieser Schrift. Wie weit aber diese beiden Methoden in die Praxis ïbergeführt wurden, entzieht sich der Kenntnis des Verfassers.

Eine Verjüngung der Fichten unter Schirm durch den natürlichen Abfall der Samen würde gewiß sich überall durchfülıren lassen, wenn man die Fichten für diesen Zweck erziehen würde; wenn aber die Schirmstellung plötzlich als ein Übergang vom Bestandsschlusse auftritt, so ist jede Schirmverjüngung Stückwerk oder Glückssache.

\section{Der Dunkelhieb.}

Das in allgemeinen Zügen bereits gekennzeichnete Hiebsverfahren kann mit allen Vor- und Nachteilen direkt Anwendung finden für Fichtenbestände der nördilichen Hemisphäre, denn die Grundzüge der Lebensgeschichte aller Fichten sind ein und dieselben. Auch in einem ohne Erziehung zum Zwock der Verjüngung erwachsenen, alten Fichtenbestande finden sich Schlußdurchbrechungen, die zuerst gemustert und behandelt werden müssen. Sind Verwüchse vorhanden, so werden diese auf ihre Brauchbarkeit geprüft und entsprechend behandelt. Hinsichtlich der Brauchbarkeit des Verwuchses sei neben den allgemeinen Regeln Seite 296 noch folgendes hervorgehoben: Fichtenvorwuehs, der längere Zeit im Druek gestanden, kann bei plötzlicher Freistellung sowohl durch Winterkälte und Besonnung (an Blattgrünbräune), wenn die Freistellung im Herbst oder Vorwinter erfolgte, oder an Chlorophyll- oder Blattgrünbleiche erkranken (Sonnenbestrahlung), wenn die plötzliche Freistellung im Spätwinter oder Frühjahre erfolgte.

Es wurde bereits ausgeführt, daß die Angewöhnung an ein stärkeres Licht für die bereits gebildeten Nadeln unmöglich ist; daß Anpassung gleichbedeutend ist mit Neubildung von Nadeln, welche bei der Fichte sehr langsam vor sich geht. Erst wenn eine größere Menge nener Triebe und Nadeln vorhanden ist, beginnt lebhafterer Höhenwuchs. Wichtig ist bei der Fichte anch die Untersuchung, ob der Vorwuchs mit seinen Wurzeln ganz im Moospolster oder auch noch im mineralischen Boden stockt. Im ersteren Falle ist der Vorwuchs äußerst vorsichtig treizustellen. Junge Pflanzen zeigen Lichtmaugel an, wenn sie dünne Nadeln bilden, wenn die Soitentriebe ganz ausfallen oder spärlich sind; ältere Pflanzen zeigon Lichtmangel durch Neigung zur Kronenverflachung. 
Torwuchs, der weniger gedrängt steht, z. B. Pflamzenentfernungen bis zu $2 \mathrm{~m}$ zeigt, ist bei den Fichten demnoch brauchbar, da die Fichten mit einheitlichem Schatte erwachsen und 2 m Abstand auch bei der Pflanzung noch als ein zulässiger Abstand erachtet werden muß. Torwuchs, der das 15. Lebensjahr ïberschritten, aber $1 \mathrm{~m}$ Höhe nicht erreicht hat, verdient leine Berücksichtigung.

Hat die Musterming der Schlufdurchbrechungen ein für die Naturverjüngung günstiges Ergebnis gehabt, so beginnt die Verjüngung des Bestandes am besten mit einem Hiebe auf unbrauchbares und selu starkes, rorherrschendes Material, so dafs die Schirmstellung und die Besamung mit den herrschenden Stämmen zu betätigen ist. Zum Vorbereitungshieb genügt es, wemn die Hälfte der ursprünglich vorhandenen Stämme verwendet wird; es ist daraut zu arhten, daß auf besseren Bodenpartien zum Schutze gegen Unkraut, in frischer Einsenkung, welche kahl gehauen zu den sogenamnten Frostlöchern der Praxis werden müssen, eine dunlilere Überschirmung erwiunscht ist.

Volles Samenerträgnis, eine Disposition, welche alle Fichtenpflanzen, junge wie alte, geschlossene wie offene Bestände zum Zapfenerträgnis treibt, z. B. 1906, ist häufiger als bei der Buche, die Benutzung mehrerer Samenjahre jedoch meist ummöglich wegen der Sturmgefahr für das Altholz. Das kommende Blütejahr ist bei allen Nadelbäumen schwieriger zu erkennen als bei den Laubbäumen; die Blütenknospen sind nur wenig dicker als die Triebknospen. Das Herabfallen zahlreicher Triebspitzen während des Spätherbstes und Winters, welche, wie die einfachsten Beobachtungen der abgeworfenen Spitzen lehren, Abbisse, von den Eichhörnchen zum Zweck des Knospengenusses verursacht, nie aber freiwillige Abstoßungen der Fichten sind, ist nur ein Zeichen dafür, daß es viele Eichhömchen gibt, nicht aber ein Anhaltspunkt für ein kiommendes Samenjahr. Die Abbisse sind nach einem Samenjahr viel häufiger, weil das Samenjahr Ursache zur Massenvermehrung dieser Nagetiere ist. Am besten wird daher der Besamungshieb zwischen /apfenreife im Herbst und Samenabfall im spätwinter bis Frühjahr geführt. Neu angeflogene Fichten sind sehr empfindlich gegen sommerdürre, da die jungen Pflanzen nicht tief genug wurzehn, insbesondere bei nicht völliger Zerstörung des Rohhumus; dazu kommt, daß3 die Fichtenbeschirmung in ungïnstigsten Falle, unmittelbar unter der Kronenprojektion, bis zu zwei Drittel der Niederschläge abfängt. Ein anderer, der größte Teil der Fichtenkeimlinge, weleher in Rohhumus gerät, stirbt durch Wurzelfäulnis, wenn nasse Witterung anhält. Dic Bodenverwundung kamn daher nur bei genügender /ersetzung des Rohhumus unterbleiben oder beschränkt sich auf die Entfernumg der Moosdecke. Das Betreten des Schlages durch Menschen und Tiere steigert die Empfänglichkeit des Bodens. Verunkrautete Stellen werden am besten sofort ausgepflanzt. Alle späteren Lichtungshiebe zugunsten 
des Fichtenanfluges sind wo möglich bei Schnee oder gelindem Frost oder 'Tauwetter vorzunehmen, doch sind gefrorene Fichtenstämmehen weniger spröde und hrïchig als die saftigen Buchenauf'sehläure. S'chon der Vorbereitungshieb, ganz besonder' aber der Besammnghieb und der Lichthieb sind bedroht von der schlimmsten Gefahr f̈ür alle Fichten, vom Sturm. Wegen ihrer stets seichten Bewurzelung ist es in ebenem Gelände, auf Hochplateaus, im sanften IJügrelland mehr '/ufall und Glüek als Berechnung gewesen. wonn eine Dunkelhiebsverjüngung voll gelungen ist. Vor f1).Jahren noch wurde das Experiment des Dunkelhiebs auf ebenem, seichtgründigem Boden gewagt; die Ergebnisse waren zumeist ungenügend oder blieben ganz aus: nur an schattenseitigen Hängen im Hochgebirge ist, wie die Beispiele in Salzkammergute zeigen, die Windgefahr so abgeschwächt. daß der Dunkelhieb mit seiner langsamen Arbeit schöne Verjüngungen zurückläßt. Mittelst des Dunkelhiebs eine die ganze Fläche gleichmäßig überziehende Bestockung zu erzielen, ist noch selten gelungen: einzelne Stellen pflegen sich gut und rasch zu besamen, andere bleiben zurück; an ihnen wird zunächst die Schirmstellung unter Hoffen auf Natursaat und Bangen vor dem Wind korrigiert: endlich wird künstlich angesät, und nach jahrelangem Terlust an Zuwachs und Nutzholz an den Schirmbäumen, durch Rindenbrand und Beschädigungen wird endlich der Dunkelhieb verlassen und zum kahlen Saumschlag mit darauffolgender Pflązung übergegangen, was man 10 und 2() Jahre früher auch hätte tun können.

Für die erste Durchbrechung im ringförmigen Dunkelschlag. Gruppenschirmschlag oder Gayerschen Femelschlag mag erwähnt werden, daß die überschirmte Anhiebsfäche im Durchmesser die halbe Baumböhe des Nachbarstandes nicht zu überschreiten braucht, die ganze Baumhöhe nicht überschreiten soll; auch die anschließenden, schirmständigen (Rändelhiebe) oder kahlen Ringhiebe (Umsäumungshiebe) sollen in der Breite zwischen einem halben und einem Baumdurchmesser sich bewegen. Ausbuchtungen und Einsenkungen im Simne der von der Natur gewollten Ungleichheit der vordrängenden Verjüngung sind besonders wichtig. Da die Vollendung der Verjüngung in dieser Form für die Fichte wegen Windgefahr unmöglich ist, muß zu kahlen Saumschlägen mit künstlicher Verjüngung übergegangen werden.

Wird ein Bestand in seinem Innern mit den eben erwähnten Gruppenschlägen bedacht, und werden gleichzeitig an der sturm. gesicherten seite des Bestandes kahle oder schirmständige S'aumschläge geführt (bayerisches oder von Hubers Verfahren, vom Begründer auch „kombiniertes Verfahren" genannt), so gestattet diese Methode größere Beweglichkeit gegenüber der Erfüllung des jährlichen Etats und genauerer Durchfïhrung einer naturgerechten Verjüngung der Fichte in einzelnen Gruppen, welche die heramnahende, künstliche Verjüngung dann in sich aufnimmt. 
Die reinen Fichtenbestände in Fomelwald liefern den Beweis, daß die Fichte zur Sturmfestiglioit erzogren werden kann und sich in dieser Form leicht, aber sehr langsam verjüngt.

\section{Die Reinbestände der Grattung Abies, reine Tamnenbestände.}

In der Baum- und Bestandsbiologie stehen die Tannen den Fichten nahe; verschieden sind sie aber in folgendem: größere Gefahr von Seite der verspäteten Fröste, dem Wildverbiß sehr stark ausgesetzt; stärkeres Schattenerträgnis, empfindlicher gegen plötzlichen Wechsel in der Belichtung: geringere (iefahr durch Insekten, weniger Rotfäule, weniger Gefahr durch Wind, schlechtere Schwebefähigkeit des Samens; Vollmasten sind seltener, Sprengmasten häufiger. Als tiefer wurzelnde Holzarten sind alle Tamen anspruchsvoller an Bodentiefe. Für die Vorwuchsmusterung ist zu beachten, daß Tannenvorwüchse bis zu 20 Jahren branchbar sein können. Die jugendliche Pflanze verrät in der dünnen Benadelung, im Ausbleiben des ersten Seitentriebes in dritten Lebensjahre (Sporn), daß sie Nangel an Licht leidet.

Die Tannenbestände Mitteleuropas entstehen aus Naturverjüngung unter Schirm; viel seltener ist eine künstliche Begründung durch Saat oder Pflanzung unter Schirm; am seltensten ist Pflanzung auf kahler, geneigter Fläche. Die künstlichen Begründungsweisen liefern nur dann brauchbare Jungwüchse, wenn sie nicht den Rehen und Hirschen zum Abfressen überlassen werden. Die europäische Tame hat ihren ursprünglichen Besitzstand gewahrt; sehr wenig ist durch künstlichen Anbau außerhalb der Heimat der Tanne entstanden, wie in Ostfriesland (Waldungen des Fürsten zu Knyphausen) und Dänemark.

A uf großen Kahlflächen erscheint die Tanne nur in geringer Zahl: kahle Saumschläge geben mehr, aber noch immer ungenügenden Tamnenanflug: im kahlen Löcherhieb kam die Tame sehr wohl verjüngt werden.

Erste Schlußdurchbrechung im Durchmesser von ein Drittel der Baumhöhe, anschließende, kahle Saumhiebe von einer Breite gleich der halben Höhe des Bestandes; Verjüngung bis zum Zusammenfließen der Gruppen durchführbar, wenigstens in weniger exponierter Lage. Für die Erziehungsverjüngung fehlt es einstweilen noch an entsprechend erzogenen Objekten.

Im Dunkelschlag liann Tame vorteilhatt verjüngt werden; im allgemeinen werden alle Hiebe etwas dunkler gehalten, als für die Fichte paßt. Es verführt aber das starke Schattenerträgnis der Tanne zum sehleppenden Verjüngungsgange, welcher nicht notwendig ist und nur Zuwachsverluste nach sich zieht; es ist durehaus keine seltene Erscheinung, daß ïber :30jährigen Jungwüchsen noch Althölzer stehen! Der saumweise Dunkelschlag mit einer Saumbreite von $1 / 2$ bis 1 Baumhöhe bedarf keiner weiteren Ausführungen; wichtig ist für 
die Tanne die Drohung der Saumrichtung in Gebirure wegen der Empfindlichkeit der Tame gegen Übersonnung und Wassermangel. Am besten behagt allen Tamen der (truppenschirmschlag (Gayers Femelschlag); es gibt schöne Beispiele, daß in dieser f́orm die Verjüngung leicht und ziemlich schnell erzielbar ist (Neuessing bei Kehlhoim). Für die Tanne gilt als Durchmesser der ersten Schluflurchbrechung ein Drittel der Baumhöhe; alle Hiebe verzögern, verschmälern und verdichten sich in der Schirmstellung. Die größte Gefahr für dio Verjüngung ist die Verschleppung. Wo Sturmgefahr sehr groß ist, muß zum Kahlsaumschlag übergegangen werden, wodurch dio Naturverjüngung der Tanne zum Stillstand kommt und zumeist eine andere Itolzart eingeführt wird.

Im Femelwald sind die Tannen geradezu Unhölzer, welcho allen anderen Holzarten Licht, Luft und Boden entziehen. Der Überhalt kann sehr wohl bei den Tannen wie bei den Fichten ausgeführt werdent wenn eine Vorbereitung für den Freistand durch rechtzeitigen Freihieb der Kronen (Erziehung) vorausgeht; lohnend ist er nicht.

\section{Dic reinen Bestënde der Gattung Fagus, reine Buchenbestände.}

Die reinen Buchenbestände, Mode während der ganzen ersten Hälfte des vergangenen Jahrhunderts in Mitteleuropa, haben gewaltig an Boden verloren; was sich erhalten hat, ist unter Schirm durch natürlichen Samenabfall entstanden; seltener unter Schirm gesäet oder gepflanzt; was davon dem Wildverbiß entgangen, ist zum Bestande erwachson; Pflanzung auf kahler, geneigter Fläche, obwohl zulässig, ist seltener zur Anwendung gelangt.

Die Schwersamigkeit und die große Empfindlichkeit der Buche gegen verspätete Fröste schließen eine Naturverjüngung auf größeren Kahlflächen aus. Nur der kahle, schmale Saumschlag und Löcherhieb vermögen noch einige brauchbare Buchenjunggruppen zu liefern.

Daf die Schirmverjüngung rasch, sicher und leicht im reinen Buchenbestand durchführbar ist, beweist die Buchenwirtschaft Dänemarks, welche der Erziehungsverjüngung nahe kommt; die Naturverjüngung ist dort erzielt durch eine entsprechende Erziehung der Buche, welehe die Zunahme der Kronenschlufauflösung bis zur Haubarkeit und die Erhaltung des Unterdrückten zum Ziele hat. Es hat sich aber dort auch gezeigt, daß zur Lösung dieser Probleme für die Buche stets eine intensive Bodenverwundung vor Abfall des Samens unerläßlich ist. Trotz der großen Empfindlichkeit für verspätete Fröste kann die unter solchen Verhältnissen rasch emporwachsende Buchenjugend schon nach zwei bis drei Lichthieben in den Freistand übergohen. Die Erziehungsverjüngung verlangt die Kronenlichtung etwa vom 50. Jahro an; die unterdrückten Buchen sind dünnstämmig erwachsen, so daß sie sich bei beginnender Durchlichtung nur teilweise aufrecht halten künneu

I ayr, Waldbau. 
und die Rolle eines Schutzbestandes nur mangelhaft erfüllen, so daß besser künstlicher Unterbau von Buchen an die Stelle tritt, der für die weitere Erziehung und Verjüngung freie Hand gibt.

\section{Der Dunkelschlag.}

Die Buchen nehmen waldbaulich eine Sonderstellung ein; sie ertragen den stärksten Lichtentzug und beschatten am stärksten; keine Baumgattung unter den winterkahlen Bäumen kommt ihnen hierin gleich. Dies erklärt ihr Streben, stets alle anderen Holzarten von demselben Standorte auszuschließen und die Herstellung einer Mischung zu erschweren. Der Dunkelschlag hat an der Buche seine Ausbildung erfahren: es nähern sich ihnen hierin die immergrünen Laubbäume der Subtropen; doch in ihrem Gesamtverhalten zeigen die immergrünen Laubbäume mehr eine Annäherung an Fichten und Tannen des kühleren Klimas als an Buchen.

Bei der M I usterung der Schlußdurchbrechungen, als der ersten Aufgabe, mit der die Verjüngung beginnt, wäre zu betonen, daß das Ausbleiben eines Aufschlages weniger in einem Fehler in der Kronendurchbrechung als in der mangelhaften Einbettung und Keimung der Bucheckern seine Erklärung findet, daß bei keiner Holzart die Bodenverwundung in Furchen oder das Behacken oder Überzichen des Bodens mit der Rollegge, mit eisernen Rechen, das Eintreiben von Schweinen so wohltätig wirkt als bei den Buchen. Bei der Musterung allenfalls vorhandenen $\mathrm{Buchena} u f \mathrm{chlages}$ ist folgendes zu beachten: nur der allerbeste, geschlossene, aus geraden Samenstämmehen gebildete Vorwuchs ist gut genug. Bei keiner Holzart ist diese Forderung so streng durchzuführen als bei der Buche; bei keiner Laubholzart drängen im jugendlichen Alter die schlechtgeformten Stämmchen so sehr in den Vordergrund, um herrschend zu werden, als gerade bei der Buche. Unbrauchbar ist daher Vorwuchs von ungleich hohem Wuchs oder 3-5 m hoher Vorwuchs, der noch von Althölzern überstellt ist, da er in diesem Falle durch Fällung und Bringung der alten Buchen so mißhandelt wird, daß er unbrauchbar ist; Buchenvorwuehs mit zahlreichem Rindenkrebs (Nectria, insbesondere nach Hagelschlag) oder Vorwuchs, der aus Stockausschlägen hervorgegangen ist, ist stets unbrauchbar. Dagegen erholt sich der allzu lange im Druck gestandene Vorwuchs der Buchen viel schneller und leichter als der von schattenertragenden Nadelhölzern; die Umpflanzung steiler Ränder des Vorwuchses ist bei der Buche schwieriger als bei den Nadelhölzern. Soll unbrauchbarer Vorwuchs entfernt werden, damit neuer sich einstellt, so ist die Rodung desselben unerläßlich; nur auf steinigem, mit grobem Geröll überschütteten oder auf schr flachgründigem (kalkigem) Boden muß man mit jedem Aufschlage vorlieb nohmen. 
Vorstehendes mag zugleich als ein Beispiel der Vorwuchsmusterung fïr alle Laub-. Seliatten-und IIallschattenholzarton gelten. In vielen Punkten mögen anch die immergrünen Vorwïchse in den Subtropen mit den Beobachtungen bei den Buchen ïbereinstimmen, in einigen anderen Punkten werden sie sich davon entfermen.

Die Terjüngung beginnt in der Regel mit dem Herausplentern der zur Samenerzeugung unbranchbar gewordenen, anbrüchigen oder auch der allerstärksten Bäume, weil deren Fällung und Verbringung nach der Besamung allzu viel Schaden verursachen wiurde.

Im Anhalt an diese Schlußdurchbrechungen versucht nun der Vorbereitungshieb eine möglichst gleichmäßige Schirmstellung mit Hilfe der bestbelironten Stämme herzustellen; auf den geringen Bodenpartien wird die Stellung lichter, auf den besseren dunkler gehalten. Der Besamungshieb, der seinen Namen deshalb führt, weil er vor oder nach Samenabfall geführt werden kann, richtet sich in seiner Stellung nach dem Lichtbedïrfnis der zu erwartenden Buchenjugend. Ist Samen an den Bäumen in genügender Menge vorhanden, dann kann der Hieb im Frühherbst, also vor, oder Spätherbst und Winter, also nach Samenabfall geführt werden. Bodenverwundung ist am besten mit der Unterbringung der Saat zu verbinden.

Tritt eine Vollmast ein, das heift werden alle Buchen von dem Bestreben, Samen zu tragen, ergriffen, so erstreckt sich die Besamung auch auf alle übrigen, mannbaren Buchenbestände, auch wenn dieselben gar nicht für Besamung eigens vorbereitet wurden. Die Tollsamenjahre liegen weit auseinander, oft 8-10. Jahre; inzwischen aber stellen sich sogenannte Sprengmasten ein, mit deren Hilfe ebenfalls ein Vollbestand, aber nur sehr langsam und ungleichmäßig zu erzielen ist. Den Besamungshieb schon im Herbst und Winter vor dem Blütejahr zu führen, ist eine gewagte Sache; es ist zwar leicht das Heramnahen eines Blütejahres an den dickgeschwollenen Ḱnospen vorauszusehen: ob aber aus der Blüte eime Frucht wird, ob nicht ein verspäteter Frost die ganze Blütenmenge rernichtet, weiß niemand; denn wo die Buche zu Hause ist, sind Spätfröste Ende Mai keine allzu große Seltenheit.

Während der Lichthiebe zugunsten des Buchenaufschlages ist die Sturmgefahr zwar gering, dagegen ist die glatte Rinde für den Freistand durch allmähliche Freistellung vorher nicht erzogener Buchen, überaus empfindlich gegen Rindenbrand, der an Stämmen und Ästen, welche von der nachmittägigen Sonne zwischen 1 und 3 Uhr beschienen, werden, durch Absterben und Abfallen der Rinde sich äußert; Pilze und Insekten besehleunigen die Zerstörung des besten Sishaftstïckes. Stehen solche Bäume noch ein oder zwei Jahrzehnte, dann bricht sie der Wind an der rindenbrandigen, inzwischen mürbe gewordenen Stelle ab. In Frostlagen verzögert sich der letzte Lichthieb bis 
zu zo Jahren nach Beginn des Vorbereitungshiebes; in geschützter Lage kann in $(j-\delta$ Jahren die Verjüngung vollendet sein. Daß die Fällung möglichst schonend tür den Auf'schlag bei schnee, milder Winterwitterung, an sturmtreien Tagen usw. gchandhabt, daß sie soviel als möglich zur Beruhigung der Pflanzen beschleunigt werden soll, bedarf kaum der Erwähnung. Es kommt hinzu, daß in manchen Gebieten an den Wunden der jungen Buchen ein Rindenparasit, Nectria ditissima, sich ansiedelt, weleher die Stämmchen verunstaltet und zu Nutzholz unbrauchbar macht. Trotz reichlicher Besamung sind im nächsten Frïhjahr oft nur wenige Pflanzen gekeimt: denn die Bucheckern sind besonders den Nachstellungen von Tieren (Wildschweine, Rehe, Hirsche, Eichhörnchen, Mäuse, Eichclhäher) ausgesetzt; viele Buchen keimen noch im Herbste, weun dieser mild ist, und erfieren dann während des Winters, und nach R. Hartig wird auch ein Teil der Buchen durch Schimmelpilze im Winterlager getötet. Die Keimlinge selbst dezimiert ein Pilz (Phythophtora) gegen dessen Ausbreitung vielleicht Bespritzen mit Bordeauxbrühe schützt. Was die Pflege des Aufwuchses anlangt, so setzt diese im jugendlichen Alter ein; es gilt roll, was oben bezïglich der Pflege des Vorwuchses gesagt wurde: mangelhafter Pflege im jugendlichen Alter, d. i. Belassung der vorwachsenden, schlechtgeformten Buchen, ist es zuzuschreiben, daß in den uns von den Altvordern überlassenen Buchenbeständen so viel unbrauchbares, mißgestaltetes Stammaterial sich findet. Daß viele Stellen im Aufschlag künstlich ergänzt werden müssen, durch Saat oder Pflanzung. und daß trotz aller Sorgfalt die Verjüngung oft ganz lückenhaft bleibt, sogar vielfach nur eine Gruppenverjüngung sich ergibt, zeigt die Geschichte des Dunkelhiebes mit seinen teils vorziiglichen, teils ganz mangelhaften Resultaten.

Es wäre besser, wemn eine durch Sprengsaaten, Korrektur der Schirmstellung, durch Unkraut und Spätfrost lückig bleibende Buchenverjüngung ganz verunglücken würde, um der Ausformung von kleinen Gruppen, der Zwischenpflanzung von anderen Holzarten vorzubeugen, somit für die spätere Zeit die schweren Ausgaben der fortgesetzten Pflege und die trotz aller Mühen minderwertige Bestandesverfassung zu verhindern; eine wohlgeratene, künstliche Verjüngung, selbst mit einer anderen Holzart, ist einer halbgelungenen, natïrlichen Buchenverjüngung stets vorzuziehen; mißlungen aber ist jede Buchen verjüngung, wenn sie nur Gruppen gibt, diekleinerals 0,3 ha sind.

Die heute noch auf groben Flächen vorhandenen, haubaren Buchenbestände Mitteleuropas verdanken dem Dunkelschlag ihren Ursprung, dem teils der glïckliche \%ufall einer Vollmast, teils eine endlose Geduld gegenüber dem Verjüngungszeitraum und der Rentabilität solcher VValdungen zur Seite stand. 
Im Gruppenhiebe lehnt sich die Bchandlung der Buchen jener der Tannen an; Sturmgefahr ist nicht $z u$ befürchten; Rindenbrand an den Stämmen des Nordostrandes der Gruppen ist empfindlich schädlich. Auch bei dieser, heute so weit verbreiteten Methode ist es wieder eine Generalmast aller Bäume, welche die besten Ergebnisse bringt und die Ausformung von reinen Kleinbeständen von 0,3 ha und darüber gestattet. Sprengmasten führen zu kleinen Gruppen, deren Vergrößerung sehr langsam und unsicher ist. Da die Kleingruppe der Buchen, umgeben ron anderen Holzarten, als durchans ungünstig bezeichnet werdon muß, wegen eigener schlechter Schaftbildung und Belästigung der Nachbarschaft, so hat der Dunkelschlag für die Buche höheren Wertals der Gruppenhieb: denn miblingt der Dunkelschlag, erzielt man immer noch Gruppen; bei Vollmast aber, bei der alles gelingt, fällt die Verjüngungsfläche größer aus, was der Gruppenhieb durch seine Arbeit auf kleinen Flächenteilen systematisch verhindert.

Die Verjüngung des Femelwaldes der Buche, gesetzlich vorgeschrieben an steilen Flußufern, vollzieht sich im Einklang mit den allgemeinen Grundzïgen dieser Wirtschaftsform.

Es ist kein naturgesetzlicher Grund zu finden, warum die natürliche Wiederverjüngung der Reinbestände der gleichen amerikanischen oder asiatischen Baumgattungen sowie auch aller übrigen Schattenholzgattungen der nördlichen Halbkugel (Psoudotsuga, Thuja, Thujopsis, Sciadopitys, immergrüne Eichen und alle übrigen immergrünen Laubbäume S. 103) durch die erwähnten Methoden mit allen ihren Vor- und Nachteilen sich nicht erzielen ließe. Tor allem ist nichts zu erkennen, was einer Erziehung solcher Bestände zum Zweck der Verjüngung und der darauffußenden Verjüngung selbst im Wege stände. Wenn man in Ostasien auf das sofortige Erscheinen ron Bambus hinweist, als eine unausbleibliche Folge jeglicher Bestandsdurchlöcherung, so muß dem entgegengehalten werden, daß die heute haubaren Bestände nicht in der Erziehungsverjüngung behandelt werden kömmen, weil sie für diese nicht erzogen wurden. Für solche Bestände muß die künstliche Verjüngung als notwendiges Übel gewählt werden, um dichte Stangenbestände zu erzielen. Wird nun bei Schatten- und Halbschatten- wie selbst bei Lichtholzarten nach Eintritt des Kronenschlusses von jedem Eingriff abgestanden, so muß jeglicher Unlirautwuchs in Europa und Amerika, auch das hartnäckigste Gras, in Asien der alles mordende Bambus aus Lichtmangel zugrunde gehen. Werden bei Eintritt der Durchlichtungen ebenso wie die S'chattenholzarten die Halbschattenholzarten und Lichtholzarten mit einer Schatten- oder Halbschattenholzart unterbaut, so ist die Rückkehr der vertriebenen, lichtbedürftigeren Unkränter unmöglich geworden. Die Nachahmung des Dunkelhiebes und des Gayerschen Gruppenhiebes im bambusreichen Ostasien ist freilich ein arger Miß3griff. Verfasser sieht nur in der Erziehungsverjüngung der 
Bestände die einzige Möglichkeit, die Bambuskalamität in den Waldbeständen Asiens und Afrikas erfolgreich zu bekïmpfen.

\section{B. Halbsehattenholzarten.}

Die Schirmvorjüngung der 11 albschattenholzarten.

Den allgemeinen Bemerkungen über die natürliche Wiederverjüngung der Halbschattenholzarten, welche auf Scite 293 anf Grund des naturgesetzlichen Verhaltens der Holzarten niedergelegt wurden, ist nur soviel hinzuzufügen als durch die spezielle Biologie der einzelnen Gattungen (S. 146 ı. f.) angezeigt erscheint. Regelrechte Verjüngungen in reinen Beständen sind überdies bis hente selten, da die Reinbestände größerer Ausdehnung fehlen; was aber auf kleiner Fläche (Gruppe) möglich ist, läßt sich auch in Klein- und Großbeständen erreichen.

Den Schlüssel für die Terjüngung der Halbschattenholzarten in reinen Beständen geben die früher erwähnten Naturgesetze, denen zufolge die Halbschattenholzarten auf gutem bis bestem Boden, in ihrem klimatischen Optimum oder selbst in wärmeren Lagen zu Schattenholzarten werden, daß sie auf geringerem Boden, in kïhlerem K'lima den Lichtholzarten sich nähern. Hierher zählen die reinen Bestände der Föhrensektionen Strobus und Cembra, die Angehörigen der Gattungen Chamaecyparis, Tsuga, Libocedrus, Cedrus, Sequoia u. a.; die Laubholzgattungen Acer, Fraximus, Ulmus, Alnus, Carpinus, Tilia und andere, früher aufgezählte Gattungen (S. 146); auf guten Böden bilden sie bis in das Baumalter geschlossene Bestände; auf geringeren Böden oder in lïhlerem Klima löst sich der Bestandsschluß beim Übergang in das Baumalter auf, sie verlichten, und der Boden verwildert wie bei den Lichtholzarten oder trägt den Vorwuchs der betreffenden Art. Bezïglich der Brauchbarkeit des Vorwuchses ist den allgemeinen Regeln wenig hinzuzufügen.

Torwuchs der Halbschattenarten wächst auch, wenn er minder gut geschlossen ist, leichter zu brauchbarem Vorwuchs zusammen. Beschädigungen werden leichter verheilt; die Gefahren durch lnsekten, Pilze, Wild- und Mansverbif und besonders auch durch verspätete Fröste sind teils geringer, teils größer als bei der Buche; das Samenerträgnis ist öfter und reichlicher, der Same flugfähiger. Gedrängte Erziehung der Jugend ist notwendig zur Erzielung von Geradschaftigkeit.

Naturverjüngungen aut kahlen Fläehen werden, je nach der Schwebefähigkeit der šämereien (groß z. B. bei den Gattungen Chamaecyparis, Libocedrus, Ulmus), bessere oder schlechtere Resultate geben. Kahlsaumhieb mit ein- his zweimal Baumhöhe als Breite, kahler Löcherhieb mit einem Inrchmesser von einer halben bis einer ganzen Baumhöhe beginnend, wird langsam fortschreitend Nachwuchs liefern. 
Beispiele fur die naturliche Verjüngung usw. B. Halbschattenholzarten. 343

Die Erziehungsverjüngung unter Śchirm hilft hinweg über die Verlegenheit bei der Entscheidung, ob aut einen konkreten Standorte die Holzarten wie Schatten- oder Lichtholzarten zu behandeln seien, da die Grundsätze der Erziehung in beiden Fällen, was Kronenschlußdurchbrechung, Unterbau und Auswahl der Stämme für die Verjüugung anlangt, die gleichen sind.

In Beständen der Halbschattenholzarten, welche für die Verjüngung nicht erzogen wurden, sich aber wegen des guten Standortes dennoch bis zur Haubarkeit geschlossen, den Boden unkrautfrei erhalten haben, mögen die bei den Schattenholzarten besprochenen Formen des Dunkelschlags und des saumweisen Dunkelschlags sinngemäße Anwendung bei ergiebiger Terwundung des Bodens finden.

Besonders passend wird sich der Gruppensehirmschlag oder Gayers Fem els chlag erweisen, da er gestattet, die best geschlossenen Partien der Bestände für Anfangstellen der·Verjüngung auszuwählen. Für die geringeren Standorte tritt die Verjüngungsweise der Lichtholzarten in Wirksamkeit. In der Regel wird man sich mit der Erhaltung einiger Gruppen (am besten einiger Kleinbestände von 0,3 ha Minimalgröße) dieser Holzart begnïgen und den Rest der Fläche anderen Holzarten überlassen, wenn nicht die Halbschattenart selbst Hauptholzart ist oder der Standort selbst zu größerer Fläche zwingt (Erlenbrücher).

Für die Verjüngung im Femelwald bedarf es keiner weiteren Erklärungen; die Verjüngung ist für Schatten- wie Halbschattenarten die gleiche.

\section{Die Reinbestände der Föhren (Pimus), Sektion Strobus, Weymouthsführen und Sektion Cembra, Zürbeln.}

Reinbestände dieser Holzarten sind in ihren heimatlichen Gebieten Europas und Amerikas durch Anflug oder Aufschlag auf Kahlflächen oder auch durch Pflanzung, in Europa zumeist durch Pflanzung, ausnahmsweise auch durch Naturverjüngung unter Schirm entstanden. Auf gutem und frischem Boden, der eigentlichen Heimat der fünfnadeligen Föhren, erhalten sich dieselben bei enger Begründung mit unkrautfreiem Boden bis in das haubare Alter geschlossen und bilden astreine Schäfte. Auf trockenem Boden verlichten sie frülızeitig und . reinigen sich schwierig. Auf den ersteren Standorten können sie wie eine Fichte oder Tanne, auf den letzteren nur wie eine zweinadelige Föhre, somit eine Lichtholzart verjüngt werden, wenn Naturverjüngung beabsichtigt ist: Gruppenschirmschlag bei der Strobe wurde auf besiseren Böden in Deutschland mit Erfolg bereits versucht. Auf Kalılflächen siedeln sich die Weymouthsföhren von einer sichlagwand aus gerno an: die Zürbeln sind behufs gröfjerer Terbreitung aut Tiere angewiesen. 
Die Erziehungsverjüngung dürfte auch hier wiederum als die beste und schnellste Naturverjüngungsform sich erweisen, selbst auf weniger frischen Böden, da bei der Lichtung des Stangenbestandes zum Unterbau mit einer Schattenholzart, am besten mit Buche, zum Schutze des Bodens geschritten wird.

Wie vorstehende Nadelbäume lassen sich sicher auch die übrigen Halbschattennadelbäume verjüngen; ihr häufigeres Samenerträgnis, bessere Samenverbreitung, größere Frosthärte als die der Schattennadelbäume lassen, wie Beispiele in Amerika, Asien und Europa zeigen, eine rasehe und reiche Ansiedelung von Jungwuchs erwarten.

\section{Reinbestände dev Gattung Crrstanea, Edellastrmien.}

Nur im Castanetum sieht man reine und gut geschlossene Bestände dieser Holzarten; da die Feinde der Früehte im Walde auch ihre Freunde sind, ist natürlicher Aufsehlag häufig. Eine regelrechte Schirmschlagverjüngung nach dem Torbild der Erziehung zur Verjüngung wäre sicher durehführbar. Stets wird eine intensive Bodenbearbeitung nach Abfall der Früchte eintreten müssen.

\section{Reinbestände der Gattung Almus, die Erlen.}

Nur soweit Erlen auf frischem, nicht versanertem Boden stehen, halten sie sich geschlossen und kann bei einer Durchlichtung der zu Boden fallende Samen auskeimen. Auf durch Stagnation nassem oder der Überschwemmung dureh Niederschläge oder empordringende Grundwasser längere Zeit ausgesetztem Boden unterbleibt ein Anflug; die besseren Stellen sind vergrast, die bodenreinen Flecke sind bald unter Wasser, bald ausgedörrt. Dort ist man zur künstlichen Terjüngung gezwungen, wenn nicht die Ausschlagsverjüngung über alle Schwierigkeiten hinweghilft.

\section{Reinbestände der Gattung Acer, die Ahornarten.}

Wenig ist davon in Europa übrig geblieben, um so schönere Beispicle von reinen, bis in das haubare Alter geschlossenen Ahornbeständen weisen Amerika und Ostasien auf. Der unter der Laubdecke geradezu ideale Boden ist außerordentlich empfänglich für die Naturbesamung, wie sich bei einer Auslichtung soleher Bestände aueh ohne Bodenverwundung ergibt. In solchen Standorten kömmen sicher alle Schirmschlagsformen Anwendung finden, wie das massenhafte Erscheinen von .Jugend unter alten Bäumen selbst auf rerunkrautetem Boden erwarten läßt.

\section{Reinbestände der Gattung Fraximus, Eschenarten.}

Auch die Reinbestände der Eschenarten bauen sich mit vollkommeneren Schaftformen auf als in Mischung mit irgendeiner anderen Holzart. Die Eschen halten sich, in engem Verbande zum Zwecke der 
Geradschaftigkeit und Vermeidung der Vergabelung begriindet, bis zum Baumalter hinreichend geschlossen und tragen von da an his zur Haubarkeit ihre eigene .Jugend als Bodenschutzholz in dichten Anflügen. Wo aber statt dessen Unkraut- und Unholzwuchs sich einstellt, da ist die Esche nicht auf ihrem besten Bonlen, oder sie wurde von Anfang an weitständig oder mit anderen Holzarten (Erlen) begründet, welche wegen Bedrïckung der Eschen später herausgenommen werden mußten. In solchen Verhältnissen ist die Naturverjüngmug nicht Berechnung, sondern Zufallsergebnis. Werden eng begrünlete Eschen bei Eintritt der Durchlichtungen unterbaut (Buchen, Erlen), kamn weder Unliraut noch eigene Verjüngung sich einstellen, bis die Haubarkeit erreicht ist und die Erziehungsverjüngung einsetzt. In nicht unterbauten oder lïekigen oder bodenschwachen (naß oder trocken) Beständen benutzt man das zufällig Gebotene und greift als Ergänzung zur Pflanzung.

\section{Reinbestünde der Gattung Carpinus, Mie Hainbuchenarten.}

Die Hainbuchen stehen auf gutem. frischem Boden den Buchen (Fagus) an Schaftschönheit und Höhe wie auch in Schattenerträgnis kaum nach; dort mögen sie auch gleich Buchen rerjüngt werden; auf mageren, steinigen Böden insbesondere mit südlicher Exposition sind die Hainbuchen niedere, krumme, schlecht geschlossene Lichtholzarten, die sich reichlich durch Samenbildung rermehren.

\section{Reinbestünde der Gattungen Clmus, Zellioura, Celtis u. ".}

Auf guten, frischen Böden und in passendem Klima (Castanetum und wärmeres Fagetum) nähern sich enge begründete Reinbestände den Eschen, auf geringen, trockenen Böden. im kühleren Klima kommen sie den Hainbuchen auf solchen Standorten am nächsten; ihre waldbauliche Behandlung bei beabsichtigter Naturverjüngung läßt sich von jener der Vergleichsholzarten ableiten. wemn nicht Erziehungsterjüngung rersucht werden sollte.

\section{(. Lichtholzarten.}

A. Verjüngung der Lichtholzarten in schirmschlag formen.

Während für die Schattenholzarten in der gegenwärtigen Bestancls. form eine langandauernde Vorbereitung zur Verjüngung die Mängel einer ungenügenden Erziehung beseitigt. könnten bei den haubaren Lichtholzarten, welche zur Zeit ihrer Verlichtung nicht systematisch unterbaut wurden und deshalb rerunkrautet sind, die Mängel dieser Erziehung nur durch hohen Kostenaufwand ansgeglichen werden, wemn eine Verjüngung derselben anf' natürlichem Wege unter Schirm heabsichtigt wäre. Unter solchen Lmständen gilt freilich der siatz, daß 
die Lichtholzart en leichter, sicherer und schneller auf künstlichem Wege verjüngt werden können. Findet sich statt Unkrant Vorw u ehs der Nutzholzarten, so erfolgt seine Musterung und Behandlung nach den früher gegebenen Andeutungen. Ist aber nur eine Unkrautdecke über den Boden gebreitet, und soll natürlich verjüngt werden, so muß dieser Bodenüberzug beseitigt und eine gründliche Bodenbearbeitung durch Roden der Stöcke, durch Unterhacken des Rohhumus, streifen- oder platzweive oder über den ganzen Bestand hin Platz greifen. Der hohen Kosten wegen greift man zur künstlichen Verjüngung; wenn aber bei dieser, der ein Kahlschlag vorhergeht, ebenfalls eine solche kostspielige Bodenbearbeitung mit daranffolgender Saat oder Pflanzung eintreten muß, so kann Verfasser nicht mehr erkennen, worin der Vorzug der künstlichen Verjüngung liegen könnte. Stellen sich die Kosten der ganzen Verjüngung mit allen Ergänzungen gleich hoch mit der natürlichen, so hat auch hier die natürliche Verjüngung den Vorzug und das Vorrecht vor der künstlichen wegen ihres Schutzes für die Jugend und ihrer Rücksichtnahme auf den Boden. Es dürfte nicht schwierig sein, anch bei den Liehtholzarten die Erziehungsverjüngung, eine Naturverjüngung unter Schirm, sowohl in einem Groß- wie in dem vorzuziehenden Kleinbestande zur Durchführung zu bringen.

Für alle gegenwärtig haubaren und haubar werdender Lichtholzbestände, welehe keinen Unterbau zum Schutze des Bodens z um Zwe cke ihrer Verjüngungsmögliehkeit unter Schirm erhalten haben, gelten folgende Regeln:

1. Auch bei den Lichtholzarten geht jeder weiteren Verjüngungstätigkeit die Musterung und Behandlung etwa vorhandener Vorwïchse voraus; nur dicht geschlossener Vorwuchs ist brauchbar; seine Freistellung kann rasch erfolgen.

2. Für Lichtholzarten kann der Dunkelschlag nur in einem abgekïrzten Verfahren eine Naturverjüngung erzielen. Statt der vielen Hiebe des Dunkelschlages werden nur zwei bis drei notwendig erscheinen; nämlich Besamungshieb und Endhieb oder Besamungshieb, Lichthieb, Endhieb.

3. Der Besamungshieb bescitigt alle eingeklemmten, schwachkronigen, rückgängigen, sehr starkkronigen Stämme des alten Bestandes.

4. Diesem Hieb geht vorans oder folgt eine intensive Bodenbearbeitung durch streifweise oder platzweise oder völlige Beseitigung des Unholz- oder Unkrautwuches, durch Vermengen des Rohhumus - nicht Hinwegschaffung desselben - mit der mineralischen Erde.

5. Bodenverwundungen und Besamungshieb werden nur in einem Samenjahr ausgeführt und zwar unmittelbar vor Abfall des Samens 
(leichtsamige Holzarten) oder unmittelbar nach Abfall des Samens (schwersamige Holzarten).

(i. Hat sich genïgende Verjüngung ergebenso) wird mit ein oder zwei Hieben die Schirmstellung beseitigt; ist jedoch, wie zu erwarten ist, die Terjüngung mangelhaft und lückig geblieben, so wirl der ganze Schirmstand gefält, jedoch so, daß das Brauchbare der Natursaat nicht zerstört wird: diese brauchbaren Teile werden durch Pflanzung, nicht durch Saat, miteinander verbunden. Unterbleibt die Naturbesamung, so folgt teils unter Schirm oder auch auf kahler Fläche am besten Pflanzung: die Saat ist zu vermeiden nach dem Grundsatz, keinen Versuch, der einmal mißlungen ist, zu wiederholen.

7. Beim saumweisen Schirmschlag können die Säume breiter, die Hiebe ebenfalls in der Zahl vermindert, in ihrer Ausführung verstärkt werden.

8. Bei Gruppenschirmschlag hat die erste Anlage eine Fläche von 1-10 Ar zu umfassen.

9. Wie beim Dunkelschlag vermindert sich auch beim Gruppenschirmschlag die Zahl der Hiebe über den einzelnen Ringen, die Ringe selbst verbreitern sich, und gelegentlich wird sich auch ein kahlerer Ring als wünschenswert für die Naturverjüngung der Lichtholzarten erweisen.

10. Naturverjüngung wird um so eher zum Ziele führen, je besser der Boden und je jünger der Lichtholzbestand.

B. Beispiele für Naturverjüngung unter Schirm von Reinbeständen der Lichtholzarten.

Rembestände der Gattung Pinus (Sektion Pinaster, Murraya, Jeffreya), Reinbestände der zuei- und dreinadeligen Fö̈lren oder Kiefern.

Reinbestände obiger Föhren verlichten und verunkrauten im höheren Alter; nur im Stangenalter, auf besserem Boden oder im kühleren, fenchteren Klima ist der Boden unkrantfrei oder doch nur so spärlich damit bedacht, daß eine Naturbesamung möglich ist. Vielfach aber verführt das Beispiel der norddeutschen Tiefebene prinzipiell die Naturverjüngung abzulehnen und jeden Vorwuchs, auch wenn er bratchbar wäre. zuvor herauszureißen, um bei der kiìnstlichen Verjüngung nicht beengt zu werden. Will man das Endziel alles waldbaulichen Strebens, die schnelle, sichere und leichte Naturverjüngung anch bei den Föhren erreichen, müssen diese bei ihrer Verlichtung mit einer sichattenholzart, am besten einer Buchen- oder anch einer Halbschattenholzart unterbaut werden. Die Erziehung des Bestandes selbst hat nach den bereits gegebenen Andeutungen und im Anhaite an den dritten Teil dieser Schrift zu erfolgen. Wenn man entgegenhält, daß die Böden der Fölıren vielfach keinen Unterbau mehr aufnehmen wollen, so liegt darin die 
dringendste Aufforderung behufs Unterbaues zu düngen und jene Büden. die noch nicht so weit heruntergekommen sind, durch Unterbau und durch die Naturverjüngung wieder zı heben. Übrigens ist der Nachweis, daß wirklich die Bodengiite und nicht das Wild daran schuld ist, weshalb ein Unterhan mit einer Schatten ertragenden Holzart als Bodenschutz nicht emporkommt, noch nicht mit unumstößlicher Sicherheit erbracht. Gerade auf den schwächsten Böden wäre der Unterbau mit Einzäunung der Fläche zu versuchen, da der Unterbau den Boden nicht noch mehr schwächt, sondern vielmehr die Auszehrung durch die anspruchsvolleren Unkräuter verhindert: in erster Linie kommen Laubbäume, Schatten- wie Hallschattenbäume, in Betracht. Nadelbäume sind weniger günstig, da sie die Niederschläge allzusehr zurückhalten und den Boden abschließen. Zur Verbesserung durch Beschattung kommt auch noch eine Nährstoffanhäufung hinzu, wenn eine Stickstoff sammelnde Pflanze (Robinia, Alnus) gewählt wird, worüber die künstliche Verjüngung nähere Ausführungen zu bringen hat.

Olme Unterbau ist die Erziehungsverjüngung unter Schirm möglich, wenn alle Schäden der Bodenverwilderung des Bestandes mit schwerem Kostenaufwand behoben werden dureh Beseitigung des Unkrautwuchses und Unterhacken und Vermischen des Rohhumus und der Bleichsandschichte, sowie des zertrümmerten Ortsteines mit dem Boden. Die Ausführung dürfte an den Kosten scheitern; der Entstehung eines solchen Zustandes rorzubengen ist eines Forstmannes würdiger und für den Waldbesitzer rentabler; das Vorbengungsmittel ist rechtzeitiger Unterbau. Wer glaubt, daß Unterbau wegen des Wildes keine Aussicht habe und das Wild die Hauptsache sei, wer glaubt, daß Kahlschläge, Bodenbearbeitung und Pflanzung billiger zu stehen kommen, wer glaubt, daß die jahrelange Kahlstellung des Bodens keinen Einfluß auf seine Güte ausübe, der wird an der einfacheren Methode der Verjüngung im Kahlschlag mit daranffolgender Saat oder Pflanzung festhalten.

Frühzeitig im Bestande entstandene Löeher dureh Schneedruck. Insekten, Pilze pflegen sich meist gut mit brauchbarem Vorwuchs zu besiedehn: isolierte Pflanzen arten bei den Lichtholzarten in loreitkronige Individuen aus: nur solcher Vorwuchs ist brauchbar, der bereits geschlossen ist oder doch in wenigen .Jahren nach der Freistellung sich schlieft. Die Behandlung des Vorwuchses ist immer eine völlige Freistellung und eine Beseitigung der schlecht geformten und vorwüchsigen Stämmchen. Naturverjüngung im kahlen Saumschlag mit einer Breite desselben ron ein bis zwei Baumhöhen gibt gute Ergebnisse, wenn der Boden intensiv bearbeitet wird. Alle drei bis fünf Jahre ist ein Samenjahr zu erwarten. Im kahlen Löcherhieb wird die erste Durchbrechung ron einem Durchmesser gleich der Baumhöhe genommen; ebenso breit sind die anschließenden kahlen Ringsäume. Da 
die Föhren ziemlich stumfeste Holzarten sind, künnen sie in dieser Form auch ganz verjüngt werden; wird diø Sturmgefalır allzu drohend, tritt Kahlsaumschlag ein. Der Überhaltbetrieb ohne Vorbereitung der Überhälter ist gefahrvoll, hilft aber die natürliche Besamung zu ergänzen.

Kulissen- oder Gassenschläge sind Saumschläge im Bestandesinnern von einer Breite von ein bis drei Baumhöhen; sie fördern zwar die Verjüngung in ilırem Tempo, erzeugen aber ungünstige Randwirkungen.

Für eine Naturbesamung im Dunkelschlagsverfahren wie auch im Gruppenschirmschlag für erwachsene Föhrenbeständo, welche keinen Unterbau für den Boden erhalten haben, gelten folgende Regeln: die Verjüngung ist um so leichter, je besser der Boden, je kräftiger die Bodenverwundung, je lufteuchter das Klima, je jünger der Bestand. Der erste Hieb im Dunkelschlag ist ein Besamungshieb, der in einem Samenjahr mit gleichzeitiger Bodenverwundung ausgeführt wird und die Hälfte bis zwei Drittel aller Bäume beseitigt. Der zweite Hieb nach drei Jahren kann ein Lichthieb, der dritte nach drei Jahren ein Endhieb sein. Die Sturmgefahr ist wegen der tiefen Bewurzelung weniger zu fürchten. Je schlechter der Boden, um so rascher mu\} die Verjüngung in den Freistand übergehen; es genügen dann Besamungshiebe und Endhiebe, damit die auf solchen künmerlichen Standorten sehr lichtempfindlichen Pflanzen möglichst bald in den vollen Genuß ron Licht und Niederschlägen gelangen.

Der Gruppenschirmschlag hat vor dem Dumkelschlag den Torzug voraus, daß für Anlage von Naturverjüngungsgruppen die am besten geschlossenen Partien des Bestandes, die besseren Böden ausgesucht werden kömnen. Die ersten Anlagen mit wenigen Schirmständern können einen Durchmesser von einer Baumhöhe erhalten; gleiches Maß gilt auch als Breite für die ringförmigen Saumhiebe; ohne Bodenverwundung bleibt das Ergebnis mangelhaft oder verführt zu allzu langem Zuwarten behufs Ergänzung der Verjüngung durch weitere Samenjahre. Bei geringerer Sturmgefahr ist die Durchführung einer solchen Terjüngung für einen größeren Bestand wohl denkbar, aber wegen der Verschleppung der Verjüngung meist nicht wünschenswert.

\section{Reinl,estände der Arten der Gattung Quercus (winterlialle Eichen). reine Eichenbestände.}

Niemand wird behaupten, daß reine Eichenbestäncie im Zeitpunkt ihrer Verlichtung nicht mit einer Schatten- oder Halbschattenbolzart unterbaut werder: könnten; niemand wird bestreiten kömnen, daß nach Beseitigung des Unterbaues (der inzwischen zwei- auch dreimal teils künstlich, teils durch Naturverjüngung [Spessart] erneuert sein kann) in einem Samenjahr der Eichen, nach kräftiger Bodenverwundung vor oder nach Abfall des Samens eine vollendet dichte Bestockung 
von Eichen durch natürlichen Aufschlag sich erzielen ließe. Auf dieses Ziel steuert die Verjüngungserziehung bei allen Holzarten systematisch hin und viele der heutigen Eichen- und Buchenmischungen stellen eine Terwirklichung dieses Gedankens dar. Wo Unterbau ganz unterblieb oder mangelhaft ausfiel, ist Verunkrautung am Boden der alten Eichen kein so schlimmes Hindernis der Besamung wie bei Föhren, da die schwere Eichel zwischen dem Unkrautwuchs hindurch zu Boden fällt nnd die Keimwurzel den Boden erreichen kann, wie Terjüngungen auf Boden mit Erica oder Vacciniumüberzug in Deutschland und Frankreich beweisen; freilich beseitigt man in Frankreich die Unhölzer unter den Alteichen, zu welchen in erster Linie die junge Buche gerechnet wird, gründlich; in Deutschland verschont man bereits angesiedelte Buchen als Sehutzpflanzen, während sie doch nur Trutzpflanzen für die Eichen sind. Überall, wo alte Eichen sind, stellen sich Eichelhäher ein, welche die Eicheln in großen Mengen kunstgerecht in den Boden einstufen.

Eichenvorwuchs mit anschluffähiger Abstufung ist brauchbar, wenn er dicht geschlossen ist. Die Musterung beschränkt sich auf die Beseitigung der schlecht geformten, vorwüchsigen Stämmchen.

Ein Dunkelschlag mit drei Hieben, Besamungshieb, Lichthieb, Endhieb, ist nur auf gleichmäßig gutem Boden mit leidlich geschlossenem Bestande möglich. Bodenverwundung durch Umhacken, Umpflügen, Schweineeintrieb und dergleichen vor oder nach Samenabfall ist unumgänglich. Besser eignet sich der Gruppenschirmschlag, bei dem es möglich ist, dic besten Bodenpartien auszuwählen und auf dieser Fläche gründliche Bodenbearbeitung vorzunehmen.

Auch die anschließenden Ringhiebe werden sich besamen, soweit der Boden gut und die Bodenverwundung im Samenjahr eine gründliche ist. Wegen der unausbleiblichen, schweren Beschädigung der Naturverjüngmng durch das Herausbringen der schweren, breitkronigen Nutzholzeichen begnügt man sich mit Erreichung guter Torwuchsgruppen.

\section{Die Reinbestünde der Gattung Betula, die remen Birlienbestände.}

Für die Naturverjüngung der Birken passen Kahlschläge, besonders kahler Saumschlag von der Breite von zwei bis drei Baumhöhen besser als Schirmschlagformen. Die Birken verlangen nackten, aber durch Regen fest geschlagenen Boden; in frisch gelockertem vertrocknet die äußerst zarte Keimpflanze.

\section{Reinbestünde der selemetterlingsblütigen Bäume.}

Robinia, Gleditschia: Cladrastis, Gymnocladus und andere werden zumeist behufs Bodenverbesserung angebaut; auf solchen Standorten sind sie ausgesprochene Lichtholzarten und verlangen deren Behand- 
lung; nur intensive Bodenbearbeitung vermag die schweren Sämereien behufs Keimung einzubetten.

\section{Beispiele für die schirmständige Naturverjüngung von gemischten Beständen.}

In dieser Schrift ist als moderner Idealwald der Kleinbestand als Reinbestand in der Erziehungsverjüngung hingestellt. An dio Stelle der Einzel- oder Gruppenmischung der Holzarten in nerhalb des Bestandes soll die Mischung der nach Holzarten verschierlenen Kleinbestände innerhalb des Waldkomplexes treten. Bereits ausführlicher behandelte Erwägungen über Güte und Massenproduktion, über Schwierigkeit und Kostspieligkeit der Erziehmng, über Schwierigkeit, Langwierigkeit und damit wiederum Kostspieligkeit der Begründung solcher Mischbestände sind es, welche zwingen, auf das pedologische Ideal der Einzel- oder Gruppenmischung der Bestände zu verzichten und sich mit einer kleinbestandsweisen Mischung des Waldes zu begnügen, wodurch der schlimmste Nachteil der großen Reinbestände abgewendet wird. Kommt hierzu noch eine Naturverjüngung, welche gestattet, die Kleinbestände schnell, sicher und leicht zu verjüngen, so fallen auch die schweren und kostspieligen Nachteile der bisherigen Reinbestände, nämlich Kahlschlagwirtschaft und künstliche Verjüngung hinweg. Da Bestände, welehe nur einen Bodenschutz oder einen nicht hauptständigen $Z$ wischenstand einer anderen Holzart tragen, nicht als gemischte, sondern als reine Bestände aufgefaßt werden müssen, ist über ihre natürliche Wiederverjüngung das Notwendigste bereits mitgeteilt: aber auch dann wird wiederum ein Reinbestand begründet, worauf später der künstliche Unterbau folgt. Wird aber an der rorhandenen Bestandsbildung festgehalten und werden die jetzt und in den nächsten .Jahren haubar werdenden mit ihrem Kronen gemischten Bestände als ideale Waldbilder nach jeder Richtung hin betrachtet und wird ihre natürliche Enneuerung wieder angestrebt, so ist zu bemerken, daß eino stammweise Misehung nur durch den Dunkelschlag annähernd gleichzeitig erzielt werden kann, wobei der erste Hieb sich nach der waldbaulich schwächsten Holzart richten muß.

Soll eine gruppenweise Mischung erzielt werden, so gibt der Gruppensehirmsehlag hierzu das zuverlässigste Mittel. Soll einer Holzart auch moch ein zeitlicher Torsprung gewährt werden, beginnt die Gruppenwirtschaft für eben diese Holzart zuerst.

Soll eine Mischung der Holzarten stamm-, trupp- und altersklassenweise erhalten werden, so kann allein der Femelhieb ein solches Waldbild schaffen und in seinem unveränderten Zustande erhalten.

Die Musterung der Schlußdurchbrechungen und ihre Behandlung, die Musterung der Vorwüchse, ob rein oder selbst gemischt, sowie ihre Behandlung hat im Anhalt an die früher gegebenen Grundsätze zu geschehen. 


\section{Gemischte Holzarten.}

\section{Bestände, gemischt aus Angchärigen tler Gattungen Picea und Abies;} gemischte Bestände ron Fichten und Tamen.

Das Streben der beiden Schattenholzgattungen, in der freien Natur Reimbestände zu bilden, weist darauf hin, daß sie im Mischwuchs unverträglich sind; im wärmeren Klima, in der vorteilhaftesten Urwaldbzw. Femelwaldverfassung schließt die Tanne jede Mitkonkurrenz der Fichten aus; im kühleren, mehr den Fichten zusagenden Klima wird die Tanne fern gehalten. Im aufgelockerten Schluß, in dem es keine Bedrängung gibt, herrschen beide friedlich zusammen. Da die Tanne als die waldbaulich schwächere Holzart durch ihre Langsamwüchsigkeit in der Jugend betrachtet werden muß, wird eine natürliche Verjüngung im Dunkelsehlag, in den Torbereitungs- und Besamungshieben allein nach der Tanne bemessen, nicht bloß in der Stellung der Belichtung, sondern vor allem auch im Freihieb schönkroniger Tannen und in der Auswahl der besseren Bodenpartien für diese Maßnahmen.

Mit den ersten Lichthieben nimmt die Aussicht für die Tanne ab; jene für die hommende Fichtengeneration $\mathrm{zu}$; indem bei den folgenden Lichthieben vorzugsweise Tamnen hinweggenommen werden, wird der zweite Teil der Verjüngung sich so abspielen, wie es die Fichten verlangen. Nur auf diesem W'ege dürfte es möglich sein, eine annähernd stammweise Mischung der .Jugend herbeizuführen; es bleibt der Nachbesserung oder Beseitigung des Übermaßes einer Holzart die Korrektur des Mischungsverhältnisses übrig.

Für den saumweisen Dunkelschlag bedarf es keiner weiteren. Beifügungen. Saumbreite und Schirmstellung richten sich wiederum nach der Tamme.

Soll eine gruppenweise Mischung beider Holzarten im Bestande vorherrschen, so ist lieine Verjüngungsform besser geeignet, dieses zu erreichen, als der Gruppenschirmschlag. Tollbekronte Tannen werden frei gehamen in solcher Zahl, als dem beabsichtigten Mischungsverhältnis entspricht; da Fichte und Tanne in diesem Verfahren gruppenweis getremnt erscheinen, ist auch die gleichzeitige Freistellung ron schön bekronten Fichten behufs. Erzielung von Fichtenanflug zulässig; wird für die Tanne ein Torsprung gewünseht, unterbleibt zunäehst die Freistellung der Fichten; die ringförmigen Erweiterungshiebe für die Tannen gewimnen allmählich eine solche Lichtmenge, daß die Ansiedelung der Tanne zum Ende liommt und an Stelle der Tanne die Fichte erseheinen wird, zumal von nun an die Gruppenhiebe allein auf diese gerichtet sind. Daß Sturmgefahr zum Verlassen dieser Methode und zum Übergang zum Kahlsaumschlag zwingen kömnen, wurde des öftern bereits angedeutet; mit dem kahlen Saumschlag endet die Naturverjüngung und begiunt die künstliche zugunsten der Fichte. 
Beispiele fur die nat urliche Verjungung usw. D. Femischte Holzarten. 353

\section{Bestünde gemischt aus den Angehörigen der Gattung Picea und Fagus, gemischte Bestïnde von Fichten und Buehen.}

Zur Erhöhung der Rentabilität der reinen Buchonbestände ist diese Mischung sehr boliebt. Je mehr Fichten in den Buchenbestand eintreten, um so wertvoller wird das Objekt, je mehr Buchen in den Fichtenbestand eintreten, um so mehr sinkt der Wert. Wühlt man statt solcher Mischbestände mehrere Kileinbestände, welche aus reiner Fichte und reiner Buche bestehen, würden sich die Nachteile einer solchen Mischung auch mit Bezug auf die Stammausformung vermoiden lassen, ohne daß dadurch auf die Vorteile der Buche für den Boden bei entsprechender Erziehung der Fichten und Unterbau mit Buchen verzichtet wäre.

Bei stammweisem Auftreten der Mischung in jugendlichem Alter als beabsichtigte Verjüngung wie als Vorwuchs siegt jene Holzart, welche zuerst ein geschlossenes Kronendach erzeugt. Schließen sich zuerst die Buchen, dann kommt keine Fichte mehr durch deren Kronendach hindurch; kommt die Fichte zuerst über die Buche hinweg, ist die Buche als hauptständig verloren; aber nirgends läßt sich in der Natur ein Beispiel finden, daß die Fichte imstande wäre, ein geschlossenes Buchenkronendach zu durchstechen. Wo der Anschein erweckt ist, als hätte die Fichte sich hindurehgearbeitet, ergibt genauere Beobachtung, daß die Fichtengiptel nie ganz überschirmt waren. In exponierten Lagen wird die Fichte im Durchstechen der jungen Buchenkronen schon durch die peitschende Wirkung der Buchenzweige verhindert. Es ist somit schwierig zu entscheiden, welche die waldbaulich schwächere der beiden Holzarten ist; es ist deshalb auch schwierig, eine stammweise Mischung der beiden Arten zu begründen, ohne daß dureh Jungwuchspflege fortgesetzt bald zugunsten der einen, bald zugunsten der andern mit Axt und Säge dazwischen getreten wird. Da bei der stammweisen Mischung die Schaftentwicklung beider Holzarten geringwertiger ist als im reinen Fichten- bzw. reinen Buchenbestande, so ist es besser auf stammweise Mischung zu verzichten.

Wer sie aber wünscht, wird unschwer dieselbe durch den Dunkelschlag, der sich nach der Buche richtet (man vergleiche den reinen Buchenbestand) erreichen können. Für die Jungwuchspflege ist zu beachten, daß in den wärmeren Lagen und im Optimum der Rotbuche diese, in den kühleren Lagen der Buche die Fichte als die Siegerin hervorgehen wird, wenn die Pflege unterlassen wird. Es ist sodann zu bedenken, da $\beta$ die unter die Buchegeratonden Fichten zugrunde gehen, daß die unter den Fichten stehenden Buchen aber sich am Leben erhalten.

Nach einer Erhebung ron Geheimrat Gaver ${ }^{1}$ ) gibt es in Bayern fast 160000 ha solcher Mischbestände; das wäre keine gïnstige Er-

1) Die Bestockungsverhältnisse der bayer. Staatswaldungen v. Dr. F. S ch n eider. Berlin 1906. Terlag von Paul Parey.

Mayr, Waldbau. 
scheinung, zumal wemn das ausgerechnete Durchschnittsprozent der Mischung von 53 Fichten, :30 Buchen und 17 übrigen Holzarten auch in der Natur sich finden würde. Voraussichtlich handelt es sich bei der Durehschnittsberechnung um vorwiegend Fichten mit geringem Prozentsatz von Buchen und vorwiegend Buchen mit geringem Anteil an Fichten, so daß der Nachteil dieser Mischungen von Buchen und Fichten in Wirhlichkeit beträchtlich geringer ist, als er infolge der Durchschnittsberechnung erscheint.

Nicht läßt sich aus dem statistischen Nachweis entnehmen, ob stammweise oder gruppenweise Nischung vorherrscht; das aber ist von Wichtigkeit, denn die stammweise Mischung ist das für den Boden günstigste, für die Nutzholzformung aber das ungünstigste Verhältnis beider. Wird bei der Verjüngung die gruppenweise Mischung beabsichtigt, so gibt der Gruppenschirmschlag hierzu die Mittel in die Hand. Durch Freihieb der best bekronten Buchen beginnt die Terjüngung; sie erweitert sich durch Ringhiebe, soweit Buchen gewünscht werden. Daß für diese Anfangsgruppe die beste Bodenpartie ausgewählt wird, Bodenverwundungu. dgl. eintritt, ist nach den vorausgehenden Bemerkungen selbstrerständlich. Es kann gleichzeitig mit der Buche oder erst nach Sicherung der Buchenvorwuchsgruppe auf gleiche Weise die Erziehung von Fichtengruppen angestrebt werden. Ist Übergang zum kahlen Saumschlag notwendig, so vollendet die Verjüngung eine Ergänzung mit Fichten durch Pflanzung.

Für die Femelverjüngung bedarf es nur des Hinweises, daß die Buche zu begünstigen sein wird, wenn, wie voraussichtlich, solche Bestände in kühleren Regionen sich finden.

\section{Tannen- und Buchenmischung; Mischungen der Gattungen Fagns und Abies.}

Diese Mischung ist in ihrem Wert etwas günstiger zu beurteilen als Fichten und Buchen, so weit beiderseitige Astreinigung und Bedrängung in Frage kommen. Ihre natürliche Wiederverjüngung im Dunkelschlag oder Gruppenschirmschlag kann im Anhalt an die Andeutungen bei Fichten und Buchen geschehen; es ist aber zu beachten, daß die Tamne als die waldbaulich schwächere Holzart erscheint.

\section{Mischungen von Angchörigen der trei Gathngen Picen, Abies und Fagus, Fichten-, Tamen- und Buchenmischbestände.}

Da ein Mischbestand nicht um so besser wird, je mehr Holzarten in Mischung treten, sondern vielmehr in seiner Schaftausformung und Nutzholzmassenerzeugung noch mehr abnimmt, so wäre es besser, solche Mischbestände in einzelne, kleinere Reiubestände aufizulösen. Soll aber die Mischung erhalten und sogar oine stammweise Mischung angestrebt werden, so kamn außer dem Femelhiob nur der Dunkelschlag das gewïnschte Ergebnis zeitigen, wenn der Vorbereitungs- 
und der Besamungshieb zugunsten der Tamne (nach den Angaben für den reinen Tannenbestand), die ersten Lichthiebe als Besamungshiebe für die Buche und das letzte Drittel der Hiebe unter Beseitigung der alten Buchen und alten Tannen mit Rüclisicht auf dio Verjüngung der Fichten ausgestaltet werden. Gemischter Vorwuchs ist wie gemischte Verjüngung stets gegen Vordringen der Fichte und Unterdrückung der Tanne zu sichern.

Am einfachsten löst die Aufgabe der natürlichen Wiederverjüngung wiederum der Gruppenschirmschlag, welcher alle drei Holzarten nebeneinander oder auch nebeneinander und hintereinander in der Reihenfolge Tanne, Buche, Fichte zu verjüngen gestattet.

Ähnliche Gesichtspunkte werden führen müssen, wenn die Aufgabe gestellt ist, andere Schatten ertragende Nadelbäume wie Pseudotsuga, Tsuga, Thuja, Thujopsis usw. mit den genannten Gattungen oder unter sich in Jischung durch Naturverjüngung zu erhalten oder neu zu begrïnden.

\section{Mischung der Gattung Picea mit zxei-und dreinadeligen Föhren (Gattung Pinus, Selition Pinaster, Murraya, Jeffreya).}

Auf ausgesprochenem Fichtenboden, seichtgründig, aber nahrungskräftig, verhalten sich die beigemischten Föhren ungünstig in der Schaftform, Astreinheit, Kernbildung; auf ausgesprochenem Föhrenboden geringerer Bonität erlangt die Fichte nicht die Kronenhöhe der Föhre; die Föhre gilt dann als rein; nur auf Föhrenboden I. und II. Bonität (sandiger Lehm, lehmiger Sand, humoser, frischer Sand) kommt eine hauptständige Mischung von Fichten und Föhren zustande; von Jugend auf halten beide Holzarten nur im kühleren Klima der Föhre, das ist im Fichtengebiet, durch das gefährliche Stangenalter hindurch im Wachstume Schritt, dort erwächst auch die Föhre mit geradem Schafte.

Wird die Fichte von der Föhre überwachsen, so erhält sich erstere, durchsticht aber später die Föhrenkrone nur in ganz windgeschützten Örtlichkeiten. Wo Windschutz fehlt, wird die Fichte von den Föhrenästen verpeischt.

Die natürliche Wiederverjüngung richtet sich nach der Fichte, indem im Dunkelschlag die ersten Hiebe bis zur Erzielung einer Besamung den Bestand als reinen Fichtenbestand betrachten: die Lichtungshiebe, welche vorzugsweise Fichten beseitigen, schatfen Licht und Raum für die Föhre. Ganz besonders eignet sich wiederum zur Herstellung einer gruppenweisen Mischung unter Auswahl der besseren, frischeren Bodenpartien für die Fichte die Gruppenschirmschlagform. Die Angaben bei den Reinbeständen finden hierbei simgemäße Anwendung. 


\section{J)ir Gattung Picea mit Angehörigen der Grattung Larix, Fichten- und Lärchemmischlorstünde.}

Alle Lärchen finden sich in ursprünglicher Wischung mit Fichten nur in der kühlsten Waldregion, sei es im Norden oder im Hochgebirge; was von solchen Mischungen in wärmeren Lagen sich findet, ist kïnstlich angelegt; nur im kïhlsten Standort, wo der S c h l u B der Kronen fehlt, liann die in Kronenmischung a f fretende stammweise Vereinigung beider Holzarten bestehen. Dort ist die Wirtschaft ein Femelbetrieb, in dem beide Holzarten sich wiederum annähernd stammweise gemischt einfinden. Im geschlossenen Fichtenbestande sind die Lärchen lïnstlich eingebracht; die natürliche Verjüngung ist so gut wie ausgeschlossen, so daß die Betrachtung dieser Mischung in das Gebiet der lï̈nstlichen Bestandesgründung gehört.

\section{Die Grattung Betula (Birlien) mit der Guttung Picea (Fichten).}

Rauheres Klima oder Bodenungunst (nasser, sumpfiger Boden) führen die beiden Holzarten häufig zusammen. Im Norden und auf hohen Bergen im Süden, in der Nähe der Waldgrenze, im aufgelösten Kronenschluß sind beide Holzarten friedlich nebeneinander selbst in Einzelmischung. Je wärmer aber das Klima, um so unduldsamer werden die Birken durch ihr Voraneilen und ihre peitschende Einwirkung auf die zarten, nachwachsenden Gipfeltriebe der Fichte. In solchen (̈rtlichkeiten ist auch eine Trennung der Holzarten in Gruppen von reinen Fichten und reinen Birken anzustreben. Sie wird erzielt durch den Gruppenschirmschlag, der die Fichte begünstigt; für die Birken genügen einige ältere, freistehende Exemplare, um den Rest der Fläche bei Bodenbearbeitung und Wiedererhärtung desselben durch Regen oder Schneebelastung mit reichlichem Birkenanflug zu bestocken.

\section{Die Gattung Abies mit der Gattung Quereus (Weifseichen), Tamen-und Eichenmischbestünde.}

Da die Tannen in Europa und Amerika etwas wärmere, in Ostasien die gleichen Gebicte bewohnen wie die Fichten, so ragt in Europa und Amerika der wärmste Teil, das natürliche Verbreitungsgebiet der Tamnen, noch in das kühlere Verbreitungsgebiet der Eichen, so daß Mischbestände beider Arten vorhanden sind. Daß die Eiche aus solchen Beständen als minderwertig, als weniger dauerhaft gilt, dürfte seinen Grund in der mangelhatten Belichtung der Eichen finden, wodurch dio Bildung des Kernfarbstoffes beeinträchtigt wird. Immer wird die Eiche in Gefahr sein, von der Tamne überwachsen zu werden. Aus gemischtem Torwuchs sind daher die Tamnen zu entfernen, wenn die Eichen genügen, um sich zu einem Jungwuchse in liurzer Keit zusammenzuschliefen. 
Beispiele fur die naturliche Verjügung usw. D. Gemischte Holzarten. 3iт

Auch im Dunkelschlag wird auf eine flächenweise Trennung hingearbeitet durch die Freistellung schön bekronter Eichen und Vorbereitungsstellung, Besamungs-, Licht- und Endhieb für die Tannen. Inı Samenjahre der Eichen ist ergiebige Bodenverwundung nötig. Durch Anflug der Tannen in die Eichengruppen und Einstufung von Eichehn in den Tannenjungwuchs durch den Eichelhäher wird immer wieder gemischter Jungwuchs entstehen, in dem die Eiche gefährdet ist.

Es empfiehlt sich daher, Eichen und Tannen von Anfang an örtlich zu trennen durch den Gruppenschirmschlag, wobei für die Eichengruppen die besten Bodenpartien und wärmsten Lagen ausgewählt werden. Daß diese Gruppenwirtschaft mit einem Freihieb normal bekronter Eichen und Tannen gleichzeitig oder nacheinander beginnt, Bodenverwundung im Samenjahre ausführt und jede Holzart nach ihrem Bedürfnis in den Ringhieben weiter behandelt, ergibt sich aus den früheren Betrachtungen; es ist aber auch diesen zu entnehmen, daß die Verjüngung nur Stückwerk sein kann.

\section{Die Gattung Quercus (Weifseichen) mit der Gattung Fagus, Eichen- und Buchenmischbestände.}

Eine umfangreiche Literatur beschäftigt sich mit dieser Mischung, welche zur Werterhöhung der reinen Buchenbestände im wärmeren Klima von Mitteleuropa als hochwillkommen begrüßt wird. Eine erdrückende Mehrheit ron Berichten weist nach, daß eine stammweise, gleichzeitige Mischung der beiden Arten teilweise schon in der. Jugend, insbesondere aber im Stangenalter zur Ansscheidung der Eichen führt, während einige Schriftsteller wiederum behaupten, daß die Eichen sich vorwüchsig oder wenigstens gleichschrittlich erhalten. Auch hier sind es Naturgesetze, die entscheiden. Je kühler im Verbreitungsgebiete der Buchen das Klima, um so sicherer wächst die Buche voran; je wärmer das Klima, um so mehr bessern sich die Aussichten für die Eiche. Im Optimum der Eiche, im Castanetum, hält sie mit der Buche im Jungwuchs öfters Schritt und überwächst sie im kritischen Stangenalter. Dort allein ist Einzelmischung der Kronen beider Holzarten zulässig. Die wärmsten Lagen von Deutschland, Mittel- und Nordfrankireich, Belgien $n a ̈ h e r n$ sich dem Castanetum. Wenn dort ein Standort für die Mischung ausgewählt wird, welcher in seiner Bodenungunst die Buche schädigt (Kalkmangel), in seiner Bodengunst (toniger sand) die Eiche fördert, so besteht die Möglichkeit, daß Eiche und Buche Schritt halten; von dieser Ausnahme abgesehen, ist in ganz Deutschland die Eiche nur durch ständige, kostspielige Stämmelung der Buche in Mischnng mit letzterer zu erhalten. Danach ist zu ermessen, daß gemischter Aufschlag oder Vorwuchs beider Holzarten fast stets zur Unterdrückung der Eiche führen muß; die Buche muß somit herausgenommen werden, wenn die Eichen an Zahl genügen, um sich bald zu schließen. 
So wertvoll die Buche als Unter- und /wischenstand. so schädlich ist die Kronenmischung, und es entspricht dem erhöhten Interesse für die wertrolleren Eichen besser, wenn die Buchen erstim Ha u b r keits alter der Eichen hauptständig werden. Dieses Ziel ist nur durch Begründung reiner Eichenbestände. welche mit Buchen später mnterbaut werden, erreichbar. Die Lösung der Buchenfrage geschieht daher nicht durch Einzeleinbau der Eichen oder anderer Nutzhölzer in Buchen. sondern durch Beibehaltung der reinen Buchen, aber Verminderung dieser Bestände in Zahl und Ausdehnung.

Sollten aber Buchen und Eichen gleichzeitig verjüngt und eine kronenweive Mischung angebahnt werden, so verlangt der Dunkelschlag die Freistellung schön bekronter Eichen und Bodenbearbeitung im Samenjahre derselben; der zwischenbestehende Buchenbestand wird in Torbereitungsstellung oder, wenn diese entbehrlich ist, in Besamungsstellung gebracht und verjüngt wie ein reiner Bestand. Durch Tiere werden Bucheln in die Eichen und Eicheln in dio Buchen eingebracht. Zweckentsprechend wird sich eine flächenweise Trennung der beiden Holzarten erweisen, wozu der Gruppenschirmschlag mit Freihieb einer Anzahl von Eichen und ebenso von Buchen am besten sich eignet. Dabei kann aber auch der Eichengruppe ein Vorsprung gegenüber den Buchengruppen an Zeit und Wachstum gegeben werden nach dem Grundsatze: der Vorsprung an Zeit muß um so größer sein, je kleiner die Gruppe. Ergibt die Fortsetzung der Erweiterungen der Buchengruppen Fehlstellen, so sind die jungen Buchen entweder wiederum mit Buchen zu ergänzen oder die Buchen sind auszureißen und die Fehlstelle ist mit Eichen oder, wenn groß genug, mit einer anderen Holzart zu besiedeln; das Belassen einzelner Buchen führt stets zu Verlegenheiten.

\section{Zuei- und dreinadelige Führen und Buchen.}

Für die Beurteilung des Wertes der Eimmischung von Buchen in Föhren oder Föhren in Buchen gelten die bei der Mischung Fichte und Buche dargelegten Motive. Auch im Buchenwalde ist nicht, wie man erwartet, die Föhre besonders schönschaftig wegen der Bedeckung durch die Schattenholzart; der Lustand, daß anf Buchenboden erster und zweiter Bonität die Föhre zur Krummwïchsigkeit, Ästigkeit, Farbkernmangel neigt, wirkt der Absicht, weleher bei der Mischung leitete, entgegen. Anderseits kam die Buche in Führenbestände nur dann hamptständig eintreten, wenn diesn auf erster und zweiter Bodengüte, somit auf lehmigren Sand und sandigen Lehm stocken. Die Föhre hält sich auf allen sandigen Böden vorwüchsig, auf sandarmen, schweren Buchenhöden wird sie im kritischen Alter von der Buche eingeholt und anf windigen Lagen verpeitscht. soll auf gutem Föhrenboden diese Mischung im Dunkelschlagverfahren verjüngt werden, so 
Beispiele fur die natürliche Verjungung usw. D. Gemischte Holzarten. 359

richtet sich die ganze Verjüngung nach der Buche; bei den Lichthieben werden von den als Schirmständer übergehaltenen Föhren reichlich noch Föhren sich einstellen. Besser wird sich der Grupponschirmsehlag eignen müssen, welcher für jede Holzart, Buchen oder Föhren den passenden Boden auszuwählen gestattet. Bei der Standfestigkeit beider Holzarten wäre auch eine volle Verjüngung in dieser Form denkbar, wenn sie nicht, wie alle Gruppenschirmschläge, allzu langsam zum Ziele führen würde.

\section{Gattung Quercus (Weifscichen) mit zuci-und dreinaleligen Führen, Eichen- und Föhrenmischbestände.}

Auch diese Mischung ist nur auf Föhrenboden erster und zweiter Bonität in wärmeren Klima zulässig; beide Holzarten bringen sich gegenseitig keinen Nutzen in der Ausbildung des Schaftes, wohl aber gewinnt etwas der Boden, obwohl beide Holzarten nicht die Verunkrautung abwenden können. Die Verjüngung im Dunkelschlag kann nur eine Freistellung schönkroniger Eichen und ebensolcher Föhren sein; Bodenverwundung im Samenjahr der Eichen unerläßlich. In den rasch folgenden Licht- und Endhieben werden die Föhren sich einstellen.

Die flächenweise Trennung, für welehe schon die wechselnde Bodengüte Anlaß gibt, wird erreicht durch den Gruppenschirmschlag, dessen Führung nach den vorausgehenden Beispielen nicht mehr zweifelhaft sein kann.

\section{Birken- und Föhrenmischbestände, die Gattung Betula mit den Sckitionen Pinaster, Murraya und Jeffreya.}

Auf drei grundverschiedenen Standorten kommen solche Mischungen auch in der Natur vor: auf sehr magerem, trockenem, sandigem Boden, auf sehr feuchtem, sumpfigem Standorte und endlich auf normalem Boden der kältesten Waldregionen der nördlichen Breiten. Bei allen Naturverjüngungen unter Schirm wird die Föhre gegenüber der allmächtigen Birke zu begünstigen sein; auf sehr magerem Boden und auf sumpfigem Boden wird die Naturverjüngung nur möglich sein, wenn sie über sehr lange Zeiträume verfügt.

Die Eiche, Gattung Quercus, mit Halbschattenlaubhölzern, wio Ulmus, Fraxinus, Carpinus, Acer, Alnus, findet sich regelmäßig in Mischung in alten Flußauen des wärmeren Fagetums. Alle Holzarten auch für die Zukunft zu sichern, ist möglich im Femelwalde: wird ihm die Überführung solcher Auwaldungen in gleichalterigen Hochwald hier vorgezogen, so ist der reine Kleinbestand mit 0,3 ha als Maximalfächengröße wohl am besten.

Die La ubholzgattungen Fraxinus, Aeer, Ulmus, Betula in Verbindung mit Nadelbäumen, wie Strobus, Picea, Abies, selbst Larix, besiedeln die alten Flußauen des kühleren Fagetums; sie alle zu er- 
halten ist möglich im Femelwalde: doch sollte auch hier bei Umwandlung in gleichalterigen Hochwald der reine Kleinbestand angestrebt werden.

Für fremdländische Gattungen, wie Juglans, Carya, Zelkowa, wäre zu beachten, daß diese schwersamigen Lichtholzarten in der Behandlung zum Zwecke einer Naturverjüngung an die schwersamige Eiche (Quercus) sich anschließen müssen; für die Strobus, Chamaecyparis, Cupressus und andere gelten die für leichtsamige Halbschattenarten entwickelten Grundsätze. Zusammen mit schwersamigen Arten gelten die leichtsamigen als die waldbanlich starken, welche erst im letzten Akte der Naturverjüngung sich einstellen dürfen; bei Mischungen von Halbschatten- mit Schattenholzarten, wie Sektion Strobus oder Cembra mit Picea, Gattung Acer, Ulmus mit Fagus, Strobus mit Fagus nähert sich die Behandlung der Halbschattenholzart jener einer Lichtholzart, bei Nischung einer Halbschattenholzart, wie die Sektion Strobus, Cembra, Chamaecyparis, T'suga mit einer Lichtholzart, z. B. der zwei- und dreinadeligen Föhren, mit Larix, wird die Behandlung der Halbschattenholzart jener einer Schattenholzart anzugleichen sein.

Die allgemeinen naturgesetzlichen Grundlagen für die Behandlung ron Mischbeständen geben über die Behandlung aller in der Natur möglichen Mischungen zum Zwecke ihrer natürlichen Wiederverjüngung Anhaltspunkte; obige Beispiele mögen genügen, um die Detailarbeit bei einer solchen Verjünging anzudeuten, ohne der praktischen Ausführung allzu bindende Vorschriften zu geben.

Einzelstehende Überhälter fördern zwar die natürliche Ansamung einer Fläche, schädigen aber die Ansiedelung und das Wachstum der Pflanzen unter ihrem Troptbereiche. Für die Besamung ist der Einzelüberhalt der beste; um jedoch der Windgefahr vorzubeugen, sollen die Überhälter allmählich in den Freistand übergeführt werden (Erziehungsverjüngung, Dunkelschlag, Gruppenhieb); bei Kahlschlag ist vorherige, allmähliche Umlichtung der Überhälter wünschenswert. Bei genügender Vorbereitung kann zwar jede $\mathrm{Holzart}$ übergehalten werden, aber nicht jede lohnt diese Behandlung: zu den lohnenden zählen nur jene, deren Gebrauchswert mit dem Durchmesser stetig steigt, das ist der Fall bei den Weißeichen, Föhren. Lärchen und wahrscheinlich auch bei vielen nichteuropäischen Baumarten, wie Juglans, Catalpa, Zelkowa und anderen.

Von Seebachs Buchennutholzwirtschaft ist eine Naturverjüngung vor der vollen Haubarkeit; verschiedene Schriftsteller weisen auf sie als ein beachtenswertes Mittel zur Erziehung von Starkholz und kräftiger Vornutzung hin, was jedoch vollkommener durch einen geregelten Durchforstungs- und Durchlichtungsbetrieb sich erreichen läft. 


\section{Elfter Abschnitt. \\ Die künstliche Wiederverjüngung.}

Bei der gegenwärtig üblichen Waldeinteilung in Großbestände, der Forderung der Verjüngung in kurzer Zeit, der Erziehung der Bestände ohne Rücksicht auf den Bodenzustand ist die Kahlschlagwirtschaft mit darauf folgender künstlicher Verjüngung immer mehr in den Vordergrund getreten; das natürliche Verjüngungsverfahren wird nur für Buchen und Tannen in größerem Umfange ausgeführt, für die ïbrigen Holzarten wird es zwar versucht, aber seine Ergebnisse sind umzureichend, ja rielerorts nicht eimmal als Beigaben für die künstliche Verjüngung willkommen, vielmehr als ein Hindernis für die gradlinige PHanzung betrachtet.

In der Tat sind die Vorzüge, welche die künstliche Verjüngung bietet, große: Die Unabhängigkeit rom Eintritt des Samenjahres wurde erst durch den leichteren Güteraustausch während der letzten Dezennien ermöglicht. Da die meisten Holzarten sich über große Landstrecken zu verbreiten pflegen, so besteht Aussicht, daß sie nicht überall gleichzeitig fruktifizieren, so daß der Fall einer völligen Wißernte im Saatgnte innerhalb des natürlichen Verbreitungsgebietes zu den Ausnahmen zählt. Je größer das Verbreitungsgebiet einer Holzart, um so unwahrscheinlicher die Gleichzeitigkeit des Samenerträgnisses. Fehlt somit an einer Örtlichkeit die Samenbildung, tritt sie an einer anderen ein; aus letzterer kamn damn Saatgut bezogen werden. Auch die Verschiedenheiten im Klima innerhalb einer Vegetationszone, kältester und wärmster Standort, vielleicht auch im Boden geben Veranlassung zu Verschiedenheiten in der Zeit des Samenerträgnisses, da das wärmere Klima bzw. der schleclıte Boden die Samenbildung begünstigen, das kühlere Klima und der bessere Boden verzögern. Für die meisten Pflanzenzüchter erweckt diese Vorstellung jedoch ernste Bedenken, weil damit Unkenntnis bezüglich der Herkunft des Samens besteht oder gerade, weil die Herkuntt aus einem kühleren oder wärmeren Klima bekannt ist. Verfasser dieser Sehrift hält an 
dem Satze fest, daß jeder Standort der typischen Holzart ein Saatgut liefert, in dem alle typischen, morphologischen und physiologischen Eigenschaften der Holzart von ihrem wärmsten bis zu ihrem kältesten Standorte enthalten sind: für jene aber, welche für jeden klimadivergenten Standort eine plysiologische Varietät oder Rasse zn erkennen glauben, ist jede Saat, die nicht vom eng heimischen Standorte stammt, verwerflich. Damit wird aber die kïnstliche Verjüngung wiederum völlig abhängig vom Eintritt des Samenjahres der betreffenden Gegend; sie geht ihres größten Vorzuges verlustig, ohne einen entsprechenden Wert dafür einzutauschen; dann die mehrere Dezennien hindurch geübte Praxis der Verwendung von Saatgut, von dessen Herkunft nichts bekannt war, als daf es irgendwo in Europa gewachsen war, hat keine Bestände geliefert mit ungünstigen Merkmalen, die als ein Einfluß der umbeliannten Heimat des Saatgutes hingestellt werden kömnten. Erst der weiter ausgreifende Handel hat Sämereien nicht erwünschter Art en oder von Artenvereinigungen (Bastarde) angeboten, worüber bei Behandlung des Saatgutes einige Ergänzungen gebracht werden sollen. Unter den hentigen Waldverhältnissen entsprechen die künstlichen Verjüngungen am vollkommensten der modernen Anforderung an eine Verjüngung, nämlich schnell, sicher und leicht. Wo Nittel reichlich zur Verfügung stehen, um Gefahren abzuwenden, kann auf eine Fällung sofort die röllige Verjüngung der Fläche folgen; wird dabei statt Saat die Auspflanzung mit mehrjährigen Pflanzen gewählt, so liegt darin noch ein Gewinn an Jahren und Zuwachs. Daß die Verjüngung sicher ist, beweisen die zahllosen, wohlgelungenen Kulturen seit vielen Dezemnien. Kann die Ballenpflanzung Anwendung finden, damn sind Verluste fast ganz ausgeschlossen. Niemand dürfte auch bestreiten, daß die künstliche Verjüngung eine sehr leichte ist. Die nötigen Vorbereitungen und manuellen Fertigkeiten sind so einfach, daß sie jeder lernen kann, ja, daß für wichtige Arbeiten, wie Bodenverwundung, Säen, Verschulen, mechanische Vorrichtungen, Maschinen, als Ersatz der Handarbeit bei Großbetrieben mit Vorteil Anwendung finden können. Da die künstliche Verjüngung in der Regel mit Kahlschlag in Verbindung tritt, so kommen zu den Vorteilen noch jene hinzu, welehe den Kahlschlagwirtschatten überhaupt zuerkannt werden müssen.

Notwendig ist die kïnstliche Verjüngung in folgenden Fällen: bei Ödlandaufforstungen, ob diese Heideflächen oder Wiesenland, sumpfige, durch Entwässermng in Waldboden umgewandelte Standorte oder ans dem landwirtschaftlichen Betriebe ausgestoßene Gelände oder entwaldete und verwilderte Berghänge (Karste) sind: bei beweglichem Boden, wie bei Dünenaufforstungen, auf den geringsten Sandböden : in Hochwaldungen, welche der Überschwemmungsgefahr ausgesetzt sind, wie in den Flufauen; bei Holzartenwechsel im Betriebe; bei dem Nutzholzvorbau und Bestandsschutzholzvorbau, bei Unterbau; bei allen 
Ergänzungen in natürlichen Verjüngungen; bei Wirtschaften des Hochwaldbetricbes, bei welchen die Holzarten vor Erreichung ihrer Samenertragsfähigkeit genützt werden, wie Papierholzhetrieb, C'luristbaumzueht: bei allen Beständen, welche künstlich auberhalb des natürlichen Verbreitungsgebietes einer Holzart in einem vom heimatlichen verschiedenen Ḱlima angelegt wurden, sei es, daß der nene Standort kühler oder wärmer als die Heimat ist: solche Bestände würden der Natur und dem Wettbewerbe mit anderen Holzarten wegen Mangels an natürlicher Wiederverjüngungsfähigkeit wieder verschwinden müssen; bei allen Beständen, welche verliehtet und verunkrautet sind: in allen Beständen, welche Anhäufung von Rohhumusmassen zeigen und in kurzer Zeit verjüngt werden sollen.

Nachteilig ist die künstliche Verjüngung wegen ihrer Kostspieligkeit, angefangen vom Einkauf' des Saatgutes bis zum Abschluß der Freilandpflanzung, wegen der Unsicherheit der Abstammung des Saatgutes, wenigstens nach Ansicht jener, welehe hierauf ohne Auswahl Gewicht legen zu müssen glauben; dazu kommen noch alle jene Nachteile, welche der kahlen Fläche, auf der die künstliche Verjüngung ausgeführt wird, überhaupt anhaften und von welchen früher berichtet wurde.

Die künstlichen Verjüngungen kann man nach dem Material, mit dem sie ausgeführt werden, in folgende Arten unterscheiden:

1. Verjüngung dureh S amen (S a a t), dessen Pflanzen an der Stelle verbleiben, an welcher das Saatgut untergebracht wurde Freilandsaaten;

2. Verjüngung durch Pflanzen, welche aus Saatgut hervorgegangen sind, das an einer Stelle ausgesät und zu Pflanzen erzogen wurde - Pflanzung:

3. Verjüngung durch oberirdische Pflanzenteile, Zweigstücke, welche vor ihrer Bewurzelung vom Mutterstamme abgetrennt wurden Stecklinge, Setzreiser, Setzstangen, Ste eklingspflanzung:

4. Verjüngung durch oberirdische Pflanzenteile, Zweigstiicke, welche nach ihrer Bew urzelung vom Mutterstamme abgetrennt wurden Absenkerpflanzung;

5. Verjüngung dureh Pflanzen, welehe sich aus Bewurzelung von Stockausschlägen der gestümmelten Mutterpflanze ergaben - A usschlagspflanzung:

(i. Verjüngung durch unterirdische Triebe (Rhizome), welche mit Wurzeln und oberirdisehen Trieben abgetrennt und verwendet werden - Rhizompflanzung;

¡. Verjüngung durch miterirdische Pflanzenteile, welche den Wurzeln angehören und vor Neubewurzelung und Triebbildung verwendet werden - Wurzelstecklinge, Wurzelpflanzung: 
8. Terjüngung durch unterirlische Pflanzenteile, Wurzeln, welche nach ihrer Triebbildung abgetrennt und verwendet werden - Wurzelausschläge, Wurzelbrutpflanzung:

9. Verjüngung durch Wurzelstöcke, welche ansgegraben und wie Pflanzen behandelt werden - Wurzelstockpflanzung, Stummelpflanzung.

\section{Die Saat.}

Das Ïberhandnehmen der Pflanzung an Stelle der Saat beweist, daß die Bedingungen, unter welchen die Saat den Vorzug verdient. immer seltener geworden sind. In der Tat wird manches, was man früher als einen besonderen Vorzug der Sa at betrachtete, heutzutage weniger hoch eingewertet, so z. B. die Möglichkeit, durch eine dichte Saat dicht geschlossenen Jungwuchs zu erziclen, welcher einen reichlichen Ertrag lileinen Nutzholzes, eine Zwischennutzung liefert: wo ein vorteilhafter Absatz dieser Ware besteht, mag eine Saat angezeigt sein; es ist jedoch bekannt, daß allzu dichte Saaten ungünstig sich verhalten, indem sie im Wachstum stocken; Saat, welche auf gutem Boden engen Stand der Bäumchen ergibt, fördert die Geradschaftigkeit und Astreinheit des Bestandes; die Saat liefert, wenn sie gelingt, einen großen Torrat an Pflanzenmaterial; sie ist billiger als die Pflanzung auf einem Gelände, das schon für die Aufuahme ron Sämereien vorbereitet ist, wie bei verlassenen, landwirtschaftlichen Gründen oder bei landwirtschaftlichem Zwischenbau, wie Haferschutzsaat und Fichte, Maisschutzsaat und Eiche; die Saat ist notwendig auf Örtlichkeiten, die für Pflanzung schwer zugänglich erscheinen, wie sehr steiniger Boden, steile Hänge.

Man kamn als Nachteile der Sa at anführen, daß es schwierig ist, die richtige Saatdichte auszuführen, einmal weil die Sämereien und jungen Keimlinge zahlreichen Feinden ausgesetzt sind, sodann weil die Witterungsverhältnisse nach der Saat noch viel mehr über das Gelingen einer Kultur entscheidet, als dies bei der Pflanzung der Fall ist; fällt die Saat zu dünn aus, ist sie schwer zu ergänzen; liommt sie zu dicht, ist sie schwer zu verdümnen, ohne die bleibenden Pflänzchen zu schädigen; Saaten verführen immer zur PHlanzengewinnung durch Herausstechen im Übermaße; wic sehr aber dieses auch nachteilig wirken kam, soll bei den Schlagpflanzungen besprochen werden. Wo die Saat größere Bodenvorbereitungen verlangt, wird sie teuer und unsicher und unterbleibt besser zugunsten der Pflanzung.

$\mathrm{De}_{\mathrm{r}}$ Saat geht roraus:

\section{A. Die Feststellung der Samengüte.}

Die Bezeichnung gute Samenqualität umfaßt eine Reihe von Eigensehaften, in welchen ein Same gut sein kam. Als Zeichen der 
Samengüte gelten a) innere gute Anlagen; b) Siamengröße; c) Samenreinheit; d) Keimzahl, Keimprozente; e) Keimenergie;f) Gebrauchswert.

a) Inneregute Anlagen.

Die Frage nach der inneren Qualität, nach den gnten Anlagen, die im Samenkorn schlummern, wird gelöst mit dor Beantwortung der Frage: Was wird vom Nutterbaume auf die Nachkommenschat't im Samenkorn vererbt? Über diesen Punkt wurden in einem früheren Abschnitte ausführliche Angaben gebracht auf Grund von Untersuchungen, welche sowohl in Versuchsgärten und im Walde als von der Natur selbst in ihrer freien Sphäre ausgeführt wurden. Auf diesen Abschnitt und seine Schlußtolgerungen bezüglich der Provenienz insbesondere muf hier verwiesen werden.

Faßt man alles zusammen, was bis heute bewiesen ist und scheidet man alles aus, was zu vermuten zwar sehr nahe liegt, aber bis heute weder durch exakte Versuche noch durch Tatsachen in der freien Natur gestützt ist, so läßt sich das Gesetz der Vererbung und damit die Bedeutung der Provenienz des Saatgutes bei den Holzgewächsen folgendermaßen formulieren.

Erblich sind :

1. Die morpho- und physiologischen Merkmale der typischen Art; nicht erblich oder nur ungenügend erblich sind die Merkmale einer Variation (lusus) und der Individualität.

2. Nicht erblich sind die Eigenschaften und Eigentümlich keiten, welche der Mutterbaum erst im Laufe seines Lebens durch Störungen von a ußen erworben hat, z. B. die Krümmungen und Krüppelungen durch Wind oder Schnee, Vergabelung, Kropfbildung, Doppelgipfeligkeit usw.

3. Nicht erblich sind die Torzüge, welche ein besonders günstiger Standort in Boden und Klima dem Mutterbaume verleiht, wie Schnellwüchsigkeit, Langschaftigkeit, Greradschaftigkeit, Gesundheit, erhöhtes Schattenerträgnis und anderes.

4. Nicht erblich sind die Vor-und Nachteile. welche ein ungünstiger Standort in Boden und Klima dem Wachstum der Mutterpflanze aufprägt, z. B. Langsamwïchsigkeit (nach Cieslar und Engler sind die Langsamwüchsigkeit, der Bau der Wurzeln und die Tracht der Fichte infolge kühleren Klimas erblich); nach den Untersuchungen in Bayern wird bei Fichten aus Schweden die Langsamwïchsigkeit nach acht Jahren wieder verloren; bei Föhren aus kühlerem Gebiete liegt vielleicht eine andere Art vor, gerade weil ihre Eigentümlichkeiten konstant und erblich zu seiu scheinen; Langsamwüchsigkeit infolge geringwertigen Borlens ist nicht erblich, ebensowenig wie andere Nachteile, z. B. zwerghafter Wuchs, 
Krummwüchsigkeit, frühzeitiges Samenerträgnis, Ästigkeit, Kurzschaftigkeit, Drehwüchsigkeit, Seichtwurzeligkeit, Rotfäule; nicht erblich ist die Winterfrosthärte des kälteren, die Frostweichheit des wärmeren Standortes und dergleichen.

5. Nicht erblich sind die Nachteile oder Vorzüge, welche die Erziehungsform dem Mutterbaume bringt, das sind Spätfrostempfindlichkeit (Kahlfäehenerzichung), Spätfrosthärte (Schirmerziehung), Sturmfestigkeit, Astreinheit, Langschaftigkeit und anderes.

6. Nicht erblich sind die Eigensehaften des Holzes, welche verschiedene Böden, verschiedenes Klima, verschiedene Erziehungsweisen hervorrufen müssen; z. B. die Härte und Engringigkeit des kühleren Ḱlimas (Gebirgsholz) bei der Lärche gegenüber den breiten Ringen und der Schwammigkeit des Holzes der wärmeren Ebene; die hervorragende Holzgüte des kühlsten Klimas (Resonnanzholz); Feinfaserigkeit, Grobfaserigkeit, Gleichmäßigkeit im .Jahresringbau, geringere oder stärkere Kernfarbeinlagerung und dergleichen.

7. Nicht erblich sind die Eigentiumlichlieiten des MIntterbaumes, welche eine Folge seines Alters sind, z. B. der niedere Wuchs eines jungen Bäumchens, der hohe eines alten, die geringe Keimzahl der Sämereien eines jungen Bäumchens, die äußere Form eines jungen oder alten Baumes als bleibende Merkmale.

Damit ist eigentlich ausgedrückt, daß alles, was typisch ist, a uch erblich ist; typisch ist der Charakter der Gattung und Spezies; typisch ist die Fähigkeit einer Holzart, sich mit solehen klimatischen Verhältnissen abzufinden, wie sie ihr natürlicher Verbreitungsbezirk vom kältesten bis zum wärmsten Standort bietet; die Fähigkeit, auf solchen Böden zu gedeihen, wie sie in ilhrem natürlichen Verbreitungsbezirk bewohnt; die Fähigkeit immer dieselben Variationen zu bilden und mit nah verwandten Arten zu Bastarden sich zu verbinden, welche die Eigenschaften der Eltern vereinigen und weiter vererben; die Fähigkeit, dieselben Standorts- und Erziehungsformen ihres natürlichen Verbreitungsgebietes anzunehmen, wenn sie außerhalb ihres Verbreitungsbezirks in gleiches Klima oder auf' gleichen Boden und unter gleiche Behandlung geraten.

\section{b) Die Samengröße.}

Auch bezüglich dieses Punktes muß anf die Ausführungen auf Seite 141 hingewiesen werden. Die Untersuchungen des Verfassers über diesen Punkt lassen keinen Zweifel, daß der Durehbrueh des Individualitätscharakters der nenen Pflanze für das spätere Verhalten in Wuchskiraft maßgebend ist, nicht die anfänglich bessere Ernährung durch den größeren Vorrat an Nahrung im Samenkorn; ein entseheidendes Gewicht bei der Auswahl des Saatgutes (Provenienz) ist somit der Korngröße nicht zuzuerkennen; wohl aber hängt nach 
den Beobachtungen von $\mathrm{Badoux^{1 }}$ ) die Keimzahl insofern von der Kolngröße ab, als die kleinen Kömer eine geringere Keimzahl besitzen als die großen.

\section{c) Samenreinheit.}

Die Verunreinigungen des Saatgutes bestehen je nach der Herkmft aus kleinen mit dem Samenkorn in Größe ammähernd gleichen Stückchen ron Rinde, Zweigen, Zapfenschuppen, Harztropfen, Steinen und dergleichen. Je nach dem Reinigungsrerfahren (Sieben, Werfen) wird die Terunreinigung bald größer, bald kleiner bleiben müissen. Je größer das Samenkorn, um so leichter sind Verumreinigumgen zu beseitigen. Die kleinsten Sämereien enthalten oft nur eine ganz geringe Kahl wirklicher Samenlïrner (Birke, Weide, Pappel). Die Gewinnungsweise des Lärchensamens erklärt dessen Verunreinigung. Die Reinheit des Saatgutes wird in Prozenten angegeben. Unter 100 als Samenkörner verkaufte und abgezählte Einheiten sind wirkliche Körner nach den langjährigen Erfahrungen der schweizerischen Samenkontrollstation zu Zürich, mitgeteilt ron Flur $\left.\mathrm{r}^{2}\right)$ :

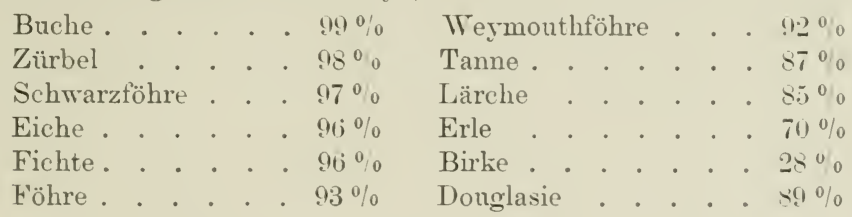

d) Keimzahl, Keimprozente.

Die Bezeichnung Keimzahl empfiehlt sich an Stelle des Wortes Keimprozente; das übliche Wort "Keimkraft" bedeutet aber zwei Eigenschaften, nämlich Keimenergie in Kraft und Zeit (Keimgeschwindigkeit) und Keimzahl als Gegensatz zur Taubheit, zwei roneinander unabhängige Eigenschaften. Wenn daher ron einem Saatgut nichts bekannit ist als die Keimzahl, kann man nicht von der Keimkraft desselben sprechen.

Die Keimzahl ist das Terhältnis der keimfähigen zu den tauben Körnern und wird auf 100 bezogen: eine Keimzahl von 70 bedeutet somit 70 keimfähige und 30 taube Körner. Die Taubheit des Kornes kann darin bestehen, daß 1. der Embryo (Keim) überhaupt fehlt, somit eine Befruchtung gar nicht stattgefunden hat, oder daß 2. der Keim vor der Aussaat abgestorben ist.

Das Ausbleiben der Befruchtung bei äußerlich normaler Ausbildung des Samenkorns ist wohl nur möglich bei Holzarten, welche holzige Früchte bilden, in welchen mehrere Sämereien eingeschlossen sind. Wird keine der Eizellen (Eichen) in einer Frucht betruchtet, kann auch die Frucht

1) Mitteilungen der schweiz. Zentrale f. forstl. Versuchswesen 1\$9.).

2) Ebenda. 
mit ihrer Anlage zu Sämereien sich nicht entwickeln. Es genügt aber die Befuchtung einer einzigen Eizelle, um die ganze Frucht und allo ïbrigen Samenanlagen zur Entwicklung zu bringen; keimfähig muß aber anch das befruchtete Samenkorn nicht sein; es kamn der Embryo zugrunde gehen; den übrigen fehlt der Keim wegen Nichtbefruchtung; sie sind stets taub.

Alter und Gesundheitszustand des Mutterbanmes erweisen sich insofern ungünstig, als allzu junge Bäume und kränkelnde Individnen zumeist taube Körner bilden; sind sie aber keimfähig, so tragen sie, entgegen der allgemeinen Vermutung, die Anlage zu einer völlig normalen Pflanze. Ebenso haben Professor Schwappachs Untersuchungen mit Föhrensamen die so naheliegende Vermutung, daß ganz alte Bäume wiederum schlecht keimfähige, d. h. sehr viel taube Samen trügen, nicht bestätigt; es besteht augenscheinlich keine Altersgrenze bezüglich der Fruchtbarkeit und der Erzeugung keimfähiger Sämereien.

Trockene Winde im Vorsommer zur Zeit der Blüte und Bestäubung fördem außerordentlich den Inselitenflug und die Bewegung des Pollens; naßkalte Witterung verhindert die Befuchtung ganz oder gestattet nur eine teilweise; ein warmer, trockener Herbst begünstigt die Bildung und 'Zufuhr von Reservematerial in die Sämereien, bedingt die Reife; unreife Körner können teilweise nachreifen, die Mehrzahl aber geht zugrunde, insbcsondere bei trockener Aufbewahrung.

Treten samenbewohnende oder -benagende Insekten in großer Anzahl auf (selbst die Sämereien der Fichten und Föhren, nicht bloß die großsamige Eichel, Buchel und Kastanie bewohnen Insektenlarven), so muß sich dadurch abermals eine Mehrung der tauben Körner ergeben.

Die Zeit des Einsammelns ist ebenfalls von Belang; solche Sämereien, die unmittelbar nach der Reife abfallen oder vom Windo nach allen Richtungen zerstreut werden, müssen kurz vor und während ihrer Reife gesammelt werden. Ist dieser Zeitpunkt aber zu früh gewählt, so wird die Reife unterbrochen und um so mehr Sämereien bleiben keimunfähig, je früher die Ernte stattgefunden hat; auch bei großen, zu Boden fallendon Sämereien bringt ein langes Zuwarten ein Verschwinden der besseren Samenkörner durch die zahlreichen Feinde der Sämereien mit sich; um frühzeitig mit dem Ausklengen beginnen zu kömnen, werden die Fölnenzapfen vielfach unreif gepflïckt und der Nachreife überlassen, worin eine weitere (quelle für Taubheit des Saatgutes liegt. Die Art und Weise ${ }^{1}$ ), wie der Same eingesammelt wird, ist sicher von Belang für die Keimfähigkeit. Daß jene Sämereien, welche die ärgsten Mifhandlungen über sich ergehen lassen müssen,

1) Geh. Rat Dr. K. Gayer u. Prof. Dr. H. Mayr, Forstbenutzung, 9. Aufl., Berlin, Paul Parey, 190:3. 
um sie aus den Fruchthïllen freizumachen, wie Lärchen, Erlen, geringe Keimzahlen besitzen, darf' nicht ïberraschen; wird bei dem Klengen zu hohe Temperatur angewendet, mindert sich dio Koimzahl; manehe vermuten, daß hierin auch dic geringere Widerstandskiaft der Keimlinge gegen die Schätte liege. Man darf füglich annehmen, daß das Herunterschlagen der Sämereien, das Dreschen und Schlagen der Sämereien behufs ihrer Reinigung, das Zerreißen oder Abschleifen der Zapfen Gewalttätigkeiten sind, welche die zarte Stelle, an der das Würzelchen hervorbrechen muß, verletzen und den Keim töten können.

A ufbewahrungszeit und A ufbewahrungsweise. Bei allen Sämereien ist die Keimzahl am löchsten unmittelbar nach der Reife. Ton da an beginnt ein stetig fortschreitender Verlust, der in erster Linie der beginnenden Abtrocknung zuzuschreiben ist. Bei einigen Holzarten geht dieser Verlust rasch, so daß schon nach wenigen Tagen nu wenige Körner noch Keimkraft besitzen; dieses ist der Fall bei den kleinsten Sämereien der Pappeln und Weiden, ein kleiner Prozentsatz erhält sich jedoch selbst monatelang: bei anderen vergehen Wochen, bei anderen Monate, selbst Jahre, ehe sie ihre Keimfähigkeit ganz verlieren. Die größten und saftigsten Sämereien, wie die Sämereien der Gattungen Quercus, Fagus, Castanea und anderer, halten sich nur vom Herbste bis zum Frühjahr voll keimfähig, wenn sie vor Austrocknung geschützt werden, was durch Aufbewahrung in Kellern, in Gruben, in gedeckten Haufen, in der Erde, selbst [nach $\mathrm{Cieslar}^{1}$ )] in sich erneuerndem Wasser u. dgl. erzielt werden kann. Am besten dürften die Errungenschaften der Neuzeit, Kühlräume, Eisschränke und andere Kalträume sich bewähren. Die Sämereien der Gattungen Larix, Abies, Tsuga, Psendotsuga, Thuja, Thujopsis, Chamaecyparis und andere verlieren durch Austrocknung bis zum Frïhjahr zwar einen Teil ihrer Keimliraft; dieselbe genïgt aber immer noch für praktische Zwecke. Die härtesten Sämereien, wie jene der schmetterlingsblütigen Bäume (Robinia, Gleditschia, Cladrastis und andere) halten sich mehrere Jahre keimfähig. Bei diesen und bei einer Reihe von anderen Holzarten geht durch die.Austrocknung vom Herbste auf das Frühjahr zwar nicht die Keimfähigkieit verloren, wohl aber verlieren sie die Eigenschatt, daß sie im Frühjahr ausgesät, im Laufe des folgenden Sommers heimen; Wasseraufnahme und Durchbrechung der harten schale geht so langsam vor sich, daß sie erst in dem auf die Saat folgenden zweiten Frühjahr zur Keimung gelangen. Man nennt solche Sämereien überliegend. Mit größtem Prozentsatz liegen über die sämereien der Gattungen: Acer, Tilia, Carpinus, Fraxinus, Juglans, Carya, Zelkowa; Cembra u.; a. Ausnahmen in den Arten vorhanden; wird die Austrocknung durch Aufbewahrung in frischer Erde verhindert, keimen

1) Dr. Ciesla r, Österreich. Forstzeitung 1×97. 
sie normal wie andere Sämereien; in einigen Prozenten besitzen auch alle früher genamnten Gattungen zuweilen Überlieger.

Die Reinigungsmöglichkeit, die Fertigkeit, taube Körner von den keimfähigen zu trennen, entscheidet selbstredend ebenfalls über die Keimzahl; wo Verschiedenheit im Gewicht zwischen taub (leicht) und keimfähig (schwer) besteht, ist die Möglichkeit gegeben, durch Werten, Schütteln u. dgl. gute und schlechte Körner zu trennen; große Samenkörner erleichtern schon durch äußere Merkmale eine Scheidung der guten und schlechten Körner; am schwierigsten sind derlei Maßregeln bei Sämereien, welche äußerlich ihre Unbrauchbarkeit nicht verraten und im Gewicht nicht verschieden sind wie die Mehrzahl der Sämereien der Holzgewächse.

Vorgenannte Momente bedingen die Keimzahl der Sämereien; es ist schwierig, den Einfluß jedes eimzelnen dieser Faktoren festzustellen, noch schwieriger aber zu entscheiden, wieweit noch, gleichgünstige Behandlung für alle Sämereien vorausgesetzt, spezifische Keimzahlenunterschiede $z$ wischen den einzelnen Baumarten, sodann wieweit noch individuelle Verschiedenheiten innerhalb der Art selbst mitspielen. Man ist nur zu leicht geneigt, anzunehmen, daß z. B. der Birkensamen immer schlecht sein muß, obwohl das, was wir als Birkensamen aussäen, in der Regel ebensoviele, ja vielfach mehr Schuppen der Zäpfchen als wirkliche Samen sind; man nimmt an, Lärchensamen müßte immer geringwertig sein, aber hier ist es allein die Behandlungsweise und die schlechte Reinigung, welche schuld ist; denn die Lärchensämereien, welche das Ausland, z. B. Japan, von seinen Lärchen liefert, und welche einen natürlichen Klengprozeß an der Sonne durchmachen, weisen oft sehr hohe Keimprozente auf.

Zahlreiche Untersuchungen über die Keimzahl wurden bereits ausgeführt, so daß man die in nachstehender Tabelle gegebenen Keimzahlen als solche betrachten kamn, mit denen sich die Praxis begnügen mag, zum Vergleiche sind die von $\mathrm{Badoux^{1 }}$ ) mitgeteilten Zahlen, welche sich auf die achtzehnjährigen Erfahrungen der schweizerischen Samenkontrollstation zu Zürich stützen, sowie die Zahlen von J o h a n n os Raf'n $^{2}$ ) in Kopenhagen, der größten und verlässigsten Firma für fremdländische Sämereien, beigefügt; die Übereinstimmung kann natürlich nur eine ungefähre sein.

Die folgende Tabelle veranschaulicht die Keimfähigkeit der Saat in Prozenten, welche von den genannten Samenhandlungen garantiert werden.

1) Badoux, Mitteilungen der schweizerischen Zentrale für Forstwesen 189.5.

2) Johannes Rafn, Mitteilungen der deutschen dendrologischen Gesellschaft 1907. 
Schulze \& Pfeil, Nach Schott.

Appel, Stainer: Badoux: H. Keller

R. $\mathrm{H}$ e $\left.B^{1}\right)$ :

\section{$\%$}

Picea excelsa . . . 75-80

Pinus silvestris. . . . 70-75

austriaca . . $65-70$

Strobus . . . $65-70$

Cembra . . . 40-50

Larix europaea . . . $30-40$

Abies pectinata . . . 40-5j

Quercus pedunculata u.

sessiliflora . . . . 55-65

Fagus silvatica . . . 55-65

Acer, Tilia, Fraxinus . $55-65$

Carpinus . . . . . -

Ulmus . . . . . . 40-50

Robinia . . . . -

Alnus . . . . . 30-40

Betula . . . . . 20-30

Salix, Populus . . . . $5-10$
$\%$

68

(65)

63

55

85

38

27

69

27

-

$-$

26

-

38

25
${ }_{0} 0$

71

70)

70

(iv)

-

35

45

81)

70

-

(6) - 80

$50-60$

$55-65$

bis 25 u. 30

$40-60$

$20-35$

$10-20$

Für außereuropäische Holzarten stellt sich nach $\mathrm{R}$ afn die Keimkraft pro 1907 gelieferter Sämereien vor der Aussaat in Europa bei

Larix sibirica auf $17-31 \%$.

Larix leptolepis aus Japan auf $19 \%$, die Keimprobe der im Versuchsgarten zu Grafrath vom Verfasser geernteten Sämereien betrug $80 \%$ ! $\mathrm{HeB} 30-40 \%$.

Chamaecyparis Lawsoniana (dänischer Herkunft) $55 \%$, Heß $40-50 \%$, gelegentlich $4-10 \%$.

Pinus Banksiana $87 \%$; Heß gibt nur bis zu $60 \%$ an.

Picea Sitkaënsis nach $\mathrm{HeB} 40-80 \%$.

Pseudotsuga Douglasii $54 \%$; He $342 \%$.

Pseudotsuga glauca $77 \%$.

Quercus rubra (in Europa gesammelt) $80 \%$; es ist zweifellos, daß die außereuropäischen Sämereien auf dem langen Transportweg in der Keimzahl geschädigt werden.

e) Keimenergie.

Die Schnelligkeit, mit der Sämereien unter günstigen Bedingungen keimen, wird als Keimenergie bezeichnet. Im Gegensatz hierzu versteht W a gner unter Energie die Kraft, mit der keimende Körner die deckende Erdkruste emporheben; sicher kann durch Verhärtung der

$\left.{ }^{1}\right)$ Dr. R. He B, Die Eigenschaften und das forstliche Verhalten der wichtigeren, in Deutschland vorkommenden Holzarten. 3. Aufl. 1905. 
Erdoberfläche, allzu tiefes Unterbringen die Keimzahl geschmälert werden. Hier ist die Energie gleich Keimschnelligkeit genommen. Sie ist als ein Zeichen besonderer Samengüte betrachtet, wenn auch damit nicht gesagt ist, daß die langsam und spät keimenden Körner nicht ebenso gute Pflanzen liefern künnten wie die zuerst erschienenen. Immerhin wird der energiseh keimenden eine größere Lebens- und Wuchsenergie zugesprochen, so daß bei Bereehnung des Gebrauchswertes dieser Falitor nieht außer acht gelassen werden sollte.

Über die Keimenergie sind Untersuchungen an Freilandsaaten bis heute nicht ausgeführt, so daß sich dieses Wort einstweilen nur auf Keimversuche im Laboratorium mit Keimplatten bezieht und jene Zahl von Körnern bedeutet, welche in den ersten sieben Tagen des Versuches gekeimt haben: Keimzahl ist dann die Summe aller keimenden bei Abschluß des Tersuches.

Nobbe hat für die Fichte die Keimenergie auf $60,4 \%$, für die Föhre auf $40,3 \%$ festgestellt. R a fn berechnet die Keimenergie für die ersten zehn Tage; er fand für Fichten verschiedener Herkunft eine Energie von $55-79 \%$, für Föhren verschiedener Herknnft von $41-63 \%$; es ergibt der Same aus voraussichtlich kühlerem Klima nach Rafns Untersuchungen eine bedeutend höhere Keimenergie, was somit auf eine Schnellwüchsigkeit gegenüber den langsamer keimenden Sämereien aus wärmeren Standorten schließen lassen würde. Fichtensamen aus dem Harz zeigt $68 \%$, aus Tirol 55 und $62{ }^{\circ} 0$, sogenannter alpiner Hochgebirgssame $79 \%$ Keimenergie. Der Föhrensame aus Schottland zeigt $41-63 \%$, jener aus Westnorwegen (Pinus lapponica des Verfassers) wies $93 \%$ auf.

Es verdient die Frage der Keimenergie weiter verfolgt zu werden.

f) Gebrauchswert.

Nobbe bezeichnet als Gebrauchswert das Produkt aus Reinheitsprozent und Keimzahl, geteilt dureh Hundert. Er läßt somit die Keimenergie ganz außer Betracht; es erscheint aber wichtig, auch diesen Faktor, wenigstens mit Rücksicht auf Freilandsaaten, mit in Rechnung zu ziehen. Nobbe führt folgende Beispiele an, welche sich auf eine zehnjährige Erfahrung stützen.

Reinheit $\%=96, \bar{\tau}$.

\section{Fichte:}

Keimenergie ( 7 Tage) (i), 4 .

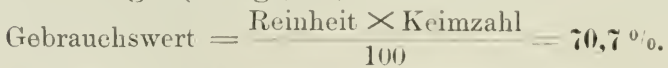

Keimzahl $=72.9 \%$.

Wird in obige Formel noch die Keimenergie eingeführt, so wird dıe Formel: $\frac{\text { Reinheit } \times \text { Keimzahl } \times \text { Keimenergio }}{10(\%)}=42,5 \%$. 
Reinheit $\%=97,8$.

Föhre:

Keimenergie (7 Tage) $=40,3 \%$.

Gebrauchswert $=\frac{97,8 \times 61,2}{100}=\mathbf{5 9 ,} \mathbf{5}^{\circ} 0$.

Keimzahl $=161,2 \%$.

Wird auch hier die Keimenergie berïcksichtigt, so ergibt sich aus $\frac{97,8 \times 61,2 \times 40,3}{100(0)}$ ein Gebrauchswert von $\mathbf{2 4 , 1} \%$.

Vielleicht erklärt dieser Gebrauchswert die auffallende Erscheinung, weshalb die Ergebnisse der Freilandsaaten oft soweit hinter den durch die Keimapparate erzielten Keimlingsmengen zurïckbleiben. Professor Bühler ${ }^{1}$ ) nimmt bei Freilandsaaten für Fichte eine Keimzahl von $8-20 \%$, für Föhre von $5-11 \%$ an; nach $\mathrm{H}_{\text {a a }}{ }^{2}$ ) liefert der raschkeimende Samen um 10\% mehr Pflanzen bei Freilandsaaten als der langsamkeimende. Die Untersuchungen über die Keimzahl der Sämereien kann man in mechanische Proben einteilen, welche die äußere und innere Beschaffenheit der Sämereien mit mechanischen Hilfsmitteln prüfen und in physiologische Proben, welche die Körner zur Keimung bringen, Keimproben.

Die Untersuchung nach äußeren Merkmalen kann nur wenig befriedigende Ergebnisse zeigen; nur an größeren Sämereien sind $a b$ norme Färbungen sofort erkenntlich; manche Holzart, wie z. B. die europäische Föhre erschwert eine Untersuchung in dieser Richtung deshalb, weil die äußere Farbe der Samenhülle zwischen hellocker, gefleckt und tiefschwarz wechselt; alle Farben enthalten gute Körner; Professor Schwappach hat durch neuere Untersuchungen bestätigt, daß den schwarzen Körmern eine größere Keimzahl zukommt. Ein besseres Merkmal als die Farbe ist die Unverletztheit der Samenhïlle, obwohl eine geplatzte Samenhülle bei den Eicheln nicht immer ein Zeichen verlorener Keimfähigkeit ist. Ist die Samenhülle runzelig, dann ist dies als ein Zeichen der allzu starken Austrocknung des Samens und als ziemlich sicherer Beweis der verlorenen Keimfähigkeit zu betrachten. Auch die Größe des Samenkornes läßt nicht immer einen sicheren Schluß auf die Keimfähigkeit zu; sehr große Körner bei den Eichen sind oft merkwürdige Mißgeburten; sehr kleine Samenkörner sind nicht immer von gleicher Keimfähigkeit wie die mittelgroßen. Die inneren Eigenschaften des Samenkormes werden durch die Schnittprobe aufgedeckt. Die normale Farbe des Sameneiweißes ist natürlich weiß; es gibt aber Sämereien, bei welchen die Samenlappen mit Sameneiweiß gelb sind, wie bei der Färbereiche, oder grün, wie bei den Ahornarten. Flecken im Endosperm, weiche,

1) Prof. Dr. A. B $₫$ hler, Aus dem Walde. 1898.

2) Haak, Zeitschr. f. Forst-u. Jagdw. 1906. 
schmierige Konsistenz desselben, vom normalen abweichender Geruch sind ebenfalls Zeichen einer verlorenen Keimfähigkeit; vielfach ist das Sameneiweiß normal, dagegen der Keim selbst schwarz geworden; solche Körner sind nicht keimfähig; zuweilen ist der Keim grün (Zürbeln, Piniolen): solche Körner sind ebenfalls keimfähig. Die Schnittprobe leistet nur bei größeren Sämereien, wie Tannensame, Eicheln, Bucheln, Nüsssen, Kastanien usw., gute Dienste.

Werden die Sämereien auf eine heiße Platte gebracht, so entwickelt sich im Innern der Samenhülle Dampf, der das Korn unter heftigem Knall zersprengt; zählt man unter 100 Körnern die Zahl der platzenden, so ergibt sich die Zahl jener Körner, welche wasserreicher sind; man hat angenommen, daß die platzenden Körner zugleich die frischen, die guten sind. So sehnell diese Feuerprobe auch ein Ergebnis liefert, so ist sie doch unbrauchbar, da alter, keimfähiger Same jederzeit durch vorheriges Einlegen im Wasser zum Platzen auf heißer Platte gebracht werden kann.

Auch die Wasserprobe, welche die Zahl der sinkenden Körner nach deren 1-2tägigem Einweichen in Wasser feststellt, ist ganz unzuverlässig, da auch die nach diesem Zeitraume noch schwimmenden Körner oft sehr gute Keimzahlen besitzen.

Am zuverlässigsten muß immer die physiologische Probe sein welche das Saatgut zum Keimen zwingt. Nur auf Grund von Keimproben, welche amtlich anerkannte Kontrollestationen ausführen, wie jene zu Tharandt, Zürich, Eberswalde, die agrikulturbotanische Anstalt zu Yünchen, können Streitigkeiten wegen ungenügender Keimzahl zum gerichtlichen Austrag gebracht werden; diese Anstalten bedürfen bei der Probe 400 Körner, nachdem vorher das Reinheitsprozent festgestellt wurde; ihre Apparate sind komplizierter Art zur Regulierung der Wärme- und Luftzirkulation; einen solchen Apparat hat Cieslar konstruiert. :Die Samenprobe selbst wird ohne Auswahl einem Saatgute entnommen, das vorher durcheinander gemischt wird, um die dureh den Transport bewirkte Schichtung von leichten und schweren Körnern wieder aufzuheben.

Bei allen Keimvorrichtungen müssen drei Bedingungen erfüllt sein: Wärme, welche möglichst gleichmäßig zwischen $20-30^{\circ} \mathrm{C}$ geboten werden soll; Feuchtigkeit, welche nicht in Tropfenform mit den Sämereien in Berührung kommen soll; Sauerst off, der mit der Luft hinzugeführt wird, während Kohlensäure abfließen kann.

Es möchte scheinen, daß die besten Proben jene sein müßten, welche in dem Keimbett gewonnen werden, das den natürlichen Keimungsverhältnissen am meisten sich nähert, somit Proben in Walderde, Gartenerde. in Blumentöpfen ('Topfproben genannt), in!̨ Kästen und anderen, insbesonders porösen Gefäßen. Gartenerde hat sich dabei als das ungünstigste Medium gezeigt, weil in ihr zahlreiche Pilze 
schlummern (besonders Phytophthora), welehe ïber das hervorbrechende Würzelchen herfallen und die weitere Keimung hindern. Ausgeglühter Sand, Sägemehl leisten bessere Dienste.

Das Einlegen oder Einwickeln einer bestimmten /ahl meist 200-300 Körner in Flanell (L a p penproben), wobei gesorgt ist, daß ein Lappenstïck aus einem mit Wasser gefüllten Gefäß kapillar Wasser den Sämereien zuführt, geben gute und schnelle Ergebnisse; bei der Flaschenprobe von Ohnesorge werden solche Lappen in Flaschen gebracht, deren Boden mit Wasser bedeckt ist; ein Stïck des Flanelles endet im Wasser und saugt Wasser auf. Das Einlegen der feuchten Lappen in zwei ineinander greifende Blumenuntersätze (Systern Kienitz) ist ein eben so einfaches wie gutes Verfahren.

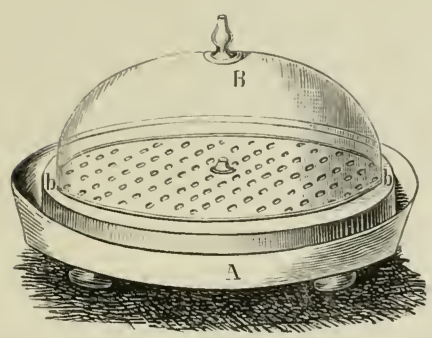

a

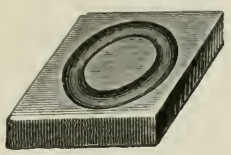

b

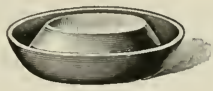

C

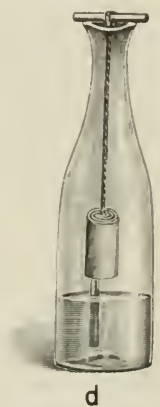

d

Abb. 19. Apparate für Keimproben: a Stainer; $b$ Nobbe: $c$ Kienitz; d Ohnesorge.

Eine Reihe von Apparaten besitzen Platten aus porösem Ton; die Oberseite nimmt die Sämereien auf; die Unterseite steht mit Wasser in Berührung (Stainer, Wiener-Neustadt, Entel, Hannemann) oder Wasser umgibt einen Körner tragenden Napf (Nobbe). Schlecht schließende Deckel oder durchbohrte Deckel verhindern eine allzu rasche Wasserabdünstung und ermöglichen den Luftzutritt.

Für den Gang der Untersuchung ist das Stadium, in dem ein Korn als gekeimt angesprochen wird, gegeben, wenn an dem hervorbrechenden Würzelchen das erste Lebenszeichen in der Krümmung der Wurzel erkennbar wird; diese Körner werden gezählt und aus dem Apparate beseitigt. Häufig ist die sogenannte Notkeimung, bei welcher zwar eine Radikula hervorgeschoben wird, welche aber sich nicht krümmt und nicht verlängert; solche Körner bleiben im Apparat und gelten als nicht keimfähig. Auch verpilzte Körner dürfen nicht beseitigt werden. Manche keimen noch trotz ihres oberflächlich sitzenden Pilzmantels. Zederbauer ${ }^{1}$ ) hat gezeigt, daß man bei geniigender

1) Zederbauer, Zeitschr. f. d. ges. Forstw. 1906. 
Wärme den Versuch schon mit 20 Tagen abschließen kann, um ein pralitisch geü̈gendes Ergebnis zu gewinnen. Dr. Hiltner und Kinzel'1 sagen, daß eine Keimprobe von 14 Tagen genügt, wenn zu den gekeimten Körnern die durch Schnittprobe als gut erkannten, nicht gekeimten gezählt werden. Nach dem Gebrauche wird die Tonplatte ausgekocht.

\section{B. Die Verkaufsmaße der Sämereien.}

Es ist nicht möglich, durch das Verkaufsmaß, z. B. Gewicht, trockenen, alten Samen auszuschließen: das Gewicht kann durch vorheriges Anfeuchten der Sämereien jederzeit korrigiert werden; das Gewicht ist nicht besser als das Hohlmaß. Im allgemeinen besteht die Gepflogenheit, größere Sämereien nach Hohlmaßen, kleinere nach dem Gewicht zu verkaufen. Um einen vergleichenden Maßstab zwischen Gewicht und Hohlmaß zu besitzen, wurde nachstehende Tabelle aus älteren Angaben der Literatur und aus den neueren Arbeiten von Prof. $\mathrm{B} u ̈ h l e r$ zusammengestellt; die Angaben für die fremdländischen $\mathrm{Holz}$ arten sind den Untersuchungen von $R$ af $u$ entnommen.

Ein Liter Samen der

Stieleiche . . . . wiegt $0,58 \mathrm{~kg}$ und enthält 190 Körner,

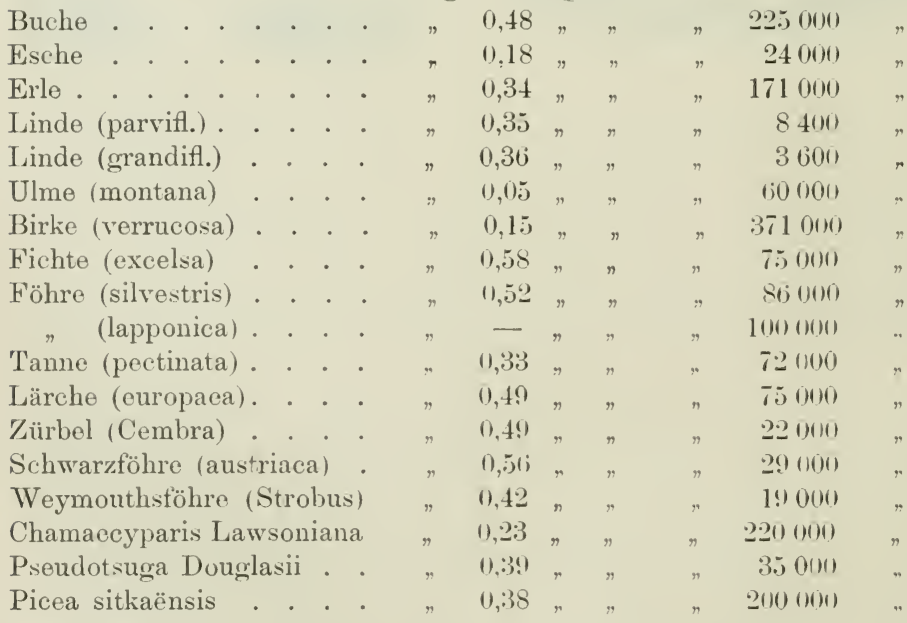

1) Dr. Hiltner und Kinzel, Naturwissenschaftliche Zeitschrift fur Landund Forstwirtschaft. 1906. 
Ein Kilogramm der nachstehenden Sämereien enthält nach Dr. R. Heß folgende Körnermengen:

\begin{tabular}{|c|c|c|c|c|}
\hline Stieleiche . & & & $2001-300$ & Körne \\
\hline Buche. . . & . . & & $4000-50000$ & r \\
\hline Esche. . & . & & $1350(1-14500$ & " \\
\hline Erle . & & & $40000011-500000$ & . \\
\hline Linde (parvifl.) & & & $24(0)(1)-2 i(1)())$ & $r$ \\
\hline Linde (grandifl.) & . & & $11000-12000$ & 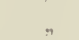 \\
\hline Ulme (camp.) . & . & & $100000-150000$ & \\
\hline Birke (verrucosa) & & & $1600000(1900000$ & ) \\
\hline Chamaecyparis Law & wsonia & & 345000 & \\
\hline Pseudotsuga Dougla & lasii . & & $85000--95000$ & \\
\hline Picea sitkaënsis. & . . & & $360000-440000$ & \\
\hline Picea excelsa. & . & • & $120000-150000$ & \\
\hline Pinus silvestris & . & . & $140000-1600000$ & \\
\hline Taune (pectinata) & . & . & $20000-2+000$ & \\
\hline Lärche (europaea) & . & & $160000-180000$ & n \\
\hline Zürbel (Cembra). & & & $3800-4500$ & . \\
\hline Pinus austriaca & & & $46000-55000$ & 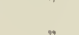 \\
\hline Wermonthskiefer (S & & & $45000-150000$ & \\
\hline
\end{tabular}

\section{Die Yorbereitung des Satgutes für die Aussaat.}

Die erste Toraussetzung für die Keimung ist Wasseraufnahme. Zum Zweck der Beschleunigung der. Keimung werden daher Sämereien, welche den Winter hindurch abgetrocknet sind, mehrere Wochen vor der Aussaat in luftfeuchte Rä ume, Keller, Mieten rerbracht, damit ihre Samenhülle hygroskopisch Wasser aufnehmen kann. Kellerräume zeigen in der Regel durchschnittlich $70{ }^{0} 0$ relative Fenchtigkeit; bei diesem Feuchtigkeitsgrade erfolgt eine Wasseraufnahme, welche bis zu $70 \%$ der Sättigung der Sämenreien mit Wasser führt. Durch Umschaufeln und Wenden der Sämereien wird eine allzu weitgehende Erhitzung rerhindert. Rascher geht die Vorbereitung bei Einlegen der Sämereien in Wasser, Regenwasser, auch Kalkwasser, verdünnte Jauche, vor sich. Am schnellsten erfolgt die Aufweichung in lauwarmem Wasser; eine zu weit gehende Wasseraufnahme ist nach Dr. Mö llers Untersuchungen (18ષ3) schädlich. Das Terfahren hat den Nachteil, daß die darauf folgende Wiederabtrocknung der Sämereien behufs Aussaat schwierig ist; man verwendet meistens trockenen Sand hierzu und schließt die Aussaat unmittelbar an. Wird statt Wasser eine starke Säure, z. B. konzentrierte Schwefelsäure genommen, welehe einige Minuten lang mit den Samenkörnem in Berührung gebracht und dann weggegossen und abgewaschen wird (Beizen), so werden dadurch äußerlich anhaftende Pilzsporen (Phỳtophthora) zum Absterben gebracht. Bei längerer Anwendung (16 bis 
20) Stunden) bezweckt dieses Verfahren auch ein Abbeizen sehr harter, dicker Samenhüllen, wie z. B. der Walnüisse, Zürbelnüsse (Hiltner 1906); solche_Sämereien keimen in kurzer Zeit (50 Tagen). Wit kochendem Wasser werden die Samen der Akazien, Gleditschien, Cladrastis u. a. abgebrüht, damit sie gleichmäfiger keimen. Am weitesten geht die Vorbereitung bei jenen großen Sämereien, welche in einem Warmbett, ähnlich den Treibkästen und Mistbecten der Gärtner, zum Ankeimen gezwungen werden (Anmalzen). Das Aussäen solcher ausgekeimter Körner ist mehr eine Pflanzung als eine Saat zu nennen.

Obige Vorbereitungen dienen auch dem Schutze durch Vertilgung anhaftender Pilzkeime; gegen tierische Feinde dient die Vermengung der Nadelholzsämereien mit Nennig, wodurch Finken und andere lästige Tiere rom Abbeißen der Keinlinge abgehalten werden; zum Schutze der Eichehn gegen Mäuse empfiehlt Schneider ${ }^{1}$ ) das Übergießen mit Petroleum; \Iortzfeld ${ }^{2}$ ) sagt, daß auch das Vermischen mit Mennig helfe.

\section{Die Anssaat.}

Die Zeit der Aussaat. Wollte man getreu der Natur folgen und aussäen zur gleichen Zeit, in der die Sämereien abfallen oder abschweben, so müßte man so ziemlich das ganze Jahr hindurch Saaten vornehmen. Richtet man sich nach der Reife und dem Grundsatz, daß die Aussaat der Sämereien.unmittelbar nach der Reife die beste sein müsse, dann würde die Herbstsaat als die richtigste erscheinen, da die weitans größte Mehrzahl der Sämereien im Herbst reift. Wenn dennoch als Regel die Frühjahrssaat gewählt wird, so findet dies im folgenden seine Begründung: 1. Es gelingt, die Sämereien durch den Winter ohne nennenswerte Verluste an Keimzahl, ja sogar besser hindurch zu bringen, als die Natur mit der Herbstsaat dies vermag. 2. Im Herbste ausgesäte Sämereien werden während des Winters ihrer besten Körner durch Mäuse, Vögel, Eichhörnchen, Hirsche, Rehe und schließlich auch durch Pilze beraubt. 3. Warme Herbstwitterung bringt größere Sämereien, besonders Eicheln, leicht zum Keimen; diese erfrieren dann während des Winters bei ungenügender Schneelage oder Laubbedeckung. 4. Besteht im Frühjahr noch die meiste Aussicht, die notwendige Arbeitskraft zu erlangen. Gegen die Frühjahrssaat spricht eigentlich nur der Umstand, daß Gefahr besteht, daß die Sämereien zu spät im Frühjahr (Ende Mai oder selbst Juni) vorgenommen werden, so daß die jungen Pflanzen schwach und unvorbereitet von den ersten Frühfrösten überrascht werden und leiden; dagegen spricht auch der

1) Schneider, Deutsche Forstzeitung $1 \varangle 97$.

${ }_{2}^{2}$ Mortzfeld, Zeitschr. f. Forst- u. Jagdw. 1896. 
unausbleibliche Verlust an Keimkraft bei grewissen Sämereien durch die Aufbewahrung bis zum Frïhjahr. Wo März und April noch zu den trockenen Ionaten zählen, wie dies in allen Ländern mit Sommerregen (insbesondere im ostasiatischen Monsungebiet) der Fall ist, da müßte die Saat unmittelbar vor dem Einsetzen des Regens (Mai, Juni) ausgeführt werden. In Europa und Ostamerika, wo die Regelmäßigkeit der Monsune dureh andere, kosmische Erseheinungen stets gestört wird, und eine längere Trockenperiode in jedem Monate des Jahres auftreten kann, ist die entsprechende feuchte Witterung nach der saat im Frühjahr reine Glücksache. Im westlichen Nordamerika, an der frostfreien kalifornischen Küste beginnt der Regen Norember; dort ist Oktober die beste Saatzeit: nördlich hiervon das Frühjahr.

Sämereien, welche im Frühjahr ausgesät, erst im folgenden Frühjahre keimen, werden „überliegendle* genannt; hierher zählen, wie schon früher angedeutet, Nüsse, Eschen, Linden, Zürbeln u. a.; können sie anderweitig gegen Abtrocknung nicht geschützt werden, empfiehlt sich Herbstsaat; gleiches gilt für jene Sämereien, die ohne sorgfältiges Einmieten (S. 369) ihre Keimkraft ganz einbüßen wie Eicheln, Kastanien u. a. Für die im Vorsommer reifenden Pappel- und Ulmensämereien ist Aussaat nach der Reife die Regel.

\section{Die Zubereitung des Keimbettes für Freilandsaaten}

(Kahlflächensaaten, Schirmsaten).

Als allgemeine Regeln gelten: 1. Da das Würzelehen möglichst bald nach der Keimung den mineralischen Boden erreichen muß, so ist bei der Bodenvorbereitung alles zu entfernen, was dies verhindern könnte, Rohhumus, Moos, Laub, Unkrautdecke. 2. Dies kann geschehen durch Abrechen, Abkratzen, Abplaggen, Abpflügen oder durch Umkippen und Tieferlegen der Rohhumusschichten (Rajolen, Rigolen) oder durch Vermengung der Laub- und Rohhumusmassen als wertvoller Düngerstoffe mit dem mineralischen Boden; liegt Ortsteinbildung vor, so müssen Pflüge in Anwendung kommen, um den Ortstein zu durchbrechen und ebenfalls mit dem Boden zu vermengen, worauf er zerfällt und selbst düngend wirkt. 3. Je größer das Hindernis, um so kostspieliger wird die Saat. 4. Wenn der Zustand des Bodens nicht ermöglicht, durch einfache und billige Mittel eine gründliehe Bodenvorbereitung herbeizuführen, dann unterbleibt beswer die Saat und tritt Pflanzung an ihre Stelle. 5. Auf kleineren verunkranteten Flächen, welche von Saatflächen eingeschlossen sind, wird nicht Bodenvorbereitung und Saat, sondern Pflanzung gewählt; noch weniger dürfen kleinere Flächen gereinigt und besäet werden, wenn sie bereits ringsum von Pflanzungen eingeschlossen sind. 6. Auch im Kahlschlagbetriebe (Saumschlag) mit darauffolgender Saat oder Pflanzung soll jede Schlußdurchbrechung des der schlaglinie vorausliegenden, 
angegriffenen Bestandes, soweit sie noch nicht verwildert ist, noch vergrößert werden, um eine Saat ausführen zu können, welche bei Herannahen der Schlaglinie als ein hochwertiger Ansgangspunkt für die anschließende Verjüngung und gewinnbringender Vorsprung an Zeit sich erweisen wird. 7 . Jede Saat gelingt unter lockerem Schirm besser als auf völlig kahler Fläche, welche für forstliche Kulturgewächse ein unnatürliches Keimbett darstellt. Die Belassung unterdrückten Materials bei den Durchlichtungen eines Bestandes (III. Teil dieser Schrift, wird sich erst bei der Terjüngung als Vorteil für den Boden durch Frischerhaltung und für die Verjüngung durch Schutz derselben erweisen: solches schützende Gestänge kann jederzeit nach Erfüllung seiner Aufgabe leicht beseitigt werden. Die Unnatïrlichkeit einer Kahlfläche für die Bestandesbegründung durch Saat wie auch durch Pflanzung illustriert Frickes Vorschlag, die kahle Fläche mit Reisig zu belegen, damit sie nicht mehr kahl ist.

Hinsichtlich der Geräte für die Bodenvorbereitung können hier nur allgemeine Gesichtspunkte gegeben werden. Wer aus dem Buche über Waldbau lernen will, ob für den ihm vorliegenden Fall ein hölzerner Rechen oder ein eiserner Pflng in Terwendung gebracht werden soll, wer erwartet, daß mnter den vielen erfundenen Geräten eines als das absolut beste bezeichnet sein wird, wird ron den rorliegenden Zeilen enttäuscht seir. WTas den ersten Satz betrifft, so kann ihm jeder landwirtschaftliche Arbeiter Auskunft geben; was letzteren betrifft, so kann bei der Unerschöpflichkeit und Mannigfaltigkeit der Terunkrautungen und Bodenverfassung selbst jedes Instrument, das erfunden wurde, für eine gewisse Ürtlichkeit das beste sein. Die Entscheidung muß dem praktischen Blick überlassen bleiben. Als allgemeine Anhaltspunkte möge Folgendes gelten: 1. Je stärker der Bodenüberzug und das Hindernis für die Keimung, desto größere und stärkere Instrumente müssen in Anwendung gebracht werden. 2. Das Beseitigen geschieht entweder durch hölzerne oder eiserne Rechen, durch die gewöhnliche Breithaue, welche als das am vielseitigsten verwendbare Gerät bezeichnet werden muß, durch Pflïge. 3. Das Vermischen mit dem mineralischen Boden beziehungsweise Untergrunde wird erzielt durch die eben genannte Haue oder Hacke, durch Sp itzen bergss Wühlapparate [Wühlspaten, Wühlrechen. Wühlrad, die dänische Rollegge $\left.{ }^{1}\right)$ ] und andere. 4. Je schwerer der Boden, desto krättiger das Geräte; Geräte, welche kontinuierlich arbeiten oder rotieren, wie Spitzenbergs Wühlrad, dänische Rollegge, fördern die Schnelligkeit der Arbeit, gegenüber jenen, welche entsprechend der Handbewegung nur in einer Richtung Arbeit leisten: dagegen erfordern letztere Instrumente

1) Dr. Metzger, Dïnische Geräte zur Bodenbearbeitung in Samenschlägen. Paul Parey, Berlin 1906. 
geringeren Kraftaufwand und gestatten eine tiefore Durchmischung des Bodens. 5. In ebenem und schwach hügeligem Gelände mit größ̈erer Ausdehnung der Saatfläche, auf der die Hindernisse durch Stöcke, Steine, Bäume fehlen oder nur ganz geringfügige sind, können gröfere Geräte mit Bespannung, wie Eggen, Pflüge, Platz greifen. 6. Um so seichter kann die Bodenbearbeitung ansfallen, je schwächer die Auflagerung von Laub oder Rohhumus, je mehr Gefahr besteht durch eine tiefere Bodenbearbeitung, unfruchtbaren Boden in das Wurzelbercich der
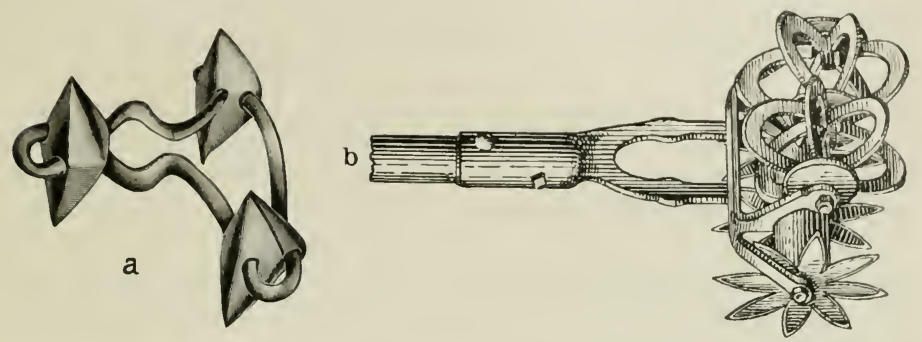

c

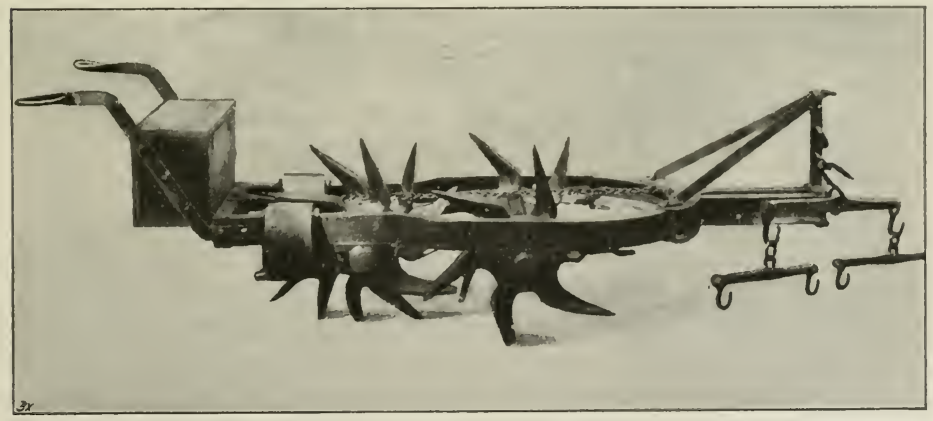

Abb. 20. Gerăte für Bodtenbearbeitung: $\iota$ Glied einer Gliecleregge, $b$ spitzenbergs Wuhlrechen. $c$ Webers Waldgrubber.

Keimlinge zu bringen. 7. Wird unmittelbar nach Beseitigung der Streudecke gesät, so empfiehlt es sich, etwas Rohhumusdecke zu belassen und diesen unterzuhacken; folgt die Saat nicht sofort, so stellt nach völliger Beseitigung der Humusdecke die Empfänglichkeit des Bodens für die Saat sich erst nach einigen Jahren ein. 8. Die einfachsten Geräte sind in der Regel die besten, weil sie nicht wertlos werden, wenn der Boden oder seine Oberflächenansformung wechsehn, vielmehr noch zu anderen Dienstleistungen als denen der Bodenvorbereitung Verwendung finden können. 
Als Geräte für Bodenvorbereitung dienen auf ebenen, hindernisfreien Böden zum Beseitigen von Laub, Moos, Nadeln: hölzeme und eiserne Rechen, Zweizack, Dreizack, Fünfzack, Spitzenbergs Wühlrechen u. a.: zur Beseitigung von holziger Bodenverwilderung Sense, Plaggenhaue, Pflanzhane, flachgehende Pflüge, tiefgehende Pflüge; bei Ortsteinbildung Untergrundspflüge.

Prof. Dr. Metzger erwähnt als dänische Geräte für Bodenbearbeitung außer der Rollegge den Laubrechen, Smiths Grabekultivator, den Buchschen Samendecker, die Dreizahnegge, Buchs Patentpflug, Godskesens Waldpflug. Freih. Schenk v. Schmitt burg ${ }^{1}$ ), Geh. Oberforstrat Thale ${ }^{2}$ ) und Rei $\beta^{3}$ ) wollen für Unkrautvertilgung einen flachstreichenden Schälpflug (verbesserten Eckertschen), auf den dann der Untergrundpflug folgt. Das prenßische Ministerium für Landwirtschaft, Domänen und Forsten empfiehlt (1907) den Regierungen die Anschaftiung des von Forstmeister Dr. Weber konstruierten, von der Firma Hansel in Gießen um 500 Mr. in den Handel gebrachten Waldgrubbers (Abb. $19 c$ ) als ,geeignet zur Bodenverwundung in Naturbesamungsschlägen und zur Herstellung und Lockerung von Saatstreifen für Nadelholzkulturen".

Die beste Zoit für Bodenvorbereitung zum Zweck der Frühjahrssaat ist der Herbst, da während des Winters eine Zerkrümelung und Lockerung des Bodens, eine Auflösung der Nährstoffvorräte, eine Vertilgung von Inselten, Mäusen, eine oberflächliche Wiedererhärtung bei allzu humosem Boden zu erwarten ist.

\section{Die Samenmenge, Satdichte.}

Um 1 ha mit Pflanzen von 1 qm Standfläche zu versehen, sind 1000() Pflanzen notwendig. Terwendet man bei Ausführung einer Fichtensaat $1 \mathrm{~kg}$ Samen, so enthält er nach früheren Angaben mindestens $100(0) 0$ keimfähige Körner: würden alle keimfähigen auch keimen und sich erhalten, müßten mit $1 \mathrm{~kg}$ Fichtensamen 10 ha Flächen voll besamt werden können. In der Praxis aber nimmt man an, daß if kg Fichtensamen mit 600000 keimfähigen Körnern notwendig sind, um 1 ha gut bestocken zu können. Gayer schlägt in seinem Waldbau sogar $15 \mathrm{~kg}$ pro Hektar vor, das wären nicht weniger als 1,5 Millionen keimfähige Körner pro Hektar; daraus könnte man schließen, daß dio forstlichen Kultivatoren gegenüber den Gärtnern und Landwirten in der Behandlung der Samen rückständig seien. Es steht jedoch zur Erwägung, daß die Bodenvorbereitung im Walde sehr viel weniger sorgfältig vorgenommen wird und werden kann, als es im Garten und für land-

1) Allgem. Forst- u. Jagdztg. 1!107.

2) Ebenda 1906.

3) Forstwirtsch. Zentralbl. 1907 . 
wirtschaftliche Nutzgewächse möglich ist, daß die Samenbedeckung mangelhafter ist, die forstlichen Keimlinge zarter und langsamer wüchsig sind als landwirtschaftliehe Sämereien, daß die forstlichen Pflanzen wegen ihrer lang dauernden Zartheit und Kleinheit einer größeren Zahl von Feinden aus der Tier- und PHanzenwelt lange Zeit ausgesetzt bleiben; immerhin aber muß zugestanden werden, daß clas Ergebnis der forstlichen Freilandsaaten, insbesondere der Kahlflächensaaten, nicht im Verhältnis zum Aufwand steht, solange nicht der Boden eine Bearbeitung erfährt, wie etwa bei Hafer- und Roggenschutzsaaten oder in den Saatgärten Es liegt ja nahe, daß der Wirtschafter Früchte seiner Arbeit sehen und nach oben hin nachweisen will. Würde die Saat im Verhältnis zur aufgewendeten Samenmenge voll gelingen, wären sämtliche Saaten viel zu dieht und eine Quelle größerer Verlegenheit als zu dünne Saat sie verursacht; daß das gewünschte Dichtigkeitsverhältnis sieh einstellt, ist, da von der Laune der Witterung ablängig, Glüeksache.

Bei Annahme einer Vollsaat sind zur Bestellung eines Hektars notwendig:

\section{Heyer : \\ K. Gayer: Terfasser:}

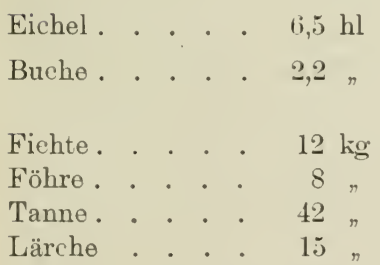

In der Mitte des 18. Jahrh. ${ }^{1}$ ) gebräuchl. Samenmenge : $3,7 \mathrm{hl}$

$\begin{array}{cc}11 \mathrm{hl} & 10 \mathrm{hl} \\ 5,5 \% & \text { für Bestandessaat: } \\ & 3 \mathrm{hl} \\ & \text { für Unterbau: } \\ 1 / 2 \mathrm{hl}\end{array}$

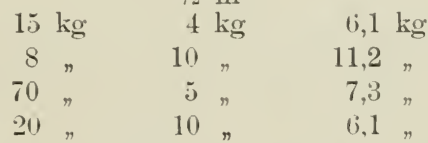

In Dänemark werden $1 j \mathrm{hl}$ Eicheln pro Hektar als Vollsaat verwendet.

Aus obigen Saatmengen läßt sich berechnen, wieviel Samen notwendig ist, wenn an Stelle der Vollsaat auf 1 ha nur Streifensaat oder Plätzesaat tritt, indem eben die Summe der Streifen oder Plätze im Verhältnis zum Hektar gesetzt die Grundlage für die Berechnung gibt. Als eine naturgesetzlich begründete Regel gilt: für Holzarten mit sehlechtem Ausformungsvermögen (VI. Abt.) dichtere Saat ${ }^{2}$ ), für solcho mit gutem dünnere, schüttere Saat.

$\left.{ }^{1}\right)$ Dr. H. Hausrath, Kleine Beiträge zur Geschichte der k(mstlichen Verjungung. (Aus Pfälzer-Forstakten) Allgem. Forst- u. Jagdztæ. 19ux.

2) Geh. Oberforstrat Frey verlangt 10-12 kg pro ha fur die Föhre, Forstwirtschaftliches Zentralbl. 1907. 
Die Siatmittel.

Selten stehen der Saat so ausgedehnte, kahle Flächen zur Verfügung, um eine der vielen śaatmaschinen anwenden zu können; je größer die Kahlfläche, um so besser zwar für die Maschine, um so schlechter aber für die Keimlinge. Die meisten der größeren Säevorrichtungen für Freilandsaaten basieren auf' dem Prinzip eines Schiebkarrens, der den Samenkasten trägt; durch Rotation des Rades wird die Ausflußmenge der Sämereien aus dem Behälter geregelt. Es mag sein, daß irgendwo solehe Maschinen, wie sie $R$ unde, Roch, Göhren, Rotter, Drewitz, Klaeß und andere konstruiert haben, noch in Gebranch sind; Verfasser hat sie nur in den Sammlungen kennen gelernt. Einige von diesen verbinden auch die Lockerung des Bodens mit der Saat und sind dann für Bespannung eingerichtet. Die Voraussetzungen für gewimmbringende Anwendung sind nur selten erfüllt, denn nicht bloß die Bodenkonsistenz und seine Oberflächengröße und Formation. sondern vor allem auch die Witterung entseheidet über die praktische Anwendbarkeit soleher Maschinen. Bei Freiland-, Riefenund Platzsaat kann ein einfaches Instrument wie das Säehorn, auch Forstrat Schulz' Saatflinte gute Dienste leisten; das beste Universal. mittel für die Saat ist immer die Hand. Daß eine Saat aus der Hand auch bei Vollsaat an Gleichmäßigkeit nichts zu wünschen übrig läßt, beweist die Saat mit landwirtschaftliehen Sämereien; um die kleinen forstlichen Sämereien leiehter sichtbar zu machen, empfiehlt sich das Auswerfen einer Mischumg von Saatgut und Sand oder Saatgut und grobem Sägmehl. Bei größeren Flächen wird die sogenannte Kreuzs a a t ausgeführt; sie besteht darin, daß die Fläche zuerst dureh Hinund Hergang nach den zwei entgegengesetzten Himmelsrichtungen. zum Beispiel $\mathbf{S}-\mathbf{N}$ besäet wird, worauf dann ein zweiter Säegang erfolgt, der nach den beiden anderen Himmelsriehtungen, $\mathbb{T}-\mathrm{O}$, hin und her sich bewegend dic Dichtigkeit der Saat verbessert.

Eine ganz eigenartige Methode ist das Ansehießen von mit Samen gefüllten Blechbüchsen an steilen, mzugänglichen Gebirgshängen, um auch Bäumen, die keinen flugfähigen Samen besitzen, die Möglichkeit der Ansiedolung zu bieten.

Größere Sämereien, wie Eicheln, Bucheln, Kastanien, Nüsse u. a., verlangen eine eigene Behandlumgswoise. Für Eichelsaat (Stufen, Stufensaat, Setzsaat) gibt es eine Reihe rou einfachen Instrumenten zur Anfertigung der lïcher behuf's Aufinahme der Eicheln. Sie alle sind von folgenden Gesichtspunkten hinsichtlich ihres Wertes zu beurteilen: Das aus der Eichel hervorbrechende Würzelchen (radicula) ist geotropisch, d. h. wendet sich sofort in die Tiefe; die Plumula, das Federchen, ist entgegengesetzt veranlagt, $d$. h. richtet sich aufwärts. Bei allen Instrumenten, welche vertikale Löcher in den Boden drücken, 
(Setzholz, Setzbrett, Setzstab, Setzpfahl, Saathammer) kommt die Eichel ebenfalls vertikal in den Boden, bald mit Spitze, bald mit dem dicken Ende nach abwärts. Liegt die Spitze nach abwärts, so kann das Würzelchen sofort in die Tiefe, während das Federchen zuerst eine Krïmmung um die Eichel herum zurïcklegen muß, um nach oben zu gelangen: da hierbei die Samenschale klafft, fängt sich zuweilen das Federchen, und nach melırfachen Krümmungen, um wiederum aus der Falle herauszukommen, verkümmert es. Liegt der dicke Teil der Eichel nach unten, die Spitze nach oben, so kann das Federchen zwar sofort geradeaus ins Freie wachsen, das Würzelchen aber ist zu einer Krümmung gezwungen, bei der es sich häufig in der aufgeplatzten Samenhülle fängt und nach einigen Windungen an Erschöpfung zugrunde geht. v. Schïtz hat auf diese Erscheinung hingewiesen, v. Fürst ${ }^{1}$ ) gibt nicht an, wie viele Eicheln bei seinen Versuchen verunglückten, konnte aber nachweisen, daß, wenn die Eicheln emporwuchsen, sie keinen Unterschied in der Entwicklung zeigten. Jenen Instrumenten dagegen, welche einen Spalt in die Erde stoßen [Saatschippchen, Eichelstufer, der hessische Eichelsetzer, die gewöhnliche, schmale Haue, Spitzenbergs ${ }^{2}$ ) Rillendruckstücke], ist ein Vorzug zuzuerkennen, weil bei ihnen die Eicheln in eine horizontale Stellung geraten, welches die natürliche Keimstellung ist. Dazu kommt, daß alle Instrumente, welche vertikale Löcher geben, die Wände und die Lochbasis erhärten müssen, was keine günstige Wirkung auf die Anfangsentwicklung tiben kann.

In newerer Zeit ist man von den oben genannten Geräten mehr und mehr zurückgekommen; sie wurden früher vorzugsweise auf nicht bearbeiteten, schwach verunkrauteten Böden angewendet. Neuerdings wird der Boden für die Aufnahme von Eicheln, Nüssen, Kastanien platz- oder riefenweise bearbeitet, und das Einlegen der Früchte erfolgt ebenso wie im Saatgarten. Für Eicheln mit oder ohne sichtbare Keimwurzeln hat Spitzenberg (l. c.) ein eigenes Druckstück konstruiert, ïber deren Brauchbarkeit die Meinungen verschieden sind. Je nach der Größe und Begrenzung der zu besamenden Flächen unterscheidet man folgende Sa tformen: Bei größeren Flächen, welche durchaus besät werden, spricht man von Volls a at; ihr geht meistens die Bearbeitung der ganzen Bodenfläche voraus. Bei Streifen-oder $\mathrm{R}$ iefensat findet eine streifenweise Bodenbearbeitung und Aussaat statt; Platzsat oder Stockplattensaat entsteht durch Besäen von mehr oder weniger kreismunden, zumeist durch das Ausroden der Stöcke gebildeten Bodenverwundungen; eine Stückriefensa t besät Riefenstücke von ca. $0,5 \mathrm{~m}$ Breite und $2 \mathrm{~m}$ Länge; Rillensaaten

1) v. Furst, Die Pflanzenzucht im Walde. 1907.

$\left.{ }^{2}\right)$ G. K. Spitzenberg, Die Sp. Kulturgeräte. 2. Aufl. Berlin, Paul Parey, $189 s$ Mayr, Waldlasu. 
sind sehr schmale Saatstreifen auf einer gartenbeetartig bearbeiteten Stelle: verlaufen die Rillen in Riefen, und zwar senkrecht zur Riefenseite, ähnlich wie die Sprossen an einer Leiter stehen, so heißt man derartige Saaten auch Leitersaten; werden wegen allzu großer Bodenbefeuchtung Gräben ausgehoben und der Aushub zu Dämmen aufgeschüttet, welche besät werden, so spricht man von Dammsat; wird die Grabensohle, der ausgehobene Damm und das benachbarte, im Niveau unveränderte Gelände besät, so nennt Cotta dies eine Graben-Muldensaat, welche die Aussicht gibt, daß, wie immer die Witterung des Jahres ausfallen möge, doch wenigstens eine der drei Niveauflächen sich bestocken werde.

Wird die Saat von nur eimer Baumart zum Aussäen gebracht, so spricht man von einer $\mathrm{R}$ einsaat; sind mehrere Sämereien gemischt (Mengesaat), so ist hierfür die Voraussetzung, daß die Sämereien annähernd gleiche Größe und Schwere haben.

Bei Föhren werden zuweilen die Zapfen mit noch eingeschlossenen Sämereien auf der Fläche ausgebreitet, mehrere Male bei sonniger Witterung mit dem Rechen hin und her gestoßen, so daß die Sämereien ausfallen und zugleich mit dem rerwundeten Boden vermengt werden; man nennt eine solche Saat $/ /$ apfensat.

\section{Sa t bedeckung.}

Die natiirlichen Grundlagen für die Saatbedeckung sind folgende: Je größer das Samenkorn, um so tiefer muß es im Boden zu liegen kommen, um so sitärker somit die Bedeckung; je lockerer das Deckungsmittel, desto tiefer die Saatlage, desto leichter die Keimung, die Durchbrechung der Decke von seiten des Keimlings, je frischer der Boden, um so rascher die Keimung, um so höher die Keimzahl. Bei Herbstsaaten, welche längere Zeit den teils bewegenden, teils erhärtenden Einflüssen von Wind und Regen ausgesetzt sind, muß die Bedeckung der Saat eine höhere sein als im Frühjahr. Daraus ergeben sich folgende Maßnahmen: Die großfrüchtigsten Sämereien, wie Kastanien, Walnüsse, Hickorynüsso und andere verlangen oin $100 \mathrm{~mm}$ tiefes Einbringen in den Boden: Ficheln sind an günstigsten eingelegt, wem sie nach den Untersuchungen von Bïhler (l. c.) $50-00 \mathrm{~mm}$, Bucheln, wenn sie 30 - 41) mm tief liegen. Für Tannen empfiehlt sich je nach Samenkorngröße $25-30 \mathrm{~mm}$; dio Sämereien der Gattung Picea verlangen je nach Korngröße 10-15 mm; gleich große Sämereien der Gattungen Pinus und Larix ebenfalls 10-15 mm; die Sämereien der Fölırenselition Cembra verlangen 30-40 $\mathrm{mm}$; Betula $2-3 \mathrm{~mm}$; für Populus, Salix, Paulownia und andere sämereien mit zartester Beschaffenheit genügt ein Andrücken oder Angießen. Aus diesem Grunde wird auch Birkensamen vielfach auf Schnce ausgesäet (Schmeesaat), damit die feimen Körner beim Auftauen des Schnees an den Boden 
sich anschmiegen und mit feiner Ėrdo oberfächlich sich vermischen; je nach der Größe der Samenkömer können alle übrigen Sämereien hinsichtlich ihrer Bedeckungsdicke an obigen Angaben angeglichen werden.

Als Deckungsmittel empfehlen sich: die lockere Ercle der Saatflächeu selbst, Sand, Humus, zerfallene Torferde; Gartenerde verwirft Weise, da mit ihr die Sporen des Keimlingspilzes (Pliytophthora) eingeschleppt werden. Sollen die Sämereien mit der Erde der Saatfläche selbst bedeckt werden, so werden ähnliche Hilfsmittel angewendet, wie sie im landwirtschaftlichen Betriebe üblich sind, nämlich das Walzen der Fläche, das Eggen und Walzen derselben, das Mischen von Sämereien und Erde mit Dornegge (Schleifbusch) und Walzen; das Hin- und Hertreiben von Schafherden hat sich gleichfalls bewährt. Kleinere Flächen oder Riefen werden mit dem hölzernen oder eisernen Rechen bearbeitet; für Riefen ist auch geeiguet der Spitzenbergische Saatbedecker, der auch im Pflanzengartenbetrieb als vorteilhaft sich bewährt hat; auch der dänische Saatbedecker (Dr. Metzger) scheint empfehlenswert $\mathrm{zu}$ sein. Fällt eine mehrtägige Trockenperiode ein, so wäre am günstigsten fleißiges Begießen der Saat morgens oder abends; allein bei Freilandsaat ist dies nur ausnahmsweise durchführbar; man wird zu anderen Mitteln zur Erhaltung der Bodenfeuchtigkeit greifen müssen, das sind Festdrücken, Festschlagen oder Walzen der Bodenoberfläche, um sie dadurch von unten herauf feucht zu erhalten; bei Freiland-, Riefen- und Plätzesaaten kann auch Bedeckung mit Zweigen, Gittern die Besonnung und Austrocknung mildern.

\section{Schutz der Sämereien und der Keimlinge.}

Keimlinge von Freilandsaaten gegen die gefährlichsten Pilzparasiten, wie Phytophthora, Hysterium schützen zu wollen, ist aussichtslos; gegen den Schüttepilz der im ersten Jahre stehenden Föhren helfen die Kupfermittel nicht: erst bei zwei- und mehrjährigen Ptlanzen wird das Bespritzen mit Bordelaiser oder auch Klebekalkbrühe balk als Radikalmittel, bald als wertlos hingestellt. Мuß eine Freilandsaat gegen Unkrautwuchs verteidigt werden, so ist dies ein Zeichen dafür, daß die Saat überhaupt nicht am Platze war, daß au ihrer Stolle Pflanzung hätte gewählt werden sollen.

Zum Schutze der Freilandsaaten, insbesondere der großen Sämereien gegen Tiere, wie Eichhörnchen, Rehe, Hirsche, Wildschweine, Eichelhäher, sowie der kleinen Sämereien gegen das Autlesen der Körner und Abbeißen der Keimlinge durch Vögel, besonders Finkenarten, helfen gründlich die Saatgitter, Rahmen, welche mit hülzernen stäben oder mit einem Drahtgeflecht überspannt sind; sie geben zugleich Schut\% gegen Sonne und Erhitzung, gegen allzu starke, schwere liegentropten gegen Vertrocknung; sie sind jedoch für Freilandsaaten meist \%v tost- 
spielig; ihre Verwendung beschränkt sich auf den Saatgarten. Gegen Rehe, Hirsche, Wildsehweine sichert sodann gründlich eine sorgfältig ausgeführte Umzämnung, wio sie bei dem Pflanzgartenbetrieb näher beschrieben werden soll. Samen und Keimlinge werden gegen obige Tiere und Austrocknung geschützt durch Auflegen von lockerem Reisig, bei Riefensaat durch Schutzfaschinen, welche auf dem Boden befestigt werlen. Derlei Deckungen sind aber zugleich ein Anlockungsmittel für Mäuse. Es wäre zu versuchen, ob die Sämereien nicht durch Einlegen in Wasser, das einen unschädlichen Bitterstoff enthält, wie Alaun, geschützt werden könnten. Der Vermengung der Nadelholzsämereien mit Memnig als eines Vorbeugungsmittels gegen das Abbeißen der Keimlinge, des Übergießens der Eicheln mit Petroleum und der Mennigbeimischung wurde bereits bei der Vorbereitung zur Aussaat gedacht. Der Schutz der Saat durch Abfangen der Schädlinge, wie der Mäuse, Werren, Tipulalarven, Maikäferlarven, ist meist auf den Saatgarten beschränkt; bei Freilandsaat muß man das Abfangen der Schädlinge meistens anderen Tieren, wie Raubvögeln, Mardern, Füchsen, Katzen, ïberlassen, deren Schonung freilich mit dem jagdlichen Gewissen des Forstmannes, mit den Forderungen des Togelschutzes nicht vereinbar ist.

Die Keimzeit, Keimruhe der Sämereien steht im Verhältnis zur Samengröße und im Verhältnis zur vorausgegangenen Austrocknung der Sämereien; es wurde bereits erwähnt, daß die Austrocknumg bei manchen Sämereien eine Verlängerung der Keimruhe vom Frühjahr der Aussaat bis zum folgenden Frühjahr bedingt; von hervorragendem Einfluß auf die Keimruhe ist sodann die Bodenwärme, somit die nach der Saat eintretende Witterung. Klare Tage mit Somnenschein und trübe oder nebelige Nächte, welche die Abkülılung des Bodens verhindern, beschleunigen die Keimung am meisten; klare Nächte heben durch Abkühlıng den Einfluß der Erwärmung durch die Besonnung wieder größtentoils auf; bei naßkalter Witterung verzögert sich die Keimung am meisten; gedeckte Sämereien keimen etwas später als nicht gedechte, wenn trübe Witterung vorherrscht, etwas früher, wenn klare Witterung, insbesonders klare Nächte die Regel bilden.

Im allgemeinen keimen große Sämereien, wie Eicholn, Bucheln, Kastanien usw., in 5-6 Wochen; mittlere Sämereien in 4-5 Wochen; lileine Sämereien, wie Fichten, die meisten Föhren, Lärchen, in 3-4 Wochen; Birken in 2-3 Wochen; Pappeln in 2-4 Tagen und Weiden in 10-12 Stunden.

\section{Die Pflanzung.}

Trotz des Bestrebens der Gayerschen Selıule, der natürlichen Wiederverjüngung wieder größere Geltung zu verschaffen, hat die künstliche immer mehr im Laufe der letzten Jahrzehnte zugenommen; 
selbst die Saat, welche der Naturverjüngung noch am meisten sich nähert, hat fortgresetzt an Boden verloren, und an ihre Stello ist die Pflanzung cretreten. Es müssen großo Vorteile mit der Pflanzung verknüpft sein, weil sie, obwohl die kostspieligste Kulturmethode, bei der gegenwärtigen Steigerung aller Arbeitslölmo deunoch als rentabel, ja, wie manche behaupten, als allein rentabel erscheint. So viel steht fest, daß die Pflanzung unter den gegenwärtigen Verhältnissen des haubaren Waldes als die schnellste, sicherste und leichteste Bestockungsmethode betrachtet werden muß. Insbesondere rilt dies 1. für versumpfte, verheidete, verunkrantete, vergraste Ödländereien, welche in IVald umgewandelt werden sollen (Steppenaufforstung, Wiederbewaldung der Gebirge): 2. starke, mit Unkrautwuchs ïberzogene Stellen im Walde, Blößen sowohl als auch unter Lichtholzarten verwilderte, verangerte Böden lohnen die Pflanzung; 3. bewegliche Böden, wie Flugsand, Düne, von Wasser bedrohte Flächen, wie solche im Überschwemmungsgebiete der Flüsse liegen (Flußauen), verlangen die Pflanzung; 4. schwerer, an der Oberfläche erhärtender, im Winter auffrierender Boden oder sehr magerer, leicht austrocknender Sandboden, anmoorige Böden sind durch Pflanzung leichter mit Bestand zu versehen; j. die Festigungen des Geländes bei Aufforstungen im Gebirge zum Schutz gegen Abrutschungen, Lawinen, Wasserrisse können rasch und erfolgreich nur durch Pflanzung betätigt werden; 6. für alle Ausbesserungen und Nachbesserungen in natürlichen und künstlichen Verjüngungen ist allein die Pflanzung rationell; 7. Pflanzung in sehr weiten Verbänden ist notwendig, wenn zwischen den Pflanzenreihen noch landwirtschaftliche Zwischennutzung für einige Jahre stattfinden soll; 8. Pflanzung bietet im allgemeinen größere Sicherheit, und ermöglicht 9. die Herstellung einer beliebigen Bestockungsdichte.

Als Hauptnachteile der Pflanzung sind in erster Linie die hohen Kosten, welche von der Aussaat des Samenkorns bis zur Freilandpflanzung laufen, zu nennen; weiter ist nachteilig das Kränkeln der Pflanzen während der ersten Jahre nach der Pflanzung; auch der Umstand, daß mit der Größe des Pflanzenmaterials die Kahl der Leidensjahre nach der Pflanzung zunimmt, die Sicherheit des Ertolges abnimmt, die Höhe der Kosten wächst, verdient Erwähnung. Wird die Pflanzung auf kahler Fläche vorgenommen, kommen noch alle Nachteile hinzu, welche den Kahlschlagformen anhaften. Solange es Ödländereien gibt, muß es Pflanzung geben. Aber es muß betont werden, daß es nach Ansicht des Verfassers ein gutes Zeichen für den Wald und für den Wirtschafter ist, wenu im Walde die Flächen, welche eine Bepflanzung erfordern, immer mehr abnehmen und die Saat- und Pflanzgärten immer weniger und kleiner werden. In der Erziehungsverjüngung ist der Weg angedeutet, der zu diesem Ziele führen kann. Die Furcht, daß damit manches Forstmannes Freude und 
Haiptbetätigung im Walde beeinträchtigt würde, darf das Ziel einer fortschreitenden, naturgerechten Waldwirtschaft nicht verrücken.

1) ie (rewinnung des Pflanzenmaterials kamn geschehen: 1. durch Anliauf' (Ankaufpflanzen); 2. aus natürlichen Vorwüchsen (Vor wuchspflanzen): 3. aus dem Überschuß von Saaten auf Kahlschlägen (śchlagpflanzen); 4. aus besonderen, für die Aufzucht angelegten Forstgärten (Gartenpflanzen, Kamppflanzen).

\section{A. Ankaufpflanzen.}

Durch die Zunahme der Waldanlagen ist in den letzten Jahrzehnten der Bedarf an Waldpflanzen so sehr gestiegen, daß sich eine Privatindustrie der lohnenden Pflanzenzucht bemächtigte; in verschiedenen Teilen von Deutschland, wo ebener, lockerer Boden zur Verfügung stand, hat sie sich niedergelassen und ist imstande, unter Benützung von großen Betriebseinrichtungen und Maschinen die Pflanzen billiger zu liefern, als es im eigenen Betriebe, vor allem den kleinen Waldbesitzern, möglich ist. Begründete und unbegründete Bedenken werden gegen den Ankauf von Pflanzen aus solchen Pflanzenzuchtanstalten erhoben. Diese Einwände von naturwissenschaftlichen Gesichtspunkten aus zu prïten, soll Zweck der nachfolgenden Zeilen sein.

Das Klima. Es liegt nahe, daß für eine rentable Pflanzenzucht nur günstiges Klima, somit wärmere Lagen mit milderem Winter gewählt werden; die großen Pflanzenzüchtereien von Deutschland, Frankreich, Österreich und anderen Ländern liegen in milden Klimastrichen. Es besteht nun unter den Forstwirten und Laien ein weit verbreitetes Bedenken, Pflanzen aus wärmeren Lagen in kühlerem Klima zu benützen. Nan nimmt eine Verzärtelung der Pflanzen an und in der Tat ist ein Körnchen Wahrheit in dieser Vermutung gelegen. Jede Holzart, anch wenn sie ihro Heimat in kühlerem Klima besitzt, ist imstande, in wärmerem Klima durch Verlängerung der Vegetationszeit zu wachsen, solange für diese Holzart die thermische Konstante nicht überschritten wird. (Man vergl. Abschnitt III S. 59.) Diese Anschmiegung an die längere Vegetationszeit geht selbstverständlich schon in der ersten kürzeren Vegetationszeit eines neuen Standortes wieder verloren. Da aber der längeren Vegetationszeit ein milderer Winter, der kürzeren Vegetationszeit des kühleren Klimas ein strengerer Winter folgt, so ist mit der Anpassung an die längere Vegetationszeit eo ipso auch eine Vorberoitung für denkommenden, milderen Winter. mit der Anpassung an die kürzere Vegetationszeit eine Vorbereitung für den kommenden, strengeren Winter verknüpft. Daraus folgt somit: Wird eine Pflanze aus wärmeren Gegenden im Herbste bezogen und auf einem kühleren Standorte ausgepflanzt, so besteht die Gefahr, daß sie in dem strengeren Winter, für den sie nicht vorbereitet ist, zurückfriert. An einheimischen Laubhölzern und ganz 
besonders an fremdländischen Laub- und Nadelhölzern ist dies zu befürchten und darauf die Klage, daß vom Süiden (resp. wärmeren K'lima) bezogene Pflanzen im Winter erfroren seien, zurückzuführen. (Un geeignete Zeit der Provenienz der Pflanzen). Wird aber die Pflanze im Frühjahr bezogon und auf einen kühleren Standort versetzt, so folgt auf die Pflanzung unmittelbar ein Sommor, der die Pflanze auf den kommenden Winter desselben Standortes vorbereitet. Der Bezug der Pflanzen aus wärmerem Klima im Frü $h_{\mathrm{j}} \mathrm{ahr}$ ist somit ohne alle Bedenken, der Bezug von Laub- und Nadelhölzern (insbesondere fremdländischen) im Herbste ist zu vermeiden.

Der Boden. Die Auffassung, man solle die Pflanzen in minderwertigem Boden aufziehen, damit sie in ihren Ansprüchen an den Boden bescheiden bleiben, ist schon deshalb irrig, weil in schlechterem Boden die Pflanzen mit weit ausgreifendem Wurzelsystem erwachsen und für eine Wiederverpflanzung ein möglichst eng begrenztes Wurzelwerk erwünscht ist. Mit vollem Recht wird guter Boden gewählt, und wo er nicht gut genug oder erschöpft ist, gedüngt. Je vollkommener die Bewurzelung, um so wertvoller ist die Pflanze.

Die A ufzucht. Die Pflanzenhandlungen erziehen ihre Pfleglinge, wie sie im forstlichen Pflanzgartenbetrieb gewonnen werden, durch Rillensaat mit und ohne darauffolgende Verschulung; die gewissenhafte Ausnutzung des Standraumes aber bedingt einen engen Saat- und Verschulverband. In diesem erwachsen die Pflanzen mit schwächeren Seitenästen aber längeren Gipfeltrieben; das Pflanzenkrönchen wird zylindrisch, während für die Verwendung eine kegelförmige Krone, stufiger Bau der Pflanzen am besten wäre, weil alle Pflanzen, welche isoliert auf nacktem Boden stehen, zuerst eine Deckung des Bodens durch Seitenäste zur Erhaltung der Bodenfeuchtigkeit erstreben: das mehr fadenförmige Material der Pflanzenhandlungen muß erst diese Kegelform im neuen Standort entwickeln, um sich heimisch zu fühlen. Mit dieser Kronenausbildung steht ein zweiter Nachteil in Zusammenhang: die Nadeln der immergrünen Holzarten haben sich in diesem seitlichen Halbschatten dünn und zart entwickelt, wie es dem seitlich mangelnden Lichte entspricht. Werden sie nun plötzlich in das volle Licht versetzt, so besteht Gefahr der Sonnenbleiche im Sommer oder des Erfrierens und Braunwerdens im Winter (Nadelbräune), da die fertiggebildete Nadel sich neuen Lichtverhältnissen nicht anpassen kann. Erst die neu entstehenden Nadeln bauen sich so auf, wie es dem neuen Lichtangebote entspricht. Während dieser Anpassung aber kümmert die Pflanze. Diese Hemmung danert um so länger, je engrer der Pflanzenverband war, je stärker die Pflanze durch den Dünger empor getrieben wurde.

Behandlung beim Versand. Alle vorhergehend geäuferten Bedenken stehen aber zurück gegenüber dem Tadel, den man ans- 
sprechen muß, wenn man die Behandlung der Pflanzen beim Ausheben, Aufbewahren und Verschicken verfolgt. Schon beim Ausheben ist eine Vertrocknumgserscheinung nicht $\mathrm{zu}$ vermeiden. Es genügen wenige Minuten um an den zartesten Wurzeln dic Wurzelhaare zu töten. Ein Ersatz aber ist nur möglich, wenn neue Wurzelspitzen sich bilden. Bei längerem Verweilen in der Sonne, in trockenen, gedeckten Räumen vertrocknen auch die Wurzelspitzen. Werden dann die Pflanzen in Bündel zusammengeschnürt, schichtenweise mit nackten Wurzeln in den Wagen aufeinandergelegt und tagelang auf große Entfernungen hin transportiert, dann darf es nicht wundernehmen, wenn die Wurzeln bis zu den Ansatzstellen am Schafte der Pflanze empor vertrocknen, die grünen Pflanzenteile und Triebe sich erhitzen und fahlgrün werden, welche Farbe in der Regel den Tod bedentet, zumal wenn die Rinde der Stämmchen runzelig geworden ist. Wenn die Pflanzenhandlungen sich nicht entschließen können, ihre Pflanzen mit feuchtem Moos in den Eisenbahnwagen zu verpacken, wie es ja vielfach bei Verpackung in Körben bereits geschieht und von den modernen Einrichtungen der Eiskühlung bei der Aufbewahrung und beim Transport Gebrauch zu machen, werden sie immer mehr von ihrer Kundschaft verlieren. Es wäre dies tief zu beklagen, denn ihre Pflanzen sind gut und billig und haben der Waldkultur mächtig Vorschub geleistet.

$\mathrm{Pre}$ is und $\mathrm{K}$ aufbedingungen. Nur eine im großen arbeitende Industrie kann so niedrige Preise für ihre Ware stellen, wie es heute die Massenzuchtanstalten vermögen; der Kleinbetrieb der Forstgärten kann damit nicht wetteifern und der Vorzug einer allenfalsigen besseren Qualität wird durch die höheren Kosten ausgeglichen. Verfasser steht auf dem Standpunkt, daß jene Bezugsquelle die beste ist, welche die Pflanzen von gew ünschter Qualität am billigsten liefert. Kann dies im eigenen Betrieb nicht erreicht werden, werden die Pflanzen angekauft. Die bisherigen Pflanzgärten für großen Betrieb einzurichten, wie schon E. Heyer 1866 verlangte, lohnt sich nur in solchen Örtlichkeiten, in welchen durch Wind oder Insektenkalamitäten große Kahlflächen für Wiederaufforstung entstanden sind.

Um Pflanzen von der gewünschten Qualität zu erhalten, muß die Bestellung Höhle, Alter und eine bestimmte Behandlungsweise (z. B. Verschulung) festsetzen; weitere Bedingungen beziehen sich auf die Verpackung und die eventuelle Zurückweisung der Sendung, wenn die immergrünen Pflanzen mit gelbgrünen, teilweise bereits abfallenden Nadeln und verschrumpften Wurzeln und Trieben anlangen.

Die Behandlung der eintreffenden Pflanzen. Sind die Nadeln der immergrünen Pflanzen noch normal grün, aber erscheinen Wurzeln und Triebe welk, eingetrocknet, so sind sämtliche Pflanzen sofort auf zwei bis drei Tage in Wasser untergetancht zu halten; oder sie werden auf' dem Boden aufeinandergeschichtet, und jede Schicht begossen 
und mit nassem Moos von der nächsten Schicht gretrennt; oder die Pflanzen werden in Erde eingeschlagen, kräftigst in allen Teilen begossen und mit Stroh oder Deckreisig gegen Wind und Sonne so lange abgeschlossen, bis sie verwendet werden können.

\section{B. Vorwnchspflanzen.}

Es ist selbstverständlich, daß nur solche Vorwuchsplanzen zur Wiederverpflanzung sich eignen, welche ihrer Größe, ihrem Alter, ihrem Habitus entsprechend als brauchbar bezcichnet werden können; über diesen Punlit gelten die Ausführungen im Abschnitt $\mathrm{X}$, Seite $29 r$. Außerdem ist folgendes zu beachten: daß Vorwuchspflanzen um so besser sind, je jünger und kleiner sie sind; daß die Pflanzen mit Erde ausgehoben werden sollen als Ballenpflanzen; daf sie aber gering oder ganz unverwendbar sind, wenn sie mit weit ausgreifenden Wurzehn oberfächlich im Humus festsitzen, so daf, sie beim Aushub nur von lockerem Humus zwischen den starken, abgestochenen Wurzeln umfüttert sind (Fichten, Birken, auch Tannen ${ }^{1}$ ); daß nur immer e ine Pflanze ausgestochen werden soll; Büschelpflanzen sind stets verwerflich; sind mehrere zusammenstehend sollen alle bis auf die beste nicht weggerissen, sondern abgeschnitten werden: daß mehrere Pflanzen zusammen nur bei Laubhölzern zulässig sind; daß die ausgehobenen Pflanzen wenigstens in den ersten. Tahren in ähnliche Lichtverhältnisse geraten sollen, unter denen sie in den letzten Jahren gestanden haben; daß die Pflanzen nur dann aus Vorwüchsen ausgestochen werden sollen, wenn diese Vorwüchse nicht zur natürlichen Verjüngung des Bestandes verwendet werden können. Als Geräte für das Ausheben der Vorwuchspflanzen kommen in Frage, je nach der Größe der Pflanzen, schwere Stechspaten, das Solinger Eisen, Flachspaten, Zylinderspaten mit nach der Schneide hin kleiner werdendem Durchmesser, Kegelspaten, Kegelbohrer. Von diesen unten abgebildeten Typen von Instrumenten eignet sich der Kegelspaten für alle Bedürfnisse; Zylinderspaten werden umso unpraktischer je größer sie sind; der Kegelbohrer ist für kleinere, seichtwurzelnde Pflanzen sehr brauchbar; daß als Grundsatz gelten muß, je kleiner die Pflanze um so kleiner kanm das Instrument sein, bedarf kaum der Erwähnung.

Sollen

\section{Schlagpflanzen}

gewonnen werden, so wird hierauf schon durch Ausführung einer dichteren Vollsaat auf der Kahlfläche, oft in Verbindung mit Giotreidebau (wie Hafer, Roggen), Bedacht genommen. Auch eine Verschulung auf Kahlschlagflächen kaun Pflanzen liefern. Dieselben Instrumente,

1) Kautsch, Beiträge zur Frage der Weißtannenwirtschaft (189:), verwirft Tannenvorwuchspflanzen ganz. 
welche vorhin beschrieben wurden, dienen auch zum Ausheben der Schlagpflanzen mit Erde, welche somit Ballenpflanzen sind. Hierbei ist jedoch zu bedenken: daß jede Pflanze durch das Herausstechen aus dem Boden beschädigt wird, und daß auch jede Nachbarpflanze, welche verbleiben soll, eine ähnliche Beschädigung erleidet; daß in der Regel eine Vielheit von Pflanzen in einem Erdballen sich findet. wolche bis auf die besten weggeschnitten werden sollten, daß dies aber in der Regel nicht geschieht, so daß Schlagpflanzen-
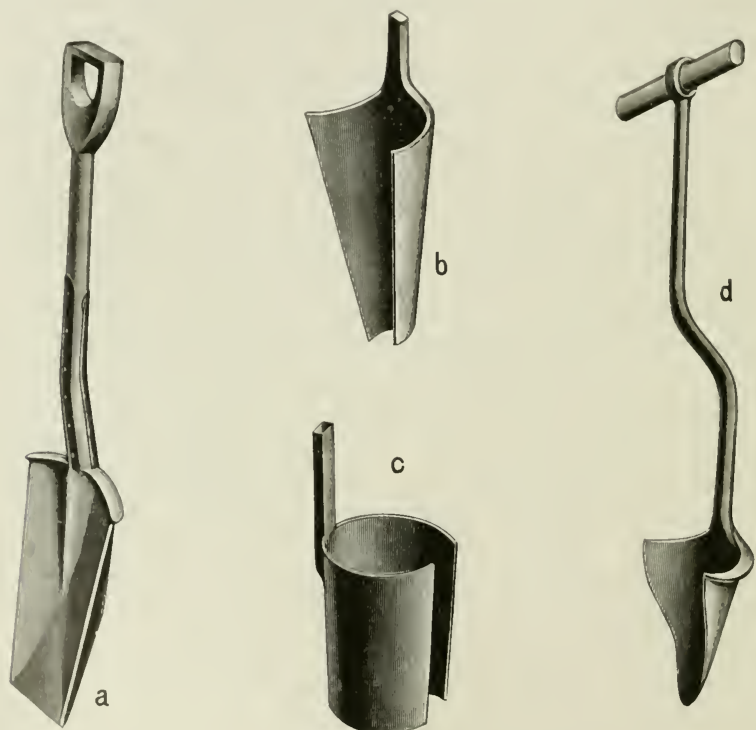

Abb. 21. Gerllte zum Ausheben von Ballenpllanzen: a amerikanischer Stechspaten, b Kegelspaten, c Hohl-oder Zylinderspaten, $d$ E. lleyers Pflanzenbohrer.

gewinnung zur Büschelpflanzung führt, welche eine Summe von Verlegenheiten in späterem Alter des Bestandes bedeutet; daß bei besonders schwerem Boden sich Wasser in den Stichlöchern ansammelt; daß bei lockerem Boden die bleibenden Pflanzen vertrocknen können; daß die Gefahr einer allzu starken Ausnützung naheliegt, welche eine ungenügende Pflanzenzahl oder zuviel an Schwächlingen zurückläßt, woraus nur mangelhafte Bestände werden; daß der Boden durch das Ausstechen der Ballen außerordentlich verschlechtert wird; daß somit nur auf den besten Böden eine solche Pflanzenzucht getrieben werden soll. 


\section{I). Gartenpflanzen, Ḱamppoflanzen.}

Über die Erziehung von Pflanzen in eigenen Forstgärten oder Kampen liegen umfangreiche Untersuchungen und ausführliche Schriften vor; es darf wohl als das beste Werk hierüber H. v. Fürsts ${ }_{n}$ Pflanzenzucht im Walde" bezeichnet werden; auf jahrzehntelange eigene Erfahrungen aufgebaut, ist das Buch in der vierton Auflage auf :38:3 Seiten angewachsen. Auch hierin liegt ein Beweis von der Z/unahine der künstlichen Verjüngung, von der Vereinfachung des forstlichen Gewerbes und von der Verlegung des Schwerpunktes der forstlichen Tätigkeit auf Kahlschlag und Pflanzenzucht.

\section{A uswahl der Örtlichkeiten für Anlage des Gartens.}

Hinsichtlich des Klimas kann auf die Ausführungen bei den Ankaufspflanzen verwiesen werden. Da man nicht für jede Pflanze einen ihrem Klima entsprechenden Garten wählen kann, so verlegt man mit vollem Rechte die Gärten stets in die günstigste Klimalage, welche ein Revierbezirk besitzt; da das Ḱlima des Hügellandes von der Exposition abhängig ist, werden nördliche und östliche Abdachungen für Kühle und Luftfeuchtigkeit liebende Holzarten, südliche Expositionen für Wärme liebende und Lufttrocknis ertragende Holzarten gewählt; wo Vertrocknumgsgefahr besteht, wie bei leichten, sandigen Böden, sind südliche Expositioneu zu vermeiden. Um möglichst den Spät- und Frühfrösten zu entgehen, wird die Anlage mitten in einem größeren Waldgebiete, mitten in einem Hochwaldbestande angelegt, so daß auch im Saat- und Pflanzengarten möglichst jene Verhältnisse obwalten, unter welchen auch die freie Natur ihre Kinder aufzieht. Die Belichtung soll nur für eine halbe Tageszeit eine volle Besonnung sein. Am vollkommensten erfüllt diese Bedingungen ein Garten von $0,1-0,3$ ha Größe, rechteckig, in einem der Haubarkeit sich näherndon Bestande einer Schattenholzart so untergebracht, daß die Nord-und Ostseiten des Gartens eine halbe, die West- und Südseiten eine viertel Baumlänge vom haubaren Bestand entfernt bleiben. Dadurch wird der schädliche Sonnenreflex an der Nord- und Ostseite eingeschränkt, der wohltuende Schatten auf der Süd- und Westseite ausgenützt, ohne daß damit der Garten in das Tropfbereich der Bäume gerät; auf einem Saumschlage soll der Garten nur dann untergebracht werden, wenn der Saumschlag so lange stille steht, bis der Garten ansgenützt und mit der Holzart der Umgebung wieder bestockt ist; an Kahlflächen, Blößen, Feldern, Wiesen soll der Garten wegen Unkrautgefahr nicht angrenzen. Bei der Bestellung des Gartens mag der nordöstliche Teil den Lichtholzarten, der übrige Teil den Schattenholzarten zugewiesen werden. Ein derartig gelegener Garten ist gegen Wind als lästige Erscheinung

1) H. v. Furst, Die Pflanzenzucht in Walde. 4. Aufl. Berlin 1907. 
beim Säen und ror allem gegen Spät- und Frühfröste gesichert, eine Gefahr, welche alle Pflanzgärten in Mitteleuropa von mehr als 0,3 ha Größe bedroht. Muß dem Garten eine größere Ausdehnung gegeben werden, so empfiehlt sich schwach geneigtes Gelände, um der kalten Luft einen Abfluß zu bieten.

Mortzfeld ${ }^{1}$ ) wählt 10 a große Kreisflächen auf bestem Boden, er verbindet dabei den Pflanzgarten mit der Bestandsbegründung, indem der Garten nach 10jähriger Benützung in eine Laubholzgruppe übergeht. Nähere Angaben sind später bei Begründung der Eiche gebracht.

Bezüglich des Bodens ist den Ausführungen über Ankaufspflanzen auf Seite 391 nichts hinzuzufügen. Der beste Boden, wenn er locker und frisch ist, ist für den Pflanzgarten gerade gut genug; auch entwässerter und verbesserter Moorboden kleinerer Ausdehnung, mitten im Walde gelegen, eignet sich. Der Pflanzgarten soll konzentrisch zwischen den Verbrauchsarten und in der Nähe eines Wasserbehälters gelegen sein.

Die Größe des Pflanzgartens wird nicht nach dem Bedarf an Pflanzenmaterial, sondern nach naturgesetzlichen Gesichtspunkten bestimmt. Die Maximalgröße ist jene, bei der die Bestandsdurchbrechung ein Frostloch zu werden beginnt; das beginnt durchschnittlich im wärmeren Mitteleuropa, wie oben angegeben, bei einer Größe von $0,3 \mathrm{ha}$, im kühleren Fagetum bei 10 a (Mortzfeld). Sind größere Flächen notwendig, so möge bedacht werden, da $B$ mehrere kleine Gärten einem großen vorzuziehen sind. Um Zahlen über das Verhältnis zwischen Pflanzgärten und Schlagflächen zu geben, sei erwähnt, daß man $4-5 \%$ der Kulturfläche für den Pflanzgarten rechnet, wenn verschultes, $2-3 \%$ wenn nicht verschultes Material in Anwendung kommt.

Pflanzgartenwechsel. Fliegende Pflanzgärten, welche den Boden nicht bis zu seiner Erschöpfung ausnützen, sind den ständigen vorzuziehen. In neuerer Zeit wird betont, ständige Gärten für Ansaat, fliegende für Verschulungen zu wählen.

Umzäunung. Lebende Zäune, Heckenzäune aus Weißdorn, Schwarzdorn, Hainbuchen, Eiben, Tannen, Fichten, Thujen, Taxus, Tsuga und anderen Schatten ertragenden Holzarten können nie so dicht aufwachsen, daß nicht Tiere sich hindurchzwängen könnten. Sie bedürfen längerer Zeiträume, bis sie ihren Zweck annähernd erfüllen, da sie, wenn aus Nadelholz, einmal, wenn aus Laubholz zweimal im Jahre kräftig beschnitten werden müssen; wichtiger sind andere Zaunformen, welche sich zumeist nach der Tiergattung richten, welche ausgeschlossen werden soll. Danach unterscheidet man Stangenzäune, Flechtzäune,

1) Mo rtzfeld, Zeitschr. f. Forst- u. Jagdw. 1896. 
Drahtzäune mit horizontal gespannten Drähten und Drahtgetlechtzäune oder Massenzäune. Neuerdings kommen immer mehr statt der vergänglichen Holzzäune die fast unvergänglichen Drahtzäune zur Anwendung. Der Draht, teils glatt, teils auch mit Blechspitzen oder Nägeln versehen (Stacheldraht), wird in einem Abstand von $10-15 \mathrm{em}$ horizontal auf Pfosten mit einem Hebelinstrumente aufgezogen und mit. Krampen angenagelt; solche horizontale Drähte sind gut gegen größere, wertlos gegen kleinere Tiere (Reh, Hase), da sie sich über kurz oder lang doch lockern durch Einsteigen von Menschen, durch Versuche der Tiere, einzudringen. Besser ist daher die vertikale Verflechtung solcher Drahtzäune mit geringwertigem Stauden- und Ästematerial.

Der beste aller Zäune ist das Drahtmaschengeflecht. Bei der Preisabnahme solcher verzinkter Drahtnetze, bei der Haltbarkeit derselben (ihre 25jährige Brauchbarkeit ist bereits festgestellt), bei der absoluten Sicherheit, die sie gewähren, sind sie auch als die billigsten zu bezeichnen. Nur ihre momentane Anschaffung ist vielleicht noch etwas höher als jene der vergänglichen Holzzäune. Je nach der Tiergattung sind Maschendurchmesser, Drahtstärke und Netzhöhe zu wählen. Es genügt übrigens zum Abhalten aller Tiere, welche nicht klettern können, eine Netzhöhe von $1 \mathrm{~m}$ und eine Überhöhung mit

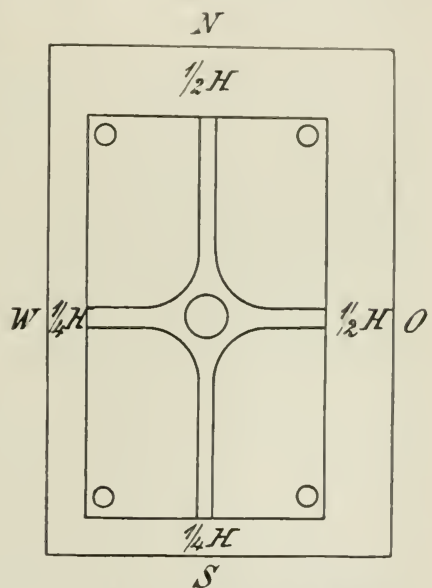

Abb. 22. Form und Lage des PHanzgartens in einem haubaren Bestande; Frklarung im Texte. ein oder zwei Sprungdrähten: der Abschluß am Boden ist am einfachsten durch Aufwerfen von Erde oder durch Versenken des Gitters oder eines Stacheldrahtes erreicht.

Sind die Drahtgeflechte auf hölzerne, imprägnierte Rahmen gespannt und geeignet an Pfosten geheftet, so können nach Auflassen des Gartens dieselben Rahmen zur Einfriedigung eines weiteren Gartens dienen. Ebenso kann aus solchen Rahmen eine beliebige Umzämung für Freilandkulturen hergestellt werden. Zur Umzäunung gehören auch einander gegenüber liegende Türen bzw. Tore, im Falle der Garten mit bespannten Fuhrwerken befahren werden soll.

\section{Arbeiten im Pflanzgarten.}

Die Bodenbearbeitung beginnt bereits im Herbst mit der Fällung der Bäume, Rodung der Stöcke, Umhacken, seltoner Umpflügen 
der Fläche bis zu einer Tiefe von $30-40 \mathrm{~cm}$ unter Beseitigung von Wurzeln und groben Steinen; Wurzeln und Unkrautwuchs werden auf Haufen zusammengebracht. Im nächsten Frühjahre werden Unkraut und Wurzeln zu Asche verbrannt, die Asche wird über die ganze Fläche verstreut und eine abermalige, seichtere, gartenmäßige Bodenbearbeitung sorgt für feine Verkrümelung und Ebmen der ganzen Fläche und Einteilung in Beete.

Die Breite der Beete soll zwischen 1-1;2- m liegen, damit die Handarbeiten in der Mitte des Beetes ron den beiden Seiten her nicht erschwert werden; die trennenden Wege sollen nicht weiter sein, als eines Mannes Fuß lang ist. Damit die Wege rechtwinkelig sich schneiden, empfiehlt sich die Anwendung eines Winkelprismas. Ein Hauptweg der Länge nach und ein zweiter, welcher senkrecht auf dem ersten steht, womit der Garten in vier gleiche Teile zerlegt wird, bilden in der Regel die Grundlage für die Beeteinteilung. Die so entstehende Pflanzen- und Saatstelle verdient vom ästhetischen Gesichtspunkte aus den Namen Garten so wenig wie eine Stelle für Gemüse- oder Getreidezucht: es gibt aber doch Pflanzenzuchtanstalten, welche wenigstens versuchen, sich das Wort Garten zu verdienen, indem die toten Punkte im Garten wie auch ein mittleres Rondell für Anpflanzung einer solitären, selteneren Holzart reserviert bleiben. Verfasser kann in diesem Punkte dem Verfasser der „Pflanzenzucht im Walde“, H.v. F ürst, nicht zustimmen; v. Fürst findet, daß solche Zierden als Luxus besser wegbleiben sollten, da gut gehaltene und gepflegte Pflanzbeete auch ohne solche überflüssige Zutaten das Auge des Sachverständigen erfreuen würden. Wir fügen hinzu, daß das Auge des Sachverständigen hier in der Regel das des Vorgesetzten ist, was es anch erklärlich erscheinen läßt, warum vielfach in der guten Erhaltung und Pflege ein Luxus getrieben wird, der überflüssig ist. Werden aber zur Zierde fremdländische, forstlich beachtenswerte Holzarten gewählt, so sind sie als Anfang einer Bestockung beim Terlassen des Pflanzgartens, das ohnedies nach zehn bis zwölf Jahren geschehen sollte, nur nützlich; bei ständigen Gärten mögen Solitärpflanzen mit den Jahren störend werden. Die Einteilung der Beete erfährt im Laufe der Benützung des Pflanzgartens Veränderungen; es sollte Regel sein, dak bei jeder nenen Bestellung der Beete mit der Beetrichtung und Beetbenutzung gewechselt würde; ein Beet, welches eine Saat trug, soll nunmehr eine Verschulung, ein Beet, welches eine Verschulung trug, soll nunmehr eine Saat aufzunehmen haben. Auch Wechsel in der Ilolzart ist angezeigt. Ehe Bodenerschöpfung eintritt, soll die Bodenverbesserung durch Düngung einsetzen, worüber am Schluf des Pflanzgartenbetriebes nähere Angaben gebracht werden. Ein notwendiges Attribut des Saat- und Pflanzgartens ist sodann eine Hütte oder Zelte, groß genug zur Unterbringung der Geräte und der Arbeiter zum Schutz gegen die Unbilden der Witterung. 
Die Bestellung der Beete durch Sämereien. Eine über die ganze Beetfläche hinweggehende Vollsaat heißt breitwürfige Saat. Sic bringt zwar mehr Pflanzen pro Beetfläche, erschwert abor die Reinhaltung der Beete von Unkrantwuchs, die Bekämpfung von Schädlingen, so daß man allgemein zur Streifensaat übergegangen ist, welche wegen ihrer Schmalheit Rillen-oder Rinnensat genannt wird.

Für kleine Sämereien, wie sie Fichten, Lärchen, mehrere Föhren und andcre Holzarten besitzen, genügt eine Rille von etwa $2 \mathrm{~cm}$ Tiefe und $3 \mathrm{~cm}$ Breite und ein Rillenabstand von 10 $\mathrm{cm}$; größere Sämereien verlangen größere Abstände in den Rillen, welche ihnen durch die Steck- oder Stufensaat gegeben wird.

Die Anfertigung der Rille geschieht am raschesten durch rotierende Instrumente: Walzen von der Breite der Saatbeete, denen in bestimmten Abständen Leisten aufgenagelt oder aufgelötet sind, drücken die Rille in den Boden durch ihr Gewicht ein, wenn sie über die Beete parallel mit deren Längsseite bewegt werden. Solche Walzen wurden von $\mathrm{S}$ a u e $\mathrm{r}^{1}$ ) erfunden: sie liefern stets die gleiche Rillenbreite und -tiefe, sind daher nur für bestimmte Sämereien anwendbar. Leichter handliche und für größere wie für kleine Sämereien brauchbarere Geräte von verschiedener Rillentiefe und -breite sind Spitzenbergs ${ }^{2}$ ) Rillenwalzen: durch stärkeres oder schwächeres Aufdrïcken werden die Rillen tiefer oder seichter. Eine Führervorrichtung gestattet den Abstand der Rillen zu ändern und einen möglichst parallelen Verlauf der Rillen einzuhalten; gelingt dies nicht vollständig, so ist dies zwar kein Schaden für die Pflanzen, aber vielleicht nicht erfreulich für das Auge des Sachverständigen.

Bezüglich der Schnelligkeit der Arbeit sind an zweiter Stelle zu nennen die Saatbretter, welche eine Länge gleich der Beetbreite besitzen und im gewünschten Abstande aufgenagelte Leisten tragen, welche wiederum einen Querschnitt von der gewünschten Rillenbreite und -tiefe besitzen. Der Querschnitt ist schwalbenschwanzartiv (Doppelrille), dreieckig oder viereckig; den dreieckigen dürfte der Vorzug zu geben sein. Damit die Rillen parallel werden, wird über die Beete der Länge nach eine Schnur gespannt, auf welche die Saatbretter so gelegt werden, daß ein das Brett in der Quere halbierender Strich genau mit der Schnur zusammenfällt. Auch die Bretter haben den Nachteil, daß eine Veränderung in dem Verbande und der Größe der Rillen unmöglich ist. Endlich wären noch Spitzenbergrs Rillendrücker sowie löffel- oder pflugartige Geräte zu nennen, mit welchen ebenfalls Saatfurchen von beliebiger Tiefe und Breite je nach der Bolastung eingedrüickt werden können. Für Saaten mit größeren Sämereien,

1) Revierförster Sauer, Forstwissenschaftliches Centralblatt 1904.

2) 1. c. 
z. B. Eicheln (Stecksaat, Stufensaat, Punktsaat), fertigen Bretter mit Zapfen oder Setzstäbe vertikale Löcher, oder das Einlegen erfolgt in tiefen Rillen, so daß die Sämereien horizontal liegen.

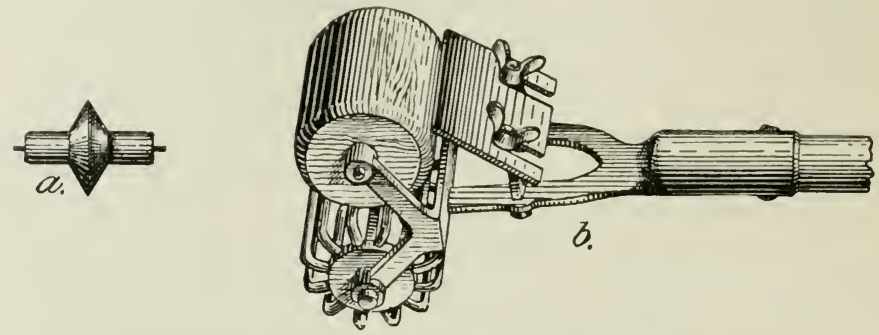

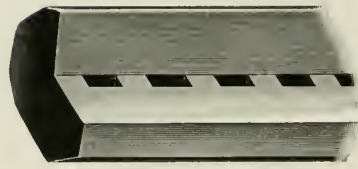

C

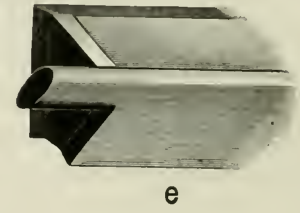

e

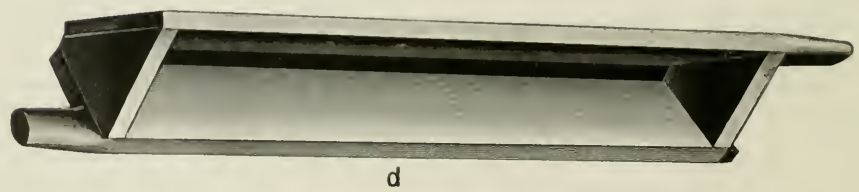

Abb. 23. Saatgerlite: a Spitzenbergs Rillenwalze, $b$ desselben Gitterwalze und Saatbedecker, $c$ Fßlingers Saatlatte, $d$ und $e$ ll affners Rillenbedecker.

Die mehrfach bereits zitierten Untersuchungen Professor B ïhlers geben zuverlässige Anhaltspunkte über die Saatdichte. Nach Bühler erhält man die größte Pflanzenmenge, wenn von den Sämereien der europäischen

Fichten, Föhren, Schwarztöhren . . . $10 \mathrm{~g}$ pro $1 \mathrm{~m}$ Rillenlänge,

Lärche, Weymonthföhre, Buche, Erle . 31) " 1 "

Tanne, Zirbel, Esche, Linde .. . . $50, n 1, n$

Stieleiche und Birke . . . . . 150, " 1 " n verwendet werden.

Die Dichtigkeit hängt sodann ab von dem Kweck, der mit der Saat verfolgt wird. Sollen die Pflanzen im Saatbeet bis zum Aus- 
ptlanzen verbleihen, so ist dïnne Saat notwendigr, sollen aber die PHanzen ein- oder zweijährig ausgehoben und wiedor verptlanzt (rorschult) werden, so sind dichte saaten zuläsisig.

Die Ansaat der Rillen geschieht mit dor Hand, wie besonders bei wrößeren oder geflügelten Sümereien; kleinere sümeroien, besonders jene der Fichten, Führen und Lärehen, lassen sich vorteilhaft auch mit einfachen Vorichtmgen einbringen. Forstrat Elilinerers Saatlatte ist eines der am läufigsten gebrauchten und einfachsten Saatgrouite. Die beigegebene Abbildung macht eine Beschreibung ïberflïssig; sie hat die Beetbreite zur Länge und wird in einem ebenso langen Troure mit sämereien gefüllt: durch eine geschickte Drehung oder mit dim Finger wird der Überschuß der Körner beseitigt; die Latte wird an die Rille angelegt und umgelippt. Fïrst empfiehlt sodamn II ör mann $s^{1}$ ) Rillensäer als ein sehr einfaches Instrument; seino nähere Konstruktion möge aus der Originalschilderung entnommen werden. Forstmeister Hacker hat einen Säeapparat ertunden, der keine Rillenanfertigung verlangt; der in regulierbarer Menge ausfliefende Samen wird von der am gleichen Instrument befestigten Walze festgedrückt, worauf die Bedeckung der Sämereien folgt.

Die Bedeckung der Sämereien. Was die Dichte der Bedeckung angeht, so ist sie durch die Rillentiefe gegeben; die Rillentiefe wird so gewählt, daß die Ausgleichung der Rille durch Eindecken mit der Beetfläche genau die richtige Bedeckungsdichte ergibt. Alle Angaben bezüglich der Freilandsaaten (Seite 386) haben auch für Gartensaat ihre Geltung; als Mittel zum Decken dienen gleichfalls dioselben Substrate: es mag hierzu kommen, daß Rillensaaten auch mit Düngererde gedeckt werden können, wie dies z. B. Forstrat Häffner in Forstenried mit einem überaus praktischen Instrument erreicht, dem Häffnerschen Saatbedecker. Diesor, einem breit gezogenen Trichter gleich, wird auf die Rille gestellt, die Düngererde wird mit der Hand hineingestreut, mit einer Seitenfläche wird die Bedeckung festgedrückt (Abb. $2: 3$ \& u. e).

Auch die ïbrigen Instrumente, wie Rechen und ganz besonders Spitzenbergs Saatbedecker (Abb. 23b) sind hier einschlägig.

Da jene Schutzmaßregeln die besten sind, welche das Erscheinen der Feinde der Sämereien verhindern, so sollen diese zuerst besprochen werden.

Um dem Unkrautwuchse vorzubeugen, empfichlt sich das Belegen der Bectstreifen zwischen den Saatrillon mit Laub, Moos, sägremehl, Torfmull, gespaltenen Stangen, Latten, Prügelı ı. dgl. Damit ist zugleich ein vortreffliches Mittel gegen Austrockmug der saat, eine außerordentliche Förderung durch die Feuchterhaltung des Bodens, ein

$\left.{ }^{1}\right)$ Hörınann. Forstwissenschaftliches Centralblatt 190:3.

Mayr. Waldbau. 
Mittel gegen Auffrieren im Winter geboten: nützliche Laufkäfer finden ihre Deckung. Keimt Unkrautwuchs zuerst empor, vor der Edelsaat, wie das die Regel ist, so muß ersteres beseitigt werden, ehe es größer wird. Bei Sämereien, welche in einer Tiefe von $2 \mathrm{~cm}$ und darüber im Boden liegen, ist das kräftige Übergießen der Beete mit kochendem Wasser ohne oder mit groblöcheriger Brause, welche hart über den Boden hinweggeführt wird, ein vortreffliches und rasch wirkendes Unkraut- und Insektenvertilgungsmittel; bei Sämereien, welche bis zu $2 \mathrm{~cm}$ tief liegen, genügt Wasser von $811^{\circ} \mathrm{C}$; dieses Begießen mit kochendem Wasser ist wohl das billigste und zugleich nützlichste Mittel der Unkraut vertilgung, das bis zur Keimung wiederholt werden kann. Es empfiehlt sich das zur Saat zubereitete Beet einige Tage ohne Saat zu belassen, damit das oberflächlich liegende Unkraut vor der Edelsaat einen Vorsprung erhält und dadurch gründlicher mit heißem Wasser vernichtet werden kamn. Keimen Unkrant und Edelsaat gleichzeitig, so muß so früh als möglich das Unkraut mit der Hand, vielleicht unterstïtzt von einem spitzen Messer, beseitigt werden, wobei gelockerte Keimlinge mit den Fingem seitlich wieder festzudrücken sind. Zum Schutze gegen Auffrieren wird nach August nicht mehr ausgejätet. Für die letzte Unkrautbeseitigung im Augnst, September genügt zwisehen den Verschulungen das Abschneiden des Unkrantes, ehe dasselbe zur Samenbildung sehreitet; die annuellen Unkräuter vernichtet dann der Winter, während ihre Wurzeln gegen das Auffrieren schützen. Das völlige Beseitigen noch im Herbst ist zwar schöner, aber auch dafür kostspieliger und weniger nützlich. Das Unkraut in den Rillen kann nur mit der Hand, jenes zwischen den Saatrillen auch mit zwei- oder dreizinkigen Gabeln, mit Miniaturpflügen (Jätepflügen), mit der Kratzbürste, welche Nägel trägt, mit Schüllermanns Lockerungsapparat ${ }^{1}$ ) und arderen beseitigt werden. Das Unkrant auf den Wegen wird mit schabenden, flach abschälenden Instrumenten entfernt.

Engerlinge sind in Gärten, welche in normaler Größe in einem haubaren Bestand angelegt werden, nicht zu befürehten; das Anbringen von Starenkästen an den Bäumen in der Umgebung der Gärten schützt gegen eine Menge von Insekten, insbesondere auch gegen den Mailäfer; auf größeren Flächen hat sich das Eindecken der Saat mit Reisig bewährt, das Einbringen von Schwefelkohlenstoff in den Boden ist nach v. Seelen gut, nach Weise wertlos. Dio Werre vertilgt man durch Anfsuchen der vertikalen Gänge und Eingießen von reichlichem kochenden Wasser; auf der Oberfläche lehendo Käfer, wie Haltica, auch solche mit hartem Panzer, wie Rüiselkäfer, bekämpft und tötet man am schnellsten durch kräftiges Übergielien der Beete mit heißem Wasser von $50^{\circ} \mathrm{C}$. Diese Temperatur schadet auch den zartesten Pflanzen

1) Schullermann, Forstwissenschaftliches Centralblatt 1903. 
nicht, tötet aber jedes tierische Leben nach Thtersuehungen des Verfassers. Gegen Mäuse helfen eingegrabene, glattwandige Töyffe, Mäısefallen, Vergiftungen mit Weizen oder Phosphorpillen. Der sehr lïstige Manlwurf kamn nur an einem Verbindungswege, den or regrelmäligg benützt, durch Maulwurfszangen, welche nach beiden seiten lin im (iange gestellt werden, abgefangen werden. Schutz gegen Vögel gewïhrt Virmischung mit Mennig, Bedeckung der Beete mit Reisig oder mit saatgitter, welche aus Holzstäben oder Drahtgeflechten grefertigt sind. Gegen Rehe, Hasen, Hirsche, Schweine und andere große T'irre hilft der Zaun, gegen das Eichhörnchen helfen Saatgitter oder besser, angesichts der sonstigen großen Schädlichkeit dieser Tierchon das Abschiefien. Die Feinde dieser Tiere, vor allem den Fuchs, den Marder, den Iltis, das Wiesel zu schonen, würde zwar dem Forstmann und seinen Pfleglingen nützen, aber dem Jäger und seinen Pfleglingen Schaden bringen; hier aber entscheidet der Jäger und wohl jeder stimmt ihm zu.

Gegen Vertrocknen der Saat, besonders der eben aufkeimenden, helfen außer den obigen Zwischenrillendeckungen auch Bestecken mit Zweigen, Hochdeckung auf Gestellen mit belaubtem oder benadeltem Reisig und im äußersten Notfalle das Begiefen mit Wasser; von letzterem abgesehen, helfen die gleichen Nittel auch gegen Spätherbst bei sehr früher, gegen Frühfrost bei sehr später Aussaat oder bei fremdländischen aus wärmeren Regionen stammenden Holzarten.

Dünn ausgeführte Saaten gestatten das Belassen der Pflanzen in den Saatrillen bis zum Zeitpunkt ihrer Brauchbarkeit für Freilandspflanzungen ohne vorheriges Umpflanzen im Garten oder Verschulen. Für solche unverschulte Pflanzen ist es wichtig, einen möglichst gleichmäßigen Abstand zwischen den Pflanzen zu erzielen; durch die Saat selbst ist das in der Regel nicht erreichbar; sie wird immer stellenweise zu dicht, stellenweise zu dünn ausfallen; es hat somit im ersten oder im zweiten Jalıre nach der Saat eine Ausdünnung der zu dichten Rillen einzutreten. Vielfach geschicht dies durch Herausschneiden des Überschusses mit einer Schere; das Herausreißen ist wenig empfehlenswert; besser erscheint das Herausheben mit einem schmalen, scharfschneidigen Instrumente, mit dem die Wurzeln der überschüssigen Pflanzen tief abgestochen und diese selbst ausgehoben werden. Durch Festdrücken der allenfalls gelockerten Umgebung ist die Arheit volleudet. Solche ausgehobene Pflänzchen werden zur Bestochung allzu locker stehender Partien oder anderweitig verwendet. Ausgedümnte Pflanzen erreichen ein .Jahr frülıer ihre Brauchbarkcit türs Freis, ilr Wurzelsystem aber ist weniger kompakt, ihr Ansheben belingt somit stärkere Verletzungen; immerhin ist die Pflanzung mit nicht verschultem Naterial sehr rentabel und sehr viel verbreitet.

Die den Pflanzen so wohltätige Bodenlockerung wird an besten mit der Beseitigung des Unkraut wuchses betätigt; als Instrumente kommen 
Häufelpflüge, lüffelartige Instrumente und mit grölitem Vorteile das im (iemuïsegarten allhekannte Gartenhäckchen in Anwendung. Sind die Saaten zwischen den Rillen eingedeckt, ist weder Bodenlockerung noch -häufelung notwendig. Werden die Erdstreifen zwischen den Saatrillen ausgejätet, gelockert und gehäufolt, so kanı damit auch eine Zwischendüngrug verbunden werden; man verwendet hicrzu flüssigen Dünger, stark vergorene Jauche oder Düngererde von Komposthaufen, wie sie später beschrieben werden soll.

Das Verschulen. Kräftige einjährige und zweijährige Pflanzen pflegt man zu verschulen; bei Zürbeln, Buchen, Hainbuchen, Linden werden anch Keimlinge mit dem kleinsten Hohlspaten ausgestochen und verschult; Föhrenpflanzen pflegt man in der Regel nicht zu verschulen, das heißt im Garten in einen weiteren Verbande mmzusetzen, sondern mit einem oder zwei Jahren sogleich ins Freie zu bringen; nur wenn auf einer lehmreicheren Stelle Ballenpflanzen erzogen werden sollen, werden auch Föhren (zwei- und dreinadelige) verschult; für alle übrigen Holzarten dagegen ist Verschulen eine allgemein übliche Maßnahme, welche folgende Vorzüge besitzt:

1. Leichtere Ausführbarkeit der Saat, welche dichter und olıne besondere Vorsicht hinsichtlich ihrer Gleichmäßigkeit geschehen kanu; 2. Gewinnung von Pflanzen mit enggepacktem Wurzelsystem; 3. von Pflanzen mit stufig, das heißt pyramidal geformten Kronen; 4. Möglichkeit einer Zwischendüngung; wünschenswert ist die Verschulung bei Erziehung von Ballenpflanzen. Als $\mathrm{Nachteile} \mathrm{stehen} \mathrm{gegenüber:}$ höhere-Kosten, Verbrauch an größeren Gartenflächen und rasche Verschlechterung der Saat- und Pflanzgärten, insbesondere bei Ausheben von Ballenpflanzen. C. Wagne ${ }^{1}$ ) nennt das durch Verschulung bei der Fichte erzengte Wurzelsystem ein unnatürliches und verlangt deshalb für die Fichte Rüekkehr zur Naturverjüngung um jeden Preis. A. Fron ${ }^{2}$ ) sagt: "Nadelholzpflanzen soll man nicht verschulen, da, von den Kosten abgesehen, die unverschulten Pflanzen besser seien als die versehulten." Die Verschulung wird mit ein-, zwei- oder schwachentwickelten dreijährigen Pflanzen und in der Regel nur einmal vorgenommen; sollen Heisterpflanzen von $2 \mathrm{~m}$ Höhe und darüber gewonnen werden, empfiehlt sich ein zwei-, selbst mehrmaliges Versehulen mit immer gröferen Abständen der Pflanzen.

Das Ansheben der Pflanzon erfolgt mit dem Stechspaten durch Öffnen eines Gräbchens parallel der ersten Saatreihe; durch einen Spatenstich zwischen der ersten und zweiten Saatrille werden dann die Pflanzen der ersten Rille in den Graben gedrückt; die zweite Rillo legt sich auf diese Weise in das Gräbchen, das an Stelle der ersten

1) Die (irundlagen der räumlichen Ordnung im Walde. 1907.

2) Silviculture. 1903. 
Rille getreten ist und so weiter. Mit dieser Methodie wird zugleich das Sortieren der Pflänzchen nach ihrer cirriße verknüpft. la es wünschenswert ist, Pflanzen von einer Gröbe auf' cin Virsthulbeet zu bringen, obwohl in kurzer Zeit ron nenem im Wuchse divergente Individuen sich zeigen. Kann die Arbeit bei trüber, nebeliger oder gar schwach regnerischer Witterung vorgenonmen werden, so ist sie vielleicht schwierig und langsam; diese Nachteile aber werden roll anfgewogen durch die Schonung der Pflanzen: ein paar Minuten Besonnung genügen zum Abtöten der Wurzelhaare und Wurzelspitzen. Mufs diese Arbeit bei somenschein und trockener Witterung geschehen, so empfiehlt sich möglichst rasches Einschlagen in die Erde, ganz untergetanchte Einlage in Wasser, nasses Moos und kräftiges Begiefen nicht blnß der. Wurzeln und der Erde, sondern auch der oberirdischen Teile und ter Bedeckung. Das Einlegen in Wasser schadet deshall nichts, weil nach des Verfassers Versuchen Pflanzen wochenlang in Wasser liegen können. ohne im geringsten zu leiden; es besteht sogar noch der Vorteil, daß Pflanzen unter Wasser nicht austreiben. Auch das Eintauchen in Lehmbrei ist viel besser als sein Ruf. Das Verbringen zum Verschulbeet und das Aufbewahren zum unmittelbaren Gebrauche geschieht am besten in nassen Tüchern (Rupf). Man kann auch Spitzenbergs Pflanzlade oder jedes andere seichte Kistchen benützen, dem ein Tuch als Deckel aufgenagelt ist, das fortwährend naß gehalten wird.

Das Verschulbeet wird etwas tiefer bearbeitet als das Saatbeet; lockerer, etwas abgetrockneter, aber nicht ausgetrockneter Boden ist tür eine rasche Arbeit notwendig. Alle Terschulungen sind im (rruncle genommen Ǩlemmpflanzungen, ausgenommen sind jene Fälle, bei welchen die Pflanze mit beigegebener Düngererde in das Loch oder in den Spalt versenkt und dort festgedrückt wird. Das Terschulen der Pflanzen kann geschehen als Lochverschulung und als Furehenverschulung; für erstere werden mit einem Instrumente, seltener mit der Hand, Löcher gefertigt, die Pflanze wird eingesenkt und dureh Beidriicken der Erde wird sie festgeklemmt; bei der Furchenverschulung werden mit einem Geräte Furchen gezogen, an deren senkrechte Wïnde die Pflanzen in bestimmten Abständen gelegt werden; durch Beizichen oder Beidrücken des Furchenaushubes schließt sich das Gräbchen; lie Pflanzen werden ebenfalls dadurch geklemmt.

Um für die Lochverschulung die gewünschte Regelmäßirkeit im Pflanzenabstande zu erzielen, gibt es Walzen oder Bretter mit Holznägeln oder Zapfen versehen, welche zuerst ïber das Beet grefïhrt werden und die Stellen für die Verschulpflanzen markieren: (ileiche: kann durch Pflanzbretter, quer über die Beete grelegt und mit Kerhen für den gewählten Pflanzenabstand versehen, erreicht werden. I)ie einfachste Methode ist folgende: Eine Schnur wird der Mittellinio der Beetlänge parallel gespannt und dieser entlang wird rerschult, wobei 
ein Yeichen an der Schnur oder ebensogut ein Zeichen am Verschulgrerät den Abstand der PHanzen kennzeichnet. Schwankt dabei der Abstand un ein paar Zentimeter hin und her, so ist dieser Mangel an Exaktheit für die Pflanzen belanglos, für die Arbeitsschnelligkeit aber wichtig; ist die Vittellinie verschult, schließen sich parallel hierzu die anderen PHanzenreihen an, wobei es vorteilhaft ist, daf die Pflanzen in der zweiten Reihe zwischen jenen der ersten Reihe zu stchen liommen.

Zur Lochverschulung dient das Setzholz, wie es im Blumen- und Gemüsegarten allgemeine Verwendung findet; forstliche Pflanzen verlangen etwas stärkere Dimensionen. Forstrat M I n tels Pflanzenblech, clas in das Loch eingehängt wird, erleichtert das Abwärtsgleiten der Wurzeh der Pflanzen. Um diesen Vorteil auszunützen, hat der Vater des Verfassers, weiland Forstmeister Cl. Mayr in Grafrath ein Gerät

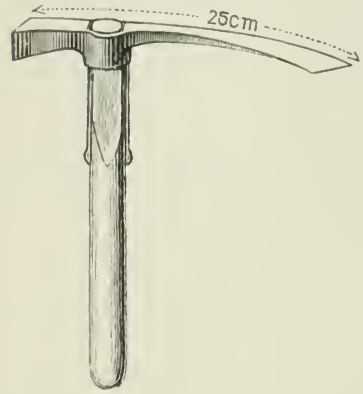

Abb. 24. Forstmeister Mayrs Kulturhammer. erdacht, das als Mayrs Pflanzhammer jahrelang in Oberbayern vielfach im Gebrauche war. Später wurde es abgeändert, die Schneiden wurden verbreitert, das schwach gekrümmte Häckichen verkürzt und gerade gestreckt, das ganze Gerät wurde leichter gemacht; dadurch aber ist es für die Verschulung minderwertig geworden, weil die Verschulspalten zu seicht sind; ebenso ist es wirkungsschwächer geworden für die Verpflanzung, weil es zu leicht geworden ist. Nebenstehende Abbildung bedarf keiner weiteren Beschreilung. Durch Anlegen der Breitseite des Hammers an die Schnur, Eindrücken des schneidenden Teiles in den Boden und Wegzichen desselben von der Schnur wird ein anch in der Tiefe erweiterter Spalt hergestellt, in welchen die an dem glatten Eisen abgleitenden Wurzehn eingesenkt werden; der Hammer wird herausgezogen, nenerdings in dem Abstande von einer Pflanze eingedrückt und die Erde an die Pflanzen angedrückt. Diese Bewegung ist eine einfache und natïrliche, verglichen mit der drehenden Bewegung oder dem mehrfachen Einstechen und Andrïcken, welche das Setzholz verlangt.

Das Einsenken der Pflanzen geschieht zuerst so tief als möglich, dann wird kurz vor dem Andrücken die Pflanze bis zu ihrer Normalhöhe, gleich dem Stande im Saatbeete, emporgehoben. Bei einjährigen Pflanzen wird der Keimling bis zn den Keimblättern (Kotyledonen) versenkt. Auch Düngererde kann vor dem Andrücken der Pflanzen beigegeben werden. Mangelhafte Lochtiefe nachlässiges Einführen der Pflanzen gibt in den Wurzeln jene Verkrümmungen, welche auf allen 
Verschulbeeten vorkommen und erst beim Ausheben der Pflanzen zum Zweck des Auspflanzens an das Tageslicht kommen.

Es ist noch zweifelhaft, ob Furchenverschulungen schneller arbeiten als eine Loch-oder Spaltverschulung mit II a yrs Pflanzhammer; jedenfalls haben sie gegenüber dem Setzholz und dem gewöhnlichen Pflanzhäckchen den großen Vorzug der schnelligkeit und größeren Sicherheit. Furchen tertigen lileinere Handpflïge; ein furchenähnlicher Spalt entsteht durch Forstmeister Strehles Pflanzblech, Furchen ergeben Hackers Verschulrechen und Hackers Verschulmaschinen, Raths') Verschulrahmen unter Anwendung eines Grabscheites oder einer großen Maurerkelle (Hätfher). Strehles Pflanzblech hat als Länge die Breite des Beetes, als Breite die Tiefe der Furche; die in den Boden eindringende Längsseite ist schneidig, der entgegengesetzte Rücken verdickt und abgerundet. Zwei Arbeiter drücken das Blech so tief als möglich in den Boden und fertigen durch Hin- und Herbewegung einen Spalt, in welchen die Pflanzen, in einem Rahmen eingehängt, eingelegt werden; durch einen zweiten Stich mit dem Blech wird die Erde an die Wurzeln gedrückt. Der Rahmen selbst besteht aus zwei Teilen, ein Teil nimmt in Kerben von bestimmten Abständen die Pflanzen auf, der andere hält sie in dieser Lage auch bei Wind und unruhiger Bewegung fest. Hackers Verschulvorrichtung hat weiteste Verbreitung in neuerer Zeit gefunden. Seine einfachsten Formen sind zwei Rechen aus starkem Eisen mit senkrecht abstehenden, breiten Zähnen an schief zum Rechen stehenden Stielen; ein Arbeiter an der linken Seite des Beetes arbeitet mit dem anderen Arbeiter an der rechten Seite zusammen, indem sie gleichzeitig die Rechen ansetzen, so daß beide Rechen zusammen gerade die Beetbreite einnehmen; sie fertigen eine Furche, an welcher ein mit Pflanzen behängter Rahmen eingelegt wird. Durch Andrücken der Erde mit den Rechen sind die Ptlanzen alle gleichzeitig eingesetzt; es erfolgt noch eine Nachbesserung mit der Hand zur Richtung der Pflanzen und zum Ebenen der Erde. Hackers Verschulmaschine ist ein zweirädriges Gestell, auf dem der Arbeiter sitzt und einen eisernen Rechen von der Breite der Beete in einem Gelenke bewegt. Die überallhin von Forstmeister $\mathrm{Rudolf} \mathrm{Hacker}$ in Königgrätz (Böhmen) verbreiteten Prospekte und die durchwegs günstigen Urteile [Gareis $\left.{ }^{2}\right)$ ] erheben den Verfasser einer eingehenden Schilderung und Abbildung. Einer Verbesserung sind Hackers Verschulrahmen zum Einhängen der Pflanzen bedürftig, da ungeschickte Bewegrungen und insbesondere Wind das Einhängen und den Transport der Rahmen sehr erschweren. An Strehles Rahmen werden durch

1) Ruhl im Forstwissenschaftlichen Centralblatt 1906.

\&) Forstmeister Gareis in Forstwissenschaftlichen Centralblatt 1903. 
eincu zweiten Rahmen, an $R$ aths Rahmen durch eine Schnur die Pflamzen festgehalten.

Das Beschneiden der Pflanzen hat sich auf ein Einstutzen der längsten Wurzelstränge zu beschränken: es ist um so mehr zulässig. ja wïnschenswert, je sorgloser die Pflanzen beim Ausheben, Sortieren und Verbringen der Luft und der Some ausgesetzt wurden. Die nenen weißen TTurzelspitzen erscheinen ohnedies nicht als Fortsetzung der alten, sondern müssen sich aus den unbeschädigt gebliebenen, noch saftigen, dickeren Wurzeln erst neu bilden. Das Einkürzen der Pfahlwurzel der Eichen ist mach den Versuchen zu Groenendael ${ }^{1}$ ) ohne Bedenken: bei Quercus rubra ist es mnginstig, bei Castanea direlit schädlich. An den oberirdischen Pflanzenteilen werden nur bei Laublı̈̈lzern allzu starke, zu Gipfeln aufstrebende Seitenäste entfornt.

Fïllt nach der Verschulung regnerisches Wetter für melurere Wochen eim, dann gelingt alles, auch die sorgloseste Verschulung. Folgt aber eine 'Trockenperiode, so werden nur jene Pflanzen, die möglichst tief' eingesenkte Wurzeln besitzen, sich durch die Prüfungszeit hindurch retten. Begicken nach der Verschulung wäre freilich das beste; in der Regel ist es jedoch nicht durchführbar, man muß sich begnügen, die Erde zwischen den Terschulreihen einzudecken, wie dieses bei den Rillsaaten bereits erwähnt wurde. Die Deckung hat von den bereit. erwähnten Torzügen noch jene, daf in der feuchter gehaltenen Erde die Wurzeln mehr an der Oberfläche sich ausbilden, während bei nicht gedeckten und austrocknenden Böden dio Wurzeln nach der Tiefe zu streben.

Yur Verschulung von Keimlingen, von Nüssen. Eicheln, Bucheln genügt meistens die Anfertigung eines Loches mit der Hand oder einer seichten Üfinung mit dem Pflanzhammer, Kulturhäckchen, Spitzenbergs Eicheldruckstüclie u. dgl.

Als beste \%eit für die Terschulung wird allgemein das Frïhjahr angenommen; in (iroenendael ${ }^{1}$ ) wurden bessere Erfolgo mit der Herbstverschulung erzielt.

Gegen verspätete Fröste schützt teilweise wenigstens eine späte Verschulung (Iolzarten des kïhleren Klimas): gegen verfiühte Fröste schützt möglichst frühe Verschulung (Holzarten aus wärmerem Klima): fïr fremdländische Arten, hesonders Laubhölzer ans wärmerem K’lima. wird immer eine llochrleckung regen Früh-und Winterfröste in dem ersten Jahre der Verschulung sich empfehlen: im zweiten Jahre kommt damn die Decke in Wegrall.

Pfllanzenabstand. Über len Abstand, in welchem verschult werden soll, entscheiden folgende allgemeine Erwägungen. 1. Je lileiner die Pflanze, um so enger die Verschulung. 2. Je länger eine Pflanze

1) Bull. Société Centrale Forestiere de Belgique 1901. 
im Verschulbeet hleiben soll, um so weiter die Verschulung. 3. Je mehr die Pflanze zur Kronenverbreiterung neigt, um so weiter der Al)stand. 千. Der größere Abstand bedeutet für Laubhilzer Siteigerung der Höhe, für Narlelhölzer Steigerung des Flächenwachstums drr línen. 5. Die Verschulungsweite weehselt nach Holzart, Boden und Kilimalagre: je besser der Boden, je wämer das Klima, ilesto enger der Verband; Lichtholzarten verlangen weiteren Verband als Sultenholzarten. 6. Soll eine PHanze zwei oder mehrmals umverschult werden, steigt der PHanzenabstand mit jeder Neuversehulung. Der beste Abstand, bei dem das meiste und beste PHanzenmaterial gewonnen werden kann, muß für jeden Garten durch Probieren festgestellt wcrden. Um eincn Anlialt zu geben, sei erwähnt, daß Forstrat $H$ äffner für seine großen Pflanzgärten zu Forstenried dieses Optimum der Ausnïtzung für Fichtr in $(i)$ em Pflanzen- und $15 \mathrm{~cm}$ Reihenabstand erreicht. Lärche und Tanne bedürfen 10:15, Laubholzhalbheister 15:15, Vollheister bis zu i) $\mathrm{em}$ und darïiber.

Eigener Torbereitungen zum Zwecke des Aushebens der Pflanzen aus dem Terschulbecte bedürfen nur Pflanzen auf lockerem Boden, welche als Ballenpflanzen Verwentung finden. Zur Festigung der Erde empfiehlt sich Begielien der Beete und Duldung einer Terunkrautung des Bodens. Um das Wurzelsystem zu engerer Entwicklung zu zwingen, werden an Tiefwurzlern ein Jahr vor der Bepflanzung die Wurzeln mit einem stemmeisenartigen Geräte abgestochen. II $u$ th empfiehlt zu diesem $Z$ Wecke seinen Wurzelverschneider: eine für verschiedene Bodentiefe verstellbare Klinge an einer pflugähnlichen Vorrichtung wird durch die Pflanzenreihen hindurchgeführt, so daß an jerler Pflanze unterirdisch an den vier Seiten ihres späteren Wurzelballens die Wurzeln abgeschnitten werden. Das Verschneiden bereitet zugleich für das Ausheben selbst vor. Der Erfolg wird gerïhmt. Auch Kaisers an einem Stocke befestigtes Wurzelschneidemesser sei erwähnt.

Das A usheben der Pflanzen aus dem Terschulbeete, in welchem dieselben je nach der Entwicklung 2-:3. Jahre verbleiben, kann mit dem gleichen Instrumente, welches schon frïher für das Ausheben von Schlagpflanzen besehrieben wturde, erfolgen. In der Regel wird der flache Stichspaten oder der schwach gewölbte Kegelspaten benützt. Werden wurzelnackte Pflanzen gewïnseht, so wird die Erde ron den Wurzeln abgesehüttelt. Wenn auch solehe Pflanzen im allgemeinen widerstandsfähig gegen Vertrocknung sind, die Wurzeln sind ebenso schonend zu behandeln und gegen Besonnung und Vertruckinung zu sichern wie die Verschulpflanzen: bei Ballenptlanzen grenügt das Aneinanderstellen der Erdballen für Aufbewahrung und Transinrt.

Mit dem Ausheben der Pflanzen ist wiederum eine M usterung zu verbinden: diese bezieht sich zunächst auf die Größe der Entwicklung, dann aber bei Laubhölzern und insbesondere bei Lärchen und 
Föhren auf Schlankheit der Pflanzenachse. Ist diese gekrümmt, sind die Pflanzon zu beseitigen, sobald sie zu den liäftigsten zählen; Schwächlinge können dagegen verwendet werden, da Aussicht besteht, daß sie frühzeitig vom Bestande selbst ausgeschieden werden, somit nư als Füllholz zu dienen haben (A uswahlpflanzung). Auf das Ausheben der Pflanzen zum $/$ wecke der Verpflanzung ins Freie erfolgt Wiederbestellung der Beete bis zur Aufnahme einer Saat (man vergleiche Seite 398) entweder durch Erdezufuhr (nach Ballenpflanzengewinnung) oder durch Düngung und Bodenbearbeitung; für letztere Arbeit eignet sich vorteilhaft die Grabgabel.

\section{Die Düngung der Pflanzgärten.}

Durch Untersuchungen von Helbig, Schröder, Dulk, Co uncler und anderen ist nachgewiesen, daß durch die jungen Pflanzen dem Boden vor allem Kalium, Phosphor und Stickstoff, auch Calcium, Magnesium, Eisen und Schwefel in größeren Mengen entzogen werden. als durch die Kohlensäurewirkung im Boden aus den Mineralien aufgeschlossen werden. Zwar schwanken die Angaben über die Menge der entzogenen Stoffe beträchtlich; allein auch ohne diese Analysen ist das Düngerbedürfnis der Pflanzen schon früher bekannt gewesen und wird auch heute noch nachgewiesen durch das empfindlichste Reagenz, das ist die Entwicklung der Pflanze selbst. Da die Feststellung des den Pflanzen mangelnden Nährstoffes, d. h. des in minimo vorhandenen und die ganze Pflanzenentwicklung bedingenden Nährstoffes eine schwierige ist, werden in der Regel mehrere Dünger gleichzeitig zur Anwendung gebracht. Über die Anwendung und Einwirkung von Düngemitteln auf die Pflanzen im Garten liegen bereits umfangreiche Untersuchungen und Äußerungen vor von Helbig, Heck, Henze, Grundner, Mathes, Kienitz, Engler, Wein, Schwappach und Möller. Aus den Schriften dieser Forseher kann zunächst entnommen werden, daß es eine große Zahl von Düngemitteln gibt, daß durch Mischungen dieser unter sich und mit Walderde wiederum eine Unzahl ron Variationen erzielt werden kann, daß alle Düngemittel eine gute Wirkung auf das Pflanzenwachstum zeigen, vorausgesetzt, daß das Übermaß vermieden wird.

Die häufigsten Düngemittel sind folgende: a) Dünger vegetabi lisehen Ursprungs: Nadeln, Laub, Moos, Unkrautstren, zerhackte Nadelholzbetriebe, Torfmull, Rohhumus, Gründüngung durch schmetterlingsblütige Pflanzen zur Bereicherung des Bodens mit Stickstoff;

b) Dünger vegetabilschen Ursprungs mit mineralischen Bestandteilen gemischt: Gartenerde, Mullerde (Humus), Teichschlamm, Torferde, Unkraut aus dem Jätungsbetriebe der Gärten, Waldstren (Rechstreu);

c) Düngerstoffe animalischen Ursprungs sind: Dünger- 
stoffe der thermischen Tierleichenvernichtung, Blutmelll der Schlachthäuser, Guano, Jauche, Knochemmehl, Hornspäne, Poudrette;

d) animaliseher und vegetabilischor I) ünger gemischt, tierische Ausscheidungen mit Stroh, Streu, Torfmulle oder Sägremehl oder Unkräuter: jo nach der Tiergattung kommt den Düngerarten wieder eine besondere Wirkung zu, wie Schat', Ziegen-, Pferde- und Rindviehmist;

e) mineralischer Dünger, Kalisalze, Kainit mit rund $12 \%$ löslichem Kali, Superphosphat mit rund $150_{0}^{0}$ löslicher Phosphorsäure, salpetersaure Salze, wie Chilisalpeter mit 15\% löslichem Stickstoff, Norge- oder Luftsalpeter (Kalkstickstoff), Staßfurter Salze, Thomasmehl, Steinmehl, Holzasche, Rasenasche, Kalkstaub, Gypsmehl, Sand, Lehm, Löß und andere;

f) mineralischer und animalischer Dünger gemischt: Straßenkot; Kalkschlamm bei Beschotterung der Straßen mit Kalk, Basaltschlamm bei Beschotterung mit Basalt; je mineralreicher das Gestein, um so wertvoller der Strafenabhub. Da obige Düngemittel nicht nur den Nährwert des Bodens erhöhen, sondern auch die physi$\mathrm{k}$ alische Beschaffenheit desselben ändern, so ist zu beachten, daf3 Düngemittel, wie Sand, Streu, Mist, Rohhumus, Mullerde und andere, den Boden lockern, somit bei schwerem Boden in erster Linie empfehlenswert erscheinen; daß Straßenschlamm, Teichschlamm, Lehm, Löß don Boden festigen, somit bei lockerem, besonders bei sandigem Boden den Vorzug verdienen.

Die Anwendung der Düngemittel. Bei der Ernte landwirtschaftlicher Gewächse verbleibt, von rübenartigen Früchten abgesehen, der Wurzelstock der Nutzpflanzen im Boden; die Ernte läfit einen vegetabilischen Dünger zurïck und beseitigt vor allem nichts vom mineralischen Boden, von der Ackererde. Im Pflanzgartenbetriebe werden alle Pflanzen mit den Wurzeln geerntet, es wird Boden beseitigt, zumal wenn das Ausheben der Pflanzen mit dem Erdballeiı geschieht; auch bei wurzelnackten Pflanzen empfiehlt es sich nicht, den letzten Rest der Erde aus den Wurzeln auszuklopfen. Für forstliche Gärten ist somit die bloße Zufuhr von Düngemitteln nicht ausreichend, es muß auch Erde, selbst Humus, beigegeben werden. Weder die vegetabilischen oder animalischen Dünger allein, noch die mineralischen Dünger allein geben Erde, Gartenerde. Erst beide zusammen geben Erde nach jahrelangen, gegenseitigen Einwirkungen aufeinander. Lie nötige Mischung, Verteilung und Verdünnung der Düngemittel aber erfolgt im Komposthaufen, der für den Pflanz- und Saatgartenbetrieb unentbehrlich ist. Es soll allgemeine Regel sein, jede Düngung im forstlichen Pflanzgartenbetriebe nur in Form godïngter Erde zu geben, wie sie der Komposthaufen liefert. Damit ist der Giefahr des 
Übermafies in Anwendung eines Dïngemittels rorgebengt, und jeder Dïnger wird in der günstigsten Form der Pflanze geboten.

Die einfachste Form solcher Düngerhauten besteht darin, daß auf' den Boden eine ungefähr :31 cm ricke Schicht ron Walderde gebracht wird; darauf kommt irgendeines der obigen Düngemittel: statt eines Nittels können auch zwei und mehrere zusammen genommen werden. Diese Sehicht soll die Dicke von $10 \mathrm{~cm}$ nicht übersehreiten. Als Decke werden $20 \mathrm{~cm}$ Walderde anfgelegt. Diese Mischung wird im Frühjahr angesetzt. im Herbste vertikal umgestochen, im nächsten Frühjahre gesiebt und als Düngererde zum Eindecken der Saat, als Beigabe zur Verschulung, als Zwischenreihendüngming und als Beeterde nach der Ballengewinnming verwendet.

Werden mehrere Schichten anfeinandergelegt, so kann die Anordnung zwischen der obersten und untersten Walderdeschicht in der mannigfaltigsten Weise variiert werden. So z. B. auf dem Boden $30 \mathrm{~cm}$ Walderde, dam 20 cm Torferde oder Stralienkot oder Teichschlamm oder Kalkstaub oder Lehm oder Löf usw.: darauf der Lnkrautwuchs ans den Beeten, der vor der Samenbildung ansgejätet werden mufi; auf diese eine Walderdeschicht ron $30 \mathrm{~cm}$. Darauf eine 10 - 15 cm starke Lage ron mineralisehem oder animalischem Dünger: als Decke wiederum $10 \mathrm{~cm}$ Walderde.

Forstrat Häffner in Forstenried bei München läßt pilzfaules Holz sammeln (nach Ansicht des Verfassers dürften sich besonders empfehlen die ron Wurzelkrebsen Agarieus melleus und Polyporus annosus und anderen Pilzparasiten besetzten Stücke und Stöeke), und mit Unkrantwhehs und Rasenplaggen zu einem kleinen Meiler aufsetzen und rerbrennen: zur abgesiebten, mit Rasen- und Faulholzasehe vermengten Erde wird Mullerde ans Wegen und Gräben in Buchenwaldungen genommen, die Mischung dam noch mit animalisehem Dünger, rorzugsweise dem Blutmchl der Schlachthänser, vermengt und als Düngererde verwendet.

Verfasser hat mii sehr großem Erfolge dem Komposthaufen eine S'chicht von Pilzfrüchten (Schwammerlingen) einverleibt, deren der Wald in manchen Jahren eine gewaltige Nenge giftiger wio ungeniefbarer Natur erzengt. Die Düngererde hat sich als sehr liräftig in ihrer Wirkung, ungefährlich und selır billig in ihrer Zubereitung gezeigt.

Wherforstmeister. We is e empfiehlt, den Waldarbeitern stets eine bestimmte Stelle zum Anmachen von Fener anzuweisen und die Ablieferung der Asche abzulohnen.

Nach IIatzfeld gibt Buchenlanb mit Rasenasche und Walderde unter Übergief.en mit Janche eine vortrefflliche Dïngererde.

Die Komposterdebereitung hat den groben Vorzug. daf man bei Beachtung genügender Beimischung von Walderde keinen Fehler in der Answahl der Düngemittel und in der Anwendung nach Zeit und Menge machen kann. 
Wie Komposterdedüngung kam auch jeder\%eit Rohhumusdüngung, Torferdedüngung ('Torfsehlamm über Winter zerfallen) Anwendung finden. "Für den Kampletrieb hat sich", saurt Oberforstmeister Dr. A. M $\left.\ddot{u} 11 \in \mathrm{r}^{1}\right)$, , der Trockentorf in allen seinen Fomen als ein herrorragendes Düngemittel erwiesen: er ist himrin allen künstlichen Düngemitteln rorzuziehen." Dr. Kienitz, v. Örtzen, Dr. Storp haben ebenfalls auf die Nutzbarmachung des Rohhumus hingewiesen. Möller empfiehlt bei Saat nach Bodenmischung dessen Überdeckungr mit is cm starker Sandschicht zur Verhinderung der Austrouknung der Sämereien und der Verunkrautung. Animalischer Dünger fester Art wird am besten untergegraben im Frähjahr oder Frühwinter; animalischer, flüssiger Dünger (Jauche), völlig ausgegoren und verdünnt, kann im Frühjahr und Sommer (als Kopfdüngung) Anwendung finden; doch liegen meist die Wurzeh zu tief, um davon vollen Gebrauch machen zu können.

Mineralischer Dünger soll nie rein, nie unmittelbar vor den Saaten oder Pflanzungen, zumeist im Herbste gegeben werden. Durch Überclüngung (insbesondere mit Holzasche) gelbliche Pflanzen sieht man sehr häufig in forstlichen Gärten. Kopfdüngung mit Asche, Gips. Kalk soll besser unterbleiben. Leicht lüsliche Salze, wie Chilisalpeter, Norgesalpeter kömmen auf den Boden gestreut werden, da sie vom Regenwasser in die Tiefe geführt werden. Das Ammoniaksuperphosphat leistet im Frühjahr als Kopfdünger vor Vegetationsbeginn gegeben nach Forstrat Dr. Mathes ${ }^{2}$ ) ausgezeichnete Dienste. Die Gründüngung geschieht durch Anbau der schmetterlingsblütigen Gewächse, wie Lupine, Klee, Wicken, Erbsen; sie sind kurz vor der Samenbildung unterzugraben. Thre Wirkung ist Lieferung von Stickstoff, ron organischer Substanz zur Humusbildung, Durchlüftung des Bodens. Prof. Engler und Glutz (l. c.) wollen auf lialkreichen Böden Ackererbse und Saubohne, auf kalkarmen gelbe Lupine, in höheren Lagen Ackererbse; bei erschöpftem Boden vor Anbau der Lupine Düngung mit Thomasmehl; auf humusarmem aber kräftigem Boden soll die Düngung unterbleiben. Werden Lupinen zweimal hintereinander angebaut, erhöht sich ihre Düngerwirkung. Da als Stickstoffsammler Bakterien notwendig sind, diese aber bei der ersten Kultur in den Böden vielfach fehlen, hat Dr. Hiltner ${ }^{3}$ ) eine Impflüssigkeit (Nitragin) empfohlen, welche eine reine Kultur der wirksamen Bakterien darstellt; mit ihr werden die Samen der s'chmetterlingsblütler ror der Aussaat benetzt. Die Impffüssigkeit mit Anweisung liefert die agrikultur-botanische Anstalt zu Jünchen. Dr. Grundner ${ }^{4}$ ) wïnscht bei (Fründüngrung

\footnotetext{
1) Dr. A. Möller in der Zeitschr. f. Forst- u. Jagdw. 1900.

2) 27. Tersammlung Thuringer Forstwirte 1904.

3) Forstlich-naturw. Zeitschrift 1ะ97.

4) Harzer Forstrerein 1896;
} 
Mischung der Erde mit solcher aus Leguminosenfeldern. Soll ein Pflanzgarten a ufgegeben werden, so wird die Trostlosigkeit einer ausgebauten Pflanzenstätte noch erhöht, wenn alle Pflanzen bis auf einige Reste aus dem Garten ausgestochen werden, so daß die Stelle mit dem kümmerlich wachsenden Inhalte in der Tat die Bezeichnung "Spital" oder "Friedhof" verdient. Nicht minder groß ist der Fehler, in solchen ansgebauten Gärten anspruchsvolle, fremdländische Baumarten anzupflanzen, "weil der Zaun ausgenützt werden soll". Besser wäre es, den Garten mit einer anspruchslosen Holzart, z. B. Föhre, Birke oder Vogelbeere auszupflanzen. Hat man aber bei der Anlage des Gartens seltenere Baumarten zur Ausschmückung benützt, und hat man den Garten vor seiner Erschöpfung verlassen, wie es Regel sein sollte, so ist der Anschluß des anfgegebenen Gartens an seine Ungebung eine leichte und durch die Vorwüchsigkeit solcher Schmuckholzarten eine Stätte der Freude und des Gewinnes und nicht mehr, wie bisher, ein häßlicher Fleck im Walde, auf dem nichts wachsen will. Man muß der sächsischen Forstbehörde zustimmen, wenn sie schon bei der Anlage des Gartens eine weitständige Auspflanzung des Gartens verlangt, auf Verbesserung durch die Düngung verzichtet, vielmehr schon nach einmaliger Ausnützung den Garten zu verlassen und ganz aufzuforsten vorsehreibt.

Die Aufbewahrung der Pflanzen. Es wäre das beste, auf das Ausheben der Pflanzen sofort die Wiederausptlanzung folgen zu lassen. Wird diese bei bedecktem Himmel oder gar bei nebeliger, schwach regnerischer Witterung ausgeführt, so ist eine Vertrocknung der Wurzeln ansgeschlossen. Werden aber die Pflanzen bei klarer, somniger Witterung in großen Mengen ansgehoben und sortiert und an einen anderen Ort verbracht, so muf die Wurzelspitze abtrocknen. Um aber ein weiteres Abtrockuen der Wurzeln hintanzuhalten, wird die Pflanze am nenen Orte in Erde eingeschlagen, kräftig anch an den oberirlischen Teilen begossen und sodam gegen Besonnmng gedeckt; auf einer Blößse hart am Nordrande eines alten Fichten- oder 'Tamnenbestandes ist der Boden und die Luft im Frühjahre am kïltesten. Anch das Einlegen der Pflanzen in feuchte, kalte Keller erfüllt diesen '/weck; am besten wäre die Anf'bewalnung im Eiskeller; Verfasser hat gefunden, daßs auch das völlige Untertanchen in einem Wassertümpel, der im Waldsehatten liegt, den Wachstumsbeginn einer Pflanze außerordentlich zurücklaält, ohne der Gesundheit der Pflanze zn schaden: die Versuche ergaben, daß bis Mitte Juli anf diese Weise Pflanzen aufbewahrt werden liömen. Für frühzeitig erwachende Holzarten empfiehlt sich das Ausheben derselben während frostfreier Tage und offenem Boden, Ausbreiten derselben auf dem Boden und starkes Eindecken mit Sichneo; darauf kommt eine Lage Deckreisig oder Stroh oder Schilf und dergleichen. Solche Hanfen erhalten sich bis Mitte, selbst Ende April, ohne daß die Ptlanzen zn treiben beginnen. 


\section{E. Freilandpflanzung.}

Pflanzzeit. Das ganze Jahr hindurch kann man pflanzen; welehe Jahreszeit aber don Vorzug verdient, hängt von folgenden Erwägungen $\mathrm{ab}$ :

Das Klima des Landstriches entseheidet insofern, als eine Winterpflanzung in jenen kühleren Regionen ausgeschlossen ist, in welchen eine gefrorene Bodendecke oder eine Schneelage während des ganzen Winters das Pflanzengeschäft verhindert. Es verhiotet sich sodann die Winterpflanzung, wenn bei wenigstens zeitwoise offenem, frostfreiem Boden der Winter die trockenere Jahreszeit darstellt, win dies im ganzen ostasiatisehen Monsungebicte der Fall ist; nur in Mittel- und Südeuropa und in Amerika, wo der Winter als fenchte Jahreszeit bezeichnet werden muß, ist auch Winterpflanzung aus klimatischen Gründen wenigstens wohl zulässig; wenn auch keine Neubildung von Wurzeln stattfindet, so wird doch durch Regen und Schneewasser eine Festigung der Pflanze erzielt, welche für das folgende Frühjahr von größtem Werte ist.

Die Sommerpflanzung ist überall vorteilhaft ausführbar, wo der Sommer eine ausgesprochene Regenzeit ist, wie in Ostasien, das von Mai an unter dem Einfluß des südlichen Regenmonsuns liegt. Kleine, wurzehnackte Pflanzen wie selbst große Bäume mit mäligen Erdballen werden mitten im Sommer verpflanzt. Die Luft ist so warm und feucht, Regen so häufig. Sonnenschein so selten, daf die Pflanzen sofort mit neuen Wurzeln sich befestigen. Wo der Witterungscharakter des Sommers ein schwankender ist, wie in Europa und Ostamerika, ist der Erfolg der Sommerpflanzung reine Glückssache. In kleinen Verhältnissen, wie bei Garten- und Parkanlagen, wo man nach ein paar trockenen Tagen gießen und spritzen kann, ist die Sommerpflanzung selbstredend ausführbar. Im großen, forstlichen Betriebe aber ist jeder derartige Vorschlag, wie z. B. Pflanzung von Föhren „mit bis fingerlangen jungen Trieben", rundweg abzulehnen. Gelingen solche Experimente im großen forstlichen Betriebe, so hat der Experimentator mehr Glück gehabt mit der Witterung als andere; ist der Sommer ausnehmend naß, glückt alles, ist er normal, verunglückt das meiste; ist er ausnehmend trocken, geht alles zugrunde.

Frühjahr und Herbst sind die normalen Pflanzzeiten für Europa, Amerika (mit Ausnahme des kalifornischen Küstenstriches) und Ostasien. Für letzteres insofern, als unmittelbar vor Begimn des sommerlichen Regens (das ist April und Mai) die Pflanzung am leichtesten und sichersten ist. Über die Frage, ob Frühjahr, ob Herbst den Vorzug verdient, sind wertvolle Untersuchungon in nenerer \%eit von Cieslar und $\mathrm{Bühler}$ ausgeführt worden. Auch Verfasser beschäftigt sich seit Jahrzehnten mit dieser Frage in seinem forstlichen Versuchsgarten. Der Lösung dürften sich folgende Ergebnisse nähern: 
Alle Pflanzen leiden durch die Ptlanzung, sie sind nicht mehr normal, wenn auch vielleicht nicht krank. Je jünger eine Pflanze, desto kïrzer ist die Leidenszeit, desto geringer der Leidenszustand: schon wegen der längeren Dauer der Leidenszeit und wegen des tief' eingreifenden Leidenszustandes (vorzeitiges Zapfenerträgnis!) sollten Pflanzen über $1 \mathrm{~m}$ Höhe nur ausnalımsweise zur Waldanlage verwendet werden. Für Pflanzen unter $1 \mathrm{~m}$ ist ein Wachstumsunterschied bei Herbst- oder Frühjahrspflanzung kaum nachweisbar; anderweitige Unterschiede können durch die auf die Pflanzung folgende verschiedene Witterung bedingt sein. Je nach den Verhältnissen der Witterung können sie auch in verschiedenem simne ausfallen. Werden Pflanzen unter $1 \mathrm{~m}$ verwendet, so können für die Entscheidung, ob Frühjahrs- oder HerbstpHanzung, andere Erwägungen Platz greifen, wie Arbeitsverhältnisse, Tageslänge und andere. In der Regel wird die Entscheidung lauten, daß unter den obwaltenden Umständen die Frühjahrspflanzung vorzuziehen sei.

Werden aber Pflanzen von mehr als $1 \mathrm{~m}$ Höhe gewählt, so macht sich der Unterschied zwischen Herbst- und Frühjahrspflanzung in folgender Weise geltend:

Bei der Herbstpflanzung bleiben im folgenden .Jahre Nadeln oder Blätter und Triebe klein; die Knospen bilden sich zu normaler Größe aus; im zweiten Jahre sind Blätter oder Nadeln normal, Triebe noch zu kurz, Knospen normal; im dritten Jahre ist alles normal geworden.

Bei der Frühjahrspflanzung bleiben in demselben Jahre Blätter oder Nadeln, Triebe und Knospen unter normaler Größe; im zweiten Jahre sind Blätter oder Nadeln noch zu klein, Triebe noch zu kurz, aber die Knospen werden normal; im dritten .Jahre werden die Blätter oder Nadeln normal, der Trieb ist noch zu kurz, die Knospen sind normal: erst das vierte Jahr bringt in allen Teilen die Normalität der Ptlanze, so wie sie dem neuen Standorte entspricht. Die Pflanzung im Herbste bzw. Winter (Frostballen) wird somit um so wichtiger, je größer die Pflanze ist. Herbstpflanzung ist abor nicht emp fehlenswert: 1 . Wenn die Pflanze den vorhergehenden Sommer in einem wärmeren K'lima zugebracht hat. 2. Wenn es sich um Pflanzen handelt, welche überhaupt einer wärmeren Klimazone angehören, welche somit keine Unterbrechung ihrer Wachstumstätigkeit, die sich bis Ende Oktober erstrecken kamn, erleiden dürfen. Durch die Terpflanzung im s'eptember oder Olitober wird das Ausreifen der Gewebe verhindert, die Pflanze ist dem Abfrieren oder Erfrieren aungesetzt. 3. Dio Nachteile unter 1 und 2 vermindern sich anch hier, je kleiner die Pflanze.

Die Frühjahrsptlanzung bleiht für Europa, Amerika und Asien bei Waldanlagen größeren Stiles die Regel; der Wasservorrat des Bodens aus dem vorhergegangenen Winter, Arbeiterverhältnisse, Tages- 
länge erklären es, wem zumeist das Frühjahr als eigentliche Pflanzzeit erscheint. Ihr Erfolg hängt neben der Arbeitsgenanigkeit von der darauf folgenden Witterung ab. Dagegen ist auf schweren Böden die Anfertigung der Ptlanzlücher im Herbste behuf's Verkrümelung des Bodens während des Winters anzuraten. Pflanzung mit Erdballen an den Wurzeln (Ballenpflanzung) ist im Herbste wie im Frühjahr und bekanntlich auch im Winter (Frostballen) ausführbar; bei kleinen Pflanzen und großen Ballen ist eine Störung im Wachstum durch die Pflanzung vielfach nicht bemerkbar.

\section{Pflanzmethoden.}

Wird beim Ausheben der Pflanzen die Erde von den Wurzeln durch schwaches Schütteln entfernt, so nennt man derartige Pflanzen wurzelnackt, ballenlos: verbleibt aber die Erde in festem Zusammenhange mit den Wurzeln, so spricht man ron Ballenpflanzen. Der Pflanzentransport verlangt zur Schonung der Wurzeln ähnliche Maßnahmen, wie sie für die Verschulung beschrieben wurden. Hollwegs (1884) und Spitzenbergs Pflanzenladen leisten gute Dienste, Hauensteins Pflanzenschoner ist für das Hochgebirge bestimmt.

1. Die Ballenpflanzung setzt einen etwas bindigen Boden roraus; zur Erhöhung dieser Eigenschaft bei etwas lockerem Boden wird in Pflanzgärten das Begießen der Pflanzen kurz vor dem Ausheben oder auch die Verunkrautung des Pflanzbeetes als wirksamstes Mittel empfohlen; das Ausheben geschieht mit den schon früher erwähnten Geräten. Mit dem gleichen Gerät wird auch das Pflanzloch gefertigt; zu Beendigung der Pflanzung bedarf es noch des festen Anschlusses des Ballens an das umgebende Erdreich; dieser wird dadurch erzielt, daß das Erdreich an den Ballen, nicht umgekehrt, angedrückt, mit dem

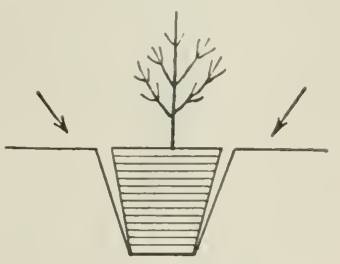

Abb. 25. Ballenptlanzung.

hulturhammer angeklopft, auch angetreten wird. Ballenpflanzung empfiehlt sich bei Einzehnachbesserungen in kräftig wachsender Umgebung, in schwerenFrostlagen, auf sehr magerem Bodon, auf' sehr verunkrautetem Boden, bei Holzarten mit frühzeitig flacher Bewurzelung (Fichten, Birken). Es rerbietet sich die Verwendung ron Ballenpflanzen, wenn diese auf weitere Strecken transportiert werden müssen: die Ballenpflanzung ist die teuerste Pflanzmethode und erschöpft am schnellsten den Boden, aus dem die Pflanzen ausgestochen werden, sie ist aber auch die sicherste Kulturmaßnahme.

2. Klemmpflanzungen werden mit keilfürmigen Geräten vorgenommen; sie fertigen im Erdreiche cinen spalt, in welchen die wurzelnackte PHanze eingesenkt wird; durch einen zweiten Stich mit 
dem gleichen Geräte und Andrücken der Erde schließt sich der Spalt. Die einfachsten Instrumente sind das Setzholz, das in der S pit z e n b e rg schen dreikantigen Ausführung kaum als Verbesserung des gewöhnlichen Setzholzes betrachtet werden kamn, das Butlarsche Pflanzeneisen, Wartenbergs Eisen, verschiedene andere unter dem Namen Pflanzeisen bekannte gestielte Geräte; sodann wären zu nennen Rembes Pflanzhammer mit gerader, M a y r s Pflanzhammer mit gebogener Klinge, Pflanzbeil, Pflanzlanze u. а. Alle diese Instrumente ermöglichen ein senkrechtes Versenken der Pflanzenwurzeln; die französische Klemmpflanze fertigt mit der Pflanzenhaue oder mit Prouvés Pflanzeisen einen schiefen Spalt, in welchen die Pflanzenwurzel eingeschoben wird, worauf mit dem Fuß der Spalt geschlossen wird. Die Klemmpflanzung
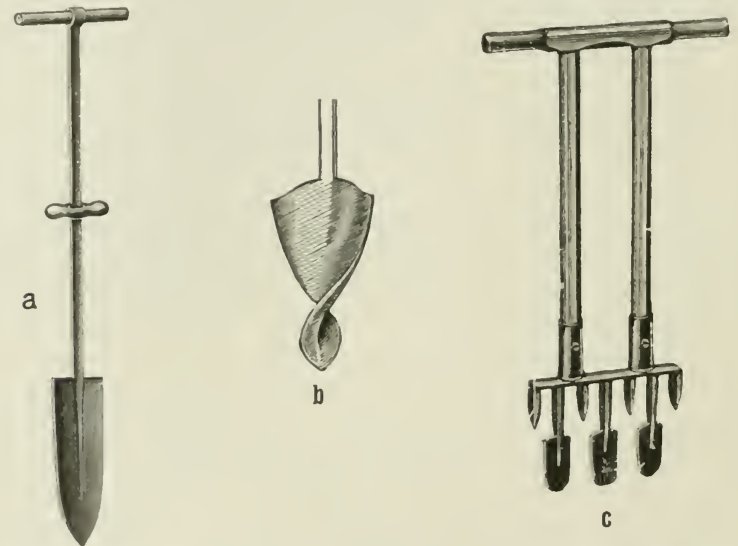

Abb. 26. "Prouves Pflanzeisen, b Spiralbohrer, c Spitzenbergs Wullspaten.

erweist sich als vorteilhaft auf lockerem, doch nicht allzu lockerem Boden; sie geht sehr schnell vor sich, ist billig und sicher; sie beschränkt sich auf kleinere Pflanzen, welehe nicht verschult sind; auf schwerem Boden werden die Spaltflächen des Bodens erhärtet, und für diesen Fall ist anch v. I) ückers Fehde gegen die Klemmpflanzung berechtigt gewesen.

3. Lochpflanzung heißt jene Pflanzmethode, bei der im Boden eine Öffnung durch Ausheben von Erde gefertigt wird, in welche wurzelnackte Pflanzen eingesetzt werden. Pflanzlöcher werden entweder gegraben mit dem Stechspaten, wenn der Boden keine oder nur wenige Stoine enthält; oder gebohrt mit den in verschiedener Größe bekannten Spiralbohrern (Abb. 2 6 ) , oder gehackt mit der gewöhnlichen oder mit Richters Pflanzhane, der Rodehaue u. a., oder gestochen mit Kegel- 
und Hohlspaten: auch der Klappspaten mag für kleine Pflanzen Anwendung finden. Bei der Pflanzung wird Erde, Walderde, Düngererde, Füllerde beigegeben. Füllerde kann nur auf' guten, lockeren B̈̈den erspart werden: dort mag die Erde, welehe ausgehoben wurde, zur Umfütterung der Wurzeln wieder benützt werden. Lockere Füllerde gestattet am besten das Einrieseln der Erde zwischen den auseinandergehaltenen Wurzeln der einzusetzenden PHlanze. Mit beiden Händen wird die Pflanze angedrückt und weiter an den Wurzeln mit Erde bedeckt. Vielfach wendet man andere Methoden an, welche noch besser die Einbettung der Wurzeln in die Erde ermöglichen. '/u diesem Fndo wird die Pflanze in der linken Hand gehalten, während die rechte Hand alle Wurzeln der Pflanze nach aufwärts legt, so daß sio von den Fingern der linken Hand noch festgehalten werden können. Im Pflanzloch wird zuvor ein kleiner Hügel errichtet, auf welchen nun die linke Hand mit der Pflanze sich locker stützt; während nun die rechte Hand Füllerde auf den Hügel bringt, werden allmählich alle Wurzeln von der linken Hand losgelassen, so daß jede größere Wurzel isoliert in Füllerde zu liegen kommt; ist die letzte Wurzel gefallen, wird Füllerde aufgelegt und festgedrückt; eine derartige Pflanzung muß als die sorgfältigste bezeichnet werden; sie hat sich besonders gegen Frühjahrund Sommertrockenperioden bewährt.

Die Lochpflanzung hat den Vorzug, daß größere Pflanzen benützt werden können, daß sie ebenfalls leicht, schnell und nicht allzu tener ausgeführt werden kann; auf sehr steinigem Boden, auf nassem, auf steilem Boden dagegen ist sie kaum durchführbar; in letzterem Falle muß das Pflanzloch möglichst in den Berg hinein versenlit werden (Nischenpflanzung).

4. Die Hügelpflanzung beschränkt sich auf liesigen, auf nassen, sumpfigen, von Hochwasser gefährdeten Boden und aut' ausgesprochene Frostlagen; im ersteren Falle ist beabsichtigt, die Pflanze über das Wasser-, im zweiten Falle über das schlimmste Frostnivean emporzuheben. Nachteilig sind Hügelpflanzungen dadurch, daß Ameisen in den Hügeln sich einnisten; erfahrungsgemäß wachsen solche Pflanzen nicht mehr weiter; in Trockenperioden sind die Hügelpflanzungen besonders gefährdet; dazı kommt, daß die Hügelpflanzung eine kostspielige Methode ist.

Die zu den Hügeln nötige Erde wird schon im Herbste gesammelt, auf Haufen gebracht und im Frühjahr am Pflanzorte in Fügreln verteilt; bei der Pflanzung wird der Hügel in der Mitte geöfthet, die Pflanze eingesetzt und der Hügel mit der abgeschwarteten Rasenplagrge gegen Verdunstung eingedeckt (M a n te uffels Hügelpflanzimg).

j. Biermanns Pflanzung. Trockene Rasenplaggen werden auf Hauten zusammengebracht und angezündet: sie schmoden zu Erde 
und Asche zusammen, sogenannter Rasenasche, mit welcher die Pflanzen als Füllercle umgeben werden.

6. Alemanns Klapppflanzung. Das Pflanzloch wird quadratisch ausgestochen, der abgezogene, halbierte Rasen dann nach der Pflanzung um die Pflanze gelegt, am besten mit den Wurzeln nach oben. Wird der ausgestochene Rasen umgokehrt auf den Boden gelegt und in diesen selhst hineingepflanzt, so wird eine derartige Kultur anch 7. Plaggenpflanzung genamnt. Werden Gräben ausgehoben und der Aushub zu Dämmen aufgeschüttet, welche bepflanzt werden, so entsteht 8. die Dammpflanzung, welche in feuchtem Gelände in ihrem Wert und in ihrer Gefahr der Hügelpflanzung sich nähert. 9. Spezielle Pflanzmethoden sind für das Hochgebirge bestimmt. In Bayern ist allgemein die Praxis, die für das Hochgebirge bestimmten Pflanzen in der warmen Ebene zu züchten, im Frühjahr in dio Berge empor zu bringen, dort einzuschlagen und bei günstiger Witterung auszupflanzen Ein Nachteil von dieser Verwendung von Pflanzen aus der warmen Ebene im Hochgebirge ist bis heute nicht konstatierbar, wohl aber hat sich die Aufzucht der kräftigen Pflanzen in der warmen Ebene für alle Kulturen sehr nützlich erwiesen. Um ganz unabhängig von der kurzen Frühjahrswitterung in Hochgebirge zu sein, hat Melchar den Torschlag gemacht, die Pflanzen in grob geflochtene Weidenkörbe zu verschulen und mit den Körben dann im Hochgebirge auszupflanzen (Melchars Körbchenkulturen). Dem gleichen Gedanken folgt Rasl mit seiner Verschulung in Blumentöpfen, welehe aus Lehm und Kuhmist grob hergestellt sind; die Pflanzen werden mit den Töpfen im Hochgebirge in die Erdo eingegraben; auch Routers Vorschlag der Verschulung in durchlöcherten Papiertöpfen olme Boden erleichtert den Transport der PHanzen und wäre für das Hochgebirge verwendbar.

11). Blockpflanzung nennt $\mathrm{Hauch}$ die Verwendung von $15 \mathrm{~cm}$ im Quadrat haltenden Erdballen, welche mit einjährigen Buchen aus dem Saatbeete ausgehoben werden. Die Saat selbst wird in $14 \mathrm{~cm}$ breiten Riefen ausgefïhrt. Jeder solche Block soll 10-20 PHanzen tragen. Die Auspflanzungr selbst wiederum geschieht in breiten, tief rajolten Streifen.

11. Werden Ballen verwendet, welche mehrere Pflanzen enthalten, die nicht beseitigt worden, so entsteht die Büschelpflanzung; sie ist ein Kind der Not, weleher besser auf andere Weise vorgebeugt wird; wo der Wildstand im Übermaß, soll er reduziert, wo Frost der Beweggrund ist, soll Kahlschlag vermieden werden.

Bodenvorbereitung. Eine Bodenbearbeitung (Rajolen bzw. Durchwühlen) ist für Bepflanzung stets grïndlicher und bis zu größerer Tiefo auszuführen, als dies für die Saat zu geschehen hat. Dieselben Bodenbearbeitungsgeräte, welcho frühor bereits erwähnt wurden, dienen 
auch hier; die Bodenbearbeitung erfolgt zumeist streif('n- oder furchenweise; auch stïcliriefen- und platzweise. Die Bestockmner soleher bearbeiteter Stellen mit Pflanzen gesehieht zumeist mittols Klemmpflanzungeu; die Lochpflanzmo wird ebenfalls erleichtert und das Wachstum der Pflanzen stets gefördert. Won diesen Gedanken ausgehend. hat 12. Spitzonborg (l. ‘c.) eine eigene PHanzweise eingeführt; seine Wühlspaten für platzweise Bodenbearheitung (Ahb. 2tic) erreichen das Ideal einer völligen Mischung des obenauf liegrenden milden oder anch des Rohhumus mit tieforen Sehichten. Sein WVühlspaten wird durch Hin- und Herwiegen in den Boden eingodrüickt, worauf im rechten Winkel zur ersten Arbeitsrichtung der Spaten abermals cingesetzt und ebenfalls hin und her mit aller Kraft bewegt wird. Die Bodenbearbeitung ist die grïndlichste. In die gelockerte Erde wird der Spaltschneider eingestoßen; die in den Spalt eingesenkte, stärkero Pflanze wird mit den Händen festgedrückt.

Eine eigenartige Bodenvorbereitung, welche nachahmenswert scheint, erwähnt Grohmann ${ }^{1}$ ) unter dem Namen 13. Überwurfkultur. Sie besteht darin, daß ein Pflanzloch mit dem Spaten gefertigt und der Aushub beiseite gelegt wird; dann wird ein zweites Pflanzloch in Angriff genommen, die oberste verunkrautete und humose Schicht abgehoben und in das erste Pflanzloch geworfen; darauf hin wird tiefer gegraben und die sich ergebendo Erde jedesmal in das erste Pflanzloch übergeworfen; anf diese Weise lagert sich die nahrungsreichste Erdschicht in jener Tiefe im Pflanzloche ab, in welcher die Wurzeln hauptsächlich sich verbreiten, und obenauf, wo die Wurzeln zumeist wegen Abtrocknung auf größerer Tiefe hin fehlen, liegt auch das minderwertige, dem Untergrunde entstammende Rohland.

14. Die Schrägpflanzung erwähnt Emeis ${ }^{2}$ ) für ein- und zweijährige Föhren, welche an einem scharf abgestochenen Rande eines Gräbchens ausgebreitet und eingedeckt werden, um das Ausfrieren zu verlindern; Verfasser würde Bedenken tragen, die ohnedies zur Schaftkrümmung neigende Föhre schon von Jugend auf $\mathrm{zu}$ einer Krümmung $\mathrm{zu}$ zwingen.

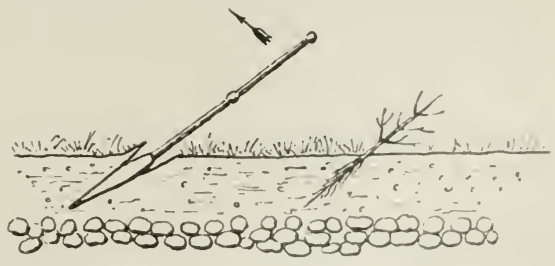

Abb. 27. Französische schragptlanzung.

15. Verschieden davon ist die französ ische Schräg p flanzung oder die Methode von Prouv ${ }^{3}$ ), welche teils mit einem eigenen Geräte

$\left.{ }^{1}\right)$ Sächsischer Forstverein 1897.

2) Allgem. Forst- u. Jagdzeitung 1899 . a ${ }^{3}$ ) V. Perona, Economia forestale 1892, der die Abb. 26 a entnommen und die Abb. 27 nachgezeichnet ist. 
(Abb. 2(ia), teils mit der einfachen Pflanzhaue derart ausgeführt wird, daß durch einen Hieb eine dümne Scholle der Erde aufgehoben, in den Spalt die PHanzo eingefügt und mit dem Fußo der Spalt wieder goschlossen wird. Es dürfte dieso Methode bei Buchenunterbau sich empfehlen: außerdem ist sie auf seichten Böden in Anwendung.

Als allgemeine, auf naturgesetzlicher Grundlage beruhende, somit fïr die Praxis beachtenswerte Regeln für alle Pflanzungen sind nachstehende Punkte zu betrachten:

1. Die Pflanze soll im neuen Boden genau so tief zu sitzen kommen, wie sie früher im Pflanzgarten gestanden hatte, und mit dieser Grenzlinie in gleichem Niveau mit der Umgebung liegen.

2. Ist feuchter Boden gegeben, feneht durch Berieselung von benachbarten Wasserbecken oder durch aufsteigendes Grundwasser, so ist die Pflanze mit ihrer Umgebung etwas über das allgemeine Niveau emporzupflanzen; Annäherung an Hügelpflanzung.

3. Auf trockenem Boden, in trockenen Klimastrichen mit längeren regenlosen Perioden (ausgesprochenes Kontinentalklima) soll die Pflanze mit ihrem Erdreich etwas un ter das allgemeine Niveau der Umgebung herabsinken, um die Pflanze in eine tiefere und feuchtere Schicht zu bringen und die Ansammlung von Niederschlagswassern zu begünstigen.

4. An steileren Hängen ist aus dem Berg eine Nische herauszuhauen, die Erde in derselben mit einem Gefäll nach dem Berge hin anzuhäufen, die Pflanze ist möglichst tief in die Nische hineinzupflanzen.

5. Stets ist nur eine Pflanze auszusetzen. Finden sich bei Nadelhölzern zwei und mehrerc zusammen, wolche aus Rücksicht auf Jagdoder Frostgefahr zunäclist beisammen bleiben sollen (Büsehelpflanzung), müsson alle bis auf die besten beseitigt werden, sobald dieser, im übrigen ziemlich fragwürdige Schutz entbchrlich erscheint.

6. Das Beschneiden ist bei Nadelhölzern auf das Einstutzen allzu langer Wurzelı, bei Lärchen und Laubhölzern auf das Beschneiclen ebensolcher Wurzeh und Seitenäste (Pyramidenschnitt der Pflanzen) zu beschräuken.

7. Beim Einpflanzen sollen die Wurzeln natürlich ausgebreitet liegen, so daß die Stämmchen in völlig vertiliale Lage geraten. Nur bei Bodenschutzholzpflanzen ist die Stellung des Stammes gleichgültig (französische Methode).

8. Mehrmaliges Festtreten oder Festdrücken der Pflanzen im ersten Jahre empfiehlt sich in Örtlichlieiten, welche vom Maulwurf häufig befahren werden.

!. Je kleiner das Pflanzommaterial, um so rascher, billiger und sicherer die Pflanzung.

Die Pflanzregeln bezïglich der Nachbesserungen sind im zwölften Abschnitte ïber die Jungwuchspflege vorgetragen. 
Der Pflanzenverband. Die Frage, welcher Pflanzenverband der beste ist, läßt sich nur danm natur- und zielgerecht beantworten, wenn man zu den bisherigen Erörterungen über Abstand der Reihen und Abstand der Pflanzen in den Reihen und Verbänden mit Rücksicht auf die Ernte auch noch die liaum minder wichtigen über dio Frage, unter welchen Verhältnissen eine Pflanze am besten gedeiht, hinzufügt. Diese nach Klima, Boden, Holzart und Emteanssicht zu erwägende naturgesetzliche Frage sollte zuerst beantwortet werden, ehe nach einem allgemeinen Schema, nach einer Wirtschaftsregel, über ganze Länder hinweg in gleichem Verbande gepflanzt wird.

Klima. Durch den Kahlschlag in Einsenkungen, auf Hochplateaux entstehen in Mittel- und Nordeuropa wie in Nordamerika und Ostasien in allen dem Fagetum und Picetum angehörigen Waldregionen ausgesproche Frostlagen. In solchen Örtlichkeiten ist daher der völlige Kahlschlag zu meiden, vielmehr aus dem schlechtesten, schwächsten Material des Bestandes, auch wenn es noch so beschädigt, verbogen und mißhandelt aus dem Abtriebe des Hauptbestandes hervorgeht, eine Schutzstellung für die Pflanzen zu bilden; dieser Schutzbestand hindert die Regelmäßigkeit des Pflanzenverbandes. Diese Störung aber ist durchaus zum Nutzen der Pflanze und des Bodens. In der Regel verfährt man umgekehrt: Um die Regelmäßigkeit des Pflanzenverbandes, die Arbeit mit der Pflanzkette oder -schnur, nicht zu beeinträchtigen, wird alles hinweggeschlagen und alle sonstigen Hindernisse auf der Fläche mit einem Aufwand an Zeit und Geld beseitigt. In empfindlicheren Frostlagen ist dieses Rasieren der Fläche ein Ausfluß der Gewohnheit, weniger der Notwendigkeit. Es ist auch nicht einzusehen, warum in Lagen, die zwar keiner besonderen Frostgefahr ausgesetzt sind, in den gewöhnlichen Kahlschlägen alles beseitigt wird, was an schwachen, unterständigen Stangen, was an Stauden, Stöcken, Steinen, Grasbüscheln u. dgl. auf der Fläche sich findet ${ }^{1}$ ). Alle diese Hindernisse für Schnur und Kette sind Klimaverbesserungen für die Pflanze, welche an ihnen den ersten Anschluß findet, der außerordentlich ihr Gedeihen fördert und die Leidensjahre der Verpflanzung abkürzt. Aus diesem Grunde wurde bei den Bemerkungen über Bodenvorbereitung zur Beseitigung dieser "Hindernisse" nicht aufgefordert, da es allgemeine Regel sein soll, so viel als möglich von diesen Hindernissen zu belassen. Es würde sich vielmehr auf Grund von Versuchen des Verfassers empfehlen, wenn eine Kahlfläche keine solche schützenden Hindornisse bietet, sie künstlich anzubringen, z. B. durch Stecklings- und Stangenpflanzung von Weidenarten, durch Überstreuen der Fläclıe mit den billigen Früchten des Vogelbeerbaumes, des Faulbaumes, der Berbe-

$\left.{ }^{1}\right)$ Dr. Frankhauser in Schweiz Zeitschr. f. das ges. Forstwesen 1K9ti und v. Fischbach in Zeitschr. f. Forst- u. Jagdw. 1900 äußern ähnliche Ansichten. 
ritzen, des Weißdorns, des roten und schwarzen Hollunders, durch Birkensaat auf Schnee und anderes. Man wende nicht ein, auf Föhrenboden sei die Maßnahme unmöglich; die Föhrenböden seien bereits so heruntergekommen, daß sie neben der Nutzholzpflanze keine anderen Gewächse mehr wegen der Wurzelkonkurrenz zu ertragen vermöchten; Föhrenböden IV. und V. Bonität mögren diesem. Jammerzustande in der Tat bereits sich nähern, aber gerade die Föhrenböden der II. und III. Bonität verlangen eindringlichst einen solchen Bodenschutz gegen die Nachteile der Kahlstellung, damit sie nicht zu geringeren Bonitäten herabsinken. Kam die Stockrodung nicht ganz unterbleiben, so mag eine Femel-oder Plenterrodung Platz greifen, daß ist eine Beseitigung jener Stöcke, welche von parasitären Wurzelpilzen. insbesondere Polyporus annosus und Agaricus melleus, befallen sind. Diese Stöcke müssen unter allen Umständen bis in die feineren, erkrankten Wurzeln gerodet werden. Ist das Staudenwerk der oben genannten Sträucher und noch rieler anderer, wie Rubus, Rosa, Prunus spinosa, Lonicera, Rhamnus, Corylus und anderer, in zusammenhängenden Massen über die Schlagfläche hin wachsend, so wird es in breiten Gassen durchhanen, welche ausgepflanzt werden. Werden diese Unhölzer sowie Gräser und Unkräuter später von den Edelpflanzen zum Absterben gebracht, so bereichern sie als wertvolle Dünger den Boden: sie zn beseitigen ist daher so irrig wie die Beseitigung des Rohhumus, beide sind willkommener, natürlicher Dünger im Walde.

In Anlehnung an alle diese wohltätigen und schützenden Objekte der Kahlfläche wird die Pflanzung ausgeführt, indem in die Stockachseln, hart neben Sträucher, Grasbüschel, Steine usw. die Pflanzen verbracht werden. Was dam noch an Kahlflächen ïbrig bleibt, mag einen regelmäßigen Verband erhalten, der mit Hilfe der $\mathrm{Pfl}$ a nz schnüre oder Pflanzketten ausgeführt werden kamn. Diese Pflanzverbandsgeräte tragen Vorrichtungen, um den gewählten Abstand der Pflanzen genau zu bezeichnen; sie werden über die Fläche gespannt, an den Merkzeichen werden kurze Stäbe in den Boden gesteckt; die Schnur oder Kette wird dann aufgenommen, nenerdings gezogen und die Markierung der Pflanzstellen wiederholt. An diesen Stellen erfolgt die Anfertigung der Jö̈cher.

Verfasser ist der Ansicht, daß auf alle Ketten und Schnüre für die Freilandpflanzung als Überflüssigkeit, Kostspieligkeit und Verzögerung der Arbeit verzichtet werden kann, wenn man bedenkt, daß eine Abweichung von dem gewählten, genanen Verbande um ein paar Zentimeter hinüber oder herüber für die Entwicklung der Pflanze gleichgültig ist. Jeder Arbeiter kam genügend genau nach dem Augenmaße oder nach der Länge seines Arbeitsgerätes den Pflanzenabstand einhalten. Eine derartig ausgeführte Kuntur, zumal unter dem wohltätigen Schutze der Strauch-, Unkrant- und Stangenwildnis sieht 
vielleicht anfänglich häßlich aus; wiehtigrer als divses, nieht von allen geteilte ästhetische Gefühl, ist der Umstand, daß wine derirtige Pflanzung, schneller, sicherer und leichter ist als die Anlace von schumgeraden Pflanzreihen in schutzloser $\ddot{\text { de. }}$

Beim Reihenverband ergibt sich die nütige PHanzenzahl pro Hektar aus der Formel: Pflanzonabstand $\times$ Reihenabstand 10 Wird die zweite Reihe so verschoben, daf in dieser jede Pflanze zwischen zwei PHanzen der Nachbarreihe zu stehen lommt, drei Pflanzen somit ein gleichseitiges Dreieck beschreiben, so nennt man dics Dreiceksverband und die Pflanzenzahl pro Hektar ist $\frac{100(10 \times 1 \cdot 15 j}{\text { Pflanzenabstand }}$ : sind Reihen und Pflanzenabstand gleich, so bilden vier Pflanzen ein Quadrat, und die Formel lautet $\frac{10000}{\text { PHanzenabstand }{ }^{2}}$; sind die Pflanzen angeordnet wio die Zahl j im Würfelspiel, so ergeben sich, wemn man die Pflanzen mit Linien sich verbunden denkt, zwei ineinander eingeschobene Quadrate; die Formel dieses Fünferverbandes lautet: $\frac{10001 \times 2}{2 \text { flanzenabstand }}{ }^{2}$, das heißt die Pflanzenzahl ist doppelt so groß als bei dem einfachen Quadratverband.

Man versteht allgemein unter enge $\mathrm{m}$ Pflanzrerband einen solchen bis $1 \mathrm{~m}$ Abstand, als weiten einen solchen mit $1-2 \mathrm{~m}$ Abstand. Bis vor wenig .Jahren galten enge Pflanzverbände insbesondere der Meterverband als Regel. In neuerer Zeit nimmt auf Grund genauerer Beobachtungen (insbesondere von Prof. Kunze in Tharandt und A. v. Guttenberg in Wien) und wegen der Erhöhung der Arbeitslöhne die Tendenz überhand, nach Terbänden zu pflanzen, welche sich zwischen den ron $1 \mathrm{~m}$ und $2 \mathrm{~m}$ bewegen.

Im allgemeinen gelten gegenwärtig folgende Zahlen:

Für Aussetzen von angekeimten Eicheln (Keimlingspflanzen) 0.(1:) bis $11,1 \mathrm{~m}$ Abstand:

für Klemmpflanzungen von ein- oder zweijährigen Pflanzen $0, \bar{m}$ Abstand;

für dreijährige nicht verschulte oder vier- bis sechsjährige verschulte Pflanzen 1:2-1,5 m;

für Vollheister ron $2 \mathrm{~m}$ und darüber.

Als allgemeine Regel muß gelten: Der Pflanzverband hat nach Klima, Boden, Holzart und Zweck der Pflanzung zu woehseln.

Je besser der Boden, je wärmer las Klima, um so weiter kann der Pflanzenabstand gewählt werden; auf geringen Böden und in kïhlen Lagen empfiehlt sich in weiten Verbänden zu pflanzen. I)r. Fank - 
hauser ${ }^{1}$ ) will im Hochgebirge $1-1,5 \mathrm{~m} ; \mathrm{v}$. Oppen ${ }^{2}$ ) verlangt für Hochlagen von $800-1000 \mathrm{~m} 1,7-1,8 \mathrm{~m}$. Frömbling wünseht ïberhaupt enge Pflanzung, um die Ansseheidung der Natur zu überlassen. Eng e Pflanzverbände empfehlen sich für $\mathrm{Hol}$ zarten, welche die Neigung haben, in lockerem Stande minderwertige, krumme Schäfte zu bilden. Hierher zählen nach den Ausführungen ïber das Ausladungsund Ausformungsvermögen in Abschnitt VI, S. 2:39 vor allem die Laubhölzer, dann zwei- und dreinadelige Föhren, Lärche, Chamaeeyparis, Thujen, Tsuga, während Strobus, Psendotsuga, Picea und Abies die gerade Schaftform bei allen Verbänden beibehalten. Engere Verbände liefern größere Massen von (zumeist geringwertigen) V orerträgen und befördern die Astreinigung. Prof. Bühler ${ }^{3}$ ) fand, daß verschiedene Pflanzweiten wie auch verschiedene Entstehungsarten einen Unterschied in der Astreinigung von 1-2m Schafthöhe, verschiedene Bodengüten aber einen solchen ron $4-5 \mathrm{~m}$ bewirken. Dr. Martin sagt, daß ans engen Pflanzungen dieselben Bestände und Kronen hervorgehen wie ans weiten. Hofrat A. T. Gutten berg ${ }^{4}$ ) verlangt weiten Verband (Maximum auf bestem Boden $2 \mathrm{~m}$ ), auf gutem Boden und bei Mangel an Absatz für Kleinnutzholz; der weite Verband hat die Entwicklungsfähigkeit der '/ukunftstämme bis zum Beginn der ersten Durchforstung zu sichern. Jolyet in Nancy wünseht nicht unter $2 \mathrm{~m}$ Abstand herabzugehen; Schiffel, Sehwappach, Schüpfer und andere neigen zu weiten Verbänden.

Als 16. Staffelpflanzung hat man folgendes Verfahren bezeichnet. Kostbares Pflanzenmaterial wird im Verband von $2-4 \mathrm{~m}$ ausgepflanzt, der Zwischenraum wird mit einer geringwertigeren Holzart, wie Birken, Hainbuchen, Erlen, ausgefüllt; sie müssen beseitigt werden, sobald sie die Hauptholzarten bedrängen. Unbrauchbar ist hierzu die Buche, weil bei ihrer Seitenbedrängung die Edelpflanzen ihre Seitenäste und Standfestigkeit verlieren und selbst nach der vorsichtigsten Entnahme der Buchen durch Wind, Regen und vor allem dureh Sehnee umgebogen werden.

Der Staffelpflanzung ähnlich ist die Z wischenpflanzung von Sträuchern an Stelle der raschwüchsigen Baumarten; der Schutz der Sträucher ist zwar geringer, dafür aber sterben diese langsam von selbst ab, da sie mit der Zeit überwachsen werden; hierbei düngen sis den Boden. Weiter empfiehlt sich insbesondere 17 . die Auswahlpflanzung. Unter dieser möchte Verfasser tolgendes Verfahren verstanden wissen: Die bei der Pflanzensortierung als die besten, schönsten, gerarlschaftigsten

1) Schweizer. Zeitschr. f. d. ges. Forstw. 1901.

2) Mitteilungen der schweizer. Zentralanst. f. forstl. Vers. 1 $\$ 9: 3$.

$\left.{ }^{3}\right)$ Zeitschr. f. Forst- u. Jagdw. 1905.

4) Österr. Forst- u. Jagdzeitung $1 \times 99$. 
und kräftigsten ansgewählten Pflanzen werten in einem Vurband von t-j $\mathrm{m}$ ausgeptlanzt; zwischen denselben liommen zwei minderguto der gleichen Holzart zu stehen, wovon starkwüchsigre Pflanzen mit Neigung zur Schaftkrümmung ausgeschlossen sind; letztere werden, wie bereits erwälnt, ganz beseitigt, wenn sie nicht für Dekorationszweeke, Alleebäume oder zu Schutzholzptlanzungen benutzt werden können. Es besteht alle Aussicht, daß die bestgeformten und schnellwüchsigsten Individuen anch fernerhin die Führung im Bestande beibehalten und nach Unterdrückung des Zwischenstandes, was schon im Stangenalter geschieht, den Hauptbestand bilden werden. Dies ist der Zeitpunkt, in dem nach der Idee der Erziehungsverjüngung der Unterbau bei allen Holzarten einsetzt. Daß diese Pflanzung für alle Holzarten paßt, daß diese Ausnützung der individuellen Wuchsgeschwindigkeit und die Anlage zur Nutzholzqualität insbesondere den späteren Erziehungshieben eine große Erleichterung bieten, daß diese Auswahlpflanzung die Ernte durch Erhöhung der Massenerträge und durch die Steigerung der Nutzholzgüte eines solchen Bostandes erhöhen muß, dürfte kaum in Zweifel gezogen werden.

Die Maßnahmen zum Schutz der Ptlanzung sind dem Abschnitt über Jungwu chspflege zugeteilt.

\section{F. Die Stecklingspflanzmng.}

Stecklinge sind Zweigstücke, welche vor der Bewurzelung von der Mutterpflanze abgetrennt und eingepflanzt werden; alle Holzarten, selbst alle Nadelhölzer lassen sich durch Stecklinge vermehren, aber nur jene Vermehrung hat ein praktisches, forstliches Interesse, welche leicht und schnell gelingt. Für die meisten Laubhölzer und insbesondere für die Abietineen unter den Nadelbäumen bedarf es besonderer Anordnung im Gewächshause, um die Wurzelbildung vor der Fäulnis des Zweigstückes hervorzurufen. Eine solche Vermehrung hat keine forstliche Bedeutung. Leicht gelingt diese Vermehrung bei der Gattung Salix, ziemlich leicht bei der Gattung Populus, bei den Gattungen Chamaecyparis, Cryptomeria, Taxus, Sciadopitys, Thuja, Thujopsis, Juniperus, Sequoia und anderen. Nur bei Chamaecyparis und Cryptomeria findet eine regelrechte Waldbegründung in Ostasien, im Gebiet des Sommerregens statt: in Europa und Amerika wäre eine solche Pflanzung reine Glïickssache, die bei einem sehr nassen Sommer zum Ziele, bei einem Durchsehnitts- und ebenso bei einem trockenen Sommer zum Absterben aller Pflanzon führen würde. Man verwendet zur Stecklingsptlanzung im Walde einjährige Zweige obiger Holzarten, welche derart abgeschnitten werden, daf noch 2-3 cm des zweijährigen Holzes am Holze verbleiben. Dieses Ende wird keilförmig zugeschnitten und so tief in den Boden gebracht, daß die Jahresgrenze zwischen dem zwei- und einjälırigen Triebe noch etwa $2 \mathrm{~cm}$ tief in den Boden kommt. Ier ganze Steckling ist $311 \mathrm{~cm}$ 
lang. Bei allen Stecklingen folgt die Bewturzelung am leichtesten an jener Grenze. '/um Auspflanzen bedient man sich eines Vorsteckhölzchens. Durch Auswahl von somnengeschützten Lagen mit tief liegendem, frischem Boden kann die Sicherheit einer solchen Kultur etwas erhöht werden.

Man hat als Einwand gegen solche forstliche Kulturen geltend gemacht, daß aus Stecklingspflanzung hervorgehende Bestände stärker an Rotfäule litten als Bestände an Kernwuclıs. Es liegt zwar nahe, daß an der Abschnittstelle des Stecklings Fäulnis einsetzen kann; ein unzweidentiger Beweis hierfür liegt jedoch his heute nicht ror. Am häufigsten ist Stecklingspflanzung zur Anlage von Weidenhegern ${ }^{1}$ ) gewählt.

Die Anlage einer gewimmbringenden Weidenzucht setzt vorans: wärmeres Klima, das ist mindestens wärmeres Fagetum mit Nutzholzzucht der Eiche und Castanetum; im kühleren Fagetum können nur warme Expositionen in Frage kommen. Da der Weidenheger auf einer Kahlfäche angelegt werden muß. sind geneigte, gegen Spätfröste etwas gesicherte Ortlichkeiten wie auch Flußnähe. Seenähe zu bevorzugen. In Spätfrostlagen, in nassen Einsenkungen ist ein Weidenheger eine verfehlte Anlage. Die Beobachtung. daß die meisten Weiden am Flußnfer wachsen, legt den Gedanken nahe, daß für den Weidenheger ein fenchter Boden günstig sein müsse. Nasser Boden erhöht jedoch die Frostgefahr und besitzt nicht den Nährwert, den eine Weidenanlage verlangt. Der Boden muß frisch, locker, tiefgründig und gut sein. Die Forderung der Tiefgründigkeit erklärt sich dadurch, daß der Boden bis auf 50 selbst $70 \mathrm{~cm}$ Tiefe bearbeitet werden muß: die Güte ist notwendig, da durch die alljährliche Rutenernte sehr große Mengen mineralischer Salze dem Boden entnommen werden.

Das Aussetzen der Stecklinge, 1-3jähriger Triebe ron $20-30 \mathrm{~cm}$ Länge, geschieht dadurch, daß mit einem Setzstab ein Loch schief in den Boden gestoßen wird, in welches die Stecklinge bis auf eine ganz kurze Spitze eingesenkt werden; ein Tritt mit dem Fuße schließt den Spalt. Aus den Lentizellen der Rinde brechen die Wurzeln hervor. Seltener wird das Einlegen der Stecklinge in Gräben oder das Anslegen der Stecklinge an den Seitenflächen einer trichterförmigen Vertiefung im Boden (Einkesseln genannt) gehandhabt. Sowohl die Weide als obige forstliche Holzarten können anch vor der Pflanzung zur Wurzelbildung gebracht werden. Es geschieht dies in Gräben, welche mit Waldhumus, abgefallenen Blättern und Nadeln angefüllt sind. Die Stecklinge werden nebeneinander in engstem Verbande bis zu zwei Drittel ihrer Länge in die sich schwach erwärmende, humose Masse

1) F. r. Förster, Die Korbweidenkultur. 1895. Deckert, Mumdener forstl. Hefte 1896. 
eingestellt und bewurzeln sich rasch; ihro weitere Verwendung ist von der Pflanzung nicht mehr verschieden.

Aus Stecklingen oder auch aus Pfanzung größerer sitangen von Weiden von 2,5-j cm Dicke und 1,5-2 m Höhe wehen dio Anlagen für den Weidenkoptholzbetrieb hervor: bei Pappeln werden auf dies'm Wege Dekorationspflanzen gewomnen zu Park- und strabenalleen, wenn man nicht vorzicht, solches Material aus Sämercien zu zichen. Freilich bei bestimmten, gürtnerisch wertvollen Variationen (Pyramidenpapuel) ist man zur Setzstangenvermehrung gezwumgen.

\section{(i. Dhsenkerpflanzung.}

Alle Holzarten lassen sich auf diesem Wege vermehren; das Verfahren besteht darin, daß schwächere Stangen oder die Zweige von stärkeren zur Erde gebogen und ihre Kronen ganz ïbererdet werden, so daß nur die Triebspitzen hervorragen. Wird für fortgesetzte Befeuchtung gesorgt, so bewurzeln alle Triebe sich selbständig; bei einigen Holzarten tritt dies schon im ersten Jahre ein, wie besonders bei Weiden, bei den übrigen Laubholzarten meist erst im zweiten, auch dritten Jahre. Obige Nadelhölzer für die Stecklingspflanzung zeigen schon im ersten, sicher im zweiten Jahre Bewurzelung. Abietineen verlangen viele Jahre hindurch Bedeckung, bis Wurzelbildung auftritt. Man kann die Wurzelbildung durch Einschnitte in der Rinde, am schnellsten clurch Ringeln (Beseitigung der Rincle bis zum Holz) an der tiefsten, übererdeten Stelle fördern. Nach Wurzelbildung erfolgt Abtrennung und Terwendung der Pflanze.

Manche Holzarten zeigen anch in der freien Natur Absenkerbildung: so insbesondere die Fichte in der kühlsten Region ihres Torkommens, in sumpfigen Örtlichkeiten. Thuja und Thujopsis, selbst auf ihren normalen Böden. Isolierter Stand begünstigt die Erhaltung der Äste bis zum Boden herab; Unkrautwuchs und Humusbildung überdecken allmählich die Seitenäste, halten sie feucht und reranlassen ihre Bewurzelung.

\section{H. Ausschlagspflanzung.}

Werden Stockausschläge im ersten oder zmeiten Jahre ihrer Bildung möglichst tief geringelt und ïbererdet, oder werden Laub- und Nadelhölzer (ausgenommen Abietineen), welche nach ihrer An-ptlanzung buschig, mit stärkeren, tief angesetzten Ästen, somit für spätere Zwecke der Nutzholzbildung ungünstig erwachsen, ebenfalls in Frïlijahr mörr lichst tief geringelt und übererdet, so bewurzeln sich die oberen Ränder aller Ringelungen; solche Pflanzen können am besten im nächsten Frühjahre abgelöst werden, nachdem während des Winters der $/ / u$ sammenhang im Holz mit der Mutterptlanze sich gelockert hat. Aut diesem Wege können neben einheimischen mit großem Vortcile seltenere Holzarten von Laub- und Nadelbäumen rasch vermehrt werden. 


\section{Rhizompflanzung.}

Nur bei den Gramineen im weitesten Sinne (mit Einschluß der Bambusaceen) sind Rhizome, unterirdische Triebe mit schuppenartigen Blättern und mit oberirdischen Trieben, Blättern und Wurzeln an den Nodien, als selbständige PHanzen im forstlichen Betriebe verwendbar.

\section{Wurzelpflanzung.}

Es ist noch nicht genügend untersucht, welche Holzarten sich durch Wurzelstecklinge vermehren lassen. Werden Gräben durch einen Laubholzstangenort wie im Niederwalde angelegt, so erscheinen im Grabenrand, wo die Wurzeln verschiedener Holzarten abgestochen sind, Ausschläge. Ulmus, Carya, Salix, Populus, Prunus, Robinia, Paulownia u. a. wurden vom Verfasser als Ausschläge liefernd erkannt. Toraussichtlich zählen auch alle Holzarten, welche ïberhaupt Wurzelbrut bilden, hierher. Aber nur für eine Holzart, für die japanische Paulownie. wird bis jetzt von dieser Eigenschaft zur Bestandsanlage Gebranch gemacht. indem Wurzelstïcke miter gleichen Verhältnissen wie Zweigstecklinge in den Boden gebracht werden, woranf sie Ausschläge entwickeln.

\section{Wurzelbrutpflanzung.}

Die unter Wurzelpflanzung genannten Holzarten besitzen fast alle die Fähigkeit, Ausschläge ans den Wurzeln bei noch lebenden Nutterstämmen emporzusenden; anch Weißerlen und vor allem den zahlreichen Sträuchern Corylus, Rosa, Rubus u. a. kommt diese Fähigkeit zu; für Sträucher ist diese Art der Termehrung die normale Verbreitung, für Baumarten aber ist das Erscheinen ron Wurzelbrut ein Zeichen der Erkrankung des Mutterbaumes, ein Zeichen des Mißbehagens, auch wenn äußerlich kein Symptom hinzntritt. Auf allen schlechten Böden neigen genamnte Holzarten am stärksten zur Wurzelbrutbildung. Verwundung der Wurzeln durch Treten, Fahren oder absichtliches Einschneiden fördert die Ausschlagbildung; am lebhaftesten setzt sie ein, wenn der Mutterstamm selbst abgeschnitten wird (PopulusArten). Zum Zwecke der Verpflanzung solcher Ansschläge wird im ersten Jahre durch einen Spatenstich die eine Seite der Verbindung mit dem Mutterstanme durchschnitten: im zweiten Jahre wird die andere Seite abgetrennt, im dritten Jahre liamn die Pflanze zur Ausptlanzung ausgehoben werden.

\section{Stummelpflanzung.}

Nach dem Abschneiden des oberirdischen Triebes oder Stämmchens wird der Wurzelstock ausgegraben und zur Einpflanzung an anderer Stelle verwendet; geübt wird dieses Verfahren bei der Birkenstummelpflanzung auf sehr mageren Sandböden, bei Ergänzung der Ausschlagstöcke im Niederwald- und Mittelwaldbetriebe. 


\section{Beispiele für die künstliche Begründung von reinen und gemischten Beständen.}

\section{A. Wahl der Holzart.}

Soll eine waldlose Stelle mit Wald bedacht werden, so ist ein Studium der naturgesetzlichen Grundlagen des Standortes, wie sio im ersten Teil dieser Schrift niedergelegt wurlen, eime ubenso wichtige, erste Voraussetzung wie die Erwägung, welcher Art der ökonomische Zweck ist, der mit der Waldbegründung erreicht werden soll.

Eine Kenntnis des Klimas des Standortes, so vollkommen, um daraus die Ḱlimazone konstruieren zu können, welcher der Standort zugeteilt werden muß, läßt sich nur dureh langjährige Beobachtungen gewinnen; für größere Ödländereien, welche aufgeforstet werden sollen, wie Steppen und Prärien, muß die meteorologische Beobachtung iuberhaupt erst die Fähigkeit des Standortes, Wald zu tragen, nachweisen; für andere, wie Moor- und Heideflächen und kleinere Steppen, welche Inseln im Walde bilden oder Waldinseln tragen, ist die Beobachtung der Holzarten noch der beste Maßstab für Beurteilung der Klimazone. Die Angleichung an fernere Gebiete, welche klimatisch bekannt sind, ist unzuverlässig, da die meteorologischen Stationen nicht in völlig öden Flächen liegen und daher stets ein milderes Klima ergeben als den neu begründeten Holzarten droht. Jede waldlose Stelle, selbst die kleinste Blöße im Walde hat überdies ein von der Umgebung verschiedenes Klima: Tafel III und IV ergeben dies deutlich. Jeder Südhang ist wärmer und trockener als ein Nordhang; ersterer kamn dem Fagetum, letzterer dem Picetum oder ersterer dem Castanetum, letzterer dem Fagetum zugeteilt werden müssen. Sind meteorologisehe Daten gewonnen, so ist die Zuteilung zur entsprechenden Klima-oder Waldzone mit Hilfo der Klimaparallelen des dritten Absehnittes eine einfache Sache. Die Holzarten der betreffenden Waldzone der nördlichen Halbkugel erseheinen anbaufähig, sobald auch der Boden für ihr Wachstum geeignet ist.

Der Boden. Ist eine Pflanzendecke rorhanden, so kann von dieser ausgehend zunächst auf die Zusammensetzung des Bodens und seine Güte geschlossen werden: der Schluß ist aber durchaus kein untrüglicher; es gibt Sträucher, Gräser und Kräuter, welche eine granz bestimmte Zusammensetzung und Beschaffenheit des Bodens bevorzugen. $\mathrm{Da}$ die genannten Pflanzen jedoch keine Bärme werden und ihre Wurzeln seicht verlaufen, so geben sie nur Anhaltspunkte über die oberflächliche Beschaffenheit des Bodens bis zu geringer Tiefe. Unter dem Wurzelbereiche kann ein sehr fruchtbarer oder granz unbranchbarer Boden (Kies, (Arundwasser, Fels) lagem, der erst ïher die Entwicklung der Bäune entscheidet. Diese Konntnis aber verwchaflt 
nur ein Bodeneinschlag und die Untersuchung des Bodens auf seine Zusammensetzung, Härte, Tief'e, seinen Wassergehalt und andere Eigenschaften. Im Anhalte an diese Daten kann aus den Ansprüichen der Holzart an die Bodengüte, wie sio der dritte Abschnitt dieser Schrift gibt, auf die anbaufähige Holzart geschlossen werden. Zur oberflächlichen Orientierung über die Bodenqualität dienen folgende Pflanzen:

Einen steinigen, kallireichen, jedoch guten Bodon zeigen an: Tussilago, Petasites, Clematis, Gentiana, Sambueus usw.

Einen Moorboden, anmoorigen, torfigen Boden: Drosera, Ledum, Sphagum, Eriophorum, Vaceinium uliginosum, Carex, Strauchbirke, Strauchföhre (Mughus), verlï̈mmerte Spirken (uncinnata), verkümmerte, stranchartige Fichten, Föhren (silvestris), Lärchen, Weiden und andere Holzarten.

Mullboden, Gartenboden, sandiger Lehm, somit guter bis bester Boden, Föhrenboden I. und II. Bonität: größere Sträucher von Prunus, Rhamnus, Crataegus und anderen; Atropa, Rubus-Arten, Fragaria, Epilobium, Carex brizoides, Convallaria, IIoose wie Polytrichum, Juncus und zahlreiche andere Gewächse.

Sand überwiegend, aber noch frisch: Moose, Farne, Gräser wie Melica, Milium und andere.

Überwiegend Sand, Frische gering: Moose wie Hypnum, Vaccinium, Vitis, Idaea, Myrtillus und andere.

Sand überwiegend, trocken: Hungermoose, Calumna, Erica, Heidegräser.

Rohhumusboden: trockene Moose wie Hypnum, dann Calunna, Vaceinium Myrtillus, Vitis Idaea und andere.

Ist auf einer Bodenfläche noch Wald vorhanden oder eine vorhergehende Bewaldung noch nachweisbar in Baum- oder Waldresten, welche inselförmig auf der waldlosen Fläche auftreten oder dieselbe begrenzen, so wird die Auswahl der anzubauenden Holzarten wesentlich erleichtert; es ist beachtenswert, daß ein Boden, welcher für die voransgehende Waldvegetation III. oder IV. Bonität war, n i ch t wieder mit derselben, sondern mit einer bescheideneren Holzart besiedelt worde. Hat aber eine landwirtschaftliche Kultur stattgefunden, so kann aus den angebauten, landwirtschaftlichen Gewächsen ebenfalls, wenn anch nicht auf die Bodengüte in größerer Tiefe, so doch auf das Klima geschlossen werden; zu diesem Ende sind den Klima- und Waldzonen des dritten Abschnittes anch die der Zone entsprechenden, landwirtschat'lichen Kulturgewächse beigegeben worden.

Ist nun festgestellt, welche Inlzarten für den neuen Standort in Frage kommen können, so wird unter diesen selbst wiederum die Auswahl zu treffen sein, je nach dem $/ / w e c k$, den der Grundeigentïmer mit seiner forstlichen Kultur beabsichtigt. Es ist nicht Aufgabe des Waldbaues, vor allem nicht dieser fïr die nördliche Halb- 
kugel hestimmten, vorlicgenden Schrift, alle die zahlreichen Holzarten mit ihren Gebranchstähigkeiten zu würdigren; as ist unmöglich, allo die zahllosen Bedürfnisse der Menschen zu besprechen und ebenso unmöglich, die Rentabilität einer Holzart voraussetzen zu künnen. \%ur Wertschätzung einer Holzart gehört nieht nur dio Kenntnis des gegenwärtigen Marktpreises, sondern auch ein Blick in die Zukunft, der gerade dadurch besonders erschwert ist, daß es Holzarten gibt, deren Produkte durch größere Angebote wertvoller, und solche, welche durch größere Angebote wertloser werden, daß yar manche Holzart aus fremden Landen eine wertvolle Bereicherung der heinischen Waldprodukte in Aussicht stellt.

\section{B. Kï̈ntliche Begrïudung der Schattenholzarten in reinen (iruppen. reinen Kileinbeständen, reinen Grofbestïnden.}

\section{Gattung Picea, reine Fichtenanlagen.}

Frühjahrssa at. Auf größerem, kahlem, hierzu bearbeitetem Boden oder auf verlassenem Ackerland empfiehlt sich bei Anwendung der Saat die Verbindung mit einer Getreidefrucht, am häufigsten Hafer (Haferschutzsaat), auch Staudenroggen, Buchweizen; Vollsaat; solche Ansaaten werden vielfach zur Gewinnung von Schlagptlanzen benützt mit den früher erwähnten Vor- und Nachteilon dieser: Streifen-, Riefen-, Stockplatten-, Furchensaaten je nach Örtlichkeit und Bedarf; bei gruppenweisem Anbau sind Stockplattensaaten zulässig. Saat unter lockerem Schirm von anderen Holzarten, am besten Lichtholzarten, gibt günstige Ergebnisse. Die Pflanzung ist gegenwärtig die vorherrschende Art der Fichtenbegründung. Klemmpflanzung mit starken, einjährigen, mit zweijährigen oder schwachen, dreijährigen Pflanzen empfiehlt sich nur auf nicht zu festen, nicht zu sehr verunkrauteten Böden. Pflanzenverband $0,5 \mathrm{~m}$ bis $1 \mathrm{~m}$. Stark verunkrautete Böden verlangen dreibis vierjährige nicht verschulte oder vier- bis sechsjährige verschulte Pflanzen mit oder ohne Erdballen; im letzteren Falle die gewöhnliche Lochpflanzung; Ballenpflanzen in Verhältnissen, welche früher besprochen wurden; Topf- und Körbchenpflanzung im Hochgebirge; Aufzucht kräftiger Pflanzungen für das Hochgebirge in der wärmeren Ebene aus keimkräftigem Saatgute; nach Cieslar und Engler ist es empfehlenswert, im Hochgebirge nur Ptlanzen aus Hochrrebirgssamen in Verwendung zu nehmen. Büschelptlanzung ist möglichst zu vermeiden. In ganz besonders gefährdeten Frostlagen, Mrulden, fonchteren Orten, ist ein Schutzbestand von Birken oder Erlen oder Führen oder Weymonthsföhren oder sibirischen Zürbeln u. dgl. nötig, unter welchen später die Fichte eingepflanzt wird. Ein solcher Vorwald ist unnötig in Örtlichkeiten, in welchen nur alle vier bis sechs Jahre ein intensiver Spätfrost auftritt; dies sind die Kahlschlags- bzw. Kablfraß-

Jl a y $r$, Waldbau. 
flächen des Hartlandbodens. Pflanzung unter Schirm von Altholz ist zulässig, insbesondere auf stark verunkrauteten Stellen. Pflanzenverband für Fichtenanlagen 1,3 bis $2 \mathrm{~m}$; der weitere Verband ist zulässig, da die Fichten stets geradschaftig erwachsen; nur für solche Holzarten (Tannen. Douglasien, Stroben) hat der we itere Verband von über $1 \mathrm{~m}$ Berechtigung. A. Schiffel ${ }^{1}$ ) verwirft die Saat ganz; Abstand 1,75 bis 2 $\mathrm{m}$; bei engerem Verband und bei Beginn des Schlusses soll die Hälfte der Pflanzen beseitigt werden. Schüpfer (Forstw. Zentralbl. 1908) will weite Verbände gegen Rotwild; gesunde und astige Schäfte seien wertvoller als reine, aber faule. Pflanzung dient sodam zur Ergänzung in Naturverjüngungen, zur Umpflanzung steilrändiger Gruppen, zur Verbindung von Vorwuchs- oder Anwuchsgruppen auf den kahlen Stellen der Durchhiebe; bei Saumschlägen in Fichtenbeständen tritt oft zwei- bis dreijährige Schlagruhe vor der Pflanzung mit Rücksicht auf den Rüsselkäfer ein.

\section{Gattung Abies, veine Tamenanlagen.}

Herbstsaat, auch Frühjahrssaat, nur unter Schirm von alten Tannen oder anderen Holzarten nach vorheriger Bodenbearbeitung; auf Kahlflächen Pflanzung mit vier- bis sechsjährigen Tannen bei geneigtem Gelände: Pfanzen mit schwächerem Material unter Schirm von Althölzern häufiger; in allen Fällen ist Schutz der Saat und der Pflanzung gegen Wildverbiß absolut notw endig; in Sachsen wird zugestanden, daß am Rückgange der Tanne allein das Wild schuld ist; in anderen Ländern weiß man es auch. sagt es aber nicht; dagegen berichtet Dr. Voit ${ }^{2}$ ) über eine Zunahme der Tanne in Unterfranken (Bayern) von 13,7 ha zu Ende des 18. Jahrhunderts auf 2301 ha zu Ende des 19. Jahrhunderts.

\section{Gattung Fagus, reine Buchenanlagen.}

Frühjahrssaat unter Schirm nach vorheriger Bodenbearbeitung; Vollsaat, Riefen-, Furchensaat, Saatbedeckung; Blockpflanzung zur Verdichtuing natürlicher Verjüngungen; Pflanzung unter Schirm mit schwächerem Gartenmaterial, enge Pflanzung; Pflanzung mit vierjährigen auch auf kahler Fläche bei geneigtem Gelände, Pflanzweite $1 \mathrm{~m}$; bei weiterem Verbando schlechtschaftig; Answahlpflanzung besonders wichtig.

\section{Halbschattenholzarten in reinen Gruppen, reinen KKleinbeständen, reinen (krofbestïnden.}

\section{Gattung Fraximus, reine Eschenamlayen.}

Herbstsaat, nur selten Frühjahrssaat, unter lockerem Schirm auf normalem, frischem, unkrantfreiem Waldboden. Pflanzung in

1) Wuchsgesetze normaler Fichtenbestände. Wien 1904.

2) Dr. E. Voit, Geschichtliche Darstellung des Einflusses der künstlichen Verjüngung auf die Verbreitung der Holzarten in Bayern. 1908. 
verunkrauteten. frischen, insbesondere mit Urtiea und Impatien als Unkräutern bestockten, selbst feuchten ()rtichkeitın: in lutzterem Falle am besten unter Schirm; aut kahler Fläche Pflanzung mit Halbheister von 1 bis 2) m Höhe, seltener Vollheister von „2 bis $\mathrm{j} \mathrm{m}$. PHanzweite 1 bis 1,5 m. Enger Verband wegen Neigung zur Krümmung und Vergabelung, Auswahlpflanzung von besonderer Wichtigheit. Die Erziehung der Escheuheister im Pflanzgarten erzielt E. Herrmann ${ }^{1}$ ) am schnellsten durch Ausheben von Pflanzen aus natürlicher Verjüngung, gleichgültig. ob krumm oder gerade; die Hauptsache ist vollkommene Bewurzelung. Diese in den Garten verbrachten Pflanzen werden nach ein oder zwei Jahren abgeschnitten; von den sich entwickelten Ausschlägen wird der beste gewählt; in zwei Jahren künnen Halbheister, in drei bis vier. Jahren Vollheister gewonnen werden, besser und schneller, als es durch Saat gelingen kann. A u ch alle übrigen Laubhölzer können auf gleiche Weise zu wert. vollen Halb- und Vollheistern erzogen werden.

\section{Gattung Alnus, Erlenarten.}

Für diese Gattung gelten dieselben Bemerkungen, wie sie für die Gattung Fraxinus gegeben sind; für die Erlen kommt Frühjahrs- statt Herbstsaat zur Anwendung.

Gattung Tilia (Lindenarten), Acer (Ahornarten), Ulmus (Ulmenarten), Carpinus (Hainbuchenarten).

Herbstsaat unter Schirm von lockerem Altholze oder auch auf kahler Fläche, auf normalem. frischem, unkrautfreiem oder bearbeitetem Waldboden: Pflanzung unter denselben Verhältnissen mit zwei- bis dreijährigen nicht verschulten, drei- bis vierjährigen verschulten Pflanzen im Abstand von 1,5 bis $2 \mathrm{~m}$; Auswahlpflanzung ron besonderer Wichtigkeit.

\section{Gattung Castanea, Erlelkastanie.}

Frühjahrssaat mit in frischem Zustande überwintertem Samen auf kahler Fläche als Stecksaat oder Keimlingspflanzung in $0, ; \mathrm{m}$ Abstand; Pflanzung meist zweijähriger Pflänzlinge auf kahler Fläche, besonders geneigtem Gelände des Castanetums. Im Fagetum nur in den wärmsten Lagen; enge Pflanzung bei Hochwaldanlage: weite ( 2 bis $4 \mathrm{~m}$ ) bei Niederwald.

Guttung Pinus, Selition Strobus, Weymouthsföhre und Combra, Zürbelführe.

Saten unter lockerem Schirm von Althölzern oder auch aut' freier Fläche sind zwar zulässig, aber selten bis jetzt ausgefühirt. Überwiegend ist Pflanzung, Klemmptlanzung auf kahlen Flächen

1) Deutsche Forstzeitung 1907. 
sowohl des Hochgebirges wie der Ebene, in etwa 1,5 bis $1 \mathrm{~m}$ Abstand. Pflanzung drei- bis fünfjähriger Angehüriger der Sektion Strobus (Pinus Peuce, Strobus u. a.) auf kahlen Flächen des normalen Bodens, wie auch in anmoorigen, fast sumpfigen Ortlichkeiten: in gleicher Weise und an gleichen Örtlichkeiten auch Pflanzung der Zürbeln mit Pflanzen von vier- bis sechsjährigem Alter und darüber. Pflanzung in besonderen Frostlagen zulässig, jedoch als Ballenptlanzung am günstigsten.

\section{Lichtholzarten in reinen Gruppen, reinen Kileinbeständen, reinen Grofbestiinden.}

\section{Gattung Pinus, Selition Pinaster, Murraya, Jeffreya, zuci-und dreinadelige Füliven.}

Frühjahrssaat. Auf unkrautfreiem oder leicht zu bearbeitendem Boden, Vollsaat, Kapfensaat; auf verunkrautetem Boden mit Rohhumus als Riefensaat mit Bodenvorbereitung; Richtung in der Ebene von $O$ nach W, auf hügeligem Gelände in horizontalen Kurven; Riefen von sehr wechselnder Breite sind gebräuchlich. Weinkauff ${ }^{1}$ ) will nur $18 \mathrm{~cm}$ Riefenbreite und Beseitigung aller Gras- und Heidebüsche auf den $60 \mathrm{~m}$ breiten, kahlen Säumen. Stockplattensaat; Stückriefensaat; Furchensaat; Saat bei kahlen Löcherhieben. Statt Saat kann auf allen genannten Örtlichkeiten bei lockerem Boden oder nach tieferer Bearbeitung Klemmpflanzung mit ein- oder zweijährigen Pflanzen im Abstand von $0,5 \mathrm{~m}$ eintreten. Ergänzung von Fehlstellen in Saaten und Klemmpflanzungen besonders nach Sehütte durch Lochpflanzung, auch Ballenpflanzung mit auserwählt schönschaftigem Material; die gepflanzte Föhre neigt überdies mehr zur Astbildung und Verbreiterung (Wolf) als die gesäte. Dr. Stötzer ${ }^{2}$ ), Frey ${ }^{3}$ ), Sehlieckman, v. Dücker u. a. verlangen dichte Begründung und Erhaltung engen Schlusses; Loch- oder Ballenpflanzung als Schutzholz, als Vorwald, in Frostlagen und auf sumpfigem Gebiete; Pflanzung zur Festigung der Dünen (Üdlandsauftorstung). Auf Örtlichkeiten, welehe von der Schütte stark heimgesucht sind, empfiehlt sich eine II engesaat von zwei Föhren, von denen die eine Schütte fester ist als die andere; zum Beispiel: mitteleuropäische silvestris und nordeuropäische (Finnland, Norwegen) lapponica oder silvestris und Banksiana und andere Mischungen. Wo die Saat mit einheimischer Föhre (silvestris) zweija dreimal wegen der Schütte ernenert werden muß, gewinnt die nordische Art (lapponica) trotz langsameren Wachstums einen Vorsprung; man vergleiche auch die Ausführungen bei Föhren mit Föhren gemischten Beständen. Oberfor stmeister $\mathrm{Hollw}$ e $\mathrm{g}^{4}$ ) hebt als Vorzüge

1) Weinkauff, Zeitschrift f. Forst- u. Jagdw. 1907.

2) Thuringer Forstverein 1905.

3) Forstw. Centralbl. 1907.

4) Zeitschr. f. Forst- u. Jagdw. 1901. 
der Kulissenverjüngung mit Saat oder Pflanzung sinjühriger Föhren auf armen und ärmsten Sand Sehutz gogen sichütte hervor.

\section{Gattung Larix, reine Lürchenumlayrn.}

Frühjahrsvollsaat oder Riefensaat anf kahler Fläthe; Kulissenoder Breitstreifensaat anwendbar; Platzsaat nur bei einer Flächenausdehnung vou mindestens 1 ha oder, wenn kleiner, 1.j-21) Jahre früher als der Anbau der Umgobung. Statt Saat in allen genannten Ütlichkeiten $\mathrm{P}$ flan z ung mit drei- bis vierjährigen verschulten Pflanzen unter Beseitigung aller krumm wachsenden Pflanzen; nur die schönsten und starkwïchsigsten Individnen sollen in der Answahlptlanzung verwendet werden; weniger günstig ist die Staffelptlanzung; Schutz gegen den Rehbock merläßlich.

\section{Gattung Quercus, Weifscichen.}

Mit Recht schlägt Oberforstmeister $\mathrm{N}$ e $\mathrm{y}$ in seinen Schriften vor, stets die Traubeneiche (sessiliflora) zu begünstigen und das siaatgut aus Gegenden zu beziehen, wo es nur Traubeneichen gibt. Anlage von Gruppen; bei Kleingruppen Altersvorsprung gegenüber der Umgebung notwendig; Anlage von Kleinbeständen und Großbeständen; im Fagetum stets wärmste Lage und bester Boden notwendig.

Frühjahrssaat. Unter lockerem Schirm Stecksaat, Vollsaat, Riefensaat, Leitersaat; letztere führt Forstmeister Endres ${ }^{1}$ ) auf $40 \mathrm{~cm}$ breiten Riefen mit (j) cm Abstand der Riefen derart aus, daß die (querrillen bei $20 \mathrm{~cm}$ Abstand derselben mit fünf Eicheln $6-5 \mathrm{~cm}$ tiet belegt werden, so daß pro Hehtar nur $7-8$ hl notwendig werden. Keimlingspflanzung ebenfalls unter Schirm; Saat mit $0,05-0,1 \mathrm{~m}$ Abstand der Früchte. Keimlingsptlanzung mit $0,2-0,5 \mathrm{~m}$ Abstand. Pflanzung mit 1/2-1 $\mathrm{m}$ hohen Pflanzen unter gleichen Verhältnissen, Abstand 1,5-2 m; Lochptlanzung; weitere Pflanzung nur bei Auswahlptlanzung zulässig.

PHanzung von Heistern mit 2 m Höhe und darüber in 2-4 $\mathrm{m}$ Abstand; Heisterpflanzıng wird von Forstmeister s' pangen berg ${ }^{2}$ ) als vorteilhaft bezeichnet: auf Föhrenboden I. und II. Bomität, damit die Eiche einen Vorsprung erhalte; im Mittel- und Niederwalcle zur Nachbesserung, in Frostlagen, in Ürtlichkeiten mit starkem Wilustande, mit Viehweideberechtigungen; entlang den Wegon und Triften. Kur Ergänzung in Ausschlagwaldungen dient auch die stummelptlanzung.

Auf sandboden kann sieb Eiche un danndauernd erhalten, wenn ihr Buche beigegeben wird, sei es in kronenweiser Mischung, sei es als Unterbau; geschieht diexes nicht, gehon die Eichen- in Föhrenwaldungen über.

1) Forstw. Centralbl. 1901.

2) Schlesischer Forstverein 189.5 . 


\section{Gattung Betula, Birlirn.}

Spätwintersaat anf Schnee; Spätherbstsaat auf gelockertem und wieder gefestigten Boden; auf allen Kahlflächen, seien sie durch Kahlschlag, vorherige landwirtschaftliche Benützung oder Kalamitäten entstanden, empfiehlt sich Birkensaat zum Schutze des Edelholzanbaues. Pflanzung mit Vorwuchsptlanzen wegen ausgreifender Wurzeln schwierig, Ballenptlanzung besser; Yorbau in Frostlagen durch Ballenpflanzung in einem Abstand von 1,5-2 m, mit Birkenheistern, insbesondere in sumpfigen, stark vergrasten Frostlagen; Stummelpflanzung auf sehr magerem Sandboden.

\section{E. Kïnstliche, gemischte Bestandesanlagen in Gruppen, in Klein- beständen oder Großbeständen.}

Nach der Idee des Kleinbestandswaldes wird nicht mehr der Bestand gemischt, sondern dieser wird klein gewählt und rein begründet; der ganze Wald setzt sich ans reinen Kleinbeständen verschiedener Holzarten und verschiedenen Alters zusammen. Soll aber nach bisheriger Überschätzung der Vorzüge der Mischbestände und Unterschätzung der Opfer an Zeit und Geld zu ihrer Begründung and Erhaltung, der Bestand selbst ans mehreren Holzarten, somit gemischt, künstlich begründet werden, so gelten folgende Grundlagen. Liegen Altholzbestände zur Verjüngung vor, so wird:

1. die künstliche Verjüngung am sichersten unter ähnlichen Verhältnissen erreicht, welche die natürliche Verjüngung verlangt; alle Gesetze für die Naturverjüngrung soleher Bestände sind mutatis mutandis auch für die künstliche Begrïndung zu beachten.

2. Soll ein gemischter Bestand künstlich verjüngt werden, so sollen jene Holzarten, für welche die standortlichen Verhältnisse eine schnelle und sichere Naturverjüngung gewährleisten, auf natürlichem Wege, die übrigen Holzarten auf' künstlichem verjüngt werden.

3. Die Naturverjüngung soll wenigstens teilweise erstrebt and erreicht werden für jene Holzarten, welche der künstlichen Verjüngung, insbesondere auf kahler Fläche, Schwierigkeiten bereiten.

4. Wenn eine natürliche Verjüngung anch als Ergänzung zur künstlichen nicht erzielbar ist, soll der Altholzbestand zur Schutzstellung für die kïnstliche Verjüngung benützt werden.

5. Wird der Altholzbestand entfernt in der falschen Voraussetzung, daß man nur anf kahler Fläche künstlich verjüngen könne, so wachsen die Schwierigkeiten der künstlichen Bestandsmischnng mit der Zunahme der Frostgefahr, des Unkrautwnchses und der Abnahme der Bodengiite.

(i. Mengesaaten von zwei und mehreren Arten verschiedener Gattungen auf Kahlflächen sind nur bei Holzarten mit annähernd 
gleicher Korngröße ausführbar und gehen in dor Recrel einen Reinbestand, in dem eine Holzart unterdrückt wird oder von Anfang an wegen umpassender Bodengüte oder Frostheschädiurmg zuritckbleibt.

7. Mengesaaten mit zwei oder mehreren Arten derselben (iattung sind zumeist zum Nutzen des Bestandes, der nach üblicher Auffassung nicht als Misch-, sondern als Reinbestand angesprochen wird.

8. Soll ein Mischbestand mit Arten verschiedener frattungen angelegt werden, so führt eine Trennung der Sämereien nach der $F$ ä che, d.h. Ansaat jeder Holzart getrennt auf Plätzen, in (mruppen oder in breiten Streifen oder Streifenverbänden (kulissenweise Mischung) zum Ziele.

9. Die Dauer der Mischung wird sodann gewährleistet, wenn eine Trennung der Sämereion nach der Zeit der Aussaat erfolgt, wobei zuerst die lichtbedürftigen und später die schattenertragenden, zuerst die waldbaulich schwächeren, später die waldbaulich stärkeren als Unterbau unter ersteren jerscheinen; diese Form führt übrigens zur stammweisen Mischung, welche sich bei genügendem Altersvorsprung der waldbaulich schwächeren auch erhalten kann.

10. Auch die platzweise oder kleingruppenweise oder streifenweise Ansaat verschiedener Holzarten kann sich erhalten, wenn die Ansaat der waldbaulich schwächeren früher erfolgt als jene der waldbaulich stärkeren.

11. Mengepflanzungen wie Pflanzungen in abwechselnden Reihen mit verschiedenen Holzarten verschiedener Gattungen gleichzeitig ansgeführt sind in der Regel so aussichtslos wie Mengesaaten; sie geben Reinbestände oder verursachen eine Summe von Verlegenheiten und Arbeiten im kritischen Alter; Mengepflanzungen ron mehreren Arten derselben Gattung, z. B. Pinus silvestris und Pinus Banksiana, können vorteilhafter als reine Bestände sein.

12. Es empfiehlt sich Trennung der Holzarten nach der Fläche wie bei der Saat, d. h. Anpflanzung derselben Holzarten in Plätzen, Gruppen, Streifenverbänden (Kulissen).

13. Es empfiehlt sich, bei kleingruppenweiser oder einreihiger Mischung jener Holzart einen Vorsprung an Zeit zu geben, welche lie waldbaulich schwächere ist, es entsteht ein streifen-oder gruppenweise gemischter Bestand oder Wald.

14. Mengepflanzung zu verschiedener Zeit ist ebenfalls zuläsiig, wenn zuerst die waldbaulich schwächere Art begründet wird. Es entsteht ein stammweise gemischter Bestand.

15. Mißlingt eine Saat, so wird sie nicht mehr wiederbolt, sondern sofort tritt Pflanzung mit derselben Holzart ein.

11. Mißlingt eine Pflanzung, so wird sie mit derselben Holzart nicht wiederholt, sondern eine andere Holzart hat als Bestandespflanze an ihre Stelle zu treten, wenn die Beseitigung der Ursache des Mißlingens unmöglich ist. 


\section{Gattung Picea (Fichten) mit Guttung Fagus (Buchen).}

Von einem haubaren Mischbestand ausgehend, wäre zunächst die Buche gruppenartig auf natürlichem Wege zu verjüngen, dann im kahlen Saumschlag mit Pflanzung von Fichten die Mischung herzustellen; es dürfte auch dic Saat von Bucheln unter den Fichten und eine Saat ron Fichten unter den Buchen oder auch die Saat unter den gleichen Holzarten zum Ziele führen.

Ausgehend vom reinen Fichtenbestande, wäre Buche unter Fichtenschutz anzusäen, so viel, als von jener erwünscht ist; dann käme kahler Saumschlag mit Pflanzung von Fichten. Ausgehend rom reinen Buchenbestand wären ebenfalls so viel Buchen entweder natürlich $\mathrm{zu}$ begründen oder künstlich unter Schirm zu säen oder auch zu pflanzen als erwünscht ist. Durch Fichtensaat unter dem Schirm der übrigen Buchen oder anch durch kahlen Saumschlag und Pflanzung von Fichten ergeben sich Buchen und Fichten in gruppenweiser Mischung.

Werden aber die alten Bestände kahl weggeschlagen oder ist überhaupt eine Kahlfläche in einen Fichten- und Buchenmischbestand umzuwandeln, so gibt es dafür zwei Wege; der eine führt zum gruppenweise der andere zum stammweise gemischten Walde. Der erste besteht darin, daß auf geneigtem Gelände Buchen und Fichten in stärkeren Pflanzen, gruppen- oder kulissenweise getrennt, ausgepflanzt werden; der zweite beginnt mit der Anpflanzung eines reinen Fichtenbestandes, der vom 50. Lebensjahre an stärker durchforstet und endlich ständig durchlichtet wird, so daß ein Unterbau von Buchen durch Saat oder Klemmpflanzung oder Lochpflanzung erfolgen kann; bis zur Haubarkeit der Fichten tritt der Buchenbestand allmählich in die Fichtenkronen ein. Eine frühere Kronenmischung hat für die Fichte ohnedies nur Nachteile und Zuwachsverlust.

\section{Gattung Picea (Fichten) mit Gattung Abies (Tannen).}

Ausgehend ron dem Mischbestande beider Holzarten wäre die Tanne zuerst und zwar auf natürlichem Wege oder durch saat oder Pflanzung unter Schirm zu verjüngen; die Fichte käme dann durch Pflanzung auf' dem kahlen Saumschlage oder durch Saat unter Schirm.

Ausgehend rom reinen Tannenbestand ist unter diesem zuerst auf natürlichem Wege oder durch Saat oder Pflanzung ein gruppenweiser Anflug von Tannen zu erstreben, worauf der Rest des Bestandes saumwoise kahl gehauen und mit Fichten ausgepflanzt wird; da die Tannen sturmfester sind, wäre gleichzeitig mit der Tannenverjüngung auch eine Fichtenansaat unter den gelichteten Tannenalthölzern möglich, wenigstens in Wind geschïtzten Lagen.

Ausgehend von reinem Fichtenbestand muß die Tanne unter dem lockeren Schirm der Fichten angesät oder eingepflanzt werden, worauf Kahlsaumhiebe einsetzen, denen Fichtenpflanzung folgt. Auf Kahl- 
Hächen wird die Mischung gruppenweise oler streifenweise betätigt, indom beide Holzarten wenigstens auf schwach geneigtem Gelände ohne allzu große Frostgefahr gepflanzt werdon kïmen.

\section{Gattung Abies (Tramen) mit Gattung Fagmes (Burhen).}

Unter einem erwachsenen Mischholzhestande kïmnen Tamne wie Buche auf natürliehem Wege oder durch Saat oder PHanzung muter Schirm oder nur eine Holzart auf natürlichom Wege, die andere durch Saat oder Pflanzung unter Schirm versucht werden. Auf' Kahlflächen ist nur Pflanzung mit kräftigerem Material, gruppenweise oder kulissenweise beide Holzarten getrennt, bei geneigtem Gelände ansfiihrbar. Auch reiner Tamenanbau, vom ju. Jahre an, immer stärkor durchforstet und durchlichtet und dann mit Buchen unterbaut gibt eine erst im Haubarkeitsalter in die Kronen der Tanne eintretende Buchenmischung.

Bei einer Mischung von Sehattenholzarten mit Halbschattenholzarten ist die Halbschattenholzart in der Behandlung einer Lichtholzart anzugleichen; bei einer Mischung ron Halbschatten- mit Lichtholzarten ist die Halbschattenholzart in ihrer Behandlung nach den Regeln einer Schattenholzart zu behandeln; so müssen Ahorne, Ulmen, Linden in Mischung mit Buchen so behandelt werden, als stünde Eiche und Buche in Frage, somit flächenweise Trennung oder Vorsprung an Zeit für die Halbschattenholzarten.

\section{Gattung Larix (Lärchen) mit einer Schatten- oder Halbschattenholzart.}

Eine Begründung von Lärchen und Fichten, Lärchen und Tamnen, Lärchen und Buchen, Lärehen und Stroben und anderen Holzarten kann mit Aussicht auf Erfolg (Ausbleiben der Krebsbeschädigung als einer tötlich en Krankheit, Erhaltung während des kritischen Stangenholzalters) nach folgenden Regeln geschehen:

1. Mengesaat von Lärche mit Fichto ist wertlos, weil hierbei die Lärche im Stangenalter anscheidet.

2. Plätzesaat der Lärche auf einer kahlen Fläche von mindestens j bis zu 10 a , bei gleichzeitiger Saat oder Pflanzung oder natïrlicher Verjüngung der umgebenden Mischholzarten; gruppenweise MLischung der Lärchen.

3. Kulissensaat (5-10) Riefen zusammen); zwischen den Lärchenkulissen Saat oder Pflanzung der Mischholzarten; kulissenweise MLischung der Lärchen.

4. Plätzesaat der Lärche auf kahler Fläche von $1,5-5$ a 1.5 bis 20) Jahre vor der Begründung der Umgebung durch saat oder Pflanzung oder natürliche Verjüngung: gruppenweise Jischung der Lürchen. 
5. Streifenweise (einreihige) Saat der Lärchen 15-20 Jahre vor der Begründung der Zwischenstreifen mit einer anderen Holzart. Streifen wechselnd oder auch mehrere Streifen der Mischholzart zwischen den Lärchenstreifen; streifenweise Mischung.

6. Plätzeweises Auspflanzen der Lärehe in der Auswahlpflanzung; Plätze von 5-10 a Größe. Gleichzeitiger Anbau der Mischung; gruppenweise Mischung der Lärchen.

7. Kulissenweises Auspflanzen der Lärche in der Auswahlpflanzung; gleichzeitiger Anbau der Mischung; kulissenweise Mischung der Lärehen.

8. Plätzeweises Anpflanzen der Lärche (Auswahlpflanzung) auf Flächen von $0,5-5$ a $10-15$ Jahre vor Begründung der übrigen Holzarten. Gruppenweise Mischung.

9. Streifenweise Auswahlpflanzung der Lärchen 15-20 Jahre vor dem Anbau der Holzarten der Umgebung. Streifen mit jenen der anderen Holzart wechselnd oder auch mehrere Streifen der Mischholzart zwischen den Lärchenstreifen.

10. Vollanbau der Lärche auf einer Kahlfäche (Kleinbestands- und Großbestandsfläche) durch Saat oder besser durch Auswahlpflanzung; zwischen den 20. und 30. Lebensjahr Unterbau der beizumischenden Schatten- oder Halbschattenholzarten wie Buchen, Hainbuchen, Eiben, Sektion: Strobus, Cembra und andere.

11. Einzelmischung von Fichte oder Tanne oder Zürbel (Cembra) mit Lärchen bei gleichzeitiger, künstlicher Begründung durch Pflanzung ist nur zulässig in den kühlsten Waldregionen, Annäherung an die alpine oder polare Region, weil dort alle Holzarten in aufgelöstem Schluß erwachsen; in tiefen Lagen würde eine solche Mischung somit ebenfalls zulässig sein, wenn es möglich wäre, so weitständig zu ptlanzen oder so fortgesetzt den Bestand zu durchlichten, daß kein Bestandsschluf eintritt.

12. Einzelmisehung bei gleichzeitigem Anbau ist stets zulässig zwischen Lärchen und Eiben, Lärchen und westländiseher Thuja, Lärchen und Thujopsis oder Sciadopity's, weil diese Holzarten mit Sicherheit überall bis zur Haubarkeit der Lärche unter deren Kronen verbleiben.

13. Einzelmischung in gleichzeitigem Anbau von Fichte (Picea überhaupt) und Lärche ist zulässig anf Böden welche oberflächlich bis 40 $\mathrm{em}$ arm von da an aber nahrungsreieher sind (Sandüberlagerung), weil durch diese Bodenverhältnisse die seichtwurzelnde Fichte zu langsamerem Wnchse gegenüber der tieferwurzelnden Lärche gezwungen wird.

14. Ausbesserung von einzehen Fehlstellen in Schattenholzliulturen mit Lärchen führt stets zum Untergang der Lärchen, wenn nicht durch einen Unglücksfall, hier Glücksfall, die Umgebung zugunsten der Lärchen geschädigt oder vemichtet wird. Daher ist gleichzeitig Einzelmischung zwischen Fichten und Lärchen, Tannen und Lärchen, Buchen und 
Lärchen zulässig, we n $\mathrm{S}$ ic herheit bestaht, daß dio droi Schattenholzarten ein Dezennium hindurch zuriekfricren oder vom Wild ver. bissen werden oder die Buchen von den Mäusen teilweiso wenigstens geringelt werden. Hänfig aber fällt in solchen Mischungen die Lärche im Stangenalter den Eichhörnchen zum Opfer, welches die glatten Teilo der Lärche ringelt.

15. Wurden Lärchen zur Ausbesserung in Fichten- und Tannenkulturen verwendet, so kanu zur Rettung der Lärchen durch Wrurzelstïmmelung (Abhamen einiger starker Wurzeln) der Fichten oder Tannen beigetragen werden; auch das Köpfen der bedrängenden sichattenholzarten ist $\mathrm{zu}$ empfehlen.

16. Wurden Lärchen durch Übersäen oder Überpflanzen von Buchenhorsten eingebracht oder zur Ausfüllung ron Lücken in Buchenverjüngungen verwendet, so muß die Buche, sobald sie mit ihrem Gieäste die Lärchenkrone erreicht, auf den Stock gesetzt werden, um die Lärche noch zu retten.

17. Am besten noch eignet sich die Lärche zur Ausfüllung in Kulturen von Lichtholzarten, aber sie kann sich dort nur halten, wenn sie auf den ihr passenden Boden kommt.

18. Nur guter, tiefgründiger Boden ist passend; auf anderen Böden wächst sie zwar die beiden ersten Jahrzehnte sehr rasch, fällt aber dann rasch ab. An den zahllosen Lärchensünden im Walde ist diese trügerische Erscheinung in erster Linie schuld.

19. Luftige Höhenlagen sind für den Anbau der Lärche keine notwendige Voraussetzung; sie passen aber der Lärche, wenn solche Höhenlagen auch guten Boden tragen; alle Lärchen lieben kalkreichen Boden mehr als kieselsäurereichen; in geschützten, selbst sehr frischen und luftfeuchten Lagen ${ }^{1}$ ) entwickeln die Lärchen schönere und höhere Schäfte unter Befolgung obiger Grundsätze.

20. Die besten und schönsten Lärchen einer Pflanzung oder auch einer Saat, und z w ar nur diese, in ungefährem Abstande von $4 \mathrm{~m}$, müssen gegen den Rehbock geschützt werden.

\section{Gattung Larix (Lürche) mit einer Lichtholzart.}

Während Schattenholzarten mit den Lärchen nur so lange friedlich und zum Nutzen der Lärchen zusammen wachsen, als ihre Kronen unter den Lärchenkronen verbleiben - es gilt dies bis zum Eintritt der Lärche in das Baumalter - passen Lärchen und Lichtholzarten auch in der Jugend und selbst im kritischen Stangenalter besser zueinander.

Lärchefindet sich mit Eiche als Oberholz in Mittelwaldungen deshalb mit großem Vorteil ein, weil sie den größten Teil ihres Lebens

${ }^{1}$ ) W. R. Fisher in Quarterly Journal of Forestry lyus sagt, dal auch das Holz röter, härter und schwerer, die Stämme viel windfester seien. 
freikronig steht. Je besser aber das Kilima der Eiche paßt - Annäherung an das Optimum im Castanetum -, desto ungünstiger (weil allzu warm) wird das Klima für die Lärche. Diese Mischung entsteht zumeist dưch Anpflanzung der Lärehe. Aus den zahlreichen Versuchen der Praxis, zweinadolige Föhren mit Lärehen zumischen, würden hochwertige Bestände hervorgegangen sein, wenn man die Lärche nicht wie eine Föhre behandelt und von ihr vermutet hätte, daß sie, entsprechend ihrem Verhalten während der ersten 10-15. Jahre, eine beseheidene Holzart sein müßte. Hätte man für die Iärehe $\mathrm{B}$ oden partien mit I. und II. Föhrenbonität gewählt, wären die zahlreichen Lärchenfriedhöfe in Föhrendickungen nicht möglich gewesen. Wird die beste Bodenstelle der Lärche zugewiesen und mit dieser unter Auswahl der besten ansgepflanzt, so erhält man eine gruppenweise Mrischung mit der Föhre; stehen größere Flächen von I. und II. Föhrenbonität zur Verfügung, so empfehlen sich ähnliche Maßnahmen wie bei der Nisehung mit Sehattenholzarten. Es dürfen aber die Gruppen kleiner und die Vorsprünge an Zeit für die Lärche kürzer gewählt werden; auch hier haben Mengesa ten von Lärchen-und Föhrensamen meist ungünstige Ergebnisse, nämlich reine Föhrenbestände gezeitigt. Daf, alle solche Mischungen später einen Unterbau mit einer Schatten-oder Halbschattenholzart erhalten müssen, bedarf kaum mehr einer besonderen Erwälnnung.

\section{Gattung (huercus (Weifseichen) mit Gattung Fagus (Buchen).}

Analog dieser Mischung sind auch andere Laubholzlichtholzarten in Misehung mit der Buche zu behandeln.

Ausgehend von haubaren, reinen Eichenbeständen sind, da branchbare Vorwüchse selten sind, natürliche Verjüngung der Eichen meist wegen Bodenverunkrautung ummöglich sein wird, unter dem Schirm der Eichen auf' den geringeren Bodenpartien Bucheln auszusäen oder Buchen zu pflanzen; auf den besten und besseren Stellen mögen die Eichen kahl hinweggenommen werden, worauf Leitersaat oder Pflanzung mit ein bis fünfjährigen Eichen erfolgt. So ergibt sich eine gruppenweise Mischung beider Arten, welehe den Verschiedenheiten im Boden entspricht.

Ausgehend von reinen Buchenbeständen wird über den besten Bodenstellen der wärmsten Klimalage eine lockere Schutzstellung aus den Buchen hergestellt, unter welcher Anbau der Eichen in Riefensaat (Leitersaat) oder dureh keimlingspllanzung in tief bearbeiteten Riefen oder durch Auswahlpflanzung stärkerer Pflanzen, seltener und nur ausnahmsweise Vollheisterpflanzung, erfolgt; bei Wahl der Pflanzung kann die Fläche auch kahl gehanen werden. Auf den schwächeren Böden wird die Buche natïrlich oder künstlich verjüngt. Ist alles guter Boden wird alles mit Eichen bestockt, die Buchen 
erst bei Beginn der Bodenverunkrautung unter dis Eichen als Unterbau eingebracht. Gegen die kulissen- oder gassenweise Beimischung der Eichen in Buchen wenden sich von Bornstedt (18:16i) und andere Schriftsteller. Bleiben Toile der Eichenbestockung bei der Tollsaat zurïck, weil sie auf minder passenden Boden geraten sind, werden diese der Buche mittels Saat oder Pflanzung zugewiesen. Frömbling will im Buchenwalde nur Traubeneiche, weil diese bescheidener sei und mit der Buche Schritt halte, wälırend der stieleiche stets geholfen werden müsse.

Ausgehend von Mischbeständen von Eichen und Buchen, werden, wenn die Eichen die besten Böden innelialten und die Buchen auf geringeren wurzeln, die Eichen meist künstlich durch Saat oder Pflanzung auf der Kahlfläche begründet, die Buchen auf natürlichem Wege verjüngt. Ist der Bestand von gleich gutem Boden, empfiehlt sich allgemeiner Anbau der Eichen und später Unterbau der Buche; stockt aber, was ebenfalls vorkommt, die Eiche auf dem geringeren, die Buche auf dem besseren Boden, so wird mit den Holzarten gewechselt, d. h. die Eiche wird unter dem Schirm der Buchen, die Buchen unter dem Schirm der Eichen eingebracht.

Eine gleichzeitige, stammweise Begründung und $\mathrm{Mischung}$ von Buche und Eiche durch Auswahlpflanzung ist nur zulässig in wärmster Klimalage und auf Boden, der kalkarm ist, ohne deshalb überhaupt arm zu sein. Auf solchen Böden wächst die Eiche in gleichem Schritt mit der durch die Kalkarmut geschädigten 13uche. In allen sonstigen Lagen ron ganz Mitteleuropa ist die Buche der Eiche gegenüber im kritischen Alter vorwüchsig, die Eiche somit später ververloren, wenn ihr nicht fortwährende, zeitraubende und kostspielige Hilfe gebracht wird.

Wie Eiche werden die Halbschattenholzarten Acer, Ulmus, Carpinus, Tilia, Fraxinus u. a. behandelt, wenn eine von ihnen an die Stelle der Eiche tritt.

Bei der Mischung Eiche mit Ahorn oder Ulme oder Esche oder Hainbuche, Erle, Linde spielen die Halluschattenholzarten die Rolle der Buche und werden ebenso behandelt wie diese.

Gattung Quercus (Weibeichen) kann gleichzeitig mit den Gattungen Taxus, Thuja, Thujopsis oder Sciadopitys durch Auswahlpflanzung begrïndet werden, da dio genamnten s'chattenholzarten stets im Wuchse gegenüber den Eichen zurủckbleiben.

\section{Gattung Quercus (Wrifseichen) mit Crattung Pieru (Fichten).}

Weder klimatisch noch biologisch-walclbaulich passen dicse beiden Gattungen zusammen; die Eiche ist stets von der dureh ihr sichattenerträgnis gewalttätigen Fichte bedroht, nur eine flächenweise Tremung. gruppen- oder kleinbestandsweise Mischung führt zum Ziele; für die 
gruppenweise Mischung ist Mortzfelds. Methode ${ }^{1}$ ) ein nachahmungswertes Torbild. Mortzfeld wählt in einem Fichtenbestande (auch in Buchen- und anderen Beständen anwendbar!) 10 a große Kulturflächen kreisförmig auf bestem Boden aus: auf diesen, gegen Wild durch einen Zaun geschützten Flächen werden zweijährige, anch 4-1jjährige Eichen in so weitem Verbande gepflegt, daß dazwischen Saaten und Verschulungen von Fichten vorgenommen werden können: 10 Jahre darauf wird der Zwischenbau verlassen, um die Eichengruppe ein Fichtenoder Buchengürtel angelegt, worauf nach abermals 10 Jahren die Verjüngung des Hauptbestandes einsetzt.

\section{Gattung Quereus (Weifseiche) und Gattung Abies (Tame).}

Gruppenweise Mischung ist wegen der beschattenden Eigenschaft der Tanne anzustreben; hierbei erhält naturgemäß die Eiche die wärmste Lage mit dem besten Boden (durch Saat oder Pflanzung) zugewiesen. während für die Tanne Naturverjüngung unter Schirm gehandhabt wird. Nach dem Schema: Eiche und Buche kam die Ausführung einer solchen gruppenweisen Mischung keine Schwierigkeiten bereiten. Weit günstiger wird allgemein der Reinanbau der Eiche (durch Saat oder Auswahlpflanzung) und der Unterbau der Tanne im Alter der Verlichtung der Eiche beurteilt. Jedenfalls eignen sich unter den Nadelhölzern die Halbschattenholzarten zum Unterbau unter Eichen besser als Tanne oder Fichte. Der allzu starken Bedrängung und Beschattung der Eiche durch Tanne dürfte auch die Minderwertigkeit der Eiche in den Tannen zugeschrieben werden. Oberförster Dr. Jäger will den allmählichen Ersatz der Weißtanne durch Buche.

\section{Gattung Quercus (Weifseiche) mit Pinus, zuci- und dreinudeliger Selition Pinaster, Murraya, Jeffreya.}

Auf kahler Fläche wird Anbau der Eiche durch Saat, Keimlingspflanzung oder Lochpflanzung auf den besten und wärmsten Standorten bis zur Größe von 1 a herab, Föhrenbau durch Saat oder Klemmpflanzung oder auch Lochpflanzung auf den übrigen geringeren Bodenpartien ausgeführt. Ist der Boden überall gleich gut (Föhrenboden I. und II. Bonität), ist zwar die örtliche Trennung durch Ansaat oder Anpflanzung der Eiche und Führe am besten, es hat sich jedoch hierbei die kulissenweise Trennung beider Holzarten weniger günstig gezeigt; plätzeweiser Anbau beider Holzarten verdient den Vorzug. Bei allen Pflanzungen mit Eiche und Föhre gelten Auswahlpflanzungen als Regel. Dr. Kienitz ${ }^{2}$ ) empfiehlt den Unterban der Föhren mit der etwas Schatten ertragenden Traubeneiche.

1) Zeitschr. f. Forst- u. Jagdw. 1896 .

9) Märkischer Forstverein 1897 . 
Gattung Quercus ( Weifsciche) mit Hulbschuttemalelhölzern (Stroluss, C'embru, ('hamaer!lparis, Tsuga und amdere).

Der gruppenweise Anbau bedarf keiner weiteren Worte. Answahl. pflanzung für alle Holzarten Regel. Unterbau der Eiche mit "2) bis 30 .Jahren durch 2 m weite Pflanzıng mit einer oder mohreren der obigen Holzarten gibt stammweise Mischung, welcher in Masse und Güte den reinen Beständen der Eiche überlegen sein werden.

Gattung Picea (Fichte) oder Abies (Tame) oder Fugus (Buche) mit zurioder dreinadeligen Föhren.

Auf ausgesprochen mineralisch kräftigerem Tannen- und Buchenboden wird die Föhre schlechtschaftig und schlechtlernig, anf ansgesprochenem Fichtenboden, mineralisch gut, aber seichtgründig, wird die Föhre kurzschäftig und krumm. Der Anbau in Mischung geschieht somit nur auf Föhrenboden, d.h. kräftigem Boden mit reichlich sandiger Beimengung. Auf Föhrenboden I und II werden bei einer Anlage, welche vom reinen Föhrenstande ausgeht, unter den Föhren Fichten oder Tannen oder Buchen ausgesät, besser gepflanzt unter Auswahl der besten Bodenstellen des Bestandes. Der Bestandesrest wird durch Absäumung mit Saat oder Pflanzung, wie früher beschrieben, verjüngt. Ist ein rückgängiger Fichten- oder Buchen- oder Tannenbestand in einen Föhrenbestand in Mischung mit einer dieser Holzarten umzuwandeln, so wird die Schattenholzart auf dem besten Boden natürlich oder künstlich unter Schirm verjüngt', worauf durch kahle Absäumung für Ansaat oder Pflanzung der Föhre gesorgt wird.

Auf einer Kahlfäche mit schwacher Neigung wird unter Auswahl des besten Bodens Fichte oder Buche oder Tanne angepflanzt; die Umgebung wird mit Föhrenpflanzen in Bestockung gebracht.

Auf Föhrenboden III. und IV. Bonität kann eine gleichzeitige Begründung von Fichte und Föhre erfolgen durch Mengesaat; auf solchen Böden bleibt die Fichte als Bodenschutz oder Füllholz unter dem Dache der Föhre; es liegt somit reiner Föhrenbestand vor.

Sollen Fichten, Buchen oder Tannen das Bodenschutzholz bilden, wird auf allen Föhrenböden im Zeitpunkte der Schlußauflösung (Stangenalter) der Föhrenbestand mit Tannen- oder Buchensaat oder mit Fichten-, Tannen- oder Buchenpflanzung (französische Methode genïgt) unterbaut.

Pinus (Selition der zuri- und dreinadeligen Fähren mit den Führen ciner fünfnadeligen Selition [Stroluus, Cembra] oder mit Chamaceynaris, Tsuga, Thuja und anderen Halbschattennadelholzbünmen gemischt).

Da die fünfnadeligen Föhren, die Weymouthsföhren und Yirben und ïbrigen Holzarten an den Boden anspruchsvoller sind als die zwei- und dreinadeligen Föhren, so kann eine Kronenmischung nur auf Föhrenboden I.-II. und III. Bonität erreicht werden; 
auf geringem Boden sinken die fünfnadeligen Föhren und die übrigen Arten zu Füll- oder Treib- und Bodenschutzholz herab. Die Mischung Strobe und Föhre haben zuerst Prof. Endres ${ }^{1}$ ) und Weinkauff ${ }^{2}$ ) empfohlen; Dr. Wappes ${ }^{3}$ ) heltt eine Reihe von Vorzügen, wie Erhaltung des Bestandesschlusses, Ausfüllung von Lücken, Nutzholzsteigerung, hervor, was alles wünschenswert wäre, wenn die Weymouthsföhre überall gegen Wildverbiß gesehützt werden könnte.

Ausgehend von einem Föhrenbestande, wird Zürben- oder Strobensamen auf Kahlfächen des Altholzes, entsprechend den besseren Bodenstellen desselben, ausgesät; besser empfiehlt sich die Klemmpflanzung mit zweijährigen oder die Lochpflanzung mit vierjährigen, bei der Zürbe auch mit sechsjährigen Pflanzen; der übrige Föhrenbestand wird wie früher angegeben, künstlich verjüngt.

Um eine stammweise Misehung herbeizuführen, empfiehlt sich ein Unterbau der zwei- und dreinadeligen Föhren im Stangenalter durch Pflanzung von Stroben oder Zürben oder einer anderen der oben genamnten Holzarten. Auf den besseren Böden werden sie allmählich hauptständig, auf den geringeren bleiben sie Füll- und Bodenschutzholz; zu letzterem Zweeke können auch Laubhölzer mit Halbschatteneigenschaften, wie Tilia, Alnus, Acer, Ulmus, Carpinus und andere, verwendet werden; sie wie die genannten Nadelbäume werden den Boden unkrautfrei zu halten vermögen, und wenn sie es auch nur bis zu Stangen bringen, mehr Nutzen geben als die Buche.

\section{Gattung Fraximus ( Esshenarten) uird häufig mit Gattung Alnus (Erlen- arten) gemischt.}

Diese Mischung ist entschieden ungünstiger als die reinen Eschenund reinen Erlenbestände. In Mischung, welche zumeist durch Pflanzung (Auswahlpflanzung) begründet wird, droht der Esche der Untergang durch die Erle. Der Esche fortgesetzt zu helfen, hat, von den Kosten abgesehen, auch deshalb keine Berechtigung, weil die Esche in Mischung mit der Erle viel weniger schönschaftig erwächst als in reinen Beständen, daher auch Gruppenmischpflanzung besser als stammweise Mischung.

\section{Föhren der Selition Pimester mit solchen derselben Selition oder der Sektion Murraya.}

Der Anbau der Silvestris- (mitteleuropäischen) mit der Lapponica(nordischen) Föhre gesehieht am besten dureh Menges a t, besonders auf Föhrenböden als Mittel gegen die Schütte, noch besser eignen sich hierzu die schnellwüchsigen Murrayaföhren (z. B. Banksiana,

1) Allgem. Forst- u. Jagdztg. 1896.

2) Forstw. Centralbl. 1896 .

?) Ebenda 1 $\$ 97$. 
Murrayana u. a.), welche gar nicht vom Schüttepilz leiden, somit in Einzelmischung die Silvestris und andore Pinasterfölnren isolieren und gegen den Schüttepilz schützen; in dicsem sinne ist auch Pinus uncinnata (die Hackenföhre) als Eimban zwischen silvestrisföhren zu bonützen. Dazu kommt, daß die Hackenföhre, dio etwas Schattrn urträgt, den Boden schützt und stets aufrechte Stämme gilut. Bankifölire ist iiberdies schneedruckfester als Silvestris.

Gattung Quercus (Weifscichen) mit anderen Laubholzlichtholzarten, einheimischen wie fremalläntischon.

Die gruppen- und flächenweise Scheidung unter Auswahlpflanzung aller Holzarten bedarf keiner weiteren Erörterung: eine stammweise Mischung, wie sie auf den besten Flußauböden zulässig ist, hat ebenfalls nach den Grundsätzen einer Auswahlpflanzung zu geschehen, wobei die flächenweise Trennung auf Truppgröße sich beschränkt, um dem Bestande den Charakter als Femelwald zu belassen.

\section{Gattung Pinus, zuei- und dreinadelige Föluren, mit Giattung Betula (Birlien) oder Aluus (Erlen).}

In der kïhlsten Waldregion oder in den übrigen Klimalagen auf geringerem Boden (Föhrenboden III.-T. Bonität), empfiehlt sich die Mischung, welche durch Eimpflanzung der Birken oder Erlen (Weißund Schwarzerlen) zur Ausfüllung von Lücken in Führenkulturen (Schneebruch-, Insekten-, Schïttelücken) erreicht werden kaun. Im Norden und auf sumpfigen Böden ist gleichzeitige Begrïndung durch Pflanzung deshalb zulässig, weil kein regelrechter hronenschluß unter solchen Verhältnissen eintritt. Erlen, insbesondere Weißerlen können auch auf geringeren, allzu feuchten wio allzu trockenen Föhrenböden als Unterbau im Stangenalter der Föhren eingebracht werden. Sie decken den Boden und erhöhen seine Fruchtbarkeit.

\section{Pims (zuei- md dreinadelig), insbesondere Pinus silvestris mit Robinia.}

Akazien- und Föhrenmischung wird vieltach empfohlen, andere Papilionaceen wären zu prïfen; auf Föhrenboden IV. Bonität ist Akazio nur noch am Waldrand zu gebrauchen $\left.{ }^{1}\right)$. Graf v. Finkenstein ${ }^{2}$ ) hebt als Vorteile der Beimischung der Akazie hervor: Erziehung ron Mullboden, Terhinderung der Moosbildung, Minderung der Fenersgefahr, Verschönerung des Waldes und wertvolle Erträge. Abtrieb zwischen 30) und 50) Jahren.

1) We ise, Mundener forstl. Hefte 1ऽ97.

2, Märkischer Forstverein 1900.

M a y.r, Waldbau. 
Alle Laubolzarten mit Ausnahme der Buche bewohuen die Auen entlang dem Unterlauf der Flüsse im Castanetum und wärmeren Fagetum; alle Laubhölzer, mit Ausnahme jener des Castanetums, bewohnen die Auen im Oberlaufe der Flüsse im kühleren Fagetum, zu ihnen gesellen sich, von oben herabgetragen, noch die Nadelhölzer und Laubhölzer des Picetums. Diese Holzarten, deren Erhaltung in ihrer Gesamtzahl Ziel der Forstwirtschaft sein muf, zu sichern, ist allein der Femelwald mit seiner einzelnen, besser truppweisen Mischverjüngung teils auf natürlichem, teils auf künstlichem Wege geeignet. Die allgemein beliebte Umwandlung solcher Waldungen in einen schlagweisen Hochwald hält Verfasser für einen Mifgriff wegen der wünschenswerten Erhaltung der Laubhölzer in solchen Örtlichkeiten, nachdem ihnen die früheren Standorte durch den Einheitswald entrissen wurden.

Es schliefat dies nicht aus, daß auch Reinbestände, am besten als Kleinbestände der für Flußauen besonders gesigneten Pappeln, Eschen, Ulmen und anderer in- und ausländischer Holzarten zur Anlage kommen. A lle Pappelart en (Populus), besonders die raschwüchsigen B a ls a m pappeln sollen durch Pflanzung ausgewählt geradschaftiger, kräftiger Individuen angebaut werden. Die Aufzucht der Pappelarten aus Samen im Pflanzgarten ist jeder andern Gewinnung von Pflanzenmaterial rorzuziehen; der Erfolg der Begründung durch Stecklinge und Setzstangen hängt von der Gunst der Witterung und von Erkrankungen der Schnittfiäche $a b$, so daß plötzliche, große Abgänge nicht selten sind; bewurzelte Stecklinge und Wurzelbrutpflanzen mögen ebenfalls Benützung finden. 


\section{Zwölfter Abschnitt. Die Ausschlagverjüngung.}

Nachdem die naturgesetzlichen Grundlagen dieser Verjüngungsweisen bereits im Abschnitt IV, den waldbaulich-biologischen Eigenschaften der Holzarten, niedergelegt wurden, erübrigt hier noch, der praktischen Nutzanwendungen dieser Regeln zu gedenken.

\section{A. Der Niederwald.}

Die Stockausschlag- oder eigentlichen Niederwald. wirtschaften mit winterkahlen Laubbäumen können nur im wärmeren Fagetum, im Castanetum und kühleren Lauretum, somit im Gebiete des raschesten Wachstums und der gröliten Stockausschlagsfähigkeit der winterkahlen Laubbäume, als gewinnbringend betrieben werden.

Als Stangenwald, zu Nutz-, Brenn- und Kohlholzzwecken, können a uf frischem und gutem Boden alle Laubholzarten bewirtschaftet werden, zu welchem Ende sie im Verband von $2-4 \mathrm{~m}$ angepflanzt werden; ihre Umtriebszeit (Alter) schwankt je nach Klima, Bodengüte und Zweck der Wirtschaft; auch Nadelhölzer können, jedoch nur im Castanetum, zu Stangenausschlagwald herangezogen werden, wie Cryptomeria, Pinus rigida, mitis und andere. A uf trockeneren Böden sind nach $\mathrm{Hamms}^{1}$ ) vortrefflicher Schrift Hainbuchen, Birken, Akazien, Acer campestre, Populus, Alnus incana (Weißerle), auf nassen Böden Erlen, Weiden und Pappeln zu wählen.

Die Anlage des Kastanienniederwaldes geschieht am besten durch Pflanzung in $4 \mathrm{~m}$ Abstand, seltener durch Saat; kalk- und kalireiche, leichte Sand- und Lehmböden sind am besten, die Umtriebszeit schwankt zwischen 15-20) Jahren; erster Umtrieb (Abhieb) nach 8 Jahren.

1) H a m m, Der Ausschlagwald. 1 $\$ 96$. 
Akazienniederwald (Robinia) auf' gutem bis geringem Boden ron mittlerer Tiefigründigkeit. Anlage durch Pflanzung in $4 \mathrm{~m}$ Abstand, Bodenbearbeitung bis auf $30 \mathrm{~cm}$ Tiefe; auch Stummelpflanzen, von einbis dreijährigen Pflanzen gewomen, finden Verwendung. Verjüngungsgräben, Brutriefen zur Erzielung von Wurzelausschlägen, sollen 0,3 bis (1,4 $\mathrm{m}$ tief sein. W W $\ddot{s} \mathrm{t}^{1}$ ) empfiehlt zur Sicherung von Wurzelknöllchen den Pflanzlöchern Füllerde beizugeben, welche ron cinem Boden genommen ist, auf welchem bereits Akazien gestanden haben.

Eichenschälwald. Zumeist Weißeichen (Albae) eignen sich hierzu, weil nur diese einen hohen Gerbgehalt in ihrer Rinde aufweisen; der Reinbestand einer. Weifeiche ist der Mischung mehrerer Weißeichen vorzuziehen. Die Anlage in dem oben erwähnten Klima erfolgt auf gutem Boden durch Pflanzung kräftiger Halbheister in einem Abstand von $4-5 \mathrm{~m}$. Dieser Verband gewährleistet die beste Entwicklung der Ausschläge (Lohden). Angesichts des Umstandes, daf heutzutage nur Schälwaldungen in wärmerem Klima, auf besserem Boden und unter guter Pflege sich als lohnend erweisen, müssen die Mittel angegeben werden, wie man den Schälwald heben beziehungsweise auf seiner Höhe erhalten, anderseits, was man tun kann, wenn aus natïrlichen Gründen eine Hebung unmöglich ist. Man vergleiche hierüber in erster Linie die Schrift von Jents $\mathrm{ch}^{2}$ ), welche an Ausführlichkeit und Zuverlässigkeit nichts zu wünschen übrig läßt. Zur Hebung dient: Vermeidung aller landwirtschaftlichen Zwischennutzungen (Hackwaldbetrieb); Beseitigung aller beigemischten Holzarten; Verzicht auf den Überhaltbetrieb; ist aber der Schälwald zu verlassen, so kann an seine Stelle treten:

1. Ein hochwaldartiger Eichenwald; man siehe Umwandlung des Niederwaldes in Hochwald im Abschnitt VIII.

2. Rodung der Eichenstöcke und Anbau von Robinia, Cladrastis, Gleditschia, Prosopis und anderen schmetterlingsblütigen Bäumen durch Pflanzung; dabei kann entweder der Niederwald torgesetzt oder ebenfalls ein Hochwald mit niederer Umtriebszeit gewählt werden.

3. Rodung der Eichenstöcke und Umwandlung dureh Saat der Klemmpflanzung in einen Föhrenbestand.

4. Umwandlung in Weinberge, Obstgärten oder in landwirtschaftliches Gelände.

5. Benützung der Eichen zur Trüffelkultur schlägt die landwirtschaftliche Presse (1908) vor.

Für die Behandlung aller Niederwaldungen gelten folgende allgemeine Regeln:

1) Wust, Deutsche Forstzeitung 1 1 97 .

2) Jentsch, l. c. 
1. Da die Wiederausschlagsfihigheit hei allen Holzarten zur Zeit des Hauptlängenwa ehstums am größten ist, ist dieses Altrr als Umtriebszeit in den Niederwaldungen und im Unterholz der Mittelwaldungen festzulegen.

2. Hiebe im Niederwalde sind Kahlhiebe und erfolgren meist im Spätwinter oder Frühjahr; im Vorwinter abgehauen leiden die Stücke während des Winters; bei Fällungen im Sommer werden die Stockausschläge mit dem Ausreifen der Triebe nicht fertig und frieren durch Frïhfrost und Winterfrost von der Spitze aus zurück.

3. Die Stockhöhe (rom Boden bis zur Abschnittfläche des Baumes) beträgt bei den Holzarten, welche am Stummelrande (Überwallungswulst) ausschlagen, $5-10 \mathrm{~cm}$; das sind Robinia, die Ulmen, Hainbuchen, Roßkastanien, Hickories und Buchen; bei allen Holzarten aber, welche vorwiegend aus schlafenden Augen Ausschläge bilden: $0-5 \mathrm{~cm}$; das sind Weißeichen, Erlen, Eschen, Birken, Ahorn, Edelkastanien, Kirsehen, Haselnüsse, Äpfelarten, Togelbeerarten; je tiefer der Hieb, desto größer die Aussicht einer selbständigen Bewurzelung der Ausschläge.

4. Je wärmer das Klima des betreffenden Standortes, desto tiefur muß der Abhieb geführt werden, da mit der Wärme die Ausschlagsregion am Stocke abwärts rückt: in kühlerem Klima ist auch aus dem Grunde, daß die Aussehlagsregion höher liegt, auch die Zahl der Ausschläge eine geringere.

5. Der Schnitt soll möglichst glatt sein; wo es durchführbar ist, wie im Edelkastanienniederwald wird an der Abhiebsstelle der IVundrand mit dem Rebmesser geglättet.

6. Der Schnitt soll eine schiefe Ebene darstellen, damit Regenwasser nicht anf der Fläche verbleibt, wodurch Fäulnis hervorgerufen wird. Einzelne Holzarten wie Hainbuche, Ahorn, Birke stoßen Säfte aus, welche durch Bakterienfäulnis eine tiefere Zerstürung des Stockes einleiten. An solchen Stöcken erlischt oft plötzlich die Ansschlagsbildung.

7. Da Licht und Wärme neben plötzlicher Säfteüberfüllung die schlafende Knospe erwecken, so wird um die Stöcke herum jeder Unkrantwuchs, Moos, Gras selbst Erde beseitigt; anderseits wird

8. durch Wiederanfüllen der Erde 1-2 Jahre nach Erscheinen der Ausschläge die selbständige Bewurzelnng dieser besonders grefördert.

9. Wo Gefahr besteht, daß die Ausschläge versagen künnten wio auf sehr trockenem Boden, in Standorten, welche der Überschwemmung ausgesetzt sind, in Frostlagen empfiehlt es sich, sogenamnte süftezieher, das heißt eine Lohde an jedem Stock zu belassen, bis die neuen Ausschläge erschienen sind, worauf der Hieb der alten nachgeholt wird.

11). Erscheint eine allzu große Zahl vou Ausschlägen, so müssen einige davon, besonders die geringeren oder die gekrümmten, beseitigt 
werden; man nennt dies Durchreiserung; Reinigungen sorgen für Beseitigung des Unholzes (Fegeholz).

11. Das Befahren der Schläge zum '/weck der Verwundung der Wurzeln, um diese zu Ausschlag anzureizen, ist nicht empfehlenswert; bessere Ergebnisse lassen sich durch Brutriefen $10 \mathrm{~cm}$ breit und $15 \mathrm{~cm}$ tief oder Brutgräben von $25 \mathrm{~cm}$ bis $40 \mathrm{~cm}$ Tiefe und Spatenbreite erzielen; es reagieren hierauf in erster Linie Holzarten, welche anch ohne Verwundung Wurzelbrut bilden.

12. Die Ergänzung der absterbenden Stöcke geschieht durch Pflanzung von Kernwüchsen, seltener durch Absenker.

\section{B. Der Mittelwald.}

Da der Mittelwald cine untere Etage enthält, welche ein Niederwald ist, und eine obere, welche einem Hochwalde in Lichtstandsform gleicht, so kommen für ihn Niederwald- und Hochwaldregeln, bezüglich der Begründung und Bewirtschaftung in Frage; für das Unterholz gelten die eben ausgeführten Leitsätze. Es gilt somit auch der oberste Satz der Niederwaldungen für den Mittelwald, daß er nur in wärmeren Klimalagen erfolgreich betätigt werden kann.

Der Mittelwald kann ein reiner sein, das heißt nur aus einer Holzart bestehen zum Beispiel als Unterholz ein Eichenschälwald, im Oberholz ebenfalls Eichen, Unter- und Oberholz aus Eschen, aus Birken oder aus Erlen. Es gibt aber auch gemischte Mittelwaldungen, wie Erlen mit Birken auf feuchteren Böden. Auf Flußauböden des wärmeren Ḱlimas (wärmeres Fagetum, Castanetum) kann jede Laubholzart Oberholz oder Unterholz sein; auf Flußauen des kühleren Klimas (kühleres Fagetum) stellen sich neben Laubholzarten im Oberholz auch Fichten ${ }^{1}$ ), Lärchen und Tannen ein. Auf trockenen (normalen) Böden tritt nach Hamm im Oberholz auf: Birke, Silberpappel, Robinie, Hainbuche, Zitterpappel, Föhre, Lärche, Kirschbäume, Äpfel- und Birnbäume ${ }^{2}$ ); im Unterholz Hainbuche, Zitterpappel, Schwarzpappel, Silberpappel, Salweide, Birke, Weißerle, Robinie und Sträncher. Auf nassem Boden des Überschwemmungsgebietes: O b e r h ol z: Baumweide, Roterle, kanadische Pappel, Schwarzpappel, Weißerle, Birke; als Unterholz Weide, Rot- und Weißerle, Pappel, Sträucher.

Allgemein ist folgendes zu beachten:

1. Die Umtriebszeit des Unterholzes muß um so kürzer sein, je kurzschaftiger das Oberholz.

2. Je niederer die Untertriebszeit, cine um so größere Zahl von Oberhölzern kann im Mittelwald übergehalten werden.

1) Nach DeBloch (Forstw. Centralbl. 1896) soll Fichte nur in Horsten im Mittelwalde vertreten sein.

2) Vilı, Pfälzischer Forstverein 1904. 
3. Auf geringen Böden kann nur eine geringe Zahl von Oberständern Fuß fassen, ohne den Unterstand allzusehr zu schädigren; aus diesem Grunde sind es die besten Bodenarten, auf welchen der Mittelwald seine größten Vorzüge aufweist.

4. Ähnlich wie schlechter Boden wirkt kühles Klima: das Schattenerträgnis der Unterhölzer nimmt im kühleren Klima ah, sio werden empfindlicher gegen Überschirmung und äußern ihre Empfindlichkeit in Herabminderung der Stockanssehläge.

5. Schatten ertragende und Schatten gebende Oberhölzer, wio Buche, Linde, Ahorn, Ulme, Esche werden nicht länger als zwei bis drei Umtriebszeiten des Unterholzes geduldet, wegen Belästigung des Unterholzes.

6. Da die Schirmfläche der Oberhölzer ständig wächst, so müssen auch im Oberholz Hiebe geführt werden, welche sich vor allem auf die nicht ausdauerfähigen Stämme beschränken; diese Auszugshauungen fallen mit dem Hiebe im Unterholz zusammen.

7. Wird ein Oberständer gefällt, so ist dort genügend Raum für einen nenen; es werden daher die Laßreitel vorzugsweise in der Umgebung eines später zu fällenden Oberständers ïbergehalten, was um so leichter geschehen kann, als die frei stehenden Oberständer in ihrer Umgebung natürliche Kernwüchse (Vorwüchse) regelmäßig hervorbringen; außerdem sollen Oberhölzer, wie die Überhälter des Hochwaldes, besonders an Wegen, Schneusen, Bestandsrändem stehen, um sie bei notwendiger, vorzeitiger Fällung ohne Schaden für den Unterstand nützen zu können.

8. Alle Ergänzungen im Unterholz erfolgeu durch Pflanzung mit solchen Arten, welche später zum Oberholz herangezogen werden können.

9. In solchen Jahren, in welchen die Oberhölzer Samen tragen, wird der Boden in ihrem Schirmbereiche entsprechend verwundet. Ergibt sich ein Aufschlag von Schatten meidenden Nutzholzarten, so sucht man dem Aufschlag durch entsprechende Aufästungs- und Lichtungshiebe im Unterholz und Oberholz Licht zu versehaffen; ebensolche Hiebe sind notwendig, wenn Kernwüchse angepflanzt werden, wie es zur Ergänzung der Unterholzstöcke aber auch des Oberholzes angezeigt erscheint.

10. Die Ergänzung des Oberholzes erfolgt nicht bloß durch Ansschläge der besten Laubhölzer, sondern auch durch Pflanzung (Halbheister bis Vollheister); wobei stets die wertrollsten Holzarten wio Eichen, Walnüsse, Akazien und andere gewählt werden sollen; sollen Nadelhölzer am Oberholz sich beteiligen, wie es in hohem Girade erwünscht ist, so muß Pflanzung von kräftigen stämmchen eintreten; ganz besonders eignet sich hierzu Führe und Lärche: für sie aber gilt 
die Auspflanzung mit strengster Auswahl raschw üchsiger und ge radachsiger Individuen als oberste Regel.

11. Bei Einzelüberhalt ist eine möglichst gleichmäßige Verteilung der Oberständer erwünseht; das Unterholz kann eine Lichtholzart sein, wenn auch ihr Zuwachs an Holz oder der Gerbgehalt in der Rinde durch die Überschirmung etwas leiden muß.

12. Bei gruppenweisem Überhalt muß das Unterholz unter den Gruppen aus einer Schattenholzart bestehen.

13. Zur Beseitigung von Wasserreisern, der trockenen Äste sind Aufästungen notwendig; nähere Angaben über Zeit und Art der Ausführung mögen im dritten Teil dieser Schrift, der von der Pflege und Erziehung der Bätume und Baumvereinigungen handelt, eingesehen werden. 


\section{Dreizehnter Abschnitt.}

\section{Anbau fremdländischer Holzarten ${ }^{1}$ ).}

Das oberste Natur- und Grundgesetz des Waldbaues, daß jede Holzart in erster Linie in ihrer natürlichen Heimat angebaut und bewirtschaftet werden soll, muß bei Übertragung einer Holzart über ihre Heimatgrenze hinaus in ein fremdes Gebiet eine Erweiterung dahin erfahren, daß jede Holzart zunäehst in ihrer Klimazone angebaut werden soll. Für die europäische Lärehe ist die Heimat in den Alpen und Karpaten, und $z$ war in kühleren Fagetum und Picetum; die Klimazone der Lärehe ist somit da: kühlere Fagetum und das Picetum nicht bloß ihrer Heimat, sondern anch des übrigen Europa sowie von Amerika und Asien. Die Heimat der Küstendouglasie umfaßt das ganze Fagetum und Picetum der Westküste von Nordamerika: die Klimazone umfaßt somit das Fagetum und Picetum der Heimat sowie die beiden Klimazonen von Ostamerika, Europa und Asien. Es kann endlich anch eine Holzart ï ber ihre Klimazone hinaus verbreitet werden, also in ein Gebiet, in welehem die Natur durch widerstrebende, klimatische Faktoren oder durch Wettbewerb anderer Holzarten der betreffenden Holzart den Eintritt verwehrt (Überschreitung der Wärme- und Kältegrenze einer jeden Holzart durch künstliehen Anbau). In einem solchen Gebiete kann die Holzart

1) Eingehende Ausfuhrungen hierúber sind in des Verfassers Schrift: Heinrich Mayr, Fremdländische Wald- und Parkbäume für Europa (Berlin, Paul Parey, 1906, 622 Seiten mit zahlreichen Abbildungen und 20 Tafeln), sowie in L $\dot{0}$ on Pardés Arboretum national des Barres (Paris 1906) enthalten; letzteres Werk gibt auf 397 Seiten Text Messungen uber Wuchsleistungen, Alter, Höhe, Anspriche an Boden usw. von 612 Holzarten; mit 94 prächtigen Abbildungen in einem Atlas. Seit 1907 erscheint auch ein großes, englisches Werk uber dio fremden Holzarten: The trees of Great Britain and Ireland by H. J. Elwes und A ug. Henry, Edinburgh. Dieses Werk enthält Angaben aber die Anbauergebnisse mit fremdlaindischen Holzarten in dem klimatisch so gunstig gelegenen GroBbritanien. Der uberaus reiche Atlas enthält Abbildungen der schönsten Bäume in vollendeter Wierlergabe. 
selbst einen Wirtschaftswert besitzen, wenn auf die normale Betätigung des Pflanzenlebens, Samenbildung, natürliche Verjüngung verzichtet, vielmehr bloß Holz erstrebt wird. Sobald aber der Mensch seine schützende Hand zurückzieht, verschwindet die Holzart allmählich wieder, das ursprüngliche Verhältnis und Gleichgewicht stellt sich wieder her; die menschliche Tätigkeit hat nur die Erkenntnis des Naturgesetzes verschleiert, nicht aber die Naturgesetze selbst aufgehoben. Ja, es gibt Äußerungen in der forstlichen Literatur, welche besagen, der Anbau einer Holzart außerhalb ihrer Klimazone beweise, daß das Naturgesetz der Abhängigkeit der Holzart und ihres Anbanes von der Klimazone überhaupt nicht existiere.

Aus dem im dritten Abschnitt Seite 61 und folgende gebrachten Ḱlimazonen für die wichtigeren Holzarten der nördlichen Halbkugel mit Ausnahme der Tropen und aus der Klimazonenparallele zwischen Europa, Ostamerika, Westamerika, China, Japan und dem Himalaya geht zwar nicht die absolute Sicherheit, so doch die größte Wahrscheinlichkeit der Anbaufähigkeit einer jeden Holzart in einem bestimmten Gebiet der nördlichen Halbkugel hervor; die absolute Sicherheit besteht deshalb nicht, weil die Klimazone nicht absolute Gleichheit, sondern nur einen Parallelismus der größten Ähnlichkeit aufweisen, auf den im folgenden näher hingewiesen werden wird.

Der europäische Wald und der atlantische Wald von Nordamerika verdanken dem gleichen Mecre ihr Dasein; gleiche meteorologische Elemente (Wanderungen von Luftverdünuungszentren) geben diesseits und jenseits der Atlantik dem Festlande den Witterungscharakter. In Nordamerika tragen Ost-, Süd- und Südostwinde, in Europa Westwinde die Feuchtigkeit ins Land, während in Europa von Osten, in Ostamerika von Westen her trockene, kontinentale Lüfte wehen und in längerer Trockenperiode den nenen Waldkulturen gefährlich werden. In beiden Gebieten verliert von den Küsten hinweg das Klima mit der Luftfeuchtigkeit seinen ozeanischen Charakter, so daß schließlich das Klima der sogenannten Prärie in Norden der Union und im Süden von Kanada denselben kontinentalen Charakter aufweist wie das Klima im Bereiche der russischen Steppe. Um einige Grade ist die wärmste Zeit (Mai bis August) in Ustamerika noch wärmer als in der parallelen Landschaft in Europa: im gleichen Verhältnis sinkt während des Winters die extremste Temperatur in Nordamerika tiefer als in Europa; Bäume aus dem Osten von Nordamerika nach Europa verpflanzt finden somit ein etwas luftfeuchteres Klima mit etwas reichlicheren Niedersehlägen, etwas geringere Sonnenwärme, etwas geringere Wintertemperatur. Nichts ist somit am europäischen Klima, was merklich ungünstig wäre; Holzarten, welche in die parallele europäische Landschaft gelangen, brauchen somit nichts in ihrer inneren Eigenschaft umzuwandeln oder mit anderen Worten sich nicht zu alklimatisieren, 
um zu gedeihen: sie finden die Verhältnisse in Europa vielfach sogar günstiger. Die Richtigkeit dieser Deduktion beweist das mehrhundertjährige Verhalten der ostamerikanischen Holzarten in Europa. An vielen Punkten Ostamerikas. in den Präriestaaten, auf Eigentumsflächen fast aller Universitäten und Schulen, in größter Vielseitigkeit insbesondere im Arnold Arboretum zu Brookline (Mass.) unter C. S. S a r g e n t. werden die dort fremden Holzarten angebaut. Gedeihen Holzarten in Ostamerika, so darf man sicher sein, daf sie auch in Europa bei entsprechender Auswahl ron Boden und Klima fortkommen werden; gedeihen sie in Ostamerika nicht, so darf man noch nicht den Schluß ziehen, daß sie auch in Europa nicht werden fortkommen können.

Gleiche klimatische Verhältnisse obwalten im Felsengebirge und seinen Abdachungen nach Westamerika (Kolorado, Idaho, Wroming). Seine Holzarten erwachsen in Ostamerika ohne Hemmungen; sie gedeihen auch in Europa, in die entsprechende K'limaparallele gebracht, ohne klimatische Störungen.

Wesentlich ungünstiger liegen die Aussichten für die westamerikanischen Holzarten in Europa. Zwar bietet Europa während der Tegetationszeit den westamerikanischen Holzarten eine größere Wärmesumme, dafür aber liegen die Wintertemperaturen in Europa sehr viel tiefer als unmittelbar an der pazifischen $\mathrm{Küste}$ : die tiefsten Temperaturen differieren bis zu $14^{\circ} \mathrm{C}$ zuungunsten Europas; erst höher im Gebirge, im Kaskadengebirge, gleicht sich der Temperaturunterschied etwas aus, ohne aber ganz zu verschwinden. In allzu tiefer Wintertemperatur liegt für die westamerikanischen Holzarten in Europa die größte Gefahr. Auch die Luftfenchtigkeit ist in Europa nicht so günstig wie an der Pazifik. Nur an der Küste des Atlantischen Ozeans und seinen Ausbuchtungen, das ist somit in Großbritannien, Nordwestfrankreich, Belgien. Holland, deutsche Nord- und Ostseeküste, finden die pazifischen Holzarten gleich große Luftfeuchtigkeit. In der Tat beweist das bisherige Verhalten der nordwestamerikanischen Holzarten die Richtigkeit der vom Terfasser vor 18 .Jahren auf Grund der Klima- und Landschaftsparallele ausgesprochenen Ansicht, daß diese Gebiete für eine Anzahl von westamerikanischen Holzarten geradezu als das Optimalgebiet in Europa sich erweisen müßten. Diesem Verhältnis nähert sich das bewaldete Hügelland von Mitteleuropa, da mit der Erhebung bis zur Zone der Fichte und Lärche hin die Luftfenchtigkeit steigt und die extremste tiefste Wintertemperatur nicht in dem Maße sinkt, als die gesamte Sommerwärme abnimmt. In den wärmeren, trockeneren, von spät- und Frühfrösten häufig heimgesuchten Ebenen mit ihren sehr tiefen Wintertemperaturen aber dürften sich für die pazifischen Holzarten die Schwierigkeiten des Anbaues bis zur Unmöglichkeit steigern. 
Tergleicht man die Temperatur der Traldzonen Europas mit jener der. Waldzonen. Japans, so bestehen kaum in die Wagschale fallende Unterschiede; wesentlich verschieden aber sind die Feuchtigkeitsverhältnisse: den japanisthen sommer beherrscht der Regenmonsun, der für die Pflanzenwelt außerordentlich günstige Bedingungen schafft; dagegen ist die Vegetationsruhe in Japan kalt und trocken; auch für die japanischen Holzarten werden nur luftfeuchte Gebiete (Küsten- oder größere Waldgebiete) mit einiger Sicherheit füu forstliche Zwecke in Aussicht genommen werden kömnen: denn es steht zu erwarten, daß die japanischen Holzarten gegen Trockenperioden während der Vegetationszeit. wie solche Europa kennt, um so empfindlicher sich erweisen werden, je kontinentaler das Klima.

Kein Land des asiatischen Kontinents nähert sich in seinem Klima enger dem von Europa als China; das ganze kontinentale Europa von der atlantischen Küiste bis zum Ural, wie von Sizilien bis Norwegen wiederholt sich, soweit dies jetzt schon beurteilt werden kamn, in seinem Klima im Riesenreiche von China. Wenn auch genauere, zahlenmäßige Angaben der klimatischen Faktoren für China nicht bekamnt sind, so ist der allgemeine Witterungscharakter schon aus der Verteilung und Zusammensetzung der Waldvegetation selbst erkenmbar. China steht noch unter dem Einflusse eines bereits abgeschwächten Regenmonsums, der aber oft bis zum Mai und Juni sich verzögert; erst mit seinem Einzug brechen Frülıling und Sommer zugleich an; es wäre zu erwarten, daß infolgedessen die chinesischen Holzarten später als andere verwandte Holzarten ihre Vegetation beginmen, somit auch gegen Spätfrost härter wären. Auf den regemreichen Sommer folgt ein trockener Herbst von kurzer Dauer und ein langer Winter mit Trockenperioden und Schneefällen im Norden und Regengüssen im Süden.

Auch das Waldgebiet des indischen Himalaya steht unter dem Einflusse des sommerlichen Regenmonsuns; bei Elevationen, welche Landschaften mit gleichen Durchschnitts-Jahrestemperaturen wie europäische Standorte in sich schließen, sind die WVinter beträchtlich milder; selbst in der Tamnenzone, welche den Wald nach oben hin abschlieft, sinkt das Thermometer augenscheinlich nicht unter $-10^{\circ} \mathrm{C}$. Es läßt sich erwarten, daß die indischen Holzarten im Winter von Mitteleuropa viel ungünstiger sich verhalten werden als die westamerikanischen; nur Südengland und die Küistengebiete von Südeuropa, die warmen und luftfeuchten Täler der Südalpen haben sich bisher als eine zweite Heimat für die kältesten Himalayabewohner erwiesen.

Der Atlas an der Nordküste von Afrika, der Kaukasus, der Ural liegen bereits außerhalb der Monsunregion: ihr Klima liegt in der Einflußsphäre jener Falitoren, welche auch das Klima von ganz 
Europa bedingen. Die griechische Strobe, die serbische Firhte, die spanisehe wie die griechische Tanne verhalten sich in den ihrer Heinat klimanahen Lagen von Mitteleuropa unter natürlichen Wuchsbedingungen nicht anders, als wären sie in den Alpen, im Schwarzwald, in den Vogesen selbst heimisch.

Aus der Klimaparallele ergibt sich die weitero Tatsache, dals damit auch für Anbauversuche und Waldanlagen mit fremdländischen Iolzarten in (1st- und Westamerika, in Japan wie in China die naturgesetzliche Basis gewonnen ist; dortige Forstwirte werden aus Vorstehendem die Unterschiede ihrer Klimate und die Holzarten erkennen, um Anbauversuche mit Aussicht auf Erfolg zu beginnen. In Japan war Verfasser der erste, der mit ungefähr 100 amerikanischen Baumarten, deren Sämereien er selbst sammelte, den Anbau eröffnete. Wie zu erwarten war, hat sich das Klima Japans bei richtiger Auswahl der Zonen für europäische wie amerikanische Holzarten gleich günstig erwiesen.

Verfasser sieht sich auf Grund von Versuchen und Beobachtungen in der freien Natur zur Feststellung gezwungen, daß auch die fremdländischen Holzarten so wenig wie die einheimischen imstande sind, sich einem fremden, vom heimatlichen wesentlich verschiedenen Klima anzupassen, sich zu akklimatisieren, d. h. ihr Inneres und Äuferes umzugestalten, so daßs sie ohne Beihilfe des Menschen weiterleben und sich vermehren könnten.

Anbauw ürdigkeit. Die größte Zahl der fremdländischen Holzarten erscheint anbauwürdig, wenn man allein ihren ästhetischen Wert, ihren dekorativen Vorzug berücksichtigt. Es fehlt aber auch nicht an Stimmen, welche den Exoten im Walde jegliche Fähigkeit, das natürliche Schönheitsgefühl im Menschen auszulösen und zu befriedigen, absprechen. Der Vater der Forstästhetik, v. Salisch auf Postel, sagt, daß nur einheimische Holzarten ästhetisch schön sein können: wenn $r$. Saliseh dabei im Ange hat vom Wilde verbissene und verunstaltete oder durch unpassende Standorte kränkelnde Exoten, so stimmt Verfasser ihm gern zu. Was aber gesund ist und gesund aussieht, hat auch Anspruch auf die volle Bezeichnung "ästhetisch schön".

Die Zahl der Auserwählten unter den Anbaufähigen vermindert sich sehr beträchtlich vom streng forstlichen Gesichtspunkte aus. Anbauwürdig sind alle Holzarten, welche einen waldbaulichen Vorteil aufweisen. Ein solcher Torteil wäre es, wenn eine exotische Holzart in ihren Ansprüchen an die Bodengüte noch bescheidener wäre als die bescheidenste unter unseren einheimischen Holzarten, als die Föhre, wenn sie also auf den geringsten Sand- und Kiesböden noch fortkommen und Erträge liefern könnte, oder wenn sie, auf gleich guten Boden mit den einheimisehen Holzarten gebracht, auf diesen in kürzerer Zeit größere, und zwar mit einheimischen Arten 
gleich gute Holzmassen erzengen würde. Es scheint, als ob es dem Vorfasser in der Tat gelungen wäre, in der Pinus Banksiana eine Holzart zu entdecken, die noch hescheidener als die einheimische Föhre und vor allen auch der unserer Föhre drohenden Schüttegefahr gegenüber geradezı immun ist; dazu kommt noch, unter gleichen Verhältnissen mit unserer Föhre eine grölere Wuchskraft und Widerstandsfähigkeit gegen Sclinee; auch die Quercus rubra, die amerikanische Roteiche, ist bescheidener in ihren Ansprüchen an die Bodengüte als die mitteleuropäische Eiche; aber es steht zu befürchten, daß, was sie auf schwächerem Boden an Quantität mehr leistet, dafür an der Qualität des Produktes wiederum verloren geht. Vor allem sei sodann auf sumpfbewohnende, fremde Holzarten aufmerksam gemacht, nachdem diese Standorte im mittleren und nördlicheren Europa nur einseitig von den einheimischen Holzarten ausgenützt werden. Unter allen Umständen werden sich als hervorragend wertvoll alle Papilionaceenbäume, soweit sie aubaufähig sind, erweisen; mit ihnen kann noch auf den geringwertigen Böden operiert und dennoch ein gutes Material erwartet werden, da sie ja imstande sind, den Stickstoff aus der Luft direkt mittels der Knöllchen an ihren Wurzeln aufzunehmen.

Die meisten Forstleute erklären es als einen Torteil einer fremdländischen Holzart, wenn sie weniger unter Wildverbiß leidet; Fichten mit stechenden Nadeln werden allen Ernstes zum Anbau an Stelle der einheimischen Fichte auf allen dem Wildverbisse besonders ausgesetzten Örtlichkeiten empfohlen; konsequent durchgeführt müßten wir allmählich zum völligen Ersatz der einheimischen Arten durch eine fremde, rehsichere Fichte schreiten; den entgegengesetzten, extremen Standpunkt nimmt jener Oberforstmeister ein, der geschrieben hat, daß man vom Anbau der W e y mouths föhre Abstand nchmen solle, ïberall, wo sie doch nur vom Wilde aufgefressen werde! Verfasser erblickt im Wildverbiß keinen Grund, um eine einheimische Holzart zurückzudrängen, und keinen, um eine fremde Holzart, die anbauwürdig ist, auszuschließen. Geh. Oberforstrat Wildbrand trifft ins Schwarze, wenn er das Wild die schlimmste Gefahr nennt, welche den Kulturen droht; dies gilt für einheimische und im verstärkten Naße für fremdländische Baumarten.

Fremde Holzarten wären sodann anbauwürdig, wenn sie auf gleichen Böden mit den einheimischen Arten angebaut bei gleicher Holzgüte in gleichen Zeiträumen zu astreineren, vollholzigeren $\mathrm{Schäften}$ aufwachsen wïrden als die einheimischen Arten, oder wenn sie, den Forderungen unseres Klimas und der Wirtschaft genügend, ein von unseren Iölzern verschiedenes, d. h. ein dauerhafteres oder festeres oder schöneres, schwereres oder leichteres, weicheres usw. Holz erzeugen als unsere einheimischen Arten. 
An verschiedenen Orten ${ }^{1}$ ) hat Verfasser darauf hingewiesen, da f alle Holzarten, deren Gattung im europäischen Walde vertreten ist, dasselbe Holz erzeugen werden wie die einheimische Art derselben Gattung; d. h. daß eine fremdländische Fichte oder Tanne oder Lärclie oder Fiche unter denselben Umständen, unter denen die einheimische Fichte, Tanne oder lärche oder Eiche gutes Holz erzeugt, ebenfalls gutes, unter denselben Umständen, unter welchen die europäischen Arten schlechtes oder schlechtestes Holz bilden, ebenfalls schlechtes oder schlechtestes Holz erzeugen müssell. Daran ändert nichts der Umstand, daß etwa in einem Lande eine Hoizart einen besseren Ruf, eine bessere Reklame besitzt als die Holzart derselben Gattung in dem fremden Lande.

Wer daher glaubt, irgendeine japanische oder amerikanisehe Holzart sei deshalb für Europa wertlos, weil sie in ihrer Heimat gar nicht benützt werde, oder deshalb besonders wertvoll, weil sie in der Heimat so hoch im Ansehen und Werte stehe, befindet sich auf einem Irrwege. Das Urteil des Auslandes ist nur brauchbar zu einer flüchtigen Orientierung, ist aber unbrauchbar zum entscheidenden Vergleich mit den Leistungen der einheimischen Arten, unbrauchbar zur Entscheidung, ob die betreffende Holzart in Europa anbauwürdig ist oder nicht.

Für den Anbau der Föhren und deren Beurteilung in Anbauwürdigkeit gilt der Satz, daB alle jene Föhren in erster Linie anbauwürdig sind, deren Sektion im heimischen Walde noch nicht vertreten ist. Von diesen allein kann ein verschiedenes, waldbauliches Verhalten, ein verschiedenes Holzprodukt erwartet werden; andererseits aber können wir mit Sicherheit voraussagen, daf keine zweinadelige Föhre der Sektion Pinaster aus Amerika oder Asien im europäischen Walde unter gleichen Umständen mehr und Besseres leisten wird als die einheimische Föhre P. silvestris.

Dennoch sollen auch Angehörige derselben Gattung und bei Föhren derselben Sektion in Europa geprüft werden überall, wo eben die europäische Art ebenfalls nicht auf ihrem heimat. lichen, ursprünglichen Standorte sich befindet, wo somit auch die europäischen Holzarten nichts anderes sind als Fremdlinge; eine solche fremdländische Holzart ist z. B. die Alpenlärche nördlich der Alpen bis an die Waldgrenze von Norwegen, ist die Föhre im ganzen westlichen Deutschland, in Nordfrankreich und in Belgien. Differenzen, die sich zwischen den Arten einer Gattung zeigen, in Nadel und Blattbildung (z. B. Fichtenarten der Gattung Picea), in der Wuchsform und Schaftbildung (Arten der Gattung Larix), im Widerstand gegen Insekten und Pilze infolge Verschiedenheit in der Vegetationsentfaltung,

1) Geheimrat Dr. K. Gayer und Prof. Dr. H. Mayr, Die Forstbenutzung, 9. Aufl., 1903. 
im Bau der Nadeln u. dgl. können groß genng sein, um den Anbau einer nah verwandten fremden Art außerhalb des naturlichen Verbreitungsgebietes der einheimischen Art zu rechtfertigen.

Alle Vorteile, welche die Anbanwürdigkeit begründen, werden von seiten der Holzarten nichtheimischer Gattungen voraussichtlich am vollkommensten erfüllt, wenn sie in einer mit dem Heimatgebiete parallelen K'limazone angebaut werden. Je weiter hinweg von dieser Zone eine Holzart in ihrer neuen Heimat gerät, um so unwahrscheinlicher wird die Anbanfähigkeit, und um so mehr werden die Vorteile schwinden, bis endlich die Grenze der forstlichen Brauchbarkeit erreicht wird; wo diese Grenze liegt, kann nur dureh Versnche herausgefunden werden.

Anbauwürdig sind endlich alle Holzarten, welche neben branchbarem Holze auch wünschenswerte Nebenprodukte, wie Harz, Gerbstoff, Zucker, eßbare Sämereien u. dgl., hervorbringen.

Um nicht alles wiederholen zu nüssen, was bezüglich der Saat und Pflanzung im allgemeinen bereits bei den einheimischen Holzarten im XI. Abschnitte erwähnt wurde, sei na elıdrücklichst auf diese Ausführnngen hingewiesen. Speziell für den Anbau der fremdländischen $\mathrm{B}$ a umarten seien noch folgende Punkte hervorgehoben.

1. Zur Beurteilung der klimatischen Verhältnisse eines Landes, wie kleinerer Gebiete und einzelner Standorte, dienen etwa vorhandene meteorologische Beobachtungen, wobei zum Vergleich mit den fremdländischen Vegetationszonen die Daten anf denselben Grundlagen berechnet werden mögen.

Wo klimatische Daten fehlen, gibt den besten Maßstab für die Beurteilung des Klimas eines Standortes das Studium der an der betreffenden Stelle ursprünglich vorhandenen oder noch vorhandenen Holzarten.

Wo meteorologische Angaben sowohl als Bätme fehlen, kann das Klima eines Standortes und benachbarter Gebiete nach den landwirtschaftlichen Kulturgewächsen beurteilt werden. Zn diesem Ende wurden den Vegetationszonen des Abschnittes auch die für die betreffende Zone typischen, landwirtschaftlichen Nutzgewächse beigefügt.

2. Holzarten, welche aus einer kühleren Klimazone in eine wärmere versetzt werden, sind der Gefahr, durch Spätfröste beschädigt zu werden, stets ausgesetzt, weil die im Frühjahr zur Verfügung stehende, größere Wärmemenge die Pflanze zu frühreitigem Vegetationsbeginne zwingt; sio sind aber gegen Früh- und Winterfröste unempfindlich.

Holzarten, welche aus dem wärmeren Klima in eine kühlere Zone versetzt werden, leiden nicht oder liaum durch verspätete Fröste, weil sie spät ihre Vegetation beginnen; dagegen genïgt ihnen oft die dargebotene Wärme nicht zum rechtzeitigen Abschluß ihrer Vegetation; sie sind in der Gefahr, durch Früh- und Winterfröste beschädigt zu werden. 
Alle künstlichen Betätigungen an den Pflanzen, wie Saat, insbesondere verspätete Saat, Verschulung, Auspflanzung, Verodelung. starke Düngung, stören im betreffenden Jahre die normale Vegetation einer Pflanze und erhöhen die Gefahr einer Beschädigung im folgenden Herbst und Winter durch Kälte, weil dadurch dis vegetative Tätigkeit der Ptlanze hinausgeschoben wird. Deckung (Hochdeckung) kann nur im ersten Jahre der Saat und im ersten Jahre der Pflanzung sowie bei Herbstpflanzung von aus wärmeren Gegenden bezogenen Exoten empfohlen werden.

3. Wegen der Kostspieligkeit des Saatgutes kommen für die fremdländisehen Holzarten, welche sich leicht verpflanzen lassen, einstweilen am besten nur Aufzucht in Saat- und Pflanzengärten und spätere Auspflanzung ins Freie in Frage.

4. Die Waldbegründung, die Bestandsanlage mag bei den fremdländischen in demselben Verbande wie bei den einheimisehen Holzarten ansgeführt werden, in erster Linie empfehlen sich große Gruppen von 1 a bis 0,3 ha und Kleinbestände von 0,3 ha bis 3 ha, und zwar, wie dies Preußen stets handhabte, in reinen Kulturen; für die Pflanzung ist Auswahlpflanzung, auch Staffelpflanzung besonders wichtig.

j. Fremdländische Holzarten zur Ausbesserung der Kulturen von einheimisehen Holzarten zu verwenden, dürfte nur bei besonders raschwüchsigen Arten, wie Roteichen, der grünen Douglasie, mit Sitkafichten anzuraten sein.

6. Alle Anbauversuche mit fremden Holzarten sind angesiehts der Kostspieligkeit des Pflanzenmaterials, des wissenschaftlichen Wertes solcher Versuche, mag das Resultat günstig oder ungünstig sein, zur Erreichung eines reinen Ergebnisses mehr noch als bei einheimischen Arten gegen Besehädigung aller Art, insbesondere durch Hasen, Rehe, Hirsche, Rüsselkäfer ısw., zu sichern. Nur bei Holzarten, welche gerade wegen ihrer Widerstandskraft gegen die genannten Feinde empfohlen werden, fällt diese Sicherung weg. In allen übrigen Fällen aber soll man, wenn man Schutz nicht bieten kann oder will, lieber auf den Anbau fremder Holzarten verzichten. Schützt man aber, so wähle man eine solche Methode, welche nur eine einmalige Ausgabe erfordert und auch bei etwaigem Personalwechsel noch fortdauernd wirkt, im Fall der nene Wirtschafter kein Interesse oder kein Verständnis für eine ernsthafte Behandlung. der Fremdländerfrage im Walde besitzen sollte. Bezüglich des Schutzes der Pflanzen und der weiteren Erziehung und Behandlung derselben wolle der dritte Teil dieser Sehrift eingesehen werden.

\section{Holzarten für Standorte mit Lamretum-Kilima.}

Feuchter bis nasser Boden: Chamaecyparis sphaeroidea, Taxodium distichum, Picea sitkaënsis.

I a y r, Waldbau. 
Guter, frischer. Sand boden: Cupressus macrocarpa, Juniperus virginiana, Pinus palustris; Robinia.

Trockener, minder gutor, kiesiger oder sandiger Boden: Albizzia, Prosopis, Robinia, Sophora, Cladrastis, Biota.

Beweglicher Sandboden (Dünen-und Binnenlandsand): Piuus insignis, rigida, clausa, corsicana, maritima.

Normalboden, gut bis sehr gut: Carya alba, Juglans nigra, Cedrus atlantica, Deodár, Cryptomeria japonica, Juniperus virginiana, Sequoia sempervirens; Buxus-Arten, Paulownia, Quercus, Trachycarpus excelsa, Kelkowa Keaki u. a.

Ste ppenböden: Picea pungens, Pinus clausa, Pscudotsuga glauca, Prosopis juliflora, Quereus rubra, variabilis, Robinia, Sophora.

\section{Holzarten fïr Standorte mit Castanetum-Kilima.}

Feuchter bis nasser Boden, stehende Nässe: Chamaecyparis sphaeroidea, Taxodium distichum, Thuja occidentalis, Picea pungens, Sitkaënsis.

Feuchter bis nasser Boden, Nässe weehselnd, Überschwemmungs - oder Infiltrationsboden von Bächen und Flüssen: Platanus occidentalis, Cercidiphyllum, Nyssa silvatica, Phellodendron, Pterocarya rhoifolia.

Sandboden II. und III. B ontät: Robinia, Albizzia, Cladrastis amurensis, Prunus serotina, Quercus rubra, Sophora; ChamaecyparisArten, Betula lenta, lutea, Maximov., Pinus, Sektion Strobus, Thujopsis, Biota.

Sandboden III. bis V. Bonität: Pinus rigida, Banksiana, Murrayana, pyrenaica, Albizzia, Betula nigra, Prosopis.

Beweglichor Sandboden. (Dünen, Binnenlanddünen): Pinus rigida, Cupressus macrocarpa, Pinus clausa, insignis, Thumbergii, corsicana, maritima, Qnercus dentata, Rosa rugosa (zur Festlegung).

Normaler, guter bis sehrguter Boden, auch Föhrenboden I. bis II. Bonität: Cedrus atlantica, Deodár, Cryptomeria japonica, Juniperus virgin., Acer sacchar., Carya alba, olivaeformis, Gleditschia, Gymnocladus, Juglans nigra, Sieboldiana, Liriodendron, Melia, Morus alba, Paulownia, Platanus, Qnereus palustris, rubra, Robinia, Chamaecyparis Lawsoniana, nutkä̈nsis, obtusa, pisifera, Libocedrus decurens, Sciadopitys, Sequoia gigantea, sempervirens, Thuja gigantea, Thujopsis, 'Tsuga dumosa, heterophylla, Sieboldii; Acanthopanax, Cercidiphyllum, Cladrastis amur., Hovenia, Cedrela, Magnolia hypolenca, Nyssa, Phellodendron japonicum, Prunus serotina, Shiuri, Pterocarya, Rhus vernicifera, Sophora, Zelkowa Keali.

Für Stoppenböden: Pinus der Sektion Jeffreya und Murraya, Pseudotsuga glauca, Picea pungens; Albizzia, Carya porcina, Cladrastis, 
Fraxinus pubescens, Prosopis, Prunus serotina, Shiuri, Quercus dentata, rubra, variabilis, Robinia, Sophora.

Für vorkarstete Standorte: Föhren der Sektion Murraya und die Schwarzföhren der Sektion Pinaster, insbesondere Pinus corsicana sowio die Laubhölzer des Sandbodens II. bis IIl. Bonität.

\section{Holzarten für Standorte mit Fagetum-Klima.}

Für die wärmsten Lagen, in denen Castanea kultiviert noch erfolgreich zum Nutz- und Fruchtbaum erwächst, sollen auch IIolzarten der vorigen Klimalage auf den entsprechenden Büden angebaut bzw. versucht werden; auf den kühleren und kühlsten Lagen können die Holzarten der folgenden Klimaregion, die Holzarten des Picetums bzw. Abietums angebaut werden.

Boden feucht bis naß; stehende Nässe, doch während der Vegetationszeit für Cirsium, Euphrasia usw. genügend trocken werdend; Moorboden, a uch torfige Unterlage, intensivste Frost lage: Picea pungens, Pinus Banksiana, Peuke, sibirica, Strobus, Thuja occidentalis.

Boden feucht. Wasser sich öfters erneuernd (Flußufer, Überschwemmungen selten). Cercidiphyllum, Fraxinus americana, nigra, Phellodendron, Platanus orientalis. Populus deltoides, monilifera, suaveolens, trichocarpa, Liriodendron.

Sandboden II. und III. Bonität: Chamaecyparis-Arten, Pinus Strobus, Thujopsis, Betula lenta, lutea, Maximovicsiana, Cladrastis, Quercus rubra, Robinia, Sophora.

Sandboden III. bis V. Bonität: Föhren der Sektion Murraya: Banksiana, Murrayana, pyrenaica, pungens; dann Pinus corsicana, Betula lenta, lutea, Maximovicsiana, Cladrastis, Robinia.

Beweglicher Sandboden. Sanddünen: Pinus Banksiana, contorta, Murrayana, rigida, corsicana.

Normaler, guter bis sehr guter Boden, auch Föhronboden I. und II. Bonität: Acer saccharum, Carya alba, Juglaus cinerea, nigra, Sieboldiana, Liriodendron, Robinia, Chamaecyparis Lawsoniana, nutkaënsis, obtusa, pisifera, Cryptomeria, Larix leptolepis, occidentalis. sibirica, Libocedrus decurrens, Pinus koreensis, Lambertiana, monticola, parviflora, pentaphylla, Peuke, sibirica, Strobus, Pseudotsuga Douglasii, glauca, Taxus cuspidata, baccata, Thuja gigantea, Thujopsis, Tsuga canadensis, heterophylla. Alle Abies- und PiceaArten; Acanthopanax, Betula lenta, lutea, Maximovicsiana, Cercidiphyllum. Cladrastis, Magnolia hypolenca, Nyssa, Phellodendron, Prunus serotina, Shinri; Fraxinus pubescens, Quercus rubra; Föhren der Sektion Murrara, Sciadopitys, Sequoia gigantea u. a. 
Für Steppenböden: Pinus der Sektion Murraya, Pseudotsuga glanca, Picea prungens, Cladrastis, Fraxinus pubescens, Prunus serotina, Shiuri, Quereus dentata, rubra, Robinia.

Für verkarstete Standorte: Föhren der Sektion Murraya, die Schwarzführen der Sektion Pinaster und die Laubhölzer des Sandbodens II. bis V. Führenbonität.

\section{Holzarten fiir standorte mit Abietum- hzw. Picetum-Kilima.}

Boden feucht bis nals, Erlenbrücherwie bei Fagetumklima: Picea pungens, Pinus Banksiana, contorta, Murrayana, Peuke, sibirica, Strobus, Thuja occidentalis.

Boden frisch bis feucht (Flußufer usw.): Fraxinus americana, nigra, Populus sowie obige Holzarten.

Sandboden II. und III. Bonität: Cladrastis, Pinus Banksiana.

Sandboden III. bis V. Bonität: Pinus Bankisiana, Murryana.

Normalboden, auch Föhrenboden I. bis II. Bonität: Pinus Peuke, sibirica, Psendotsuga Douglasii, glauca, Thujopsis, Sciadopitys, Tsuga canadensis, heterophylla, alle fremden Picea-, Abiesund Larix-Arten a u Berhalb des ursprünglichen Verbreitungsgebietes der verwandten europäischen Arten; Acanthopanax, Cladrastis.

Bew eglicher S andboden: Picea alba, Pinus Banksiana, rigida.

Mooriger Boden, Hochmoore: Pinus Banksiana, Murrayana, pumila.

\section{Holzarten für das Alpinetum hzw. Polaretum.}

Normaler Boden: Pinus pumila, Tsuga Pattoniana, Pinus sibirica.

\section{Holzarten für besondere forstliche Zwecke.}

Aus den vorhergehenden Anbauplänen ergibt sich die Verwendung der Baumarten nach Bodon und Klima.

Holzarten gegen WildverbiB: Picea alba, pungens.

Holzarten als Vorbau in Frostlagen mit feuchtem oder normalem Boden: Pinus Banksiana, Murrayana, Peuke, Strobus.

Holzarten für Unterbau unter Eichen, Föhren (I. und II. Bonität im Castanetum- und Fagetum-Klima), Lärchen (im FagetumKlima); der Unterban soll später am Hauptbestande sich beteiligen: Cedrus-Arten (nur Castanetum), Chamaecyparis-Arten, Libocedrus, Pinus der Sektionen Strobus und Cembra, Sciadopitys, Taxus, ThujaArten, Thujopsis; Acer saccharum, Ulmus laciniata, Zelkowa Keaki.

Holzarten für Niedorwaldbetrieb: Carya alba, Magnolia hypolenca, Paulownia, Robinia.

Bamarten, herrorragend durch Schnellwëchsigkeit, Holzmassenerzeugung: Populus deltoides, monilifera, suaveolens, 
trichocarpa, Paulownia imperialis; Sequoia gigantea, Picea sitkaënsis, Pseudotsuga Douglasii, Pinus Banksiana.

Holzarton zur Ausfüllung von Pilzlöehern in Nadelholzkulturon: Cladrastis, Prunus serotina, Querens rubra, Robinia.

Holzarten für Standorte, wolche vom Schüttopilz verseucht sind: Pinus lapponica, Föhren der Sektionen Murraya (wie Banksiana, Murrayana u. a.), der Sektionen Strobus und Crmbra; diese beiden bei besseren, frischeren Böden; abgesehen sei hier von auf solchen Böden anbaufähigen Laubhölzem.

Holzarten für Hochgebirgsaufforstungen: Pinus flexilis, aristata, Balfouriana, Tsuga Pattoniana, Pinus pumila.

Holzarten als Oberholz in Mittelwaldungen: Chamaecyparis-Arten, Cryptomeria, Larix-Arten, Libocedrus, Pinus der Sektion Cembra und Strobus, Psendotsuga-Arten, Sequoia; Acer saccharum, Carya alba, Catalpa, Cercidiphyllum, Juglans-Arten, Liriodendron, Magnolia hypoleuca, Paulownia, Phellodendron.

Holzarten, herrorragend durch Schattenerträgnis: Sciadopitys, Taxus-Arten, Thujopsis dolabrata, Acanthopanax, immergrüne Laubbäume.

Holzarten, hervorrageud dureh Stockaussehlagfähigkeit: Camellia, Carya alba, Catalpa, Cereidiphyllum, Cladrastis, Hovenia. Liriodendron, Magnolia hypoleuca, Paulownia, Robinia, Phellodendron.

Der vierte und fünfte Abschnitt dieser Schrift enthalten eine eingehende systematische, biologisehe und waldbauliche Beschreibung aller wichtigeren europäischen, amerikanischen und asiatischen Baumarten vom Lauretum bis zum Polaretum; aus diesen Abschnitten möge der Leser sich das forstliche Gesamtbild einer jeden Holzart zusammenfügen; er mag, im Falle ihm die kostbaren Gaben der Vorurteilslosigkeit und der Freiheit der Bewegung im Walde gewährt sind. eigene Versuche, wenn auch bescheidenen Umfanges, einleiten, wie dies so viele Wirtschafter im Walde bereits getan haben; fühlt er sich unsicher, und bedarf er einer Hilfe, so mögen vielleicht die im Eingang dieses Abschnittes zitierten Schriften als Führer dienen.

Alles, was bisher im vorliegenden Waldbau vorgetragen wurde, hat sich gleichmäßig auf Europa wie Amerika und Asien bezogen; in diesem Abschnitt mußte eine Trennung eintreten; denn was für Europa fremdländisch ist, ist für Amerika oder Asien heimisch: diese Weltteile dagegen nennen die europäischen Holzarten fremdländische. Es sollen hier nur die für Europa fremden Baumarten, und zwar solche von diesen behandelt werden, welche auf Grund bisherigen Studiums der Holzarten, ihrer Biologie, ihrer Heimat und auf Grund 
der bisherigen Anbauergebnisse ${ }^{1}$ ) als wertvolle Bereicherungen der spärlichen europäischen Waldflora zum Anbau empfohlen werden können; anch einiger europäischer, aber für mitteleuropäische Landschaften fremder Hlolzarten soll gedacht werden.

Bis hente müssen als die wichtigsten Einführungen im mitteleuropäischen Walde nachstehende Holzarten bezeichnet werden.

Pseudotsuga Douglasii (Carr.), die Küstendouglasie, auch grüne Douglasie genannt.

In Europa wird ihre Raschwüchsigkeit, in Westamerika die vorzügliche Holzqualität gerühmt. In den preußischen Staatsforsten ist der Anbau im Großbetriebe des Waldbaues angeordnet worden, in Bayern und den übrigen Staaten wird sie wenigstens geduldet; behandelt wie eine Fichte, jedoch nur auf gutem und tiefgründigem Boden, hat die Küsten- oder grüne Douglasie alle Erwartungen noch übertroffen; getäuscht hat sie nur jene, welche eine schnellwüchsige Douglasie anzubaien meinten, an ihrer Stelle aber die langsamwüchsige Art unter den Händen hatten. Je weiter ab ein Anbaugebiet vom Einfluß des Neeres liegt, um so mehr bedarf die grüne Douglasie eines leichten Schutzes von Halbschatten- oder Lichtholzarten, nicht so fast gegen verspätete Fröste (sie leidet durch solche ebenso wie die blane Art), als vielmehr gegen die schlimmste Gefahr in der. Jugend, zumal im Verpflanzjahr, das ist Beschädigung durch Herbstfröste (Düngung der Saatbeete deshalb nicht anzuraten) und Blattgrünt o d mit Nadelschütte, Knospen- und Gipfeltod durch s trenge Winterfröste. Vier bis sechs Jahre nach der Auspflanzung mag der Schutz beseitigt werden. Von der Meeresküste bis zu $300 \mathrm{~m} \mathrm{Erhebung}$ mag die grüne Douglasie zur Ausfüllung von Lücken und Kulturen Verwendung finden, von da an aufwärts ist ihre andauernde Vorwüchsigkeit gegenüber Fichte, Tanne, selbst Buche noch fraglich; die Aufzucht ist von jener der Fichte nicht verschieden; der Anban soll in reinen Klein- und Großbeständen erfolgen. Weitständig gepflanzt $(4-5 \mathrm{~m})$ erzielt sie in schottland nach $\mathrm{Schwappach}$ in $4: 2$ Jahren $27 \mathrm{~m}$ Höhe und einen mittleren Durchmesser von $4.7 \mathrm{~cm}$; in enger Pflanzung $(1,3 \mathrm{~m})$ in Freising bei Müuchen nach den Aufnahmen von Prof. Dr. Sehüpfer: Alter 23 Jahre, Boden mittelmäßig; mittlere

1) Prof. Dr. A. Schwappach in Zeitschr. für Forst- u. Jagdwesen; Prof. Dr. R. Hartig in Forstl. naturw. Zeitschrift; Prof. Dr. A. Cieslar in Zentralblatt f. d. ges. Forstw: : Prof. Dr. Lorey in Allgem. Forst- u. Jagdztg.; Prof. Dr. H. Ma yr in Forstwissenschaftl. Centralbl.; Prof. Dr. Somerville sowie die Publikationen der Royal English und der Royal Scotch Arboricultural Societies berichten aber englische, L. Pardé, Hickel, Fron uber französiche Anbauergebnisse. 
Baumhöhe 12,\$ m, mittlerer Durchmesser 11,1 cm, Schaftmasse $215 \mathrm{fm}$ pro Hoktar; Fichte würde auf demselben Standorte nur $40 \mathrm{fm}$ im gleichen Alter ergeben. Im Sachsenwalde stehen nach Oberförster Titze pro Hektar mit 29 .Jahren $407 \mathrm{fm}$, d. i. der doppelte Ertrag der Fichte. Im europäischen Optimum (Großbritannien) leistet die Douglasie nach den Mitteilungen der Royal English und Royal Scotch Arboricultural Societies mehr als jede andere Nutzholzart.

Pseudotsuga glauca (Mayr), die blaue Douglasie, auch Koloradodouglasie gonannt.

Daß sie anfänglich langsam wächst, ist ein Fehler in den Augen der Forstwirte und der modernen Forstwirtschaft. Allein vom zehnten L.ebensjahre an wird ihr Wuchs lebhaft, wenn sie auch nicht mit ihrer schnellwïchsigen Schwester oder mit der einheimischen Fichte Schritt zu halten vermag. Ihr Holz ist so wertvoll wie das aller Donglasien, in Güte am meisten der Lärche sich nähernd.

Je weiter ab vom Meere ihr Anbangebiet liegt, um so wertvoller wird diese Art, denn sie ist zwar ebenso empfindlich gegen Spätfröste wie die grüne Art, dafür aber ganz unempfindlich gegen tiefe Winterfröste; Nadelbräune, Knospen- und Gipfeltod sind bei dieser Art unbekannt. Sie ist die wertvollste Einführung in den zerklüfteten Waldungen des Binnenlandes bis in die Steppenregion. Man kann es niemand verdenken, wenn er in einem Gebiet, in welchem die grüne Art rasch emporeilt, die langsamwüchsige als wertlos bezeichnet; die Verallgemeinerung aber ist falsch. Verfasser sieht keinen Grund, von seiner Ansicht abzugehen, daß die langsamwiichsige Art ein sehr wertvoller Nutzbaum für Europa ist und für andere Kontinentalgebiete sein wird.

\section{Picea Sitkaënsis (Car.), Sitkafichte.}

Ursprünglich angebaut als Fichte, die sich gegen den Wildverbiß selbst zu schützen vermag, hat sie sich mehr durch ihre Wuchsgeschwindigkeit (während der ersten Dezennien wenigstens) als durch ihre Sicherheit gegen den Wildverbiß Beachtung verschafft. Es muß aber trotz allen gegenteiligen Behauptungen solcher Schriftsteller, welche bloß einen einzigen Standort kennen, daran festgehalten werden, daß die Sitkafichte überall, wo die europäische Fichte (excelsa) ursprïnglich heimisch ist, sich schlechter, weil frostempfindlicher während des Frühjahres (Spätfröste), und während des Winters (Nadelbräune, Gipfeltod) verhalten hat als die europäische Fichte, daß sie überall, wo die europäische Fich te nicht ursprünglich heimisch ist, das sind alle Standorte in Mitteleuropa unter $40 u \mathrm{~m} \mathrm{Elevation,}$ schnellwüchsiger ist als die europäische Fichte. Dort hat sie sich auf frischem bis feuchtem, selbst anmoorigem Boden bewährt, während sie 
auf gleichen Standorten über $400 \mathrm{~m}$ Elevation ohne einen Schutzbestand ron Erlen, Birken, Stroben u. a. wertlos ist.

$$
\text { Picea pungens (Engrlm.). Steehfichte. }
$$

Diese Fichte ist zwar auch anfangs langsamwüchsig, verbessert sich aber hierin ebenso wie die blane Douglasie: wie ist entschieden frosthärter als die Sitkafichte: ihre Nadeln sind zwar stechender, jedoch scheint sie ron den Rehen und Hirschen in erster Linie deshalb gemieden zu werden, weil sie in ihren Nadeln und Trieben gleich der Picea alba und Picea Engelmannii einen die Tiere abstoßenden Geruch in sich trägt. Dadureh dürfte ihr. Wert noch größer sein als der der Sitkafichte.

\section{Picea alba (Link.), Weißfichte.}

Als Nutzholzart augenscheinlich ohne Wert, hat sie sich als Schutzholzart, als Windbrecherin besonders in Dänemark als unentbehrlich erwiesen.

\section{Pinus Strobus (I.), die Weymouthsföhre, Strobe.}

Daß man die fünfnadeligen Föhren, wie die Stroben und Zürbeln, nicht wie zweinadelige Föhren (silvestris, austriaca) behandeln dürfe. ist allmählich Gemeingut aller Forstwirte geworden; aber immer noch gibt es Anbaurersuche mit Stroben auf schlechten, trockenen, sandigen Böden dritter und geringerer Güte, auf denen die Weymouthsföhre ihren Feinden nicht entrinnen kann. v. Wangenheims Empfehlung 1787 , der auf Grund seiner Studien in Nordamerika schrieb, daß sie in „Lehmböden mit Sand, Gartenerde oder Humus vermischt, auf lockeren, "her feuchten als trockenen Böden" angebaut werden soll, hat man zu Anfang des vorigen Jahrhunderts gefolgt; aus dieser Zeit sind sehr schöne haubare Bestände in Deutschland vorhanden; erst die letzten Jahrzehnte haben wieder zur richtigen Wertsehätzung and zur richtigen waldbaulichen Behandlung der Stroben zurückgeführt. Die Strobe verdient den weitgehendsten Anbau wegen ihrer waldbaulichen Vorzüge (leichte Verpflanzbarkeit, Frosthärte, bessere Widerstandskraft gegen Schneedruck und Schnechruch, gegen Sturm, Raschwïchsigkeit, Bodenverbesserung. Schattenerträgnis) und wegen ihres rom Holze der europäischen Arten verschiedenen Holzes; das Holz junger Bäunchen ist selbstverständlich minderwertig wie bei allen Holzarten, da der Anteil des Keruholzes gering; im erwachsenen Banm ist das Holz dem der Zirbe völlig gleich, dessen Güte niemand bezweifelt. Thre Verwendung in kleinen Reinbeständen auf frischem, feuchtem Boden, auf Föhrenboden I.-III. Bonität, als Unterbau unter Lichtholzarten ist vollauf gerechtfertigt: gerechtfertigt aber auch die Auslagen für den Schutz gegen den schlimmsten Feind, das Wild. Gegen den 
zweitgrößten Feind, den Wurzelkrehs Agaricus melleus, schützt noch am besten die Staffelpflanzung mit /wischenban von Frlen, Birken odor Sträuchern und stetiger Überwachung dersollen mit schere und Axt bis zum Dickungsichluf, in welehem Alter dic /wischenbäume fall'n können.

\section{Pinus Bankiana (Lamb.), Banksföhre.}

Nach allen Berichten scheint die Banksföhre auf geringen und goringsten Sandböden wie auf nassen, sumpfigen, anmoorigen Böden in schlimmster Frostlage Besseres zu leisten wie die einheimische silvestris ; sie ist völlig frosthart, meidet aber nassen Tonboden; auf solchen Büclon wird ihr Gipfel frühzeitig gelb und stirbt ab. Ihre aufwärts gerichteten Äste, ihre kurze Benadelung sichern sie gegen sichneebruch. In sumpfigen Frostlagen gibt es keine Föhre mit spärlicherer Beastung, ihre gelbliche Färbung während des Winters ist besonders auffällig, aber kein Zeichen der Erkrankung, da sie dabei schnollwüchsig bleibt. Als Torbauholzart auf solchen Örtichkeiten mit späterem Unterbau einer Fichte ist sie hochwertig, da bei ihr die Aufästung des Vorwaldes wegfällt. Legende ist, daß ihr Holz grobfaseriger sei als jenes der Silvestris, Legende, daß sie nur ein strauch wird. I)ie Bankstöhren ron Grafrath sind jetzt 2.jährig mit $10 \mathrm{~m}$ Höhe und tadellos geradem, einheitlichem Schafte; in Gartenland (Park) freistehend gepflanzt, fängt sie buschartig an wie viele andere Föhren auch: in Amerika wird sie $25-35 \mathrm{~m}$ hoch. Die Banksföhre ist sehr leicht zu verpflanzen, für (̈)dlandsaufforstungen, als Anstüllıng in Föhrenkulturen oder als Hauptholzart auf schlechtem Sandboden; zur Beimischung (Mengesaat) auf Kahlflächen mit großer Schüttegefahr verdient sie woitgehendste Verbreitung; sie leidet nicht durch die Schütte, wenig durch Knospenwickler, stark unter Wildverbiß.

Pinus austriaca (Höss.), die österreichische Schwarzföhre, ist in allen ihren Eigenschaften als warme, kalkreiche Lagen liebende Holzart wohl bekannt: sie leidet jedoch sehr durch Schneedruck und Schneebruch, so daß ihr Anbau im mittleren Europa nur bei Elevation bis zu $400 \mathrm{~m}$ sich empfiehlt: von da an aufwärts kann die schönschaftige, kurz benadelte, gegen Verbif gesicherte und ebenfalls frostharte Pinus corsicana, die korsische Schwarzföhre, an ihre stelle treten auf allen buchen- und fichtenmüilen, auf allen kiesigen, sandigen Böden; beide sind in großen Gruppen oder Reinbeständen anzulegen.

Tsuga canadensis (Carr.), die kanadische Tsugc oder Schierlingstanne, Tsuga heterophylla (Sar!.) syn., M I rten siana (Cur.), westamerikanische Tsuge.

sind zwei Baumarten, deren Gattung im europäischen Walde vollständig fehlt. Sie bilden prächtige Bestände von wertvollem, dauerhaftem, in 
Europa unbekanntem Holze und enthalten große Mengen von Gerbstoff in der Rinde; diese Gründe sind groß genug, um ihren Anbau im Walde unter gleichen Verhältnissen, wie bei den Douglasien erwähnt, zu betätigen. Die Pflanzung in großen Gruppen oder reinen Kleinbeständen bietet keinerlei Schwierigkeit.

Robinia Pseudoacacia (L.), Robinie, falsche Akazie.

Die Heimat dieses allbeliannten, hochwertigen Baumes ist das Castanetum von Ostamerika; dort ein seltener Baum, verdankt die Robinie ihrer wohlriechenden Blüte die Einführung in Europa und weitere Verbreitung. Inzwisehen ist sie einer der wichtigsten Laubbäume aus der Fremde geworden. Nur soweit Eichennutzholzzucht betrieben werden kann, also im milden Klima, kann auch mit der Robinie ein nutzbringender Niederwald auf geringwertigem, kiesigem, sandigem Boden angelegt werden. Auch als Oberholz im Mittelwald verdient die Robinie die größte Beachtung. Für Hochwald ist besserer Boden beansprucht. $\mathrm{Vadas}{ }^{1}$ ) empfiehlt in seiner nenen Schrift die Robinie als erste Generation nach heruntergekommenen Laubwaldungen; in Mischwaldungen ist die Robinie zehn Jahre vor dem Hieb der übrigen Holzarten zu fällen, um andere Holzarten vor der Erdrückung durch Robinienaussehlag und Wurzelbrut zu sichern. Zur Aufforstung der Steppe in Ungarn und Rußland als eine der besten Holzarten erkannt, hat sie auch im Föhrenwalde Wert zur Ausnutzung und Verbesserung der geringsten Bodenarten, zur Ausfüllung von Pilzlöchern und dergleichen; der Anbau geschieht durch Saat oder Pflanzung; Schutz gegen Hasen, Kaninchen und in der Nähe der Stadt auch gegen Menschen ist notwendig.

\section{Juglans nigra (L.), sehwarze Walnuß.}

Der Beschreibung der Nußarten im VI. Abschnitt ist hinzuzufügen, daß der Anbau in reinen Kleinbeständen oder großen Gruppen geschehen soll; ein späterer Unterbau mit Buchen wird notwendig sein; nur im Castanetum und wärmeren Fagetum auf bestem Boden kommt ein Anbau in Frage. Es mag Aussaat der Nüisse auf platz- oder streifenweise tief bearbeiteten Böden. Auspflanzung angekeimter Nüsse oder auch Pflanzung gewählt werden. Forstrat E. Böhmerle ${ }^{2}$ ) befürwortet wegen Schwierigkeit dor Pflanzung und Wachstumsstockung die Saat unmittelbar im Walde; nigra ist der regia vorzuziehen. Staffelpflanzung nach Forstmeister $\mathrm{Rebmann}{ }^{3}$ ), der langjährige Erfahrungen in ausgedehnten Kulturen gesammelt, in 4-5 m Abstand. Das Zurückfrieren in kalten Wintern, besonders im ersten Winter nach der Pflanzung, ist

1) Vadas, Forstliche Versuche (Ungarn). 190s.

$\left.{ }^{2}\right)$ Waldbauliche Studien uber den Nußbaum und die Edelkastanie. 1906.

3) Allgem. Forst- u. Jagdztg. 190:3. 
weniger auf geneigten als auf ebenen Kahlflächen zu fürchten. Juglans Sieboldiana (Maxim.), Siebolds Walnuf aus Japan scheint noch rascher zu wachsen und frosthärter zu sein als die amerikanische, schwarze Nuß.

\section{Carya alba, weiße Hickory.}

Wendet man dieser ausgezeichneten Holzart, welche das elastischste Nutzholz unter den Laubbäumen erzeugt, jenes Interesse zu, das sie verdient, so empfiehlt sich ihr Anbau durch Saat in Reinbeständen als Niederwald oder als Hochwald in kleinen Reinbeständen und großen Gruppen in gleichen Klimalagen wie bei den Walnüssen; auch als Oberholz im Nittelwald ist die weiße Hickory hochwertig, doch bedarf die Pflanze wegen ihrer langsamen Jugendentwicklung einiger Fürsorge gegenüber den Ausschlägen des Unterstandes im Mittelwald. Die Auspflanzung ist wegen der sehr langen, weichen, saftigen Wurzeln mit sehr spärlichen, feineren Wurzeln schwierig. Für die Saat soll stets der Boden tief und kräftig bearbeitet werden. Schwappach ${ }^{1}$ ) verlangt lockere Pflanzung, da in engem Schlusse die Pflanzen wegen dichter Belaubung schlanker wachsen und durch Regen leicht umgedrückt werden.

Quercus rubra (L.), Roteiche.

Da diese Art schneller wüchsig ist als die europäischen Weißeichen, da sie mit weniger gutem Boden vorlieb nimmt, mag die Roteiche auf Böden angebaut werden, welche eine rentable Eichenzucht nicht mehr ermöglichen; ihr Holz ist immerhin ein Eichenholz von ähnlicher, aber nicht von gleicher Güte wie jenes der Weißeichen. Für die Faßdaubenindustrie ist das Roteichenholz unbrauchbar; geringer ist auch die Dauer des Holzes, und für eine gewinnbringende Schälwirtschaft enthält die Rinde der Roteiche zu wenig Gerbstoff. Anlagen in Gruppen oder kleinen Reinbeständen auf Föhrenböden III., Fichtenböden II. und III., Buchenböden II., III. bis IV. Bonität auf kiesigem Boden; nach den bisherigen Ergebnissen in Grafrath selbst in Lagen, welche den Weißeichen bereits zu kühl sind. (Geh. Obertorstrat Frey ${ }^{2}$ ) empfiehlt die Roteiche zur Nachbesserung in Kulturen mit Weißeichen.

Als frostharte Holzarten von schnellstem Wuchs verdienen melirere Pappelarten, wie Populus deltoides (Marsh) (syn. Canadensis), P. monilifera (Ait.) und andere Balsampappeln, Beachtung. Ha usrath ${ }^{8}$, Hartig, Zircher u. a. berichten über außerordent-

1) Prof. Dr. Schwappach, Deutsche Forstzeitung 1907.

2) Zeitschr. f. Forst- u. Jagdw. 1905.

$\left.{ }^{3}\right)$ Dr. Hausath berichtet in Forstwissenschaftliches Centralblatt 1s96: Mit 31 Jahren $2.99 \mathrm{fm}$ pro Baum. 
liche Leistungen; $\mathrm{zu}$ diesen sind aber gute, frische Auböden im Inundationsgebiete der Flüsse notwendig. Stagnierende Wasser sind stets zu meiden ${ }^{1}$ ). Das Holz der von der Forstwirtschaft systematisch unterdrücliten Pappeln ist dureh die Papier-, Zündholz- und Möbelindustrie wertvoll geworden., Ihr Anbau kann durch Pflanzung bewurzelter Stecklinge, seltener durch Setzstangen erfolgen. In neverer Zeit hat man die Aufzucht cler Pappeln im Forstgarten ans Samen mit Erfolg durehgeführt: über die Saat mit Pappelsämereien wurde früher die nütige Andeutung gegeben. Forstrat Hofmann hat die Saat zuerst mit Erfolg gehandhabt.

Der '/uekerahorn, Acer saccharum (Marsh), sollte wegen des Zuckergehaltes des Saftes als Schatten-, als Allee und als Waldbaum weitgehenden Anbau finden; er ist dem Spitzahorn in Behandlung und Verhalten gleich. Von europäischen Holzarten verdienen wiederholte Empfehlung:

Taxus baceata (L.), die Eibe. Nahezu ausgerottet, ob ihres vorzüglichen, rotbraunen Nutzholzes, verschmäht von den Forstwirten, weil sie sehr langsam wächst, ist die Eibe im ganzen kontinentalen Europa im Aussterben begriffen. Conventz hat eine vorzügliche Monographie über die Eibe verfaßt; Zweck dieser Zeilen ist, der Eibe wiederum eine Stätte im Walde zu verschaffen und sie trotz ihrer Langsamwïchsigkeit zu empfehlen als Unterbau unter Lichtholzarten an Stelle der Rotbuche; unter Eichen, Föhren und Lärchen ist sie gegen Frost gesehützt, auf der Kahlfäche aber leidet sie, besonders durch Nadelbräune und Abfrieren des Gipfels im Winter.

Die beiden europäisehen Zürbeln, die Alpenzürbel und die sibirische Z/ürbel (Pinus Cembra [L.] und Pinus sibirica [Mayr]), verdienen Anbau auf kahlen, frostigen, auch anmoorigen bis sumpfigen Flächen, für welche auch die Weymouthsföhre oder Erle als Bestockung passen würden; beide Holzarten eignen sich sodann wie Eibe zum Unterbau unter den Lichtholzarten.

Die europäische Hackenföhre, Pinus uncinnata (Riamcl.), ist ein vorzüglicher Baum für Festigung der Dünen, für die Aufforstung der sumpfigen, frostreichen Einsenkungen und kann auf Fehlstellen der einheimischen Föhre zur Ausfüllung neben der Banksföhre dienen. P. E. Mïller weist anf' den wohltätigen Einfluf dieser Misehung hin; auf' besseren Böden und im wärmeren Picetum wird die Hackenföhre ein Baum bis zu $25 \mathrm{~m}$.

Auf einige fremde Holzarten soll hier noch dip Aufmerksamkeit gelenkt werden; sie sind noch nicht lange genug geprüft, um ihre Vorteile oder ihre Anbanfähigkeit sicher zu kemen; Verfasser muß auf

1) Hauptmann Kern, Deutsche Forstztg. 1902. 
die ansführlicheren Angaben seiner im Eingang dieses Abschnittes zitierten Schrift hinweisen. Es wird verwundern, daß zu dieser Gruppe der Fremdländer Larix leptolepis (Gord.), die japanische Lärche, nicht gerechnet ist.

Dieser Modeliebling der Forstwirte hat von seinem Nimbus bereits viel eingebüßt, seit dem Verfasser der Nachweis gelang (18!16), daß die japanische Lärche im zweiten Lebensjahrzehnte gegenüber der europäischen im Wuchs zurückbleibt, daf sie somit, zur Ausbesserung von Fichten- oder Buchenkulturen benützt, noch rascher als die einheimische Lärche in ihrer Umgebung untertauchen wird. Es bleibt höchstens noch der Vorzug, daf die japanische Lärche etwas weniger von Insekten und bis heute so gut wie gar nicht vom Lärchenkrebs leidet. Ihr allenfallsiger Anbau ist mit der einheimischen Lärche Seite 441 bereits besprochen.

Die sibirische Lärche, Larix sibirica (Leel.), ist zwar anfangs langsamer wüchsig - was bei Anlage von reinen Kleinbeständen weniger bedenklich ist als bei Einmischung mit anderen Holzarten -, aber ihr Schaft ist am erwachsenen Baume und, wie die bisherigen zehnjährigen Versuche des Verfassers gegenüber der europäischen und japanischen Lärche bereits erkennen lassen, so tadellos gerade, daß sie dennoch empfohlen werden muß.

Von den Chamaecyparis-Arten, insbesondere von Law sons S cheinzypresse (Cham. Law soniana [Parl.]) sind auf guten Böden in milden Lagen bereits so hoffnungsvolle Kleinbestände und Gruppen vorhanden. daß diese Holzart, welche ein vorzügliches, wohlriechendes, feines, dauerhaftes Nutzholz gibt, nicht mehr aus dem europäischen Walde verschwinden sollte.

Die Gattung Thuja zählt zu den ihrigen eine sumpfige, kalte Erlenörtlichkeiten bewohnende Art (Thuja occidentalis $[L$.$] , der ostameri-$ kanische Lebensbaum) und eine zweite Art, welche ebenfalls sehr bodenfrische Lagen, aber weniger kalte, der Esche und Ulme zusagende Lagen bevorzugt, Thuja gigantea (Nutt.), die Riesenthuja von Westamerika. Beide Arten geben hochwertiges Nutzholz.

Thujopsis dolabrata (Sieb. et Zucc.), die japanische Hiba, und Sciadopitys verticillata (Sicb. ct Zucc.), die japanische Schirmtanne, sind zwar zwei sehr langsam wachsende, Schatten ertragende Nadelbanmarten, die sich aber dennoch empfehlen als Unterbau unter Lichtholzarten (Eiche, Föhre, Lärche) und als kleine Rein. bestände wegen ihres vorzüglichen Holzes.

Im Castenetum von ganz Südeuropa, im gleichen Klimagebiete des westlichen Mitteleuropa und auch in den wärmsten Lagen des Fagetums des übrigen Vitteleuropa sollten als Hauptnutzholz neben den 
spärlichen and mangelhaften, europäischen Nutzarten folgende Waldbäume zum Anbau gelangen:

Catalpa speziosa (Ward.), westlicher Trompetenbaum, wegen seines sehr dauerhaften Holzes.

Liriodendron tulipiferum (L.), Tulpenbaum, wegen des sehr schön gefärbten, gleichmäßig gewachsenen, mittelharten, danerhaften Holzes, das als Blindholz alle übrigen Baumarten übertrifft.

Magnolia hypoleuca (Sieb. et Zuce.), Homagnolie, eine im wärmeren Fagetum noch winterharte Magnolie mit gleichem Holze wie Liriodendron.

Paulownia imperialis (Sieb. et Zucc.), Paulownie, mit einem ganz eigenartigen, der vielseitigsten Verwendung fähigen, außerordentlich leichten und weichen Holze.

Prunus serotina (Ehh.) und Prunus Shiuri (F. Schmidt). Traubenkirschbäume, mit wertvollem, rotgefärbtem Kernholze; sie mögen auf geringeren kiesigen oder sandigen Böden angebaut werden.

Zelkowa Keaki (Sirb.), Keaki, aus Japan ist ein sehr raschwïchsiger, hartes, wertvolles Nutzholz liefernder Baum und verdient sicher Verbreitung auf nahrungsreichem, tiefgründigem Boden.

An Nadelholzarten besitzt Süd- und Westeuropa vielfach nur forstlich minderwertige Föhren oder Zypressen; wo der Boden eine andere Holzart nicht duldet, mag natürlich die bereits vorhandene Föhre neben einer fremdländischen, wie z. B. Pinus palustris, bleiben; für die besseren Böden aber, die noch lange nicht alle in landwirtschaftlichen Besitz übergegangen sind, sollten im ausgedehntesten Umfang fremdländische Nadclbäume, in erster Linie Cedrus atlantica (Man.), a tl antische Zeder, Cryptomeria japonica (Don.), Kryptomerie, und Juniperus virginiana ( $L_{\text {. }}$, , der Bleistiftwacholder, zum Anbau gelangen; sie sind alle hochwertig, für das kontinentale Fagetum jedoch, somit ganz Deutschland, zur Nutzholzproduktion, welche andere Anforderungen an eine Pflanze stellt, als daBsic nur als Zierbaum aufwächst, kaum melır geeignet. 


\section{Vierzehnter Abschnitt. Ödlandsaufforstung.}

Von der nachfolgenden Abhandlung sind ausgeschlossen alle jenen kahlen Flächen, welche Naturereignisse, wie Insekten oder Wind, verschuldet oder betriebsmäßiger Kahlschlag hervorgerufen haben; ausgeschlossen sind sodann alle Blößen im Walde, ob sie vergrast oder versumpft seien, ob sie alter Herkunft oder erst durch einen falschen Kahlhieb (Frostlöcher) entstanden und wegen allzu großer Schwicrigkeit der Wiederbewaldung seit Jahren der Vergrasung überlassen seien; sie alle in Wald zurückzuführen, ist nur eine Frage des Geld- und Zeitaufwandes; die Verjüngungsmethode (zumeist Pflanzung mit dem stärksten Material) bietet nur mechanische Schwierigkeiten. Es muß aber nachdrücklich mit Jankowsky ${ }^{1}$ ) und anderen betont werden, daß die Aufforstung solcher begraster Blößen durchaus nicht immer wünschenswert ist; Wiesengründe rentieren vielfach höher als Wald, und versumpfte Stellen sind wichtiger als Wasserbehälter für die Umgebung und das tiefer liegende Waldland denn als schlecht rentierende und kostspielige, sogenannte "Meliorationen". Wer der Ästhetik im Walde eine hervorragende Bedeutung zuerkennt, muß gerade auf die Erhaltung der Waldblößen und Waldsümpfe das größte Gewicht legen. Das Ödland, von dessen Aufforstung hier die Rede sein soll, ist soit Jahrhunderten ein solches. An seine Aufforstung soll erst dann gegangen werden, wenn die Frage, ob durch die Umwandlung in Wald ein Gewinn finanzieller oder klimatischer oder wirtschaftlicher Art erreichbar ist, gelöst ist. Kann dieses bejaht werden, so ist für die Umwandlung in Wald, für die Wahl der Holzart, der Kulturmothode, der ferneren Bewirtschaftung von grundlegender Bedoutung, daß man die Ursache der Entstehung und des Fortbestehens des Ödlandes erkennt. Hierbei behilflich $\mathrm{zu}$ sein, ist das Ziel der Feststellungen über die naturgesetzlichen Existenzbedingungeu der Waldungen im ersten Teil dieser Schrift. Im kurzen Auszug sei hier wiedorholt:

1) J ankowsky, Begrındung naturgemäßer Hochwaldbestiinde. 3. Aufl. 1904. 
1. Vergleicht man die Fläche, welche waldlos aus natürlichen Ursachen ist, mit jener, deren Waldlosigkeit der Tätigkeit des Menschen zugesprochen werden muß, so ïbertreffen die Ödflächen, von welchen einstens der Mensch den Wald beseitigt hat, an Umfang längst jene Flächen, welche aus natürlichen Gründen der Ansiedelung von Bäumen unzugänglich waren. Alle Ödländereien in $\mathrm{nerhalb}$ der $\mathrm{ach}$ Waldregionen dernördlichen II albkugel sind Menschenarbeit, Arbeit der Axt und des Feners: alle (̈)dländereien, welche außerhalb oder zwischen den Waldregionen liegen, sind natürlichen Ursprungs. Zu den Werken des Menschen gehören die Ödländereien der Nittel- und Hochgebirge; Europa und Japan forsten dieselben auf: Amerika schafft einerseits umfangreiche neue Ödländer, beginnt anderseits alte mit Wald $\mathrm{zu}$ versehen; China konserviert sein ungeheures Ödland in untätigem Gleichmut. Hierher zählen sodamn die Sandflächen des Binnenlandes, die in Waldgebiete vorspringenden, aus dem Walde herausgeschlagenen oder herausgebrannten Steppen oder Prärien, die Karste, Heideflächen, ja selbst viele Sümpfe und Moore. Den Aufforstungen aller dieser Ödländereien stellen sich keine naturgesetzlichen, nur mechanische Hindernisse entgegegen, freilich stellen sie hohe Anforderungen an Zeit, Geld und waldbauliche Kunst.

2. Im ersten Teil dieser Schrift wurde festgestellt, daß alle Ländereien der nördlichen Halbkugel, auf welchen während vier Monaten (Mai, Juni, Juli, August) weniger als $50 \mathrm{~mm}$ Niederschläge fallen, waldlos sind, auch wenn die relative Feuchtigkeit über $50 \%$ während derselben Zeit liegt, daß ferner Steppe herrscht, wenn zwar die Niederschläge reichlicher sind, aber die relative Feuchtigkeit unter $50 \%$ herabgeht. Für solche Flächen genügt es, den Wald e in mal auf künstlichem Wege zu begründen, damit er sich selbst erhalte durch seine Eigenschaft, mit den zum Boden gelangenden Niederschlägen haushälterisch umzugehen. Liegen aber in einem Gebiet sowohl Niederschläge als Luftfeuchtigkeit während derselben Zeit unter den angegebenen Minimalbeträgen, so kann nur eine dauernde Bewässerung Wald begründen und erhalten; fehlt diese Möglichkeit, so fehlt naturgemäß die Möglichkeit einer Aufforstung.

3. Wald fehlt in allen Gebieten, in welchen die Durchschnittstemperatur der vier Monate Mai, Juni, Juli, August unter $10^{\circ} \mathrm{C}$ herabsinkt; das ist die alpine oder auch die polare Grenze des Waldes; über dieser oder nördlich von dieser noch einen Wald, z. B. mit einer fremden Holzart, begründen zu wollen, ist ein nutzloses, weil naturwidriges Beginnen.

4. Sumpfige Gebiete sind waldlos, wenn ein Überschuß an Wasser rorhanden, wie bei jenen, welche erst in der Umwandlung aus seichten Wasserbecken in Sumpf und in Wald begriffen sind; daß Waldgebiete durch die waldvernichtende Tätigkeit des Menschen wieder versumpfen 
können, wurde schon oben und im ersten Teile dieser Schrift angedeutet. Aus natürlichen Gründen sind sodann waldlos odor doch haumarm die Hochmoore. Sic in Wald unzurandeln, verlangt die tiefsten Eingritte gegen die das Hochmoor immor mehr vergrößernden und erhöhenden Faktoren.

j. Waldlos aus natürlichen Gründen müssen allo (rebiete sein, deren Obertlächen von Winden in Bewegung gehalten werden, wie Flugsandbildungen des Bimenlandes und der Küiste.

i. Auch das mitten in WTaldregionen gelegeno Ödland, das Dezennien hindureh anderen Zwecken (Viehweide, Getreidebau, Wiese) gedient hat, soll hier einbezogen werden. Wiesen und Ackerland ausgoschieden, berechnet Dr. (Frie ${ }^{1}$ ) das europäische (idland auf 2.200() (Quadratmeilen, das deutsche allein auf 3,7 Mill. Helitar.

Das Ödland der Mittelgebirge. Als Tiehweide, insbesondere für Schafe und Rinder benutzt, gibt es meist geringe Erträge. Seine Aufforstung ist nicht schwierig, eine Festigung des Geländes, Verbauung der Wasserrisse meist entbehrlich: Oberforstmeister Ney will nur die Hänge in Wald umwandeln, die Kuppen und Hochplateaux aber als meistens gute Erträge liefernde Weiden- und Wiesentlächen erhalten wissen. Die Eifel ist mit Fichten und Föhren wieder autgeforstet; die Rhön soll mit Tannen, Lärchen und Fichten zu WVald werden; sicher wäre auch Pinus uncinnata rorteilhatt. Das Üdland der Auvergne, nach den Augaben von Dr. Fankhauser ${ }^{2}$ ) 25001 ha groß, wird mit der in der Auvergne heimischen Föhre (Bastard der Auvergne nach Ansicht des Vertassers) in Wald umgewandelt: die größte Schwierigkeit ist der Widerstand der Bevölkerung. Die schwäbische Alb erhält auf schwächeren Böden Schwarzföhre und einheimische Föhre, auf besseren die Fichte und Lärche; als Laubholz sind Weißerle, Togelbeere, Mehlbeere, Linde und Robinie benützt. Das Kallödland wird durch Vorbau mit obigen Holzarten, wozu auch die Bastardföhre der Auvergne zu versuchen wäre, bepflanzt: auf Kalksteinböden, besonders reinem Kalk und Dolomit, wo nach H. von Li burna u ${ }^{3}$ ) die Weide die nachteiligsten Folgen zeigt, wären auch Rot- und Weißbuche zu verwenden. Steile Hänge und Berghuppen im Gebicte des .Jura, des Buntsandsteines, des Plänerkalkes zu bewalden, setzt roraus, daß auf der Südseite des Berges in horizontalen Streifen vou unten, auf der Nordseite von o ben begonnen wird: dadureh wird die Neukultur auf der Südseite an den Nordrand der alten sich ansehließen und an erhöhter Bodenfeuchtigkeit gewimnen : die Aufforstung geschieht am sichersten mit starken Ballenpflanzen.

1) Dr. Grieb, Das europäische Ödland, seine Bedeutung und Kultur. 1słฬ.

\#) Dr. Fankha user, Das Ödland der Auvergue. Schweiz. Zeitschr. f. Forstwesen $190 \%$.

8) Österreich. Vierteljahr'sschr. 1ऽ96. 
Das Ödland des Hochøebirges. Glänzende Ergebnisse weisen anf diesem Gebiet der Auftorstung Südfrankreich, die Schweiz und Tirol auf. Großen Schwierigkeiten begegnet die Verbauung der Wildbäche, die Festigung des Geländes, die Aufforstung des Einzuggebietes der Wildbäche (Pcrimeter). Hauptholzarten sind Arve oder Zürbel als beste, dann Fichte, Lärche, auch die Hackenföhre (uncinnata): fremdländische Arten sind im XIII. Abschnitt genannt. Eblin ${ }^{1}$ ) betrachtet das Gebiet der Alpenrose als ehemalige Waldfläche, welche somit wieder. Wald werden kann. Professor Engler ${ }^{2}$ ) sagt: "Völlige Sicherheit gegen Lawinen gibt nur der gut bestockte Plenterwald"; wo Bauten notwendig seien, soll man permanente, nicht hölzerne aufführen. Zur Erzielung der Ungleichaltrigkeit soll Vorwuchs benutzt werden; unter der Alpenerle erscheine reichlich Fichte; Pflanzung in Trupps von 3-5 Pflanzen, Abstand der Trupps 2-4 m. Engler verlangt bei Hochgebirgsanfforstungen mit Fichte die Abstammung der Pflanzen von Hochgebirgsfichten, da für die Aufforstung günstige Eigenschaften erblich seien; es bedarf noch der Angabe, bei wolcher Erhebung die Hochgebirgsfichte beginnt, die Tieflandsfichte endet; im bayerischen Hochgebirge werden mit bestem Erfolge Fichtenpflanzen verwendet, welche von irgendwelchen Fichten abstammen und im Tieflande zu liräftigen Exemplaren erzogen werden. Über die Aufforstung im Hochgebirge Südfrankreichs hat P. Demontzey ein klassisches Werk geschrieben: "Traité pratique clu reboisement et du gazonnement des montagnes", (übersetzt von A. von Seckendorł 1880). Um der Abwärtsdrückung der Pflanzen durch den tanenden Schnee entgegenzuwirken, empfiehlt $\mathrm{Coaz}^{3}$ ) die Nischenpflanzung mit einem gegen den Berg hin gesenkten Pflanzloch und einen Stein am Fuß der Pflanze. Es wäre zu prüfen, ob nicht fremdländische Baumarten (XIII. Abschnitt) benutzt werden kimnten.

Karste. Bald durch Schaf-, bald durch Ziegenweide, bald durch Fener, Kahlschläge, Strounutzung entstandene und in diesem Zustande fortbestehende Entwaldungen, vorwiegend in Kalkgebirgen, nennt man Karste. Da in verkarsteten Gebirgen ganz schlechte bis sehr gute Böden wechseln, muß anch eine größere Fülle von Holzarten angebaut werden, um zu verhindern, daß eine oder einige Holzarten das Übergewicht erhalten. Es wäre für die spätere Behandlung, für allenfalsige Kalamitäten von Wichtigkeit, so vicl als möglich kleine Reinbestände mit zahlreicher Abwechslung in den Holzarten zu begründen. Als Hauptholzarten, welche vorwiegend ausgepflanzt werden, kommen zur An-

1) Schweiz. Zeitschr. 1901.

2) A. Engler, Über Verbau und Aufforstung von Lawinenzügen. Zeitschr. f. d. ges. Forstw. 1907.

$\left.{ }^{3}\right)$ Oberforstinspektor Coaz, Schweiz. Zeitschr. f. Forstw. 1903. 
wendung die Schwařföhre (Pinus austriaca), die Paroliniföhre (Pinus pyrenaica), die gewöhnliche Föhre. Fichte, Lärche, Weißerle, Hopfenbuche, Blumenesche, sodann Robinie, Acer Negundo (violaceum), Eiche, selbst Edelkastanie, wenn Klima und Bodenverhältnisse dieses gestatten. Hierzu kommen noch fremdländische Baumarten, deren empfehlenswerteste im vorigen Abschnitte erwähnt wurden. Eine umfangreiche Literatur, vorwiegend in österreichischen, forstlichen \%eitschriften, gibt über den Fortgang dieser Arbeit im österreichischen Karst regelmäßige Aufsehlüsse. K. R u b b i a bezeichnet die Verbesserung des Bodens durch möglichst raschen Bodenschutz und Bestandesschluß als erste Aufgabe, die zu enger Pflanzung führt: die Saaten sind zumeist erfolglos gewesen. Die Schwarzföhre entspricht am besten: sio ist dort einer Halbschattenholzart gleich; in höheren Lagen dient sio als Vorwald für Tanne und Fichte. (Mitteilungen an den VIII. internationalen Kongreß zu Wien 1907.)

Heideflächen. Auf allen Flächen, auf welchen an Stelle des Waldes Heide (Calluna vulgaris) getreten ist ${ }^{2}$ ), hat der Boden weitgehende Umgestaltung durch sie erfahren: ihre abgestorbenen Wurzelund Stengelteile verwittern außerordentlich langsam zu einem saner reagierenden, mit Sand vermischtem Rohhumus, unter welchem meist eine ausgebleichte Sandschicht (Bleichsand) liegt. Vielfach schreitet die Bodenverschlechterung noch weiter fort, indem unter dem Bleichsand die in die Tiefe geführten, humosen Lösungen den Sand zu Ortstein zusammenkleben, wie P. E. Müller und Ramann nachgewiesen haben. Ist die Heide erst spärlich vertreten, mit nacktem, lockerem Boden zwischen den Büschen, damn kann ohne weitere Bodenbearbeitung an die Aufforstung getreten werden: als Holzart kommt bei magerem Boden wohl die einheimische Föhre in erster Linie in Betracht; das schließt aber nicht aus, daß es auch unter den übrigen europäischen oder auch amerikanischen und asiatischen Föhren noch Holzarten gilut, die der einheimischen hierin überlegen sind, da das Heidegebiet auch für die einheimischen ein Neuland, eine Fremde ist. Es ist höchst wahrscheinlich, daß fremde Heideaufforstungsholzarten, z. B. die Sitkafichte, Pungensfichte, Besseres leisten als die mitteleuropäische und nordische Fichte, welche auf den Heidefläehen ebenso Fremdling ist wie ihre amerikanischen oder asiatischen Schwestern.

Auf der dänischen Heide ${ }^{2}$ ) hat sich bereits die Picea alba. die amerikanische Weiffichte, als Windbrecherin viel wertvoller rezeigt als die europäische Art excelsa. Man pflanzt auch die europäische Lärehe

1) Dr. Grieb, Das europäische Odland, seine Bedeutung und Kultur (1\&94), sagt, daß die Luneburger Heide vor 200 Jahren noch mit Eichen bewachsen war.

${ }^{2}$ ) Dr. Netzger, Einiges uber die Heide in Jutland und deren Aufforstung. Mandener forstl. Hefte $1 \varangle 98$ 
an; sie ist dort ebenso fremd wis eine amerikanische oder asiatische Art: wenn es ein Gebiet gibt, in welchem eine Prüfung der fremden Holzarten in erster Linie geradezu ein Gobot der Pflicht und Notwendigkeit ist, so sind es die Heideflächen. Eine andere für die dänische Heide völlig fremde Holzart ist die Hackentöhre, Pinus uncinnata, welche durch Zufall nach Dänemark kam; sie hat sich so vortrefflich bewährt, daß man jahrzehntelang glaubte, sie müßte eine amerikanische Holzart sein und nannte sie Pinus inops; es gibt Wirtschafter und Pflanzzïchter, die diese irrige und rückständige Auffassung heute noch teilen, weil sic nicht- lesen und nicht reisen. Wo die Heide bereits eine zusammenhängende Decke bildet, muß sie mit starken Sensen, mit kräftigen Hauen abgeschnitten oder abgeplaggt werden; vielfach gren̈̈t auch die Heide abzubrennen; der mit der Plaggenhane oder dem śchälpfluge abgeschälte Heideboden wird zerhackt und mit dem Untergrund auf 20 ('m Tiefe vermischt. Im nächsten Frïhjahr dann wird geeggt, Lupinen gesät, und in die Lupinenstoppeln werden mit dem Keilspaten zweijährige Föhren auch Fichte und Lärche eingeptlanzt (Greve ${ }^{1}$ ). Liegt unter der Heide Ortstein, so ist die Durchbrechung dieser Steinschicht notwendig, was nur mit starken Untergrundspflügen, Dampfpflïgen geschehen kann. Der emporgebrachte Ortstein verwittert, zerfällt und trägt durch seine Auflösung sogar zur Terbesserung des Bodens bei.

Heideflächen entstehen sehr leicht im regulären Kahlschlagbetriebe, insbesondere auf heißen Südhängen, nach Föhren- und Fichten- selbst Buchenbeständon, wenn bereits Rohhumus sich angehäuft hatte. Während bei Fichte und Föhre an der Rohhumusbildung mangelhafte Erziehung bzw. Mangel des Unterbaues schuld ist, stockt die Buche anf ungünstigem sitandort, wenn sie Rohhumus bildet. Der Kahlschlag führt in solchen Fällen Verheidung herbei, welcher in ihrer typischen Bodenschichtung nur der Ortstein fehlt; vielfach treten auch Heidelbeere, Vaccinium Myrtillus und Vaccinium Vitis Idaea, die Preiselbere, an die Stulle der Heide. Sie üben die gleiche Wirkung anf den Boden ans, obwohl Heide cine schattentliehende, Heidel- und Preiselbeere schattenertragende Pflanzen sind. Auf solchen Böden wachsen die Fichten sehr langsam und schließen sich spät: nachdem sie Mäusen eine williommene Zufluchtsstätte geboten haben, so daß alle anderen Holzarten außer Fichten kaum emporzulingen sind, besonders schwierig die auf solchen sitandorten oft sehr wohltuende Lärche. Die nordwestdentsche Heideanfforstung ist in der Literatur am besten bekannt durch das Handbuch der Heideaufforstung von Forstrat v. Bentheim und Dr. ( i r äbner 1!ot, durch F. Frdmanns Selurift: "Die Heideaufforstung und dio Weiterbehandlung der aus ihr hervor-

I) Forstmeister Greve, Die Heideflächen. \%eitschrift f. Forst- u. Jagdw. 1906. 
gegangenon Bestände 19(14", durch Landestorstrat $₹$ ua et-Faslem, welcher über hannoverische Heideauftorstung in verschiedenen Vereinen und Schriften Mitteilungen brachte und dureh Forstrat Ht tos Vortrag im Deutschen Forstverein 1913). Die Nordwestdentsche Heile umfaßt nach rdmann mindestens 300000 ha. In Hannover sind bereits unter Mitwirkung (Quaet-Faslems 2) 1000 ha aufgeforstet. Auch auf der Nordwestdeutschen Heide wird ein Windmantel von Picea alba und aut schlechtestem Boden von Pinus uncinnata angelegt. Wo geringere Verheidung besteht wird Föhremzapfensaat ausgeführt; Flugsandflächen werden durch Heideplaggen, Steckzaun, Bedeckmng mit Stangen und Reisig, Sandgräser, Sandhafer gebunden. Die Kultur der Hauptbolzarten, Fichte und Föhre geschieht bei Einzelmischung bald reilen- oder streifenweise, bald in kleineren Gruppen. Eiche verlangt ein schutzholz; außerdem werden auch Lärche, Birke, Weißerle, Akazie unrl Weymouthsföhren angebaut. Buche und Tanne unter Vorwald von Lärche und Akazie; alles Pflanzung. Nach der Pflanzung wird der Boden noch fortgesetzt gelockert, um das Wiedererscheinen der Heide zu verhindern: Nordseiten sind für Lärche und Tanne passend. Lärche bleibt auf der Heide längere Zeit vorwüchsig, da die Fichte auf der Heide sehr langsam wächst, was auch die verheideten Fichtenkulturen auf der oberbayerischen Hochebene (Grafrath) bestätigen. P. E. Mïller führt das langsame Wachstum der Fichte auf Mangel an Stichistoff zurück; eine Durchptlanzung mit Hackenföhre und der gewöhnlicheren Föhre hebt das Gedeihen, weil, wie P. E. Müller vermutet, deren Mykorhizen den Stickstoff der Luft direkt aufnehmen; besser dürfte nach Ansicht des Verfassers sich Alnus incana oder eine der japanischen Erle, wie Alnus tinctoria, bewähren. Welche unter den fremdländischen Holzarten überhaupt sich besonders für Heideaufforstung eignen könnten, müßten erst Versuche größeren Umfangs feststellen.

Grasflächen, Prärie, Steppe. Wo diese Oberflächen aut natürlichem Wege entstanden waren, wurden sie auf künstlichem noch weiter vergrößert auf Kosten des Waldes; auf künstlichen wie natürlichen Steppen wurde durch die Tätigkeit der Prärialptlanzen nicht eine Verschlechterung des Bodens sondern vielmehr eine Anhäufung von Humusmassen hervorgerufen, welchen eine nachlialtig hohe Fruchtbarkeit zukommt. Aber das mechanische Hindernis der Steppenvegetation selbst in Verbindung mit den unvermeidlichen Feuern hindert die Rücklehr des Waldes. Setzt hier die aufbauende, menschliche Tätigkeit ein, so entsteht ein Wald, der an Wuchskraft las Höchste leistet, freilich bei leichtholzigen Bäumen auch das Minimum an Güte hervorbringt. Je nach der Niederschlagsmenge und der Luftenchtigkeit mïssen die Maßnahmen zur Auftorstung der steppe getroffen werden. Für die regenreiche Steppe (über $511 \mathrm{~mm}$ Niederschläge der vier Monate Mai bis August) genügt die künstliche Begründung von 
Wald, um bei schonender Weiterbehandlung Wald für alle Zeiten zu sichern. Die ungarischen, südrussischen, die ostamerikanischen bis zum Rande des Felsengebirges, die ungeheneren Grasflächen des nördlichen China mit Einschluf seiuer entwaldeten Gebirge bedürfen nur einer Anpflanzung von Waldbaumarten, um sie in Wald mit seinen reichen Segnungen für das Tiefland und für die Bevölkerung umzuwandeln.

Die wichtigste Voraussetzung für die Aufforstung der Steppe ist die Vernichtung des Graswuchses; das Fener genügt hierzu nicht, sonst wäre längst die Steppe vom Erdboden verschwunden. Bei allen Präriefeuern bleibt der Grasstock unversehrt und gewinnt durch die Aschendüngung, die nach dem Brande zurïckbleibt. Hier hilft nur Beseitigung des Steppenwuchses durch Ansroden mit der Haue oder durch Zerstückelung und Übererdung durch den Pflug.

Ist dieses geschehen, so kann Saat oder Pflanzung mit einoder zweijährigen Waldbäumen verschiedener Gattungen eintreten. Nach dem Bericht von G. N. Wyssotzky ${ }^{1}$ ) über die russische Steppe ist die Tertilgung des aufkommenden Unkrautes nach der Pflanzung einige Male während der Vegetationszeit ebenfalls mit dem Pflug oder der Hane zu wiederholen. Mit der oberflächlichen Lockerung wird auch die Abdunstung des spärlichen Wassers aus den tiefen Bodenschichten eingeschränkt. Dieses Verfahren wird wiederholt, bis die Pflanzung sich schließt. In Südrußland eignet sich am besten zur Aufforstung die Eiche (Quercus pedunculata); um rasch einen Seitenschutz zu geben hat man auch schneller wachsende Holzarten (Ahorn, Esche, Ulme) dazwischen gebaut; aber die Schwierigkeit diese Holzarten im Zaume zu halten, hat dazu geführt, von der Esche und Ulme abzusehen und dafür Feldahorn, Linde, Birke und Apfelbäume sowie Sträucher und Halbbänme wie den tartarischen Ahorn, Evonymus und andere, zu wählen. Wie bei dem Anbau fremder Holzarten hat sich anch auf der Steppe die Füllstrauchpflanzung besser bewährt als die Füllholz- oder Staffelptlanzung, wenn auch hier die Beiholzarten nicht in den Pflanzenreihen der Eichen, sondern zwischen zwei Eichenreihen zu stehen kommen. Für die südliche Steppe von Rufland sind anch fremdländische Bäume mit Anssicht auf Gewinn zum Anbau gelangt, nämlich Gleditschia, MLorus, Juniperus virginiana und Robinia Pseudoacacia; letztere besonders auf Sandböden. Für die ungarische Steppe hat sich neben Eiche ebenfalls Robinia bewälırt; daß für die europäischen Steppengebiete noch andere, fremdländische Baumarten die Prüfung verdienen, kann nicht zweifelhaft sein; ans diesem Grunde wurden im vorigen Abschnitt passende Holzarten hierfür empfohlen.

1) Bericht der 8. Sektion des intern. landw. Kongresses zu Wien 1907. 
Auf der amerikanischen Steppe war es eine für die Besiedelung dringend notwendige Einleitung, daß man die Kraft des Windes brach. Man benutzt hierzu vielfach die europäischen Holzarten Fichte, Föhro, Lärche und besonders als Setzstangen ausgepflanzte Pappeln. Erst in den letzten Dezennien wählt man Holzarten ans, welche dem gleichen 'Wock entsprechen und dabei noch die Aussicht auf ein wertvolles Produkt eröff̉nen.

Moore $\left.{ }^{1}\right)$. Grünlands- oder Flachmoore sollen nur dann aufgeforstet werden, wenn ihre Umwandlung in guto Wiesen nicht rentabler erscheint als Waldkultur. Soll aufgeforstet werden, dann eignen sich nach vorheriger Entïässerung am besten hierzu Fichten, Erlen, Birken, Föhren (Silvestris), Hackenföhre und fremde Ilolzarten.

Der Hoch-oder Buckelmoorbildung im Walde selbst vorzubeugen. ist Sache des Waldbaues; die Ursache der Hochmoorbildung liegt in der saueren Reaktion des Rohhumus, welche dio Ansiedelung der niederen Vegetation des Hochmoores begünstigt. Graf zu Leiningen ${ }^{2}$ ) nennt die Ausbreitungszone des Hochmoores die Kampfzone; "siegreich bleibt die anspruchlosere Hochmoorvegetation, die Feindin des Waldes". Die Erziehung der Bestände (III. Teil) hat mit der Bildung von Rohhumus jener von Hochmooren in kühlen Lagen vorzubeugen. Die Wiederbewaldung der Hochmoore verlangt zunächst ebenfalls eine Entwässerung, dann eine Abtorfung, sobald die Torfschicht über $1 \mathrm{~m}$ Höhe Mächtigkeit besitzt. Auf der abgetorften Flächo wird die erste oberste, humose Decke, welche behufs Torfgewinnung beseitigt wurde, wieder ausgebreitet und eine Pflanzung mit Fichte, auch Frle, Birke und Föhre besonders Hackenföhre oder fremden Holzarten durchgeführt. Sowohl bei Flach-wie bei Hochmooren wird mit der forstlichen Kultur nach der Abtorfung gewartet, bis sich wieder leichte Begrünung eingestellt hat.

Es wurde vor 30 Jahren bereits vom Vater des Verfassers dieser Schrift nachgewiesen, daß unkrautfreie Torfe, feuchte, anmoorige Flächen sehr wohl mit der Riesenpreißelbeere Vaceinium macroc arpum besiedelt werden können. Diese "Kronsbeere" liefert sehr hohe Erträge, freilich auch eine Frucht, die im Aroma der gewöhnlichen Preißelbecre (Vaccinium Vitis Idaea) nachsteht.

Beweglicher Sandboden der Küste (Dünen) und des Binnenlandes verlangen als erstes die Festlegung des Sandes. Die großartigsten Aufforstungen weist die Südwestkïste Frankieichs auf, wo bereits 181)2 mit der Aufforstung der beweglichen Sandmassen und

1) Bayerns Noore sind ausfuhrlich beschrieben von Dr. A. Baumann in Forstl. naturw. Zeitschr. 1 894.

2) Graf zu Leiningen, Die Waldvegetation präalpiner, bayerischer Hochmoore. Naturw. \%eitschr. f. Land- u. Forstwirtsch. 1907. 
Dünen der Gascogne von Villers und Peychon begonnen wurde; nach Jentzsch') lagen 800000 ha nahezu brach; sie wurden mit Pinus maritima aufgeforstet. Bei Dünenaufforstung wird zuerst durch niedere, in ihrer Größe landeinwärts ansteigende Flechtzäune eine Tordüne errichtet ${ }^{2}$ ), an welcher der vom Wind landeinwärts getriebene Sand sich fängt. Diese Torlüne wird mit I)ünenpflanzen wie dem Sandrohre (Arundo arenaria) oder dem Sandhafer (Elymus arenarius) oder der Sandkegge (Carex arenaria) bepflanzt. Hinter der Vordüne kann dann eine Festigung des Sandes durch Flechtzäune und häufiger durch Deckwerk gegeben werden; als Decken werden Föhrenäste. Wachholderbüsche, Heidekrautplaggen, Schilfrohr, Besenpfriemen, selbst Seetang, Moorbodenabhub und anderes so gelegt, daß ein Quadrat oder Rhombus gebildet wird, in dessen Mitte dann die Aufforstungspflanze zu stehen kommt. Auf den beruhigten Sandflächen werden gewöhnlich Föhren (Pinus silvestris) [auf frischem Boden auch Erle, Birke, Fichte und Weibfichte ${ }^{3}$ )] oder Hackenföhre oder korsische Föhre ${ }^{4}$ ) im mittleren Europa, Pinus maritima und aleppensis im südlichen Europa, Pinus rigida in Ostamerika, Pinus insignis in Westamerika, Pinus Thunbergii, sinensis und andere in Ostasien angepflanzt; schon unter dem Schatten der Föhren verschwindet das Sandgras Elymus (Psamma). Flugsand im Binnenland wird nach Festigung durch Pappel- und Weidenstecklinge oder durch Deckwerk am häufigsten mit Robinia bestockt.

Schutthalden und anderes bewegliche Gelände im Gebirge werden am besten mit tiefw urzelnden Holzarten, somit unter Ausschluf der Fichte zur Ruhe gebracht. K. v. Fischbach schlägt Stecklingskultur mit der anspruchlosen Saalweide vor; Föhren wie Pinus uncinnata und Pumilio sowie der Sektion Murraya, auch Pinus aristata sowie Erlenarten dürften in erster Linie zu versuchen sein.

Rauchschadenödland. Viele Rauchschadengebiete sind zwar noch nicht ganz ̈̈dland, aber auf dem besten Wege es zu werden; K. R e u $B^{5}$ ) sagt, die Aufforstung ron Rauchblölien bei gleichbleibender oder gar verstärkter Einwirkung des Rauches habe keine Aussicht auf Erfolg. Da das Laubholz widerstandsfähiger als das Nadelholz ist. so verschwindet letzteres früher als ersteres; es kann somit vorüber-

1) Jentzsch, Forstw. Centralbl. 1907.

$\Rightarrow$ Abromeit, Bock und Jentzsch in: Handbuch des deutschen Dunenbaues, herausgegeben von Gerhardt 1900 .

$\left.{ }^{3}\right)$ Nach E. D. van Dissel hat sich die Weißfichte (Picea alba) in Holland nicht bewährt; dagegen haben die österreichische und korsische Föhre gute Ergebnisse aufzuweisen (Catalogus van de tentoonstelling voor oceanographie te Marseilles 1906).

4) Planting of sand-dunes at Hokham von D. M unro. Quarterly .Jurnal of Forestry 1908.

5) K. ReuB, Referat in der \&. Sektion des intern. Kongresses zu Wien 1907 . 
gehend durch Umwandlung der Nadel- in Laubholzbestände, der Laubholzhochwaldungen in Niederwaldungen geholfen werden; über die Dauer der Widerstandskraft entscheiden neben der Giftwirkung Klima, Boden und Alter der Holzart sowie deren Behandlung. Dr. Wislicenus betont in seinem Referate, daß der Ersatz der sehr ranchempfindlichen, aber wertvollen Fichte (und der Tanne) durch rauchhärtere Holzarten nicht gerechtfertigt sei; wo der Wald auch ästhetische und sanitäre Zwecke für die Stadtbevölkerung zu erfüllen habe, sei die Umwandlung direkt geboten. Nach Unbescheid ${ }^{1}$ ) soll in die Fichten reihenweise die Buche eingemischt werden; zum Anbau eignen sich sodann Eiche, Roteiche, Erle, Birke, amerikanische Esche; für diese Holzarten soll ein Mittelwaldbetrieb eingerichtet werden; auch Bergföhre, Weymouthsföhre (־), Balsampappel seien brauchbar; dic Sitkafichte soll härter als die einheimische sein; auf die Ahorne, besonders den Zuckerahorn und die amerikanische Ulme für Rauchgebiete (Großstädte) hat Verfasser vor 19 Jahren ( Waldungen von Nordamerika", 1890) hingewiesen.

Eisenbahnlichtungen sollen innerhalb bewaldeter Gebiete waldfrei bleiben, in Steppen bewaldet sein - zum Abfangen des treibenden Schnees. Danckelmann und Birner befürworten (189.5) die Eisenbahnstreifen mit Stauden wie Caragana arborescens und frutescens zum Schutze der Singrögel zu bepflanzen; sie ließen sich durch Aufzucht von Christbäumen auch finanziell besser ausbeuten. In Steppengebieten kämen die bereits erwähnten Holzarten in räumiger Stellung in Frage.

Auf landwirtschaftlichem Gelände werden alle Nadelhölzer frühzeitig rotfaul und sterben unter Einwirkung von Polyporus annosus ab. Prof. Dr. Albert und Zimmermann ${ }^{2}$ ), welche diese Erscheinung gründlich untersuchten, empfehlen entweder tiefgehende Bodenbearbeitung oder Verzicht auf Föhre und Fichte als erste Generation; an ihre Stelle könnten Weißerle, Aspe, Roteiche, Akazie treten; Lücken im vorhandenen Laubholzbestande sind mit obigen Holzarten zu füllen. Beachtenswert ist sodann, daß mit der Wärme des Klimas die Rotfäule in ihrer Häufigkeit gesteigert und in ihrem Auftreten verfrüht wird.

$\left.{ }^{1}\right)$ Sächsischer Forstverein 1897 .

2) Zeitschrift für Forst- u. Jagdw. 190s. 


\section{Dritter Teil.}

\section{Walderziehung und Waldpflege.}

Eine Baumvereinigung von beliebiger Größe, welche auf unpassendem Boden oder in ungünstiger Klimalage oder in einer für Boden oder Klima oder Holzart ungeeigneten Methode begründet wurde, kann auch durch die natur- und kunstgerechteste Pflege und Erziehung nicht dem höchsten Werte, welcher dem gegebenen Standorte abgewirtschaftet werden könnte, zugeführt werden. Es sind daher das Studium der naturgesetzlichen Grundlagen des ersten Teiles und die darauf fußende Waldbegründung nach den Andeutungen des zweiten Teiles die nötigen Voraussetzungen für den dritten Teil der Tätigkeit des Forstmannes im Walde, für die Pflege und Erziehung des Geschaffenen. Verfasser zögert nicht zu behaupten, daß Pflege und Erziehung kaum minder schwierig sind als die Begründung, weil sie ein tieferes Eindringen in die Lebensgeschichte der Bäume voraussetzen, daß die Erziehung vom praktischen Gesichtspunlite des Endzieles aller wirtschaftlichen Tätigkeit aus, das ist, den geschaffenen Bestand zur höchsten Wertleistung in kürzester Zeit zu bringen, geradezu als die wichtigste A ufgabe des Forstmannes betrachtet werden muß. In allen Waldbaubüchern und auch im vorliegenden ist der hierüber handelnde Teil dem Umfange nach der kleinste, weil er bis vor kurzem überhaupt als minder wichtig betrachtet wurde und erst seit etwa dreißig Jahren Gegenstand ernstlicherer Forschung geworden ist. Die Anschauung und die daraus folgende Tätigkeit zahlreicher Forstwirte begegnen auf diesem Gebiet noch heute vielfach sich mit den Ansichten jener Laien, welche sagen, daß der Wald, einmal gliicklich begründet, ohne Zutun des Mensehen am besten aufwachse. Es zählt hierher die mangelhafte Pflege der.Jungwüchse, die bis vor ein paar. Jahrzehnten nur in unermüdlichem Auspflanzen aller entstehenden Lücken bestand, aber die gefährlichsten Glieder der aufwachsenden .Jugend, die krummen, ästigen, vorgewachsenen, duldete; in allen heranreifenden Beständen sind sie als Zeugen einer mangel- 
haften Pflege eine schwere Schädigung der Nutzholztüchtigkcit des Bestandes und eine Quelle der Verlegenheiten für die Erziehung. Auch jenen, welche sagen, daß sie ihre Bestände erziehen, wenn sie nur im Wettkampfe bereits ausgeschiedenes, unterdrücktes Material herausforsten, muß man entgegenhalten, daß ihre [Jurchforstung gar keine Erziehung ist, sondern nur eine Nutzung, welcher an manchen Orten vielleicht ein prophylaktischer Wert gegen Insekten und Feuer, aber selten ein finanzieller Gewinn zukommt.

Sind Saat oder Pflanzung ausgeführt, sind die Erstlinge der Naturrerjüngung erschienen, so beginnen auch sofort Pflege und Erziehung. 


\section{Fünfzehnter Abschnitt.}

\section{Pflege und Erziehung der Hochwaldungen.}

\section{Jungwuchspflege.}

Zur Pflege des Jungwuchses gehören: Nachbesserungen, Reinigungen und Schutz der Pflanzen gegen Unbillen aller Art bis zum Eintritt des Bestandesschlusses.

\section{a) Nachbesserungen.}

Versäumnissen hierin begegnet man im Walde nur selten; jede Lücke wird vielmehr sorgfältig ausgebessert, zwar oft mit einer Holzart, welche später wiederum verschwindet, weil sie überwachsen wird; aber ausgebessert ist alles. Dieser lobenswerte Eifer kann auch zum Üboreifer werden; zur Verschwendung an Zeit, Geld und Pflanzenmaterial. In nachstehendem sind auf Naturgesetze gegründete Regeln für eine rationelle Nachbesserung festgelegt.

1. Bei allen Nachbesserungen wird stets die Pflanzung angewendet mit dem wüchsigsten Material (Auswahlpflanzung).

2. Bei allen Nachbesserungen wird stets die Holzart der Umgebung gewählt; oine Nachbesserung mangelhafter Naturverjüngungen mit anderen Holzarten, z. B. von Buche mit Fichte, führt nur zu schädlichen, meanderartig verschlungenen Nlischungsrändern.

3. Durch Pflanzung leidet jede Holzart während der folgenden zwei bis drei Jahre im Höhenwuchse; eine Nachbesserung jeder Fehlstelle wird daher nur dann vorgenommen, wenn Aussicht besteht, daß die Nachgebesserte mit der Umgebung noch Schritt halten kann. Dies ist nur dann gegeben, wenn die Nachbesserung in dem a uf die Pflanzung folgenden Jahre bereits geschieht. Wird auch in diesem Falle auf Nachbesserung verzichtet in der Hoffnung, daß auch Fehlstellen bis zu drei, ja sechs Pflanzen später sich doch schließen, so ist damit zugestanden, daß der Pflanzverband von Anfang an zu eng war. Vergehen aber zwei bis vier Jahre, so ist 
4. Dio Nachbessermng einer fehlenden Pflanzo \% wischon zwoi $\mathrm{kräftig}$ angewaehsenen, in einer Planzung voll 1 bis $1,5 \mathrm{~m}$ Abstand, da aussichtslos, zu unterlassen; dio Lücke schließt sich in wenigen Jahren.

5. Boträgt der Pflanzenabstand mehr als $1, \div \mathrm{m}$, so wird die einzelne, tehlende Stelle ergänzt.

6. Fehlen zwei Pflanzen in einem Verbande von 1 bis $1,5 \mathrm{~m}$, so wird eine Pflanze ergänzt, und zwar genau in der Mitte der beiden fehlenden Pflanzen; beträgt der Pflanzenabstand über $1,5 \mathrm{~m}$, so werden beide ergänzt; bei flächenweisem Absterben von mehr als fünf Pflanzen wird nur eine zentrale Gruppe ausgebessert, zur Verhinderung der allzu starken Beastung der Fehlstellenränder; Föhrensaaten, durch Schütte dezimiert mit einzelnstehenden, wolfartig sich entwickelnden Überresten, werden voll durch Pflanzung ergänzt zur Erzielung günstiger Schaftformen.

7. Hat die Pflanzung bereits eine Höhe von $2 \mathrm{~m}$ und mehr erreicht, so werden einzelne und selbst doppelte Fehlstellen nicht mehr mit einzelnen Pflanzen ergänzt; für größere Lücken kommt eine gruppenweise Nachbesserung in Frage derart, daf vom Zentrum ausgehend nach den Lückenrändern hin gepflanzt wird, jedoch so, daß zwischen den Bestandspflanzen und der Nachbesserung ein Abstand gleich der halben Höhe der ersten verbleibt. Hat die Pflanzung $4 \mathrm{~m}$ erreicht, bleibt ein $2 \mathrm{~m}$ breiter Saum der Lïcke frei von aller Nachbesserung, entgegen der Ansicht, daf bis zum Bestandsrande hin zu pflanzen ist; am Bestandsrande kann später nur die Axt oder die Aufästungssäge helfen. Liegt eine größere Abgangsfläche an einem Südhange, so beginnt die Nachbesserung am tiefsten Punkte und schreitet saumweise allmählich nach oben vor, wenn die Ausbesserung nicht in einem Jahre betätigt wird.

\section{b) Reinigungen.}

Folgende Arbeiten müssen deshalb als besonders wichtig betrachtet und durchgeführt werden, weil sie für den späteren Nutzbestand entscheidend sind und ihre gewissenhafte Durehführung Aufwand an Arbeit und Geld in späteren Jahren einspart; die Mangelhattigkeit der erwachsenen oder der Haubarkeit sich nähernden Bestände in Nutzholztüchtigkeit und Gesundheit (Rotfäule), die Verlegenheiten bei den Durchforstungen und Durchlichtungen in den qegenwärtig vorhandenen Beständen sind zum großen Teile auî mangellafte Reinigungen in den Jugendjahren eines Bestandes zurüclizuführen.

1. Allmähliche Beseitigung der zum Zwecke der Verjüngung auf der Kahlfläche belassenen oder absichtlich eingeptlanzten, vorher orler. nachträglich auf natürlichem Wege angeflogenen Büsche von Unhölzern, wie Salweide, Pappeln, Birken, von Halbbäımen und strüuchern orler 
von eingedrungenen, nicht erwünschten anderen Holzarten. Schädigen sie bessere Holzarten nicht, so bleiben sie, bis sie selbst einen Wert besitzen; am Windrande empfiehlt sich die frühzeitige Beseitigung, damit später nicht allzu große Lücken entstehen.

2. Aufästen des zum Schutze in Frostlagen angelegten Vorwaldes ron Föhren, Birken, Weiden, Pappeln; völlige Beseitigung erst dann, wenn dieselben verwertbare Dimensionen erreicht haben, ohne der Umgebung allzusehr Schaden zugefügt zu haben.

3. Aushauen der breitästigen, auf Kosten besserer Nachbarn sich ausladenden Edelhölzer (Wölfe, Kollerbüsche).

4. Beseitigung aller Individuen, welche Schaftverkrümmung oder Schaftvergabelung zeigen; das Beseitigen eines Gabelastes hat keinen nachhaltigen Erfolg, da in der Regel nach einigen. Jahren durch innere Anlage die Verunstaltung sich wiederholt; bei Buchen und Föhren sind es gerade derartige minderwertige Individuen, welche die größte Wuchskraft entwickeln; sie sind zu beseitigen ohne Rücksicht auf etwaige Lückenbildungen.

5. Bei Eichen, Buchen sind dann besonders jene Stämmchen herauszunehmen, welche Neigung zur Klebeästigkeit zeigen, oder an welchen Krebswülste entstanden sind.

6. Bei der Tanne sind alle Stämmchen mit Hexenbesen in der Hauptachse herauszunehmen; die Hexenbesen an den Seitenzweigen können verbleiben, da eine Einschränkung der Krankheit aussichtslos und der zur Beule führende Hexenbesen an der Achse ziemlich selten auftritt.

7. In Büschelpflanzungen sind alle Pflanzen bis auf die beste abzuschneiden oder zu rerstümmeln, wenn das in diesem Falle wohltätige Verbeifen oder Verschlagen von seiten des Wildes nicht eingetreten sein sollte.

8. Auflösung aller Zwiesel so frühzeitig als möglich durch Beseitigung des schwächeren Triebes mittelst Baumschere oder Säge; bei Laubhölzern sollen steil aufgerichtete Äste eingekürzt, wagerechte belassen werden.

A. Schiffel'1) glaubt, daß mit verschieden dichter Begründung (Buche und Eiche dicht, Lärche locker, Fichte mehr als $1,75 \mathrm{~m}$ ) die kostspielige Jungwuchspflege entbehrlich werde; das verschiedene Ausformungsvermögen dürtte jedoch diese Hottinung vereiteln.

A uswahlpflanzung dürtte cher die Jungwuchsptlege verbilligen.

') A. Nchiffel, Wuchsgesetze normaler Fichtenbestände. Wien 1904. 


\section{c) Sonstige Maßnahmen für Pflege und Schut\%.}

1. Laubholzpflanzen, welche ihre Gipfel verloren durch Wildverbiß, Frostbeschädigung. Fegen des Rehbockes und andere Ursachen, werden tief am Boden abgeschnitten, d. h. auf den Stock gesetzt: das Anteeren der Gipfel schadet stets; sie können nur durch einen Zaun erfolgreich geschützt werden.

2. Allzu dicht stehende natürliche oder künstliche Saaten werden durchschnitten mit der sogenannten Vorwuchsschere, Durchforstungsschere, oder mit der Heppe durchhanen einzeln oder in sich kreuzenden Gassen.

3. Bei Laub- und Nadelhölzern wird der Aufmunterungsschnitt empfohlen, d. h. das Einstutzen der Seitenäste zu einer pyramidenförmigen Krone, wodurch der Höhenwuchs gefördert wird. Es erscheint unter allen Umständen ein billigeres Verfahren, volı vornherein die am schnellwüchsigsten und geradschaftigsten veranlagten Individuen allein zur Pflanzung (Auswahlpflanzung, Staffelpflanzung, Zwischenstrauchpflanzung) zu benützen.

4. Schutz der Jungwüchse gegen Beschädigung durch Tiere und Pilze ist vielfach Gegenstand einer besonderen Lehre. nämlich des Forstschutzes, von welchem Gegenstande eine ausgezeichnete Bearbeitung mit allen Quellennachweisen, aus denen geschöptt wurde, vorliegt ${ }^{1}$ ). Es kann sich hier nicht um Aufzählung der zahlreichen Maßnahmen gegen die Feinde der Jungwüchse handeln; die in den letzten Jahrzehnten mit zunehmender Erkenntnis über den wahren Schaden durch Wild im Wald entdechten und gehandhabten Mittel sollen in Kürze besprcchen werden, da es noch Jungwüchse genug gibt, welche der Wirtschafter völlig sich selbst, überläßt in der Hoffnumg, daß schon einmal der Zeitpunkt kommen werde, in dem die Pflanzen im Kampfe gegen das Wild siegen werden. wenn auch 15 und 21) Jahre - welcher Zuwachsverlust! - darüber hingehen sollten. Noch größer aber ist die Zahl jener wohldurchdachten, mit aller Mühe ausgeführten Kulturen (Gruppen vols Tannen, Unterbau von Buchen usw.), welche nach kurzer Zeit wieder völlig verschwinden - allein durch Wildverbiß. Es klingt sehr traurig, aber leider stimmt es für manchen Revierbezirk, was Prof. Schwappach in seinem Referate auf dem internationalen Kongref zu Wien 1907 vortrug: "Laubholznachzucht, Anbau der Weißtanne, gemischte Bestände, Kulturen von fremdländischen Holzarten, Naturverjüngung, Horstwirtschaft, Unterbau, kurz, das ganze schöne Repertoire des modernen Waldbaues, worüber die tiefsinnigsten Abhandlungen geschrieben werden, und mit deren Nützlichkeit alle Fachgenossen einverstanden, sie scheitern sümtlich nur zu ntt bei der praktischen Anwendung am Wildschaden." Andererseits gibt es auch

1) R. HeB. Der Forstschutz. 3. Aufl. 
Jungwïchse, für deren Schutz gegen Wild mehr verausgabt wird, als seinerzeit für die Begründung benötigt wurde. Auf Grund einer umfangreichen Erhebung über die Schutzmittel und ihre Wirkung in den Staat:waldungen des Königreichs Bayern kommt Verfasser zu folgenden Feststellungen: Reiht man die Maßnahmen nach ihren Erfolgen ein, nach der Sicherheit der Wirkung, so steht obenan der / $/$ a un, wie er bei der Anlage der Saat- und Pflanzgarten im elften Abschnitt beschrieben wurde; unter den Käunen ist der beste das Drahtgeflecht; wird es auf' Rahmen gespannt, so können während des Sommers einzelne Fächer entfernt werden, um den Tieren den Zutritt zur Grasvertilgung zu gewähren: im Herbste werden die Tiere wieder rertrieben und die Drahtfächer wieder eingeschaltet. Sachgemäf und alljährlich mit größtem Fleiße durchgeführt, geben sodann guten Schutz alle Mittel, welche ein mechanisches Hindernis gegen den Verbiß bedenten, wie das Belegen des (ripfeltriebes mit Werg, Haaren, Blechkronen, spiraldrähten und dergleichen; häufig kommen schon Klagen von geringerem Erfolg bei den ïbel riechenden, übel schmeckenden Substanzen, welche auf den Gipfeltrieb geschmiert werden, als da sind: Teer, entsäucrter Teer, Mischungen ron Teer mit Jauche oder mit Kuhmist oder mit (̈), Kalkschlamm, Schwefelschlamm, Raupenleim, Xyloservin und andere; am wenigsten Erfolg zeigen übel riechende Mittel, welche eine .Jungwuchsanlage mit einem Kordon zu sichern suchen, z. B. mit Teer beschmierte Stricke werden gespannt, Lappen mit Pilirofoeditin werden aufgehängt. Belegen der Kulturen mit Reisigund Astwerk hat sich nützlich erwiesen.

Rechnet man alle Arbeiten, welche der Schutz gegen Wild verlangt, zusammen, so muf man zugestehen, daß die geringste Arbeitsleistung die einmalige Anfertigung des Zaunes ist; alle übrigen Schutzmaßnalımen müssen alljährlich wiederholt werden, und man kann ron schr gutem Boden und sehr kräftigem Wachstum der Pflanzen sprechen, wem nach fünf Jahren der Schutz überflüssig wird: er zieht sich aber oft zehn und mehr Jahre hinaus. Dazu kommt aber noch folgendes: Die Erhebung hat gezeigt, daß die einfachen Schutzmittel, wie Teer und andere, gegen Wild nur dann ihren Zweck erfüllen, wenn sie vällig sachgemäls durchgeführt werden: ihre Anwendung verlangt daher eine besondere Sorgtalt und eine ständige Überwachmug der Arbeit. Fehlt der nötige Fleiß und für manche Substanzen die nötige Torsicht, so ist, wie die Erhebung gezeigt hat, zu befürchten, daß das angewandte Mittel schädlicher wird als das Wild, gegen welches die Pflanze geschützt werden soll. Dies gilt ganz besonders von allen Schutzmitteln, welche Teer verwenden.

Was die Dauer der Wirkung der Sehutzmittel anlangt, so steht abermals obenan der Zaun. Wird er ans Drahtgeflecht hergestellt, so sind die Erfahrungen bezüglich der Haltbarkeit soleher Ge- 
flechte noch nicht alt genug, um eine Dauergrenze geben zu liönuen; Verfasser hat verzinkte Drähte seit 25 Jahren, verzinkte (ieflechto scit 15. Jahren in Gebrauch; sie sind noch so gut wio neu; nur die hölzernen Pfosten mußten innerhalb 2.) Jahren dreimal erneuert werden; bei hölzernem Zaun mußte innerhalb derselben Zeit dreimal eine völlige Answechselung eintreten; die übrigen Schutzmittel müssen alljïhrlich ernenert werden.

Was die Kosten der Sicherung anlangt, so steht zweifellos als einmalige und höchste Ausgabe obenan der Zaun. Es muß den Wirtschaftern überlassen bleiben, alle Kosten für Sicherung mit anderen Mitteln ebenso korrekt zu berechnen, wie dies bei der Anlage des Zaunes geschieht, bei welcher alle Kosten in einem Zeitpunkte zusammenlaufen. Es nul3 aber aus der Erhebung konstatiert werden, daß immer mehr die Überzengung sich durchringt, daß für größ ere Gruppen ja Schläge von Jungwïchsen das beste schutzmittel, der Zaun, auch das billigste ist. In den französischen Staatswaldungen werden zum Schutze gegen Kaninchen die Grenzen gegen Privatwaldungen auf viele Kilometer hin mit Drahtgeflecht versehen.

In der ganzen Schrift sind keine Kostenvoranschläge zu finden: absichtlich wurden sie weggelassen als zu geringwertig; Kostenanschläge, die um ihr Doppeltes, ja bis zum zehnfachen Betrage, je nach Örtlichkeit und Unständen, variieren, sind wertlos. Die nenere Zeit hat sich in Verbilligung der Schutzmittel und Vertenerung der Arbeitslöhne so geändert, daß alle früheren Anschläge wertlos geworden sind und die gegenwärtigen es ebenso sein müssen, da voraussichtlich in nächster Zeit wiederum sich alles hierin ändert: wo der Bedarf wächst, mindert sich der Preis der Schutzmittel. Man kam im Interesse des Waldes und seiner Rente nur wünschen, daß an Stelle des Einzelschutzes einer jeden Pflanze der Flächenschutz durch den Zaun tritt.

Wird am Einzelschutze festgehalten, oder ist derselbe notwendig aus lokalen Gründen, zu denen, gegenüber fremdländischen Arten, auch die Verweigerung der Mittel durch die vorgesetzte Behörde zählt, so ist Folgendes zu beachten.

5. In Fichtenjungwüchsen, welche in einem Verbande unter $1,5 \mathrm{~m}$ Abstand emporwachsen, sei es daß sie aus Saat oder enger Pflanzung hervorgegangen sind, ist es eine Verschwendung, jede PHanze schützen zu wollen; es genügt, wenn jede zweite mit dem schutzmittel bedacht wird. Hierdurch werden $50 \%$ an den Kosten der sicherung eingespart und den Tieren des Waldes, deren Ansrottung niemand wïnscht, ist Nahrung geboten.

6. In der Auswahl, in iler Staffel- oder Zwischenstranchpflanzung werden selbstredend nur die Elitepflanzen der Edelholzarten in weitem Verband geschützt; insbesondere gilt dies gegen das Verfegen durch den Rehbock. 
7. Wemn es nicht gelingt, ein Schutzmittel gegen das Schälen der Stangen durch das Hirschwild zu finden - vielleicht ist in dem Flammingerschen Baumkratzer dies gefunden -, so ist Hirschwild mit einer Waldwirtschaft, welche rechnet, nicht vereinbar.

8. Das Eichhörnchen, das, wie alle Nager, cine Massenvermehrung erfährt, ist wegen seines schweren Schadens in Saatgärten, wegen des Ausgrabens und Verzehrens der Sämereien. wegen Abschälens der glatten Rinde an jungen und alten Bäumen, wegen Abbeißens der Gipfelknospen mit nachfolgender Verzwieselung, durch Abschuß auf ein minder schädliches $\mathrm{Maß}$ (ein unschädliches gibt es bei diesem Tiere überhaupt nicht) zu vermindern.

?. Die Schonung der Feinde aller warmblütigen Schädlinge ruft zwar die Entrüstung der .Jäger im Walde hervor; in einem $\mathrm{Ab}$ schnitte, der sich der Pflege des Waldes widmet, klingt die Empfehlung minder unverständlich; ja, gegenüber dem Jäger, welcher als das schädlichste Tier für die Jagd den Fuchs bezeichnet, muß der waldbauende Forstwirt eingestehen dürfen, daß für den Wald der Fuchs - das nützlichste Tier ist.

In manchen Örtlichkeiten ist der Maulwurf der nenen Kultur schädlich, indem er die mit Füllerde versehenen Pflanzenlöcher durchwühlt, die Pflanzen lockert, so daß sie bei trockener Witterung erliegen. Es empfiehlt sich das mehrmalige Festtreten der Pflanzen während des ersten Sommers.

11. Je mehr das Rechnen im Walde üblich wird, um so mehr treten jene Bekämpfungsmittel gegen Insekten und Pilze zurïck, welche auf Vernichtung der bereits vorhandenen Schädlinge abzielen, um sn mehr treten die Vorbengungsmittel in den Vordergrund: gegen den Rüsselkäfer hilft die Beseitigung oder Entrindung seiner Brutstellen, der Stöcke: gegen den Wurzelkrebs durch Agaricus melleus und Polyporus annosus hilft ebenfalls die Rodung der Stöcke und, wo diese in toto nicht zulässig ist, die schon früher erwähnte Femelrodung der Melleus- und Annosus-Stöcke; die Schutzmittel gegen die Schädlinge des Waldes müssen vorbeugender, somit zumeist waldbanlicher Natur sein, wenn sie durchgreifend und billig sein sollen. Gegen die Schütte hilft vielfach das Bespritzen mit Kupfermitteln; nicht scheint Naturverjüngung, nicht die Düngung ein Vorbeugungsmittel zu sein; aber der Anbau schüttefester Föhren hilft in besonders gefährdeten Standorten gründlich; gegen die Maikäferlarve hilft Vermeidung größerer Kahlfächen; gegen Nomnen, Spamer, Borkenkäfer und andere Termeidung grofer reiner Bestände durch Kleinbestandsmischung des Waldes.

11. Gegen Unkrautwuchs, wic hochaufischießende Gräser, rankende, kletternde, schlingende, breitbuschige Sträucher, hilft nur das Abschneiden, Herunterziehen, Aushauen; es genügt, diese lichtbedürftigen 
Pflanzen dem Licht zu entzichen und unter die Krone des Jungwuehses zu stoßen oder zu treten; Graswuchs gibt durch seine Beseitigung sogar Gewinn; der oft verdächtigte Efeu ist harmlos.

12. Schutz gegen Schnee, besonders an Hängen gegen das Abgleiten des tauenden Schnees bietet die Coazsche Nischenpflanzung mit Verwendung von Steinen: auch das Aneinanderbinden der Pflanzen in den senkrechten Reihen von einer Bergkuppe 'zur 'Talsohle mittelst Strohseiles oder auch mit Stangen ist in Verwendung gekommen. Am besten dürtte in solchen Fällen immer die Verwendung möglichst kleinen Pflanzenmaterials in terrassierten Streifen sich bewähren: ist letzteres untunlich, so werden kleine Pflanzen stets den größeren vorzuziehen sein. Gegen das Umdrücken der Pflanzen durch S'chneebelastung hat man das Abschütteln des Schnees mit gutem Erfolg angewendet; solche abnormen Schneefälle sind Ausnalımen, so daß nicht alljährlich die Maßnahme notwendig wird: eine Pflanze, die in den Wurzeln gezerrt ist, vermag sich von selbst nicht mehr aufzurichten, sie muß angeheftet werden, wie es notwendig ist, zum

13. Schutze gegen Wind. Das beste Mittel ist Verwendung möglichst kleinen Materiales und weitständige Pflanzung: für Heisterptlanzung: kann das Aubinden, wie es bei hochstämmigen Obstbäumen üblich ist, notwendig werden: an solchen vom Wind gefährdeten Örtlichkeiten sollte die Heisterpflanzung unterhleiben: sie ist ohnedies für den gegenwärtigen, wirtschaftlichen Betrieb zu teuer.

\section{Stangenwuchspflege.}

Die Stangenwuchspflege umfaßt den Zeitraum vom Beginn des Bestandsschlusses bis zu seiner künstlichen Auflösung; ihr Z Ziel is t Förderung der Schaftschönheit und Güte. Mit dem Eintritt des Bestandsschlusses beginnt der gedrängte Schluß, der dichteste Schluß, in dem die Seitenäste abgestoßen und das Höhenwachstum gefördert wird. Es muß ein Ziel des natur- und wirtschaftgerechten Waldbates sein, diese Zeit der Ästereinigung nicht über Gebühr auszudehnen, während dieser Zeit aber möglichst jene Faktoren zu verstärken, welche die Ästeabstoßung heschleunigen. Je dichter der Schluß, um so rascher und sicherer die Abtötung der Äste durch Lichtentzug, desto rascher durch Ansammlung von Luftfeuchtigkeit die saprophytische Zerstörung der getöteten Äste. In diesem Alter mu d aher der Bestandsschlu $\mathrm{B}$ ängstlich erhalten werden: die positiven und negativen Maßregeln, welche am besten „Reinigungon“ genannt werden. sind in diesem Alter folgende:

1. Beseitigung von krummwüchsig sich entwickelnden, im Wachstum den übrigen voraneilenden, besisere Indiviluen in den Kronen bedrängenden Stangen ohne Rücksicht auf' Schlufidurchbrechung; 
2. Heraushamen von $/$ wieseln, welche erst im Stangenalter durch Schneebruch, durch Knospenabbiß oder Gipfelschälen der Eichhörnchen, durch Pilze entstehen (dio /wiesel der Jungwuchsperiode wurden rechtzeitig in dieser beseitigt); auch diese Operation darf auf Bestandsschluß keine Rücksieht nehmen;

3. Beseitigung allenfalls in diesem Alter noch vordrängender Unhölzer, ebenfalls ohne Rücksirht anf Schluß.

4. Dagegen wird unterlassen: die Herausnahme der unterdrückten noch lebenden Individuen, gleichgültig ob sie der Hauptholzart oder einer Unholzart oder nur Straucharten angehören; das vielfach ïbliche Putzen der Stangenhölzer ist eine schädliche Maßnahme, welche vielleicht der Ästhetik, sicher nicht dem Nutzen ihren Ursprung verdankt.

5. Wo keine Fenersgefahr besteht (solche Örtlichkeiten gibt es in feuchteren Waldgebieten sehr viele!, wo nicht Insektengefahr es verbietet, soll auch alles ahsterhende und abgestorbene Material belassen werden, weil es den Bestand füllt, seine Luftfeuchtigkeit noch erhöht, und durch Zusammenfaulen den absterbenden Ïsten saprophytische Infektionssporen zïchtet und dem Boden Nutzen bringt. Die Insektengefahr wird durch derlei schwaches Stangenholz in der Regel weit überschätzt. An den dümmen Stangen leben zumeist die harmloseren, mehr wissensehaftlich als forstlich bemerkenswerten Insekten. Auch das Heraushamen der durch Wurzelkrebs, wie Agaricus melleus getöteten Stämme verursacht nur Kosten, bringt aber keinen Wert; das Umsichgreifen der Wurzelkrebskrankheiten erfolgt und unterbleibt, wie Beobachtungen im Walde lehren, trotz Stämmchenrodung und trotz sicherheitsgräben; der /eitpunkt der Bekämptung dieser Krankheiten ist der Zeitpunkt der Verjüngung (Stockrodung).

Man hat vielfach getadelt, daf die Praxis in diesem Alter des gedrängtesten Schlusses nicht aurchforstend eingreift, daß sie wartet bis das Material, das genützt wird, die Arbeitskosten deckt. Aus diesem Systeme aber sind vollendet astreine Bestände hervorgegangen. Terfasser zweifelt, daß unter Führung von Durchforstungsregeln, welche im gechängtesten Schlul, einen Erziehungsfehler der Wirtschaf't erblicken, ebenso astreine und ebenso hochentwickelte Schäfte und in so kurzer Keit sich ausformen kömnen. Die Erhöhung des Wertes auch des schwächsten Stangenholzes, wie es der Bestand im gedrängten Sehluß ausscheidet, hat dazu gefïhrt, daf. gegenwättig eine wahre Jagd auf diese Individuen betrieben wircl, die viel zu frül einsetzt und um eines kleinen Gewinnes oder nur der „Sauberkeit“ willen ein unersetzliches Mittel für die Stammespflege preisgibt; daß auch Erziehungssysteme erdacht wurden, welche im gerlrängten Bestandesschlusse einen der Wertserzeugung schärlichen Zustand erblicken, soll später gezeigt werlen. 
Es ist nicht nötig, ja nicht einmal rätlich, daß der gedrängte Schlußs so lange beibehalten wird, bis die Schäfte auf' wïnsch'nswerte Schafthöhe astrein geworden sind; es genügt und entspricht ciner naturund rentengerechteren Erziehung, wenn bis zur gewünsohten Baumhöhe hinauf die Schaftäste abgetötet wurden; das Reinigen, das Abstoßen, erfolgt dann in dem folgenden [ebensabschnitt des Banmes durch den Zahn der Zeit; während dieser Zeit treten aber wichtigere Aufgaben am einzelnen Baum in den Vordergrund: lie Steigerung des Massenzuwachses; der Stangenwuchspflege fällt die Förderung der Schaftgüte, der Baumwuchs. pflege die Förderung der Sehaftmassen zu; vom Eintritt des Bestandsschlnsses bis rund zum 30.-40. Jahre soll deshalb rer Bestand so dicht als möglich geschlossen erhalten werden. Wenn man einwendet, daß die Schneegefahr schon vor diesem Alter eine Schlußdurchbrechung fordert, so übersieht man, daß unsere Föhre auch dadurch gegen Schnee nicht geschützt werden kann, weil im Stangenalter das Holz stets allzu spröde und brüchig ist; man übersieht, daf die Schneegefahr für die übrigen Holzarten doch nur bei außerordentlichen Kalamitäten, welche glücklicherweise selten sind, merklichen Schaden den Jungwüchsen zufügen kann, - mit und ohne frühzeitige Auflichtung.

6. Entstehen Löcher im Stangenholze durch Schnee, Insekten, Pilze, Blitz und andere Ursachen, so werden sie mit möglichst schnellwachsenden Holzarten ausgefüllt, in der Weise, daß dem Lochrande parallel ein Streifen, gleich der halben Höhe des Bestandes frei bleibt. Bei 10 m Durchmesser der Blöße würde bei $111 \mathrm{~m}$ Bestandshöhe kein Nutzholz, sondern, wenn nötig. nur eine Schutzholzpflanzung eintreten können.

7. Nach Erreichung der Astreinigung und Asttötung bis zur wirtschaftlich nötigen $\mathrm{Baumhöhe} \mathrm{setzen} \mathrm{die} \mathrm{Durchforstungen}$ ein. Verfasser ${ }^{1}$ ) hält daran fest, daß Durehforstungen nach der ursprünglich gegebenen Deutung und Bedeutung des Wortes solche Maßregeln sind, welche nur unterdrüchtes Material dem Bestande entnehmen, so daß dadureh der Bestandsschluß gar nicht (schwache Durchforstung) oder nur für ganz kurze Zeit (starke Durchforstming) durchbrochen wird. A. We ise sagt in seinem Leitfaden für den Waldhan 1903 , daß ein Hieb, der so weit geht, daß zur Decknng dos Bodens besondere Maßnahmen nötig sind, nicht mehr unter den Begrift' einer Durehforstung fällt. Verfasser ${ }^{1}$ ) hat jene Maßnahmen, welche den $/$ weck haben den Bestandsschluß dauernd zu durchhrechen. damit noch ein Bodenschutzholz sich erhalten oder neu in den Bestand cingefügt

1) H. M a yr, Die Erziehungshiebe der neueren Schule, Allgem. Forst-u. Jagdzeitung 1 s.s9. 
werden kann, Durehlichtungen genannt und muß nicht bloß aus prinzipiellen, sondern auch aus praktischen, wirtschaftlichen Gründen an dieser Unterscheidung festhalten, was mit den folgenden Ausführungen näher begrïndet werden soll. Mit den Durchlichtungen beginnt auch cin nener Abschnitt im Leben eines Bestandes.

Die I urchforstungen innerhalb der Stangenwuchspflege begimmen zwischen dreifigstem und vierzigstem Lebensjahre und zwar zunächt in der sehwächsten Form, der Beseitigung der Toten und völlig Unterdrückten; die zweite mäligige Durchforstung nach etwa fünf Jahren (allgemein genommen sobald neues Durchforstungsmaterial sich ausgeschieden hat) greift neben bereits unterdrückten auch noch die eben mit der Krone untertauchenden Individuen heraus; die dritte nach weiteren fünf Jahren nimmt neben unterdrïckten und toten die in den Kronen von den starken Nachbarbäumen eingeengten, schlanken, vom Winde auf die Nachbarkronen geschleuderten und von diesen wieder zurïckgeworfenen Stangen (Peitscher genannt), und löst allzu enge (Yruppen durch Beseitigung der minderwertigen Stämme auf, so daß mit dieser starken Durchforstung, ungefähr im fünfzigsten Lebensjahr der Baumvereinigung, die Serie der Durchforstungen abschließen kann, worauf die Durchlichtungen folgen. Das Material, das bei den Durchforstungen anfällt, zählt alles, um mit der Praxis zu sprechen, zur. Tor-oder $/ \mathrm{w}$ is chennutzung.

Waren Jungwuchspflege und Stangenwuchspflege energisch und sachgemäß durchgefülırt, so findet die Durchforstung keine Stämme mehr, welche wegen Nutzholzfehler beseitigt werden müßten; der Grundsatz der Schlußerhaltung, beziehungsweise Wiederherstellung kann somit bei den Durchforstungen festgehalten werden. Eine Durchlöcherung des Kronenschlusses kann nur durch Beseitigung erkrankender oder getöteter Individuen oder vom Schnee gebrochener Stämmchen gerechtfertigt sein.

\section{Baumwuchspflege und -Erziehung.}

War die erste Hälfte der Umtriebszeit der Ausschaltung aller zu Nutzholzzwecken unbrauchbaren Holzarten und Stämmchen, der Astreinigung der besten Bestandsglieder gewidmet, so liegt der Schwerpunkt der Erziehung während der zweiten Hälfte der Umtriebszeit in der Erziehung von Holzmassen, welche sich an den mit Eliteschäften versehenen Bäumen bis zur Haubarkeit aulegen. Sind Jungwuchs- und Stangenholzpflege und -erziehung sachgemäß und energisch durchgeführt worden, so bleibt für die folgenden IIicbe nur noch jenes Material übrig, das beseitigt werden muß, damit die Kronen der Hauptstämmesich nicht melr schließen können; die Hiebe beabsichtigen somit eine Durchbrechung des Kronenschlusses und 
völlige Freistellung der Kronen; solche Hiebe dürfen nicht Durchforstung genamnt werden, ohne die Begriffe zu verwirren und langre Erklärungen nötig zu machen, was man unter solchen Durchforstungen zu verstehen hat. Verfasser hat sie Durchlichtungen genannt und alles Material, das sie entnehmen, ist zur H a uptnutzung zu zählen. Mit etwa 50 Jahren einsetzend werden Durchlichtungen ebenfalls anfẳnglich mäßì etwa alle fünf Jahre wiederholt, vom achtzigsten Jahre an wird ein Zwischenraum von zehn Jahren genügen, bis zur Haubarkeit; der Abstand der Kronen soll in der ersten Hälfte der Baumwuchspflege etwa $1 \mathrm{~m}$, in der letzten Iülfte etwa ㄴ $\mathrm{m}$ betragen; es entspricht dies einem Standraum der Bäume von rund 2.) qm, so daß pro Hektar rund 400 Stämme sich finden, von denen jeder $1-3 \mathrm{fm}$ Derbgehalt, je nach Holzart. Boden und Klima besitzen kann. Damit wäre erreicht, daß der Haubarkeitsbetrag eines derartig erzengten Bestandes nicht geringer ist, als die Haubarkeitserträge der bisher erzogenen Bestände. Nachdem aber auf dem bisherigen Wege der Durchforstung nur 2.5\% der Haubarkeitsmassen an $\%$ wischennutzungen gewomnen wurden, so stehen dieser Summe gegenüber die Durchforstungserträge mit rund $20 \%$ und die Durchlichtungserträge von rund $5.5 \%$ der Haubarkeitsmasse im neuen Walde. In der bisherigen Erziehung ist die Gesamtleistung des Waldes die Summe der Haubarkeitserträge $\left(A_{u}\right)$ plus der Durchforstungserträge (Df) im Alter a, b, c . . n; Holzertrag, somit $=A_{u}+D f_{a}+D f_{b}+D f_{c}+\ldots+D f_{n}$. Im neuen Walde ist die gesamte Leistung $=A_{n}+D f_{a}+D f_{b}+\ldots+D f_{n}$ $+\mathrm{Dl}_{\mathrm{a}}$ (Durchlichtungen) $+\mathrm{Dl}_{\mathrm{b}} \ldots .+\mathrm{Dl}_{\mathrm{n}}$.

Die Holzmasse ist im ersten Falle $=A_{u}+\begin{gathered}A_{u} \\ 4\end{gathered}$, im zweiten Falle $A_{u}+\frac{3 A_{u}}{4}$. Mran kann daher als Ideal, anf welches die Erziehung hinstreben soll, eine Formel bezeichnen, welche lautet: Gesamte Derbholzleitung $=2 \mathrm{~A}_{\mathrm{u}}$, da $\mathrm{Df}_{\mathrm{a}}+\mathrm{Df}_{\mathrm{u}}+\ldots+\mathrm{Df}_{\mathrm{n}}+\mathrm{Dl}_{\mathrm{a}}$ $+\mathrm{Dl}_{\mathrm{b}}+\ldots+\mathrm{Dl}_{\mathrm{n}}=\mathrm{A}_{\mathrm{u}}$, das heift die Vorerträge a us Durchforstungen und Durchlichtungen sollten gleich werden dem Haubarkeitsertrage, ohne daß dieser unter die Hanbarkeitsgröße der bisherigen Wirtschaften herabgeht.

Es mag sein, dats dieses Ideal sich nicht üherall und bei allen Holzarten erreichen läfot; die dänische Erziehung und Wirtschaft hat es für vier Holzarten : Eiche, Buche, Föhre, Fichte, erreicht, beziehungsweise ist sie dem Ideale sehr nahe gekommen. Bei den günstigeren, klimatischen Bedingungen Mitteleuropas ist kaum zu zweifeln, dali das Ziel erreichbar ist; denn durch die bisherige Methorle des geschlossenen Bestandes sind vier Faktoren der Urproduktion nur ungrenügend ausgenützt worden, das sind Wasser, Licht, Wärme und Bodengïte, ohne daß etwas an diesen Falitoren eingespart oder angehäuft worden wäre 
für kommende Baumgeschlechter und Ienschengenerationen. Damit aber der Boden hierbei nicht in Güte durch Verwilderung sich verschlechtere, ist Schutz des Bodens nötig durch einen Bodenschutz, der mit der natürlichen Auflichtung der Licht- und Halbschattenarten, mit der Durchlichtung der Schattenholzarten einsetzt. Diesen Boden. schutz kann keine Baumgattung der nördlichen Halbkugel besser gewähren als die Gattung Fagus, die Buchen, weil sie die einzige ist unter allen winterkahlen Laubbäumen, welche einen vollen Schatten selbst anderer Schattenbäume noch erträgt; sie geht schließlich kaum an Licht-, sondern an Wassermangel zugrunde. Im Castanetum wird der Unterban möglich sein, trotzdem dieses nicht die klimatische Heimat der Rotbuche ist, da die Überschirmung und Überschattung die der Buche nachteilige, allzu grofie Erhitzung im Sommer mildert; im Fagetum ist die Buche in ihrem urheimatlichen Klima, im wärmeren Picetum gedeiht sie als Unterbau, da die Überschirmung auch die der Buche schädlichen, allzu großen Kälteextreme mildert; in Castanetum und Picetum wird sie ein Stranch bleiben, was ihrer Rolle als Bodenschutz nur günstig ist: im Fagretum wird sie zum Füll- und Triebholze und schließlich zum Hauptstande aufzustreben suchen. An Stelle der Buche können auch Halbschattenholzarten wie Erle, Hainbuche, Ahorn, Linde oder selbst, wemn anch weniger vorteilhaft für den Boden und die Hauptholzarten, immergrïne Halbschattenholzarten (Nadelbäume) treten ; Näheres hierüber wird im Abschnitt XVIII, Bodenpflege, gebracht werden.

Unter den weiter unten aufgeführten Durchforstungs- und Durchlichtungssystemen der forstlichen Praxis und Literatur finden sich solche, welche in der Erhaltung des lebenden, unterdrückten Materials einen Ersatz für den Unterban erblicken; man rühmt die Beweglichkeit des Wirtschafters in der Handhabung der Durchlichtungen in den Kronen, da durch das unterdrückte Naterial der nötige Bodenschutz gegeben sei. Für Licht- und Schattenholzarten trifft diese Voraussetzung nicht zu, weil das Untertauchende und Unterdrückte sich nur so weit am Leben erhalten und nur eine solche Krone bilden kamn als der Lichtzuftuß durch das Dach der Herrschenden zuläßt. Lichtdurchlässigkeit des Hanpthestandes und Kronenentwicklung des unterdrückten oder Nebenbestandes stehen in innigstem Zusammenhang. Beide aber ergänzen sich zu einer Summe des Lichtentzuges für den Boden, welche gleich ist der Beschattung der normal geschlossenen Holzart. Es ist somit muter dem Dache des Unterstandes plus des Hauptbestandes einer Lichtholzart nicht heller und nicht dunkler als unter dem Dach eines natürlich gelichteten Lichtholzbestandes, das heißt der Boden verunkrantet; es ist unter dem Unterstande und Hanptbestande eines Schattenholzes z. B. Fichte, Tamne selbst Buche nicht heller oder dunkler als unter dem natür- 
lichen, geschlossenen Dache der betreffenden Schattenholzart, das heißt, am Boden findet ungenügende Zersetzung der Abfallsstofle, Anhäutung von Rohhumus statt; der Boden bleibt somit bei Verwendung dos unterdrückten Materials als Borlenschutz in der gloich ungünstigen Lage, als ob der Bestand boi schattenholzarten zeitlebens geschlossen, bei Lichtholzarten nicht unterbaut worden wäre. Gewinn für den Boden beginnt erst dann, wenn an Stelle der unterdrückten Lichtholzarten eine Halbschatten- oder Schattenholzart, wonn an Stelle der unterdrückten immergrünen Schattenholzart eine winterkahle Sehattenholzart tritt. Das unterdrückte Material wird willkommen und nützlich sein bei der Verjüngung als Schutz des Bodens und der nenen Waldgeneration.

Es ist eine dureh die Praxis längst festgestellte Tatsache, dal. nirgends eine Samenverjüngung so rasch, so leicht, so willig und so sicher sich abspielt als auf frisch verwundetem Buchenboden; dem die beiden wichtigsten Momente sind hier vereinigt: bestes Keimbeet und Fehlen des Unkrautwuchses. Dieses günstige Verhältnis herzustellen und bei der Verjüngung auszunützen, ist einer der Zwecke des Unterbaues aller Holzarten. Der zweite ist die wahre Bewegungsfreiheit in den Durchlichtungshieben; soll aber gleichzeitig das Untertauchende und Unterdrückte vor der Verkümmerung bewalırt werden, muß dei den Durchlichtungen auch auf den Nebenbestand Rücksicht genommen werden; die freie Bewegung ist dadurch grehemmt.

Es wurde bei der vorausgegangenen Darstellung der .Jungwuchs-, Stangenwuchs- und Baumwuchspflege und -Erziehung vermieden, eine komplizierte Einteilung der Glieder eines Bestandes nach Kronenklassen zu geben; je einfacher die Unterscheidung, desto besser. Die gegebene Einteilung lehnt sich mehr den ältesten Bezeichnungen, wie besonder's Cotta, König und andere sie gaben, und den neueren von Kraft an. Es werden unterschieden: tote, unterdrïelite (noch lebende), eben untertauchende, mit der Krone noch eingeklemmte (eingeklemmte), herrschende und vorherrschende Stämme. Was darunter zu verstehen ist, braucht keiner weiteren Erklärung, dio aber sofort notwendig wird, sobald man die Klassen mit Buchstaben bezeichnet und mit diesen weiter operiert. Es wurde vermieden, irgendeine Einteilung der Stämme nach Sehaftgüteklassen, wie Heck sio rorgeschlagen hat, zu wählen. Es bedarf für den Forstwirt, selbst den ungebildeten, nicht einer Erklärung, was ein \%wiesel, ein kranker, ein krummer oder krebsiger Baum ist, und es berlart' nicht der Vorschrift, daß, wenn ein solcher Baum einen besseren Nutzstamm bedrängt, der erstere fallen muß. Es sei aber zugegeben, daß vielo Forstwirte in Gehorsam gegen den Grundsatz der ängstlichen Erhaltung des Bestandsschlusses den untertauchenden, schönschäftigen Stamm beseitigen und den krummschäftigen. vordrängenden Tangenichts am Lehen lassen. 
Es liegt in der Biologie des Bestandes begründet, daß alle Übergänge von einer Stufe zur anderen vorhanden sein müssen, da ja im Laufe des Bestandslebens Tausende von Stämmen aus herrschenden allmählich zu unterdrückten werden und absterben.

Da Verfasser im ganzen Verlaufe der vorliegenden Schrift die Absicht verfolgt hat, neben der eigenen Ansicht auch jene anderer Schriftsteller und Forscher gelten zu lassen, so sollen in nachfolgender kurzer Zusammenstellung die bisher ausgedachten oder ausgeübten Durchforstungssysteme gebracht werden. Hinsichtlich der Geschichte der Durehforstungen sei auf die Arbeiten von Franz von Baucr, in jüngster Zeit von Dr. Carl La aschke (Nendamm 1902) und Dr. Vinz. Schüpfor 1903 hingewiesen.

Die unten gegebenen Durchforstungssystem gehen alle von Beständen aus, in welchen während der Jung - und Stangenwuchsperiode die wichtigste Pflege und Erziehung versäumt w urde. Diese Voranssetzung triftt allerdings für die weitaus größte Mehrzahl der aufwachsenden Bestände zu, so daß in der Tat im Zeitpunkt, in dem die Durchforstung beginnt, noch Unhölzer, breitästige Torwüchse (Protzen', zwieselige, krebsige und krummschäftige Individuen vorhanden sind, zu deren Ungunst dann Regeln (freie Durchforstung nach Heck, Plenterdurchforstung nach Borggreve) oder Ausnahme von den Regeln des Durchforstungssystems aufgestellt werden. Es erhellt daraus aber deutlich, daß die Durchforstungen außerordentlich erleichtert, verbilligt und vereinfacht werden, wemn schon bei der Bestandsbegründung $\mathrm{A} u s w a h l p f l a n z u n g$ eintritt und in der J ung wuchsptlege, bei der es am leichtesten, billigsten und schadlosesten geschehen kann, alles beseitigt wird, was nicht wert scheint, dabes Baum wird.

G. L. Hartig gibt in seiner Anweisung zur Holzzuclit die Regel, daß nur ganz oder halb abgestorbenes, völlig übergipfeltes Holz heransgehauen werden dürfe; seine Vorschrift ist somit eine Durchforstung. Professor Dr. Hausrath ${ }^{1}$ ) erwähnt, daß die noch jetzt gültigen sogenanuten IJartigschen Durchforstungsregeln nicht von Hartig, sondern von $\mathrm{Duhamel}$ d u $\mathrm{M}$ oncea u, dem berühmtesten Forstmanne des 18. Jahrhunderts, stammen; Hartigs Verdienst sei es, diesen Regeln durch eine populäre Darstellung zum Durchbruch verholfen zu haben.

H. Cotta und Pfoil 1820 wollen in dem Augenblicke, in welchem Bestandsschluf eintritt, mittels Durchlichtungen verhindern, daß die Kronen sich bedrängen. So oft als möglich sollen diese Hiebe wiederholt werden.

Ch. Liebich vertritt die sngenannte Prager Schule, welche statt

1) Forstwissensch. Centralblatt 1896. 
Durchforstungen Maßnalmen verlangt, welche man als Durchlichtungen bezeichnen muß. Jeder Stamm soll einen entsprechenden Sitandraum erhalten; alle 10 Jahre wiederholen sich die Hiebe; damit künftighin diese "Durchforstungen", welehe (damals) nur wertloses Material lieferten, in Wegfall kämen, soll sehr weitständig gepflanzt werden.

Hundeshagen will nur die Herausnahme des abgestorbenen Materials.

Pfoil 1860 will anfangs nur Unterdrüclites, später Durchlichtung bei Fichte, bei Eiche nur Durchforstung.

Fcistmantel will oftmals durchforsten, aber bloß im Nebenbestande.

K. Heyer will ebenfalls nur das Übergipfelte in anfangs kürzeren, später längeren Perioden nach dem Grundsatz: "Früh, oft und mäßig“" herausnehmen.

Grabner ist der Erste, welcher den Gedanken ausspricht, daß der Nebenbestand erhalten werden soll, daß die herrschenden Stämme von Jugend an freizuhauen sind, damit sie ohne jeden Kampf mit den Nachbarn in das Haubarkeitsalter übergehen; seine Methode ist somit keine Duchforstung, sondern eine Durchlichtung.

Fischbach will, daß das Unterholz in der 2-3fachen Zahl der Haubarkeitsstämme zum Zweck der Bodenüberschirmung erhalten bleibe.

speidels wïrttembergische Wirtschaftsregeln wollen Erhaltung des Nebenbestandes als Bodenschutzholz und entsprechende Pflege des Hauptbestandes durch Freihieb in den Kronen nach Abschluß des Hauptlängenwachstums.

Burckhardt unterscheidet eine dunkle, eine mäßige oder gewöhnliche und eine starke oder vorgreifende Durchforstung; bei allen drei Graden wird der Nebenbestand zuerst herausgehauen.

Kraft hat eine Einteilung der Stämme und Stämmchen eines aufwachsenden Bestandes gegeben, welche am meisten Anerkennung gefunden hat. Sie lantet: Vorherrschende Stämme, herrschende, gering mitherrschende, beherrschte: letztere zerfallen wiederum in zwischenständige oder eingeklemmte und teilweise unterständige (nach der $\mathrm{Be}$ zeichnung des Verfassers dieser Schrift ,untertauchende“); endlich ganz unterdrückte, welche teilweise noch lebensfähigo oder absterbende oder bereits abgestorbene sind. Seine Regeln für die Erziehung der Bestände lauten: Sicherung guter Stammformen durch Vorminderung starker Eingriffe in die Schlußverhältnisise der Stangenorte behufs Erzielung astreiner und vollholziger Schäfte; allmähliche Lockerung des Bestandsschlusses zur Gesunderhaltung der Kronen: daher für junge Stangenorte Enttemung der Eingeklemmten: für ältere stangen- und Baumorte Herausnalime der Mitherschenden behufs Freistellung der Herrschenden (Durchlichtungen). 
Borggreves Plenterdurchforstung, deren Wesen bereits früher bei der Reformwaldwirtschaft besprochen wurde, beginnt erst mit dem (iv). Jahre in Beständen, in welchen bis dahin ein rationelle Erziehung gefehlt hat. Sie nimmt Vorherrschende (Protzen) in der Absicht einer hochwertigen Vornutzung und in der Hoffnung eines Eintretens der bedrängten Nachbarn, welche bessere Formen zeigen, in die dadurch entstandenen Lücken; dieses Verfahren wird alle 10 Jahre wiederholt.

Wagener beginnt den Kronenfreihieb der 400 Frohwüchsigsten pro Hektar schon vom 20.-30. Lebensjahr an; es sollen somit gerade in dem Augenblick, in dem der dichteste Schluß für die Astreinigung nach Ansicht des Verfassers am notwendigsten wäre, Durchlichtungen (Kronenabstand $50-70 \mathrm{~cm}$ ) eingelegt werden; der Füllbestand wird nur schwach durchforstet: alle zehn Jahre wiederholen sich die Durchlichtungen oder die Kronenfreihiebe: nach der zweiten Durehlichtung: tritt bereits Unterban ein.

Bohdanecki in Worlik will ebenfalls den Bestandesschluß als eine die Kronen der Hauptstämme und die Ausnützung des Bodens schädigende Erscheinung frühzeitig auflösen; die Krone muß in einem bestimmten Verhältnis zur Gesamtlänge des Stammes stehen, damit die beste Holzgïte mit einer Jahresringbreite von 3-4 $\mathrm{mm}$ entstehe (Millimeterbetrieb genannt): der Nebenbestand ist gleichgültig.

A. Schiffel ${ }^{1}$ ) gibt für Fichten folgende Durchforstungsregeln:

1. Ohne Rücksicht auf die Art der Begründung und auf die Bonität sind in den. Jungwïchsen die Eingriffe wiederholt und in dem Naße fortzusetzen, daß eine Reinigung (Dürrwerden) der untersten Äste so lange hinausgeschoben wird, bis der Bestand die Höhe von mindestens $5 \mathrm{~m}$ (bei besseren Bonitäten mehr) erreicht hat.

2. Die Schaftreinigung soll allmählich fortschreiten und darf der halben Schaftlänge erst dam gleichkommen, wenn der Bestand das Maximum des Höhenzuwachses bereits erreicht oder überschritten hat. Hauptziel sei das Drängen im Bestande (Dickungsschluß, Dichtschluß, gedrängter Schluß nach früherer Darstellung) zu verhindern.

3. Bei der Durchführung der Durchforstungen in der Stangenholzperiode tritt unter allen Umständen die Baumindividualität in ihr Recht; auf eine möglichst gleichmäßige Verteilung des Wuchsraumes für alle entwicklungsfähigen Stämme sei zu achten.

4. Nach Erreichung der Schaftreinigung bis zur halben Schaftlänge im Stadium der Höhenzuwachskulmination ist die Hauptanfgabe der Bestandeserziehung gelöst; fortab ist eine weitere gleichmäßige Schlußunterbrechung unuötig, und es sind die weiteren Durehforstungen in größeren Zwischenräumen und mäßig durchführbar. Schiffel will

1) A. Schiffel, Wuchsgesetze normaler Fichtenbestände. Wien 1904. Zeitschrift für das ges. Forstwesen 1906. 
nicht die Begünstigung von Elitestämmen, sondern aller gutwïchsigen, normalkronigen; die dichteste Erziehung verlangen Buche und Ficho, die lockerste die Lärche; allgemeine Regeln für Beginn der 1)urchforstungen gibt es nicht.

Michaelis ${ }^{1}$ ) will durch fortgesetzte Steigermug der Durchforstung im Herrschenden (das sind somit Durchlichtungen) eine fortgresetzte Steigerung des Y W wachses erzielen; da beigleichbleibenden Z u w a c hs e mit der Durchmesserzunahme die Jahrringsbreite abnehmen muß, würde bei Zuwachszunahme ein 6 l leichbleiben der.J a liresringe, das Kiel der Erziehung, sich erreichen lassen.

Martins ${ }^{2}$ ) Vorschläge gehen dahin, daß nach Herstellung einer guten Schaftform die Kreisflächensumme des Bestandes ermittelt wird; diese soll ron da an gleichgroß bleiben; was über sie hinaus zuwächst, soll im Wege periodischer Durchforstungen (dürften später in Durchlichtungen übergehen) weggenommen werden.

A. Schwappa $\mathrm{ch}^{3}$ ) faßt die Aufgabe der Bestandeserziehung in die Worte zusammen: Ausbildung guter Schaftformen mit genügender Stärke und ron tadelloser Holzbeschaffenheit in möglichst kurzer /seit unter steter Rücksichtnahme auf Bodenpflege.

Er verlangt insbesondere Rücksichtnahme aut die biologischen und physiologischen Eigenschaften der verschiedenen Holzarten und auf die höhere Bedeutung des Jugendstadiums für Massen- und Werterzeugung. Tanne, Fichte und Lärche sollen bis zur Beendigung des Hauptlängenwachstums in lockerem Schluß gehalten werden, so daß bis zu diesem Zeitpunkt die Kronenlänge nur allmählich auf ein Drittel der gesamten Schaftlänge herabsinkt. Eichen und Buchen verlangen dichten Schluß in der Jugend, der durch frühzeitig beginnende Aushiobe aller schlechtwïchsigen, kranken Stämme, durch Auflösmng von Gruppen und Bescitigung der Konkurrenz zweier gleichstarker Nachbarn allnählich unter steter Schonung des noch lebensfähigen, unterständigen Materials immer mehr gelockert wird. Die Kiefer ist im wesentlichen den vorigen gleich, doch etwas freier zu erziehen. Nach Beendigung des Hauptlängenwachstums tritt die Aufgabe zur Förderung des Stärkezuwachses in den Vordergrund; die hierfür empfohlenen Hiebe zählen zu den Durchlichtungen. Bei der Bestandeserziehung darf der Trunsch nach Massenerzengung niemals die Rücksicht auf die gute Beschaffenheit des zu erziehenden Nutzholzes in den Hintergrund drängen.

Ney verlangt Schonung des Unterdrückten, Durchlichtungen erst nach dem Hauptlängenwachstum.

$\left.{ }^{1}\right)$ Michaelis, Gute Bestandespflege mit Starkholzzucht. 1907.

$\left.{ }^{2}\right)$ Dr. Martin, Zeitschrift für Forst- u. Jagdw. 19)2.

${ }^{3}$ ) Prof. Dr. A. Schwappach, Referat aber die Begrandung und Erziehung von Waldbeständen unter Rucksichtnahme auf hohen Massenzuwachs und gute Holzqualitiit. Internat. landw. Kongreß. Wien 1907. 
v. Fürst will den Kampf zwischen den Dominierenden erleichtern durch Entnahme der Bedränger: er will aber auch das Unterholz beseitigen, um den bleibenden Bestand zu fördern.

Eclaircie par le hat oder Hochdurchforstung ist eine in Frankreich schon 1790 in den Fichenhochwaldungen geübte Durchlichtung, welche sich vorzugsweise unter Führung von Broilliard und Boppe aus dem Mittelwald heraus entwickelte. Diese Methode schont das Unterständige, greift aber in den herrschenden Bestand kräftig ein (Durehlichtung), damit die Kronen sich nach allen Seiten hin, wie bei Oberhölzern des Mittelwaldes, entwickeln können; gruppenständiges Oberholz des Nittelwaldes ist daher nach dieser Auffassung ebenso schädlich wie gruppenweises Zusammenstehen stärkerer Individuen, womit auch die Verjüngung in den Gruppenformen eine Verurteilung erfährt.

Die Dänische Durchforstung ist nur in der ersten Hälfte der Umtriebszeit eine Durchforstung, ron da an eine Durchlichtung; das Verfahren hat daher "Dänische Durchforstung und Durchlichtung“ oder „Dänische Erziehung“ zu heißen. Durch Reisen und Schriften ron Dr. Metzger ist diese sehr beachtenswerte Erziehungsmethode in der forstlichen Literatur näher bekannt geworden. Zwar ist das Verfahren vorzugsweise an der Buche ausgeführt worden; es wird aber auch an Eiche, Föhre und Fichte gehandhabt und dïrfte für alle Holzarten passen oder doch sehr beherzigenswerte Lehren zur Behandlung dieser in sich schließen. Das Verfahren unterseheidet: Ha uptstämme, d. h. solche, welche wegen ihrer Geradschaftigkeit und gleichmäßigen Bekronung: zu begünstigen sind, und schädliche Nebenstämme, d. h. solche, welche die zu erhaltenden Hanptstämme belästigen; dann unbrauchbarc Stämme, d. h. solche, welche keine Nutzholzeigenschaft zeigen: sodamn nitzliche Nebenstangen, welche die Astreinigung des Hauptstammes bis zur beabsichtigten Höhe zu fördern haben; endlich indifferente Stämme, welche noch nicht erkennen lassen, ob sie Hauptstämme werden oder zu schärllichen Nebenstämmen herabsinken.

Die Dänische Durchlichtung entfernt stets die schädlichen Stämme, die unbrauchbaren Stämme, versehont aber die indifferenten und nützlichen. Der Unterstand wird somit versehont; die lirone soll $4 / 10$ der Schaftlänge betragen; nachdem der Schaft auf $15 \mathrm{~m}$ Länge von den Ästen gereinigt ist, beginnen die Durchlichtungen. Tor Eintritt des Samenjahres setzt eine gründliche Bodenlockerung mit Pfügen und Eggen ein. Nach Samenabfall wird abermals geeggt, Fehlstellen werden angesät. Die Fläche wird mit Kalkstaub überstreut. Wegen des kräftigen Wuchses der Pflanzen kann frühzeitig gelichtet werden; die Eichen werden ebenso behandelt, nur müssen sie, wenn Verunkrautung sich zeigt, mit Buchen unterbaut werden. I) Ergebnisso diieser Dänischen Erziehung beweisen, daß es mit Durchlichtungen gelingt, die Vor- 
nutzungen den Haubarkeitserträgen in Masse grleichzubringen, ohne die Haubarkeitserträge unter die normalen sink'n zu lassen.

H. Borgmanns horst - und gruppenweise Lichtwuehs durchforstung ist eine erst mit dem jo. Lebensjahre rles Bestandes - hier Fichte und Tamne - beginnende Durehlichtung, welche sich auf 10 a große Flächen im Bestande gleichmäßig verteilt; innerlıalb der Gruppen finden Hiebe von fünf zu fïnf Jahron statt, weleho allmählich die bestgeformten Stämme in möglichst regelmäßige Entfernung von $6 \mathrm{~m}$ bringen sollen; die unterständigen noch lebensfähigen Stangen bleiben erhalten; mit dem 75 . Jahre beginnt von der Mitte der Horste aus die Verjüngung.

Vogl in Kogl (Salzkammergut) verlangt bis zum 50. Jahre in steigender Stärke Durchforstungen; von da an beginnen Durchlichtungen, bis schließlich nur 200-300) starke Stämme pro Hektar übrig bleiben, welche aufgeästet werden. Frühzeitig tritt V'erjüngung ein; die Vorwïchse werden ebenfalls aufgeästet; so entsteht eine femelwaldartige Bestandesverfassung, welche große Sicherheit gegen Wind und volle Ausnützung des Lichtungsgewächses gewährt. Die Verjüngung ist eine natürliche; wo sie lückig bleibt, wird gepflanzt; die Fällung der Lichtwuchsstämme über $i-8 \mathrm{~m}$ hohem Vorwuchse verursacht nicht solche Beschädigung, daß nicht alles sich wieder verwïchse.

Uriehs Lichtwuchskulissenbetrieb beschränkt das Wagenersche Verfahren auf Betriebsstreifen ron $15-20 \mathrm{~m}$ Breite, zwischen welchen Streifen von $40-60 \mathrm{~m}$ Breite liegen bleiben, welche in der bisher üblichen Methode durchforstet werden sollen. Urichs Kulissendurchlichtung sucht die bedenklichsten Erscheinungen in W a gen ers Durchlichtung: Laubverwehung, Verunkrantung und Verwilderung des ganzen Bestandes, durch die Zwischenstreifen hintanzuhalten. Vom 70 . Jahre an werden auch diesc $/$ wischenstreifen der Durchlichtung geöffnet. Im (1). Jahre kanı der Bestand gleichmäßiig durchlichtet sein und in die Verjüngung eintreten. Urich denkt bei seinem Verfahren zunächst an die Buche.

Hecksfreie Durchforstung soll frei sein von jerter si.hul. und Schablone, frei in der Wahl der zu beseitigenden und zu belassenden Stämme. Man kann Heck hierin zustimmen, wenn er meint, daß in jedem Bestande eine andere Methode oder mehrere Metholen oder selbst ein Gebräu verschiedenster Methoden der Durchforstung und Durchlichtung der richtigen Erziehung entsprechen kann; wem wir einmal die Biologie der Holzart genamer kennen unıl diese Kenntnis eine allgemeine Verbreitung gefunden hat, wird jeder von sollst die richtige für den Bestand passende Erziehungsweise herausfinden. Einstweilen aber nüissen wir uns immer noch mit Vorschriften darïber, was 
unter allen Umständen erhalten und unter allen Umständen beseitigt werden $\mathrm{mu} \beta$, begnügen.

Heck gibt Schaftgüteklassen für seine Durchforstung, womit er beweist, da13 er Bestände meint, in denen selbst das ABC der Jungwuchs- und Stangenwuehspflege versäumt oder sogar verboten wurde. In seinen Klassen sind Stockausschläge, sehr stark vergabelte Zwiesel, krumme, rauhästige und kurzschaftige Stämme enthalten: er geht somit von Beständen ans, in denen jegliche rationelle Pflege mangelte. Der Freihieb der besten und besseren Schaftformen kennzeichnet Heeks "Freie Durchforstung“ als eine "Freie Durchlichtung". Der Bestandessehluß soll im allgemeinen, das Unterdrückte im besonderen erhalten werden.

v. Salisch geht von der waldbaulich als selbstverständlich erscheinenden Voraussetzung aus, daßs unter Lichtholzarten (Eichen) unterständige Schattenholzarten (Buchen) nicht beseitigt werden sollen: es ist ja eine der wichtigsten waldbaulichen Regeln die Lichtholzart mit einer Schattenholzart zu unterbauen. Er dehnt nun dies aus ästhetischen Rücksichten auch auf andere Holzarten aus und verlangt Erhaltung des Lnterdrückten, Freihieb des Herrschenden, Auflösung ron Gruppen kräftig entwickelter Stämme. Weise hat diese Durchforstung Posteler-Durchiorstung genannt, sie ist aber eine Durch lichtung.

Kožeśniks (1898) und Haugs (1899) Durchforstung nach Stammzahltafeln geht von der Toraussetzung aus, daf es für jede Holzart, jegliches Alter, jeglichen Standort eine bestimmte Stammzahl geben muß, bei weleher die wertrollsten und größten Holzmassen pro Flächeneinheit erzielt werden. Sie verlangen daher die Aufstellung von Stammzahltafeln für jede Holzart, jedes Alter, jeden Standort mittels Probeflächen, welche in möglichst normalem, das heißt gesehlossenem Bestande auszuwählen wären. Wenn eine solche Untersuchung ïberhaupt durehgeführt werden kann, dann scheitert die allgemeine Anwendung der Stammzahltafeln wieder an der Schwierigkeit der Angleichung eines konkreten Falles an die Tafeln. Wären alle diese Schwierigkeiten zu überwinden, so könnten ja solche Tafeln mit Stammzahlen immerhin nach Absicht der Erfinder zur Berthigung der Wirtschafter dienen, wenn sie über die Stärke des Eingriftes im Zweifel sind. Einem solchen Gerlankengange folgt auch Schiffel (l. c. 1!1)4): Als ungefährer Maßstab für die Stärke des Eingriffes kamm nach erfolgter Bonitierung die Stammzahl der Ertragstafel für die Lichtsehlußform (der Fichte) gelten.

Die forstlichen Versuchsanstalten verfolgen mit ihren Durchforstungsmethoden clie genane, wissenschaftliche Feststellung des Einflusses versehiedener Durehforstungsgrade und -systeme auf $\mathrm{Zu}$ wachs in Masse und Güte, sowie auf den Zustand des Bodens. Wenn sie somit auch den Zielen der praktischen Forstwirtschaft dienen, ist 
flechte noch nicht alt genug, um eine Daurgrenze geben zu können; Vertasser hat verzinkte Drähte seit 25 Jahren, verzinkte (ietlechte seit 1i Jahren in Gebrauch; sie sind noch so gnt wie neu; nur die hölzernen Pfosten mußten innerhalb 2; . Jahren dreimal erneuert werden; bei hölzernem Zaun mußte immerhalb derselben /eit dreimal eine völlige Auswechselung eintreten: die übrigen Schutzmittel müssen alljährlich ernenert werden.

Was die Kosten der Nicherung anlangt, so steht zweifellos al einmalige und höchste Ausgabe obenan der Zaun. Es muß den Wirtschaftern überlassen bleiben, alle Kosten für Sicherung mit anderen Mitteln ebenso korrekt zu berechnen, wio dies bei der Anlage des Zaunes geschieht, bei welcher alle Kosten in einem Zeitpunkte zusammenlaufen. Es muß aber aus der Erhebung konstatiert werden, daß immer mehr die Überzeugung sich durchringt, daß f̈ür größere Gruppen ja Schläge von Jungwüchsen das beste Schutzmittel, der Zaun, auch das billigste ist. In den französischen Staat:waldungen werden zum Schutze gegen Kaninchen die Grenzen gegen Privatwaldungen anf viele Kilometer hin mit Drahtgeflecht versehen.

In der ganzen Schrift sind keine Kostenvoranschläge zu finden: absichtlich wurden sie weggelassen als zu geringwertig; Kostenanschläge, die um ihr Doppeltes, ja bis zum zehnfachen Betrage, je nach Örtlichkeit und Umständen, varïeren, sind wertlos. Die neuere Zeit hat sich in Verbilligung der Schutzmittel und Verteuerung der Arbeitslöhne so geändert, daß alle früheren Anschläge wertlos geworden sind und die gegenwärtigen es ebenso sein müssen, da voraussichtlich in nächster Zeit wiederum sich alles hierin ändert: wo der Bedarf wächst, mindert sich der Preis der Schutzmittel. Man liam im Interesxe des Waldes und seiner Rente nur wünschen, daß an Stelle des Einzelschutzes einer jeden Pflanze der Flächenschutz durch den Zaun tritt.

Wird am Einzelschutze festgehalten, oder ist derselbe notwendig aus lokalen Gründen, zu denen, gegenüber fremdländischen Arten, auch die Verweigerung der Mittel durch die vorgesetzte Behörde zählt. so ist Folgendes zu beachten.

5. In Fichtenjungwüchsen, welche in einem Verbande unter $1.5 \mathrm{~m}$ Abstand emporwachsen, sei es daß sie aus Saat oder enger Pflanzung hervorgegangen sind, ist es eine Verschwendung, jede Pflanze schützen zu wollen; es genügt, wenn jede zweite mit dem scchutzmittel bedacht wird. Hierdurch werden $5 \%$ an den Kosten der Sicherung eingespart und den Tieren des Waldes, deren Ausrottung niemand wünscht, ist Nahrung geboten.

15. In der Auswahl, in der Staffel-oder //wischenstrauchpflanzung werden selbstredend nur die Elitepflanzen der Edelholzarten in weitem Verband geschützt; insbesondere gilt dies gegen das Vertegen durch den Rehbock. 
7. Wenn es nicht gelingt, ein Schutzmittel gegen das Schälen der Stangen durch das Hirschwild zu finden - vielleicht ist in dem Flammingerschen Baumkratzer dies gefunden -, so ist Hirschwild mit einer Waldwirtschaft, welche rechnet, nicht vereinbar.

8. Das Eichhörnchen, das, wie alle Nager, eine Nassenvermehrung erfährt, ist wegen seines schweren Schadens in Saatgärten, wegen des Ausgrabens und Verzehrens der Sämereien, wegen Abschälens der glatten Rinde an jungen und alten Bäumen, wegen Abbeißens der Gipfelknospen mit nachfolgender Verzwieselung, durch Abschuß auf ein minder schädliches $\mathrm{Maß}$ (ein unschädliches gibt es bei diesem Tiere überhaupt nicht) $\mathrm{zu}$ vermindern.

9. Die Schonung der Feinde aller warmblütigen Schädlinge ruft zwar die Entrüstung der Jäger im Walde herror; in einem Abschnitte, der sich der Pflege des Waldes widmet, klingt die Empfehlung minder unverständlich; ja, gegenüber dem Jäger, welcher als das schädlichste Tier für die Jagd den Fuchs bezeichnet, muß der waldbauende Forstwirt eingestehen dürfen, daß für den Wald der Fuchs - das nützlichste Tier ist.

In manchen Ürtlichkeiten ist der Maulwurf der neuen Kultur schädlich, indem er die mit Füllerde versehenen Pflanzenlöcher durchwühlt, die Pflanzen lockert, so daß sie bei trockener Witterung erliegen. Es empfiehlt sich das mehrmalige Festtreten der Pflanzen während des ersten Sommers.

10. Je mehr das Rechnen im Walde üblich wird, um so mehr treten jene Belämpfungsmittel gegen Insekten und Pilze zurïck, welche auf Vernichtung der bereits vorhandenen Schädlinge abzielen, um so mehr treten die Vorbeugungsmittel in den Vordergrund; gegen den Rüsselkäfer hilft die Beseitigung oder Entrindung seiner Brutstellen, der Stöcke: gegen den Wurzelkrebs durch Agaricus melleus und Polyporus annosus hilft ebenfalls die Rodmng der Stöcke und, wo diese in toto nicht zulässig ist, die schon früher erwähnte Femelrodung der Mellens- und Amnosus-Stöcke; die Schutzmittel gegen die Śchädlinge des Waldes müssen vorbengender, somit zumeist waldbaulicher Natur sein, wenn sie durchgreifend und billig sein sollen. Gegen die Schütte hilft vielfach das Bespritzen mit Kupfermitteln; nicht scheint Naturverjüngung, nicht die Düngung ein Vorbeugungsmittel zu sein; aber der Anbau schüttefester Föhren hilft in besonders gefährdeten Standorten gründlich; gegen die Maikäferlarve hilft Vermeidung größerer Kahlffächen; gegen Nonnen, Spanner, Borkenkäfer und andere Vermeidung großer reiner Bestände durch Kleinbestandsmischung des Waldes.

11. Gegen Unkrautwuchs, wie hochaufschießende Gräser, rankende, kletternde, schlingende, breitbuschige Sträucher, hilft nur das Abschneiden, Herunterziehon, Aushauen; es genügt, diese lichtbedürftigen 
Pflanzen dem Licht zu entziehen und unter die Krone des Jungwuchses zu stoßen oder zu treten; Graswuchs gibt durch seine Beseitigung sogar Gewinn; der oft verdächtionte Efeu ist harmlos.

12. Schutz gegen Schnee, besonders an llängen gegen das $\mathbf{A b -}$ gleiten des tauenden Schnees bietet die Coazsche Nischenpflanzung mit Verwendung von Steinen; auch das Aneinanderbinden der PHanzen in den senkrechten Reihen von einer Bergkuppe 'zur Talsohle mittelst Strohseiles oder auch mit Stangen ist in Verwendung gekommen. Am besten dürfte in solchen Fällen immer die Terwendung möglichst kleinen Pflanzenmaterials in terrassierten Streifen sich bewähren: ist letzteres untunlich, so werden kleine Pflanzen stets den größeren vorzuziehen sein. Gegen das Umdrücken der Pflanzen durch Schneebelastung hat man das Abschütteln des Schnees mit gutem Erfolg angewendet: solche abnormen Schneefälle sind Ausnahmen, so daß nicht alljährlich die Maßnahme notwendig wird; eine Pflanze, die in den Wurzeln gezerrt ist, vermag sich von selbst nicht mehr aufzurichten, sie muß angeheftet werden, wie es notwendig ist, zum

13. Schutze gegen Wind. Das beste Mittel ist Verwendung möglichst kleinen Materiales und weitständige Pflanzung; für Heisterptlanzung kamn das Anbinden, wie es bei hochstämmigen Obstbäumen üblich ist, notwendig werden; an solchen vom Wind gefährdeten Örtlichkeiten sollte die Heisterpflanzung unterbleiben: sie ist ohnedies für den gegenwärtigen, wirtschaftlichen Betrieb zu tener.

\section{Stangenwuchspflege.}

Die Stangenwnchspllege umfaßt den Zeitraum vom Beginn des Bestandsschlusses bis zu seiner künstlichen Auflösung; ihr Z $\mathrm{iel}$ is t Förderung der Schaftschönheit und Güte. Mit dem Eintritt des Bestandsschlusses beginnt der gedrängte Schluß, der dichteste Schluß, in dem die Seitenäste abgestoßen und das Höhenwachstum gefördert wird. Es muß ein Ziel des natur- und wirtschaftgerechten Waldbaues sein, diese Zeit der Ästereinigung nicht über Gebühr anszudehnen, während dieser Zeit aher möglichst jene Faktoren zu rerstärken, welche die Ästeabstoßung heschleunigen. Je dichter der Schluß, um so rascher und sicherer die Abtötung der Äste durch Lichtentzug, desto rascher durch Ansammlung von Lufteuchtigkeit die saprophytische Zerstirrung der getöteten Âste. In diesem Alter mup daher der BestandsschluB ängstlich erhalten werden: die positiven und neqrativen Maßregeln, welche am besten "Reinigungen“ genannt werilen. sind in diesem Alter folgende:

1. Beseitigung ron krummwüchsig sich entwickelnden, im Warhstum den übrigen voraneilenden, bessere Individuen in den Kronen bedrängenden Stangen ohne Rüchsicht aut Schluldurchlorechung; 
2. Heraushauen von $/$ wieseln, welche erst im Stangenalter durch Schneebruch, durch Knospenabbiß oder Gipfelschälen der Eichhörnchen, durch Pilze entstehen (die Zwiesel der Jungwuchsperiode wurden rechtzeitig in dieser beseitigt); auch diese Operation darf auf Bestandsschluß keine Rücksicht nehmen;

3. Beseitigung allenfalls in diesem Alter noch vordrängender Unhölzer, ehenfalls ohne Rücksicht auf Schluß.

4. Dagegen wird unterlassen: die Herausnahme der unter. drückten noch lebenden Individuen, gleichgültig ob sie der Hauptholzart oder einer Unholzart oder nur Straucharten angehören; das vielfach übliche Putzen der Stangenhölzer ist eine schädliche Maßnahme, welche vielleicht der Ästhetik, sicher nicht dem Nutzen ihren Ursprung verdankt.

5. Wo keine Fenersgefahr besteht (solche Örtlichkeiten gibt es in feuchteren Waldgebieten sehr viele!, wo nicht Insektengefahr es verbietet, soll auch alles absterbende und abgestorbene Material belassen werden, weil es den Bestand füllt, seine Luftfeuchtigkeit noch erhöht, und durch Zusammenfaulen den absterbenden Ïsten saprophytische Infektionssporen züchtet und dem Boden Nutzen bringt. Die Inselitengefahr wird durch derlei schwaches Stangenholz in der Regel weit überschätzt. An den dümnen Stangen leben zumeist die harmloseren, mehr wissenschaftlich als forstlich bemerkenswerten Insekten. Auch das Heraushauen der durch Wurzelkrebs, wie Agarieus melleus getöteten Stämme verursacht nur Kosten, bringt aber keinen Wert; das Umsichgreifen der Wurzelkrebskrankheiten erfolgt und unterbleibt, wie Beobachtungen im Walde lehren, trotz Stämmchemrodung und trotz Sicherheitsgräben; der Zeitpunkt der Bekämpfung dieser Krankheiten ist der Zeitpunkt der Verjüngung (Stockrodung).

Man hat vielfach getadelt, daß die Praxis in diesem Alter des gedrängtesten Schlusses nicht aurchforstend eingreift, daß sie wartet bis das Material, das genützt wird, die Arbeitskosten deckt. Aus diesem Systeme aber sind vollendet astreine Bestände hervorgegangen. Verfasser zweifelt, daß unter Führung von Durchforstungsregeln, welcho im gedrängtesten Schlul, einen Erziehungsfehler der Wirtschaft crblicken, ebenso astreine und ebenso hochentwickelte Schäfte und in so kurzer /eit sich ausformen kömnen. Die Erhöhung des Wertes auch des schwächsten Stangenholzes, wie es der Bestand im gedrängten Schluß ausscheidet, hat dazu geführt, daß gegenwättig eine wahre Jagd auf diese Individuen betrieben wird, die viel zu früh einsetzt und um eimes kleinen Gewinnes oder nur der "Sauberkeit" willen ein unersetzliches Mittel für die Stammesptlege preisgibt; daß auch Erzielıungssysteme erdacht wurden, welche im gerlrängten Bestandesschlusse cinen der Wertselzeugung schädlichen Zustand erblicken, soll später gezeigt werden. 
Es ist nicht nötig, ja nicht einmal rätlich, daß der gechrängrte schluß so lange beibehalten wird, bis die Schäfte aut' wïnschenswerte S'chafthöhe astrein geworden sind; os genügt und entspricht ciner naturund rentengerechteren Erziehung, wenn bis zur gewiunschten Baumhöhe hinaut die Schaftäste abgetötet wurden; das Reinigren, das Abstoßen, erfolgt dan in dem folgenden Lebensabschnitt des Baumes durch den Zahn der Zeit; während dieser Zeit treten aber wichtigore Aufgaben am einzelnen Baum in den Vordergrund: die Steigerung des Massenzuwachsos; der S'tangenwuchspflege fällt die Förderung der Schaftgïte, der Baumwuch pflege die Förderung der Schaftmassen zu; rom Eintritt des Bestandsschlusses bis rund zum 30.-40. Jahre soll deshalb der Bestand so dicht als möglich geschlossen erhalten werden. Wenn man einwendet, dali die Schneegefahr schon vor diesem Alter eine Schlußdurchbrechung fordert, so übersieht man, daß unsere Föhre auch dadurch gegen Schnee nicht geschützt werden kann, weil im Stangenalter das Holz stets allzu spröde und brüchig ist; man übersieht, daß die Schneegefahr für die übrigen Holzarten doch nur bei außerordentlichen Kalamitäten, welche glücklicherweise selten sind, merklichen Schaden den Jungwüichsen zufügen kann, - mit und olne frühzeitige Auflichtung.

6. Entstehen Löcher im Stangenholze durch Schnee, Insekten, Pilze, Blitz und andere Ursachen, so werden sie mit möglichst schnellwachsenden Holzarten ausgefüllt, in der Weise, daf' dem Lochrande parallel ein Streifen, gleich der halben Höhe des Bestandes frei bleibt. Bei $10 \mathrm{~m}$ Durchmesser der Blöße würde bei $111 \mathrm{~m}$ Bestandshöhe kein Nutzholz, sondern, wenn nötig. nur eine Schutzholzpflanzung eintreten können.

7. Nach Erreichung der Astreinigung und Asttötung bis z u r wirtschaftlich nötigen $\mathrm{Banmhöhe} \mathrm{setzen} \mathrm{die} \mathrm{Durchforstungen}$ ein. Terfasser ${ }^{1}$ ) hält daran fest, daß Durchforstungen nach der ursprünglich gegehenen Deutung und Bedeutung des Wortes solche Mafregeh sind, welche nur unterdrïclites Material dem Bestande cutnehmen, so daß dadurch der Bestandsschluß gar nicht (schwauhe Durchforstung) oder nur für ganz liurze /eit (starke Durchforstung) durchbrochen wird. A. W e ise sagt in seinem Leitfaden für den ITaldbau 1903, daß ein Hieb, der so weit geht, daß zur Deckung des Bodens besondere Maßnahmen nötig sind, nicht mehr unter den Begriff einer Durchforstung fällt. Terfasser ${ }^{1}$ ) hat jene Maßnahmen, welche den $/ w^{\prime} \cdot k$ haben den Bestandsschluß dauernd zu durchbrechen, damit noch ein Bodenschutzholz sich erhalten oder neu in den Bestand eingefügt

3) H. Marr, Die Erziehungshiebe der neueren Schule, Allgem. Forst- u. Jaguzeitung 1899 . 
werden kann, Durchlichtungen genannt und muß nicht bloß aus prinzipiellen, sondern auch ans praktischen, wirtschaftlichen Gründen an dieser Unterscheidung festhalten, was mit den folgenden Ausführungen näher begrïndet werden soll. Mit den Durchlichtungen beginnt auch ein nener Abschnitt im Leben eines Bestandes.

Die Durchforstungen innerhalb der Stangenwuchspflege beginnen zwischen dreißigstem und vierzigstem Lebensjahre und zwar zunächt in der schwächsten Form, der Beseitigung der Toten und völlig Unterdrückten; die zweite mälige Durchforstung nach etwa fünf Jahren (allgemein genommen sobald neues Durchforstungsmaterial rich ausgeschieden hat) grcift neben bereits unterdrückten auch noch die eben mit der Krone untertauchenden Individuen heraus; die dritte nach weiteren fünf Jahren nimmt neben unterdrückten und toten die in den Kronen von den starken Nachbarbäumen eingeengten. schlanken, vom Winde auf die Nachbarkronen geschleuderten und von diesen wieder zurückgeworfenen Stangen (Peitseher genannt), und löst allzu enge Gruppen durch Beseitigung der minderwertigen Stämme auf, so daß mit dieser starken Durchforstung, ungefähr im fünfzigsten Lebensjahr der Baumvereinigung, die Serie der Durchforstungen abschließen kann, worauf die Durchlichtungen folgen. Das Material, das bei den Durehforstungen anfällt, zählt alles, um mit der Praxis zu sprechen, zur Vor-oder Zw ischennutzung.

Waren Jungwuchspflege und Stangenwuchspflege energisch und sachgemäß durchgeführt, so findet die Durchforstung keine Stämme mehr, welehe wegen Nutzholzfehler beseitigt werden müßten; der Grundsatz der Schlußerhaltung, beziehungsweise Wiederherstellung kann somit bei den Durchforstungen festgehalten werden. Eine Durchlöcherung des Kronenschlusses kann nur durch Beseitigung erkrankender oder getöteter Individuen oder rom Schnee gebrochener Stämmehen gerechtfertigt sein.

\section{Baumwuchspflege und -Erziehung.}

War die erste Hälfte der Umtriebszeit der Aussehaltung aller zu Nutzholzzweeken unbrauchbaren Holzarten und Stämmehen, der Astreinigung der besten Bestandsglieder gewidmet, so liegt der Schwerpunkt der Erziehung während der zweiten Hälfte der Umtriebszeit in der Erziehung von Holzmassen, welche sich an den mit Eliteschäften versehenen Bäumen bis zur Haubarkeit aulegen. Sind Jungwuchs- und Stangenholzpflege und -erziehung sachgemäß und energisch durchgeführt worden, so bleibt für die folgenden Hiebe nur noch jenes Material übrig, das beseitigt werden muß, damit die Kronen der Hauptstämme sich nicht mehr sehließen können; die Hiebe heabsichtigen somit eine Durchbrechung des Kronenschlusses und 
völlige Freistellung der Kronen; solche Hiebe dürfen nieht Durchforstung genanut werden, ohne die Begriffe zu vorwirren und lange Erklärungen nötig zu machen, was man unter solchen Durchforstungen zu rerstehen hat. Verfasser hat sie Durehliehtungen genannt und alles Material, das sie entnehmen, is t $\mathrm{zur} H$ a uptu ut $\mathrm{zung}$ zu zählon. Mit etwa 50 Jahren einsetzend werden I)urehlichtungon ebenfalls anfänglich mäßig etwa alle fünf .Jalıre wiederholt, vom achtzigsten .Jahre an wird ein Zwisehenraum von zehn Jahren genügen, bis zur Haubarkeit; der Abstand der Kronen soll in der ersten Hälfte der Baumwuchsptlege etwa $1 \mathrm{~m}$, in der letzten Hälfte etwa $\stackrel{\mathrm{m}}{\mathrm{m}}$ betragen: es entspricht dies einem Standraum der Bäume von rund 2.) qm, so daß pro Helitar rund 400 Stämme sich finden, von denen jeder 1 -3 f fm Derbgehalt, je nach Holzart. Boden und Klima besitzen kann. I)amit wäre erreicht, daß der Haubarkeitsbetrag eines derartig erzengten Bestandes nicht geringer ist, als die Haubarkeitserträge der bisher erzogenen Bestände. Nachdem aber auf dem bisherigen Wege der Durchforstung nur $25 \%$ der Haubarkeitsmassen an Zwischennutzungen gewonnen wurden, so stehen dieser Summe gegenüber die Durehtorstungserträge mit rund $20 \%$ und die Durchlichtungserträge von rund $.5 \%$ der Haubarkeitsmasse im neuen Walde. In der bisherigen Erziehung ist die Gesamtleistung des Waldes die Summe der Haubarkeitserträge $\left(A_{u}\right)$ plus der Durchforstungserträge (Df) im Alter a, b, c ....n; Holzertrag, somit $=A_{u}+D f_{a}+D f_{b}+D f_{c}+\ldots+D f_{n}$. Im neuen Walde ist die gesamte Leistung $=A_{n}+D f_{a}+D f_{b}+\ldots+D f_{n}$ $+\mathrm{Dl}_{\lrcorner}$(Durchlichtungen) $+\mathrm{Dl}_{\mathrm{b}} \ldots .+\mathrm{Dl}_{\mathrm{n}}$.

Die Holzmasse ist im ersten Falle $=A_{u}+\begin{gathered}A_{u} \\ +\end{gathered}$, im zweiten Falle $A_{u}+\frac{3 A_{u}}{4}$. Man kann daher als Ideal, auf welches die Erziehung hinstreben soll, eine Formel bezeichnen, welche lautet: Ge $\therefore$ amte Derbholzleitung $=2 \mathrm{~A}_{\mathrm{u}}$, da $\mathrm{Df}_{\mathrm{a}}+\mathrm{Df}_{\mathrm{b}}+\ldots+\mathrm{Df}_{\mathrm{n}}+\mathrm{Dl}_{\mathrm{a}}$ $+\mathrm{Dl}_{\mathrm{b}}+\ldots+\mathrm{Dl}_{\mathrm{n}}=\mathrm{A}_{\mathrm{u}}$, das heift die Vorerträge a us D u reh. forstungen und Durchlichtungen sollten gleich werden dem Haubarkeitsertrage, ohne dal dieser unter die Hanbarkeitsgröße der bisherigen Wirtschaften herahgeht.

Es mag sein, daf dieses Ideal sich nicht ïberall und bei allen Holzarten erreichen läßt; die dänische Erziehung urd Wirtschaft liat es für vier Holzarten: Eiche, Buche, Föhre, Fichte, erreicht, heziehungsweise ist sie dem Ideale sehr nahe gekommen. Bei den günstigeren, klimatischen Bedingungen Mitteleuropas ist kaum zu zweifeln, dal.i das Ziel erreichbar ist; denn durch die bisherige Methode des geschlossenen Bestandes sind vier Faktoren der Lrproduktion $11 u$ ungenïgend ausgenützt worden, das sind Wasser, Licht, Wärme und Bodengïte, olne daß etwas an diesen Faktoren eingespart oder angrehäuft worden wäre 
für kommende Baumgeschlechter und Menschengenerationen. Damit aber der Boden hierbei nicht in Güte durch Verwilderung sich verschlechtere, ist Schutz des Bodens nötig durch einen Bodenschutz, der mit der natürlichen Auflichtung der Licht- und Halbschattenarten, mit der Durchlichtung der Schattenholzarten einsetzt. Diesen Boden. schutz kann keine Baumgattung der nördlichen Halbkugel besser gewähren als die Gattung Fagus, die Buchen, weil sie die einzige ist unter allen winterkahlen Laubbäumen, welche einen vollen Schatten selbst anderer Schattenbäume noch erträgt; sie geht schlieflich kaum an Licht-, sondern an Wassermangel zugrunde. Im Castanetum wird der Unterhau möglich sein, trotzdem dieses nicht die klimatische Heimat der Rotbuche ist, da die Überschirmung und Überschattung die der Buche nachteilige, allzu grofie Erhitzung im Sommer mildert; im Fagetum ist die Buche in ihrem urheimatlichen Klima, im wärmeren Picetum gedeiht sie als Unterbau, da die Überschirmung auch die der Buche schädlichen, allzu großen Kälteextreme mildert; im Castanetum und Picetum wird sie ein Strauch bleiben, was ihrer Rolle als Bodenschutz nur günstig ist: im Fagetum wird sie zum Füll- und Triebholze und schlieblich zum Hauptstande aufzustreben suchen. An Stelle der Buche können auch Halbschattenholzarten wie Erle, Hainbuche, Ahorn, Linde oder selbst, wenn auch weniger vorteilhaft für den Boden und die Hauptholzarten, immergrüne Halbschattenholzarten (Nadelbäume) treten ; Näheres hierüber wird im Abschnitt XVIII, Bodenptlege, gebracht werden.

Unter den weiter unten aufgeführten Durchforstungs- und Durchlichtungssystemen der forstlichen Praxis und Literatur finden sich solche, welche in der Erhaltung des lebenden, unterdrüekten Naterials einen Ersatz für den Unterbau erblicken; man rühmt die Beweglichkeit des Wirtschafters in der Handhabung der Durchlichtungen in den Kronen, da dureh das unterdrückte Material der nötige Bodenschutz gegeben sei. Für Licht- und Schattenholzarten trifft diese Voraussetzung nicht zu, weil das Untertanchende und Unterdrïckte sich nur so weit am Leben erhalten und nur eine solche Krone bilden kann als der Lichtzufluß durch das Dach der Herrschenden zuläßt. Lichtdurchlässigkeit des Haupthestandes und Kronenentwicklung des unterdrückten oder Nebenbestandes stehen in imnigstem Kusammenhang. Beide aber ergänzen sich zu einer Summe des Lichtentzuges für den Boden, welche gleich ist der Beschattung der normal geschlossenen Holzart. Es ist somit unter dem Dache des Unterstandes plus des Hauptbestandes einer Lichtholzart wicht heller und nicht dunkler als unter dem Dach eines natürlich gelichteten Lichtholzbestandes, das heißt der Boden verunkrantet; es ist unter dem Unterstande und Hauptbestande eines Schattenholzes z. B. Fichte, Tanne selbst Buche nicht heller oder dunkler als unter dem natür- 
lichen, geschlossenen Dache der betreftenden schattenholzart, das heißt, am Boden findet ungenügende Zersetzung der Al,fallsstoffe, Anhäufung von Rohhumus statt; der Boden hleibt somit bei Verwondung des unterdrückten Materials als Bodenschutz in der gleich ungünstigen lage, als ob der Bestand boi s.hattenholzarten zeitlebens geschlossen, bei Lichtholzarten nicht unterbaut worden wäre. Gewimn für den Boden beginnt erst dann, wem an Stelle der unterdrückten Lichtholzarten eine Halbschatten- oder Schattenholzart, wonn an Stelle der unterdrückten immergrünen S'chattenholzart eine winterkahle Schattenholzart tritt. Das unterdrückte Material wird williommen und nützlich sein bei der Verjüngung als Schutz des Bodens und der nenen Waldgeneration.

Es ist eine durch die Praxis längst festgestellte Tatsache, dali. nirgends eine Samenverjüngung so rasch, so leicht, so willig und so sicher sich abspielt als auf frisch verwundetem Buchenboden; dem die beiden wichtigsten Momente sind hier vereinigt: bestes Keimbeet und Fehlen des Unkrautwuchses. Dieses günstige Verhältnis herzustellen und bei der Verjüngung auszunützen, ist einer der Zwecke des Unterbanes aller Holzarten. Der zweite ist die wahre Bewegungsfreiheit in den Durchlichtungshieben; soll aber gleichzeitig das Untertauchende und Unterdrückte vor der Verkümmerung bewahrt werden. muß dei den Durchlichtungen auch auf den Nobenbestand Rücksicht genommen werden; die freie Bewegung ist dadurch gehemmt.

Es wurde bei der vorausgegangenen Darstellung der Jungwuchs-, Stangenwuchs- und Baumwuchspflege und -Erziehung vermieden, eine komplizierte Einteilung der Glieder eines Bestandes nach Kronenklassen zu geben; je einfacher die Unterscheidung, desto besser. Die gegebene Einteilung lehnt sich mehr den ältesten Bezeichnungen, wie besonders Cotta, König und andere sie gaben, und den neneren von Kraft an. Es werden unterschieden: tote, unterdrückte (noch lebende), eben untertauchende, mit der Krone noch eingeklemmte (eingeklemmte), herrschende und vorherrschende Stämme. Was darunter zu verstehen ist, braucht keiner weiteren Erklärung, die aber sofort notwendig wird, sobald man die Klassen mit Buchstaben bezeichnet und mit diesen weiter operiert. Es wurde vermieden, irgendeine Einteilung der Stämme nach Schaftgüteklassen, wie II eck sie vorgeschlagen hat, zu wählen. Es bedarf für den Forstwirt, selbst den ungebildeten, nicht einer Erklärung, was ein \%wiesel, ein kranker, ein krummer oder krebsiger Baum ist, und es beclart' nicht der Vorschrift, daß, wenn ein solcher Baum einen besseren Nutzstamm bedrängt, der erstere fallen muß. Es sei aber zugegeben, daß viele Forstwirte im Gehorsam gegen den Grundsatz der ängstlichen Erhaltung des Bestandsschlusses den untertanchenden, schönschäftigen Stamm heseitigen und den krummschäftigen. vordrängenden Taugenichts am Lehen lassen. 
Es liegt in der Biologie des Bestandes begründet, daß alle Übergänge von einer Stufe zur anderen vorhanden sein müssen, da ja im Laufe des Bestandslebens Tausende vou Stämmen aus herrschenden allmählich zu unterdrückten werden und absterben.

Da Verfasser im ganzen Verlaufe der vorliegenden Schrift die Absieht verfolgt hat, neben der eigenen Ansicht anch jene anderer Schriftsteller und Forscher gelten zu lassen, so sollen in nachfolgender kurzer Zusammenstellung die bisher ausgedachten oder ansgeübten Durchforstungssysteme gebracht werden. Hinsiehtlich der Geschichte der Durchforstmigen sei auf die Arbeiten von Franz von Baner, in jünster Zeit von Dr. Carl Laschke (Neudamm 1902) und Dr. Vinz. Schüpfer 1903 hingewiesen.

Die unten gegebenen Durehforstungssysteme gehen alle von Beständen aus, in welchen während der Jung-und Stangenwuchs periode die wichtigste Pflege und Erziehung versänmt wurde. Diese Voranssetzung trifft allerdings für die weitaus größte Mehrzahl der anfwachwenden Bestände zu, so daß in der Tat im Zeitpunkt, in diem die Durehforstung beginnt, noch Unhölzer, breitästige Vorwüchse (Protzen, zwieselige, krebsige und krummschäftige Individuen vorhanden sind, zu deren Ungunst dann Regeln (freie Durchforstung nach $\mathrm{Heck}$, Plenterdurchforstung nach Borggreve) oder Ausnahme von den Regeln des Durchforstungssystems aufgestellt werden. Es erhellt daraus aber deutlich, daß die Durchforstungen außerordentlich erleichtert, verbilligt und vereinfacht werden, wenn schon bei der Bestandsbegründung A uswahlpflanzung eintritt und in der J ung wuchspflege, bei der es am leichtesten, billigsten und schadlosesten geschehen kann, alles beseitigt wird, was nicht wert scheint, dats es Banm wird.

G. L. Hartig gibt in seiner Anweisung zur Holzzncht die Regel, daß nur ganz oder halb abgestorbenes, völlig übergipfeltes Holz herausgehauen werden dürfe; seine Vorschrift ist somit eine Durehforstung. Professor Dr. Hansrath ${ }^{1}$ ) erwähnt, daß die noch jetzt gïltigen sogenanuten Hartigsehen Durchforstungsregeln nieht von Hartig, sondern von Duhamel du Monceau, dem berïhmtesten Forstmanne des 18. Jahrhunderts, stammen; Hartigs Verdienst sei es, diesen Regeln durch eine populäre Darstellung zum Durchbruch verholfen zu haben.

H. Cotta und Pfeil 1820 wollen in dem Angenblicke, in welchem Bestandsschluß eintritt, mittels Durchlichtungen verhindern, daß die Kronen sich bedrängen. So oft als möglich sollen diese Hiebo wiederholi werden.

Ch. Liebich vertritt die sogenannte Prager Schnle, welche statt

1) Forstwissensch. Centralblatt 1896. 
Durchforstungen Maßnalmen verlangt, welche man als Durchlichtungen bezeichnen nuß. Jeder Stamm soll einen entsprechenden standraum erhalten; alle 10 Jahre wiederholen sich die Hiebe; damit künftighin diese "Durehforstungen", welche (damals) nur wertloses Material lieferten, in Wegfall kämen, soll sehr weitständig gepflanzt werden.

Hundeshagen will nur die Herausuahme des abgestorbenen Materials.

Pfeil $18 t i 0$ will anfangs nur Unterdriicktes, später Durchlichtung bei Fichte, bei Eiche nur Durchforstung.

Feistmantel will oftmals durchforsten, aber bloß im Nebenbestande.

K. Heyer will ebenfalls nur das Übergipfelte in anfangs kïrzeren, später längeren Perioden nach dem Grundsatz: "Früh, oft und mäßig“ herausnehmen.

Grabner ist der Erste, welcher den Gedanken ansspricht, daß der Nebenbestand erhalten werden soll, daß die herrschenden Stämme von Jugend an freizuhamen sind, damit sie ohne jeden Kampf mit den Nachbarn in das Haubarkeitsalter übergehen; seine Methode ist somit keine Duchforstung, sondern eine Durchlichtung.

Fischbach will, daß das Unterholz in der 2-3fachen Zahl der Haubarkeitsstämme zum Zweck der Bodenüberschirmung erhalten bleibe.

Speidels wïrttembergische Wirtschaftsregeln wollen Erhaltung des Nebenbestandes als Bodenschutzholz und entsprechende Pflege des Hauptbestandes durch Freihieb in den Kronen nach Abschluß des Hauptlängenwachstums.

Burckhardt unterscheidet eine dunkle, eine mäßige oder gewöhnliche und eine starke oder vorgreifende Durchforstung; bei allen drei Graden wird der Nebenbestand zuerst herausgehauen.

Kraft hat eine Einteilung der Stämme und Stämmchen eines aufwachsenden Bestandes gegeben, welche am meisten Anerkennung gefunden hat. Sie lautet: Torherrschende Stämme, herrschende, gering mitherrschende, beherrschte: letztere zerfallen wiederum in zwischenständige oder eingeklemmte und teilweise unterständige (nach der Bezeichnung des Verfassers dieser Schrift "untertauchende“); endlich ganz unterdrückte, welche teilweise noch lebensfähige oder absterhende oder bereits abgestorbene sind. Seine Regeln für die Erziehung der Bestände lauten: Sicherung guter Stammformen durch Verminderung starker Eingriffe in die Schlußverhälnisse der Stangenorte behuf's Erzielung astreiner und vollholziger sichäfte: allmähliche Lockerung des Bestandsschlusses zur Gesunderhaltung der Kronen: daher fiir jungre Stangenorte Entfenung der Eingeklemmten: für ältere Stangen- und Baumorte Herausnahme der Mitherrschenden behufis Freistellung der Herrschenden (I)urchlichtungen). 
Borggreves Plenterdurchforstung, deren Wesen bereits früher bei der Reformwaldwirtschaft besprochen wurde, beginnt erst mit dem (i). Jahre in Beständen, in welchen bis dahin ein rationelle Erziehung getehlt hat. Sie nimmt Vorherrschende (Protzen) in der Absicht einer hochwertigen Vornutzung und in der Hoffinung eines Eintretens der bedrängten Nachbarn, welche bessere Formen zeigen, in die dadurch entstandenen Lücken; dieses Verfahren wird alle 10 Jahre wiederholt.

Wagener beginnt den Kronenfreihieb der 400 Frohwüchsigsten pro llektar schon rom 20.-30. Lebensjahr an; es sollen somit gerade in dem Augenblick, in dem der dichteste Schluß für die Astreinigung nach Ansicht des Verfassers am notwendigsten wäre, Durchlichtungen (Kronenabstand $50-711 \mathrm{~cm}$ ) eingelegt werden; der Füllbestand wird nur schwach durchforstet; alle zehn Jahre wiederholen sich die Durchlichtungen oder die Kronenfreihiebe: nach der zweiten Durchlichtung: tritt bereits Unterbau ein.

Bohdaneck $\dot{y}$ in Worlik will ebenfalls den Bestandesschluß als eine die Kronen der Hauptstämme und die Ausnützung des Bodens schädigende Erscheinung frühzeitig auflösen; die Krone muß in einem bestimmten Verhältnis zur Gesamtlänge des Stammes stehen, damit die beste Holzgüte mit einer .Jahresringbreite von $3-4 \mathrm{~mm}$ entstehe (Millimeterbetrieb genannt); der Nebenbestand ist gleichgültig.

A. S(lhiffel ${ }^{1}$ ) gibt für Fichten folgende Durchforstungsregehn:

1. Ohne Rücksicht auf die Art der Begründung und auf die Bonität sind in den .Jungwüchsen die Eingriffe wiederholt und in dem Maße fortzusetzen, daß eine Reinigung (Dürwerden) der untersten Äste so lange hinausgeschoben wird, bis der Bestand die Höhe von mindestens $5 \mathrm{~m}$ (bei besseren Bonitäten mehr) erreicht hat.

2. Die Schaftreinigung soll allmählich fortschreiten und darf der halben Schaftlänge erst dann gleichkommen, wenn der Bestand das Maximum des Höhenzuwachses bereits erreicht oder überschritten hat. Hauptzicl sei das Drängen im Bestande (Dickungsschluß, Dichtschluß, gedrängter Schluß nach früherer Darstellung) zı verhindern.

3. Bei der Durchführung der Durchforstungen in der Stangenholzperiode tritt unter allen Umständen die Baumindividualität in ihr Recht; auf cine möglichst gleichmäßige Verteilung des Wuchsranmes für alle entwicklungsfähigen Stämme sei zu achten.

4. Nach Erreichung der Schaftreinigung bis zur halben Schaftlänge im Stadium der Höhenzuwachskulmination ist die Hauptaufgabe der Bestandeserziehung gelöst; fortab ist cine weitere glcichmäßige Schlußunterbrechung unnötig, und es sind die weiteren Durchforstungen in größeren Zwischenräumen und mäßig durchführbar. Schiffel will

1) A. Schiffel, Wuchsgesetze normaler Fichtenbestände. Wien 1904. Zeitschrift fur das ges. Forstwesen 1906. 
nicht die Begünstigung von Elitestämmen, sondern aller gutwüchsigen, normalkronigen; die dichteste Erziehung verlangen Buche und Eiche, die lockerste die Lärche; allgemeino Regehn für Begrinn der Durchforstungen gibt es nicht.

II ichaelis ${ }^{1}$ ) will durch fortgesetzte Steigerung der Durchforstung im Herrschenden (das sind somit Durehliehtungen) eine fortgesetzte Steigerung des Zuwa chses erzielen; da bei gleichbleibendem $\mathrm{Zuw}$ a chse mit der Durchmesserzunahme die Jahrringsbreite abnehmen muß, würde bei Zuwachszmahme e in Gleiehbleiben der Jallres. ringe, das Ziel der Erzichung, sich erreichen lassen.

Martins ${ }^{2}$ ) Vorschläge gehen dahin, daf nach Herstellung einer guten Schaftform die Kreisflächensumme des Bestancles ermittelt wird; diese soll ron da an gleichgrof bleiben; was über sio hinaus zuwächst, soll im Wege periodischer Durchforstungen (dürften später in Durchlichtungen übergehen) weggenommen werden.

A. Schwappach ${ }^{3}$ ) faßt die Aufgabe der Bestandeserziehung in die Worte zusammen: Ausbildung guter Schaftformen mit genügender Stärke und ron tadelloser Holzbeschaffenheit in möglichst kurzer Zeit unter steter Rücksichtnahme auf Bodenpflege.

Er verlangt insbesondere Rücksichtnahme auf die biologischen und physiologischen Eigenschaften der verschiedenen Holzarten und auf die höhere Bedeutung des Jugendstadiums für Massen- und Werterzeugung. Tanne, Fichte und Lärche sollen bis zur Beendigung des Hauptlängenwachstums in lockerem Schluß gehalten werden, so daß bis zu diesem Zeitpunkt die Kronenlänge nur allmählich auf ein Drittel der gesamten Schaftlänge herabsinkt. Eichen und Buchen verlangen dichten Schluß in der Jugend, der durch frühzeitig beginnende Aushiebe aller schlechtwüchsigen, liranken Stämme, durch Auflösung von Gruppen und Beseitigung der Konkurrenz zweier gleichstarker Nachbarn allmählich unter steter Schonung des noch lebensfähigen, unterständigen Naterials immer mehr gelockert wird. Die Kiefer ist im wesentlichen den vorigen gleich, doch etwas freier zu erziehen. Nach Beendigung des Iiauptlängenwachstums tritt die Aufgabe zur Förderung des Stärkezuwachses in den Vordergrund; die hierfür empfohlenen Hiebe zählen zu den Durchlichtnngen. Bei der Bestandeserziehung darf der Wunsch nach Jassenerzeugung niemals die Rücksicht auf die gute Beschattenheit des zu erzichenden Nutzholzes in den Hintergrund drängen.

Ney verlangt Schonung des Unterdrüekten, Iurchlichtungen erst nach dem Hauptlängenwachstum.

1) Ulichaelis, Gute Bestandespflege mit starkholzzucht. 1907.

2) Dr. Martin, Zeitschrift fur Forst- u. Jagdw. 191:.

3) Prof. Dr. A. Schwappach, Referat uber die Begrandung und Erziehung von Waldbeständen unter Rucksichtnahme auf hohen Masscuzuwarhs und gute Holzqualität. Internat. landw. KongreB. Wien $194 \overline{.}$ 
v. Fiürst will den Kampf zwisehen den Dominierenden erleichtern durch Entnahme der Bedränger; er will aber auch das Unterholz beseitigen, um den bleibenden Bestand zu fördern.

Eclaircie par le haut oder Hochdurchforstung ist eine in Frankreich schon 1790 in den Eichenhochwaldungen geïbte $\mathrm{Durch}$ lichtung, welche sich vorzugsweise unter Führung von Broilliard und Boppe aus dem Mittelwald heraus entwickelte. Diese Methode schont das Unterständige, greift aber in den herrschenden Bestand kräftig ein (Durchlichtung), damit die Kronen sich nach allen Seiten hin, wie bei Oberhölzern des Mittelwaldes, entwickeln können; gruppenständiges Oberholz des Mittelwaldes ist daher nach dieser Auffassung: ebenso schädlich wie gruppenweives Zusammenstehen stärkerer Individuen, womit auch dic Verjüngung in den Gruppenformen eine Verurteilung erfährt.

Die Dänische Durchforstung ist nur in der ersten Hälfte der Umtriebszeit eine Durchforstung, ron da an eine Durchlichtung; das Verfahren hat daher „Dänische Durchforstung und Durchlichtung“ oder "Dänische Erziehung" zu heißen. Durch Reisen und Schriften von Dr. Metzger ist diese sehr beachtenswerte Erziehungsmethode in der forstlichen Literatur näher bekannt geworden. Zwar ist das Verfahren vorzugsweise an der Buche ausgeführt worden; es wird aber auch an Eiche, Föhre und Fichte gehandhabt und dürfte für alle Holzarten passen oder doch sehr beherzigenswerte Lehren zur Behandlung dieser in sich schließen. Das Verfahren unterscheidet: Ha uptstämme,d. h. solche, welche wegen ihrer Geradschaftigkeit und gleichmäßigen Bekronung zu begünstigen sind, und schädliche Nebenstämme, d. h. solche, welche die zu erhaltenden Hauptstämme belästigen; dann unbrauchbare St ämme, d. h. solche, welche keine Nutzholzeigenschaft zeigen: sndam niitzliche Nebenstangen, welche die Astreinigung des Hanptstammes bis zur beabsichtigten Höhe zu fördern haben; endlich indifferente Stämme, welche noch nicht erkennen lassen, ob sie Hauptstämme werden oder zu schädlichen Nebenstämmen herabsinken.

Die Dänische Durchlichtung entfernt stets die schädlichen Stämine. die unbranchbaren Stämme, verschont aber die indifferenten und nützlichen. Der Unterstand wird somit versehont; die Krone soll $4 / 10$ der Schaftlänge betragen; nachdem der Schaft auf $15 \mathrm{~m}$ Länge von den Ästen gereinigt ist, beginnen die Durchlichtungen. Vor Eintritt des Samenjahres setzt eine gründliche Bodenlockerung mit Pflügen und Eggen ein. Nach Samenabfall wird abermals geeggt, Fehlstellen werden angesät. Lie Fläche wird nit Kalkstaub ïberstrent. Wegen des liräftigen Wuchses der Pflanzen kamn frülnzeitig gelichtet werden; die Eichen werden ebenso behandelt, nur müssen sie, wemn Verunkrautung sich zeigt, mit Buchen unterbaut werden. Die Ergebnisise dieser Dänischen Erziehung beweisen, daß es mit Durchlichtungen gelingt, die Vor- 
nutzungen den Haubarkeitsorträgen in Masie gleichzubringen, olme die Haubarkeitserträge unter die normalen sinken zu lasien.

H. Borgmanus horst - und gruppenweise Lichtwuchs. durchtorstung ist eine erst mit dem 51). Lebensjahre des Bestandes - hier Fichte und Tanne - beginnende Durchlichtung, welche sich auf 10 a große Flächen im Bestande gleichmäßig verteilt: innerhalb der Gruppen finden Hiebe von fünt zu fünf Jahren statt, welche allmählich die bestgeformten Stämme in möglichst regelmäßiçe Entfernung von $6 \mathrm{~m}$ bringen sollen; die unterständigen noch lebensfähigen stangen bleiben erhalten; mit dem 75 . Jahre beginnt von der Mitte der IIorsto aus die Verjüngung.

Vogl in Kogl (Salzkammergut) verlangt bis zum ju). Jahre in steigender Stärke Durchforstungen; von da an beginnen Iurchlichtungen, bis schließlich nur 200-300 starke Stämme pro Hektar übrig bleiben, welche aufgeästet werden. Frühzeitig tritt Verjüngung ein: die Torwüchse werden ebenfalls aufgeästet; so entsteht eine femelwaldartige Bestandesverfassung, welche große Sicherheit gegen Wind und volle Ausnützung des Lichtungsgewächses gewährt. Die Verjüngung ist eine natürliche: wo sie lïckig bleibt, wird gepflanzt: die Fällung der Lichtwuchsstämme über ti-8 m hohem Vorwuchse verursacht nicht solche Beschädigung, daf nicht alles sich wieder verwïchse.

Urichs Lichtwuchskulissenbetrieb beschränkt das Wagenersche Verfahren auf Betriebsstreifen von 15-20 $\mathrm{m}$ Breite, zwischen welchen Streifen von 41$)-60$ m Breite liegen bleiben, welche in der bisher üblichen Methode durchforstet werden sollen. Urichs Kulissendurchlichtung sucht die bedenklichsten Erscheinungen in W ageners Durchlichtung: Laubverwehung, Verunkrautung und Verwilderung des ganzen Bestandes, durch die Zwischenstreifen hintanzuhalten. Tom 70 . Jahre an werden auch diese Zwischenstreifen der Durchlichtung geöffnet. Im (w). Jahre kamn der Bestand gleichmäßig durchlichtet sein und in die Verjüngung eintreten. Urich denkt bei seinem Verfahren zunächst an die Buche.

Heckstreie Durchforstung soll trei sein von jerler sichule und Schablone, frei in der Wahl der zu beseitigenden und zu belasienden Stämme. Man kann Heck hierin zustimmen, wenn er meint, daß in jedem Bestande eine andere Methode oder mehrere Methoden oder selbst ein Gebräu verschiedenster Methoden der Durchtorstung und Durchlichtung der richtigen Erziehung eutsprechen kann; wemn wir einmal dio Biologie der Holzart genauer kennen und dirse Kenntnis eine allgemeine Verbreitung gefunden hat, wird jeder von sellst die richtige für den Bestand passende Erzielungssweise herausfinden. Einstweilen aber müssen wir uns immer noch mit Vorschritten dariber, was 
unter allen Umständen erhalten und unter allen Umständen beseitigt werden $\mathrm{mu} ß$, begnügen.

Heck gibt Schaftgüteklassen für seine Durchforstung, womit er beweist, daf er Bestände meint, in denen selbst das ABC der Jungwuchs- und Stangenwuchspflege versäumt oder sogar verboten wurde. In seinen Klassen sind Stockansschläge, sehr stark rergabelte Zwiesel, krumme, rauhästige und kurzschaftige Stämme enthalten; er geht somit von Beständen aus, in denen jegliche rationelle Pflege mangelte. Der Freihieb der besten und besseren Schaftformen kennzeichnet Heeks „Freie Durchforstung“ als eine „Freie Durchlichtung“. Der Bestandes. schluß soll im allgemeinen, das Unterdrïckte im besonderen erhalten werden.

v. Śalisch geht von der waldbaulich als selbstverständlich erscheinenden Voraussetzung aus, daß unter Lichtholzarten (Eichen) unterständige Schattenholzarten (Buchen) nicht beseitigt werden sollen : es ist ja eine der wichtigsten waldbaulichen Regeln die Lichtholzart mit einer Schattenholzart zu unterbauen. Er dehnt nun dies aus ästhetischen Rücksichten auch auf andere Holzarten aus und verlangt Erhaltung des Unterdrückten, Freihieb des Herrsehenden, Auflösung ron Gruppen kräftig entwickelter Stämme. Weise hat diese Durchforstung Posteler-Durchiorstung genannt, sie ist aber eine Durchliehtung.

Kožeśniks (18918) und Haugs (1899) Durchforstung nach Stammzahltafeln geht von der Voraussetzung aus, daß es für jede Holzart, jegliches Alter, jeglichen Standort eine bestimmte Stammzahl geben muß, bei welcher die wertvollsten und größten Holzmassen pro Flächeneinheit erzielt werden. Sie verlangen daher die Aufstellung von Stammzahltafeln für jede Holzart, jedes Alter, jeden Standort mittels Probeflächen, welche in möglichst normalem, das heißt geschlossenem Bestande auszuwählen wären. Wenn eine solche Untersuchung überhaupt durchgeführt werlen kann, dann seheitert die allgemeine Anwendung der Stammzahltafeln wieder an der schwierigkeit der Angleichung eines konkreten Falles an die Tafeln. Wären alle diese Schwierigkeiten zu überwinden, so könnten ja solche Tafeln mit Stammzahlen immerhin nach Absicht der Erfinder zur Beruhigung der Wirtschaiter dienen, wenn sie über die Stärke des Eingriftes im Zweifel sind. Einem solchen Gedankengange folgt auch Schiffel (l. e. 19114): Als ungefährer Maßstab für die Stärke des Eingriffes kann nach erfolgter Bonitiermg die Stammzahl der Ertragstafel für die Lichtschlnßform (der Fichte) gelten.

Die forstlichen Tersuchsaustalten verfolgen mit ihren Durehforstungsmethoden die genane, wissenschaftliche Feststellung des Einflusses versehiedener Durchforstungsgrade und -systeme auf Zuwachs in Masse und Güte, sowie auf den Zustand des Bodens. Wenn sie somit anch den Zielen der praktischen Forstwirtschaft dienen, ist 
es doch unzulässign, laß die Praxis Durchforstungsmethoden, welches zur wissenschattlichen Erkenntnis der Naturgesetze führen, deshalb als rückstänclig bezeichnet, weil sic dieselben nicht mehr anwendet; aber zulässig, ja wünschenswert wäre es, daß jeder Praktiker, jucler Theoretiker mit menen Gedankien und Auregungen sowohl dis Forschung wic die Praxis befruchten sollte, ohne daß sie sich gegenseitig in die drme fallen mit dem Vorwufe der Rückständigkeit.

Für die Zwecke ihrer Untersuchungen unterscheiden die forstlichun Versuchsanstalten eine niedere oder gewöhnliehe I urch forstung: schwach, mäßig und stark: eine danernde hronendurchbrechung tritt nicht ein; der von Prof. Bühler hinzugefïgte Grad I) als ${ }_{n}$ sehr starke Durchforstung ist eine mäßige Durchlichtung. welche noch keinen Unterbau oder kein Unterholz nötig macht. Aut Teranlassung von Prot. Schwappach ist zu dieser Serie von Versuchen eine neue hiuzugefügt worden als Hochdurehforstung. Sie pflegt die dereinstigen Hauptstämme und schont das Beherrschte.

Die schwache Hochdurehforstung ist eigentlich eine Mafinahme zur Beseitigung früherer Versäumnisse, denn /wiesel. schlecht geformte Stämme, Sperrwüchse (Wölfe) sollten in einem Bestande, in welchem die Durchforstung anhebt, nicht mehr vorhanden sein; es ist aber diese schrache Hochdurchforstung nux cine starke Durehforstung der bisherigen Praxis, die eine V'erstärkung in der Auflösung von Gruppen gleichwertiger stämme erfährt.

Erst die starke Hochdurchforstung ist eine Durchlichtung. weil sie die Pflege einer verschieden bemessenen Anzahl von Haubarkeitsstämmen durch Beseitigung der Nachbarstämme anstrebt. Veröffentlichungen über den Einfluß verschiedener Durchtorstungsgrade liegen ron Kunze, Schwappach, Hefele und nenerdings besonders eingehend ron Flury ror.

Weise (19103) nennt alle Maßnahmen, welche nur unterdrücktes Material beseitigen, "Durchforstungen rom schwachen Holze her" : solche, wolche hauptsächlich in dem mitherrschenden oder noch nicht ganz unterdrückten Materlal sich bewegen, „Durchforstungen von der Mitte her", und solche, welche mit Hinwegnahme der stärkiten Stämme beginnen ,Durchforstungen rom Starken her". Da bei letzteren (z. B. Borggreve) immer wieder Bestandesschluß eintreten soll, so zählen eigentlich nur die „Durchforstungen von der Mitte her". wenigstens teilweise, zu den Durehlichtungen. W $\mathrm{e}$ ise sagt. daß für die rerschiedenen I,ebensabschnitte dos Bestandes wahrscheinlich lie I) urchforstung verschieden gehandhabt werden muß, wenn man die höchsten Bestandeswerte erzichen will, nie aber soll man grundsätzlich bestimmen, daß ein Bestand stets in dieser, ein anderer stets in jener Weise durehforstet werden müsse. 
Broillar $\left(^{1}\right)$ sagt, daß durch Kronendurchforstung (Durchlichtung) die Qualität des Eichenholzes sich verbessere, der Buche gleichbleibe. der Nadelhölzer sich verschlechtere; für letztere sei daher Durchforstung (Beseitigung von überschirmten, kranken und kranklaften Stämmen) besser.

Forstmeister $\mathrm{V}$ üller ${ }^{2}$ ) will in reinen Eichen- oder Eichen- und Buchenstangenorten alle nicht als Zukunftsstämme zu bezeichnenden Stangen in $1-1,5 \mathrm{~m}$ über dem Boden köpfen: dadurch werden $1 / 2-^{2}{ }_{3}$ aller Stangen entgipfelt, wodurch ein Bodenschutz- und Treibholz entsteht.

Heß (1906) gestattet bei der ersten Durchforstung nur unterdrücktes, absterbendes, totes Holz zu beseitigen; erst bei der zweiten Durchforstung darf auch krankes, krebsiges, gekrümmtes, drehwüchsiges, vom Winde geschobenes Material beseitigt werden, wenn es herrschend ist. „Die Grundregeln für Anfang, Wiederholung und Stärke der Durchforstungen liegen auch jetzt noch in den Heyerschen Worten: früln. oft und mäßig. Nur sind die drei Begriffe, insbesondere das Wort ,mäßig je nach Holzart, Standort und Holzalter verschieden zu interpretieren."

Auch ein Vorschlag des (Oberforstrats $\mathrm{R}$ en $\beta^{3}$ ) verdient Frwähnung und Erwägung; er will insbesondere bei Fichten streifenweisen Wechsel zwischen schwacher, mäßiger und starker Durchforstung.

Verfasser hat seine Ansichten über Pflege und Erziehung reiner Bestände in den Betrachtungen über Jungwrichs-, Stangenwuchs- und Baumwuchspflege niedergelegt. 'Teilweise als Ergänzungen obiger (Hrundsätze, toilweise als Ersatz derselben für alle jene Bestände, welchen eine energische Jungwuchs-und Stangenwuchspege im Sinne der Erörterungen a uf Seite 492 u. ff. nicht oder nur unvollkommen zuteil wurde und auch künftighin nicht zuteil werden soll, wären für reine und gemischte Bestände folgende Regeln zu beachten:

1. Bis zum 50. Lehensjahre eines Bestandes hat der Blick nicht anf dic Kronen, sondern zuerst auf die Śchäfte sich zu richten: bei Beginn der $\mathrm{I} u \mathrm{rchlichtungen} \mathrm{richtet} \mathrm{sich} \mathrm{der} \mathrm{Blick}$ a uf die Kronen; die erste Hiche, mag man sie Durehforstung oder Reinigung - das klassische Försterlatein kemnt die köstliche Bezeichnung "Iäuteration" - nennen, haben stets zuerst jene Stämme zubeseitigen, welche unerwünschten Baumarten angehören oder welche umgebogen. schaftkrank, krebsig, zwieselig, krummschaftig, stark drehwüchsig, vergabelt, mit Klebeäston behaftet, dick beastet oder gipfolkrank sind,

1) Revue des Eaux et Forêts 1901.

$\left.{ }^{2}\right)$ Osterr. Forst- u. Jagdzeitung 1901

3) Österr. Forstzeitung 1901. 
ohnekütksicht a uf den Bostandesschluk; nach dem in). Lebensjahre werten kranke Stämme, wie z. B. vom Föhrenschwamme, Trametes pini, befallene Stämme (Schwammhieb) und absterbende Stämme jederzeit, sehlecht geformte und Unhölzer nur dann wegrgenommen, wenn die Durchbrechung nicht allzu groß ist neler durch einen gruppenweisen Unterbau wieder unsehädlich gemacht werden kamn.

2. Tote Stämme können selbstrerständlich jederzeit und übrrall zur Fällung gebracht werden: Käfer- und Insektengefahr kamn sogar hierzu zwingen.

3. Es ist eine nicht zu rechtfertigende Verschwendung an /eit. und Geld, sogenannte schonendste oder schwache Durchforstung anf unterdrücktes Buschwerk und Gestänge auszuführen, deren Entnehmen dem Bestande nichts nützen, deren Verbleiben ihm nichts schaden kann, deren Verkauf nicht einmal die Werbungskosten deckt. Die Praxis nennt das Beseitigen dieser in älteren Stangenorten und of ${ }^{t}$ noch im Baumalter von der Jugendzeit her vorhandenen oder erst später aufgekommenen Unterwüchse das .,Putzen“ des Bestandes. Wenn schon Ästhetik hier den Ausschlag geben soll, so findet Verfasser die ungeputzten Bestände schöner als die geputzten.

4. Nach den Ausführungen über die biologischen Eigenschaften der Baumvereinigungen drängt das Ausladungs- und Ausformungsvermögen bei Eichen, Birken, Erlen, Fichten, Tannen, Douglasien und anderen, wenn sie aus gleichalterigen Verjüngungen hervorgegangen sind, die bestgeformten Stämme zur Herrschaft, während bei Föhre Lärche, Tsuga. Buchen und anderen Laubhölzern die minder gut geratenen, ja oft die schlechtest geformten Individuen als Protzen zur Herrschaft gelangen; bei ersteren Holzarten bringt somit das Zuwarten bis zur ersten Durchforstung dem Zukunftsmassen- und Gütegehalt des Bestandes keine Einbuße, während bei der letzteren Gruppe der Hauptbestand $u m$ so mehr mißgeformte Stämme enthalten muß, je länger mit der ersten Durchforstung gewartetwird: für erstere Gruppe kann mit der ersten Durchforstung gewartet werden. bis ihre Ausführung auch finanziellen Gewinn bringt; für letztere Gruppe ist eine möglichst frühzeitige, erste Durchforstung nach Punkt 1 eine notwendige Kulturmaforegel, welche durchgefühırt werden muß, auch wenn sie Geld kostet.

5. Jencr Stamm ist stets zu entfernen, welcher einen wertvolleren in der Krone belästigt: der auf der Süd- und Westseite stehende Schädling muß früher fallen als der aut' der Nord- und Tstseite befindliche.

6. Das Köpfen eines S'chädlings ist bei allen Holzarten zulässig, ausgenommen die Burhe: bei ihr ist stets Abhieb am Borlen dem Köpfen vorzuziehen. 
7. An höheren Stangen, welche nicht geköpft werden können, empfiehlt sich das Abhaclien einer oder mehrerer liräftiger Seitenwurzeln (Wurzelstümmelung) des Schädlings, der dadurch gezwungen wird, einige Jahre langsamer zu wachsen, so daß die wertvolleren Nachbarn einen Vorsprung im Höhenwuchs erhalten. Das Stümmeln ist sodann auch da vorzuzichen, wo das dureh Köpfen oder Abschneiden gewonnene Staudenwerk nicht verkauft werden kann, vielmehr im Bestande als im höchsten Grade fenergefährlich belassen werden muß: auch das Ringeln der Stämme ist nicht vorteilhaft, weil Nadelhölzer sofort, Laubhölzer nach wenigen Jahren abtrocknen und Insekten- und Feuersgefahr erhöhen.

8. Können zwieselige Stänme nicht ganz beseitigt werden, so darf der schwächere Stamm nur dam noch abgesehnitten werden, wenn er am Abhieb oder sichnitt weniger als $5 \mathrm{~cm}$ Durchmesser besitzt. In solehc'n Fällen ist Aussicht, daß die Wunde in weniger als fünf Jahren sich schließt; ist der J)urchmesser größer, so würde nur WVundfäulnis oder Infektion eintreten, welche auch den Hauptstamm ergreifen wïrde. Es ist daher dringend rätlich, einen $/ w$ wieselast von über $5 \mathrm{~cm}$ Durchmesser nicht abzutrennen - die Praxis schneidet am Zwiesel den unterdrückten Stamm regelmäßig ab - vielmehx denselben seinem natürlichen Tode preiszugeben. Er wird damn von saprophytischen Pilzen bewohnt und zerstört, welche wiederum ein Schutzmittel gegen parasitische Pilze sind.

!. In einem stammweise gemischten Bestande ist die Erhaltung der Mischung durch die gefährlichste Periode des Dickungs- und Stangenalters nur möglich mittels Durehlichtungen (Eclaircie, dänische Durchforstung und andere).

10. Jedes Erziehungsiystem, mag es ans dem reichen Schatze der Literatur gewählt oder eigene Erfindung sein, muß den Weg von schwachen zu stärkeren Eingriffen eiuhalten: jedes sprungweise, jedes plötzliche Eingreifen ist ganz besonder's bei Sehattenholzarten gefälırlich: weniger bedenkliche Folgen durch Schneebelastung, Regerbelastumg, Winde, Rindenbrand sind bei Halbschatten- und bei Lichtholzarten zu gewärtigen.

11. Bei Durchlichtungen ist das Belassen des unterdrückten Nebenbestandes als Bodenschutzholz nur damn von Wert, wenn das Unterdrüclite die Stranchhöhengrenze, d. i. \& m, noch nicht überschritten hat; ist der Unterstand liöher, so ist es besser, ihn ebenfalls zu beseitigen und für einen neuen Unterstand durch Unterbau zu sorgen.

Man kann diesen elf Durehforstungsgeboten noch ein zwölftes hinzufügen: Die Praxis braucht koine Stammkionenklassen, keine Stammschaftklassen, wie sie tür vergleichende Untersuchungen nötig sind. Sie soll frei sein, das Eviehumgssystem zu wällen, welehes dem Bestande not tut. Soweit obige elf Gesetze auf Naturgesetzen beruhen. 
kann anch die freiesto Durchforstung sieh ilurer nicht entschlagen; die Erziehung des Bestandes soll nicht frei sein nach 'der individuellen Anftassung des Wirtschafters, sondern nach dem individuellen Bedürfnisse des einzelnen Bammes; nur in diesem sinne kann man von einer freien Erzichung sprechen.

Die A uszeichnung der Durchforstungen und Durchlichtungon goschieht mit dem allbekannten Baumreißer oder Risser; rabei sollte das untergebene, ungebildete und arbeitende Personal in die Irlee der. Auszeichnung eingeweiht werden, damit der Wirtichafter von dieser zeitraubenden Arbeit möglichst entlastet werden kann; als b este Zeit erscheint die Vegetationsruhe, die Zeit der Blätterlosigkeit für Laubbäume, weil nux während dieser /eit ein genaues Studium der Kronenentwicklung bei Betrachtung von unten gewonnen werden kann. Wer die Laubhölzer nur dann voneinander unterscheiden kann, wenn sie Blätter tragen, verdient nicht die Auszeichnung ,auszeichnen “ zu dürfen.

A ufästungen. Die Beseitigung der Äste kamn geschehen vor deren Absterben (Grünästung) oder nach demselben (Trockenästung). Die Trockenästung beabsichtigt in erster Linie die Verbesserung der Nutzholzqualität des geästeten Stammes und erst in zweiter Linie eine Nutzung oder einen anderweitigen Crewinn. Sind die Ausgaben für die Trockenästung durch Verkauf des Materials ganz oder doch zum größten Teile gedecht, oder ist die hierdurch erzielte Güte- und Wertsteigerung der Haubarkeitsstämme grof genug, so ist sie in allen Bestandes-, Boden- und Klimaverhältnissen durchzführen. Kož eśnik verlangł die Trockenästung an den auserwählten Nutzstämmen der Föhre rom 40. Jahre an auf besseren Böden; sie soll mit der Leiter bis zu $10 \mathrm{~m}$ Höhe durchgeführt werden: Ästung mittels Säge. Das Astreißen, das Herunterreißen der trockenen Äste, wie es zumeist der ärmeren Bevölkerung gewährt wird, muß als ein der Nutzholzqualität des Baumes nachteiliger Usus bezeichnet werden, der abgeschafft werden sollte. Das Schwergewicht des ganzen Trockenastes befördert das Heransbrechen des Astes an seiner Anhaftungsstelle; durch Ïberwallung entstelıt an dieser Stelle ein kleiner Napf, der das vom Stamme herabfließende Wasser auffängt und längere Zeit aufbewahrt, wodmeh die Zerstörung und Auflösung der Astbasis gefördert wird; wird aber durch das Herunterreilien des Astes die Hebelwirkung vermindert, erhält sich der Aststummel längere /seit und wird von den neuen Holzschichten des Stammes eingeschlossen. Die Trockenästung hat selbstredend auf de'n Zuwaclis des Baumes keinen Einfluß.

Die Grünästung oder A nfästung wird stets von unten nach oben ausgeführt; sie ist seit langen Jahren Gregenstand von Untersuchungen, um ihren Einfluß auf den Baum zu ermitteln. '/uerst hahen 
Nördlinger und Kienitz, damn R. Hartig, HeB und Kunze aus ihren Ergebnissen berichtet. Sie fanden, daß eine starke Ästung, welche cin Drittel der ganzen Krone beseitigt, eine geringe Zunahme des Höhenwuchses, aber auch eine Abnahme des Stärkewuchses bewirkte. Aus Gründen, die bereits bei der natürlichen Ästung durch den Bestand-schluß erwähnt wurden, vermag eine Grünästung die /one des stärksten /uwachses nach aufwärts zu verlegen, wodurch eine Formverbesserung (Tollholzigkeit) eintritt: bei der künstlichen Ästung aber wird dieser Gewinn zumeist ausgeglichen durch einen Verlust an Zuwachs unterhalb der Ästung, welcher bei der natürlichen Ästung wegfällt. R. Hartig glaubt durch die Ästung die Gütequalität des Holzes (nur die Schwere wurde untersucht) beeinflussen zu können; er fand eine Zunahme des spezifischen Gewichtes, das Verhalten der \%uwachsgröße wurde nicht geprïft. Kunze fand bei Ästungen bis auf sieben Astquirlen eine Abnahme des Längstriebes.

Die Grünästung hat sodann bei immergrünen Holzarten den Zweck, Deck- und Dekorationsreisig, bei Birken Besemreisig zu gewinnen, Unterwuchs und Unterpflanzungeu gegen Wuchsstockungen und Beschädiggung durch Überschirmung zu schützen, die Feuersgefahr zu mindern, die Schäden der Fällung bei Beseitigung eines stark beasteten Stammes in natürlicher Verjüngung einzuschränken, Straßen, Wege und Waldschneisen trocken zu legen, den ausgewählten Pflanzen bei der staffel und /wischenstrauchpflanzung wenigstens anfänglich eine Hilfe zu geben und andere.

Die Grïnästung wird derart ausgeführt, daß der Ast möglichst nahe am Schaft abgetrenut wird; um Beschädigung des Stammes zu vermeiden, wird allgemein empfohlen - aber nicht abgewandt - erst etwas von unten her einzusägen, dann von oben her abzuschneiden. Neuerdings wird bei stärkeren Ästen die Stum melästung empfohlen; sie besteht darin, dal.j der Ast etwa einen halben Meter vom Stamm entfernt olne weitere Vorsicht abgesägt wird, worauf dann sofort oder auch später die genaue Abtrennung am Schaft leicht und olne Verletzung des Schaftes betätigt werden kann. Nachteilig ist die doppelte Arbeit, die sich aber bei besonders wertvollen Objekten z. B. Oberhölzern im Mittelwald, Überhältern im Hochwald, rechtfertigen dïrfte.

Je nach der Wuchsliraft des Baumes können Äste bis zu $10 \mathrm{~cm}$ Durchmesser der Wunde beseitigt werden: regelmäßig sollte über $j$ bis $7 \mathrm{~cm}$ nicht gegangen werden; von $3 \mathrm{~cm}$ aufwärts soll Schutz der Wunde durch Teeranstrich erfolgen. Wemn eimige Tage gewartet werden kaun, his die śchnittfläche etwas abtrocknet, so wirkt der Teeranstrich nachhaltiger. Burkhardt, Hoyer, Hempel und Engler nehmen $7 \mathrm{~cm}$, Tramnitz, Schwappach und andere nehmen $\overline{\mathrm{cm}}$ als oberste Grenze. Für die Nadelhölzer dürten $5 \mathrm{~cm}$ nicht überschritten werden; am besten wird die Frünästung der Nadelbäume ganz vermieden. Bei 
Autiistung der Wasserreiser, vorzugsweise an Oberholzeichen, hat nach den Vorsuchen des Verfassors es sich bewährt, wenn jede, auch die kleinste Schnittfläche mit der Umgebung tüchtig mit dem Pinsel angeteert wird, wodurch die noch vorhandenen schlatenden Augen, aus denen sich neue Wasserreiser entwickeln wïrden, zum Absterben gebracht werden.

Anch jenen Verfahrens soll gedacht werden, bei welchem an Oberholzeichen im ersten Jahre nur das unterste, im zweiten das mittlere, im dritten .Jahre das oberste Drittel der Wasserreiser beseitigt wird worauf eine Neubildung von Klebästen unterbleiben soll.

Zur Ästung sollte nur die Säge verwendet werden; wird der Baum mit der Leiter oder mit dem von Hefele verbesserten Zehnpfundsehen Steigerahmen oder mit Steigeisen oder mit dem von Hofrat Friedrich erfundenen Grimpeur bestiegen, so sind die üblichen Baumsägen für den Obstbau zugleich die besten Entästungsgeräte; unter den auf Stangen angebrachten Sägen hat Alers Flügelsäge viel Anerkennung gefunden. Stoßeisen sollten nur bei trockenen, äußerlich bereits etwas mürbe gewordenen Ästen zur Anwendung gelangen. 


\section{Sechzehnter Abschnitt.}

\section{Pflege und Erziehung der Ausschlagwaldungen.}

Die Ausschlagwaldungen verlangen nur geringen Aufwand an Arbeit und Zeit. Sind bei dem Niederwaldbetrieb oder bei dem Unterholz des Mittelwaldes zu viel Ausichläge auf einem Stocke erschienen, so wird ihre Zahl zugunsten der bestgeformten vermindert im Wege einer Durchforstung, welche gewöhnlich Durchreiserung genannt wird. Sie erstreckt sich auch auf kranke, umgebogene, unterdrückte und tote Lohden. E. M $\left[\mathrm{r}^{1}\right.$ ) hat nachgewiesen, daß der Zuwachs der bleibenden Lohden so aufierordentlich sich steigert, daß der finanzielle Effekt auf das Doppelte der nicht durchforsteten Fläche sich erhöhen kann. Werden Kernwüchse oder Ausschläge edler Holzarten durch Ausschlagslohden minderwertiger Holzarten beeinträchtigt, so werden letztere zurückgeschnitten oder ganz hinweggenommen. In Schälwaldungen ist die Beseitigung eindrängender Unholzarten (des Fegeholzes) für die Rentabilität des Betriebes von Wichtigkeit.

Im Akazienniederwalde sind kümmerlich aufwachsende Kulturen anf den Stock zu setzen, damit sich kräftige Triebe bilden: in den ersten. Jahren ist der Boden zwischen den Pflanzen roh zu behacken; mit fünf Jaliren beginnt die Durchforstung und alle fünf Jahre wird sie wiederholt. Schutz gegen Hasen und Kaninchen durch Bestreichen mit Fett oder 'Teer ist nötig. Beim Abhiebe können anch die Stöcke herausgehauen werden, so dali die Wurzelabhiebe frei liegen und selbständige Ausschläge entstehen, nachdem die Stockausschläge durch Wind und Schnee leicht am Stocke abbrechen. Weidenheger sind wie Papierheger in Ostasien unkrantfrei zu halten.

Die Pflege des Oberholzes des. Mittelwaldes umfafit folgende Arbeiten: Aufästungen (Dürr- und Grünästming), Bekämpfung der Wasserreiserbildung sind im vorhergehenden Abschnitt geschildert worden; Schutz gegen Rindenbrand wird durch Anbinden von Rindenstücken

1) E. Mer, Revue des Eaux et Forêts $190 \%$. 
an der sïdwestseite der glattrindigen Bäume orreicht; zopftrockene, pilzkranke, absterbende und tote Oberhölzer sind nach vorheriger Entästung dureh Hiebe, welche Auszughaungen heißen, herauszunehmen; das Abwerten der trockenen (Gipfel (Hirschhörner) hat sich nach Prof. Schuberg nicht bewährt.

Der Mittelwald verlangt nicht blok dio Durchreiserung und Durchforstung des Unterholzes, sondern anch Hiebe im Oberholz, wenn nicht natïrliche Ereignisse deren Zahl auf das Normale bereits heralgemindert haben. Solehe Hiebe (ebenfalls Auszughaunngen genannt) werden mit dem Hiebe des Unterholzes verbunden und beabsichtigen dis Zahl der Überhälter wegen der Zunahme ihrer Kronen und der clureh diese geübten Besehirmung des Unterstandes zu reduzieren. Die Lehrmeister des Mittelwaldes sind die Franzosen. So mögen auch ilnre Regehn, welche Boppe und Jolyet ${ }^{1}$ ) in ihrem Waldbau nitteilen, hier Platz finden. Sie nemnen die Überhälter des ersten Umtriebes balivanx (Laßraitel), des zweiten modernes, des dritten und vierten anciens, des fünften und sechsten Umtriebes vieille écorce. Für Eichen gelten als Regeln, daß die Zahl der balivaux pro Hektar 50, der modemes 30, der anciens 20 und der vieille écorce 10, somit die Summe der Überhälter pro Hektar 110 sein sollen. Trotz der Reduktion der Stammzahlen zeigt der Flächenraum, den die Kronen bedecken, eine Vergrölỉerung von $750 \mathrm{qm}$ der modernes auf $900 \mathrm{qm}$ der vieille écorce. Daß das Unterholz nicht Eichenschälwald sein kann, ergibt sich aus der grolien Zahl der Oberhölzer. Die Autoren nemnen die Hainbuche das beste Unterholz der Mittelwaldungen. Diese Zahlen im Oberholz gelten zunächst für Eiche und andere Lichtholzarten wie Pappcl, Birke und zwar in ihrem günstigsten Klima; es läßt sich erwarten, daß je nach Wechsel des Ḱlimas und der Bodengüte die Zahl der ÜberhäIter behuf's größter Ausnützung des Luft- und Lichtraumes über dem Unterholze ohne allzu große Behinderung des letzteren verschieden sein muli.

Bei Umwandlung des Mittelwaldes in Hochwald ist erste Sorge die Pflege der Kernwüchse durch Freihicb: $\mathrm{Ney}^{2}$ ) verlangt dies alle acht Jahre: außerdem Durchforstungen und Durchreiserungen auf rückgängiges und unterdrücktes Material. Wenn das Lnterholz so alt geworden ist, daß es bei Belassung eines ausreichenden Schutzhestandes für eine gruppen- oder kleinbestandsweise Verjüngung nicht mehr ausschlägt, beginnt die Fällung desselben.

1) Boppe et Jolret, Les forêts. Traité de silviculture. 1901.

2) Oberforstmeister Ney, Versammlung des deutschen Forstvereins zu Nitraßburg 1907 . 


\section{Siebzehnter Abschnitt.}

\section{Bodenpflege und Bodenverbesserung.}

Eines der ersten Gesetze des Waldbanes mul. lauten: darauf hin zu arbeiten, daß trotz der intensitiven Ausnutzung der Bodenkraft diese nicht abnimmt, der Boden somit nachhaltig die erhoffte Rente geben kann: ja, wenn es durch waldbauliche Maßnahmen ohne allzu große Kosten möglich ist, sollen geringere und schlechte Böden fortschreitend sich verbessern.

Die Mittel, welche dem Waldbau zur Erreichung dieses hohen Zieles zur Verfügung stehen, sind mannigfach und sollen im nachfolgenden erörtert werden:

1. Die Erhaltung des Bodens selbst, durch Schutz gegen seine Entführung durch Winde (Flugsandbildung), durch Wasser (Abschwemmung im Gebirge), gegen seine Abwärtsbewegung und Lockerung durch Weidetiere, dureh unpflegliche Bringmethoden u. dgl.

Der Entstehung der erwähnten Mißstände bengt eine weise Forstpolitik vor, indem sie verlangt, daß solche Örtlichkeiten ständig mit Wald bestockt bleiben, und sorgt, daf solche Waldungen in Hände gelangen, in denen ihr Bestand gesichert ist. Das wird am allervollkommensten erreicht, indem der Staat die Waldungen entweder selbst an sich bringt oder in den Besitz von Korporationen gelangen läßt, welche unter seiner Kontrolle stehen (wie Gemeinden, Stiftungen und andere juristisehe Personen). Die waldbauliche Behandlung solcher Schutzwaldungen beschränkt sich auf eine Naturverjüngung unter Schirm. Diese Forderung erfüllt am besten der Femelwaldbetrieb, sowohl der umlaufende wie der periodisehe. Wenn dabei auf eine truppständige Vereinigung der gleich alten Stämme hingewirkt wird durch Vereinigung in kleinen Gruppen oder Trupps, so ist doch eine gewisse RegelmäBigkeit und Verstärkung der Benützung solcher Waldungen möglich, ohne daß deren Hauptzweck, Schutz des Geländes und Erhaltung der Bewaldung gefährdet wäre; man vergleiche den nächsten Abschnitt. 
2. Erhaltung bzw. Herstellung oines normalon Feuchtiglieitsgehaltes im Boden.

a) Dio Sicherung der normalen Feuchtigkeitsmenge geschieht einmal durch Bewahrung oiner normal verwitternden Borlondecke, damit humose, die Feuchtigheit haltende Bestandtoile dem mineralischen Boden beigenengt werden. Sodann bedingt ein lock e rer Bestandesschluß die Frischerhaltung des Bodens; der Bestandesschluß soll nicht zu dicht sein, damit uicht zu viel der Niederschläge von den Kronen zurückgehalten werden, und nicht zu locker, aber loch dicht genug, um dio Abdunstung des Wassers aus dem Boden zu verzögern: für jede Holzart, jede Holzartenmischung, jedes Klima, jeden Boden wird einem anderen Schlußgrade jene goldene Mitte zukommen. Ist der Boden allzu trocken, so mag durch Bewässerung, wemn diese durchführbar ist, abgeholfen werden.

b) Bewässerung ist für den Wald nur notwendig in Gebieten, welche Steppen sind, weil in ihnen während der wichtigsten Vegetationszeit genügende Niederschälge fehlen. Wo eine Bewässerung durch oberirdische Zuleitung des Wassers, wie sie in Kalifornien ist, nicht geschehen kann, wird das Untergrundwasser durch Pumpen und Sichöpfwerke zur Bewässerung herbeigeholt werden müssen; da löst die Frage der Bewässerung nicht der Waldbau, sondern die Wasserbautechnik. Waldbau zur Auftorstung des Geländes kann erst einsetzen, wenn die Bewässerung gesichert ist.

In allen Waldgebieten von Europa, Amerika und Asien, in denen die Niederschläge tür das Aufwachsen von Wald vollkommen genügen, löst die ganze Frage der Waldbewässerung - der Waldbau; wo die Technik zu Hilfe kommen soll oder muß, da ist der Beweis erbracht, daß Waldbau, Waldwirtschatt und Waldpflege falsch waren. Eine Bewässerung des Waldes immerhalb der natürlichen Waldgebiete ist weder nötig noch wünschenswert, und die L e o Anderlind schen Vorschläge zur Flächenbewässerung des Waldes behufs Förderung des Zuwachses, zur Überflutung behufs Vertilgung der Insekten, Erhaltung größerer Wasserstände in den Flüssen, zur Sicherung ihrer Schiftbarkeit usw. gehören in das Gebiet der Phantasien. Für bewaldete Gebiete ist die beste Bewässerung - die Unterlassung der Entwässorung.

c) Entwässerung. Dauernde Entwässerungen sind nur bei ausgedehnten, mit mangelhattem Holzwuchse bestockten oder holzleeren Versumpfungen auszuführen: ist die Fläche zugleich vertorft, so wird zuerst eine Entwässerungsanlage durchgeführt und die Fläche abgetorft. soll die Fläche wieder Torf' werden, wird die Entwässerungsanlage wieder beseitigt: soll sie dauernd mit Holzwuchs versehen werden, wird die Entwässerungsvorrichtung erhalten: letzteres gilt auch für Grünlands- oder Flächenmoore, welche mit einem besseren Waldbestande versehen werden sollen. 
Es gibt zallheiche Fälle im Walde, in denen nur eine vor übergeliende Entwässerung angezeigt ist, um die Schwierigkeiten für Waldbegrüindung oder für das Aufwachsen des Waldes zu beheben. Ist die Verjüngung geschehen, hat sieh der Waldzustand gehoben, so ist für weitere Drainage durch den Wald selbst gesorgt. S'olche vorübergehende Entwässerungen sind Versenkungen des Grundwassers z. B. durch Stïckgräben, welche in tiefere Sickergruben ausmïnden (System $K$ a iser); Ringgräben fangen das nach einer Mulde zuströmende Tagwasser auf; Entwässerungsgräben mit Faschinen ausgefüllt und mit Erde bedeckt erleichtern die Kultur der Fläche; solange sie Wasser führen, widerstehen die Faschinen der Fäulnis und erfüllen sie ihren Zweck; wird den Gräben durch den heranwachsenden Bestand allmählich das Wasser entzogen, so verfaulen die Faschinen, und es verfallen die Gräben, nachdem sie ihre Schuldigkeit getan liaben. Versumpfungen kleinster Ausde hn ung werlen in gebirgigen Geländen oft dadurch rerursacht, daß eine kleine Nulde von cinem morschen Baumstamm oder von angehäuften Ast- und Laubmassen abgeschlossen wird, so daß W'asser sich anstaut. Die Beseitigung der Hindernisse genügt, wemn man nicht vorzieht, solche Stellen als Wasserbehälter oder aus ästhetischen Gründen unberührt zu lassen.

Es ist für viele oin Keichen des Fleißes, für den Verfasser ein /eichen des Überfleißes, wenn jede, selbst die kleinste Versumpfung im Walde dureh Entwässerung, „unsehädlich“ gemacht, wenn jede Wieso im Walde durch Aufforstung "verbessert" wird. Beide nützen in der Regel in der gegenwärtigen Verfassung melır, als wenn sie mit sehweren Geldopfern in Wald umgewandelt werden. Über diesen Punkt wurde bereits früher gesprochen.

WV asserarbeiten größeren Umfanges. wie sie Korrektionen von Flüssen, 'T'ieferlegung von Seen erfordern, wirlien füir das umliegende Gelände immer als Entwässerung. Sind die Bodenverhältnisse gute und die Niedersehlagsmengen sehr reichlich geboten, wie dies z. B. in Mitteleuropa bei allen Elevationen ïber $3011 \mathrm{~m}$ der Fall ist, so ist die Entwässerung für die benachbarten, bewaldeten rebiete belanglos; je geringwertiger aber der Bodeu, je geringer dio Erhöhung und damit die Niederschlagsmenge während der Vegetationszeit, um so gefïhrlicher kann eine solche Wasserentfïhrung tü̈ den anstoßenden Wald werden. Andererseits sichern Flußkorrektionen und Dammbauten gegen Überschwemmung der Waldungen entlang dem Ufer der Flïsso.

Überschwemmungskatastrophen gibt es anch im ganz umberölkerten Urwalde. Die gefährlichsten Wassermassen der Kulturländer kommen in der Regel nicht aus den Reginnen der oberen, sondern der mittleren Flußlänfe, wo der Wald am meisten beseitigt, der größte Teil der fallenden Niederschläge nicht mehr in den Boden einsinken kam, viel- 
mehr durch Gräben und Kinalisationen für dio möglichst beschleunigte Abfuhr des Wassers in die Flüsse gesorgt ist.

Immerhin sehwäeht der Wald die Hochwasser- und Wassermangelwirkung ab, indem er, wie schon früher crwähnt, für eine gleichmäßige Verteilung der oberirdiseh abfließenden oder in den Boden einsickernden Wassermengen sorgt; auch aus diesem Grunde ist es wünschenswert, daß der Staat vor allem die Gebirgswaldungen in seine Hände bringt, um die für das Tiefland wichtige Kontinuität der Bewaldung zu sichern. Um im gebirgigen Gelände den Wald zu unterstützen und den Wasserablauf möglichst einzuschränken, haben sieh Stüekgräben vortreff'lich bewährt; sie sind zuerst in der Rheinpfalz (18j(0) zur Anwendung gekommen.

3. Erhaltung bzw. Herstellung eines normalen Loekerungsgrades im Boden.

Ein normaler Lockerungsgrad wird dureh die Waldvegetation selbst und die Tiere des Bodens allmählieh hervorgerufen: Toranssetzung hierfür sind jedoch passender Bestandessehluß, Streumisehung und Sicherung einer normalen Verwitterung der Abfallstoffe. Mehrfach sind in nenerer Zeit direkte Bodenlockerungen im Walde durch versehiedene Werkzenge empfohlen worden; besonders ist hierin Dänemark vorangegangen. Es muß erst abgewartet werden, ob das Mehr an Zuwachs so groß oder größer ist als das Mehr an Ausgaben Die beste Bodenlockerung läßt sich freilich erzielen in Verbidung mit Bodendüngung; welches Düngemittel festen Boden lockert und lockeren festigt, wurde bei der Dïngung des Pflanzgartens bereits besproehen.

Durch Kahlschlag freigelegter Boden erhärtet; unter Schirm besamter Boden bleibt in seinem normalen Loekerheitsgrade. Terheideter Boden neigt zur Bildung von Bleiehsand und Humussandstein oder Ortstein. Dieser letzteren Bodenentartung vorbeugend, wirkt der Ausschluß der Heide durch Zwischenbau oder Unterbau einer beschattenden Laubholzart. Damit lälist sich auch eine allgemeine Boden. verbesserung erzielen, welehe in Föhrenbeständen III.-V. Bonität zur Pflicht für den Wirtschafter wird. Damit aber eine anspruchsvollere Laubholzart Fuß fassen kann, wird eine Düngung flächenweise, streifenweise oder punktweise, je nach der gewählten Begründungsart der Föhre und ihres Zwischen- oder Unterbaues, notwendig werden. lst Ortstein bereits vorhanden, so mag er mit dem Untergrundsptlug durchbrochen werden, worauf Föhrenanbau und Laubholzzwischenbau (wenn nötig letzteren nach vorheriger Bodendüngung) in wechselnden Sitreiten erfolgt. Zufolge der geringen Bodengüte bleibt das Laubholz unterständig. Schutz gegen Wild ist unentbehrlich, selbst bei geringstem Wildstande. 
4. Erhaltung des Gleichgewichts zwischen Verbrauch und Aufschließung des vorhandenen mineralischen Reservenährgehaltes des Bodens.

Die Aufschließung der Reservemineralien im Boden kann nur unter Mitwirkung von Kohlensäure erfolgen; diese aber entsteht im Boden durch Auflöstung der Abfallstoffe der Bäume als da sind: Laub, Nadeln, Zweigstücke, Rinden- und Holzteile, Knospenschuppen, Blïten- und Friichtereste und andere, sowie durch Verwesung von Tieren, Pilzfäden, Bakterien u. dgl. Ihre normale Kerstörung, die normale Auflösung kann nur bei einem bestimmten Fenchtigkeitsgrade und bei Anwesenheit von Bakterien, Tieren und wachsenden Wureln sich abspielen. Die Bodenfrische wird gesichert durch einen mäßigen Bestandesschluß, wie zu 2 a oben erörtert wurde.

Schädlich, weil die normale Zersetzung der Streuabfälle unterbrechend oder hindernd, sind:

a) Alle Mafnalımen, welche den mäßigen Bestandesschluß jählings unterbrechen, vor allem Kahlschlag, der die Terbrennung, Terflüchtigung, Verwehung oder Erhärtung der Streu nach sich zieht oder ihre rasche Aufzehrung durch Unkrautwuchs bewirkt; ähnlich wirken plötzlich einsetzende starke Durchlichtungen, allzu tiefes Untergraben der Streu bei Bodenbearbeitungen.

b) Ungeeignete Erziehungsformen, wie Beibehaltung eines allzu dichten Bestandesschlusses bei Eintritt ins Baumalter; dadurch wird die Zerstörung der Abfallstoffe verlangsamt oder ganz aufgehoben und Rohhumusanhäufung herbeigeführt; die Verheidung des Bodens unter Lichtholzarten verursacht Bleichsand-, im schlimmsten Falle sogar Ortsteinbildung.

Nützlieh sind:

a) Mischung der Holzarten, da Mischstreu sich leichter zersetzt als reine Streu. Nach der Methode des Verfassers wïrde sich durch den allgemeinen Unterban aller Holzarten beim Eintritt ins Jurchlichtungsalter stet. Mischstren ergeben, wolche zwar anch durch die Kronenmischung verschiedener Holzarten, aber nur mit großen anderweitigen Uptern erreicht werden kann.

b) Verbot der Streunteruahme, Ablösung von Streurechten, Erschwerung der Stremnutzung durch Bodensträucher, Gestattung der Streuentnahme nur anf den besseren und hesten Böden, solange bis die Streublogabe ganz eingestellt werten kann; Abgabe dor Streu, wo sie durch falsche Erzielıung des Bestandes angehänft wurde und Korrektur der Erziehung in der '/ukuntt.

c) Schutzmittel gegen Streucntführung durch den Wind und Strenvernichtung durch Fener; Anlage von W indmänteln und Feuermänteln am Bestandsrande, in Europa am 
Südwest-, West- und Nordwestrande, oder auch bei lockerstehenden Waldungen durch Wiederholung von Wind- und Fenermänteln im Bestandsimmern. Olıne Windmantel erstreckt sich die Laubverwehung und Bodenaushagerung bis auf $100 \mathrm{~m}$ ins Innere des Bestandes. Als Windund Fenermantel dienen: die Anlage eines schmalen, niederwaldartig behandelten Streifens von Laubhölzern; AnpHanzung von Fichte, Tanne und anderen Schatten ertragenden, immergrünen Nadelbäumen in mindestens zwei bis drei Reihen. Die Vortrefflichkeit derartiger lebender Zäune als Schntzmittel gegen Laubverwehung und Bodenfener wird aber zunichte gemacht, wenn den Nachbarstämmen das Überwachsen solcher Zäune gestattet wird; auch Laubhölzer können für solche Zäune (z. B. Buchen besonders der Abart "Süntelbuche") Verwendung finden. Frey ${ }^{1}$ ) sagt, daß dauernde Waldmäntel heckenartig geschnitten werden, somit Laubholz sein müssen; Laubholzsträucher eignen sich ebenfalls; Fichten und Tannen entlang den Bestandsrändern seien ungeeignet. Über Fenerstreifen und ihre Behandlung sind die Erfahrungen und Veröffentlichungen von Dr. Kienitz (Allgemeine Forst- und Jagdzeitung verschiedener Jahrgänge) grundlegend.

Jan hat sodann empfohlen sowohl zum Schutze gegen Randaushagerung als zum Besten des ganzen Bestandes und seiner sicherung gegen Wind den Rand eines Bestandes nicht zu durchforsten, damit er sich als Wind mantel dicht geschlossen erhält; besser dürften starke Durchforstungen und Durchlichtungen zum Ziele führen, da sie die Astbildung begünstigen; die dänische Waldranderziehung (Metzger) ist hierfür der beste Beweis; solche Säume sollten aber mindestens 느 $\mathrm{m}$ weit von der Nachbargrenze abstehen, damit der Nachbar nicht die Beseitigung der Äste verlangen kann. Derartige Wind- oder Waldmäntel sollen eine Breite von $5 \mathrm{~m}$ besitzen. Vorzügliche Dienste leisten sodann jene Pflanzen, welche die Natur, sich selbst überlassen, als Windbrecher anzubauen pflegt, das sind die zahlreichen Sträucher; aber aneh von diesen ist der hohe Bestand fernzuhalten. Schüpfer ${ }^{2}$ ) will weitständige Pflanzung am Waldrande und von Jugend auf kräftige Durchforstung; auch im Innern des Waldes sollten die Süd- und Westränder der Bestände derart behandelt werden als ein den Wald festigendes Gerippe. Auch der Vorschlag Thalers ${ }^{3}$ ) an Wegrändern, Schneusen zum Schutze des Bestandes und aus ästhetischen Gründen eine Art Überhalt der sehönsten wie anch breitkroniger, kurzschaftiger, knorriger

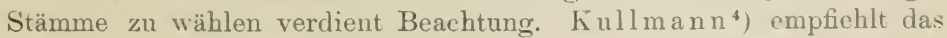
Belegen der Laubwaldränder mit Reisig zum Festhalten der Stren:

1) Allgem. Forst- u. Jagdztg. 1905.

2) Forstw. Centralbl. 1909.

$\left.{ }^{3}\right)$ Allgem. Forst- u. Jagdztg. 190s.

4) Allgem. Forst- 11. Jagdztg. 1904. 
yegen Rindenbrand der Buchen, Fichten und andere soll Reisig am Stamme $3-6 \mathrm{~m}$ hoch mit Blumendraht befestigt werden. Reu $\beta$ will die Waldränder durch Auflegen von Steinen aut den Wurzeln festigen.

Als Windmäntel sowohl gegenüber dem Bestande als gegenüber der Lanbverwehming wirken die Loshiebsstreifen, welche mit den stärksten Pflanzen der schnellwüchsigsten, immergrünen Nadelbäume bepflanzt werden sollen. Diese Loshiebsstreifen haben den Zweck, den gegen Osten hin liegenden Bestand und Boden zu schützen, wem der gegen Westen vorliegende Bestand frühzeitiger, wegen höheren Alter's, beseitigt werden muf. Solche Streifen anzusäen oder gar der Natur zur Besamung zu ïberlassen, ist verfehlt.

Isoliermäntel werden bei der Gruppenverjüngung notwendig erachtet, z. B. um Eiche gegen Fichtenumgebung zu sichern; hierzu wird Buche empfohlen, die aber gegen anliegende Eichen nicht minder gewalttätig ist als Fichte; eher diirfte das Ziel mit Lichtholzarten wie Lärchen, Föhren und anderen erreicht werden; nur kleine Gruppen bedürfen des Schutzes: sie mit solch gefährlicher Umgebung anzulegen, war von Anfang an ein Mißgriff; bei Klein- und Großbeständen ist es besser die Berührungsränder als Wege oder Schneusen auszubanen.

Die Aufzehrung des Humus durch Unkraut und Strauchwuchs würde dem Wald keinen Schaden, sondern nur Gewimn bringen, wemn der Unkrant- und Stranchwuchs dureh den Waldwuchs selbst wieder vernichtet würde; denn in diesem Falle kämen zu den aus dem Boden aufgenommenen Nährstoffen noch jene als Dïngemittel hinzu, welehe der Luft entstammen. Da aber der Unkrautwuchs, besonders (iras, genützt oder anderweitig als der Kultur hindernd beseitigt wird, so ergibt sich für den Waldboden nicht nur kein Gewinn, sondern sogar cin Verlust an Nährwerten. Es ist aus diesem Grunde und besonders wegen der physikalischen Bodenverbessermng -.. Erleichterung der Durchlüftung, der Zufuhr ron Wasser mit Kohlensäure in Lösung - wertvoll. den Unkirantwuchs durch Unterbau nuter Lichtholzarten oder auch unter durchlichteten sehattenholzarten zu vernichten oder ganz zu verhindern.

Der Unterbau. Wie Borggreve spricht auch Fricke ${ }^{1}$ ) dem Unterbau jeden Wert ab; er schade als Mitzehrer eher; Fichtenunterban unter Eichen sei unschädlich, anch wenn die Fichte in die Eichenkrone hineinwachse! Als Mitzehrer kommt Unterbau doch nur dann in Betracht, wenn er zum Treibholze emporwächst; dazu aber bedarf es eines guten Bodens, der den Unterban anch ohne Schaden ertragen kann.

Yu Unterbaubolzarten eignen sich in erster Linie Laub. höl\%er, da sie die Hälfte des Jahres nicht belaubt sind und damit

\footnotetext{
1) Märkischer Forstverein 1900.
} 
Licht, Luft und Regen freien Zutritt zum Boden gestatten, was der normalen Auflösung der Streu förderlich ist; immergrüne, schattenertragende Nadelbäume wic Fichten und Tannen, Eihen sind hier am ungünstigsten und so ungünstig wie immergrüne Laubholzarten; besser als diese sind immergrüne Halbschattholzarten wie Weymonthsföhren, Zürbeln, Scheinzypressen und andere. Unter den Laubhölzern steht an erster Stelle die Buche (Fagus), welche mit Reeht die Mrutter des Bodens, die Stiefmutter für andere Holzarten genannt wird; an zweiter Stelle sind Alums, sodann Hainbuchen, Ahorne, Ulmen, Linden u. a.; unter den Nadelhölzernsind die Stroben die Bodenmütter. Dr. Kienitz ${ }^{1}$ ) rät den Unterbau der Föhre mit der Schatten ertragenden Traubeneiche; Weis ${ }^{2}$ ) schätzt die Hainbuche unter Föhren höher als die Rotbuche; Fr. Boden empfiehlt die Süntelbuche (Fagus silvatica lusus tortuosa) als Windmantel; sie wäre auch als Unterbau wohl zu gebrauchen. Bodenschutz geben auch Sträucher wie Himbeeren, Hollunder, Haselstrauch. Brombeere, Brennessel und andere. Prof. Sch wap pach sagt, daß die im Walde durch die Vogelwelt eingebrachten oder aufliegenden Laubhölzer in viel umfangreicherem Maßstabe als es jetzt der Fall ist, ein für günstige Streumischung und Humuszersetzung ausreichendes Unterholz schaffen würden. wenn die Pflanzen nicht fortwährend vom Wilde vernichtet oder wenigstens verbissen wïrden.

Der Unterbau kann bei der Buche, Hainbuche, Linde durch Saat geschehen, indem mit der Kulturhacke eine flache scholle vom Boden abgehoben wird, unter welche ein paar Körner gelegt werden: durch eimen Tritt mit dem Fuße schließt sich der fast horizontale Spalt; eine solche Stecksaat im Abstande von $20-40 \mathrm{~cm}$ erstreckit sich als Vollsaat über den ganzen, zu unterbauenden Bestand. Sicherer ist Ptlanzung mit ein- bis dreijährigen (im letzteren Falle schwachen) Buchen und den übrigen Holzarten. Es wird dabei dasselbe Instrument wie für die Saat benützt, der Boden jedoch tiefer und von $50 \mathrm{zu} 50 \mathrm{~cm}$, schief eingehackt, wie dies bei der französischen Klemmpflanzung beschrieben wurde und die Pflanze eingeschoben; ein Tritt mit dem Fuf schließt den Spalt; ob der Bodensehutz gerade- oder krummschäftig emporwächst ist gleichgültig. Die Rolle eines Füllholzes in Lichtholzbeständen zur Abstofiung der Äste und Unterdrückung der Wasserreiserbildung sollte dem Unterban nur auf den beiden ersten Bodenbonitäten zugewiesen werden; überdies ist die Reinigung der S'chäfte über eine bestimmte Länge hinaus kein finanzieiler Gewinn, viclmchr ein Verlust an Masse und Rente.

1) Märkischer Forstverein 1900.

2) Ebenda 189४.

II a r $\mathbf{r}$, Wallbau. 
Fichten unter Föhren werden in der Regel schon bei der Saat. als Mengesaat von Fichten und Föhren begründet; wird die Fichte zu dicht gesät, leidet auch die vorwachsende Föhre. Wird Unterbau gepflanzt, soll allgemein stets $1 \mathrm{~m}$ Abstand von den /ukunftsstämmen, nicht von den $Z$ wischenstämmen eingehalten werden.

Wïrde den Holzarten neben Bodenschutz auch die Aufgabe eines Treibholzes im Jungwnchsalter eines Bestandes zufallen, z. B. bei der Staffelpflanzung, so würden, wie schon erwähnt, sich hierfür Lichtund Halbschattholzarten besser eignen als Schattenholzarten, welche die Nutzliolzart zu einer astlosen, schlanken Rute emportreiben, welche ohne Stïtze sich nicht aufrechthalten kann. Um Pflanzen zu sparen hat man den streifenweis en Unterbau sowie den gruppenweisen Unterbau des Bestandes vorgeschlagen. Die volle Wirkung übt jedoch nur der totale. Unterbau der ganzen Fläche aus. Der Gedanke möglichst an Pflanzen bei dem Unterbau zu sparen, hat Berechtigung wemn der Unterbau mit starken Pflanzen, welche eine normale Lochpflanzung erfordern, ausgefüllt werden soll; ein derartiger Unterbau beschädigt die Wurzeln des Hauptbestandes und ist ror Wildverbiß ebensowenig gesichert, wie die billigere Klemmunterpflanzung oder die Untersaat.

5. Erhöhung des vorhandenen Nährgehaltes des Bodens durch Düngung, Freilanddüngung.

Es wird allgemein angenommen, daß bei Beschränkung der Nutzung: auf die oberirdische Holzmasse, bei Vermeidung der Streu- und Stockholzgewinnung der Nährgehalt des Bodens sich nicht abmindert, ja sogar sich erhöht und solche Holzarten. welche reichlich Streuabfälle liefern wie Buchen, Schwarzföhren, Weymouthsföhren, Roteichen und andere werden, geradezu bodenverbessernd genannt. Es dürfte dem höchsten Maße der Erwartung nach dieser Richtung hin voll entsprechen, wenn durch die oberirdische Holzgewinnung das Gleichgewicht zwischen Entnahme und Aufschließung der Nährstoffe im Walde erhalten wird. Ist mit der Nutzung eine bodenschädliche Form verknüpft, wie der Kahlschlagbetrieb, der eine oft' melır als zehnjährige Unterbrechung der normalen Bodentätigkeit mit sich bringt, so liefern, die mit jeder Umtriebszeit auf Sandboden abnehmenden Erträge in diesem Betricbe den Beweis, daf unsere Hoffuung auf Erhaltung des Gleichgewichts, anf Nachhaltigkeit sich nicht erfüllt. Auf den besseren und besten Bonitäten ist dic Abnahme der Bodengüte bis hente nicht nachweisbar; der negative Beweis ist aber wegen der Unvollkommenheit der Untersuchungsmethoden kein positiver für die Erhaltung oder gar 'Junahme der Bodenkraft. Die zunchmenden Vorschläge für Freilanddüngung sprechen für Abnahme der Bodenkraft. 
Es liegt in der Natur der künstlichen Düngung, daß nur die Oberfläche des Bodens angereichert werden kann, somit nur den Waldpflanzen in der frühesten Entwicklung die Vorteile zugute kommen können. Aus diesem Grunde ist die Düngung der Saat- und Pflanzgärten längst in Übung und auch in dieser Schrift an geeigneter Stelle gebührend berücksichtigt. Die Düngung der Freikulturen, besonders bei Ödlandsaufforstungen, gehört erst den letzten Dezennien an, wenn man ron der Bierm a n 11 schen Rasenaschegewinnung und Düngrung absieht. Daß die Düngung, wie erwartet werden muß, zunächst das An- und Aufwachsen der Aufforstungspflanzen sichert und fördert, steht heute bereits fest. Der Wert der Entwässerung und Kalkdüngung von Moorflächen behuf's Umwandlung in Wald durch die seichtwurzelnde Fichte kann nicht bestritten werden; für die tiefwurzelnden Föhren aber muß erst der Fortgang der Düngungsversuche zeigen, ob der erhöhte Aufwand sich rentiert.

Auf Sand- und Heideböden ist mit Kainit- und Thomasphosphat ein schnelleres Wachstum der eingepflanzten Föhre in der ersten Jugend recht wohl möglich; doch stehen die Ergebnisse in keinem Verhältnisse zum Düngerverbrauch. So z. B. wird berichtet, daß auf dem Gute Hanloh in Westfalen ,armer, grüner Sand für drei Versuche von je $1_{4}$ ha Größe ansgewählt wurde. Auf der Fläche I wurde mit 4 Zentnern Kainit und 4 Zentnern Thomasschlacke, auf Fläche II mit 8 Zentnern Kainit und 8 Zentnern Thomasschlacke gedüngt; Fläche III blieb düngerfrei. Achtjährige Föhrenpflanzen erreichten: minimale Höhe auf I $1,35 \mathrm{~m}$; auf II $1,5 \mathrm{~m}$ : auf III $0,8 \mathrm{~m}$ : maximale Höhe auf I 1,75 ; auf II 2,2.5; auf III $1,20 \mathrm{~m}$.

Die gewaltige Düngermenge von 16 Zentnern auf ${ }^{1} 4$ ha hat die Höhe, welche auf dem ,armen, grünen Sand" ohne Düngung erreicht wurde, nicht verdoppelt. Dazu kommt, daß eine Leistung von 2,2 m für achtjährige Föhren eine mittelmäßige ist, daß mit jedem Jahre die Wurzeln immer mehr dem Düngerbereiche entrücken, so daß die Düngermenge gar nicht ausgenützt wird.

"Bahnbrechende Versuche" wurden auf "vollständig unfruchtbarem Boden" ausgeführt. Mit derlei Kraftausdrücken wird eine ziemlich skrupellose Reklame von seiten der Syndikate der Thomasphospatfabriken betrieben, welche mit Recht viele Wirtschafter in der Düngerverwendung im Walde vorsichtig gemacht hat. Es ist gut, daß den Berichten der Fabriken auch zuverlässigere Berichte von unparteiischen Forstmännern gegenüberstehen und einwandfreie Versuche in Preußen, Belgien, Holland, der Schweiz und anderen I,änderm einguleitet wurden.

Professor $\mathrm{S} c \mathrm{~h}$ wappach ${ }^{1}$ ) komnte keine Wirkung bei Vordüngung, d. h. Düngung vor Anbau der Holzart wahrnehmen; Nachdüngung hat

1) Zeitschrift f. Forst- 11. Jagdw. 1907. 
sich bei im Wuchs stockenden Verjüngungen wirksam erwiesen: Zwischendüngung in Löchern zwischen den Pflanzen und Anfällen derselben mit Noorerde hat sich bewährt. Bodenlockerung wirkt wie Düngung, weshalb Schweineeintrieb angeraten wird. Nach Beobachtungen des Verfassers wühlt das Schwein allzu große Löcher in den Boden und verzehrt zahllose, feine Wurzeln; Professor Jentseh ${ }^{1}$ ) sagt, es sei den Holländern durch Bodenbearbeitung und Düngung gelungen, den Umtrieb ihrer Schälwaldungen auf 11)-12 Jahre zu ermäßigen, während im angrenzenden Westdeutschland erst ein Umtrieb von 15-20 .Jahren gleiche Erträge liefere. In einer späteren Bemerkung schränlit Jents $\mathrm{Ch}^{2}$ ) sein Urteil wiederum ein mit dem Satz, daß die bisherigen Ergebnisse in Belgien und Holland die Brauchbarkeit der Walddüngung noch nicht beweisen würden. Nach Dr. Hornberger ${ }^{8}$ ) besitzen die meisten Versuche im Walde keine Beweiskraft, weil sie keine exakten Versuche seien; sie sind wegen Wechsels in Boden, Luft, Wärme, Bewässerung, Bodenbearbeitung allzu verschieden und nicht vergleichbar.

Die Einwirkung des Kalkes bei Freilanddüngung ist unbestritten. Dr. Vater empfiehlt die Kalkung des Rohhumus und Bodenbearbeitung; Kalkung bzw. Mergelung, sagt Dr. Hornberger, wirkt auf sehr viele Böden wohltätig. Die Einwirkung des Kalkes auf Rohhumus ist von P. E. Müller und Fr. We is ${ }^{4}$ ) eingehend untersucht worden. Dureh Kalk wird der Stickstoff des Rohhumus in eine für die Pflanzen assimilierbare Form übergeführt, worauf die günstige Wirkung der Kalkung und Bearbeitung des Bodens in Buchenverjüngungen zurückgeführt werden muß. Nach $\mathrm{R}$ amm ergibt Düngung mit Thomasmehl und Kainit bei Tannensaaten, nach Erdmann Kalk mit Bodenbearbeitung für Eiche auf Flottlehm gute Ergebnisse; Oberförster Koch will Beisaat der Lupinen in Fichtenkulturen. Nach Engler und Glutz ${ }^{5}$ ) geben Ackererbsen und Sauerbohnen auf kalkreichem Boden, Lupinen auf lehmreichem Boden, gelbe Lupinen auf kalkarmem Boden und in höheren Lagen die Ackererbse eine Anreicherung des Bodens mit Stickstnff. Bei erschöpftem Boden soll vor dem Anbau der Lupinen eine mäßige Düngung von Thomasmehl vorausgehen: anf humusarmem, aber mineralisch noch kräftigem Boden soll die künstliche Düngung unterlassen werden.

Verfasser möchte das Augenmerk jener, welchen die traurigsten Waldungen, nämlich Föhrenbestände IV. und V. Bonität, zur Bewirtschaftung unterstehen, auf die Freilanddüngung solcher Bestände

1) Mindener Forstliche Hefte 1900.

$\left.{ }^{2}\right)$ Forstw. Centralbl. 1:101.

3) Zeitschr. f. Forst- u. Jagdw. 1:908.

4) Naturwissenschaftl. Zeitschr. f. Land- u. Forstwirtschaft 190:\%

5) Mitteilungen der schweiz. Zentralanstalt f. Forstwesen 190:3. 
mit Kainit, Thomasmehl, Rasenasche und andere kalireiche l) ïnger hinweisen: die Düngung hätte in Streifon zwischen den Pflanzreihen oder Saatriefen, oder punktweise an den Pflanzstellen liurz vor der allgemeinen Bodenverunkrantung solcher Krüppelhestäncle zu erfolgen, nicht um durch die Düngung dem Boden Nährstoffe zur Hebung dess Zuwachses znzutühren - das wären kostspiclige Festmeter - , sondern, um dadurch den Unterbau einos Laubholzes (Buchen, Hainbuchen, Weißerlen und andere) zu erziclen. Nur durch Laubholzmuterbau kann der Boden allmählich mit dem geringsten Aufwand an Mitteln anf eine höhere Bonitätsstufe gehoben werden, selbstverständlich vorausgesetzt, daß, wie bei jedem Unterbau so auch hier, Stremntzung und Wildverbiß unterbleibt.

Wemn der Erle dieselbe Eigenschaft wie der schmetterlingsblütigen Robinie, den Lupinen, Kleearten und anderen Papilionaceen zukommt, daf sie den Stickstoff ans der Luft aufnimmt und durch Verwesung ihrer Wurzeln in reichlicher Menge dem Boden zuführt, dann ist diese natürliche Düngung der künstlichen vorzuziehen: denn die Erle und alle schmetterlingsblütigen Bäume verbessern den Boden auch physikalisch, wirken in größere Tiefe, geben selbst Erträge und rerursachen die geringsten Kosten. Erle freilich wird als Einbau und Unterban. mit und unter Föhren, auf Böden unter III. Bonität ohne Düngung kaum mehr verwendet werden können.

Vor allem muß betont werden, daß die düngende Wirkung der Stren nie durch künstliche Dünger ersetzt werden kamn; Ersatz für Entgang an mineralischen Nährstoffen durch die Streunutzung ist zwar leicht und billig; aber die physikalische Wirkung der Streu ersetzt kein mineralisches Düngemittel. 


\section{Achtzehnter Abschnitt. Schutzwaldpflege.}

Als Schutzwalduugen bezeichnet man solche Waldungen, deren Beseitigung eine besonders nachteilige, deren Anbau eine besonders wohltätige Wirkung hervorbringt. Am weitesten gefaßt ist der Begriff Schutzwaldung in jener Anschauung, welche die Bewaldung eines bestimmten Teiles der Bodenfläche eines Landes verlangt, damit den Bewohnern das notwendige Holz nachhaltig gesichert sei. Wo der Holzbedarf gering ist, wie vor allem in den wärmeren Klimaten, wo die Bevölkerung geringe Ansprüche an den Wald für industrielle Anlagen erhebt, mag diese Forderung erfüllbar sein. Fast alle größeren Kulturvölker der Erde sind gezwungen - die Vereinigten Staaten werden in Bälde folgen - von den Holzvorräten anderer Nationen zu zehren. Selbst Deutschland, von dessen Bodenfläche $25 \%$ bewaldet sind, muß alljährlich Holz im Werte von 300 Mill. Mark vom Auslande beziehen.

Angesichts dieser Erscheinung muß als erste Forderung erhoben werden, daß alles a ufforstbare $\ddot{~})$ dland im eigenen Lande in Wald umgewandelt werden soll, $u$ m den Holzbezug von auswärts einzuschränken und ertragloses oder ertragarmes Land in ertragreiches Waldland umzuwandeln. Baumlose Flächen, welche höhere Erträge durch anderweitige Benutzung geben, zählen hier nicht zum Ödland. Holz mangelt vor allem den Steppenregionen; für die Besiedelung und Urbarmachung dieser, für die Kultur und Entwicklung ihrer Bewohner ist Bewaldung die wichtigste Anfgabe, zu der schon die Schutzlosigkeit gegen die Unbillen der Witterung drängt. Abb. 1 S. 17 gibt dio wichtigsten, durch Nangel an Niederschlägen waldlosen Gebiete der Erde (in horizontaler Strichelung) wieder: hinzu kommen noch ungeheure, rom Menschen erst entwaldete und brach gelassene Gebiete, in welche der Wald aus eigener Kratt nicht wieder zurïckwandern kann oder darf. Aus den naturgesetzlichen Grundlagen ergibt sich weiter, daß von diesen waldlosen Flächen nur ein kleiner Teil nicht aufforstungsfähig ist; nicht bewaldbar sind sodann jene I،andflächen im 
Norden und auf den höchsten Bergen, denen die nötige Wärmemenge für das Dasein von Wald fehlt. In der Abbildung 1 sind diese Flächen lurch vertikale Strichelung gekennzeichnet, wobei die waldlosen Regrionen der höchsten Bergspitzen bei der Kleinheit des Maßstabes selbstrerständlich nicht wiedergegeben werden konnten. Über die Aufforstung ron Ödland handelt der XIV. Abschnitt.

Als erstrebenswerte Wirtschattsfigur und Wirtschaftseinheit erscheint bei allen diesen Waldneuanlagen der K le inbestand mit seiner Erziehung zur Verjüngung. Durch letztere allein besteht Sicherheit, daß das Ödland nicht zurückkehrt und die schweren Kosten der ersten Waldanlage bei der Begründung der zweiten und folgenden Waldgenerationen in Wegfall kommen. Als Begründungsart hat sich allein die Pflanzung mit starkem Material (Strauchzwischenpflanzung, Auswahlpflanzung) als wirksam gegen die zahlreichen Pflanzenfeinde auf den Üdländereien erwiesen.

Allgemein ist die Anschauung verbreitet, daß das Klima eines Landes eine wesentliche Änderung erleiden muß, wemn einstens waldreiches Land entwaldet oder einstens waldloses Land bewaldet wird. In der Tat bestätigt die Beobachtung, daß Steppenklima zu Waldklima sich verhält wie Kontinental- zu Insularklima. Der Wald wirkt wio das Meer nivellierend auf die Extreme in Temperatur und Feuchtigkeit. Die Wirkung des Waldes erstreckt sich jedoch nur über ein paar hundert Meter von seinem Dache hinweg in das waldlose Gebiet und erschöpft sich auf diesem Wege in Erhöhung der Luftfeuchtigkeit um einige Prozente und der Abstumpfung der Extreme um einige, waldbaulich und gärtnerisch freilich sehr wichtige Grade. Unmöglich kann diese geringe Erhöhung der Luftfenchtigkeit und diese geringe Erniedrigung der Temperatur genügen; um die Niederschlagsverhältnis:o eines Landes wahrnehmbar zu verändern, und die von Blanford im mittleren Indien gefundenen Zahlen über Steigerung der Niederschläge nach Wiederbewaldung harren noch der Bestätigung und Aufklärung. Aber Blanfords Beobachtung ist in alle Bücher übergegangen als Bestätigung einer weit verbreiteten Anschaunng im Volke. Die Aufforstungen in den regenarmen Gebieten der deutschen und englischen Kolonier: von Südafrika sind ausgeführt in der Hotfinung, daß der neu zı begründende Wald die Niederschlagsmenge im Lande mehren und die kostspieligen Bewässerungsanlagen enthehrlieh machen werde. Wenn auch die Hoffnungen auf erhöhte Niederschläge sich vorausicichtlich nicht erfüllen werden, so bleibt die Hoftinung auf eine bessere, gleichmäfige Verteilung der gefallenen Niederschläge im Boden nach der Bewaldung. Mit allem Fleiß und mit reichlichsten Mittelu sollte daher dort aufgeforstet werden zur Zurückhaltung der Wasserabdunstung, zur Erhöhung der Sickerwassermengen, aus welchen Quellen und die Wasserläufe der Flüsse gespeist werden. Wald. der eine solche Rolle 
erfüllt, sei es in den Steppen oder innerhalb der Waldregionen selbst im Gebirge, im Hügellande, ist Schutzwald. Man neigt zur Ansicht, daß es cine Bewaldungsfläche gebe, z. B. jene ron Dentschland mit 250 ${ }^{\circ}$, welche bezüglich der Wasserversorgung als „normal“ zu bezeichnen wäre. Man neunt deshalb Länder, welche diese Kahl nicht erreichen, waldarm, solche, welche sie übertreffen, waldreich: waldnormal aber köunen dabei alle sein. Die normale Bewaldungszahl muf. für jedes Land eine andere sein und eigens ermittelt werden. Sie ist die Summe aller Sehutzwaldungen. Schutzwaldungen sind zunächst alle Waldungen der Hochgebirge (Talsohlen ausgeschlosien); Länder mit Hochgebirgscharakter, wie z. B. Schweiz und Tirol, erhalten schon dadurch eine sehr hohe, normale Bewaldungszahl; in Ländern mit Mittelgebirgen wird sie nieder sein, in ebenem Gelände kamn sie Null sein, da dort Schutzwaldungen aus naturgesetzlichen Gründen fehlen können. In Ländern mit Kontinentalklima werden Schutzwaldungen umfangreicher sein müssen als in solchen mit Insularklima.

Die meisten Forstgesetze verbieten in den Sehutzwaldungen der Gebirge den Kahlschlag, in der Erkenntnis, daß durch plötzliche Bodenentblößung der Abwaschung der feinen Erde, der Vergrasung, der Feuergefahr am meisten Vorschub geleistet wird; der urwaldartige Charakter des Femel- oder Plenterwaldes erfüllt am besten die Forderungen des Gesetzes, erschwert aber die Nutzung und beeinträchtigt die Rentabilität solcher Waldungen. Als ein Ausweg erseheint hier der Kleiubestandswald, der in schmale saumschläge ausgeformt wird; jeder Saum besteht, wenn möglich, aus einer anderen Holzart, wird zur Verjüngung erzogen und im beschleunigten Schirmschlage verjüngt. Soweit noch Buchen wachsen - als Unterbau steigt sie viel hölier die Berge hinan denn als Baum -- werden zum Unterbau Buchen benützt; wo es der Buche zu kalt wird, mag eine straucherle oder Sorbus an ihre Stelle treten. Die Richtung dieser Saumhiebe ergibt sich aus einer frïheren Betrachtung Seite 31: dieser samweisen Kleinbestandswirtschaft nähert sich $\mathrm{C}$. Wagners Blendersaum, entfernt sich aber prinzipiell von diesem dadurch, daß für den saumweisen Kleinbestand Reinbestand mit späterem Unterbau als Wirtschaftsziel gilt. Die Verjüngung des sammweisen Kleinbestandes erfüllt auch die Forderung des Gesetzes, weil sie keinen Kahlschlag voraussetzt: vom Kahlschlag aber hat diese Wirtschaftsform das Beste angenommen: seine lohe Rentabilität und große Einfachheit.

Als Schutzwald ist autizufassen solcher Wald, der die Abrutschung ler Erdschichten auf geneigten, von Quellen durchrieselten Iängen verhindern soll. Nur die Bestände einer tiefwurzelnden Holzart können diese Forderung erfüllen. Die seishtwurzelnde Fichte erhöht durch das (iewicht der stämme die Gefahr; Föhren, Lärehen und 
Laubhölzer, als liäftige PHanzen ausgepflanzt, verbindon dis gleitendo Schichte am besten mit der Unterlage, selbst wenn diese nur von schmalen Spalten zerklïftet ist. Solche Haugwaldungren wären am besten im Femelbetrieb zu behandeln.

Als Schutzwald erscheint eine locker" Anhäufung von Bänmen, welche hindern, daß die Weicletiere mit ihren Tritten das fruchtbare Gelände abwärts bewegen, lockern und der Abwaschung überliefern. Der anfgelöste Femelschlag schadet an wenigsten der Weide und sthütıt am besten den Boden.

Soll Wald im Hochgebirge gegen Lawinen schützen, so muß der Wald der größten Standfestigkeit die besten Dienste geben. Ein Wald von tiefwurzelnden Holzarten und seine Erziehung in aufgelösten Schlusse ergeben sich aus diesen Forderungen von selbst. Muß die seichtwurzelnde Fichte gewählt werden, ist ihre freiständige Erziehung und femelartige Terjüngung vorzusehen; der Femelwald hat die größte, der gleichalterige, geschlossene Hochwald die geringste Standfestigkeit.

Als Windbrecher schützt der Wald landwirtschaftliches Gelände (besonders wichtig beim Reisbau in überschwemmten Feldern), Gärten mit Zier- und Nutzbäumen, Ansiedelungen an den Mceresküsten, in ebenen Geländen, vor allem in Steppengebieten. Um möglichst schnell das Ziel zu erreichen, werden immergrüne Holzarten mit tiefer Bewurzelung, rasch wachsend, auf gutem Boden, in weitem Verbande angepflanzt. Je nach Klima und Boden werden Föhren, Pseudotsuga, Tsuga, selbst Lärchen und Fichtenarten, Chamaecyparis, Thuja, dann auch Laubhölzer, immergrüne und winterkahle Verwendung finden können. Da der Schutz ständig gegeben werden soll, kann nur eine Femelwirtschaft in solchen Windmänteln Platz greifen.

Als Schutz gegen Wasser, gegen Überflutungen bei Hochwasser, ist der Wert des Waldes gering. Er hält wohl bei Flüssen, welche vom Gebirge mit Geschieben beladen herabeilen, letztere zurück, verliert aber selbst an Wert, da in ihm die wertrolleren Baumarten aus. scheiden. Im Unterlaufe der Flüsse ist der Schutzwert des Waldes gering. Der Wald der besten Laubhölzer erstreckte sich einstens im Unterlauf des Mississippi bis hart an den Vater der Ströme. Heute haben Hochwasser den Wald auf mehrere Kilometer Breite zu beiden Seiten des Stromes weggerissen; sein Wert als Schutz gegen Hochwasser war somit Null.

Nach Prof. Dr. Hondas ${ }^{1}$ ) Berichten hat der Wald an der Küiste Japans bei schweren Hoehflutkatastrophen durch Winde (Taifun) oder Erdbeben sich dadurch wohltätig erwiesen, daß er die Masse des in das Festland einflutenden Wassers verminderte und die aus dem

1) Dr. S. Honda, Bull. Tokio 19飞9. 
Festlande vom zurüclifließenden Wasser mitgeschleppten Menschen, Holzhäuser und Holzgeräte absiebte. Föhren, Wacholder (Juniperus) und Eichen (Quercus dentata) haben sich dabei bewährt; in den Tropen dürften die Mangrovewaldungen der Küste ähnlichen Schutz bieten. Für solche Waldungen ist Femelbetrieb nötig.

Ler Schutz des Waldes gegen Sandverwehungen, gegen Wanderdünen, ist gering; Wald selbst wird von der Wanderdüne allmählich vernichtet, indem diese im Walde in ungeminderter Schnelligkeit weiterschreitet; hier hilft nur das Übel an der Wurzel zu fassen, nämlich zu verhindern, daß Sandmassen in Bewegung gesetzt werden; diese Festigungsarbeit bespricht der Abschnitt ïber Aufforstung von ()dländereien.

Aus hygienischen Gründen kann ein Wald schutzwald sein beziehungsweise kann seine Begründung wünschenswert erscheinen. Soll cine menschliche Niederlassung gegen giftige Gase, wie sic Fabriken in der Luft ausstoßen, gesichert werden, soll gegen Ruß und Staul, Schutz gegeben werden, so dürften wegen ihrer geringeren Empfindlichkeit gegen Gifte, Laubhölzer, wie Ulmen, Ahorn, Linden, Akazien. Eichen sich besser eignen als die besser sicbenden Nadelhölzer; letztere sind die besten Staubschützer; die Bewirtschaftung solcher WValdungen ist Femelung.

Soll eine malariatische, fiebcrische, versmmpfte Landschaft assaniert werden, so genügt die Umwandlung in Wald wegen der entwässernden Wirkung der Bäume, wenn die Feuchtigkeit dem empordringenden Untergxundwasser zuzuschreiben ist; rührt der Überschuß von Tagwasser, so kann eine Bewaldung das T̈bel noch vergrößern. In solchen Fällen hat die Entwässerung an Stelle der Bewaldung zu treten. Ist Bewaldung zu wählen, so nehme man Baumarten, welche bei ihrer Nutzung das wertvollste Produkt geben; daß schon der Duft gewisser Baumarten (Koniferen, Eukalyptus) luftreinigend wirke, wird von verschiedenen Seiten bestritten. Für solche Waldungen ist Kleinbestandswirtschaft und -erziehung, behufs späterer natürlicher Wiederverjüngung empfehlenswert.

Es darf nicht verschwiegen werden, daß hygienische Gründe auch zur Vernichtung des WTaldes zwingen können; um den Menschen und seine Haustiere gegen schädliche Insekten (Buio, 'T'setse) zu schätzen, ist in manchen Örtlichkeiten (Ostasien, süudafrika) das einzige Radikalmittel die Zerstörung der Ileimat dieser Peinigor, les Waldes. Es dürfte sich in diesen Fall empfehlen, alle Ortschaften mit einem Ring von landwirtschaftlichem Gelände zu ungeben, um sie vom Walde zu isolieren; eines Tersuches wert ist der Gedanlie, ob nicht ein breiter Gürtel von scharfriechenden Sträuchern und Bäumen (Eukalyptus, Zanthoxylou und anderen), der die Ortschaften gegen den Wald hin abschließt, die lästigen Dipteren abzuhalten vermag. 


\section{Neunzehnter Abschnitt. \\ Waldpflege aus ästhetischen Gründen.}

Es kann nicht zugestanden werden, dem ästhetischen Empfinden und den Ansprüchen der Schönheitspflege eine entscheidende Bedeutung bei der Wahl der Holzart, der Einteilnng, der waldbaulichen Behandlung eines Waldes, der öffentliches Eigentum ist, einzuräumen. Solche Waldungen müssen heutzutage in erster Linie der Rente gewidmet sein. Wer in seimem Privatwalde die Ästhetik, die Schönheitspflege, an erste Stelle setzt, wio im Lustpark. wer Affektionswerten die Behandlung seines Waldes unterordnet wie im Wildparkwald, treibt eine rentenarme Wirtschaft; das ist sein Recht und seine Sache!

Der Wildparkwald. Die Hege und Aufzucht des Wildes verlangt in der Auswahl der Holzarten Futter und Schutz bringende Bäume. Futter geben Eichen, Buchen, Roßkastanien, Edelkastanien, Wildobst, Togelbeeren und zahlreiche beerentragende Sträncher und Kräuter; sie alle anzubauen und zu pflegen, und zwar in einem solchen lichtfreien Betriebe, daß sie möglichst oft fruktizieren, ist eine der Hauptaufgaben des Waldbaues im Wildpark. Der Mittelwald leistet die Aufgabe am besten: um aber Deckung $\mathrm{z}$ geben, sind Dickungen ron immergrünen Nadelbäumen wie Fichten, Tannen sind geschlosiene Hochwaldungen nötig. Wiesen und Wildremisen, breite Schneusen für Jagdzwecke sind unentbehrlich. Der Wildparkbetrieb weist Waldbilder auf, welche im natur- und rentengerechten Kulturwald verpönt sind, wie Unterbau der Eichen mit Fichtendickichten, abgrefressene Kulturen, angerissene oder geschälte Stangenhölzer, hohe Umtriebszeiten für das frühzeitiger stammfaule Nadel- und Laubholz. Der Kulturwaldbetrieb ist Waldban auf der Grundlage der Naturgesetze der Holzarten, des Klimas und des Bodens; die Waldpflege ist Kampf gregen die Schädlinge im Walde, zu deren schlimmsten das Wild zählt. Der Parkwaldbetrieb ist Waldbau auf der (Frundlage der Naturgesetze zur Erhaltung und Vermehrung der Schädlinge im Walde, der jaurdbaren Tiere. Nicht ein Lehrbuch über Waldbau, sondern ein solches über Jagd hat daher mit der Wildparkwirtschaft sich zu befassen. 
Der I ustparkbetrieb setzt die Schönheitspflege als oberstes Prinzip der waldbanlichen Auswahl der Holzart, der Begründungsform und ganzen Erziehung. Noch mehr als im Wildparkbetriebe sinkt im Parkwalde die Rente aus dem Walde herab. Bei der Auswahl der Bäume und Sträucher genügen im Lustparkbetriebe die einheimischen Holzarten nicht; er ist frei von dem Vorurteile als ob fremdländische Gewächse nicht imstande wären, in dem Beschauer Befriedigung des Schönheitsgefühles zu erwecken; verwendet er doch gerade an den hervorragendsten Punkten eine fremdartige Holzart mit Vorliebe. Steht ihm ein fremdländisches Gewäclıs nicht zur V'erfügung, benutzt er einheimische Spiolarten, Variationen, Luxus in Blätter- und Kr ronenformen, in Farben und Blïten. Er meiclet freilich ein gruppen-oder gar bestandsweises Zusammenhäufen solcher Formen, weil sie den Eindruck dessen erwecken wïrden, was sie wirklich sind, krankhafte Erscheinungen und Mißgeburten der heimischen Flora. Verfasser erkennt den Wert der heimischen Bäume, Halbbäume und Sträucher für Schönheitspflege unbedingt an, kamn aber nicht finden, dals fremdländische Baumarten, wenn ander's sie normal mit saftigem Grün emporwachsen, häßlich sein müssen, weil sie nicht europäische oder gar nicht „deutsche Bäume“ sind. Solche schönen Gefüble haben den Bäumen gegenüber keine Berechtigung, weil auch Bäume nicht den Patriotismus besitzen an der deutschen Grenze halt zu machen. Die „dentsche Eiche" ist in ihren Wohltaten und Leistungen unseren westlichen Nachbarn, den Franzosen, den Engländern, den Ungar: gegenüber viel gnädiger als gegen uns. Die "deutsche Buche* ist ebenso schön in Frankreich, England, Dänomark und Österreich wie in Deutschland. Jeder Baum, mag er herstammen, woher er will, ist in seiner Art, wenn gesund und normal erwachsend und erwachsen, schön und geeignet zur Zierde für Park und Wald: Vertasser liat in einer Gartenbauschrift den Satz aufgestellt, daB von zwei Baumarten, welche in ihrem ästhetischen Werte gleich sind, jene angebaut werden soll, welche, wenn sie wieder beseitigt werden muß, einen höheren Wert in ihrem Holze besitzt. Reine, gleichmäßige Bestände einer Art wirken ungünstiger als gruppen- und truppweise, als stammwoise gemischte Waldbestände; auch der Kleinbestandswald, welcher an Stelle großer, reiner Bestände kleine, reine Bestände in verschiedenster Abwechslung der Art und des Alters im Walde verlangt, ist ästhetisch höher stehend zu betrachten. Die gleichmäßige Verteilung der stämme in einem Bestande ist auf die Dauer langweiliger als eine Abwechslung zwischen Stämmen und Gruppen; cine Bammgruppe aus „ästhetischen Gründen" auflösen heißt ihre Ästhetik zerstören.

Unter der Wirtschaft gilt mit Recht dor Kahlschlag als die häßlichste Form, weniger deshalh, weil er plötzlich an Stelle des Hochwaldes eine Prärio setzt, sonderı vielmehr, weil solche Kahlflächen, 
zwar abwechslungsreich in Gräsern. Blumen- und Blattpflanzen, in Beerenkräutern und -stauden aller Art stets genaue, geomotrische Figuren darstellen; geradezu ïde ist der Niederwald; höler steht der Mittelwald insbesondere seine hochwaldartige Form: Ilochwall in Plenter- oder Femelform ist das ästhetische Wallideal. Freilich fallen anch bei dem Femelhiebe starke, liebgewonnene Stämme und sie müssen fallen, um das Buschwerk zu erhalten und Jungwuchs nachzuziehen. Mit dieser Feststellung erschöpft sich auch das Interesse, das der Waldbau an der Lustparkwirtschaft nimmt.

Dor Schönheitsptlege im Wirtschaftswalde sind in den letzten Jahrzehnten zahlreiche Schriften gewidmet worden; allen voran ist die Forstästletik von Salisch (II. Aufl. 1902) zu nennen; man kann sie betrachten als eine natürliche Realition gegen die unnatürliche Unifizierung des Waldes mit einer Holzart, im Sürlen von Deutschland mit Fichte, im Norden mit Föhre. Niemand wird leugnen, daf. der Schönheitspflege im Walde ein Platz gebiihrt, sobald dieser ohne Einbufe oder nur mit einem geringfügigen Entgang an Rente eingeräumt werden kann.

Der Schönheitspflege obliegt die Sorge dafür, daß das Ange eines jeden, der in den Wald flüchtet zur Erholung, am Walde und seinen Gliedern sich erfrete. $\mathrm{Er}$ erwartet Schönheit, Erhabenheit, unverfälschte Natur; an Stelle des klappernden, monotonen Lärmes, des Pfeifens und Tutens des wachsenden Verkehrs in der Stadt will er Naturlaute hören, wie das Rauschen des Windes in den Bäumen, das Ächzen der sich reibenden Stämme und Äste, das Singen, Pfeifen, Summen und Trommeln der fliegenden, springenden, flatternden, kletternden Tierwelt; er ersehnt im Walde an Stelle des Staubes und Geruches ätherische, harzige Düfte, reinen Ozon, reine Lüfte. Je weniger von all den gehofften Genüssen der Wald dem Wanderer bictet, je weniger dieser abgezogen wird von den alltäglichen Sorgen seines Lebens, um so geringer seine geistige und leibliche Erholung, um so niederer der ästhetische Wert des Waldes. Die Ästhetik des Waldes muß in der Erfüllung dieser Grundgedanken ihr Arbeitsfeld erblicken; sie kann es ohne merkliche Schädigung der Rente, obwohl in unmittelbarer Nähe der Stadt es sich rechtfertigen läßt eine törmliche Parkwaldwirtsehaft zu betreiben: „Die räumliche Ausdehnung einer solchen Wirtschaft" sagt Weise ${ }^{1}$ ) vortrefflich, "braucht nur eine sehr bescheidene zu sein und meist genügt ein schmaler Schleier, um dahinter die Waldwirtschaft in beliebiger Form unbehelligt durch den Anspruch des Publikums treiben zu können." Verfasser hat schon vor Jahren den Gedanken angeregt, die Stälte selbst sollten für eine parkartige Verbindurg ihres Weichbildes mit dem Walde sorgen, indem sie

1) W. Weise, Leitfaden fur den Waldbau 1903. 
die dem Wege zum Wald anliegenden Grundstücke aufkaufen und parkartig mit Laubhölzern bewalden sollten.

Im folgenden sind einige Aufgaben der Waldästhetik angedeutet: von Salisch. Sektionschef L. Dimitz ${ }^{1}$ ), Oberforsträte Wilbrand und Thaler, Prof. Siefert ${ }^{2}$ ), Dr. Schinzing ${ }^{3}$ ), Oberlandforstmeister Dr. Stötzer u. a. haben den Wert und die Ziele der Waldästhetik hervorgehoben. Dr. Kienitz ${ }^{4}$ ) hat an der Birke gezeigt, daf vielfach Waldästhetik und Waldschutz Hand in Hand gehen.

Jeder Holzart, welche am betreffenden Standorte überhaupt wachsen kann, sei eine ihrer Bedeutung entsprechende, wenn auch noch so bescheidene Stelle im Walde eingeräumt; den Sträuchern, den Schlingund Kletterpflanzen seien die Bestandsränder insbesonders an warmen Hängen zugewiesen; dem prächtigen Efeu falle das Halbdunkel der Baumschäfte unter den Kronen zu; je mehr Stämme von ihm überkleidet sind, desto besser und schöner, denn der Efeu ist an sich völlig unschädlich. Man erhalte kleine Blößen, kleine versumpfte Örtlichkeiten in ihrem Urzustande, belasse die Steine, Felsblöcke in den Waldungen, verschone hohle ohnedies fast wertlose Laubbäume für Höhlenbrüter oder bringe künstliche Brutstellen an. Man schone so lange als möglich besonders hohe, besonders dicke Bäume, welche die Wanderer im Walde immer bewundern und in Höhe und Alter so gerne überschätzen, während sie die dünnen Stämmehen immer unterschätzen; man hege sorgfältig vereinzelto Monstrositäten, vielgipflige, linorrige, verunstaltete, sogenannte malerische Bäume, Abnormitäten in Form und Farbe, kropfige, rerschlungene, vergabelte Bäume; man schneide aus dem Wirtschaftswalde einzelne Partien mit besonders starken, alten Bäumen als Naturdenkmäler aus, um einige, wenn auch ganz bescheidene Andentungen an den einstigen Urwald zu erhalten. Ess gebührt Prof. Dr. Conventz das Verdienst diese Frage aufgegriffen und durch Beschreibung der vorhandenen Naturdenkmäler in Preußen erfolgreich gefördert zu haben; Dr. H. Klein in Baden, Stützer in Bayern und andere sind ihm gefolgt. Längst sind Vorschriften zum Schutze seltener Kileinpflanzen erlassen $\left.{ }^{5}\right)$; für selten gewordene Waldbäume wie Eiben, Zirben, Prunus, Sorbus, Pirus und andere fehlen sie.

Den wärmsten Dank aller studierenden F'orstwirte, aller Freunde des Waldes, seiner s'chönheit und seiner ethischen Kraft haben sich die Fürsten von Śchwarzenberg in Böhmen gesichert, indem sie ein wirkliches Stück Urwald am Bergo Kubany bei Eleonorenhain von

1) Über Naturschutz und Pflege des Waaldschönen. 1907.

2) Der deutsche Wald, Festrede 1905.

3) Allgem. Forst.- u. Jagdztg. 1907.

4) Märkischer Forstverein 1 $89 \%$.

5) H. Conventz, S'chutz der natürlichen Landschaft, vornehmlich in Bayern. 1907. 
jeder Benützung, jeder verändernden Tätiglieit dur.h den Menschen ausschlossen. Terfasser möchte den vor vielen Jahren dem Fürsten gegenüber bereits ausgesprochenen $\mathrm{W}$ unsch wiederholen, daß der. Urwald gegen Wild geschützt werdo, um den Unterwuchs und Anflug, ein Charakteristikum des Urwaldes, zu retten.

Urwïchsige, aber nicht urwaldartige Waldreste sind in Dentschland vielfach erhalten, am schönsten im Großherzogtum (Olrlenburg. Die Amerikaner gelten in Europa als die schlimmsten Waldverwüster; sie waren auch die ersten, welche Urwaldreste größter Ansdehnumg als "Nationaleigentum" vor weiterer Verwüstung zur wissenschaftlichen Belehrung und ethisehen Bewertung dem Feuer und der Axt entrissen. Fällt im Kulturwalde ein alter, morscher, hohler Baum zu Boden, so lasse man ihn liegen, wenn er ohnedies nur geringwertig oder ganz wertlos ist. Sein ästhetischer Wert als Erinnerung an den ehemaligen Urwald, als Baumleiche, für alt und jung als Ruhebank erkoren, ist viel höher, denn sein reeller als Häufchen Asche. Man lasse die Pilzfrüchte mit Ausnahme jener wenigen, welche als Schädlinge der Büume erkannt oder wohlschmeckend sind; man verschone allen Unterwuchs, dessen Beseitigung dem Wald keinen Nutzen, vielmehr Sehaden bringt, da man den kleinen Vögeln im Walde die Sicherheit gegen ihre Feinde raubt. Man überwache oder halte besser ganz fern jene gewerbsmäßigen Vernichter der Waldästhetik, jene Hyänen des Waldes, welche von städtischen Unternehmern angeworben, in Scharen in den Wald geschickt werden, um alles, was den Wald schmückt, auszureißen und in riesige Körbe oder Säcke zu stopfen. Zentnerweise werden Moose und Farne abgerupft, die Seerosen aus den Teichen gefiseht, alles, was bunte Blüten, Früchte, Herbstblätter trägt, schonungslos zerrissen, und zurück bleibt buchstäblich die Verwüstung. All dieser šchmuck des Waldes wandert in die Staclt und nach wenigen Tagen oder selbst wenigen Stunden ästhetischen Genusses in die Kehrichttonnen. In der Nähe der Städte ist diese aus Mitgefühl für Arme hervorgegangene Duldung zu einer die Schönheit des WTaldes vernichtenden, die Jagd belästigenden, den einsamen Wanderer im Walde in Ruhe und sicherheit bedrohenden Plage geworden. Das Bestreben. den Wald in die Stadt zu zaubern, vernichtet allen Zauber im Walde. Der Genuß ist nur echt in der freien Natur selbst; dahin sollen die Städter wandern; für ihre Bedürfnisse an Blumen- und Pflanzenschmuck in Ilause sorgen die Gärtner.

Man vernichte im Walde schonungsslos Sperber und Habichte. schone die Eulen, Bussarde, Rüttelfalken, spechte, den waldbaulich äußerst nützlichen Eichenstufer, den Eichelhäher; der Schrei der Eulen in lauwarmer Sommernacht, das Kreisen der Bussarde am blauen Himmel, das Rütteln des Falken hoch in den Lüften, das Hümmern der Spechte und ihr Ruten, der Spottgosang des balzenden Eichel- 
hähers, alles das sind ästhetische Genüsse ron seltener Kraft und Nachhaltigkeit.

Man entwässere, wenn es sein muß, nur in offenen Gräben, um das herrliche, ästhetische Wasser in der Sonne glitzern zu sehen, um es zu hören, wenn es über Hindernisse hinweglärmt. Man vermeide alles, was an die menschliche Tätigkeit im Walde allzuoft erinnert, wenn es Mittel gibt, das gleiche auf weniger aufdringlichem Wege zn erreichen. Man vermeide Leimringe an den Bäumen in der Nähe der Waldwege, "wenn dies ohme Gefahr für den Wald gesehehen kann, vermeide den Wald mit äblen Gerüchen zu erfüllen, um die Tiere von den Kulturen zu schenchen, wemn es besser wirkende Mittel gibt; wenn eingezäunt werden muß, wähle man eine geschmackvolle Form oder einen Zaun, den man erst sieht, wenn man auf ihn stößt (Drahtzaun), und wenn im Walde Verbote über schielien, Hundeführen, Betreten der Kulturen und dergleichen gegeben werden müssen, so sage man dies in empfehlender, nicht in gebietender Form, damit die zahlreichen Besucher und Freunde des Waldes, welche dem lieben Walde zuliebe gerne folgen, nicht jählings und auf' s'chritt und Tritt ans aller. Frenden, Träımereien und Genüssen geworfen werden; die schlimmen Elemente hält die Furcht vor dem schützenden Beamten mit besserem Erfolge fern als angedrohte Paragraphen und Strafen.

Auch der ästhetisch schönste Wald wird auf das Gemüt des Nenschen nicht einwirken kömnen, wenn der Menseh nicht erzogen ist zur Empfünglichkeit für ästhetische Genüsse, wenn ihm nicht von Kindheit an im Hausgarten und in der Schnle eingeimpft wird, daß auch Bäume Lebewesen sind, daß ihr sinnloses Ausreißen und Zerfetzen ebenso häßlich ist wie das Zertreten, Morden und Quälen der Tiere, die auf dem Boden kriechen und von Unverständigen als giftig oder schädlich hingestellt werden. In den Schulen sollte, wie Forstinspektor Syrutscheli verlangt, ein Teil des Schulgartens als Saatund Pflanzgarten ausgeschieden sein, in welchem Säen und Pflanzen gezeigt und zur Beobachtung des Werdeganges der Waldbäume angeregt werden kömnte. Der Arbor day der amerikanisehen Schulen verdient Nachahmung: belehrende Ausflïge in Wald und Flur gehören in das Schulprogramm. Wer Wald mag noch so reich an ästhetischen Reizen und Objekten für Beobachtung und Kerstreunng sein, wer das Sehen nicht gelernt hat, schant hermm und sicht nichts.

Der hochverehrte Altmeister des Waldbaues, Karl Gayer, eine künstlerische, feinfühlende Natur, ein Feind aller Künste und Künsteleien im Walde, der unermüdliche Kämpfer für Rückkehr zur Natur, hat die letzten Worte, welche scin lebhafter Geist ersann und seine formgrewandte Feder niederschrieb, der Ästhetik im Walde gewidmet. Mit seinen letzten Worten, welche er zu Beginn des Jahres 1907 an die 
Öffentlichkeit richtete, soi dieser Abschnitt geschlossen: "D as S chönheitsgefühl wird um so reicher befriedigt, je gewissenhafter die Grundsätze einer naturgesetzlichen Wald. behandlung überhaupt Beachtung finden; denn die Gesetze der Natur stellen uns einzig und allein auf den Boden der Wahrheit und damit der ungezwungenen Schönheit." 


\section{Zwanzigster Abschnitt.}

\section{Der Kleinbestandswald,}

\section{Vorschläge für eine natur- und rentengerechtere Waldwirtschaft.}

Im eigentlichen Sinne des Wortes ist der dem Urwalde am meisten sich nähernde Plenter- oder Femelwald die Wirtschaft auf kleinster Fläche; denn alle für den betreffenden Standort passenden Holzarten, alle Altersklassen drängen sich auf kleinster Fläche zusammen; eine kahle Stelle größer als ein Trupp kann nicht entstehen; die Verjüngung ist eine natürliche im sogenannten Femelschluß. Diese urspüngliche, natürliche Waldform gilt noch heute und galt der nach geometrischen Figuren strebenden Forsteinrichtung des vergangenen Jahrhunderts als ein Chaos, in das nur Ordnung gebracht werden könne durch Wirtschaften, welehe bei der Verjüngung eine großflächenweise Beseitigung der Bäume - aller Stämme beim Kahlschlag, eines Teiles der Stämme beim Schirmschlag - vorschreiben. Damit verschwauden die Femelwaldungen in der Ebene und im Hügellande, selbst im Hochgebirge und an ihre Stelle traten gleichaltrige Waldungen größter Ausdehnung: der erste Schritt vom jungholzreichen Femelwalde zum gleichmäßigen Hochwalde war leicht; der Übergang zur nächsten Waldgeneration vollzieht sich bereits unter erhöhten Schwierigkeiten, so daß erhöhte Ansgaben für künstliche Verjüngung notwendig werden. Der Übergang vom Femel- zum gleichaltrigen Hochwald in großen Beständen hat schwere Gefahren gebracht, so daß noch heute der Fomelwald als das Waldideal zur Erhaltung der Holzarten, der Bodenkraft, zur Sicherung gegen Naturereignisse gilt. Zu ihm zurückzukehren, ist eine Unmöglichkeit geworden, denn er entspricht nicht den Forderungen einer rentablen Waldwirtschaft von hente. Nur die aus dem Urwaldzustande erst heranstretenden Waldungen, welche an Absatz und Personal Mangel leiden, sind in Ermangelung einer intensiveren Bewirtschaftung dem periodischen Femelbetrieb unterworfen. In den dichter bevölkerten Kulturländern muß die Rentabilität mehr und mehr in den Vordergrund der vom Walde zu leistenden Anfgaben treten, und eine rentable, d. h. rationelle Wirtschaft wird heutzutage 
zu einem Kompromiß zwischen dem ökonomischen Prinzipe des nützenden Menschen und dem naturgesetzlichen der aufbanenden Naturkräfte zu gelangen suchen.

Die einfachste und bequemste aller Wirtschaften, der Kahlsehlag, wird nur der Rentabilität voll gerecht, die Forderungen der Natur vernachlässigt er, nicht ungestraft, wie die schweren Wallkatastrophen beweisen; er vertreibt die Holzarten zugunsten einiger weniger, er vermindert langsam aber stetig die Bodengüte. Gayer hat dem reinen Bestande seinen Mischbestand, der künstlichen Verjüngung seine natïrliche in Gruppenform unter Schirm entgegengestellt. C. Wagner sucht in seinem "Blendersaum", im saumweisen Schirmschlage, Naturverjüngung und Holzartenmischung zu erzielen. Gayers Methode hat, da die Bestände für ihre Verjüngung nicht erzogen wurden, vielfach ganz versagt, vielfach nur Stückwerk ergeben; der langsame Verjüngungsgang hat schwere Nachteile für die Rentabilität gebracht, und was die Mischbestände anlangt, so nehmen sie auch in Bayern, wie die offiziellen Ausweise ergeben, nicht zu und der größte Teil dessen, was heute, kurz nach seiner Begründung, als kleingruppenweiser oder stammweiser Mischbestand erscheint, wird im kritischen Alter des Stangenholzes ohne fortgesetzte Hilfe und Kostenaufwand wieder reiner Bestand werden. Im Kahlschlag wie im Schirmschlag müssen die Reinbestände größter Ausdehnung zunehmen, solange die Einteilung des Waldes, welche auf dem Großfächenprinzip beruht, beibehalten wird.

Will man der Ausdehnung und den Nachteilen der Reinbestände erfolgreich entgegenarbeiten, muß man die Axt an die Wurzel des Übels anlegen, an die Forsteinrichtung, deren Einwirkung auf die ganze Waldwirtschaft aus früher Zeit her noch in der Gegenwart jede freiere Entwicklung einer naturgemäßen Waldbehandlung hemmt. Die Einteilung des Waldes mußgeändertwerden aus Gründen, welche naturgesetzlicher Art sind, der reine Bestand aber mu beibehalten werden aus Gründen, welche finanzieller Natur sind.

Die Einteilung in Distrikte und Abteilungen mag aus betriebstechnischen Gründen beibehalten werden, die Unterabteilung aber, der heutige Bestand, soll abermals aufgeteilt werden in Bestände von 0,3 bis 3 Hektar Größe, in Kleinbostände, welohe ständige Wirtschaftsfiguren sind; jeder Kleinbestand besteht aus einer anderen Holzart, in sich aber ist er ein reiner Bestand. Wo Ausformung des Geländes wie Gebirge und Hochgebirge, Sandboden, nasser Standort, kühles Ḱlima es wünschenswert erscheinen lassen, liann dieselbe Holzart auch im benachbarten Kleinbestande sich anschließen, und mag die Einheit biszu j Hektar Größe steigen; es ist aber wünschenswert, daß solche Nachbarbestände grölere Altersdift'erenzen zeigen.

Alle Kleinbestände werden so begründet und erzogen (durchforstet 35 * 
und durchlichtet), daß sie etwa zwischen dem vierzigsten und fünfzigsten Lebensjahr mit einer Schatten- oder einer Halbschattenlolzart (letztere nur unter Lichtholzarten) unterbaut werden können. Daß der Unterbau zu Füll- und Triebholz wird, ist nur auf den besten Bonitäten und nur unter Lichtholzarten williommen; in diesem Falle aber ist der niedriger bleibende Teil des Unterbanes, wo immer er entbehrlich erscheint, als überflüssiger Zehrer am Boden zu beseitigen. Sucht der Unterbau zwischen Halbschatten- und Schattenholzarten emporwachsen, wird er auf den Stock gesetzt. Der Unterbau verwirklicht die Torzïge, welche der gemischte Bestand auf den Boden ausübt, in gleicher Vollkommenheit, ohne die wertvollen Bestandsglieder in der Krone zu beeinträchtigen.

Die Durchlichtungshiebe der zweiten Lebenshälfte sichern gegen Naturereignisse: Kraft und andere nach ihm denken sich die Durchlichtungen allmählich so verstärkt, daß natürliche Verjüngung sich einstellt. Kommt sie wirklich, so erscheint sie zu früh; sie beeinträchtigt die Erzichungshiebe, die zwei Zwecken dienen sollen, hemmt die Nutzung des Altbestandes und wird, weil vorwüchsig, schwer durch die Nutzung geschädigt. Der Kleinbestandswald will diese vorzeitige Verjüngung durch Unterbau verhindern. E. André sagt 1832: Wer seine Waldungen richtig durchforstet, hat vom Sturme nichts zu fürchten und kann eine Besamung haben, wamn und wie er will.

Die kleinbestandsweise Mischung der Holzarten in einem Walde sorgt dafür, daß Kalamitäten durch Insekten, Stürme, Schnee nicht über den Rahmen des Kleinbestandes hinausgreifen.

Die Verjüngung ist eine natürliche unter Schirm mit allen Vorzügen, welche dieser Verjüngungsform zukommen, aber ohne ihre großen Fehler der Langsamkeit und Ungleichheit. Den Zeitpunkt des Eintrittes der Verjüngung mag die Forsteimichtung bestimmen; sie findet den K'leinbestand stets verjüngungsbereit. Die froistehenden Althölzer tragen öfter und reichlicher Samen, der Boden ist durch den Unterbau stets aufnalimefähig. Auf Toile oder auch im ganzen Umfange des Kleinbestandes wird in einem Samenjahre nach Abfall des Samens (bei Fichten und Föhren auch liurz vor Abfall des Samens) die Hälfto aller Stämme gefällt und gerodet, der Unterbau gerodet, soweit er nicht zu otwaigem Schutze der Verjüngung nötig erscheint. ITo die Rodung als Bodenverwundung noch nicht genügt, mag eine solche mit eigenen Werkzeugen hinzutreten. Alle unsere bisherigen Erfahrungen über Naturverjüngung müßten Lüge sein, wenn nicht eine gründliche Besamung der Fläche eintreten würde. Nach einem oder zwei Hieben wird der alte Bostand ganz beseitigt, die Verjüngung des ganzen Kleinbestandes lian in $j-6$ Jahren vollendet sein; wo ein Teil des ehemaligen Unterbaues zum Schutz belassen wurde, möge er fallen, 
womn er seine Schuldigkeit getan: wo Nachhilte nötig ist, wird die wird die gleiche Ilolzart gepflanzt. Diese Naturverjüngrmeg ist schnell, sicher und leicht, entspricht somit allen Anfordermengen an einrn rentablen und naturgesetzlichen WValdbau.

Die ersten Bedenken gegen diese neue Wirtschaft werden der Flächengröße des Kleinbestandes gelten, welche zahlreiche Wege und Schneusen verlangen. Mustert man heute sehon in don wenigen Betrieben, in welchen Jungwuchspflege, Durehforstung und Durchlichtung auf der Höhe der heutigen Forderungen stehen. so sind sie alle gezwungen gewesen, die heutigen Bestände aufzuhanen, um ilır Inneres zugänglich zu machen. Die Größe der Bestände ist schuld, weshalb sie im Dickungalter der Pflege, im Stangenalter der entsprechenden Durchforstung sich entziehen. Mangels an Wegen ist manches Waldgebiet ohne Rente. Im intensiven Betriebe durchziehen schon heute den "Bestand" zahlreiche Waldwege, meist ganz zufällig und ziellos entstanden. Der Kleinbestandswald beseitigt, wemn möglich, alle Wege, welche den Bestand selbst durchkreuzen, und legt sie an die Bestandesgrenzen. Die Melirzahl dieser Wege bedarf keines Aufhaues und keines Ausbaues; sie ergeben sich von selbst an der Berührung zweier Bestände, weil verschiedene Holzarten aufeinander treffen (man vergleiche die Abb. 12 und 13 Seite 240 und 241). Diesen Weg als umproduktive Fläche zu betrachten und bei der Anlage und Flächenberechnung auszuscheiden, ist ebenso unzulässig, als die zahllosen, durchwurzelten Lücken und Berührungsränder verschiedener Holzarten innerhalb des Waldes als unproduktiv anzusprechen. Erst jene Wege, welche ciner daucrnden Zurichtung bedürfen und damit für die Wurzeln der Bäume und für die Holzproduktion unzugänglich geworden sind, können als unprodulitiv bezeichnet werden. Das Aufhauen der Schneusen ist im K'leinbestande nicht nötig, da die einzelnen Bestände durch den Holzartenwechsel genügend voneinander geschieden sind. Breito Schneusen für Jagdzwecke zu hauen, kann einem Wirtschaftswalde nicht zugemutet werden. Daß überhaupt die Jagd im Kleinbestandswalde zu kurz küme, dürfte weder der moderne, jagdelnde Forstwirt noch der veraltete, wirtschaftelnde .Jäger behaupten.

Der Anbau der Holzarten in Kleinbestande soll den Forderungen der naturgesetzlichen Grundlagen des Waldbaues und der zu erhottenden Rentabilität entsprechen; erstere verlangen, daß alle Holzarten, auch die bisher verstoßenen, auf den ihnen passenden Standorten angebaut werden sollen: das Relief der Holzarten soll genau das Relief der standörtlichen Verschiedenheiten in Wald. wiedergeben; nur bei größerer, flächenweiser Gleichheit des sitandortes werden die Klembestände eine quadratische odor rechteckigrs Figur erhalten können; die Rentabilität reguliert das Verhältnis drer 
anzubauenden Holzarten, wobei jene, welche gegenwärtig die rentabelsten sind, in den Vordergrund treten mögen.

Man wird sodann einwenden, daß es schwierig oder unmöglich sei, einen Kleinbestandswald kartographisch darzustellen. Das mag sein. In den bayerischen Wirtschaftsregeln ist sogar die Einzeichnung jeder Verjüngungsgruppe in einem Bestande gefordert. Wer prinzipiell die Gruppengröße über 0,3 ha ausdehnt, hat bereits den Kleinbestandswald. Es muß der Forsteinrichtung überlassen bleiben, sich mit diesem neuen Walddetail abzufinden, da sie um ihrer selbst willen dasselbe nicht ablehnen darf. Augenscheinlich nimmt die Anwendbarkeit, ja Notwendigkeit der Kleinbestandswirtschaft zu, je wärmer das Ḱlima, je besser der Boden, je größer die Zahl der Holzarten ist, welche eine Waldregion beherbergt, und welche anbauwürdig erscheint. Im amerikanischen Walde mit seiner Baumartenfülle dürfte der Kleinbestand die beste Form einerseits zur Erhaltung wichtiger Arten, andererseits zur Begründung und zur Aufziehung derselben darstellen. C.A. Schenk in Bilmore sagt in seiner Silviculture 1904: "Amerikanische Forstwirte werden für lange Zeit hinaus wenig Gelegenheit haben, Durehforstungen auszuführen." Wo sie dringend notwendig wären zur Erhaltung der gewünschten Arten im Kampfe gegen die übermächtigen Unhölzer, werden sie unterbleiben, da die Flächengröße, die Zahl der Unhölzer, die Unabsetzbarkeit des Materials und die Höhe der Löhne dies verbieten werden. Die mühovoll begrïndeten, wertvollen Nutzholzarten werden unter die große /ahl der minderwertigen Arten wieder untertauchen. Dieses Problem löst nur der Reinbestand, dem ein Kahschlag mit kïnstlichor Begründung dureh Pflanzung vorausgeht; nur der Kleinbestand schränkt die Reinbestände auf dio naturgesetzlich zulässige Größe ein, sichert die Erhaltung der wertvolleren Holzarten und gestattet die Durchführbarkit allenfallsiger Reinigungen, Durehforstungen und Durehlichtungen. Erst in der zweiten Waldgeneration kanu an eine natürliche Wiederverjüngung solcher Kleinhestände gedacht werden.

Für den ostasiatischen, den artenreichsten Wald, gilt das gleiche. Alle Versuche, die dort mit einer gruppenweison Naturverjüngung im sinne Gayers unternommen wurden, haben fehlgeschlagen an der Überhandnahme der Unhölzer, vor allem des Bambus, und an der Unmöglichkeit, die Edelhölzer gegen die Unhölzer zu schützen, ohne die zu erwartende Rente aus dem Walde für die Erziehung des Waldes aufzubrauchen. Nur im Kahlsehlag und dureh sofortige Aus pflanzung der Kleinbestandsfläche mit einer Holzart kamn der Kampf gegen die Unhölzer erfolgreich und die Erziehung möglichst cinfach und billig gestaltet werden.

Vor allem müßtte die Aufforstung aller $̈$ d dländereien, der steppen oder Prärien, der Sandwüsten, der Sümpfe nach dem System 
des Kleinbestandswaldes geschehen; die Erziehung zur Verjüngung allein gibt neben anderen Vorteilen die Aussicht, daß später eine Vorjüngung ohne Kahlschläge durchgeführt und damit der Rückkehr des ïdlandes vorgebeugt werden kann.

In der schmalen, saumweisen Ausgestaltung endlich wird, wio Beispiele zeigen, der Kleinbestandswald auch im stärker geneigten Gelände, sclbst im Hochgebirge sich bewähren: er erfüllt die Forderungen der Schutzwaldgesetze und gestattet dem Besitzer eine regelrechte, rentenreichere Benïtzung seines Waldes.

Aber nicht bloß für den winterkahlen Laubwald und füir den Nadelwald, auch für den immergrünen Laubwald der $\mathrm{Subtropen,} \mathrm{ja} \mathrm{selbst}$ für den tropischen Wald von Afrika, Amerika und Asien mit seinem Maximum an Baumarten und Ninimum an Wirtschaftern und seinen größten Schwierigkeiten in Begründung, Pflege und Erziehung verlangt eine rereinfachte, geregelte und rentable und dennoch naturgesetzlich aufgebaute Forstwirtschaft die Preisgabe des unregierbaren, ausgedehnten Mischwaldes und seinen Ersatz durch einen klembestandsweise gemischten Wirtschaftswald, der zunächst durch Kahlschlag mit darauffolgender Pflanzung, n icht Sat, seine Inszenierung und durch Erziehung zur Verjüngung: und Unterbau später seine natürliche Wiederverjüngung erfahren müßte.

Es wird wohl längerer Zeiträume bedürfen, bis diese Vorschläge für eine neue Waldwirtschaft, für welche es an Vorläufern in der Literatur und Vorbildern in der Natur nicht fehlt, Anhänger und Verwirklichung finden werden; die neue Waldwirtschaft bedeutet ja einen Verzicht auf so vieles, was einfach und bequem ist, wie den Kahlschlag, die Durchforstungen auf das Unterdrückte, schließlich die Saatgärten und ihre Kleinarbeit; sie bedeutet die Aufgabe so mancher Liebhabereien in Holzarten und Kulturmethoden, so manchen Vorurteiles gegen andere Holzarten; aber sie bedeutet dafür auch größere Holzmassen verschiedener Güte in kürzerer Zeit, Verminderung der Kosten für Begründung und Erziehiung des Waldes, Erhaltung der Bodengiite, Schutz der Jugend, rechtzeitige Nutzung des Alten, Rückkehr bisher verstossener Holzarten, Sicherheit des Waldes gegen Gefahren aller Art und für viele Millionen, welche den Wald aufsuchen zur Erholung, ästhetischen Genuß durch den Holzartenwechsel und durch die Rückkehr der vom Einheitswalde vertriebenen, gefiederten Tierwelt. 


\section{Sachregister.}

(Die römischen Zahlen hinter den Stichwörtern bedeuten: I. Naturgesetzliehe

Grundlagen. II. Begründung. III. PHege und Erziehung.)

Abemaki I 208.

Abies I 87, 90, 103, 111, 124, 128, 136, $138,143,145,148,149$. II 283.

- halsamea I 64, 66, 151.

- cephaloniea I $64,65,151$.

- eoneolor I 64, 66, 151 .

- firma I 63, 151.

- grandis I $64,66,151$.

- homolepis I $65,152$.

- Nordmanniana I 64, 65, 152.

- pectinata $164,65,108,152$.

- Pindrau I 65, 66, 67, 152.

- Jinsapo I $64,65,152$.

- sibirica I 64, 152 .

- Veitehii I 66, 152 .

- Webbiama I 65, 66, 153.

-, reine Bestände II $336,434$.

- und Fagus II 352, 441.

- und Picea II 352, 440.

- und Pinus II 314, 328, 447. ind Qnereus II 356, 446.

Abietum I 65.

- für, Fremdländische Arten II 468.

Abkühlung I 8\&, 226.

Absehwemmung II 270.

Absenker I 142, 145, 180, 215.

- -ptlanzung II 429.

Alotrichsalter II 293.

Abwaschung I 244.

Aeanthopanax I 63, 65. II 467.

Acer 1 (i3). 64, 65, 103, 104, 128, 136, 143, 182. II $2 \times 3,34 \%, 344,4: 35$.

- californicum I 183.

- campestre I 183.

- Negmido I 18:3.

- - pruinusum I 18:3.

- - vislaceum I 183.

-- nigrum I 183.

- pictum I 183.

- platamoides I 183.

-- I'sendoplatanus I 183 .

- rubrum I 64, 184.

- saceharim I 64,184 . II 476 .

Aesenlus I 62, 68, 103, 104, 137. II 287.

Ästhetik III 5:39.

Agariens melleus I 155, 159, 162, 166, 173. II $2 \times 8$.

- shitake I 198.

A gaven I 27,61.

Ahorn = Aeer.

Ajanische Fichte 1 16:3.

Akagashi I 208.

I. Niturgesctzliche Grundlagrn.
Akumatzu I 166.

Akazie = Robinia.

Akinire I 212

Akklimatisation I 79, 104, 105.

Akkomodation I 104, 114.

Albizzia I 63 . II 466 .

Alder I 185.

Alders I 184.

Alepurö̈hre I 166.

Alkalibö̈len I 112.

Alhmination 1104.

Alnus I 64, 65, 66, 67, 90, 103, 111, 112, $143,144,184$. II $283,342,344,435,483$.

- glutinosa I 110, 184.

- ineana I 110, 144, 185.

- maritima I 110.

- rubra $1110,185$.

- viridis I 213.

Alpenbrandwirtsehaft II 271, 291.

-lärehe I 159.

- -walderinze I 19.

- weidewirtsehaft II 269. -zürbel I 74. 174. II 476 .

Alpinetum I $19,38,47,58,66,71,158$, $167,213,244$.

- für, Fremdländische Holzarten II 468 .

Amerikanisehe Buche I 192.

- Christusdorn I 194.

- Edelkastanie I 189.

- Hainbuelie I 187.

- linde I 211.

- Pappelholz I 196.

- Platame I 200.

- Roterle 1185.

- Rotföhre I 167.

- Sihusserbaum I 194.

- Ulme I 212.

- WriBeiche I 204.

Anbauergelmisse I 115, 209, 246.

Aubanfähigkeit I 52 . für fremillänlisehe Holzarten II 457 .

Anbatugebiet 1, 123, 138.

-, künstliches 156,74 .

- natiirliches I 74 .

Anb:un, künstlicher I 163.

Anbanwiirdigkeit [ 174.

Anciens III 490.

Anemone I 103.

Antlng II 294.

Ankanfptlanzen II 390 .

- (Auf\%uclit) II 391.

- (Behandlung" II 391, 392. 
Anlage, individuelle I 12々.

Anmalzen der sämereien il :378.

Anpassung I 79, 104, 114.

Ansaat, künstliche I 226, 2:32.

-, natürliche I 226, $2: 32$.

Araragi I 179.

Araucaria 157.

Arbor vitae I 180.

Arbutus ehalapensis I 61, 6i:.

Artencharaktere I 126.

Arve I 174.

Aslies I $19 \%$.

Asiatische liorkeichr I 20.5.

Assimilation I 95, 101, 2:31.

Astbruch I $203,229$.

Astigkeit I $22 \cdot 2$.

Astreinigung I 98, 13:2, 2:35. II 266, 289.

- waldbetricb II $27 \%$.

- - - Häichenweisir II 277

- - femelbetrieb II 277 .

- - -wirtschaft II $28: \overline{3}$.

Asumaro 1180.

Atlantische \%eder I 154.

Atterenisation I 114.

Aueplenterwaldungen II 279.

Aufüstung 1203 . III 517.

Aufästumgshieb II 297.

Aufbewahrung der Sämereien $1 / 369$.

Aufforstung I 171, 176, 209, 214, 244.

Auflichtung II 301.

Aufschlag II 294.

Aunes I 134.

Ausfornuugsvermögen I 206, 139.

Aushebev der Ptanzen II 409.

Ausladungsvermög('n I 206, 2:39.

Anslichtuing II 269.

Ausschlag I 142.

- -betrieb II 272.

-fäligkeit I $79,142.14: 3,17:$.

- formen II 285.

-_ -ptlanzung II 4:9.

- verjüngung II 451 .

- vermögen I 216.

-wald I 248 . II 27\%. III 520.

-

-waldungen II $281,283,2 \times 5$.

- -wurzeln I 14:3.

Auswahlptlanzung II 410, 426.

Auszughaumng III 521.

Anwalitung I 214. II 450.

Bald Cypress I 178.

Balivaux III 521 .

Ballenptlanzung II 417.

Balsam fir I 151 .

- -pappeln II 475.

- -tanne I 151.

Bambusarten I 145.

- -waldungen II 277.

Banksöhre II 473 .

Basswood I 211.

Bastarde I 119, 126. 169, 200, 210, 220.

Bastarifiohre der Auvergne I 169.

Baumfeldwirtschaft (Cottas) II 271.

Baumgattungen, klimatypische I 67, 72. -, zonentypische I 72 .

\section{Naturgesetzlirhe Grundlagen.}

Baumgenuss'nsehaft I 217.

- - grenze I 13

- hasel 1214.

- -kronenimurnlicht I 96, 9x.

- -krumensehluß I 13:3.

- luft I $>7$.

- -schattenlicht I 96, 99.

- -vereinigume I :218, 230, 2:33. II 250 , $2 \times 1,2 \times 4.994$.

- Wuchsptlege III 502.

Baverisches Ferfibren il $261,327$.

Berech I 19:.

liechecs I 191 .

Bigrüuclungr, küustliche II 361 .

-, natïrlich" II $2 \times 6$.

Beinweitle I 215.

Beizen der Sämereien II:377.

Berberis vuluraris I 213.

Berberize I 21:3.

Bergahorn I 183.

- -erle I 213.

- -ulme I 212.

Berührungsstreifen II 253.

Besamungshieb II $259,3: 1$.

- (ins Volle) JI 259

Beschattung I 88 .

Beschneiden der Ptlanzen I 13:3. II 408.

Bestände, gemischte I 218, 22:3, 2:5. II 281 $328,350,351,438$.

-, reine I $218,223,231$. II $316,43: 3$.

- - gleichalterige I 235.

-- _ (Nachteile) I 2:2.

- - (Vorteile) I 220.

Bestandsbegrïndung I $2: 2$. II $2 \times 6,431$.

- -biologie 1219 , 2:39.

- durchbrechung II 256.

- -erzichung I 93, 132. II :304.

- formen I 246.

- -größe I 246.

- löcher I $99,2 \varepsilon 9$.

- -ränder I 99, 227. II 25:3.

- schattenlicht I $97,100$.

- -schluß 1 7ః, 86, 89. 101, 131. II 292.

- wirtschaft II $25: 3$.

Betrieb, kahlschlauweiser I 219

- Iandwirtschaftlicher II 273.

Betriebsformen II 249.

Betula $164,65,66,67,87,90.99,103$. $104,107,111,112,136.133,143,185$. II $359,436$.

- humilis I 213.

- lutea I $1 \times 6$.

- nana I 213.

- occidentalis 1 1 6.

- paprrifera I 1 $\mathbf{1} 6$.

- pubescens I 186.

- verrucusal | $1 \geq 6$.

- und Pices II 3.51\%.

- und J'inus II :35\%, 449.

Bewässerung III 52:3.

Bigshellbark Hickory I 188.

- trees I 167, 17\%

Bindirkeit I 112, 11:?.

Bindung des Budens I 244.

Binuenluft I 92, 2927.

- -wärme I $22 \%$. 
Biota orientalis I $62,6 i 3,64,65,15.3$.

Birches I 185.

Birkbergüberhaltbetrieb I 271.

- - -wirtschaft II 271.

Birkenbestände II 350,43 i.

Birken und Fiehtenmischbestände II 356.

- und Föhrenmisehbestände II 359, 449.

- zone I 19.

Black bireh I 186.

- Cotton wood I 201.

- maple I 183.

- spruce I 164.

- Walnut I 195.

Jlasenrost I 173.

Blattbleiche I 12, 88 .

- loräune I 186.

- größe I 78.

- -grüntod I 171,175 .

Blattmenge I 78 .

- -mosaik I 98.

Blaue Duuglasie I 176. II 467, 468, 471.

Bleichsandbildung I 4:3, 109.

Bleistiftholz $1155,157$.

Blendersaum II 260.

- - (C. Tagners) II 204.

- - -sehlag I 228, 245.

Blitzgefahr II 266.

Blockpflanzung (Haueh) II $4: 0$.

Blue spruee I 164 .

Blüteberinn I 1:1.

- -bildung I 147.

- -jahr I 139.

Blumenesche I 214.

Blutbuehenbildnng I 121.

Boden I 34, 106, 115, 121, 126, 132, 147. II $281,302$.

-, dïrrer I 112.

- fenchter I 19, 112, 193, 200.

- Hachgründiger I 107.

- frischer I 112. II 303.

- geringer I 110. II 282.

-, guter I 110, 213, 215, 23:.

-, nährstuffarmer I 112.

-, nasser I 112. II 30\%.

-, sauer reagierender I 112.

-., schlechter I 110.

-, seichtgrïntiger I 107.

-, tiefgrïndiger I 106, 180, 189, 191, 203.

-, trockener I 112.

-, versumpiter I 112 .

- aufschließung I 36.

- bearbeitung II 303 .

- -durehfenehtung I 113.

- -durehlïftung P 36.

- - einschlag II 4:32.

- -empfänglichkeit II 338 .

- -entblößung II 281.

- fenehtigkrit I $25,68,86,110,11 \%, 144$, 227. 11288.

- -güte I $78,106,110,141,219,231,245$. II 252 .

- -konsistenz I 40.

- -mangel I 42.

- -menge I 106.

- -nährgehalt I 111.

- -neigung II 282.

I. Naturgesctzliche Grumdlagen.
Bodenpflege III 522.

- -pilze I 112, 113.

- -rassen I 122.

- -sehutz II 267.

- - -holz I 215.

- -temperatur I $36,71,86,115$.

- tiefi I 106, 162.

- -verbesserung I 109. II 278. III 522.

- -vergiftung $\mathbf{I} 40$.

- -vermagerung II $27 x$.

- -vorbereitung II 379.

- -wärme I 84, 115, 116.

Bouleaux I 185.

Bix, Eiler I 183.

Boxes I 186.

Broussonetia II 273.

Bruchboden I 184.

Brïeher I 37.

Brutiafiilire I 171.

Buchenarten I 191.

- bestände II $327,4: 34$.

- -hochwald, modifizierter II 267.

- -stockaussehlag I 121.

- zone I 18\%.

Buchen- und Eichenmisehbestände II 357, 444.

- und Fiehten- — - II 353, 440.

- und Föhren- - - II 358, 447.

- und Tannen- - - II 354, 441.

Buchs I 187.

- arten] [ 186.

Bnchtensäume II 309.

Buckelmoure I 33. II 487.

Büschelptlanzung I 128. II 420.

Buis I 186.

Buna I 192.

Buntfichte I 163.

Bur oak I 20.5.

Buseliformen I 120.

- -wald II $27: 3$.

Butternut I 195.

Buxus I 61, 63, 103, 104, 144, 186.

- microphyHar I 186

- sempervirens I 1>7.

California live oak 1208.

Calluma I 103.

Camollia I 62,63 .

Canoe birch I 156.

Carpinus I 62, 63, 64, 65, 99, 10:3, 104, 107. $136,143,187$. II 283.

- americana I 187.

- Betulus I 187.

- cordata I 187.

- (kïnstl. Begr.) II 435.

- (natürl. Begr.) II 360.

Castanea I $67,87,107,111,137,143,188$. II 345,435 .

- eronata I $63,189$.

- dentata I 63, 189.

- vesea I 61, 6:3, 189.

- -niederwald II 451.

Castanetum I $47,57,67,73,82,150$. II $277,291$.

- für, Fremdländische Holzarten II 466.

Castanopsis I 61 . 
Catalpa I 36, 136, 190.

- speciosa I 190. II 478.

Cedars I 153.

Célres I 153.

Cedrus I 153. II 342.

- ntlantica I 62,154 . II 478 .

- Deodar I 62, 63, 154.

- Libani I 6:3, 154.

- Überhälter II $\$ 60$.

Celtis I 62, 63. 345 .

Cembra I $90,103,111,137,174$. II $2 \times 3$, $342,345,435$.

Cephalotaxus I 63.

Ceratonia I 61 .

Cereidiphyllum I 63, 65, 128, 143.

- japonicum I 190.

Cerisiers I 201.

Chamaecyuaris I $63,65,87,90,103,111$, $125,128,136,143,144.154$. II 283,342 .

- Lawsoniana I 64, 155. II 477.

- nutkaensis I $63,64,155$.

- obtusa I 155.

- pisifera I 156.

- sphaeroidea I $63,64,156$.

Chamaeropspalme I 63,64 .

Charmes I 187.

Chataigniers I 188.

Chênes I 209.

Cherry-trees I 201.

Chesnut I 189.

Chesnut oak I 205.

Chesnuts I 188.

Chinesische Birne I 199.

- Rotföhre I 168.

- Thuje I 153.

- Ulme I 212.

- Wachliolder I 157.

Clristbaumbetrieb I 291.

Christuzdorn I 194.

Cinnamomum Camphora I 62. 190.

Cladrastis amurensis I 65, 110, 191.

Clematis vitalba I 213.

Clorophyll I $85,150,154$.

- tod I 15t, 161, 186.

Colorado Douglas fir I 176.

- Donglasie, blane Douglasie I 49 .

Cornus I 103.

- mis I 214.

- sanguiner I 214.

Corylus I 10:3, 135, 143.

- Avellaua I 214.

- Colurna I 214.

Crataegus I 103.

- monogyna I 214.

- oxyacantha I 214.

Cryptomeria I 6:3, 65, 10:3, 125, 14:3, 144. II 283.

- japonica I $62,6: 3,132,156$. II 478 .

Cunninghamia sinensis I $62,63,143$.

Cupressus I 90, 125, 156.

- macrocarpa I 61, 90, 157.

- sempervirens I 90, 157.

- torulosa I $62,90,157$.

Cyprès I 156.

Cypress I 156.

I. Naturgesetzliche Grunillagen.
Dänische Durehforstung III 510 . (ieräte? II 382 .

Dammptlanzing II 420 .

- -sait II 386.

Darmstälter Saatgut I 127.

Devodar I 154.

- -zo der I 154.

l)iehtigkeit des Kirnuensehlusseg 1 2:3:

Diekenwaehstum I :-)8.

Dickungsalter I 239.

- -schluß I 2:39.

Doppelgipfelbildnug I 228. III 494 .

])uglasien I 59 .

Donglas tir I 176.

Mrehwüchsigkeit I 124,127 .

Dïnenaufforstung I 16i, 171. II $4>7$.

- -bildung I 40.

- sand I 110, 113.

Dïngung I 109. III 530.

Duftbruch I 32.

Dunkelschlag II 261, 29:2.

- -Häehenweiser II 319 .

Dunkelschlag, ringförmiger II 260, 299, 325.

-, saumweiser II 259, 3:2:3.

- -verjüngung II 258,301 .

Durchforstung I 100,233 . II $258,279,300$, III 501 .

- - griff I 228.

- -lichtung I 100. II 266, 279, 292, 300. III 502 .

- -lichtungshieb I 235.

- -lüftung I $87,112$.

- -reiserung III 520 .

- -schuittsstandram I 233.

- - tempera $\mathrm{tur}$ I $60,85,208$.

Eclaircie III 510.

Edelkastanien I 67, 1ธ8, 207, 210. II 342, $4: 35$.

- -zone I 59.

Edgewörthia II 273.

Eibenarten I 17s. II 476.

Eichenarten ] 202. II 349,4:37.

- mit Lichtholzarten II 449 .

-, immergrïne I 103, 208. II 341.

Eichen- und Buchenmischbestände II 357 , 444.

- und Fichtenmischbestïnde II 445.

- und Föhrenmisehbestände II 359, 446 .

- und Halbschattenholzarten II $4+7$.

- und Tannenmischbestäude II 356, 446.

- -sehälwald II 45:2.

- - -umwandlung II 452.

- -winterkahle I ȳo, 206.

Eigensehatten. prbliche I 118.

-, inclividuelle I 138.

- variable I 138.

-, waldbanliche 1 148, 165, 220, 24ti.

Einsclatftigkeit I 202.

Finteilung des Wildes II 280, 293.

Fintritt des samenertrages I 137.

Einzelmischung I 2IK.

- ülorhalt II 265.

Fisenbahnlichtıng (Anfforstung) II 459.

Eisregen I 32.

Elms I 211. 
Elsässer zweihiebiger Hochwald II 266.

Elsbeer II 216.

Endhieb II 299, 303.

Engelmannsfichte I 16:3.

Engerlinge II 402.

Enshu If 402.

Entgipfelnngshiel, 1247.

Entwĭsserung 111523.

-, Kaisers III 524 .

Epicías I 160.

Erables 1 18:.

Erblichkeit I 120, 127, 1:33.

- des Zuwachsvermögens I 12:3, 142.

Erfrieren I 86.

Erhaltung der Bodenkraft I 237.

Erhitzung I 13, 89, 226.

Erholungswirtschaft II 269.

Erlenarten I 184.

- -bestände II 4:35.

Erle mit Esselie II 448.

Erlenbrücher I 226.

- -bruchboden I 193.

Ersatzgipfel II 249.

Erwärmung I 12, 87.

- der Erdobertläehe I 226.

- der Luft I 226.

Erzichungsformen 1122.

- -methode I 127.

- -verjüngung II $262,284,287,300,318$. $1 I 1546$.

- -wirtschaft II 262.

Esehenarten I 192.

- bestände II 4:34.

Eschen mit Erle II 448.

- blätteriger Ahorn I 183.

Eurouaische Birke I 186.

- Bnche I 192.

- Edelkastanie I 189.

- Edeltanme I 152.

- Eibe I 179.

- Esche I 193.

- Fichte I 16:3.

- Hopfenbuche I 197.

- Läirehe I 80, 159.

- Lebenseiche I 208.

- Walmub I 195.

Evonymus I 103, 135, 214.

Figretum I $38,57,67,82,153,160,165$, 244. II $291,298$.

- für fremdländische Holzarten II 467.

Fagus I 87, 99, 103, 104, 111, 132, 137, $1: 88,14: 3,191$. II 283.

- Englierana I 64.

- ferruginen $164,192$.

- japonica I 65. 19:.

- Sieholdii I $655,192$.

- silvatiea I 64, 108, 192.

- simensis I 64.

- (künstl. Begr.) II 4:34.

- (matürl. Begr.) II 337.

- und Abies II 354, 411.

- mil Picea II 353, 440.

- und Quercus II 357, 444.

Faschinenwald II 273.

Faulbaum 1216.
Fegeholz III 520 .

Feldahorn I 18:3.

Felsenföhre I 173.

- kirsche 1215.

Femelbetrieb II 253, 262, 279, 284, 290.

-, periodischer II 264.

-, zonenweiser II 262.

Femelhieb II 255, 269, 327.

- -hochwald II 285.

- -pHanzung II 269.

- rhizombetriel, II 267 .

- schlag I 245. II 325.

— -, Gayers II 261, 299.

- verjüngung II 260.

- schluß I 234.

- -verjüngung, zomenweise II 262.

- wald I 231, 238. II 25\%, 264, 280, 283.

- - wirtschaft - Femellsetrieb.

Fernwirkung von Flïssen und seen I 31.

Feuchtigkeit I $20,27,36,53,58,71,111$, $125,219,228,245$.

-, relative I 58 .

Feuchtigkeitsmangel I 36 .

- -iibersehuß I 37, 109.

Fener I 22:3, 245, 248. II 250, 254.

- -mantel III 5:7.

- probe II 374.

- -scheinzypresse I 155.

- -streifen III 527.

Fichtenarten I 160.

- zone $=$ Picetum.

- -bestände 11 :332, 433.

- und Birkenmischbestände II 356.

- und Buchemmischbestände II :353, 440.

- und Lärchenmisehbestände II 356, 441 .

- und Tanmenmischbestände II 352. 440.

Firs 1149.

Flachmoore 135,37 . II 487.

- -wurzler I 107.

Flasehenprobe (Ohnesorg) II 375.

Flatterulme I $21 \%$.

Flaumhaurige Fïche I 206.

Flechtenansatz I 92, 158.

- moore 138.

Florida-Lehenseiche I 209.

Flïgehnïsse I :202.

Flugsant I 110, 113, 215.

- bildung II 270 .

FluBanen I 184, 190, 196, 200. II 274, 359, 450.

Föhn I 137.

Föhren I 165.

- Reinbestände II $34 \overline{7}, 436$.

- Kiefern)artell, gemischt II 44, 48

- und Birkenmischbestände II 359, 449.

- und Bnchenmischbestänle II 358 .

- und Fichemmischbestänle II 359.

- und Robinie II 449.

- -ïberhälter II 360 .

Formile I 12:.

Formen I 11s, 120.

Fracraria I 103.

Fraxinus I $62,63,64,99,103,104,111$, $112,1228.136,143,192$. II $28: 3$.

- alloi I 193.

- americana I 193.

1. Naturgesetzliche Grundlagen. II. Begründung. 11I. Pflege und Erziehung. 
Fraximus eincrea \ 193.

- excelsior I 193.

- mandshurica I 65, 19:3.

- oregona I 64, 193.

- Orims I 214.

- pubesceris I 194.

- (küustl. Begrr.) II 434.

- (natïrl. Begr.) II 344.

Freilanddüngung III 530 .

- -pflanzung I 115.

- -saat II 379.

- ständer I 132.

- stand I 86, 89, 101, 161, 175, 235. II 257, $259,266$.

- formen I 122.

- -stellung I 132, 150, 191. II 296, 299.

Fremdländische Holzarten, Anbau II 457.

- - für bes. Zweeke II 468.

Frînes I 192.

Frost I 97, 102, 113, 179, 226. II 254, 259, 300 , 30:3.

- -beschädigung I 226.

- -empfindlichkeit I 8\%, 172.

- -löcher I 88, 161, 185. II 302.

Frühfrost I $69,82,86,88,209,21: 230$. II $285,464$.

Fruelitjalire I 139.

Fruchtwechsel II 271.

Fujiki I 211.

Fujimatzu I 159.

Fujisophore I 211.

Füllholz III 529.

- -strauchptlanzıng II 486 .

Furchenverschulumg II 405.

Futterlaubniederwald II 273.

Garryseiche I 205.

Garteuptlanzen II 395.

Gebrauchswert (Samen) II :372, 37:3.

Geißblatt I 215.

Gelbbirken I 111, 18.5.

- -töhre I 173.

Generalmast I 238.

Genciviers I 157.

Geradsehaftigkeit I 75, 124, 160, 167, 206. II $25.5,29 \cdot 2$.

Geräte für Bodenbearbeitung II 380 .

Gerbereiche I 205.

Gerberpasanie I 198.

Geröllboden I 178.

Gewebeulme I 212.

Gewicht der sämereien I 136. II 376, 377.

Gingkyo I 47, 99, 143, 144.

Gipfelbrueh I 229.

- -lürre I 131, 203. II 266.

- -knospentod I $82,164,178$.

- - verbiß I 151.

- -verlust I 12\%.

Gleditschia I $63,9 !, 137,194$.

- juponica I 194.

- T'riacanthos I 194.

Grabgabel II 410 .

- muldensaat (Cuttas) II :386.

Grapholithea II 288.

Grasflächen (Aufforstung) II 485.

Grauesche I 193.

1. Naturgesetzliche Grundlagen.
Grane WalnuB I 19\%.

Graupelı 1 :36.

Grenzen, natïrlieh» I 56.

Griechische Strulue I 174.

- 'Tamar I lis1.

Größenklasse: der Bäume I 1:35.).

(iroßbestind I 2:39. II 257, 283.

- -kalılschlag 1125.5.

- -wirtschaft II 251, 253, 256.

Große Kïstentamue I 151.

Grobfruchteiche I 205.

Großfrürhtige Donglasie I 177.

(iroßlickory I 188.

-- -sträuchı̀ I 135, 216.

Grïnästung III 517.

- -dïngung II 413. III \$32.

- - betrieb I 213.

Grünc Douglasie - Küistendouglasie.

Grünerle I 213.

- -landsmoore I 37.

- - (Aufforstung) II 487.

Grundwasser I 26, 107, 131 .

- -senkung I 20:3.

- -spiegel I 131, 178.

- -stand II 297.

- -staumng I 203.

Gruple, gemisehte I 218.

-, reine I 219.

Gruppenschlag II 315.

- -wald II 258, 283.

- -wirtschaft II $253,255,256$.

Gürtelprärie I 42.

Gymnocladus [ 63, 110.

- dioica I 194.

Hackenföhre I 168. II 476.

Hackwald II $2 ₫ 5$.

- -wirtsehaft II 273.

Hagel I 20, 36, 82, 93, 229. II 288.

Hainbuche II $287,2 \times 9,34: 2,435$.

Halbbäuıne I 103, 107, 17\%, 186, 202.

- -, immergrïne I 215.

- -masten I 139.

- -schattenbäıme I 216.

- - -holzarten $[78,103,155,174,184$, $187,193,199,211,214,222$. II 293,342 , $4: 34$.

- - -hölzer I 173, 182.

- - -pflanzen I 103.

Hartriegel I 214.

Harzwaldluetrimb II 269.

Haselnuß I 214.

Hauber rwirtscliaft II 273.

Hauptabtriebsalter II $2 \times 9$.

- -ausseheidungsalter I 2:3:3.

- bestandlublzmassor I 2:2:3.

- -längenwadistum I 232.

- vegetationsmomate I 58.

Hock(i)I I 214.

Heclera I $10: 3$.

IIeirle I 4:3, 244.

- -Häıhr'n (Aufforstung) II $4<3$.

IIrinlneks I 180, 181.

Herbstfärbmg I !2, 1<2, $1 \times 4,196$.

- - firost I \&:3, 196.

IIrrkunft des silutgutes I I19, 124, 142. 
Herzwurzler I $107,150,158,176,189,192$, 193.

Hètres 1191.

Hiba I 180. II 477.

Hickories I 188.

Hickoryarten I 188.

Himalayastrobe I 48, 173.

- -tanue I 150.

- -weymouthsföhre I $17:$.

- -zeder I 154.

Hinoki I 150.

Hinterlicht I 96, 100, 218.

Hippophä̈ rhamnö̈des I 214.

Hirsehhörner III 521.

Ho I 197.

Hochdurehforstung III 510 .

- -gebirgsfichte I 123.

- moore I 35, 33, 43.

- - (Aufforstung) II 487.

-, nordische Föhre I 166.

- wald I 75, 187. II 249, 280, 284.

- -, iloppelalteriger II 266.

- - -ideal (I'reßlers) II 269.

- - mit Landwirtschaftsbetrieb II 270.

- - mit Kahlschlagform II 285.

- - mit Femelbetrieb II 285.

- - nachteile II 250.

- - rorteile II 249.

- - -umtrieb II 279 .

- - zweihiebiger II 267.

Holzartenerziehung I 68.

- - parallele I 61 .

- - wahl II 4:31.

Homagnulie I 197. II, 478.

Honlolärche I 159.

Honey-Locust I 194.

Hopfenbuche I 197.

Hurnbatum I 187

Hornbeam I 187.

Horotherme I $15,35,46,69$.

Horst I 217.

Hovenia I 63.

- dulcis I 194, 201.

Hovenie I 194.

v. Hubersches Verfahren II 261, 327.

Hügrelptlanzung II 419.

- - (Manteuftel) II 419.

IIiilsen I 215.

Hundszunge 1216.

Hutweidewirtsehaft II 269.

Ibuki I 157.

Ifs I 178 .

Ilex Ayuifolium I 215.

Immergrüne Kastanieneiche I 197.

Indian silver fir I 153.

Individualitas I 121.

Individualitäten [ $105,108,121$.

Individualitätseigensehaften I 122.

Individnen I $82,119,133,217,219$.

—, isoliert stehende I 2:30.

Insekten [ 73, 76, 110, 118, 146, 217, 223. II $250,254,2 \times 8,300$.

Insolation I 14, 21, 85, 89.

-, wärme I Y:).

Inubuna I 192.
Inu enshu I 191.

Iramomi I 163.

Isoliermantel III 528 .

Italienische Pappel I 200.

Itaya-Ahorn I 183.

- Kaede I 183.

Jahresisotherme I 14.

-ringban I 76.

- - -breite I 76, 207, 237.

- -temperatur I 14, 59 .

Japanische Balsampappel I 200.

- Buche I 192.

- Buchs I 186.

- Christusdorn I 194.

- Donglasie I 177.

- Edelkastanie I $1 \times 9$.

- Eibe 1179.

- Flügelnuß I 202.

- Inpfenbuche 1197.

- Kirsche I 201.

-- Kolleiche I 207.

- Korkbaum I 198.

- Lärehe I 159. II 477.

- Linde I 211.

- Rotföhre [ 166.

- Sehirmtanne I 177. II 477.

- Schwarzföhre I 168.

- stieleiche I 205, 239.

- Thuje I 179.

- Tsuga I 1s1.

Jeffireya I 90, 103, 112, 172.

- föhren I 172. II 347.

—, Mischbestände II 355 .

Jeffreysföhre I 172.

Jeffrey Pine I 172 .

Jerseyföhre I 171 .

- Pine I 171 .

Juglans I 47, 62, 63, 64, 87, 111, 13:3, 137, $138,14: 3,195$. II 283.

- einerea I 195.

- mandshuriea I 19.5.

- nigra I 108, 195. II 474.

- Sieboldiana I 195. II 475.

—, Überlsälter II 360.

- regia I $6 \%, 63,195$.

-, (natürl. Begr.) II 360.

Jungwuehs I 176. II 303.

- -ptlege I 128. III 492.

Juniperus I 66, 90, 135, 137, 157.

- chinensis I $62,6: 3,157$.

- virginiana I $61,63,157$. II 478.

Kadsura I 190.

Kältegrenze I $73.87,122,142,158,208$. II $2 \times 1$.

- -rarietät I 123.

Kahlhieb II 272, 295.

- -verjüngung II 254.

-schlag I 111, 113, 226, 246. II 272, $279,280,284,295,305$.

- - -betrieb I 178. 11 252, 269, 285, 293.

- - -niederwald II 285.

- - , ringförmiger II 256, 300.

_- saumweiser II 256 .

- - -verjüngung II $253,254,268,295$.

Kaisereiche I 204.

\section{Naturgesetzliche Grundlagen. II. Begründung. III. Pflege und Ėrzichung.}


Kakteen I 27.

Kalifornische Lebenseiche I 208.

- Lorbeer 1212.

- Rotriche I 207.

Kalkboden I 213.

- (anzeigende PHanzen) II 43:2.

- -düngung III $5: 2$.

- formation I 187.

Kampptlanzen II 395.

Kampherbaum I 190.

Kanadische Pappel I 200.

- Tsuga I 181 .

Kaaramatzu I 159.

Karolinenföhre I 171.

Karste I 42, 171, 244.

-. Aufforstung II $4 \$ 2$.

liashiwa I 204.

Lastanie = Castanea.

Kaukasische Flügelnuß I 202.

- Keaki I 213.

Kaukasusfichte I 164.

Kawagurumi I 202.

Keaki I 212, 213. II 342, 435.

Keimbett I 136, 226.

- -energie II 371 .

- fahigkeit I 141, 197. II 371.

— -kraft I 141.

- - des siatgutes I 160.

Keimling I $13,25,86,88,117,161,165$.

- -proben II 373.

- -prozent II 367.

- -ruhe II 388.

Keimung II 285 .

- zahl II $367,371$.

- -zeit II 388.

Kiefern = Föhren.

Kiesgeröllboden I 220

Kiri I 193.

Kirschenarten I 201.

Kiwada I 198.

Klappptlanzung (Alemann) II 420.

Kilebräste I 121, 130.

Kleearten I 103.

Kleinbestand I 217, 218, 219, 237, 239. II $257,282,283,284$.

- -kahlschlag II 255.

- -wald III 546.

- wirtschaft II 253, 256, 260.

Klemmptlanzung II 417.

- -unterpflanzung III 529, 530 .

Klima I 11, 35, 53, 68, 115, 121, 138, 165, 2:37. II 291.

-, montanes I 153.

- rassen I 122.

Klimatologie I 5.5, 58, 224.

- -varietät I $81,123,141$.

- verschiebung I 20 .

- -zone I 56, 50, 160, 191, 224.

Körbehenpflanzung (MeIchar) II 420.

Körnerzahl der Sämereien II 377.

Kolıradodouglasie = Blaue Douglasie.

Kometsuga i 181 .

Kompositionsbetrieb II 266.

Komposthaufen II 411, 412.

Konara I 205.

Kopfausschlagformen II 274. liopf holz für Bremuholzzucht II 274.

- - futterlaubbetrieb II 274.

- - weidenbetrieb II 274 .

Koreazürbel [ 175.

liork I '208.

- bildumg I 144, 198, 208.

- -eichen I 208.

- -ulme I 212.

- -waldwirtschatt II 269.

Korngewicht I 141.

- -größe [ 141.

Kornelkirselie I 214.

Korsikanische Schwarzfïhre I 167. II 473.

Koyamaki I 177.

lirauseiche I 204.

Kreuzdorn I 216.

- -saat II $3 \varangle 4$.

Kriechföhre I 167.

- formen I 120.

Kronendach I 225.

- - geschlossenes I 225.

- -freihieb II 268.

- -mischung II 322.

- -schluß I 138, 150. II 255, 258, 271.

- - liehter I 233.

- - lockerer I 23:3.

— - verhältnis I 232.

Kropf holzzucht II 274.

Krïppelwald II 249.

- - betrieb I 171.

Krummholzföhre I $20,48,167$.

- - -regetation I 70 .

- -schaftigkeit I 127, 158.

- -wüchsigkeit I 121, 124, 126, 159.

Krytomerie I 156.

Kuchenbatm I 190.

Küstendonglasie I 170,176 . II $467,468,470$.

- -klima I 5:3.

- -sequoie I 178.

Kugelscheinzrpresse I 156.

Kulissenhieb 'I 228 .

- -kahlschlag II 256.

- -überhalt it 266.

Kulturhammer II 406.

Kunugi [ 203.

Kuri i 189.

Kuroesomatzu [ 163.

Knromatzu I 168.

Kuro Shiuo I 16, 24.

Kurznadelige Föhre I 171.

- -schaftigkeit I 158.

- triebbegrünung I 83 .

liuss I 190.

Kusu [ 190.

Lackbaum I 209.

Lärchenarten I $1 \mathrm{is}$.

- -bestände, kïnstl. Begr. II 437 .

- -krehs I 159.

- -oberholz II 454,

- -ïberhälter II 360 .

— u. Fichte'n II :3.5\%, 441.

- - Föhren II 444.

- - Fichen II 443.

- - Halbschattenholzarten II $4 \mathbf{4}$.

- Lichtholzarten II 441. 
Lärchen $u$. schattenholzarten II 441.

- -wiesen II 269.

Landwirtsehaftliches Gelände, Aufforstung II 489.

Lappenprobe II 375.

Larches I 158.

Laricetum | 65 .

Larix I $20,90,99,103,104,111,125,12 \times$, $136,138,143,145,148,15 \%$. II $283,437$.

- americana I 64, 66, 159.

- dahurica I 66, 67.

- europaea I 64, 65, 66, 133, 159.

- kurilensis I 66, 67 .

- leptolepis I 65, 66, 159.

- oceidentalis I $31,64,66,160$.

- Prineipis Rupprechtii I 66, 67.

- sibirica I 64, 65, 66, 67, 119, 133, 160. II 477.

-_- und Picea, künstl. Begr. II 441.

_ _ nat. Begr. II 356.

Laßraitel II 275, III 521.

Laterite I 72.

Laubbäume | 146, 181. II 283, 341.

- busehwald, immergrïner I 16.

- -lecke I 101.

- -holz-1Jalbschattenarten 11 28:3.

- - - Lichitholzarten II 283.

- - Schattenholzarten II 283.

Laturetum I 60, 61, 71, 153, 156, 158, 171, $186,190,203,205,207,209,21 \%, 215$. II 277 .

- für, Fremdl. Holzarten II 465.

Laurus nobilis I $61,215$.

Lawinenbildung II 270.

Lawsonie I $63,155$.

Lawsons Scheinzypresse I 15.5. II 477.

Lebenshaun I 179, 180.

- eiche I 208.

Legföhre I 108.

Lehm I 110, 113.

J.eitersaat II 386.

libanonzeder I 154.

Libocedrus I 103.

- decurrens I 6:3, 64 .

- macrolepis 163.

-, nat. Begr, II 342.

Lichenetum I :3!), 244.

Licht I $34,93,115,13 \%, 147,14 \%$. II 25.5.

- bedïrfnis I $7 x, 96,104,148,19 \times, 215$, 219, 2:31.

- -entzug । 94, 101, 14×, 15.), 16\%, 206, 2:31. II 2:57, 296.

-formen I 192

-, gemischites I 95.

- -ginnß । 104, 111, 14:3, 15:3. II 259.

- gestalt I 105.

- hiebe 11 259, $299,303$.

- Lolzarten $178,10: 3,138,157,166,17 \%$, $177,1 \times 2,185,194,199,214,2: 33$. II $\therefore 45,4: 36$.

- intensität I 94, 97.

- - -minimum I 96.

-. -klima I 93, 105.

- -mangel | 94, 105, 149, 23๙.

- menge I 89, 105.

- - inelle I 94.
Lichtungsbetrieb II 267.

- -hieb II 259.

Liehtwuchsbetrieb (Wagener) II 267.

- (v. Seebach) II 267.

-. horstweiser (Burgmann) II 268.

- Kulissenbetrieb (Urieh) II 26\%.

Ligustrum rulgare I 215.

linden | 211.

-, künstl. Begr. II 4:35.

-, nat. Begr. II 342.

Liquidambar I 63.

- styraeiflua 1196.

Liriodendron I 47, 63, 64, 103, 104, 136 .

- tulipiferum I 196. II $47 x$.

Litzaea I 6\%.

Live oak I. 209.

Lablolly P'ine I 172.

Lochhiigelpflanzmug II 419.

- pflanzming II 418, 419.

- -verschulung II 405.

Locker (Boden) I 113.

Lockermngsapparat (Sehüllermann) II 402.

locust I 209.

Lodgepoles Pine I 171.

| Löcherhieb II 255.

, kahler II 256, 313. -wirtsehaft II 260.

Löss I 40,73, 110.

Lohheckenbetrieb II 273.

Longleaved l'ine I $17 \%$.

Lonicera I 113, 135.

-_ Caprifolium I 215

-- xylusteum I 215.

Lorbeerbaum I 210, 212, 215.

Iuftfenchtigkeit I 21.

- - -mangel I 26.

- strïme I 23, 54, 72. -wurzeln I 143.

Lustparkwirtschaft II 270. III. 540.

Linsus I 120, 138, 200.

Maackie I 191.

Machilus I 62.

Magnolia I, 47, 87, 103, 111. 137, 143, 196.

- crantiftora I 61.

- hypolenea I 63, 65, 197. Il 478.

-, immergrün I 62.

- Kubushi I 63.

Mandelweide I 210.

Mandschureiesche i 193.

- -walnuB I 195.

M:monacsile 1 214. aples I 182.

Mabluteder I 183.

Mäuseverbiß II 254.

Merere, steineme I 42.

Mereresstrïmungen I 16, 18, 23.

Melizes I 158.

Mematzo I 166.

IIengepilanzung II 439. -saat II : : $60,438$.

Mrirgel I 110.

Ilesquit 1201 .

Nischbestände I $12,15,25,89,97,100$, 104, 108. 11328. -stren III 526.

I. Naturgesetzliehe Grundlagen. 11. Begründung. III. Pflege und Erzichung. 
Misehung, rruppenweise 1 -223.

-, kleintlïchenweise I 223.

-, stammweise I $2: 33$.

- Nirliteile I 220.

- Vorteile I 220.

Mistheete I 115.

Mittelenropäisehe Rotföhre I 168.

Mittelwald I 132, 145, 199, 214, 249. II 281.

-, cruppenstäudiger II 276.

- hochwaldartiger II 276.

- Nichteile II 275.

-, nicderwaltartiger II 276.

- -sehluß II 2.34.

- truploständiger II 276.

- PHlege III .20.

- -uugen II 27.5278.

-, Vorteile II 275.

Modernes III 521.

Momitaune I 151.

Montereyföhre 1171.

- -pine I 171.

- -zvpresse I 157.

Moorboden I 1:3, 19, 73, 109, 2:0.

- ang. PHanzen II 432.

- Aufforstung II 487.

Moosansatz I 9:3.

Mortzfelds Methode II 446.

Inllboden ang. I'Hanzen II 432.

Murraya I 90, 103, 112, 169. II 347, 436.

-, Mischbestände II :55, 448.

Ilntationes I 120.

Mykorhiza I 113.

IIrrtle-tree I 212.

Nachbesserungen III 492.

Nachhieb II 259, 32:.

Nadelbleiche I 88.

- -bräune I 88, 101, 150, 175.

- -hölzer I 13:3, 14.5, 240.

- -lichtholzarten II 283.

- -röte I $86,227$.

Nïhrgehalt I :39, 110, 223.

Nanakamado I 197.

Natakmungi I 208.

Naturbesamung II 288, 295.

_-verjüngung II 245, 280, 991.

- - Kahlschlag II 305.

Negundo aceroides I 183.

Nepalzypresse I 157.

Netzuko I 179.

Neulandbildming I 199.

Niederschläge I $20,24,36,4 \succ, 53,228$, 237. II 243, 280.

-wald I $75,145,205,207.211,214$. II $273,278,28: 3$.

- - -betrieb [ 101, 189, 210, 197, 203, 215.

II 273,451 . III 520 .

- - -kahlsehlag II 27.5.

- - überhaltbetrieb II 273.

Nigrae (Eichen) I 206.

Nikkotanne I 152.

Nischemptlanzung II 419.

Nitragin II 413.

Vordlandfichten I 123.

Nordmanustanne [ 152.

Nothofagns I 157.
Noyers I 195.

Nutkisehcinzyjuresse [ 155.

Nutzholzwirtsehaft (IIomburgs) II 267.

Nyssa silvatica I $6: 3$.

Oaks I 212.

Oberholy I $2: 34$. II 27.5 .

- -lieht I 96, 98.

Òdländereien I 68. II $291,479$.

- -aufforstungen I 170. II 284, 479, 482.

Ohio I 212.

Olea I 61.

Omatzu I 168.

Ombrohore I 26, 28.

- , steppe I 30 .

Omorikafichte I 164.

Onara I 204.

Onigurumi I 195.

Optimum (klimatisches) I 7:3, 122, 159, 168, $189,203$.

Oregon ash I 193.

- -esche I 193.

Orientalische Platane I 200.

- Thuje I 153.

- Zypresse I 157.

Ormes I 211.

Ortsteinbildung I 43, 109. III 525, 526 .

Ostamerikanische Lärche I 159.

- Strobe I 174.

- Thuje I 180. II 477.

Österreichische Schwarzföhre I 166.

Ostrya I 62, 63, 65, 197.

- carpinifolia I 197.

- japonica I 197.

Palmetum I 61, 71.

Papilionaceen I 194.

Paper birch I 1 6.

Papierbirke I 186.

- -heger II 273. III 520 .

Pappelarten I 200. II 283, 450.

Parkettföhre I 172.

Paroliniföhre I 171.

Pasania I 62, 197.

- cuspidata I 198.

- densiflora I 198.

Pansanien I 197.

Paulownia imperialis I $63,136,145,198$. II 478.

Pazifische Balsampappel I 201.

Pechföhre I 172.

I'crsea I 61.

Peuples I 200.

Pfahlwurzel I 150, 165, 176, 194, 203.

- -wurzler I 106, 113, 126.

Pflanzbeil II 418.

- blech (Mantel) II 406.

- -eisen (Butlar) II 418.

- (I'romvé) II 418.

- (Wartenberge) II 418.

- -enaufbewahrung II 414.

- -garten II :395.

- - -dïngung II 410.

- -haminer (IIfayr) II 418.

- - (Renibe) II 418 .

- -have II 418.

I. Naturgesetzliche Grundlagen. II. Begründung. III. I'llege und I:rziehung. I ayr, Waldbau. 
Pflanzenketten II 424.

- -lanze II 418.

- -methoden II 417.

- -regeln II 422.

- -schnüre II 424.

Pflanzung (Biermanns) II 419, 420.

-, Nachteile II 389 .

-, Torteile II 389.

- zeit II 415.

Pflege der Hochwallungen III 492.

- - Ausschlagwaldungen III 520.

- - Sehutzwaldungen III 534.

- des Waldes aus ästhetischen Gründen III 539.

Phellodendron I 63,65 .

- japonicum I 198.

Picea I $20,65,87,99,103,104,107,111$, $112,128,136,143,145,148,160$.

- ajanensis I $65,66,163$.

- alba I $64,66,162$. II 283,472 .

- bieolor I $65,66,163$.

- Engelmannii I 64, 65, 66, 163.

- excelsa I $64,65,66,108$.

- hondoënsis I $66,67$.

- Morinda $\perp$ 65, 66, 163.

- nigra I 64, 66, 164.

- obovata I $64,67,119,164$.

- Omorica I 65, 164.

- orientalis I $64,65,164$.

- pungens I $64,65,66,133,164$. II 472.

—, reine Best. II $332,433$.

- sitkaënsis I $64,66,164$. II $467,468,471$.

- und Abies II 3.52, 440.

- - Betula II 356 .

- Fagus $11353,440$.

- Larix II $356,441$.

Picetum I $38,47,50,65,70,72,82,115$, $150,158,165,168,170,174,176,180$, $182,184,202,205,213,244,291,298$.

- für, Fremdl. Holzarten II 468.

Pichta I 152.

Pignut Hickory I 188.

I'ilzkultur I 198.

- -pasanic I 198.

Pinaster I $90,103,112.165$. II 347.

- -föhreı (Kiefern) I. 165.

-, Mischbest. II 365.

Pindrau I 152.

Pindrow I 152.

Pines I 165.

Pin oak I 207.

Pins 1 16.5.

Pinsapo I 152.

Pinus I 87, 104, 107, 145, 148, 165.

- aleppensis I $61,62,166$.

- austriaea I $62,64,119,166$. II 473.

-- Banksiana I $64,66,133,169,170,171$. II 473 .

- Cembra I 65, 66, 174. II 476.

- corsicana I 62,119 . II 473.

- densiflora I $63,66,166$.

- excelsa [ $48,62,63,65,173$.

- inops I 63, 171.

- insignis $161,63,171$.

- Jeffreyi I $63,64,119,172$.

- Koreensis I 65, 66, 175.
Pinus Lambertiana I $64,174$.

- lapponica I $65,66,119,124,166$.

- Laricio = corsieana.

- leukodermis I 64, 167.

- maritima I 61, 62, 167.

- mitis I 63, 132, 143, 171, 172.

- Mughus I 119, 126, 167.

- Murrayana I $64,65,132,171$. II 468 .

- palustris I $61,63,171,172$. II 466.

- Penke I 64, 65, 174. II 468.

- Piuaster I 167.

- ponderosa I $63,64,66,173$.

- pumila I 67,126 . II 468 .

- Pumilio I 20, 33, 108, 124, 126, 134, 167.

- pyrenaica I 171.

- resinosa I $64,66,167$.

- rigida I $63,64,132,143,172$.

- scopulorum I 63, 64, 65, 119, 173.

- sibirica I $64,65,119,175$. II 476 .

- silvestris I $64,65,124,125,13: 3,134$, $168,239$.

- sinensis I $62,63,65,66,168$.

- Strubus I 64, 66, 174 II 472.

- Thumbergii I $62,63,168$. II 466.

- uncinnata I 33, 65, 71, 119, 168, 171. II 476 .

- uncinnato $\times$ silvestris I 90,169 .

- und Betula II 359.

Pirus communis I 135, 137, 198, 199.

- Malus I 199.

Plaggenpflanzung II 420.

Plane-tree I 199, 200.

Platanen I 199.

Platanus [ 62, 112, 199.

- oecidentalis I 6:3, 200 .

- orientalis I 200.

Platzsaat II 385.

Plenterschluß I 235.

- -verjüugung II 327 .

- -wald II 252, 264.

_- -wirtschaft II 253, 262.

Plum tree I 152.

Poplars I 200.

Populus I 63, 64, 65, 66, 67, 99, 10:, 104, $111,112,136,143,144,200$.

- alba I 200.

- camadensis II 475.

- deltoides II 475.

- monilifera I 200. II 475.

- nigra I 200.

- tremula I 200.

- trichocarpa I 64, 201.

Prärie, Aufforstung II 485.

Prosopis julitlora I 64,201 . II 466.

Prutzen II 268.

Provenienz des Saatgutes I 119, 124, 126, 142. II 287.

Prmiers 1 201.

P'rumis I 6:3, 64, 65, 103, 137, 14t, 201.

- avium I 201.

- Mahaleb I 215.

- Padus I 215.

- Pseudocerasus I 201.

- serotina I 63,202 . II 478.

- Shiuri I 202. II 478.

- spinosa I 216. 
Psendotsuga [ 87, 103, 111, 124, 128, 136, $138,143,175$. II 28:3. 341 .

- Douglasii I $63,64,66,119,176$. I[ 467 , $468,470$.

glauca [ 64, 66, 119, 176. II 467, 468, 471.

- japonica I 65, 119, 177.

- maeroearpa I 61, 63, 177.

- Überhälter II 360 .

Psychroliore I 26.

Pterocarya I 62, 202.

- fraxinifolia 1202.

- rhoifulia I 202.

Pyramidempappel I 145.

Pyrenäenfïhre I 171.

l'yrus $=$ P'irus.

Quaffibine I 194.

Quereus I 88, 99, 104, 107, 111, 132, 137, $143,148,202$. I[ 283.

- acuta I 62, 208.

- Aegilops I 208.

- alba [ 63, 64, 204.

- bicolor I 204.

- californica I 207.

- Cerris I 62, 207.

- conferta I 204.

- crispula I 65, 204.

- dentata I 64, 65, 204.

- Garryana I 62, 64, 205.

- Ilex [ 62, 208.

- macrocarpa I 6:3, 64, 205.

- occidentalis I 208.

- palustris I 64, 207.

- pedunculata I 62, 64, 205 .

- pubescens I 62, 64, 206.

- rubra I 207. II 475.

- serrata I 6:3, 207.

- sessiliflora I 62, 64, 206.

- Suber I 61, 208.

- tardissima I 207.

= variabilis I $63,208$.

- virens I 61, 209.

- und Abies II 356, 446.

- und Fagus II 357, 444.

- und Pinus II 359, 446.

-, reine lBestände II $349,437$.

-, gemischte Bestände (Iichth.) II 449.

Rändelhieb II 261, 300, 325.

Rainweide I 215.

Rajolen $=$ Rigolen.

Rasse I 118.

Rauchiscliaden-Aufforstung II 488.

Rauhreif [ 32.

Red ash I 194.

- birch I 186.

- cedar I 157, 179.

- fir I $167,176$.

- maple I 184.

- oak I 207.

- wood I 178.

Reformwald (Burggrew) II 268.

Regen I 20, 36, 91. II 254.

Regeneration II $3: 38$.

Regenmenge I $58,60,89,140$. II 302 . - schatten I 28, 72 .
Reif [ 31.

Reife der sämereien I 140.

Reinbestäncte I 219. II 254,304 .

Reinleitsproz'nt II 367 .

Reinigung (Namen) II 370.

Reinigungen III 49:3.

Reinsaat 1[ 385 .

Reproduktionskraft I ? 09.

Reservabestand II 266 .

Reutbergwirtscluaft II 27.

Rhamuus eathartica [ 216.

- Frangula I 216.

Rhizome I 245. II 277.

Rhizomptlanz'n I 145.

- wald II 249, 277, 281.

Rhododendron I 6 :

Rhus vernicifera I 63, 209.

Richtung der Saumsehläge I[ 32:;

Riefensaat II :385.

Riesensequoie [ 178.

- -thuje I 197.

Rigolen II 379.

Rillenbedecker (Häffner) II 400, 401.

- -saat II 385

- -säer (Hörmann) II 401.

Rindenbrand I 12, 89, 162, 192. II 266, 289. III 520, 528.

Ringfemelbetrieb II 264.

- - Tiieb II 256.

Rimuensaat I[ 399.

Robinia I 99, 103, 107, 110, 111, 112, 134, $143,144,145$. II $2=8$.

- Pseudoacacia I 63, 110, 209. II 474.

Rock Pine I 173.

Röderwald II $271,285$.

Rohhumus I 43, 101, 109. II 296, 432.

- -boden (anzeigr. I'tlanzen) 432.

Rotahorn I 184.

- -buch" = Buche.

- -eichen I 206, 207. I] 475.

- -erle I 185.

- faiule I $60,145,162$. II 489.

Rotheekenbetrieb II 273.

Rubrae (lichen) I 206.

Rüsterarten [ 211.

Saatbedecker (Häffner) II 400, 40i.

- - (Spitzenberg) II 401.

- -bedeckumir II 288, 386, 401.

- -becte I 13,88, 115.

- -dcckungsmittel II $3 \times 7$.

- - dichte II 382, 400.

- -gitter II 387 .

- -latte (Eßlinger) II 401.

- mitteI II :34.

- nachteito II 364 .

- -schut\% II :387.

- -vorteile [I 364.

Säeapparat (Hacker) II 401.

Saikachi I 194.

Sakura I 201.

Salix I $64,65,66,67 \%, 10:\}, 111,112,136$, $13 \times, 143,144,209$.

- allua [ 210.

- amygdalina I 2I0.

- Cajrea I 216. 
Salix daphnoides 1210.

- purpurea I 210.

- viminalis I 210.

- (Sahlweide) I 216.

Sambuens I 103, 135.

Samen I 206. II 249, 292.

- -bildung I 101, 138.

- -ernte I 141.

- -erträgnis $179,137,237$. II 301.

- größe I 141. Ir 366.

- -giito II 36t.

- -hïlle I 140, 150.

- innere Anlagen II 365.

- -jahr I 187, 138, 301.

- koru I 86, 117, 12:), 136.

- -menge I 138 . II $38^{\circ}$.

Sand I 13, 110, 113, 158, 219.

- boden l 165, 170, 176.

- - anz. Pflanzen II 4:32.

- -doru [ 214.

Sapindusfichte I I6t.

Sapins I 149.

Sassafras officinale $163,210$.

Sauerdorn 213.

Saules [ 209.

Sammfemelbetrieb (Nev) II 264.

- -hielısbreite II 312.

- - -richtung II 311.

- schlagformen II 309.

- -schlag, gebruchener II 256.

_- kahler II 256, 261.

S'awara 1156.

Sichïlwald II 273,278 . III 520 .

Schaftform I $85,87,89,206,236$.

- -längre I 75.

- reinigung I 2:35.

- verkiirzung 1222.

Schatten'rträgnis I 113, 178, 1>0, 190, 206. $208,215,231$.

-holzarten I 78, 10\%, 102, 113, 132, 134, $162,186,222$. II $256,293,331,433$.

Seheinzypressen I 154.

Schirmbeschattming I 102.

- bestand, Nachteile I 257.

- - Vorreile I 257.

- diclite II 258.

_- -hieb II $295,302$.

- - -verjüngung II 257.

- - gruppenw. I 24.5.

- _ ringförmig II 800 .

- -, sammwoiser (Wagner) I 24\%.

- - verjüngung II $254,257,294,316$.

- _ - ringfiorm. II 260.

- stïnder II 303.

- -standsformen I 122.

- -verjüngung 11 28x, 289.

- _, Iliph ins Volle II :304.

_- der Nohattenholzarten [I 3:31.

Schiurikirsche l 202 .

Schlagabraum II 271.

Schlehdorn I 21.5.

Sehloichwaldwirtschaft II 262, 327 .

richleifbusch II 387.

Schlingstrauch I 120, 215. III 495.

schlubdurchbrechung II 294.

- -grad I 232.

I. Liaturgesetzliche Grumblagen.
Schmuckbaumbetrieb I 270.

Schnce 1 20, 3:3, 36, 92, 126, 229, 250, 254, 257. 11Г 499.

- bruch I 9:, 162, 165, 173.

- rlruck I 92, 150, 158, 162, 170, 172.

- saat II 386.

- -schunb I 9:3.

Selmeitelbremulıolzbetrieb II 274.

- -betrich II $272,274$.

- futterlanbbetrieb II 274.

- mittelwald II $276,283$.

- -streubetriob II 274 .

Schnellwïchsigkeit I 77, 101, 10.), 121, $1: 32,231$. If 299,800 .

Sichnittprobe II 373 .

Schönschaftigkeit I 125. II 462.

Schrägutlanzung (Emeis) II 421.

- (I'rouvé) II 421.

Schntthalden I 110, 113. II 488.

Schutz II 259. III 495.

- holzarten I 185, 216.

- pflanzen I 210.

- -wald I 247. II 285. III $5: 34$.

- - -wirtschaft II 270. III 534.

Schwarze Erle I 185.

Schwar\%fichte I 164.

- -eiche I 103, 206.

- fïhre II 473.

Schwarzer Nhorn I 183.

Schwarze Walum I 195. II 474.

Schwarzpappel I 200.

Sciadopitys verticillata I 63, 65, 103, 124, 143, 144, 177. II 341, 477.

Seichtgrïndigkeit I[ 292.

- -wurzler [ 113, 162.

Seitenbesamung II 289.

- -heschirmung II 239.

Selbstbegießung I 92 .

- -saat I 13.

Sempervirentos (Fichen) I 208.

Sequnia I $47,59,103,125,143.144,147$, 177. II 342 .

- gigantea I 6t, 178.

- sempervireus I 61, 178.

Setzholz II 385.

- (Npitzenberg) II 418.

shellbark Ilickory I 18๙.

Shii I 198.

Shinanoki I 211.

Shioji I 19:3.

Shirabe I 152.

Shiuri 1202.

Shortlatpine [ 171.

Nibirische Fiehte I 119, 164.

- Iarrhe I 160. II 477.

- Tamne I 150, 152.

- Vïirbel I 175. II 476.

Siebolds Buche I 192.

- Tsuge [ 181.

- Wahub I 19.. II 475.

Silberpappel I 200 .

silene I 10:3.

Silver fir I 1.51.

Sitkafichte I 164. II 467, 468, 469, 47 I.

sohlwride = viahweide.

fimmerfrust I 83, 184, 193. 
Sommerklima I 16.

- linde I 211.

- -tomperatur I 15, 56, 87.

sopliora I $6: 3,210$.

- japonica I 211.

- plitycarpa I 211.

sorbus I 64, 65, 66, 67, 137, 211.

- aucuparia I 199.

- Iomestica I 199.

Siäteiche I 207.

— -frost I $69,81,89,230$. II $272,280,288$.

- saat I 82, 150. 161.

Spanische Tanne I 152.

speicrling I 199.

sperberbaum I 199.

Sipessartwirtschaft II 266.

viphagneen I $39,43$.

sipiebeiche 1207.

Spindelbaum I 214.

Spiralbuhrer II 418.

Sirke I 168.

Fipitzahorn I 183.

splinttemperatur I 85.

Siporn (Tamme) I 149. II 336.

sipruces I 160 .

Sitärkezuwachs I 74, 14:3, 236.

staffelpflanzung II 426.

Nitammausschläge I 142.

- trieb 1142.

- - -wald II 25:3, 273, 283.

sitandortsformen I $80,122$.

standortsklima I 55.

- -raum I 23.5 .

Staugenwald II 4.51.

- -wuchspHlegre III 499.

stechifichte I 164. II 472.

Stechpalme I 215.

Steckling I 121, 142, 144.

- - ptlanzung II $4: 27$.

Niteple I $25,26,27,28,29,30$.

- -aufforstung II 485.

Nitereulia I $6: 3$.

Steruföhre I 167

sticleiche I 61), 205, 239.

Stockabhieb I 82 .

— -aussehläge I 142, 214. II 273, 278, 297.

- - -betriebe II 272.

Stockplattensaat II 385.

Sträucher I 103, 107, 135.

-, immergrïne I 215.

Strandföhre I 167.

strauchloirke I 213.

- -flora I 13.

- -lolzbetriob II 273.

streifensaat II 385.

Sitreublall I 76.

- -anhäufung I 1.50.

- -еntzug I 219.

- -miselinug I 21s.

- zersetzumg I :36.

Sitroben = Firobus.

Sitrobus I $90,10: 3,111,112,125,136,185$, 203. II $342 .: 313,4: 5,472$. III 529 .

itufen II 3.54 .

- -saat II 384.

sitückriefensaat II $: 395$.

I. Naturgesetzliche Grundlagen.
Sitiokrillonsaat. II 261.

Stïmmelungsbetriob II 273.

Stummelästumg $11 \mathrm{II} 518$.

- -pflam\%m11 II 4:30).

Sturm sielse anch Wind II $250,251$.

- festigkeit I 150, 158, 189, 2*3.

- -gefalir IL '261, 26i6, 292. - sicherunir I 218. III 546.

sulitroyxu [ $12,46,57,60,72,219$. I[ 291. III 5.51.

siulframzïsische Fïlre I 169.

Nilgar maple I 184.

Nurri [ 157.

خiumpfföhre I 167.

- -taxodie I 17s.

Sivamp white oak I 204.

sivect gum I 196.

sycomore I 200.

Taedaföhıre I 172.

'Tumarack I $15 \%, 159,160$.

Taubarkoak I 198.

Taumenarten I 149.

- -bestände II 336, 434.

- und Buche II 354, 441.

- und Eiche II 356, 446.

- und Fichte II $3.56,440$.

- nnd Föhre II 328.

Tan I 20, 24, 31, 36, 91, 226.

Tauriselie Föhre 1167.

'Taxodium distichum I 6.3, 90, 103, 112, 124,178 . II 283.

Taxus I 65, 90, 99, 10:3, 132, 137, 143, 144. 17 s.

- baceata I 65, 179. II 476.

- cuspidata I 179.

Temperatur I 12, 35, 46, 53, 58, 192.

- -koustante I 59 .

- -umkehr I 69,81 .

- verschicbungen I 226.

Tetra (meno) therme I 15.

Thermohore, alpine I 18, 69.

- polare I 15,69 . steppe I : 30 .

Thinja I 4T, 63, 65, 90, 103, 104, 112, 136. $138,143,144,179$. II 283.341 :

- gigantea I $64,90,179$. II 477.

- japoniea I 90, 179.

- occidentalis I 63, 64, 66, 90, 180. II 477.

Thujopsis dolabrata $I 63,65,103,138,144$, 1ิ่u. II 341,477

Tideland-spruce 1164.

Tieflandaficht، I 12:3.

Tiere, schäulliche I $99,164,166,176$. II 49.5.

Tilia I $64 .(65,103,136,14: 3,211$. II $: 342$, $34.5,4.35$.

- amoricana I 211.

- grameliflura 1211.

- jajminia I 211.

- parvifulia I 211.

Tillenl I 211

To11 [ 107, 110, 11:3, 201.

'lopf

— (lieuter) If 420.

- -jruben 11374.

Torf I 19,39, 192, 213. 
Torreya I 62, 63 .

'Traubeneiche I 206, 239.

- -kirsche I 202, 215. II 478 .

Treibholz III 5:30.

Treppeukahlsehlag II 309.

Trompetenbaum I 190, II 478.

Tropen I 12, 54, 56, 72, 219. III 551.

Trupp I 217, 218. II 252, 257.

Tsuga I 65, 87, 103, 111, 125, 123, 143, 180. II 283,342 .

- canadensis I 66, 134, 181. II 473.

- diversifolia I 65, 181.

- heterophylla I 64, 66, 181. II 473.

- Mertensiana = heterophylla.

- Sieboldii I 63, $1 \times 1$.

Tsuge $=$ Tsuga.

Türkisehe Hasel I 214.

- Weichsel I 215.

Tuliptree I 196.

T'ulpenbaum I 196.

Überfallswind I 92.

- -flutung I 39.

- -gangswaldungen II 277, 279.

- hälter II 360 .

- halt II 265.

- - bandweiser II 266.

- - bestand II 266.

- - - -weiser II 266.

- - betrieb I 132. II 257, 266.

- - freistand II 267.

- - -gruppenweiser II 266.

... - (Nachteile) II 266.

_ _, streifenweiser II 266 .

- - (Vorteile) II 266.

- -sandung I 39.

- -sehirmung I 82, 97, 102, 149, 158, 235. II 299.

- -sehwemmung I 54, 247. II 270.

- -somnung I $95,97$.

- -verdunstung I 25, 32, 85 .

- -wallungsknospen II $27 \mathrm{~s}$.

- -wallungswulst I 145. II 274.

- -wurfkultur (Grohmamn) II 421.

Ulmenarten I 211. 1I 342, 435.

Ulmus I $62,63,64,65,99,103,108,111$, $112,136,143,144,211$. II $2 \times 3,345,435$.

- alata I 6:3.

- americana 1212

- effusa I 212.

- laciniata I 212.

- montana I 212.

- parvifolia I 212.

- suberosa I 212.

Umbellnlaria californica 1 61, 212.

Umsäumung $11 \cdot 261$.

- -hieb $11300,325$.

Ungarisehe Eiche I 204.

Unhölzer I 96.

- -kräuter I 43, 96. II 259. 111528.

- - , forstliche I 10:3.

- -krautbeseitigung ir 401.

- -krantwuchs 1 144, 191, 226. II 270, 295.

Unterbau I 132, 214, 216, 222. 11 266, 293. III 528,530 .

- grundbefenchtung I 27 .
Untergrundwasser I 111.

- -hol\% I 214, 216, 2:34. Il 275.

- -licht I 96, 98.

- saat 111530.

- -satzprobe (Kienitz) II 375.

Urashiromomi I 152.

Urushi I 209.

Urwald I 39, 43, 111, 147, 209, 231, 237, 2:3. II 252, 253, 264, 270, 2×2.

-, bewirtschaftetor II 264 .

-, geregelter II 264.

- -schluB I 147.

Vaecinium I 103.

Valoneaeiche 1207.

Variabilität I 126.

Variation I 105.

Varietas 1119.

Varietät I 11<, 200.

Vegetation I 225.

-, alpine I 19

- -begim I \&1, 121, 161.

- -laver I 15, s0.

- -grenze I 67.

- -schluß I x1, 121, 190.

- -therme I 59,80 .

- -wärme I $18,83$.

- -wasser I 84, 131.

- zone I $56,61,67,79,81,219$. II 277.

Veitchstanne I 152.

Verästelungsbetrieb II 277.

- biß I 150, 162, 165, 203.

Verbreitungsfähigkeit I 48, 105, 136, 138.

- -gebiet I 73, 74, 119, 189, 206, 219, 292.

- -vermögeu I 2:39.

- zone I 125.

Verdämmung iI 254.

- duustung I 21, 26, 37, 43, 84, 89, 229.

- - einigung I 224.

- - erbung I 231.

- fahren, kombiniertes II 261, 335.

- -gabelung I 119.

- halten gegen Vïrme I 118.

- -jüngung II 249.

— - gem. Bestände I 22:3. II 328, 4:3.

- - gruppenweise II ¿60.

- -, horst- und grupjenweise II 260.

- kïnstliche I $79.90,135$. II 251 , 256, $259,269,290,304$.

- - natiirliche I $79,90,135,230$. II 256 , 284 .

- - art II 284.

- - betrieb II 290.

- _ , küustlicher II 284.

- - formen II 249, 281.

- - - gang II 290, 301 .

- - - hieb II $295,304$.

- - -zeitraum II 251, 254.

_ - - allgemeiner II 304.

- - spezieller II 304.

- zentren (Gruppen im sinue Gayers)

II $26 i 1$.

Verkaufsmaße der Sämereien II 376 .

Verkrïppelungsbetrieb II 276.

Verlichtung I '22'2, 233. II 293.

Vermehrung I 145.

\section{Naturgesetzliche Grundlagen. II. Begründung. III. 1'flege und Erziehung.}


Vermehrnng durch sämereien I 135.

-, natïrliche I 135.

- , ungeschlechtliche I 121, 145.

Verschulmaschine (Inacker) II 407.

- -rahmen (Rath) II 407.

- -rechen (Hacker) II 407.

Versehulungsabstand II 408.

- -zeit II 408.

Verunkrautung I 78, 101, 117. I[ 262, 294.

Verwandtschaft, morphologisch-anatomische I 220.

-, systematische I 220.

- der Hulzarten I 52.

Verwitterung I 11, 35, 42, 72, 109, 115.

Viburnum I 135.

- Lantana I 216.

- Opulus [ 216.

Vielgipfeligkeit I 178, 181.

Viermonatstemperatur I 15, 68.

Virginiseher Wachholder I 157.

Vieille écorce III 521.

Vogelbeere I 199.

- -kirsche I 201.

Vollernte I 139.

- -licht I 105, 194, 197, 209.

- -mast I 139 II 261.

- -saat II 385.

Vorbereitungshieb I 101, 138. II 258, 262.

Vorbereitung der Sämereien II 377.

Vorderlicht I 96, 99, 130, 218.

Yordüngung III $5: 1$.

Vorgriffshieb II 295.

Vorhieb II 258.

Vorliehtung II 310.

Vorwüchsigkeit I 231. II 300.

Vorwuehs II 294, 296.

- -behandlung II 299.

-, gemischter II 298.

- -horst II 299.

- (Kahlschlag) I 88. II 30.5.

-, Musterung II 296.

- -pflanzen I 88. II 393.

-, reiner II 298.

-, verbutteter II 296, 299.

W achholder I 157.

Wärme I $35,39,53,58,144,150$. II 255.

- -ableitung I 12.

- -ansprïche der Holzarten I 58.

- -bedürfnis I 180.

- -entzug II 257.

- -genuis I 143.

- -grenze I 73, 159, 16:3, 219.

- -mangel I 19, 125.

- -menge I 14, 89.

- -rückschlag I 54.

- überschuß I $60,125$.

Waldästhetik III 539 .

- -bandweiser I 218.

- -begründung [ 97, 245.

-, bestandsweise gemiseht I 218. II 284.

-, ehinesischer I 69.

-, chinojapanischer I 50.

- -einteilung II 283 .

- -erziehung I 109. III 490.

-, europäischer I 49, 243.

I. Naturgesetzliche Grundlagen.
Walelfeldwirtschaft II 270.

Waldfeuchtigkeit 122 .

- -gebiete, europanische 169.

- - westamerikanische 169.

- grenze $126,55,91,161,185,227$.

- -, alpine I 18, 210 .

- polare I 15, 18, 210.

- - therme I 15.

- - vegetation I 19.

- - verschiebung I 19.

- - -wärme I 15.

-, nordamerikanischer I 246.

-, ostamerikaniseher I 50.

_, ostasiatischer I $50,248$.

- -pflege I 245. III 490, 539.

- -rïinder I 214.

- -rebe I 213.

- -regiouen I 20, 25, 45, 49.

- - indische I 45.

- -, kanadische I 45.

- -, nordmexikanische [ 46.

- - ostamerikanische I 69.

- -, ostasiatiscle I 69.

- -, sibirische I 45 .

_ -, atlantische der Alten Welt I 45, 243.

- - , - - Neuen Welt I 45.

- -, pazifische der Alten Welt I 45.

- - , - Neuen Welt I 45.

-, stammweiser I 218.

-, subtropischer I 56.

-, truppweiser I 218.

- -typen I 46.

- -weidewirtschaft I 269.

- -zonen I 46, 55, 56, 191, 224.

Walnußarten I 195.

Walnuts I 195.

Wanderdünen I 40.

Warzenbirke. I 186.

Washingtonia I 61 .

Wasser I 41.

- -bedürfnis [ 231.

- -genuß I 98 . II 259.

- -mangel I 13, 94, 109, 170, 185, 231, 238.

- -probe II 374.

- -reiser I 130, 203, 206. II 289.

- -überschuß I 2:31.

Teichholzscheinzypresse I 156.

Weidenarten I 209.

TV-heger I 210. II 273, 428.

Weißbirke I 186.

- -buche I 187.

- -dorn I 214.

- -Hickory I 188.

- -eiche I 10:3, 203. II 437.

- - überhälter II 360.

- erle I 18.5.

- -esche I 193.

- -fichte I 162. II 47.2.

- -rindige Föhre I 167.

- -tanne [ 89.

Westamerikanisehe Birke I 186.

- Lärche I 160.

- Silbertanne I 151.

- Thuje II 477.

- Tsuge I 181. II 473 .

Westliche Korkeiche I 208.

II. Begrundung. III. Pflege und Erziehung. 
Westlicher Trompetenbaum I 190.

Western Catalpa I 190.

- Hemloek I 181.

Weymonthsföhre = Strobe, Strobus.

White ash I 193.

- cedar I 155, 156, 180.

- elm I 212.

- fir I 151.

- oak I 204, 205.

- I'ine I 174.

- spruce I 162, 16:3, 164.

Widerstand gregen schnee II 288.

- - Wind $180,93,165,183$. II 288.

Wiederbewaldung I 171,175 .

- -verjüngung II 251, 272, 338.

- - , künstliehe $11361,362,363$. - - , natürliehe [ 101, 150, 160, 22:3, 258,

Wiesenban II 285.

- moore I 37.

Wildbesehädigung I 173, 193.

Wildblackeherry 1202.

Wilde Birne I 199.

- Apfel I 199.

Wildparkwirtsehaft II 269. III 5:39.

- -verbiß II 25t, 300, 303. III 495.

Wrillows I 209.

Wind I 33, 92, 126, 230. II 254, 256, 257, 288.

- -bruch 1 92, 151.

- -mantel III 526.

- sehub I 93.

- sehutz II 302.

- -wurf I 92.

Winterfürbung I 86.

- frost I 82, 88. II 280.

- -linde I 211.

- -temperatur I $15,59,69,82,87,208$, $212,225$.

Wirtschaftsformen II 249.

Wölfe II 297.

Wuchsfehler II 250.

I. Naturgesctzliche Grundlagen.
Wühlspaten (Spitzenberg) II 418, 421.

Wurzelanssehlïge I 142,215 .

- -brut I 142, 144 .

- - ptlanzung II 4:30.

- -konkurrenz I 106, 238.

- -krebs I 43, 155, 160, 176.

- -pHanzung II 430 .

- -rersehneider (Muth) II 409 ,

- schluß I 133, 238.

- -schneidemesser (Kaiser) II 409.

- -stecklinge I $143,144$.

- -stümmelung I 138.

Yachidamo I 193.

Yellow Cypress I 15.).

- I'ine I 173.

- Poplar I 196.

Zaun I 214. III 496.

Kedern I 153.

Zeit der Aussaat II 378.

- - Bodenbearbeitung II 382.

- - P'flanzung II 415 .

Zelkowa I 62, 133, 212. II 345, 360.

- erenata I 213.

- Keaki I 63, 213. II 4:35, 478.

- - -ïberhälter II 360.

Zerreiche I 207.

Zirben = Zürbeln.

Zitterpappel I 113, 201.

Zonenbildung I 70, 89, 205.

Zopftroeknis I 131, 203.

Zubereitung des Keimbettes II 379.

Zuekerahorn I 184.

Zürrbeln I 174. II 435.

Zusammensetzung der Waldungen I 49 : Zwergbirke I 213 .

Zwieselbildung I 128.

Zwischenuutzung, landw. II 285.

- -pflanzung = Staffelpflanzung.

- -strauchpflanzung II 486 .

Zypressenarten I 156.

1I. Begründung. III. P'flege und Erziehung. 


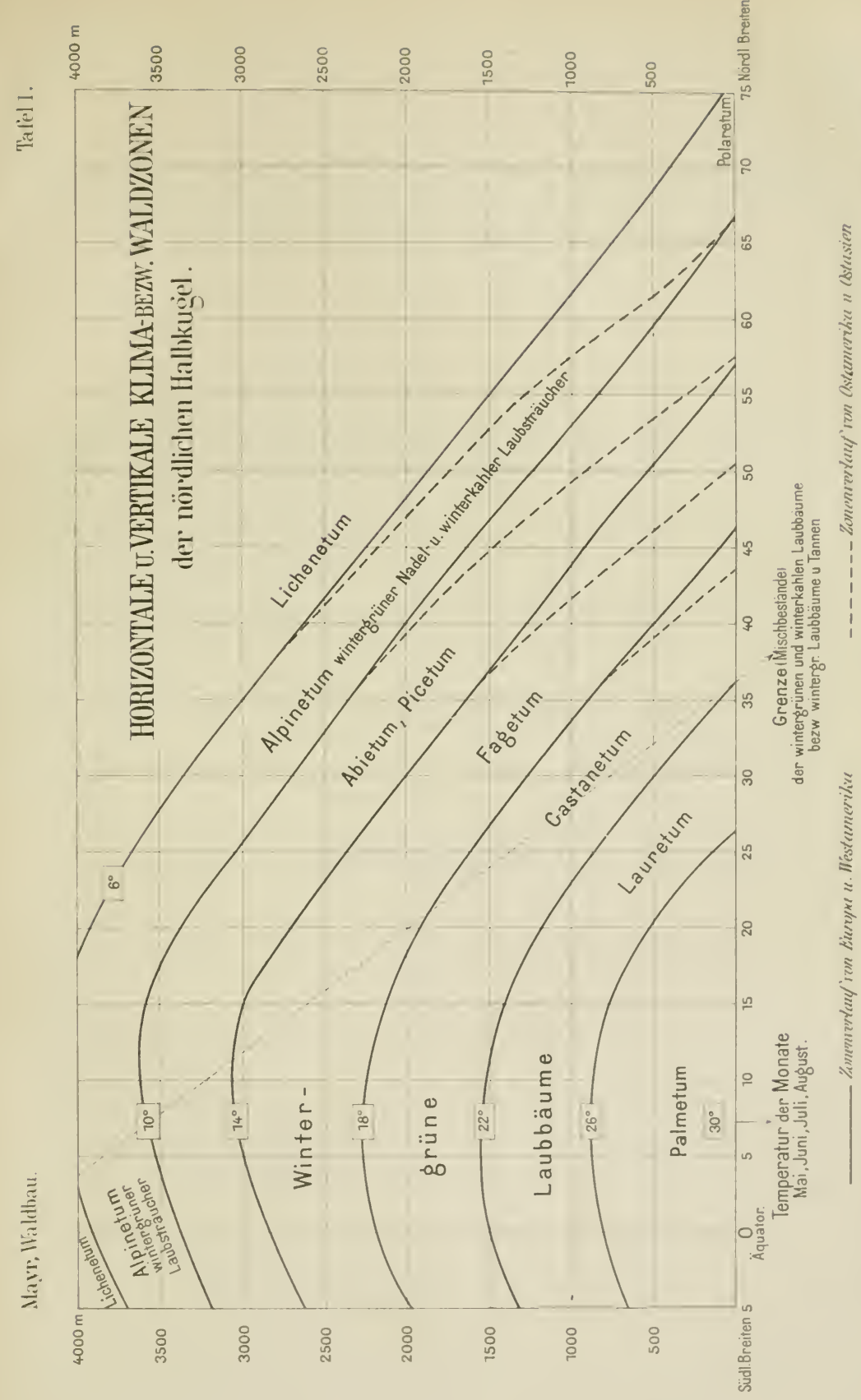





\section{VERTEILUNG DER'TEMPERATUR IN LUFT UNd BODEN. MITTSOMMER bei klarer,windstiller Witterung.}

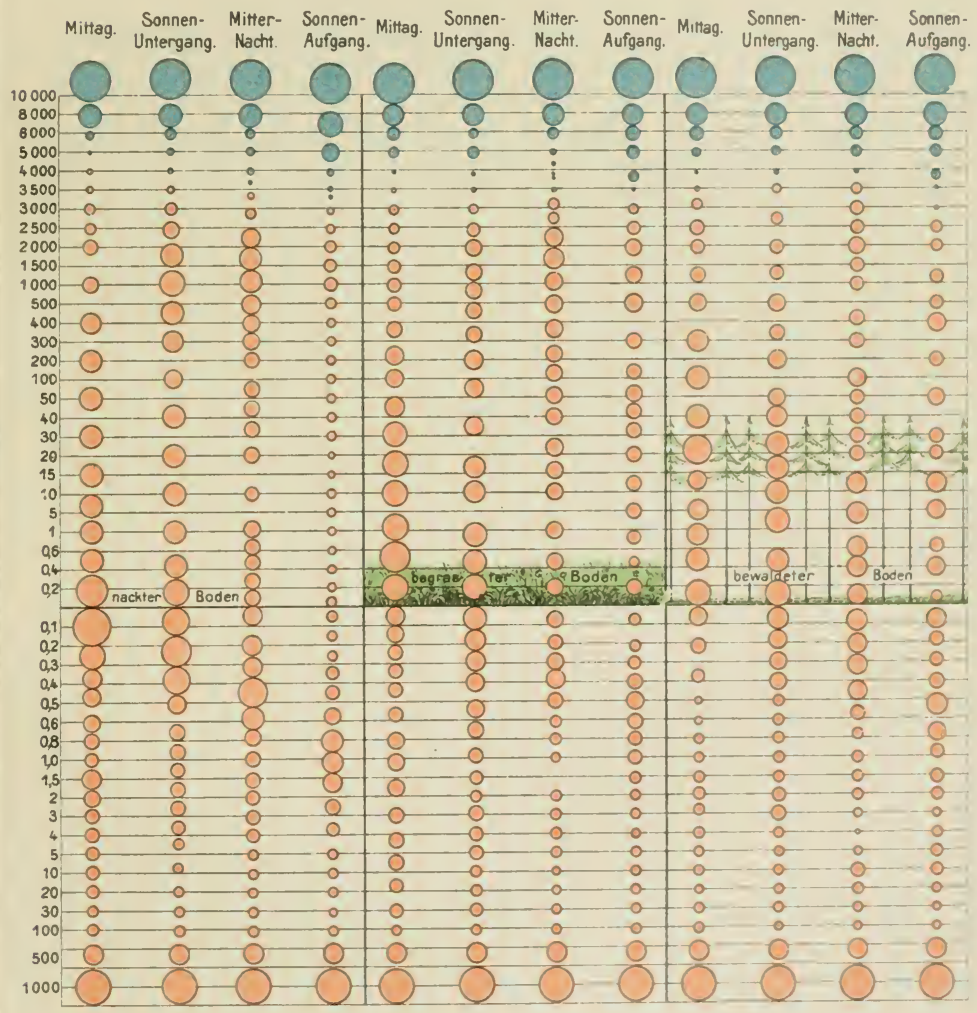

Der Zu-und Abnahmeder Temperatur über $0^{\circ}$ (rot) und unter $0^{\circ}$ (blau) entsprechen die GröBenverhältnisse der Kreıse. 



\section{VERTEILUNG DER TEMPERATUR IN LUFT UND BODEN. MITTWINTER bei klarer,windstillerWitterung.}

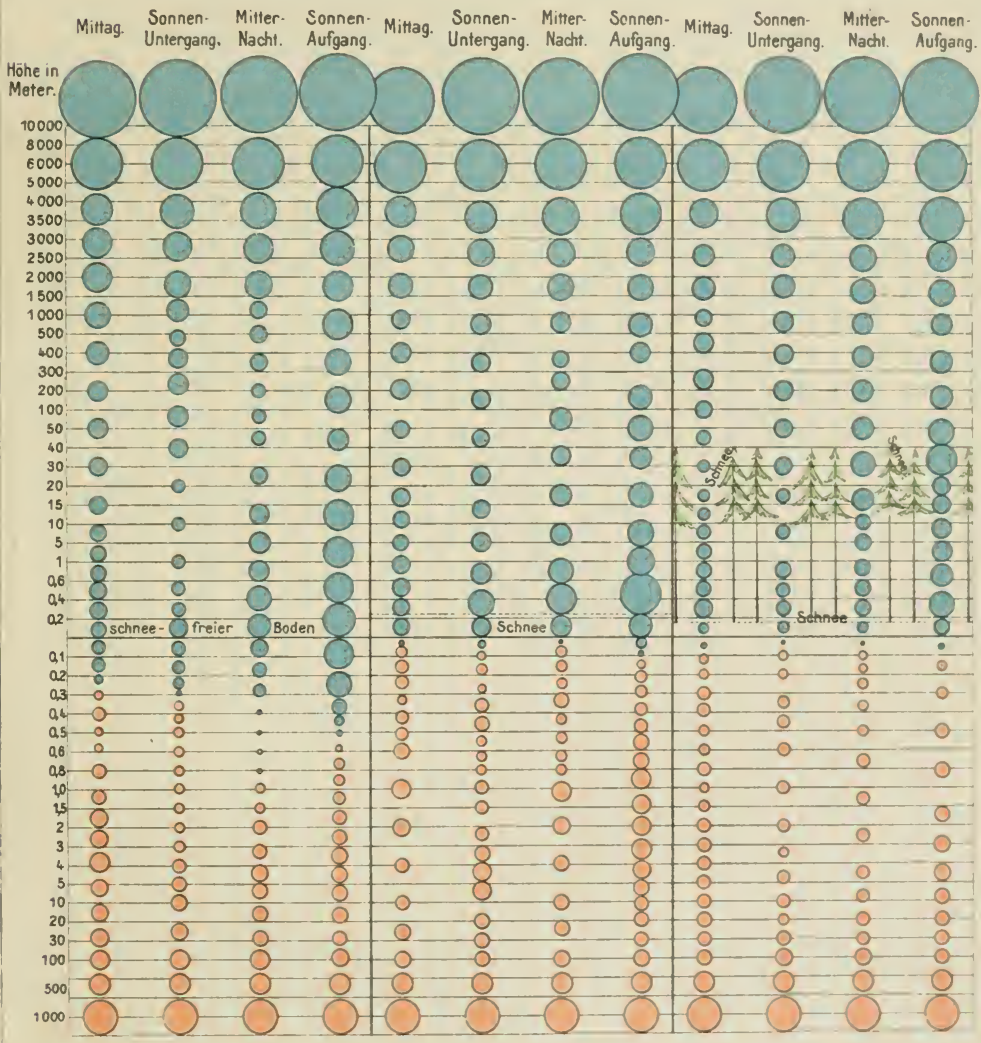

Der Zu-und Abnahmeder Temperatur über $0^{\circ}$ (rot) und unter $0^{\circ}$ (blau) entsprechen die GröBenverhältnisse der Kreise. 



\title{
Die Forsteinrichtung.
}

Von

Dr. Friedrich Judeich,

weil. Kgl. Sächs. Geheimer Ober?orstrat, Direktor der Forstakademie zu Tharandt.

Sechste, ergänzte Auflage

inn

Dr. Max Neumeister,

Kgl. Sächs. Geh, Oberforstrat, Direktor der Forstakademie zu Tbar:snit.

Mit einer Karte in Farbendruck. Gebunden, Preis 10 M. 50 Pf.

\section{Illustriertes Forst- und Jagd-Lexikon.}

Zweite, neubearbeitete Auflage.

Unter Jlitwirkung von

Prof. Dr. Bühler-Tübingen, Prof. Dr. Conrad-Aschaffenburg, Forstrat Elslinger-Speyer, Forstmeister Freiherr v. Nordenflycht-Lödderitz, Oberforstmeister Runnebaum-stade. Prof. Dr. Spangenberg-Aschaffenburg, Prof. Dr. Weber-Miinchen, Prof. Dr. Wilhelm-IV'ien herausgegebon ron

Dr. Hermann von Fürst,

Königl. Oberforstrat und Direktor der Künigl. forstlichen Hochschule Aschaffenburg.

Mit 860 Textabbildungen. In Halbleder gebunden, Preis 23 M.

\section{Die}

\section{Begründung naturgemäßer Hochwaldbestände.}

Von

Oberförster Rudolph Jankowsky.

Dritte, vermehrte Auflage.

Mit vier lithographischen Tafcln. Preis 3 M. 50 Pf.

\section{Der forstliche Hochbau.}

\author{
Maximilian Lizius,
}

Kgl. bayr. Forstmeister und Dozent für forstliche Baukunde an der Kgl. Forstlehranstalt Aschaffenburg. Mit 247 Textabbildnngen. Preis $6 \mathrm{M}$.

\section{Handbuch des forstlichen Wege- und Eisenbahnbaues.}

Nach dem Nachlasse des Kgl. bayr. Forstmeisters M. Lizius bearbeitet ron

K. Dotzel,

Kgl. bayr. Forstmeister und Dozent an der Forstlehranstalt Aschaffenburg.

Mit 245 Textabbildungen. Gebunden, Preis 7 M. 50 Pf.

$\mathrm{Zu}$ beziehen durch jede Buchhandlung. 


\title{
Fremdländische Wald- und Parkbäume für Europa.
}

\section{Yon}

Dr. Heinrich Mayr,

Professor der forstlichen Produktionslehre an der Universität zu IIünchen.

Mit 258 Abbildungen im Texte und 354, zum Teil farbigen Abbildungen auf 20 Tafeln.

In Prachtband gebunden, Preis $22 \mathrm{M}$.

\section{Monographie \\ der Abietineen des Japanischen Reiches. Von}

Dr. Heinrich Mayr,

Professor der forstlichen Produktionslehre an der Universitï zu München.

Mit 7 kolorierten Tafeln. Kartoniert, Preis $12 \mathrm{M}$.

\section{Die Forstbenutzung.}

\author{
Von \\ Dr. Karl Gayer, \\ Geheimer Rat und Professor an der Universität zu München.
}

Neunte, vermehrte Auflage,

bearbeitet unter Mitwirkung

von

Dr. Heinrich Mayr,

Professor der forstlichen Produktionslehre an der Universität zu München.

Mit $3+1$ Textabbildungen. Gebunden, Preis $1+\mathrm{M}$.

\section{Die Eigenschaften und das forstliche Verhalten der wichtigeren in Deutschland vorkommenden Holzarten.}

Leitfaden für Studierende, Praktiker und Waldbesitzer.

\section{Von}

Dr. Richard Heß,

Geh. IIofrat, o. ö. I'rofessor der Forstwissenschaft und Dircktor des Forstinstituts an der Ludwigs-Universitiit zu Giefsen.

Dritte, vollständig neubearbeitete Auflage.

Gebunden, Ireis $10 \mathrm{M}$. 
Verlag von Paul Parey in Berlin SW.. Hedemannstralse 10.

\title{
Die Technik des Forstschutzes gegen Tiere.
}

\section{Anleitung zur Ausführung}

von Vorbeugungs- und Vertilgungsmalsregeln in der Hand des Revier. verwalters, Forstschutzbeamten und Privatwaldbesitzers.

\section{Dr. Karl Eckstein,}

Prof. an der Forstakademie Eberswalde, Dirigent der zoologischen Abteilung des forstlichen Versucbswesens in Preulsen.

Mit 52 Textabbildungen. Gebunden, Preis 4 M. 50 Pf.

\section{Kauschingers Lehre vom Waldschutz.}

\author{
Sechste Auflage.
}

$H$ erausgegeben ron

Dr. H. von Fürst,

Königlicher Oberforstrat, Direktor der forstlichen Hocbschule in Aschaffenburg.

Mit 5 Tafeln. Gebunden, Preis + M.

\section{Leitfaden der Forstinsektenkunde.}

\author{
Von
}

Dr. Otto Nüßlin,

Grofsh. Bad. Hofrat, Pro'essor der Zoologie und Forstzoologie an der Technischen Huchschule,

Vorstand am Grofsh, Naturalienkabinett in Karlsrube.

Mit 356 Textabbildungen und den Bildnissen hervorragender Forstentomologen In Leinen gebunden, Preis $10 \mathrm{M}$.

\section{Forstliche Zoologie.}

Ton

Dr. Karl Eckstein,

P'rofessor an der Königl. Forstakademie in Eberswalde.

Mit 660 Textabbildungen. Gebunden, Preis 20 M.

\section{Lehrbuch \\ der Mitteleuropäischen Forstinsektenkunde.}

Dr. J. F. Judeich,

weil. Kgl. Sächs. Gieh. Oberforstrat und Direktur

der Forstakademie zu Tharandt, ion

und Dr. H. Nitsche,

Professor der Zoulogie an der Forstakademie

Als achte Auflage von Ratzeburgs

Waldverderber und ihre Feinde

in vollstiindiger L'marbeitung horausgegeben.

Mit Ratzeburgs Bildnis, 8 bunten Tafeln und 35 ? Textabbildungen.

Zwei Bände in Großoktai:. Gebunden, Preis to .1.

Zu beziehen durch jede Buchhandlung. 
Verlag von Paul Parey in Berlin SW., Hedemannstrafse 10.

\section{Handbuch der kaufmännischen Holzverwertung und des Holzhandels.}

Für Waldbesitzer, Forstwirte, Holzindustrielle und Holzhändler.

$$
\text { Von }
$$

Leopold Hufnagl,

Fürstlicher Zentralgüter direktor.

Zweite, gänzlich neubearbeitete Auflage.

Mit 28 Textabbildungen. Gebunden, Pris S M.

\section{Massentafeln zur Bestimmung des Holzgehaltes stehender Waldbäume und Waldbestände.}

Nach den Arbeiten der forstlichen Versuchsanstalten des Deutschen Reichs und Österreichs

herausgegeben von

Kammerrat Dr. Grundner und Prof. Dr. Schwappach.

Ziceite Auflage. Gebunden, Preis 2 M. 50 Pf.

\section{Lehrbuch der Holzmesskunde.}

\section{Ton}

Dr. Udo Müller,

a. o, Professor der Forstwissenschaft an der Technischen Hochschule zu Karlsruhe.

Jit 115 Textabbildungen. Gebunden, Preis 12 .1. 50 Pf.

\section{Anleitung zur Aufnahme des Holzgehaltes der Waldbestände.}

Dr. M. F. Kunze,

Geh. Hofrat, Professor an der Forstakademie Tharandt.

Zaceite Auflage. Kartoniert, Preis $2 \mathrm{M}$.

\section{Hilfstafelı für Holzmassen-Aufnahmen.}

Von

Dr. M. F. Kunze,

Geb. Hofrat, Professor an der Forstakademie Thirandt.

Zweite Auflage. Kartoniert, Preis 1 M. 50 Pf. 



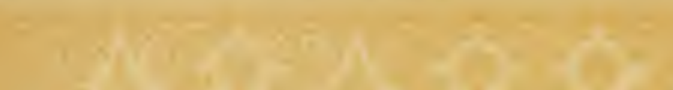

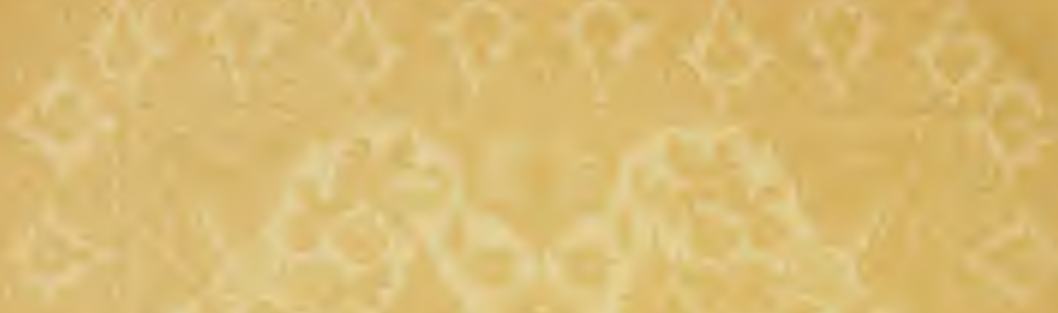

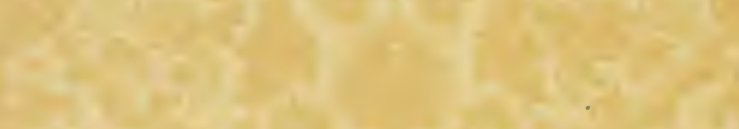

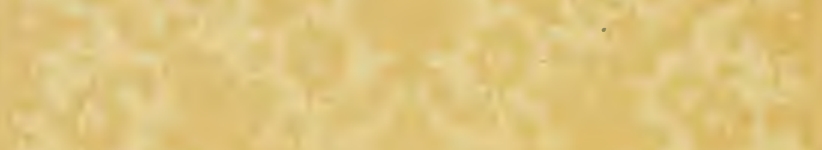

$-4$

$\sqrt{2}+x^{2}$

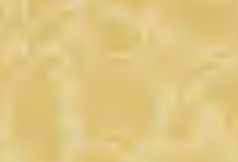

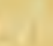<smiles>C1CCC1</smiles>

$$
\begin{aligned}
& \sqrt{2+2}+2
\end{aligned}
$$

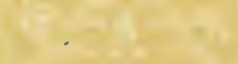

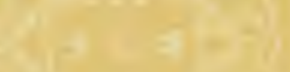

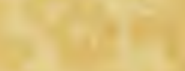

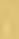

4.

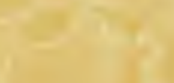

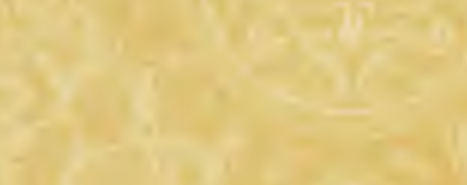$$
+2
$$<smiles>c1ccccc1</smiles><smiles>C1CCCC1</smiles><smiles>CCCCCCCCC</smiles><smiles>CCC</smiles>
+15

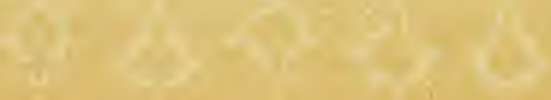




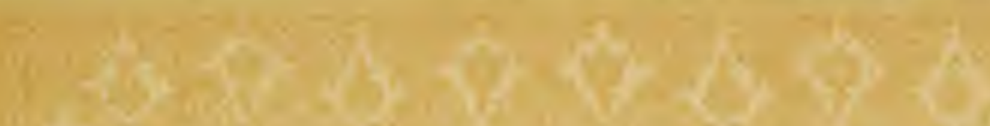

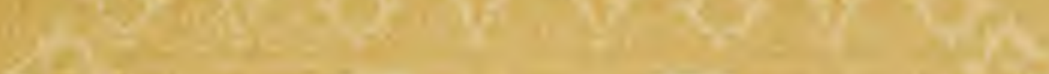

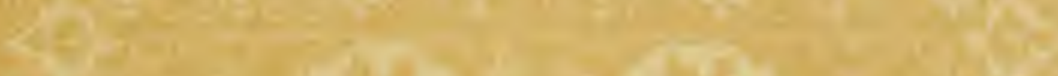

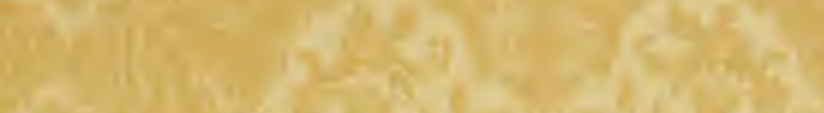

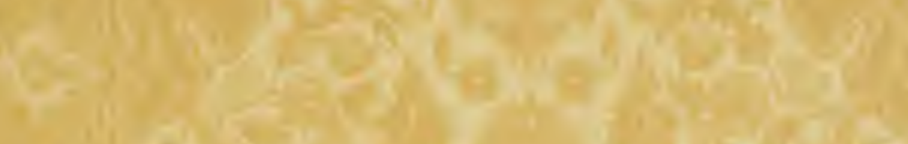

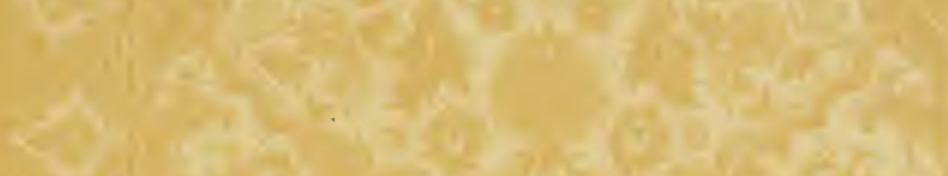

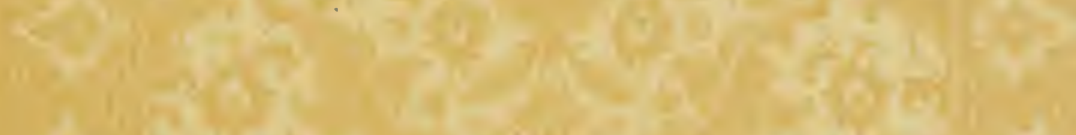

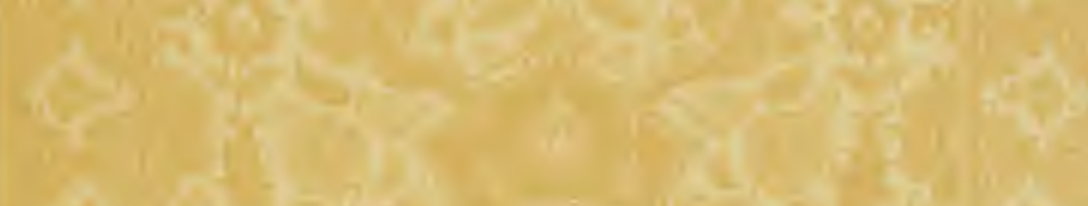

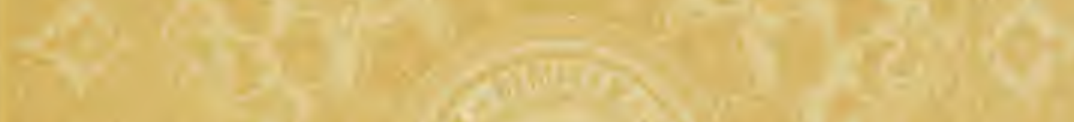

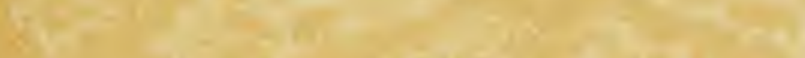

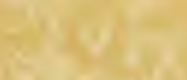

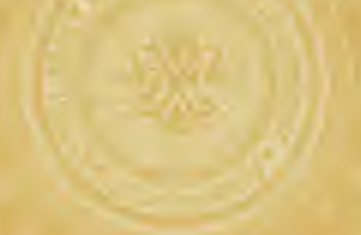

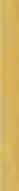

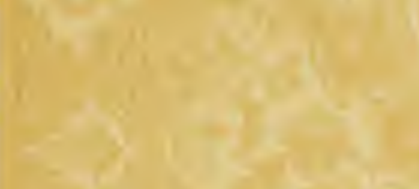

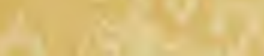

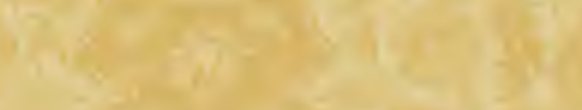

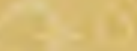

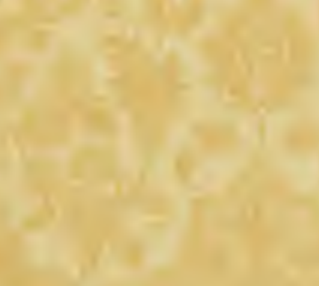

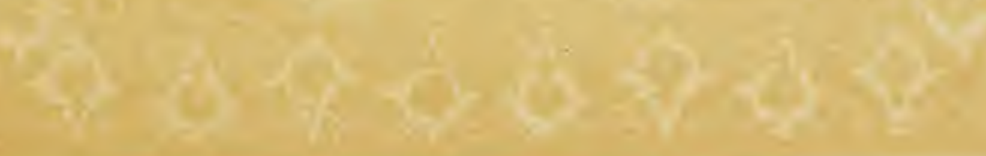




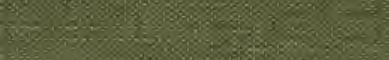

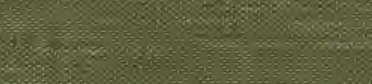

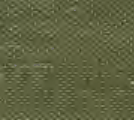

3.

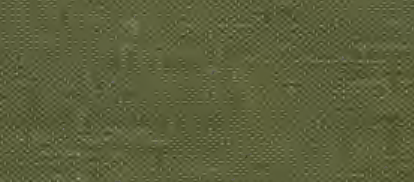

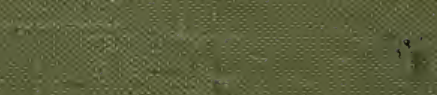

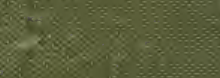

W

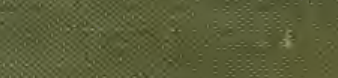

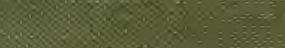

$x \times$

$\therefore: x_{x}$

$4 x^{2}$

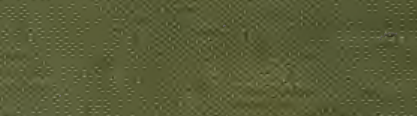

$4 \times$

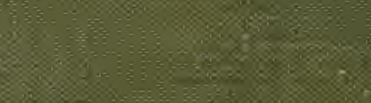

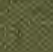

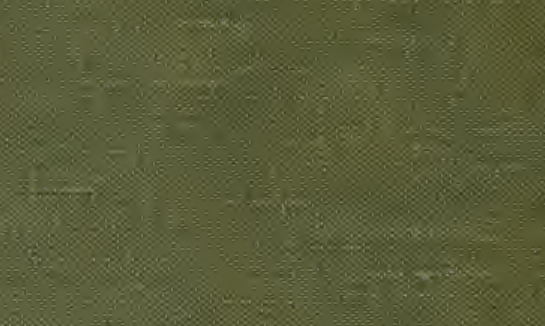

8

(1)

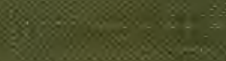
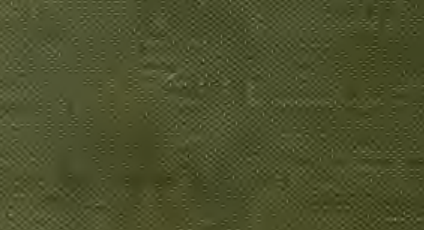

sis

$x=3$ 